\title{
Characterization of Oxy-combustion Impacts in Existing Coal-fired Boilers
}

\author{
Final Technical Report
}

Reporting Period Start Date: October 1, 2008

Reporting Period End Date: September 30, 2013

Principal Investigators:

Bradley Adams, Kevin Davis, Constance Senior, Hong Shig Shim, Brydger Van Otten Reaction Engineering International

Andrew Fry, Jost Wendt, Eric Eddings

University of Utah

Alan Paschedag

Siemens Energy

Christopher Shaddix

Sandia National Laboratories

William Cox

Corrosion Management

Dale Tree

Brigham Young University

December 2013

DOE Cooperative Agreement No.: DE-NT0005288

Reaction Engineering International

746 E. Winchester St., Suite \#120

Murray, UT 84107

(801) 364-6925 


\section{Disclaimer}

This report was prepared as an account of work sponsored by an agency of the United States Government. Neither the United States Government nor any agency thereof, nor any of their employees, makes any warranty, express or implied, or assumes any legal liability or responsibility for the accuracy, completeness, or usefulness of any information, apparatus, product, or process disclosed, or represents that its use would not infringe privately owned rights. Reference herein to any specific commercial product, process, or service by trade name, trademark, manufacturer, or otherwise does not necessarily constitute or imply its endorsement, recommendation, or favoring by the United States Government or any agency thereof. The views and opinions of authors expressed herein do not necessarily state or reflect those of the United States Government or any agency thereof. 


\begin{abstract}
Reaction Engineering International (REI) managed a team of experts from University of Utah, Siemens Energy, Praxair, Vattenfall AB, Sandia National Laboratories, Brigham Young University (BYU) and Corrosion Management Ltd. to perform multi-scale experiments, coupled with mechanism development, process modeling and CFD modeling, for both applied and fundamental investigations. The primary objective of this program was to acquire data and develop tools to characterize and predict impacts of $\mathrm{CO}_{2}$ flue gas recycle and burner feed design on flame characteristics (burnout, $\mathrm{NO}_{\mathrm{x}}, \mathrm{SO}_{\mathrm{x}}$, mercury and fine particle emissions, heat transfer) and operational concerns (fouling, slagging and corrosion) inherent in the retrofit of existing coal-fired boilers for oxy-coal combustion. Experimental work was conducted at Sandia National Laboratories' Entrained Flow Reactor, the University of Utah Industrial Combustion Research Facility, and Brigham Young University. Process modeling and computational fluid dynamics (CFD) modeling was performed at REI.
\end{abstract}

Successful completion of the project objectives resulted in the following key deliverables:

1) Multi-scale test data from $0.1 \mathrm{~kW}$ bench-scale, $100 \mathrm{~kW}$ and $200 \mathrm{~kW}$ laboratory-scale, and $1 \mathrm{MW}$ semi-industrial scale combustors that describe differences in flame characteristics, fouling, slagging and corrosion for coal combustion under air-firing and oxygen-firing conditions, including sensitivity to oxy-burner design and flue gas recycle composition.

2) Validated mechanisms developed from test data that describe fouling, slagging, waterwall corrosion, heat transfer, char burnout and sooting under coal oxy-combustion conditions. The mechanisms were presented in a form suitable for inclusion in CFD models or process models.

3) Principles to guide design of pilot-scale and full-scale coal oxy-firing systems and flue gas recycle configurations, such that boiler operational impacts from oxy-combustion retrofits are minimized.

4) Assessment of oxy-combustion impacts in two full-scale coal-fired utility boiler retrofits based on computational fluid dynamics (CFD) modeling of air-fired and oxygen-fired operation.

This research determined that it is technically feasible to retrofit the combustion system in an air-fired boiler for oxy-fired operation. The impacts of $\mathrm{CO}_{2}$ flue gas recycle and burner design on flame characteristics (burnout, $\mathrm{NO}_{\mathrm{x}}, \mathrm{SO}_{\mathrm{x}}$, mercury and fine particle emissions, heat transfer) and operational concerns (fouling, slagging and corrosion) were minimal, with the exception of high sulfur levels resulting from untreated flue gas recycle with medium and high-sulfur coals. This work focused on combustion in the radiant and convective sections of the boiler and did not address boiler system integration issues, plant efficiencies, impacts on downstream air pollution control devices, or $\mathrm{CO}_{2}$ capture and compression.

The experimental data, oxy-firing system principles and oxy-combustion process mechanisms provided by this work can be used by electric utilities, boiler OEMs, equipment suppliers, design firms, software vendors, consultants and government agencies to assess retrofit applications of oxy-combustion technologies to existing boilers and to guide development of new designs. 


\section{Table of Contents}

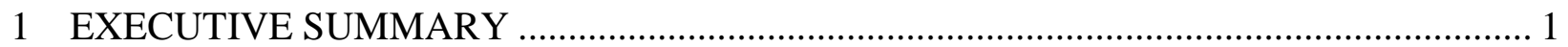

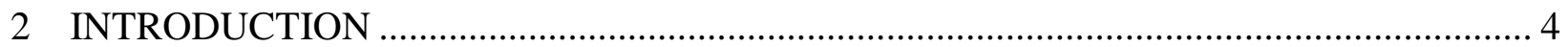

2.1 Oxy-fuel Combustion Retrofit Overview ………………………………………....... 5

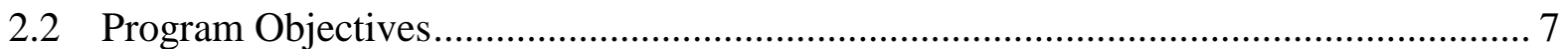

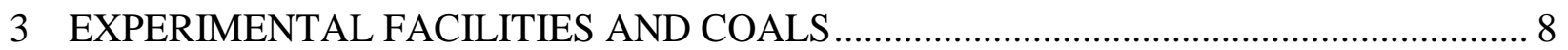

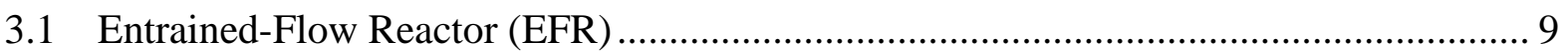

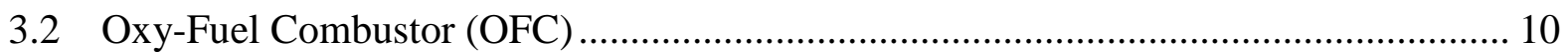

3.2.1 Furnace Design ....................................................................................10

3.2.2 Flue Gas Recycle System Design and Implementation ......................................12

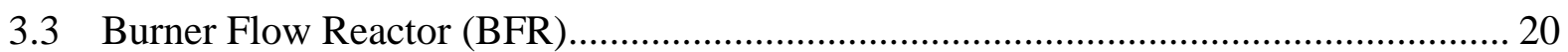

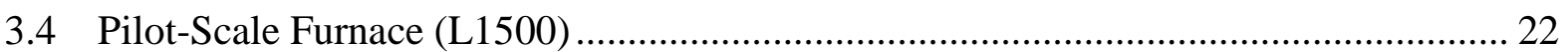

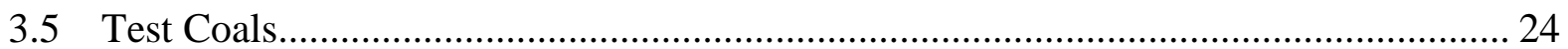

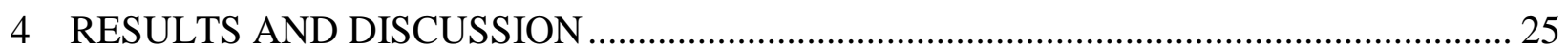

4.1 Pilot-Scale Oxy-Research Burner Development ............................................................ 26

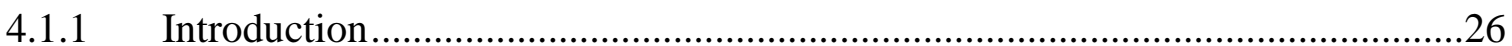

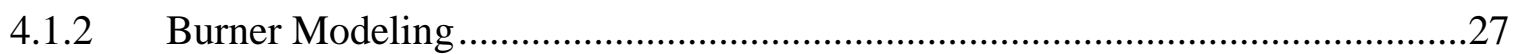

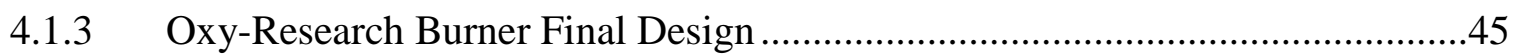

4.2 December 2009 to January 2010 L1500 Burner Tests.................................................... 50

4.2.1 Introduction and Test Strategy.....................................................................50

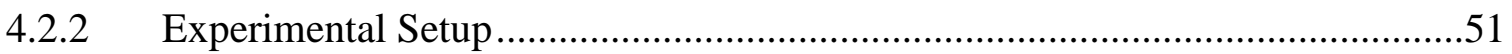

4.2.3 Scoping Tests and Air-Fired Operation ..........................................................55

4.2.4 Comparison between Air and Oxygen Operation ...............................................59

4.2.5 Retrofit Burner Test Results and Discussion ...................................................62

4.2.6 Oxy-Research Burner Test Conclusions.........................................................

4.3 April 2010 L1500 Burner Parametric Tests................................................................. 74

4.3.1 Introduction and Test Strategy .....................................................................

4.3.2 Experimental Setup....................................................................................

4.3.3 Oxygen Injection Results and Discussion..........................................................79

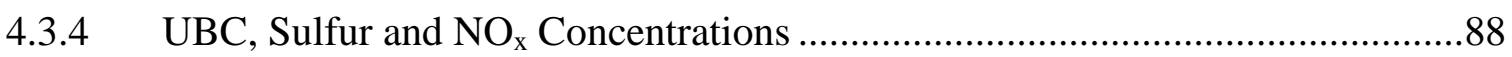

4.3.5 Radiation Intensity Measurements..............................................................92

4.3.6 Parametric Burner Test Conclusions …………................................................

4.4 December 2009 Metals Emissions Testing................................................................ 100

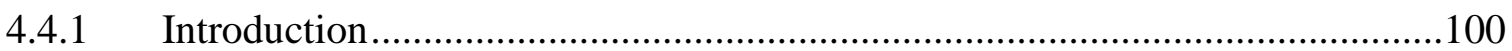


4.4.2 Experimental Setup ...............................................................................100

4.4.3 Results and Discussion .............................................................................101

4.4.4 Metals Testing Conclusions ..........................................................................109

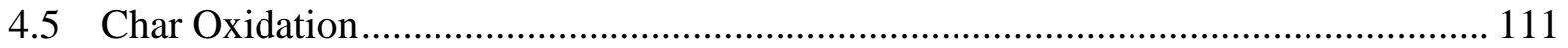

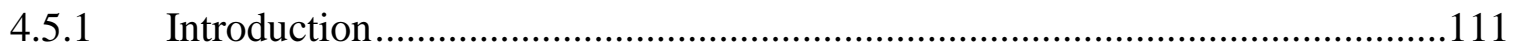

4.5.2 Experimental Investigation .....................................................................112

4.5.3 Measurement Results .................................................................................115

4.5.4 Char Oxidation Particle Modeling ……………...........................................117

4.5.5 Char Oxidation Mechanism Summary..............................................................126

4.5.6 CFD Modeling with the Extended Single-film Model ......................................127

4.5.7 Entrained Flow Reactor (EFR) Validation .......................................................131

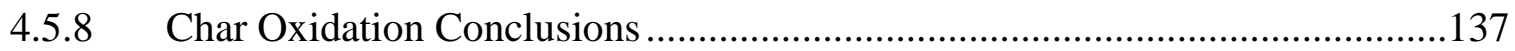

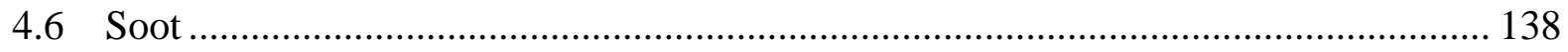

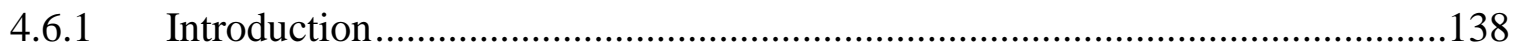

4.6.2 Experimental Setup ................................................................................138

4.6.3 OFC Results and Discussion........................................................................142

4.6.4 Additional Testing in the BFR..................................................................147

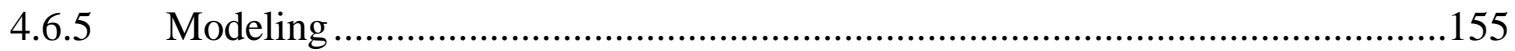

4.6.6 Soot Conclusions ..................................................................................163

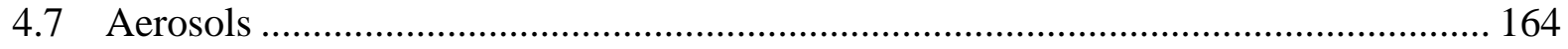

4.7.1 Introduction ..............................................................................................164

4.7.2 Experimental Setup ...............................................................................172

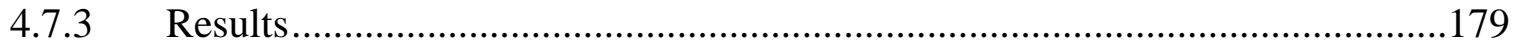

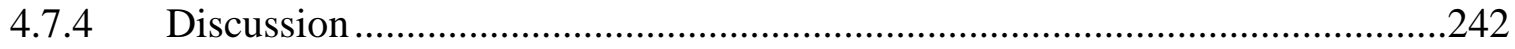

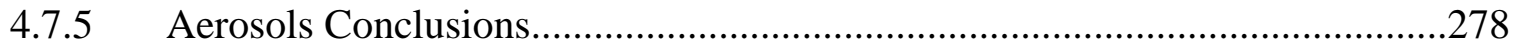

4.8 Slagging and Fouling ........................................................................................ 280

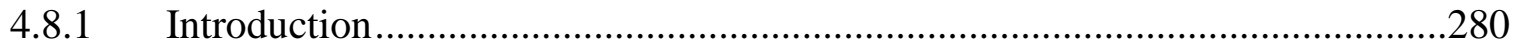

4.8.2 Ash Analysis Results and Discussion ............................................................280

4.8.3 Mineral Matter Transformation Model .............................................................291

4.8.4 Slagging Modeling.......................................................................................304

4.8.5 Fouling Modeling.......................................................................................

4.8.6 Slagging and Fouling Conclusions ...............................................................337

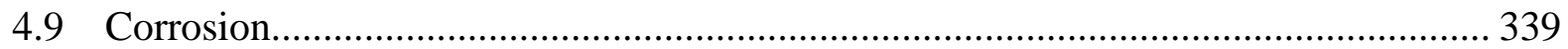

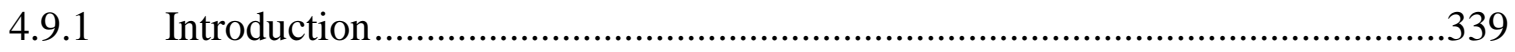


4.9.2 Mechanism Review and Development …………..........................................340

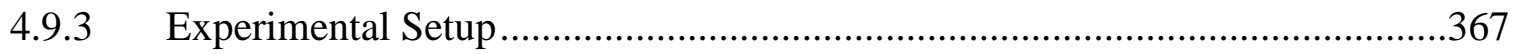

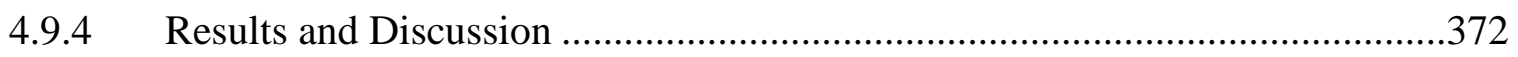

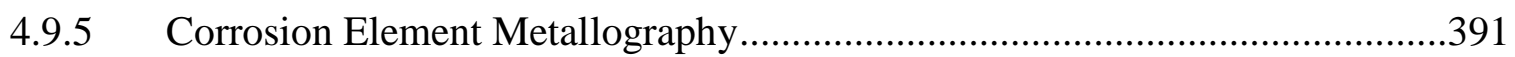

4.9.6 Effect of Mercury Additive on Dew-point Corrosion.........................................407

4.9.7 Corrosion Mechanism Refinement .................................................................416

4.9.8 Corrosion Conclusions..................................................................................

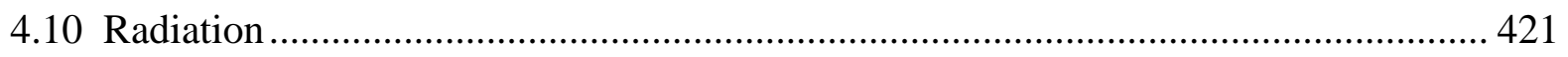

4.10.1 Evaluation of Radiation Property Models..........................................................421

4.10.2 Gas-phase Radiation Properties …………………..........................................421

4.10.3 Gas-phase Heat Flux Comparison ……………….........................................427

4.10.4 Particle-phase Radiation Properties ...............................................................430

4.10.5 Combined Particle and Gas-phase Heat Transfer Comparison...........................433

4.10.6 Radiation Property Comparison Summary …………………………………....438

4.112013 Mercury Additive Testing............................................................................... 439

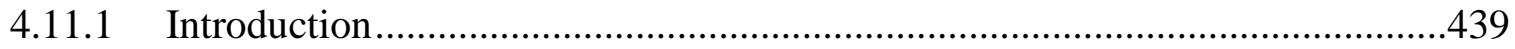

4.11.2 Mercury Measurement Recalibration ...............................................................439

4.11.3 Pilot-scale Mercury Test Results and Discussion...............................................447

4.11.4 Mercury Testing Conclusions .........................................................................486

4.12 L1500 Modeling and Data Comparison..................................................................... 488

4.12.1 L1500 Model Overview .............................................................................488

4.12.2 Comparison of Predicted and Measured Results ................................................489

4.12.3 Updated Char Oxidation Mechanism.................................................................493

4.12.4 Updated Gas Emissivity Mechanism ................................................................497

4.12.5 L1500 Comparison Summary ………………...............................................501

4.13 CFD Modeling of Full-Scale Retrofits .................................................................... 502

4.13.1 Oxy-Retrofit Burner Development ................................................................502

4.13.2 PacifiCorp Hunter 3 Overview …………………………………………....511

4.13.3 Investigation of Sub-model Impacts ...............................................................513

4.13.4 Hunter 3 Oxy-Retrofit Process Modeling ..........................................................519

4.13.5 Hunter 3 Oxy-Retrofit CFD Modeling ………...............................................522

4.13.6 Hunter 3 Modeling Conclusions ......................................................................563

4.13.7 DTE River Rouge 3 Overview...................................................................564

4.13.8 River Rouge 3 Process Modeling ……………….............................................566 
4.13.9 River Rouge 3 CFD Modeling ...................................................................568

4.13.10 River Rouge 3 Modeling Conclusions............................................................588

4.13.11 Mercury Modeling of Full-scale Retrofits ......................................................590

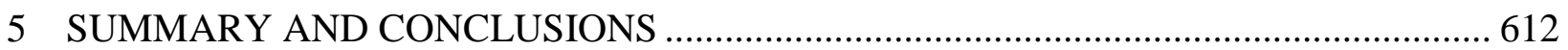

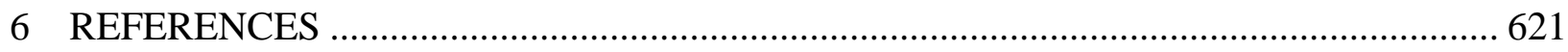

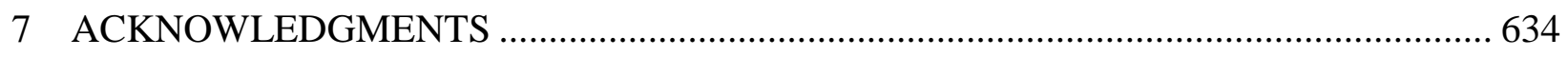

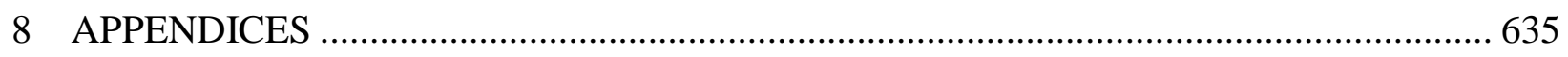

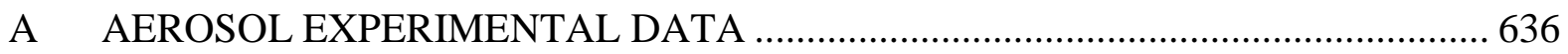

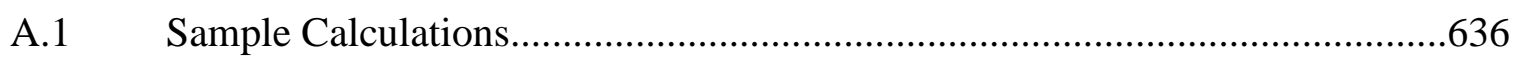

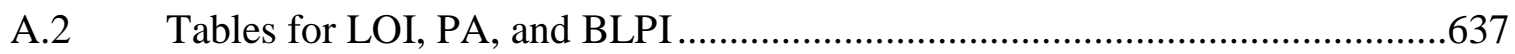




\section{List of Acronyms}

\begin{tabular}{|c|c|}
\hline Acronym & Definition \\
\hline ACI & Activated Carbon Injection \\
\hline AIM & Aerosol Instrument Manager \\
\hline APCD & Air Pollution Control Devices \\
\hline APS & Aerodynamic Particle Sizer \\
\hline ASTM & American Society for Testing and Materials \\
\hline BET & Brunauer-Emmett-Teller \\
\hline BFR & Burner-Flow Reactor \\
\hline BLPI & Berner Low Pressure Impactor \\
\hline BSR & Burner Stoichiometric Ratio \\
\hline BYU & Brigham Young University \\
\hline CAD & Computer Aided Design \\
\hline CCSEM & Computer-Controlled Scanning Electron Microscopy \\
\hline CEM & Continuous Emissions Monitor \\
\hline CFD & Computational Fluid Dynamics \\
\hline COG & Coke Oven Gas \\
\hline CPD & Chemical Percolation Devolatilization \\
\hline CPU & CO2 Processing Unit \\
\hline CR & Corrosion Rate \\
\hline DOE & Department of Energy \\
\hline DTE & Detroit Edison \\
\hline ECN & Electrochemical Noise \\
\hline EDS & Energy Dispersive Spectrometry \\
\hline EERC & Energy and Environmental Research Center \\
\hline EFR & Entrained-Flow Reactor \\
\hline EOR & Enhanced Oil Recovery \\
\hline EPA & Environmental Protection Agency \\
\hline EPRI & Electric Power Research Institute \\
\hline ESP & Electrostatic Precipitator \\
\hline EWBM & Exponential Wide-Band Model \\
\hline FGD & Flue Gas Desulfurization \\
\hline FGR & Flue Gas Recycle \\
\hline GDP & Gross Domestic Product \\
\hline GPU & Gas Processing Units \\
\hline HEPA & High Efficiency Particulate Absorption \\
\hline HFLOI & Hot Foil Loss on Ignition \\
\hline ICP-MS & Inductively Coupled Plasma Mass Spectrometry \\
\hline IFRF & International Flame Research Foundation \\
\hline IPCC & Intergovernmental Panel on Climate Change \\
\hline LNB & Low NOx Burner \\
\hline LOI & Loss on Ignition \\
\hline MATS & Mercury and Air Toxics Standards \\
\hline
\end{tabular}


MMT

NB

NBM

NIST

OEM

OFA

OFC

OL CEM

PA

PRB

PSD

REI

RFG

SCR

SEM

SGE

SKIPPY

SMPS

SR

$\mathrm{SR}_{\mathrm{I}}$

$\mathrm{SSH}$

TGA

UBC

VOC

WSGGM

XRD
Mineral Matter Transformation

Narrow Band

Narrow Band Model

National Institute of Standards and Technology

Original Equipment Manufacturer

Over-Fire Air

Oxy-Fuel Combustor

Ohio Lumex Continuous Emissions Monitor

Photoacoustic Analyzer

Powder River Basin

Particle Size Distributions

Reaction Engineering International

Recycled Fuel Gas

Selective Catalytic Reduction

Scanning Electron Microscope

SteamGen Expert

Surface Kinetics in Porous Particles

Scanning Mobility Particle Sizer

Stoichiometric Ratio

Stoichiometric Ratio at Ignition

Secondary Superheater

Thermogravimetric Analyzer

Unburned Carbon-in-Ash

Volatile Organic Compound

Weighted Sum of Gray Gas Model

X-Ray Diffraction 


\section{EXECUTIVE SUMMARY}

Oxy-combustion firing is a promising technology to isolate $\mathrm{CO}_{2}$ emissions from coal combustion for ready capture and sequestration. Due to the large infrastructure of coal-fired power plants in the United States, it may be beneficial to convert existing air-fired coal power plants to oxygen-fired plants. However, there are a number of technical questions that must be addressed concerning the retrofit of airfired coal boilers. Building or retrofitting a furnace that is designed for oxy-firing would be quite different from air-firing due to the difference in gas volumes, gas heat capacities, flame ignition, radiative heat transfer, particle and acid gas clean up requirements, and potential deposition and fouling issues. This work aims to determine differences between air versus oxy-firing of these key properties, and to evaluate these impacts in terms of oxy-firing retrofits for existing coal-fired boilers.

During this five-year program, Reaction Engineering International (REI) managed a team of experts from University of Utah, Siemens Energy, Praxair, Vattenfall AB, Sandia National Laboratories, Brigham Young University (BYU) and Corrosion Management Ltd. to perform multi-scale experiments, coupled with mechanism development, process modeling and CFD modeling, for both applied and fundamental investigations. The primary objective of this program was to acquire data and develop tools to characterize and predict impacts of $\mathrm{CO}_{2}$ flue gas recycle and burner feed design on flame characteristics (burnout, $\mathrm{NO}_{\mathrm{x}}, \mathrm{SO}_{\mathrm{x}}$, mercury and fine particle emissions, heat transfer) and operational concerns (fouling, slagging and corrosion) inherent in the retrofit of existing coal-fired boilers for oxy-coal combustion. Experimental work was conducted at Sandia National Laboratories' Entrained Flow Reactor, the University of Utah Industrial Combustion Research Facility, and Brigham Young University. Process modeling and computational fluid dynamics (CFD) modeling was performed at REI.

Successful completion of the project objectives resulted in the following key deliverables:

1) Multi-scale test data from $0.1 \mathrm{~kW}$ bench-scale, $100 \mathrm{~kW}$ and $200 \mathrm{~kW}$ laboratory-scale, and $1 \mathrm{MW}$ semi-industrial scale combustors that describe differences in flame characteristics, fouling, slagging and corrosion for coal combustion under air-firing and oxygen-firing conditions, including sensitivity to oxy-burner design and flue gas recycle composition.

2) Validated mechanisms developed from test data that describe fouling, slagging, waterwall corrosion, heat transfer, char burnout and sooting under coal oxy-combustion conditions. The mechanisms were presented in a form suitable for inclusion in CFD models or process models.

3) Principles to guide design of pilot-scale and full-scale coal oxy-firing systems and flue gas recycle configurations, such that boiler operational impacts from oxy-combustion retrofits are minimized.

4) Assessment of oxy-combustion impacts in two full-scale coal-fired utility boiler retrofits based on computational fluid dynamics (CFD) modeling of air-fired and oxygen-fired operation.

A significant amount of data was generated during the program via experiments, theoretical development and modeling. This included work in all key combustion-related aspects of boiler combustion, i.e., flame behavior, heat transfer, pollutant emissions, and operational issues such as slagging and corrosion. Key technical results from the program are summarized below for oxy-firing conditions. Results are grouped under different research areas.

\section{Firing System and Oxy-combustion Burner}

- An oxy-combustion flame can be designed to provide stability and heat transfer characteristics similar to an air-fired flame. The use of $\mathrm{O}_{2}$ and FGR provide additional degrees of freedom in burner design and operation.

- Flame stability is most influenced by oxygen injection on burner primary/secondary boundary. 
- Flame intensity can be most influenced by primary $\mathrm{O}_{2}$ injection.

- Oxygen needed to match air-fired heat transfer depends on firing system (26\% and 23\%, respectively, for the two full-scale assessments in this program).

- FGR properties impact flame properties and overall heat transfer.

- Reduced flue gas flow under oxy-firing may require convective pass adjustments.

Operational Impacts

- Ash aerosol properties and expected slagging behavior are similar to air-firing.

- Corrosion rates are similar unless flue gas recycle creates high $\mathrm{SO}_{2}$ and $\mathrm{H}_{2} \mathrm{O}$ levels. Similar to airfired systems, corrosion rates are dependent on metal temperature and local stoichiometric ratio.

- Mercury control additives such as bromine appear to contribute to low temperature corrosion, e.g., in conditions similar to air preheater temperatures.

\section{Pollutant Emissions}

- Oxy-firing produces lower $\mathrm{NO}_{\mathrm{x}}$ emissions, but similar $\mathrm{NO}_{\mathrm{x}}$ concentrations depending on the extent of FGR reburning in the furnace.

- Flue gas recycle can produce much higher $\mathrm{SO}_{2}$ and $\mathrm{SO}_{3}$ concentrations ( $\sim 5 \mathrm{x}$ over air-firing) with untreated FGR. This suggests FGR should be treated to mitigate $\mathrm{SO}_{2}$ for medium and high-sulfur coals.

- Soot formation is more dependent on the flame stoichiometric ratio resulting from the local $\mathrm{O}_{2}$ concentration and fuel/oxidant mixing than on air or oxy-firing. For similar aerodynamic conditions, oxy-firing does produce lower soot concentrations.

- Char oxidation under oxy-firing is enhanced via steam and $\mathrm{CO}_{2}$ gasification reactions. These additional reactions must be accounted for to properly model coal reactions. Oxy-firing tended to produce lower LOI levels than air-firing.

- Hg measurement techniques showed no bias under oxy-firing. The effectiveness of bromine additives for $\mathrm{Hg}$ control was reduced under oxy-firing, likely due to higher halogens and $\mathrm{SO}_{3}$ concentrations in the untreated FGR.

\section{Retrofit Modeling}

- REI's Glacier CFD code was used to model the $1 \mathrm{MW}$ L1500 pilot-scale furnace under air and oxy-fired conditions. Comparisons of predicted gas temperatures, $\mathrm{CO}, \mathrm{CO}_{2}, \mathrm{H}_{2} \mathrm{O}, \mathrm{SO}_{2}$ and $\mathrm{O}_{2}$ concentrations, gas emissivity, and wall heat flux were made. In addition, advanced sub-models for calculating char oxidation, soot and gas emissivity were evaluated to determine impacts on predicted results. Predicted results showed reasonable agreement with measured data, capturing all correct trends. The extended char oxidation single film model resulted in notable changes in predicted burnout rates, LOI and CO concentrations. Enhanced soot model had negligible impact on results, likely due to particles dominating radiant emission in the furnace flames. For similar reasons, the enhanced gas-phase emissivity model had negligible impact on predicted results.

- Two full-scale utility boilers, PacifiCorp’s Hunter 3 and DTE's River Rouge 3, were selected for oxy-retrofit assessment. The oxy-retrofit firing system design included two main tasks - oxyburner design (conducted by Siemens) and process modeling of system heat transfer and steam properties. Based on these results, a conceptual oxy-retrofit design was identified for each boiler 
which identified $\mathrm{O}_{2}$ concentrations in the $\mathrm{O}_{2}$-FGR mixture should be 25\% for Hunter 3 and 23\% for River Rouge 3, suggesting that the desired $\mathrm{O}_{2}$ concentration is unit dependent.

- REI's Glacier CFD code was used to model air-fired and oxy-fired conditions for the two boiler retrofits. The modeling results suggested that an appropriate mixture of $\mathrm{O}_{2}$ and flue gas recycle can reasonably match heat transfer in an existing coal boiler. The actual $\mathrm{O}_{2}$ values required were $26 \%$ for Hunter 3 and 24\% for River Rouge 3, slightly higher than predicted with the process modeling. Model results further identified that there are not any insurmountable differences in combustion performance or operational impacts when converting from an air-fired system to oxyfiring. Predicted results (along with test results) suggest that high sulfur flue gas recycle streams should be treated to reduce sulfur levels. This will help avoid operational problems related to corrosion and mercury control.

This research determined that it is technically feasible to retrofit the combustion system in an air-fired boiler for oxy-fired operation. The impacts of $\mathrm{CO}_{2}$ flue gas recycle and burner design on flame characteristics (burnout, $\mathrm{NO}_{\mathrm{x}}, \mathrm{SO}_{\mathrm{x}}$, mercury and fine particle emissions, heat transfer) and operational concerns (fouling, slagging and corrosion) were minimal, with the exception of high sulfur levels resulting from untreated flue gas recycle with medium and high-sulfur coals. This work focused on combustion in the radiant and convective sections of the boiler and did not address boiler system integration issues, plant efficiencies, impacts on downstream air pollution control devices, or $\mathrm{CO}_{2}$ capture and compression.

The experimental data, oxy-firing system principles and oxy-combustion process mechanisms provided by this work can be used by electric utilities, boiler OEMs, equipment suppliers, design firms, software vendors, consultants and government agencies to assess retrofit applications of oxy-combustion technologies to existing boilers and to guide development of new designs. 


\section{INTRODUCTION}

Energy production remains a key element in gross domestic product (GDP) and quality of life for people throughout the world. Historically, countries, including the US, have relied on plentiful and inexpensive fossil fuels for energy production. Combustion releases the energy of these fossil fuels, but also releases carbon dioxide $\left(\mathrm{CO}_{2}\right)$ as a by-product of combustion. Atmospheric research by the Intergovernmental Panel on Climate Change (IPCC) has suggested deleterious effects on ecosystems around the world as a result of increasing $\mathrm{CO}_{2}$ concentrations in the atmosphere, and many government agencies around the world, including the US EPA, have created or begun work on regulations aimed to limit atmospheric $\mathrm{CO}_{2}$ emissions. This includes regulations on the use of fossil fuels for power generation. Coal is the leading source of fuel for the US power generation industry. As a result, in order for coal to continue to play an important role as an energy provider, a method for reducing $\mathrm{CO}_{2}$ emissions must be developed.

Fossil fuels contribute to the observed increases in $\mathrm{CO}_{2}$, and coal is one of the greatest emitters of $\mathrm{CO}_{2}$ per unit of energy. However, coal is widely utilized due to its abundance and low cost. Therefore it is desirable to identify $\mathrm{CO}_{2}$ control technologies that will allow continued use of coal. Currently there are three main technologies under development. They are often referred to as pre-combustion capture or IGCC, post-combustion capture, and oxy-firing. All three aim to provide a high quality $\mathrm{CO}_{2}$ stream from the coal combustion process that would be ready for sequestration or use for enhanced oil recovery (EOR) activities. The focus of this research is oxy-firing which is a combustion environment composed of oxygen and recycled flue gas, which would be primarily $\mathrm{H}_{2} \mathrm{O}$ and $\mathrm{CO}_{2}$.

Due to the large infrastructure of coal-fired power plants in the United States, an approach that would allow the conversion of existing air-fired coal power plants to oxygen-fired plants has many economic and environmental benefits. However, there are a number of technical questions that must be addressed concerning the retrofit of air-fired coal boilers. Building or retrofitting a furnace that is designed for oxyfiring would be quite different from air-firing due to the difference in gas volumes, gas heat capacities, flame ignition, radiative heat transfer, particle and acid gas clean up requirements, and potential deposition and fouling issues. As a result, this work aims to determine differences between air versus oxy-firing of these important properties. More specifically, this work aims to address oxy-firing retrofits for existing coal-fired boilers.

Oxy-firing retrofit involves converting a conventional air-fired pulverized coal boiler to an oxy-fired boiler. Since oxy-firing involves burning coal in a combustion environment composed of oxygen and recycled flue gas rather than air, the combustion conditions examined by this work were kept similar to air-fired conditions in order to match similar temperatures, heat fluxes, and flue gas volumes as closely as possible. Since these three factors are all of critical importance to the design and optimization of an airfired boiler, retrofit applications must work as closely as possible to these given parameters. 


\subsection{Oxy-fuel Combustion Retrofit Overview}

Oxy-fuel combustion utilizes an air separation unit to provide the oxygen stream for oxy-fired combustion. The current state of the art is to utilize integrated air separation units (ASU) along with the $\mathrm{CO}_{2}$ processing unit (CPU) in order to maximize efficiency. Industrial gas providers indicated in their process optimization that an $\mathrm{O}_{2}$ concentration of $95-97 \%$ purity provides the greatest overall efficiency (Shah 2011) (Trainer 2011).

Oxygen production is one of the greatest energy penalties of the process and leads to a considerable cost increase when compared to air-fired combustion. As a result, industrial gas suppliers such as Praxair, Linde, Air Products, and Air Liquide are focusing research on how to reduce the cost of oxygen production to make oxy-firing more cost competitive compared to air firing and other $\mathrm{CO}_{2}$ mitigation technologies.

Oxy-firing also provides several benefits compared to air-firing. The near elimination of $\mathrm{N}_{2}$ from the combustion atmosphere greatly reduces thermal $\mathrm{NO}_{\mathrm{x}}$, and the resulting high concentration stream of $\mathrm{CO}_{2}$ can be efficiently captured for storage or utilized for enhanced oil recovery efforts. Furthermore, during oxy-firing, the amount of flue gas recycle can be varied giving different $\mathrm{O}_{2}$ concentrations, rather than the fixed $20.9 \% \mathrm{O}_{2}$ concentration of air. This is yet another degree of freedom which engineers and operators may use in order to optimize combustion and boiler performance.

However, there are still many unknowns regarding oxy-fuel combustion. $\mathrm{CO}_{2}$ and $\mathrm{N}_{2}$ tend not to be reactive species at standard pressures and temperatures, but the environment in a pulverized coal boiler is much hotter with temperatures greater than $2000 \mathrm{~K}$ possible. $\mathrm{CO}_{2}$ and $\mathrm{N}_{2}$ have different heat capacities, radiation properties, and varying effects on mass transfer rates as well. Due to these fundamental differences, research is necessary to determine how replacing $\mathrm{N}_{2}$ in the combustion environment with $\mathrm{CO}_{2}$ could potentially alter the mechanisms governing particle formation in the flue gas.

There is also a considerable difference in flue gas volume which would affect convective heat transfer as well. Since air is $20.9 \% \mathrm{O}_{2}$, an oxy-fired environment that was $32 \% \mathrm{O}_{2}$ with the balance of the combustion atmosphere provided by recycled flue gas has only $60 \%$ of the flue gas volume as the airfired case. The higher oxygen content is required under oxy-fired conditions in order to achieve a matched calculated adiabatic flame temperature between air and oxy-fired conditions due to the difference in physical properties such as heat capacity of $\mathrm{CO}_{2}$ compared to $\mathrm{N}_{2}$.

Retrofit applications would have to keep as many parameters in terms of temperatures, heat flux, energy input, and-most importantly-heat transfer as similar to air-fired conditions as possible. Since these applications would not be grassroots new construction, a narrower acceptable operating range had to be accepted.

Furthermore, unknowns such as how an oxy-fired combustion atmosphere may affect aerosol formation in the furnace have to be addressed. Aerosol formation eventually leads to ash deposition or fouling of boiler heater tubes as particles begin to stick to heat transfer surfaces. This build up on heat transfer surfaces affects the efficiency of the power generating unit as the fouled boiler tubes no longer transfer as much heat to the streams driving the generating turbines, and thus causes plant efficiency to decrease and costs to increase.

In addition to this critical operational issue, a change in the aerosol composition or size distribution may also affect a retrofitted plant's ability to meet emissions requirements for particulate matter since not all of the combustion flue gas would be captured and stored and some would inevitably be released to the atmosphere. 
Further complicating the retrofit applications, an optimized standard flue gas recycle composition has yet to be identified. For example, a simplified example of an oxy-fired retrofit boiler has been shown in Figure 2.1-1. In this example there are devices to remove particulate matter, moisture, and sulfur in the flue gas. As a result, there are many locations from which flue gas may be withdrawn and recycled. Flue gas may be removed before any treatment, in which case the recycled flue gas would contain particulate matter, $\mathrm{CO}_{2}, \mathrm{H}_{2} \mathrm{O}$, and $\mathrm{SO}_{2}$. Or, flue gas could be withdrawn after the particulate control leaving $\mathrm{CO}_{2}$, $\mathrm{H}_{2} \mathrm{O}$, and $\mathrm{SO}_{2}$. Alternatively, flue gas could be recycled on a dry basis consisting of primarily $\mathrm{CO}_{2}$ and residual $\mathrm{SO}_{2}$ that survived the condensation process. Finally, flue gas that has been treated to reduce particulate matter, $\mathrm{H}_{2} \mathrm{O}$, and $\mathrm{SO}_{2}$-leaving only dry $\mathrm{CO}_{2}$ - could be utilized.

The different recycled flue gas conditions have very different chemical compositions which would also affect their heat capacity and could potentially influence the combustion process, aerosol formation, and furnace operation in unforeseen ways.

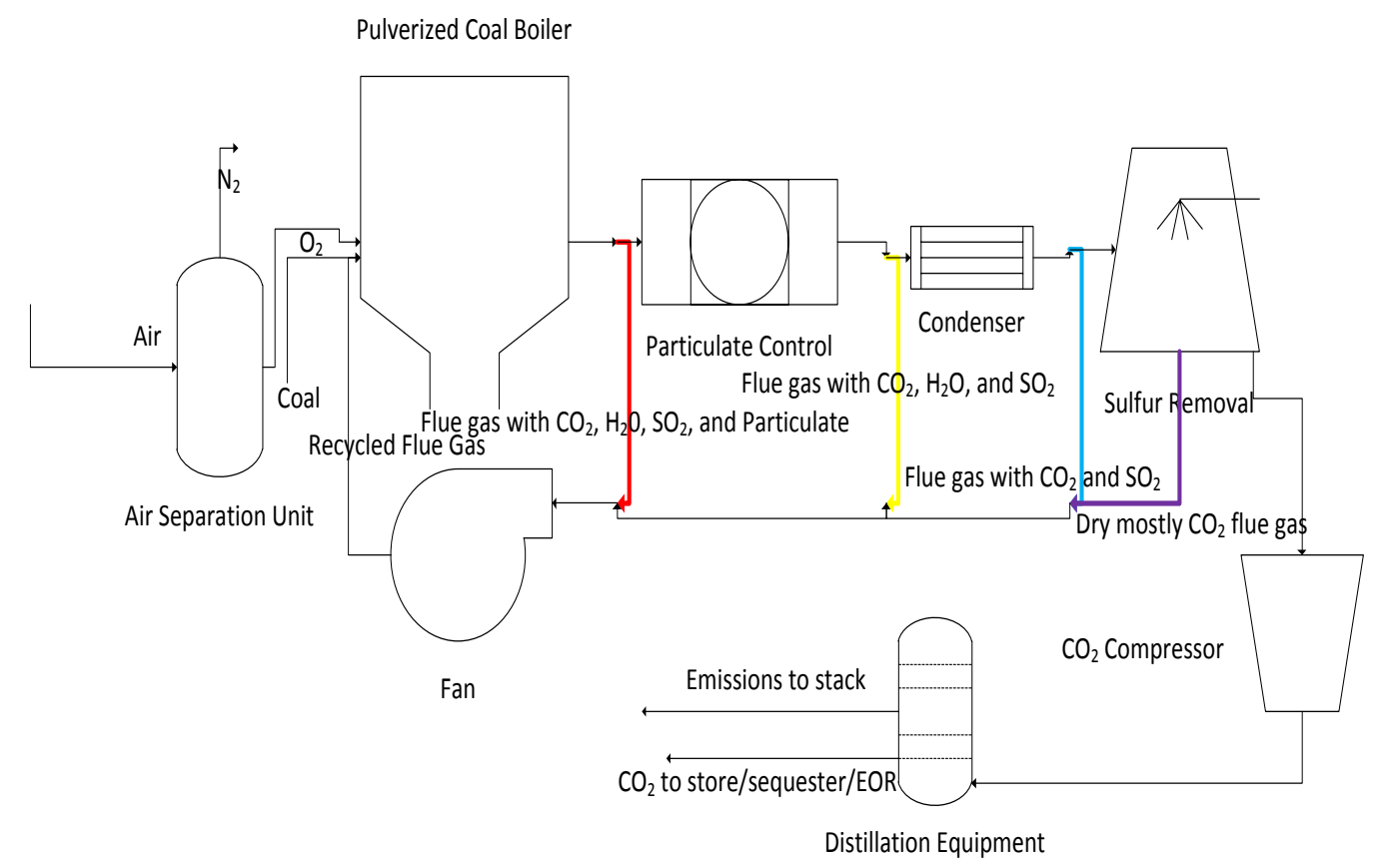

Figure 2.1-1: Process flow diagram of flue gas recycle options for oxy-fired combustion.

Research is required to identify key operational challenges and limitations associated with oxy-coal firing and to guide development of oxy-coal retrofit systems. 


\subsection{Program Objectives}

Reaction Engineering International (REI) managed a team of experts from University of Utah, Siemens Energy, Praxair, Vattenfall AB, Sandia National Laboratories, Brigham Young University (BYU) and Corrosion Management Ltd. to perform multi-scale experiments, coupled with mechanism development and CFD modeling, for both applied and fundamental investigations in order to elucidate the impacts of retrofitting existing pulverized coal-fired utility boilers for oxy-combustion.

The primary objective of this program was to acquire data and develop tools to characterize and predict impacts of $\mathrm{CO}_{2}$ flue gas recycle and burner feed design on flame characteristics (burnout, $\mathrm{NO}_{\mathrm{x}}, \mathrm{SO}_{\mathrm{x}}$, mercury and fine particle emissions, heat transfer), fouling, slagging and corrosion, inherent in the retrofit of existing coal-fired boilers for oxy-coal combustion. Experimental work was conducted at Sandia National Laboratories' Entrained Flow Reactor, the University of Utah Industrial Combustion Research Facility, and Brigham Young University. Computational fluid dynamics (CFD) modeling was performed at REI.

Successful completion of the project objectives resulted in the following key deliverables:

1) Multi-scale test data from $0.1 \mathrm{~kW}$ bench-scale, $100 \mathrm{~kW}$ and $200 \mathrm{~kW}$ laboratory combustor-scale and 1 MW semi-industrial scale combustors that describe differences in flame characteristics, fouling, slagging and corrosion for coal combustion under air-firing and oxygen-firing conditions, including sensitivity to oxy-burner design and flue gas recycle composition.

2) Validated mechanisms developed from multi-scale test data that describe fouling, slagging, waterwall corrosion, heat transfer, char burnout and sooting under coal oxy-combustion conditions. The mechanisms were presented in a form suitable for inclusion in CFD models or process models.

3) Principles to guide design of pilot-scale and full-scale coal oxy-firing systems and flue gas recycle configurations, such that boiler operational impacts from oxy-combustion retrofits are minimized.

4) Assessment of oxy-combustion impacts in two full-scale coal-fired utility boiler retrofits using computational fluid dynamics (CFD) modeling of air-fired and oxygen-fired operation, together with the information generated in this research.

The experimental data, oxy-firing system principles and oxy-combustion process mechanisms provided by this work can be used by electric utilities, boiler OEMs, equipment suppliers, design firms, software vendors, consultants and government agencies to assess retrofit applications of oxy-combustion technologies to existing boilers or to guide development of new designs. 


\section{EXPERIMENTAL FACILITIES AND COALS}

To obtain fundamental data describing oxy-combustion processes, testing was performed on multiple scales. The facilities described in this section are listed in order of increasing scale. A bench-scale entrained-flow reactor operated at Sandia National Laboratories was used primarily to investigate the influence of $\mathrm{CO}_{2}$ char gasification reactions under flue gas recycle (high $\mathrm{CO}_{2}$ concentration) conditions. A lab-scale furnace (rated up to $100 \mathrm{~kW}$ ) at the University of Utah was employed for the study of aerosol formation as well as slagging and fouling mechanisms. A lab-scale furnace (rated up to $200 \mathrm{~kW}$ ) at Brigham Young University was employed for additional soot measurements. A pilot-scale furnace (rated up to $1.5 \mathrm{MW}$ ), also at the University of Utah, was used extensively to test flame behavior, trace pollutant emissions including mercury, slagging, corrosion rates, oxy-coal burner operation and flue gas recycle impacts.

This section describes the physical setup and the major equipment used at each facility. Because operating conditions and instrumentation varied depending on the experiment, those details are described in later sections where each distinct experiment and its results are discussed in detail. 


\subsection{Entrained-Flow Reactor (EFR)}

In order to evaluate the importance of $\mathrm{CO}_{2}$ char gasification during oxy-fuel combustion, char combustion temperature measurements were performed in the optical entrained flow reactor at Sandia National Laboratories in Livermore, California. Figure 3.1-1 shows a schematic of the combustion-driven laminar entrained flow reactor and associated particle-sizing pyrometry diagnostic that were employed in this research. The flow reactor features an uncooled matrix burner that produces a high-speed, hightemperature flow into which coal particles are introduced. The matrix burner can produce combustion environments at temperatures ranging from 1000-2100 K with oxygen concentrations ranging from 0-60 vol-\% in either a $\mathrm{N}_{2}$ or $\mathrm{CO}_{2}$ diluent. Furthermore, moisture levels in the reactant gas can be tailored through judicious choice of fuel gases entering the burner at the base of the reactor.

Pulverized coal particles are fed at a low feed rate (typically from 0.5-1.0 g/hr) using a custom-designed agitated bed feeder and delivered along the centerline of the flow reactor via a very low flow of entrainment gas. The particles are heated to more than $1200 \mathrm{~K}$ in less than $10 \mathrm{~ms}$ residence time $\left(10^{5} \mathrm{~K} / \mathrm{s}\right.$ heating rate) and complete devolatilization within a residence time of $15-20 \mathrm{~ms}$. A helium-quench, watercooled sampling probe with a micropore filter is used to sample partially reacted particles at well-defined residence times in the reactor for characterization of char burnout, char and ash chemistry, and char pore properties via ultimate/proximate/ash analysis, Hg porosimetry, BET, SEM, etc. Quartz plate walls contain the flow reactor gases and permit optical measurements to be performed on the entrained particles as they burn.

The reactor operates at ambient pressure (1 atm) and uses a diffusion-flamelet-based Hencken burner to provide a high-speed, high temperature gas flow. Solid fuel particles were introduced at the furnace centerline through a $0.75 \mathrm{~mm}$ stainless-steel tube using a carrier gas flow. For the experiments reported here, the coal feed rate was kept sufficiently low $(\sim 0.6 \mathrm{~g} / \mathrm{hr})$ to assure that the injected particles burned in isolation from one another. A $46 \mathrm{~cm}$ tall $5 \mathrm{~cm} \times 5 \mathrm{~cm}$ square quartz chimney isolates hot combustion gas carrier flow with the reacting particles from the surrounding air and enables in situ optical measurements on the particles injected into the flow.

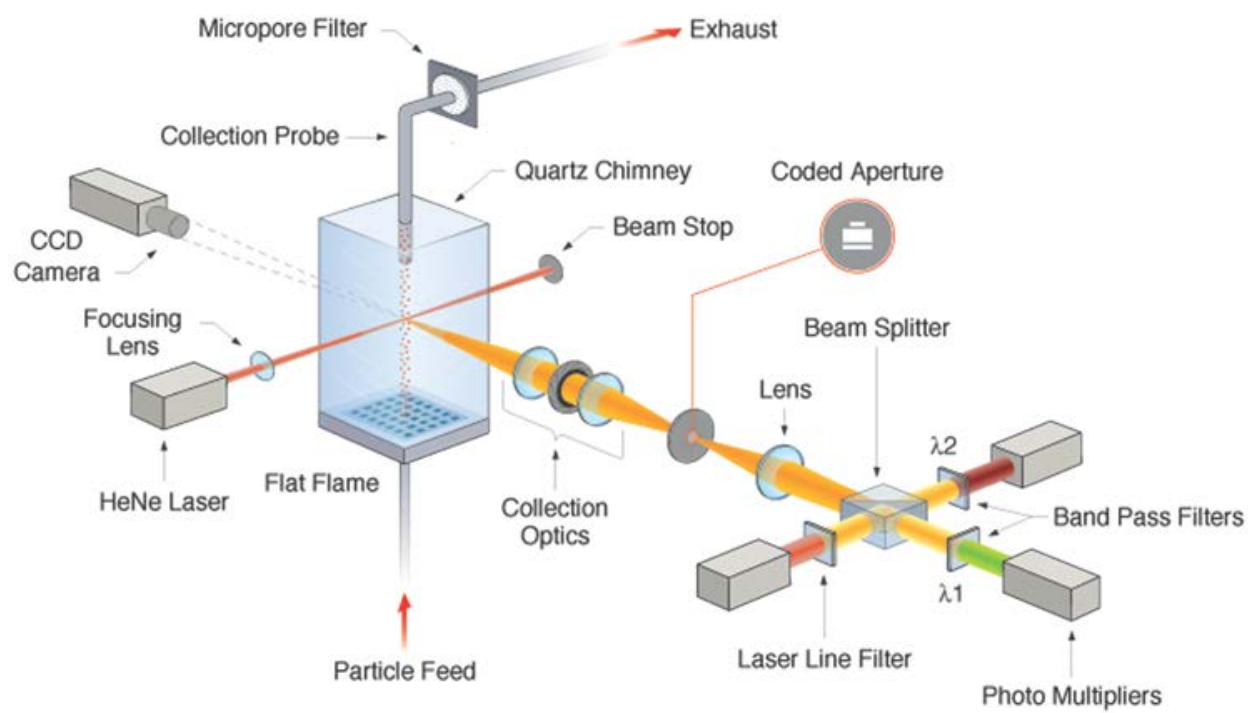

Figure 3.1-1: Schematic of Sandia's laminar entrained flow reactor for coal combustion studies. The particle-sizing pyrometry diagnostic is shown to the right of the flow reactor. 


\subsection{Oxy-Fuel Combustor (OFC)}

The University of Utah owns and operates many pilot-scale furnace facilities. One particular unit has become known as the OFC or oxy-fuel combustor. It is well described in (Morris 2009) but has been included here as well for convenience. It was initially designed and built to perform air and oxy-fired combustion experiments with once through $\mathrm{CO}_{2}$. This furnace operates typically at a $37 \mathrm{~kW}$ thermal firing rate calculated with the higher heating value of a coal. It was rated to as high as $100 \mathrm{~kW}$, but the lower firing rate was found to be much safer and easier to manage. Unlike the other test furnaces used in this research which were already configured for oxy-coal firing, the OFC required a number of modifications to accommodate oxy-coal testing. As a result, a detailed description of the furnace and modifications, including the flue gas recycle system implemented during these tests, is included here to provide background for other researchers interested in modifying pilot-scale furnaces for oxy-coal firing.

\subsubsection{Furnace Design}

The furnace itself is a refractory-lined, down-fired, pulverized coal unit with electric wall heaters in the flame zone, which is the top cylindrical section, to keep the walls at a constant temperature. There are nine sampling ports along the vertical section of the furnace allowing for sampling from a variety of locations. Thermocouples for temperature readings are located throughout the furnace. A schematic of the furnace is shown in Figure 3.2-1.

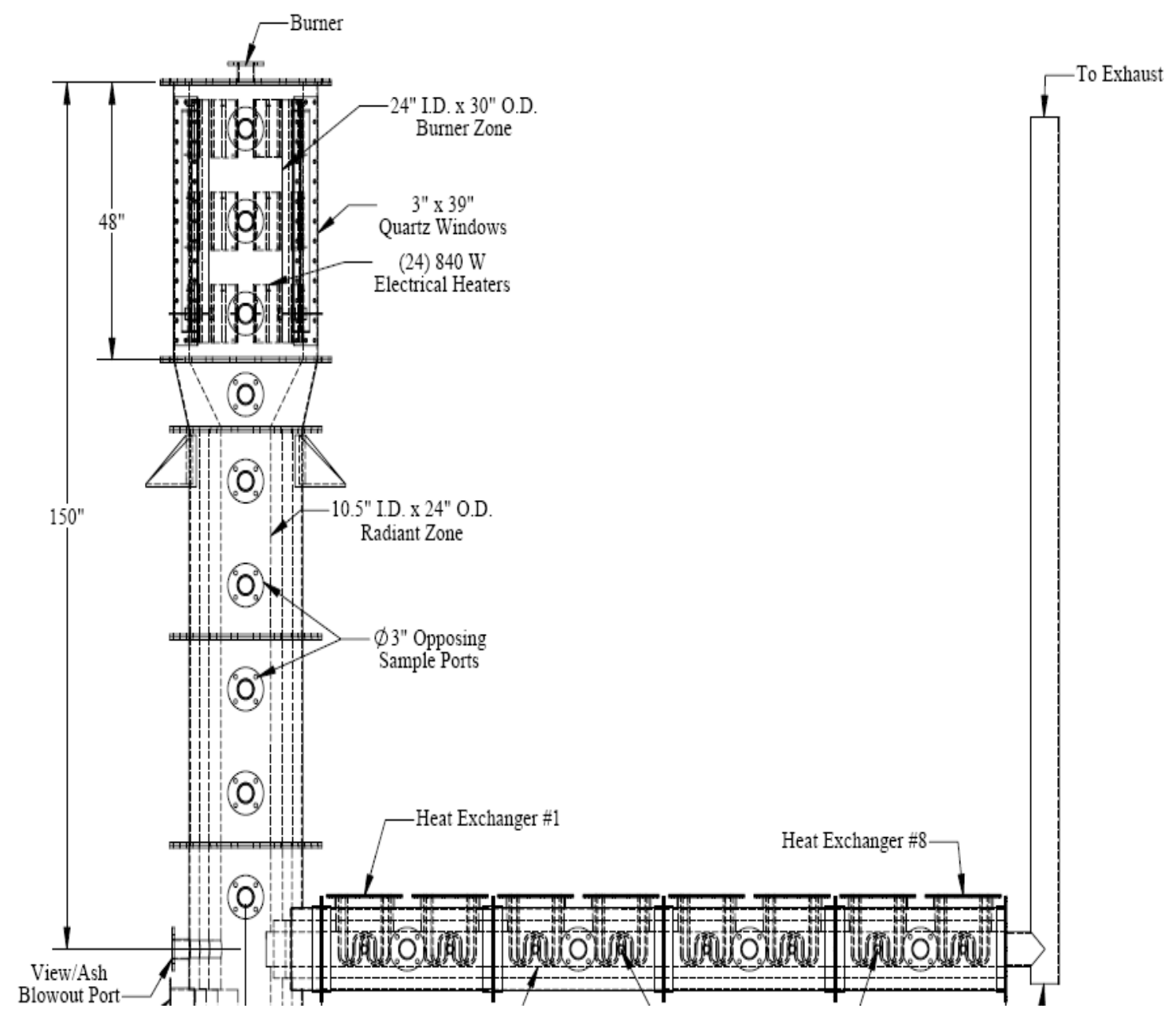

Figure 3.2-1: Schematic of the oxy-fuel combustor shell. 
In the experiments described in this report, all sampling took place at the lowest sampling port (number nine) before the flue gas was directed horizontally through the heat exchangers and then out the exhaust. The only exceptions were the soot tests performed with BYU where sampling occurred at port five just below the diameter reducing section. The ninth port from the top at ground level was used for all other experiments. This sampling location provided an easy work area with ample room to position equipment and was also at the same level as one of the thermocouples allowing for temperature readings of the flue gas as sampled. A thermocouple located opposite the sampling port also allowed for temperature readings at this position. For combustion experiments, the wall heaters were set to a value of $1850^{\circ} \mathrm{F}$ $\left(982^{\circ} \mathrm{C}\right)$ to ensure consistent combustion conditions within the research furnace.

All furnace controls were controlled by an OPTO22 control system with a graphical user interface on a PC in the control room. Furnace residence time, temperatures, and mixing were designed to be as close to a full scale unit as possible. The residence time varied from approximately 2 seconds under air-fired conditions to about 3.8 seconds under OXY32 conditions. This was a calculated value and not a measured value. Gas temperatures of the combustion section exceeded $2000^{\circ} \mathrm{F}(1373 \mathrm{~K})$ which was the measuring limit of the available thermocouples.

The coal feeder was a K-tron twin auger type feeder which had an operating range of 0-2,000 rpm corresponding to a feed rate of 0-20 lbs of coal per hour, which was necessary to maintain the same thermal firing rate over three coals with very different heating values.

The coal feeder fed coal into a steel eductor and was transported to the burner by the primary stream providing the necessary motive air. An electric heater controlled by the OPTO22 control system was used to preheat the primary stream to $350^{\circ} \mathrm{F}(450 \mathrm{~K})$ before the eductor. Due to the high moisture content of the PRB coal, primary air preheating was necessary to prevent the coal, which was fed as-received with 23.69\% moisture, from plugging the eductor.

The primary air was delivered by a 25 horsepower Sullair compressor which provided compressed air through the workshop. The primary air and the secondary air were monitored and controlled by the use of calibrated mass flow controllers which were all controlled with OPTO 22 by a computer work station in the control room of the combustion laboratory. The primary air used an HFC $202 \mathrm{~S} / \mathrm{N}$ while the larger secondary flow required an HFC 203 S/N.

After the retrofit of the furnace, the secondary air was provided by the same blower (Republic Blower model HRB-400) used for recycle flue gas operation, and a 1" sch. 40 valve with an electronic controller and pneumatic positioned was used to provide the necessary pressure drop to control the amount of air in the secondary stream.

For the once through $\mathrm{CO}_{2}$ conditions, both the $\mathrm{O}_{2}$ and the $\mathrm{CO}_{2}$ used in these experiments were generously provided by Praxair. Praxair also provided liquid storage tanks for both the $\mathrm{CO}_{2}$ and the $\mathrm{O}_{2}$. These tanks were both plumbed into the primary and secondary air lines for the burner and controlled through manual valves to select $\mathrm{O}_{2}$ and $\mathrm{CO}_{2}$ instead of air for combustion. The $\mathrm{O}_{2}$ lines were cleaned and used materials such as copper and cleaned stainless steel specified by Praxair's safety recommendations in order to maintain a safe and consistent flow of $\mathrm{O}_{2}$ for use in experiments.

The $\mathrm{O}_{2}$ tank was specially constructed on a concrete drip pad for safety so that the asphalt parking lot could not be fuel for combustion, and was surrounded by concrete pylons and a gated fence to prevent accidental damage or contact with the tank body, heat exchangers, valves, or regulators. All tank and valve adjustments were handled by Praxair service employees. Students only operated the valve that allows oxygen to be fed to the 870 combustion laboratory. 
The $\mathrm{CO}_{2}$ tank provided the necessary dilution $\mathrm{CO}_{2}$ for the combustion atmosphere under once through oxy-fired conditions in the OFC as well as providing the primary stream $\mathrm{CO}_{2}$ for the flue gas recycle conditions and the quench gas for the dilution sampling probe. The $\mathrm{CO}_{2}$ from the tank was controlled by one master valve outside of the building adjacent to the tank and was plumbed into the primary or secondary streams as needed.

It was very important that the $\mathrm{O}_{2}$ flow be shut off from the furnace until the $\mathrm{CO}_{2}$ flow through the furnace was established. Additionally, while changing from air delivery to $\mathrm{O}_{2} / \mathrm{CO}_{2}$ delivery, it was very important that flue gas oxygen analyzers were not sampling the flue gas as an oxygen free $100 \% \mathrm{CO}_{2}$ environment would have destroyed the sensor within the analyzer.

A simple axial burner with swirl was used in order to provide the coal flame for these experiments. The burner was constructed from stainless steel. The burner consisted of three concentric cylinders which comprise the primary jet, through which fuel and motive air or $\mathrm{O}_{2} / \mathrm{CO}_{2}$ were fed, an annulus for natural gas which was not used for any combustion experiments, and the secondary jet, through which the remaining air or $\mathrm{O}_{2} / \mathrm{CO}_{2}$ or flue gas recycle stream was fed to provide enough oxidant for combustion. The primary jet was composed of 3/8" schedule 40 stainless steel pipe with the annulus being a $1 / 2$ " schedule 40 stainless steel pipe, and the secondary being a 11/4" stainless steel schedule 40 pipe with three swirl vanes at approximately a 30 degree angle from vertical wrapped around the annulus.

Motive force for the flue gases was provided by an induced draft fan which provided the necessary suction to draw the flue gases out of the furnace. A damper could be opened to the proper using OPTO 22 controls to maintain the desired pressure within the furnace.

Due to the small scale laboratory experiments an air pollution permit is not required for the University of Utah's combustion facility and there are no emissions control devices found on the OFC except a bag house which is often bypassed when not performing flue gas recycle tests to prevent moisture buildup on the bags while firing natural gas to preheat the furnace.

Two analyzers were used for recording concentration of oxygen in the flue gas: a Yokogawa Zirconium Oxide and a Horiba $\mathrm{O}_{2}$ MPA-510. Three analyzers were used for measuring $\mathrm{CO}_{2}$ concentrations. A ZRH infrared $\mathrm{CO}_{2} / \mathrm{CO}$ by California Analytical Instruments was used for air-fired combustion and measured concentrations of less than $20 \%$ by volume, but was also used to monitor CO in the $0-1,000$ ppm range for all conditions. Another ZRH infrared $\mathrm{CO} 2 / \mathrm{CO}$ by California Analytical Instruments, was used for all oxy-fired conditions and could measure $\mathrm{CO}_{2}$ up to $100 \%$ concentration and $\mathrm{CO}$ in terms of percent volume. Finally a California Analytical Instruments $\mathrm{ZRE} \mathrm{CO}_{2}$ Gas Analyzer was used for both air and oxy conditions as a backup analyzer.

In addition to the $\mathrm{O}_{2}$ and $\mathrm{CO}_{2} / \mathrm{CO}$ analyzers, an $\mathrm{NO} / \mathrm{NO}_{2}$ and an $\mathrm{NO}$ analyzer were also utilized to monitor combustion conditions. The $\mathrm{NO} / \mathrm{NO}_{2}$ analyzer, Thermal Environmental $42 \mathrm{CHL}$, and the NO analyzer, Horiba NO CLA 51055, were both calibrated using an NO in $\mathrm{N}_{2}$ standard for air-fired calibrations and an $\mathrm{NO}$ in $\mathrm{CO}_{2}$ standard for oxy-fired calibrations.

\subsubsection{Flue Gas Recycle System Design and Implementation}

The flue gas recycle system was designed to be retrofitted to the existing oxy-fuel combustor (OFC). It had to meet several criteria. The system needed to be flexible enough to systematically remove particles, water vapor, and $\mathrm{SO}_{2}$. Furthermore, each contaminant removal device in the system was designed to be bypassed so that any one of the contaminants could be allowed to remain in the recycled flue gas to determine its effects on the furnace aerosol particle size distribution as well as chemical composition. 
A blower from Canada Blower, 1” control valve from Rust Automation, and v-cone pressure drop flow meter were specified and installed to withstand particle laden flow. The blower was driven by a Baldor Reliance M2394T electric motor and the housing was a New York blower E05536-100. This setup regrettably did require a significant amount of modification since it was not delivered exactly as specified. The housing had to be sealed with silicon sealant and a shaft seal had to be created. This may have altered the performance of the blower from the factory, but was necessary to minimize air in leakage, and since it was not an off the shelf product, no guarantees were made about its performance, especially given the application.

A bag house was installed to remove particles, and a condenser/scrubber combined system was designed and fabricated to allow removal of water and/or $\mathrm{SO}_{2}$ depending on whether lime is added to the water column in the condenser. The plumbing for the bag house and scrubber system detail is shown in Figure 3.2-2. Flue gas flowed out of the bag house and then around to the bottom of the scrubber where it was bubbled up through the vessel and then exited to the recycle blower.

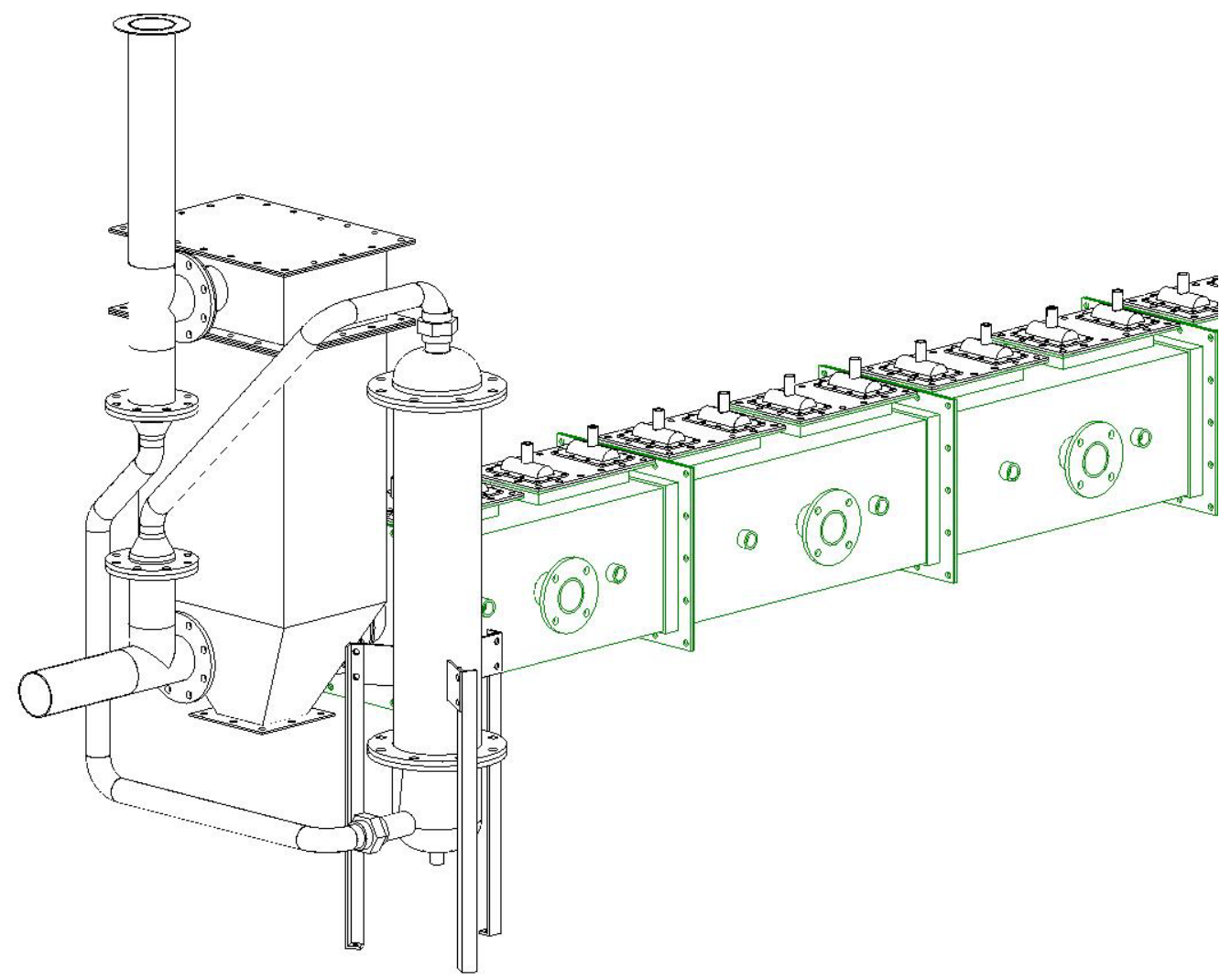

Figure 3.2-2: Schematic of bag house and scrubber assembly plumbing.

The condenser and scrubber unit could be filled with slurry composed of lime and water to provide sulfur removal, or just a water bath, to provide the necessary cooling to condense much of the water vapor in the flue gas. The design was very simple and utilized an 8” schedule 40 stainless steel pipe approximately $1 \mathrm{~m}$ in length that was capped with flanges on each end. Flue gas was then bubbled up through the water column cooling the gas and condensing water vapor for removal from the flue gas. When lime was added to the water column, the $\mathrm{CaO}$ reacted with $\mathrm{SO}_{2}$ in the flue gas producing $\mathrm{CaSO}_{3}$ and $\mathrm{CaSO}_{4}$ which then precipitates out in the bottom of the column providing sulfur capture. This system could also be bypassed by simply disconnecting the column from the flue gas recycle system. The details for the scrubber can be seen in Figure 3.2-3. 


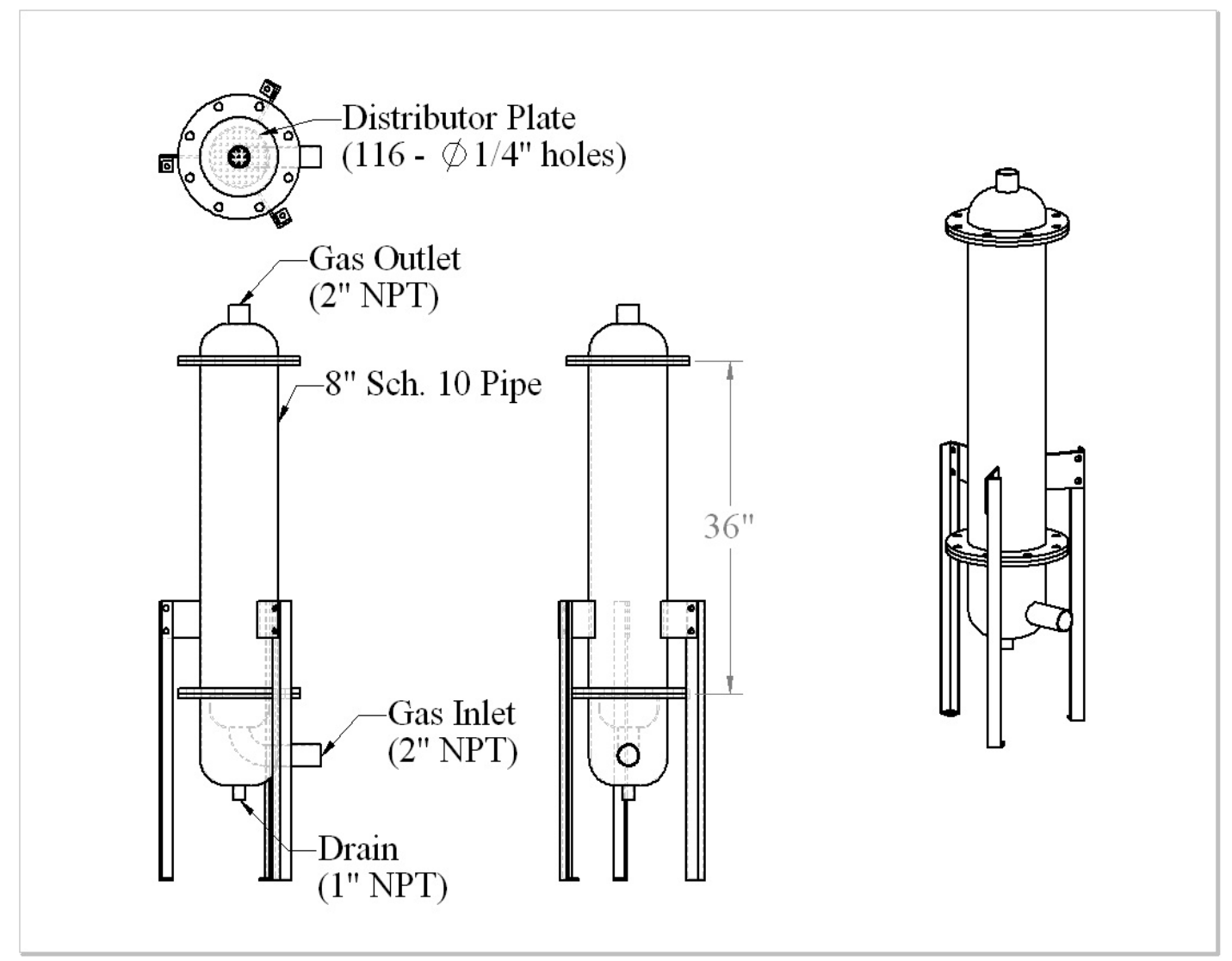

Figure 3.2-3: Scrubber assembly.

In order to facilitate the removal of select contaminants a bag house was constructed from stainless steel plate for particle capture. The bags could simply be removed from the bag house to allow particle laden flow if necessary. The bag house was designed and fabricated in house and utilized six fabric filters. These filters were rated to $473 \mathrm{~K}$ and made of Nomex cloth. The filter size was 5.5 ” by 31 " $(14 \mathrm{~cm}$ by $78.75 \mathrm{~cm}$ ) and readily available from McMaster-Carr. A total of six bags were used, and a pulse system was designed to prevent buildup of particles on the fabric filter. The pulse occurred at 10-minute intervals, but could be set for any period of time using the OPTO22 control system for the OFC. The pulse was controlled by a solenoid that allowed either compressed air or $\mathrm{CO}_{2}$ from an external tank to be directed into the bag to shake off any large deposits of particulate. $\mathrm{CO}_{2}$ from the tank was used for the pulses during oxy-fired conditions to reduce air in leakage. The bag house was located following the heat exchanger section and just before the scrubber/condenser column. A detailed image is shown in Figure 3.2-4.

The desire to recycle both sulfur and particle scrubbed flue gas as well as untreated particle laden flue gas created significant challenges and one blower was not able to be specified that would tolerate high temperatures and particle laden flow while also being able to overcome the significant pressure drop created by the water or slurry column within the scrubber/condenser unit.

As a result, two blowers were utilized. One was a high pressure unit rated at 100 " of $\mathrm{H}_{2} \mathrm{O}$ (25kPa), which was a Republic Blower model HRB-400, while the other was a low pressure unit rated at 20" of $\mathrm{H}_{2} \mathrm{O}$ (5kPa) capable of handling temperatures up to $450^{\circ} \mathrm{F}(505 \mathrm{~K})$ and particle laden flow for use under untreated flue gas recycle conditions. The low pressure unit was sourced from Canada Blower which 
used a Baldor Reliance M2394T electric motor and a New York blower E05536-100 housing specified for $1,000 \mathrm{ft}^{3} / \mathrm{hr}\left(28.3 \mathrm{~m}^{3} / \mathrm{hr}\right)$ but was in reality $40 \mathrm{x}-50 \mathrm{x}$ oversized. This blower had fatal air in leakage as delivered and required the installation of a shaft seal to prevent air in leakage at the point where the drive shaft entered the blower housing. Without this seal in place, it was not possible to achieve stable oxyfired flue gas recycle conditions. With this in place and an extensive amount of sealing of the blower housing assembly with silicon sealant, air in leakage was kept to a minimum and $90 \%$ concentration of $\mathrm{CO}_{2}$ on a dry basis was possible.

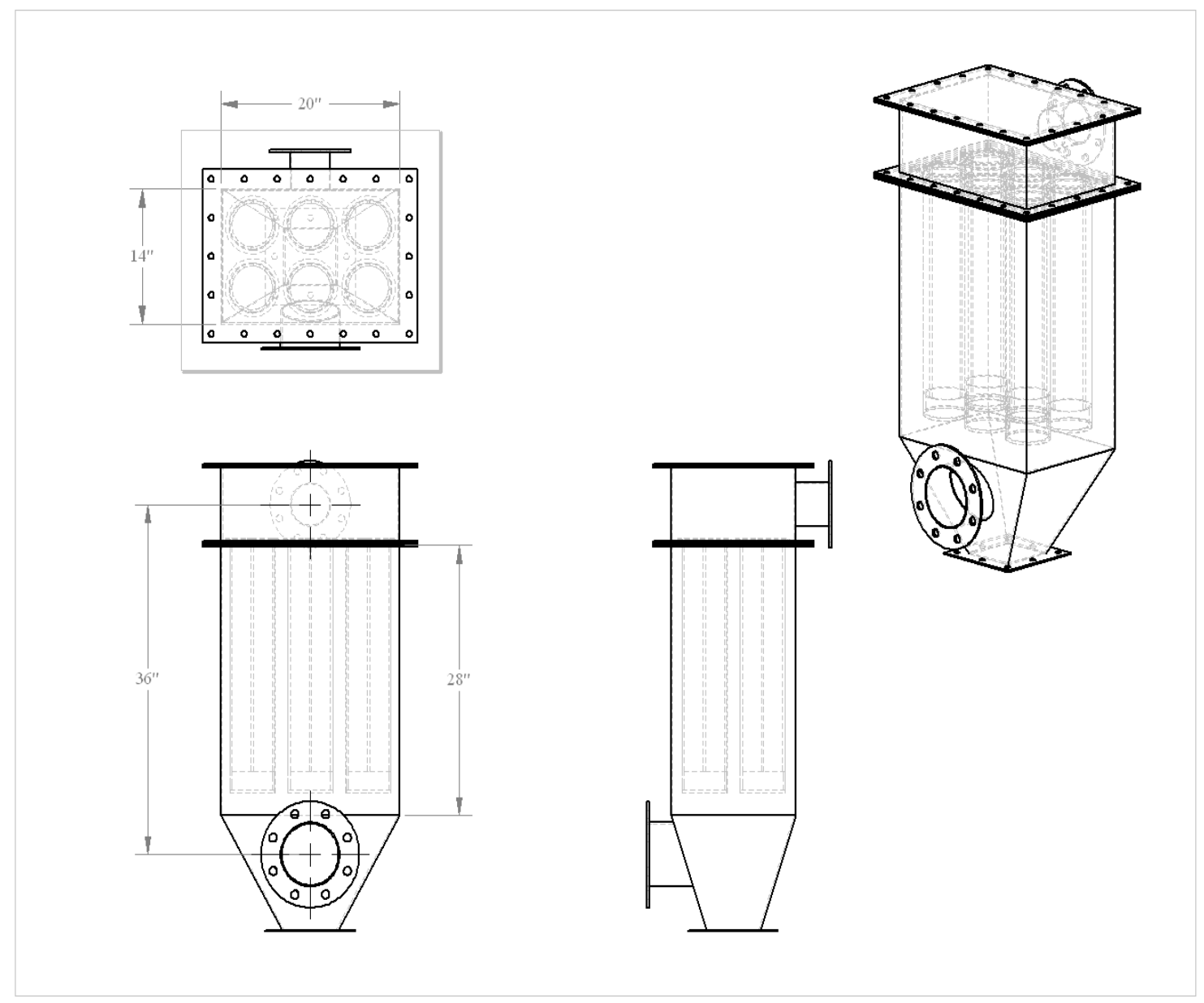

Figure 3.2-4: Bag house diagram.

Recycle loops around each blower were utilized in order to help balance pressures throughout the system and deal with the oversized blower. While this did add complexity, it was critical for stable operation of the system with minimal air in leakage. The inlet valve on recycle loop for the high pressure Republic blower was a manual valve that was opened when the blower was in use. The valve on the recycle loop around the blower was automated with a ABZ valves YT-100RDm532S00 electric controller and pneumatic positioned to provide control of the pressure of the blower. The isolation valve on the inlet of the large blower was automated with the same system and used to provide the necessary pressure drop to meter the flow of the flue gas drawn out of the furnace. Initially, the valve on the recycle loop of the large low pressure valve had been automated, but testing proved that the controller should be moved to the blower inlet for better control. Butterfly valves were utilized to provide the necessary flexibility in pressure drop to achieve balanced pressure through the system. The system was plumbed with stainless 
steel pipe to minimize corrosion. The plumbing for the isolation of each blower and their respective connections to the recycle system are also shown in Figure 3.2-5.

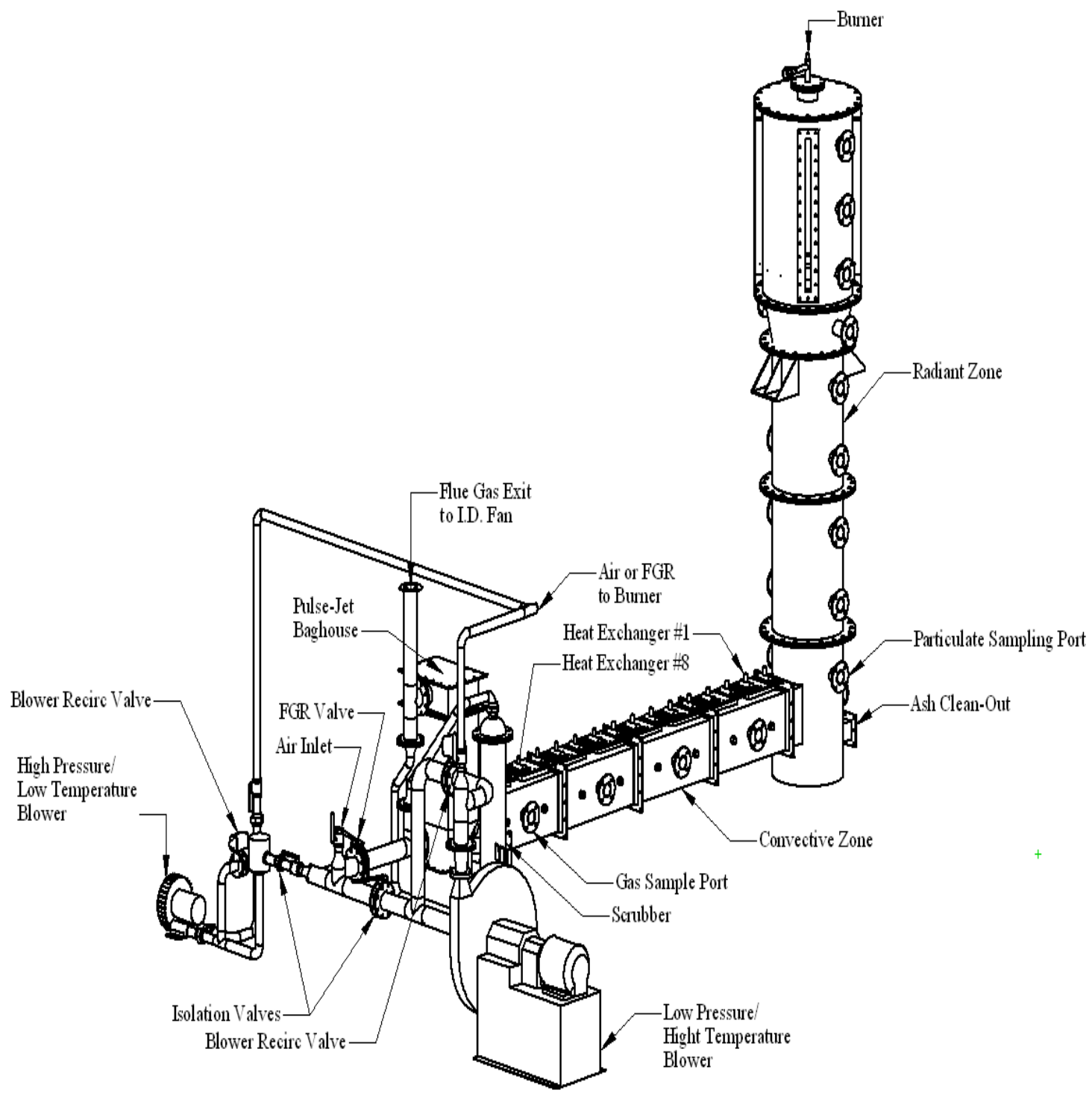

Figure 3.2-5: Schematic of flue gas recycle system added to the OFC.

Due to space and temperature constraints, the blowers and the accompanying valves were located outside of the research building as shown in Figure 3.2-6.

When operating under flue gas recycle (FGR) conditions involving treated flue gas, the flue gas was directed through the bag house and then through the condenser/scrubber unit. An isolation valve would be in the open position allowing the flue gas to enter into the blower section of the FGR loop. Isolation valves were shut around the larger high temperature blower and the isolation valve for the inlet of the high pressure blower was placed in the open position. A particle filter on the high pressure blower inlet was also utilized to provide the necessary protection from potential particulate damage to the blower in case of bag house failure. The blower also utilized an automated valve to control the rate of recycle around the blower itself. This was necessary to maintain the appropriate pressure throughout the 
recycle system, as well as for adapting to the greater pressure drop through the condenser as water vapor condensed and increased the total height of the water column within the device. A detailed diagram illustrating this process is shown in Figure 3.2-7.

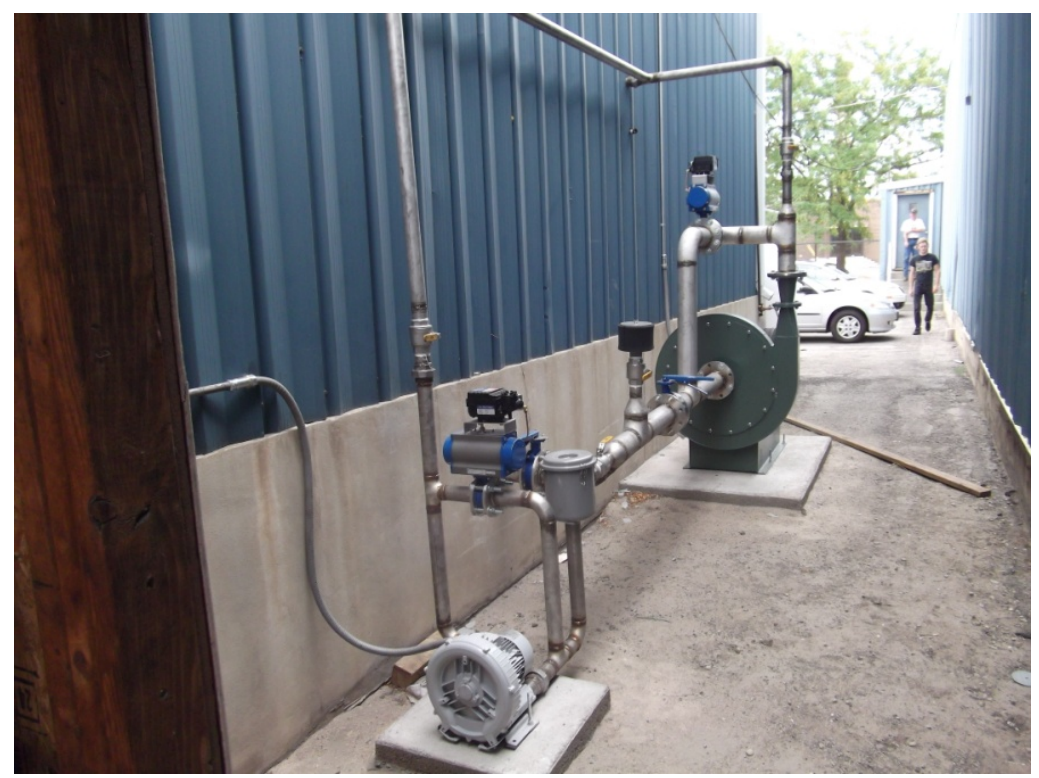

Figure 3.2-6: Picture of the blower configuration outside research building.

The process for recycling untreated flue gas was very similar to the process for recycling treated flue gas. However, the bags were removed from the bag house and the condenser and scrubber were bypassed by replacing the flanged connections of the condenser and scrubber with a section of pipe that allowed for direct flow from the exit of the bag house to the isolation valve for the blower section of the recycle loop.

Once the isolation valve was open, allowing the flue gas to enter the blower section of the loop, the valves for the air inlet and the isolation valves for the smaller high pressure blower had to be shut. The isolation valves for the larger blower were then opened allowing for the untreated flue gas to be recycled into the furnace. This is illustrated in the process flow diagram in Figure 3.2-8. 


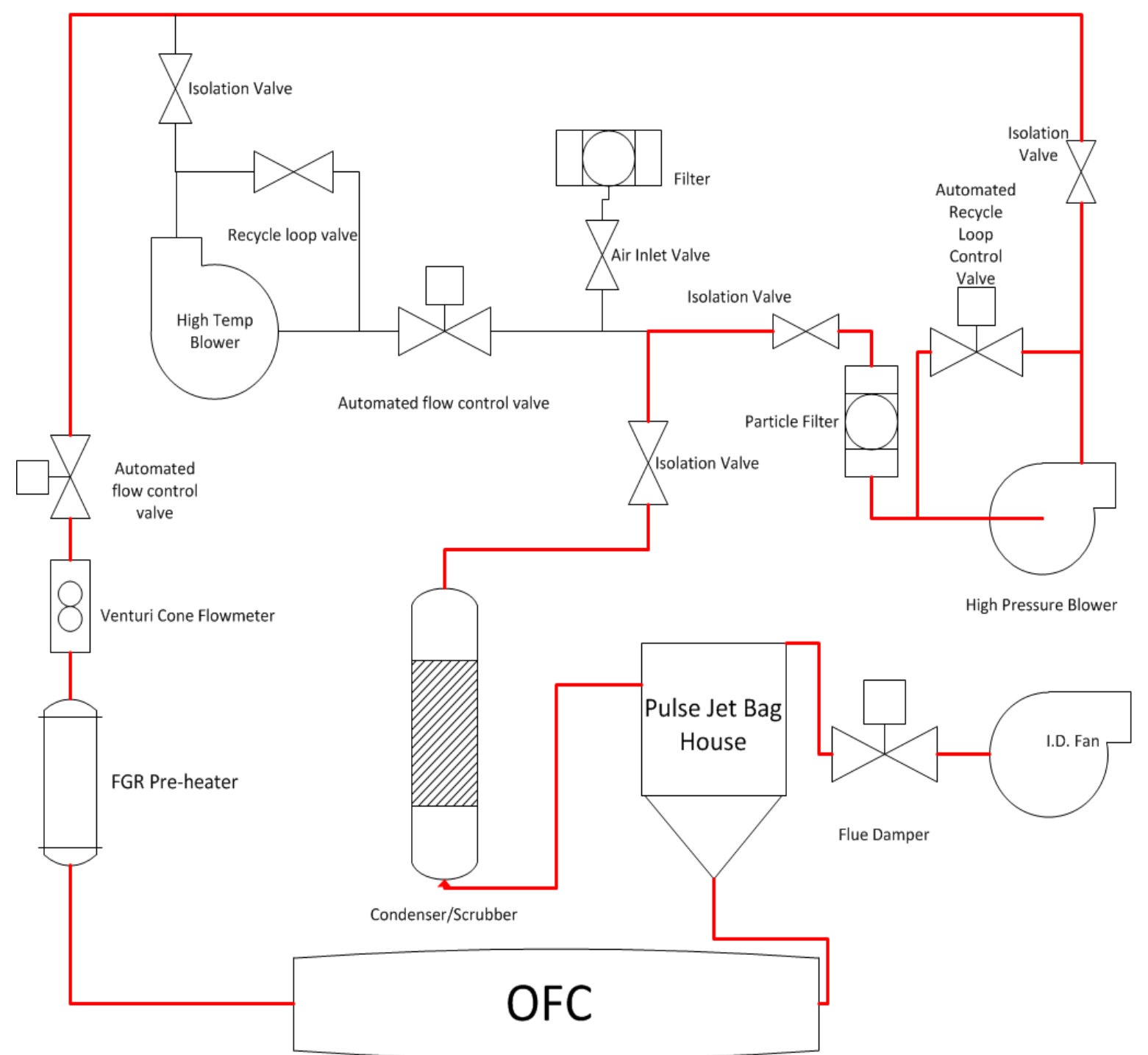

Figure 3.2-7: Process flow diagram for treated flue gas recycle conditions. 


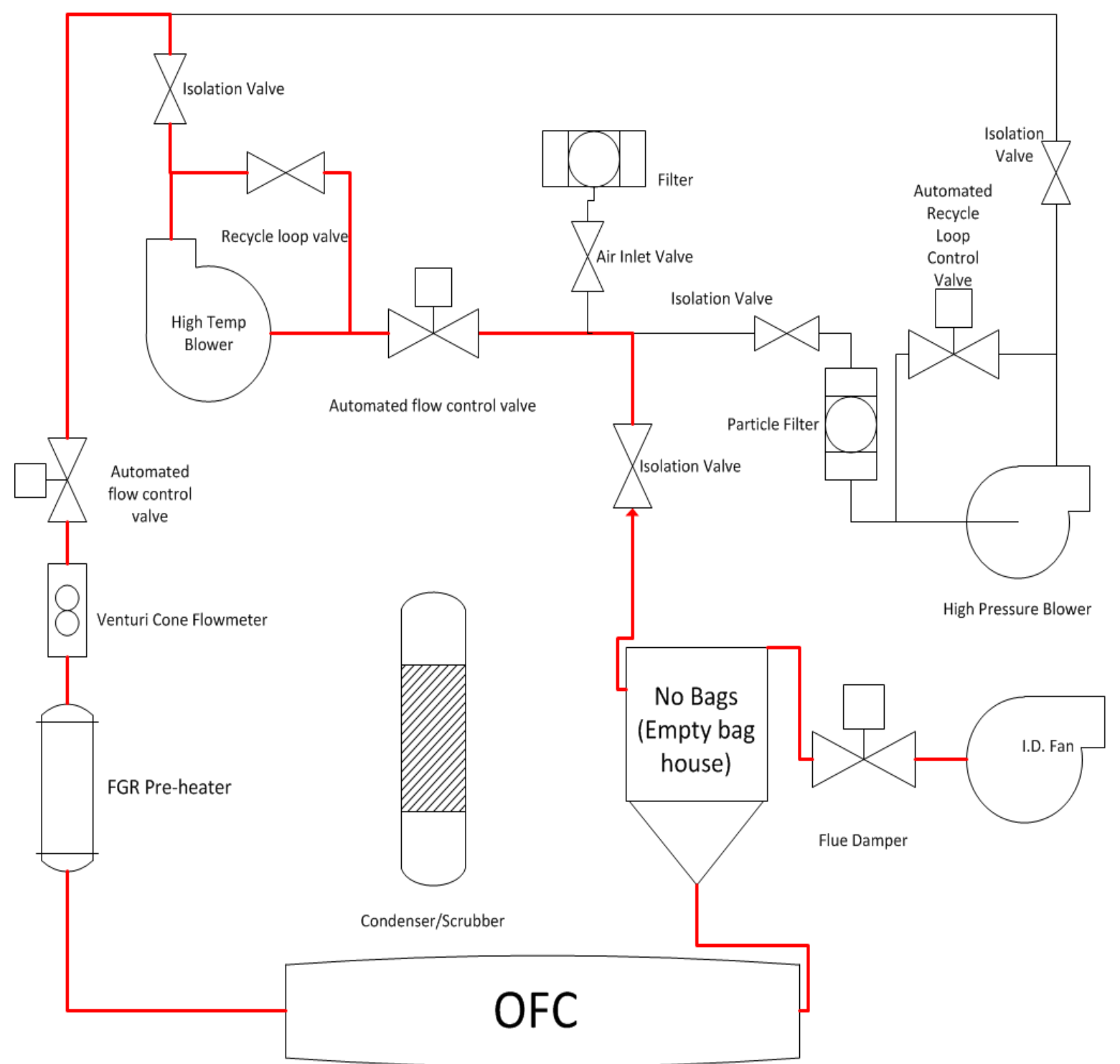

Figure 3.2-8: Process flow diagram for untreated flue gas recycle experiments. 


\subsection{Burner Flow Reactor (BFR)}

The Burner Flow Reactor (BFR) is a $200 \mathrm{~kW}_{\text {th }}$ cylindrical, down-fired, pulverized coal reactor located at Brigham Young University (BYU). It was retrofit for oxy-coal combustion previous to this program. A schematic of the BFR is shown in Figure 3.3-1. The furnace is composed of a top section where the burner is located, six identical sections stacked on top of each other, and a bottom conical section where the combustion gases exit the reactor. The six identical sections combine to make a combustion chamber with a height of $240 \mathrm{~cm}$ (not including the conical section) and a diameter of $75 \mathrm{~cm}$. There are four groups of access ports aligned axially located every 90 degrees around the circumference of the BFR for a total of 24 access ports. The outer wall of the reactor contains a water jacket to keep the outside cool, and the inner wall is constructed of a refractory material and a layer of insulation separates the inner and outer layers.

The burner has inlets for the primary fuel/oxidizer stream and the secondary oxidizer stream. The fuel stream enters through a tube at the top of burner and is injected into the combustion chamber at the top of a water cooled quarl. The secondary stream enters through an upper plenum and travels into a movable block swirl generator. The triangular blocks on the swirl generator are adjustable to allow for a swirl number between 0 and 1.7. When the secondary oxidizer travels through the quarl, its tangential momentum forces it outward radially and creates a low pressure region just below the quarl. This low pressure causes gases and particles to circulate upward toward the burner thus increasing the mixing and stabilizing the flame.

A water cooled probe was used to inject tertiary oxidizer (or burn-out oxidizer) approximately half way down the reactor in order to achieved staged combustion. The tertiary oxidizer can consist of air or $\mathrm{O}_{2} / \mathrm{CO}_{2}$ mixtures but cannot contain recycled flue gas.

Secondary oxidizer was either air or a mixture of recycled flue gas (RFG) and $\mathrm{O}_{2}$. Both $\mathrm{O}_{2}$ flow rate and recycled flu gas flow rate were varied in order to achieve target overall stoichiometric ratios (SR). The desired fraction of $\mathrm{O}_{2}$ in the secondary was achieved by increasing or decreasing the recycle flow rate at a fixed $\mathrm{O}_{2}$ flow rate. The flue gas handling system was insulated to keep the secondary oxidizer temperature above $350^{\circ} \mathrm{F}\left(177^{\circ} \mathrm{C}\right)$ at all locations. The flow rate of the RFG was monitored by oxygen concentration measurements before and after adding a known amount of oxygen into the stream. Adjustments in the RFG flow rate were made by adjusting the flue gas recycle (FGR) fan speed.

This furnace was used for additional soot measurements during the program. 

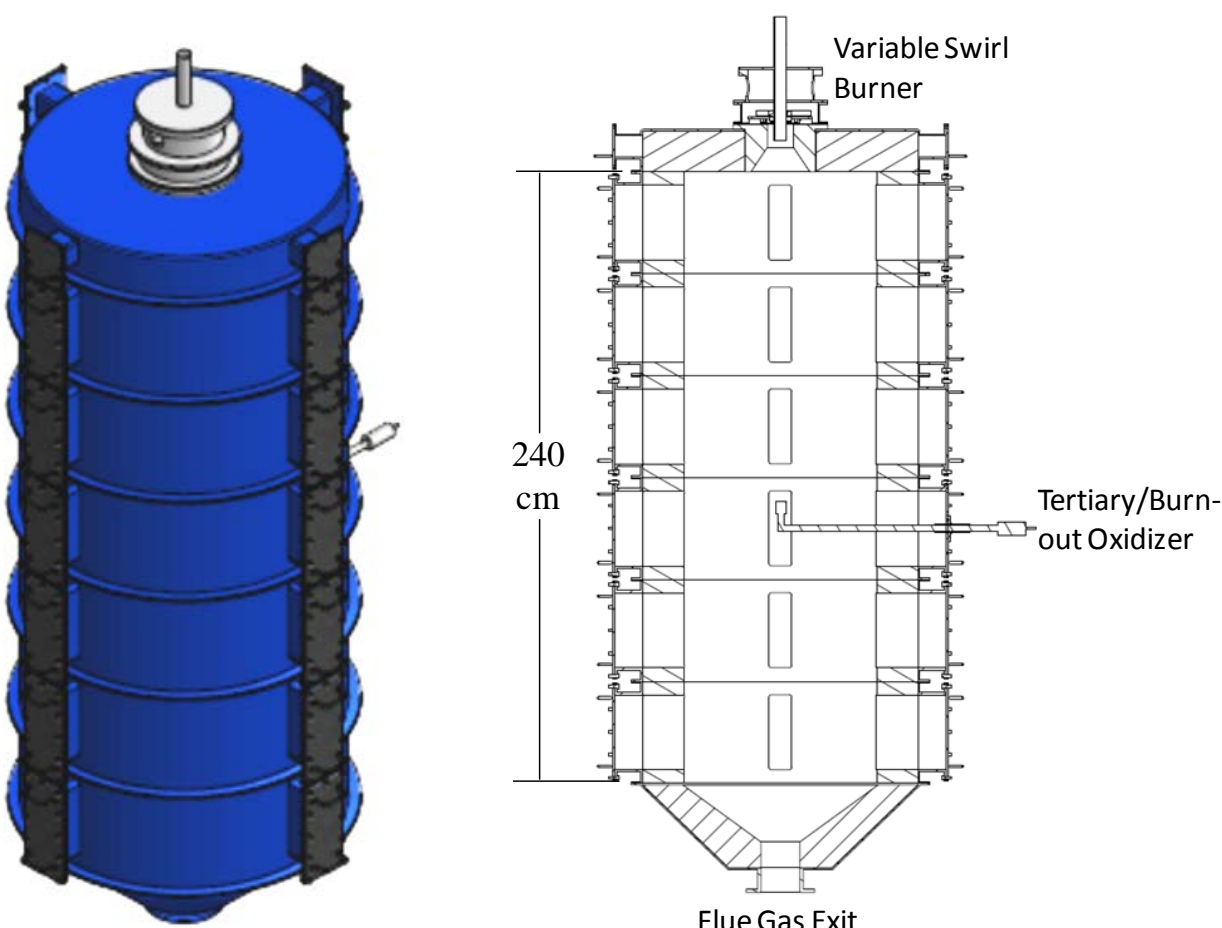

Flue Gas Exit

Figure 3.3-1: Schematic of Burner Flow Reactor (BFR) at Brigham Young University. 


\subsection{Pilot-Scale Furnace (L1500)}

The L1500 is a $5 \mathrm{MBtu} / \mathrm{hr}(1500 \mathrm{~kW})$ pulverized coal furnace that was developed in the early 1990's to investigate $\mathrm{NO}_{\mathrm{x}}$ control strategies at the University of Utah. The furnace was operated at $3.5 \mathrm{MBtu} / \mathrm{hr}(\sim 1$ $\mathrm{MW}_{\mathrm{t}}$ ) for the tests during this program. The reaction zone of this furnace has a one-meter, square cross section and is approximately 14 meters in length. The length is divided into 10 sections, each with various sampling and injection ports. The furnace is refractory lined, with cooling panels in the first four sections to maintain realistic boiler temperature profiles. The multiple ports are located in each of the reactor sections allow numerous alternative configurations of sampling, overfire air, and reagent injection.

A major objective of this furnace design is to study pollutant formation and control, carbon utilization, and ash management in a system which operates similar to commercial boilers. Therefore, the L1500 pilot-scale furnace has the following characteristics:

- Simulates the range of temperature histories that are found in commercial units.

- Includes the ability to fire single or multiple gas burners and/or coal burners.

- Has the provision for evaluating different slag screen designs for improved ash management.

- Has the capability to test different reburning and burnout air injection locations and velocities for emissions control.

- Provides simulated waterwall area (if desired) for deposition studies.

- Permits multiple locations for coal injection such that coal and/or gas can be used as reburning fuels independent of main firing burner.

- Has adequate sample/observation ports for measuring all inputs and outputs as well as ports to allow detailed species and temperature profiles to be obtained.

- Has a completely instrumented control room adjacent to the facility to control the operation of the furnace and to record and analyze data.

The overall combustion facility includes the air supply system, water supply and cooling system, L1500 combustor, fuel supply systems (either gas or coal or both), a flue-gas cooling chamber, scrubber, and induced-draft fan and a stack.

This furnace was retrofitted for oxy-coal combustion research previous to the current test program. Modifications to this furnace included a baghouse for particulate removal from the flue gas, a flue gas recycle system, and oxygen storage and metering equipment. The furnace is equipped with a bank of analyzers to measure major flue gas constituents, a high temperature camera to record video of flame behavior, many access ports for measurement, sample collection and reagent injection. Praxair provided the oxygen and $\mathrm{CO}_{2}$ tanks and oxygen and $\mathrm{CO}_{2}$ gases for the testing in this program. Feed lines to the L1500 furnace and the radiative section are shown in Figure 3.4-1. Downstream heat exchangers and baghouse can be seen in the schematic diagram in Figure 3.4-2.

Subsequent to the initial program testing, the ductwork between the convective section and baghouse on the furnace was extended to increase flue gas cooling and provide a temperature profile more representative of flue gases exiting an economizer in a utility boiler. This provided a more realistic environment in which to evaluate mercury control additive performance and low temperature bromine corrosion. A photograph of the modified section is shown in Figure 3.4-3.

Additional furnace details relevant to the specific tests conducted are described in the individual test result sections of this report. 


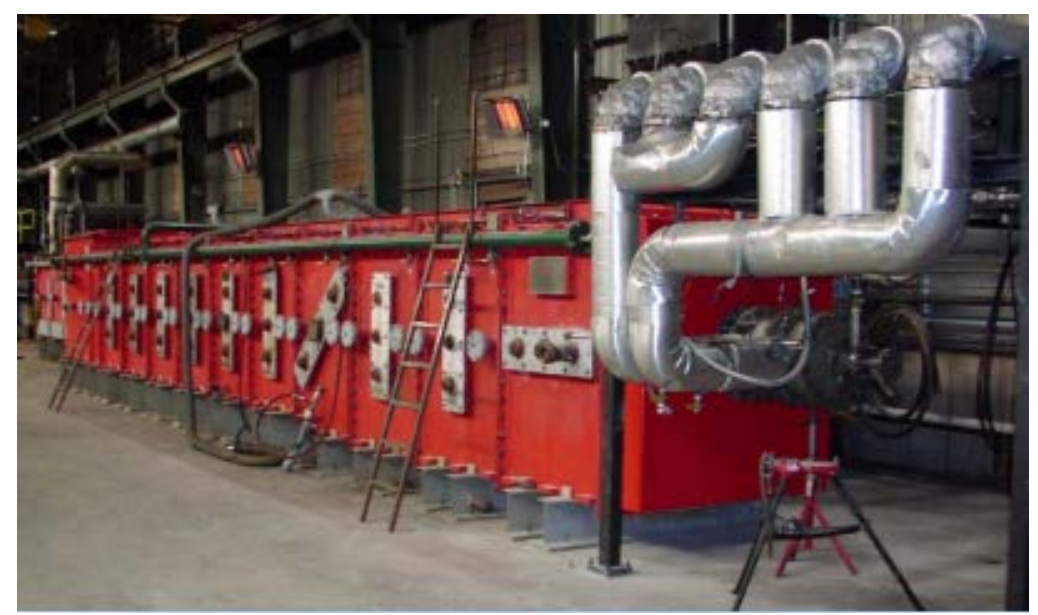

Figure 3.4-1: L1500 facility at the University of Utah.

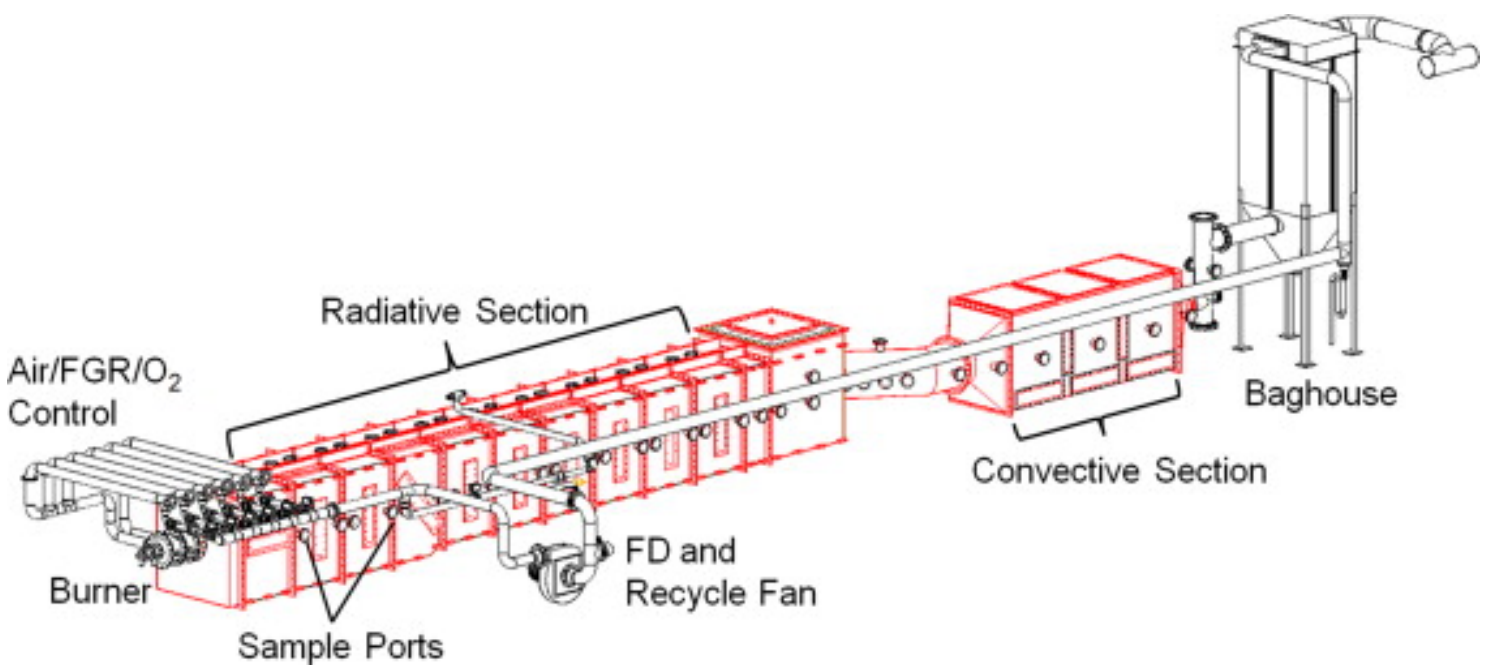

Figure 3.4-2: Schematic diagram of L1500 furnace, heat exchangers, and baghouse.

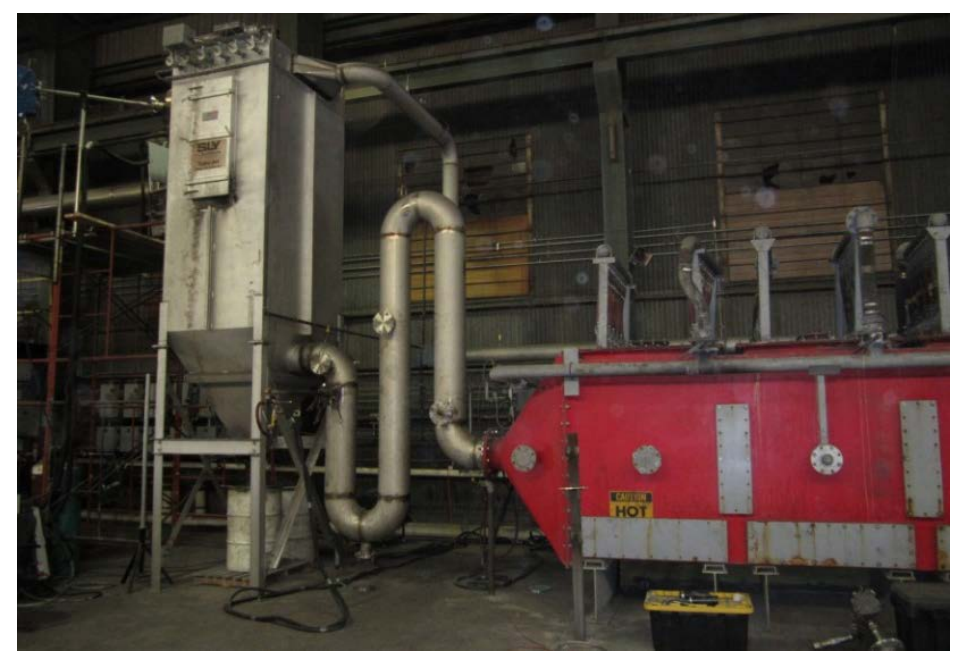

Figure 3.4-3: Picture of modified ductwork at L1500 furnace exit. 


\subsection{Test Coals}

In order to systematically evaluate the effects of coal composition on oxy-combustion properties, a certain set of coals was selected for evaluation. For the majority of the project three coals were used: western low sulfur bituminous from Utah (Skyline), low sulfur sub-bituminous from Powder River Basin (North Antelope), and high sulfur bituminous from the Illinois basin (Shay). These coals represent similar chemistry to those which are widely used throughout the US, thus providing practical results which could be translated to a wide range of coals used in the US as well as coals used abroad with similar chemical compositions. In addition to these coals, a fourth coal from Alabama (Pratt North River) was used for mercury testing at the end of the program. This medium-sulfur bituminous coal was chosen because of its relatively high mercury content. Table 3.5-1 shows the results of proximate and ultimate analyses performed on each of these coals.

Table 3.5-1: Coal composition analysis for the coals investigated throughout this report.

\begin{tabular}{|c|c|c|c|c|}
\hline \multicolumn{5}{|c|}{ Coal Analysis } \\
\hline & Utah Skyline & $\begin{array}{l}\text { PRB North } \\
\text { Antelope }\end{array}$ & $\begin{array}{l}\text { Illinois \#6 } \\
\text { Shay }\end{array}$ & $\begin{array}{c}\text { Alabama } \\
\text { Pratt }\end{array}$ \\
\hline $\mathbf{C}$ & 70.60 & 53.72 & 64.67 & 69.23 \\
\hline $\mathbf{H}$ & 5.05 & 3.57 & 4.51 & 4.82 \\
\hline $\mathbf{N}$ & 1.42 & 0.78 & 1.12 & 1.69 \\
\hline $\mathbf{S}$ & 0.53 & 0.23 & 3.98 & 2.22 \\
\hline $\mathbf{O}$ & 10.39 & 13.07 & 8.08 & 6.54 \\
\hline Ash & 8.83 & 4.94 & 7.99 & 13.14 \\
\hline Moisture & 3.18 & 23.69 & 9.65 & 2.38 \\
\hline Volatile Matter & 38.60 & 33.36 & 36.78 & 35.64 \\
\hline Fixed Carbon & 49.39 & 38.01 & 45.58 & 48.85 \\
\hline HHV, Btu/lb & 12,606 & 9,078 & 11,598 & 12,659 \\
\hline \multicolumn{5}{|c|}{ Mineral Matter Analysis } \\
\hline $\mathrm{Al}$ as $\mathrm{Al}_{2} \mathbf{O}_{3}$ & 14.52 & 14.78 & 17.66 & 25.91 \\
\hline $\mathrm{Ca}$ as $\mathrm{CaO}$ & 6.11 & 22.19 & 1.87 & 3.41 \\
\hline $\mathrm{Fe}$ as $\mathrm{Fe}_{2} \mathrm{O}_{3}$ & 5.09 & 5.20 & 14.57 & 13.20 \\
\hline Mg as MgO & 1.39 & 5.17 & 0.98 & 1.18 \\
\hline Mn as $\mathrm{MnO}$ & 0.02 & 0.01 & 0.02 & 0.04 \\
\hline $\mathbf{P}$ as $\mathbf{P}_{2} \mathbf{O}_{5}$ & 0.59 & 1.07 & 0.11 & 0.83 \\
\hline $\mathrm{K}$ as $\mathrm{K}_{2} \mathrm{O}$ & 0.57 & 0.35 & 2.26 & 2.33 \\
\hline $\mathrm{Si}$ as $\mathrm{SiO}_{2}$ & 60.89 & 30.46 & 49.28 & 44.78 \\
\hline $\mathrm{Na}$ as $\mathrm{Na}_{2} \mathrm{O}$ & 1.41 & 1.94 & 1.51 & 0.47 \\
\hline $\mathrm{S}$ as $\mathrm{SO}_{3}$ & 2.33 & 8.83 & 2.22 & 3.72 \\
\hline $\mathrm{Ti}$ as $\mathrm{TiO}_{2}$ & 0.88 & 1.30 & 0.85 & 1.25 \\
\hline
\end{tabular}




\section{RESULTS AND DISCUSSION}

The following sections describe the technical results from the experiments and modeling tasks on the program. The experimental descriptions, model setups, results and discussions are for the most part selfcontained in each section. The exception to this is the references, which are combined at the end of this report.

Each of the several experiments and studies described in this section was designed to generate fundamental data and mechanisms and/or sub-models to thoroughly characterize the differences between air-fired and oxy-fired coal combustion.

The first four sections (4.1 through 4.4) outline the development and testing of a burner that was designed to accommodate several configurations of oxy-fired coal combustion in the L1500 pilot-scale furnace. Parametric testing of this burner was subdivided into two test periods: December 2009 to January 2010 and April 2010; test results are reported for each period. Flame attachment, flame shape, furnace wall temperature, heat flux, and $\mathrm{SO}_{2}$ and $\mathrm{NO}_{\mathrm{x}}$ concentrations were analyzed under varying burner configurations and operating conditions. During air-fired testing, manipulated variables included the primary air/fuel ratio, secondary air distribution, and burner staging. Parameters investigated under oxyfire conditions included the primary $\mathrm{O}_{2}$ concentration, burner stoichiometric ratio, and primary gas/fuel mass ratio. Metals testing for mercury, arsenic and selenium was also conducted during this period.

The next seven sections (4.5 through 4.11) describe the effects of oxy-combustion on char oxidation, soot, aerosols, slagging and fouling, corrosion, radiative heat transfer and mercury control additives. Each section describes the instrumentation and methods (or, in the case of modeling studies, the equations and numerical models) employed in setting up and performing the experiment. Where appropriate, these sections provide detailed theoretical mechanisms for air-fired combustion that have been refined and updated to describe oxy-fired operation. The results from each of these studies have been carefully developed into quantitative models and integrated into REI's Glacier computational fluid dynamic (CFD) code.

The last two sections describe the major CFD modeling efforts for the program. The first of these describes a comparison between predicted and measured results for the L1500 pilot-scale furnace. The second describes the simulations of two full-scale oxy-retrofit systems, one for PacifiCorp's Hunter Unit 3, the other for DTE's River Rouge Unit 3. The final section also contains a summary of mercury simulation results for the two oxy-retrofit boilers based on REI's MerSim process simulator. 


\subsection{Pilot-Scale Oxy-Research Burner Development}

\subsubsection{Introduction}

The existing burner on the University of Utah's pilot-scale furnace is a dual-register, low-NOx burner with a nominal firing rate of $1.47 \mathrm{MW}(5 \mathrm{MBtu} / \mathrm{hr})$. The existing low- $\mathrm{NO}_{\mathrm{x}}$ burner is detailed in Figure 4.1-1.

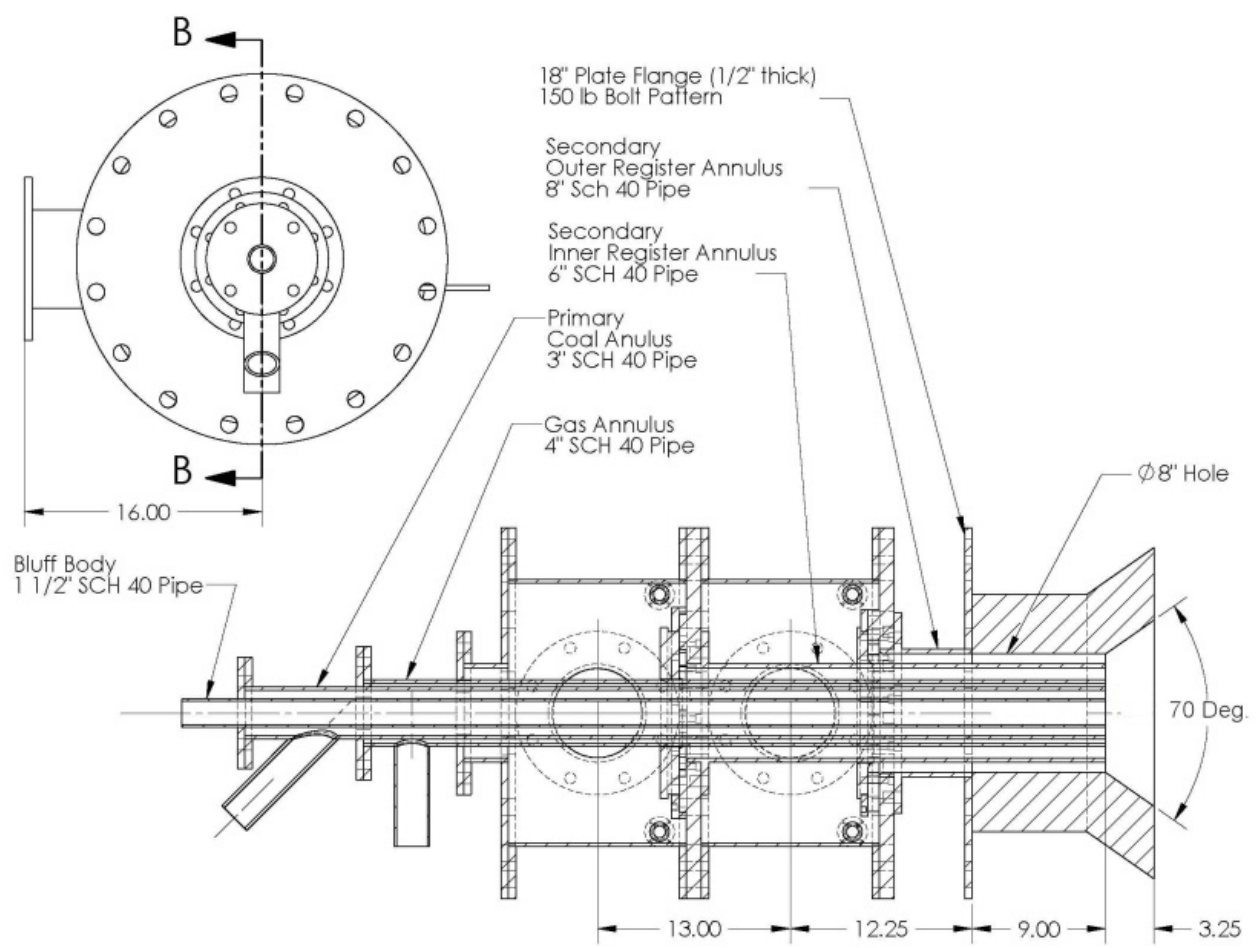

Figure 4.1-1: Low-NO $\mathrm{N}_{\mathrm{x}}$ burner currently installed on the L1500.

Recently, some effort was focused on more tightly controlling the temperature profile of the furnace and eliminating transient thermal behavior. In accordance with this effort, new cooling panels were installed on the walls of the first four sections of the furnace and the furnace was derated to 1.03 MW (3.5 $\mathrm{MBtu} / \mathrm{hr}$ ). These adjustments were successful in producing a stable furnace temperature profile. However, the velocities at the burner face are now somewhat low, resulting in a stable and attached flame almost irrespective of operating condition. A burner designed for a firing rate of $1.03 \mathrm{MW}$ (3.5 MBtu/hr) would allow stability response to burner operating conditions that is representative of a full-scale commercial burner. In addition to size benefits, the new burner should have integrated hardware for targeted oxygen injection in the primary and in the inner secondary registers.

Directly stated, the design criteria for the oxy-research burner were:

- Flexible mixing strategies for FGR, $\mathrm{O}_{2}$ and fuel. This capability is inherent in the gas train of the L1500, where $\mathrm{O}_{2}$ and FGR can be mixed in any ratio, in any register of the burner.

- The flame should be attached within the quarl at operating conditions of $1.03 \mathrm{MW}$ (3.5 MBtu/hr) for both air and oxy-fired operation.

- Hardware should be incorporated for targeted oxygen injection within the primary and the inner secondary registers. 
The initial design of the oxy-research burner was based on a patented commercial-scale design by Siemens Energy Inc. This design was reduced to a 1.03 MW (3.5 MBtu/hr) firing rate using a constant velocity scaling technique evaluated by the IFRF (Smart and Morgan 1992) (Smart, van de Kamp and Morgan 1989). The initial design was evaluated and compared to operation of the existing burner using CFD modeling. CFD modeling was then used to evaluate a series of geometry and operational modifications that would allow the burner to meet the design criteria.

\subsubsection{Burner Modeling}

\subsubsection{Overview}

The following discussion is an overview of the cases that were modeled in support of the design of the oxy-research burner. A total of 19 cases have been modeled. These cases are listed in chronological order in Table 4.1-1 including an identifier and a brief case description. The case identifier includes information about the operating conditions unique to each case for clarity in reporting the results.

The first two cases modeled, LNB-A and LNB-O, were of the existing low- $\mathrm{NO}_{\mathrm{x}}$ burner under air and oxyfired conditions. The purpose of these cases was to identify typical temperatures and radiative heat transfer in the near burner region of the furnace. This information was used in the design of the new burner.

Table 4.1-1: Description of all cases modeled.

\begin{tabular}{ll}
\multicolumn{1}{c}{ Case Identifier } & \multicolumn{1}{c}{ Case Description } \\
\hline LNB-A & Existing Low-NOx Burner (Air-Fired) \\
LNB-O & Existing Low-NOx Burner (Oxy-Fired) \\
OXY-A & Oxy-Research Burner, Design 1 (Air-Fired) \\
OXY-O & Oxy-Research Burner, Design 1 (Oxy-Fired) \\
OXY-Vel80A & Oxy-Research Burner, Design 1, 24.4 m/s (80 ft/s) Primary (Air-Fired) \\
OXY-Vel80O & Oxy-Research Burner, Design 1, $24.4 \mathrm{~m} / \mathrm{s}$ (80 ft/s) Primary (Oxy-Fired) \\
OXY-Vel70A & Oxy-Research Burner, Design 1, $21.3 \mathrm{~m} / \mathrm{s}$ (70 ft/s) Primary (Air-Fired) \\
OXY-Vel70O & Oxy-Research Burner, Design 1, 21.3 m/s (70 ft/s) Primary (Oxy-Fired) \\
OXY-Vel60A & Oxy-Research Burner, Design 1, 18.3 m/s (60 ft/s) Primary (Air-Fired) \\
OXY-Vel60O & Oxy-Research Burner, Design 1, 18.3 m/s (60 ft/s) Primary (Oxy-Fired) \\
OXY-ParA & Oxy-Research Burner, Design 2, 21.3 m/s (70 ft/s) Primary (Air-fired) \\
OXY-ParO & Oxy-Research Burner, Design 2, 21.3 m/s (70 ft/s) Primary (Oxy-Fired) \\
OXY-ParLO2 & Oxy-Research Burner, Design 2, Low Primary O2 (Oxy-Fired) \\
OXY-ParPRBA & Oxy-Research Burner, Design 2, PRB Fuel (Air-fired) \\
OXY-ParPRBO & Oxy-Research Burner, Design 2, PRB Fuel (Oxy-Fired) \\
OXY-ParREFA & Oxy-Research Burner, Design 2, Refined Mesh (Air-Fired) \\
OXY-Qua4A & Oxy-Research Burner, Design 2, 10.16 cm (4 in.) Quarl (Air-Fired) \\
OXY-Qua6A & Oxy-Research Burner, Design 2, 15.24 cm (6 in.) Quarl (Air-fired) \\
OXY-Qua4O & Oxy-Research Burner, Design 2, 10.16 cm (4 in.) Quarl (Oxy-Fired) \\
\hline
\end{tabular}

The cases OXY-A and OXY-O were the first air and oxy-fired cases, respectively, modeled of the initial design of the oxy-research burner and the conditions used in the model were those recommended by Siemens for operation of this burner. Based on the OXY-A and OXY-O modeling results it was determined that lower primary velocities should be investigated for a burner of this scale. The next six cases, OXY-Vel80A through OXY-Vel60O, were designed to investigate the behavior of the burner as a 
function of velocity, under air and oxy-fired conditions. The results of these cases indicated that the airfired conditions could be used to establish the stability of the burner for specific design criteria and that a $21.3 \mathrm{~m} / \mathrm{s}(70 \mathrm{ft} / \mathrm{s})$ primary velocity was a reasonable compromise between flame stabilization location and typical burner velocities.

The next step in burner design was to reassign the burner shape parameters to accommodate a $21.3 \mathrm{~m} / \mathrm{s}$ (70 ft/s) primary, a bluff body for targeted oxygen injection in the primary and hardware to inject oxygen in the inner register of the secondary. Based on these design modifications, five conditions were modeled. The OXY-ParA and OXY-ParO cases incorporated conditions that were expected to be "typical". The OXY-Par LO2 case was used to determine the flame stabilization location at a low primary $\mathrm{O}_{2}$ concentration. The OXY-ParPRBA and OXY-ParPRBO cases were air and oxy-fired combustion of the PRB coal (resulting in a slightly higher primary velocity). The OXY-ParREFA was designed to investigate the sensitivity of the model to mesh refinement. This case uses identical conditions to the OXY-ParA case but the meshing scheme was refined from about 900,000 cells to approximately 1.9 million cells to evaluate the sensitivity of results to computational grid refinement.

Based on the parametric modeling, it was determined that the flame stabilization location could be pulled closer to the burner by lengthening the quarl. The cases OXY-Qua4A and OXY-Qua6A have identical operating conditions to OXY-ParA with the quarl adjusted from 2 inches to 4 and 6 inches, respectively. The OXY-Qua4O case uses identical conditions to OXY-ParO but with a 4-inch quarl.

\subsubsection{Modeling Conditions}

The geometry of the oxy-research burner is characteristic of Siemens patented burner design, including a flower shaped primary, flame stabilization tabs and straightening vanes on the inner secondary. A diagram of the burner geometry and key design parameters is detailed in Figure 4.1-2. The values of the key design parameters for cases OXY-A through OXY-Vel60O are included in Table 4.1-2. A 1-inch quarl was used for the OXY-A and OXY-O cases and a 2-inch quarl was used for the remainder of these cases.

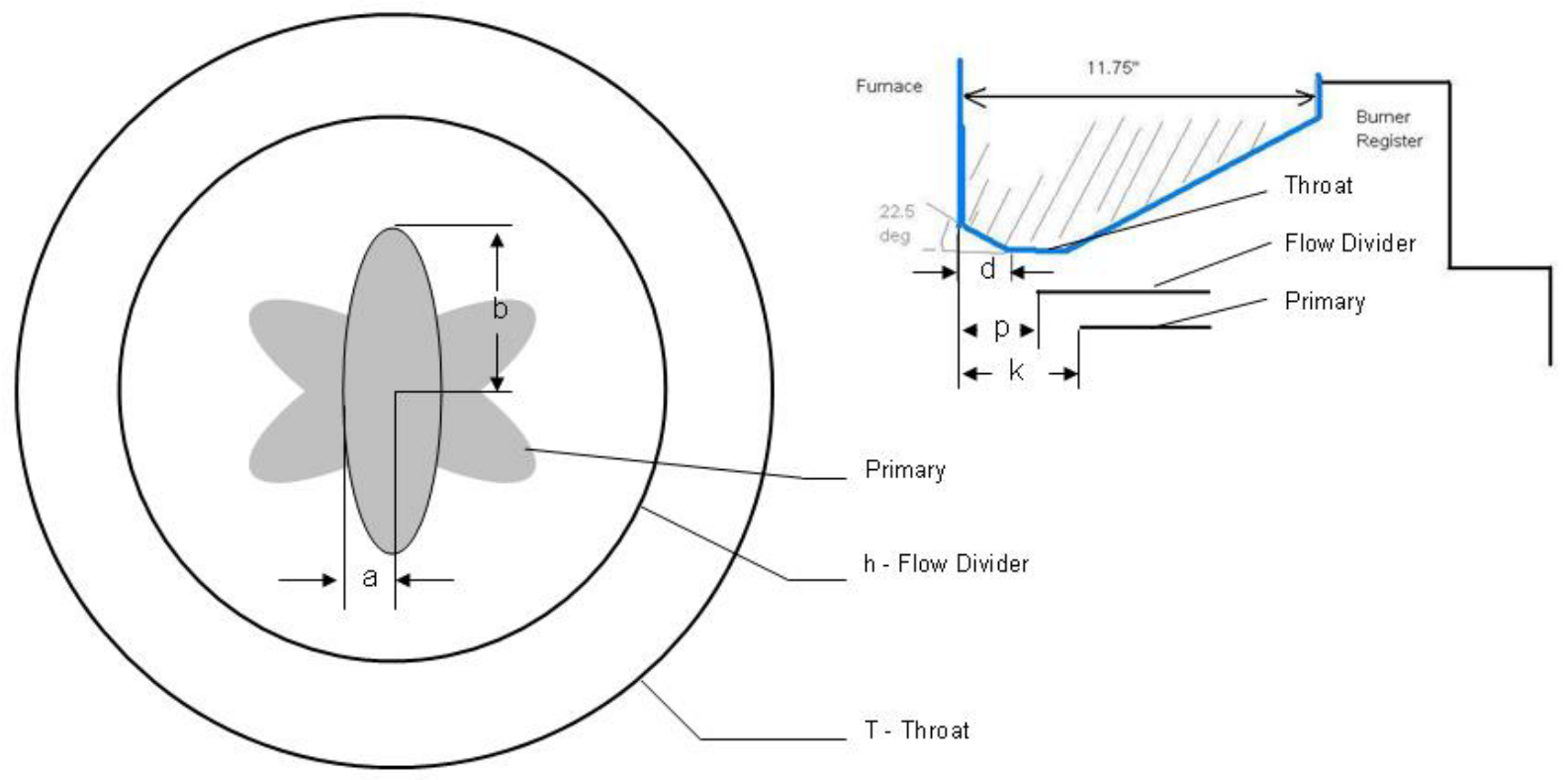

Figure 4.1-2: Initial geometry for the oxy-research burner. 
Table 4.1-2: Initial geometry parameters for the oxy-research burner.

\begin{tabular}{lll|l|l|}
\hline Parameter & \multicolumn{1}{c|}{ Description } & \multicolumn{1}{c|}{ Value $(\mathbf{c m})$} & \multicolumn{1}{c}{ Value (in.) } \\
\hline $\mathrm{a}$ & Ellipse Short Axis & 1.12 & 0.44 \\
$\mathrm{~b}$ & Ellipse Long Axis & 3.71 & 1.46 \\
\hline $\mathrm{d}$ & Primary Wall Thickness & 0.51 & 0.2 \\
\hline $\mathrm{p}$ & Quarl Depth & 2.54 or 5.08 & 1.0 or 2.0 \\
$\mathrm{k}$ & Divider Setback & 7.62 & 3.0 \\
\hline $\mathrm{h}_{\mathrm{i}}$ & Burner Setback & 10.16 & 4.0 \\
$\mathrm{~h}_{\mathrm{o}}$ & Divider ID & 11.44 & 4.51 \\
$\mathrm{t}$ & Divide OD & 12.40 & 4.88 \\
\hline & Throat Diameter & 17.15 & 6.75
\end{tabular}

Assumed coal compositions were used for the burner design modeling. Although coal suppliers had been determined at this point in the project, analyses of the delivered coals were not yet available. As received analyses from the coal suppliers were used, with the bituminous coal assumed to be dried to $3 \%$ moisture and the PRB dried to $10 \%$ moisture in the milling process. The compositions used for the purposes of design modeling are detailed in Table 4.1-3.

Table 4.1-3: Assumed coal compositions for all modeling cases.

\begin{tabular}{ll|l|}
\hline & \multicolumn{3}{|c|}{ After Drying (Fired) } \\
\hline & Bit. Coal & PRB Coal \\
\hline C (wt \%) & $71.31 \%$ & $63.51 \%$ \\
\hline H (wt \%) & $5.04 \%$ & $4.17 \%$ \\
\hline O (wt \%) & $10.14 \%$ & $14.42 \%$ \\
N (wt \%) & $1.28 \%$ & $0.77 \%$ \\
\hline S (wt \%) & $0.57 \%$ & $0.37 \%$ \\
\hline Ash (wt \%) & $8.66 \%$ & $6.76 \%$ \\
\hline Moisture (wt \%) & $3.00 \%$ & $10.00 \%$ \\
\hline Volatiles (wt \%) & 40.47 & 37.24 \\
\hline HHV (kJ/kg) & 29114.5 & 25339.4 \\
\hline HHV (Btu/lb) & 12517 & 10894
\end{tabular}

The coal particle size distribution was assigned by using size distributions of coals previously processed by Headwaters Energy Services, who is also processing the coals for this project. The size distribution used is detailed in Table 4.1-4 and is assumed to be the same for both coals.

Inlet temperatures for both FGR and air in the secondary registers were assumed to be $533 \mathrm{~K}\left(500{ }^{\circ} \mathrm{F}\right)$ for all cases modeled. The primary gases were assumed to be $338.7 \mathrm{~K}\left(150^{\circ} \mathrm{F}\right)$ for all cases. These temperatures are typical operating conditions for the L1500. The conditions for heat transfer were held constant for all cases modeled. These conditions are detailed in Table 4.1-5. 
Table 4.1-4: Assumed coal particle size distribution for all modeling.

\begin{tabular}{|l|l|l|}
\hline Size Bin & \multicolumn{1}{|c|}{$\begin{array}{c}\text { Diameter } \\
\text { (micron) }\end{array}$} & \multicolumn{1}{|c|}{$\begin{array}{c}\text { Mass } \\
\text { Fraction }\end{array}$} \\
\hline 1 & 6.7 & 0.025 \\
\hline 2 & 13.4 & 0.05 \\
\hline 3 & 19.0 & 0.075 \\
\hline 4 & 25.4 & 0.1 \\
\hline 5 & 34.1 & 0.15 \\
\hline 6 & 48.2 & 0.2 \\
\hline 7 & 69.1 & 0.15 \\
\hline 8 & 93.6 & 0.1 \\
\hline 9 & 124.7 & 0.075 \\
\hline 10 & 173.6 & 0.05 \\
\hline 11 & 272.2 & 0.025 \\
\hline
\end{tabular}

Table 4.1-5: Assumed heat transfer conditions for all modeling.

\begin{tabular}{ll}
\hline Refractory Wall Emissivity & 0.7 \\
\hline Inlet Boundary Emissivity & 1.0 \\
\hline Refractory Wall Thermal Resistance $\left(\mathrm{m}^{2} \mathrm{~K} / \mathrm{W}\right)$ & 0.13 \\
Refractory Wall Skin Temperature $(\mathrm{K})$ & 355.4 \\
Inlet Boundary Temperature For Radiation & Gas Temperature \\
Convective Coil Equivalent Emissivity & 0.7 \\
\hline Convective Coil Thermal Resistance $\left(\mathrm{m}^{2} \mathrm{~K} / \mathrm{W}\right)$ & 0.001 \\
Convective Coil Fluid Temperature $(\mathrm{K})$ & 322.0
\end{tabular}

For the purposes of this modeling effort, the composition of the flue gas recycle was assumed to be constant for all cases, independent of fuel type. A summary of the FGR compositions used is presented in Table 4.1-6.

Table 4.1-6: Recirculated flue gas composition for all modeling.

\begin{tabular}{|l|l|}
\hline \multicolumn{3}{|c|}{ Based on Bituminous Coal } \\
\hline \multicolumn{1}{|c|}{$\mathrm{O}_{2}($ vol \%) } & 3.2 \\
$\mathrm{~N}_{2}($ vol \%) & 0.6 \\
$\mathrm{CO}_{2}($ vol \%) & 83.6 \\
$\mathrm{H}_{2} \mathrm{O}($ vol \%) & 12.4 \\
$\mathrm{SO}_{2}($ vol \%) & 0.1 \\
\hline
\end{tabular}

Operating conditions that are unique to cases LNB-A through OXY-O are presented in Table 4.1-7 and conditions that are unique to cases OXY-Vel60A through OXY-Vel80O are presented in Table 4.1-8. 
Table 4.1-7: Unique modeling conditions for the existing low-NO $\mathrm{N}_{\mathrm{x}}$ burner and the initial modeling of the oxy-research burner.

\begin{tabular}{|c|c|c|c|c|}
\hline & LNB-A & LNB-O & OXY-A & OXY-O \\
\hline Firing Rate (MBtu/hr) & 3.5 & 3.5 & 3.5 & 3.5 \\
\hline Fuel & Bit. Coal & Bit. Coal & Bit. Coal & Bit. Coal \\
\hline Oxidizer & Air & $\mathrm{O} 2+\mathrm{FGR}$ & Air & $\mathrm{O} 2+\mathrm{FGR}$ \\
\hline Burner SR & 0.9 & 0.9 & 0.9 & 0.9 \\
\hline Total Coal Flow (kg/s) & 0.03523 & 0.03523 & 0.03515 & 0.03515 \\
\hline Total Coal Flow (lb/hr) & 279.6 & 279.6 & 279.0 & 279.0 \\
\hline Primary Gas / Fuel & 1.8 & 1.8 & 1.86 & 2.36 \\
\hline Primary Velocity (m/s) & 20.5 & 14.4 & 26.8 & 25.3 \\
\hline Primary Velocity (ft/s) & 67.2 & 47.2 & 88 & 83 \\
\hline Primary Flow (kg/s) & 0.06342 & 0.06342 & 0.06539 & 0.08281 \\
\hline Primary Flow (lb/hr) & 503.3 & 503.3 & 519.0 & 657.2 \\
\hline Inner Sec. Flow (kg/s) & 0.06007 & 0.06656 & 0.03561 & 0.02320 \\
\hline Inner Sec. Flow (lb/hr) & 476.8 & 528.3 & 282.6 & 184.1 \\
\hline Outer Sec. Flow (lb/hr) & 0.18022 & 0.19968 & 0.20178 & 0.21942 \\
\hline Outer Sec. Flow (lb/hr) & 1430.3 & 1584.8 & 1601.4 & 1741.4 \\
\hline Primary Feed 02 (wt \%) & N/A & $24.6 \%$ & N/A & $17.7 \%$ \\
\hline Inner Sec. Feed $\mathrm{O} 2$ (wt \%) & N/A & $24.6 \%$ & N/A & $41.9 \%$ \\
\hline Outer Sec. Feed O2 (wt \%) & N/A & $24.6 \%$ & N/A & $17.7 \%$ \\
\hline
\end{tabular}

Table 4.1-8: Unique modeling conditions for the oxy-research burner with varying primary velocity.

\begin{tabular}{|c|c|c|c|c|c|c|}
\hline & $\begin{array}{c}\text { OXY- } \\
\text { Vel60A }\end{array}$ & $\begin{array}{c}\text { OXY- } \\
\text { Vel70A }\end{array}$ & $\begin{array}{c}\text { OXY- } \\
\text { Vel80A }\end{array}$ & $\begin{array}{c}\text { OXY- } \\
\text { Vel600 }\end{array}$ & $\begin{array}{c}\text { OXY- } \\
\text { Vel700 }\end{array}$ & $\begin{array}{c}\text { OXY- } \\
\text { Vel800 }\end{array}$ \\
\hline Firing Rate (MBtu/hr) & 3.5 & 3.5 & 3.5 & 3.5 & 3.5 & 3.5 \\
\hline Fuel & Bit. Coal & Bit. Coal & Bit. Coal & Bit. Coal & Bit. Coal & Bit. Coal \\
\hline Oxidizer & Air & Air & Air & $\mathrm{O} 2+\mathrm{FGR}$ & $\mathrm{O} 2+\mathrm{FGR}$ & $\mathrm{O} 2+\mathrm{FGR}$ \\
\hline Burner SR & 0.9 & 0.9 & 0.9 & 0.9 & 0.9 & 0.9 \\
\hline Total Coal Flow (kg/s) & 0.035154 & 0.035154 & 0.035154 & 0.035154 & 0.035154 & 0.035154 \\
\hline Total Coal Flow (lb/hr) & 279.0 & 279.0 & 279.0 & 279.0 & 279.0 & 279.0 \\
\hline Primary Gas / Fuel & 1.24 & 1.45 & 1.65 & 1.62 & 1.91 & 2.21 \\
\hline Primary Velocity (m/s) & 18.29 & 21.33 & 24.38 & 18.29 & 21.33 & 24.38 \\
\hline Primary Velocity (ft/s) & 60 & 70 & 80 & 60 & 70 & 80 \\
\hline Primary Flow (kg/s) & 0.04355 & 0.05080 & 0.05805 & 0.05707 & 0.06731 & 0.07755 \\
\hline Primary Flow (lb/hr) & 345.6 & 403.2 & 460.7 & 452.9 & 534.2 & 615.5 \\
\hline Inner Sec. Flow (kg/s) & 0.03597 & 0.03597 & 0.03597 & 0.02390 & 0.02390 & 0.02390 \\
\hline Inner Sec. Flow (lb/hr) & 285.5 & 285.5 & 285.5 & 189.7 & 189.7 & 189.7 \\
\hline Outer Sec. Flow (kg/s) & 0.22637 & 0.21911 & 0.21186 & 0.25705 & 0.24679 & 0.23655 \\
\hline Outer Sec. Flow (lb/hr) & 1796.6 & 1739.0 & 1681.4 & 2040.1 & 1958.7 & 1877.4 \\
\hline Primary Feed 02 (wt \%) & N/A & N/A & N/A & $27.2 \%$ & $22.6 \%$ & $19.3 \%$ \\
\hline Inner Sec. Feed 02 (wt \%) & $\mathrm{N} / \mathrm{A}$ & $\mathrm{N} / \mathrm{A}$ & N/A & $41.0 \%$ & $41.0 \%$ & $41.0 \%$ \\
\hline Outer Sec. Feed $\mathrm{O} 2$ (wt \%) & N/A & N/A & N/A & $14.9 \%$ & $15.7 \%$ & $16.4 \%$ \\
\hline
\end{tabular}


Following completion of the modeling OXY-Vel60A through OXY-Vel80O, the burner geometry was modified to incorporate a bluff body for targeted oxygen injection in the primary and the parameters for the primary geometry were modified to produce a primary velocity of $21.3 \mathrm{~m} / \mathrm{s}(70 \mathrm{ft} / \mathrm{s})$. The revised burner geometry is detailed in Figure 4.1-3. The geometric parameters for the revised oxy-research burner are included in Table 4.1-9.

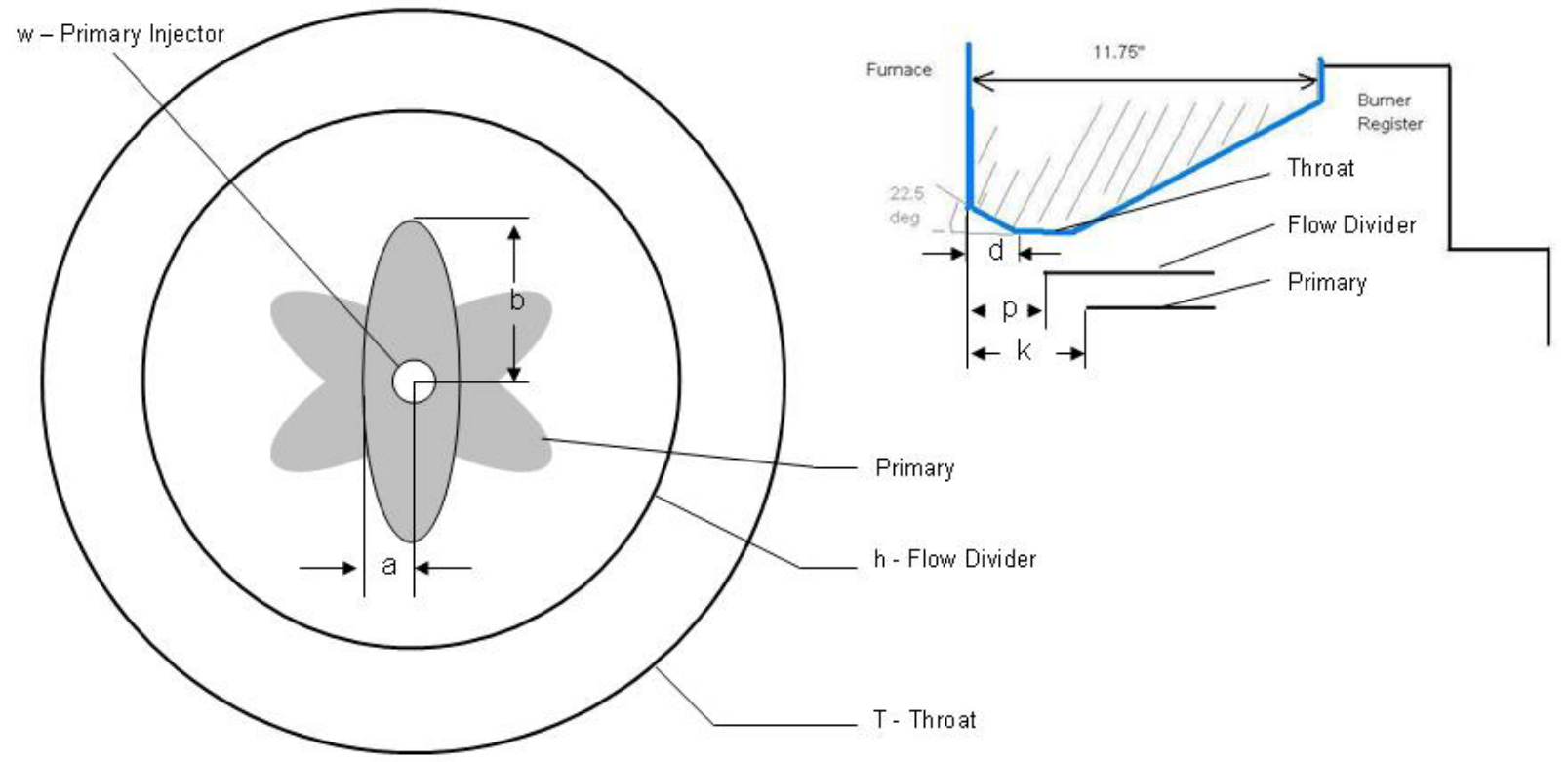

Figure 4.1-3: Revised geometry for the oxy-research burner.

Table 4.1-9: Revised geometry parameters for the oxy-research burner

\begin{tabular}{|c|c|c|c|}
\hline Parameter & Description & Value (cm) & Value (in.) \\
\hline $\mathrm{a}$ & Ellipse Short Axis & 1.40 & 0.55 \\
\hline \multirow[t]{2}{*}{$\mathrm{b}$} & Ellipse Long Axis & 4.29 & 1.69 \\
\hline & Primary Wall Thickness & 0.76 & 0.3 \\
\hline d & Quarl Depth & $5.08 *$ & $2.0^{*}$ \\
\hline $\mathrm{p}$ & Divider Setback & 7.62 & 3.0 \\
\hline k & Burner Setback & 10.16 & 4.0 \\
\hline $\mathrm{h}_{\mathrm{i}}$ & Divider ID & 12.26 & 4.825 \\
\hline $\mathrm{h}_{\mathrm{o}}$ & Divide OD & 13.21 & 5.2 \\
\hline $\mathrm{t}$ & Throat Diameter & 17.15 & 6.75 \\
\hline $\mathrm{w}$ & Primary Injector OD & 2.13 & 0.84 \\
\hline
\end{tabular}

Operating conditions that are unique to cases OXY-ParA through OXY-ParREFA are presented in Table 4.1-10 and operating conditions that are unique to cases OXY-Qua4A through OXY-Qua4O are presented in Table 4.1-11. 
Table 4.1-10: Unique modeling conditions for the oxy-research burner for $21.3 \mathrm{~m} / \mathrm{s}$ primary velocity and parametric conditions.

\begin{tabular}{|c|c|c|c|c|c|c|}
\hline & OXY-ParA & OXY-ParO & $\begin{array}{c}\text { OXY- } \\
\text { ParLO2 }\end{array}$ & $\begin{array}{c}\text { OXY- } \\
\text { ParPRBA }\end{array}$ & $\begin{array}{c}\text { OXY- } \\
\text { ParPRBO }\end{array}$ & $\begin{array}{c}\text { OXY- } \\
\text { ParREFA }\end{array}$ \\
\hline Firing Rate (MBtu/hr) & 3.5 & 3.5 & 3.5 & 3.5 & 3.5 & 3.5 \\
\hline Fuel & Bit. Coal & Bit. Coal & Bit. Coal & PRB & PRB & Bit. Coal \\
\hline Oxidizer & Air & $\mathrm{O} 2+\mathrm{FGR}$ & $\mathrm{O} 2+\mathrm{FGR}$ & Air & $\mathrm{O} 2+\mathrm{FGR}$ & Air \\
\hline Burner SR & 0.91 & 0.91 & 0.91 & 0.91 & 0.91 & 0.91 \\
\hline Total Coal Flow (kg/s) & 0.03515 & 0.03515 & 0.03515 & 0.04048 & 0.04048 & 0.03515 \\
\hline Total Coal Flow (lb/hr) & 279.0 & 279.0 & 279.0 & 321.3 & 321.3 & 279.0 \\
\hline Primary Gas / Fuel & 1.88 & 2.45 & 2.52 & 1.88 & 2.44 & 1.88 \\
\hline Primary Velocity (m/s) & 21.9 & 21.0 & 21.0 & 25.0 & 24.4 & 21.9 \\
\hline Primary Velocity (ft/s) & 72 & 69 & 69 & 82 & 80 & 72 \\
\hline Primary Flow (kg/s) & 0.06606 & 0.08606 & 0.08859 & 0.07610 & 0.09877 & 0.06606 \\
\hline Primary Flow (lb/hr) & 524.3 & 683.0 & 703.1 & 604.0 & 783.9 & 524.3 \\
\hline Inner SA Flow (kg/s) & 0.03597 & 0.02390 & 0.02500 & 0.03401 & 0.02201 & 0.03597 \\
\hline Inner SA Flow (lb/hr) & 285.5 & 189.7 & 198.4 & 269.9 & 174.7 & 285.5 \\
\hline Outer SA Flow (kg/s) & 0.20384 & 0.22805 & 0.22442 & 0.19272 & 0.20968 & 0.20384 \\
\hline Outer SA Flow (lb/hr) & 1617.8 & 1809.9 & 1781.1 & 1529.5 & 1664.1 & 1617.8 \\
\hline Primary Feed 02 (wt \%) & N/A & $17.1 \%$ & $5.6 \%$ & N/A & $17.3 \%$ & N/A \\
\hline Inner Sec. Feed O2 (wt \%) & N/A & $41.0 \%$ & $47.0 \%$ & N/A & $41.2 \%$ & N/A \\
\hline Outer Sec. Feed $\mathrm{O} 2$ (wt \%) & N/A & $17.1 \%$ & $20.8 \%$ & N/A & $17.3 \%$ & N/A \\
\hline Primary SR & 0.1961 & 0.2133 & 0.0919 & 0.2297 & 0.2515 & 0.1961 \\
\hline
\end{tabular}

Table 4.1-11: Unique modeling conditions for the oxy-research burner for $21.3 \mathrm{~m} / \mathrm{s}$ primary and varying quarl depth.

\begin{tabular}{|c|c|c|c|}
\hline & OXY-Qua4A & OXY-Qua6A & OXY-Qua4O \\
\hline Firing Rate (MBtu/hr) & 3.5 & 3.5 & 3.5 \\
\hline Fuel & Bit. Coal & Bit. Coal & Bit. Coal \\
\hline Oxidizer & Air & Air & $\mathrm{O} 2+\mathrm{FGR}$ \\
\hline Burner SR & 0.91 & 0.91 & 0.91 \\
\hline Total Coal Flow (kg/s) & 0.03515 & 0.03515 & 0.03515 \\
\hline Total Coal Flow (lb/hr) & 279.0 & 279.0 & 279.0 \\
\hline Primary Gas / Fuel & 1.88 & 1.88 & 2.45 \\
\hline Primary Velocity (m/s) & 21.9 & 21.9 & 21.0 \\
\hline Primary Velocity (ft/s) & 72 & 72 & 69 \\
\hline Primary Flow (kg/s) & 0.06606 & 0.06606 & 0.08606 \\
\hline Primary Flow (lb/hr) & 524.3 & 524.3 & 683.0 \\
\hline Inner Sec. Flow (kg/s) & 0.03597 & 0.03597 & 0.02309 \\
\hline Inner Sec. Flow (lb/hr) & 285.5 & 285.5 & 189.7 \\
\hline Outer Sec. Flow (kg/s) & 0.20384 & 0.20384 & 0.22805 \\
\hline Outer Sec. Flow (lb/hr) & 1617.8 & 1617.8 & 1809.9 \\
\hline Primary Feed 02 (wt \%) & N/A & N/A & $17.1 \%$ \\
\hline Inner Sec. Feed 02 (wt \%) & N/A & N/A & $41.0 \%$ \\
\hline Outer Sec. Feed 02 (wt \%) & N/A & N/A & $17.1 \%$ \\
\hline
\end{tabular}




\subsubsection{Modeling Results}

The first step in the design process was to model the existing burner and the initial oxy-research burner under air and oxy-fired conditions. Temperature and CO concentration plots were generated from the modeling results and used to determine the flame stabilization location. A temperature plot of the furnace cross section (viewed from the side) in the near burner region is presented in Figure 4.1-4 for cases LNBA through OXY-O. The CO concentration plots for the same cases are presented in Figure 4.1-5. It is apparent from comparing the LNB-A and LNB-O cases that the adiabatic flame temperature is slightly lower for the oxygen case. This is an expected result since a $27 \mathrm{vol} \% \mathrm{O}_{2}$ is used in the overall mixture of the $\mathrm{O}_{2}$ and FGR. This condition is chosen to match overall heat transfer, not flame temperature and the results are consistent with results in other studies.
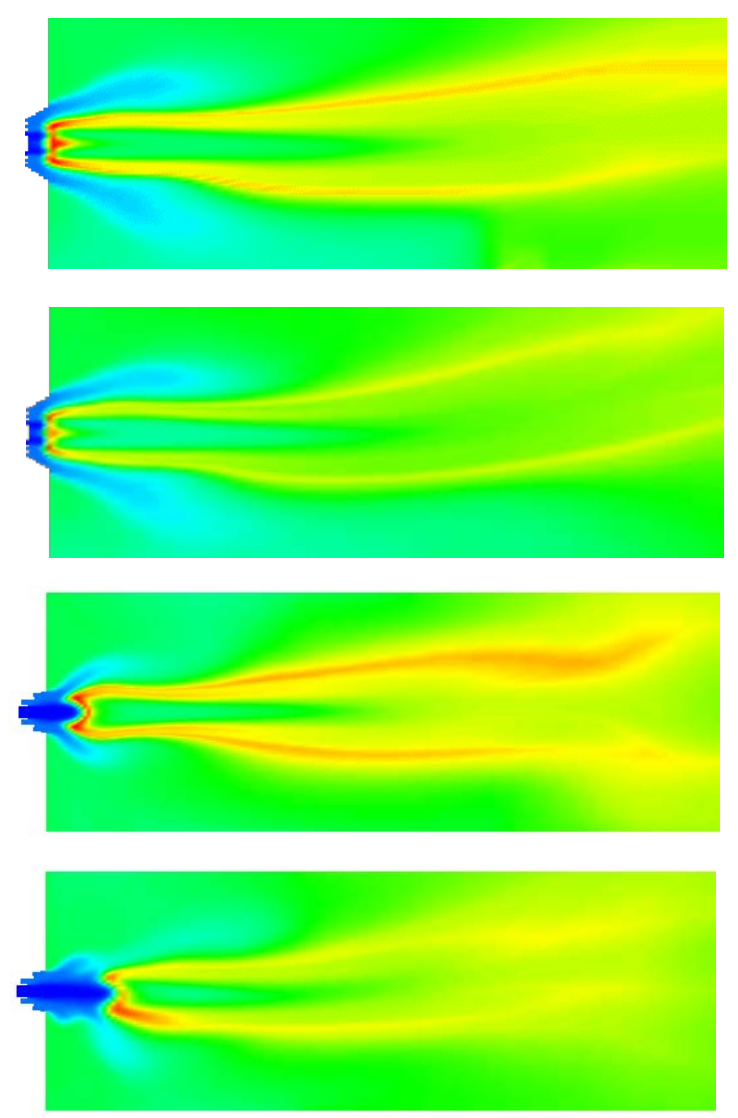

LNB-A

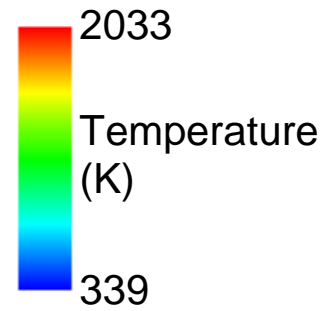

\section{LNB-O}

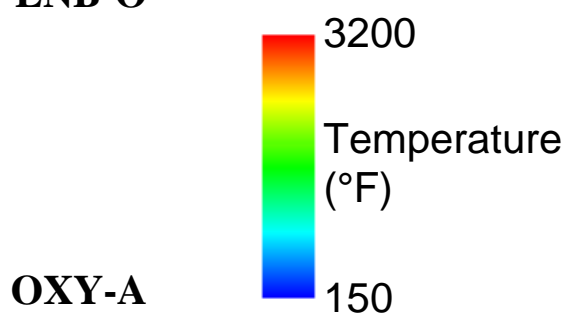

\section{OXY-O}

Figure 4.1-4: Temperature plots for cases LNB-A through OXY-O.

It is also apparent from the modeling results that the flame stabilizes at the quarl outlet with the existing, low- $\mathrm{NO}_{\mathrm{x}}$ burner for both the air and oxy-fired cases. The initial oxy-research burner design has a flame stabilization location that is well outside the quarl for both the air and the oxygen cases, but the standoff distance is much greater for the oxygen case. The CO concentration plots provide a clear picture of the flame stabilization location and indicate that the initial oxy-research burner design requires modification. Some factors that are expected to contribute to this standoff distance include: a very short quarl, $2.54 \mathrm{~cm}$ (1 in.) compared to $8.9 \mathrm{~cm}$ (3.5 in.) in the LNB, high primary velocities, almost $27.4 \mathrm{~m} / \mathrm{s}(90 \mathrm{ft} / \mathrm{s})$ compared to 15.2 and $21.3 \mathrm{~m} / \mathrm{s}$ (50 to $70 \mathrm{ft} / \mathrm{s}$ ), and significant space within the LNB for the gases to expand, caused by a large bluff body and an unused gas annulus between the primary and inner secondary registers. 
The asymmetry of the flame in all conditions is due to buoyancy of the hot flue-gas and the effect of gravity on large versus small particles (large particle are actually deposited on the floor of the furnace, where they continue to oxidize).
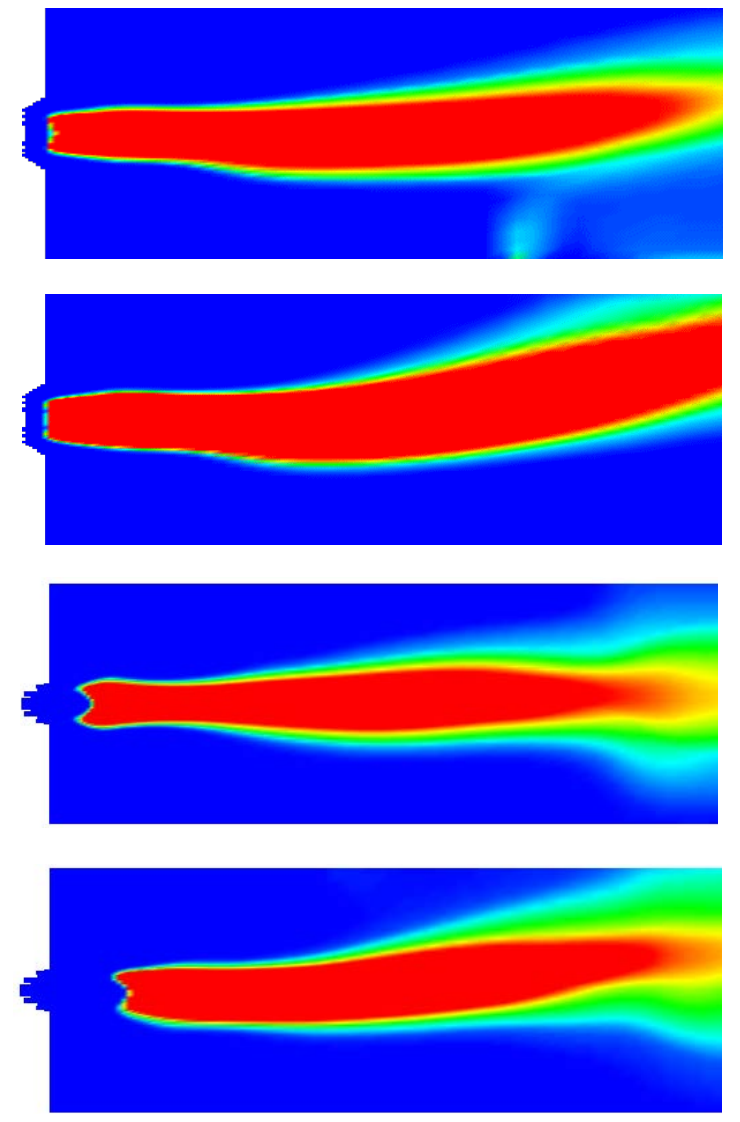

\section{OXY-A}

\section{OXY-O}

Figure 4.1-5: CO concentration plots for cases LNB-A through OXY-O

The next round of modeling investigated the impact of primary gas velocity on flame stabilization location. The geometry of the burner was held static for these simulations, with the exception of the quarl depth which was increased from 2.54 to $5.08 \mathrm{~cm}$ (one to two inches). Gas was removed from the primary and distributed to the inner and outer secondary registers, while maintaining the ratio of flow between the inner and outer register. The drawback to this approach is that the primary oxidizer gas / fuel ratio is not constant for each case. As the primary velocity decreases, there is less oxidant available to the fuel in the primary. These two variables were expected to counteract each other to a degree. The temperature plots for cases OXY-Vel80A through OXY-Vel60O are presented in Figure 4.1-6 and the CO concentration plots are provided in Figure 4.1-7. 

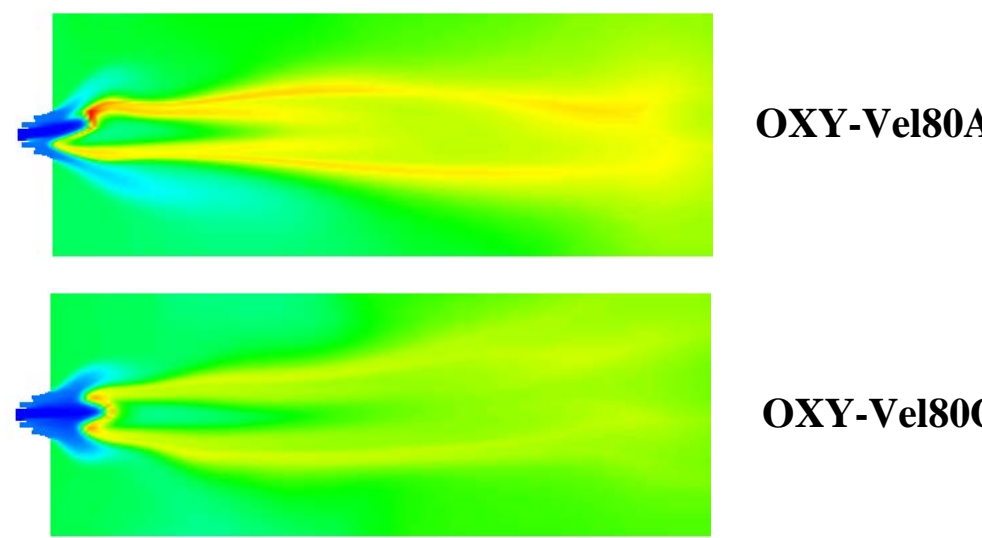

OXY-Vel800

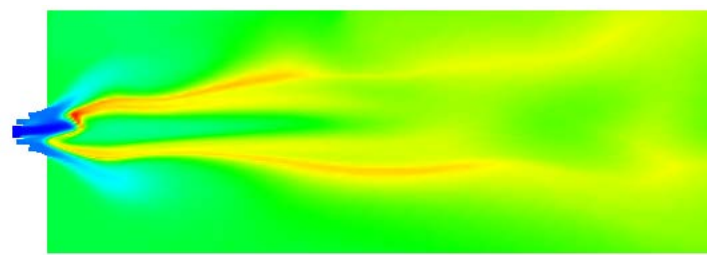

OXY-Vel70A

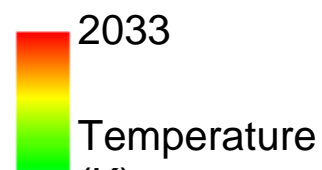

(K)

339

OXY-Vel80O

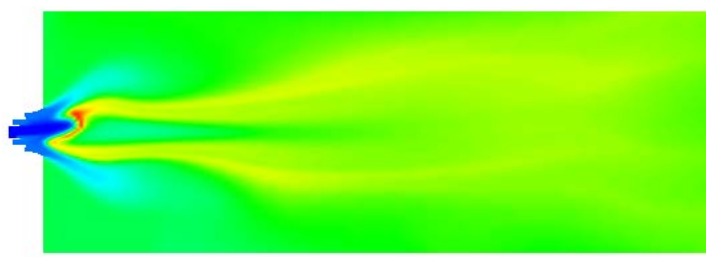

OXY-Vel70O

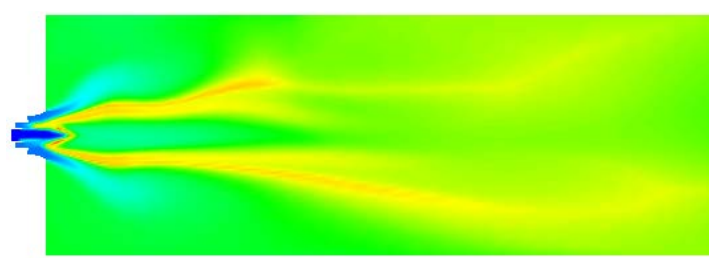

OXY-Vel60A

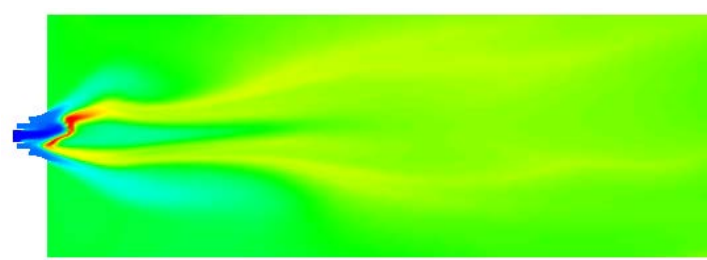

OXY-Vel60O

Figure 4.1-6: Temperature plots for cases OXY-Vel80A through OXY-Vel60O. 

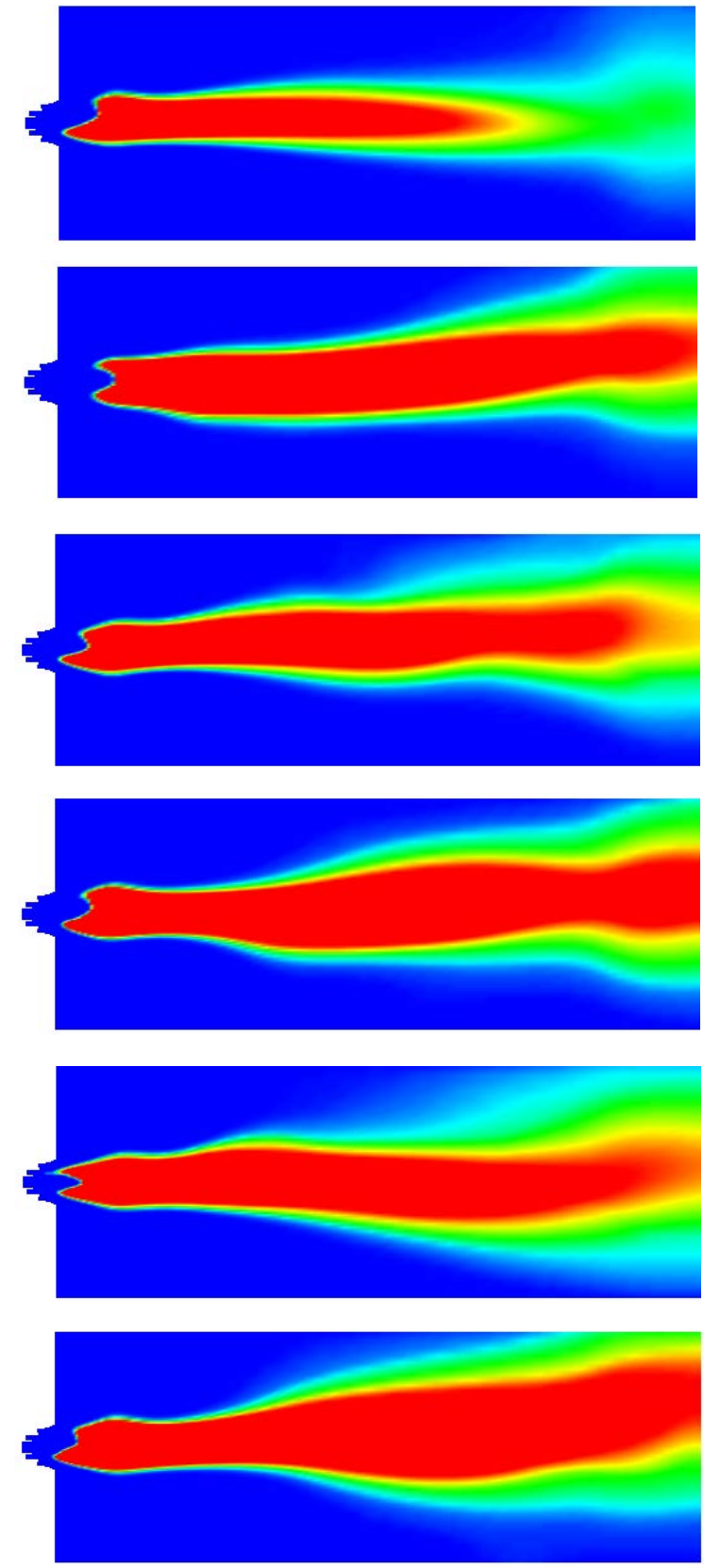

\section{OXY-Vel600}

OXY-Vel80O

OXY-Vel70A

OXY-Vel70O

OXY-Vel60A

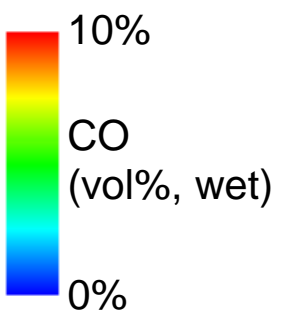

Figure 4.1-7: CO concentration plots for cases OXY-Vel80A through OXY-Vel60O.

The results from the primary velocity cases show that the flame stabilization location is more strongly tied to the primary velocity than to the primary gas / fuel ratio. While the $24.4 \mathrm{~m} / \mathrm{s}(80 \mathrm{ft} / \mathrm{s})$ air-fired case shows that the flame originates inside the quarl, the oxy-fired case is still detached. Both of the $21.3 \mathrm{~m} / \mathrm{s}$ (70 ft/s) cases have flames originating in the quarl. Although the $18.3 \mathrm{~m} / \mathrm{s}(60 \mathrm{ft} / \mathrm{s})$ case is well attached inside the quarl, this velocity is too low to represent full-scale burner behavior. Based on these results, it was decided that a primary velocity of $21.3 \mathrm{~m} / \mathrm{s}(70 \mathrm{ft} / \mathrm{s})$ could provide an appropriate flame stabilization location. Another curious trait of the velocity modeling is the asymmetry of the burner in the near-quarl region. This is likely due to operating conditions that could result in an unstable (fluttering) flame location. 
The next step was to redesign the burner geometry to include a bluff body for targeted oxygen injection in the primary and to produce a primary gas velocity of $21.3 \mathrm{~m} / \mathrm{s}(70 \mathrm{ft} / \mathrm{s})$. This new geometry was modeled for typical air and oxygen conditions and for conditions where the flame standoff distance may be greater. These conditions included firing with a PRB coal and a condition where a minimum concentration of oxygen was used in the primary during oxy-combustion. The minimum concentration of oxygen was determined using patents for low-NO $\mathrm{N}_{\mathrm{x}}$ burner operation by (J. E. Anderson 1989). The OXY-ParA case was also re-run with significant refinement in the meshing strategy in order to determine the impacts of modeling approach on flame stabilization location. The temperature plots for cases OXY-ParA through OXY-ParREFA are presented in Figure 4.1-8 and the CO concentration plots for the same cases are presented in Figure 4.1-9.
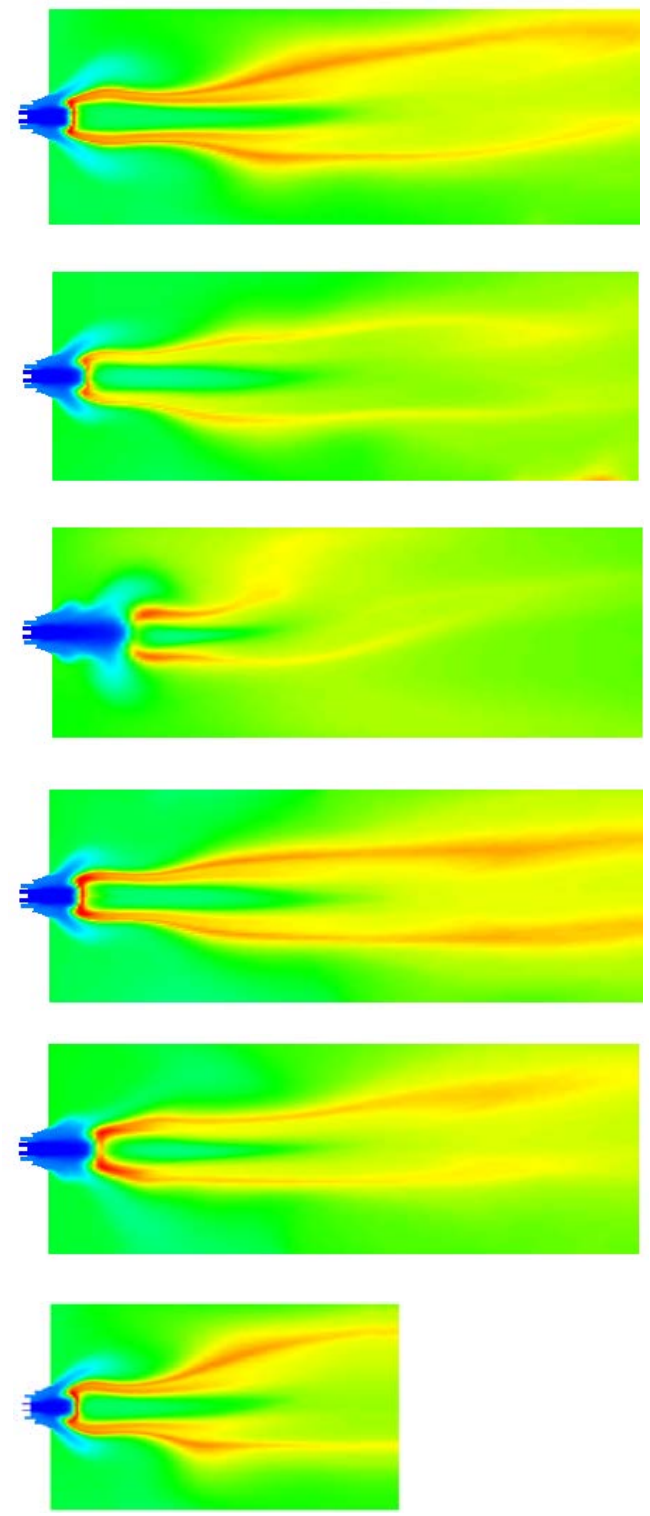

OXY-ParA

Figure 4.1-8: Temperature plots for cases OXY-ParA through OXY-ParREFA.
OXY-ParLO2

OXY-ParPRBO

2033

Temperature

$(\mathrm{K})$

339

3000

Temperature

$\left({ }^{\circ} \mathrm{F}\right)$

OXY-ParPRBA 150

\section{OXY-ParREFA}



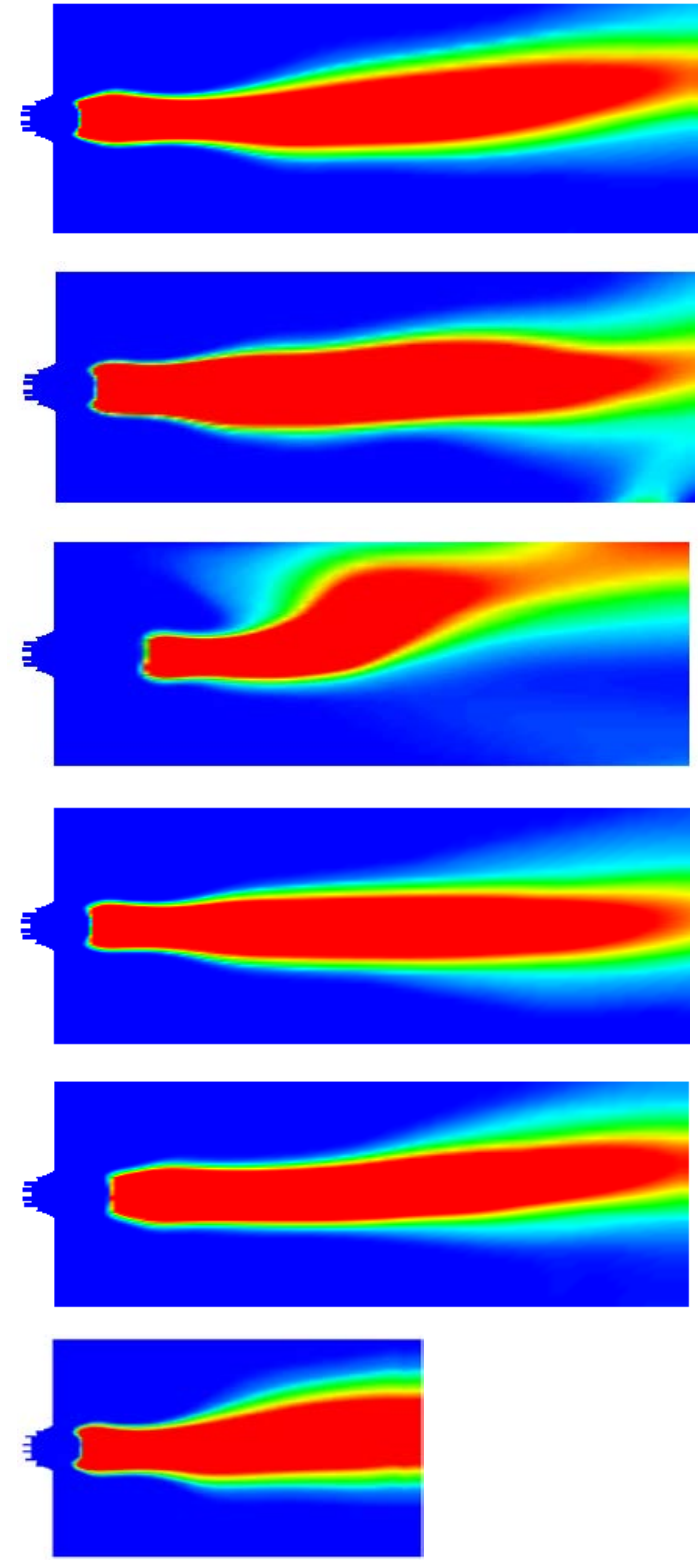

OXY-ParA

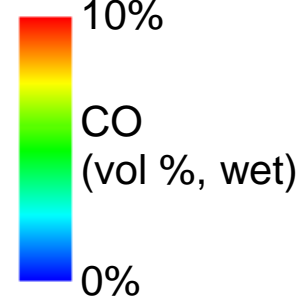

OXY-ParO

OXY-ParLO2

OXY-ParPRBA

OXY-ParPRBO

\section{OXY-ParREFA}

Figure 4.1-9: CO concentration plots for cases OXY-ParA through OXY-ParREFA.

These results indicate that the revisions to the geometry are not sufficient to attach a flame inside the quarl. Cases Oxy-ParA and OXY-ParO have flames that are still detached. In addition, the low-oxygen case has a flame that is substantially blown off. Firing the PRB coal pushed the flame back slightly for the air case and more significantly for the oxygen case. The refined mesh model produced essentially the same results for the flame position as the coarse mesh model, indicating that the chosen level of refinement used in the model is appropriate.

The next step was to investigate the impact of quarl depth on flame stabilization location. In the previous modeling, the quarl depth was $5.08 \mathrm{~cm}$ (two inches). The existing low- $\mathrm{NO}_{\mathrm{x}}$ burner has a quarl depth of $8.9 \mathrm{~cm}$ (3.5 inches). For the next modeling runs, 10.16 and $15.24 \mathrm{~cm}$ (four and six inch) quarls were tested. The temperature plots for cases OXY-Qua4A through Oxy-Qua4O are presented in Figure 4.1-10 and the CO concentration plots for the same cases are presented in Figure 4.1-11. The OXY-ParA case is also included in these plots to include the $5.08 \mathrm{~cm}$ (2 in.) quarl for comparison. These plots are aligned 
such that the face of the burner in each plot is aligned and therefore the face of the quarl (and end wall of the furnace) is in a different relative position. In this way the distance from the burner face to the flame stabilization location can more easily be seen.

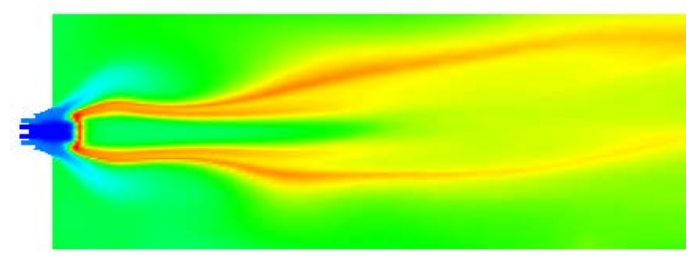

OXY-ParA

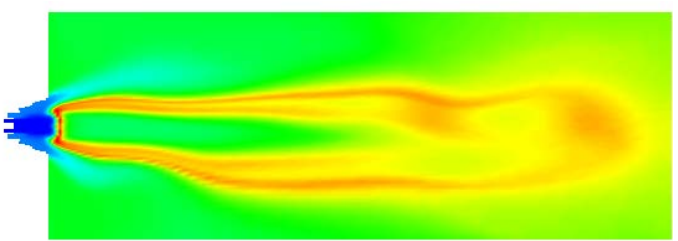
2033

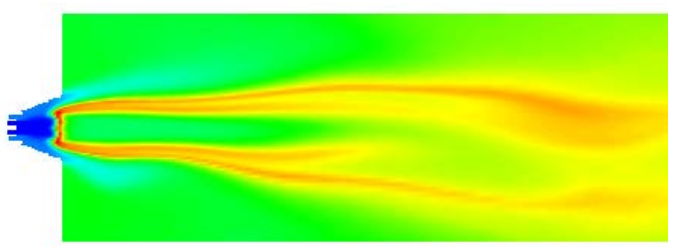

OXY-Qua4A
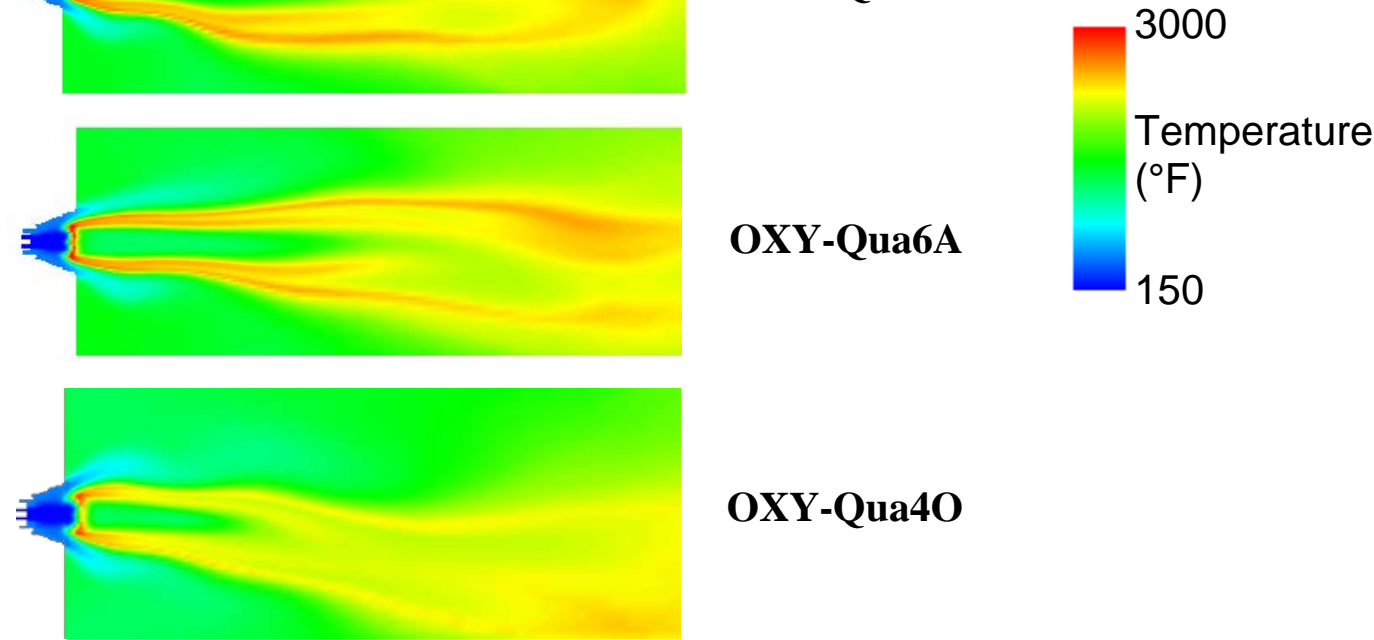

Figure 4.1-10: Temperature plots for cases OXY-Qua4A through OXY-Qua4O, with case OXYParA plotted for comparison.

As the burner quarl is extended, the quarl moves out toward the flame and the flame moves slightly back toward the face of the burner. A more quantitative analysis displayed that a $5.08 \mathrm{~cm}$ (two inch) increase in the depth of the burner quarl moves the flame back towards the burner face by approximately $1.27 \mathrm{~cm}$ (half inch), in a linear relationship. These results show that the $10.16 \mathrm{~cm}$ (4 inch) quarl promotes flame stabilization at the outlet of the quarl and the $15.24 \mathrm{~cm}$ (six inch) quarl has a flame well inside. 


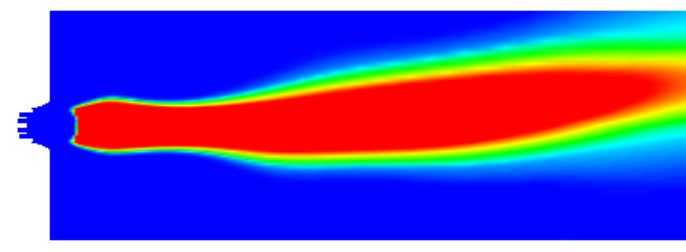

OXY-ParA
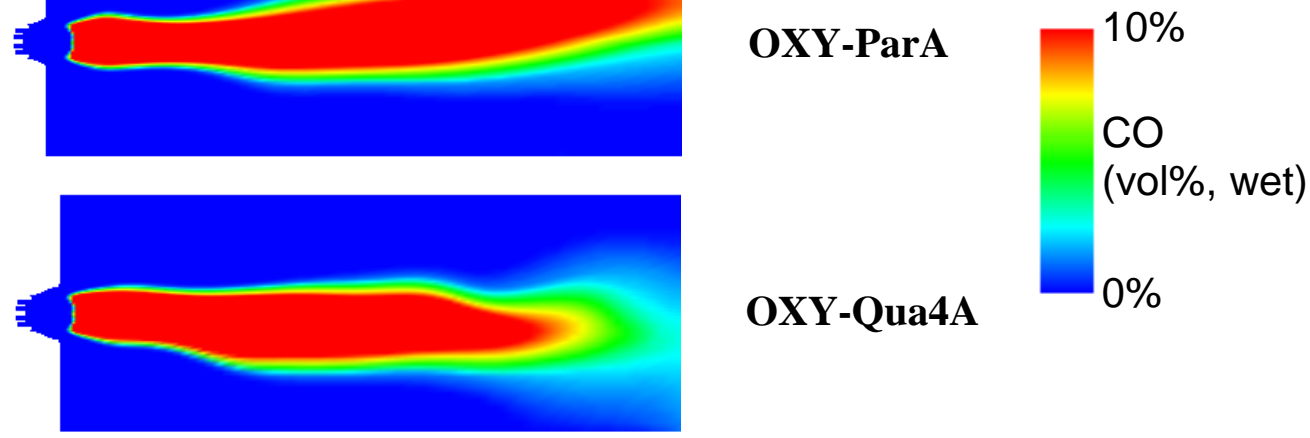

OXY-Qua4A

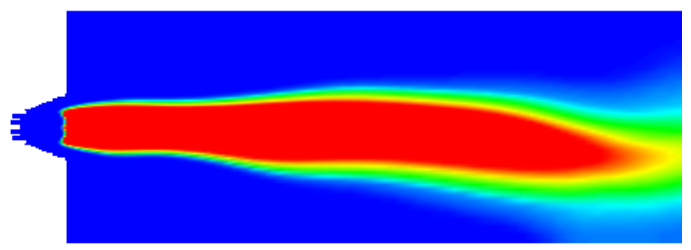

OXY-Qua6A

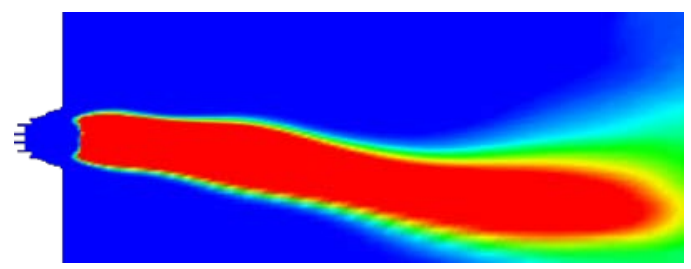

\section{OXY-Qua40}

Figure 4.1-11: CO concentration plots for cases OXY-Qua4A through OXY-Qua4O, with case OXY-ParA plotted for comparison.

Based on these modeling results it was decided that the modified geometry with the 4 inch quarl would meet the criteria for flame stabilization location. Finally, the behavior of the existing low- $\mathrm{NO}_{\mathrm{x}}$ burner and the oxy-research burner are compared with temperature plots in Figure 4.1-12 and with CO concentration plots in Figure 4.1-13.

From these results it can be seen that the flame stabilization location is very similar for the existing and the oxy-research burner. However, it appears that the flame length is shorter for the oxy-research burner. 


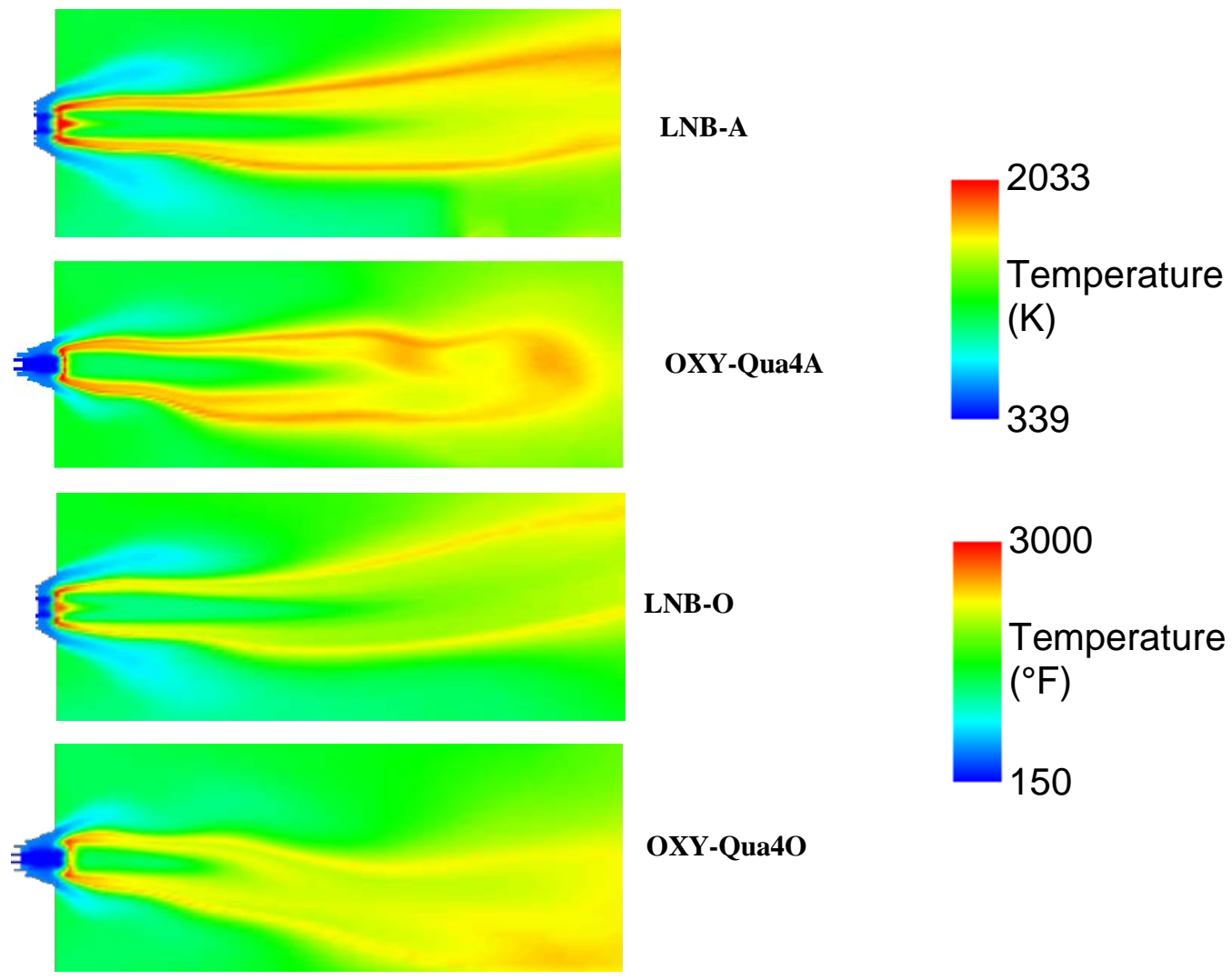

Figure 4.1-12: Temperature plots for the existing low- $\mathrm{NO}_{\mathrm{x}}$ burner compared to the finalized design of the oxy-research burner under air and oxy-fired conditions. 


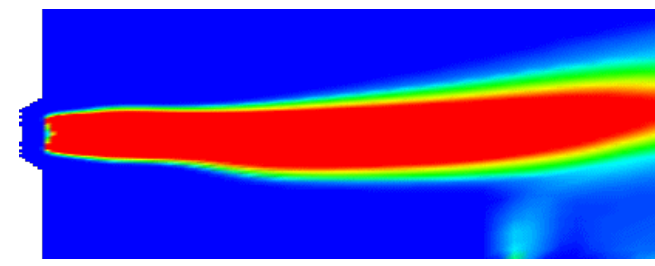

LNB-A $10 \%$

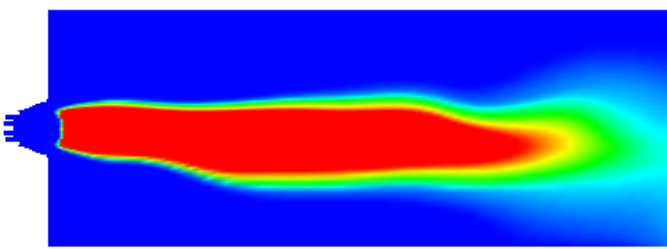

\section{OXY-Qua4A}
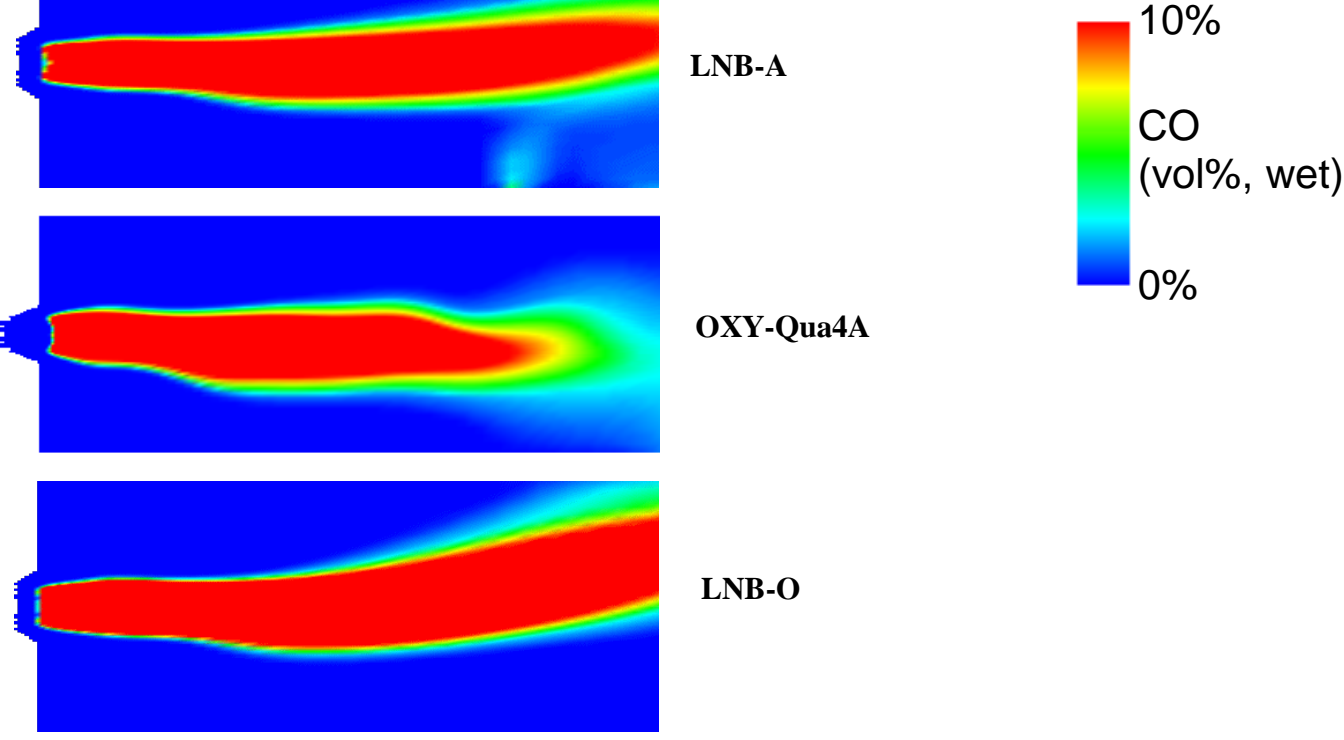

LNB-O

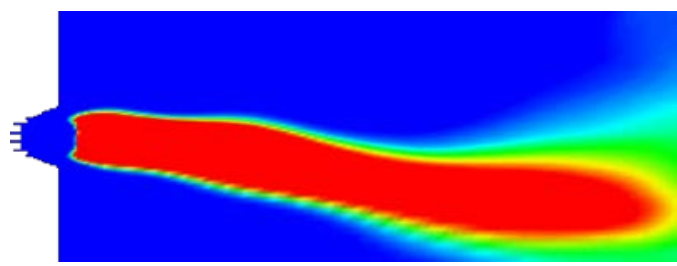

OXY-Qua40

Figure 4.1-13: $\mathrm{CO}$ concentration plots for the existing low-NO $\mathrm{N}_{\mathrm{x}}$ burner compared to the finalized design of the oxy-research burner under air and oxy-fired conditions.

\subsubsection{Model Results Summary}

CFD modeling results suggested that the constant velocity scaling method did not produce the desired flame behavior for the oxy-research burner. Using this method of design resulted in a flame stabilization location that was well outside the burner quarl. In an effort to correct this behavior, the primary gas velocity was reduced, the quarl was lengthened and the burner face setback relative to the quarl was lengthened. These modifications produced a flame stabilization location that was in the desired location at the quarl outlet.

These results suggest that the dominating parameter governing flame shape and stability is not solely velocity. In an effort to more plainly understand the burner behavior, the modeling results were analyzed for average particle temperature as a function of position in the furnace. These data were generated and plotted for the existing low- $\mathrm{NO}_{\mathrm{x}}$ burner, for the original oxy-research burner design and for the final oxyresearch burner design, both for air and oxy-fired conditions. Figure 4.1-14 presents these results in a comparison of the existing low- $\mathrm{NO}_{\mathrm{x}}$ burner and for the original oxy-research burner design. The location of the quarl location is indicated in this plot for clarity. 


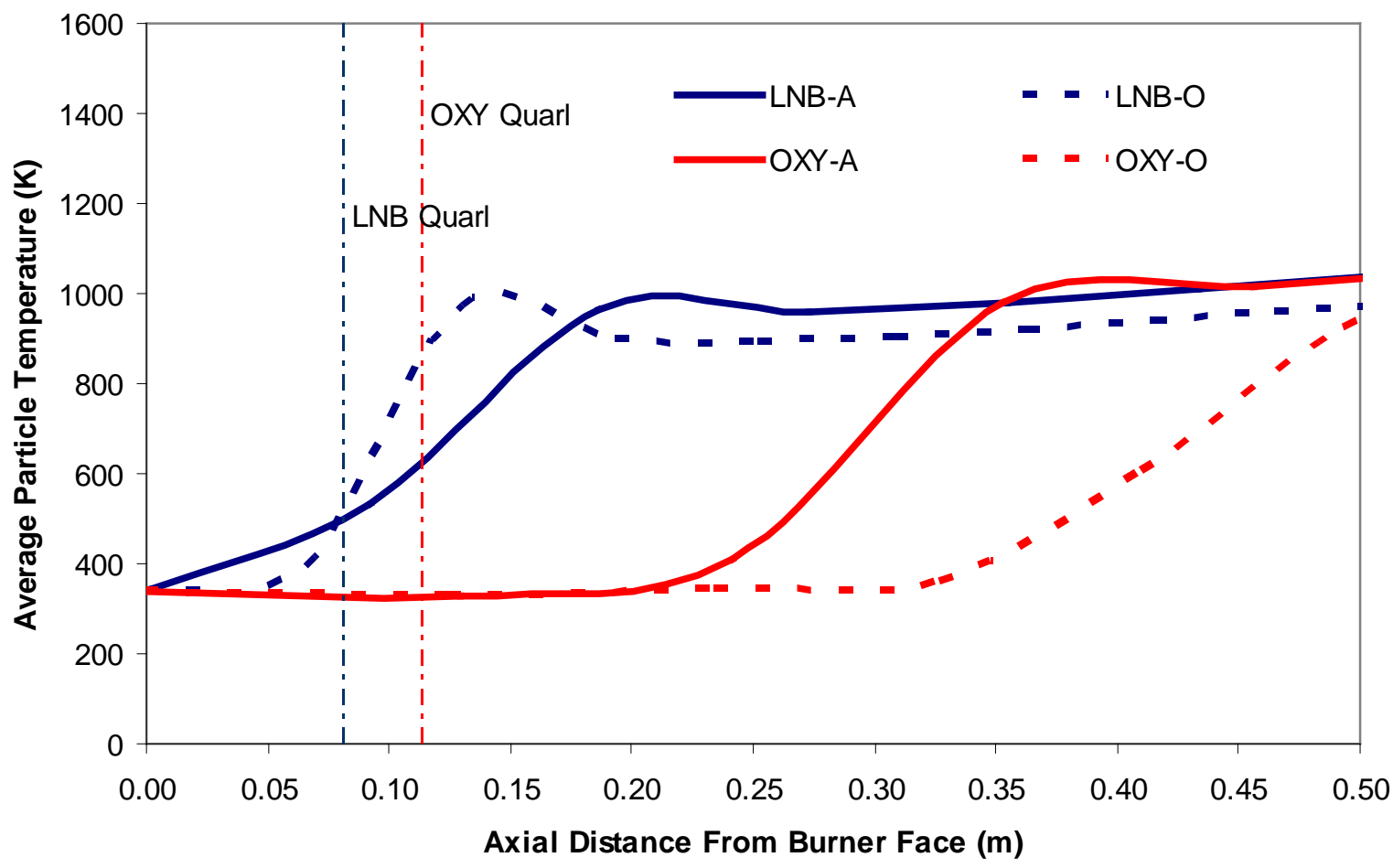

Figure 4.1-14: Particle temperature profile for the existing burner and the original oxy-research burner design.

Figure 4.1-14 shows that the steep increase in average particle temperature matches the observed flame stabilization location from the temperature profile and CO plots. For the existing burner, the flame stabilizes at the quarl exit for both the air and the oxygen cases. The flame for the oxy-research burner as originally designed is far outside the quarl. The low- $\mathrm{NO}_{\mathrm{x}}$ burner behaves differently than the original oxy-research burner with respect to air and oxygen. The oxy-fired curve for the low-NO $\mathrm{N}_{\mathrm{x}}$ burner heats up much more quickly than the air case, whereas the behavior is opposite for the original oxy-research burner design. This can be explained by two factors. First, the velocities for the two oxy-research burner cases are similar, but the velocity for the low- $\mathrm{NO}_{\mathrm{x}}$ burner oxy-fired case is significantly lower than the air case. This explains why the particles in the oxy-fired case heat up at a shorter distance from the low- $\mathrm{NO}_{\mathrm{x}}$ burner face than in the air-fired case. The second factor explains why the temperature of particles in the oxy-fired case is slower to heat than in the air-fired case for the oxy-research burner. This is likely due to the lower temperature flame in the oxy-fired case providing a lower radiant intensity to the particles. It is apparent from this plot that the original oxy-research burner design does not meet the design criteria.

Figure 4.1-15 compares the particle temperatures for the low- $\mathrm{NO}_{\mathrm{x}}$ burner and the final oxy-research burner design. Again, the behavior represented by the particle temperatures very closely matches the behavior of the flame stabilization location relative to the quarl exit that was observed in the temperature and $\mathrm{CO}$ concentration plots. This indicates that the flame behavior is very closely related to the rate that the particles are heated. In order to maintain similar burner behavior when scaling a burner, the particle temperature profile should be maintained. The particle temperature profile is influenced by many factors including: gas velocity, radiation intensity, particle size and hot flue gas recirculation characteristics inside of the quarl. Figure 4.1-15 also indicates that the flame stabilization location for the oxy-research burner, in its final design configuration, is expected to fulfill the design criteria. 


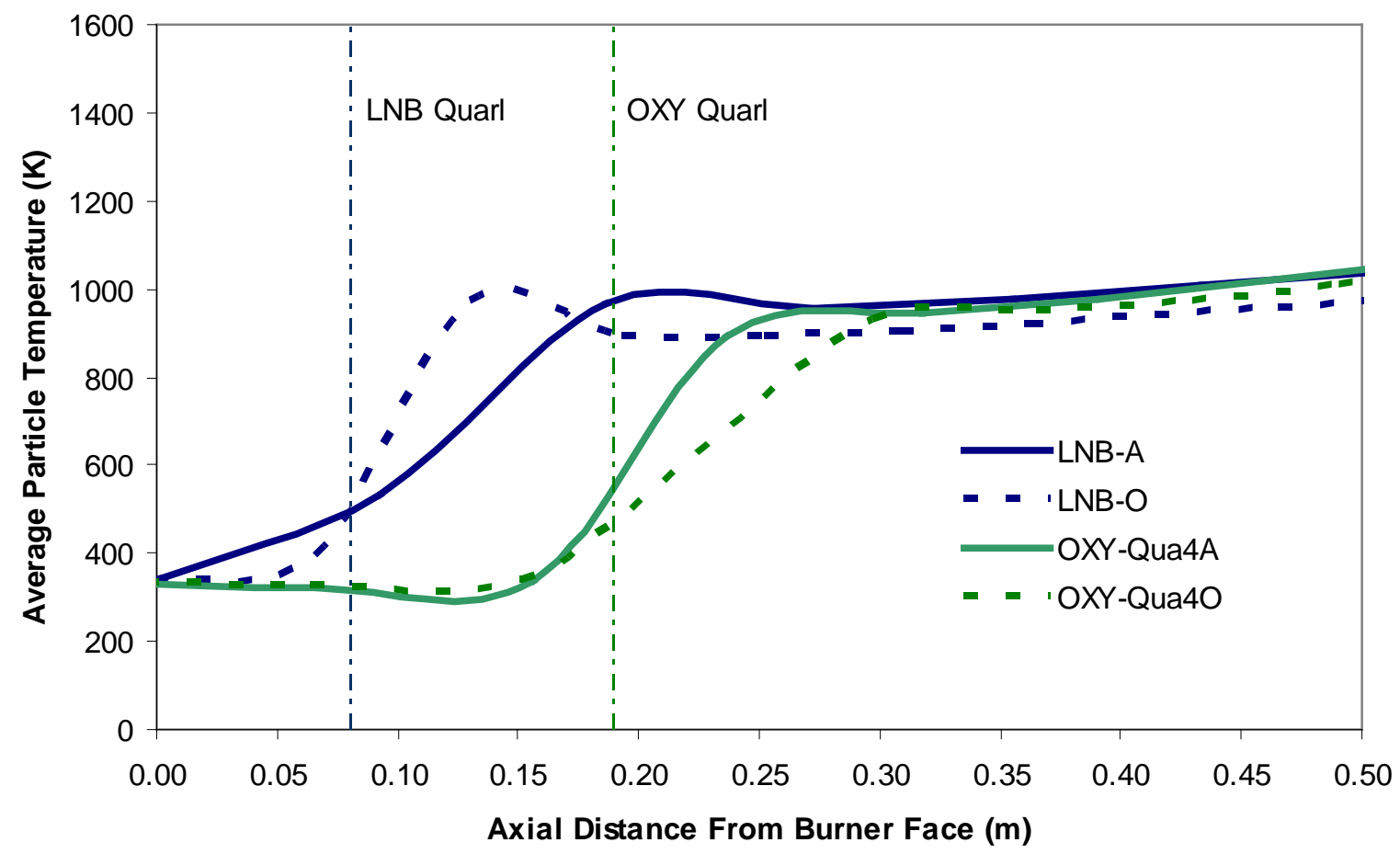

Figure 4.1-15: Particle temperature profile for the existing burner and the final oxy-research burner design.

\subsubsection{Oxy-Research Burner Final Design}

Following the extensive CFD work, the final geometry requirements for the oxy-research burner were sent to the Siemens designer for modifications and detailing. Additional considerations were made in the overall design to allow the burner and burner plate to be installed on the L1500 with minimal modification to the existing infrastructure, while allowing the original burner to be easily interchanged for future and existing programs. These considerations included:

- Installation of a pilot burner and a natural gas plenum and distributor within the quarl for overnight operation and for furnace heat up and cool down.

- Inner and outer secondary air plenum design to accommodate the existing gas train connections.

- Connectors and penetrations for flame scanners and thermocouples in the quarl region to integrate with the furnace control system.

- Overall dimensions of the burner plate to meet tight installation tolerances.

- Configuration of the burner plate refractory to accommodate the oxy-research burner's quarl, natural gas distribution system and plate design.

These modifications to the burner design have been completed and virtual pictures of the oxy-research burner were generated by the designers with CAD software. These pictures are presented as Figure 4.1-16 through Figure 4.1-19. In these pictures, some of the major components have been labeled. Figure 4.1-16 is a view from the top of the furnace looking down at the burner and burner plate. In this figure, the existing gas train connections to the inner and outer secondary plenums are shown along with the pilot burner penetration and the swirl control. 


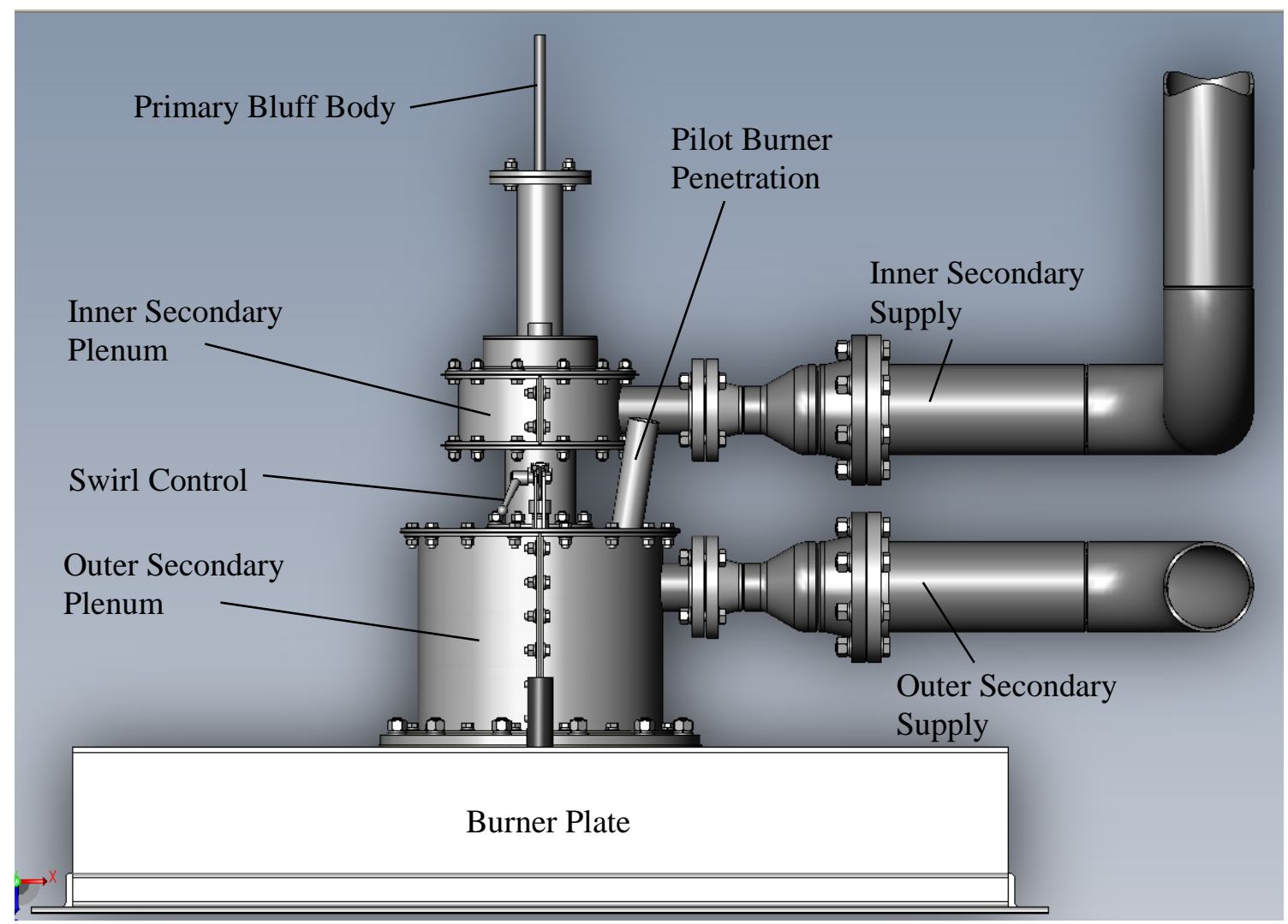

Figure 4.1-16: Top view of the oxy-research burner. 
Figure 4.1-17 provides a side view of the oxy-research burner. In this view the natural gas and coal pipe connections can be seen.

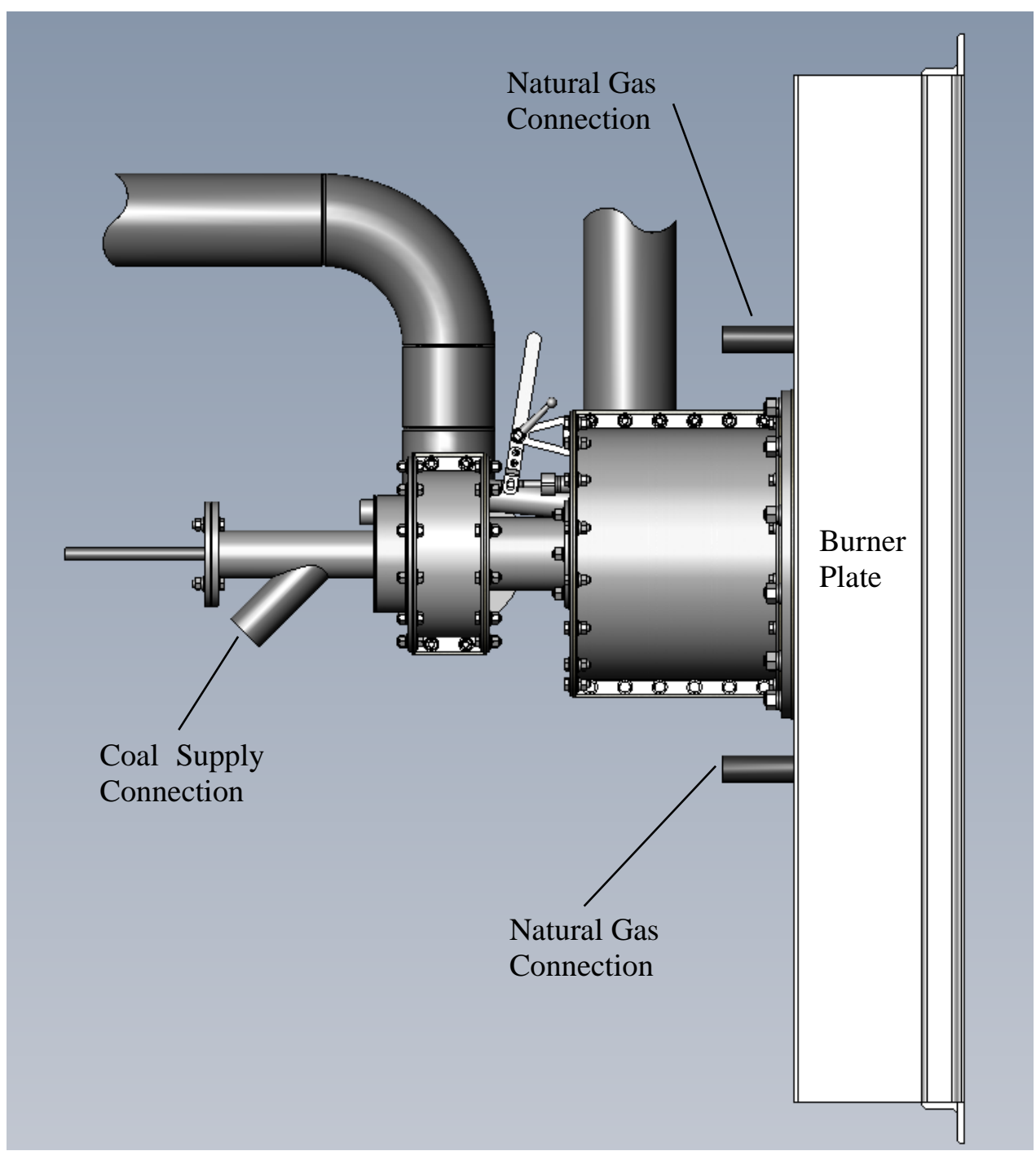

Figure 4.1-17: Side view of the oxy-research burner. 
Figure 4.1-18 is a side cross section of the burner and Figure 4.1-19 is an expanded cross sectional view. These views provide some insight on the arrangement of each of the annulus in the burner throat.

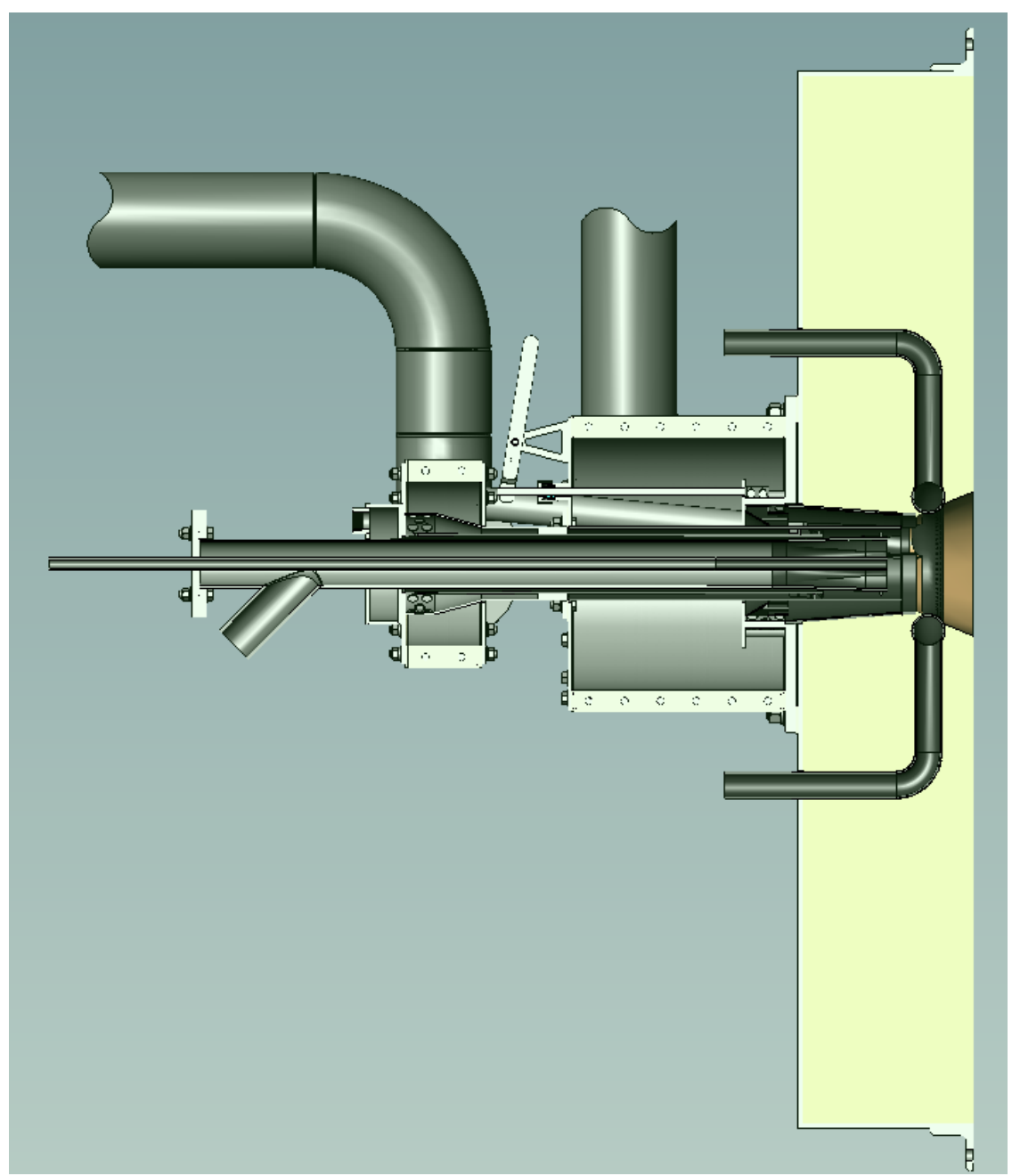

Figure 4.1-18: Side cross-section view of the oxy-research burner. 


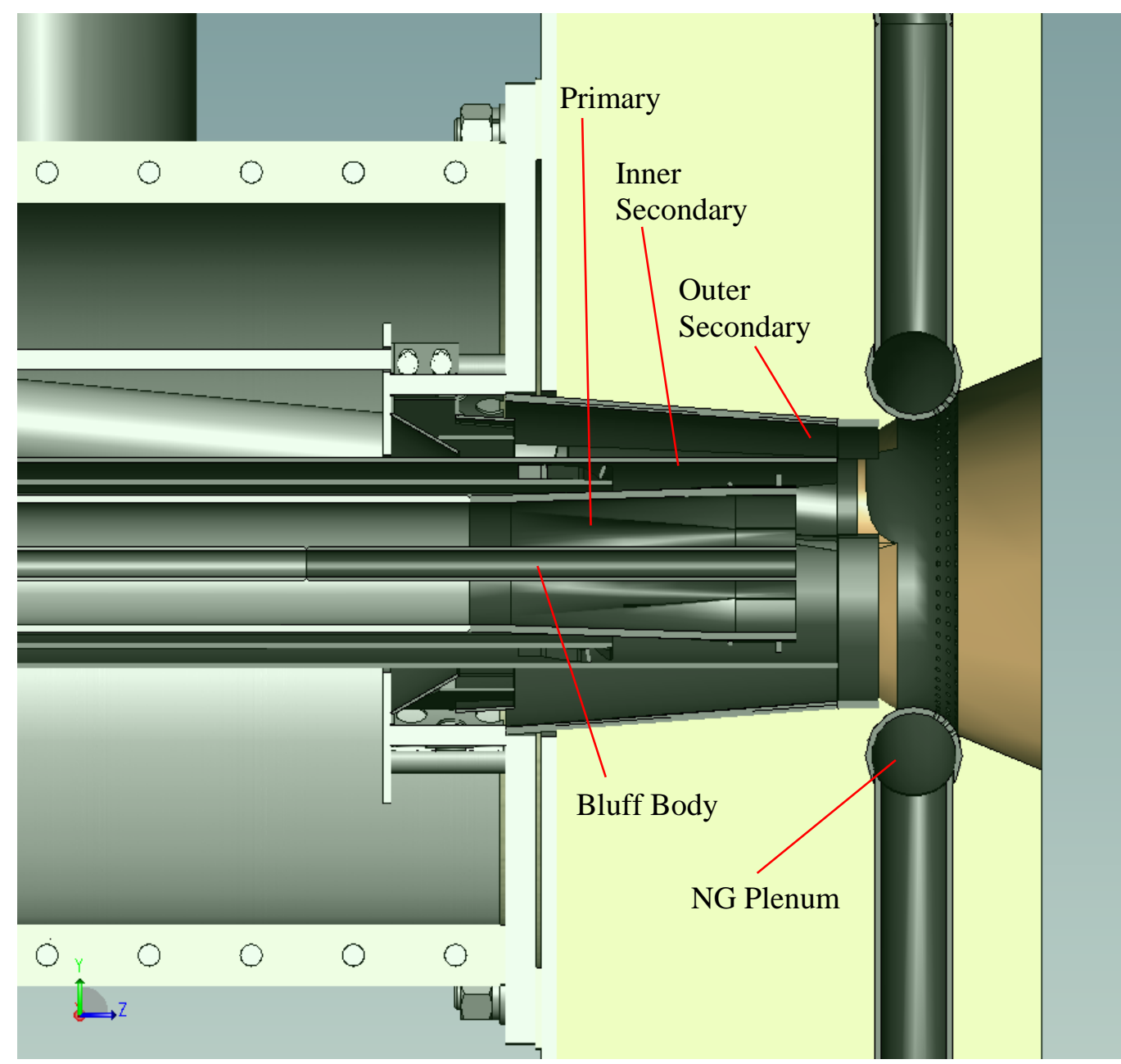

Figure 4.1-19: Side cross-section view of the oxy-research burner throat. 


\subsection{December 2009 to January 2010 L1500 Burner Tests}

\subsubsection{Introduction and Test Strategy}

The number of degrees of freedom for operation increases dramatically when retrofitting a coal firing system for oxy-combustion. This is largely to the ability to independently control the flow rates of both oxygen and flue gas recycle to each firing system inlet and to use an infinite number of mixing strategies for these streams. For the purposes of the burner parametric testing in the L1500, the variables of operation that were varied are as follows:

- Primary

- FGR Rate, Blended $\mathrm{O}_{2}$ Rate, Injected $\mathrm{O}_{2}$ Rate, Injected $\mathrm{O}_{2}$ Pattern (design of the injection nozzle), Bluff Body

- Inner Secondary Register

- FGR Rate, Blended $\mathrm{O}_{2}$ Rate, Injected $\mathrm{O}_{2}$ Rate, Gas Temperature

- Outer Secondary Register

- FGR Rate, Blended $\mathrm{O}_{2}$ Rate, Gas Temperature, Swirl

- Over-Fire Air (Oxygen)

- FGR Rate, $\mathrm{O}_{2}$ Rate, Gas Temperature

- Natural Gas Ring

- $\mathrm{CO}_{2}$ Rate, $\mathrm{O}_{2}$ Rate

Due to safety guidelines and for continuity between the multi-scale test data on this program, some operational constraints have been implemented. These constraints are as follows:

- $\quad$ Coal Flow Rate - The firing rate will be $3.5 \mathrm{MBtu} / \mathrm{hr}$

- Excess $\mathrm{O}_{2}$ will be $3 \%$, dry

- $\mathrm{O}_{2}$ in the $\mathrm{O}_{2} /$ FGR mixture will be $27 \%$ or $32 \%$

- Primary $\mathrm{O}_{2}$ Concentration can be varied between 0 and 23.5\%

- Secondary $\mathrm{O}_{2}$ Concentrations can be varied between 0 and 50\% (100\% may be possible)

The experimental program on the L1500 was designed to include four weeks of burner parametric testing (including system shakedown) and six weeks of corrosion testing. The experiments summarized in this section encompass the first three weeks of burner parametric testing, including one week of shakedown. Shakedown, burner scoping tests and experiments were performed during the period of 12-07-09 to 1218-09. All of these tests were performed using the Skyline (Utah Bituminous) coal. Additional experiments were performed during the week of 01-11-10; however, this period of testing was cut short due to a failure of the furnace cooling system, causing damage to some of the heat exchangers in the furnace, and due to a worn primary air blower. Both of these hardware issues were corrected before the initial corrosion tests.

Given the number of independent variables and the infinite number of potential settings for each, a strategy was implemented to target the most useful combination of conditions for the burner parametric testing. Instead of performing a broad sweep across all operating conditions, it was decided to guide the testing by attempting to answer questions relevant for oxy-retrofit of utility boilers. The questions that appear to be the most compelling are:

1. When retrofitting an existing air-fired burner, what are the best conditions for the primary? How may these conditions be impacted by hardware and safety constraints? Which of the following should be matched with the air-fired conditions in the primary?

a. Gas/fuel mass ratio 
b. $\mathrm{O}_{2} /$ fuel mass ratio

c. Momentum

d. Velocity

2. What is the lowest primary $\mathrm{O}_{2}$ concentration that will produce a stable flame? Can the burner be operated with no added oxygen in the primary (oxygen content of the primary will be determined by the FGR $\mathrm{O}_{2}$ concentration)? How is the low primary $\mathrm{O}_{2}$ stability affected by the following?

a. Inner secondary register $\mathrm{O}_{2}$ concentration

b. Bluff body

c. Swirl

3. What is the difference in flame behavior between $\mathrm{O}_{2}$ blending (mixing $\mathrm{O}_{2}$ with FGR prior to the gases entering the burner) and $\mathrm{O}_{2}$ injection (introducing $\mathrm{O}_{2}$ at the burner face through lances)? Injection of $\mathrm{O}_{2}$ near the burner face may have some advantages in a retrofit for materials and safety, while blending $\mathrm{O}_{2}$ in the wind box or before may be better for ease of retrofit and control.

4. Can the heat transfer profile of the furnace (both radiative and convective heat transfer) be adjusted by independently controlling the $\mathrm{O}_{2}$ in the overall $\mathrm{O}_{2} /$ FGR mixture for the burner region and after the over-fire gas?

5. What are the impacts of burner stoichiometric ratio on flame stability and $\mathrm{NO}_{\mathrm{x}}$ formation and destruction?

The test plan for the first two, two-week periods of testing were designed to test operating conditions relevant to these questions and surrounding operating conditions.

There may be some conditions that would be more favorable for retrofit than others. An $\mathrm{O}_{2}$ injection system at the burner face was previously mentioned that may reduce, or eliminate many of the safety issues associated with enriched $\mathrm{O}_{2}$ streams and combustible materials. Another of these conditions may be to operate with matched $\mathrm{O}_{2}$ concentrations in the inner and outer registers of the secondary. This condition forfeits a degree of freedom. However, if $\mathrm{O}_{2}$ can be mixed into the bulk secondary gas stream as opposed to independent controls for every secondary register of every burner, the amount and complexity of the equipment may be significantly reduced. Because of its potential importance for retrofit this condition will be called "Pseudo Air" throughout the reporting on these experiments. "Pseudo Air" may be more appropriate to apply to a condition where the primary $\mathrm{O}_{2}$ concentration was also matched with the two registers of the secondary, but this condition may not be attainable due to safety considerations in the primary register and in order to match heat transfer in the furnace.

\subsubsection{Experimental Setup}

In preparation for experimentation on the L1500, modifications were made to the existing measurement and sampling equipment and new equipment was fabricated and installed, including the oxy-research burner. This section of the report describes those modifications.

\subsubsection{Flame Video}

The University of Utah has a Lenox FireSight 6545 high temperature camera for use in the L1500. Historically this camera has only been used while the burner is off and the furnace is hot, in order to view the buildup of deposited ash in the region of the burner and quarl. The camera was previously never used to collect video depicting the flame because there was no port available to provide the appropriate viewing angle. When Siemens fabricated the new burner plate for the L1500 a port was included for this 
purpose. Figure 4.2-1 provides a diagram of the camera, the camera port in the burner plate and the viewing angle.
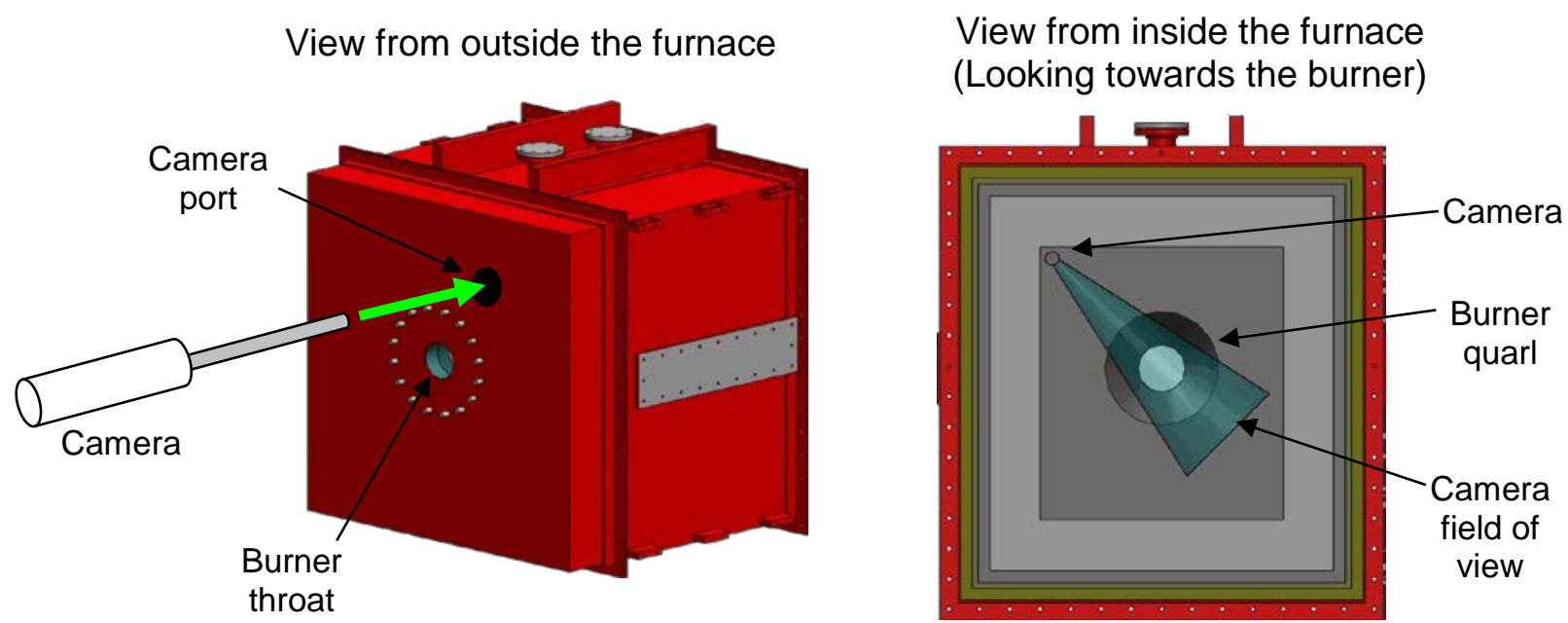

Figure 4.2-1: Description of camera configuration and the field of view.

The Lennox FireSight camera has a white cylindrical body which houses the temperature control equipment for the lens. The lens itself is mounted at the end of a stainless steel rod with the viewing angle of the lens orthogonal to the axis of the cylinder and rod. As depicted in Figure 4.2-1 the rod section of the camera is inserted through the port on the burner plate pointing down the axis of the furnace. The depth of camera penetration is adjusted until the quarl exit is at the edge of the video frame and the view of the root of the flame is maximized. Still frame pictures produced with this camera configuration are presented in Figure 4.2-2.

The still frame pictures in Figure 4.2-2 help to envision the orientation of the camera. However, the furnace sidewall and floor are opposite their expected location. This is because the camera inverts the picture left to right. This effect must be considered when interpreting video of the flame behavior. The exit of the burner quarl in the burner plate refractory can be seen in these pictures. Using a ruler it can be determined that the viewable region of the camera extends about 1.5 quarl diameters into the furnace from the quarl exit. The diameter of the quarl at its exit is 10 inches. So the camera is displaying a region that extends about 15 inches into the furnace.

There is a toggle switch on the body of the camera that may be used to adjust the contrast of the picture. The settings on this switch are unmarked and difficult to differentiate. It is also very easy to inadvertently disturb this setting while removing and installing the camera on the furnace. Despite the fact that this setting is left constant for each days testing, it is wise to compare only the color and luminosity of flames that were photographed on the same day. 


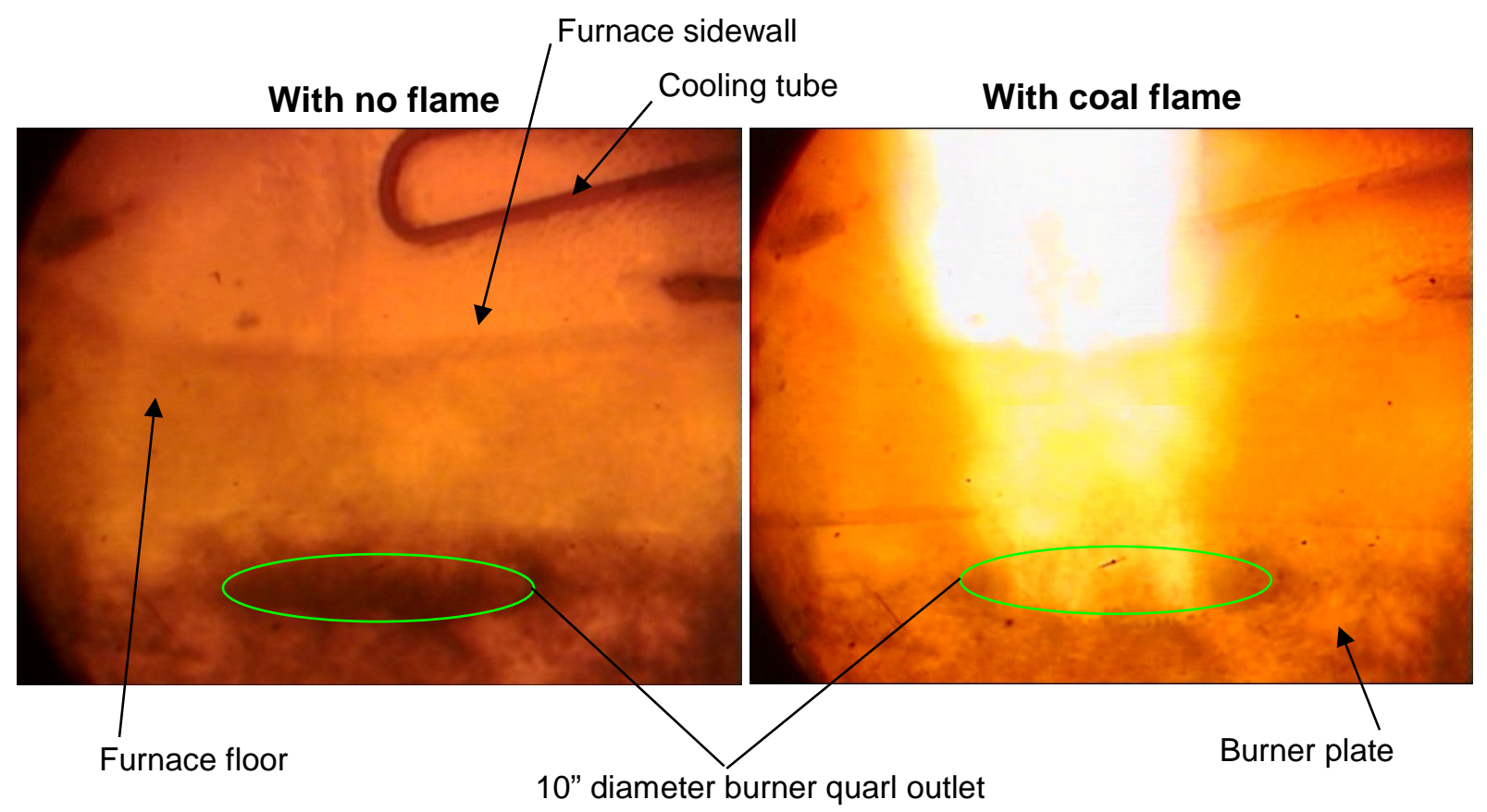

Figure 4.2-2: Still pictures from the furnace camera with and without flame.

\subsubsection{Sampling Seal System}

Great care must be taken when inserting sample probes and measurement devices into the furnace to limit the amount of air infiltration allowed under oxy-fired conditions. Traditionally, under air-fired conditions, the furnace is operated at slightly negative pressure at the desired sample location and a port is removed to insert a probe or to collect a sample. This is typically done with the flame on and there is little disturbance to the operating conditions. Under oxy-fired conditions, air in leakage caused by an open port under negative pressure conditions would cause a perturbation in $\mathrm{CO}_{2}$ concentration that could take up to an hour to purge from the system, due to the recycled flue gas. To avoid this problem and to allow access for furnace sampling and measurement, special access ports were designed. These ports bolt directly to the 4" flanges on the L1500. A water cooling jacket extends into the furnace from the face of the 4" flange to the inside surface of the refractory. The inside diameter of this cooling jacket is $25 / 8$ ". On the outside of the furnace there is a $2 \frac{1}{2} 2$ " ball valve and then outside that is a packing system designed to seal on the outside of a 2" pipe.

To integrate with this new seal system, all of the probes used with the L1500, including the suction pyrometer, heat flux probes and gas and solid sampling probes, have been redesigned with an outside diameter of 2 3/8" (characteristic of a 2" pipe). When installing a probe into the furnace under oxy conditions, the probe is inserted through the packing mechanism and then the packing is adjusted to provide a seal around the pipe. Once the seal has been adjusted, the ball valve is opened and the probe may be inserted to the desired depth in the furnace. A picture of the sampling seal system is provided as Figure 4.2-4. Eight of the sealed sample ports were fabricated by the University of Utah and will be installed on the center ports of the sections 1 through 5 and 7 through 9 of the L1500. Section six is occupied by the over-fire air nozzles.

\subsubsection{Heat Flux}

Four new heat flux probes were designed and fabricated for the L1500. These probes operate by transferring heat from the furnace to water through a well-defined surface area. The temperature of the 
cooling water at the inlet and outlet of the probe and the flow rate of water through the probe are measured. These values along with the heat capacity of the water are used to calculate the total heat transferred to the water. For this value to be useful for calculating a meaningful heat flux, the heat transfer must be limited to a restricted surface area with uniform incident radiation. These probes were constructed of 2" SCH 10 stainless steel pipe. The tip of each of these probes was "blanked off" by welding a circular piece of 1/8" stainless steel plate inside the 2" pipe, $1 / 2$ " from the end of the pipe. A second circular plate was welded to the end of the pipe creating a half inch cavity in the end of the pipe. Water is supplied to and removed from this cavity by $1 / 2$ " stainless steel tubing that each penetrate the inner stainless plate and extend through the center of the 2" pipe to the outside of the furnace. An even flow of water is provided to the cavity at the tip of the probe by dividing the cavity in half with a perforated plate. Such a construction allows cooling water to be supplied to and removed from the cavity while essentially eliminating heat transfer to the water in delivery and removal. The probes are installed in the furnace with their faces (heat transfer surfaces) at the same plane as the surface of the refractory inside the combustion chamber and even with the water jackets on the sealed sample ports. The clearance between the inside of the sample port and the outside of the heat flux probe is 1/8" and the surface temperatures are nearly the same (water filled) eliminating the driving force for heat transfer through the sides of the cavity. It is reasonable to assume that all of the heat transfer is limited to the $23 / 8$ " diameter flat surface of the probe. A cross section view of the heat flux probes is included as Figure 4.2-3.

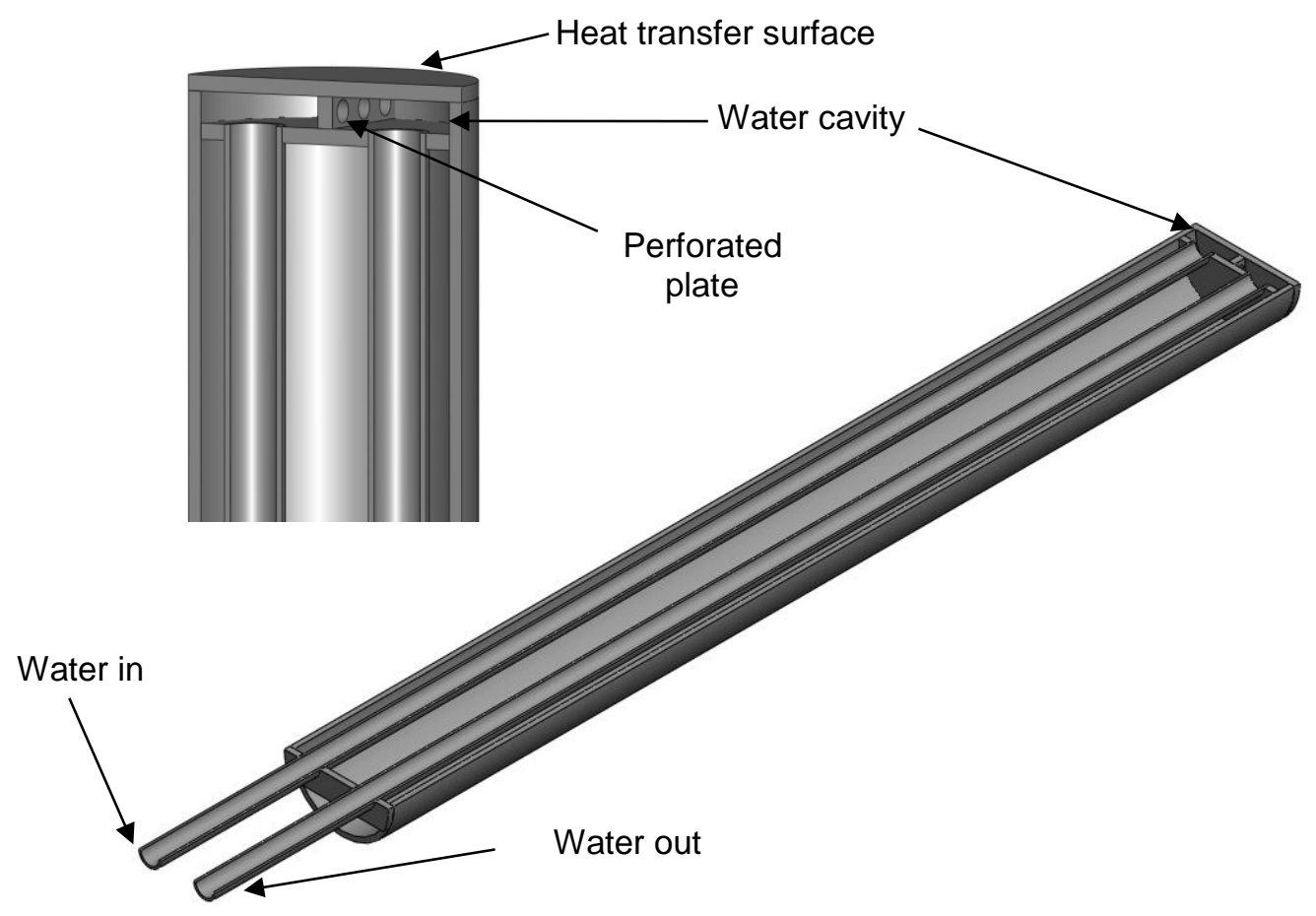

Figure 4.2-3: Cross section view of heat flux probes.

A picture of the heat flux probe installed in a sampling seal system is shown in Figure 4.2-4. 


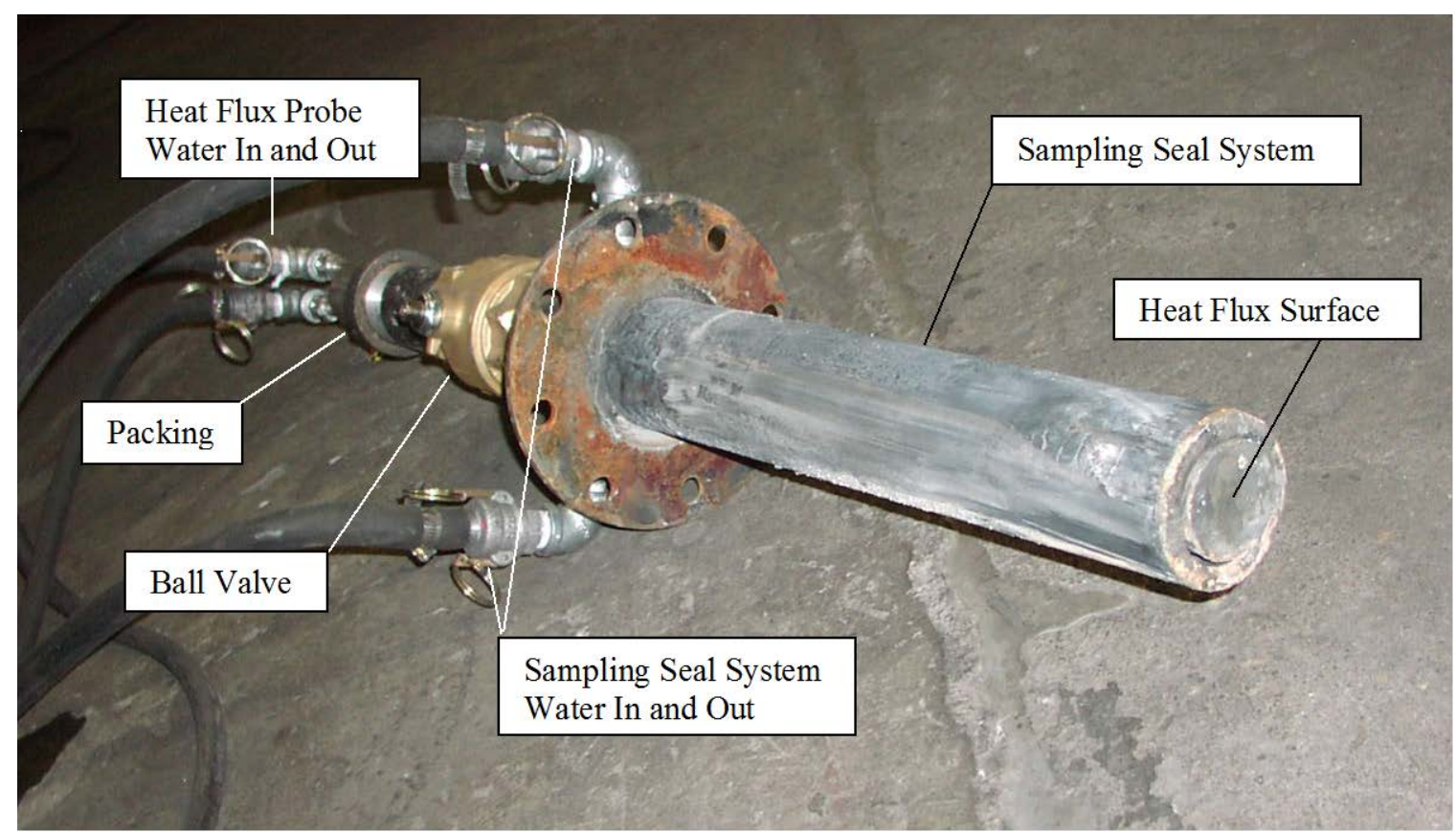

Figure 4.2-4: Heat flux probe installed in the sampling seal system.

\subsubsection{General Measurements}

As mentioned previously, the suction pyrometer and gas and solid sampling probes have been refabricated so that they are compatible with the sealed sample ports. These probes will be used to profile the furnace for temperature, concentration of major gas species and solid samples.

\subsubsection{Scoping Tests and Air-Fired Operation}

During the first two-week test period, several days were spent just playing with the burner under air and oxy-fired conditions without collecting data. The purpose of this effort was to become familiar with the burner's operating characteristics and to begin to carve out a known region of conditions that produce a stable and attached flame and to find the boundary where the flame detaches. These tests will be referred to as "Scoping Tests". One of the key discoveries during this period was that the flame does not flicker, or bounce between attached or detached conditions. For a given set of operating conditions, the flame is either attached or detached. Still frames from video taken when the flame is attached and when the flame is detached are presented in Figure 4.2-5. Above the photo, the date and test number of the video from which the still frame was taken is indicated in red.

In the detached flame photo of Figure 4.2-5, ignition of the coal particles can be seen in the upper left corner of the flame. From our observation throughout all of the testing to date, when the flame is not attached inside of the quarl, ignition of the coal particles occurs at the edge of the viewable region in the video, which is about 15 inches from the quarl exit. 
12-16-09 (4)

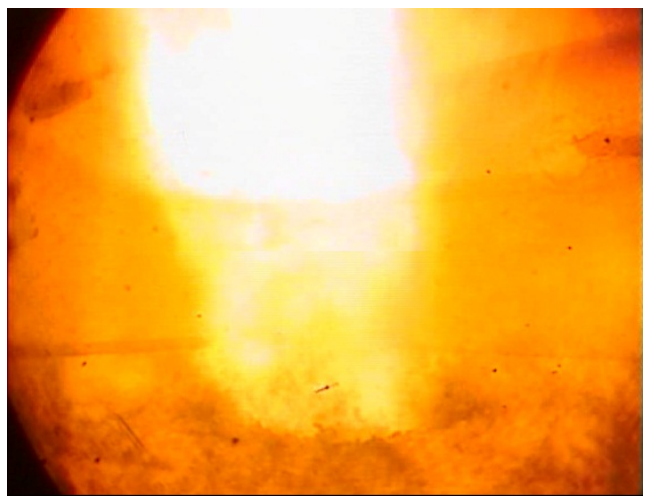

Figure 4.2-5: Example photos of flame attachment and detachment.
12-16-09 (Detached)

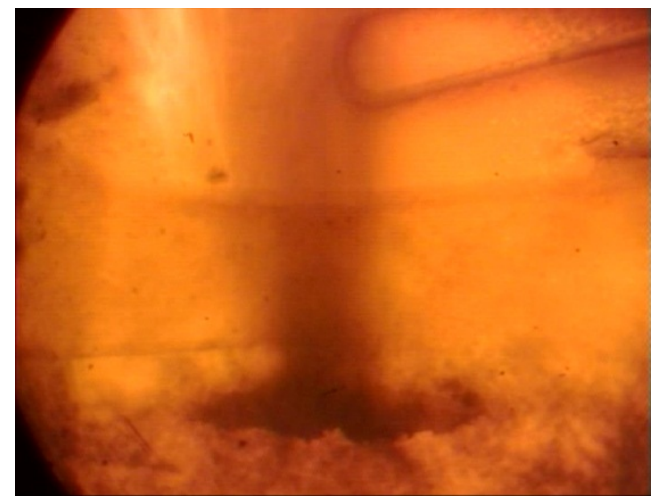

During the scoping tests it was also determined that variation of the swirl setting on the outer secondary register has little effect on the flame shape and attachment. Results of this modeling indicate that when fully engaged the outer secondary swirl produces a tangential/axial velocity ratio of about 0.6. The low tangential velocity predicted by the model supports the observations made during experimentation. If there is an indication of sufficient benefit, the swirl vanes may be modified for future testing.

Scoping tests indicated that an air/fuel ratio of 2.2 was determined to be the upper limit for an attached flame under air-fired conditions. The same tests for oxy-fired conditions provided mixed results depending on other operating parameters and will be explored in more depth during the parametric testing.

The scoping tests also provided the opportunity to experiment with methods of attaching a detached flame, other than outer secondary swirl. The most useful of these is to enrich the inner secondary register in oxygen under oxy-fired conditions. This method of attaching a flame was used often throughout the burner parametric testing.

Data was collected while firing the burner under air-fired conditions. The three operational conditions that were varied for these tests were: inner/outer secondary mass split, burner stoichiometric ratio (staging) and primary air/fuel ratio. The outer register swirl was set for the strongest swirl and all other conditions were fixed as described earlier. The over-fire gas was introduced at section 6 of the furnace for all of these tests.

The inner/outer secondary mass split was varied from zero mass in the inner register to $25 \%$ of the secondary mass through the inner register. Siemens indicated that they expected a 10/90 split to be the optimum condition. At the 25/75 condition and for higher inner secondary mass flows, the flame was detached. The condition producing the minimum $\mathrm{NO}_{\mathrm{x}}$ concentration was a 5/95 split, although the 10/90 condition was very similar. Figure 4.2-6 provides a curve for $\mathrm{NO}_{\mathrm{x}}$ versus secondary air distribution. 


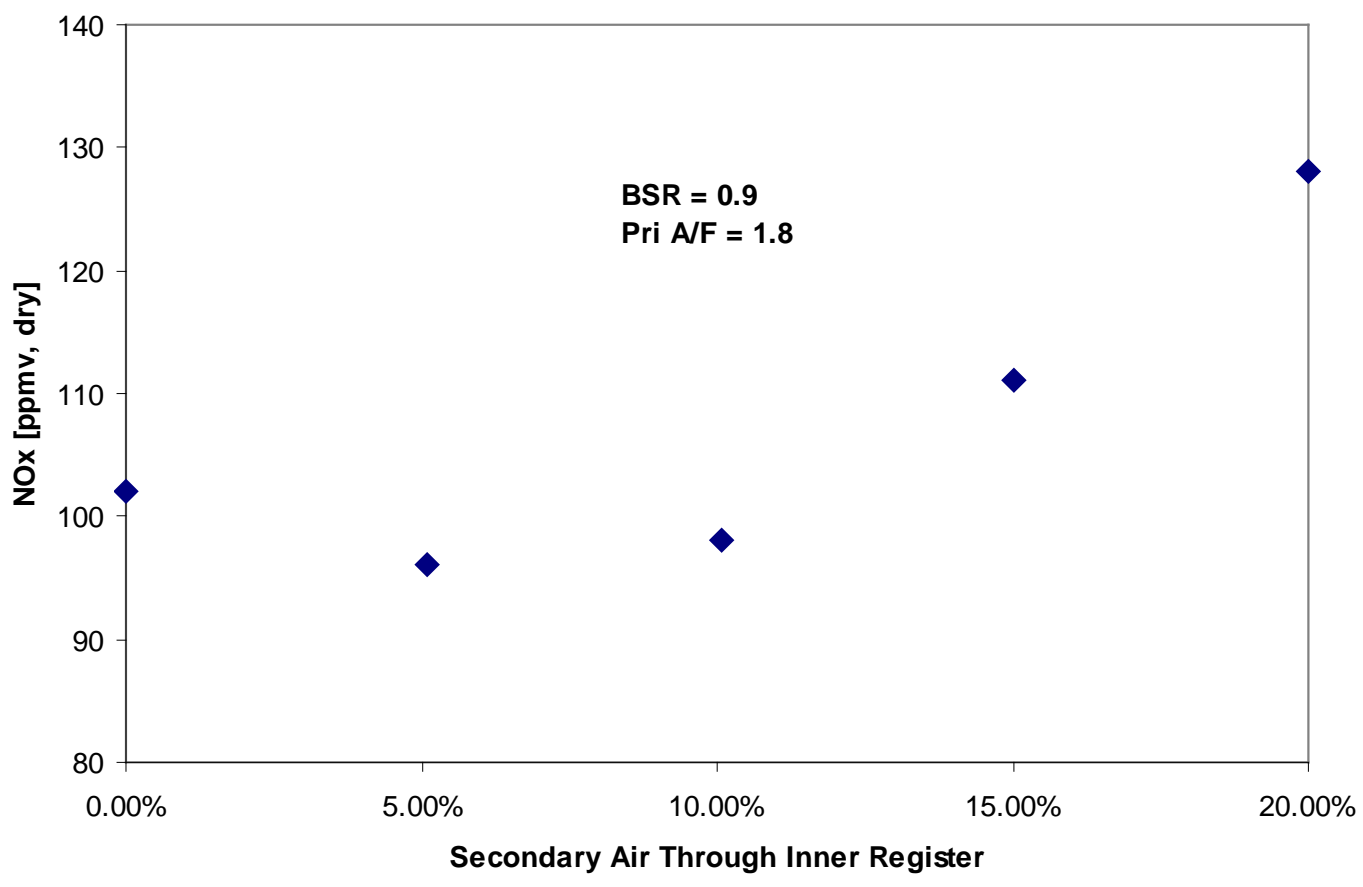

Figure 4.2-6: Impact of burner secondary air split on $\mathrm{NO}_{\mathrm{x}}$ concentration under air-fired conditions.

The shape of the flame is dependent on the distribution of the secondary air. Pictures of the flame for the 0/100 and 20/80 secondary air distributions are presented in Figure 4.2-7. The date and the test number of the video from which these still frames were extracted are indicated in red. The conditions associated with that test are indicated in black. For the condition where there is no air in the inner secondary register (0/100, right side photo), the flame is wide and not very well defined. When $20 \%$ of the secondary air is introduced through the inner register, the flame is narrower and better defined.
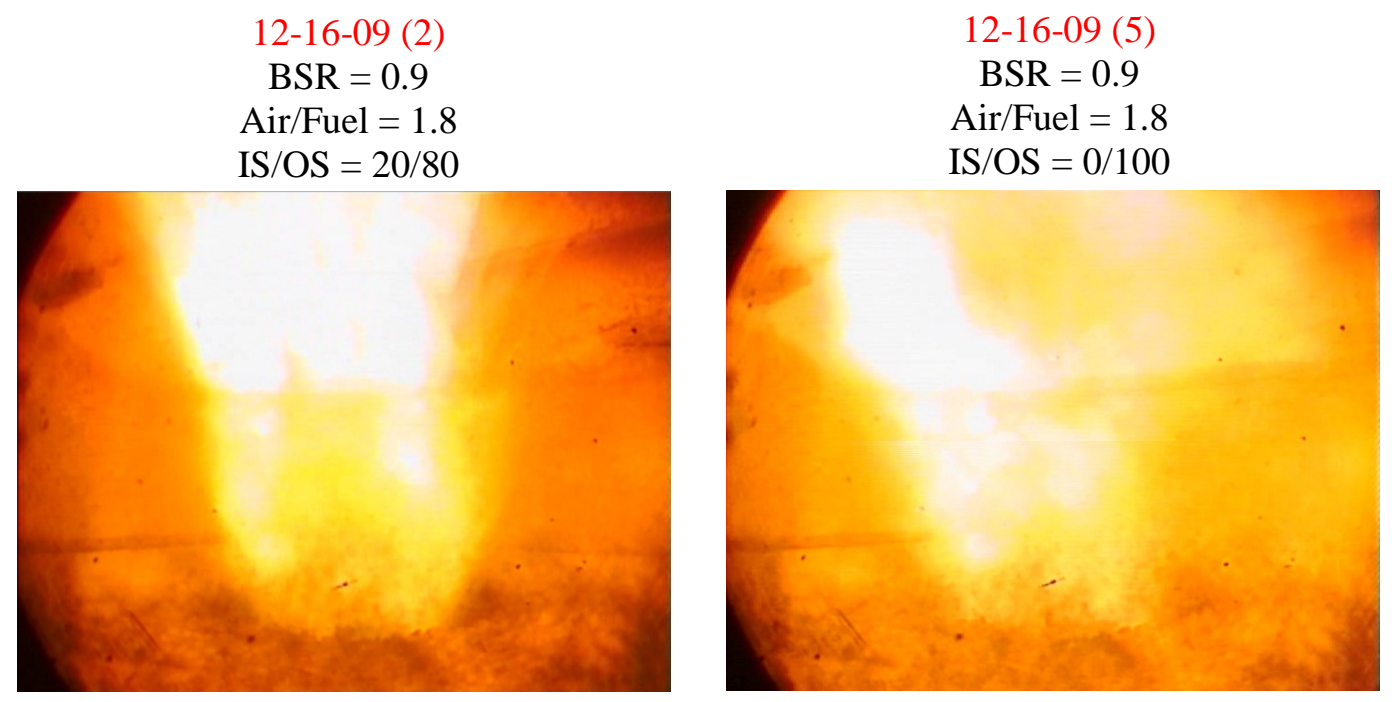

Figure 4.2-7: Dependence of flame shape on secondary air distribution for air-fired conditions. 
The burner stoichiometric ratio (BSR) was varied between 0.8 and 1.15. The latter condition is representative of $3 \% \mathrm{O}_{2}$, dry in the flue gas, or no staging. For these tests, the air split between the inner and outer register of the secondary was held constant at 10/90 and the primary air/fuel ratio was also varied between 1.5 and 2.0. A plot of the $\mathrm{NO}_{\mathrm{x}}$ concentration versus BSR is presented in Figure 4.2-8. A plot of the $\mathrm{NO}_{\mathrm{x}}$ concentration versus primary air/fuel ratio is presented in Figure 4.2-9. These two plots indicate that the $\mathrm{NO}_{\mathrm{x}}$ concentration is tied strongly to BSR, but there is little or no correlation between $\mathrm{NO}_{\mathrm{x}}$ and primary air/fuel ratio.

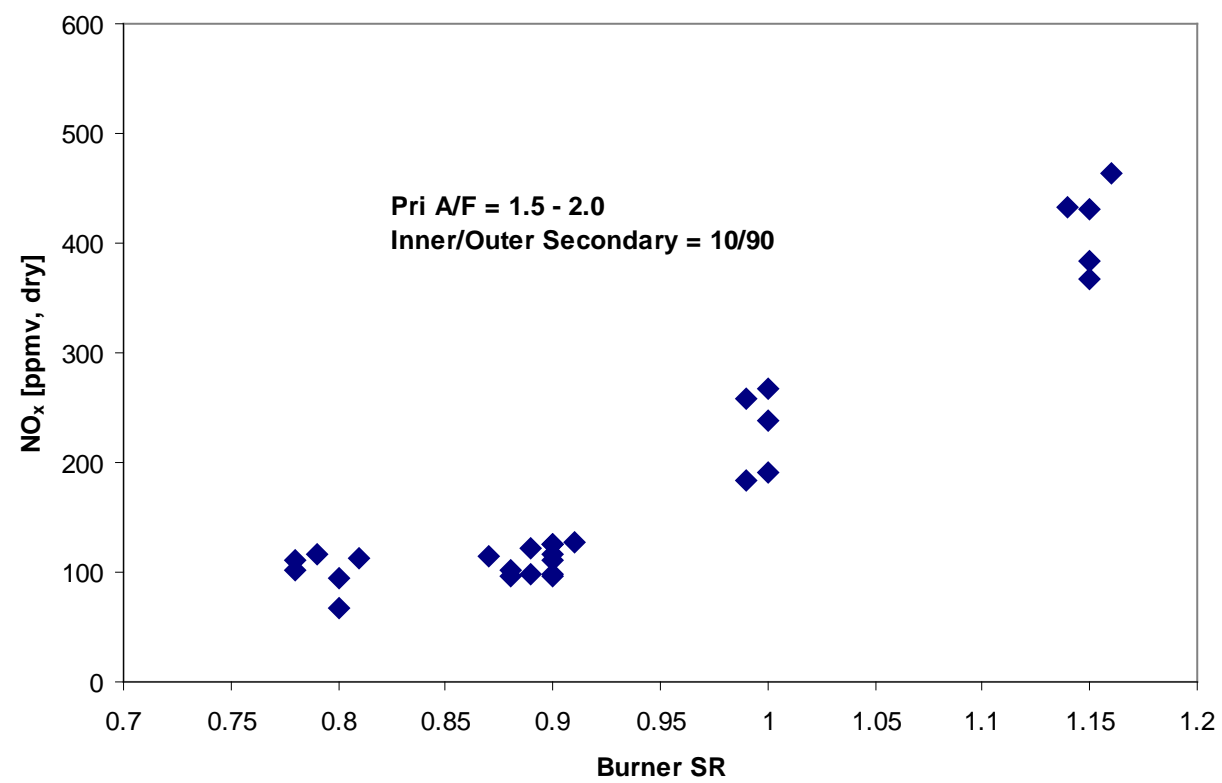

Figure 4.2-8: Impact of burner stoichiometric ratio on $\mathrm{NO}_{\mathrm{x}}$ concentration under air-fired conditions.

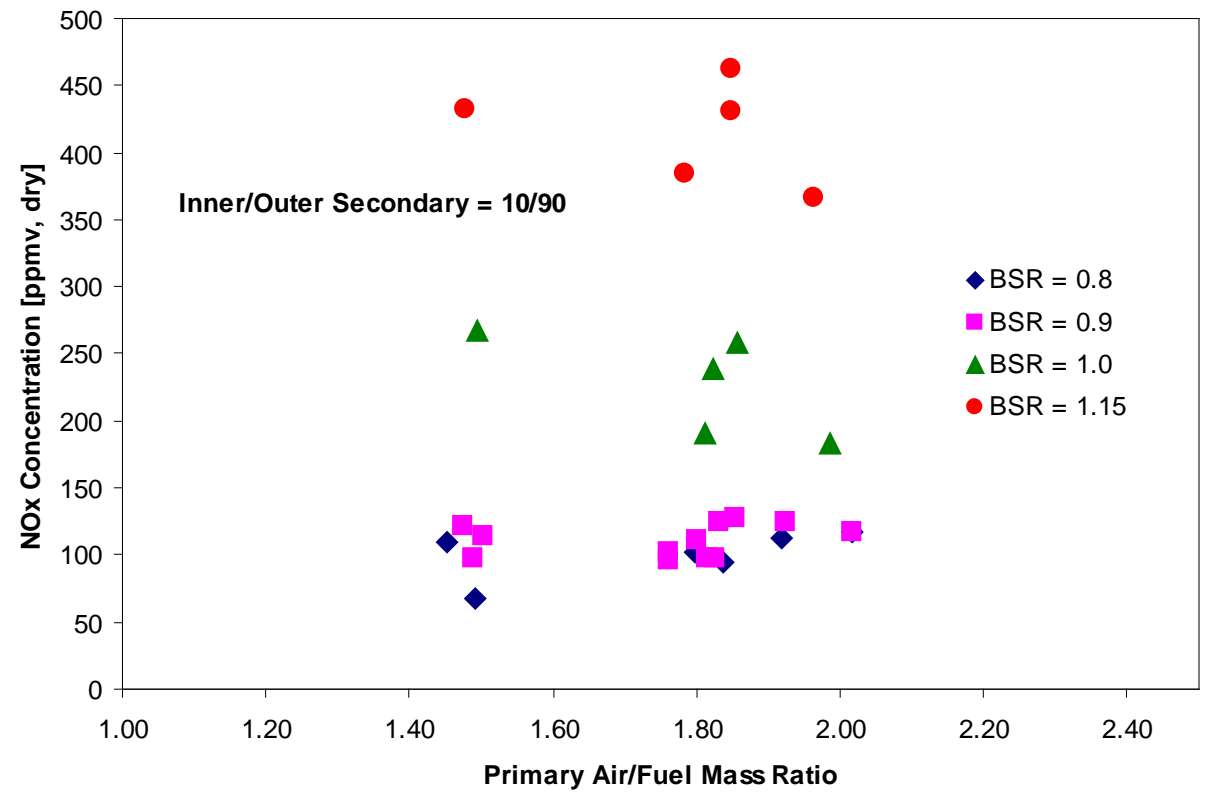

Figure 4.2-9: Impact of burner primary air/fuel ratio on $\mathrm{NO}_{\mathrm{x}}$ concentration for air-fired conditions. 
The shape of the flame was also dependent on the burner stoichiometric ratio, as can be seen in Figure 4.2-10. At a low BSR, the flame is dim and appears to be continuing to widen as it leaves the field of view. For the condition where excess oxygen is provided at the burner, the flame is much more luminous and the flame seems to be tapering as is leaves the field of view.

$$
\begin{gathered}
\text { 01-12-10 }(2) \\
\text { BSR }=0.80 \\
\text { Air/Fuel = } 1.5 \\
\text { IS/OS = 10/90 }
\end{gathered}
$$

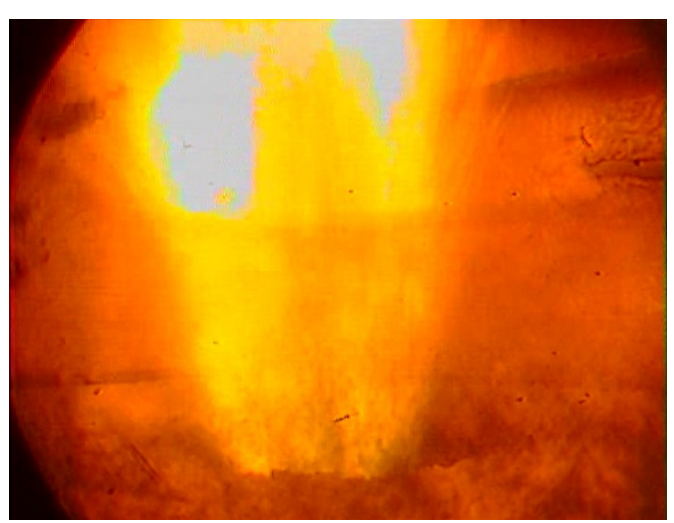

01-12-10 (4)

$\mathrm{BSR}=1.14$

Air/Fuel $=1.5$

$\mathrm{IS} / \mathrm{OS}=10 / 90$

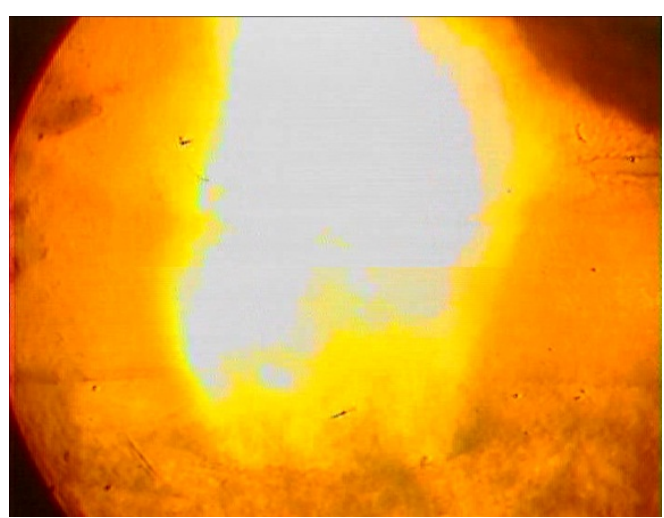

Figure 4.2-10: Dependence of flame shape on burner stoichiometric ratio under air-fired conditions.

There is very little difference in flame shape with the variation of the primary air/fuel ratio as can be seen in Figure 4.2-11.

$$
\begin{gathered}
\text { 01-12-10 (3) } \\
\text { BSR = 0.90 } \\
\text { Air/Fuel = 1.5 } \\
\text { IS/OS = 10/90 }
\end{gathered}
$$

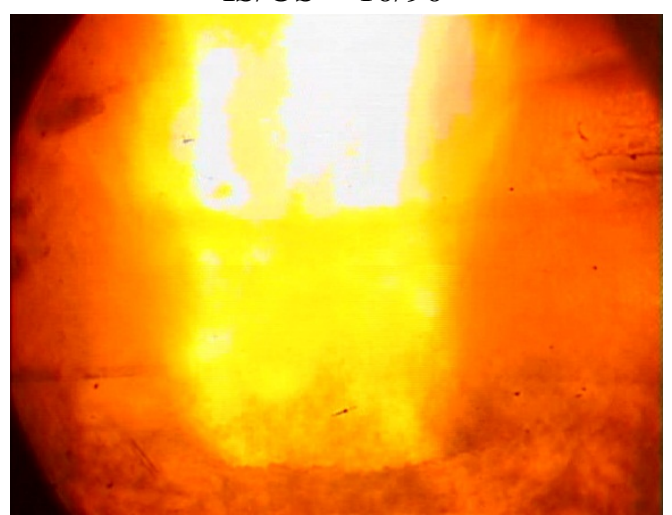

01-12-10 (8)

$\mathrm{BSR}=0.90$

Air/Fuel $=1.8$

$\mathrm{IS} / \mathrm{OS}=10 / 90$

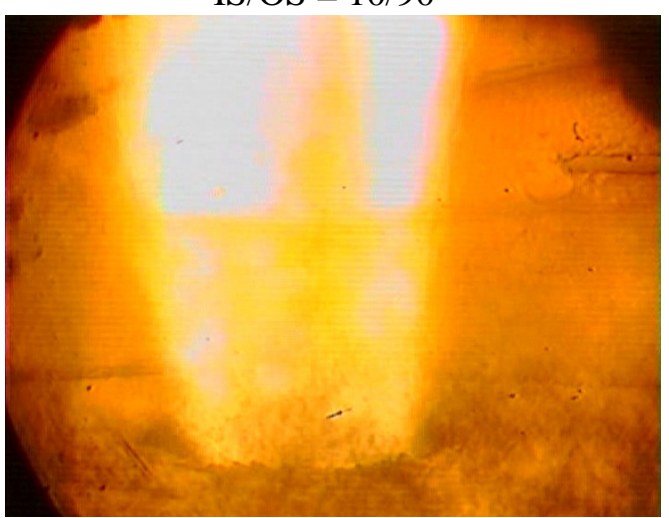

Figure 4.2-11: Dependence of flame shape on primary air/fuel ratio under air-fired conditions.

\subsubsection{Comparison between Air and Oxygen Operation}

Experiments were performed directly comparing air-fired conditions and oxy-fired conditions that may most closely match the air conditions. Photos of the flame under these conditions are presented in Figure 4.2-12. Again, the data and test number are indicated in red and the conditions of the test are indicated in 
black text. The oxy-fired conditions for this comparison were chosen to match heat transfer and not adiabatic flame temperature. Therefore the concentration of $\mathrm{O}_{2}$ in the overall $\mathrm{O}_{2} /$ FGR mixture is $27 \%$. This is consistent with the pictures and video. Because of the safe operating limit, the $\mathrm{O}_{2}$ in the primary may not exceed $23.5 \%$. For the purposes of this comparison, the primary $\mathrm{O}_{2}$ concentration for the oxyfired case was matched with the air case at $21 \%$.

The luminosity of the flame is expected to be lower for the $27 \%$ oxygen case than the air case, because the flame temperature is lower. This is consistent with the pictures in Figure 4.2-12. The shape of the flame appears to be similar for the oxy and the air cases. The ignition of the oxy-flame may be somewhat delayed from the air case, but that may be hard to separate out from the lower luminosity.

On 12-16-09 the furnace was operated in the morning on air and data was collected for 5 test conditions. The time period between each of these tests was approximately 20 minutes. Following the fifth test, the furnace was switched to firing with oxygen and FGR. This switch caused a delay between tests 5 and 6 of approximately 20 minutes, which is typical for switching from air to oxy-fired conditions and waiting for the nitrogen to purge from the system. Oxy-fired tests were performed for the remainder of the afternoon. A plot of $\mathrm{CO}_{2}$ and $\mathrm{SO}_{2}$ concentrations against test number for 12-16-09 is presented in Figure 4.2-13. These data are useful in evaluating our mass balance and air infiltration under oxy-fired conditions.
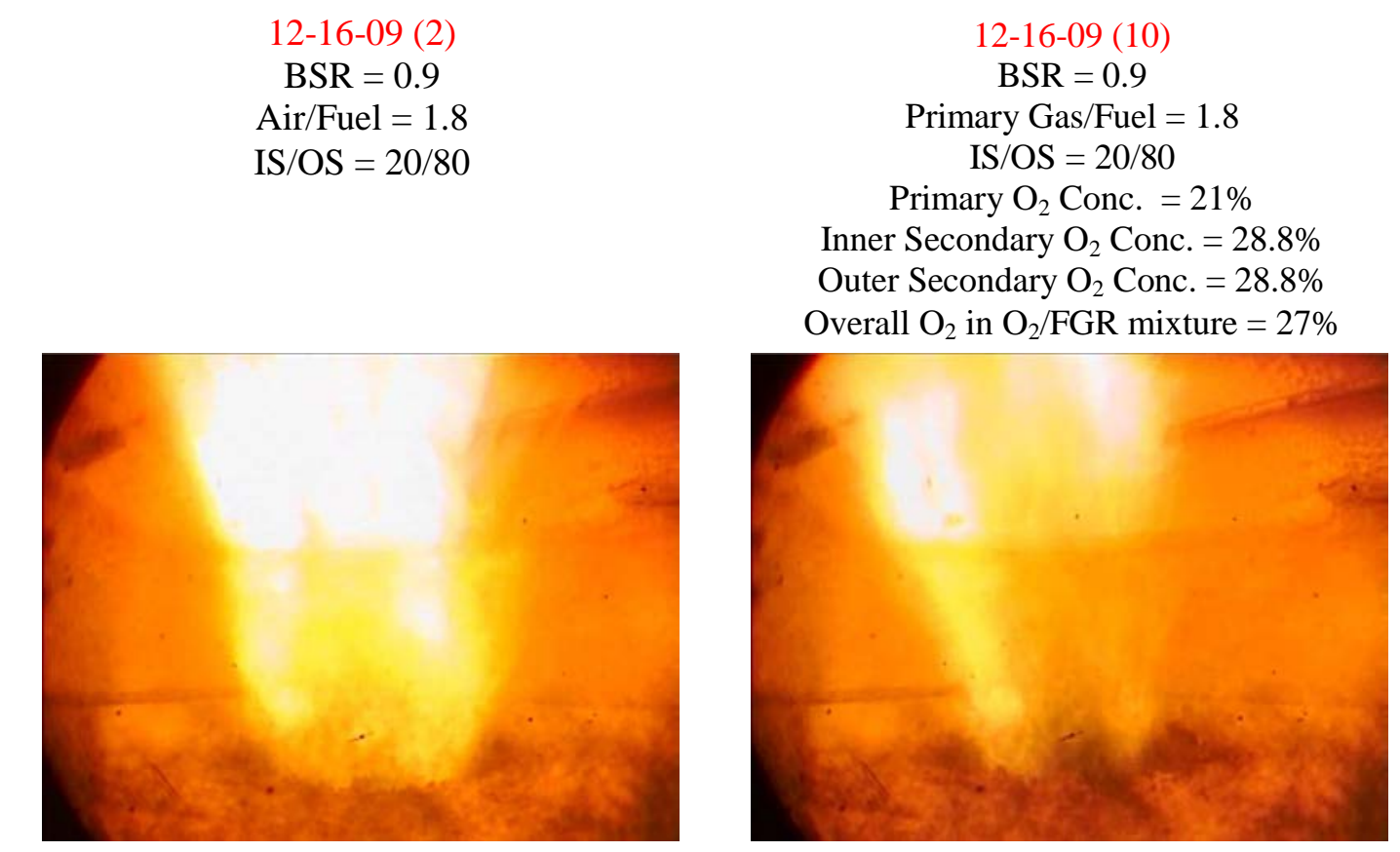

Figure 4.2-12: Comparison of air- and oxy-fired flames while firing a Utah bituminous coal. 


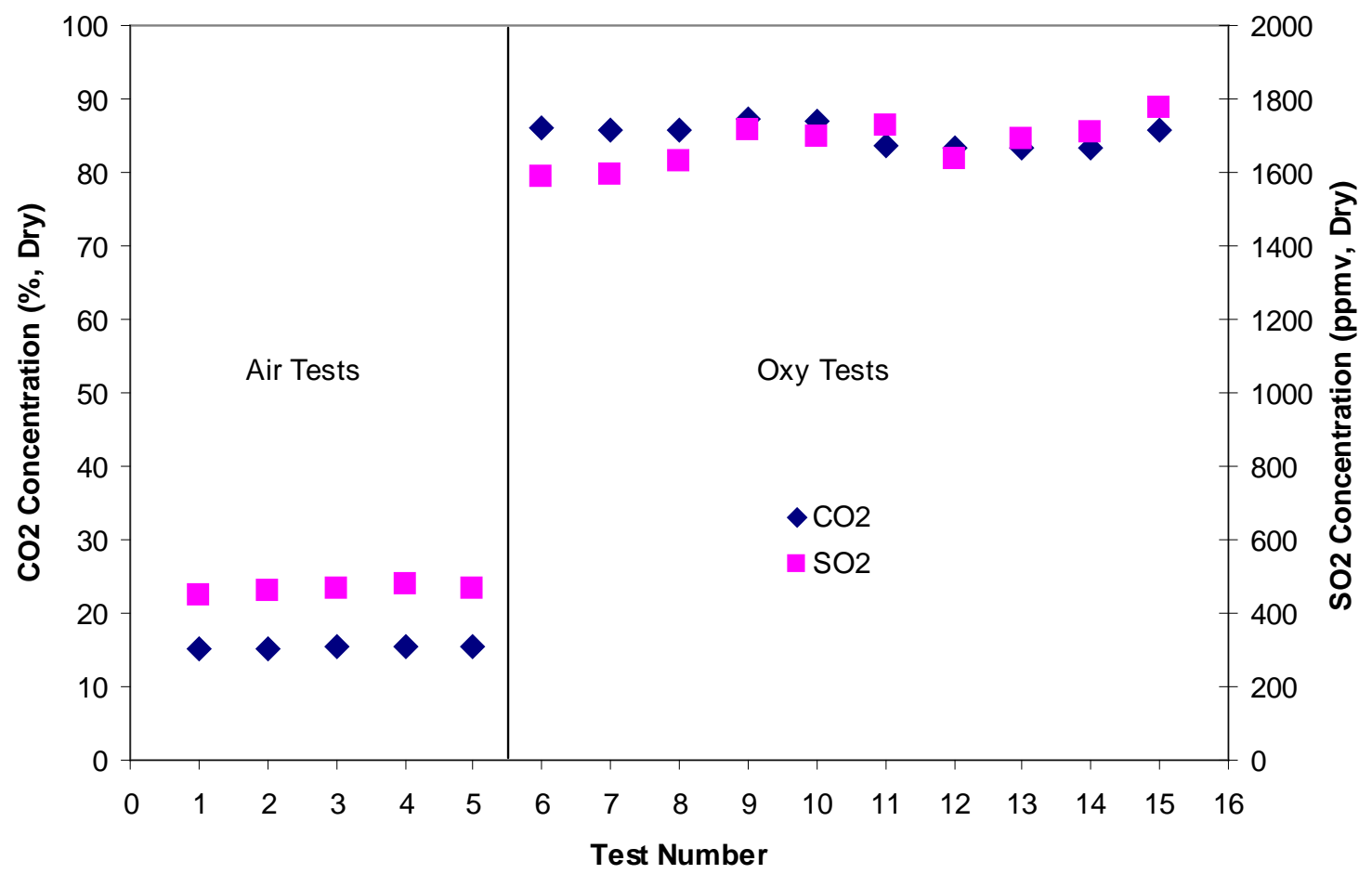

Figure 4.2-13: $\mathrm{CO}_{2}$ and $\mathrm{SO}_{2}$ concentrations by test number for air and oxy conditions on 12-16-09.

For air-fired conditions, the expected (calculated) dry $\mathrm{CO}_{2}$ concentration was $15.6 \%$ and the measured concentrations were an average of $15.4 \%$, indicating an excellent carbon mass balance. The expected $\mathrm{SO}_{2}$ concentration in the flue gas was 438 ppmv, dry and the measured $\mathrm{SO}_{2}$ concentration was 463 ppmv, dry. These values represent a 5.5\% error in the sulfur mass balance. This difference may be due to variability of sulfur in the coal or to analytical error. However, the closure is good.

Under oxy-fired conditions, the expected dry $\mathrm{CO}_{2}$ concentration, without air infiltration, is 95.9\%. From Figure 4.2-13 it can be seen that the measured values averaged $85.1 \% \mathrm{CO}_{2}$, dry. If all of the difference is assumed to be air infiltration, the leakage amounts to about $75 \mathrm{lb} / \mathrm{hr}$, or $2.8 \%$ of the stoichiometric air. Due to the FGR, the expected $\mathrm{SO}_{2}$ concentration increases to almost $2700 \mathrm{ppmv}$, dry. The measured values are an average of 1677 ppmv, dry. These data indicate that approximately 38\% of the sulfur is removed in the system. A large portion of the sulfur removal likely occurs with the condensation of moisture in the FGR system.

The vast majority of the air infiltration into the L1500 occurs at the primary and secondary recycle blowers. The amount of leakage may be limited by balancing the pressure to atmospheric at the blower. This is easily achieved when running with constant primary conditions across a long period of time. During the scoping tests, a dry $\mathrm{CO}_{2}$ concentration of $94.5 \%$ was achieved using this method. However, during parametric testing, where the primary conditions are changing constantly, 85-90\% dry $\mathrm{CO}_{2}$ concentrations are achievable.

Furnace wall temperatures for the air and for the oxy-fired tests on 12-16-09 are presented in Figure 4.2-14. The slight temperature gradient throughout the day is typical of the first day of firing on coal throughout the day. The period where data is absent, between the air and the oxy tests, is when the furnace was being switched from air to oxy-fired conditions. During this period coal was being fired at 3.5 MBtu/hr but the firing was some intermediate combination of air, oxygen and FGR throughout this period. 


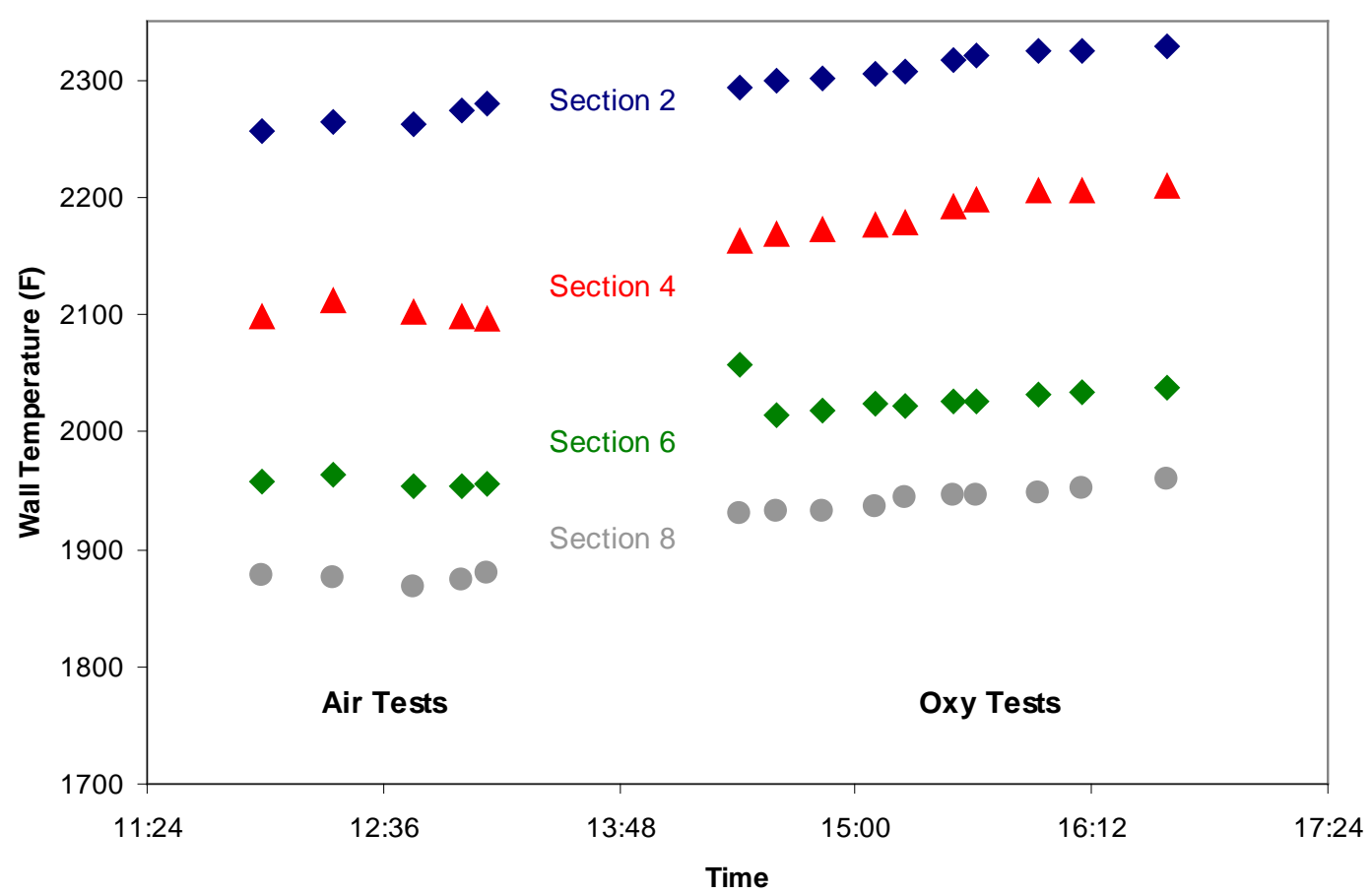

Figure 4.2-14: Furnace wall temperatures for air and oxy-fired conditions on 12-16-09.

The data presented in Figure 4.2-14 indicate that there may only be a slight increase in wall temperature in the furnace when switching from air to oxy-firing with $27 \% \mathrm{O}_{2}$ in the $\mathrm{O}_{2} / \mathrm{FGR}$ mixture. This difference is probably more pronounced for sections further downstream of the burner.

\subsubsection{Retrofit Burner Test Results and Discussion}

Experiments were performed to determine the best retrofit condition for the primary register of the burner. The conditions tested here were matched primary: gas/fuel mass ratio, momentum and velocity. For each of these primary conditions, the tests were initiated at a condition with a stable flame by enriching the inner secondary register up to 50\% oxygen. The mass split between the inner and outer registers was maintained at 20/80 for all testing. The oxygen in the inner secondary register was then reduced in increments until the two secondary registers had the same $\mathrm{O}_{2}$ concentration, or the "Pseudo Air" case.

Figure 4.2-15 provides a comparison of the flame shape for each of these potential retrofit conditions with "Pseudo Air" in the secondary registers. The behavior of the flame displayed in Figure 4.2-15 suggests that operating with a gas to fuel ratio matched to the air-fired case will result in an attached flame, while the matched velocity case will not. It is important to keep in mind that all three of these conditions provide a primary stoichiometric ratio that is lower than the air-fired condition, which is 0.191 . In order to match the stoichiometric ratio with the air-fired condition, the primary $\mathrm{O}_{2}$ concentration would have to be raised significantly above $23.5 \%$ (a potentially unsafe condition) or the primary gas to fuel ratio would have to be increase above 2.0. The latter condition has already been proven to result in a detached flame. 


$$
\begin{gathered}
\text { Matched Gas/Fuel Ratio } \\
\text { 12-16-09 }(10) \\
\text { BSR }=0.9 \\
\text { Primary Gas/Fuel = } 1.80 \\
\text { IS/OS = 20/80 } \\
\text { Primary } \mathrm{O}_{2} \text { Conc. }=21 \% \\
\text { Primary SR }=0.162
\end{gathered}
$$

Inner Secondary $\mathrm{O}_{2}$ Conc. $=28.8 \%$

Outer Secondary $\mathrm{O}_{2}$ Conc. $=28.8 \%$

Overall $\mathrm{O}_{2}$ in $\mathrm{O}_{2} /$ FGR mixture $=27 \%$

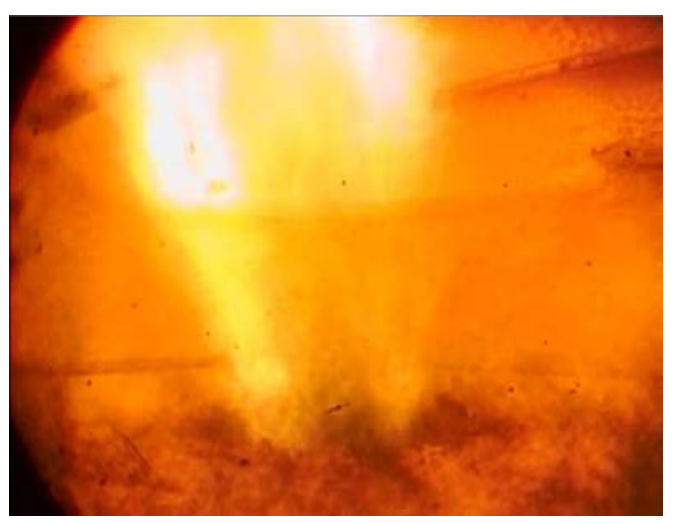

\section{Matched Momentum}

12-16-09 (15)

$\mathrm{BSR}=0.9$

Primary Gas/Fuel $=1.90$

IS $/ \mathrm{OS}=20 / 80$

Primary $\mathrm{O}_{2}$ Conc. $=21 \%$

Primary SR $=0.164$

Inner Secondary $\mathrm{O}_{2}$ Conc. $=28.9 \%$

Outer Secondary $\mathrm{O}_{2}$ Conc. $=28.9 \%$

Overall $\mathrm{O}_{2}$ in $\mathrm{O}_{2} /$ FGR mixture $=27 \%$

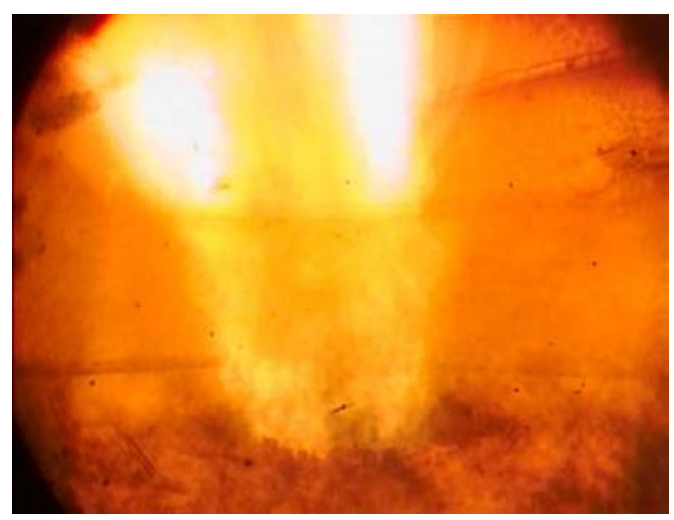

Matched Velocity

12-16-09 (11)

$\mathrm{BSR}=0.9$

Primary Gas $/$ Fuel $=2.0$

IS $/ \mathrm{OS}=20 / 80$

Primary $\mathrm{O}_{2}$ Conc. $=21 \%$

Primary SR $=0.179$

Inner Secondary $\mathrm{O}_{2}$ Conc. $=29.0 \%$

Outer Secondary $\mathrm{O}_{2}$ Conc. $=29.0 \%$

Overall $\mathrm{O}_{2}$ in $\mathrm{O}_{2} /$ FGR mixture $=27 \%$

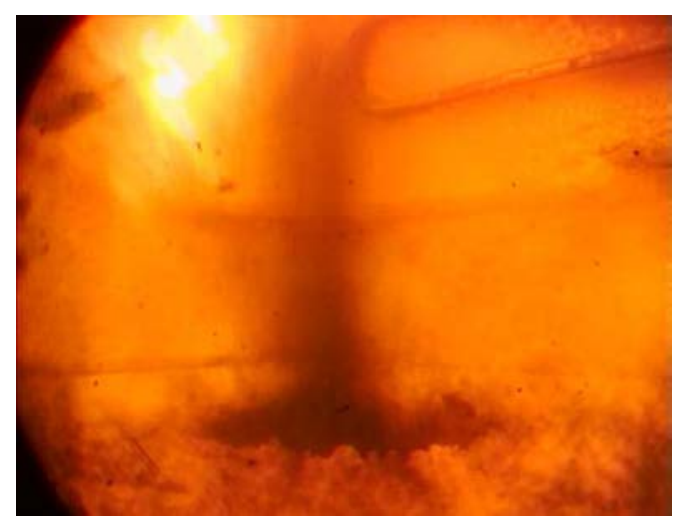

Figure 4.2-15: Flame behavior of various retrofit conditions for the primary while oxy-firing. 


\subsubsection{Low Primary $\mathrm{O}_{2}$ Experiments}

Experiments were performed to determine the effect of low primary $\mathrm{O}_{2}$ concentrations and to find the lowest $\mathrm{O}_{2}$ concentration that would support an attached flame. A similar methodology was used for these tests as for the primary retrofit condition tests. The primary gas/fuel mass ratio was maintained at 1.8, the inner secondary/outer secondary mass ratio was maintained at 20/80 and the BSR was maintained at 0.90 for all of these tests. For each primary $\mathrm{O}_{2}$ concentration tested, the inner secondary register $\mathrm{O}_{2}$ concentration was initiated at $50 \%$ and then reduced until the "Pseudo Air" condition was reached. Pictures of the flame for 21, 15, 10 and 3\% primary $\mathrm{O}_{2}$ concentration conditions are presented in Figure 4.2-16. The $21 \%$ primary $\mathrm{O}_{2}$ concentration condition was tested and the picture was taken two days prior, therefore, the difference in coloration and intensity between that picture and the other three is likely due to a slightly different contrast setting. Each of these flames is well attached in the quarl despite the low primary $\mathrm{O}_{2}$ concentrations.

The heat flux data has been analyzed for the period during the low primary $\mathrm{O}_{2}$ testing. These data appear to be significantly impacted by the inlet water temperature. There may also be some perturbations in cooling water flow rate at certain time periods, caused by the cooling tower control system. Since the cooling water flow through each probe is measured by a total volume meter, the flow rate is determined over a long period of time and the calculated heat flux would not account for perturbation in cooling water flow rate. In addition, it was determined that the heat flux probes were not as sensitive to the flame conditions as originally planned. This is likely due to the hot refractory walls in this furnace. Much of the radiation to the heat flux probe may be from the walls and not the flame. In spite of these limitations, there is some interesting heat flux data associated with the low primary $\mathrm{O}_{2}$ testing. These data are presented in Figure 4.2-17 where the heat flux to each of the four probes is plotted for each test on 12-1809.

During the $15 \%$ primary testing, the Section 1 heat flux is fairly consistently higher than the Section 4 heat flux. As the primary $\mathrm{O}_{2}$ concentration is decreased, the Section 1 heat flux decreases in relation to the Section 4 heat flux. This is indicating that the heat release from the flame is moving down the furnace as the primary $\mathrm{O}_{2}$ concentration is decreased (i.e. a longer flame for low primary $\mathrm{O}_{2}$ conditions). This behavior was in line with our expectation. The overall heat flux to all of the probes decreases slightly throughout the day. This is due to fouling of the heat transfer surface of the probes. The heat flux reported for Section 4 is higher than in Sections 2 and 3 for most of the testing. There are two possible explanations. The first possibility is that the one of the cooling panels in section four was removed prior to this testing. The missing cooling panel is on the same wall on which the heat flux probe is mounted. The missing cooling panel may increase the wall temperature of the opposite wall and in turn the radiation to the probe. The other explanation is that the over-fire oxygen is introduced just downstream of the Section 4 heat flux probe, causing additional heat release. For future testing, the cooling tower operation will be controlled more tightly and other factors will be addressed to clean up these data. 
12-16-09 (10)

$\mathrm{BSR}=0.9$

Primary Gas/Fuel $=1.80$

IS/OS $=20 / 80$

Primary $\mathrm{O}_{2}$ Conc. $=\mathbf{2 1 . 5 \%}$

Primary SR $=0.162$

Inner Secondary $\mathrm{O}_{2}$ Conc. $=28.8 \%$

Outer Secondary $\mathrm{O}_{2}$ Conc. $=28.8 \%$

Overall $\mathrm{O}_{2}$ in $\mathrm{O}_{2} /$ FGR mixture $=27 \%$

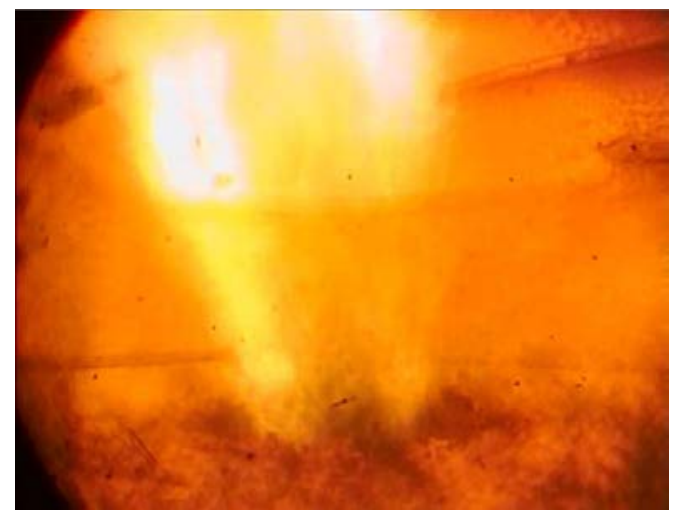

12-18-09 (12)

$\mathrm{BSR}=0.9$

Primary Gas/Fuel $=1.80$

$\mathrm{IS} / \mathrm{OS}=20 / 80$

Primary $\mathrm{O}_{2}$ Conc. $=\mathbf{1 0 . 4 \%}$

Primary SR $=0.077$

Inner Secondary $\mathrm{O}_{2}$ Conc. $=32.8 \%$

Outer Secondary $\mathrm{O}_{2}$ Conc. $=32.8 \%$

Overall $\mathrm{O}_{2}$ in $\mathrm{O}_{2} /$ FGR mixture $=27 \%$

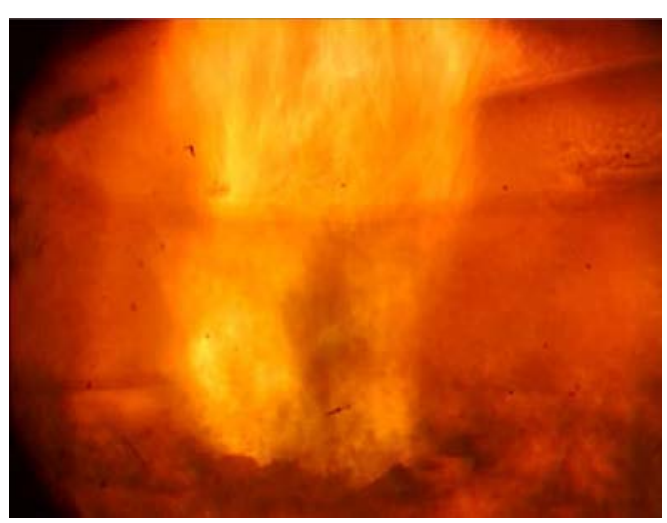

12-18-09 (6)

$\mathrm{BSR}=0.9$

Primary Gas/Fuel $=1.80$

IS $/ O S=20 / 80$

Primary $\mathrm{O}_{2}$ Conc. $=\mathbf{1 5 . 3 \%}$

Primary SR $=0.114$

Inner Secondary $\mathrm{O}_{2}$ Conc. $=30.8 \%$

Outer Secondary $\mathrm{O}_{2}$ Conc. $=30.8 \%$

Overall $\mathrm{O}_{2}$ in $\mathrm{O}_{2} /$ FGR mixture $=27 \%$

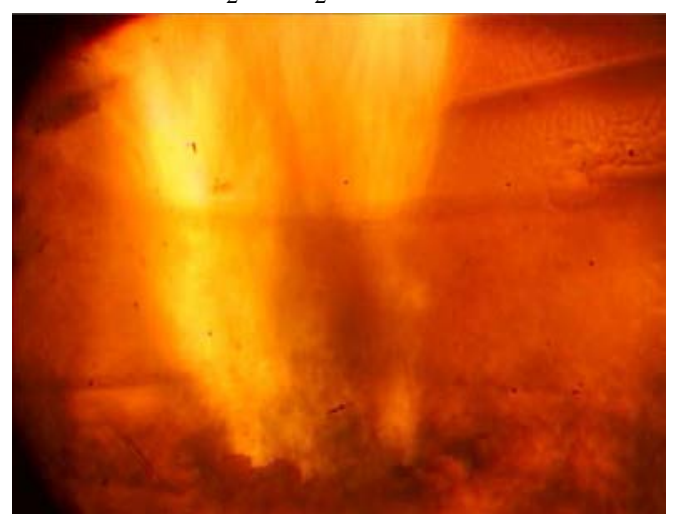

12-18-09 (16)

$\mathrm{BSR}=0.9$

Primary Gas/Fuel $=1.80$

IS/OS $=20 / 80$

Primary $\mathrm{O}_{2}$ Conc. $=\mathbf{2 . 7 \%}$

Primary SR $=0.02$

Inner Secondary $\mathrm{O}_{2}$ Conc. $=34.5 \%$

Outer Secondary $\mathrm{O}_{2}$ Conc. $=34.5 \%$

Overall $\mathrm{O}_{2}$ in $\mathrm{O}_{2} /$ FGR mixture $=27 \%$

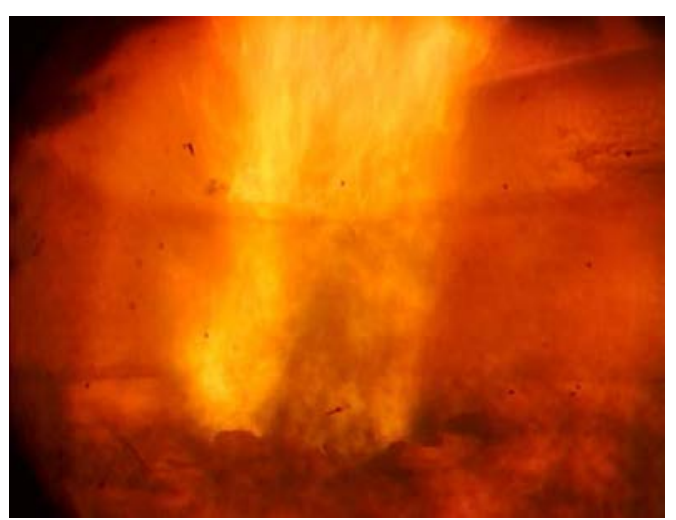

Figure 4.2-16: Flame behavior of low primary $\mathrm{O}_{2}$ conditions while oxy-firing. 


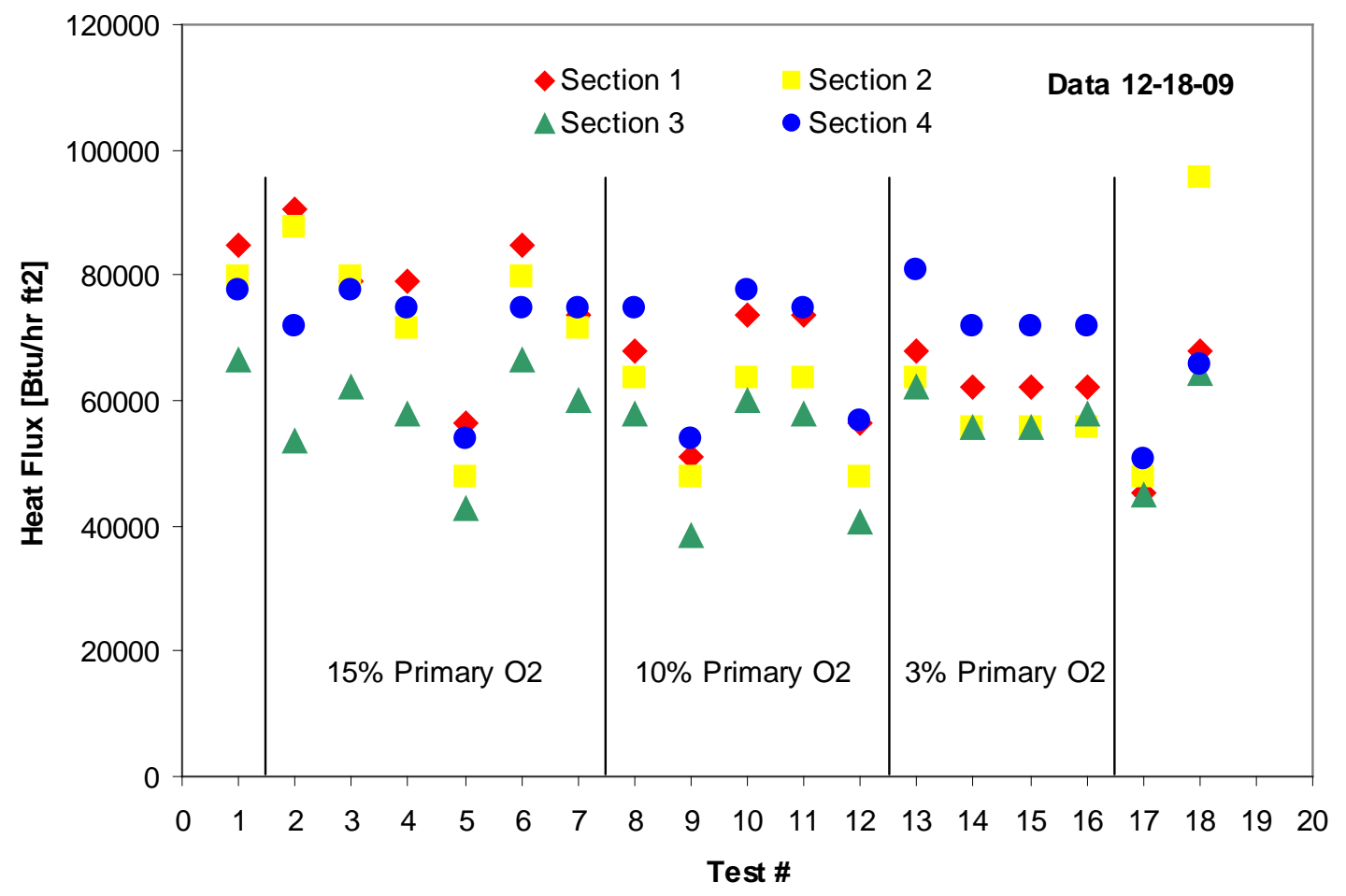

Figure 4.2-17: Heat flux probe data for the low primary $\mathrm{O}_{2}$ tests.

\subsubsection{Staging Experiments}

Experiments were performed to determine the effect of staging on the oxy-fired flame behavior and pollutant emission. These tests were performed with a 1.8 primary gas/fuel ratio, $21 \% \mathrm{O}_{2}$ in the primary, an inner/outer secondary mass split of $20 / 80$ and $40 \% \mathrm{O}_{2}$ in the inner secondary register. Four staging conditions were tested, including BSRs of 0.8, 0.9, 1.0 and 1.08. Pictures of the flame at each of these conditions are presented in Figure 4.2-18.

Figure 4.2-18 shows that under oxy-fired conditions, the flame intensity increases as the BSR increases. This is similar to the flame behavior under air-fired conditions. However, within the field of view, there is no indication that the flame length is decreased with increasing BSR as was evident with the air flame in Figure 4.2-10.

The dependence of $\mathrm{NO}_{\mathrm{x}}$ concentrations in the furnace on BSR for oxy- and air-fired conditions is presented in Figure 4.2-19. The dependence of furnace $\mathrm{NO}_{\mathrm{x}}$ concentration on BSR is very similar for airand oxy-fired conditions and a BSR of 1.0 or lower. Some of the oxy-fired conditions at a primary gas/fuel ratio of 2.0 (high primary velocity) and at $3 \%$ primary $\mathrm{O}_{2}$ concentration display higher $\mathrm{NO}_{\mathrm{x}}$. This is likely due to instability in the flame, despite the attached nature of the flame. At a BSR higher than 1.0, the $\mathrm{NO}_{\mathrm{x}}$ concentration is higher for the oxy-fired conditions. This may indicate that at low BSRs, the recycled $\mathrm{NO}_{\mathrm{x}}$ is effectively reburned, while at higher BSRs some of the recycled $\mathrm{NO}_{\mathrm{x}}$ persists. It is important to remember that under these oxy-fired conditions the recycle ratio is such that only $30 \%$ of the flue gas is emitted to the atmosphere, significantly reducing emissions. 


$$
\begin{gathered}
01-14-10(3) \\
\text { BSR }=\mathbf{0 . 8 1} \\
\text { Primary Gas/Fuel = } 1.80 \\
\text { IS } / \mathrm{OS}=20 / 80 \\
\text { Primary } \mathrm{O}_{2} \text { Conc. }=21.7 \% \\
\text { Primary } \mathrm{SR}=0.166 \\
\text { Inner Secondary } \mathrm{O}_{2} \text { Conc. }=41.1 \% \\
\text { Outer Secondary } \mathrm{O}_{2} \text { Conc. }=26.3 \% \\
\text { Overall } \mathrm{O}_{2} \text { in } \mathrm{O}_{2} / \text { FGR mixture }=27 \%
\end{gathered}
$$

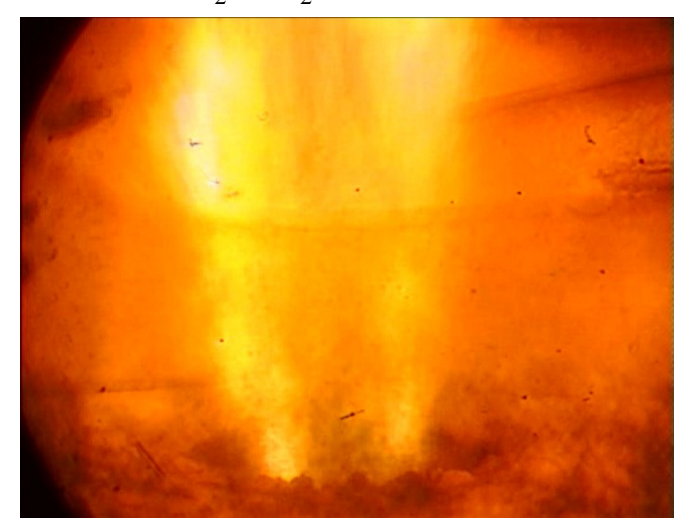

$$
\text { 01-14-10 (4) }
$$$$
\mathrm{BSR}=0.99
$$

Primary Gas/Fuel $=1.80$

IS/OS $=20 / 80$

Primary $\mathrm{O}_{2}$ Conc. $=21.6 \%$

Primary SR $=0.161$

Inner Secondary $\mathrm{O}_{2}$ Conc. $=40.1 \%$

Outer Secondary $\mathrm{O}_{2}$ Conc. $=25.7 \%$

Overall $\mathrm{O}_{2}$ in $\mathrm{O}_{2} /$ FGR mixture $=27 \%$

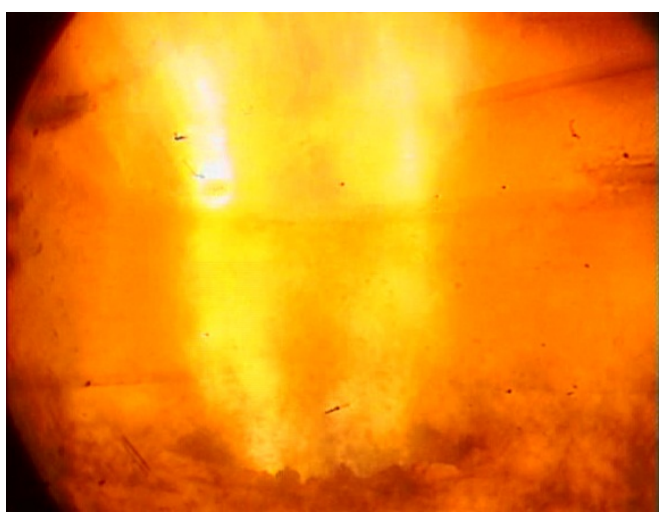

01-14-10 (2)

$\mathrm{BSR}=\mathbf{0 . 9 2}$

Primary Gas/Fuel $=1.80$

IS $/ O S=20 / 80$

Primary $\mathrm{O}_{2}$ Conc. $=21.3 \%$

Primary SR $=0.163$

Inner Secondary $\mathrm{O}_{2}$ Conc. $=40.7 \%$

Outer Secondary $\mathrm{O}_{2}$ Conc. $=25.9 \%$

Overall $\mathrm{O}_{2}$ in $\mathrm{O}_{2} /$ FGR mixture $=27 \%$

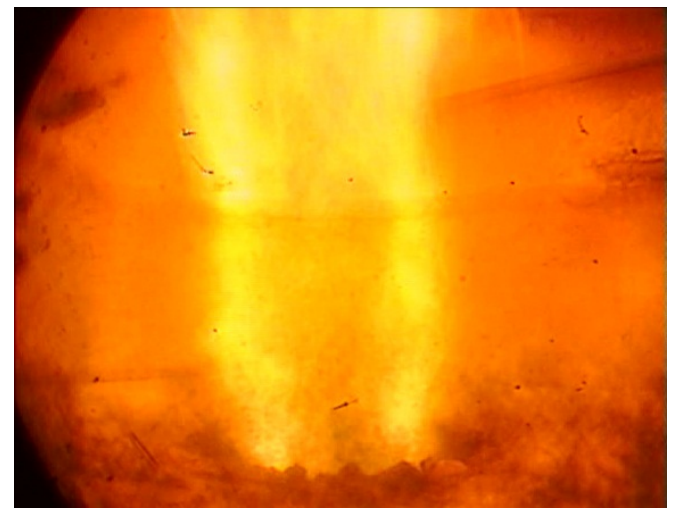

01-14-10 (5)

$\mathrm{BSR}=\mathbf{1 . 0 8}$

Primary Gas/Fuel $=1.80$

IS $/ \mathrm{OS}=20 / 80$

Primary $\mathrm{O}_{2}$ Conc. $=21.7 \%$

Primary SR $=0.165$

Inner Secondary $\mathrm{O}_{2}$ Conc. $=40.3 \%$

Outer Secondary $\mathrm{O}_{2}$ Conc. $=25.5 \%$

Overall $\mathrm{O}_{2}$ in $\mathrm{O}_{2} /$ FGR mixture $=27 \%$

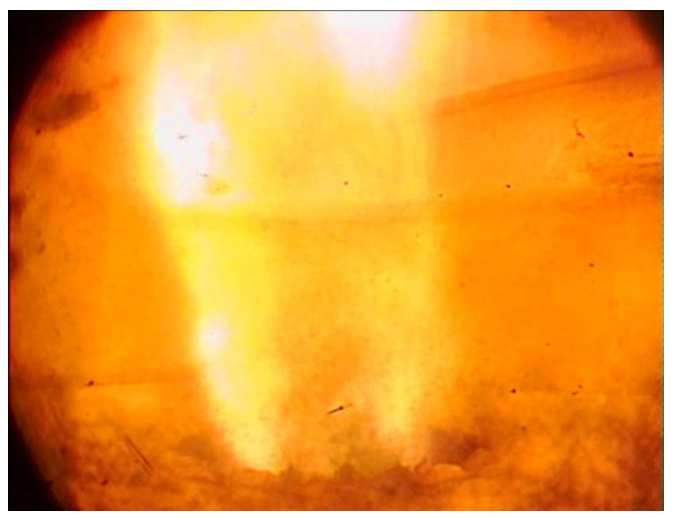

Figure 4.2-18: Flame behavior dependent on burner stoichiometric ratio for oxy-fired conditions. 


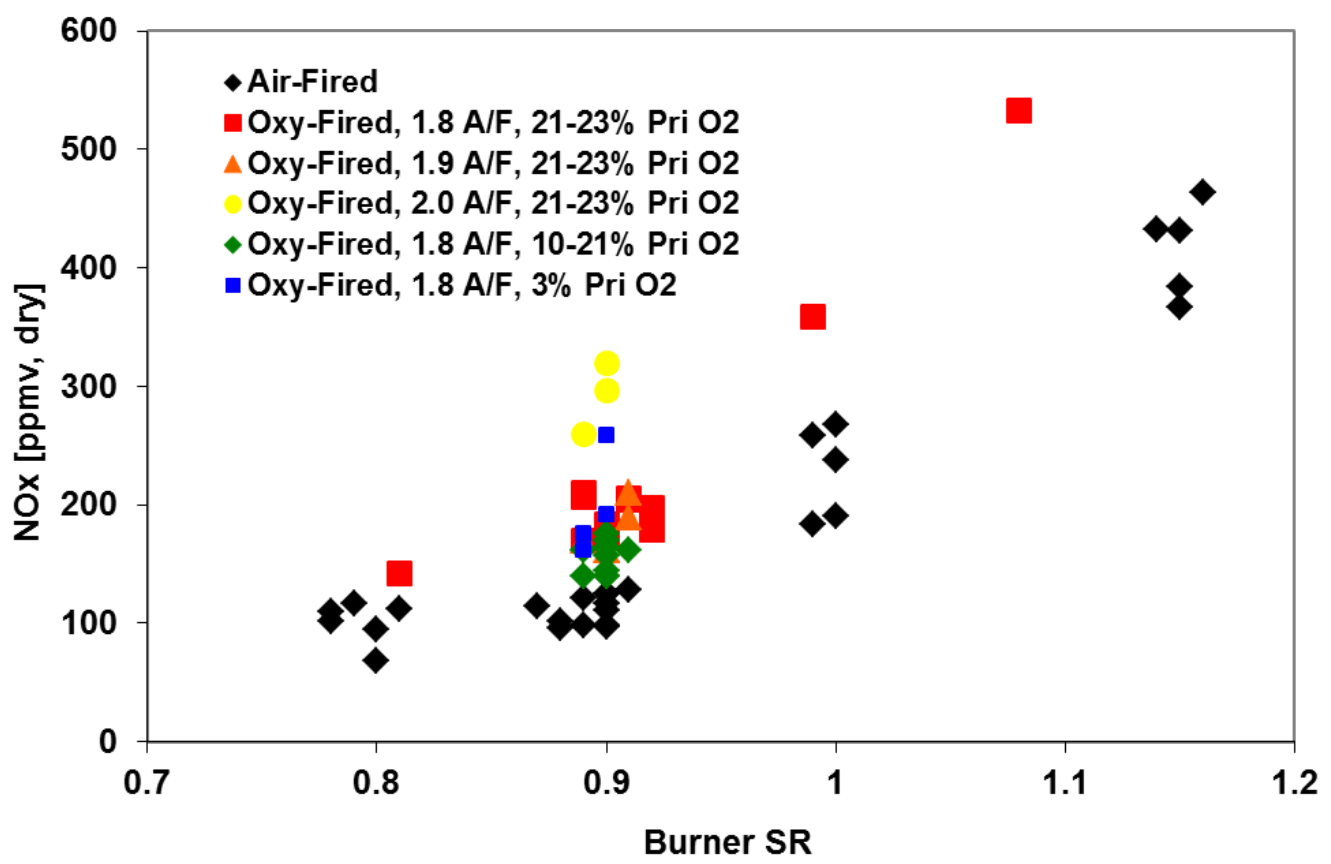

Figure 4.2-19: Furnace $\mathrm{NO}_{\mathrm{x}}$ concentration dependence on burner stoichiometric ratio for oxy- and air-fired conditions.

\subsubsection{Post-Test Burner Inspection}

During the first two-week testing period the burner developed a problem with the natural gas ring. One of the two pipes embedded in the refractory that deliver natural gas to the ring cracked along with the refractory. Cracks in the furnace refractory are common and do not pose a problem to the test program. The crack in the natural gas delivery system posed a problem. The natural gas was leaking through the crack in the refractory and into the furnace. In turn, the natural gas flame was stabilizing on the crack in the refractory instead of within the burner quarl. The natural gas flame is used to heat the furnace in preparation for the testing and to heat the furnace overnight when it is not firing coal so this problem does not affect the data collected, but poses a difficulty for operation of the furnace. To correct this problem a larger bluff body was constructed in order to reduce the cross sectional area of the primary to produce appropriate primary velocities when natural gas was introduced through the primary. This solution works well enough to support the remainder of the tests. It also leaves the natural gas ring without a cooling gas and could affect the longevity of the ring. Without this ring the shape of the quarl that is important to burner operation would be lost.

Following the first two weeks of testing, the furnace was opened and the burner and the crack in the burner plate refractory were photographed. These pictures are presented as Figure 4.2-20 through Figure 4.2-22. 


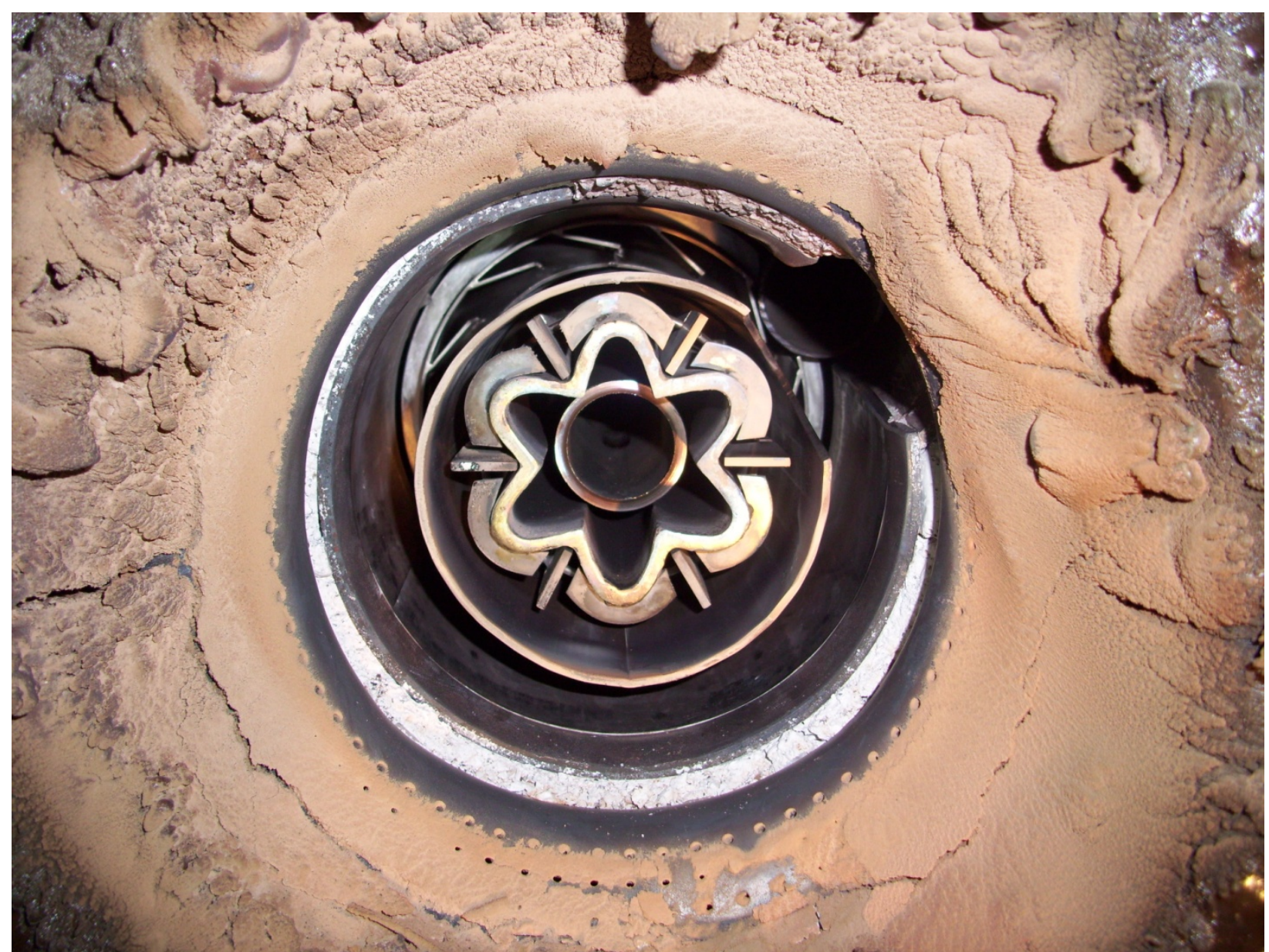

Figure 4.2-20: Oxy-research burner in the L1500 following the first two-week test campaign.

In Figure 4.2-20 the burner is still covered in deposits from the two week test program. Deposition of material did not enter the quarl past the natural gas ring. There were more deposits on the outer region of the quarl in line with the igniter penetration and these deposits potentially indicated a disturbance in the gas flow in that region. The bluff body pictured here is of the large diameter used for natural gas firing. 


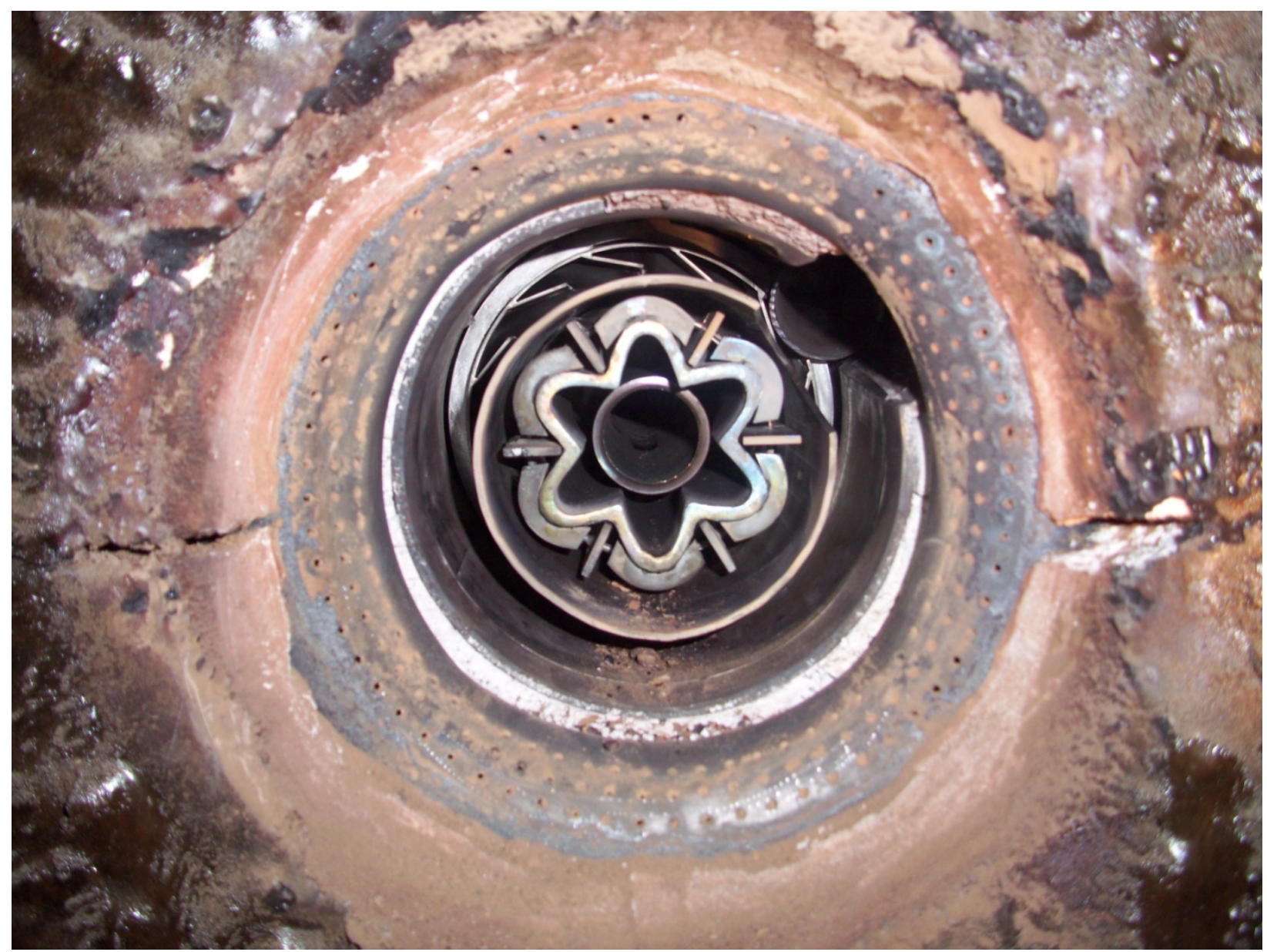

Figure 4.2-21: Oxy-research burner in the L1500 after cleaning away deposited material.

Figure 4.2-21 shows the burner and quarl after the deposits had been cleaned away. The natural gas ring is still intact, maintaining the shape of the quarl, and does not show any sign of heat damage. The horizontal crack through the burner plate refractory can be seen on both sides of the quarl.

Figure 4.2-22 shows the crack on the left side (from within the furnace) of the burner. The section indicated is where the natural gas flame was attaching. The slag layer on the refractory is slightly different in this region.

Following the inspection of the burner, the testing team was confident that operating with natural gas in the primary under gas-fired conditions will not cause damage to the burner or the natural gas ring. 


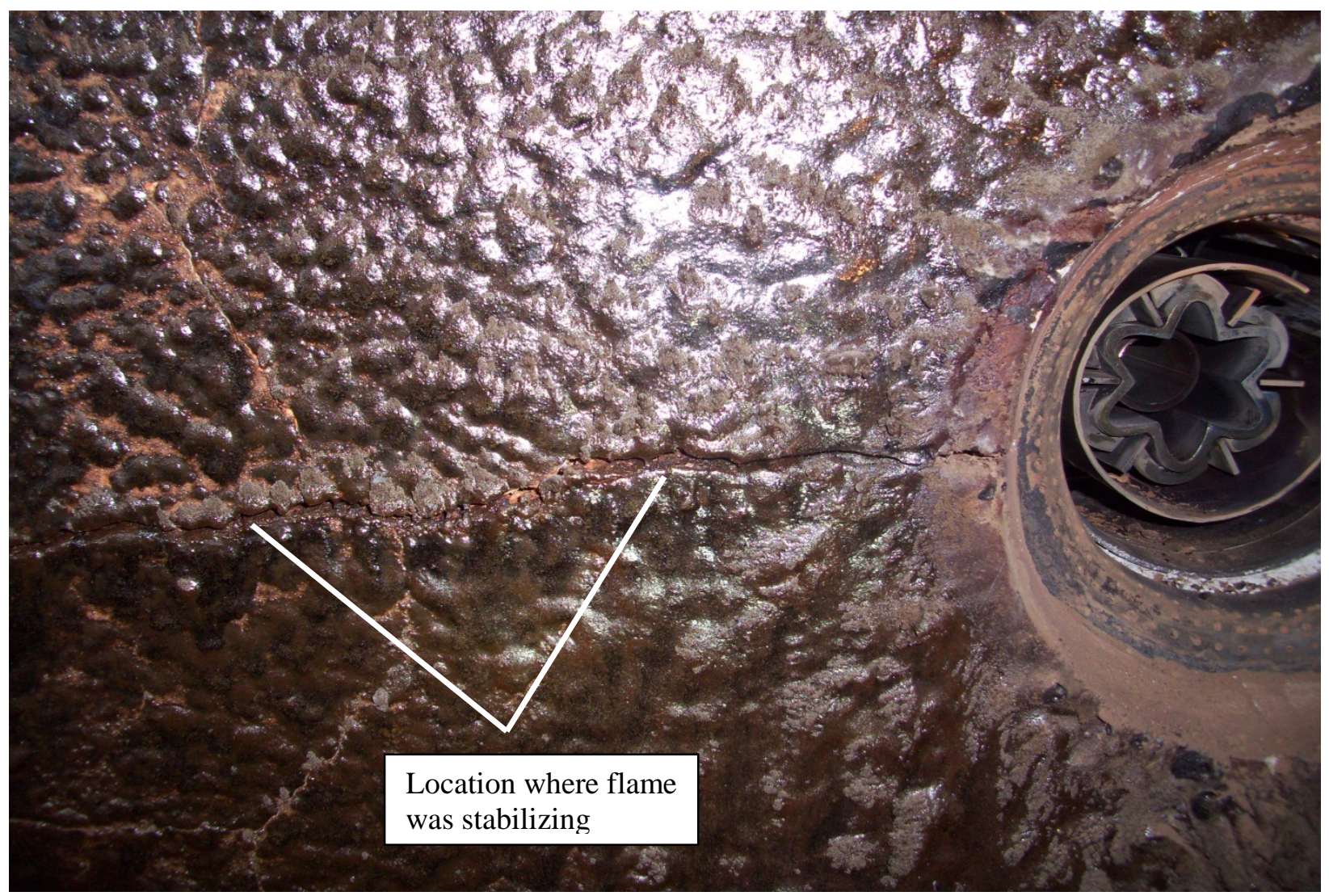

Figure 4.2-22: Crack in the refractory on the burner plate where the natural gas was leaking and the flame was stabilizing.

\subsubsection{Oxy-Research Burner Test Conclusions}

Three weeks of air- and oxy-fired experiments were performed on University of Utah's pilot-scale furnace, the L1500. These tests included a week of shakedown and several days of scoping tests, where operating conditions were quickly changed and a rough map of the operating limits of the burner was made without recording data. All of the experiments where data were collected were performed using the Skyline (Utah Bituminous) coal. The data that were collected were focused in the following four areas:

1. Air-fired conditions to be used for comparison with oxy-fired data. This data set is essentially a multiple condition baseline and encompasses variation of the primary air/fuel ratio, secondary air distribution and burner staging.

2. Oxy-fired conditions elucidating potential retrofit conditions for the burner primary. The conditions investigated here include matching the primary gas/fuel mass ratio, momentum and velocity with air-fired conditions.

3. Oxy-fired conditions where primary $\mathrm{O}_{2}$ concentrations ranging from $21-3 \%$ were implemented. The $3 \%$ primary condition represents no $\mathrm{O}_{2}$ enrichment of the primary, which may be a desirable condition in a retrofit scenario.

4. Oxy-fired conditions with burner stoichiometric ratios ranging from 0.8 to 1.08 .

Conclusions drawn from the air-fired experiments were: 
- Material balance on carbon closes to within $2 \%$ and on sulfur to within $6 \%$.

- The burner will operate with either the flame attached within the quarl, or with the flame stabilizing at approximately 15 inches downstream of the quarl exit. There was no condition observed where the flame flickered in the intermediate region.

- Outside secondary swirl adjustment is mostly ineffective at changing the flame shape or reattaching a blown off flame.

- The flame stabilized within the quarl for inner/outer secondary mass splits of $0 / 100$ through 20/80. The flame was blown off for conditions with $25 \%$ of the secondary mass or more through the inner register. The low $\mathrm{NO}_{\mathrm{x}}$ condition was at an inner/outer secondary mass split of 5/95. Siemens indicated that they expected the optimum operating condition to be 10/90.

- When the burner was operated unstaged, the flame was intense, short and wide. As the burner was more deeply staged, the flame was less intense, elongated and became narrower. The furnace exit $\mathrm{NO}_{\mathrm{x}}$ concentration was very dependent on staging from a BSR of 0.9 and 1.15 , but there was little difference between the $\mathrm{NO}_{\mathrm{x}}$ levels at BSRs of 0.8 and 0.9 .

- The flame stabilized within the quarl with primary air/fuel ratios up to 2.2. At a primary air/fuel ratio of 2.2, the flame was weak at the base and seemed to be ready to blow off. There was little dependence of $\mathrm{NO}_{\mathrm{x}}$ on primary air/fuel ratio.

General conclusions from the oxy-fired experiments were:

- Air infiltration into the furnace under oxy-firing conditions occurs primarily through the primary and secondary Air/FGR blowers. This leakage may be controlled tightly by balancing the blower at atmospheric pressure, which is possible when primary gas conditions are constant, resulting in dry $\mathrm{CO}_{2}$ concentrations as high as $94.5 \%$. For the majority of these tests the $\mathrm{CO}_{2}$ concentration was between $85 \%$ and $90 \%$, corresponding to air leakage of up to $75 \mathrm{lb} / \mathrm{hr}$, or $2.8 \%$ of the stoichiometric $\mathrm{O}_{2}$.

- Under oxy-fired conditions, approximately 38\% of the sulfur is removed from the system, possibly with moisture condensation in the flue gas recycle line.

- The inner secondary $\mathrm{O}_{2}$ concentration may be increased to attach a detached flame.

Conclusions from the primary retrofit conditions experiments were:

- Matching the gas/fuel mass ratio in the primary and matching the primary momentum with airfired conditions both result in a flame stabilized within the quarl while operating with Pseudo Air in the secondary registers.

- Matching primary velocity with the air-fired conditions results in a blown off (detached) flame.

- Matching mass of $\mathrm{O}_{2}$ in the primary is not possible in this experimental system and may not be desirable in a burner retrofit because of the potentially unsafe conditions at primary $\mathrm{O}_{2}$ concentrations above $23.5 \%$ or because of the high primary velocity at low $\mathrm{O}_{2}$ concentrations.

- The primary stoichiometric ratio for all conditions tested was lower than that for the air-fired system. 
Conclusions from the low primary $\mathrm{O}_{2}$ experiments were:

- A flame can be stabilized with no oxygen enrichment of the primary ( $3 \% \mathrm{O}_{2}$ in the primary) while using Pseudo Air in the secondary registers.

- Heat flux measurements indicate that as the primary $\mathrm{O}_{2}$ is reduced, the flame length becomes longer.

Conclusions from the oxy-fired staging experiments were:

- Staging the burner under oxy-fired conditions does not seem to have the same impact on the length and width of the flame as with air-fired conditions. The luminosity of the flame is still reduced with deeper staging.

- Under stoichiometric and staged conditions, oxy-fired conditions produce very similar furnace exit $\mathrm{NO}_{\mathrm{x}}$ concentrations to the air-fired conditions. At unstaged conditions the furnace exit $\mathrm{NO}_{\mathrm{x}}$ concentration is much higher for oxy-firing than for air-firing. Likely recycled $\mathrm{NO}_{\mathrm{x}}$ is reburned under stoichiometric or staged conditions.

- Depending on the recycle ratio, $\mathrm{NO}_{\mathrm{x}}$ emissions will be significantly reduced under oxy-fired conditions. 


\subsection{April 2010 L1500 Burner Parametric Tests}

\subsubsection{Introduction and Test Strategy}

The L1500 tests were designed to develop data sets that describe flame characteristics, corrosion, sooting propensity and radiation as it differs between air- and oxy-fired conditions. Previous sections have included a detailed description of the equipment used for this testing, including the furnace, burner and measurement equipment. For this program, the L1500 has been fit with an oxy-coal research burner that was co-developed by REI and Siemens Energy. This burner was designed for both air- and oxy-firing of pulverized coal across a wide range of conditions. The specific design of this burner allows the independent mixing of oxygen and FGR in each of its three registers (primary, inner secondary and outer secondary). It also allows oxygen injection near the burner face in the primary and in the inner secondary.

Burner parametric testing was performed in the L1500 using the oxy-coal research burner from December 2009 to January 2010 and again in April 2010. Tests results from December 2009 to January 2010 were summarized in previous sections. Those tests were focused on investigation of different burner retrofit strategies when converting from air- to oxy-combustion. The matched primary mass to fuel ratio, momentum and velocity were tested. Low primary $\mathrm{O}_{2}$ and various $\mathrm{O}_{2}$ mixing strategies were investigated where $\mathrm{O}_{2}$ was blended with FGR upstream of the burner register plenums. Some conclusions from those tests include:

- Matching the gas/fuel mass ratio or momentum of the primary, both result in a stable flame

o High density $\mathrm{CO}_{2}$ allows lower primary velocity at these matched conditions

- Matching primary velocity results in a detached flame and is likely not a good retrofit strategy

0 Indicates a fundamental difference for devolatilization and ignition between air- and oxyfired conditions

- A stable flame can be produced with no $\mathrm{O}_{2}$ enrichment of the primary $\left(3 \% \mathrm{O}_{2}\right.$ in the FGR stream)

- The outer secondary swirl vanes are mostly ineffective

This section of the report will focus on burner parametric testing that was performed in the L1500 in April 2010 during corrosion testing. These tests were designed to investigate strategies where oxygen is injected near the burner face instead of blended with FGR prior to the burner registers. In addition, the outside secondary swirl vane assembly was modified to increase swirl and mixing. It has been theorized in the literature that due to safety constraints, it is unlikely that oxy-coal combustion will be performed in utility boilers with enrichment of oxygen in the coal-carrying gas (Zanganeh and Shafeen 2007) (Toftegaard, et al. 2010). This constraint would render the primary $\mathrm{O}_{2}$ concentration equal to the flue gas exit $\mathrm{O}_{2}$ concentration, about 3\% dry. The experiments performed here are targeted towards low primary $\mathrm{O}_{2}$ conditions for this reason.

\subsubsection{Experimental Setup}

In previously reported burner parametric results, only Utah Skyline coal was used. Similarly, for all of the burner parametric experiments reported here, Utah Skyline coal was fired at 3.5 MBtu/hr. However, it should be noted that in the interim (February-April 2010), Utah, Illinois and PRB coals were all fired in a variety of tests. Proximate and ultimate analyses of each of these coals are presented in Table 4.3-1.

The furnace was staged with a burner stoichiometric ratio of 0.9 for all tests, unless otherwise specified. A crucial component of the L1500 hardware for these tests is the Lennox Firesight high temperature camera. This camera is used to monitor and record the characteristics of the flame for various combustion settings. The configuration of the camera relative to the furnace is detailed in Figure 4.2-1. 
Previous tests indicated that the flame terminates anywhere from six to eight feet downstream of the quarl exit, depending on conditions. For deeply staged conditions with low primary $\mathrm{O}_{2}$ the flames may be even longer. Video collected in the April 2010 test campaign is not quite as clear as that collected during the earlier burner tests, indicating some degradation to the camera optics throughout the program. In addition, buildup of slag near the burner quarl was also evident in the latter test program.

\subsubsection{Burner Modification}

A modification was made to the burner prior to the April 2010 test program. This modification was designed to strengthen the swirl, or the tangential component to the gas velocity, in the outer secondary register. In order to perform this modification, the burner was removed from the furnace and disassembled. The swirl vane assembly was removed from the burner and the vanes were extended by 1.5 inches. The front and rear division plates of the assembly were also extended to accommodate the longer vanes. Triangular caps were also placed on the outlet to each vane in order to inhibit axial flow out of the assembly. Figure 4.3-1 and Figure 4.3-2 contain pictures of the vane assembly before and after the modification.

Table 4.3-1: Coal and Mineral Matter Analysis.

\begin{tabular}{|c|c|c|c|}
\hline & Skyline & PRB & Illinois \\
\hline \multicolumn{4}{|c|}{ Coal Analysis } \\
\hline $\mathbf{C}$ & 70.60 & 53.72 & 64.67 \\
\hline $\mathbf{H}$ & 5.05 & 3.57 & 4.51 \\
\hline $\mathbf{N}$ & 1.42 & 0.78 & 1.12 \\
\hline $\mathrm{S}$ & 0.53 & 0.23 & 3.98 \\
\hline $\mathbf{O}$ & 10.39 & 13.07 & 8.08 \\
\hline Ash & 8.38 & 4.94 & 7.99 \\
\hline Moisture & 3.18 & 23.69 & 9.65 \\
\hline Volatile Matter & 38.60 & 33.36 & 36.78 \\
\hline Fixed Carbon & 49.39 & 38.01 & 45.58 \\
\hline HHV, Btu/lb & 12,606 & 9,078 & 11,598 \\
\hline \multicolumn{4}{|c|}{ Mineral Matter Analysis } \\
\hline Al & 14.52 & 14.78 & 17.66 \\
\hline Ca & 6.11 & 22.19 & 1.87 \\
\hline $\mathbf{F e}$ & 5.09 & 5.20 & 14.57 \\
\hline Mg & 1.39 & 5.17 & 0.98 \\
\hline Mn & 0.02 & 0.01 & 0.02 \\
\hline $\mathbf{P}$ & 0.59 & 1.07 & 0.11 \\
\hline $\mathbf{K}$ & 0.57 & 0.35 & 2.26 \\
\hline Si & 60.89 & 30.46 & 49.28 \\
\hline $\mathrm{Na}$ & 1.41 & 1.94 & 1.51 \\
\hline $\mathrm{S}$ & 2.33 & 8.83 & 2.22 \\
\hline $\mathbf{T i}$ & 0.88 & 1.30 & 0.85 \\
\hline
\end{tabular}

* All values in mass \% unless otherwise specified 


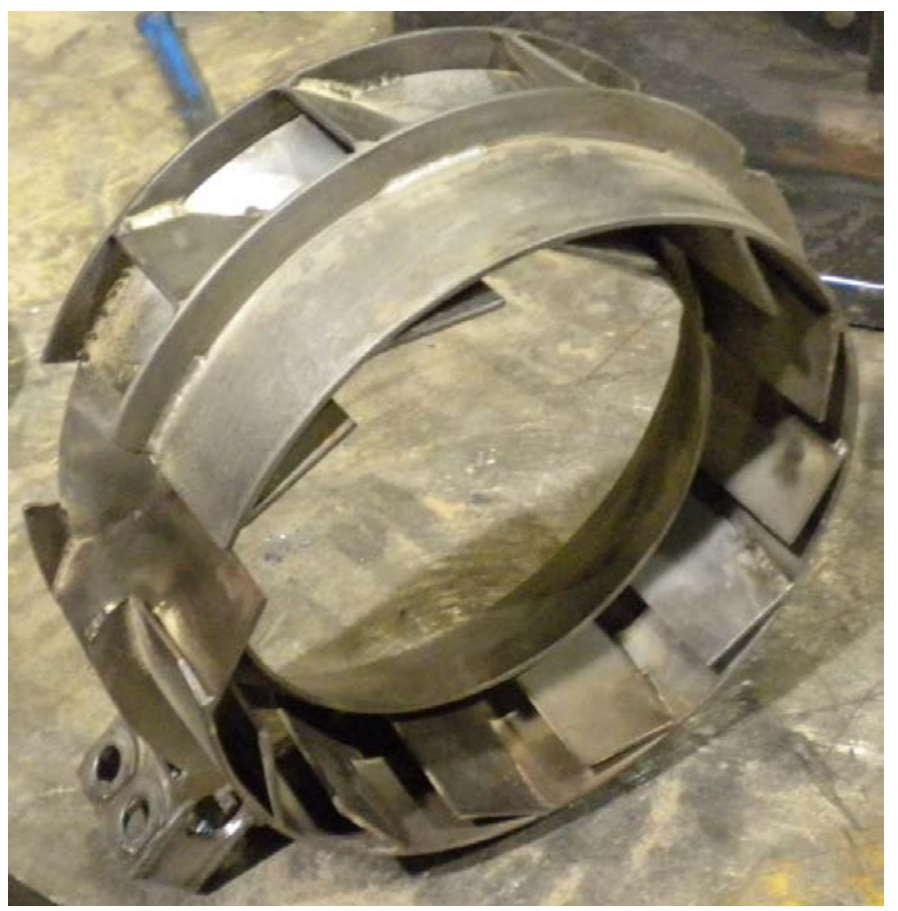

Figure 4.3-1: Outside secondary swirl ring before modification.

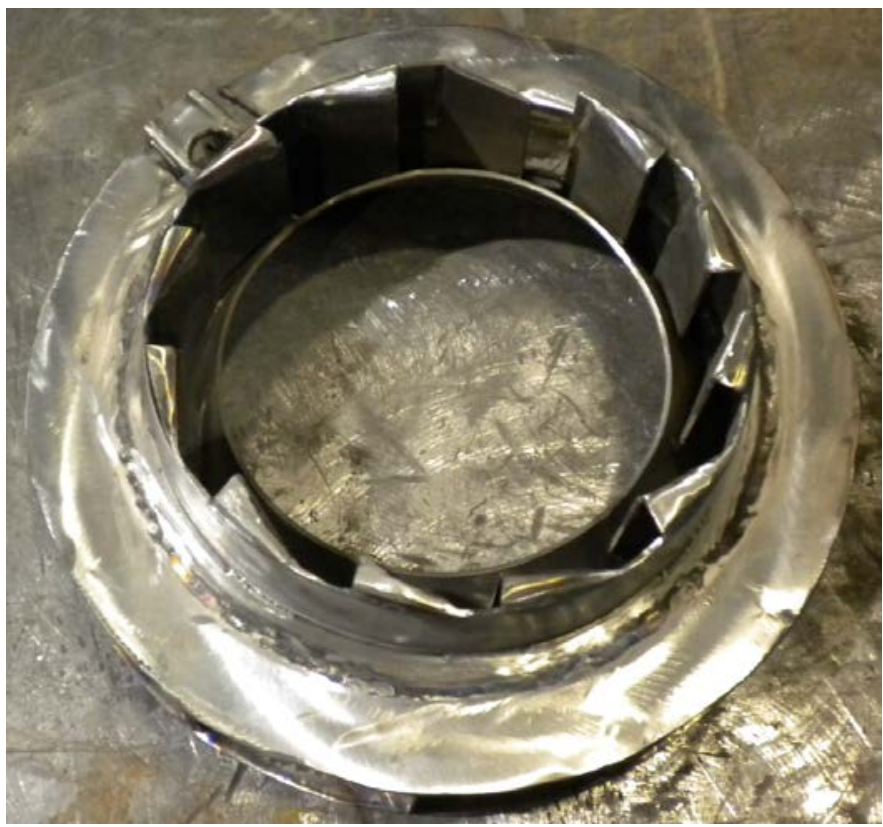

Figure 4.3-2: Outside secondary swirl ring after modification.

The modification detailed in Figure 4.3-1 and Figure 4.3-2 was accomplished without complications or interruption to the test schedule.

\subsubsection{Oxygen Injection Configuration}

The main focus of these tests was to investigate the flame behavior characteristics as oxygen enrichment was removed from the primary and alternatively introduced at the burner face. Oxygen injection was 
performed using three different injector configurations. Two of these configurations introduced oxygen through the bluff body, one with the oxygen introduced axially and the other with oxygen introduced radially. The final injection configuration used the injection nozzles in the inner secondary register.

The bluff body on the oxy-coal research burner is a $1 / 2$ " SCH 40 pipe. The purpose of this bluff body is to facilitate oxygen injection into the primary gas stream at or near the burner face. Radial injection of oxygen through the bluff body was accomplished by fitting a nozzle containing 8 holes of 0.125 ” diameter to the end of the $1 / 2$ ” pipe. The wall thickness of the nozzle, the diameter of the holes and the length of the nozzle were all sized to provide a pressure drop of the injected oxygen sufficient to ensure even distribution and radial velocity of the gas. The pressure drop calculations were performed using the primary oxygen flow rate from typical oxy-combustion conditions in the L1500 while firing Skyline coal. Dimensions of this nozzle are provided in Figure 4.3-3.

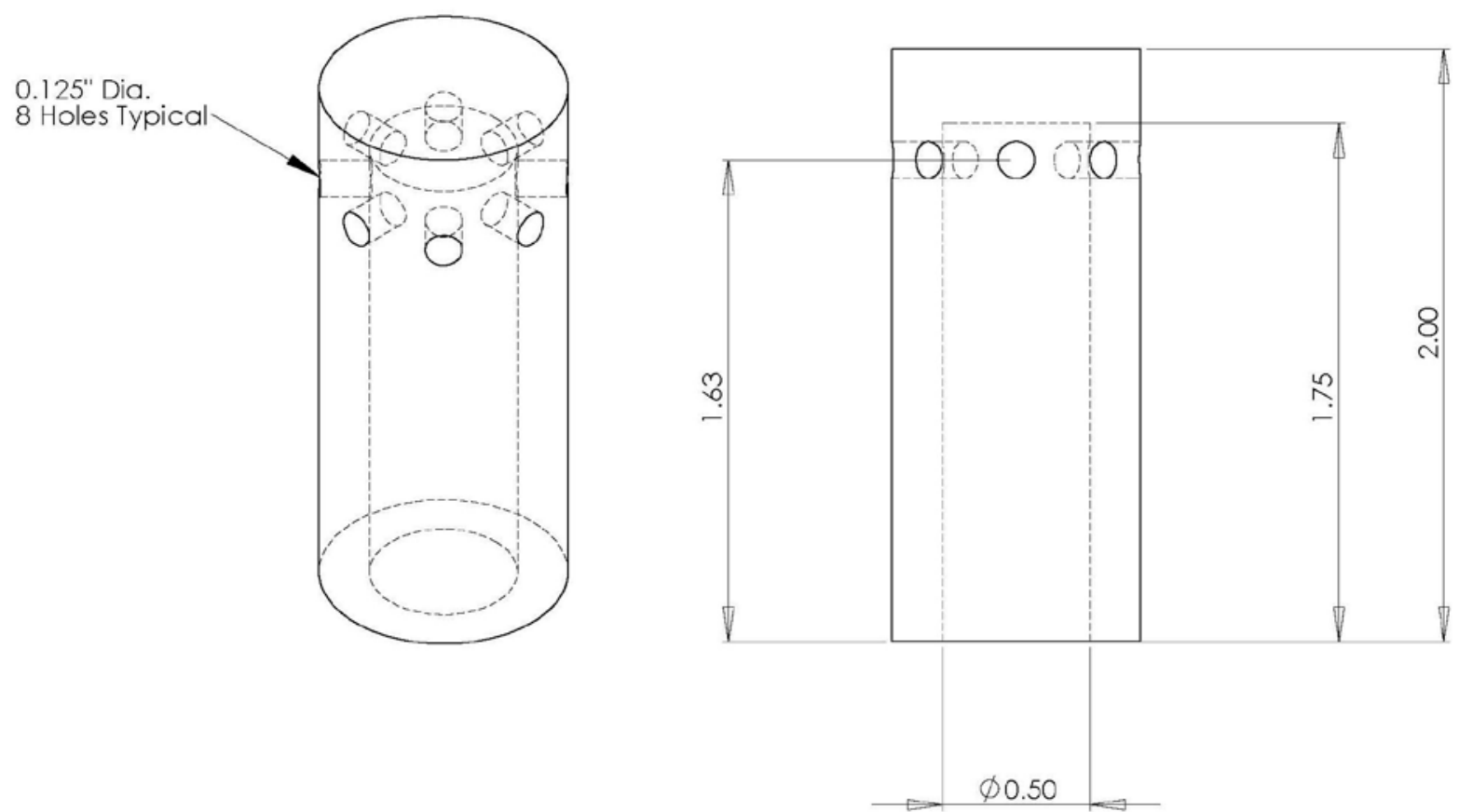

Figure 4.3-3: Bluff body nozzle for primary oxygen injection.

The length of the bluff body was sized such that the centerline of the 0.125 ” holes was oriented halfway through the burner quarl. The purpose for introducing the oxygen at this location was to avoid igniting or damaging any of the steel surfaces of the burner, a condition that is likely when oxygen impinges on a hot steel surface with fuel in close proximity. A drawing of the cross section of the burner, quarl and radial injection lance are presented in Figure 4.3-4. Although some of the burner details are missing in this drawing, the relative dimensions of the various components are accurate. 


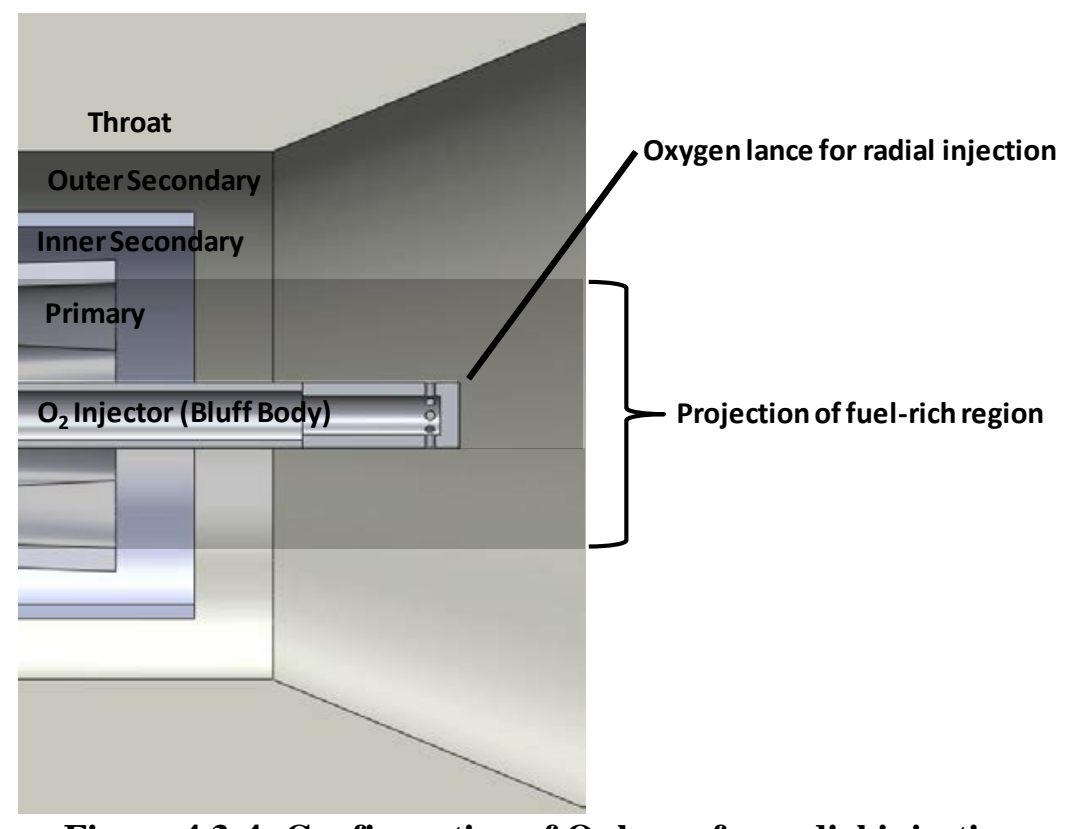

Figure 4.3-4: Configuration of $\mathrm{O}_{2}$ lance for radial injection.

Figure 4.3-4 shows the radial injection nozzle with the nozzle openings halfway through the burner quarl. A projection of the fuel rich region is shaded a darker color of grey. Identification of this region will be important later for understanding the behavior of the burner when injecting oxygen.

When oxygen was injected through the bluff body axially, the opening at the end of the bluff body was an unmodified section of the pipe, with the same cross section. The length of the axial injection lance was the same as the radial injection lance with the nozzle. This was done so that the point of oxygen injection would be the same in both cases. A drawing of the cross section of the burner, quarl and axial injection lance are presented in Figure 4.3-5. Again, a projection of the fuel-rich region is shaded in grey.

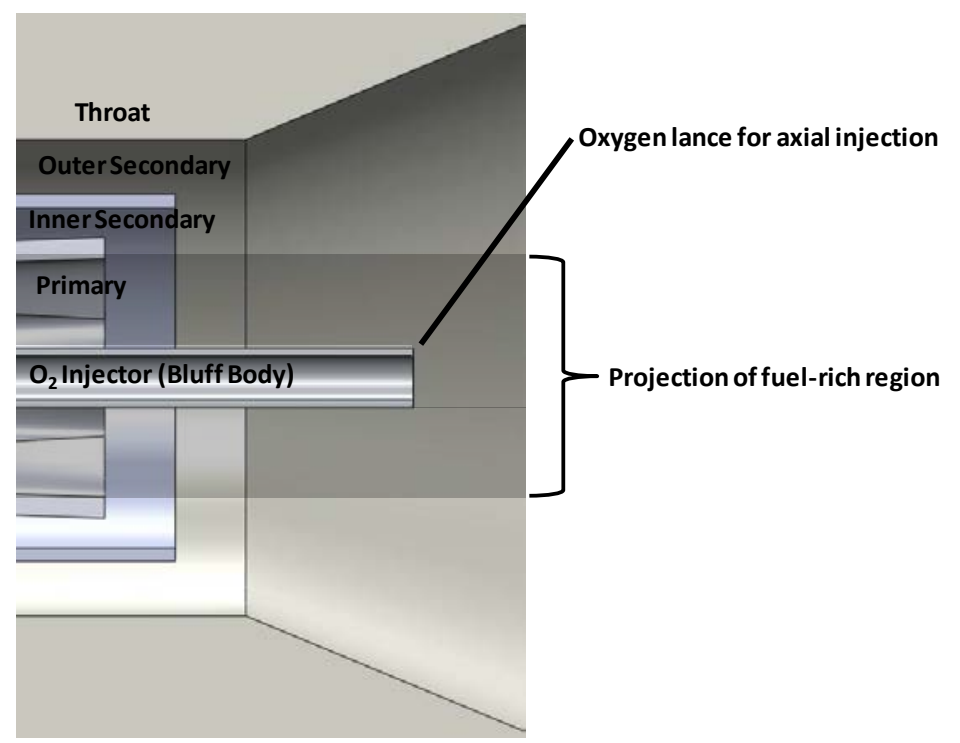

Figure 4.3-5: Configuration of $\mathrm{O}_{2}$ lance for axial injection. 
There are 12 injection nozzles in the inner secondary. These nozzles are $1 / 4$ ” stainless steel tubes that are butted up next to the outside surface of the primary coal pipe, with one nozzle on each side of the six axial stabilization tabs. These nozzles terminate at approximately 7" upstream of the exit of the coal pipe. Oxygen can be introduced through these nozzles without igniting the hot steel surfaces of the burner because there is expected to be no recirculation of fuel into the inner secondary. Figure 4.3-6 shows a model of the burner detailing the location of these nozzles and a side cross section of the burner detailing the burner components, quarl and bluff body as they were configured when oxygen was injected through the inner secondary nozzles.

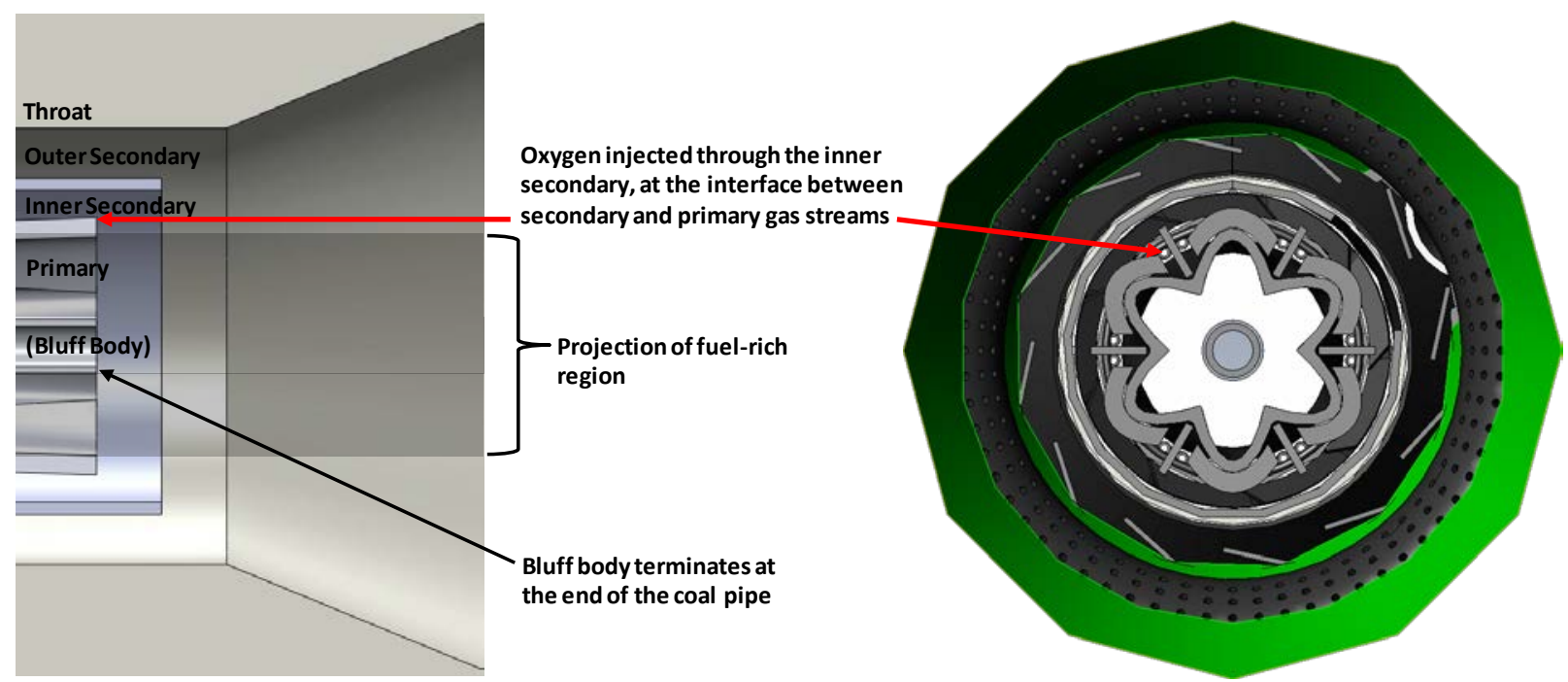

Figure 4.3-6: Configuration of $\mathrm{O}_{2}$ lance for inner secondary injection.

Figure 4.3-6 shows that when oxygen is injected through the inner secondary nozzles, the bluff body terminates at the same location as the primary coal pipe. In these tests the bluff body is just a place holder and there is no reactant flow through it. The termination point of the inner secondary injection nozzles is far enough upstream of the termination of the primary coal pipe that they do not appear in this figure. However their radial location is indicated in the figure.

\subsubsection{Oxygen Injection Results and Discussion}

The results of burner parametric testing that are presented in this section of the report are for experiments performed while firing Skyline coal at 3.5 MBtu/hr under air and oxy-fired conditions with staged combustion at a BSR of 0.9. These are the same conditions that were used for previous burner parametric testing. However, comparison of these results with those that have been presented for previous tests should be performed carefully, keeping in mind that the burner has been modified prior to performing the experiments that have been reported on here.

\subsubsection{Burner Modification}

At the time when the outer secondary swirl assembly was modified, the burner had been in service for six weeks. The burner was disassembled in preparation for the modifications and at this time the plenums for each of the registers were inspected for buildup of recycled particulates and indication of oxidized surfaces due to high $\mathrm{O}_{2}$ concentrations during oxy-combustion. The shells of the inner and outer secondary plenums are each constructed in two halves. When the burner was disassembled, one half of the shell was removed before the condition of the plenum was inspected. A very light dusting of fine particulate was observed on the inside shell of the plenum, on the side that was oriented downward. There was no observed location within the plenum with significant particle buildup. In addition, there 
was no indication of significant oxidation of the carbon steel surfaces. A picture of the outer secondary register plenum at the time of inspection is included as Figure 4.3-7.

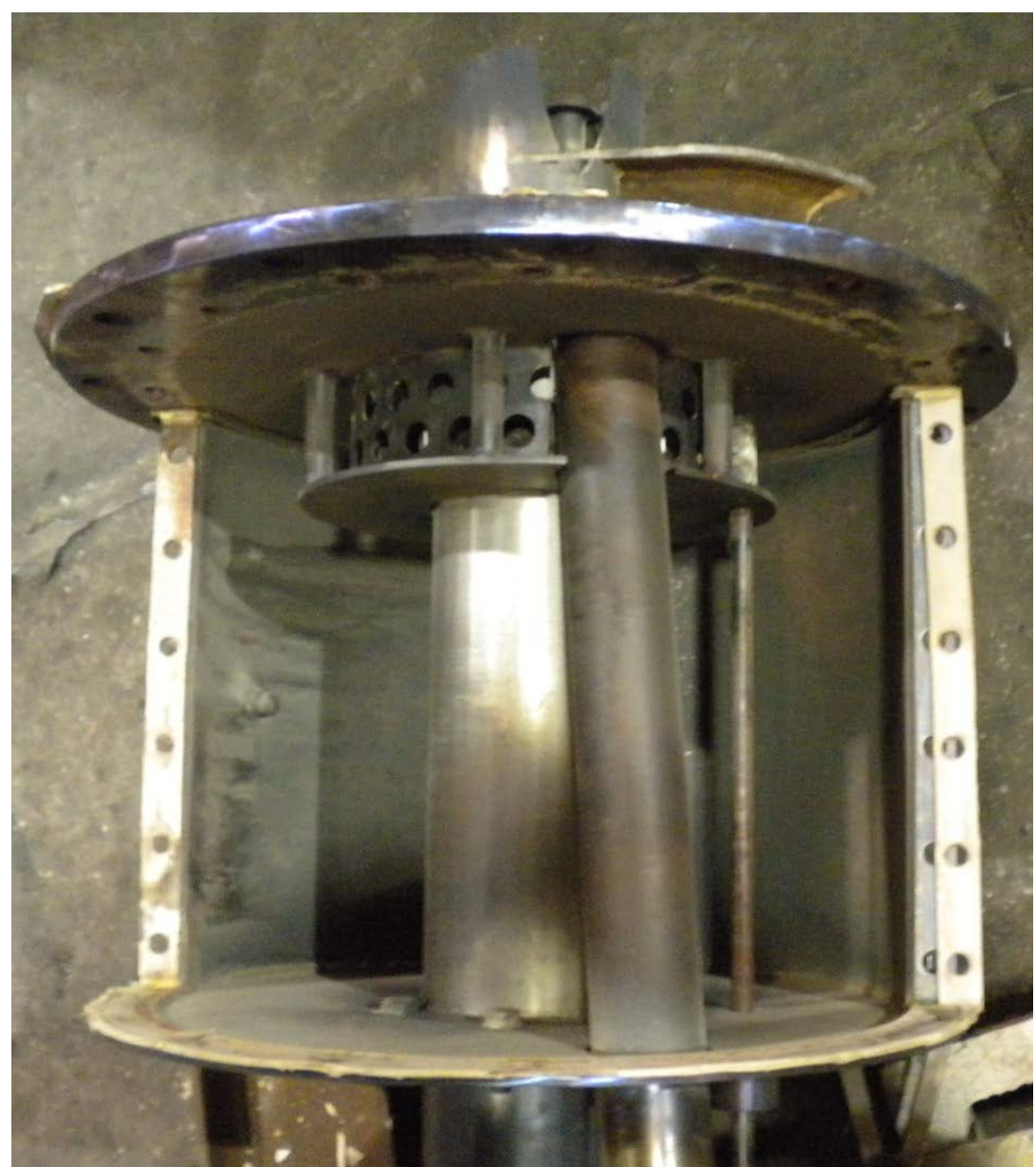

Figure 4.3-7: Outer secondary register plenum during burner modifications.

The modification to the burner outside secondary swirl vanes was evaluated prior to the burner parametric testing. The first order of business was to determine the upper limit of primary air to fuel mass ratio that would support an attached flame under air-fired conditions. During the previous burner parametric tests the limit was determined to be 2.2 before the flame was blown off. In these tests the limit was determined to be 2.05. For each of these conditions the velocity was calculated and determined to be identical. The different gas to fuel ratios produce the same velocity because the primary gas temperature has increased between the Dec. 2009 tests and the April 2010 test. The increase in primary gas temperature occurred because air for combustion is collected outside the building and the primary gas is not temperature controlled. There was a vast difference in outside ambient air temperature between Dec 2009 and April 2010. This behavior and analysis indicates that the modification to the burner had no effect on the maximum primary velocity that would attach a flame.

Further experiments were performed to determine the impact of the modification on inner/outer secondary mass split. In previous experiments it was determined that the inner/outer secondary mass split could be varied in the range of 5/95 to 20/80 and still attach a flame. When the mass split was increased to 25/75, the flame would detach. After the modification, it was determined that the flame would remain attached with an inner/outer secondary mass split up to 40/60, displaying a fairly significant change in behavior due to the modification. 
Visual inspections on flame characteristics were also performed. Prior to the modification, there was little or no difference in the shape of the flame, or the coal distribution between conditions where the swirl was fully engaged (100\%) and disengaged (No Swirl). Experiments were performed while firing with air at a primary velocity just high enough to detach the flame. In this way the shape of the coal dense region could be evaluated. The inner/outer secondary split was maintained at 20/80, a condition where the tangential velocity of the outside secondary could be fairly strong. Video was collected while there was no swirl and while there was $100 \%$ swirl. Still frames from these videos are presented in Figure 4.3-8.

$$
\begin{gathered}
\text { BSR }=0.9 \\
\text { Primary Gas/Fuel = } 2.06 \\
\text { IS/OS }=20 / 80 \\
\text { (Air-Fired, No Swirl) }
\end{gathered}
$$

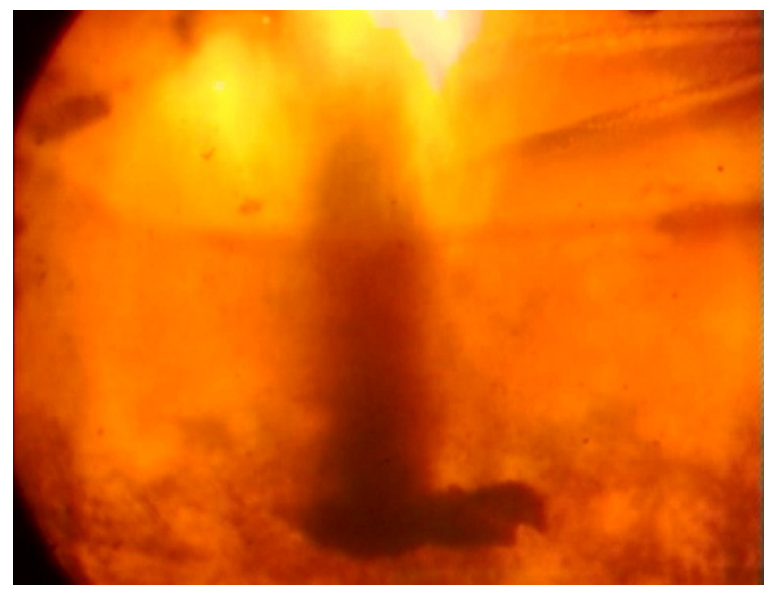

$$
\mathrm{BSR}=0.9
$$

Primary Gas/Fuel $=2.08$

IS/OS $=20 / 80$

(Air-Fired, 100\% Swirl)

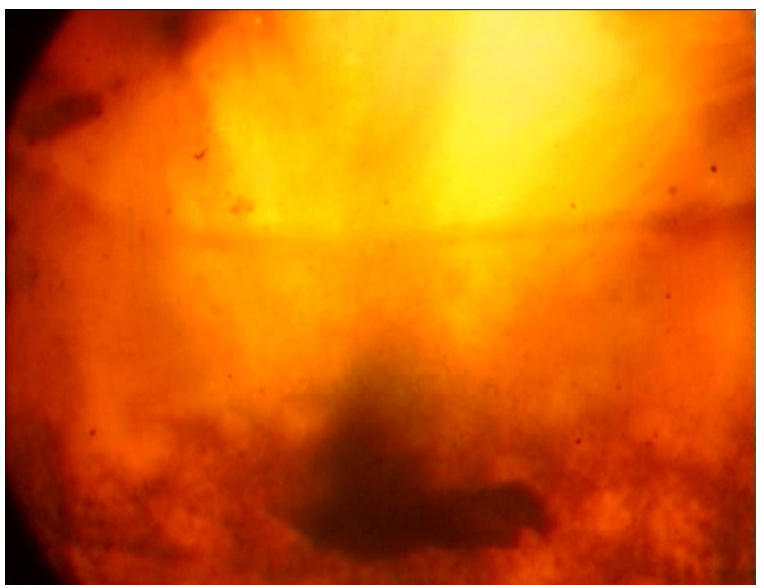

Figure 4.3-8: Still pictures of an air-fired flame with and without swirl after the burner swirl modification.

Figure 4.3-8 shows that the shape of the coal dense region changes significantly when the swirl is $100 \%$ engaged. When there is no swirl, the coal is injected into the furnace and there appears to be little distribution in the radial direction. When the swirl is set to $100 \%$ the shape of the coal dense region becomes more cone shaped and the flame although still detached pulls back towards the burner.

The remainder of the burner parametric testing was performed with the swirl set at $100 \%$. Slightly different flame shapes and burner behavior is expected for these experiments than those that were performed in Dec. 2009. However, the constraints on primary velocity remain the same for both sets of experiments. For the experimental results presented here, comparisons will only be made between parametrics and baselines that were both performed post burner modification.

\subsubsection{Primary Oxygen Replacement Tests}

Experiments were performed to investigate the flame shape and stabilization location when removing oxygen from the primary and introducing it through the various injection lance configurations. These tests were performed while oxy-firing at conditions where the flame was flickering between being attached within the quarl and blown off. These conditions were chosen because there would be a clear indication of whether the injection strategy produced favorable results. To produce a flickering flame, the primary air to fuel ratio was set at 2.05, the inner/outer secondary mass ratio to 20/80, the primary $\mathrm{O}_{2}$ 
concentration was $21 \%$ and the concentrations of $\mathrm{O}_{2}$ in the inner and outer registers of the secondary were the same. The overall $\mathrm{O}_{2}$ concentration in the $\mathrm{O}_{2} / \mathrm{FGR}$ mixture was $27 \%$. Figure $4.3-9$ shows the flame at two times while operating at these same conditions. One image shows the flame detached and one shows it attached within the quarl on one side. For this test, the axial injection lance was installed. It will be used as the baseline condition with which injection tests will be compared.

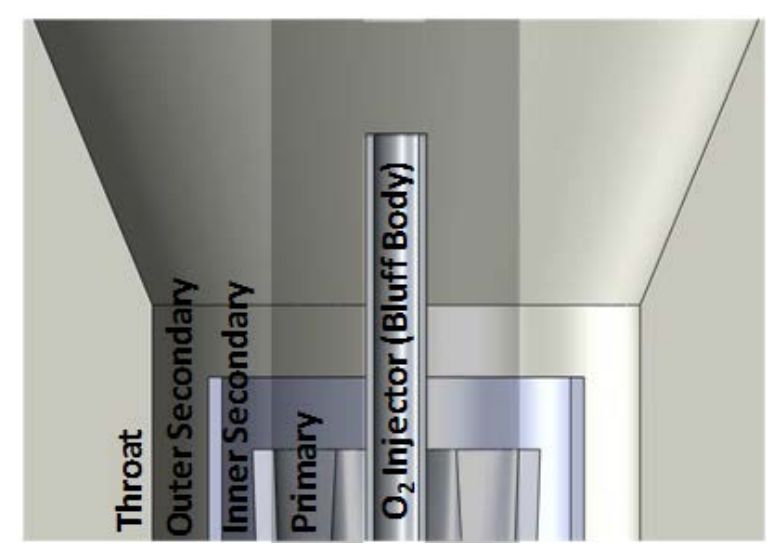

$$
\mathrm{BSR}=0.9
$$

Primary Gas/Fuel $=2.08$

$\mathrm{IS} / \mathrm{OS}=20 / 80$

Primary $\mathrm{O}_{2}$ Conc. $=21.4 \%$

(Premixed)

Primary SR $=0.188$

Inner Secondary $\mathrm{O}_{2}$ Conc. $=29.8 \%$

Outer Secondary $\mathrm{O}_{2}$ Conc. $=29.2 \%$

Overall $\mathrm{O}_{2}$ in $\mathrm{O}_{2} /$ FGR mixture $=27 \%$

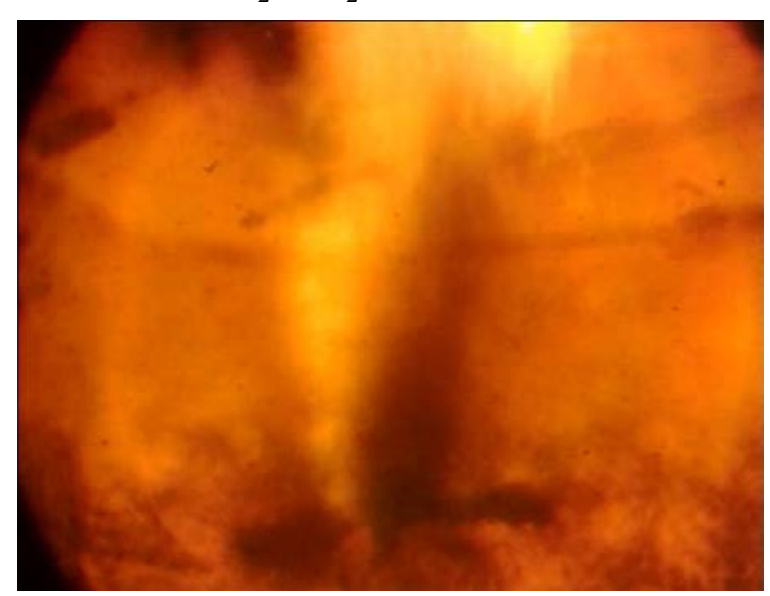

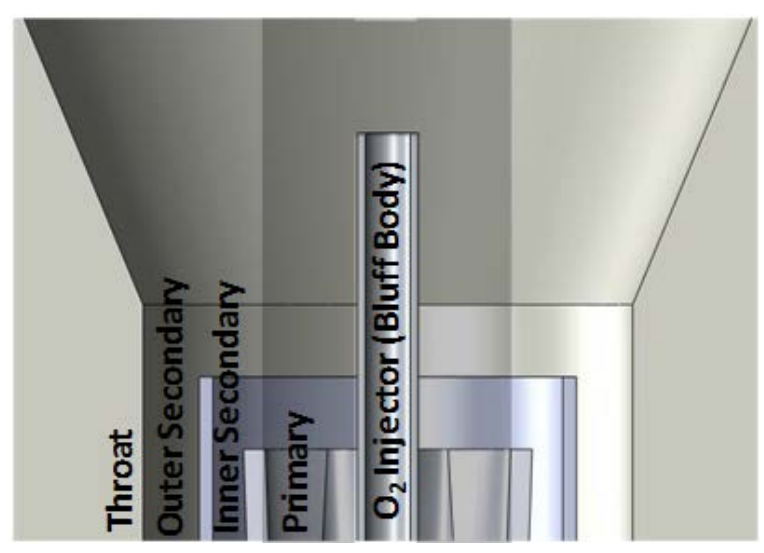

$$
\mathrm{BSR}=0.9
$$

Primary Gas $/$ Fuel $=2.08$

IS $/ O S=20 / 80$

Primary $\mathrm{O}_{2}$ Conc. $=21.4 \%$

(Premixed)

Primary SR $=0.188$

Inner Secondary $\mathrm{O}_{2}$ Conc. $=29.8 \%$

Outer Secondary $\mathrm{O}_{2}$ Conc. $=29.2 \%$

Overall $\mathrm{O}_{2}$ in $\mathrm{O}_{2} /$ FGR mixture $=27 \%$

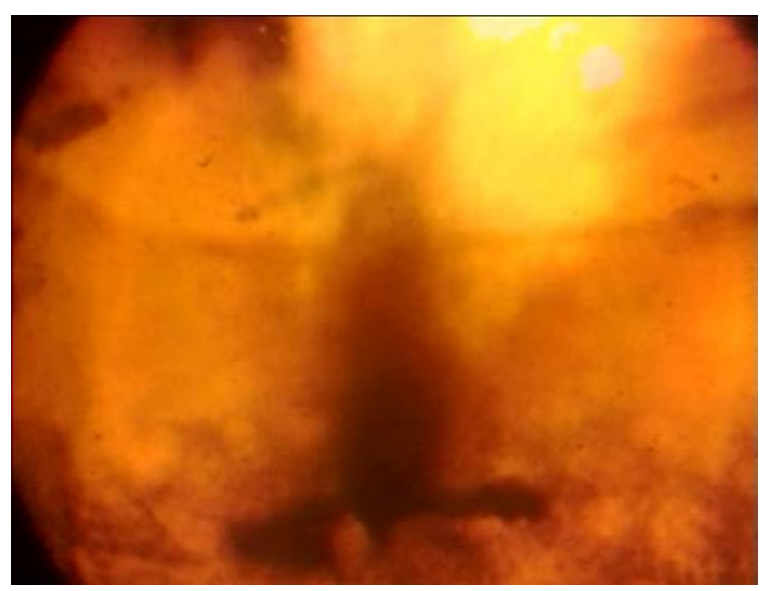

Figure 4.3-9: Still pictures of flames from the baseline conditions for oxygen injection tests.

When oxygen was injected through any of the injection lance configurations, oxygen enrichment of the primary was discontinued, leaving the primary with an $\mathrm{O}_{2}$ concentration equal to that of the exit flue gases. The mass of oxygen removed from the primary is replaced with FGR from the inner secondary in order to maintain the primary velocity. The same amount of $\mathrm{O}_{2}$ that had been previously enriched in the primary was then introduced through the injection lance. Figure 4.3-10 presents the results from the axial injection tests, including lance and injection configuration, conditions tested and still frames from the videos of the flame for each condition. 


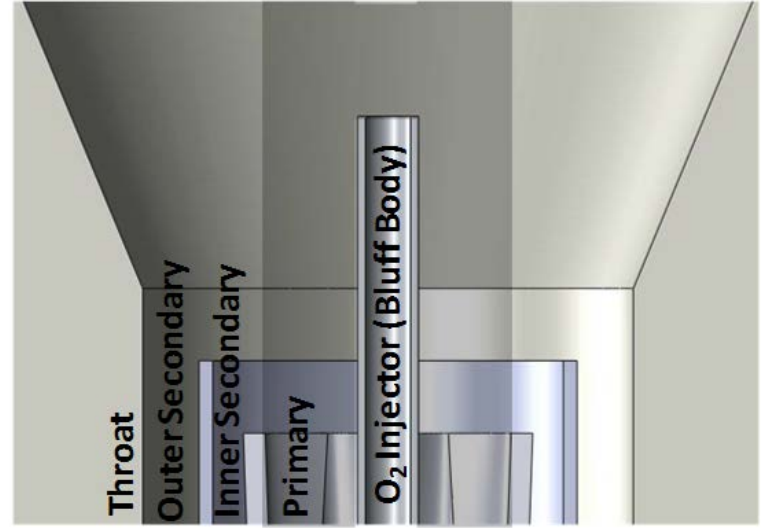

$\mathrm{BSR}=0.9$

Primary Gas $/$ Fuel $=2.08$

IS $/ O S=20 / 80$

Primary $\mathrm{O}_{2}$ Conc. $=21.4 \%$

(Premixed)

Primary SR $=0.188$

Inner Secondary $\mathrm{O}_{2}$ Conc. $=29.8 \%$

Outer Secondary $\mathrm{O}_{2}$ Conc. $=29.2 \%$

Overall $\mathrm{O}_{2}$ in $\mathrm{O}_{2} /$ FGR mixture $=27 \%$

(Baseline)

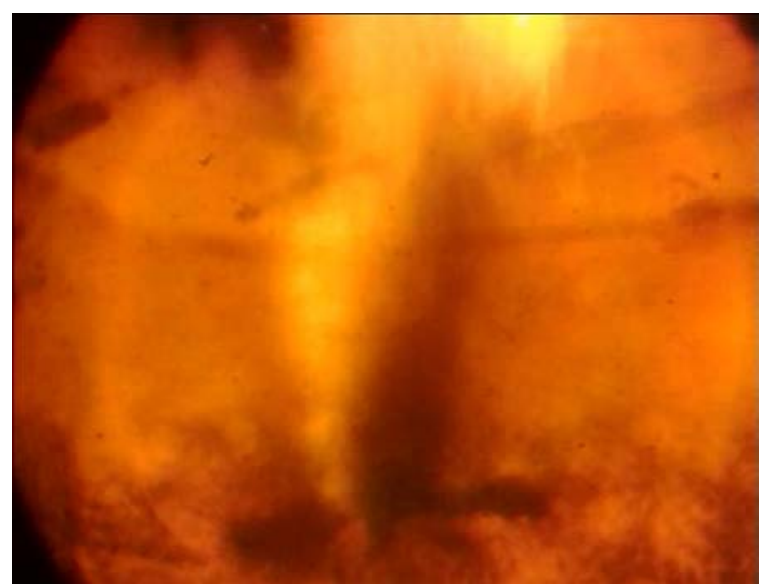

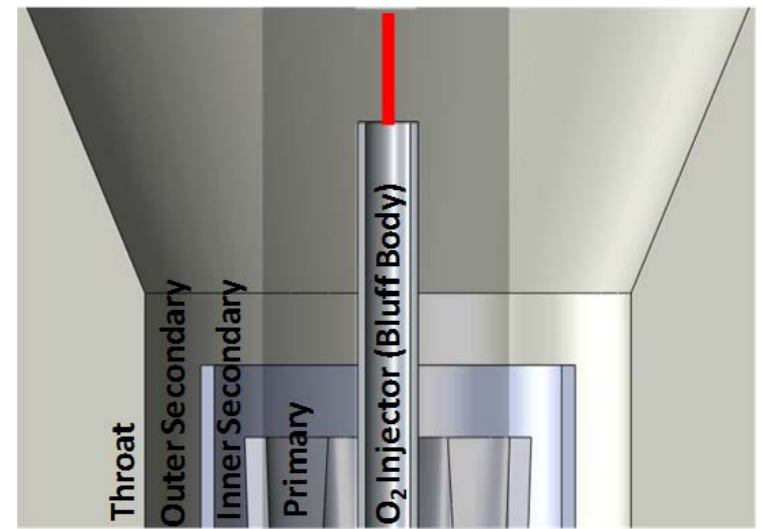

$\mathrm{BSR}=0.9$

Primary Gas/Fuel $=2.05$

IS/OS $=20 / 80$

Primary $\mathrm{O}_{2}$ Conc. $=2.46 \%$

(Premixed)

Primary SR $=0.018$

Inner Secondary $\mathrm{O}_{2}$ Conc. $=38.1 \%$

Outer Secondary $\mathrm{O}_{2}$ Conc. $=29.5 \%$

Overall $\mathrm{O}_{2}$ in $\mathrm{O}_{2} /$ FGR mixture $=27 \%$

$103 \mathrm{lb} / \mathrm{hr} \mathrm{O}_{2}$ (Axial Injection)

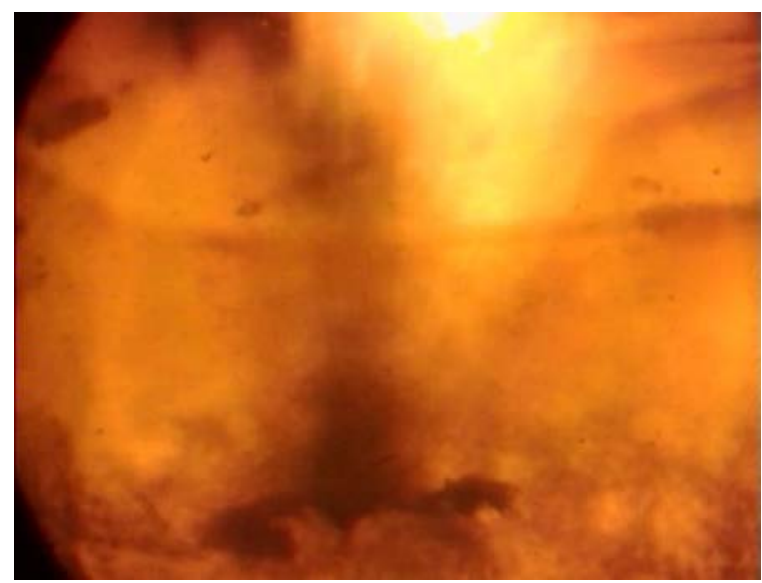

Figure 4.3-10: Still pictures of a flame with axial $O_{2}$ injection compared with a baseline flame.

The flames in Figure 4.3-10 indicate that the axial injection condition results in a detached flame, possibly more so than the baseline condition. This result should not be surprising. In the baseline condition the oxygen is uniformly distributed throughout the primary gases and in proximity to the coal. In the injected case the oxygen is concentrated in the center of the primary and introduced only at a point where ignition is expected.

The same experiment was performed while using the radial injection lance. In order to better understand this experiment, a jet in cross flow calculation was performed to determine the expected streamline of the 
$\mathrm{O}_{2}$ relative to the coal rich region (Patrick 1967). The result of this calculation is presented in Figure 4.3-11.

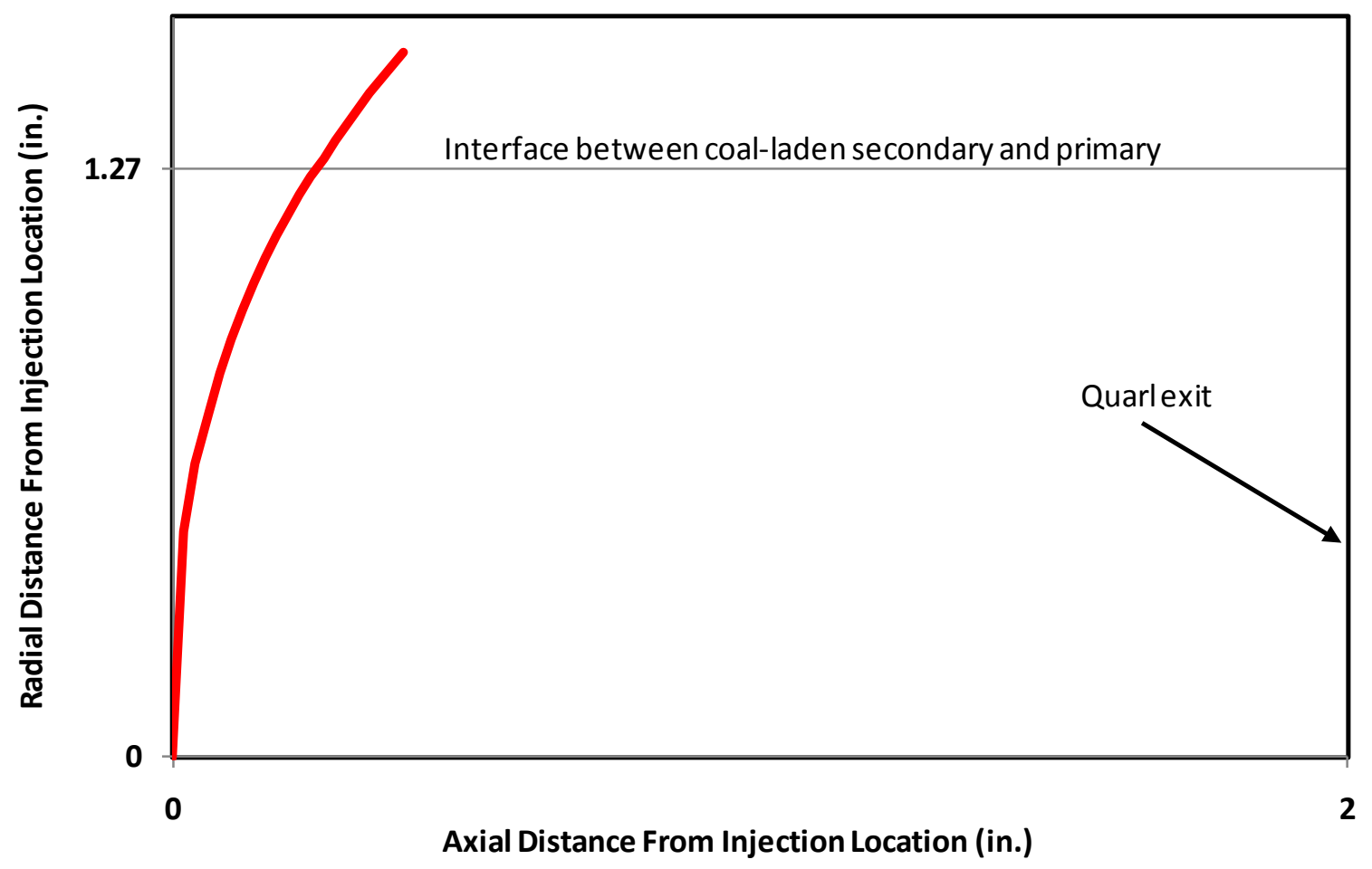

Figure 4.3-11: Predicted penetration of radially injected $\mathrm{O}_{2}$ for primary oxygen replacement.

Figure 4.3-11 shows that with the chosen radial injector configuration and flow rate of $\mathrm{O}_{2}$, the oxygen jet fully penetrates the coal-rich region well before the exit to the quarl. The conditions of the radial injection experiment and still frames from the video of the resulting flame are presented in Figure 4.3-12 and compared with the baseline condition. The predicted streamline from the jet in cross flow calculation are also superimposed over the burner cross section drawing in Figure 4.3-12. 


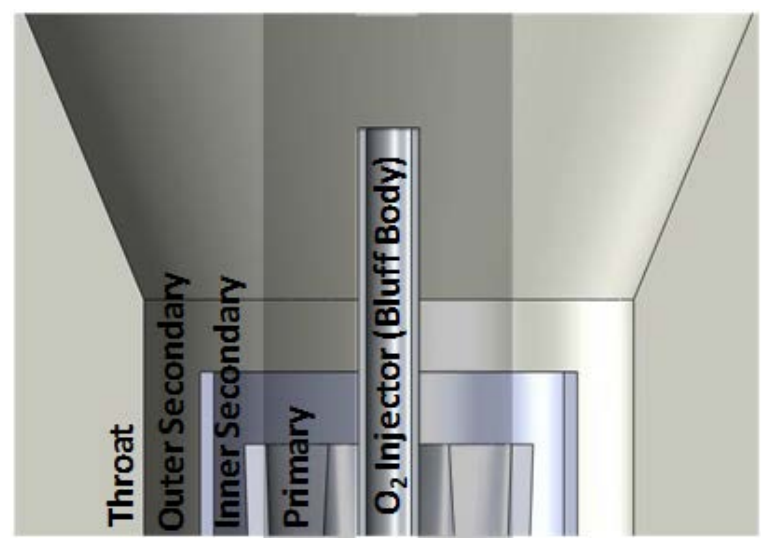

$\mathrm{BSR}=0.9$

Primary Gas/Fuel $=2.08$

IS/OS $=20 / 80$

Primary $\mathrm{O}_{2}$ Conc. $=21.4 \%$

(Premixed)

Primary SR $=0.188$

Inner Secondary $\mathrm{O}_{2}$ Conc. $=29.8 \%$

Outer Secondary $\mathrm{O}_{2}$ Conc. $=29.2 \%$

Overall $\mathrm{O}_{2}$ in $\mathrm{O}_{2} /$ FGR mixture $=27 \%$

(Baseline)

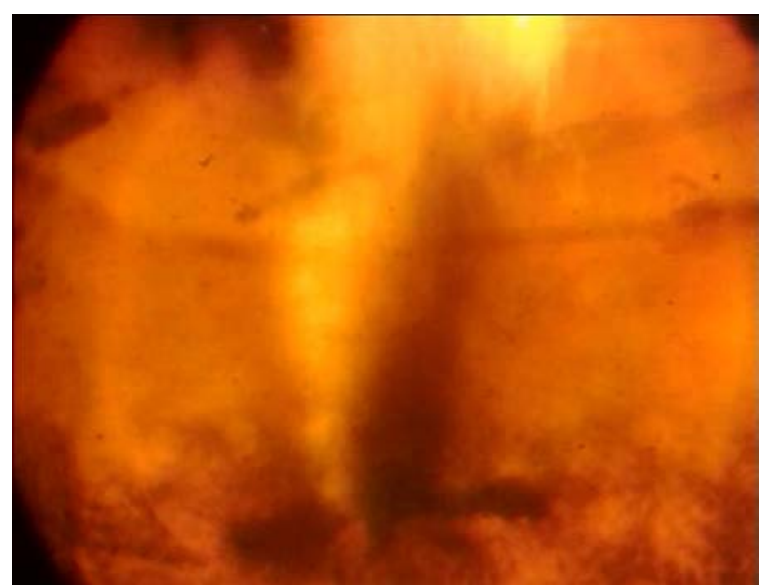

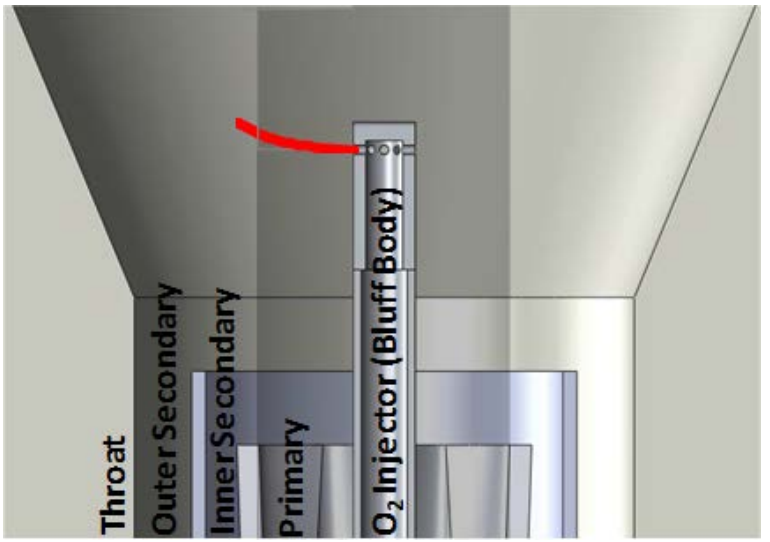

$\mathrm{BSR}=0.9$

Primary Gas/Fuel $=2.05$

IS/OS $=20 / 80$

Primary $\mathrm{O}_{2}$ Conc. $=2.33 \%$

(Premixed)

Primary SR $=0.020$

Inner Secondary $\mathrm{O}_{2}$ Conc. $=29.5 \%$

Outer Secondary $\mathrm{O}_{2}$ Conc. $=29.2 \%$

Overall $\mathrm{O}_{2}$ in $\mathrm{O}_{2} /$ FGR mixture $=27 \%$

$103 \mathrm{lb} / \mathrm{hr} \mathrm{O}_{2}$ (Radial Injection)

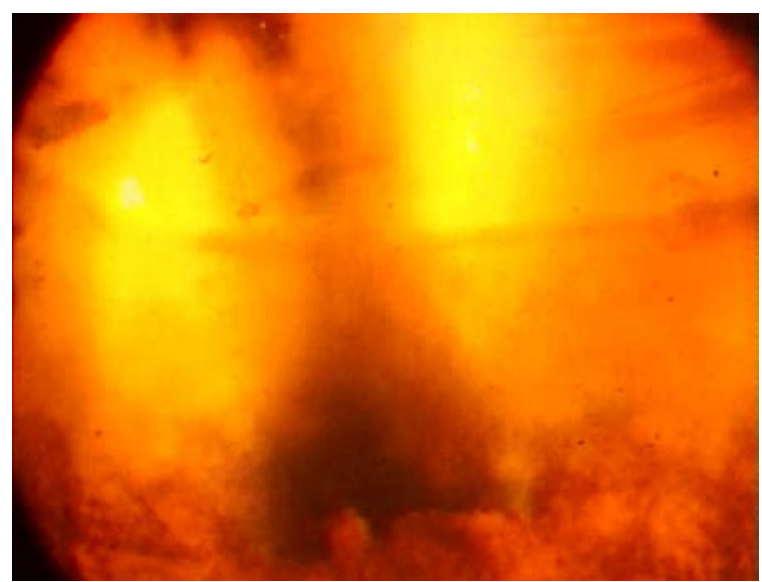

Figure 4.3-12: Still pictures of a flame with radial $\mathrm{O}_{2}$ injection compared with a baseline flame.

The flames in Figure 4.3-12 show a strong impact on flame shape from the radial $\mathrm{O}_{2}$ injection. The coal seems to be more widely distributed as it leaves the quarl. The ignition seems to occur closer to the quarl exit on the detached side of the flame and the flame is much brighter within the field of view. However, the flame is not attached for these conditions.

The same experiment was performed when $\mathrm{O}_{2}$ was injected through the nozzles in the inner secondary. The results from this experiment are presented in Figure 4.3-13. 


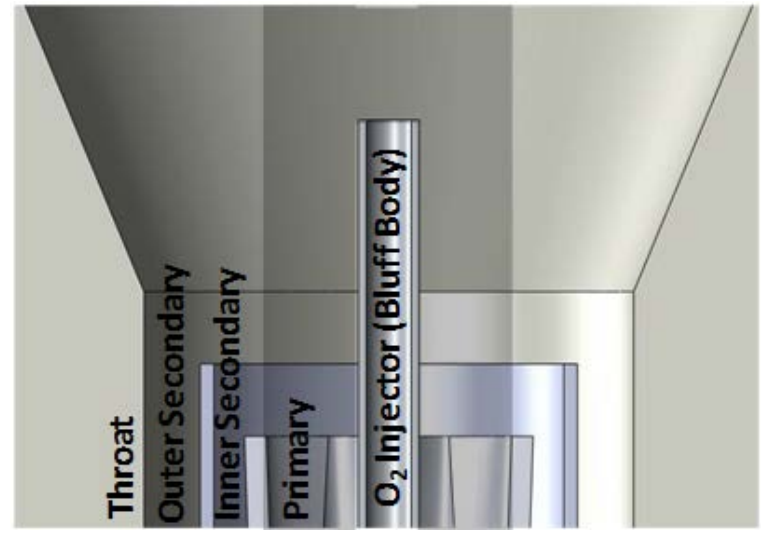

$\mathrm{BSR}=0.9$

Primary Gas/Fuel $=2.08$

IS/OS $=20 / 80$

Primary $\mathrm{O}_{2}$ Conc. $=21.4 \%$

(Premixed)

Primary SR $=0.188$

Inner Secondary $\mathrm{O}_{2}$ Conc. $=29.8 \%$

Outer Secondary $\mathrm{O}_{2}$ Conc. $=29.2 \%$

Overall $\mathrm{O}_{2}$ in $\mathrm{O}_{2} /$ FGR mixture $=27 \%$

(Baseline)

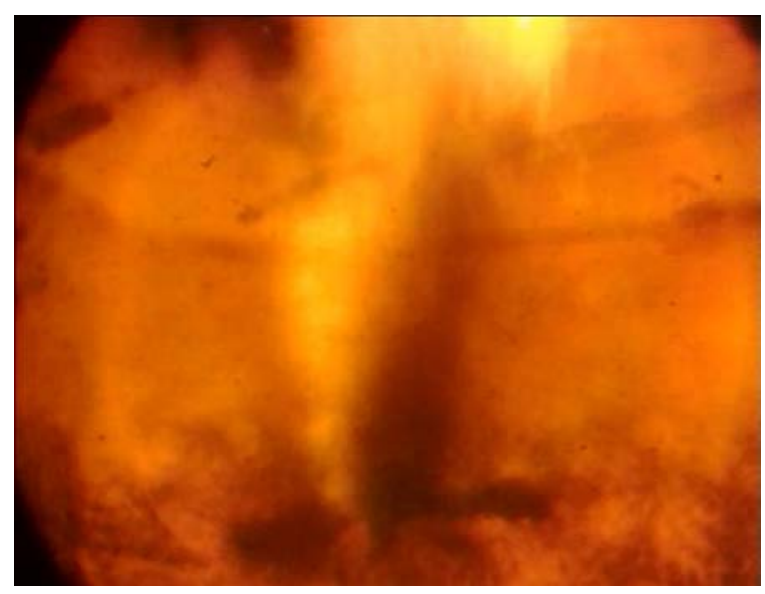

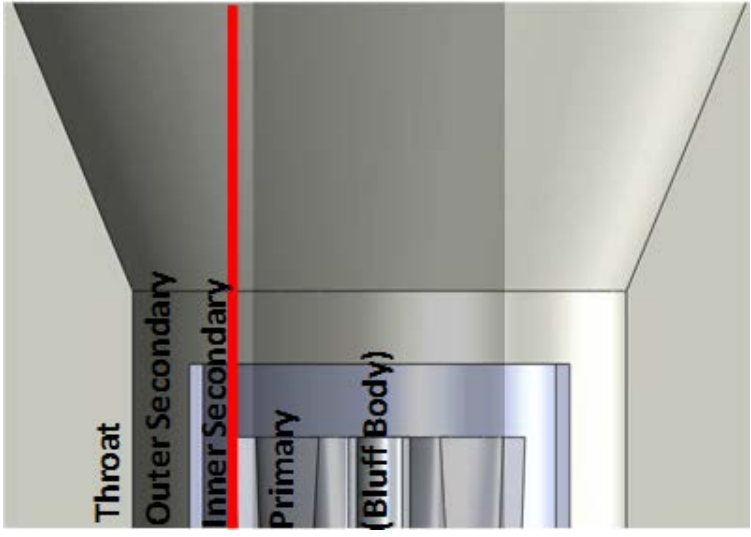

$\mathrm{BSR}=0.9$

Primary Gas/Fuel $=2.06$

IS/OS $=20 / 80$

Primary $\mathrm{O}_{2}$ Conc. $=2.62 \%$

(Premixed)

Primary SR $=0.022$

Inner Secondary $\mathrm{O}_{2}$ Conc. $=40.6 \%$

Outer Secondary $\mathrm{O}_{2}$ Conc. $=29.4 \%$

Overall $\mathrm{O}_{2}$ in $\mathrm{O}_{2} /$ FGR mixture $=27 \%$

$100 \mathrm{lb} / \mathrm{hr} \mathrm{O}_{2}$ (Secondary Injection)

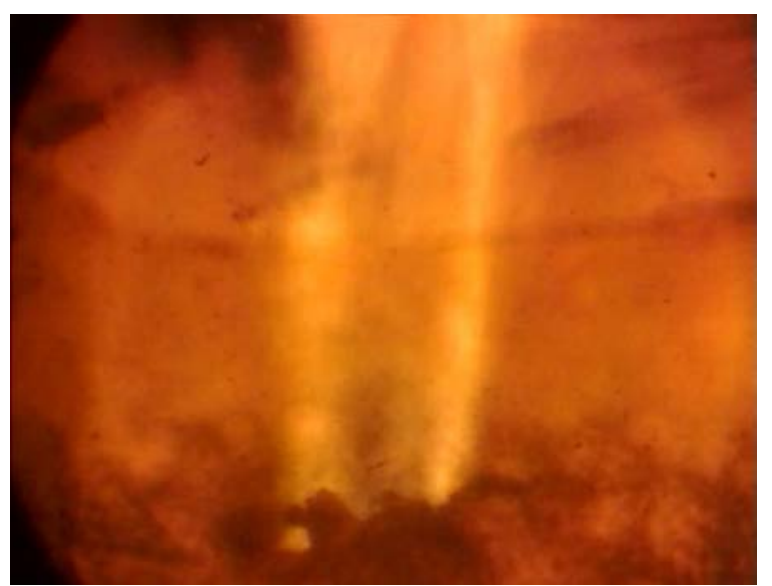

Figure 4.3-13: Still pictures of a flame with inner secondary $\mathrm{O}_{2}$ injection compared with a baseline flame.

Figure 4.3-13 shows that when oxygen is injected through the nozzles in the inner secondary, the flame is strongly attached within the quarl.

The results from these three oxygen injection tests indicate that oxygen can be removed from the primary and introduced through injectors at the burner face and a stable flame can be achieved. However the location where the injection occurs is very critical to the flame stability. In our experiments, injection through the inner secondary was successful where injection into the primary through the bluff body was not. When $\mathrm{O}_{2}$ is injected along the boundary between the inner secondary it is likely mixed rapidly with the coal-rich region. This mixing is stimulated by shear between the differing gas velocities of the 
primary and inner secondary. In addition when injecting through the inner secondary register, the oxygen is present in the FGR as the gases travel across the flame stabilization tabs also promoting mixing of the oxygen and fuel-rich region.

\subsubsection{Primary Oxygen Enrichment Tests}

In addition to the primary oxygen replacement tests, small amounts of oxygen were introduced into the fuel-rich region to determine if oxygen injection could be used to stabilize a flickering flame. For these tests the baseline conditions from the previous tests was used. Additional oxygen was introduced through the radial injection lance with no other changes to the operating conditions. Three different oxygen injection rates were tested during these experiments including 5, 10 and $17 \mathrm{lb} / \mathrm{hr}$. Predicted streamlines for the injection $\mathrm{O}_{2}$ are presented in Figure 4.3-14 and were produced by performing the jet in cross flow calculation.

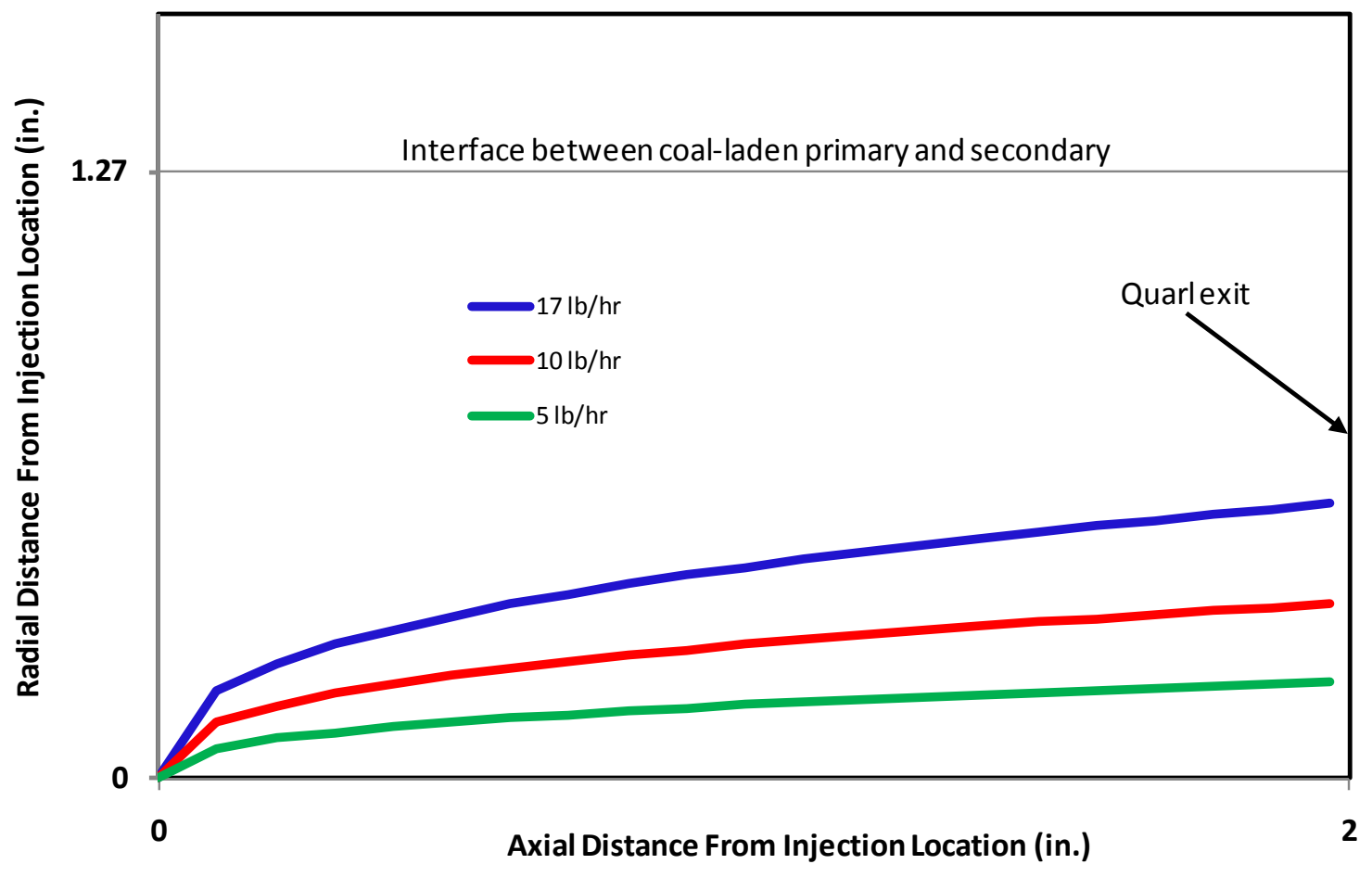

Figure 4.3-14: Predicted penetration of radially injected $\mathrm{O}_{2}$ for primary oxygen enrichment.

Figure 4.3-14 indicates that at these low flow rates, the streamlines of the injected oxygen remain well within the fuel rich-region. Results from the experiment where $10 \mathrm{lb} / \mathrm{hr}$ was introduced through the radial lance are presented in Figure 4.3-15. 


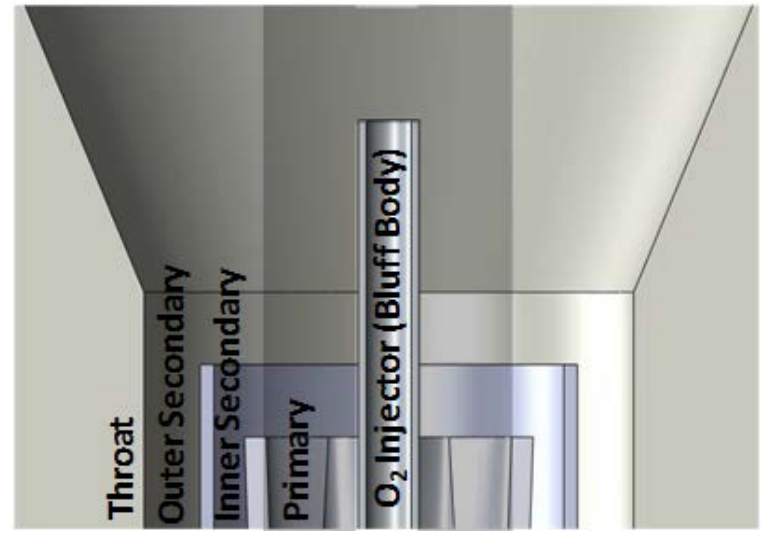

$\mathrm{BSR}=0.9$

Primary Gas/Fuel $=2.08$

IS/OS $=20 / 80$

Primary $\mathrm{O}_{2}$ Conc. $=21.4 \%$

(Premixed)

Primary SR $=0.188$

Inner Secondary $\mathrm{O}_{2}$ Conc. $=29.8 \%$

Outer Secondary $\mathrm{O}_{2}$ Conc. $=29.2 \%$

Overall $\mathrm{O}_{2}$ in $\mathrm{O}_{2} /$ FGR mixture $=27 \%$

(Baseline)

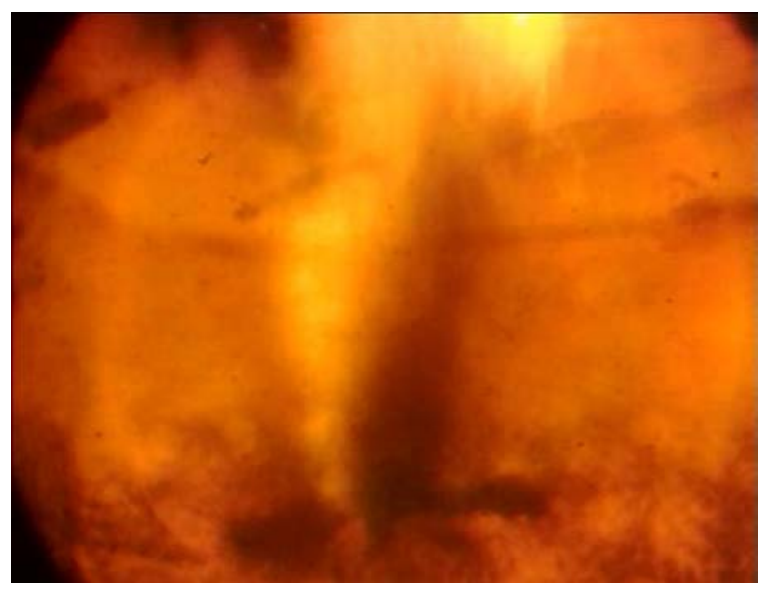

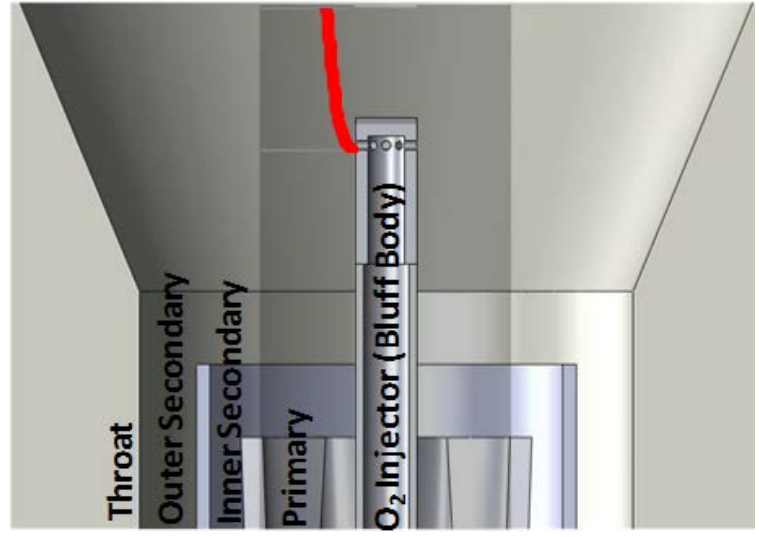

$\mathrm{BSR}=0.9$

Primary Gas $/$ Fuel $=2.11$

IS/OS $=20 / 80$

Primary $\mathrm{O}_{2}$ Conc. $=23.3 \%$

(Premixed)

Primary SR $=0.207$

Inner Secondary $\mathrm{O}_{2}$ Conc. $=28.3 \%$

Outer Secondary $\mathrm{O}_{2}$ Conc. $=27.7 \%$

Overall $\mathrm{O}_{2}$ in $\mathrm{O}_{2} /$ FGR mixture $=27 \%$

$10 \mathrm{lb} / \mathrm{hr} \mathrm{O}_{2}$ (Radial Injection)

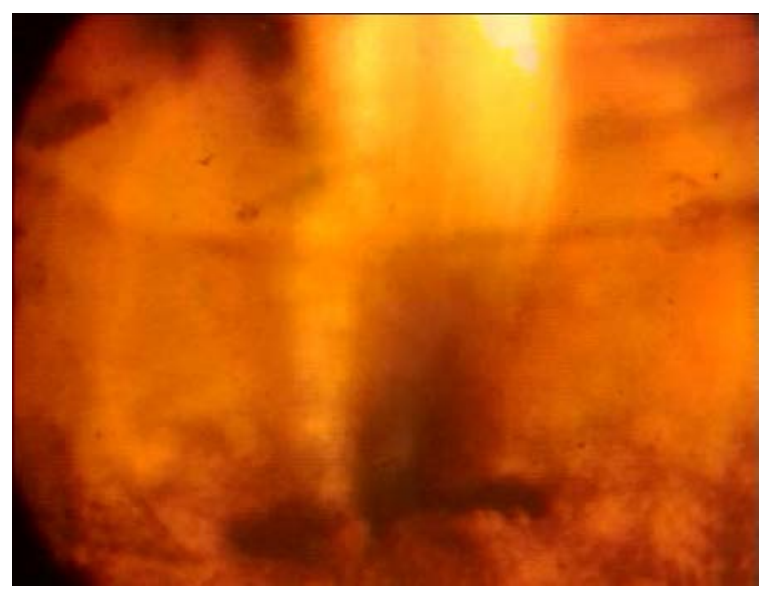

Figure 4.3-15: Still pictures of a flame with radial $\mathrm{O}_{2}$ injection for primary oxygen enrichment compared with a baseline flame.

Figure 4.3-15 indicates that there is no difference on the flame shape and ignition when enriching the primary with injected $\mathrm{O}_{2}$. The results were the same for all three of the injection rates tested. These results further indicate that injection of $\mathrm{O}_{2}$ within the fuel rich region is not as effective as injection of the oxygen on the boundary between the inner secondary and primary gas streams.

\subsubsection{UBC, Sulfur and $\mathrm{NO}_{\mathrm{x}}$ Concentrations}

Unburned carbon-in-ash (UBC) measurements were made for the Utah, PRB and Illinois coals tested. Ash samples were collected from entrained flow and from the baghouse. Results of these measurements are 
shown in Figure 4.3-16. For the PRB coal, oxy-firing resulted in slightly hirer unburned carbon in ash $(0.3 \%$ vs. $1 \%)$ although all measurements were very low. For the bituminous coals, oxy-firing resulted in lower UBC, most notably for the Illinois coal. Although not plotted, the UBC values reported for the Utah Skyline coal were similar to those reported at PacifiCorp’s Hunter 3 plant which fires this coal.

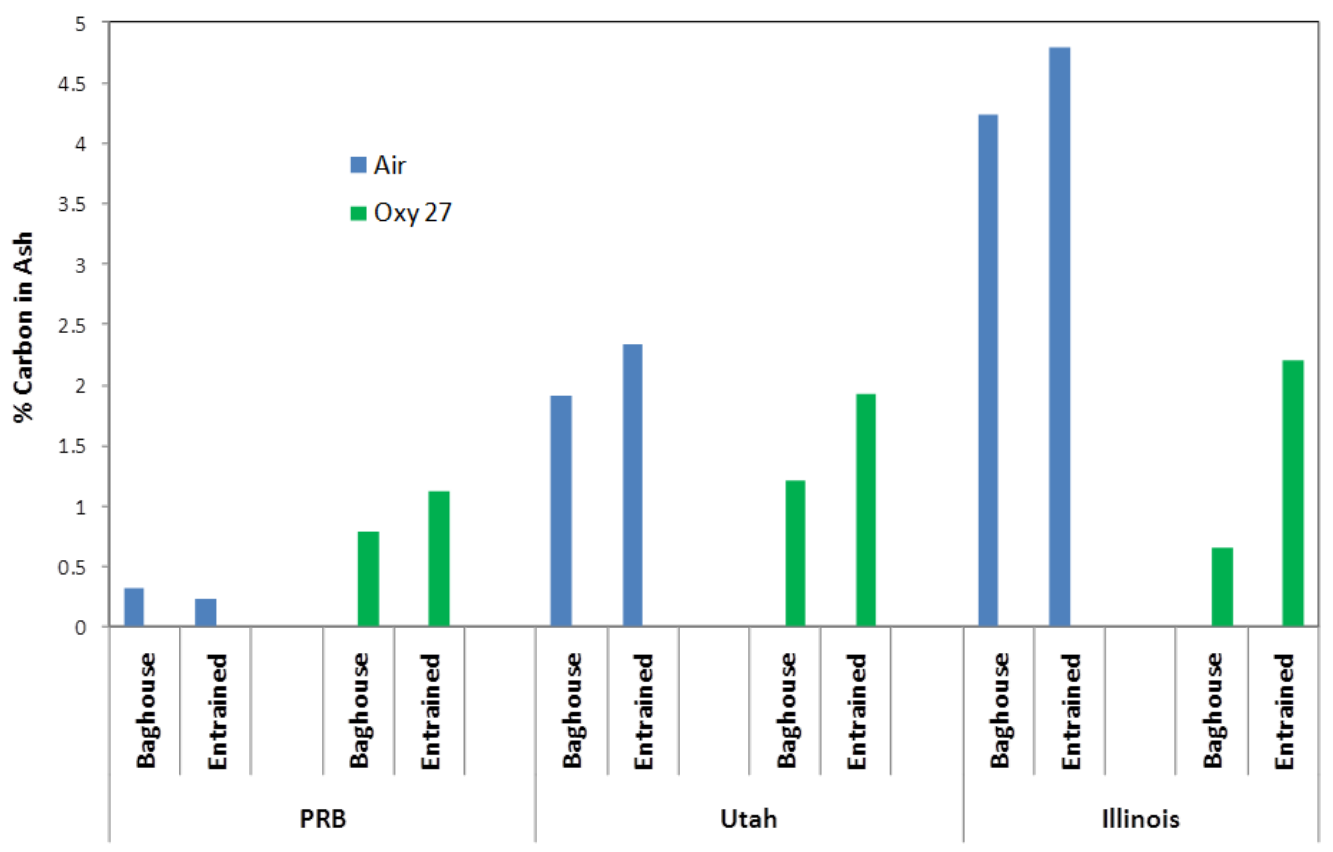

Figure 4.3-16: Measured unburned carbon-in-ash (UBC) for L1500 tests.

Expected and measured gas phase sulfur values are listed in Table 4.3-2, along with the percentage error in closing the sulfur mass balance. Note the very high levels of expected and measured $\mathrm{SO}_{2}$ for the untreated flue gas recycle cases. Flue gas recycle used with oxy-firing resulted in approximately a factor of five increase in the $\mathrm{SO}_{2}$ level over air-firing conditions. These high levels of $\mathrm{SO}_{2}$ (and implied increases in $\mathrm{SO}_{3}$ concentration) can potentially impact surface corrosion rates and mercury capture effectiveness.

Table 4.3-2: Gas phase sulfur balance for L1500 tests.

\begin{tabular}{|l|c|c|c|}
\hline Condition & $\begin{array}{l}\text { Expected SO } \\
\text { (ppmv, dry) }\end{array}$ & $\begin{array}{l}\text { Measured SO } \\
\text { (ppmv, dry) }\end{array}$ & $\begin{array}{l}\text { Error } \\
\text { (\%) }\end{array}$ \\
\hline PRB - Air & 262 & 129 & 50.8 \\
\hline PRB - Oxy & 1373 & 289 & 79.0 \\
\hline Utah - Air & 444 & 446 & 0.6 \\
\hline Utah - Oxy & 2,407 & 1,754 & 27.1 \\
\hline Illinois - Air & 3,601 & 3,219 & 10.6 \\
\hline Illinois - Oxy & 19,558 & 17,642 & 9.8 \\
\hline
\end{tabular}

The sulfur balance was improved when the effects of sulfur in the condensate, entrained ash and baghouse ash were also considered. Figure 4.3-17 plots the incoming and outgoing sulfur for the three test coals under air and oxy-firing conditions. The balances are within 10\%. Figure 4.3-18 plots the total sulfur balance in a different format to illustrate the balance of the accuracy. 


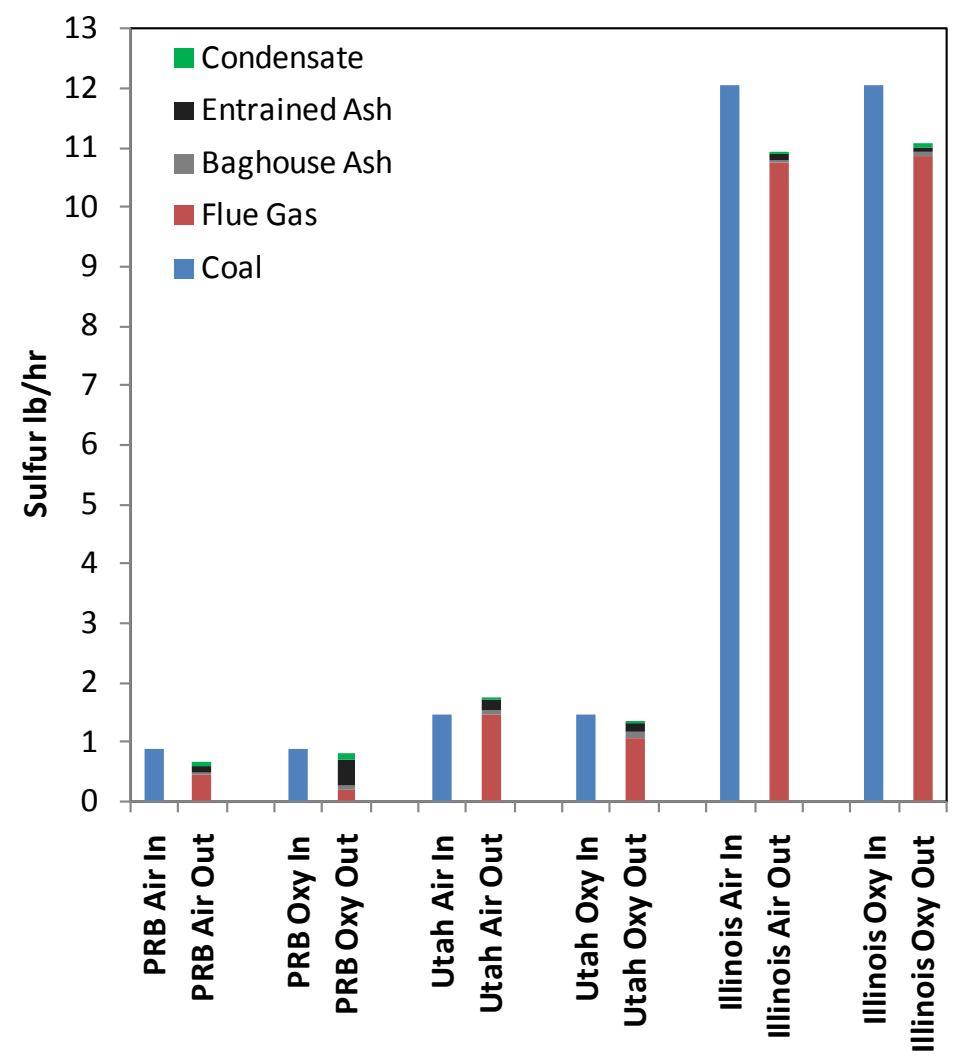

Figure 4.3-17: Total sulfur mass balance for three test coals under air and oxy-firing conditions.

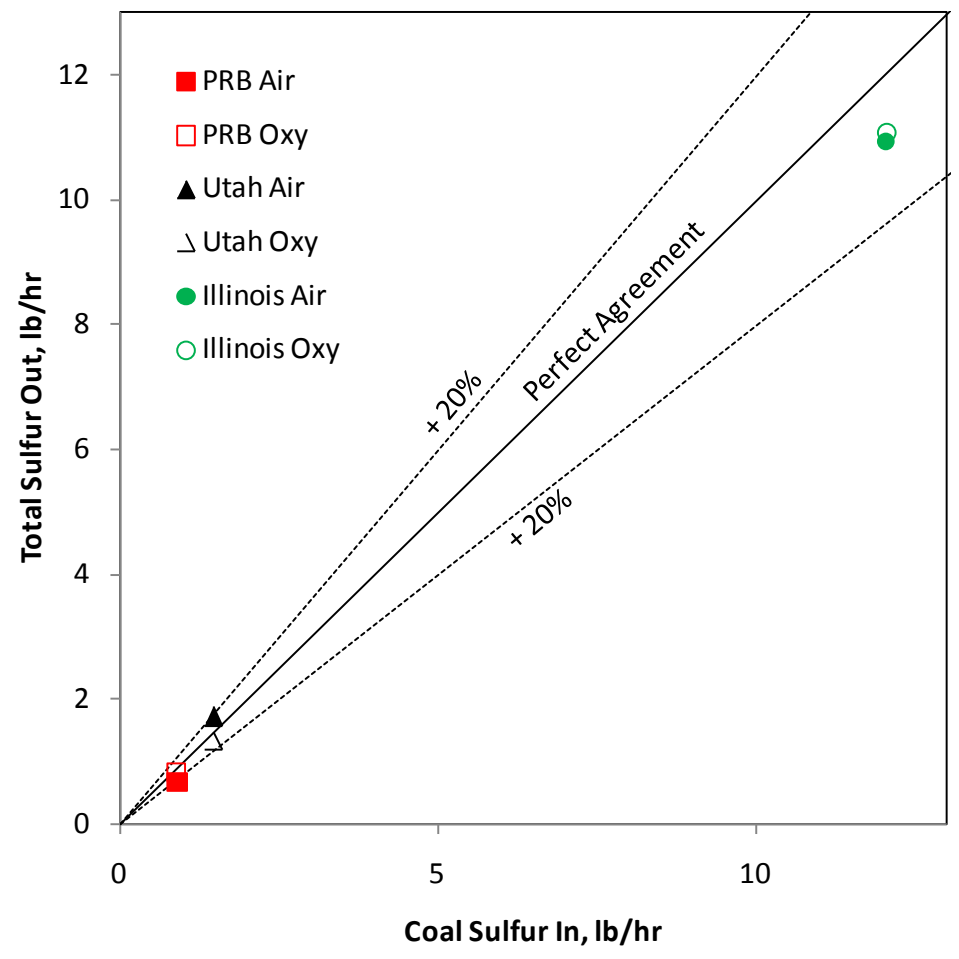

Figure 4.3-18: Total sulfur mass balance for three test coals. 
$\mathrm{NO}_{\mathrm{x}}$ emission and concentration data from these tests were combined with data from the previous air and oxy-firing tests. Results shown here include data collected while firing the Skyline coal and new data for the PRB and Illinois coals. The furnace exit $\mathrm{NO}_{\mathrm{x}}$ concentration is included as Figure 4.3-19 and the $\mathrm{NO}_{\mathrm{x}}$ emission plot is included as Figure 4.3-20.

There is quite a bit of scatter in $\mathrm{NO}_{\mathrm{x}}$ concentration at a BSR of 0.9 in Figure 4.3-19. This scatter comes from the large number of data points that were recorded at this condition and data points were included where the flame was unstable or blown off. Most of the unstable or blow off flames occurred while oxyfiring, in support of tests like those reported in this section of the report. Ignoring the outlying data points at a BSR of 0.9, the concentration plot in Figure 4.3-19 shows similar $\mathrm{NO}_{\mathrm{x}}$ concentrations for air- and oxy-fired conditions when operating below the stoichiometric ratio of 1 . At superstoichiometric ratios, the $\mathrm{NO}_{\mathrm{x}}$ concentration is generally much higher for the oxy-fired conditions. These trends seem to indicate that recycled $\mathrm{NO}_{\mathrm{x}}$ is effectively reburned at substoichiometric ratios. The plot of emitted $\mathrm{NO}_{\mathrm{x}}$ in Figure 4.3-20 shows that due to the low volume of gas emission while oxy-firing with $\mathrm{FGR}$, the $\mathrm{NO}_{\mathrm{x}}$ emitted is much lower for all conditions tested.

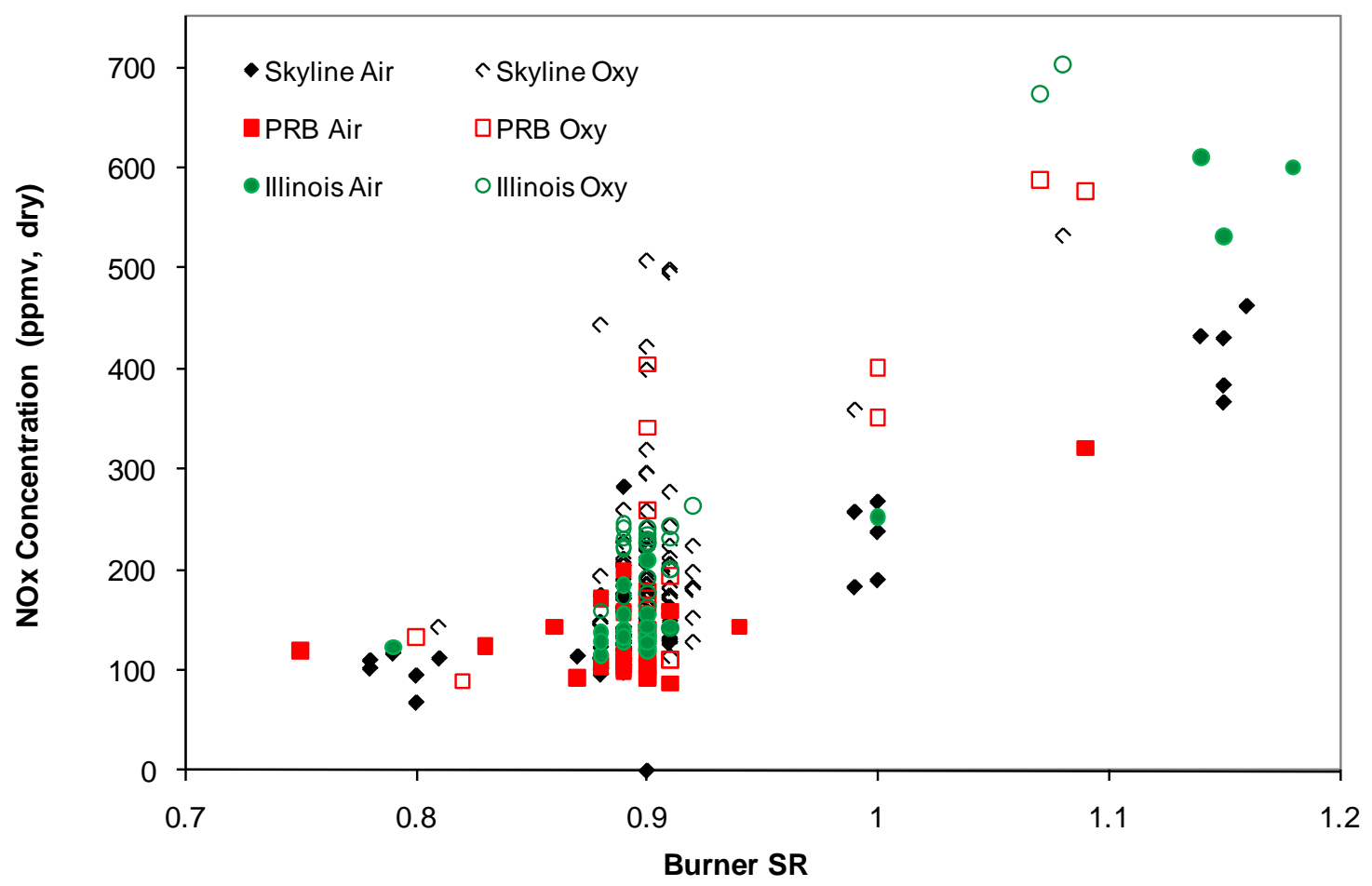

Figure 4.3-19: Furnace exit NOx concentrations for all coals with air and oxygen/FGR. 


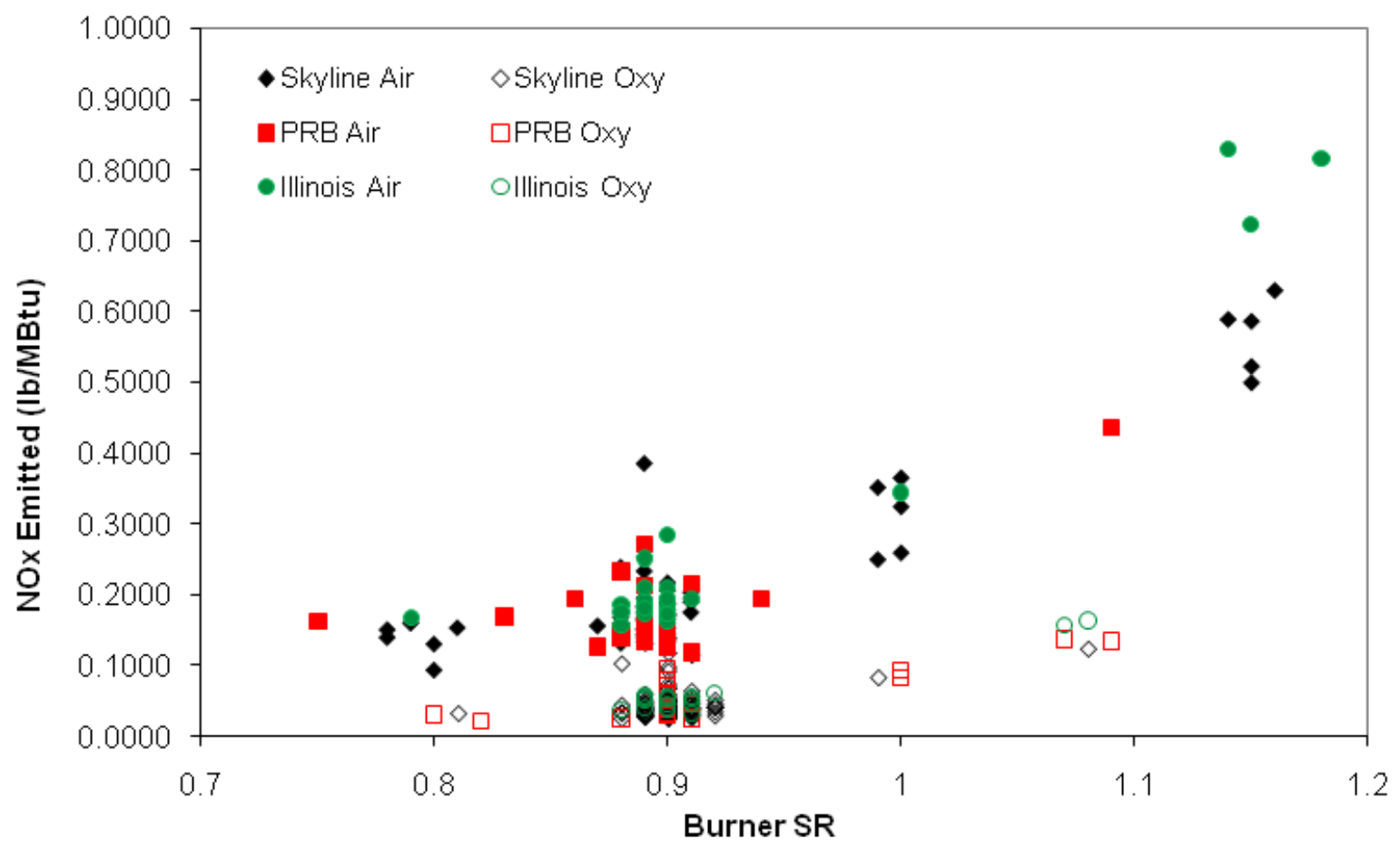

Figure 4.3-20: Emitted $\mathrm{NO}_{\mathrm{x}}$ for all coals with air and oxygen/FGR.

\subsubsection{Radiation Intensity Measurements}

Passive radiation measurements were performed on the L1500 by personnel from NETL ORD. Radiation data were collected from the $29^{\text {th }}$ of March through the end of the test campaign. Conditions of the experiments throughout this period included air- and oxy-combustion of the Illinois and Utah coals. Burner operating conditions throughout this period spanned various burner stoichiometric ratios and also included oxygen injection testing. These radiation data have provided valuable information comparing the furnace behavior between air and oxy-fired conditions and have added further insight into the effects of targeted oxygen injection.

\subsubsection{Instrumentation}

Four electromagnetic radiation detection devices of three different types (one monochromator and three total radiometers) were used to measure the emitted electromagnetic combustion flame radiation. Sapphire windows allowed line of sight optical access in the center of the first three sections of the furnace. These locations are detailed in Figure 4.3-21. The radiation detection devices were placed just outside of the window ports. The sapphire windows pass through approximately $90 \%$ of electromagnetic radiation below $5000 \mathrm{~nm}$ while absorbing most radiation above $5000 \mathrm{~nm}$. Two Thorlabs Thermal Power Sensors were used at furnace sections 1 and 3. Measurements were taken at furnace section 2 using either the Newport Thermopile Detector or the Newport Cornerstone 260 Monochromator. A description of each of these devices follows. 


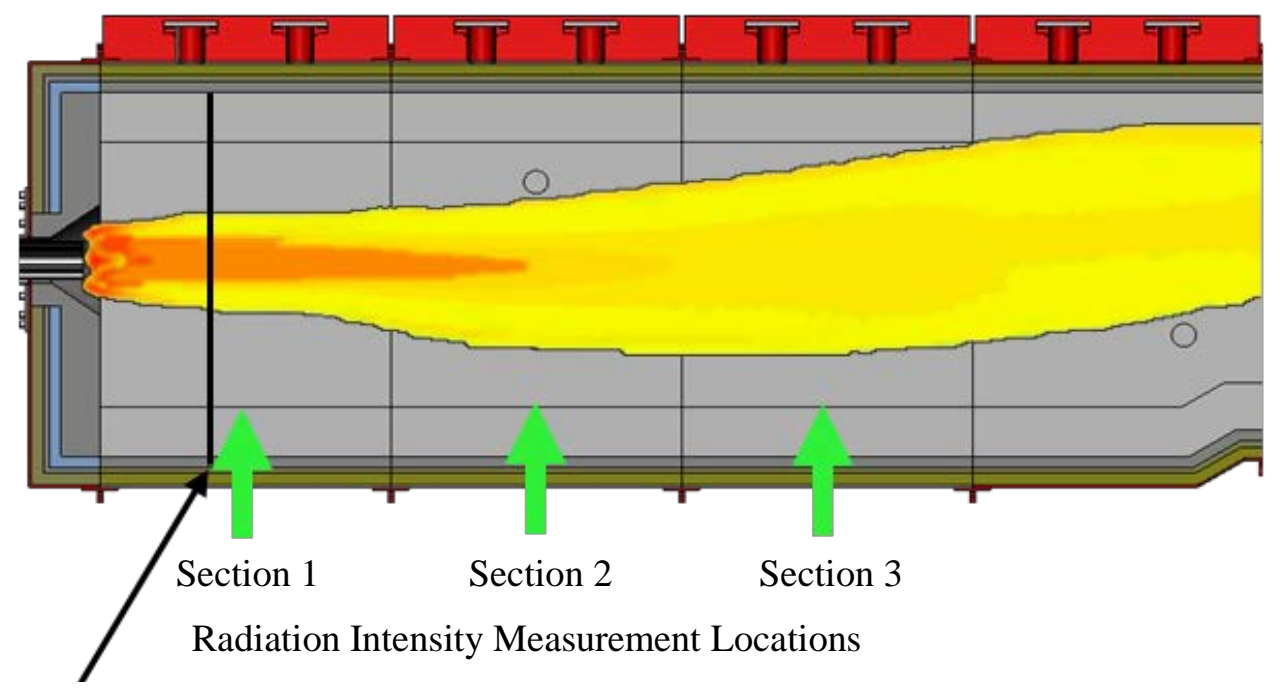

Limit of Camera View

\section{Figure 4.3-21. Cross section of the $\mathrm{L} 1500$ and locations of radiation measurements relative to the} camera field of view.

Thorlabs Thermal Power Sensors are total radiometers that also measure wavelength independent total incident power. The incident flame energy strikes an active sensor plate and then flows through a heat sink to the back of the sensor. Thermocouples within the heat sink allow for the incident power to the active sensor plate to be calculated. This power is then converted to a voltage that can be read by a digital meter. Proper zeroing of the sensor is performed by allowing the heat sink and active sensor to come into thermal equilibrium, results in a linear voltage vs. power response. No wavelength correction is required as the wavelength response is nearly linear from the UV $(\sim 200 \mathrm{~nm})$ to the mid IR $(\sim 20 \mu \mathrm{m})$. The response time of thermal sensors is generally fairly slow $(\sim 5-10 \mathrm{sec})$, but special circuitry within these devices can lower that response time to close to one second. Two of these sensors were utilized each with a different maximum power threshold: $30 \mathrm{~W}$ and $3 \mathrm{~W}$. The $30 \mathrm{~W}$ and 3 watt sensors have respective aperture diameters of .5 and .375 inches. The $30 \mathrm{~W}$ sensor was used on furnace section 1 and the 3W sensor on section 3 . In order to make the two measurements comparable the absolute reading was divided by the area of the aperture to give a heat flux.

The Newport Thermopile Detector is also a total radiometer that measures wavelength independent total incident power. The thermopile detector is composed of an absorbing material whose temperature will increase when exposed to the combustion flame radiation. The temperature increase experienced by the absorbing material is converted in a voltage via a series of thermocouple junction miniature arrays. The voltage is converted into its equivalent power by an attached power meter. This detector has a spectrally flat response from $19 \mathrm{~nm}$ to $10 \mu \mathrm{m}$ with a power range of $20 \mathrm{~mW}$ to $15 \mathrm{~W}$. This detector is $19 \mathrm{~mm}$ and was also normalized to give an equivalent heat flux.

The Newport Cornerstone 260 Monochromator is able to measure incident electromagnetic radiation as a function of wavelength. A series of optical lenses, low-pass optical filters, and concentrating mirrors are used to collimate, concentrate, and focus the emitted flame radiation into the monochromator. Inside the monochromator, a diffraction grating is used to split the furnace beam into discrete wavelengths and steer a particular wavelength into a solid-state detector that measures the energy magnitude carried by that wavelength. The monochromator records the energy intensity at only one wavelength position at any given moment. A full spectrum scan is generated by continuously stepping from one wavelength position to the next, thus resulting in a spectrum of flame energy vs. wavelength. A typical scan can run from 400 $\mathrm{nm}$ to $5000 \mathrm{~nm}$ with a $0.1 \mathrm{~nm}$ step size. 
The data presented here were collected with the two Thorlabs Thermal Power Sensors and the Newport Thermopile Detector. The monochromator data was not deemed reliable, therefore, whenever no data is presented for furnace section 2 it is because the monochromator was installed on furnace section 2 when the data was collected.

\subsubsection{Intensity Measurements}

The raw radiation intensity data is somewhat noisy due to the frequency of data recording (one data point per second) which resolves fluctuations due to flickering and bouncing of the flame. An example of the raw data is presented in Figure 4.3-22 on a day when staged vs. unstaged combustion was being investigated for air and oxy-combustion conditions while firing Illinois coal. The flow rate of air or FGR through the outer secondary register of the burner is plotted in Figure 4.3-22 and is a good indication of when the conditions are shifted between staged and unstaged combustion. The normalized radiation intensity measurement for furnace sections 1 and 3 are also presented.

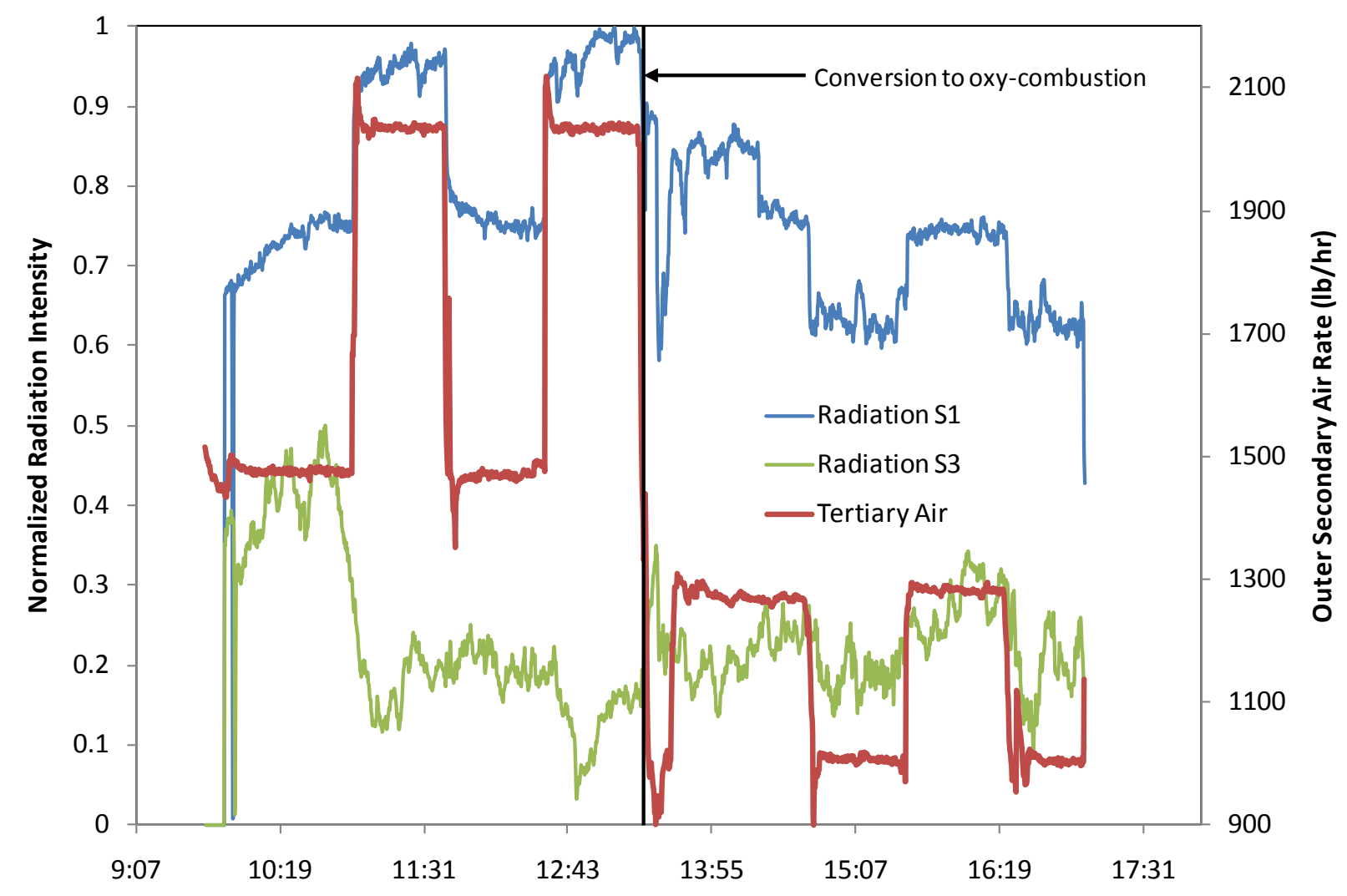

Figure 4.3-22. Raw radiation intensity data collected during staging experiments for air and oxyfired conditions.

Figure 4.3-22 indicates that the response of the radiation measured in furnace section 1 (S1) is tightly coupled with the burner stoichiometric ratio. However the radiation measured in furnace section 3 (S3) is impacted by staging less and is less steady through constant conditions. The relative change in radiation from air- to oxy-fired conditions is also represented in these data. 
The data supplied by NETL ORD was analyzed in a manner similar to the corrosion data collected on this project that has been previously reported. The behavior of the pilot-scale furnace was analyzed over the entire test program for periods when the furnace was operating at a steady state, representative of the desired set point conditions. The radiation data for these periods were averaged and cataloged according to the combustion conditions. Time weighted averages of the cataloged radiation data were produced for all radiation data belonging to the same combustion condition. These reduced data will be presented and compared for conditions of interest in the remainder of this section.

The averaged and normalized radiation intensity for air- and oxy-combustion conditions are compared in Figure 4.3-23. Both the air- and oxy-combustion conditions were produced while firing the Utah Skyline coal with a BSR of 0.9 . The oxy-combustion condition also includes $27 \% \mathrm{O}_{2}$ in the overall mixture of $\mathrm{O}_{2}$ and FGR.

Figure 4.3-23 shows a marked decrease in radiation intensity when converting from air- to oxy-firing with the given conditions. The relative decrease in measured radiation intensity moving from air to oxy-firing for sections 1, 2 and 3, respectively, was $25.4 \%, 10.4 \%$ and $17.8 \%$.

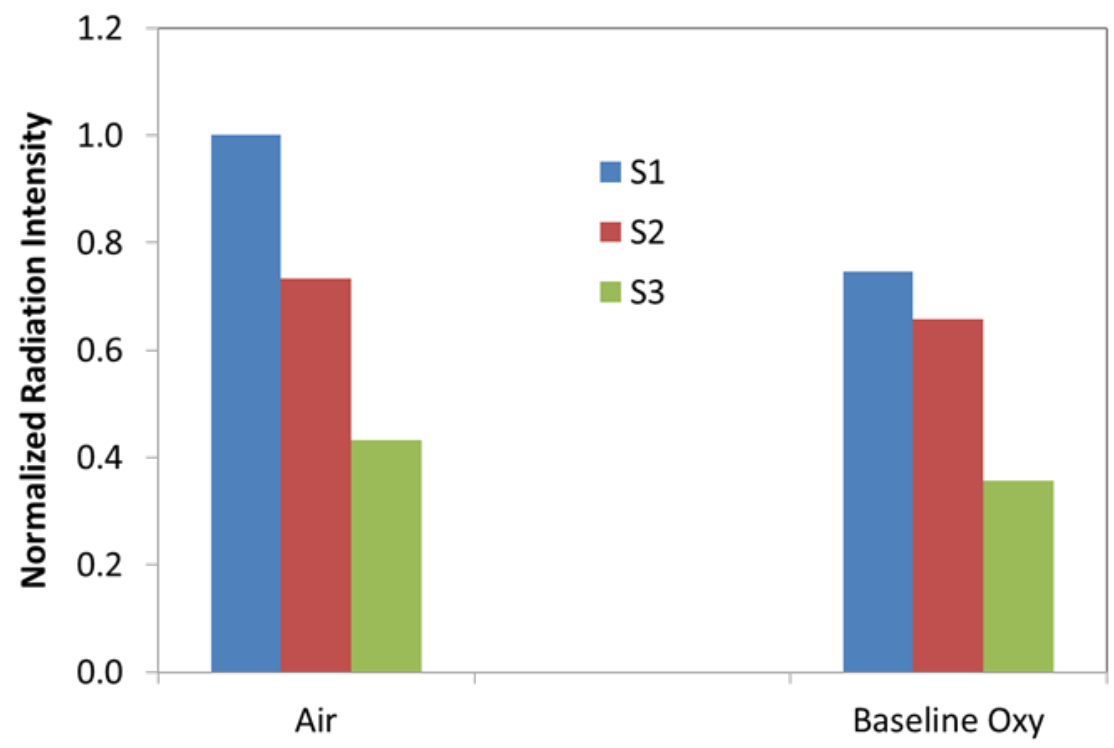

Figure 4.3-23. Comparison of the averaged and normalized radiation intensity for air-combustion, oxy-combustion while firing Utah Coal at a BSR of 0.9 .

Radiation from the hot refractory furnace walls contribute, along with the flame, to the measured radiation intensity. The amount that the walls contribute to the measurement was estimated by averaging the measured radiation for a one minute period after an oxy-skyline flame was extinguished and comparing this to the measured radiation for a one minute period prior to extinguishing the flame. The data are presented in this way in Figure 4.3-24. 


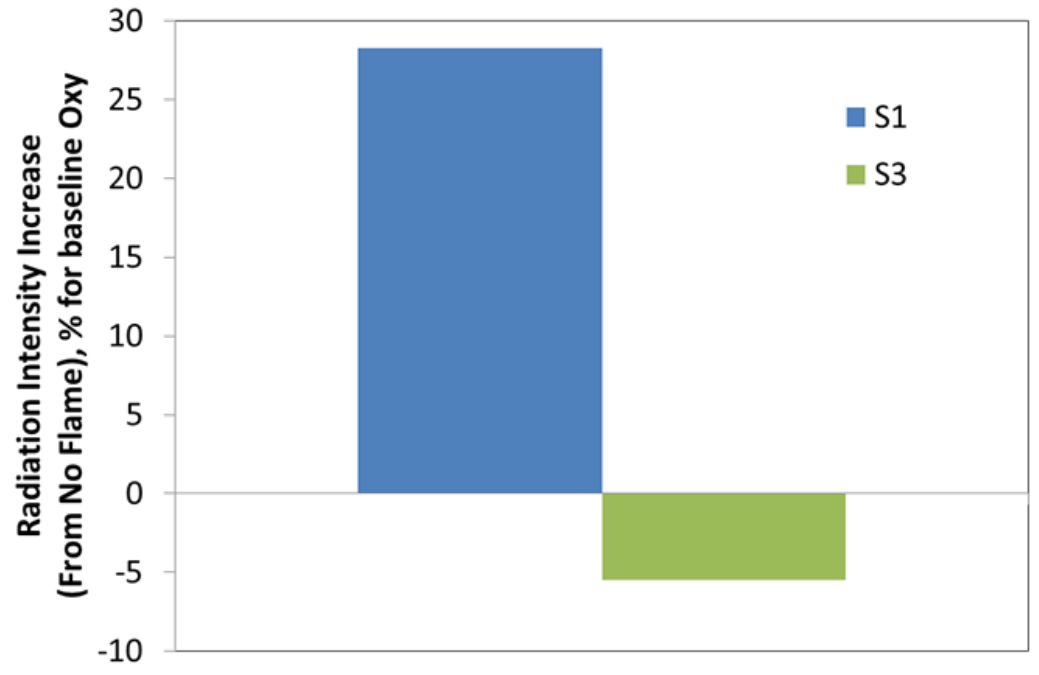

Figure 4.3-24. Increase in radiation intensity from the no flame condition for baseline oxycombustion.

Figure 4.3-24 shows that extinguishing the flame has a significant impact on the radiation measurement at S1 but not at S3. For these conditions the measured average wall temperature was similar for the air- and oxy-fired data shown elsewhere in this report, so this result should be applicable to all the data presented. A short 1 minute interval around the flame extinguishing was chosen so that wall cooling would not impact the data. The insignificant change at S3 indicates that either the background wall radiation is overwhelming the flame radiation at S3, or the flame is compact and not reaching the S3 port during this event.

The data presented in Figure 4.3-22 detailing staged and unstaged firing of Illinois coal were averaged and normalized for each period of discrete firing conditions. These averaged data are presented in Figure 4.3-25 which detail the behavior of staged and unstaged flames for both air and oxy-fired conditions with Illinois coal.

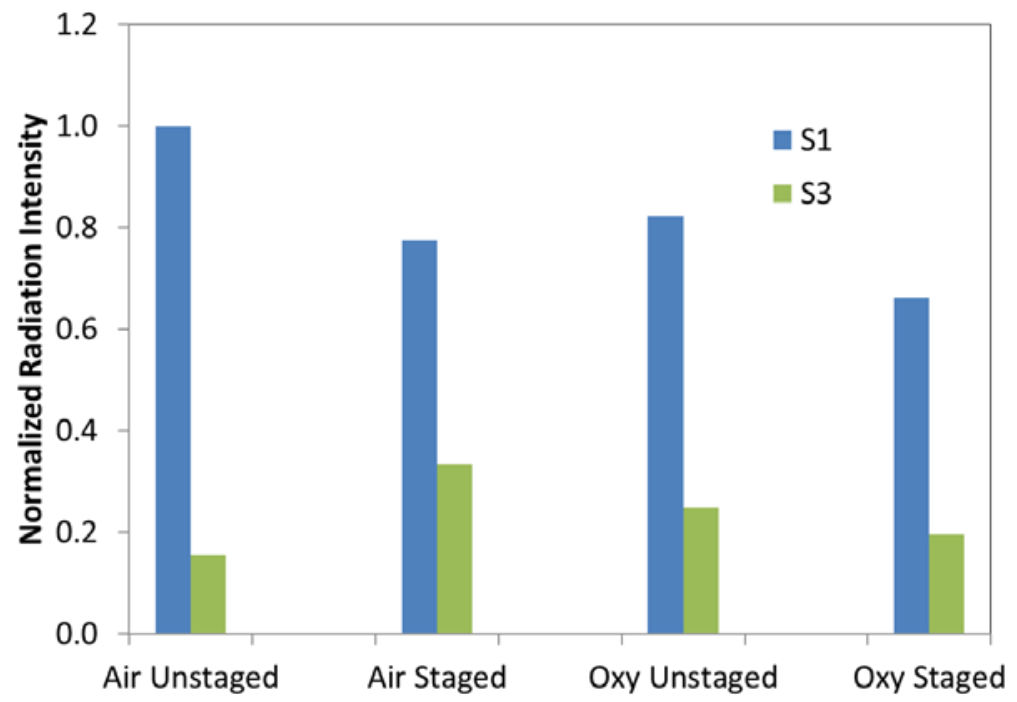

Figure 4.3-25. Comparison between averaged and normalized radiation intensity for the staged and unstaged conditions presented in Figure 4.3-22 while firing Illinois coal. 
The air-fired data in Figure 4.3-25 show that as the furnace is staged, the intensity of the flame in section one decreases and the intensity in section three increases. This behavior is consistent with expectations that under staged conditions the flame will tend to be longer. While oxy-firing, the flame intensity in section one behaves similarly to air-fired conditions, where the intensity reduces with staging. The relative intensities measured in section one for the air- and for the oxy-fired conditions are consistent with the behavior presented in Figure 4.3-23, with generally lower intensity for the oxy-fired condition.

In previous reports, flame images were presented for various strategies of oxygen injection while oxyfiring Utah bituminous (Skyline) coal. These images suggested that oxygen injection provided the most benefit for flame stabilization when introduced on the boundary between the inner secondary and primary gas streams. The images also suggested that there was little influence on the flame when the oxygen was injected into the primary gas stream in an axial direction and the primary radial injection condition resulted in a bushier, more radially dispersed flame, but was not beneficial for flame attachment. These conclusions were based upon images that revealed the behavior of only a fraction of the flame. Radiation measurements taken during this testing provide another layer of understanding to these test conditions. Averaged and normalized radiation intensity data are presented for the baseline oxy-combustion condition and for the three oxygen injection cases in Figure 4.3-26.

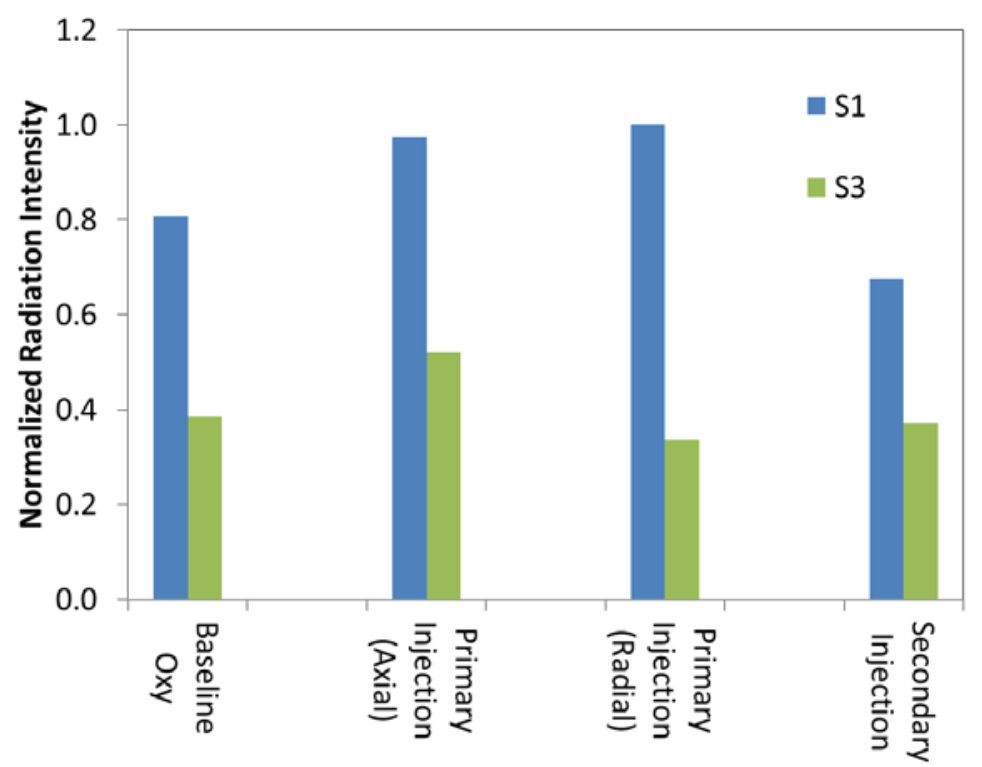

Figure 4.3-26. Averaged and normalized radiation intensity data collected during oxygen injection experiments.

Figure 4.3-26 shows that the most intensely radiating flame is provided by conditions where the oxygen is injected axially in the primary. The likely reason that the primary injection provides a more intense flame is because the oxygen concentration is ultimately much higher in the region of dense fuel. That result was not apparent in the flame images because mixing of the oxygen and coal occurs downstream of the camera field of view described in Figure 4.3-21. The least intensely radiating flame occurs when the oxygen is introduced on the boundary of the inner secondary and primary gas streams. This may occur because the oxygen is more removed from the fuel and as it mixes with the fuel and internally recirculated flue gas, which could reduce the local adiabatic flame temperature. 
Simply stated, injection of oxygen on the boundary of the primary and secondary can strongly attach a flame by putting additional oxygen in the location where ignition of the fuel occurs, and injection of oxygen within the primary will significantly increase the luminosity of the flame.

It is also noteworthy that the luminosity profile of the Baseline Oxy condition in Figure 4.3-26 is nearly identical to that of the Oxy condition in Figure 4.3-23. These data sets were collected at different periods in the testing with only slightly different primary velocities. The difference in magnitude between the two data sets is due to the different basis of normalization.

\subsubsection{Radiation Intensity Summary}

Data describing radiation behavior of air- and oxy-coal flames have been collected by NETL personnel in University of Utah's pilot-scale furnace (L1500) while firing Utah Skyline and Illinois Shea bituminous coals. These data have been reduced and compared for conditions of interest and have provided valuable insight into the behavior of oxy-coal flames.

A comparison was made between the radiation intensity from air- and oxy-coal flames while firing Utah Skyline fuel. The oxy-fired conditions for this comparison where chosen to provide matched radiative heat transfer with the air-fired condition, which was expected to occur with an overall $\mathrm{O}_{2}$ concentration of $27 \%$ in the $\mathrm{O}_{2} /$ FGR mixture. These data indicate that the radiation is lower for the oxy-fired condition by $25.4 \%, 10.4 \%$ and $17.8 \%$ for furnace sections 1 through 3 respectively.

Under air-fired conditions, staging the flame shifts radiation intensity from section one to section three, while under oxy-fired conditions, staging the flame generally reduces the flame intensity.

Radial injection of oxygen into the primary stream of the burner produces a more intensely radiating flame than baseline oxy-fired conditions while injection of oxygen on the boundary of the primary and secondary gas streams results in less radiation intensity (but a well-attached flame). When combined with previously reported results these results suggest:

- Injection of oxygen on the boundary of the primary and secondary can strongly attach a flame by putting additional oxygen in the location where ignition of the fuel occurs;

- Injection of oxygen within the primary will increase the radiative intensity of the flame.

\subsubsection{Parametric Burner Test Conclusions}

Prior to these tests the burner register plenums were inspected for deposits of recycled particulates and signs of oxidation of the carbon steel surfaces. There were only slight traces of fine particulate on the inside surfaces of the plenums and there were no signs of oxidation or damage from the high $\mathrm{O}_{2}$ concentrations used on this program.

The swirl vane assembly in the outer secondary register was shown to be mostly ineffective at inducing tangential velocity in previous burner parametric testing. Prior to these experiments the assembly was modified, increasing the length of the vanes and modifying the geometry to limit axial flow. The modified swirl assembly demonstrated a strong influence on shape of the coal carrying gases in the near burner region. The limit of inner/outer secondary mass splits that would produce an attached flame was increased from 20/80 to 40/60. The modification had no impact on maximum gas velocity that would produce an attached flame.

Tests were performed where $\mathrm{O}_{2}$ enriching the primary, under oxy-fired conditions, was removed and introduced instead through one of three oxygen injection lance configurations near the burner face. $\mathrm{O}_{2}$ 
was injected axially through the bluff body, radially through the bluff body and through nozzles in the inner secondary, near the boundary between the inner secondary and primary. These tests were performed at conditions where the flame was oscillating between attached and detached so as to give a strong indication of the effectiveness of the injection strategy. Axial injection of $\mathrm{O}_{2}$ through the bluff body resulted in a permanently detached flame. Radial injection through the bluff body distributed the coal widely as it exited the burner quarl and increased the luminosity of the flame but did not result in an attached flame. Injection through the inner secondary nozzles strongly attached the flame. These results indicate that oxygen injection on the boundary between the inner secondary and primary registers is most effective for flame ignition and stabilization. This is likely due to high mixing in this region due to shear between the layers of gases at different velocities. Ensuring oxygen arrives at this region is likely more important than the location from where the oxygen is introduced.

Experiments were performed to test $\mathrm{O}_{2}$ injection into the primary for flame stabilization. For these tests the burner was operated at conditions where the flame was flickering between attached and detached and the premixed primary $\mathrm{O}_{2}$ concentration was 21\%. $\mathrm{O}_{2}$ was injected radially through the bluff body at three different mass flow rates to further enrich the primary in oxygen. These tests showed no difference in flame stability and attachment. This result further reinforced that oxygen injection should be performed in such a way that the boundary between the inner secondary and primary is targeted.

The furnace exit $\mathrm{NO}_{\mathrm{x}}$ concentration and the $\mathrm{NO}_{\mathrm{x}}$ emission were plotted for all conditions tested on this program, including three coals and air and oxy-fired conditions. These plots indicate that at burner stoichiometric ratios below one, furnace $\mathrm{NO}_{\mathrm{x}}$ concentrations are similar for air and oxy-fired conditions. At BSRs greater than one, $\mathrm{NO}_{\mathrm{x}}$ concentrations are much higher for oxy-fired conditions. These data indicate that recycled $\mathrm{NO}_{\mathrm{x}}$ is effectively burned under substoichiometric conditions. $\mathrm{NO}_{\mathrm{x}}$ emissions are much lower for oxy-combustion because of the low volume of emitted.

A comparison was made between the radiation intensity from air- and oxy-coal flames while firing Utah Skyline fuel. Data indicate that the radiation is lower for the oxy-fired condition by $25.4 \%, 10.4 \%$ and $17.8 \%$ for furnace sections 1 through 3 respectively. Under air-fired conditions, staging the flame shifts radiation intensity from section one to section three, while under oxy-fired conditions, staging the flame generally reduces the flame intensity.

Radial injection of oxygen into the primary stream of the burner produces a more intensely radiating flame than baseline oxy-fired conditions while injection of oxygen on the boundary of the primary and secondary gas streams results in less radiation intensity (but a well-attached flame). These results support previous flame observations that: 1 ) injection of oxygen on the boundary of the primary and secondary can strongly attach a flame by putting additional oxygen in the location where ignition of the fuel occurs, 2) injection of oxygen within the primary will increase the radiative intensity of the flame. 


\subsection{December 2009 Metals Emissions Testing}

\subsubsection{Introduction}

This section summarizes metals emission testing conducted under air and oxy-fired conditions that occurred from December 3, 2009 to December 22, 2009 at the University of Utah's Industrial Combustion and Gasification Research Facility. Metals measurements were taken from two furnaces: L1500 multi-fuel furnace, and 100KW Oxy-Fuel Combustor (OFC). The oxy-combustion conditions were run with 27 vol\% $\mathrm{O}_{2}$ (wet) in the $\mathrm{O}_{2} /$ FGR mixture.

\subsubsection{Experimental Setup}

Combustion gases and ash and coal samples from these tests were used to perform a trace metals material balance. REI engineers collected samples of the gas-phase trace metals on Method 30B activated carbon traps for both air and oxy-fired conditions. The flue gas was removed from the duct using an Apogee QSIS inertial separation probe. Carbon traps were connected to the outlet of this probe. During sampling, the carbon traps and sample probe were temperature-controlled to conditions recommended by the carbon trap manufacturer $\left(100^{\circ} \mathrm{C}\right)$.

Gas-phase trace metals concentrations were determined by collecting samples on Ohio Lumex, 3-section, Method 30B traps. These were analyzed for mercury, arsenic and selenium by SGS labs using a digestion method, with the exception of the traps taken on the OFC which were analyzed only for mercury by Ohio Lumex. Samples used for gas-phase mercury speciation measurements (L1500 only) were collected using the Ohio Lumex, 5-section, speciating mercury traps, which were analyzed by Ohio Lumex. Each of these measurements was performed three times at each location and condition described previously using the recommended dual traps for each sample. Measurement in triplicate provides statistical confidence in the results.

Coal and in-flight ash samples were collected twice during each of the air and oxy-fired conditions on the L1500 and once during each of the air and oxy conditions on the OFC. Additional hopper ash samples were taken on the L1500 for comparison. These solid samples were analyzed for mercury (analyses performed by SGS labs and Ohio Lumex) as well as arsenic and selenium (analyses performed by SGS labs and Brooks Rand labs).

Two samples of the flue gas were collected at the probe location for each of the air and oxy-fired conditions in Tedlar sample bags after the water had been condensed out in a chiller. They were analyzed by Empact Analytical for the following species: $\mathrm{N}_{2}, \mathrm{CO}_{2}, \mathrm{O}_{2}, \mathrm{CO}$, He, Methane, Ethane, Propane, IButane, I-Pentane and C6+. Empact Analytical performed these analyses using gas chromatography with both a thermal conductivity and a flame ionization detector. In their analysis, Empact also identified peaks that may represent other major species.

\subsubsection{Measurements}

Mercury measurements were performed by REI personnel at each of the two furnaces using Ohio-Lumex carbon traps. The Method 30B sampling equipment at the stack was provided by CleanAir Engineering. An Apogee QSIS inertial separation probe was used to pull sample flue gas from the high-dust environment in the duct. Two sample streams were taken from the probe and passed into a temperature controlled box $\left(100^{\circ} \mathrm{C}\right)$ containing the carbon traps. On the OFC, mercury sampling was performed in the back-end ductwork ahead of the baghouse. The mercury sampling location for the L-1500 testing was located after the heat exchangers and before the baghouse. The temperature of the flue gas at the sampling locations is shown in Table 4.4-1. The sample temperatures were higher during oxy-firing for the OFC whereas the L1500 exhibited the opposite trend. Three sets of samples were taken at each 
condition. On the L1500, one sample set consisted of two parallel 30B carbon traps with a sample time of 30 minutes followed by two parallel mercury speciation traps with a sample time of one hour. For the OFC, one sample set consisted of two parallel 30B carbon traps with a sample time of 30 minutes. The 30B carbon traps taken on the L1500 were analyzed for total arsenic, selenium and mercury by SGS labs using digestion methods. The mercury speciation traps from the L1500 along with the 30B carbon traps from the OFC were analyzed for mercury by Ohio Lumex using their RA 915+ analyzer coupled with the RP-91C pyrolysis furnace.

Table 4.4-1: Flue Gas Temperature at Sampling Locations.

\begin{tabular}{llc}
\hline \hline Furnace & Conditions & Sampling Temperature $\left({ }^{\circ} \mathrm{F}\right)$ \\
\hline L1500 & Air-fired & 423 \\
L1500 & Oxy-fired & 404 \\
OFC & Air-fired & 350 \\
OFC & Oxy-fired & 380 \\
\hline \hline
\end{tabular}

During testing on the L1500, coal and in-flight ash samples were also taken between each sample set. The coal and ash samples taken from the L1500 were analyzed for arsenic, selenium and mercury by SGS labs. The coal and fly ash samples were further analyzed for Hg by Ohio Lumex and for As and Se by Brooks Rand labs. Additionally, one hopper ash sample was taken from the L1500. This was also analyzed for all three metals by SGS labs. During testing on the OFC, coal and ash samples were taken once during each condition. The coal and ash samples from the OFC were analyzed for mercury by Ohio Lumex.

Flue gas samples were taken between sample sets using 20L Tedlar bags. These samples were collected after the water had been removed from the gas in a chiller. They were analyzed by Empact Analytical for the following species: $\mathrm{N}_{2}, \mathrm{CO}_{2}, \mathrm{O}_{2}, \mathrm{CO}$, He, Methane, Ethane, Propane, I-Butane, I-Pentane and C6+. Empact Analytical performed these analyses using gas chromatography with both a thermal conductivity and a flame ionization detector. In their analysis, Empact also identified peaks that may represent other major species.

\subsubsection{Results and Discussion}

\subsubsection{Coal Analyses}

The ultimate, proximate, and ash composition analyses of the Utah bituminous coal burned during testing is shown in Table 4.4-2. Coal samples were analyzed for arsenic, selenium and mercury. Results are shown in Table 4.4-3. Of the eight coal samples sent to SGS (from the L1500), all but one sample were below the arsenic detection limit, only one sample was below the selenium detection limit, and four samples were below the mercury detection limit. To better quantify the metals concentration in the coal samples, all eight samples were further analyzed for Hg by Ohio Lumex and for As and Se by Brooks Rand labs. Both Ohio Lumex and Brooks Rand had lower detection limits. 
Table 4.4-2: Ultimate, Proximate and Ash Composition Analyses of Utah Bituminous Coal Burned During Testing.

\begin{tabular}{|c|c|}
\hline Moisture (\%) & 3.18 \\
\hline Ash (\%) & 8.83 \\
\hline C (\%) & 70.60 \\
\hline H (\%) & 5.06 \\
\hline N (\%) & 1.42 \\
\hline S (\%) & 0.53 \\
\hline O (\%) & 10.38 \\
\hline Volatile (\%) & 38.60 \\
\hline Fixed C (\%) & 49.39 \\
\hline HHV (Btu/lb) & 12606 \\
\hline \multicolumn{2}{|c|}{ Ash Composition (\%) } \\
\hline $\mathrm{Al}$ as $\mathrm{Al}_{2} \mathrm{O}_{3}$ & 14.52 \\
\hline $\mathrm{Ca}$ as $\mathrm{CaO}$ & 6.11 \\
\hline $\mathrm{Fe}$ as $\mathrm{Fe}_{2} \mathrm{O}_{3}$ & 5.09 \\
\hline $\mathrm{Mg}$ as $\mathrm{MgO}$ & 1.39 \\
\hline $\mathrm{Mn}$ as $\mathrm{MnO}$ & 0.02 \\
\hline $\mathrm{P}$ as $\mathrm{P}_{2} \mathrm{O}_{5}$ & 0.59 \\
\hline $\mathrm{K}$ as $\mathrm{K}_{2} \mathrm{O}$ & 0.57 \\
\hline $\mathrm{Si}$ as $\mathrm{SiO}_{2}$ & 60.89 \\
\hline $\mathrm{Na}$ as $\mathrm{Na}_{2} \mathrm{O}$ & 1.41 \\
\hline $\mathrm{S}$ as $\mathrm{SO}_{3}$ & 2.33 \\
\hline $\mathrm{Ti}$ as $\mathrm{TiO}_{2}$ & 0.88 \\
\hline
\end{tabular}

In cases where SGS measured Hg above the detection limit, their results do not agree with the Ohio Lumex analyses. This suggests the digestion method employed by SGS to measure mercury was not appropriate for these low level samples. Both coal samples from the OFC were sent to Ohio Lumex for $\mathrm{Hg}$ analysis only. The average coal $\mathrm{Hg}$ content measured by Ohio Lumex was $0.010 \pm 0.005 \mu \mathrm{g} / \mathrm{g} \mathrm{AR}$.

In cases where SGS measured As or Se above the detection limit, these measurements are similar to the Brooks Rand measurements. The average coal As content measured by Brooks Rand Labs was 1.1 \pm 0.7 $\mu \mathrm{g} / \mathrm{g}$ AR and the average Se content measured by Brooks Rand Labs was $1.4 \pm 0.2 \mu \mathrm{g} / \mathrm{g}$ AR. 
Table 4.4-3: Trace Metal Analyses of Coal.

\begin{tabular}{|c|c|c|c|c|c|c|c|c|}
\hline \multirow[b]{2}{*}{ Date/Time } & \multirow[b]{2}{*}{ Furnace } & \multirow[b]{2}{*}{ Condition } & \multicolumn{3}{|c|}{ SGS } & \multicolumn{2}{|c|}{ Brooks Rand } & \multirow{2}{*}{$\begin{array}{c}\text { Ohio } \\
\text { Lumex } \\
\mathbf{H g} \\
\boldsymbol{\mu g} / \mathbf{g} \\
\mathbf{A R} \\
\end{array}$} \\
\hline & & & $\begin{array}{c}\text { As } \\
\mu \mathrm{g} / \mathrm{g} \\
\mathrm{AR}\end{array}$ & $\begin{array}{c}\text { Se } \\
\mu g / g \\
\text { AR } \\
\end{array}$ & $\begin{array}{c}\mathbf{H g} \\
\mu \mathrm{g} / \mathrm{g} \\
\mathrm{AR} \\
\end{array}$ & $\begin{array}{c}\text { As } \\
\mu \mathrm{g} / \mathrm{g} \\
\mathrm{AR} \\
\end{array}$ & $\begin{array}{c}\text { Se } \\
\mu \mathrm{g} / \mathrm{g} \\
\mathrm{AR} \\
\end{array}$ & \\
\hline 12/17/09 13:10 & L1500 & Air & $<1$ & 2 & 0.019 & 1.8 & 1.2 & 0.0055 \\
\hline 12/17/09 16:55 & L1500 & Air & $<1$ & 2 & 0.019 & 1.1 & 1.8 & 0.0058 \\
\hline 12/18/09 11:35 & L1500 & Oxy & 2 & 2 & $<0.019$ & 1.4 & 1.4 & 0.0147 \\
\hline 12/18/09 14:40 & L1500 & Oxy & $<4$ & $<4$ & $<0.019$ & 2.4 & 1.4 & 0.0116 \\
\hline 12/22/09 12:00 & OFC & Air & & & & & & 0.0177 \\
\hline 12/22/09 13:53 & OFC & Oxy & & & & & & 0.0178 \\
\hline
\end{tabular}

\subsubsection{Ash Analyses}

Like the metals analyses for the coal, many ash samples were below SGS detection limits for arsenic, selenium and mercury. The ash samples from the L1500 were analyzed by SGS labs for arsenic, selenium and mercury, by Ohio Lumex for $\mathrm{Hg}$, and by Brooks Rand for arsenic and selenium. The ash samples from the OFC were analyzed by Ohio Lumex for mercury only. Results from the ash analyses are shown in Table 4.4-4. For cases where SGS measured Hg, As or Se above the detection limit, their measurements agree with those of Ohio Lumex or Brooks Rand Labs.

One hopper ash sample from the L1500 was taken in addition to the in-flight ash samples. These samples were taken for comparison purposes only and are not used in mass balance calculations. Depending on the location of flue gas sampling, the ash samples taken from the baghouse hoppers may not be representative of metals capture by ash at the point where flue gas was sampled. The L1500 hopper ash contained significantly more arsenic, selenium and mercury compared to the in-flight ash samples (airfired conditions), because the flue gas sampling location was upstream of the baghouse. Additional mercury, arsenic and selenium may be captured on the cake which builds up on the filter bags. This additional metal content would have been double measured, first in the flue gas upstream of the baghouse and then again in the baghouse ash. Due to the uncertainties associated with the baghouse hopper ash samples, only in-flight ash samples were used for mass balance calculations. It is also interesting to note that arsenic capture by fly ash increased during oxy-firing of the L1500 with flue gas recycle.

Table 4.4-4: Trace Metal Analyses of Fly Ash.

\begin{tabular}{|c|c|c|c|c|c|c|c|c|}
\hline \multirow[b]{2}{*}{ Date/Time } & \multirow[b]{2}{*}{ Furnace } & \multirow[b]{2}{*}{ Condition } & \multicolumn{3}{|c|}{ SGS } & \multicolumn{2}{|c|}{ Brooks Rand } & \multirow{2}{*}{$\begin{array}{c}\text { Ohio } \\
\text { Lumex } \\
\mathbf{H g} \\
\boldsymbol{\mu g} / \mathbf{g} \\
\text { dry }\end{array}$} \\
\hline & & & $\begin{array}{c}\text { As } \\
\mu \mathrm{g} / \mathrm{g} \\
\text { dry }\end{array}$ & $\begin{array}{c}\text { Se } \\
\mu \mathrm{g} / \mathrm{g} \\
\mathrm{dry}\end{array}$ & $\begin{array}{c}\text { Hg } \\
\mu \mathrm{g} / \mathrm{g} \\
\text { dry }\end{array}$ & $\begin{array}{c}\text { As } \\
\mu \mathrm{g} / \mathrm{g} \\
\text { dry }\end{array}$ & $\begin{array}{c}\text { Se } \\
\mu \mathrm{g} / \mathrm{g} \\
\mathrm{dry}\end{array}$ & \\
\hline 12/17/09 13:10 & L1500 Hopper & Air & 31 & 14 & 0.21 & & & \\
\hline 12/17/09 14:05 & L1500 & Air & 10 & 6 & 0.06 & 7.5 & 6.5 & 0.0553 \\
\hline 12/17/09 16:30 & L1500 & Air & 11 & $<4$ & $<0.02$ & 8.4 & 3.6 & 0.0123 \\
\hline 12/18/09 11:35 & L1500 & Oxy & 34 & 5 & 0.04 & 28.7 & 5.7 & 0.0363 \\
\hline 12/18/09 14:15 & L1500 & Oxy & 40 & $<4$ & $<0.02$ & 35.6 & 3.8 & 0.0140 \\
\hline 12/22/09 11:45 & OFC & Air & & & & & & 0.1660 \\
\hline 12/22/09 14:10 & OFC & Oxy & & & & & & 0.1430 \\
\hline
\end{tabular}




\subsubsection{Gas Phase Metals Measurements}

Mercury, arsenic, and selenium concentrations in the flue gas were measured using method 30B carbon traps. Speciated mercury measurements were taken using 5-section mercury speciation traps. The 30B carbon traps from the L1500 were analyzed by SGS labs for total arsenic, selenium and mercury. The 30B carbon traps from the OFC and the speciating mercury traps (L1500 only) were analyzed for mercury by Ohio Lumex. The 30B carbon traps contained an average of $0.83 \mathrm{~g}$ of carbon. Of the 24 carbon traps sent to SGS, all traps were below the detection limit for arsenic and selenium $(<1 \mu \mathrm{g} / \mathrm{g}$ carbon $=<80$ $\mu \mathrm{g} / \mathrm{dscm}$ flue gas @ 3\% $\left.\mathrm{O}_{2}\right)$ while all but one trap were below the detection limit for mercury $(<0.02 \mu \mathrm{g} / \mathrm{g}$ carbon $=<1.6 \mu \mathrm{g} / \mathrm{dscm}$ flue gas @ 3\% $\mathrm{O}_{2}$ ). Due to the small mass of carbon in the traps available for testing, these traps could not be sent to another lab for further analysis as the coal and ash samples were. Therefore, the 30B carbon traps cannot be used for mass balance calculations. As these traps consisted of all the gas-phase arsenic and selenium measurements, a mass balance on arsenic or selenium was not possible. However, the coal and ash measurements may be used to infer gas-phase concentrations.

The 30B carbon traps from the OFC and the speciating mercury traps from the L1500 were sent to Ohio Lumex for analysis. These traps are made by Ohio Lumex for mercury measurements and their analysis system is designed to analyze these traps for mercury. Hence, their detection limits for mercury are significantly lower. Results were obtained for all traps (Table 4.4-5). A mass balance on mercury may be obtained using these traps analyzed by Ohio Lumex.

The emissions were higher for oxy-firing of the L1500 versus air-firing: $1.78 \pm 0.16 \mu \mathrm{g} / \mathrm{dscm} @ 3 \% \mathrm{O}_{2}$ and $0.69 \pm 0.15 \mu \mathrm{g} / \mathrm{dscm} @ 3 \% \mathrm{O}_{2}$, respectively. However, the oxy-fired conditions in the L1500 where expected to yield much higher than measured gas-phase mercury concentrations due to low dilution of the combustion products while using flue gas recycle. During air-firing of the OFC, emissions were slightly higher $\left(0.95 \pm 0.03 \mu \mathrm{g} / \mathrm{dscm} @ 3 \% \mathrm{O}_{2}\right)$ than during oxy-firing $\left(0.80 \pm 0.15 \mu \mathrm{g} / \mathrm{dscm} @ 3 \% \mathrm{O}_{2}\right)$. For the OFC, the ranges of emission for air and oxy conditions overlap with the consideration of one standard deviation.

The average flue gas mercury speciation during air-firing of the L1500 was $55 \pm 7 \%$ oxidized and the average during oxy-firing was $59 \pm 6 \%$ oxidized. Either air- or oxy-firing made no significant difference in the mercury speciation.

Table 4.4-5: Trap Results from Ohio Lumex.

\begin{tabular}{|c|c|c|c|c|c|}
\hline Furnace & Condition & Trap Type & $\begin{array}{c}\text { Hg }^{\mathrm{T}} \\
\left(\mu \mathrm{g} / \mathrm{dscm} @ 3 \% \mathrm{O}_{2}\right)\end{array}$ & $\begin{array}{c}\mathrm{Hg}^{2+} \\
\left(\mu \mathrm{g} / \mathrm{dscm} @ 3 \% \mathrm{O}_{2}\right)\end{array}$ & \% Oxidized \\
\hline L1500 & Air & Speciation & 0.53 & 0.29 & $56 \%$ \\
\hline L1500 & Air & Speciation & 0.73 & 0.35 & $47 \%$ \\
\hline L1500 & Air & Speciation & 0.83 & 0.51 & $61 \%$ \\
\hline L1500 & Oxy & Speciation & 1.70 & 0.95 & $56 \%$ \\
\hline L1500 & Oxy & Speciation & 1.96 & 1.08 & $55 \%$ \\
\hline L1500 & Oxy & Speciation & 1.67 & 1.10 & $66 \%$ \\
\hline OFC & Air & 30B & 0.96 & & \\
\hline OFC & Air & $30 \mathrm{~B}$ & 0.93 & & \\
\hline OFC & Air & $30 \mathrm{~B}$ & 0.98 & & \\
\hline OFC & Oxy & $30 \mathrm{~B}$ & 0.74 & & \\
\hline OFC & Oxy & $30 \mathrm{~B}$ & 0.69 & & \\
\hline OFC & Oxy & $30 \mathrm{~B}$ & 0.98 & & \\
\hline
\end{tabular}




\subsubsection{Mass Balance}

Mass balance closure is defined as the total mercury in outlet streams (flue gas and ash) divided by the mercury input from coal. A mass balance closure for mercury between $80 \%$ and $120 \%$ is generally considered acceptable. Mass balance calculations were only possible for mercury using speciated gas phase measurements taken from the L1500 and total gas phase measurements taken from the OFC. All arsenic and selenium gas phase measurements were below detection limits. Good mass balance results give confidence in the measurements, which is important considering the extremely low metal levels measured in the coal, ash and the gas phase.

A mercury mass balance was calculated for the L1500 and OFC. Ash carryover was assumed to be 37\% for the L1500 and 88\% for the OFC for both air-fired and oxy-fired conditions. The ash carryover is lower for the L1500 due to ash dropout in the furnace before the baghouse (low velocities). Mass balance closure for two furnaces is shown in Figure 4.4-1. The three columns represent the three gas phase measurements and the solid black line represents the average.

For the L1500, closure ranged from $21 \%$ to $106 \%$ with an average of $61 \pm 43 \%$. Under air conditions, mass balance closure averaged $100 \pm 6 \%$ and under oxy-conditions $22 \pm 1 \%$. While excellent mass balance closure was achieved on the L1500 during air-firing, a mass balance could not be closed during oxyfiring. This is likely due to flue gas recycle. The L1500-oxy case was the only case in which flue gas recycle was employed. It is suspected that mercury may be depositing somewhere in the recycle path, thus creating a low bias on the outlet mercury measurements. Because a mass balance could not be closed for the L1500-oxy case, these measurements are not reliable and removal calculations are suspect.

For the OFC, the mercury mass balance closure ranged from $83 \%$ to $113 \%$ with an average value of $99 \pm 15 \%$. The average mass balance closure during air-firing was $112 \pm 1 \%$ and the average during oxyfiring was $86 \pm 4 \%$. The mass balance closure fell between the acceptable limits of $80 \%$ and $120 \%$ for all OFC tests. 


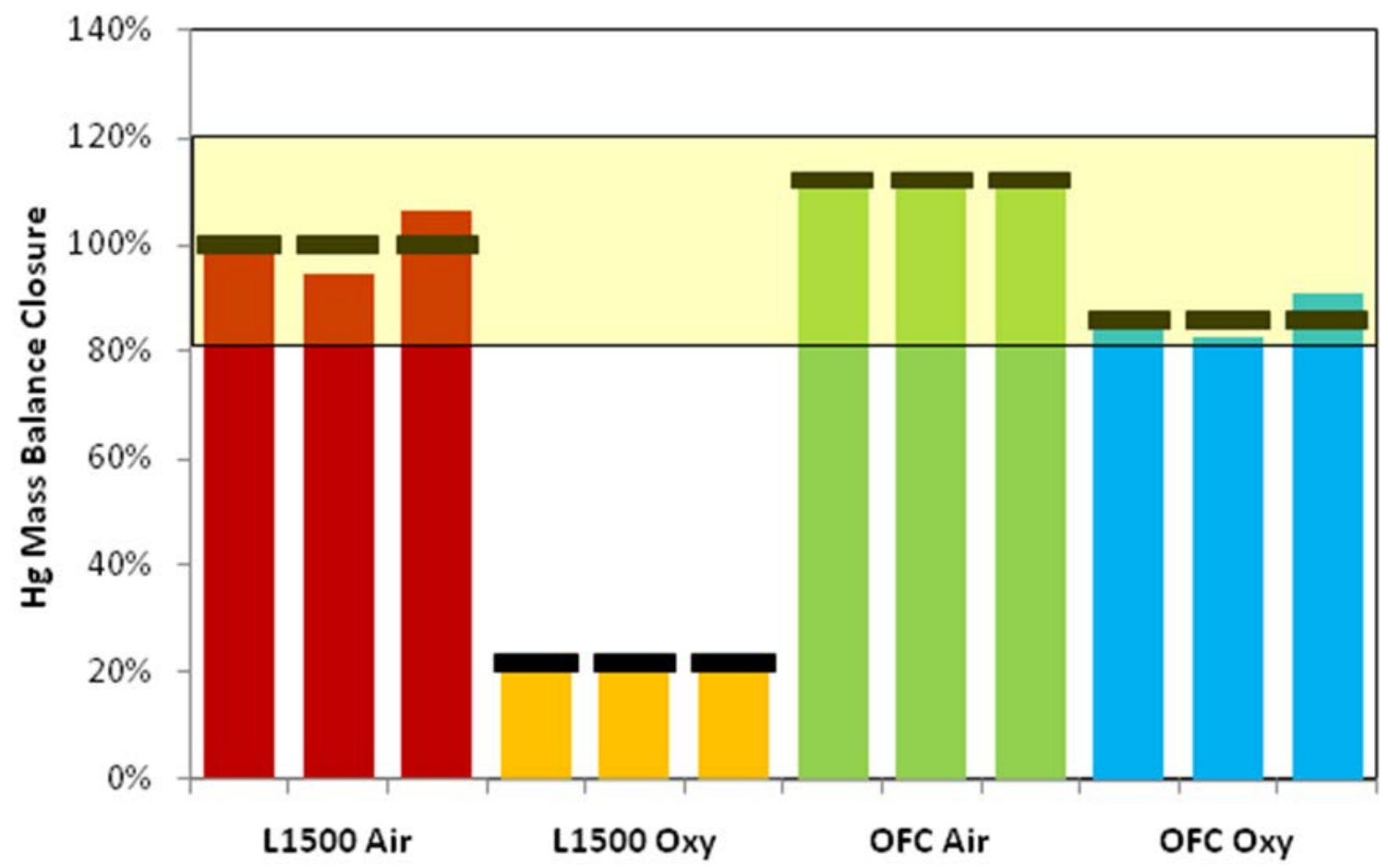

Figure 4.4-1: Mercury mass balance closure.

\subsubsection{Metals Capture}

Metals capture is defined as either one minus the gas phase metal rate divided by the coal metal rate or the ash metal rate divided by the coal metal rate. The first definition may only be used in cases where the gas phase concentration was measureable (mercury concentration in the L1500 measured by speciating trap or mercury concentration in the OFC measured by 30B trap). For all arsenic and selenium cases, the second removal definition must be used.

Figure 4.4-2 illustrates the mercury removal using gas phase measurements. The three columns represent the three gas phase measurements and the solid black line represents the average. The air- or oxy-fired conditions do not seem to have a large impact on mercury removal, except in the case of the L1500. However, the L1500-oxy results are not reliable due to the poor mass balance closure. For the L1500, airfiring gave $16 \pm 17 \%$ removal and oxy-firing gave $84 \pm 3 \%$ removal. Air-firing the OFC yielded $61 \pm 1 \%$ removal and oxy-firing yielded $77 \pm 4 \%$ removal.

The low levels of mercury removal seen in the L1500 may be in part due to the low amount of unburned carbon (UBC) in the fly ash. UBC in ash is responsible for mercury capture by fly ash. The fly ash taken from the L1500 was not dark, suggesting good burnout and low UBC. It is important to note that under oxy-fired conditions on the OFC there were difficulties with the coal feeding system. Coal was not being fed steadily, but rather pulsed as evidenced by the $\mathrm{O}_{2}$ readings on the furnace. As a result, the fly ash sample was very dark and contained a very high level of UBC, which may explain the increased mercury removal under oxy-fired conditions. 


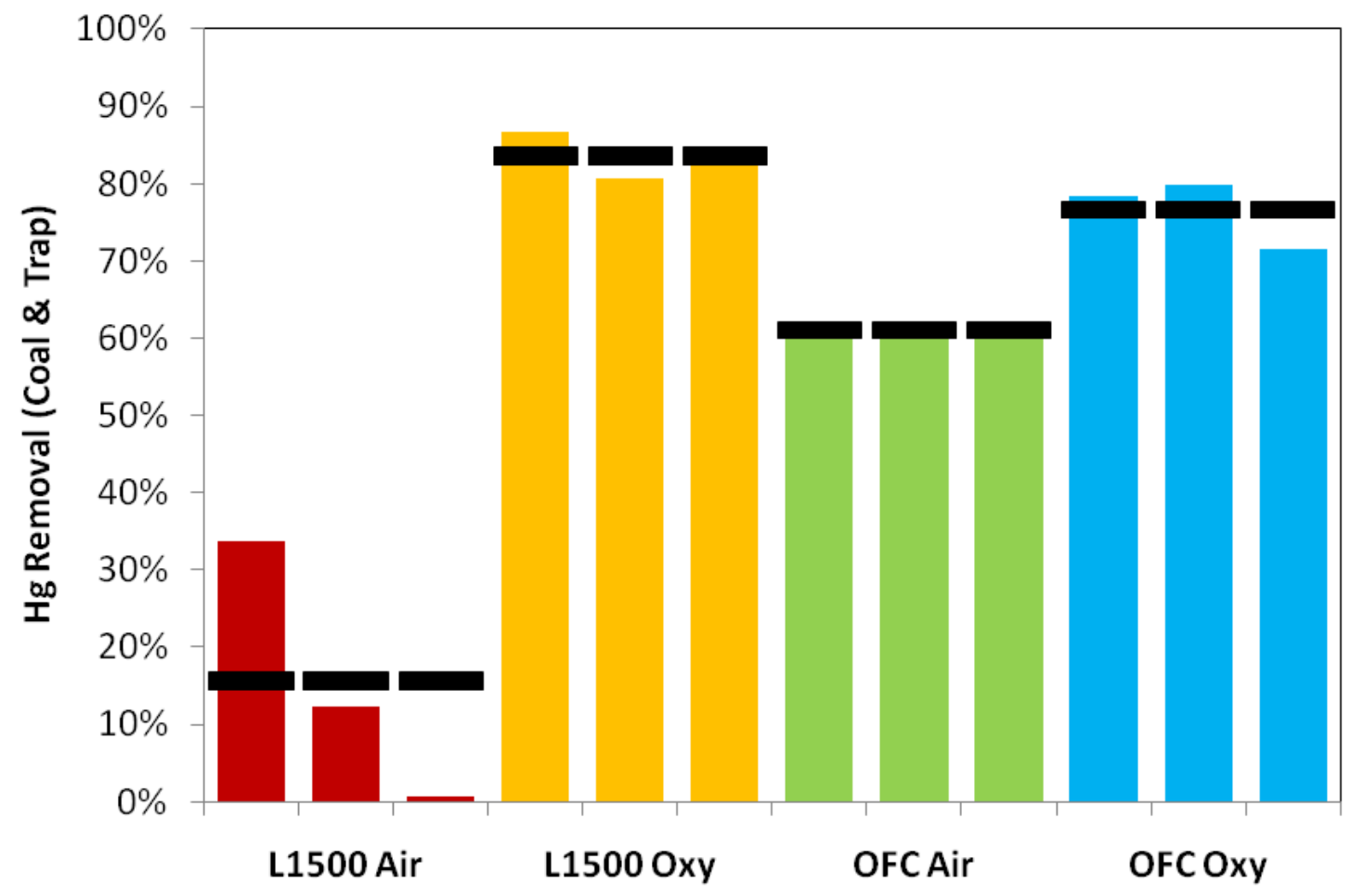

Figure 4.4-2: Mercury removal calculated using coal input and gas phase trap measurements.

The number of coal and ash samples for each furnace under each condition corresponds to the number of mercury, arsenic and selenium removal calculations that may be performed using the second definition (ash/coal). These results are shown in Table 4.4-6. The L1500-oxy calculation is not applicable due to flue gas recycle after the ash sampling location. Once again, these results show wide variability due to extremely low concentrations. For cases where mass balance closure was good, the mercury removal results are comparable to the removal results above. Mercury removal was higher for the OFC-oxy case when the coal and gas phase measurements were used, but lower when the coal and ash measurements were used. Because only one coal and one ash sample were taken from the OFC during each condition, it is unclear how precise these measurements were.

Table 4.4-6: Metals Removal Calculations Using Coal and Ash Measurements.

\begin{tabular}{ccccc}
\hline Furnace & Condition & $\begin{array}{c}\text { Hg Removal } \\
\text { \% (Coal \& Ash) }\end{array}$ & $\begin{array}{c}\text { As Removal } \\
\text { \% (Coal \& Ash) }\end{array}$ & $\begin{array}{c}\text { Se Removal } \\
\text { \% (Coal \& Ash) }\end{array}$ \\
\hline L1500 & Air & $79 \%$ & $33 \%$ & $44 \%$ \\
L1500 & Air & $17 \%$ & $61 \%$ & $16 \%$ \\
L1500 & Oxy & NA & NA & NA \\
L1500 & Oxy & NA & NA & NA \\
OFC & Air & $73 \%$ & & \\
OFC & Oxy & $63 \%$ & & \\
\hline \hline
\end{tabular}




\subsubsection{Flue Gas Composition Measurements}

Empact analytical analyzed flue gas samples collected from the L1500 during air- and oxy-firing conditions. Species identified include $\mathrm{O}_{2}, \mathrm{~N}_{2}, \mathrm{CO}, \mathrm{CO}_{2}, \mathrm{He}, \mathrm{H}_{2}$, methane, ethane, propane, isobutene, nbutane, isopentane, n-pentane, hexanes+. Several other peaks were identified that could possibly be ethylene, propylene, $\mathrm{C} 4$ olefins and $\mathrm{C} 5$ olefins. Results from the flue gas analyses are shown in Table 4.4-7. Results show an increase in flue gas $\mathrm{CO}_{2}$ and a decrease in flue gas $\mathrm{N}_{2}$ under oxy-fired conditions. However, the $\mathrm{O}_{2}$ concentrations were elevated in all samples above what was expected for the flue gas based on operating conditions. This suggests significant air contamination. Three of the eight flue gas samples contained a measurable amount of methane, but no other hydrocarbons were measured. However, the air contamination may have diluted the flue gas samples to such a large extent that the VOC levels were below detection. It is unlikely, but not impossible, that the air contamination occurred during sampling. A mercury mass balance was closed successfully using the same gas train, which suggests the sampling system was air tight.

Table 4.4-7: Flue Gas Composition.

\begin{tabular}{lcccc}
\hline Furnace & L1500 & L1500 & L1500 & L1500 \\
Condition & Air & Air & Oxy & Oxy \\
Date & $12 / 17 / 09$ & $12 / 17 / 09$ & $12 / 18 / 09$ & $12 / 18 / 09$ \\
Time & $12: 45$ & $15: 15$ & $11: 40$ & $14: 15$ \\
\hline He & 0 & 0 & 0 & 0 \\
$\mathbf{H}_{2}$ & 0 & 0 & 0 & 0 \\
O$_{2} /$ Ar & 18.61 & 17.75 & 18.50 & 18.91 \\
$\mathbf{N}_{2}$ & 78.86 & 79.20 & 64.09 & 64.97 \\
CO & 0 & 0 & 0.01 & 0 \\
CO & & 3.05 & 17.40 & 16.12 \\
Methane & 0 & 0 & 0 & 0 \\
Ethane & 0 & 0 & 0 & 0 \\
Ethylene? & 0 & 0 & 0 & 0 \\
Propane & 0 & 0 & 0 & 0 \\
Propylene? & 0 & 0 & 0 & 0 \\
Isobutane & 0 & 0 & 0 & 0 \\
N-Butane & 0 & 0 & 0 & 0 \\
C4 olefins? & 0 & 0 & 0 & 0 \\
Isopentane & 0 & 0 & 0 & 0 \\
N-Pentane & 0 & 0 & 0 & 0 \\
C5 olefins? & 0 & 0 & 0 & 0 \\
Hexanes+ & 0 & 0 & 0 & 0 \\
\hline Total & 100 & 100 & 100 & 100 \\
\hline \hline
\end{tabular}

The flue gas analyses were corrected for air contamination by reducing the $\mathrm{O}_{2}$ concentration to $3 \%$. The $\mathrm{N}_{2}$ concentration was also reduced based on the composition of air. The resulting flue gas composition was normalized. This gave reasonable results for all air-fired cases, but for oxy-fired cases the amount of $\mathrm{N}_{2}$ leakage calculated exceeded the measured $\mathrm{N}_{2}$. Hence, for oxy-fired cases, the air leakage was calculated so as to yield a final normalized composition with $0 \% \mathrm{~N}_{2}$. The results of these calculations are shown in Table 4.4-8. While these corrected compositions are more reasonable, the results are still not 
accurate based on coal combustion calculations. For air-firing of the L1500, the predicted $\mathrm{CO}_{2}$ concentration was 16 vol\% dry while the corrected analysis showed 17-19 vol\% dry. For oxy-firing of the L1500, the predicted $\mathrm{CO}_{2}$ concentration was 96 vol\% dry while the corrected measurements showed 91-92 vol\% dry.

Table 4.4-8: Flue Gas Compositions Corrected for Air Leakage.

\begin{tabular}{lcccc}
\hline \hline Furnace & L1500 & L1500 & L1500 & L1500 \\
Condition & Air & Air & Oxy & Oxy \\
Date & $12 / 17 / 09$ & $12 / 17 / 09$ & $12 / 18 / 09$ & $12 / 18 / 09$ \\
Time & $12: 45$ & $15: 15$ & $11: 40$ & $14: 15$ \\
\hline He & 0 & 0 & 0 & 0 \\
H2 & 0 & 0 & 0 & 0 \\
O2/Ar & 3 & 3 & 7.75 & 9.23 \\
N2 & 77.95 & 80.11 & 0 & 0 \\
CO & 0 & 0 & 0.05 & 0 \\
CO2 & 19.05 & 16.89 & 92.19 & 90.77 \\
Methane & 0 & 0 & 0 & 0 \\
Ethane & 0 & 0 & 0 & 0 \\
Ethylene & 0 & 0 & 0 & 0 \\
Propane & 0 & 0 & 0 & 0 \\
Propylene & 0 & 0 & 0 & 0 \\
Isobutane & 0 & 0 & 0 & 0 \\
N-Butane & 0 & 0 & 0 & 0 \\
C4 olefins & 0 & 0 & 0 & 0 \\
Isopentane & 0 & 0 & 0 & 0 \\
N-Pentane & 0 & 0 & 0 & 0 \\
C5 olefins & 0 & 0 & 0 & 0 \\
Hexanes+ & 0 & 0 & 0 & 0 \\
\hline Total & 100 & 100 & 100 & 100 \\
\hline \hline
\end{tabular}

\subsubsection{Metals Testing Conclusions}

Trace metals measurements were taken on two furnaces at the University of Utah's Industrial Combustion and Gasification Research Facility: L1500 multi-fuel furnace and oxy-fuel combustor (OFC). Coal, fly ash, and gas phase measurements were taken to determine metals removal, mercury speciation, and metals mass balance closure. A Utah bituminous coal was burned under air- and oxy-fired conditions on all three furnaces. The levels on mercury, arsenic and selenium in the coal were extremely low. The average coal $\mathrm{Hg}$ content measured was $0.010 \pm 0.005 \mu \mathrm{g} / \mathrm{g}$ AR, the average As was $1.1 \pm 0.7 \mu \mathrm{g} / \mathrm{g}$ AR and the average Se was $1.4 \pm 0.2 \mu \mathrm{g} / \mathrm{g}$ AR. As a result, the ash and gas phase concentrations were also extremely low. Gas phase measurements were only above detection limits for mercury using speciated traps on the L1500 and 30B carbon traps on the OFC. No gas phase arsenic or selenium measurements were viable. As a result, a mass balance calculation was only possible for mercury. The mercury mass balance closure in the acceptable region (80\%-120\%) for most tests with the exception of the L1500 oxyfired case: 


$$
\begin{aligned}
& \text { Mercury Mass Balance } \\
& \text { - L1500-air }=100 \pm 6 \% \\
& \text { - L1500-oxy }=22 \pm 1 \% \\
& \text { - OFC-air }=112 \pm 1 \% \\
& \text { - OCF-oxy=86 } \pm 4 \%
\end{aligned}
$$

Good mass balance closure lends confidence to the measurements. The L1500-oxy case was the only instance where flue gas recycle was used. It is suspected that mercury was collecting somewhere along the recycle path resulting in a low bias on the outlet mercury.

Mercury removal calculated using the coal and gas-phase measurements showed wide variability due to the low measured concentrations:

$$
\begin{aligned}
& \text { Mercury Removal } \\
& \text { - L1500-air }=16 \pm 17 \% \text { - L1500-oxy }=84 \pm 3 \% \\
& \text { - OFC-air=61 } \pm 1 \% \text { OCF-oxy }=77 \pm 4 \%
\end{aligned}
$$

Air- or oxy-firing conditions did not have a large effect on mercury removal, with the exception of the L1500. However, because a mass balance could not be closed for the L1500-oxy case, these results are not reliable. For the OFC, oxy-combustion resulted in slightly higher mercury removal. The elevated levels of mercury removal seen in the OFC-oxy case were due to high levels of unburned carbon in ash. Measured mercury oxidation levels also showed wide variability:

$$
\begin{aligned}
& \text { Mercury Oxidation } \\
& \text { - } \mathrm{L} 1500-\mathrm{air}=55 \pm 7 \% \text { - } \mathrm{L} 1500-\mathrm{oxy}=59 \pm 6 \%
\end{aligned}
$$

Air- or oxy-fired conditions did not have a significant effect on mercury speciation.

Arsenic and selenium removal was calculated using coal and ash measurements (two measurements per condition on the L1500):

$$
\begin{gathered}
\text { - } 1500-\text { air }=47 \pm 20 \% \\
\text { - L1500-air }=30 \pm 20 \%
\end{gathered}
$$

The L1500-oxy calculation is not applicable due to flue gas recycle after the ash sampling location.

Flue gas composition at the sample location was also measured. No significant VOCs were observed. However, the flue gas samples showed significant air contamination which may have diluted the VOCs to below detection. After correcting the compositions to account for air in-leakage, firing under oxycombustion conditions showed elevated levels of $\mathrm{CO}_{2}$ and smaller concentrations of $\mathrm{N}_{2}$ as expected. The compositions were still not as expected based on combustion calculations. 


\subsection{Char Oxidation}

\subsubsection{Introduction}

Char burnout conditions are expected to be significantly different in oxy-coal combustion systems due to the differences in gas composition and, potentially, particle heating rates. For oxy-combustion systems with flue gas recycle, there will be a $\mathrm{CO}_{2}$-dominated gas environment, potentially with significant amounts of moisture. There are a number of design challenges for oxy-combustion systems, including heat transfer, recycle parameters, and oxy-fuel burner operation (flame stability, pollutant formation, properties of fly ash and deposits, char burnout). Improved understanding of char oxidation behavior in the oxy-combustion environment will help guide retrofit designs.

One of the key areas of uncertainty with char oxidation under oxy-coal firing is the role of gasification reactions. There are questions about the impact of the reaction rate of $\mathrm{CO}_{2}$ gasification on burnout, the accuracy of kinetic rates for reactions with $\mathrm{CO}_{2}$ and $\mathrm{H}_{2} \mathrm{O}$ at high temperatures, and the effect of endothermicity on overall char consumption. Traditionally single-film models have been used to represent char oxidation behavior. Simplified versions of these models can be configured for implementation in CFD codes, but a balance must be maintained between model accuracy and computational efficiency. This research focuses on identifying the elements of the single-film model to upgrade in order to improve overall CFD predictions of oxy-coal combustion.

Previous studies have shown that particle boundary and gasification reactions are relevant for oxycombustion. Previous work has included use of the Surface Kinetics in Porous Particles (SKIPPY) code (B. Haynes August 1999) to calculate char oxidation and $\mathrm{CO} / \mathrm{CO}_{2}$ production at a coal particle surface. This is a detailed 1D steady-state code used to model consumption of spherical porous char particle and resolves species and temperature profiles. It utilizes GRI-MECH 3.0 gas-phase kinetics (w/o nitrogen reactions), CHEMKIN II surface kinetics, heterogeneous reaction mechanism, char properties and combustion environment specified by the user. Previous studies have shown that boundary layer reactions appear to be relevant for particles larger than $60 \mu \mathrm{m}$ under oxy-combustion and that both steam and $\mathrm{CO}_{2}$ gasification reactions should be included to obtain good predictions in both $\mathrm{N}_{2}$ and $\mathrm{CO}_{2}$ environments.

This work used the following three-step approach to evaluating, improving and using the char oxidation model:

1. Experimental investigation

- Optical measurements on individual particles burning in controlled lab-scale environments $\left(\mathrm{O}_{2}, \mathrm{H}_{2} \mathrm{O}\right.$ concentrations; $\mathrm{N}_{2}$ or $\mathrm{CO}_{2}$ diluent)

- Measured particle temperature-size data as basis for model comparison and estimation of fitting parameters for CFD simulations

2. $\quad$ Extended Single Film model

- Include (heterogeneous) steam and $\mathrm{CO}_{2}$ gasification reactions in commonly employed oxidation-only single film model

- Fit rate parameters to match observed temperatures of $100 \mu \mathrm{m}$ particles burning in $\mathrm{N}_{2}$ (with $12 \%$ and $\left.36 \% \mathrm{O}_{2}\right)$ and $\mathrm{CO}_{2}\left(36 \% \mathrm{O}_{2}\right)$

- Predict char combustion characteristics for both environments at different $\mathrm{O}_{2}$ concentrations and sizes between 10 and $200 \mu \mathrm{m}$

3. Implementation, verification and validation

- Implement into REI’s Glacier CFD code

- Verify and validate predictions through EFR simulation

- Validate through pilot- and full-scale simulations 


\subsubsection{Experimental Investigation}

For comparisons with predictions of different char combustion models, size-classified coal particles were entrained into mixtures with 12, 24 or 36 mole- $\% \mathrm{O}_{2}, 16 \%$ moisture, and $\mathrm{CO}_{2}$ or $\mathrm{N}_{2}$ as balance gas. Particle temperature-size data were collected at locations between 25 and $125 \mathrm{~mm}$ above the burner face. At these locations, the gas temperatures were $1680 \pm 40 \mathrm{~K}$, with a peak at about $1700 \pm 10 \mathrm{~K}$ at $50 \mathrm{~mm}$ above the burner surface and a subsequent linear decay with height in the furnace (Geier, Shaddix and Haynes 2010). The total burner product flow rate was $60 \mathrm{slpm}$ (standard liters per minute), which includes 0.03 slpm of diluent flow for conveying the particles through the feed tube ( $0.75 \mathrm{~mm}$ ID).

Figure 4.5-1 shows the gas temperature profiles for the investigated flow conditions and the range of measurement locations. These profiles were obtained from thermocouple measurements (25- $\mu \mathrm{m}$, type-R fine-wire thermocouple) that were corrected for radiative losses (Shaddix 1999).

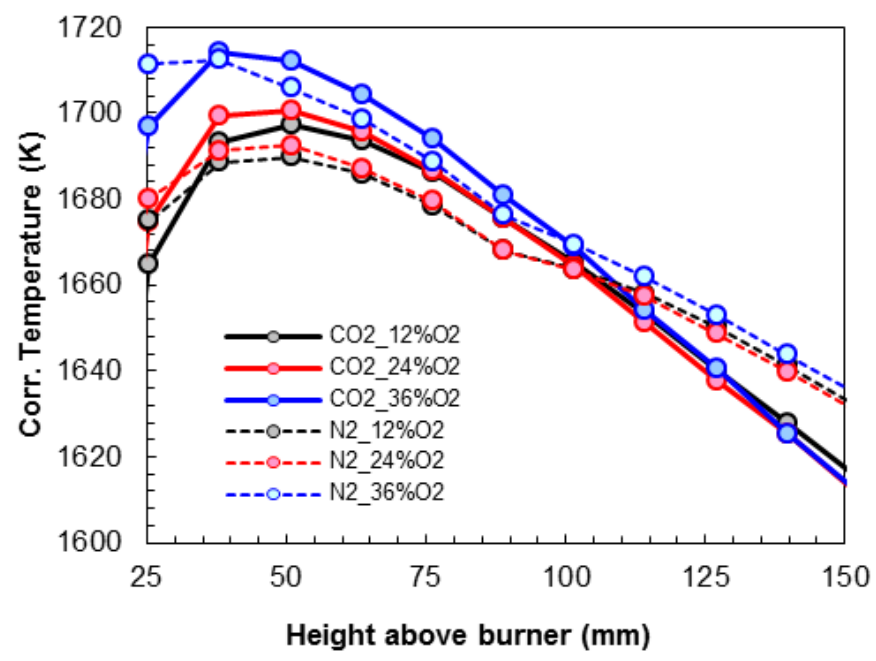

Figure 4.5-1: Radiation-corrected thermocouple measurements of gas temperature profiles in the entrained flow reactor.

\subsubsection{Materials}

The experimental data shown are for a western U.S., low-sulfur, high-volatile bituminous coal (Utah Skyline) and a low-sulfur subbituminous coal from the Powder River Basin (North Antelope), with proximate and ultimate analyses shown in Table 4.5-1. Analysis of three coal size fractions (53-75 $\mu \mathrm{m}$, 75-106 $\mu \mathrm{m}$ and 106-125 $\mu \mathrm{m}$ ) confirmed size-independent elemental composition and ash contents. The data presented here correspond to a coal particle feed of 75-106 $\mu \mathrm{m}$. 
Table 4.5-1: Proximate and Ultimate Analysis of Coals.

\begin{tabular}{lcccc}
\hline & \multicolumn{2}{c}{ Utah Skyline } & \multicolumn{2}{c}{ Noal Type Antelope } \\
Proximate & wt\%, as rec'd & wt\% dry & wt\%, as rec'd & wt\% dry \\
\hline moisture & 3.18 & & 23.69 & \\
ash & 8.83 & 9.12 & 4.94 & 6.47 \\
volatiles & 38.60 & 39.87 & 33.36 & 43.72 \\
fixed C & 49.39 & 51.01 & 38.01 & 49.81 \\
\hline & & & & \\
Ultimate & wt\% dry & wt\% DAF & wt\% dry & wt\% DAF \\
\hline C & 70.60 & 80.24 & 53.72 & 75.27 \\
H & 5.05 & 5.74 & 3.57 & 5.00 \\
O (by diff.) & 10.39 & 11.81 & 13.07 & 18.31 \\
N & 1.42 & 1.61 & 0.78 & 1.09 \\
S & 0.53 & 0.60 & 0.23 & 0.32 \\
\hline
\end{tabular}

\subsubsection{Char Preparation}

Experimental measurements were made of the char combustion temperatures for North Antelope and Utah Skyline char particles for two oxygen concentrations in a $\mathrm{CO}_{2}$ bath gas. In contrast to previous practice, in which raw coal particles were fed into the combustion-driven optical entrained flow reactor for the char combustion measurements, the char particles were generated first in an electrically heated flow reactor operated at $1200{ }^{\circ} \mathrm{C}$. In comparing the measured char combustion temperatures for these 'ex situ' produced chars relative to in situ formed chars, it is apparent that the ex situ chars of North Antelope coal are slightly less reactive than the in situ chars in the $12 \% \mathrm{O}_{2}$ furnace, but are more reactive than the in situ chars in the $36 \% \mathrm{O}_{2}$ furnace, suggesting an influence of the volatile flame on the resultant char reactivity for in situ formed chars. For the Utah Skyline coal, no substantial differences are found in the burning rates of the in situ and ex situ formed chars. For optimal consistency and kinetic accuracy, it is recommended that all future data be collected with ex situ formed chars.

\subsection{Single Particle Temperature-Size Data for Coal versus Char Feed}

A concern with feeding raw coal particles into the optical entrained flow reactor to measure char combustion rates is whether or not the coal devolatilization process produces char particles with differing inherent reactivities for different furnace operating conditions. Certainly operation at significantly different characteristic gas temperatures may be expected to alter the char reactivity, but possibly even operation at different oxygen levels may influence the devolatilization process, as noted by the absence of soot formation about bituminous coal particles when introduced into higher- $\mathrm{O}_{2}$ concentration environments (Murphy and Shaddix 2006) (Shaddix and Molina 2009). In particular, at the low particle feed rates used for measurements of isolated char particle combustion, the individual particles have volatile-fed envelope flames form around them during devolatilization (Shaddix and Molina 2009). These volatile flames provide additional heating of the coal particles, and the volatile flame temperature increases and its standoff from the particle decreases as the furnace oxygen content is increased (Murphy and Shaddix 2006) — both factors leading to increased heating of the coal particle. Any variation in char particle reactivity resulting from differences in the devolatilization process in the optical entrained flow reactor are clearly undesirable from a kinetics standpoint, wherein the model comparisons with data over a range of reactor conditions necessarily assume the char material itself is not changed for those different conditions.

To assess whether this concern warrants attention in the current project, the char combustion characteristics of an ex situ formed char and the traditional in situ formed chars were compared for both North Antelope and Utah Skyline coals for our typical optical entrained flow reactor temperature of 1700 
$\mathrm{K}$ and 12 vol-\% and 36 vol-\% $\mathrm{O}_{2}$ in $\mathrm{CO}_{2}$. Both coal and char particle feeds were sieved to a 75-106 $\mu \mathrm{m}$ the size fraction. Ex situ char particles were prepared by feeding raw coal particles (75-150 $\mu \mathrm{m}$ for North Antelope and 75-106 $\mu \mathrm{m}$ for Utah Skyline) into an electrically heated drop tube furnace operating at 1200 ${ }^{\circ} \mathrm{C}$ and 1.3 bar of absolute pressure. The particle residence time in the reactor was $0.25 \mathrm{~s}$, before entering a water-cooled, gas-quench collection probe.

Figure 4.5-2 shows an overlay of the experimental char combustion measurements for the in situ and ex situ coal char particles of the two coals. For the North Antelope coal, at $12 \% \mathrm{O}_{2}$ the in situ char particles are burning at slightly higher temperatures than their ex situ counterparts, suggesting somewhat higher reactivity for the in situ chars produced under those furnace conditions. In contrast, in the $36 \% \mathrm{O}_{2}$ environment the in situ North Antelope char particles are less reactive than the char particles prepared in the drop tube furnace. This suggests that, for the North Antelope coal, the higher temperature, more compact volatile flame around the particles devolatilizing in the higher $\mathrm{O}_{2}$ environment produces char particles with lower reactivity than those char particles produced in the optical entrained flow reactor when operating at lower $\mathrm{O}_{2}$ levels.

The Utah Skyline char particles show nearly identical reactivity for in situ and ex situ formed char, whether the optical entrained flow reactor is operating at 12 vol-\% or 36 vol- $\% \mathrm{O}_{2}$. Thus, for this coal, there does not appear to be any improvement in kinetic information to be attained by preparing char particles ex situ. However, in general, to minimize concerns over potential influences of the devolatilization process in the optical entrained flow reactor, it is probably best to always produce chars ex situ with a well-defined, repeatable technique, as has been done here with a drop tube reactor. The good agreement of the char particle combustion temperatures for ex situ and in situ formed chars shown here suggests that the ex situ process that has been implemented is representative of the high temperature, high heating rate devolatization process traditionally experienced by coal particles introduced into the combustion-driven optical entrained flow reactor.
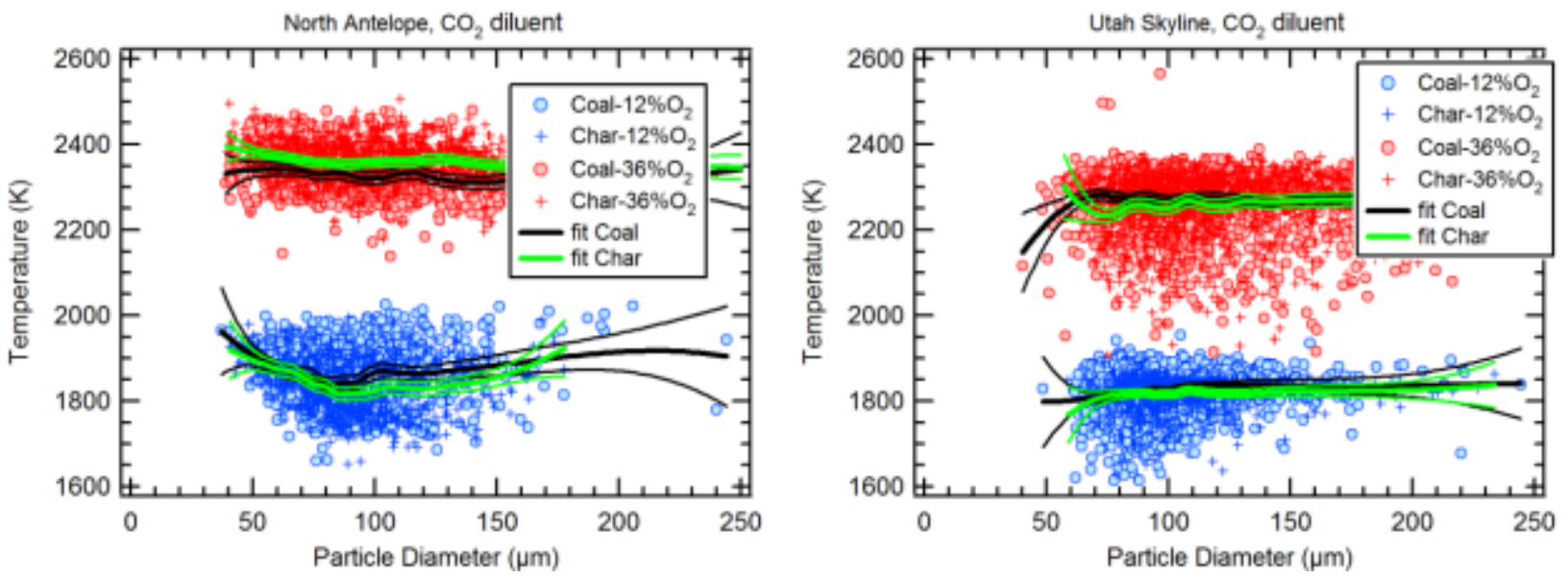

Figure 4.5-2: Effect of char preparation: measured char combustion temperatures of North Antelope and Utah Skyline coal and char particles, both sieved to 75-106 $\mu \mathrm{m}$, burning in optical entrained flow reactor operating at $1700 \mathrm{~K}$ gas temperature, $12 \%$ and $36 \% \mathrm{O}_{2}$ in $\mathrm{CO}_{2}$ diluent. Curves are obtained with LOESS algorithm with the nearest third of total data points included in the smoothing window (thin lines specify $99 \%$ confidence intervals). 'Coal' refers to raw coal feed into the optical entrained flow reactor, whereas 'char' refers to char particles prepared ex situ, in a drop tube furnace operating at $1200{ }^{\circ} \mathrm{C}$. 


\subsubsection{Measurement Results}

\subsubsection{Burn-out Times}

Typical time-lapse photographs of coal particles burning in the $1700 \mathrm{~K}$ environment are shown in Figure 4.5-3 and Figure 4.5-4. As expected, the burnout times for both coals decrease with decreasing particle size and increasing excess oxygen concentration. The char combustion of high-volatile Utah Skyline coal is preceded by a longer period of devolatilization and volatiles combustion than the subbituminous North Antelope coal. The burn-out times of particles of comparable size further appear to be longer for Utah Skyline coal than for North Antelope coal, despite observable ignition delay of North Antelope coal particles. For both coals, $\mathrm{CO}_{2}$ environments yield somewhat longer burn-out times and increased ignition delays as compared with nitrogen environments, which is in agreement with previous findings for similar coals (Murphy and Shaddix 2006) (Molina and Shaddix 2007) (Shaddix and Molina 2009) (Shaddix and Molina 2008).
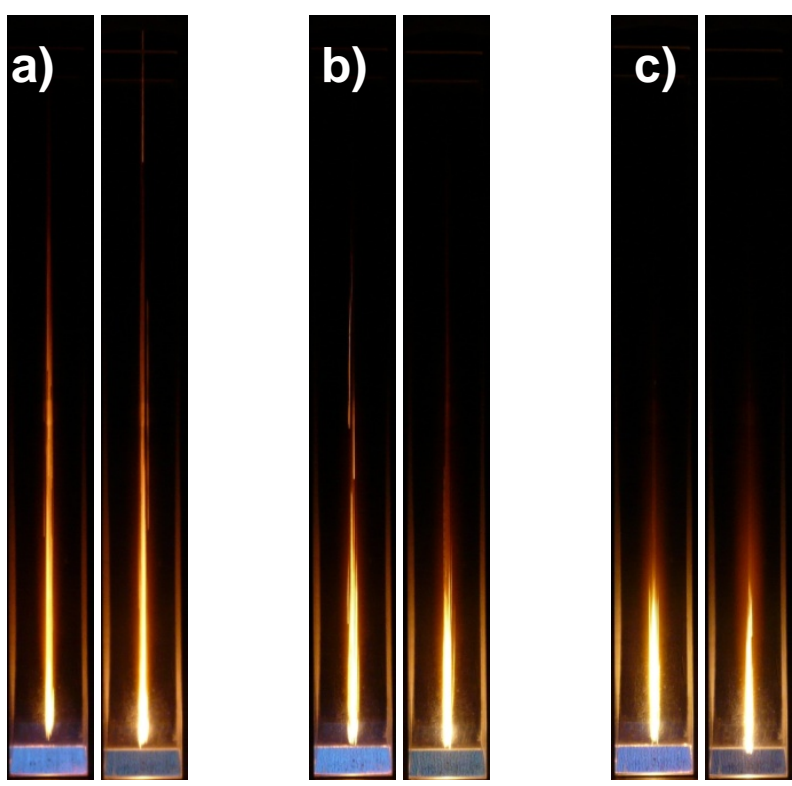

Figure 4.5-3: Utah Skyline bituminous coal particles (75 - $106 \mu \mathrm{m})$ burning in $\mathrm{CO}_{2}$ (left images) and $\mathrm{N}_{2}$ (right images) environments at $1700 \mathrm{~K}$ gas temperature. (a) $12 \% \mathrm{O}_{2}$, (b) $24 \% \mathrm{O}_{2}$, (c) $36 \% \mathrm{O}_{2}$. 

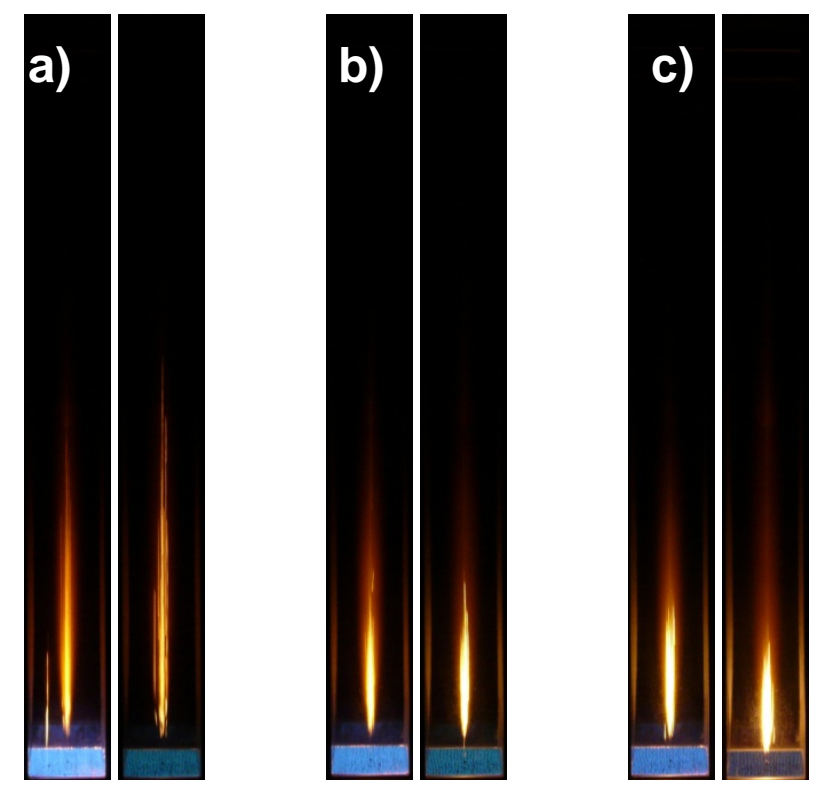

Figure 4.5-4: North Antelope bituminous coal particles (75 - $106 \mu \mathrm{m})$ burning in $\mathrm{CO}_{2}$ (left images) and $\mathrm{N}_{2}$ (right images) environments at $1700 \mathrm{~K}$ gas temperature. (a) $12 \% \mathrm{O}_{2}$, (b) $24 \% \mathrm{O}_{2}$, (c) $36 \%$ $\mathbf{O}_{2}$.

\subsubsection{Comparison of Char Particle Combustion in $\mathrm{N}_{2}$ and $\mathrm{CO}_{2}$ Atmospheres}

Figure 4.5-5 and Figure 4.5-6 show the measured temperature-size pairs for the investigated conditions. As expected, increasing oxygen concentrations yield higher particle temperatures for both $\mathrm{CO}_{2}$ and $\mathrm{N}_{2}$ environments. Particle temperatures are higher for combustion in nitrogen (a consequence of the lower diffusivity of $\mathrm{O}_{2}$ in $\mathrm{CO}_{2}$ (Shaddix and Molina 2008)), with a less pronounced difference for the higher rank Utah Skyline coal (in agreement with the findings in (Shaddix, Hecht, et al. 2009)). Similar to the results presented in (Geier, Hecht and Shaddix 2009), however, particle temperatures appear to be nearly independent of particle size for both coals and diluents over the range of investigated oxygen concentrations. Only at lower oxygen levels, temperatures seem higher for particles less than $100 \mu \mathrm{m}$ in diameter (see $12 \% \mathrm{O}_{2}$ results in Figure 4.5-6). In order to improve the ability to compare measurement results with modeling results, average temperatures for $10 \mu \mathrm{m}$-wide size bins were computed.

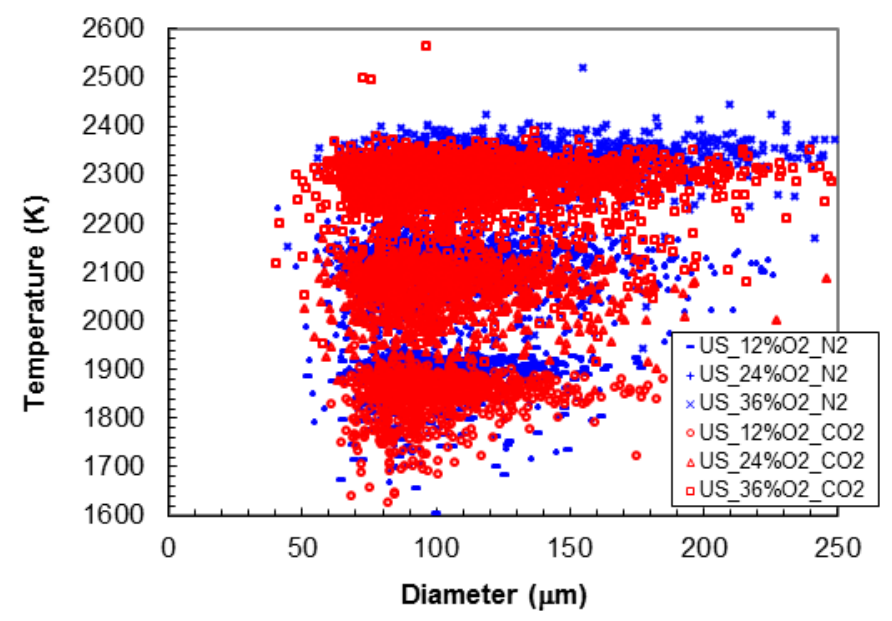

Figure 4.5-5: Measured particle temperatures and sizes for Utah Skyline coal particles (75 $106 \mu \mathrm{m}$ ) in $\mathrm{CO}_{2}$ (red) and $\mathrm{N}_{2}$ (blue) environments and 12\%, 24\%, and $36 \% \mathrm{O}_{2}$ mole fractions. 


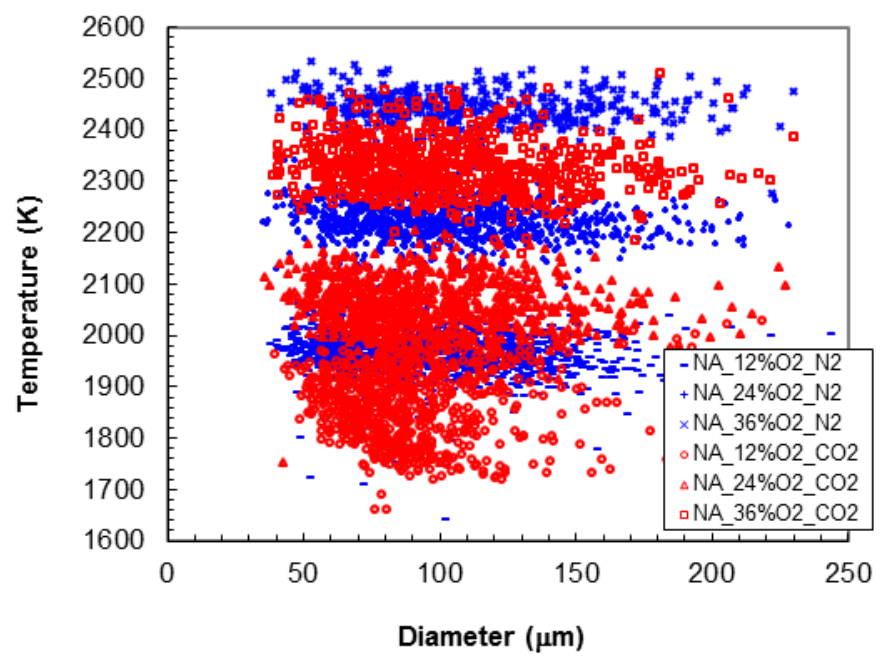

Figure 4.5-6: Measured particle temperatures and sizes for North Antelope coal particles (75 $106 \mu \mathrm{m}$ ) in $\mathrm{CO}_{2}$ (red) and $\mathrm{N}_{2}$ (blue) environments and 12\%, 24\%, and $36 \% \mathrm{O}_{2}$ mole fractions.

\subsubsection{Char Oxidation Particle Modeling}

\subsubsection{SKIPPY Predictions}

Steady-state combustion of single, isolated particles was modeled using SKIPPY (Surface Kinetics in Porous Particles) (Ashman and Haynes 1999). The program includes both heterogeneous (gas-solid) and gas-phase chemical reactions to predict species concentrations and temperature within the particle pores, at the outer char surface, and within the boundary layer surrounding the char particle. SKIPPY was previously used to evaluate the importance of boundary layer conversions for different particle sizes (Geier, Hecht and Shaddix 2009), and to evaluate the importance of the $\mathrm{CO}_{2}$ gasification reaction on char consumption during oxy-fuel combustion of pulverized coal (Hecht, et al. 2011). As reported in (Geier, Hecht and Shaddix 2009), the use of a $\mathrm{CO}_{2}$ diluent gas reduces the particle burning rate, except for particles small enough that they are burning with largely kinetic control. Further, CO oxidation in the boundary layer results in higher burning rates, except for particles smaller than $50 \mu \mathrm{m}$ in size, and appears to have the strongest impact for $\sim 75 \mu \mathrm{m}$ particles.

Single-particle char combustion modeling was performed for the North Antelope coal for both $\mathrm{N}_{2}$ and $\mathrm{CO}_{2}$ diluent datasets using the SKIPPY code. The results show that a factor of 20 variation in the assumed reactive surface area density is required to match the simulation to the experimental data, whether one employs a presumed, "best guess" $\mathrm{CO}_{2}$ char gasification rate, or not. Slightly better predictions are obtained when using the $\mathrm{CO}_{2}$ char gasification rate. When using the $\mathrm{CO}_{2}$ char gasification rate but neglecting boundary layer reactions (which tend to increase the char particle temperature, especially for oxygen-enriched conditions), a much lower variation in reactive surface area with particle temperature needs to be assumed. Thus, employing a single-film model with combined oxidation and gasification reaction steps appears to provide a computationally tractable approach to matching predictions with the experimental data.

For comparison of model and experimental results, the surface reaction mechanism provided in (Molina, Sarofim, et al. 2002) was used and reactive specific char surface area adjusted to match observed and predicted temperatures of $100 \mu \mathrm{m}$ particles (the obtained surface areas for $12 \%$, 24\%, and $36 \% \mathrm{O}_{2}$ were, respectively, $9.4 \mathrm{~m}^{2} / \mathrm{g}, 1.1 \mathrm{~m}^{2} / \mathrm{g}$ and $0.4 \mathrm{~m}^{2} / \mathrm{g}$ ). This approach permits differences in the number of reactive surface sites in different gas environments (for which no other information was available) and provides a means of calibrating the model. Under the reasonable assumption of size-independent internal 
specific surface area, size effects can be assessed. Table 4.5-2 lists the parameters for the kinetics rate constants for the heterogeneous oxidation reactions used (Molina, Sarofim, et al. 2002), with an addition reaction postulated in (Hecht, et al. 2011). The gas phase reaction kinetics used GRIMECH 3.0 (Smith, et al. n.d.), without nitrogen reactions.

Table 4.5-2: Heterogeneous Reaction Mechanism used in SKIPPY.

\begin{tabular}{|c|c|c|}
\hline Reaction & $A\left(\mathrm{~g} / \mathrm{cm}^{2} \mathrm{~s}\right)$ & $E(\mathrm{~kJ} / \mathrm{mol})$ \\
\hline Heterogeneous oxidation: & & \\
\hline C_s $+\mathrm{O}_{2}=>\mathrm{CO}+\mathrm{O} \_\mathrm{s}$ & $3.3 \mathrm{E}+15$ & 167.4 \\
\hline $\mathrm{O} \_\mathrm{s}+2 \mathrm{C}(\mathrm{b})=>\mathrm{CO}+\mathrm{C} \_\mathrm{s}$ & $1.0 \mathrm{E}+08$ & 0 . \\
\hline $\mathrm{C} \_\mathrm{s}+\mathrm{O}_{2}=>\mathrm{O}_{2 \_} \mathrm{s}+\mathrm{C}(\mathrm{b})$ & $9.5 \mathrm{E}+13$ & 142.3 \\
\hline $\begin{array}{l}\mathrm{O}_{2} \mathrm{~s}+2 \mathrm{C}(\mathrm{b})=>\mathrm{C} \_\mathrm{s}+\mathrm{CO}_{2} \\
\mathrm{CO}_{2} \text { gasification reaction: }\end{array}$ & $1.0 \mathrm{E}+08$ & 0. \\
\hline $\mathrm{C} s+\mathrm{CO}_{2}=>\mathrm{CO}+\mathrm{O} s+\mathrm{C}(\mathrm{b})$ & $1.50 \mathrm{E}+15$ & 251.0 \\
\hline
\end{tabular}

The predictions with SKIPPY for the described mechanism (a) without $\mathrm{CO}_{2}$ gasification reaction and (b) with $\mathrm{CO}_{2}$ gasification reaction included, as well as (c) a single-film model (i.e. a "frozen" boundary layer) that also includes the heterogeneous $\mathrm{CO}_{2}$ gasification reaction, are shown in Figure 4.5-7 for the North Antelope coal. For the normal SKIPPY simulations, with or without inclusion of the $\mathrm{CO}_{2}$ gasification reaction, the predicted temperatures for all oxygen concentrations are in reasonable agreement with measured temperatures for particle sizes greater than about $70 \mu \mathrm{m}$ in size. With the specific surface areas chosen to match temperatures of $100 \mu \mathrm{m}$ particles for the model that includes $\mathrm{CO}_{2}$ gasification, best agreement is clearly obtained for that model. Without the $\mathrm{CO}_{2}$ gasification reaction, higher temperatures are predicted for all particle sizes and oxygen levels. For the smallest sizes (below $50 \mu \mathrm{m}$ ), similar temperatures are predicted by all models. The lower temperatures are caused by higher convective heat loss that smaller particles experience, reducing the rates of both $\mathrm{O}_{2}$ and $\mathrm{CO}_{2}$ reactions on the particle surface and reducing the effect of exothermic or endothermic chemical reactions on particle temperature.

Due to a higher activation energy, the gasification reaction rate constant is more sensitive to a temperature drop than the rate constant for oxidation, which results in char consumption rates dominated by the rate of oxidation for these small particles. As is clearly evident in Figure 4.5-7 and Figure 4.5-8, differences in model assumptions manifest themselves the most for larger sizes, where species diffusion becomes relevant for char consumption rates. For all oxygen concentrations, the endothermic gasification reaction reduces particle temperature as expected, but interestingly, the temperature difference becomes independent from size as particle sizes increase. Omission of CO conversion in the boundary layer clearly results in significantly under-predicted temperatures for all sizes larger than $60 \mu \mathrm{m}$, with a more pronounced effect at higher oxygen concentrations. 


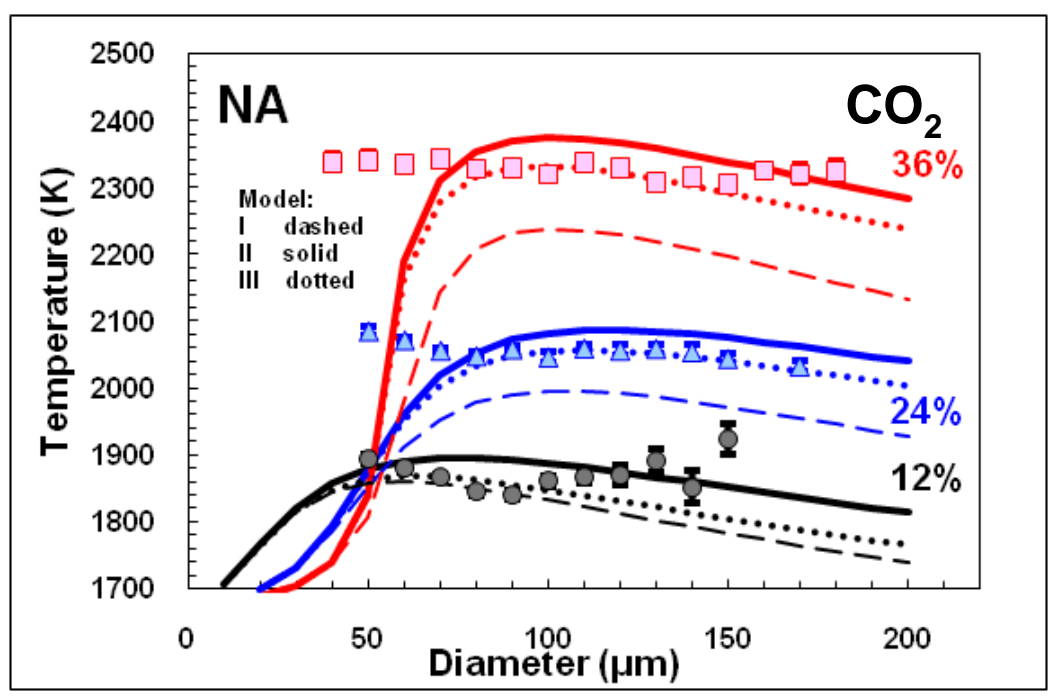

Figure 4.5-7: Predicted and measured particle surface temperatures for the North Antelope coal for three free-stream $\mathrm{O}_{2}$ concentrations, $16 \%$ moisture and $\mathrm{CO}_{2}$ bath gas. Solid lines: without $\mathrm{CO}_{2}$ gasification reaction: dotted lines: $\mathrm{CO}_{2}$ gasification reaction included, dashed lines: $\mathrm{CO}_{2}$ gasification reaction included, but gas phase reaction kinetics turned off (“single-film”).

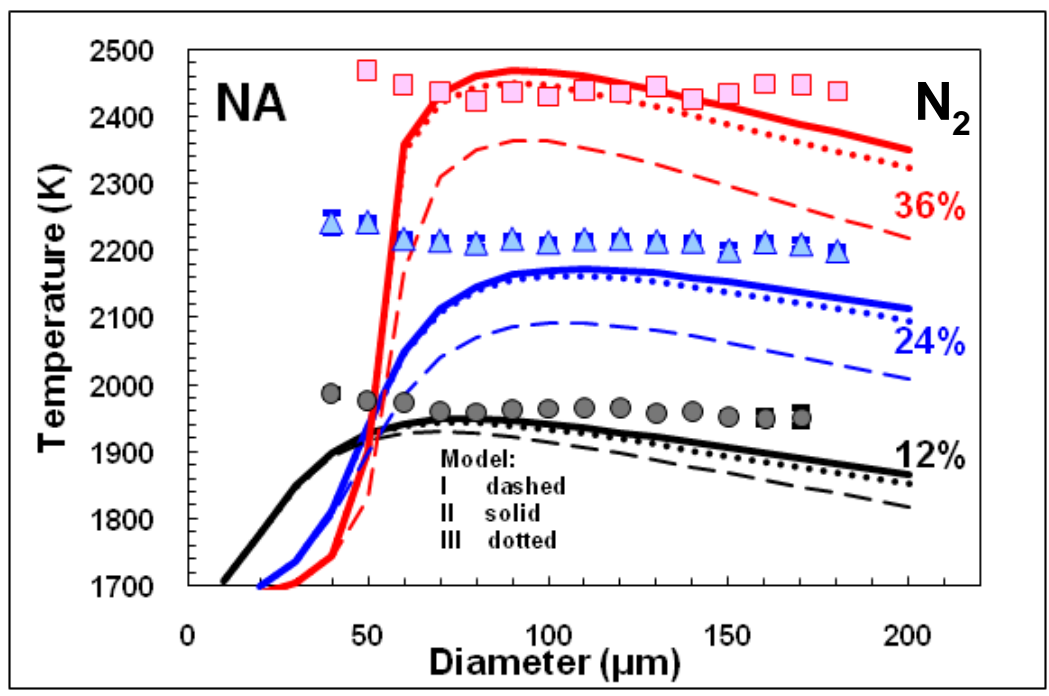

Figure 4.5-8: Predicted and measured particle surface temperatures for the North Antelope coal for three free-stream $\mathrm{O}_{2}$ concentrations, $16 \%$ moisture and $\mathrm{N}_{2}$ bath gas. Solid lines: without $\mathrm{CO}_{2}$ gasification reaction: dotted lines: $\mathrm{CO}_{2}$ gasification reaction included, dashed lines: $\mathrm{CO}_{2}$ gasification reaction included, but gas phase reaction kinetics turned off ("single-film").

Figure 4.5-7 and Figure 4.5-8 also show that model predictions disagree with experimental results for particle sizes below $70 \mu \mathrm{m}$. For all oxygen concentrations, temperatures in that size range are considerably under-predicted. Particularly troublesome is that lower temperatures are predicted for higher oxygen concentrations for particle sizes below $50 \mu \mathrm{m}$, which is not what one would expect. In addition, the predicted temperature drop for larger particles is also somewhat too high, although for $24 \mathrm{~mole} \% \mathrm{O}_{2}$ the profile based on the full model (with $\mathrm{CO}_{2}$ gasification) agrees well with measured temperatures. 


\subsubsection{Influence of Parameter Variations on Predictions of the Detailed Char Combustion Model}

Previous simulations using the Surface Kinetics in Porous Particles (SKIPPY) code have shown that using either a base oxidation model or an oxidation model together with a $\mathrm{CO}_{2}$ gasification reaction requires a factor of 20 variation in the assumed reactive surface area density to match the simulation results to the experimental data over the investigated range of furnace oxygen concentrations ( 12 vol- $\%$ to 36 vol-\%). However, by including a steam gasification reaction (with literature-supported reaction rate parameters), the SKIPPY simulations show quite good agreement with the full set of experimental data for Skyline (bituminous) and North Antelope (PRB sub-bituminous) project coals without any assumed variation in the assumed reactive surface area density. These results imply that modeling char consumption as a single-step oxidation process may only be valid for narrow ranges of combustion environments (in terms of steam and carbon dioxide concentrations), and therefore it may be necessary to account for both steam and $\mathrm{CO}_{2}$ concentrations to produce appropriate estimates of char temperatures and burning rates.

To further test this hypothesis, the influence of different modeling parameters in SKIPPY on the predictions of char combustion temperatures, in comparison to the experimentally measured char temperatures, was investigated. The first parameter examined was the assumed reactive surface area density, which is known to have a high uncertainty. The reactive surface area during high temperature combustion is less than the microporosity and perhaps the mesoporosity of the char particles, because oxygen has a very limited time to diffuse into the char pores before reacting at high temperatures. It is generally believed that a surface area density on the order of $10-20 \mathrm{~m}^{3} / \mathrm{g}$ is appropriate for most coal char particles, but little information is available about the magnitude of this quantity. In practice, SKIPPY simulations of pulverized coal combustion show a complementary influence of the presumed reactive surface area density and the presumed char kinetic rate. Either factor can be used to increase or decrease the predicted char combustion rate or the two factors can be varied in opposite directions to offset one another.

The goal of varying the assumed reactive surface area density was to evaluate whether this parameter can be used to give appreciably better agreement with the experimental data, both in terms of the predicted char combustion temperature rise as the gaseous oxygen content increases and in terms of the variation of char combustion temperatures as a function of particle size. Figure 4.5-9 shows the results of varying the assumed reactive surface area over a very wide range of $2-50 \mathrm{~m}^{3} / \mathrm{g}$, while varying the oxidation preexponential factor to give comparable particle temperature predictions for $100 \mu \mathrm{m}$ particles in the 12 vol$\% \mathrm{O}_{2}$ environment. The figure shows that variation of the assumed surface area density has a minor influence on the predicted increase in char combustion temperatures as the local oxygen concentration is increased, such that the char combustion rate (temperature) is always over predicted for high levels of local oxygen in the gas. Thus, the observed trend of over predicting the influence of local oxygen concentration on char combustion rates cannot be rectified by varying the assumed reactive surface area density (within a reasonable range). Also, very little change in the predicted char particle temperatures as a function of particle size is evident as the assumed surface area density is varied, such that a significant difference in this functional relationship is evident for the model predictions and the data for elevated oxygen concentrations. 


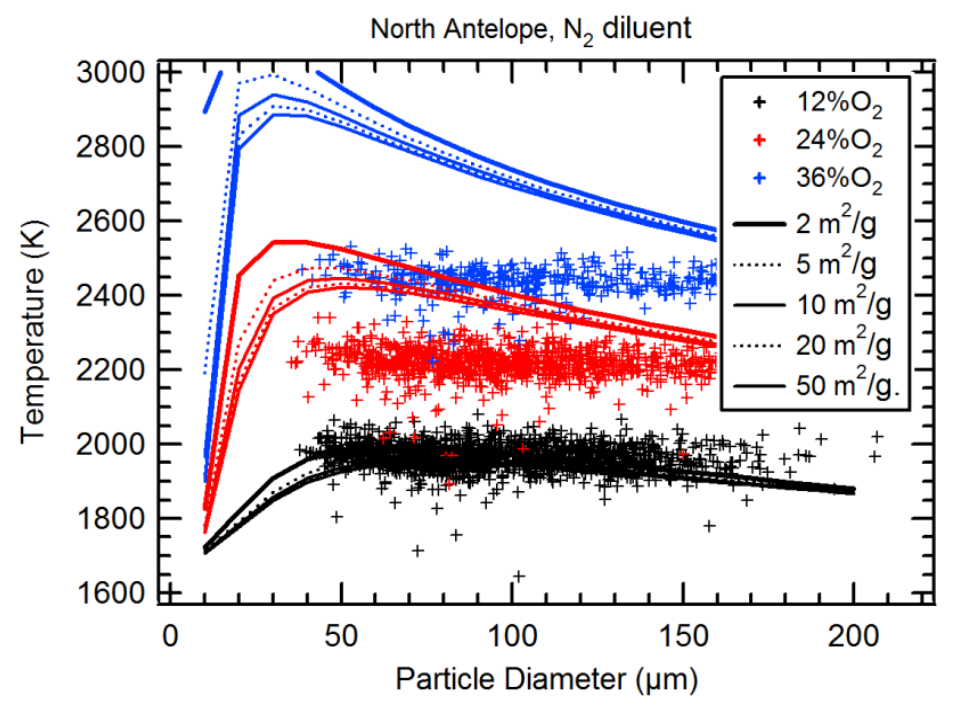

Figure 4.5-9. SKIPPY predictions of particle surface temperatures for three freestream $\mathrm{O}_{2}$ concentrations, $16 \%$ moisture and $\mathrm{N}_{2}$ diluent compared with measured data for North Antelope char. The different model prediction lines correspond to different assumed reactive surface area densities, as indicated in the legend.

The activation energy of char oxidation is fairly well established (at least at low to moderate temperature regions applicable for thermogravimetric studies) as being in the vicinity of $40 \mathrm{kcal} / \mathrm{mol}$. However, there is likely to be some variation in the activation energy for different coal chars produced in somewhat different thermal environments and possibly as a function of the temperature at which char oxidation is occurring. To investigate the influence of this parameter on the SKIPPY simulations, the assumed char oxidation activation energy for the main carbon oxidation reaction

$$
2 \mathrm{C}(\mathrm{s})+\mathrm{O}_{2} \rightarrow 2 \mathrm{CO}
$$

was varied between 30 and $40 \mathrm{kcal} / \mathrm{mol}$. The Tognotti relation [1] for the ratio between direct $\mathrm{CO}$ and $\mathrm{CO}_{2}$ production during char oxidation was used to modify the activation energy for the secondary carbon oxidation reaction

$$
\mathrm{C}(\mathrm{s})+\mathrm{O}_{2} \rightarrow \mathrm{CO}_{2}
$$

to be $6 \mathrm{kcal} / \mathrm{mol}$ less than the assumed activation energy for the main oxidation reaction. Finally, the preexponential for these two reactions were varied to give a consistent prediction of oxidation rate at $800^{\circ} \mathrm{C}$. Figure 4.5-10 shows the results from this set of simulations. Clearly the activation energy has some influence on the predicted char combustion temperatures as a function of local gaseous oxygen concentration, but a careful examination of the figure indicates that even over this wide range of variation of activation energy there is no consistent agreement with predictions and observations over the range of oxygen concentrations investigated (i.e., the base $40 \mathrm{kcal} / \mathrm{mol}$ kinetics gives good agreement at $12 \mathrm{vol}-\%$ $\mathrm{O}_{2}$ but grossly overestimates temperatures in $36 \mathrm{vol}-\% \mathrm{O}_{2}$, while the $30 \mathrm{kcal} / \mathrm{mol}$ kinetics gives decent agreement for 36 vol- $\% \mathrm{O}_{2}$ but grossly underestimates temperatures for 12 vol- $\% \mathrm{O}_{2}$ ).

To further explore the consequences of varying the assumed reactive surface area density AND the oxidation activation energy, combined variation of these two parameters was performed, while matching predicted char combustion temperatures for $100 \mu \mathrm{m}$ particles in the 12 vol- $\% \mathrm{O}_{2}$ environment. Figure 4.5-11 shows the results of this exercise, which explicitly demonstrates that the variation in reactive surface area density and oxidation activation energy are complementary, such that the same dependencies 
on local gaseous oxygen concentration and particle size can be achieved by matching very different values of these two variables. The implication of this result is that these two variables cannot be used to generate any significantly improved agreement between the experimental data and the SKIPPY simulations using just a char oxidation mechanism. Consequently, it appears that char gasification reactions are an integral part of the char particle energy balance during oxygen-enriched combustion conditions, such that they need to be included in any char kinetic modeling that will have applicability over a range of local oxygen concentrations.

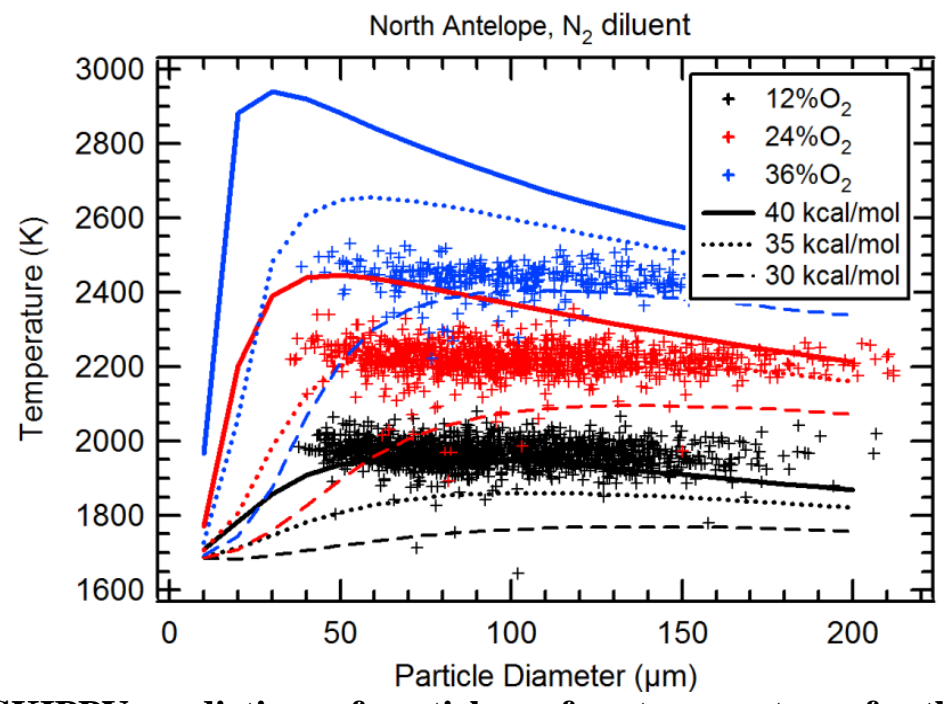

Figure 4.5-10. SKIPPY predictions of particle surface temperatures for three free-stream $\mathrm{O}_{2}$ concentrations, $16 \%$ moisture and $\mathrm{N}_{2}$ diluent compared with measured data for North Antelope char. The different model prediction lines correspond to different assumed oxidation activation energies, as indicated in the legend.

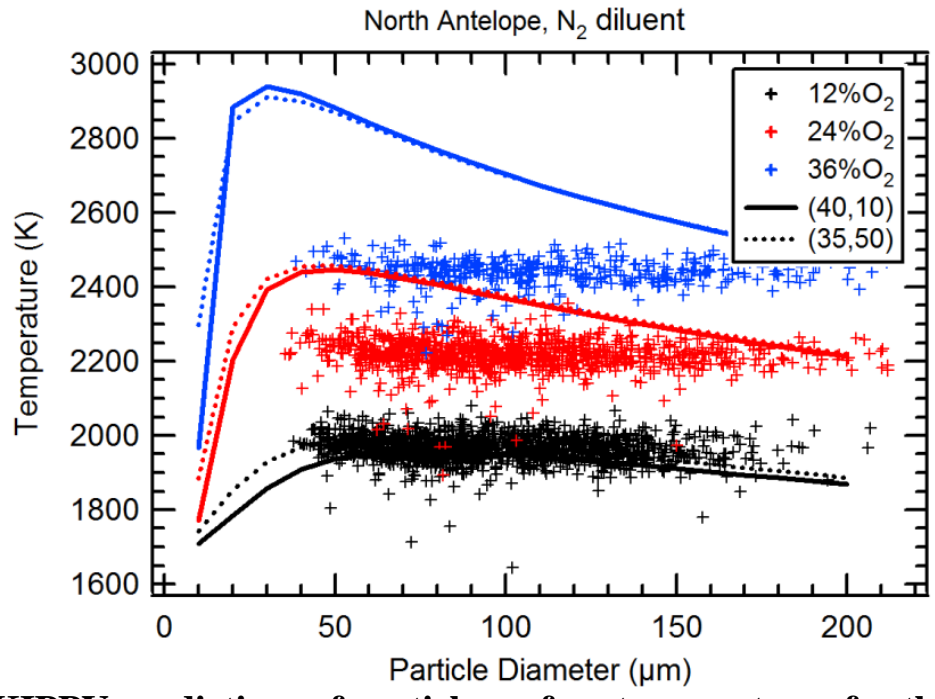

Figure 4.5-11. SKIPPY predictions of particle surface temperatures for three free-stream $\mathrm{O}_{2}$ concentrations, $16 \%$ moisture and $\mathrm{N}_{2}$ diluent compared with measured data for North Antelope char. The different model prediction lines correspond to different assumed combinations of oxidation activation energy and reactive surface area density, with assumed values for these two variables indicated by the parentheses in the legend. 
Based on the findings from this series of SKIPPY simulations, work was undertaken to write a flexible single-film model of char combustion that includes char oxidation and char gasification reactions. This model will be used to tune the gasification rate parameters (principally the Arrhenius rate pre-exponential factors) to give model predictions that are anticipated to show good agreement with the experimental data on char particle combustion temperatures collected earlier in the program. This model was then ready for incorporation into the Glacier model framework for CFD simulations of oxy-fuel boilers.

\subsubsection{Extended Single Film Model}

Establishment of a model to account for gasification reactions on the char surface, in addition to the oxidation reaction, relies on the same simplifying assumptions used in the derivation of the single-film model as outlined e.g. in (Turns 1996). In essence, an instantaneous energy balance and equation for conservation of mass are formulated on a homogeneous, non-porous, chemically reacting, spherical particle with reactant species diffusing from an infinite boundary to the particle surface. As no reactions are assumed to take place in the gas phase, the location of species conversion occurs only on the char surface and is based on the following heterogeneous reactions:

$$
\begin{aligned}
& \mathrm{C}(\mathrm{s})+(1+\psi) / 2 \mathrm{O}_{2} \rightarrow \psi \mathrm{CO}_{2}+(1-\psi) \mathrm{CO} \\
& \mathrm{C}(\mathrm{s})+\mathrm{CO}_{2} \rightarrow 2 \mathrm{CO} \\
& \mathrm{C}(\mathrm{s})+\mathrm{H}_{2} \mathrm{O} \rightarrow \mathrm{H}_{2}+\mathrm{CO}
\end{aligned}
$$

The $\mathrm{CO}_{2} / \mathrm{CO}$ production ratio is modeled as $\mathrm{CO}_{2} / \mathrm{CO} \equiv \psi /(1-\psi)=0.02 p\left(\mathrm{O}_{2, \mathrm{~s}}\right)^{0.21} \exp (3070 / T)$ (Tognotti, Longwell and Sarofim 1990), where $p\left(\mathrm{O}_{2, \mathrm{~s}}\right)$ is the oxygen partial pressure at the particle surface in atm, and $T$ is the particle surface temperature. The carbon production rate in $\mathrm{kmol} /\left(\mathrm{m}^{2} \cdot \mathrm{s}\right)$ follows from for an " $n$ th-order" Arrhenius kinetics rate law for each reactant according to

$$
\dot{s}_{\mathrm{C}(\mathrm{s})}^{\prime \prime}=-A_{i} T^{b_{i}} \exp \left(-\frac{E_{i}}{R T}\right)\left[\mathrm{R}_{i, s}\right]^{n_{i}}
$$

where $\left[\mathrm{R}_{i, s}\right]$ is the molar concentration of reactant $\mathrm{R}_{i}=\left\{\mathrm{O}_{2}, \mathrm{CO}_{2}, \mathrm{H}_{2} \mathrm{O}\right\}$ at the particle surface in $\mathrm{kmol} / \mathrm{m}^{3}$, $E_{i}$ is the activation energy in $\mathrm{kJ} / \mathrm{mol}$, and universal gas constant $R=8.3145 \mathrm{~J} /(\mathrm{K} \cdot \mathrm{mol})$. Reaction orders of $1\left(n_{i}=1\right)$ are frequently employed in CFD codes for these reactions, a choice justifiable mainly on numerical rather than physical grounds (according to classical Thiele analysis, apparent reaction orders are constrained to lie between 0.5 and 1 for Zone II combustion with partial reactant penetration of the porous char (Thiele 1939) (Mulcahy and Smith 1969). To follow the customary use of expressing the rate law in terms of reactant partial pressure instead of molar concentration, the temperature exponent $b_{i}=1$. With these assumptions, the pre-exponential factors $A_{i}$ are given in units of $\mathrm{m} / \mathrm{s}$.

The energy balance for steady-state consumption of char according to reactions 1-3 assumes the same form as for the traditional single-film model (Geier, Shaddix and Haynes 2010) (Murphy and Shaddix 2006), but with additional expressions for gas properties and overall heat of reaction. As $\mathrm{CO}_{2}$ is both a reactant and a product species, the differential equations for species conservation are somewhat more involved, but can still be solved analytically as long as constant gas properties are assumed. Due to reaction coupling through the individual char consumption rates, a solver for systems of nonlinear equations is generally necessary, however. While information on gas properties and other required input parameters can be readily obtained, kinetics rate parameters must be found empirically by fitting the model to the experimental data. For the limited amount of data at hand, typical literature values are substituted for the gasification activation energies here, leaving at most four parameters for the fit. The obtained rate parameters for the models discussed below are summarized in Table 4.5-3 and Table 4.5-4, with numerical subscripts 1-3 referring to reactions 1-3. 
Table 4.5-3. Rate Parameters For Utah Skyline Char Conversion.

\begin{tabular}{c|cccccc}
\hline Model & $\begin{array}{c}A_{1} \\
\mathrm{~m} / \mathrm{s}\end{array}$ & $\begin{array}{c}E_{1} \\
\mathrm{~kJ} / \mathrm{mol}\end{array}$ & $\begin{array}{c}A_{2} \\
\mathrm{~m} / \mathrm{s}\end{array}$ & $\begin{array}{c}E_{2} \\
\mathrm{~kJ} / \mathrm{mol}\end{array}$ & $\begin{array}{c}A_{3} \\
\mathrm{~m} / \mathrm{s}\end{array}$ & $\begin{array}{c}E_{3} \\
\mathrm{~kJ} / \mathrm{mol}\end{array}$ \\
\hline II & 0.0146 & 1.5 & 300 & 251.0 & 0 & 0 \\
IIIa & 0.0334 & 13.9 & 340 & 251.0 & 100 & 221.8 \\
IIIb & 0.0981 & 29.4 & 390 & 251.0 & 300 & 221.8 \\
IIIc & 0.499 & 50.6 & 440 & 251.0 & 1000 & 221.8 \\
\hline
\end{tabular}

Table 4.5-4. Rate Parameters For North Antelope Char Conversion.

\begin{tabular}{c|cccccc}
\hline Model & $\begin{array}{c}A_{1} \\
\mathrm{~m} / \mathrm{s}\end{array}$ & $\begin{array}{c}E_{1} \\
\mathrm{~kJ} / \mathrm{mol}\end{array}$ & $\begin{array}{c}A_{2} \\
\mathrm{~m} / \mathrm{s}\end{array}$ & $\begin{array}{c}E_{2} \\
\mathrm{~kJ} / \mathrm{mol}\end{array}$ & $\begin{array}{c}A_{3} \\
\mathrm{~m} / \mathrm{s}\end{array}$ & $\begin{array}{c}E_{3} \\
\mathrm{~kJ} / \mathrm{mol}\end{array}$ \\
\hline II & 0.0278 & 3.6 & 500 & 251.0 & 0 & 0 \\
IIIa & 0.116 & 25.5 & 590 & 251.0 & 100 & 221.8 \\
IIIb & 0.751 & 53.3 & 680 & 251.0 & 300 & 221.8 \\
IIIc & 22.2 & 99.4 & 740 & 251.0 & 1000 & 221.8 \\
\hline
\end{tabular}

\subsubsection{Results and Discussion}

Figure 4.5-12 shows the measured char particle temperature data for Utah Skyline char particles burning in $\mathrm{N}_{2}$ (left) and $\mathrm{CO}_{2}$ (right) diluents together with best-fit single-film model predictions corresponding to the rate parameters shown in Table 2. Consistent with the findings in (Shaddix and Molina 2008), measured temperatures are, for comparable $\mathrm{O}_{2}$ concentrations, on average lower in the $\mathrm{CO}_{2}$ environment. The data suggest that particle temperatures are nearly independent of particle size, with a mild negative correlation with size for lower oxygen concentrations. The data show an average char particle size of $100 \mu \mathrm{m}$ (consistent with the coal feed range of 75-106 $\mu \mathrm{m}$ ), so temperature data for the reported sizes between 97 and $103 \mu \mathrm{m}$ are therefore used to fit the models. To properly balance the model fits to variations in particle temperature (as the $\mathrm{O}_{2}$ content in the gas is varied) and to the presence or absence of significant $\mathrm{CO}_{2}$ concentrations, the different models shown in Tables 2 and 3 were adjusted manually to best match data for $12 \%$ and $36 \% \mathrm{O}_{2}$ in $\mathrm{N}_{2}$ and $36 \% \mathrm{O}_{2}$ in $\mathrm{CO}_{2}$ bath gas.

The best-fit results for a traditional oxidation-only model (Model I, not shown here) cannot predict the data well for both $\mathrm{N}_{2}$ and $\mathrm{CO}_{2}$ environments, and the obtained best-fit activation energies are zero or even negative, clearly in discord with physically reasonable values, indicating model inadequacy. These results have been previously reported (Geier, Shaddix and Haynes 2010). Figure 4.5-12 shows the best-fit singlefilm model results when including gasification reactions. Model II includes char gasification by $\mathrm{CO}_{2}$, but ignores steam gasification. This model, with three fitting parameters (a typical value of $251 \mathrm{~kJ} / \mathrm{mol}$ (Geier, Shaddix and Haynes 2010) was assumed for the activation energy of the gasification reaction), can, as expected, predict the temperatures around the fitting particle size $100 \mu \mathrm{m}$ and gives reasonable fits for both $\mathrm{N}_{2}$ and $\mathrm{CO}_{2}$-dominated environments. However, the value of the apparent activation energy of the oxidation reaction is physically unrealistic and thus indicative of model inadequacy. As $16 \%$ moisture was present in the test environments, it is possible that steam gasification plays a role in determining the char particle temperature. In that case, CFD model predictions may rapidly lose their validity at other levels of moisture when Model II is used. 

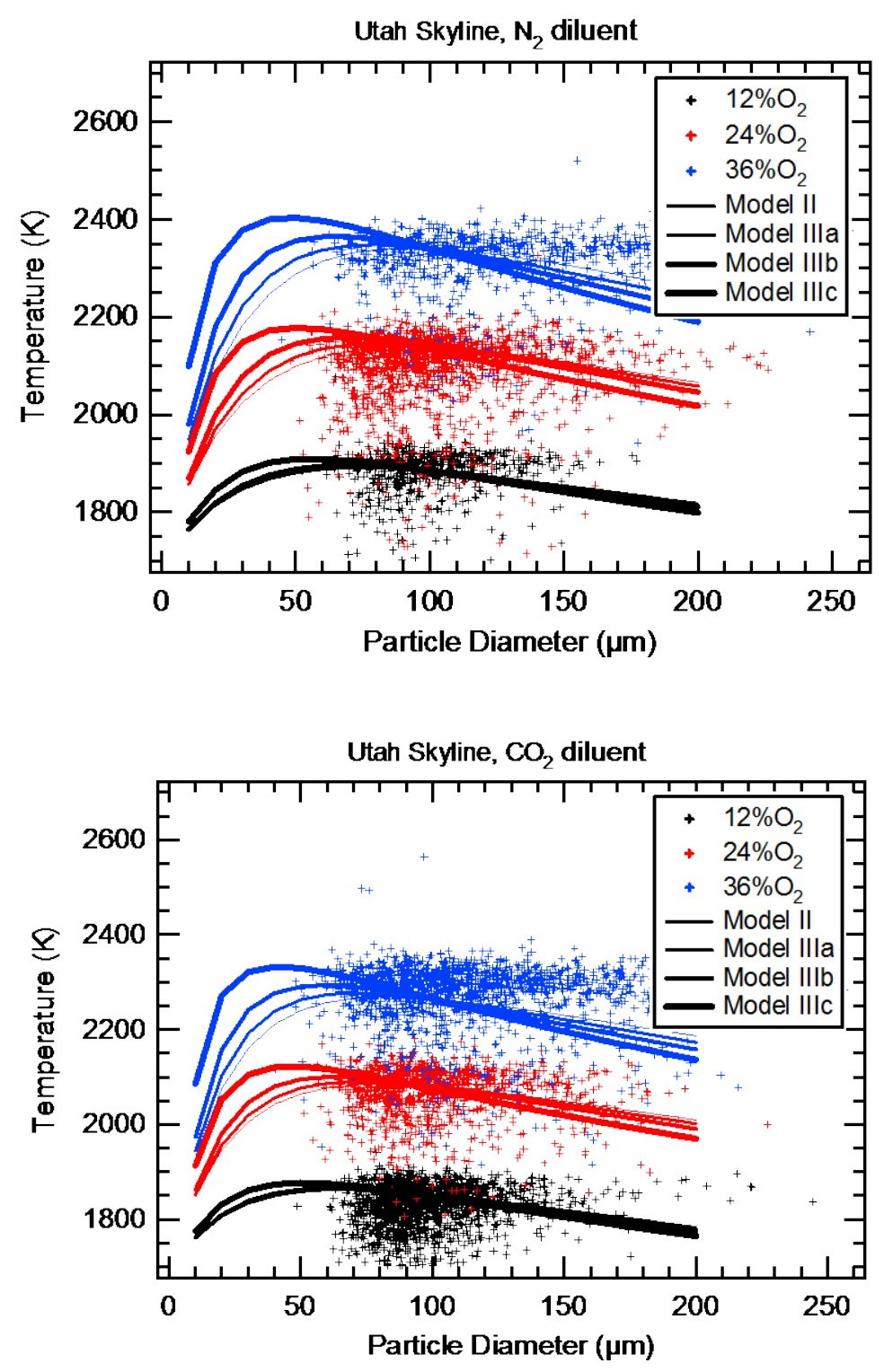

Figure 4.5-12. Predicted and measured (symbols) Utah Skyline char particle temperatures for three free-stream $\mathrm{O}_{2}$ concentrations, $16 \%$ moisture, and $\mathrm{N}_{2}$ and $\mathrm{CO}_{2}$ bath gas. Curves are predictions by models that allow for char consumption through oxidation and both steam and $\mathrm{CO}_{2}$ gasification. Models IIIa-c refer to different pre-exponential factors for the steam gasification reaction (Table 4.5-3).

Figure 4.5-12 also shows the prediction results for Model III, when including the steam gasification reaction together with $\mathrm{CO}_{2}$ gasification. Results for sub-models a-c of Model III correspond to different assumed values of the pre-exponential factor $A_{3}$ of the steam gasification reaction, while holding the activation energy fixed at $222 \mathrm{~kJ} / \mathrm{mol}$ (C.R., et al. June 6-10, 2010). Obviously, models with $A_{3}$ between 0 and $1000 \mathrm{~m} / \mathrm{s}$ can all be reasonably fitted to the $100 \mu \mathrm{m}$ data, which is no surprise given the constant moisture level for all data. A unique solution would require matching to data over a wide range of steam levels. Another means of differentiating the results for different assumed values of the steam gasification rate is to compare the derived best-fit apparent char oxidation activation energies. As shown in Table 2, the best-fit apparent activation energy for the oxidation reaction varies between 14 and $51 \mathrm{~kJ} / \mathrm{mol}$. These 
are rather low values, but with an $A_{3}$ value of $1000 \mathrm{~m} / \mathrm{s}$ at least it is approaching the expected Zone II char oxidation $\mathrm{E}_{\mathrm{a}}$ of $\sim 80 \mathrm{~kJ} / \mathrm{mol}$ (R.H. and J.K. Sun 1998). The best-fit char oxidation activation energy may be low because the assumption $n_{\mathrm{O} 2}=1$ may be too large. While frequently used in CFD codes, this assumption has been questioned by the scientific community (R.H. and Calo 2001). Alternatively, Langmuir kinetics models have been proposed as being more appropriate than power-law kinetics models, at least for steam and $\mathrm{CO}_{2}$ gasification reactions. Another reason for unrealistically low oxidation activation energies, however, is the likely relevance of $\mathrm{CO}$ conversion in the boundary layer (as suggested by previous detailed modeling), which is ignored in the single-film models discussed here. Note that fits with lower presumed activation energies of the two gasification reactions have also been performed, corresponding to Zone II behavior for those reactions, but this yields even lower values of the derived activation energy of the oxidation reaction.

Figure 4.5-13 shows experimental data and model predictions for North Antelope char particles. These particles burn hotter than the Utah Skyline particles, corresponding to their higher reactivity (as expected for a lower rank coal). The trends in both the data and the model fits are similar to those previously described for the Utah Skyline coal, except that the best-fit oxidation activation energies are somewhat higher. In particular, an apparent activation energy of $53 \mathrm{~kJ} / \mathrm{mol}$ is obtained for the oxidation reaction when a steam gasification pre-exponential of $300 \mathrm{~m} / \mathrm{s}$ is used. Therefore, for best self-consistency in the temperature dependence of char oxidation, it is recommended that the model parameters highlighted in yellow in Table 4.5-3 and Table 4.5-4 be used.

\subsubsection{Char Oxidation Mechanism Summary}

The traditional single-film $n$ th-order Arrhenius char oxidation model was extended by including additional heterogeneous reactions of char with $\mathrm{CO}_{2}$ and $\mathrm{H}_{2} \mathrm{O}$, as is required to accurately predict char particle temperatures and char consumption rates in both conventional and oxy-combustion environments. Particle temperatures from two-color pyrometer measurements of char particles burning in $\mathrm{N}_{2}$ and $\mathrm{CO}_{2}$ dominated gas environments were compared with predictions from the developed models with the goal to assess their predictive performance as part of CFD software. The results suggest that char consumption characteristics can be predicted reasonably well with the extended single-film model for a wide range of $\mathrm{O}_{2}$ and $\mathrm{CO}_{2}$ concentrations. Despite the wide application range, however, best-fit values of kinetic parameters are somewhat outside the range of physical meaningfulness, likely reflecting limitations from the neglect of CO conversion in the boundary layer, varying penetration of reactants into the char particle, and uncertainties in the actual heterogeneous reaction mechanism. 

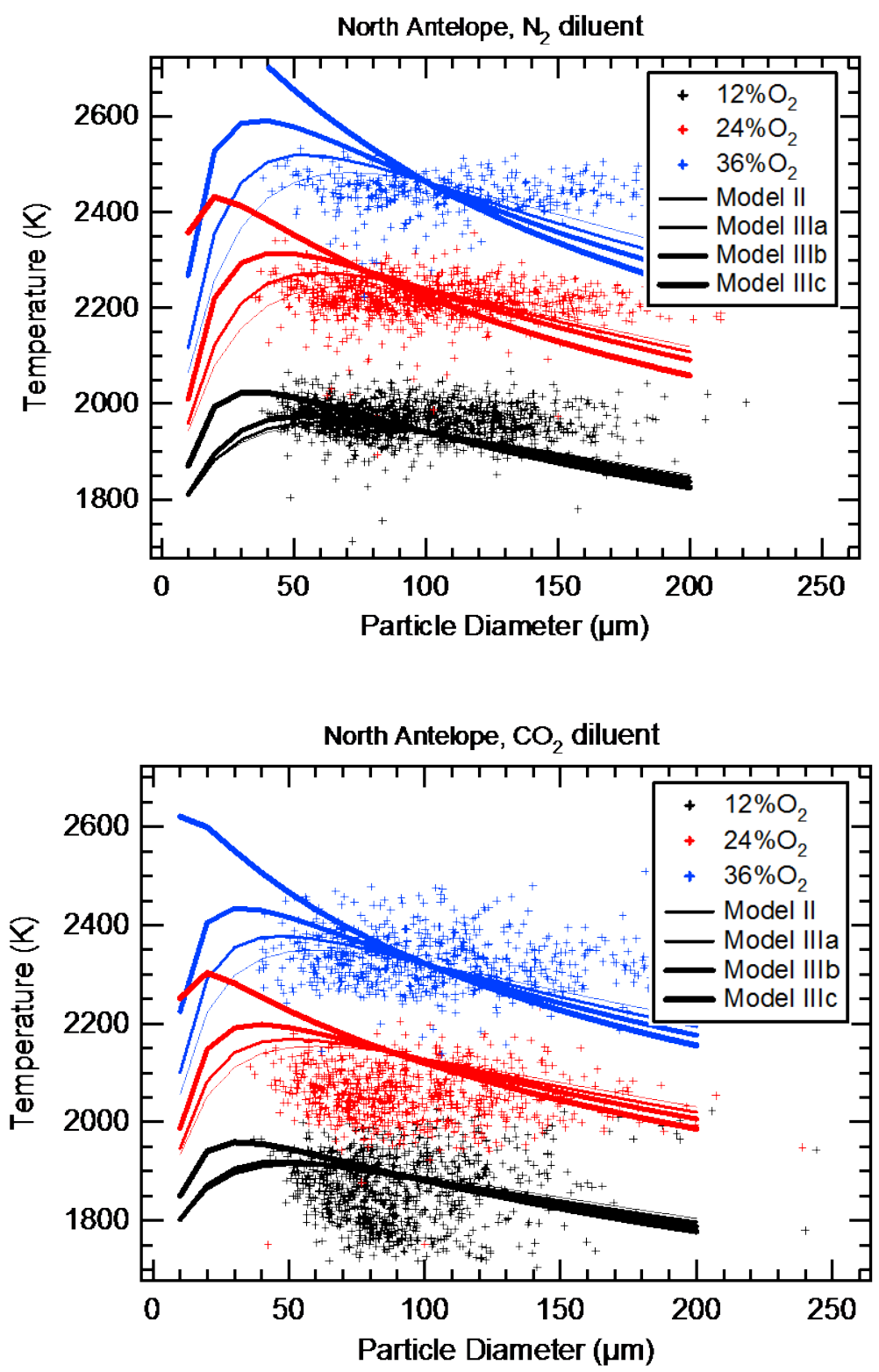

Figure 4.5-13. Predicted and measured (symbols) PRB North Antelope char particle temperatures for three free-stream $\mathrm{O}_{2}$ concentrations, $16 \%$ moisture, and $\mathrm{N}_{2}$ and $\mathrm{CO}_{2}$ bath gas. Curves are predictions by models that allow for char consumption through oxidation and both steam and $\mathrm{CO}_{2}$ gasification. Models IIIa-c refer to different pre-exponential factors for the steam gasification reaction (Table 4.5-4).

\subsubsection{CFD Modeling with the Extended Single-film Model}

According to recent work at Sandia, a single-film char reaction model typically employed in CFD may not be accurate as boundary reaction becomes more important for larger particles (> $60 \mu \mathrm{m})$ and $\mathrm{CO}_{2}$ and possibly $\mathrm{H}_{2} \mathrm{O}$ gasification reactions may need to be considered to assess total char burnout rate in oxyfiring conditions. Further study is being pursued on the importance of gasification reaction with a model including full chemistry with gasification reactions. On the other hand, it is important to understand what environment particles will actually experience under oxy-firing conditions. In this section, L1500 CFD 
modeling studies are compared to understand the differences of environment that particles could experience under air- and oxy-firing conditions.

\subsubsection{CFD Case Descriptions}

Case1A and Case2O compared here are L1500 CFD simulation cases and their operating conditions are summarized in Table 4.5-5. Case1A and Case2O are air- and oxy-firing cases, respectively, and both cases burn bituminous coal at a firing rate of 3.5MBtu/hr with $3.2 \%$ excess $\mathrm{O}_{2}$. Particle size distribution used in modeling was 74\% passing through 200 mesh and 99\% through 50 mesh. Calculated stoichiometric adiabatic temperatures with primary oxidant were $3,600^{\circ} \mathrm{F}$ and $3,085^{\circ} \mathrm{F}$ for Case $1 \mathrm{~A}$ and Case2O, respectively. Flue gas recirculation (FGR) was used in Case2O assuming $\mathrm{CO}_{2} 83.6 \%, \mathrm{H}_{2} \mathrm{O}$ $12.4 \%, \mathrm{O}_{2} 3.2 \%, \mathrm{~N}_{2} 0.6 \%$ and $\mathrm{SO}_{2} 0.1 \%$.

Table 4.5-5: Operating Conditions for Case1A and Case2O.

\begin{tabular}{|c|c|c|}
\hline & Case 1A & Case 20 \\
\hline Firing Rate (MBtu/hr) & 3.5 & 3.5 \\
\hline Oxidizer & Air & $\mathrm{O}_{2}+\mathrm{FGR}$ \\
\hline Total Coal Flow (lb/hr) & 279 & 279 \\
\hline PAFlow (lb/hr) & 524.3 & 683 \\
\hline PAFlow/Coal Mass Ratio & 1.88 & 2.45 \\
\hline PA Temperature ( ${ }^{\circ} \mathrm{F}$ ) & 150 & 150 \\
\hline PA Velocity (ft/s) & 72 & 69 \\
\hline PA Stoichiometric Ratio & 0.1961 & 0.2133 \\
\hline PAFeed $O_{2}(w t \%)$ & N/A & $17.10 \%$ \\
\hline $\mathrm{O}_{2}$ concentration (volumn) in PA & $20.70 \%$ & $23.20 \%$ \\
\hline InnerSA Flow (Ib/hr) & 285.5 & 189.7 \\
\hline Outer SA Flow (lb/hr) & 1617.8 & 1809.9 \\
\hline Inner SA Feed O2 (wt\%) & N/A & $41.00 \%$ \\
\hline Outer SA Feed O2 (wt\%) & N/A & $17.10 \%$ \\
\hline Inner SA Temperature ( $\left.{ }^{\circ} \mathrm{F}\right)$ & 500 & 500 \\
\hline Outer SA Temperature ( $\left.{ }^{\circ} \mathrm{F}\right)$ & 500 & 500 \\
\hline Burner Stoichiometric Ratio & 0.91 & 0.91 \\
\hline
\end{tabular}

\subsubsection{CFD Predicted Environment for Particles}

Flue gas temperature and $\mathrm{O}_{2}$ concentration profiles inside of the furnace are shown Figure 4.5-14. As expected from the lower adiabatic flame temperature, Case2O shows lower flue gas temperature profile than Case1A. Figure 4.5-14 also shows $\mathrm{O}_{2}$ concentration profiles from the two cases. Relatively high $\mathrm{O}_{2}$ concentration near the burner can be found in Case2O and both cases show similarly low $\mathrm{O}_{2}$ concentrations along the center of the furnace representing a core fuel rich zone of the flame. Significant differences between Case1A and Case2O can be found in $\mathrm{CO}_{2}$ and $\mathrm{H}_{2} \mathrm{O}$ concentrations (see Figure 4.5-15) due to flue gas recirculation used in oxy-firing case. This illustrates that gasification reaction can be important and proper treatment for $\mathrm{CO}_{2}$ and $\mathrm{H}_{2} \mathrm{O}$ gasification may need to be implemented into a model to estimate char consumption accurately under oxy-firing conditions. 


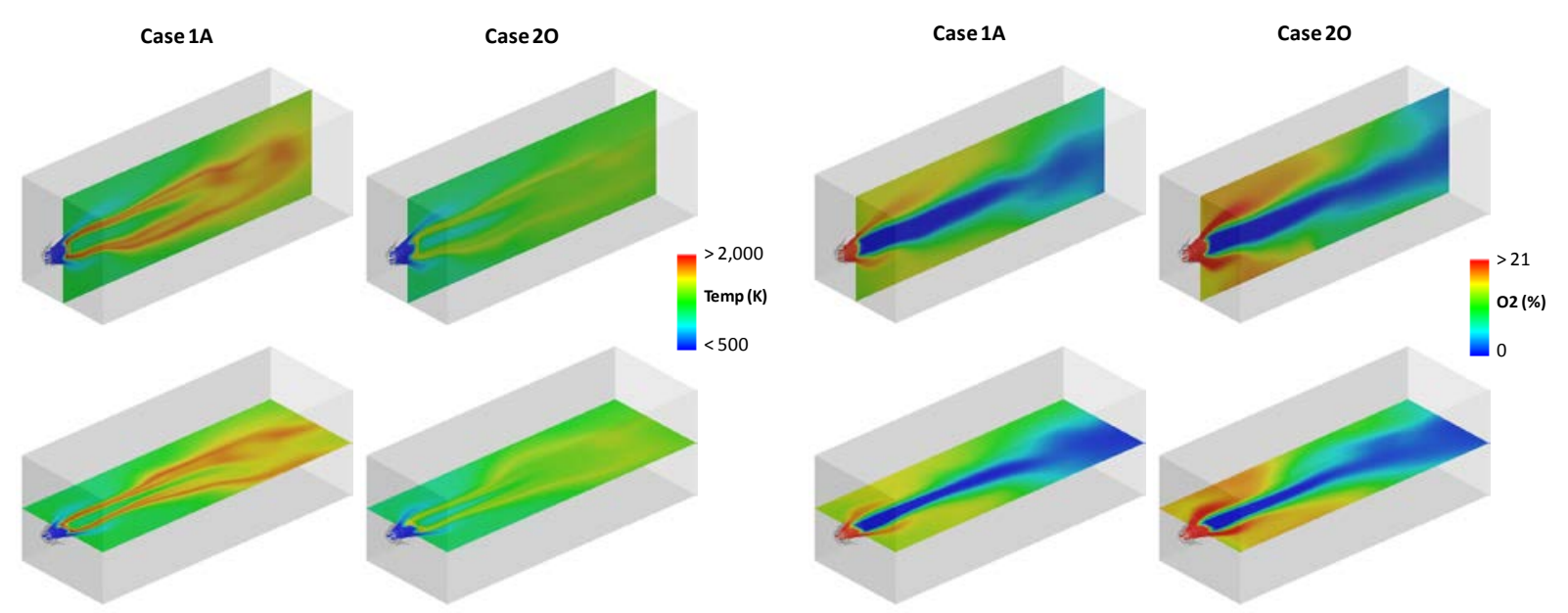

Figure 4.5-14: Flue gas temperature and $\mathrm{O}_{2}$ concentration profiles for Case1A and Case2O.
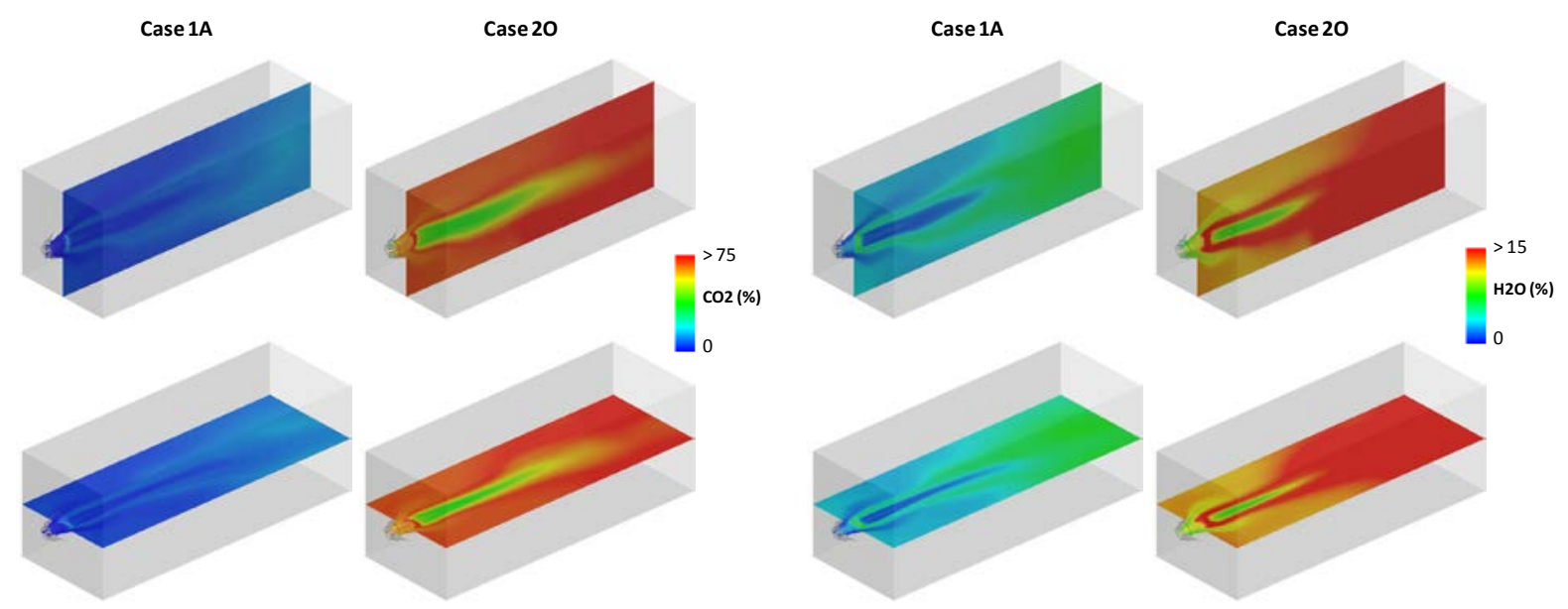

Figure 4.5-15: $\mathrm{CO}_{2}$ and $\mathrm{H}_{2} \mathrm{O}$ concentration profiles for Case1A and Case2O.

Figure 4.5-16 shows the particle trajectories calculated for Case1A and Case2O colored by oxygen concentration along the particle trajectory. Based on these trajectories, the oxygen concentrations each particle experienced before complete burnout are shown in Figure 4.5-17. The main difference was that under oxy-firing conditions, 36\% of particles experienced oxygen concentrations higher than 21\%, whereas there were no particles that experienced such high $\mathrm{O}_{2}$ concentrations under air-firing conditions.

The higher $\mathrm{CO}_{2}$ and $\mathrm{H}_{2} \mathrm{O}$ concentration (Figure 4.5-15) and higher $\mathrm{O}_{2}$ concentrations (Figure 4.5-17) that particles experience under oxy-combustion imply that gasification reactions may need to be considered to accurately describe char reactions in a CFD model. 


\section{Case 1A}

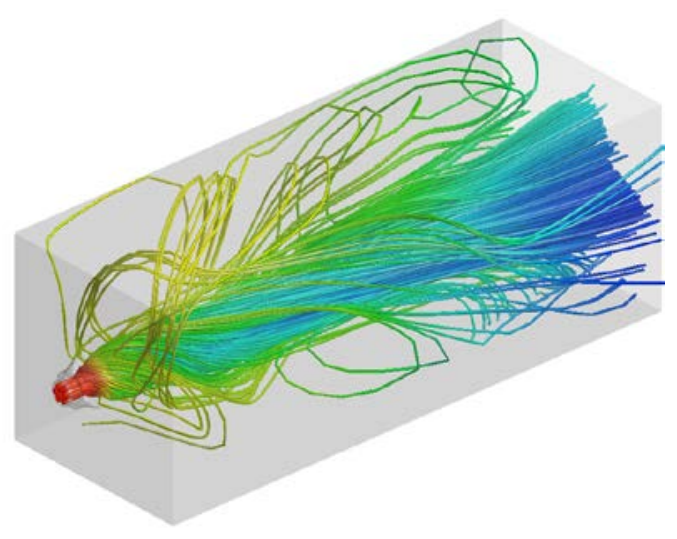

Case 20

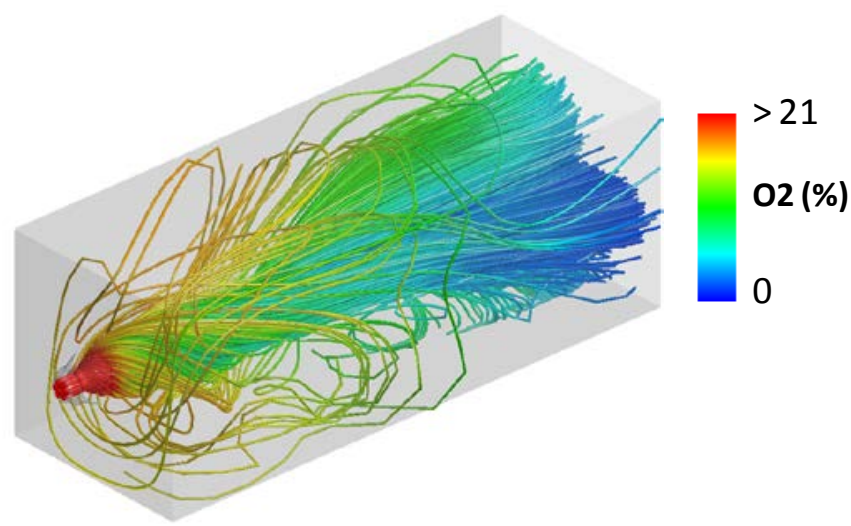

Figure 4.5-16: Particle trajectories colored with oxygen concentration scale for Case1A and Case20.

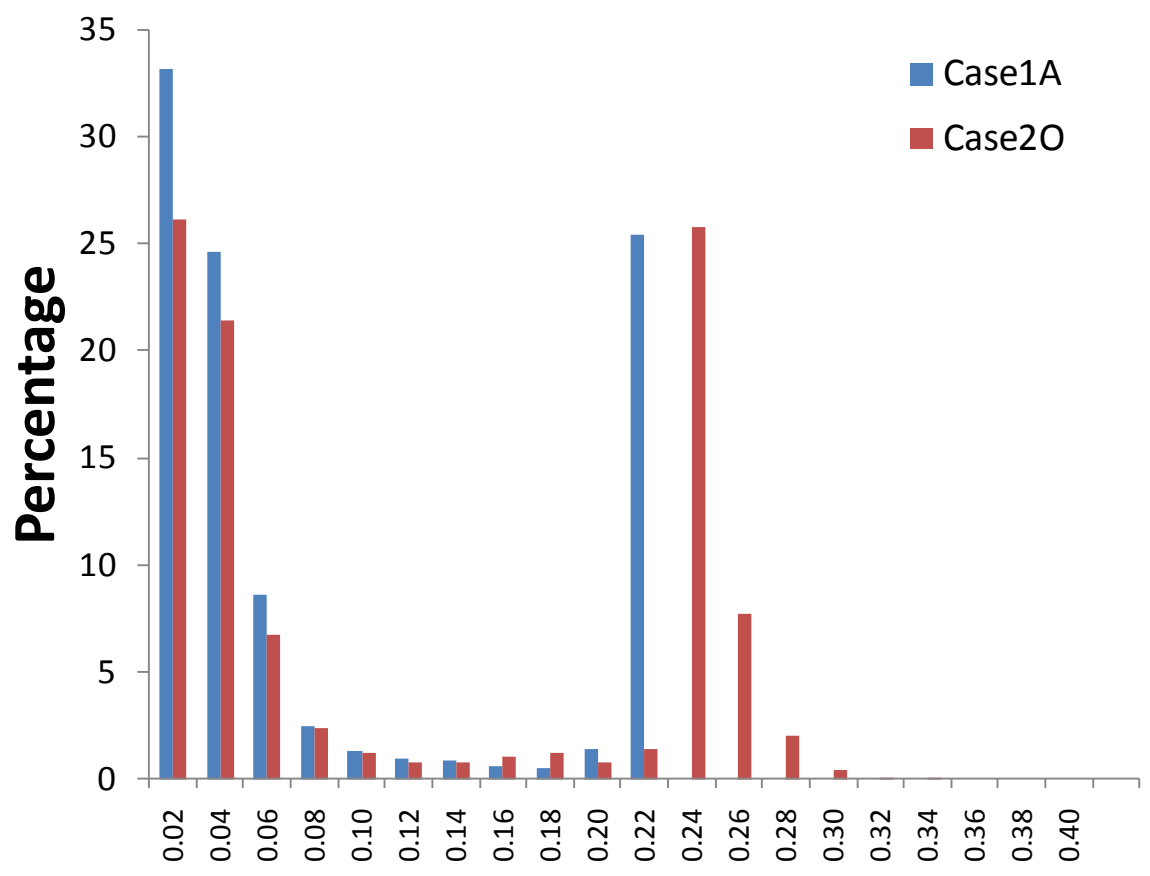

\section{Oxygen Mole Fraction Bin}

Figure 4.5-17: Oxygen concentration distributions particles experience based on the predicted particle trajectories for Case1A and Case2O.

Further CFD modeling of the extended char oxidation model in the L1500 pilot-scale can be found in Section 4.12.3. This includes comparisons between predicted and measured CO data. 


\subsubsection{Entrained Flow Reactor (EFR) Validation}

In this section, the extended single film model was evaluated within REI's CFD code, Glacier, and its particle temperature predictions for the entrained flow reactor used at Sandia were compared with those from the standard char reaction model.

\subsubsection{Entrained Flow Reactor (EFR) and Operating Conditions}

Particle size and temperature data were obtained using an optical entrained flow reactor in a configuration described previously. The combustion-driven reactor relies on a diffusion-flamelet-based Hencken burner to produce a high-temperature gas flow at ambient pressure $(1 \mathrm{~atm})$ into which coal particles are introduced at the furnace centerline. The particle carrier flow rate is very small relative to the overall burner flow rate and compositionally matches the diluent in the main reactant flow (i.e. $\mathrm{N}_{2}$ or $\mathrm{CO}_{2}$ ). The coal particles were delivered to the flow reactor at a rate sufficiently small $(\sim 0.6 \mathrm{~g} / \mathrm{hr})$ to assure that injected particles burned in isolation from one another. The hot, post-combustion gas flow is shielded from the surrounding air by means of a $46 \mathrm{~cm}$ tall $5 \mathrm{~cm} \times 5 \mathrm{~cm}$ quartz chimney, which also provides optical access for in situ optical measurements on particles injected into the flow.

Size-classified coal particles were entrained into mixtures with 12, 24 or 36 mole- $\% \mathrm{O}_{2}, 16 \%$ moisture, and $\mathrm{CO}_{2}$ or $\mathrm{N}_{2}$ as balance gas. Particle temperature-size data were collected at locations between 25 and $125 \mathrm{~mm}$ above the burner face. At these locations, the gas temperatures were $1680 \pm 40 \mathrm{~K}$, with a peak at about $1700 \pm 10 \mathrm{~K}$ at $50 \mathrm{~mm}$ above the burner surface and a subsequent linear decay with height in the furnace. The total burner product flow rate was $60 \mathrm{slpm}$ (standard liters per minute), which includes 0.03 slpm of diluent flow for conveying the particles through the feed tube ( $0.75 \mathrm{~mm}$ ID).

To compare particle temperatures predicted by the extended single film model with those by standard CFD global char reaction model, the same reactor operating conditions were used in CFD simulation. Figure 4.5-18 shows the computational mesh generated for the entrained flow reactor. 


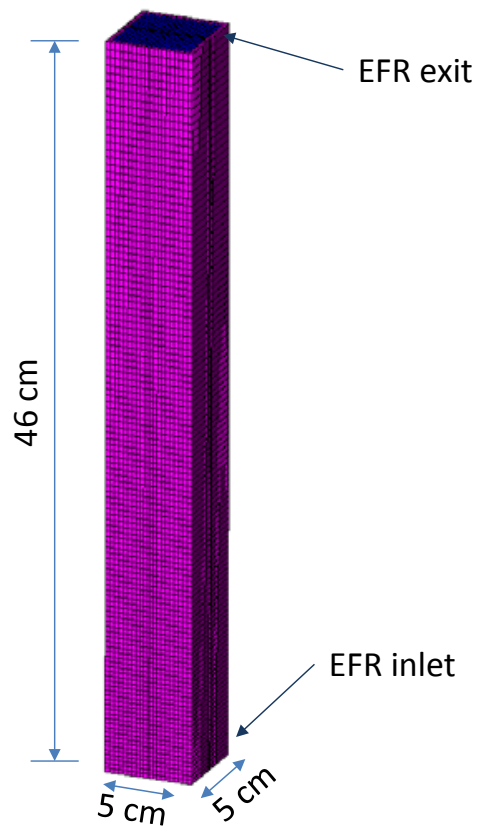

Figure 4.5-18. Computational mesh generated for the entrained flow reactor: the total number of cells is 53,802 .

The experimental data shown are for a western U.S., low-sulfur, high-volatile bituminous coal (Utah Skyline) and a low-sulfur subbituminous coal from the Powder River Basin (North Antelope), with proximate and ultimate analyses shown in Table 4.5-6. Analysis of three coal size fractions (53-75 $\mu \mathrm{m}$, 75-106 $\mu \mathrm{m}$ and 106-125 $\mu \mathrm{m}$ ) confirmed size-independent elemental composition and ash contents. The data presented here correspond to a coal particle feed of 75-106 $\mu \mathrm{m}$.

Table 4.5-6. Proximate and Ultimate Analysis of Coals.

\begin{tabular}{|c|c|c|c|c|}
\hline \multirow[b]{2}{*}{ Proximate } & \multicolumn{4}{|c|}{ Coal Type } \\
\hline & $\begin{array}{l}\text { Utah } \\
\text { wt } \% \text {, as } \\
\text { rec'd }\end{array}$ & $\begin{array}{l}\text { kyline } \\
\text { wt\% dry }\end{array}$ & $\begin{array}{l}\text { North } \\
\text { wt\%, as } \\
\text { rec'd }\end{array}$ & $\begin{array}{l}\text { Antelope } \\
\text { wt\% dry }\end{array}$ \\
\hline moisture & 3.18 & & 23.69 & \\
\hline ash & 8.83 & 9.12 & 4.94 & 6.47 \\
\hline volatiles & 38.60 & 39.87 & 33.36 & 43.72 \\
\hline fixed C & 49.39 & 51.01 & 38.01 & 49.81 \\
\hline Ultimate & wt $\%$ dry & $\mathrm{wt} \% \mathrm{DAF}$ & wt\% dry & wt $\%$ DAF \\
\hline $\mathrm{C}$ & 70.60 & 77.44 & 53.72 & 56.51 \\
\hline $\mathrm{H}$ & 5.41 & 5.93 & 6.22 & 6.54 \\
\hline O (by diff.) & 13.21 & 14.49 & 34.11 & 35.88 \\
\hline $\mathrm{N}$ & 1.42 & 1.56 & 0.78 & 0.82 \\
\hline $\mathrm{S}$ & 0.53 & 0.58 & 0.23 & 0.24 \\
\hline
\end{tabular}




\subsubsection{EFR Simulation Results}

The extended single film char reaction model relies on the same simplifying assumptions used in the derivation of the single-film model as in (Turns 1996) and includes char gasification reactions as well as oxidation and the description of $\mathrm{CO} / \mathrm{CO}_{2}$ production ratio. The reported kinetic parameters for each heterogeneous reaction in the previous report were used in this study (see Table 4.5-7). The extended single film model with the kinetic parameters was discussed previously and paper (M. Geier, C. Shaddix, et al. June 5-9, 2011) in detail.

Table 4.5-7. Rate parameters for Utah Skyline and North Antelope char conversion.

\begin{tabular}{l|llllll}
\hline \multirow{2}{*}{ Coal } & $A_{1}$ & $E_{1}$ & $A_{2}$ & $E_{2}$ & $A_{3}$ & $E_{3}$ \\
$\mathrm{~m} / \mathrm{s} / \mathrm{mol}$ & $\mathrm{m} / \mathrm{s}$ & $\mathrm{kJ} / \mathrm{mol}$ & $\mathrm{m} / \mathrm{s}$ & $\mathrm{kJ} / \mathrm{mol}$ \\
\hline Utah Skyline & 0.499 & 50.6 & 440 & 251.0 & 1000 & 221.8 \\
North Antelope & 0.751 & 53.3 & 680 & 251.0 & 300 & 221.8 \\
\hline
\end{tabular}

Figure 4.5-19 to Figure 4.5-21 show the measured and the predicted gas temperature profiles along the centerline of the EFR in 12, 24 or $36 \%, 16 \%$ moisture, and $\mathrm{N}_{2}$ and $\mathrm{CO}_{2}$ as balance gas. The predicted gas temperatures shown here are from the CFD simulation with the extended single film char reaction model. The predicted gas temperature profiles are consistent with those measured except the initial peak at 0.05 $\mathrm{m}$ or less from the burner face. These peaks are resulted from the steady state nature of the CFD calculation, while the actual experiments were performed in a very dilute environment. As fuel source is steadily accumulated along the centerline of the reactor, the combustion of these fuel sources increases the gas temperature nearby and forms the peaks. The calculations also slightly underestimate the gas temperature downstream in $\mathrm{N}_{2}$ environment, but the differences from the measurements are not significant. The temperature profiles (not shown here) predicted by the standard CFD code were also consistent with the measured gas temperatures.
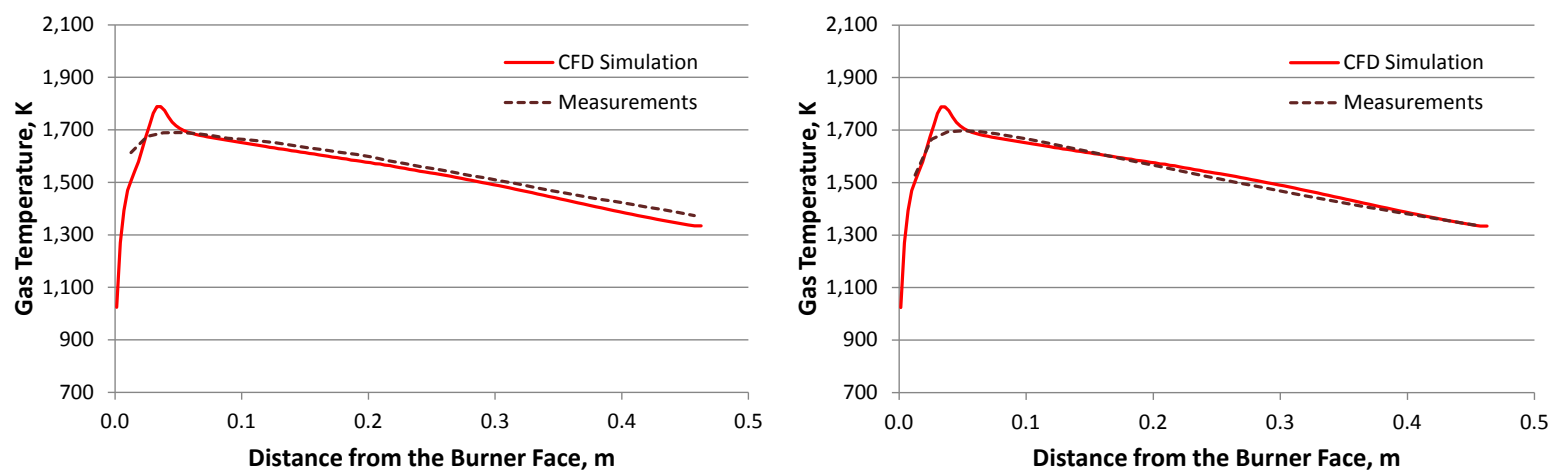

Figure 4.5-19. Comparison of the gas temperatures along the centerline of the reactor: $12 \% \mathrm{O}_{2}$ in $\mathrm{N}_{2}$ (left) and $\mathrm{CO}_{2}$ (right). 

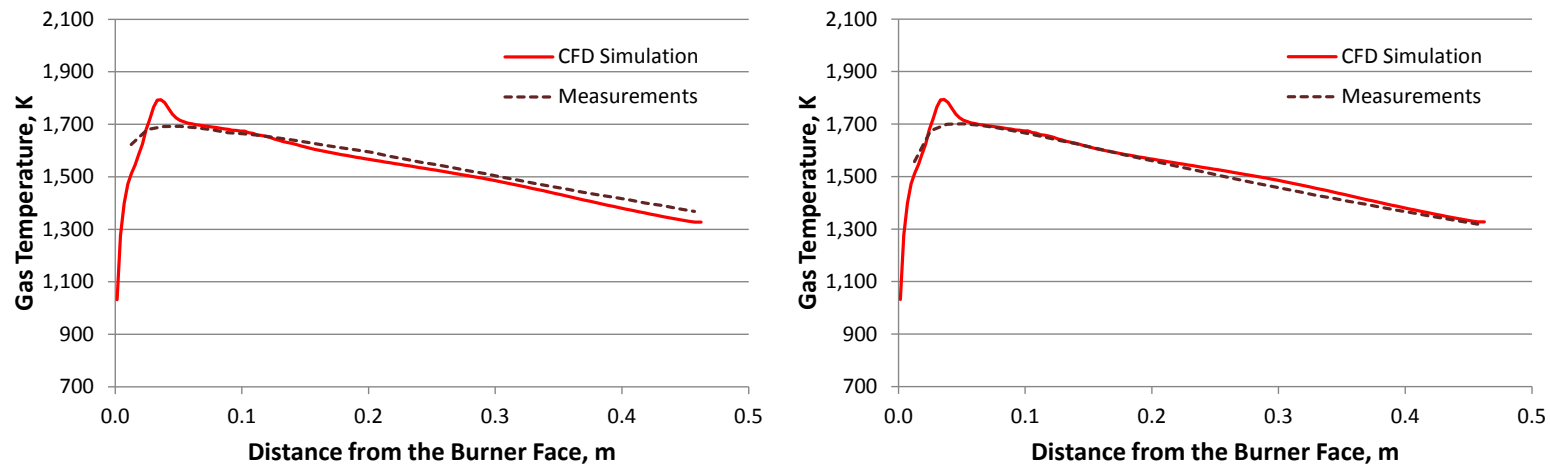

Figure 4.5-20. Comparison of the gas temperatures along the centerline of the reactor: $24 \% \mathrm{O}_{2}$ in $\mathrm{N}_{2}$ (left) and $\mathrm{CO}_{2}$ (right).
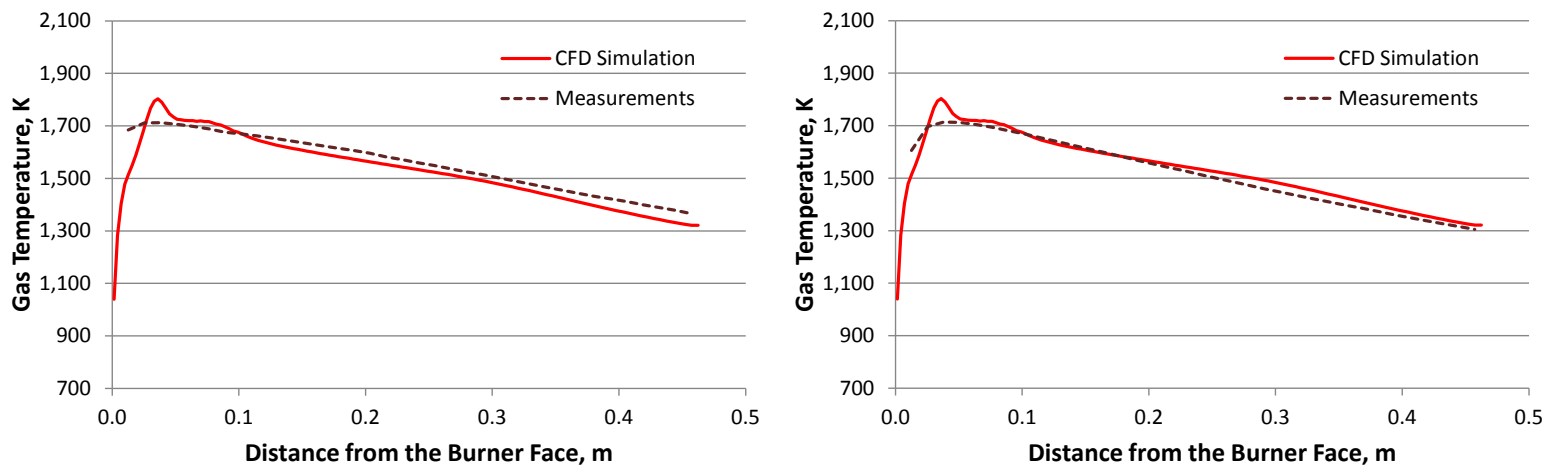

Figure 4.5-21. Comparison of the gas temperatures along the centerline of the reactor: $36 \% \mathrm{O}_{2}$ in $\mathrm{N}_{2}$ (left) and $\mathrm{CO}_{2}$ (right).

Figure 4.5-22 shows the comparison of the predicted particle temperatures with the measured ones for Utah Skyline coal in 12, 24, or $36 \%, 16 \%$ moisture, and $\mathrm{N}_{2}$ as balance gas. The measured particle temperatures were plotted as a function of the particle size, while the predicted particle temperature plotted at 85 and $95 \mu \mathrm{m}$ in particle diameter for easy comparison. The predicted particle temperatures from the standard CFD code (circles) significantly underestimate the particle temperature and the difference in the particle temperature increases with increasing $\mathrm{O}_{2}$ concentration in the environment. However, the predictions made by the CFD simulation with the extended single film model and the relevant kinetic parameters (squares) agree well with the measurements.

Figure 4.5-23 shows the comparison of the particle temperatures when $\mathrm{CO}_{2}$ is used as a balance gas. As shown in the figure, the overall agreement was better when the extended single film model was used, even though some differences were still observed. 


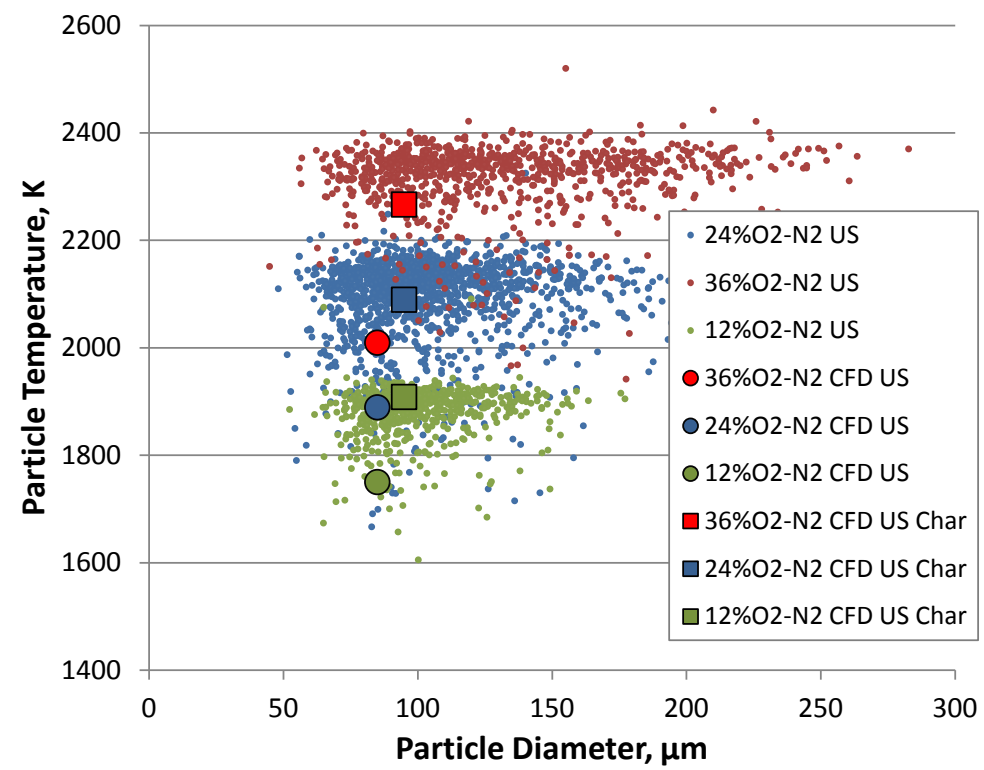

Figure 4.5-22. Comparison of the predicted particle temperatures with the measured for Utah Skyline coal in 12, 24, or $36 \% \mathrm{O}_{2}, 16 \% \mathrm{H}_{2} \mathrm{O}$, and $\mathrm{N}_{2}$ as balance gas.

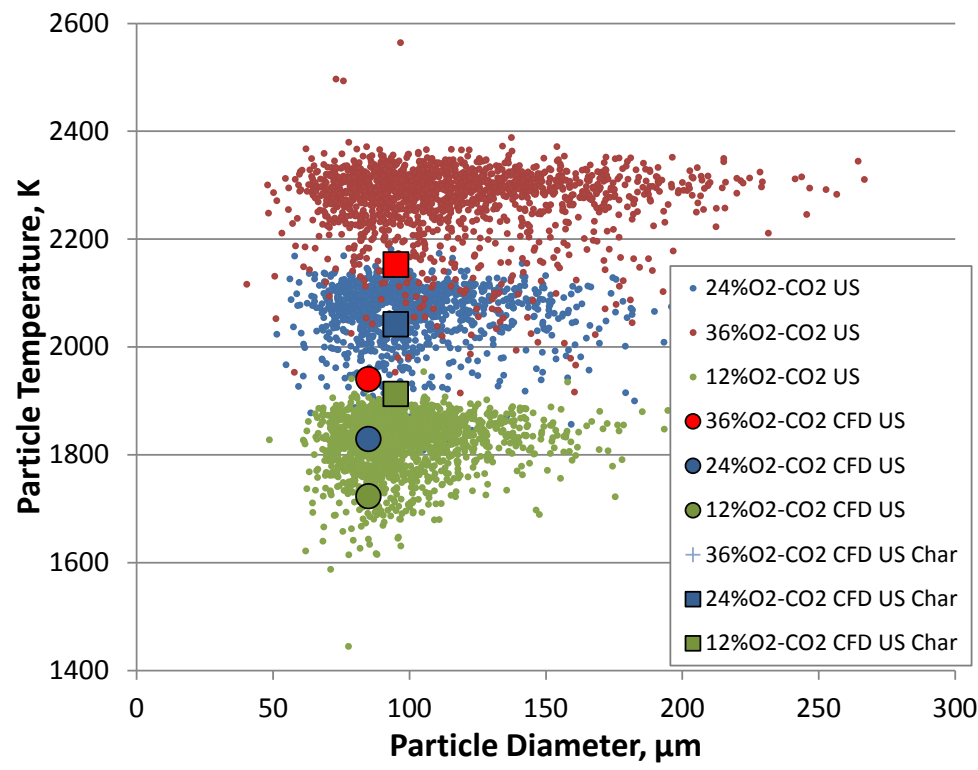

Figure 4.5-23. Comparison of the predicted particle temperatures with the measured for Utah Skyline coal in 12, 24, or $36 \% \mathrm{O}_{2}, 16 \% \mathrm{H}_{2} \mathrm{O}$, and $\mathrm{CO}_{2}$ as balance gas.

Figure 4.5-24 and Figure 4.5-25 show the comparison of the predicted particle temperatures with the measured for North Antelope coal in 12, 24, or 36\%, $16 \%$ moisture, and $\mathrm{N}_{2}$ or $\mathrm{CO}_{2}$ as balance gas. As expected for a lower rank coal, the particle temperatures are higher than the Utah Skyline particles. The trends in the comparisons are similar to those previously described for the Utah Skyline coal. 


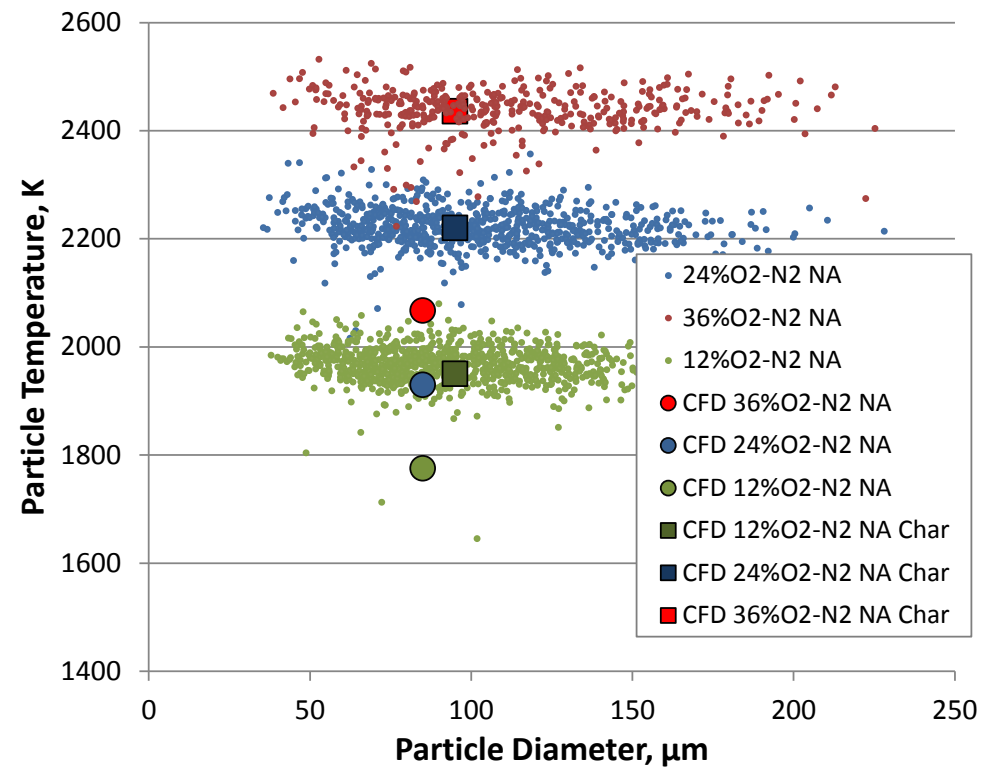

Figure 4.5-24. Comparison of the predicted particle temperatures with the measured for North Antelope coal in 12, 24, or $36 \% \mathrm{O}_{2}, 16 \% \mathrm{H}_{2} \mathrm{O}$, and $\mathrm{N}_{2}$ as balance gas.

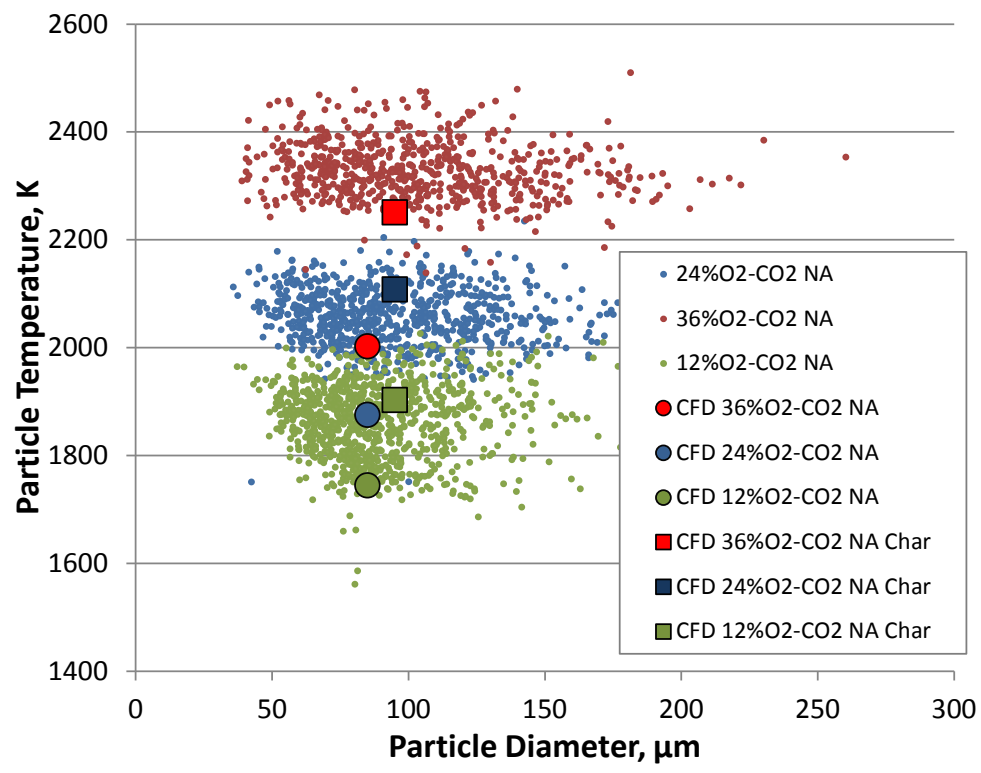

Figure 4.5-25. Comparison of the predicted particle temperatures with the measured for North Antelope coal in 12, 24, or $36 \% \mathrm{O}_{2}, 16 \% \mathrm{H}_{2} \mathrm{O}$, and $\mathrm{CO}_{2}$ as balance gas.

\subsubsection{EFR Validation Summary}

Overall agreement with the measured values in the predicted particle temperature and therefore particle reaction rates in both $\mathrm{N}_{2}$ and $\mathrm{CO}_{2}$ rich environments are better with the extended single film char reaction model. These comparisons, however, were made under relatively high $\mathrm{O}_{2}$ concentration and needs careful further assessment in applying to various operating conditions. In conclusion, the extended single 
film char reaction model was successfully implemented into Glacier and could reproduce the Sandia's results.

\subsubsection{Char Oxidation Conclusions}

In summary, an extended single film model was developed that improved prediction of char oxidation for the oxy-combustion environment. The extended film model was based on measured data taken for conditions representative of air-fired and oxy-fired environments. Comparison to data showed that reliable CFD predictions seem feasible for both conventional and oxy-combustion environments if steam and $\mathrm{CO}_{2}$ gasification reactions are included in Single-Film model. Activation energies for oxidation were closer to anticipated values but are relatively small for $n O x=1$. This is an indication for model inadequacy. Char consumption rates appear to be similar for both $\mathrm{CO}_{2}$ and $\mathrm{N}_{2}$ environments at equal $\mathrm{O}_{2}$ concentrations, but are sensitive to gasification rates at high particle temperatures (due to high $\mathrm{O}_{2}$ concentrations). When compared with data from the EFR, the new char oxidation model resulted in good agreement with the measured char consumption rates. The model was further evaluated for pilot-scale and full-scale systems, as reported in Section 4.12 and Section 4.13. 


\subsection{Soot}

\subsubsection{Introduction}

In 2010, line-of-sight soot measurements were obtained in the L1500 furnace at the University of Utah for both air and oxy-fired conditions with two coals; a sub-bituminous Powder River Basin (PRB) coal and a bituminous Skyline Utah coal. The measurements were collected at a single axial distance from the burner. Soot was found to be a strong function of stoichiometric ratio (SR). An increase in SR was found to produce a decrease in soot. The soot volume fraction of the oxy-combustion cases was slightly lower for both coals and the soot produced by the PRB coal was higher than soot produced by the Skyline coal. Additional details for these results can be found in the annual 2010 report.

In the winter of 2011, soot measurements were obtained in the $125 \mathrm{~kW}$ Oxy-Fuel Combustor (OFC) at the University of Utah. Although three coals were utilized, useful data were obtained for only the PRB and Skyline coals. These data were taken at three axial locations for air -fired conditions, for oxy-fired conditions where $\mathrm{CO}_{2}$ was used as an oxygen diluent and for oxy-fired conditions with recycled exhaust gas used as the oxygen diluent. As with the L1500 data, a strong trend of decreasing soot with increasing SR was observed; however, there was no measurable difference between soot levels in air and oxy-fired cases when measured at the same SR In the OFC, the Skyline coal produced the more soot than the PRB coal.

A conceptual model for soot formation in coal flames is proposed as a means of explaining the results. The results suggest that parameters such as: fluid dynamics, coal reactivity, and coal composition play a more significant role in soot formation and oxidation than chemical effects that are caused by replacing $\mathrm{N}_{2}$ with $\mathrm{CO}_{2}$. Changes in flow patterns and ignition caused by oxy mixtures are the drivers for changes in soot.

\subsubsection{Experimental Setup}

\subsubsection{Background}

One frequently used method for measuring soot in flames is line of sight laser light extinction. If the complex refractive index of soot is known and assumptions are made regarding the soot shape or morphology, the average soot volume fraction along a given path can be determined. Measuring soot in a coal flame is more challenging than pure hydrocarbon flames because of the presence of other solid particles such as coal, char, and ash. Transmittance of two laser beams at two separate wavelengths can be used to overcome this difficulty.

Soot particles, coal, char and ash all absorb light volumetrically, and as such the transmittance of light through the particles is subject to Beer's law as shown in Eq. 4.6-1; $\kappa$ is the extinction coefficient and $\mathrm{L}$ is the path length. For spherical particles, the extinction coefficient is the product of: 1) $Q_{e x t}$, the fraction of incident light on a particle that is absorbed by the particle, 2) The projected surface area of a particle, and 3) the number density $(N / V)$ of the particles as shown in Eq. 4.6-2. The extinction coefficient is therefore the key parameter that must be determined to convert extinction measurements to soot volume fractions.

$$
\tau=\frac{I}{I_{0}}=\exp (-\kappa L)
$$




$$
\tau=\frac{I}{I_{0}}=\exp \left(-Q_{e x t} \frac{\pi d^{2}}{4} \frac{N}{V} L\right)
$$

When determining the extinction coefficient, the size parameter $\alpha=\pi \mathrm{d} / \lambda$ can be helpful in identifying simplifications which can be made. Table 4.6-1 shows the relationship between the size parameter and the extinction coefficient based on information from (Kerker 1969). The dependence of $\mathrm{Q}_{\text {ext }}$ on wavelength is strong for small particles but becomes independent of wavelength for large particles. This difference in the dependence of the extinction coefficient on wavelength is utilized to separate the extinction of coal, char, and ash from soot particles.

Table 4.6-1: Dependence of the extinction coefficient on the size of particles.

\begin{tabular}{|l|l|l|}
\hline $\begin{array}{l}\text { Size } \\
\text { Parameter }\end{array}$ & $\mathrm{Q}_{\mathrm{ext}}$ & Comment \\
\hline$\alpha<0.1$ & $\begin{array}{l}\text { Rayleigh Limit } \\
Q_{\text {ext }}=4 \frac{\pi d}{\lambda}\left|\frac{m^{2}-1}{m^{2}+2}\right|\end{array}$ & $\begin{array}{l}\text { Unagglomerated soot particles are in } \\
\text { this size range }\end{array}$ \\
\hline $0.1<\alpha<50$ & $\begin{array}{l}\text { Full Mie Solution } \\
\mathrm{Q}_{\mathrm{ext}}=\mathrm{f}(\lambda, \mathrm{m}, \mathrm{d})\end{array}$ & $\begin{array}{l}\text { Soot can be in the lower end of this } \\
\text { size range }\end{array}$ \\
\hline $50<\alpha$ & $\mathrm{Q}_{\mathrm{ext}}=2.0$ & $\begin{array}{l}\text { Ash and coal particles are in this size } \\
\text { range }\end{array}$ \\
\hline
\end{tabular}

The total extinction for the two groups of particles is given by Eq. 4.6-3 where the total transmittance is the product of the extinction due to soot and the extinction due to coal, char and ash (сca).

$$
\tau=\frac{I}{I_{0}}=\exp \left(-\kappa_{\lambda, \text { soot }} L\right) \exp \left(-\kappa_{c c a} L\right)
$$

Using two measured wavelengths, an equation for each measured transmittance can be written. Taking the natural $\log$ and subtracting one transmittance equation from the others produces Eq. 4.6-4. In this equation, the two terms $\kappa_{\mathrm{cca}} \mathrm{L}$ can be cancelled because there is no wavelength dependence of the coal char and ash leaving only the extinction coefficient $\kappa_{\lambda}$ soot to be determined from the measurement of the ratio of transmittance at two wavelengths as shown in Eq. 4.6-5.

$$
\begin{aligned}
& \ln \frac{\tau_{\lambda 1}}{\tau_{\lambda 2}}=\left(-\kappa_{\lambda 1, \text { soot }} L-\kappa_{\text {cca }} L\right)-\left(-\kappa_{\lambda 2, \text { soot }} L-\kappa_{c c a} L\right) \\
& \ln \frac{\tau_{\lambda 1}}{\tau_{\lambda 2}}=\left(-\kappa_{\lambda 1, \text { soot }} L-\kappa_{\text {cca }} L\right)-\left(-\kappa_{\lambda 2, \text { soot }} L-\kappa_{c c a} L\right)
\end{aligned}
$$

(Hottel and Broughton 1932) introduced an empirical correlation for soot transmittance as a function of wavelength where $\kappa_{\lambda, \text { soot }}=\mathrm{K} / \lambda^{1.39}$. This leads to Eq. 4.6-6 where KL represents the optical thickness. Note that Hottel and Broughton's correlation is not homogeneous, therefore care should be taken to use micrometers to express the wavelengths and path lengths in order to be consistent with the previous measurements. 


$$
\ln \frac{\tau_{\lambda 1}}{\tau_{\lambda 2}}=\left(\kappa_{\lambda 2, \text { soot }}-\kappa_{\lambda 1, \text { soot }}\right) L=K L\left(\frac{1}{\lambda_{2}^{1.39}-\lambda_{1}^{1.39}}\right)
$$

Once the optical thickness KL is determined, the soot volume fraction can be determined. There are numerous models that can be used to relate the measured $\mathrm{KL}$ of the soot to a soot volume fraction. All of these models require information on the soot particle size, shape, and complex index of refraction. Again, an empirical approach was selected. Utilizing the correlation from Hottel and Broughton combined with Eqs. 4.6-1 and 4.6-2, the relationship between KL and soot number density N/V can be determined as shown in Eq. 4.6-7. Using the definition of soot volume fraction $f_{v}=\mathrm{N} \pi \mathrm{d}^{3} / 6 \mathrm{~V} f_{v}$ can be solved as shown in Eq. 4.6-8

$$
\begin{aligned}
\frac{K L}{\lambda^{1.39}} & =Q_{e x t} \frac{\pi d^{2}}{4} \frac{N}{V} L \\
f_{v} & =\frac{2 K}{3 d Q_{e x t} \lambda^{1.39}}
\end{aligned}
$$

Substituting the expression for Qext from the Rayleigh limit in Table 4.6-1 into Eq. 4.6-8 and selecting an appropriate value (Ferguson, et al. 1987) for the refractive index leads to the final expression used to calculate soot volume fraction as shown in Eq. 4.6-9.

$$
f_{v}=\frac{K}{4 \lambda^{0.39}}
$$

The value produced is admittedly an approximation. The error is estimated to be on the order of $\pm 50 \%$ (Tree and Peart 2000). The assumptions made are that the soot particles are uniformly distributed, spherical, and obey Hottel and Broughton's emittance correlation. As long as the soot morphology is relatively constant between measurements of various coals or operating conditions, the relative changes in measured soot should be valid. Because soot is produced by the recombination of stable hydrocarbons that have decomposed from the parent fuel, soot properties tend to be relatively constant between fuels.

\subsubsection{Equipment and Materials}

Line-of-sight measurements were obtained in the Oxy-Fuel Combustor (OFC) at the University of Utah. The OFC shown in Figure 4.6-1 is a down-fired, $125 \mathrm{~kW}$, pulverized-coal reactor. The burner consists of a central primary tube and an annular secondary flow with $30 \mathrm{deg}$. swirl vanes. The burner zone is $1.2 \mathrm{~m}$ in length and $0.60 \mathrm{~m}$ in diameter, is electrically heated, and has vertically oriented optical access windows. A purge tube was installed that would slide vertically up and down the window on both sides to keep the window free of deposits. The same laser extinction measurement was set up to measure horizontally along a line of sight across the reactor diameter as was used previously in the L1500 tests. Over-fire or staged oxidizer was added in the transition zone of the reactor for cases that were overall fuel rich in the burner zone. The OFC is equipped for continuous monitoring of $\mathrm{O}_{2}, \mathrm{CO}_{2}, \mathrm{CO}, \mathrm{NO}_{\mathrm{x}}$, and $\mathrm{SO}_{2}$. 


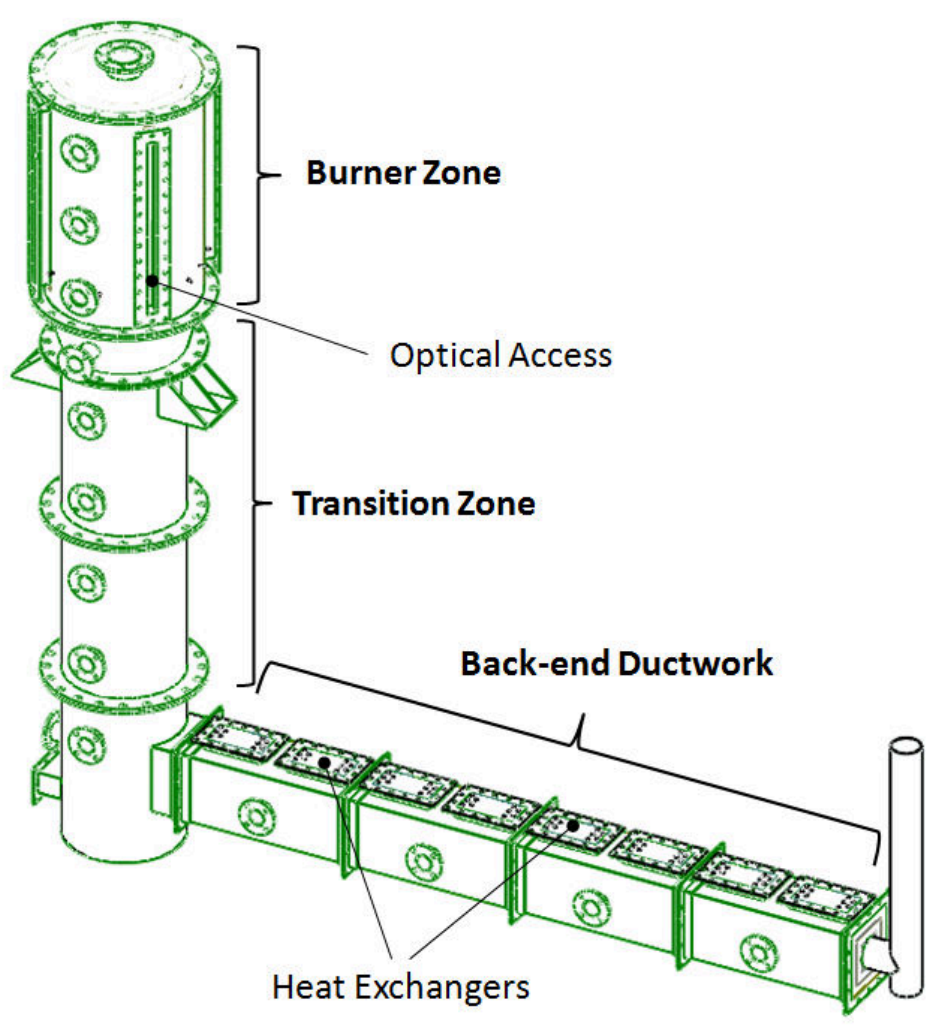

Figure 4.6-1: The University of Utah’s Oxy-Fuel Combustor.

Three coals were measured with three different oxidizers at three locations and three different stoichiometric ratios as listed in Table 4.6-2. The three SRs allowed investigation of overall fuel rich, fuel lean, and stoichiometric conditions. Coal was burned in air, a mixture of $\mathrm{O}_{2}$ and $\mathrm{CO}_{2}$ and a mixture of $\mathrm{O}_{2}$ and flue gas recycle. For the oxy combustion conditions, the target $\mathrm{O}_{2}$ concentration in the mixture of $\mathrm{O}_{2}$ and diluent was $27 \%$ (vol, wet). However, in practice the concentration of $\mathrm{O}_{2}$ ranged between $26 \%$ and $30 \%$. Coal was conveyed to the burner with primary air for the air combustion cases and with a mixture of $\mathrm{O}_{2}$ in $\mathrm{CO}_{2}$ for the oxy- and FGR-combustion cases. The flue gas was recycled from the OFC for the FGR cases. All secondary oxidizers were heated to $260{ }^{\circ} \mathrm{C}\left(500{ }^{\circ} \mathrm{F}\right)$.

Table 4.6-2: Test matrix showing coals and targeted operating conditions.

\begin{tabular}{|l|l|l|l|}
\hline Coals & $\begin{array}{l}\text { Stoichiometric } \\
\text { Ratios }\end{array}$ & Oxidizers & Locations \\
\hline Illinois \#6 & 0.9 & Air & Base \\
Skyline & 1.0 & Oxy $\left(30 \% \mathrm{O}_{2} 70 \% \mathrm{CO}_{2}\right)$ & Center \\
PRB & 1.15 & FGR $\left(30 \% \mathrm{O}_{2}\right.$ in flue gas $)$ & Tip \\
\hline
\end{tabular}

The flames in all experiments were lifted from the burner. Transmittance measurements were taken near the base of the visible flame, the center of the flame, and the tip of the flame. Measurement locations are given in Table 4.6-3. 
Table 4.6-3: Axial location of soot measurements.

\begin{tabular}{|l|l|l|l|}
\hline Coal & Base $(\mathrm{m})$ & Center (m) & Tip (m) \\
\hline Illinois & & & \\
\hline Air & 0.21 & 0.53 & 0.82 \\
\hline Oxy & 0.37 & 0.50 & 0.70 \\
\hline FGR & N/A & N/A & N/A \\
\hline PRB & & & \\
\hline Air & 0.19 & 0.53 & 0.86 \\
\hline Oxy & 0.36 & 0.51 & 0.67 \\
\hline FGR & 0.36 & 0.51 & 0.67 \\
\hline Skyline & & & \\
\hline Air & 0.21 & 0.54 & 0.78 \\
\hline Oxy & 0.33 & 0.51 & 0.70 \\
\hline FGR & 0.34 & 0.51 & 0.70 \\
\hline
\end{tabular}

\subsubsection{OFC Results and Discussion}

The measured soot volume fractions for the Skyline coal are shown as a function of the overall burner stoichiometric ratio in Figure 4.6-2. The soot volume fraction is seen to decrease with increasing SR. Because soot is formed in fuel rich regions, it would normally be expected that a leaner mixture (higher SR) would produce less soot as is indicated by the data. A careful look at the data reveals that the green symbols (soot volume fraction of the flame tip) are generally below the blue symbols (soot volume fraction at the base of the flame) with the red symbols in-between. For the majority of the data, the soot concentration measured at the base of the flame is higher than the soot concentration at the tip and decreases with increasing distance from the burner. Differences between the oxidizer mixture (air vs oxy vs FGR) are not discernible in Figure 4.6-2 although it will be seen in a subsequent figure that there is a slight decrease in soot volume fraction for the oxy-fired and FGR-fired cases. The primary trend of decreasing soot with increasing SR therefore has two smaller trends superimposed on the primary trend being a decrease in soot with increasing distance from the burner and a decrease in soot when $\mathrm{O}_{2} / \mathrm{CO}_{2}$ or $\mathrm{O}_{2}$ /flue gas are the oxidizers.

The measured soot volume fractions for the PRB coal as a function of overall burner SR are shown in Figure 4.6-3. The same trend of decreasing soot with increasing SR can be seen in the PRB data although there are a few data points near SR 1.15 that are not in good agreement with the remainder of the data. The trends relating to the measurement location or oxidizer composition are not measurable in the PRB data. The total amount of soot produced by PRB is about half that of the Skyline coal at a given SR. This lower value of soot is near the measurement limit which is around 2.5 E-08 and makes trends in the data more difficult to identify.

Problems with the alignment of the laser beam and optical detector caused the loss of almost all of the Illinois \#6 coal data. The one or two points that were obtained appeared to be similar in magnitude to the Skyline coal. 


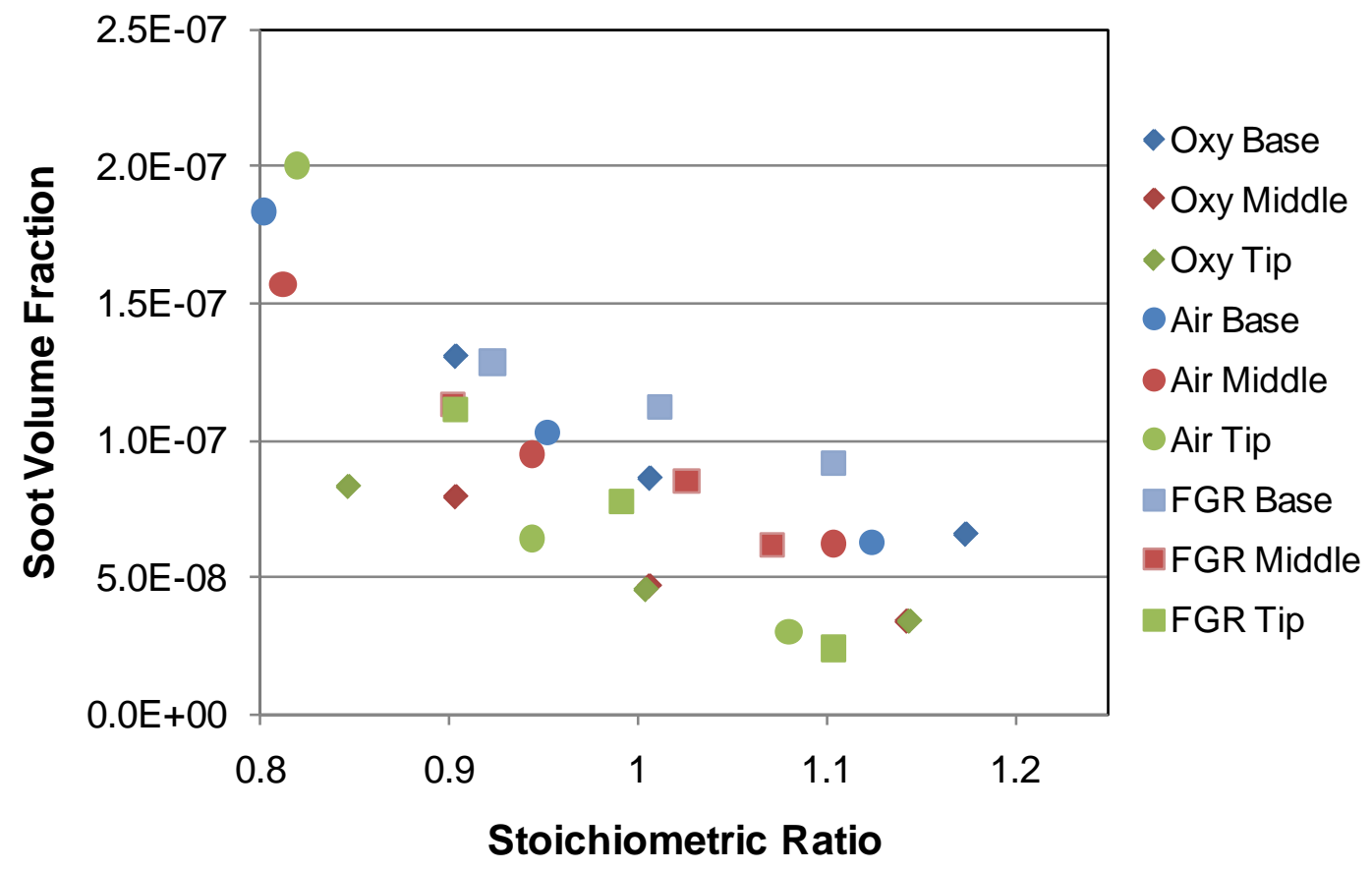

Figure 4.6-2: Soot volume fraction of Skyline coal as a function of overall stoichiometric ratio.

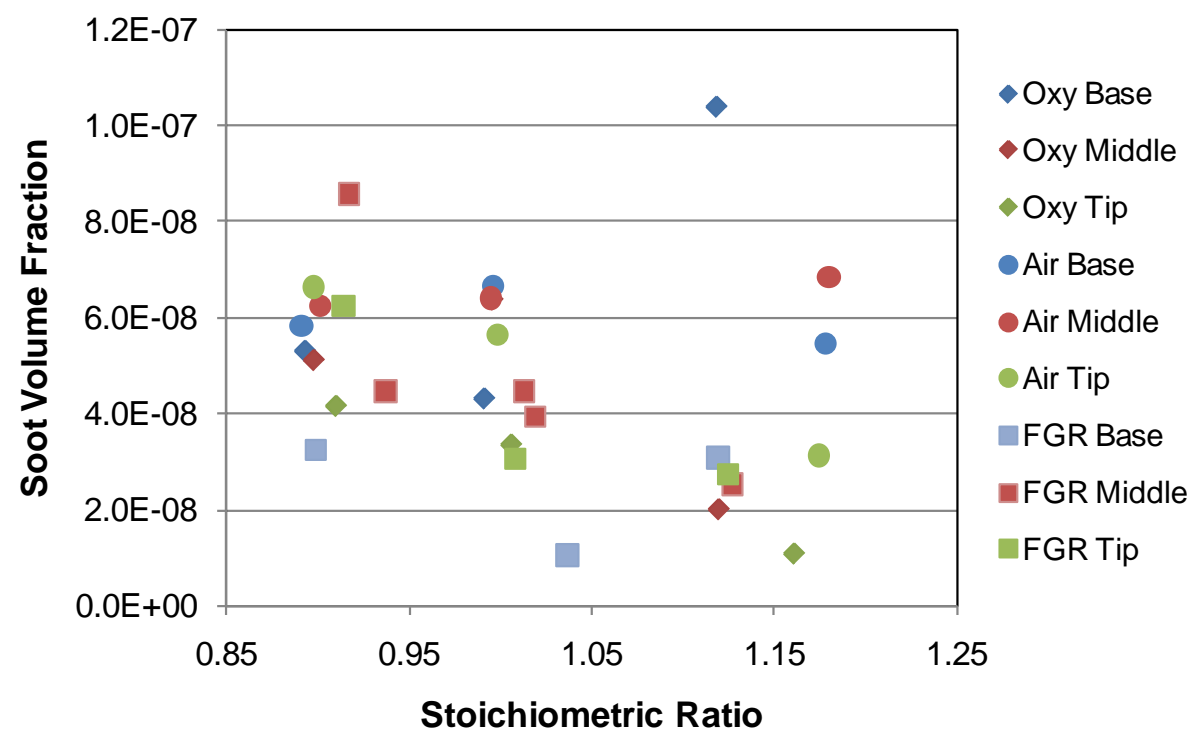

Figure 4.6-3: Soot volume fraction of PRB coal as a function of overall stoichiometric ratio.

A plot of the average soot volume fraction of all position and SRs for each oxidizer mixture is shown in Figure 4.6-4. The average soot volume fraction of the air combustion cases is seen to be the highest while the $\mathrm{O}_{2} / \mathrm{CO}_{2}$ mixture (oxy) and the $\mathrm{O}_{2}$ /flue gas mixture are smaller and similar in magnitude. The error bars represent an estimate of the measurement uncertainty. The error bars suggest that the difference between soot volume fractions of the Skyline air and Skyline oxy are measurable, but differences between the PRB coals are too small to be conclusive. 


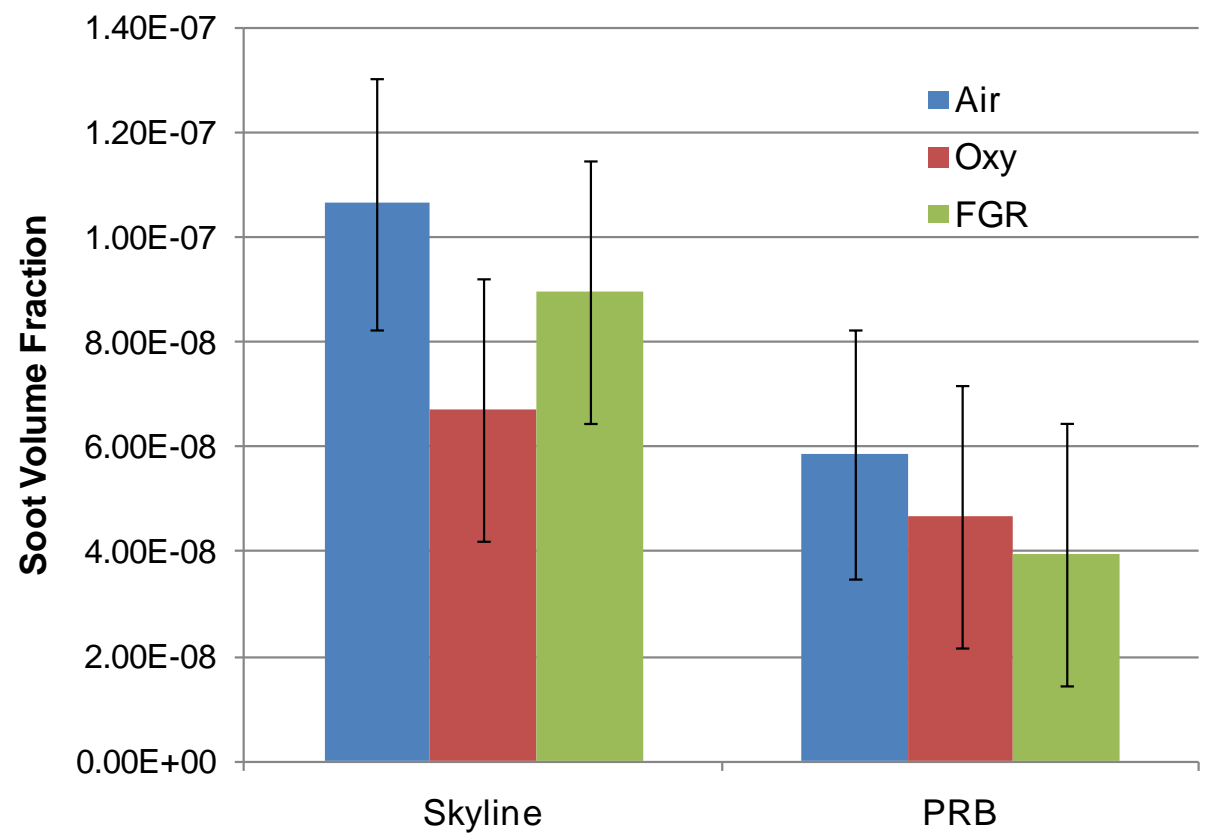

Figure 4.6-4: Average of all soot volume fractions for the Skyline and PRB coals for each oxidizer mixture.

Overall, the total soot volume fractions measured are relatively small when compared to other flames in the literature. Diesel flames can have a soot volume fraction of $1.0 \times 10^{-5}$ while laboratory diffusion flames produce soot volume fractions of $1.0 \times 10^{-6}$ (Tree and Svensson 2007). The low soot volume fraction may be attributed to the relatively high SR of the premixed mixture. Only approximately $50 \%$ of the oxygen required to burn coal is needed to burn the volatiles. Once the primary fuel mixture reaches a SR of 0.5 or higher, there is little probability of forming soot in a coal flame because there is enough oxygen to consume all of the volatiles.

In order to better understand the behavior of soot in the OFC, a model is introduced for soot formation based on soot formation in Diesel flames as described by (Dec 1997) and pulverized coal flame structures as described by (van der Lans, Glarborg and Dam-Johansen 1997). In order to understand soot formation in a coal flame, consider the simplified schematic shown in Figure 4.6-5 of a Type 1 coal flame (van der Lans, Glarborg and Dam-Johansen 1997). In this flame the coal momentum is large enough to penetrate through the reverse flow recirculation zone produced by swirl produces a lifted, long, relatively narrow, mixing limited flame. This flame type represents well the observed flame behavior in the OFC. 


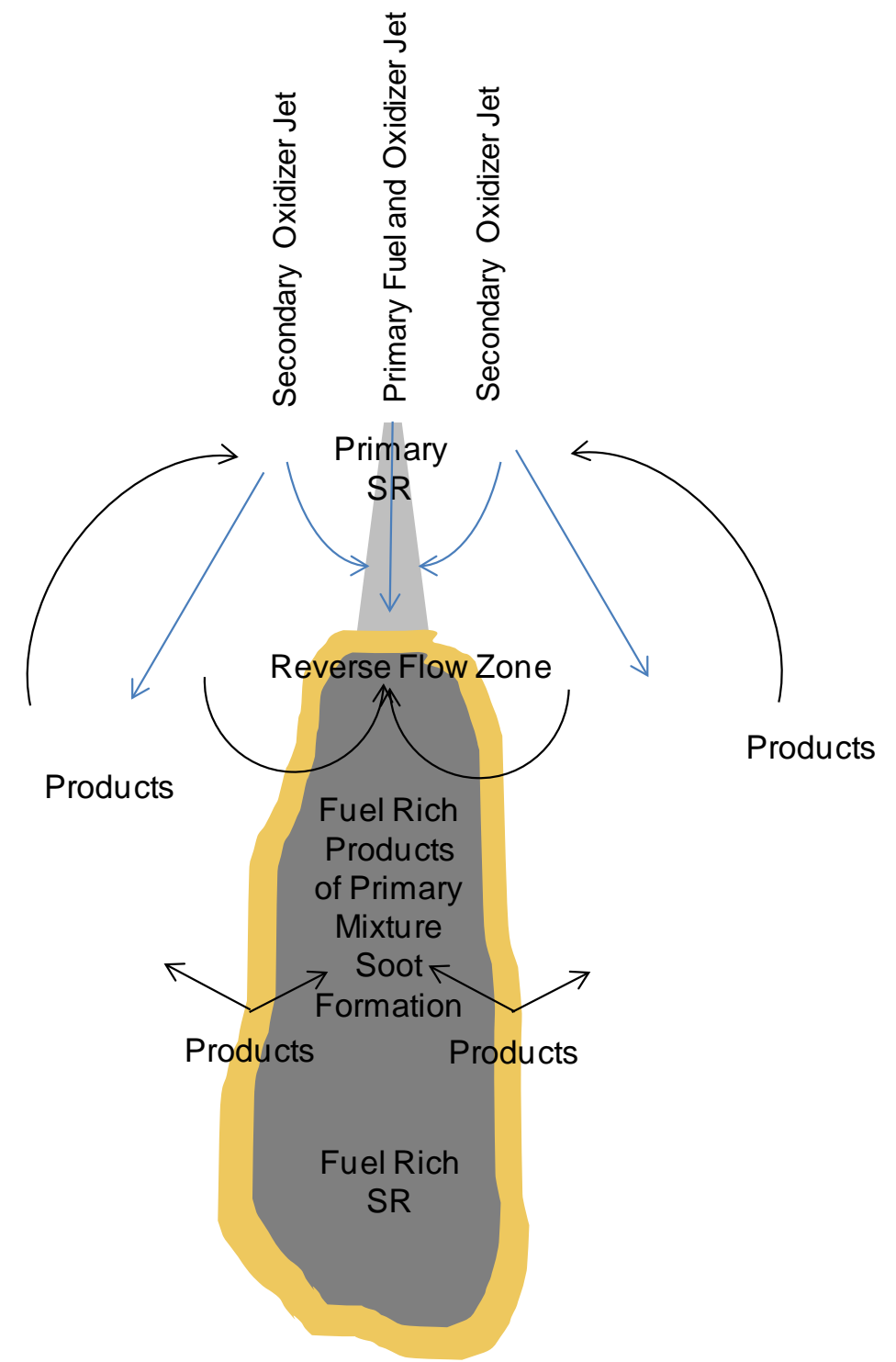

Figure 4.6-5: Schematic diagram of a lifted, pulverized-coal flame.

Pulverized coal and primary oxidizer enter the combustion zone through a center primary tube. Because the coal is normally conveyed with air, a portion of the air required to oxidize the fuel is already premixed with the coal for a fuel-rich premixed mixture. The SR of this mixture in the OFC experiments was approximately 0.2 for all three oxidizer conditions. The primary fuel mixture must be heated before it will react. Upon entering the combustion chamber, the mixture is heated by radiation and by mixing with combustion products heating the coal particles and producing volatiles. If a strong reverse flow recirculation zone is created, heating of the primary mixture will be rapid and the fuel will attach near the burner. If slow, the flame will be lifted. The flames in the OFC are lifted while those in the L1500 are attached. A lifted flame allows more entrainment of the secondary oxidizer into the primary stream, leaning out the fuel rich mixture prior to ignition. The premixed fuel and oxidizer react rapidly to form rich premixed products of combustion. The rich products are surrounded by flames at the interface of the fuel and oxidizer regions. While only one large flame is shown in the schematic, numerous small flamelets of various lengths and shapes may be formed depending on the flow structures and turbulence 
produced by the burner flow dynamics. Each of these flamelets is supplied by a premixed fuel oxidizer mixture that reacts to form premixed products.

Among the rich products of combustion are stable hydrocarbons (tars and other aromatic hydrocarbons) produced during devolatilization which can survive the initial combustion event and combine to form soot. Soot is therefore produced in fuel rich regions surrounded by flames. Most of the soot will oxidize as it passes through the flame producing a luminous yellow color. Soot concentration can be increased by: 1) Reducing the SR of the mixture inside the fuel rich core of the flame, 2) Burning a fuel (coal) that produces a greater amount of stable hydrocarbons that are more likely to produce soot, or 3) Altering the kinetic mechanisms that produce and oxidize soot by changing the mixture composition. Soot is oxidized on the oxidizer side of the flame and is dependent on $\mathrm{O}_{2}$ concentration and temperature. One of the objectives of this work is to determine how oxy-combustion alters the soot formation and oxidation process of coal flames.

The most prominent impact on soot formation in the OFC was an increase in overall SR causing a decrease in measured soot concentration. It is useful to define three different SRs in order to discuss soot formation. The first is the SR of the primary fuel and oxidizer. This value is easily calculated from the primary fuel and oxidizer flow rates and establishes a lower limit for the SR at the time of ignition as it can only increase with entrainment of the secondary oxidizer. The second SR of interest is the SR at the point of ignition or premixed SR. This SR represents the air fuel ratio when the volatiles are consumed and is the value most directly applicable to the amount of soot formed. Increasing the amount of oxygen entrainment prior to ignition will increase the premixed SR ratio and decrease soot formation. The final SR is the overall SR of the burner zone and represents the total air and fuel delivered by the burner. When the overall SR is increased, the SR of gases entrained into the primary fuel and oxidizer becomes more lean causing the premixed SR to increase relative to a low overall SR. Thus, an increase overall SR should increase the premixed SR and decrease soot formation.

The second most prominent feature in the soot concentration data was a decrease in soot concentration with increasing distance from the burner. Since oxygen is being entrained or mixed into the flame with increasing distance from the burner, after reaching a peak where the soot is formed from the unburned volatiles, the soot is oxidized from that point downstream. The data suggest that the measurement point at the base of the flame is downstream of the initial soot formation zone and soot decreases in the downstream direction as it is oxidized.

The final less prominent observation is that soot decreased with oxy-combustion and possibly with FGR oxy-combustion. When the $\mathrm{O}_{2} / \mathrm{CO}_{2}$ oxidizer was used, the axial positions in Table 4.6-3 show that the flame became even more detached from the burner. The base of the flame for air combustion was measured at $0.2 \mathrm{~m}$ but shifted to $0.36 \mathrm{~m}$ for oxy and FGR combustion. This increased lift-off length may be evidence of increased oxidizer entrainment. In addition to the longer lift-off length, the oxy and FGR gas velocities are lower than air combustion which would increase the residence time prior to ignition for the oxy and FGR combustion flames. With additional oxygen entrainment prior to ignition, the oxy and FGR flames should produce less soot.

The final observation is that PRB coal produced less soot in the OFC than the Skyline coal. There are two possible explanations for this result. The first is that PRB is a lower rank coal and will produce less tar and more lighter hydrocarbons than the Skyline coal. PRB should therefore produce less soot.

The second possibility involves mixing. Both PRB and Skyline coal have the same lift-off length suggesting that amount of oxidizer and product gas entrainment into the primary jet prior to ignition is similar. The PRB coal has a lower stoichiometric A/F ratio than Skyline; therefore, if they both start at the 
same SR in the primary tube and have the same amount of oxidizer entrainment, the PRB coal will have a higher SR at the point of ignition and produce less soot.

Interestingly, the amount of soot formed in the L1500 is higher for PRB than Skyline. This can be explained by mixing but not by the composition of the coal volatiles. The L1500 flame is not lifted which indicates that the primary mixture is rapidly heated by product gases being recirculated into the primary stream. The entrained gas is therefore composed more of product gases and less of oxidizer in the L1500. The product gases of PRB can be expected to contain less oxygen because of the rapid burnout and high reactivity of PRB coal compared to Skyline.

\subsubsection{Additional Testing in the BFR}

Experimental results for the L1500 and OFC furnaces at the University of Utah have been summarized above. This section focuses on additional soot testing completed at Brigham Young University.

\subsubsection{Introduction}

In the summer of 2011, soot in the Burner Flow Reactor (BFR) at Brigham Young University was measured at two swirl ratios, three SRs, and three locations for the PRB coal. The soot volume fraction measured varied from $2 \times 10^{-8}$ to $18 \times 10^{-8}$. The low soot volume fractions were found at low swirl high S.R producing similar conditions and results to the OFC. The high soot concentrations were measured at high swirl, low secondary velocity matching conditions and results in the L-1500. Increasing secondary oxidizer flow rate and decreasing swirl number (detaching the flame) were found to decrease soot consistent with increased mixing prior to ignition. These variables had a greater influence on soot than overall SR, oxygen concentration, or whether or not the oxidizer was air or $\mathrm{O}_{2} / \mathrm{CO}_{2} / \mathrm{RFG}$ mixture.

A conceptual model for soot formation in coal flames is proposed as a means of explaining the results from all three tests. The extent of premixing of oxidizer and fuel prior to volatiles ignition is the predominant factor in soot formation. Swirl and burner flow dynamics have the greatest influence on premixing. High char reactivity and high coal tar content then determine the amount of soot produced at a given premixed SR The influence of oxidizer diluents such as $\mathrm{N}_{2}$ or $\mathrm{CO}_{2}$ were not clearly measurable and are therefore of lesser importance.

\subsubsection{Experimental Method}

The technique used for measuring soot in flames was based on the line of sight laser light extinction, described previously. Similarly the optical set-up was similar to that used previously. Figure 4.6-6 shows a schematic diagram of the five main components of the measurement system.

(1) The signal was generated by a $100 \mathrm{~mW}$, multi-line, polarized, argon-ion laser of which the most prominent wavelengths are 528.7, 514.5, 496.5, 488.0, 476.5, and $457.9 \mathrm{~nm}$ all at different intensity levels. The beam of light traveled through the flame of each experimental facility where the beam was attenuated by particles in the flame.

(2) The beam was then collected in an integrating sphere which diffusely scattered the light on the inside surface of the sphere. There are two ports on the integrating sphere where band-pass $1 \mathrm{~nm}$ filters and photodiode sensors were placed to collect the intensity of the beam. The filters passed the 514.5 and $457.9 \mathrm{~nm}$ wavelengths.

(3) After each of the intensities was measured by the photodiodes, the signal was amplified.

(4) The amplified signal was then digitized by a data acquisition device.

(5) The digitized signal was recorded by a laptop computer. 
The laser and signal collecting optics were placed on tripods to allow for easy adjustment and portability which facilitated measurements on the three different combustion facilities.

The same coals, Utah Skyline bituminous and North Antelope Powder River Basin (PRB) subbituminous, were used for these experiments as were used for the other L1500 testing. The Utah coal has moderate levels of moisture and volatile content and it also has a moderate heating value. The PRB coal has a high moisture content and a high volatile content as well as a relatively low heating value.

It is important to remember that the soot measurement is a line-of-sight technique. The path length across each facility will be used to calculate the soot volume fraction rather than the actual path length through the flame which may only occupy a fraction of the reactor width. All of the soot measurements have been collected perpendicular to the average flow direction and therefore differences in measured soot may be attributed to position in addition to other flow variables.

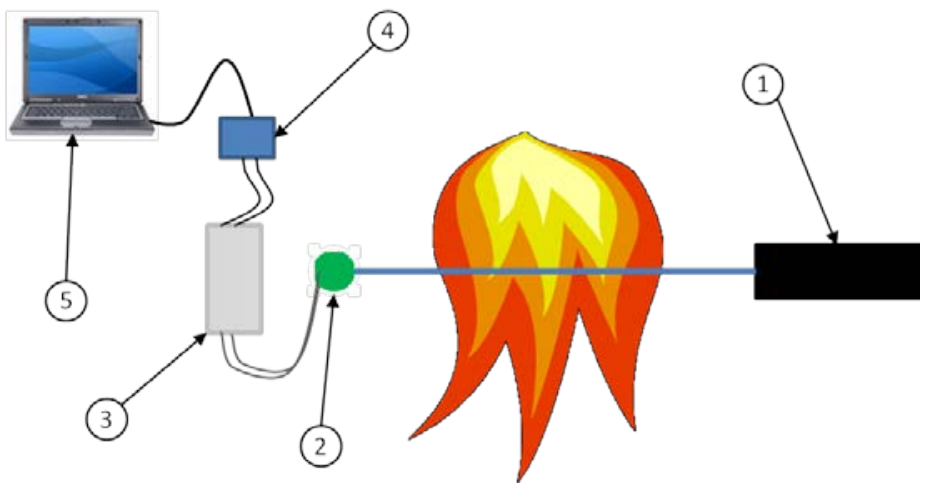

Figure 4.6-6: Schematic of signal generating, collecting, and processing equipment: 1) multi-line Ar+ laser, 2) integrating sphere, 3) photodiode amplifiers, 4) data acquisition device, 5) laptop computer.

\subsubsection{Burner Flow Reactor}

The Burner Flow Reactor (BFR) is a $200 \mathrm{~kW}_{\text {th }}$ cylindrical, down-fired, pulverized coal reactor and is shown in Figure 4.6-7. It is composed of a top section where the burner is located, six identical sections stacked on top of each other, and a bottom conical section where the combustion gases exit the reactor. The six identical sections combine to make a combustion chamber with a height of $240 \mathrm{~cm}$ (not including the conical section) and a diameter of $75 \mathrm{~cm}$. There are four groups of access ports aligned axially located every 90 degrees around the circumference of the BFR for a total of 24 access ports. The outer wall of the reactor contains a water jacket to keep the outside cool, and the inner wall is constructed of a refractory material and a layer of insulation separates the inner and outer layers.

The burner has inlets for the primary fuel/oxidizer stream and the secondary oxidizer stream. The fuel stream enters through a tube at the top of burner and is injected into the combustion chamber at the top of a water cooled quarl. The secondary stream enters through an upper plenum and travels into a movable block swirl generator. The triangular blocks on the swirl generator are adjustable to allow for a swirl number between 0 and 1.7. When the secondary oxidizer travels through the quarl, its tangential momentum forces it outward radially and creates a low pressure region just below the quarl. This low pressure causes gases and particles to circulate upward toward the burner thus increasing the mixing and stabilizing the flame. 
A water cooled probe was used to inject tertiary oxidizer (or burn-out oxidizer) approximately half way down the reactor in order to achieved staged combustion. The tertiary oxidizer can consist of air or $\mathrm{O}_{2} / \mathrm{CO}_{2}$ mixtures but cannot contain recycled flue gas.

Secondary oxidizer was either air or a mixture of recycled flue gas (RFG) and $\mathrm{O}_{2}$. Both $\mathrm{O}_{2}$ flow rate and recycled flue gas flow rate were varied in order to achieve target overall SRs. The desired fraction of $\mathrm{O}_{2}$ in the secondary was achieved by increasing or decreasing the recycle flow rate at a fixed $\mathrm{O}_{2}$ flow rate. The flue gas handling system was insulated to keep the secondary oxidizer temperature above $350{ }^{\circ} \mathrm{F}$ $\left(177^{\circ} \mathrm{C}\right)$ at all locations. The flow rate of the RFG was monitored by oxygen concentration measurements before and after adding a known amount of oxygen into the stream. Adjustments in the RFG flow rate were made by adjusting the flue gas recycle (FGR) fan speed.
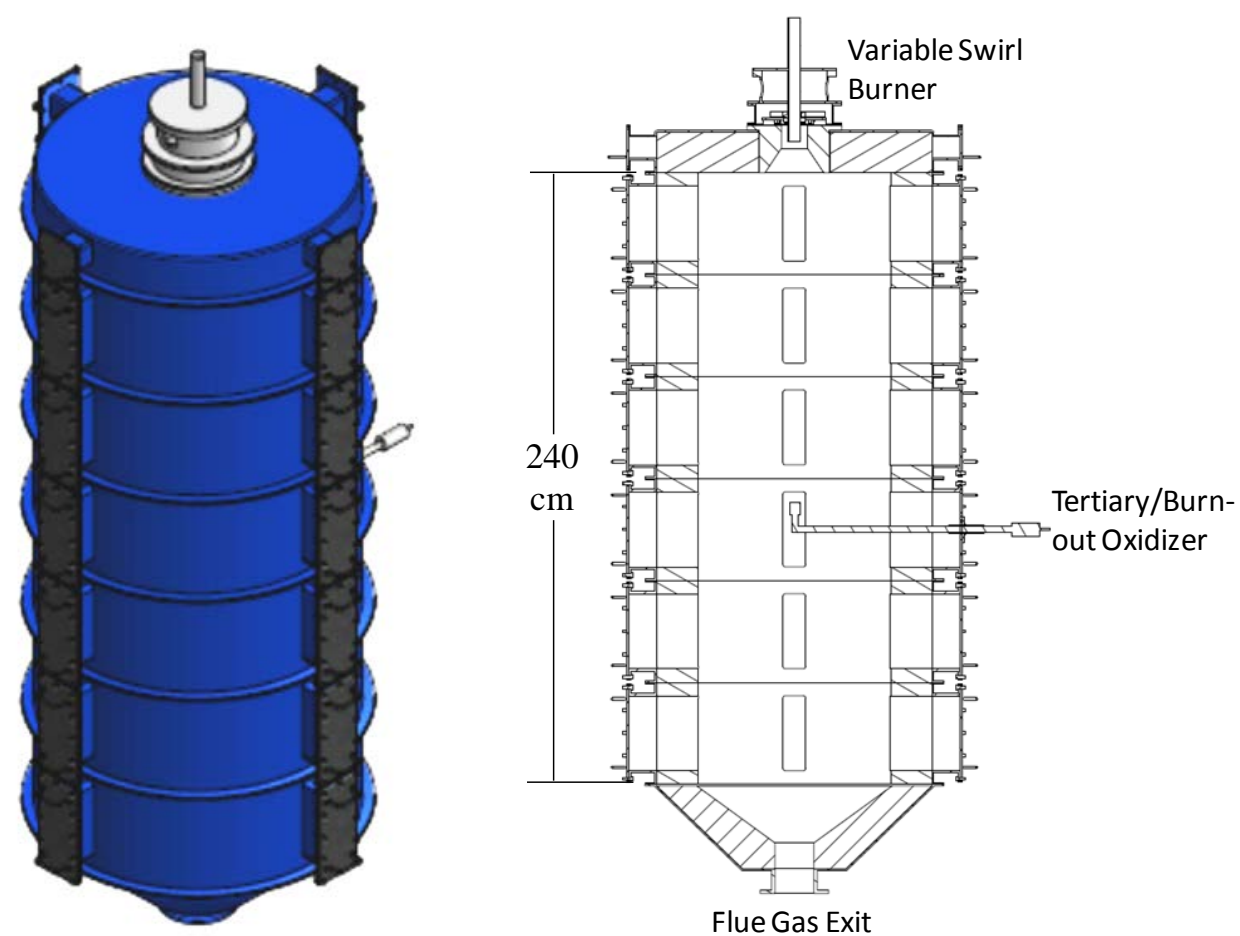

Figure 4.6-7: The Burner Flow Reactor at Brigham Young University.

Independent operating variables for the BFR experiments are listed in Table 4.6-4. For air combustion, measurements were taken at three SRs, four positions, and two swirl numbers. The same tests were repeated for oxy-combustion except that for each air combustion condition, the secondary recycle flow rate was varied to produce three secondary oxidizer oxygen concentrations.

Table 4.6-4: Test matrix showing all variables tested.

\begin{tabular}{|l|l|l|l|l|}
\hline Oxidizer & Swirl & $\begin{array}{l}\text { Secondary } \mathrm{O}_{2} \text { Vol \% } \\
\text { (Oxy Only) }\end{array}$ & SR & $\begin{array}{l}\text { Axial Distance from } \\
\text { Burner Exit }\end{array}$ \\
\hline Air & 0.6 & 35 & 0.85 & $7.5 \mathrm{~cm}$ \\
\hline Oxy-FGR & 1.35 & 30 & 1.0 & $27.5 \mathrm{~cm}$ \\
\hline- & - & 25 & 1.15 & $47.5 \mathrm{~cm}$ \\
\hline- & - & - & - & $67.5 \mathrm{~cm}$ \\
\hline
\end{tabular}


The same Powder River Basin (PRB) subbituminous coal was used in the BFR as was used in the L-1500 and OFC. The coal was fed by a loss-in-weight feeder and it was entrained into a stream of $\mathrm{CO}_{2}$ for oxyfired cases and air for air-fired cases and then delivered to the burner of the BFR. The coal was fed at a constant rate for all tests to provide $140 \mathrm{~kW}$ of thermal energy to the BFR.

Ports with small holes were used to allow a path for the laser beam instead of purged windows to eliminate error due to fouling on the windows; window fouling was a significant problem with the OFC testing. The holes in the access ports were approximately $3.2 \mathrm{~cm}$ (1.25 in.) in diameter and allowed a clear path for the laser to traverse the reactor. To avoid ambient air leaning into the reactor through these holes, the BFR was operated under slightly positive pressure $\left(2 \mathrm{~cm} \mathrm{H}_{2} \mathrm{O}\right)$.

\subsubsection{BFR Experimental Results}

Visual inspection of the flame was performed when possible through small windows installed at two of the access ports. The BFR flame was observed to be detached for the data taken at a swirl number of 0.6 but was attached for swirl number 1.36. The data will therefore be reported at these separate swirl numbers.

Soot volume fractions as a function of oxidizer flow rate for all of the data taken at a swirl number of 1.36 are shown in Figure 4.6-8. Data for air-fired combustion are shown with solid symbols and oxy-fired data are open symbols. The color of the data points indicates the location where the soot was measured. The data grouped at each unique mass flow rate represent a unique SR and $\mathrm{O}_{2}$ concentration. A trend of decreasing soot with increasing secondary mass flow rate can be seen. Measurements from air and oxyfired conditions appear to follow the same trend even though SRs and oxygen concentration is changing along the trend line.

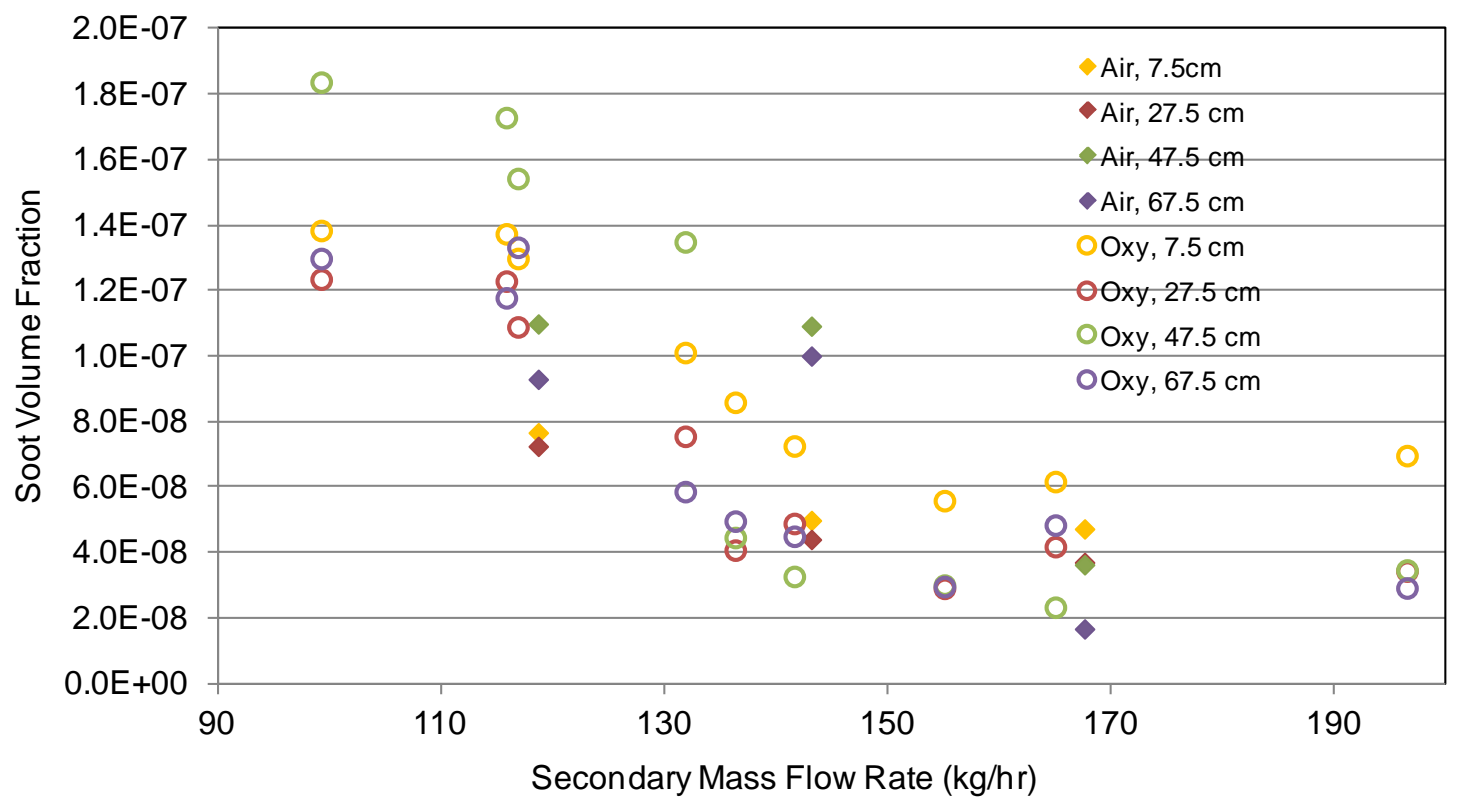

Figure 4.6-8: Soot volume fraction as a function of secondary oxidizer flow rate for a swirl of 1.36.

The vertical scatter in the data in Figure 4.6-8 is produced by measurements at various measurement locations. A higher flow rates, the soot volume fraction near the burner at $7.5 \mathrm{~cm}$ appears to be higher than downstream locations. When the data in Figure 4.6-8 are split into two groups (above $150 \mathrm{~kg} / \mathrm{hr}$ or 
high flow rate and below $150 \mathrm{~kg} / \mathrm{hr}$, or low flow rate) the results (Figure 4.6-9) for average soot volume fraction versus axial position can be seen. The figure shows that for higher flow rates, soot is highest near the burner and decreases with increasing distance from the burner while at low flow rates, there does not appear to be a correlation between soot volume fraction and position.

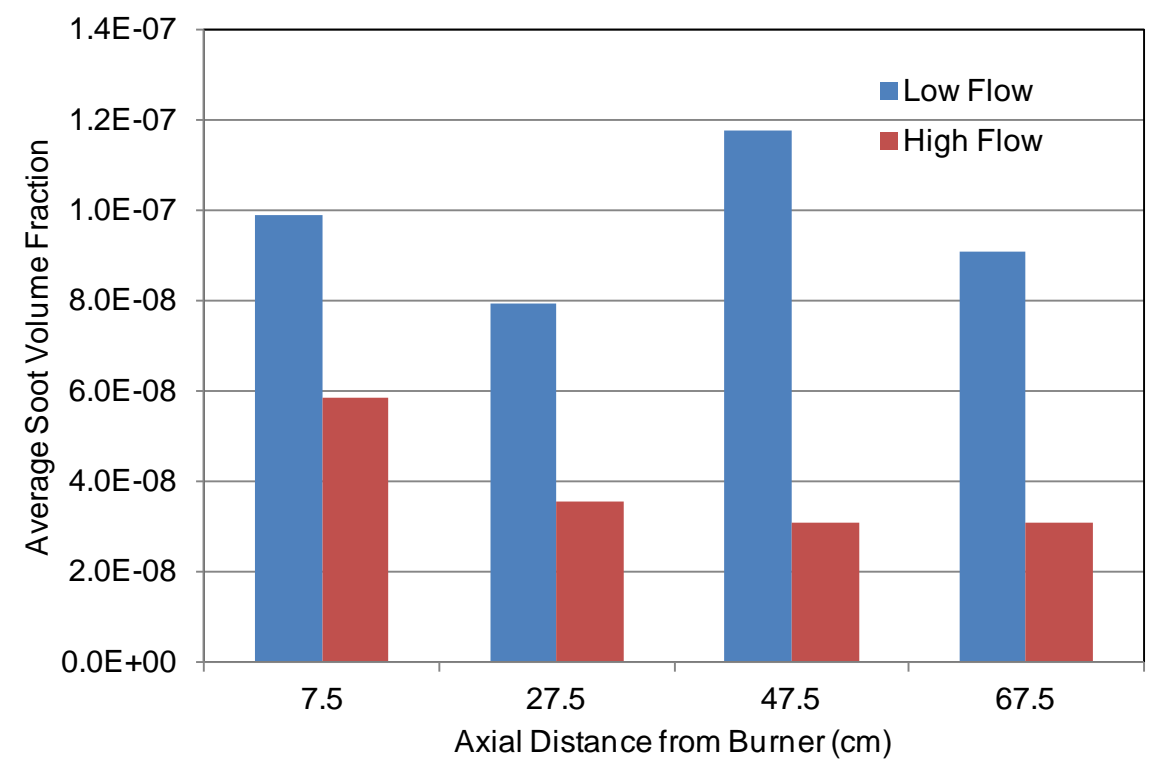

Figure 4.6-9: Average soot volume fraction as a function of position for a swirl number of 1.36 divided into high (greater than $150 \mathrm{~kg} / / \mathrm{hr}$ ) and low (lower than $150 \mathrm{~kg} / \mathrm{hr}$ ) flow.

Since the soot volume fraction is a function of position, in order to more clearly identify the effect of SR and oxygen concentration on soot volume fraction, the soot volume fraction was averaged for each unique combination of SR and oxidizer $\mathrm{O}_{2}$ concentration. The error bars represent the relative uncertainty of the measurement. The result is shown in Figure 4.6-10 where the symbol shape is used to identify the SR associated with each data point. The figure shows how generally increasing SR correlates with decreasing soot volume fraction but the correlation exist not because there is more oxygen available but because higher SRs require higher mass flow rates. Also identified on Figure 4.6-10 are the oxygen concentration of the SR $=0.85$ data points for oxy-combustion. The oxygen concentrations of all other oxy-combustion data follow the same trend with the highest concentration 30\% being associated with the lowest secondary mass flow rate for each SR Interestingly, the highest secondary oxygen concentration is associated with the highest amount of soot. This again illustrates the dominance of secondary flow rate on soot formation because generally, higher $\mathrm{O}_{2}$ concentrations should reduce soot. Finally, it is observed that the soot volume fraction from air combustion falls within the correlation of the oxy-combustion results suggesting that differences between air and oxy-combustion soot formation is most strongly related to the flow rate and associated flame shape and mixing.

Soot volume fractions for all of the data taken at a swirl number of 0.6 are shown in Figure 4.6-11. The data are presented in the same format and scale as Figure 4.6-8. The first observation is that the soot volume fractions measured at low secondary flow rates are significantly lower than the 1.36 swirl number data. Only a very small decrease in soot volume fraction is seen with increasing secondary oxidizer flow rate. A similar scatter in the data with measurement location is seen. 


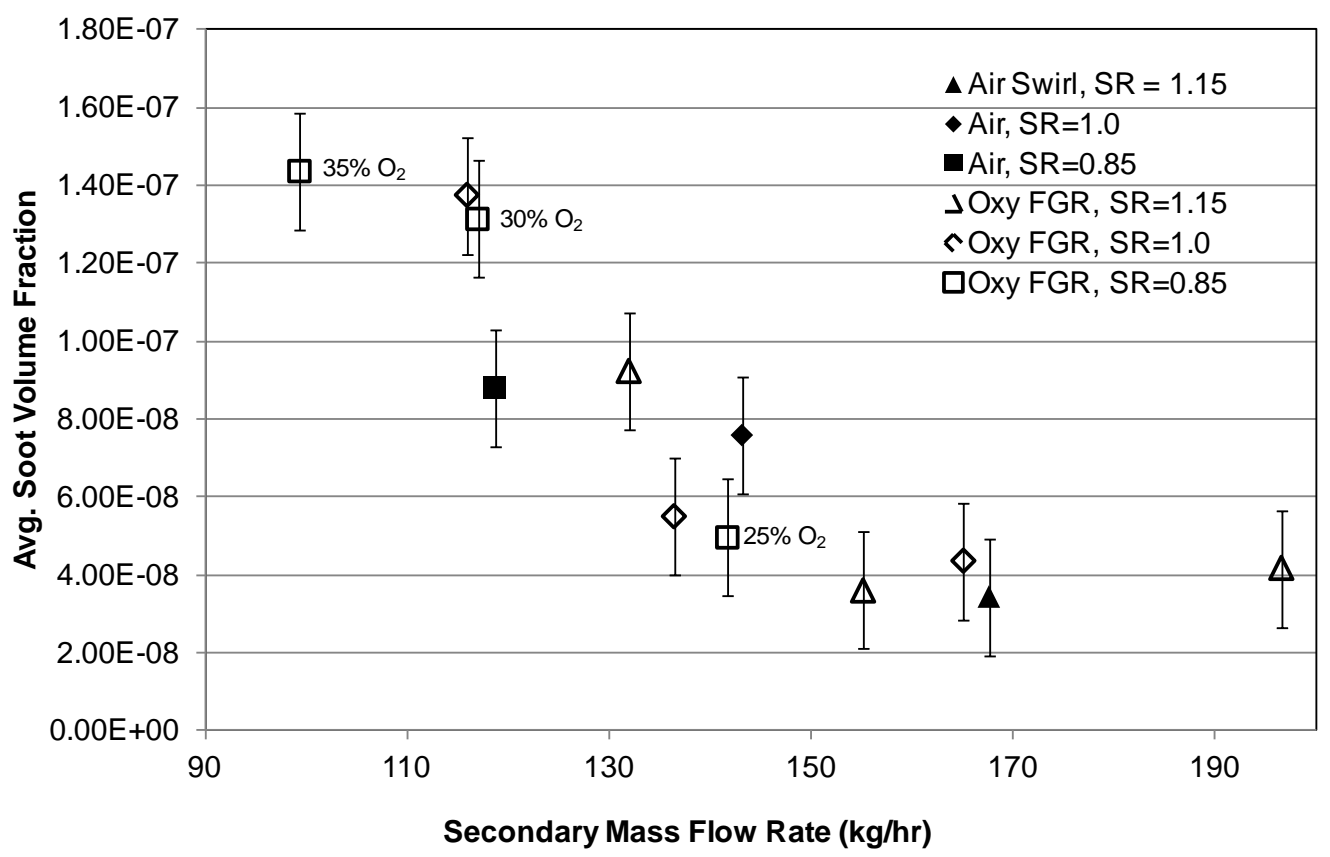

Figure 4.6-10: Average soot volume fraction of four locations as function of secondary mass flow rate for a swirl number of $\mathbf{1 . 3 6}$.

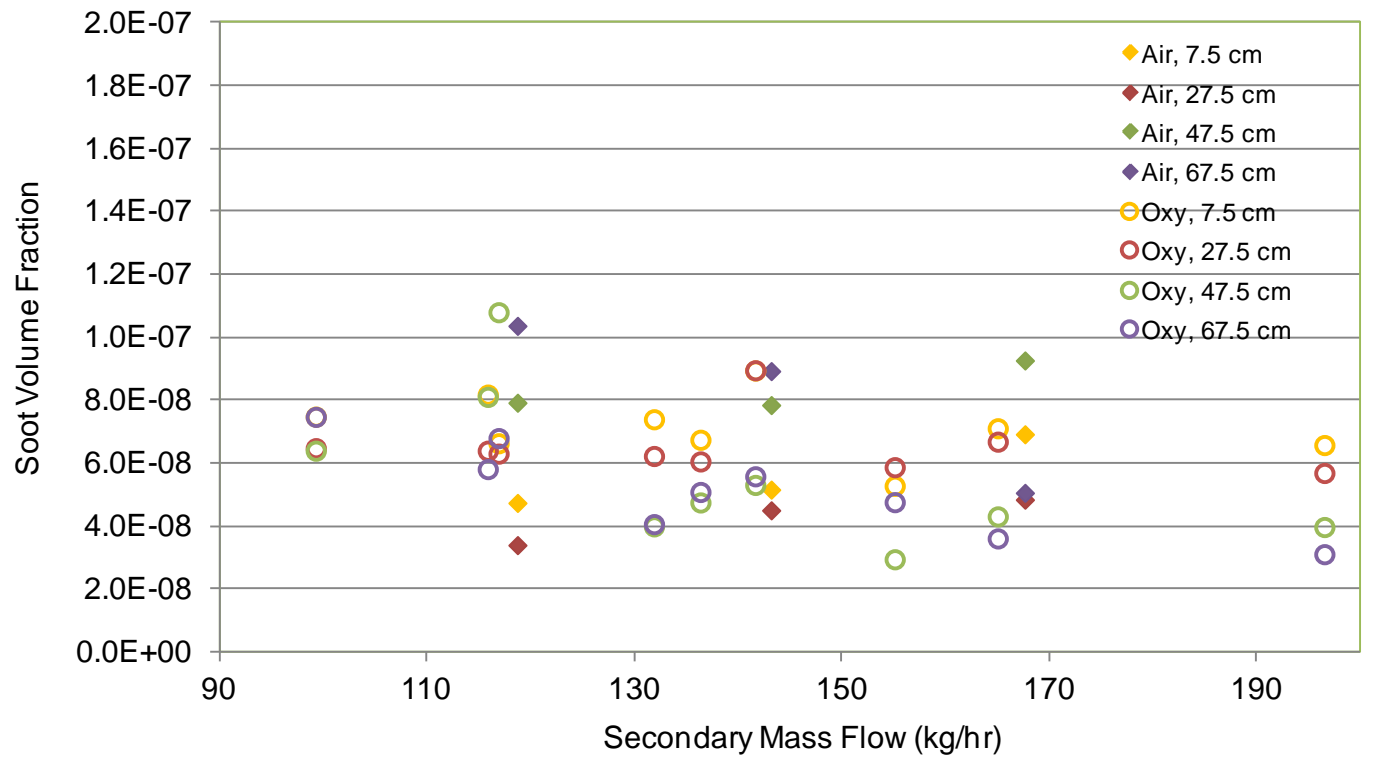

Figure 4.6-11: Soot volume fraction as a function of secondary air mass flow rate for a swirl number of 0.6 .

As with the 1.36 swirl data, results have been split into low (less than $150 \mathrm{~kg} / \mathrm{hr}$ ) and high (greater than $150 \mathrm{~kg} / \mathrm{hr}$ ) flow rates and averaged in Figure 4.6-12. A low flow rate, the soot volume fraction does not correlate with position but at higher flow rate, the soot volume fraction decreasing with increasing distance from the burner. 


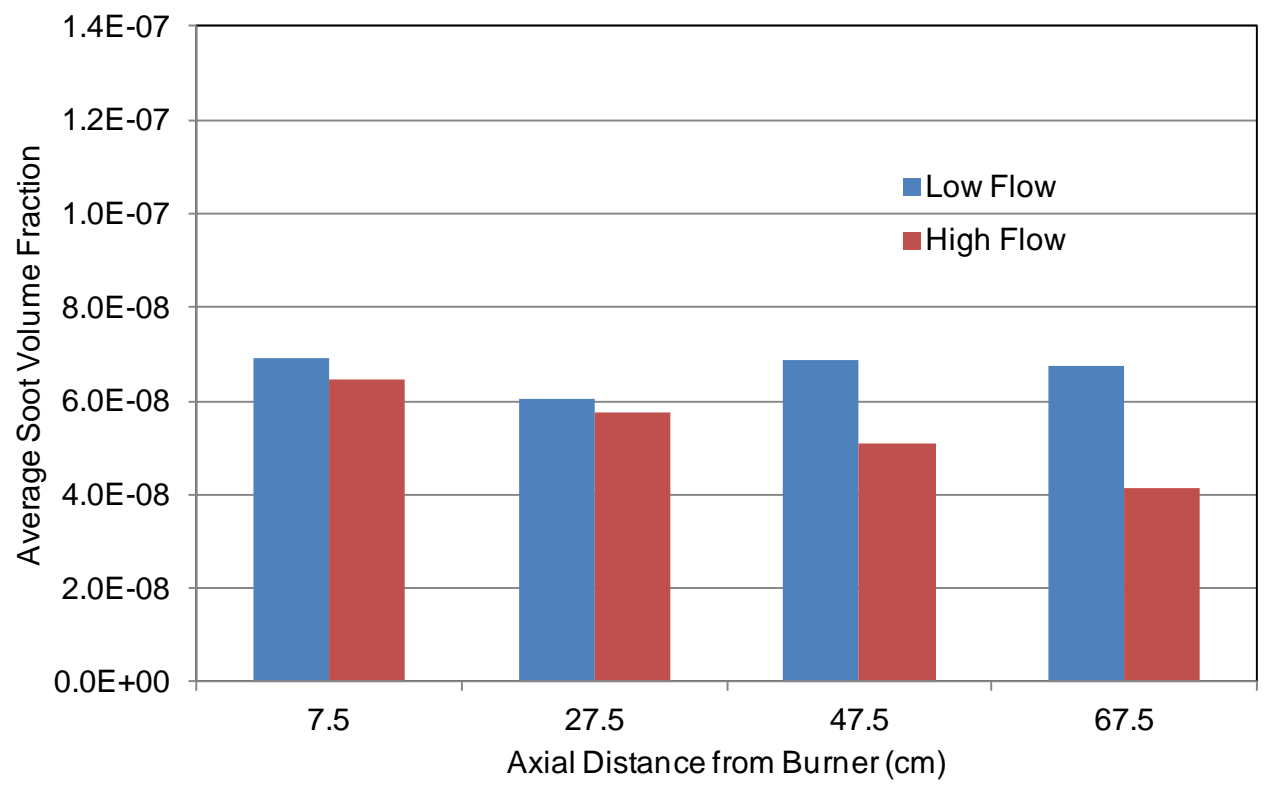

Figure 4.6-12: Average soot volume fraction as a function of position for a swirl number of 0.6 divided into high (greater than $150 \mathrm{~kg} / / \mathrm{hr}$ ) and low (lower than $150 \mathrm{~kg} / \mathrm{hr}$ ) flow rates.

The 0.6 swirl number soot volume fraction data presented in Figure 4.6-11 were averaged and are presented in Figure 4.6-13 to show SR and oxygen concentration. At this lower swirl number, all operating conditions appear to produce similar soot volume fractions regardless of SR, oxygen concentration or secondary oxidizer flow rate.

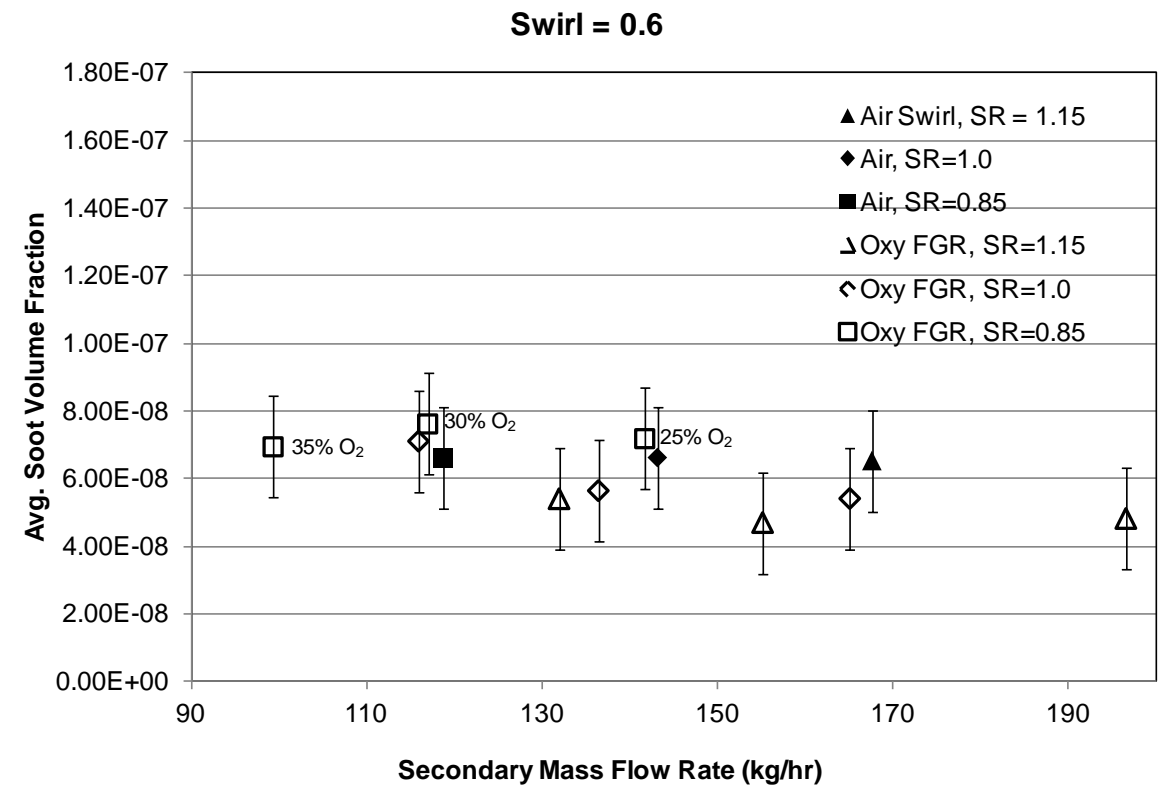

Figure 4.6-13: Average soot volume fraction of four locations as function of secondary mass flow rate for 0.6 swirl number. 


\subsubsection{BFR Discussion}

Consider again the simplified schematic shown in Figure 4.6-5 of a type 1 coal flame (van der Lans, Glarborg and Dam-Johansen 1997). The flame represents the flame structure in the OFC flame and in the 0.6 swirl number BFR flames. The BFR flame at 1.36 swirl and the L1500 flames are type 2 (van der Lans, Glarborg and Dam-Johansen 1997) being shorter and attached to the quarl. Unlike the flame shown in Figure 4.6-5, the type 2 flame will be wider and shorter with little or no lift off distance between the burner exit and the root of the flame (see Figure 4.6-14).

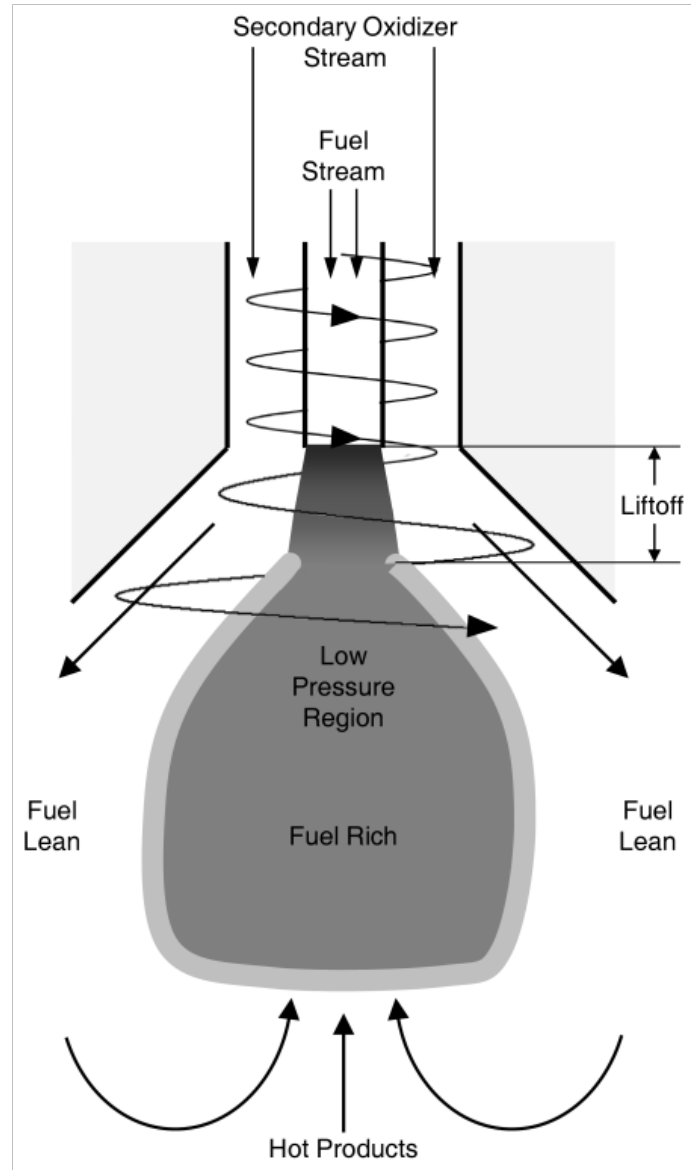

Figure 4.6-14: Schematic of an attached pulverized coal flame (type 2).

Pulverized coal and primary oxidizer enter the combustion zone at the center of the burner. Because the coal is normally conveyed with air, a portion of the air required to oxidize the fuel is already premixed with the coal producing a fuel-rich premixed mixture. The SR of this mixture in the L1500 and OFC experiments was approximately 0.2 for all oxidizer conditions, 0.2 for air conditions on the BFR, and 0 for the oxy FGR cases on the BFR. Soot formation is controlled by the amount of mixing of fuel and oxidizer prior to ignition of the volatiles or the $\mathrm{SR}$ at ignition $\left(\mathrm{SR}_{\mathrm{I}}\right)$.

If a strong reverse flow recirculation zone is created, heating of the primary mixture will be rapid and the $\mathrm{SR}_{\mathrm{I}}$ will be low producing more soot. Highly reacting and high volatile coals will also reduce $\mathrm{SR}_{\mathrm{I}}$. The L1500 and BFR, swirl number $=1.36$ are examples of more highly sooting flame structures. The lifted flames of the OFC and BFR, swirl number $=0.6$ are examples of flame structures that produce less soot by entraining more oxidizer prior to ignition and increase $\mathrm{SR}_{\mathrm{I}}$. 
Increasing the flow rate of the secondary oxidizer increases mixing between the fuel and oxidizer and increases $\mathrm{SR}_{\mathrm{I}}$. Although the flame schematic in Figure 4.6-5 is drawn as one large flame, the structure of a coal flame is much more complex and consist of numerous small flamelets of varying length and shape as discussed by (Damstedt, et al. 2007). Increasing the secondary oxidizer flow rate increases turbulence, breaking the flamelets into smaller fragments each surrounding a fuel rich mixture. It is therefore difficult to completely eliminate the fuel rich regions even though excess oxygen is present.

Using this conceptual model, the data measured in the three reactors can be explained. The L1500 burner produced an attached, swirled flame that produced a fuel rich low NOx flame with relatively high soot formation for a coal flame. Within the fuel rich region soot formation is controlled by fuel and oxidizer properties. PRB char reacts more rapidly with the oxidizer premixed into the fuel stream and produces a lower $\mathrm{SR}_{\mathrm{I}}$ than the Skyline coal. The mass flow rate of oxidizer in the secondary stream is higher for $27 \%$ $\mathrm{O}_{2}$ in FGR which increases mixing and reduces soot formation in the oxy-combustion cases. The OFC flames are lifted with larger amounts of oxidizer entrainment causing low soot formation and reducing the influence of fuel or oxidizer type. The air flames ignited closer to the burner producing a shorter distance for oxidizer entrainment and a lower $\mathrm{SR}_{\mathrm{I}}$. Oxy-flames ignited farther from the burner and had lower soot formation. Both flame types were produced in the BFR. The more attached flames at a swirl of 1.36 produced a more fuel rich near burner region and subsequently more soot. The soot was reduced by increasing the secondary mass flow rate which increased mixing between the fuel and oxidizer or by decreasing he swirl and detaching the flame.

\subsubsection{BFR Soot Testing Summary}

In addition to previous soot data taken on the L1500 and OFC furnaces, soot concentration measurements have been obtained on the BFR furnace for two coals at different furnace locations over a range of three stoichiometric ratios, three different oxidizers and two burner swirl numbers. The results show a decrease in soot concentration with increasing overall SR for all conditions. The soot concentration was generally highest at the base and decreased with increasing distance from the burner in all but the BFR tests with low secondary oxidizer flow rates. The trends in soot concentration can be explained by a mixing based model of a coal flame with soot formation. The key to soot formation is the SR of the fuel oxidizer mixture at the time of ignition, $\mathrm{SR}_{\mathrm{I}}$. Oxy-combustion would appear to have more impact on soot formation through changes in fuel and oxidizer mixing than it does by chemical effects impacting the kinetic reactivity of soot formation and oxidation processes.

\subsubsection{Modeling}

Soot is one of the important elements affecting the radiative heat transfer characteristics in a coal combustion system and proper assessment of soot formation should be considered in modeling. In order to understand soot behavior under oxy-firing conditions, the advanced soot model that has shown good agreement with the measurements under air-firing condition (Shim, et al. 2003) will be used. The predicted soot concentration and radiative profiles will be compared with the measurements available under air- and oxy-firing condition at L1500 and will be revised, if necessary. In this report, the preliminary results from the application of the advanced soot model to the existing air- and oxy-cases are discussed.

\subsubsection{Soot Model}

The advanced soot model combines chemical percolation devolatilization (CPD) model and semiempirical soot reaction model and account for soot evolution and its related heat transfer characteristics in a combustion system (Shim, et al. 2003) (Brown and Fletcher 1998). In the model, coal derived soot is assumed to form from tar only as shown in Figure 4.6-15 that illustrates the principal pathway for the formation of coal derived soot. Coal particles go through devolatilization upon injection into a combustion system and form char, light gas, and tar. Tar yields vary with coal type, temperature, heating 
rate, and pressure and can be modeled by existing coal particle models based on measured characteristics from the coal. Tar produced from coal devolatilization can be oxidized, gasified to light gas, or converted to primary soot. Then primary soot particles can be either oxidized or agglomerated. To accurately describe soot formation, the model should be able to describe both the transport of tar and conversion to soot.

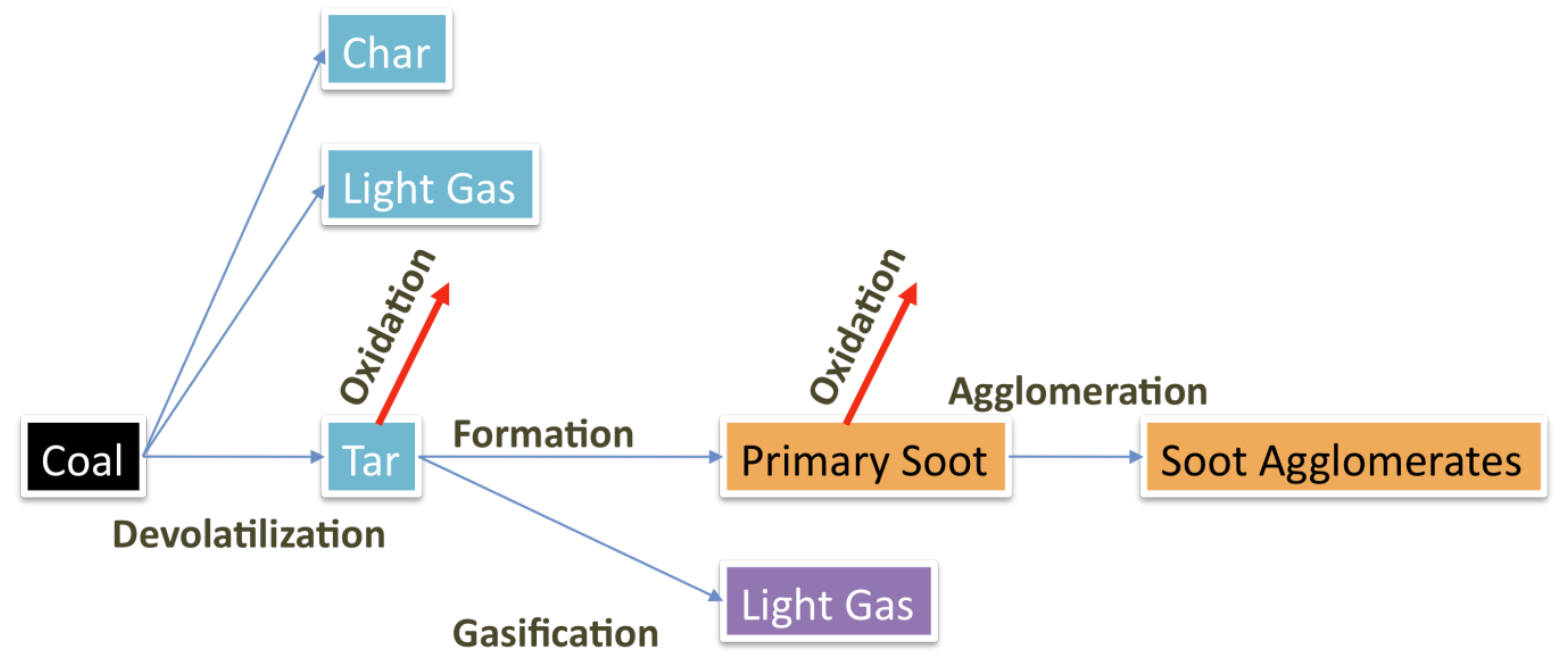

Figure 4.6-15: Principal pathway for the formation of coal derived soot.

An overview of the soot model is provided here; more details can be found in (Brown and Fletcher 1998). In the model, conservation equations, source terms, and boundary conditions for three-dimensional calculation of soot mass fraction $\left(\mathrm{Y}_{\mathrm{C}}\right)$, soot particles per unit mass $\left(\mathrm{N}_{\mathrm{C}}\right)$, and tar mass fraction $\left(\mathrm{Y}_{\mathrm{T}}\right)$ are generated. The boundary conditions for soot mass fraction, tar mass fraction, and the soot particles per unit mass are similar to the boundary conditions for other flow field variables in REI's Glacier CFD code, as shown in Table 4.6-5.

Table 4.6-5: Boundary Conditions for the Transport Equations.

\begin{tabular}{llll}
\hline Location & Soot Mass Fraction $\left(\mathrm{Y}_{\mathrm{C}}\right)$ & Tar Mass Fraction $\left(\mathrm{Y}_{\mathrm{T}}\right)$ & $\begin{array}{l}\text { Soot Particles per Unit } \\
\text { Mass }\left(\mathrm{N}_{\mathrm{C}}\right)\end{array}$ \\
\hline Primary & 0.0 & 0.0 & 0.0 \\
Secondary & 0.0 & 0.0 & 0.0 \\
Walls & $\mathrm{d} / \mathrm{dx}_{\perp}=0.0$ & $\mathrm{~d} / \mathrm{dx}_{\perp}=0.0$ & $\mathrm{~d} / \mathrm{dx}_{\perp}=0.0$ \\
Outlet & Quadratic extrapolation & $\begin{array}{l}\text { Quadratic extrapolation } \\
\text { Symmetry Plane }\end{array}$ & $\begin{array}{l}\text { Quadratic extrapolation } \\
\mathrm{d} / \mathrm{dx}_{\perp}=0.0\end{array}$ \\
\hline
\end{tabular}

The equations for conservation of the mass of soot $\left(\mathrm{Y}_{\mathrm{C}}\right)$ and $\operatorname{tar}\left(\mathrm{Y}_{\mathrm{T}}\right)$, and the number of soot particles $\left(\mathrm{N}_{\mathrm{C}}\right)$ are:

$$
\vec{\nabla} \cdot\left(\rho_{g} \vec{u} X\right)=\vec{\nabla} \cdot\left(\frac{\mu}{\sigma} \vec{\nabla} X\right)+\rho_{g} S_{Y}
$$

where $\mathrm{X}$ is the conserved variables $\left(\mathrm{Y}_{\mathrm{C}}, \mathrm{Y}_{\mathrm{T}}\right.$, or $\left.\mathrm{N}_{\mathrm{C}}\right)$, $\mathrm{S}$ represents the source terms $\left(\mathrm{S}_{\mathrm{YC}}, \mathrm{S}_{\mathrm{YT}}\right.$, or $\left.\mathrm{S}_{\mathrm{NC}}\right)$ for each transport equation, $\mu$ is the turbulent viscosity, $\sigma$ is the turbulent Schmidt number, $\rho$ is the timeaveraged density, and $u$ is the Favre-averaged velocity. Soot volume fraction $\left(f_{v, C}\right)$ is assumed to be small 
(i.e. $\rho_{\text {tot }} \cong \rho_{\mathrm{g}}$ ). Diffusivity is represented through the turbulent Schmidt number; standard values of the Schmidt number (700) are used for the transport equations for $\mathrm{Y}_{\mathrm{C}}$ and $\mathrm{N}_{\mathrm{C}}$ (Kennedy, Kollmann and Chen 1990) (Fairweather, Jones and Lindstedt 1992). For the tar mass fraction equation $\left(\mathrm{Y}_{\mathrm{T}}\right), 0.7$ is assumed for the Schmidt number, which is the value commonly assumed for the gas-phase Schmidt number (Hill and Smoot 1993). Soot and tar source terms are derived based on the soot formation mechanism shown in Figure 4.6-15. The source terms for the $\mathrm{N}_{\mathrm{C}}$ equation are derived following (Fairweather, Jones and Lindstedt 1992). The $\mathrm{N}_{\mathrm{C}}$ agglomeration term comes from the Smoluchowski particle rate equation, as described by (Haynes 1991) and (Ulrich 1971). Source terms for the conservation equations are:

$$
\begin{gathered}
S_{Y C}=\dot{r}_{F C}-\dot{r}_{O C} \\
S_{Y_{T}}=\dot{r}_{F T}-\dot{r}_{F C}-\dot{r}_{G T}-\dot{r}_{O T} \\
S_{N C}=\left(\frac{N_{a}}{M_{C} C_{\text {min }}}\right) \dot{r}_{F C}-\dot{r}_{A N}
\end{gathered}
$$

where

$$
\begin{array}{ll}
\dot{r}_{F T}=S P_{t a r} & \text { Formation of Tar } \\
\dot{r}_{O T}=\rho_{g}\left[c_{T}\right]\left[c_{O 2}\right] A_{O T} e^{-E_{O T} / R T} & \text { Oxidation of Tar } \\
\dot{r}_{G T}=\left[c_{T}\right] A_{G T} e^{-E_{G T} / R T} & \text { Gasification of Tar } \\
\dot{r}_{F C}=\left[c_{T}\right] A_{F C} e^{-E_{F C} / R T} & \text { Formation of Soot } \\
\dot{r}_{O C}=S A_{v, C} \frac{p_{O 2}}{T^{1 / 2}} A_{O C} e^{-E_{O C} / R T} & \text { Oxidation of Soot } \\
S A_{v, C}=\rho_{g}\left(\pi N_{C}\right)^{\frac{1}{3}}\left(\frac{6 Y_{C}}{\rho_{C}}\right)^{\frac{2}{3}} & \text { Soot Surface Area } \\
\dot{r}_{A N}=2 C_{a}\left(\frac{6 M_{C}}{\pi \rho_{C}}\right)^{\frac{1}{6}}\left(\frac{6 k T}{\rho_{C}}\right)^{\frac{1}{2}}\left(\frac{\rho_{g} Y_{C}}{M_{C}}\right)^{\frac{1}{6}}\left(\rho_{g} N_{C}\right)^{\frac{11}{6}} & \text { Agglomeration of the particle per unit mass }
\end{array}
$$

The average carbon soot density is assumed to be $1950 \mathrm{~kg} / \mathrm{m}^{3}$, and the collision frequency constant $\left(\mathrm{C}_{\mathrm{a}}\right)$ is assumed to be 3. Table 4.6-6 gives Arrhenius parameters used in the model. Tar yields are calculated from the Lagrangian particle phase equation which uses the CPD model (Fletcher, et al. 1992) to determine devolatilization rates and tar yields. When ${ }^{13} \mathrm{C}$ NMR data are not available as input parameters for the CPD model, a correlation (Genetti and Fletcher 1997) can be used to estimate ${ }^{13} \mathrm{C}$ NMR parameters from the proximate and ultimate analysis. 
Table 4.6-6: Transport Equation Source Terms.

\begin{tabular}{|c|c|c|c|}
\hline Term & A & $\mathrm{E}(\mathrm{kJ} / \mathrm{gmol})$ & Source \\
\hline$\dot{r}_{F T}$ & NA & NA & $\begin{array}{l}\text { Particle phase } \\
\text { calculations }\end{array}$ \\
\hline$\dot{r}_{O T}$ & $6.77 \times 10^{5}(1 / \mathrm{s})$ & 52.3 & (Shaw, et al. 1990) \\
\hline$\dot{r}_{G T}$ & $9.77 \times 10^{10}(1 / \mathrm{s})$ & 286.9 & $\begin{array}{c}\text { (Ma, Fletcher and Webb } \\
\text { 1996) }\end{array}$ \\
\hline$\dot{r}_{F C}$ & $5.02 \times 10^{8}(1 / \mathrm{s})$ & 198.9 & $\begin{array}{c}\text { (Ma, Fletcher and Webb } \\
\text { 1996) }\end{array}$ \\
\hline$\dot{r}_{O C}$ & $1.09 \times 10^{4}\left(\mathrm{~K}^{1 / 2} / \mathrm{s}\right)$ & 164.5 & Lee et al. \\
\hline$\dot{r}_{A N}$ & NA & NA & $\begin{array}{l}\text { (Fairweather, Jones and } \\
\text { Lindstedt 1992) }\end{array}$ \\
\hline
\end{tabular}

$\mathrm{Y}_{\mathrm{C}}$ values calculated from the above equations can be used to calculate the soot volume fraction $\left(\mathrm{f}_{\mathrm{v}, \mathrm{C}}\right)$ using the following equation.

$$
f_{v, C}=\left(\frac{\rho_{g}}{\rho_{C}}\right) Y_{C}
$$

Then the soot volume fraction is used to determine the soot emissivity $\left(\varepsilon_{C}\right)$ (Sarofim and Hottel 1978):

$$
\varepsilon_{C}=1-\left(1+350 f_{v, C} T L_{e}\right)^{-4}
$$

where $\mathrm{T}$ is the temperature $(\mathrm{K})$ and $\mathrm{L}_{\mathrm{e}}$ is the mean beam path length $(\mathrm{m})$.

The emissivity may be related to the absorption coefficient ( $\kappa)$ through Bouguer's Law

$$
\kappa=-\left(\frac{1}{L_{e}}\right) \ln (1-\varepsilon)
$$

giving

$$
\kappa_{C}=\left(\frac{4}{L_{e}}\right) \ln \left(1+350 f_{v, C} T L_{e}\right)
$$

This absorption coefficient is then summed with the calculated absorption coefficient for the radiating gases (i.e., $\mathrm{CO}_{2}$ and $\mathrm{H}_{2} \mathrm{O}$ ) to form a total absorption coefficient.

\subsubsection{Case Descriptions}

L1500 CFD cases Case1A and Case2O are compared here and their operating conditions are summarized in Table 4.6-7. Case1A and Case2O are air- and oxy-firing cases, respectively, and both cases burn bituminous coal at a firing rate of $3.5 \mathrm{MBtu} / \mathrm{hr}$ with $3.2 \%$ excess $\mathrm{O}_{2}$. Particle size distribution used in modeling was 74\% passing through 200 mesh and 99\% through 50 mesh. Calculated stoichiometric adiabatic temperatures with primary oxidant are 3,600 and 3,085 $\mathrm{F}$ for Case1 A and Case2O, respectively. 
Flue gas recirculation (FGR) was used in case2O assuming $\mathrm{CO}_{2} 83.6 \%, \mathrm{H}_{2} \mathrm{O} 12.4 \%, \mathrm{O}_{2} 3.2 \%, \mathrm{~N}_{2} 0.6 \%$ and $\mathrm{SO}_{2} 0.1 \%$.

Table 4.6-7: Operating Conditions for Case1A and Case2O.

\begin{tabular}{|c|c|c|}
\hline & Case 1A & Case 20 \\
\hline Firing Rate (MBtu/hr) & 3.5 & 3.5 \\
\hline Oxidizer & Air & $\mathrm{O}_{2}+\mathrm{FGR}$ \\
\hline Total Coal Flow (lb/hr) & 279 & 279 \\
\hline PA Flow (lb/hr) & 524.3 & 683 \\
\hline PA Flow/Coal Mass Ratio & 1.88 & 2.45 \\
\hline PA Temperature ( ${ }^{\circ} \mathrm{F}$ ) & 150 & 150 \\
\hline PA Velocity (ft/s) & 72 & 69 \\
\hline PA Stoichiometric Ratio & 0.1961 & 0.2133 \\
\hline PA Feed $\mathrm{O}_{2}$ (wt\%) & N/A & $17.10 \%$ \\
\hline $\mathrm{O}_{2}$ concentration (volumn) in PA & $20.70 \%$ & $23.20 \%$ \\
\hline InnerSA Flow (Ib/hr) & 285.5 & 189.7 \\
\hline OuterSA Flow (lb/hr) & 1617.8 & 1809.9 \\
\hline Inner SA Feed O2 (wt\%) & N/A & $41.00 \%$ \\
\hline Outer SA Feed O2 (wt\%) & $\mathrm{N} / \mathrm{A}$ & $17.10 \%$ \\
\hline Inner SA Temperature ('F) & 500 & 500 \\
\hline Outer SA Temperature ( $\left.{ }^{\circ} \mathrm{F}\right)$ & 500 & 500 \\
\hline Burner Stoichiometric Ratio & 0.91 & 0.91 \\
\hline
\end{tabular}

\subsubsection{Simulation Results}

Table 4.6-8 shows the overall simulation results for the two cases, case1a_soot and case2o_soot. Similar to the previous results without the advanced soot model, oxy-firing case, case2o_soot predicted lower exit temperature than case1a_soot about $150^{\circ} \mathrm{F}$. CO concentration and LOI increased in oxy case, while the volatile yield was lower in the oxy case. The soot flow rate based on the advanced soot model predicted to be higher in air case than oxy case.

Table 4.6-8: Overall Simulation Results.

\begin{tabular}{ccc} 
& case1a_soot & case2o_soot \\
\hline Temperature at Exit $\left({ }^{\circ} \mathrm{F}\right)$ & 2,060 & 1,909 \\
CO at Exit (vol\%, wet) & 3.73 & 3.96 \\
LOI & 60.0 & 62.2 \\
Volatile Yield & 65.2 & 62.7 \\
Soot Flow at Exit (lb/hr) & 5.07 & 3.29 \\
\hline
\end{tabular}

Figure 4.6-16 shows the mass weighted average of gas temperature as a function of distance from the burner face. Air case, case1a_soot shows relatively higher gas temperature than case2o_soot along the whole furnace length simulated here resulting in higher exit temperature.

Figure 4.6-17 shows the incident heat flux profiles on the fire-side walls for case1a_soot and case2o_soot. Overall incident heat flux profiles illustrate that the heat flux is non-uniform and air case has higher heat 
flux. This can be clearly by plotting the average incident heat flux as a function of the distance from the burner face (see Figure 4.6-18). Higher heat flux can be caused from various combustion environments including gas temperature, gas composition $\left(\mathrm{CO}_{2}\right.$ and $\mathrm{H}_{2} \mathrm{O}$ in particular), and particles such as char and soot.

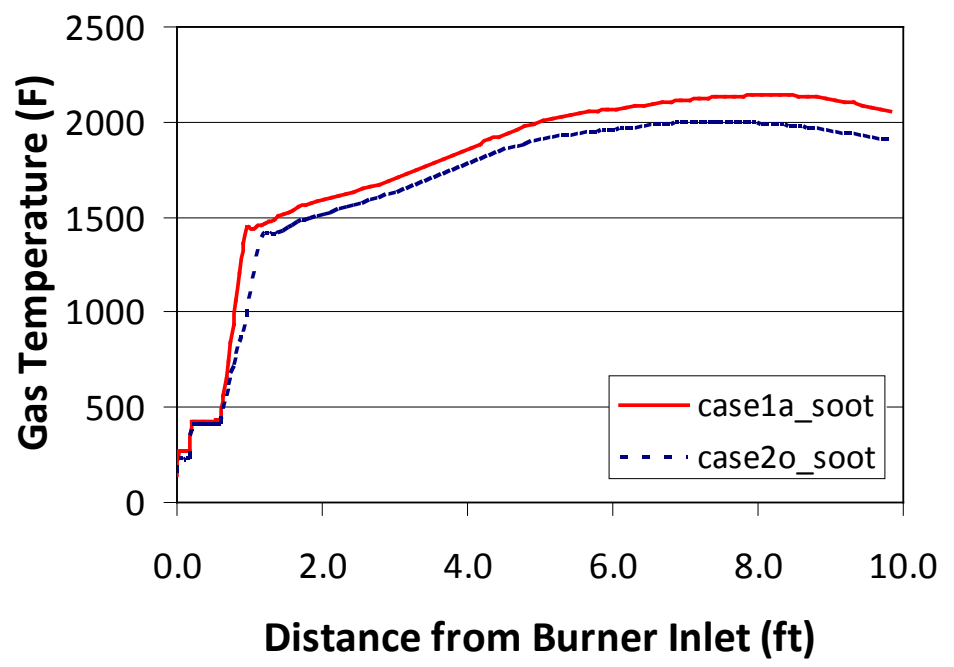

Figure 4.6-16: Mass weighted average of gas temperature as a function of distance from burner inlet.

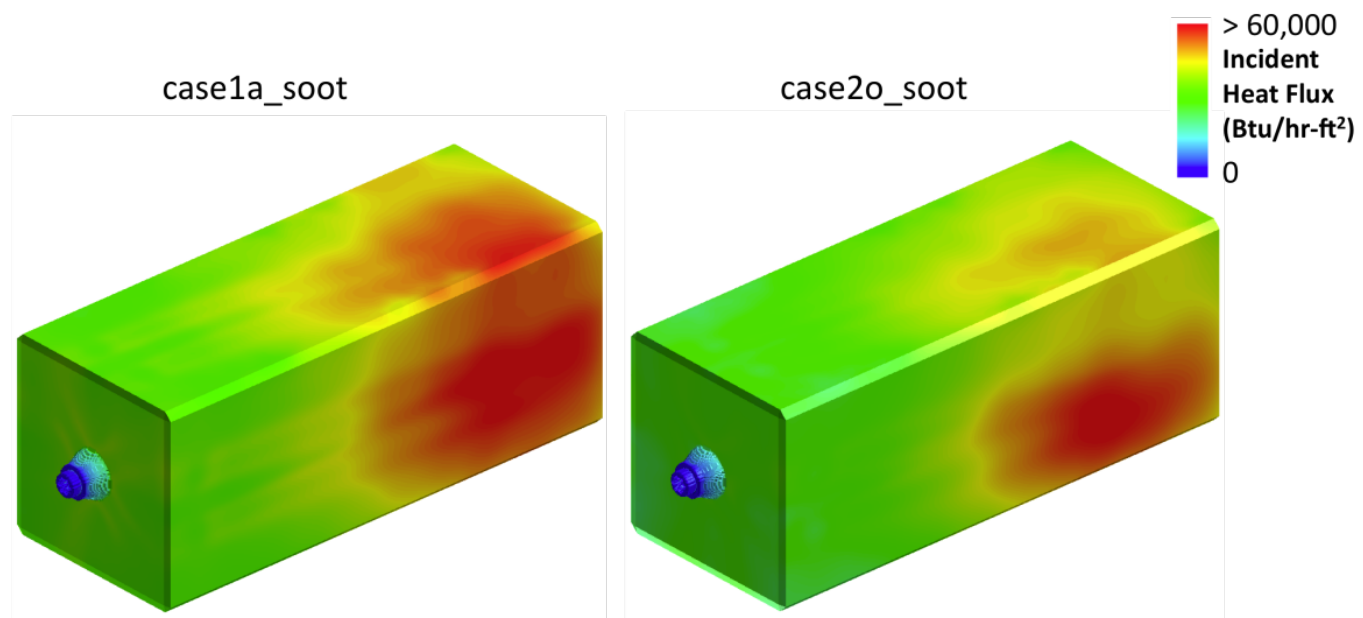

Figure 4.6-17: Incident heat flux profiles on the fire-side walls for case1a_soot and case2o_soot. 


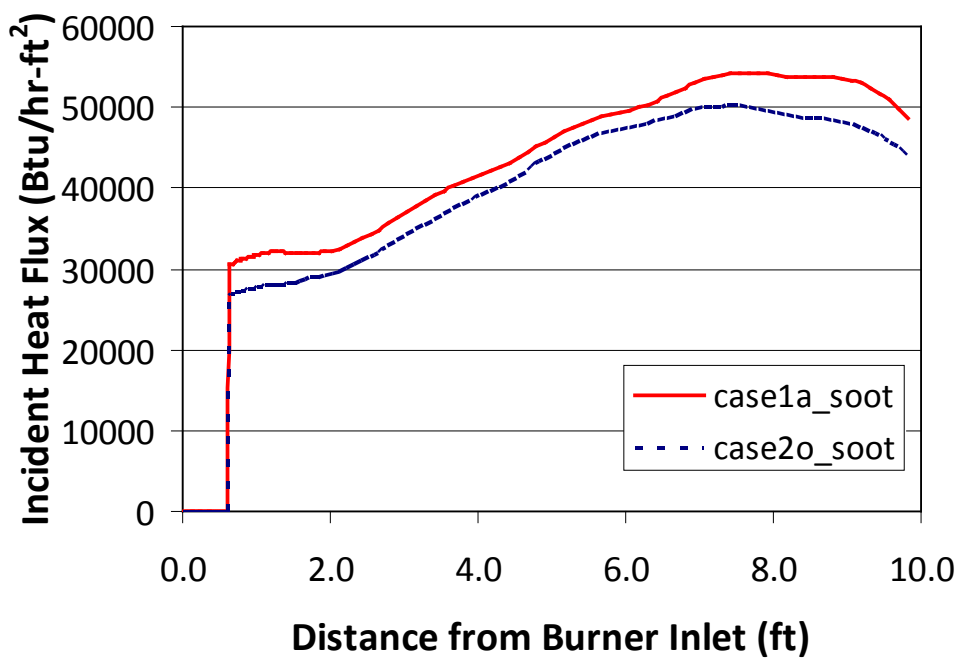

Figure 4.6-18: Average incident heat flux on the fire-side wall for case1a_soot and case2o_soot.

Figure 4.6-19 shows the tar mass fraction profiles and the mass weighted average of tar mass fraction as a function of the distance from the burner face. Air case forms tar earlier and show the tar in broader regions in the furnace than the oxy case, even though the maximum tar mass fraction can be found in the oxy case. Figure 4.6-20 shows the soot volume fraction profiles and the mass weighted average of soot volume fraction as a function of the distance from the burner face for each case. As expected from the tar mass fraction profile, case 1a_soot forms soot earlier than the oxy case. However, case2o_soot catches up the air case at around $1.8 \mathrm{ft}$ and forms slightly higher soot volume fraction before the air case overlaps again and shows more soot downstream. This result is very promising as recent testing results at BYU shows similar behavior with higher soot volume fraction in air case at about $6 \mathrm{ft}$ from the burner face under similar operating conditions (Tree, Stimpson and Fry 2010).
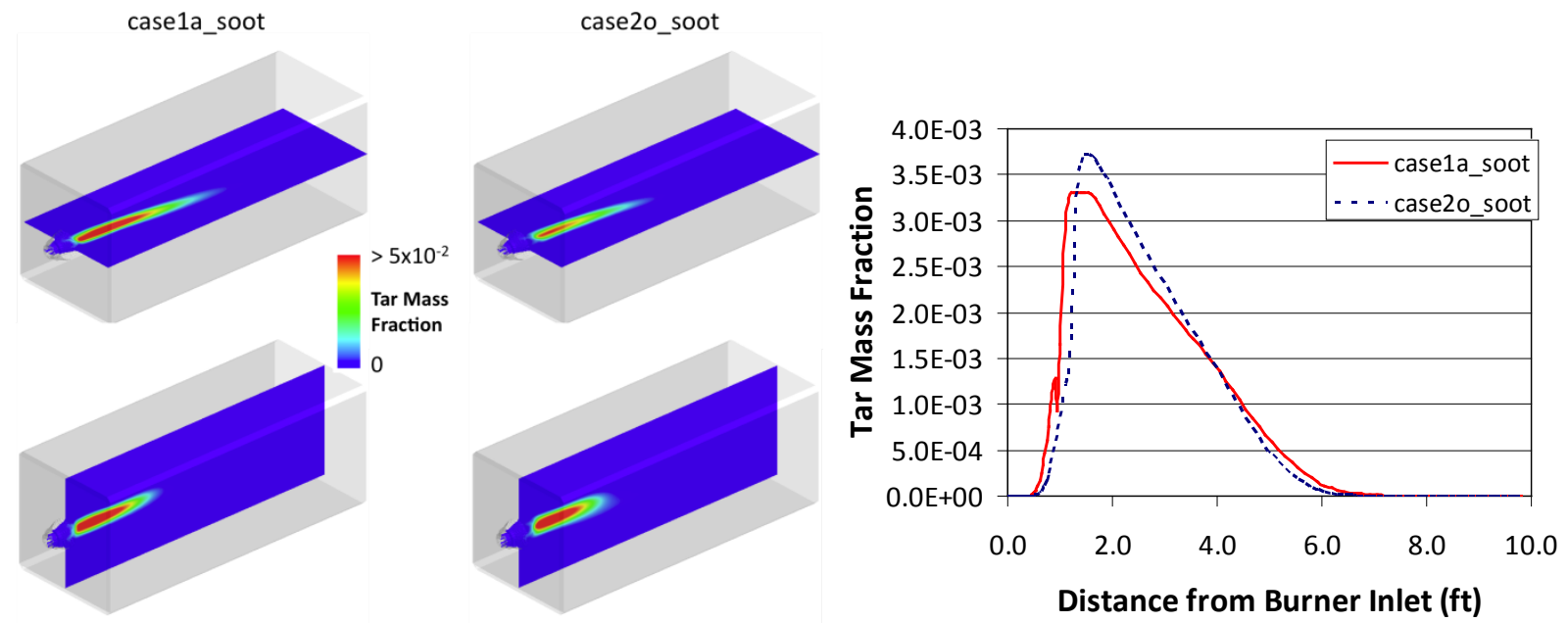

Figure 4.6-19: Tar mass fraction profiles and mass weighted average of tar mass fraction as a function of distance from burner inlet for case1a_soot and case2o_soot. 

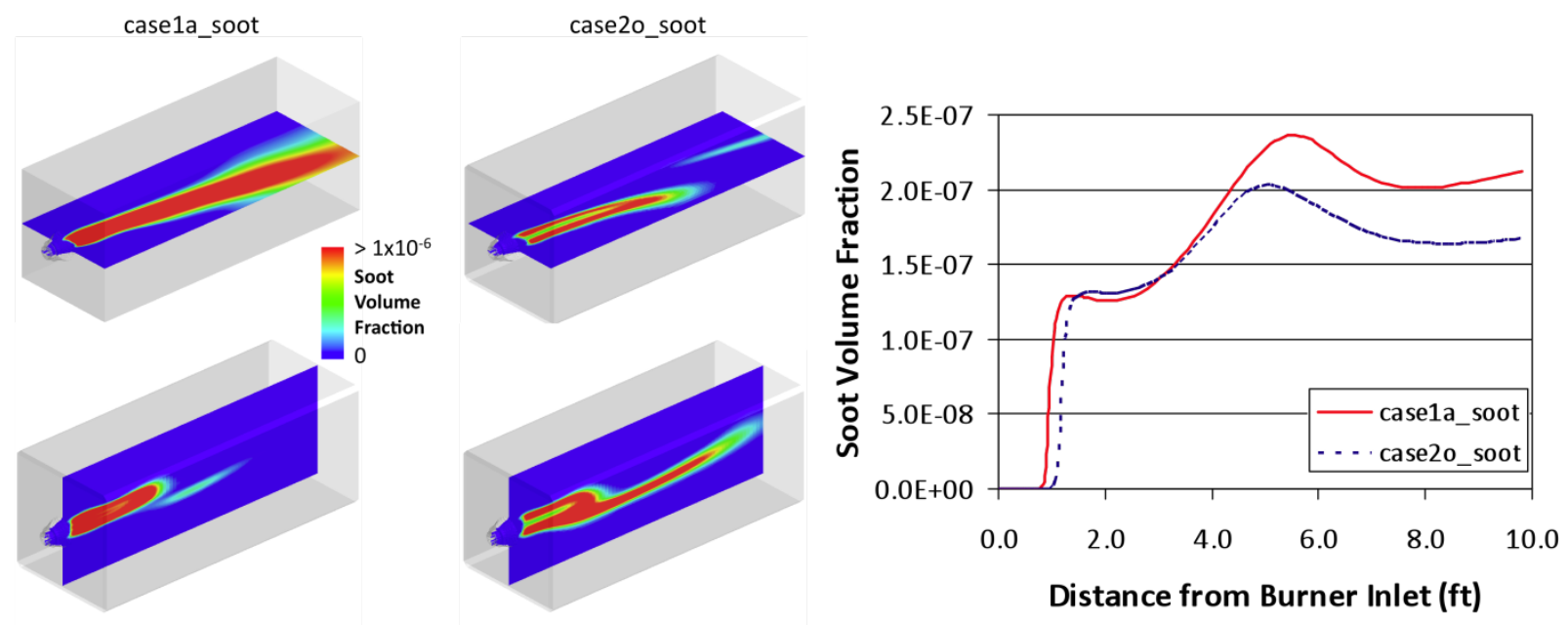

Figure 4.6-20: Soot volume fraction profiles and mass weighted average of soot volume fraction as a function of distance from burner inlet for case1a_soot and case2o_soot.

Figure 4.6-20 also shows very asymmetric soot volume fraction profiles for each case. The fine soot particles once formed follows the main flow in the furnace. This is illustrated in Figure 4.6-21 showing the soot volume fraction profile along the vertical and the horizontal lines at $1.8 \mathrm{ft}$ from the burner face. Soot is more concentrated on left hand lower part of the furnace when it's seen from the model exit.

Figure 4.6-22 shows the soot volume fraction iso-surface overlaid with the oxygen profiles. It shows that soot exists in oxygen deficient zone and quickly disappears as it meets oxygen in gas.

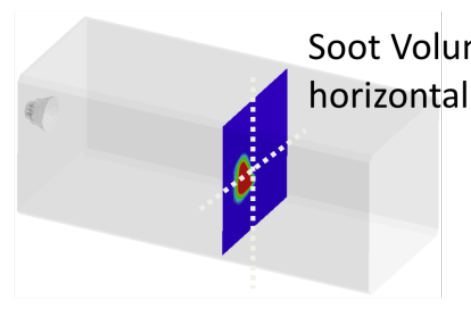

case1a_soot

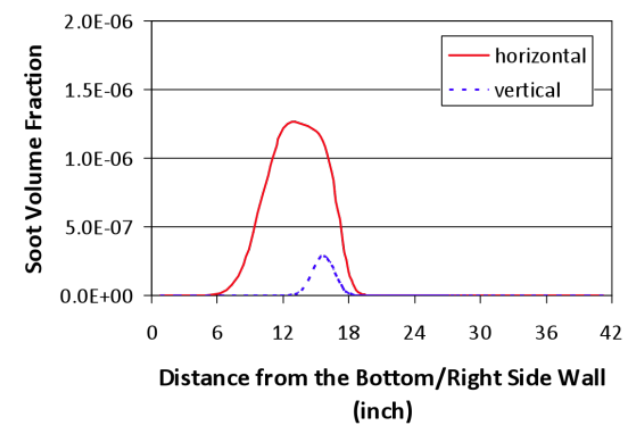

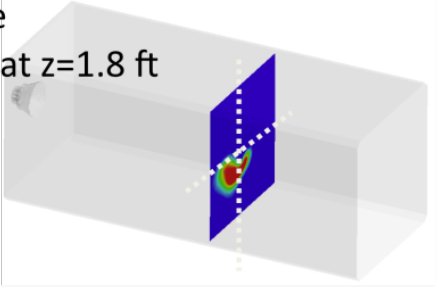

case2o_soot

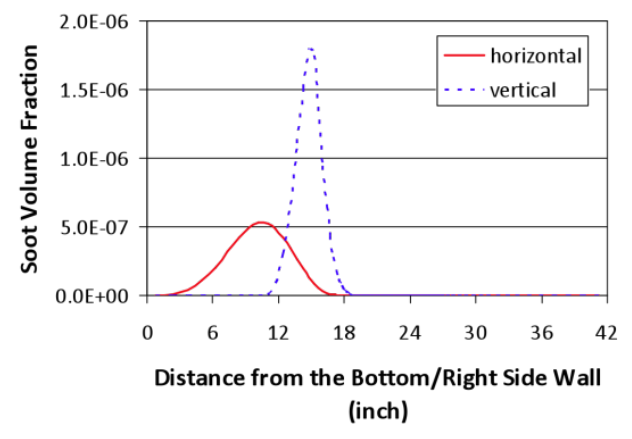

Figure 4.6-21: Asymmetric soot volume fraction profiles along the horizontal and the vertical lines at $1.8 \mathrm{ft}$ from the burner face for case1a_soot and case2o_soot. 

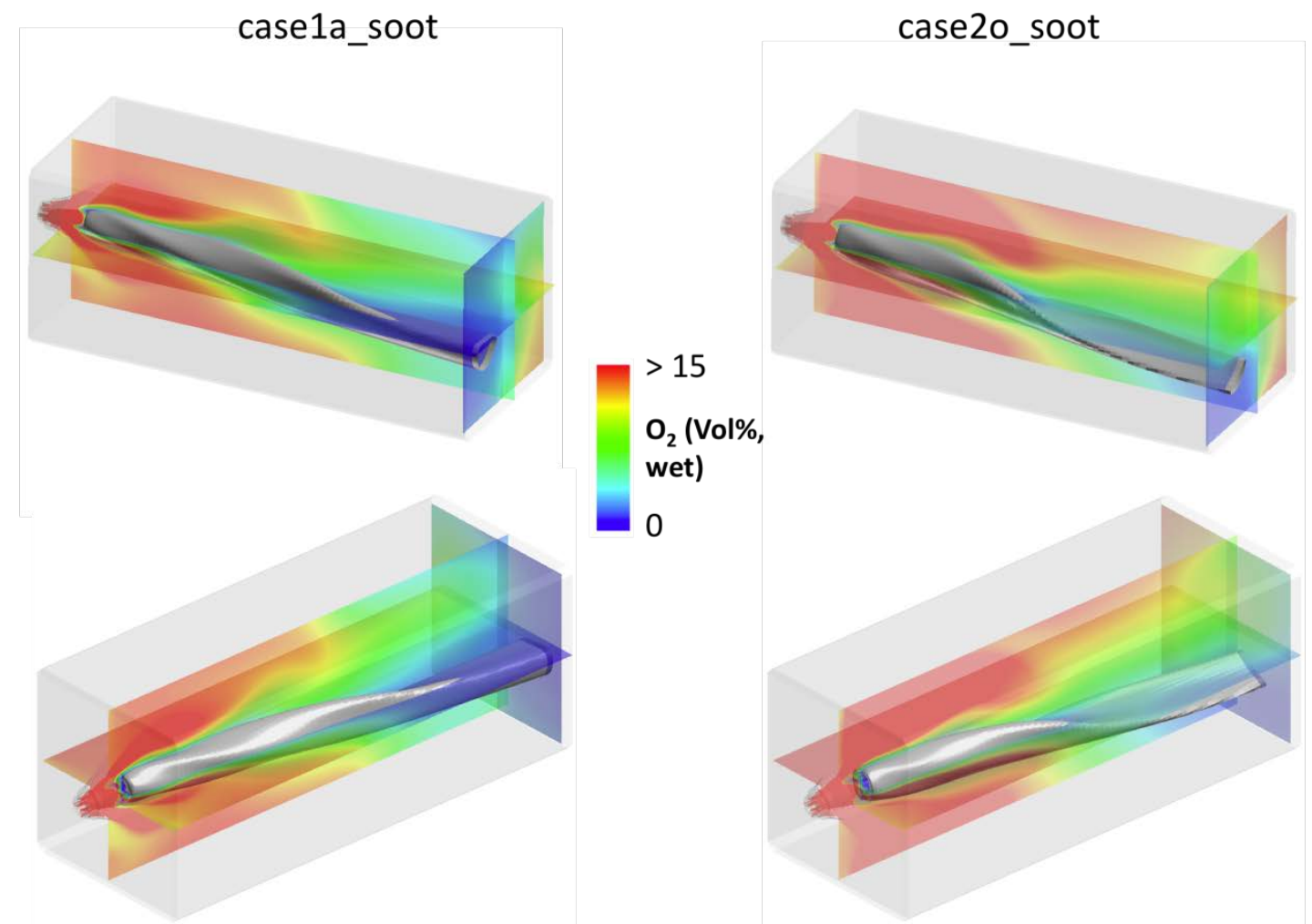

Figure 4.6-22: Soot volume fraction iso-surface (gray) at $1 \times 10^{-6}$ overlaid with the oxygen profile for case1a_soot and case2o_soot.

\subsubsection{Soot Conclusions}

Soot concentration measurements were obtained for two coals at three locations over a range of three stoichiometric ratios and three different oxidizers. The results show a decrease in soot concentration with increasing overall SR. The soot concentration was highest at the base and decreased slightly with increasing distance from the burner. The trends in soot concentration can be explained by a mixing based model of a coal flame with soot formation. The key to soot formation is the SR of the fuel oxidizer mixture at the time of ignition. Oxy-combustion would appear to have more impact on the mixing of fuel and oxidizer by changing flow rates and ignition characteristics than it does on chemical effects impacting the kinetic reactivity of soot formation and oxidation processes.

A soot model implemented in the Glacier CFD code was shown to capture expected effects of formation and oxidation. Soot was found to form in oxygen-lean zones and correlate well with tar mass fraction distribution. As oxygen mixed with soot-laden zones, the soot was oxidized. Consistent with the pilotscale measurements, soot behavior correlated with flame SR and mixing. Oxy-firing conditions were shown to produce lower soot concentrations moving downstream from the burner. The higher soot volume fractions in the air-fired case also correlated with slightly higher wall heat flux profiles, although the heat flux is also impacted by other variables such as flame temperature and composition so this correlation is difficult to isolate. 


\subsection{Aerosols}

\subsubsection{Introduction}

The primary focus of this research was to determine the differences in aerosol composition between air firing and oxy-firing. At this point, very little research has been done to determine how the change in combustion environment will affect aerosol formation under practical firing conditions involving selfsustaining combustion flames. Differences may be expected as a result of enhanced or suppressed mineral vaporization in the ash due to increased temperatures resulting from a higher oxygen concentration, or decreased as a result of $\mathrm{CO}_{2}$ providing local cooling or inhibiting the vaporization of refractory oxides (Jia 2011). Furthermore, increased $\mathrm{SO}_{2}$ concentrations under an untreated flue gas recycle regime could produce greater amounts of sulfate minerals which could greatly increase slagging, the buildup of ash material on heat transfer surfaces. Also, an increase or decrease in vaporization of material would lead to a difference in particle size distribution which may affect particulate control devices.

Changes in the combustion atmosphere could also affect the efficiency of combustion as high $\mathrm{CO}_{2}$ concentrations could reduce the transport of oxygen to char particles and thus cause an increase in loss on ignition (LOI). Given the energy penalty of separating air into $\mathrm{O}_{2}$ and $\mathrm{N}_{2}$ in order to provide the oxygen for oxy-fired combustion, a decrease in the completeness of combustion of the fuel would result in further efficiency losses in a retrofit application.

As a result the scope of this work aimed to conduct experiments and collect aerosol data over a suitable range of once through and flue gas recycle oxy-fired conditions utilizing different common US coals. These data includes size segregated ash chemistry, total ash for loss on ignition measurements, particle size distribution, and black carbon or soot concentration.

The size segregated ash chemistry data provided information that may be useful for related research on deposition and heater tube fouling. In addition, this information may be used to determine the effectiveness of capture by electrostatic precipitator devices as well as potential health effects issues as a result of atmospheric release.

Total ash collection allowed for loss on ignition measurements to determine combustion efficiency of different combustion atmosphere scenarios. The percentage of oxygen and the change in combustion atmosphere from air to oxy-fired may play an important role in the effectiveness of char particle burnout, which is another important efficiency consideration for oxy-coal firing.

Particle size distributions are also important pieces of information which can aid in determining mechanisms of formation as well as providing an overall roadmap of particle mass in various size ranges which can be useful in predicting emissions, fouling, and ash buildup within the furnace.

Black carbon or soot concentration is very important because it is a black body radiator, and therefore a very efficient radiation heat transfer source within the furnace. Thus its concentration or change in concentration may be useful information for those wishing to model heat transfer within an oxy-fired furnace. Furthermore, as a black body radiator, soot has climate forcing impacts as well when it is released into the atmosphere.

Thus the importance of this work was to examine how retrofitting from air to oxy-fired combustion affected the combustion aerosol characteristics of three coals: a Utah low sulfur bituminous, Illinois high sulfur bituminous, and Powder River Basin (PRB) sub-bituminous coal. 
In order to accomplish this, a research strategy was put together which guided the experimental investigations into potential changes in the aerosols formed in a coal fired boiler.

\subsubsection{Research Strategy}

In order to systematically evaluate the effects of combustion atmosphere on aerosol formation, a set of combustion conditions had to be determined. In this case, the baseline scenario for comparison is airfired or conventional combustion, now referred to as case AIR. Two oxy-fired combustion conditions were selected that would be in the range of operating conditions used in a retrofit application. The first matched the radiant heat flux of the flue gas in air-fired combustion by utilizing a $27 \% \mathrm{O}_{2}$ and $73 \% \mathrm{CO}_{2}$ environment which will be referred to as case OXY27. Finally, in order to approximately match a calculated adiabatic flame temperature, the scenario $32 \% \mathrm{O}_{2}$ and $68 \% \mathrm{CO}_{2}$, referred to as case OXY32, was to be examined (T. F. Wall 2007).

It was then decided to keep flue gas $\mathrm{O}_{2}$ concentration constant rather than use constant stoichiometric ratio for the experiments. When the oxygen concentration of the oxidant stream changes, and stoichiometric ratio was kept constant, as shown in Table 4.7-1, the concentration of the flue gas changed significantly. Since the effect of flue gas composition on aerosol formation is the topic investigated in this work, it was decided to keep the flue gas oxygen concentration on a dry basis constant rather than the stoichiometric ratio. Furthermore, this applies to flue gas recycle conditions as well.

Under equivalent flue gas recycle conditions, the percentage of oxygen in the oxidant stream would be equal to once through $\mathrm{CO}_{2}$ in terms of burner stoichiometry. Burner stoichiometry is the stoichiometry of all material, coal, oxidant, and diluents entering the burner. This is defined as the system operationally since the concentration of oxygen entering the burner on a molar basis is very important. If this concentration were to get too high due to lack of flue gas recycle, catastrophic results would occur. Therefore, it is important to understand that when operating a furnace, the burner is defined as the system, and the stoichiometry is calculated at the burner for all work featured here. Thus, the stoichiometric ratio of the burner is the same for once through conditions or flue gas recycle conditions when the oxidant stream has the equivalent molar percentage.

Table 4.7-1: Comparison of air and oxy-fired dry flue gas concentrations under a constant stoichiometric ratio.

\begin{tabular}{|l|r|r|r|r|r|r|}
\hline & Utah Coal & Dry Gas & & & \\
\hline & Air & OXY27 & OXY32 & FGR32 & FGR32 \\
\hline System SR & 1.164 & 1.164 & 1.164 & 1.164 & 1.027 \\
\hline Burner SR & 1.164 & 1.164 & 1.164 & 1.628 & 1.103 \\
\hline Sys. Inlet $\mathrm{O}_{2}$ & $20.9 \%$ & $27 \%$ & $32 \%$ & $100 \%$ & $100 \%$ \\
\hline $\mathrm{CO}_{2}$ & $15.59 \%$ & $96.04 \%$ & $95.41 \%$ & $83.19 \%$ & $95.89 \%$ \\
\hline $\mathrm{SO}_{2}$ & $0.04 \%$ & $0.05 \%$ & $0.06 \%$ & $0.23 \%$ & $0.27 \%$ \\
\hline $\mathrm{N}_{2}$ & $81.35 \%$ & $0.17 \%$ & $0.20 \%$ & $0.72 \%$ & $0.83 \%$ \\
\hline $\mathrm{O}_{2}$ & $3.01 \%$ & $3.74 \%$ & $4.33 \%$ & $15.86 \%$ & $3.01 \%$ \\
\hline $\mathrm{PM}\left(\mathrm{mg} / \mathrm{m}^{3}\right)$ & 6.71 & 12.43 & 18.91 & 51.93 & 59.86 \\
\hline
\end{tabular}

The only difference when operating the furnace is that in a 32\% oxy-fired case, a once through scenario would be $32 \% \mathrm{O}_{2}$ and $68 \% \mathrm{CO}_{2}$ at the burner, while a recycled flue gas condition would be $32 \% \mathrm{O}_{2}$ and $68 \%$ recycled flue gas species at the burner which may contain $\mathrm{CO}_{2}, \mathrm{H}_{2} \mathrm{O}$, and $\mathrm{SO}_{2}$. The concept of 
varying flue gas composition has been illustrated in Table 4.7-2 to further aid in the understanding between the differences of air, once through, and flue gas recycle oxy-fired conditions.

However, if defining the system more broadly as the entire recycle system, boiler, coal feeder, and oxygen inlet, then the only inputs are the coal and the oxygen. At this point the oxygen is pure $100 \%$ oxygen, and thus at the equivalent stoichiometric ratio of air or once through fired where the oxygen is diluted by the nitrogen or $\mathrm{CO}_{2}$ from a tank. Obviously if the only mass entering the system is pure oxygen, then at the same stoichiometric ratio, the excess oxygen in the flue gas is going to be significantly higher. By conservation of mass, if the only inputs are the oxygen and coal, then the only products leaving the system are the combustion products of these two constituents. As a result, since there is no diluent from this definition, the oxygen concentration appears much higher. A comparison of the dry exhaust gas composition for this scenario compared with air, once through oxy-fired, and flue gas recycle conditions is shown in Table 4.7-1.

Flue gas concentration is also what is used industrially and for continuous emissions monitoring, so it was determined to be the most relevant and sensible and easy to understand constant. All tests were performed with $3 \% \mathrm{O}_{2}$ in the flue gas unless otherwise noted. Alternative flue gas oxygen concentrations of $0 \%, 1 \%$, and $2 \%$ were utilized in order to examine the effects of stoichiometry on black carbon emissions. Lower excess oxygen was needed in order to increase the amount of soot produced in an increasingly fuel rich environment.

With regard to the recycled flue gas, there are three constituents of interest in the flue gas besides $\mathrm{CO}_{2}$ in this research. These include water vapor, $\mathrm{SO}_{2}$, and particles which may buildup in high concentrations due to repeated recycling through the furnace. As a result, aerosol measurements were made with flue gas with no contaminants removed, $\mathrm{SO}_{2}$ and moisture removed, and with particles removed to see how the large differences in concentration would affect aerosol formation and chemistry.

Mercury has also been identified as a potential problem for $\mathrm{CO}_{2}$ processing units regarding corrosion, but had not been identified as such at the start of this work and was not investigated (Shah 2011). Mercury would also be present in higher concentrations under oxy-firing for the same reasons that $\mathrm{SO}_{2}$ and particulate matter are present in higher concentrations due to the lack of nitrogen in air for dilution. As a result, this greater mercury concentration may also be a consideration in retrofit applications. However this concern became more apparent after this research had been completed.

A sample comparison of air-fired, once through oxy-fired, and untreated flue gas recycle oxy-fired conditions have been provided to further illustrate this point. The moisture content for FGR values are representative of observed values. However the air and once through values had to use calculated values since a moisture analyzer was not yet installed. The tables indicated that there were some issues with sampling particulate at the very high moisture concentrations under flue gas recycle which may have resulted in underreporting of the particulate concentration particularly for the Utah coal in Table 4.7-2. Flue gas comparisons for the PRB and Illinois coals have been reported in Table 4.7-3 and Table 4.7-4, respectively. All values correspond to $3 \% \mathrm{O}_{2}$ flue gas on a dry basis. 
Table 4.7-2: Utah flue gas comparison between air, once through oxy-fired, and untreated flue gas recycle oxy-fired.

\begin{tabular}{|l|r|r|r|}
\hline & Utah & Flue Gas & \\
\hline & Air & OXY32 & Dirty FGR \\
\hline Burner SR & 1.164 & 1.103 & 1.103 \\
\hline $\mathrm{H}_{2} \mathrm{O}$ & $6.63 \%$ & $10.90 \%$ & $28.00 \%$ \\
\hline $\mathrm{CO}_{2}$ & $14.56 \%$ & $86.17 \%$ & $67.70 \%$ \\
\hline $\mathrm{SO}_{2}$ & $0.04 \%$ & $0.06 \%$ & $0.20 \%$ \\
\hline $\mathrm{N}_{2}$ & $75.96 \%$ & $0.19 \%$ & $2.00 \%$ \\
\hline $\mathrm{O}_{2}$ & $2.81 \%$ & $2.68 \%$ & $2.10 \%$ \\
\hline
\end{tabular}

Table 4.7-3: PRB flue gas comparison between air, once through oxy-fired, and untreated flue gas recycle oxy-fired.

\begin{tabular}{|l|r|r|r|}
\hline & \multicolumn{1}{|l|}{ PRB } & Flue Gas & \\
\hline & Air & OXY32 & Dirty FGR \\
\hline Burner SR & 1.165 & 1.1 & 1.1 \\
\hline $\mathrm{H}_{2} \mathrm{O}$ & $10.14 \%$ & $15.65 \%$ & $38.00 \%$ \\
\hline $\mathrm{CO}_{2}$ & $14.74 \%$ & $81.65 \%$ & $58.04 \%$ \\
\hline $\mathrm{SO}_{2}$ & $0.02 \%$ & $0.04 \%$ & $0.06 \%$ \\
\hline $\mathrm{N}_{2}$ & $72.41 \%$ & $0.14 \%$ & $2.00 \%$ \\
\hline $\mathrm{O}_{2}$ & $2.69 \%$ & $2.52 \%$ & $1.90 \%$ \\
\hline
\end{tabular}

Table 4.7-4: Illinois flue gas comparison between air, once through oxy-fired, and untreated flue gas oxy-fired.

\begin{tabular}{|l|r|r|r|}
\hline & \multicolumn{1}{|l|}{ Illinois } & \multicolumn{1}{l|}{ Flue Gas } & \\
\hline & \multicolumn{1}{l|}{ Air } & OXY32 & Dirty FGR \\
\hline Burner SR & 1.165 & 1.099 & 1.099 \\
\hline $\mathrm{H}_{2} \mathrm{O}$ & $7.36 \%$ & $11.62 \%$ & $31.00 \%$ \\
\hline $\mathrm{CO}_{2}$ & $14.33 \%$ & $85.04 \%$ & $63.00 \%$ \\
\hline $\mathrm{SO}_{2}$ & $0.33 \%$ & $0.52 \%$ & $1.90 \%$ \\
\hline $\mathrm{N}_{2}$ & $75.19 \%$ & $0.17 \%$ & $2.00 \%$ \\
\hline $\mathrm{O}_{2}$ & $2.80 \%$ & $2.65 \%$ & $2.10 \%$ \\
\hline
\end{tabular}

\subsubsection{Previous Research}

Very little aerosol work has been done on practical oxy-fired coal flames. Due to the large costs associated with operating pilot or near pilot scale facilities, many research groups have utilized drop tubes or single coal particle research combustors to examine oxy-fired mechanisms. However, much work has been done regarding coal combustion aerosols regarding conventional air-fired combustion. 
While there was literature covering most all aerosol topics under conventional air firing combustion, oxyfiring had more gaps in the available literature, which this work is intended to help fill. Stanger and Wall have put together an extensive literature review regarding acid gas formation, fate, and impacts under oxy-firing (Stanger and Wall 2010). However, much of the review they provide does not address any aerosol issues and instead focuses on acid gas pollutant reduction, heat transfer, and thermodynamics (Croiset and Thambimuthu 2001) (Stanger and Wall 2010). As a result, most aerosol data have come from drop tube furnaces and simulation (Bejarano and Levendis 2008) (Jia 2011) (Rantham, et al. 2009) (Sheng, et al. 2007) (Zheng and Furimsky 2003) with few pilot scale experiments being performed utilizing practical flames (Morris 2009) (Wall, et al. 2009). Pilot scale and demonstration plants also were not focused on aerosol issues, but with operational concerns of flame stability and ignition as well as heat transfer and acid gas formation (Goh and On 2008) (Yamada 2007). Thus most of the literature review must focus on mechanisms understood under air-fired conditions.

In air-fired combustion it has been shown that there are three particle modes consisting of mineral matter in a condensed vapor phase with particle diameter less than $1 \mu \mathrm{m}$, a fine fragmentation mode centered near $1 \mu \mathrm{m}$, and a larger bulk mode all of which are dependent upon coal rank and mineral (B. H. Buhre 2005) (Linak, et al. 2002) (W. S. Seames 2003). The fine fragmentation mode centered near $1 \mu \mathrm{m}$ has not always been recognized, and was an evolution of the previous research which focused on an inclusion mode and a vaporization mode (Sarofim, Howard and Padia 1977). However, as more research focused on the health effects of fine particles and the need to understand fine particle formation, Linak's work showed that there were in fact three modes, and that this new fine fragmentation mode was of critical importance for understanding fine particle emissions. This work was further validated by Seames, who also focused research on this mode and its importance regarding trace element partitioning (W. S. Seames 2003).

The researchers showed that these three modes were created by three main mechanisms which have been illustrated in Figure 4.7-1. They showed that the largest particles were created by coalescence of mineral inclusions within the coal matrix (Sarofim, Howard and Padia 1977). As the coal burned away, mineral inclusions coalesced into larger particles that created this bulk mode which is made up of particles several microns in diameter up to a range of 100 microns in diameter. This mode is responsible for the majority of particle mass which is relatively easy to capture in pollution control devices (de Nevers 2000). 


\section{PARTITIONING MECHANISMS}

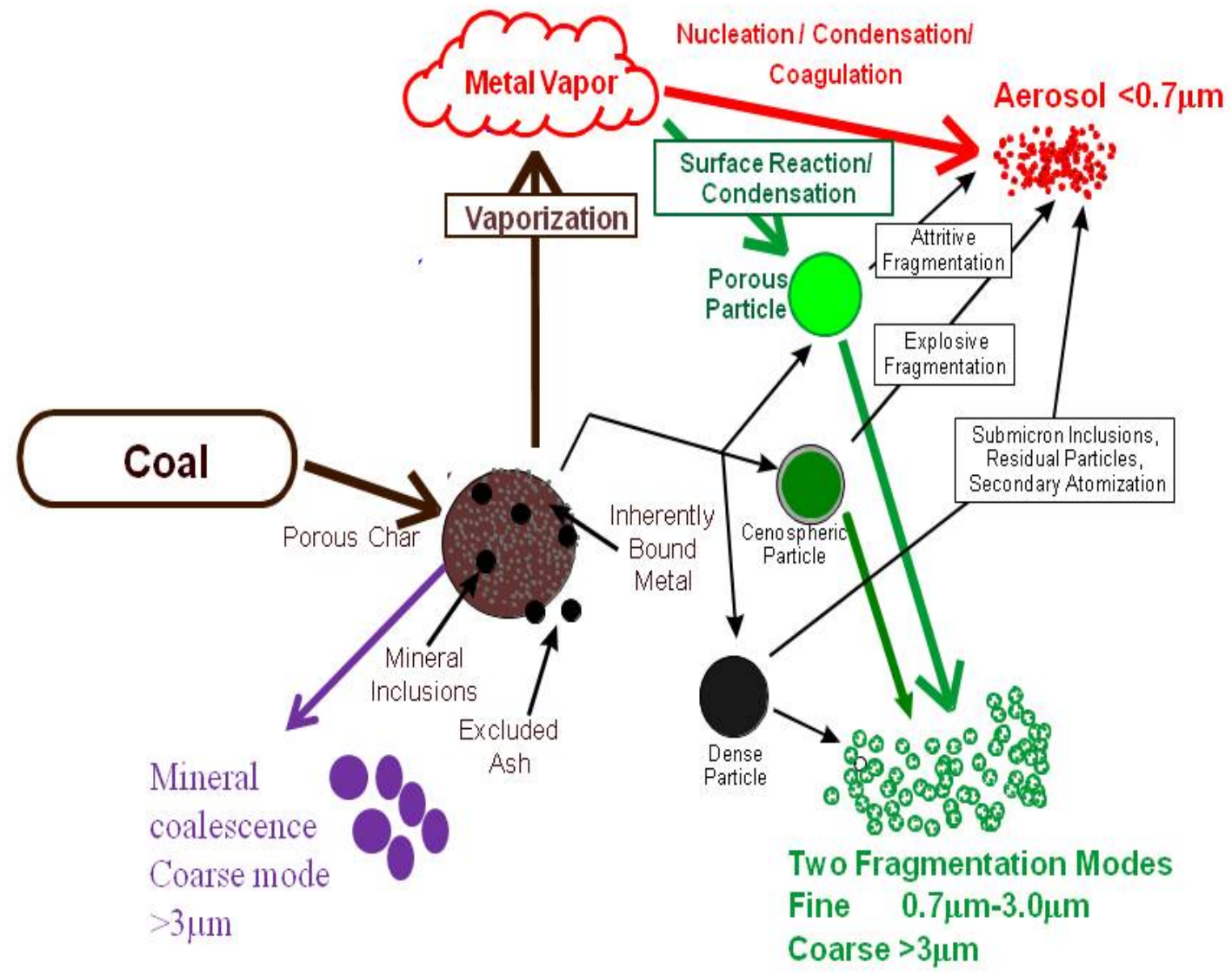

Figure 4.7-1: Illustration of ash partitioning mechanisms.

Since these particles would be formed by large inclusions of mineral matter within the coal matrix, it was not expected that significant differences would be noted as a result of changing combustion atmosphere conditions.

The coalescence mode was expected to be a function of coal composition with relatively small changes in chemistry expected as a result of varying combustion conditions. Any changes would likely be due to different condensation of metal vapors on the particle. However, this would be a relatively small contribution to the mass of the particle, and thus would not dramatically change the chemistry of the particle.

The second mode, centered at a particle diameter of approximately one micron, is formed by fragmentation of mineral inclusions as they are broken apart during the combustion of the coal particle in the boiler (W. S. Seames 2003). Since these particles were formed by breaking up cenospheric particles composed of a hollow shell of semimolten mineral matter, Dr. Seames noted, after thorough SEM examination, that these particles had a much greater surface area relative to their diameter than spherical particles due to the mechanical fracturing of the mineral inclusions and particles that lead to jagged edges. This greater surface area could allow for these particles to undergo more chemical reactions in varying 
combustion atmospheres due to their greater tendency to undergo surface chemistry reactions as a result of their larger surface area to volume and mass ratios. Furthermore, these particles would also provide surfaces for the condensation of metal vapors which would have a greater impact on the chemistry of the particle due to their lower mass than the large coalescence particles.

Since these particles were formed largely by the mechanical cleaving and breaking up of existing cenosphere particles, it was not expected that their chemical composition would fundamentally alter when changing from an air to oxy-fired combustion atmosphere. However, as previously mentioned, the greater surface area of these particles would allow a greater opportunity for any surface chemistry to occur, and the changes in particle chemistry would be more evident than in the larger coarse mode.

Potential gasification of char particles by $\mathrm{H}_{2} \mathrm{O}$ or $\mathrm{CO}_{2}$ in an oxy-fired recycle flue gas environment may affect the breaking up of mineral matter and the subsequent formation of cenosphere particles, but this would likely be a greater impact on particle size distribution rather than particle chemistry since the governing chemistry would likely be the mineral matter that was found in the coal particle rather than the size of particle fragments. The extent to which this mechanism may affect aerosol composition of this size range of particles needed to be investigated for verification.

Finally the third mode described in work by Linak, Seames, Buhre, Senior, and Quann is a vaporization mode in which metals are vaporized and then condense into small droplets which may coagulate and form particles that are typically 700nm and smaller. The formation of these particles occurs when metals in the coal and coal ash are vaporized under high temperatures in the furnace. Then, when the flue gases are cooled, they can condense and form droplets which coagulate and cool further into solid particles.

The tendency of a metal to vaporize is based on numerous factors. Gallagher showed that organically bound alkalis were more likely to vaporize (Gallagher, Bool, et al. 1990). He further indicated that vaporization of sodium could be reduced by including alumino-silicates. At higher temperatures, the alkali would react and condense with alumino-silicates and silicates to form less volatile alkali aluminosilicates and thus reduce the amount of alkali material in the submicron condensed vapor fume (Gallagher, Peterson and Wendt 1996). This again indicated that the amount of alkali metals found in the condensed vapor phase would likely be dominated by coal chemistry composition and temperature rather than combustion atmosphere; however this also needed to be validated. It was also unknown whether the combustion atmosphere changes would alter the vaporization potential of all metals.

For example, alkali and alkaline metals which have relatively low vaporization temperatures and make up the primary constituents of the condensed vapor mode may be more likely to vaporize as a result of the higher oxygen content of an oxy-fired condition. Conversely, the greater concentration of $\mathrm{CO}_{2}$ and its higher heat capacity and greater resistance to mass transfer than $\mathrm{N}_{2}$, may inhibit vaporization as it locally cools particles and reduces the rate of oxygen transport to the char particle causing a slower and low temperature burn. This unknown also needed to be investigated.

Also, mechanisms have been proposed involving reductions of oxides by $\mathrm{CO}$ to mineral suboxides in order to achieve greater volatility so that species such as $\mathrm{SiO}_{2}$ may be found in the submicron fume (Buhre, et al. 2007) (Senior and Flagan 1982) (Quann and Sarofim 1982). Senior and Flagan proposed a mechanism whereby the oxide of a refractory metal such as $\mathrm{SiO}_{2}$ would be reduced by $\mathrm{CO}$ to form the products $\mathrm{SiO}$ (volatile) and $\mathrm{CO}_{2}$ and the suboxide would be oxidized when exposed to an oxygen rich zone outside of the near char particle regime. In an oxy-fired environment, the high concentration of $\mathrm{CO}_{2}$ would be expected to limit this reaction and therefore suppress the amount of refractory metals found in the submicron fume. 
Drop tube studies have shown that combustion temperature and not combustion atmosphere were the primary drivers of metal vaporization during coal combustion by two studies from Sheng in 2007 (Sheng, et al. 2007) (Sheng, et al. 2007). Drop tube studies conducted at the University of Utah concluded that temperature was the dominant driver of metal vaporization; however the higher concentration of $\mathrm{CO}_{2}$ did reduce the vaporization of refractory metals as expected (Jia 2011).

Results from a pilot scale study on ash by Wall showed that there was not a significant difference in aerosol chemistry when switching from air to oxy-fired; however differences in fouling and ash deposition were noted (Wall, et al. 2009). Wall and Sheng showed that higher oxygen concentrations, up to $40 \% \mathrm{O}_{2}$, were necessary for a similar particle size and chemical composition in their tests. Furthermore, there was no change observed in particle chemistry from air to oxy-firing for the fine fragmentation modes or coalescence modes as they were products of mineral composition within the coal and remain unchanged in the combustion process (Sheng, et al. 2007) (Wall, et al. 2009).

This was also confirmed by Yu, who noted that there were no significant differences between bulk ash aerosol chemistry when switching from air to oxy-fired. Although deposition rates were found to have increased under oxy-firing conditions, these differences were attributed to aerodynamic and local temperature changes rather than a change in aerosol chemistry as a result of a change in the combustion atmosphere (Yu, et al. 2011).

Ash chemistry research under air-fired conditions has been well developed and can be used in modeling tools to show how mineral matter from fly ash can form deposits on boiler tubes thus reducing furnace efficiency and causing mandatory shut downs (Huang, et al. 1996) (Wang and Harb, Modeling of Ash Deposition in Large Scale Combustion Facilities Burning Pulverized Coal 1997). While research by Yu et al. showed that aerodynamic rather than chemical differences may have been responsible for the changes of ash deposition on surfaces within the furnace, it was still necessary to examine the changes in aerosol chemistry and particle distribution in a practical self-sustaining flame so that data could be gathered to aid in the development of future deposition models or studies under oxy-fired combustion.

Furthermore, most previous data by Sheng and Wall did not collect aerosols over a wide range of submicron particle diameters from a self-sustaining flame, and all of Sheng's work utilized a drop tube furnace which does not accurately reflect aerosol and flue gas mixing or concentration.

Since it would be expected that the most significant changes would occur in the submicron region in a practical coal flame, it was necessary to have a better understanding of the submicron particle diameter chemistry as well as having data that could lend itself towards modeling of practical self-sustaining flames.

In addition to understanding ash chemistry and particle size distribution for modeling ash deposition within the furnace, ash studies have provided valuable insight regarding health effects of coal combustion particles released into the atmosphere and subsequently inhaled (Fernandez, Wendt and Witten 2005) (Fernandez, et al. 2001). Fernandez showed that fine particles that were easily inhaled could cause serious lung injury. Since all ash would not be captured under oxy-fired conditions and particles would still be released to the atmosphere, the size and chemical composition data provided by oxy-fired experiments would be useful for predicting any changes in potential health effects as a result of an oxyfired retrofit.

Research has indicated that specifically soot is one of the most toxic combustion aerosols (I. M. Kennedy 2007) (Linak, et al. 2007). As previously mentioned, not all aerosols would be captured in an oxy-fired process, so changes in aerosol formation, particularly those found to have significant health effects, need to be well understood. 
Soot formation under air-fired coal combustion is also well documented, with research having shown that soot formation is a direct result of tar yield, particle temperature, oxidation environment, and residence time (Fletcher, et al. 1997) (Ma, Fletcher and Webb, Conversion of Coal Tar to Soot During Coal Pyrolysis in a Post-Flame Environment 1996). Fletcher's research group has also shown important applications of soot in heat transfer as a result of black body radiation from particles with large surface to volume ratios, which is an operational concern, as well as in fuel $\mathrm{NO}_{\mathrm{x}}$ formation which is an emissions concern. Thus, understanding of soot formation under oxy-fired conditions is a high priority from both an emissions perspective and an in furnace performance perspective.

As a result, in order to understand the differences between soot production between air and oxy-fired conditions, single particle studies of soot formation have been carried out. The soot research indicated that $\mathrm{CO}_{2}$ substitution decreases volatilization, suppresses ignition, creates a larger cooler soot cloud, and required 28-30\% $\mathrm{O}_{2}$ in order to approach air-fired ignition performance (Murphy and Shaddix 2006) (Shaddix and Molina, Particle Imaging of Ignition and Devolatilization of Pulverized Coal During OxyFuel Combustion 2009). By reducing volatilization, the building blocks of soot particles, Shaddix's research group showed that oxy-firing would reduce soot formation on a fundamental level compared to air firing.

In addition to the data available regarding ash chemistry and soot, there were also data comparing char burnout and coal ignition in air and oxy-fired conditions of various coals. The overall trend clearly shows that at equivalent oxygen concentrations, oxy-firing reduced char burnout and that to achieve similar performance, an $\mathrm{O}_{2}$ concentration of $30 \%$ was necessary (Bejarano and Levendis 2008) (Borrego and Alvarez 2007) (Rantham, et al. 2009).

Char oxidation and burnout information are important when attempting to determine combustion process efficiency. An increase in unburned carbon in the ash would indicate a decrease in combustion efficiency. Since efficiency is a critically important factor in retrofit applications due to the large energy penalties associated with oxygen production and $\mathrm{CO}_{2}$ compression, understanding ignition loss would be essential to a retrofit application and must be balanced with competing factors.

Since Bejarano, Borrego, and Rantham indicated that concentrations of $30 \%$ and higher $\mathrm{O}_{2}$ would be necessary to match burnout performance of air firing; a smaller volume of flue gas would be carried through the furnace compared to an air-fired condition which could significantly affect heat transfer performance and therefore steam generating performance.

Thus when examining a retrofit from air to oxy-fired conditions, it is necessary to balance the need to maintain similar flue gas volumes for which the existing boiler was built, but to also account for the necessary increase in oxygen to maintain similar char burnout and combustion efficiency since an oxyfired combustion environment reduces ignition compared to an air-fired combustion environment (Zhang 2010).

\subsubsection{Experimental Setup}

\subsubsection{Particle Probes and Aerosol Instruments}

A wide variety of experimental equipment was utilized during the experiments. Several sampling systems were constructed and implemented to capture aerosol samples for analysis. Two particle probes were used to draw samples for the experiments performed in this research. The first probe utilized was very simple and did not utilize dilution. It featured a 1" pipe which was measured to be 7/8” inner 
diameter. This was then sleeved by 1.5” tubing to form a water jacket to keep the probe cool. It was used in order to take a total ash sample for the loss of ignition measurements.

In order to collect the samples, there had to be a filter housing that enclosed the filter, a vacuum pump to provide vacuum to draw the sample out of the furnace, and a rotameter to control the flow. The rotameter was a 50 SCFH unit from Dwyer.

The amount of flow through the probe, which was to be as close to isokinetic as possible, was determined using the following equations from Hinds (Hinds 1999).

$$
\begin{gathered}
\frac{Q_{s}}{Q_{0}}=\left(\frac{D_{s}}{D_{0}}\right)^{2} \\
U_{s}=U_{0}
\end{gathered}
$$

where $Q_{s}$ is the volumetric flow rate of the sample in the probe of diameter $D_{s}$ and $Q_{0}$ is the volumetric flow through a circular duct with a diameter $D_{0}$. As a result, the velocity of the bulk gas in the duct is the same as the sample velocity in the probe.

The velocity given for air-fired conditions ranged between $2.30 \mathrm{ft} / \mathrm{s}(0.701 \mathrm{~m} / \mathrm{s})$ to $2.45 \mathrm{ft} / \mathrm{s}(0.747 \mathrm{~m} / \mathrm{s})$ as the temperature of the flue gas varied from $1100^{\circ} \mathrm{F}\left(593^{\circ} \mathrm{C}\right)$ to $1200^{\circ} \mathrm{F}\left(649^{\circ} \mathrm{C}\right)$. This velocity can be calculated knowing the known inner diameter of the furnace, the known temperature of the gas from a thermocouple reading, the known flue gas composition and coal firing rate, and the ideal gas law. The ideal gas law has been deemed sufficiently accurate for air pollution sampling (de Nevers 2000). The airfired cases required a flow rate through the probe of 34.5 to $36.5 \mathrm{cfh}$ or about 16.3 to $17.3 \mathrm{lpm}$ for airfired conditions. These calculations can be repeated to show the flow needed for oxy-fired conditions as well, which turn out to be about $11.5 \mathrm{lpm}$ for all 32\% oxy-fired conditions. As particles deposited on the filter, the rotameter valve could be opened further to allow continuing sample flow through the probe and filter. This apparatus is shown in Figure 4.7-2.

The second probe utilizes a stainless steel water jacket as well as a having a quench gas jet at the tip of the probe allowing for dilution of the sample as well as quenching reactions and reducing the amount of coagulation of small particles (Hinds 1999). This probe was used for all SMPS, PA, and BLPI data collection. The probe had a measured inner diameter of 0.265 ” or $6.73 \mathrm{~mm}$.

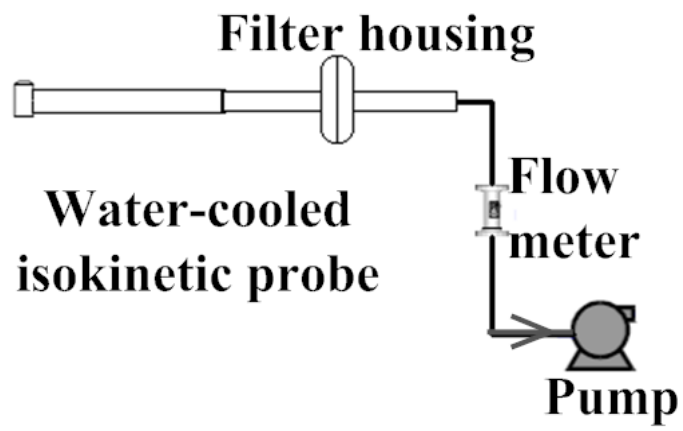

Figure 4.7-2: Sampling system for bulk fly ash collection.

When setting up the sampling system for photoacoustic analyzer and SMPS/APS analysis, or for sample collection with the impactor, the dilution probe was used in conjunction with a mass flow controller that metered the rate of dilution nitrogen into the sampling probe. It was found that at the controller manufacturer's (Sierra) recommended ideal operating feed pressure of quench gas, the flow of nitrogen 
pulsed wildly through the probe due to the complicated bends of the nitrogen inlet near the probe tip. As a result, the inlet pressure of nitrogen or $\mathrm{CO}_{2}$ to the mass flow controller was reduced from the recommended 85 psi to 45 psi to provide a steady flow. As a result of the change in inlet pressure and using nitrogen or $\mathrm{CO}_{2}$ for dilution rather than air, measurements had to be taken with a gillibrator bubble flow meter or calibrated dry gas meter to verify the actual flow rate through the mass flow controller at a given setting.

When taking simultaneous particle instrument measurements for particle size distributions using a TSI DMA scanning mobility particle sizer (SMPS) 3022 with a 3080 electrostatic classifier and a TSI aerodymanic particle sizer (APS) 3321 along with a prototype photoacoustic analyzer, a dilution probe as well as dilution manifold were used. The SMPS was used in order to determine the particle size and mass distribution for particles in the 15-660 nanometer range.

The SMPS and the APS were used in conjunction with the dilution manifold and were controlled with a desktop PC work station using proprietary TSI Aerosol Instrument Manager (AIM) software. One program version controlled the SMPS, and the other controlled the APS. The data from the SMPS and APS are saved as raw scans, and then must be exported as a tab delimited text file which can be opened in Excel for analysis or may be analyzed together using TSI's data merge software module to combine the SMPS and APS scans into one scan that ranges from a particle diameter of $15 \mathrm{~nm}$ to $20 \mu \mathrm{m}$. This software module can average several scans together and give the average curve as a tab delimited text file for further analysis.

The photoacoustic analyzer was developed by Pat Arnott and is well described in his own work (Arnott, et al. 1999) (Arnott, et al. 2005). The photoacoustic analyzer used a 1047nm wavelength laser. This wavelength was readily absorbed by black carbon. The absorption caused the particles to heat up in a resonance chamber and caused the air around the particle to expand. This expansion was detected by microphones which translated the acoustic signal into a concentration in terms of $\mu \mathrm{g} / \mathrm{m}^{3}$. A data point was collected every 8 seconds while the instrument recorded data.

The PA, like the SMPS, was controlled by a desktop PC. However, the PA is controlled through a Labview software interface. Using the Labview software, a selection switch exists that will allow for recording of the data as a tab delimited text file that can be opened in Excel. Labview will only record data when this is selected.

The equipment setup for use with the SMPS/APS and PA was rather involved. The dilution probe was used with a mass flow controller to meter the amount of nitrogen from either a cylinder or a liquid nitrogen dewar. However during flue gas recycle conditions, $\mathrm{CO}_{2}$ was utilized from the liquid $\mathrm{CO}_{2} \operatorname{tank}$ provided by Praxair. The sample was withdrawn from the probe using an eductor which utilized clean dry motive air, which was then used for sample dilution. The motive air is supplied by compressed air which is filtered through progressively smaller particle filters and oil and water separators to protect the mass flow controller which regulates the amount of motive air to the eductor. The motive air is then finally sent through HEPA filters to ensure a clean dilution stream. The dilution at the probe tip and then at the eductor resulted in a compound dilution, which was important to remember when calculating data.

Flow through the probe is controlled by a critical orifice from O'Keefe controls. Usually a number 40 or 41 was used that was measured to have a flow rate of 8.45 or $9.35 \mathrm{lpm}$, respectively, using a Gillibrator bubble flow meter. A pressure gauge also verified the necessary 2:1 pressure drop across the orifice necessary to maintain constant choked flow. Suction was provided using an eductor with highly purified motive air that was treated with particulate filters and moisture and oil removal. The highly purified air was controlled by an up to $200 \mathrm{lpm}$ mass flow controller and flowed through the eductor creating suction. 
Occasionally, the critical orifice would become plugged with ash and would need to be cleaned so that sampling could be resumed. This was more typical with the higher moisture and ash content PRB coal.

After flowing through the critical orifice and eductor, the diluted sample stream was sent into the dilution manifold. The dilution manifold consists of a large tube with several sampling ports. As a result, it is possible to operate the SMPS, APS, and the PA simultaneously. The dilution probe allowed for injecting a quench gas, either $\mathrm{N}_{2}$ or $\mathrm{CO}_{2}$, at the tip to prevent coagulation and condensation within the probe. The amount of dilution was varied to maintain as close to isokinetic sampling velocity as possible, and typically resulted in dilution ratio in the probe of approximately 3:1.

The twice diluted sample then flowed into the dilution manifold where multiple instruments simultaneously measured the sample. Also, the mass flow controllers and the critical orifice allowed for accurate determination of a total dilution factor and the ability to closely match isokinetic sampling conditions. Flow rates were checked with dry gas meters and gillibrator bubble flow meters to verify flow rates. The dilution probe with the SMPS/APS and PA particle instruments sampling system is illustrated in Figure 4.7-3.

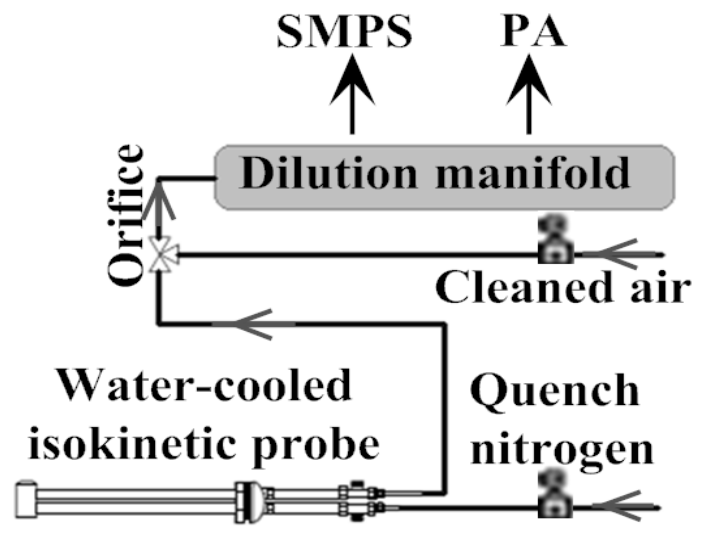

Figure 4.7-3: Sampling system schematic for simultaneous particle instrument measurements.

The setup used for sampling with the Berner Low Pressure Impactor (BLPI) was less complicated than the sampling system necessary for the PA and SMPS. It simply utilized the dilution probe with nitrogen from a cylinder or dewar controlled by the mass flow controller. The diluted sample was then sent through the BLPI while a 3 hp vacuum pump provided the necessary vacuum to create choked flow through the impactor where the last stage acts as a critical orifice. The flow through the impactor was measured with a Gillibrator bubble flow meter at $24.1 \mathrm{lpm}$. This was used in conjunction with the amount of dilution nitrogen or $\mathrm{CO}_{2}$ at 21-22.2 lpm depending on flue gas velocity to determine the dilution ratio of the sample flowing through the impactor.

Samples that were collected to be analyzed for chemical composition were collected using a coated substrate with Apezion $\mathrm{H}$ Grease using a Millipore Isopore membrane filter type $0.4 \mu \mathrm{m}$ on a collection plate in the BLPI. Size segregated samples collected by the impactor were then subject to chemical analysis by ICP-MS or EDS.

When sampling the bituminous coals, a cyclone was utilized to capture larger supermicron particles so that sampling time could be extended to collect sufficient mass on the submicron particle stages without overloading the stages containing larger super micron particles. This sampling schematic is shown in Figure 4.7-4 and the impactor cross section with particle cut off diameters is shown in Figure 4.7-5. 


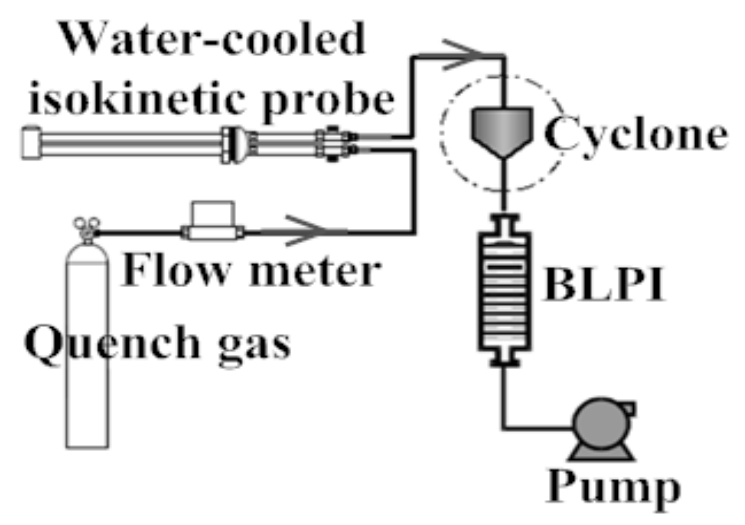

Figure 4.7-4: Sampling schematic for collection size segregated samples with the low pressure impactor.

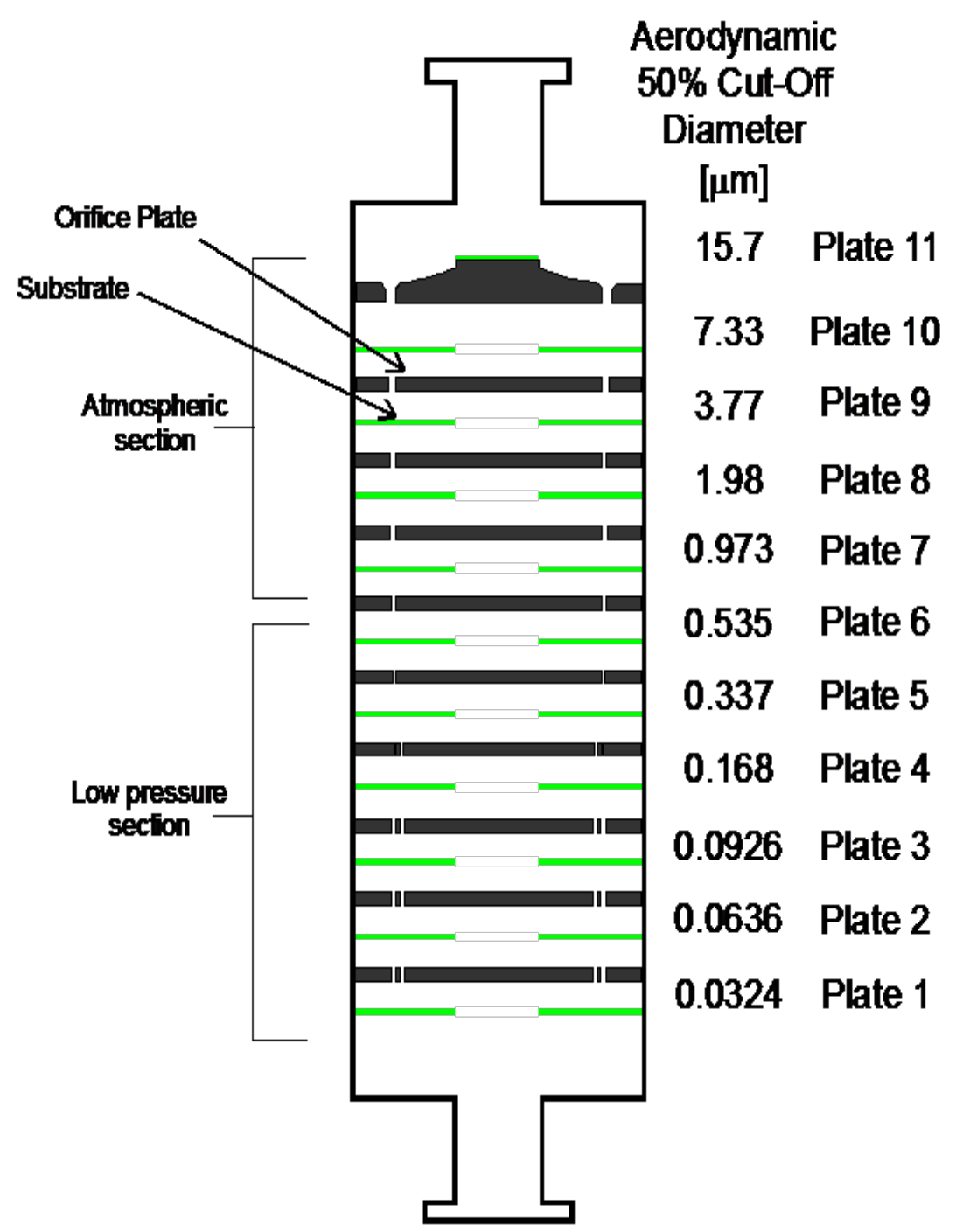

Figure 4.7-5: Diagram of the Berner low pressure impactor which shows the aerodynamic cut off diameter for each stage. 


\subsubsection{Coals Examined}

Three coals were examined under air, once through oxy-fired and oxy-fired with flue gas recycle. They were Utah low sulfur bituminous, PRB sub-bituminous, and Illinois high sulfur bituminous coal. This allowed for a wide range of coal types and chemistries as well as representation of two highly utilized coals in the US, the PRB and Illinois. Coal composition can be found in Table 4.7-5.

The coals were pulverized off site by a Headwaters facility in Alabama to produce a consistent coal grind with an average particle diameter of 70 microns. The coal was then packaged into super sacks, flushed with nitrogen and sealed for transport and storage. The coal was kept in a storage warehouse adjacent to the combustion laboratory.

Samples of multiple super sacks were collected and sent to Huffman Laboratories in Golden Colorado for analysis. Throughout the research experiments the consistency of the Utah coal was found to be very uniform. The PRB coal's moisture content varied from one super sack to the next and sometimes from top to bottom within the sack. The Illinois coal was found to be more consistent but not at the same level as the Utah coal.

Table 4.7-5: Coal composition table for coals examined.

\begin{tabular}{|c|c|c|c|c|c|c|c|c|c|c|c|}
\hline \multicolumn{12}{|c|}{ Coal An alysis (on an as-received basis) } \\
\hline Sample & LOD & Ash & C & $\mathrm{H}$ & $\mathbf{N}$ & s & $O$ (diff) & $\begin{array}{l}\text { Volatile } \\
\text { Matter }\end{array}$ & $\begin{array}{c}\text { Fixed } \\
\text { Carbon }\end{array}$ & $\begin{array}{l}\mathrm{HHV} \\
\mathrm{BTU} / \mathrm{b}\end{array}$ & \\
\hline & $\%$ & $\%$ & $\%$ & $\%$ & $\%$ & $\%$ & $\%$ & $\%$ & $\%$ & & \\
\hline Utah & 3.18 & 8.83 & 70.60 & 5.05 & 1.42 & 0.53 & 10.39 & 38.60 & 49.39 & 12606 & \\
\hline PRB & 23.69 & 4.94 & 53.72 & 3.57 & 0.78 & 0.23 & 13.07 & 33.36 & 38.01 & 9078 & \\
\hline Illinois & 9.65 & 7.99 & 64.67 & 4.51 & 1.12 & 3.98 & 8.08 & 36.78 & 45.58 & 11598 & \\
\hline \multicolumn{12}{|c|}{ Ash Analysis } \\
\hline & $\begin{array}{c}\mathrm{Al} \\
\text { as } \\
\mathrm{Al}_{2} \mathrm{O}_{3}\end{array}$ & $\underset{\text { as }}{\mathrm{Ca}} \mathrm{CaO}$ & $\begin{array}{c}\mathrm{Fe} \\
\text { as } \\
\mathrm{Fe}_{2} \mathrm{O}_{3}\end{array}$ & $\begin{array}{c}\mathrm{Mg} \\
\text { as } \mathrm{MgO}\end{array}$ & $\underset{\text { a } 5 \mathrm{MnO}}{\mathrm{Mn}}$ & $\underset{\text { as } \mathrm{P}_{2} \mathrm{O} 5}{\mathbf{P}}$ & $\underset{\text { as } \mathrm{K}_{2} \mathrm{O}}{\mathbf{K}}$ & $\underset{\text { as }}{\mathrm{Si}}$ & $\underset{\text { as } \mathrm{Na}_{2} \mathrm{O}}{\mathrm{Na}}$ & $\underset{\text { as }}{\mathrm{S}} \mathrm{SO}_{3}$ & $\begin{array}{c}\mathrm{Ti} \\
\mathrm{As} \\
\mathrm{TiO}_{2}\end{array}$ \\
\hline & $\%$ & $\%$ & $\%$ & $\%$ & $\%$ & $\%$ & $\%$ & $\%$ & $\%$ & $\%$ & $\%$ \\
\hline Utah & 14.52 & 6.11 & 5.09 & 1.39 & 0.02 & 0.59 & 0.57 & 60.89 & 1.41 & 2.33 & 0.88 \\
\hline PRB & 14.78 & 22.19 & 5.2 & 5.17 & 0.01 & 1.07 & 0.35 & 30.46 & 1.94 & 8.83 & 1.3 \\
\hline Illinois & 17.66 & 1.87 & 14.57 & 0.98 & 0.02 & 0.11 & 2.26 & 49.28 & 1.51 & 2.22 & 0.85 \\
\hline
\end{tabular}

\subsubsection{Air-fired and Once-Through $\mathrm{CO}_{2}$ Conditions}

Baseline tests had to be run in order to determine the effects of switching from air-fired combustion to oxy-fired combustion. Tests were conducted at 36.6kW (125,000 BTU/hr) for each coal. Each coal was examined under air firing conditions at a stoichiometric ratio of approximately 1.17 which corresponds to $3 \% \mathrm{O}_{2}$ concentration in the flue gas. Aerosol samples were collected with the BLPI at this condition for each coal for analysis by EDS and ICP-MS to determine size segregated aerosol chemistry.

Bulk ash was also collected for each coal under air-fired conditions at $0 \%, 1 \%, 2 \%$, and $3 \% \mathrm{O}_{2}$ in the flue gas in order to plot ignition loss (LOI) as a function of stoichiometric ratio. Ultrafine particle data were also collected with an SMPS at $0 \%, 1 \%, 2 \%$, and $3 \% \mathrm{O}_{2}$ in the flue gas in order to examine the change in 
ultrafine particle size distributions. The photoacoustic analyzer was used simultaneously with the SMPS to monitor the changes in black carbon or soot emissions as a function of stoichiometric ratio. An APS was used to measure particle size from 0.5 to 20 microns, and was added midway through the experiments, so APS data were not available for all conditions.

In order to determine the effects of retrofit oxy-firing on aerosol formation and composition, an oxy-firing condition had to be chosen and examined. Two oxy-fired conditions were chosen and required analysis under DOE contracts DE-FC26-06NT42808 and DE-NT0005015. The first was $27 \% \mathrm{O}_{2}$ and $73 \% \mathrm{CO}_{2}$, referred to as OXY27, which was to match the heat flux of air firing. The second was $32 \% \mathrm{O}_{2}$ and $68 \%$ $\mathrm{CO}_{2}$ which was to match the calculated adiabatic flame temperature and is referred to as OXY32.

Both OXY27 and OXY32 firing conditions at $0 \%, 1 \%, 2 \%$, and $3 \% \mathrm{O}_{2}$ in the flue gas were reexamined for each coal and compared to the air-fired baseline for particle size distributions, ignition loss, and black carbon. Samples were also collected at $3 \% \mathrm{O}_{2}$ in the flue gas with the BLPI in order to compare size segregated ash chemistry. Both OXY27 and OXY32 cases utilized once through $\mathrm{CO}_{2}$ and $\mathrm{O}_{2}$ generously supplied by Praxair from external tanks rather than recycled flue gas. This simulated completely cleaned flue gas with all moisture, particles, and other contaminants removed.

\subsubsection{Recycled Flue Gas Conditions}

In addition to testing the once through $\mathrm{CO}_{2}$ cases to get a more fundamental understanding of the difference in aerosol formation in an $\mathrm{O}_{2} / \mathrm{CO}_{2}$ combustion atmosphere, tests were also completed using recycled flue gas to simulate a practical oxy-fired retrofit combustion environment. However, there was no consensus on the ideal recycled flue gas composition since there is an energy penalty for each contaminant that is removed from the flue gas, but recycling large amounts of steam, $\mathrm{SO}_{2}$, and particulate also have significant challenges. As a result, a total of six recycled flue gas conditions were examined in order to determine the effects of flue gas recycle composition on aerosol formation in practical retrofit environments.

Since no significant differences were noticed between cases OXY27 and OXY32, only a 32\% $\mathrm{O}_{2}$ firing rate was examined initially. This matched the calculated adiabatic flame temperature and was similar to most literature studies for ease of comparison.

The recycled flue gas final experiments involved a series of six conditions which were divided such that two conditions existed for each coal. One condition for each coal focused on completely untreated flue gas recycle with all contaminants present, and another condition was implemented which required the removal of at least one significant contaminant. For the Utah coal the contaminant removed was particulate matter. The PRB tests removed particulate matter and moisture in the cleaned scenario because it was such a high moisture coal, large differences in flue gas moisture content could be observed. Finally, the Illinois coal was examined with particulate removal, and sulfur and moisture removal to compare with a very high $\mathrm{SO}_{2}$ untreated flue gas combustion environment. The conditions are listed and summarized as follows:

1. Utah coal without any contamination removal.

2. Utah coal with particle removal utilizing the bag house.

3. PRB coal without any contamination removal.

4. PRB coal with particle and moisture removal from recycled the flue gas.

5. Illinois coal without any contamination removal.

6. Illinois coal with $\mathrm{SO}_{2}$, moisture, and particle removal from the recycled flue gas. 
During the flue gas recycle experiments, particle size distributions with the Berner low pressure impactor (BLPI), SMPS, and APS were collected. Size segregated samples were collected using the BLPI for chemistry analysis by ICP-MS as well as EDS.

Due to issues with the PA, the soot measurements were taken at a later date under untreated recycle conditions with a reduced $\mathrm{O}_{2}$ concentration of $27 \%$. These tests were run in conjunction with Dale Tree's research group at Brigham Young University.

It should also be mentioned that these conditions were exponentially more difficult to run than the once through oxy-fired cases. A tremendous amount of time troubleshooting the larger blower was needed in order to maintain flue gas $\mathrm{CO}_{2}$ concentrations of $85 \%$ or higher. Furthermore, once a steady state was achieved, it was very easily interrupted.

As a result, every accommodation possible was made to sample under steady state repeatable conditions, but the inherent instability of the furnace under the flue gas recycle conditions meant that there was a greater chance of error for measurements taken under these conditions. Thus, data presented in Chapter 4 should be examined with this caution in mind, and interpretation should take into consideration the variability in furnace conditions. Perceived differences in conditions should also be examined with these caveats in mind.

\subsubsection{Results}

Results are presented in this section for all experiments carried out in this research. Results are presented in subsections based on the experiment performed and phenomenon explored rather than on the coal utilized. Comparisons were done between air and oxy-firing as well as between coals of different ranks and chemical composition. As a result, loss on ignition results are reported for all coals in Section 4.7.3.1 followed by black carbon measurements in Section 4.7.3.2. Particle size results are in Section 4.7.3.3 and chemistry results are presented in Section 4.7.3.4.

\subsubsection{Loss on Ignition}

Loss on ignition (LOI) is a measurement used in order to determine the amount of unburned carbon in the ash of the coal. This important metric showed the level of burnout of the coal char particles and can thus be used as a metric for combustion efficiency or completeness. Carbon in the ash is not only important for gauging combustion performance, but it is also a critical measurement with low acceptable limits for reusing fly ash as concrete aggregate (Hower, Robl and Thomas 1999). If a plant is currently selling its fly ash for reuse, then it is important to understand how a retrofit may affect its fly ash disposal processes as well as combustion performance.

LOI measurements were completed in order to determine the differences in combustion efficiency of airfired combustion with the once through oxy-fired combustion OXY27 and OXY32 cases at 0\%, 1\%, 2\%, and $3 \% \mathrm{O}_{2}$ in the flue gas. Bulk ash samples were collected and deposited on filter paper. The ash was then collected and analyzed for percent on a gravimetric basis after the sample was dried and then heated using a Fossil Energy Research HFLOI instrument. Error bars indicated one standard deviation between four replicates.

\subsection{Utah Skyline}

Figure 4.7-6 shows LOI in weight percent ash versus flue gas $\mathrm{O}_{2}$ percentage for air, and once through $\mathrm{CO}_{2}$ cases OXY27 and OXY32. The data show that at higher oxygen percentage, LOI is reduced for all combustion cases with the OXY32 generally having the lowest LOI of all of the combustion cases. However, the range of scatter and error bars at the $0 \% \mathrm{O}_{2}$ in the flue gas case are very large and make

subtle differences in higher $\mathrm{O}_{2}$ concentration tests difficult to discern. Furthermore, it is very difficult to 
precisely control the furnace at exactly $0 \% \mathrm{O}_{2}$ concentration in the flue gas indicating that some data were collected at conditions richer than a stoichiometric ratio of 1 . That would create wide scatter and potentially give erroneously high LOI readings. As a result, the same data have been plotted for the $1 \%$, $2 \%$, and $3 \% \mathrm{O}_{2}$ in the flue gas on expanded scale cases in Figure 4.7-7 in order to examine the differences in LOI at more appropriate conditions.

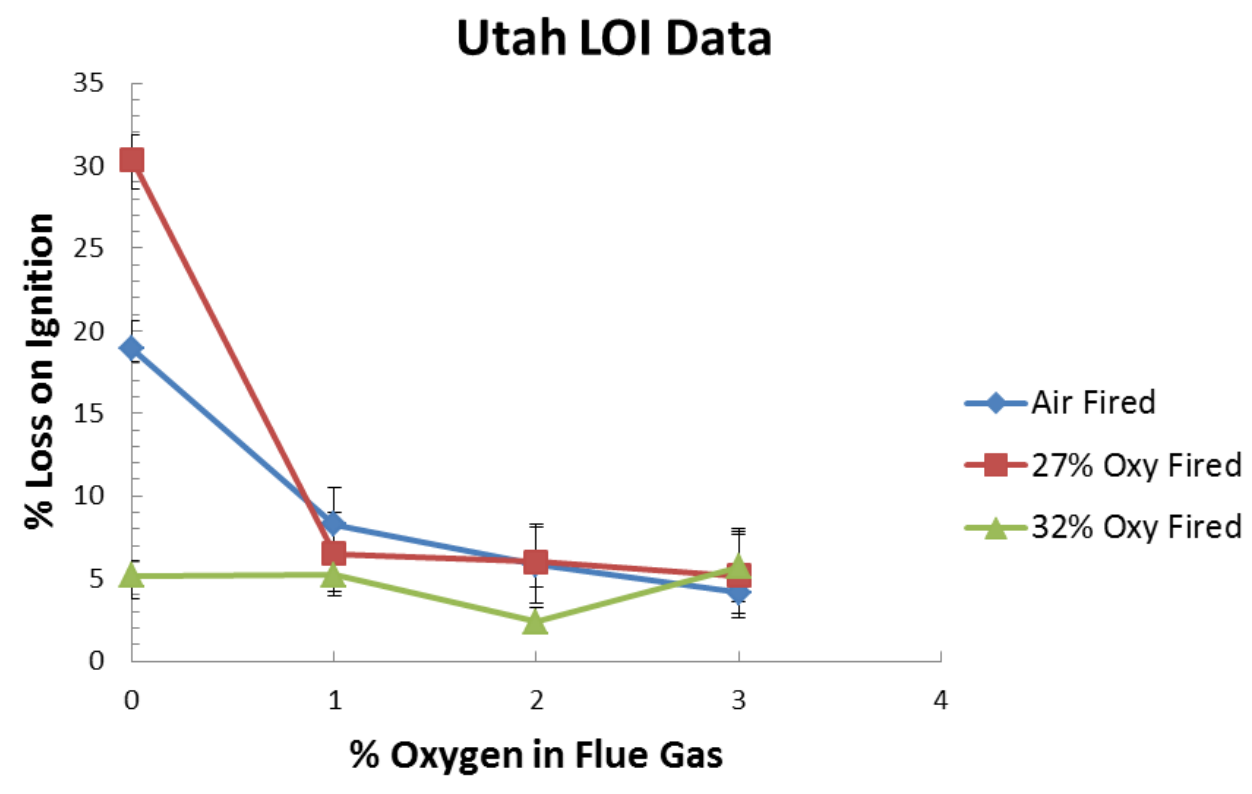

Figure 4.7-6: LOI data for Utah coal fired experiments under air and once through $\mathrm{CO}_{2}$ conditions.

\section{Utah LOI Data}

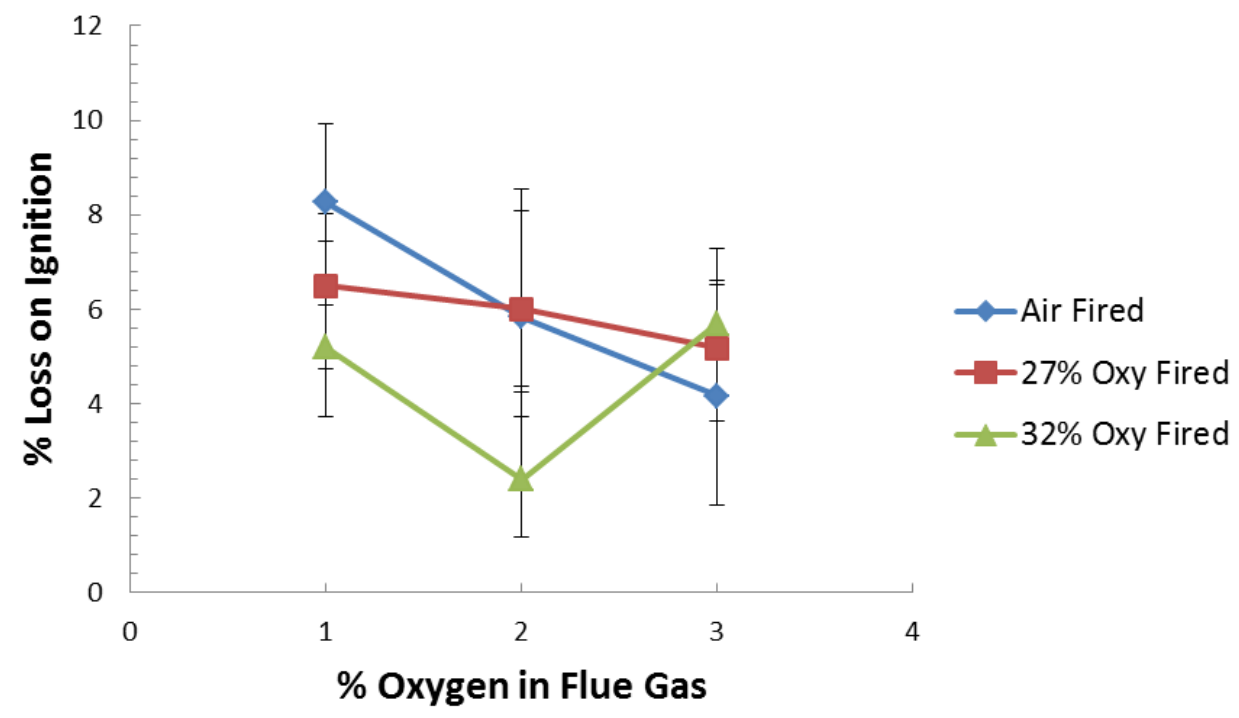

Figure 4.7-7: Utah LOI data for 1, 2, and 3\% flue gas oxygen cases. 
The data in Figure 4.7-7 showed that the OXY32 case was generally the most efficient combustion condition except for the rapid rise in LOI with $3 \% \mathrm{O}_{2}$ in the flue gas which was due to a furnace upset that was not realized at the time. As a result, at $3 \% \mathrm{O}_{2}$ in the flue gas, which was the most likely plant operating condition, all combustion conditions had a similar LOI which are within each data point's standard deviation.

\subsubsection{2 $P R B$}

The PRB coal was also examined under the similar conditions and firing rate. There were obvious trends in the data as shown in Figure 4.7-8. The oxy-fired conditions all had LOI lower than the comparable air-fired combustion scenario. Furthermore, in each case, the LOI increased from $2 \% \mathrm{O}_{2}$ in the flue gas to $3 \% \mathrm{O}_{2}$ in the flue gas. This indicated that there was a systematic issue related to firing the PRB in the furnace across all combustion conditions. This issue was discussed in Section 2.2.5.1.

\section{PRB LOI Data}

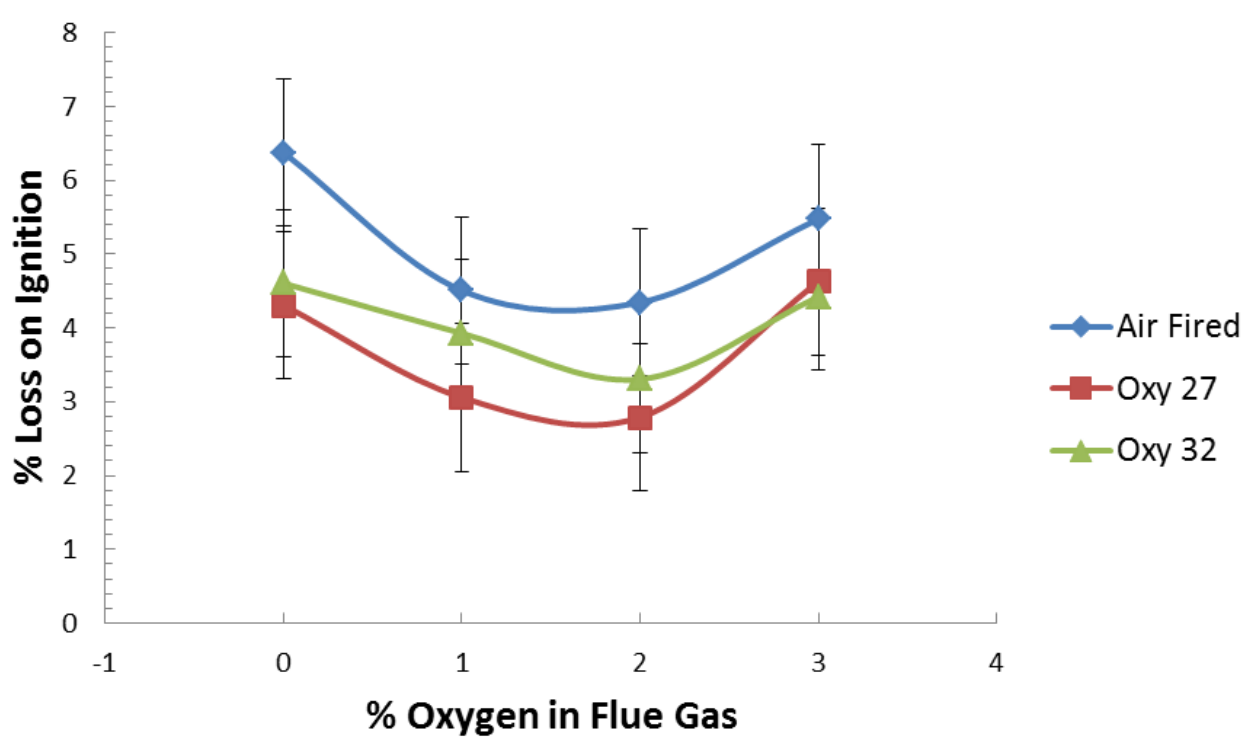

Figure 4.7-8: PRB LOI data for air and once through $\mathrm{CO}_{2}$ cases.

\subsection{Illinois}

The Illinois coal, a bituminous coal similar to the Utah coal except for the much higher sulfur content, was also examined under the same firing conditions. However, it shared the same trend as the PRB subbituminous coal of having a lower LOI for all oxy-fired conditions above $0 \% \mathrm{O}_{2}$ in the flue gas. Unlike the PRB coal, the Illinois coal's LOI decreased or stayed constant as the flue gas $\mathrm{O}_{2}$ concentration was increased. These trends were illustrated clearly in Figure 4.7-9.

Unlike the Utah coal and PRB coal, the Illinois coal seemed less dependent upon the amount of excess oxygen in the flue gas with only minor differences being observed in the LOI under any conditions where the stoichiometric ratio was greater than 1. 


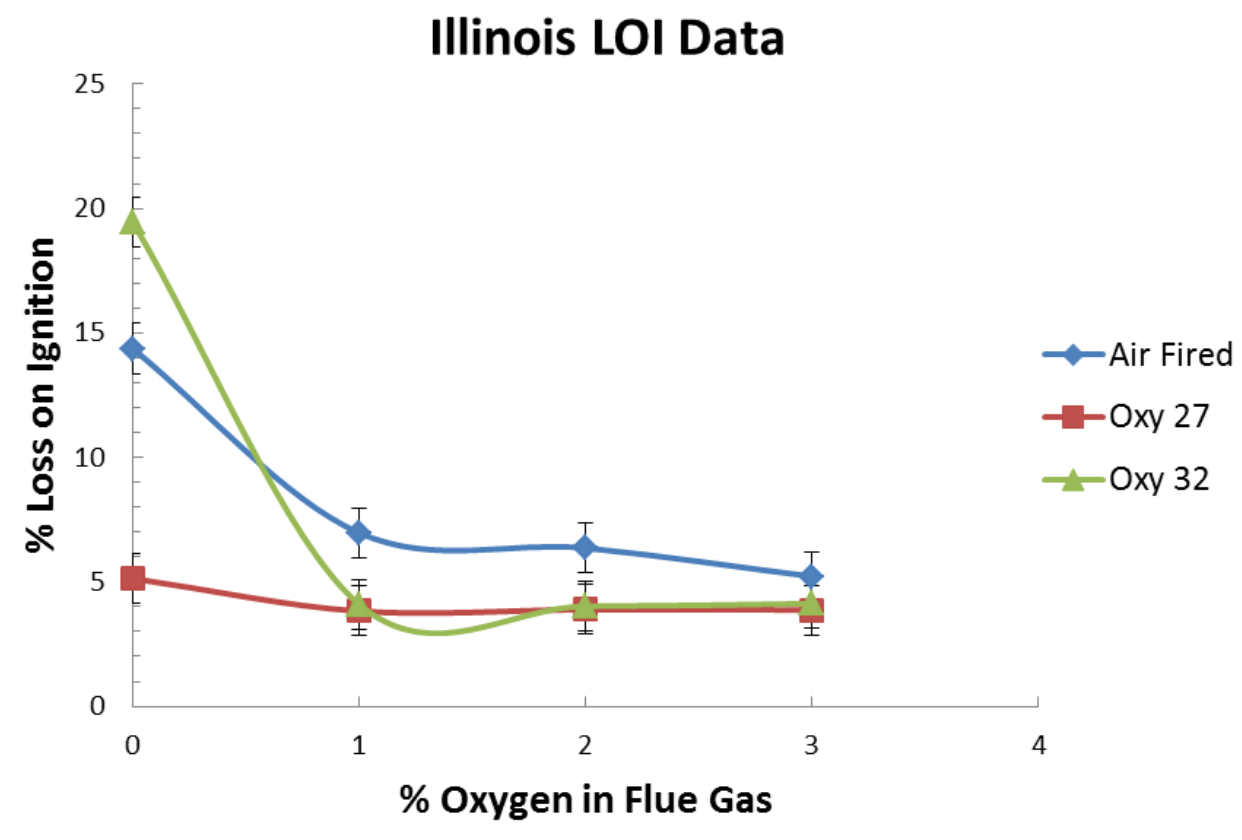

Figure 4.7-9: Illinois coal LOI results for air and once through $\mathrm{CO}_{2}$ experiments.

\subsubsection{Black Carbon Aerosol Results}

Black carbon aerosol concentrations in the flue gas were measured over a wide range of combustion conditions with online measurements being recorded with the photoacoustic analyzer. The initial sampling set was recorded under air-fired conditions for all three coals at $0 \%, 1 \%, 2 \%$, and $3 \% \mathrm{O}_{2}$ in the flue gas. Another set of data also at $0 \%, 1 \%, 2 \%$, and $3 \% \mathrm{O}_{2}$ in the flue gas was recorded for the OXY27 and OXY32 cases.

Due to the operational difficulties of stepping through the small percentages of excess $\mathrm{O}_{2}$ under FGR conditions since the oversized blower takes a significant amount of time to arrive at steady state since $95 \%$ of the flue gas is recycled around the blower's internal recycling loop, sampling took place under a given set of stoichiometric ratios for FGR tests that were conducted in cooperation with BYU. During these tests, three stoichiometric ratios were examined. The base was $3 \% \mathrm{O}_{2}$ in the flue gas which varied between SR 1.1 to 1.17 depending upon oxy-firing or air firing and coal type. The second was SR 1, and the third SR 0.9. These oxy-tests were also conducted at $27 \% \mathrm{O}_{2}$ and with once through $\mathrm{CO}_{2}$ and again with untreated FGR.

Black carbon results are presented for each coal in turn. These results include black carbon for air firing, oxy-firing with once through $\mathrm{CO}_{2}$, and oxy-firing for once through $\mathrm{CO}_{2}$ except for the Illinois coal. Finally, in the last section, the effects of coal composition are presented.

\subsection{Utah Skyline}

The Utah skyline coal showed that under lower stoichiometric ratios, oxy-firing produced a significant decrease in black carbon emissions. However, at higher stoichiometric ratios there were similar emissions on a $\mu \mathrm{g} / \mathrm{m}^{3}$ concentration basis as shown in Figure 4.7-10. It was also noticeable that the same uptick in the OXY32 case from $2 \% \mathrm{O}_{2}$ to $3 \% \mathrm{O}_{2}$ was present in these data as well, which were collected at a different time. 
Even though the black carbon concentrations appeared similar, it was important to recognize that there was a greater volume of flue gas under air-fired conditions than under oxy-fired conditions. For this reason, it was useful to compare emissions on a mass per unit of coal basis so that the amount of soot produced per equivalent unit of energy input could be compared as shown in Figure 4.7-11. Each gram of coal produced a certain volume of flue gas, so this was used to calculate a constant by which the results could be compared on an equivalent basis without the effects of varying flue gas volumes leading to a misunderstanding of the results.

\section{Utah Skyline BC}

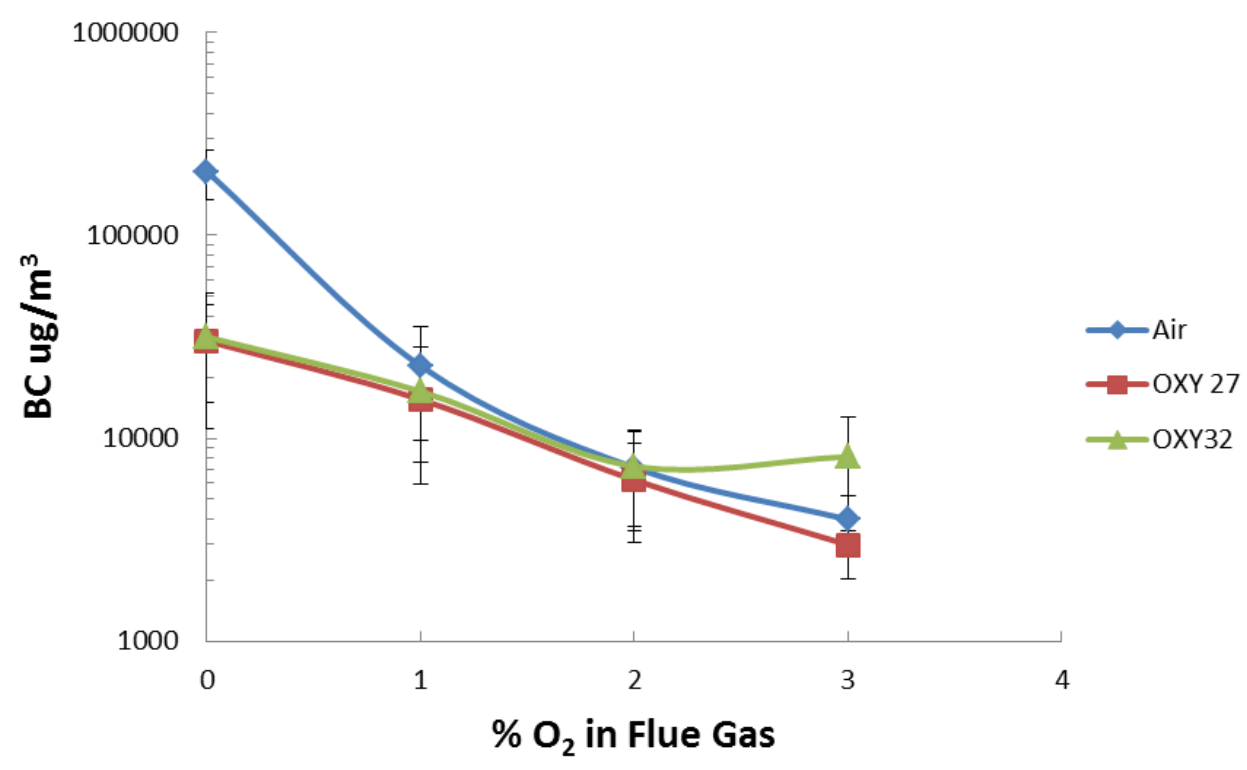

Figure 4.7-10: Utah Skyline black carbon data for the once through $\mathrm{CO} 2$ and air-fired cases on a $\mu \mathrm{g} / \mathrm{m}^{3}$ concentration basis.

In addition to the initial once through experiments, tests were also conducted in partnership with BYU (D. R. Tree, et al. 2011). In these tests, air was once again examined along with OXY27 and a 27\% $\mathrm{O}_{2}$ untreated FGR case. These tests were run at an SR of 0.9 and 1 and another case with $3 \% \mathrm{O}_{2}$ in the flue gas where the stoichiometric ratio was not the same due to the change in oxygen concentration. These tests again showed that oxy-firing reduced soot emissions when compared to a flame of the same firing rate with the Utah Skyline coal as illustrated in Figure 4.7-12.

The second round of black carbon testing also showed that at higher stoichiometric ratios, the untreated FGR case reduced black carbon production compared to the once through OXY27 case for the Utah Skyline coal in Figure 4.7-12, in which the stoichiometric ratio label of the abscissa is the stoichiometric ratio at the burner and not the system stoichiometric ratio. This is the case for all subsequent data reported in this dissertation. 


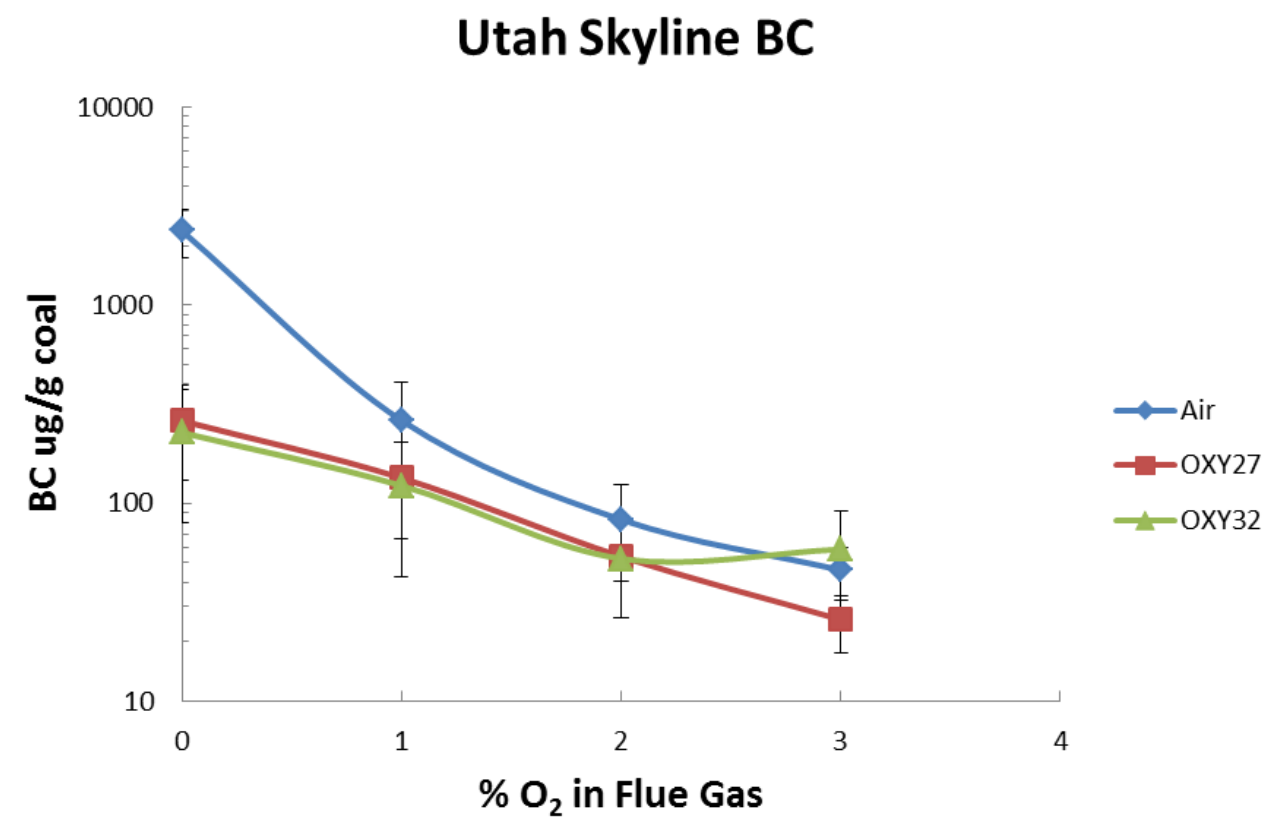

Figure 4.7-11: Utah Skyline black carbon data for the once through $\mathrm{CO}_{2}$ and air-fired cases on a $\mu \mathrm{g} / \mathrm{g}$ coal basis.

\section{Utah Black Carbon Concentration}

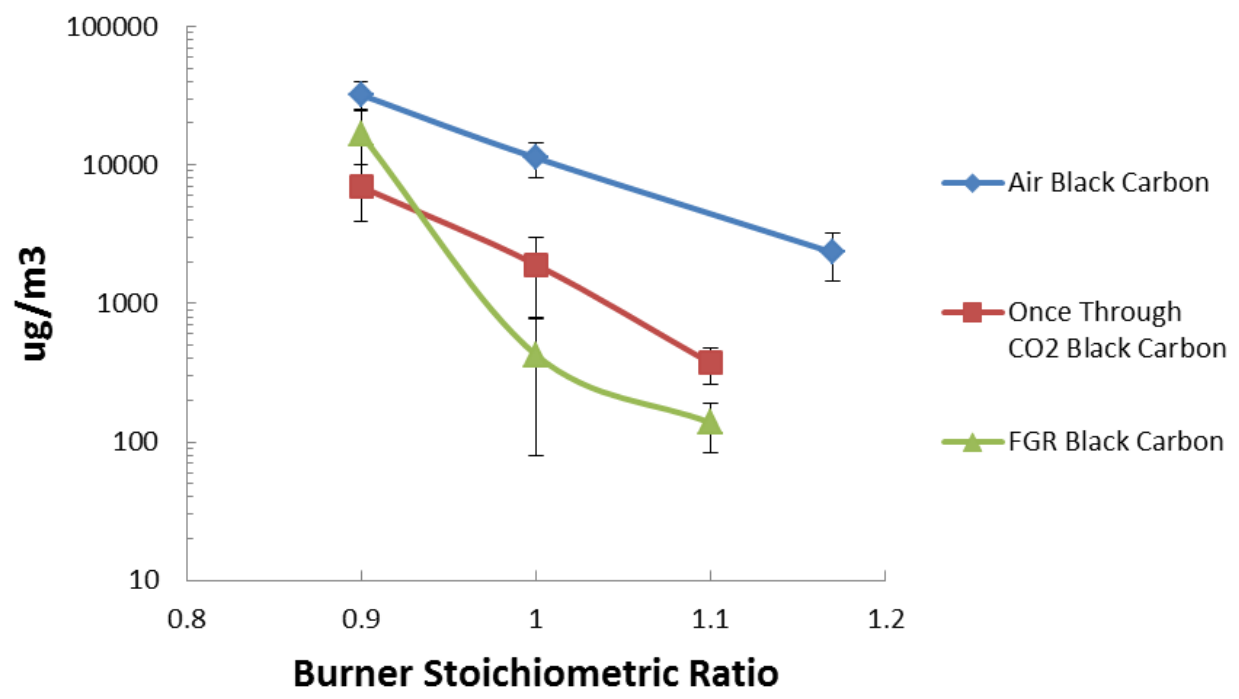

Figure 4.7-12: Black carbon comparison of air firing, once through $\mathrm{CO}_{2}$ at $27 \% \mathrm{O}_{2}$, and flue gas recycle conditions at $27 \% \mathrm{O}_{2}$ for Utah coal.

\subsubsection{2 $P R B$}

The PRB coal was also subjected to the same tests as the Utah Skyline coal. The PRB coal proved to be problematic and was difficult to analyze under similar firing rates and conditions as the Utah Skyline coal. Due to PRB's high moisture content, feeding problems as well as sampling challenges existed. For 
this reason, several attempts were made to sample the PRB coal under the same conditions as the Utah Skyline coal. Unfortunately this proved to be intractable, and the results of the initial round of testing with PRB produced far more soot aerosols than would be expected of such a low volatile yield coal. Additionally, the PRB seemed to produce considerably more soot under OXY32 conditions than under air-fired conditions. For these reasons, the PRB results have been deemed questionable for the first round of experiments, but have been presented here for the sake of completeness in Figure 4.7-13.

The PRB coal was tested again for black carbon concentration when conducting the soot tests in conjunction with BYU's laser experiments. During these tests, sampling and feeding techniques had been refined for the PRB coal and data were much easier to collect. In these experiments the trend of reducing black carbon emissions during oxy-firing was also observed in Figure 4.7-14.

Unlike the Utah coal, the PRB coal showed no significant differences at higher stoichiometric ratios when comparing the OXY27 case to the untreated FGR case. Both cases seemed to have similar sooting behavior at higher stoichiometric ratios, although at the deeply staged SR 0.9 condition, the Utah coal and PRB coal had significantly more soot under the untreated FGR condition as compared to the once through OXY27 condition.

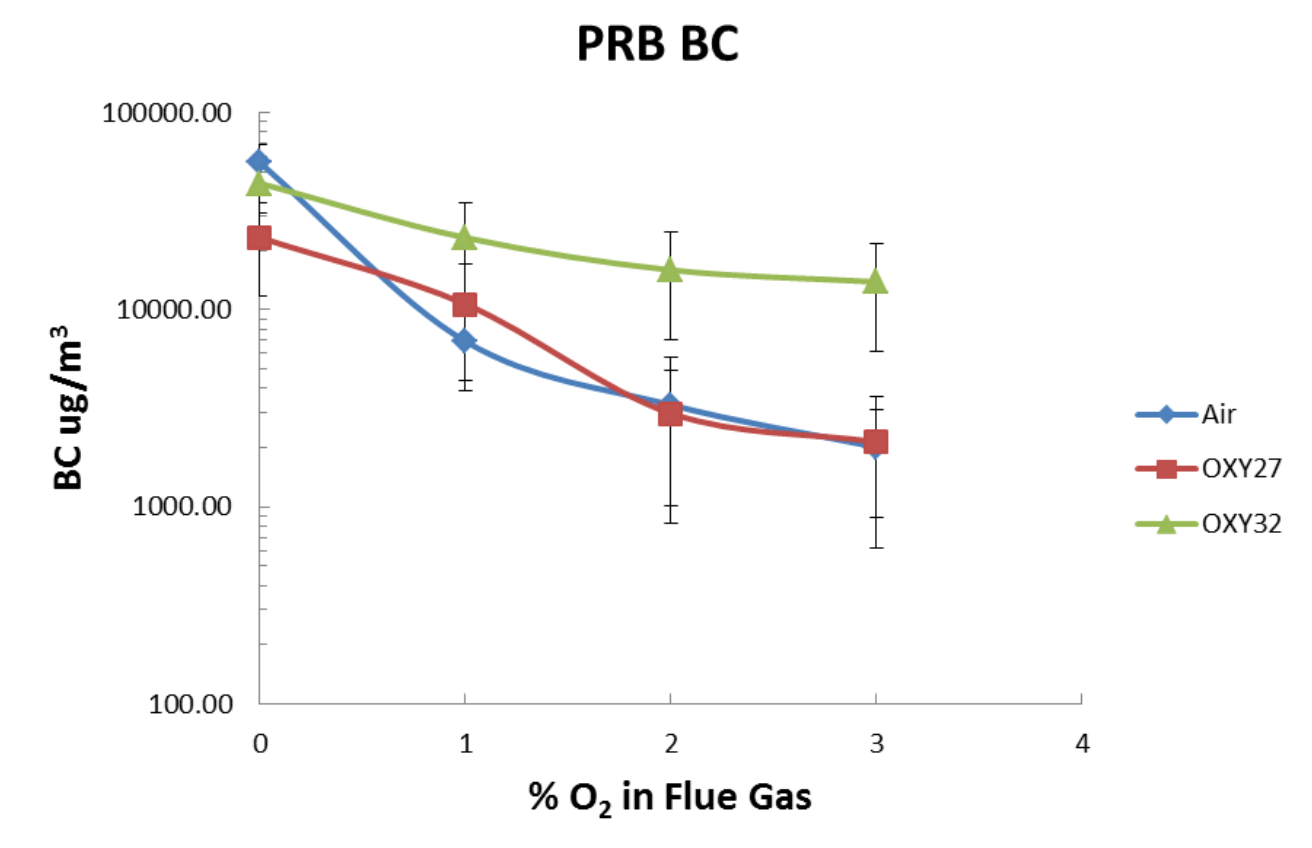

Figure 4.7-13: PRB black carbon concentration on a $\mu \mathrm{g} / \mathrm{m}^{3}$ concentration basis. 


\section{PRB Black Carbon Concentration}

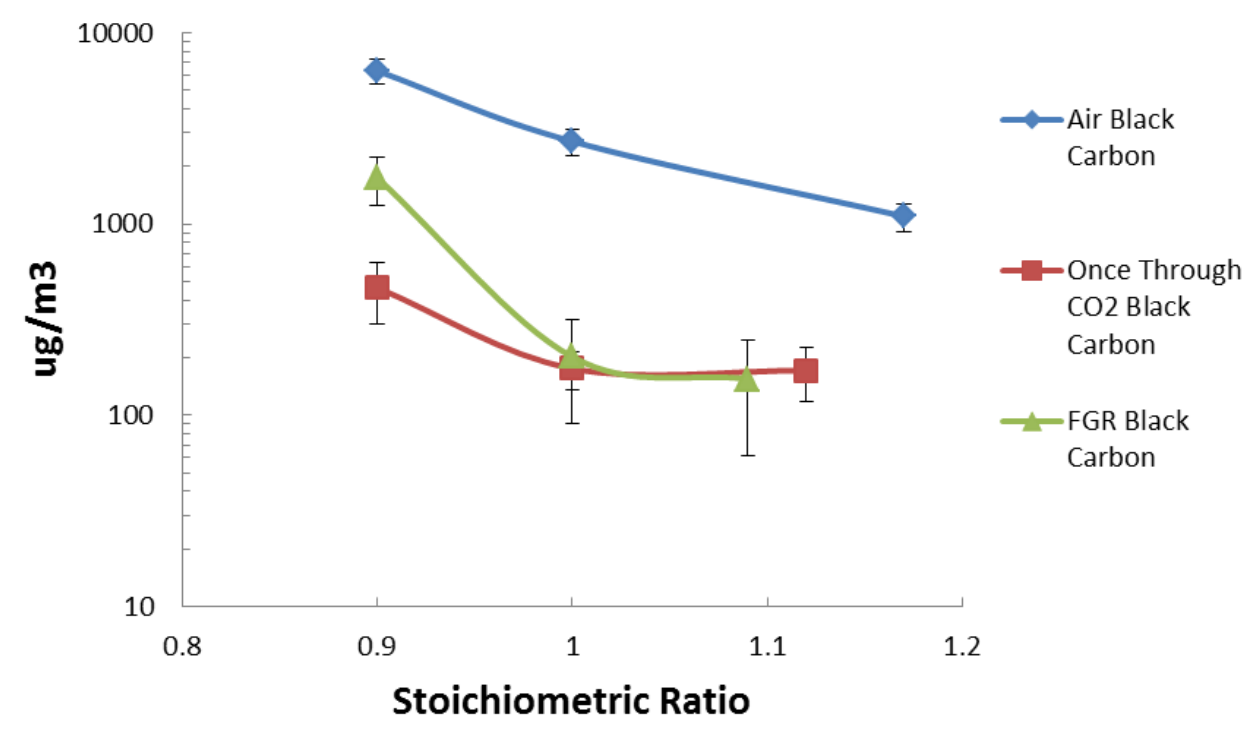

Figure 4.7-14: Black carbon comparison of air firing, once through $\mathrm{CO}_{2}$ at $27 \% \mathrm{O}_{2}$, and flue gas recycle conditions at $27 \% \mathrm{O}_{2}$ for $\mathrm{PRB}$ coal.

\subsection{Illinois}

The Illinois coal results for black carbon also showed a decrease in black carbon concentration when changing from air to oxy-fired conditions. The differences were not as pronounced as with the Utah coal, but a decrease did exist, particularly as the excess oxygen in the flue gas was decreased as shown in Figure 4.7-15.

When the oxygen concentration reached $3 \%$ in the flue gas, it was very difficult to discern a difference in concentration between the air and oxy-fired conditions. However, the concentration, as mentioned previously, does not give an accurate assessment of sooting behavior per energy input due to the difference in flue gas volumes from the air, OXY27, and OXY32 cases. In order to compare the amount of black carbon produced by each flame equally, the data are also plotted in a $\mu \mathrm{g} / \mathrm{g}$ coal basis as shown in Figure 4.7-16, and these data were very similar to those on Figure 4.7-15. 


\section{Illinois Black Carbon Concentration}

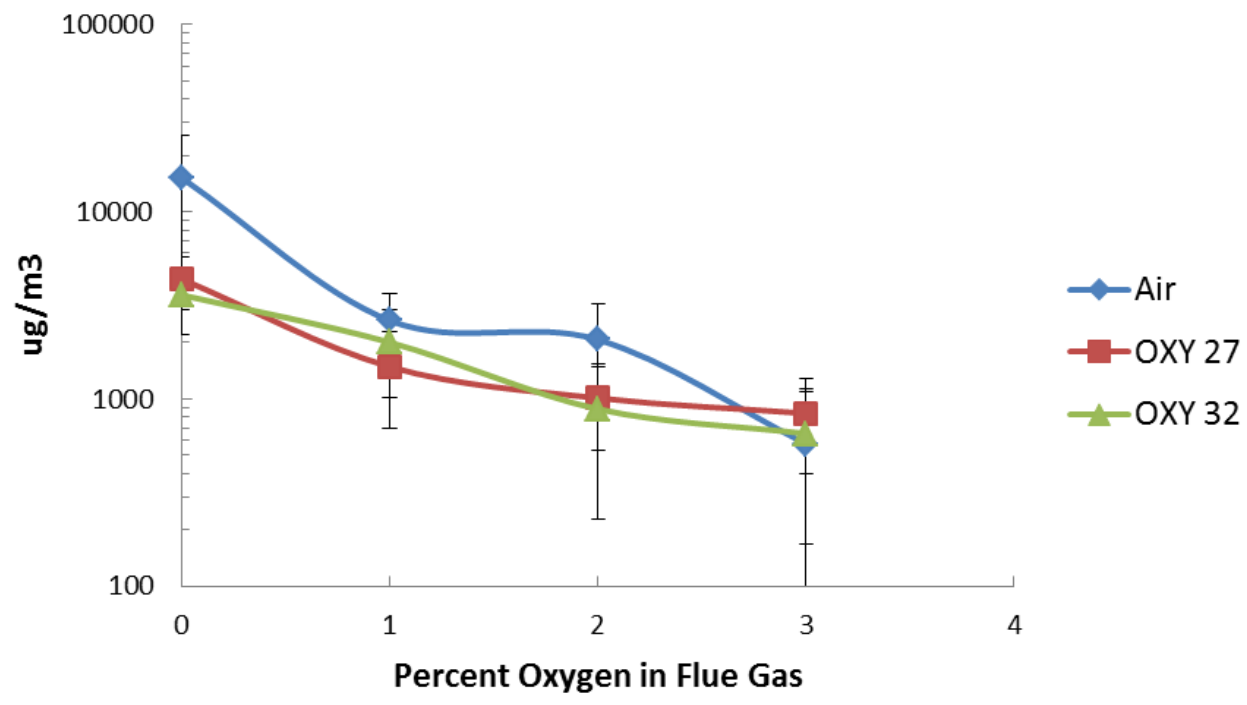

Figure 4.7-15: Illinois black carbon concentration for air, 27\% oxy, and 32\% oxy-fired experiments.

\section{Illinois Black Carbon}

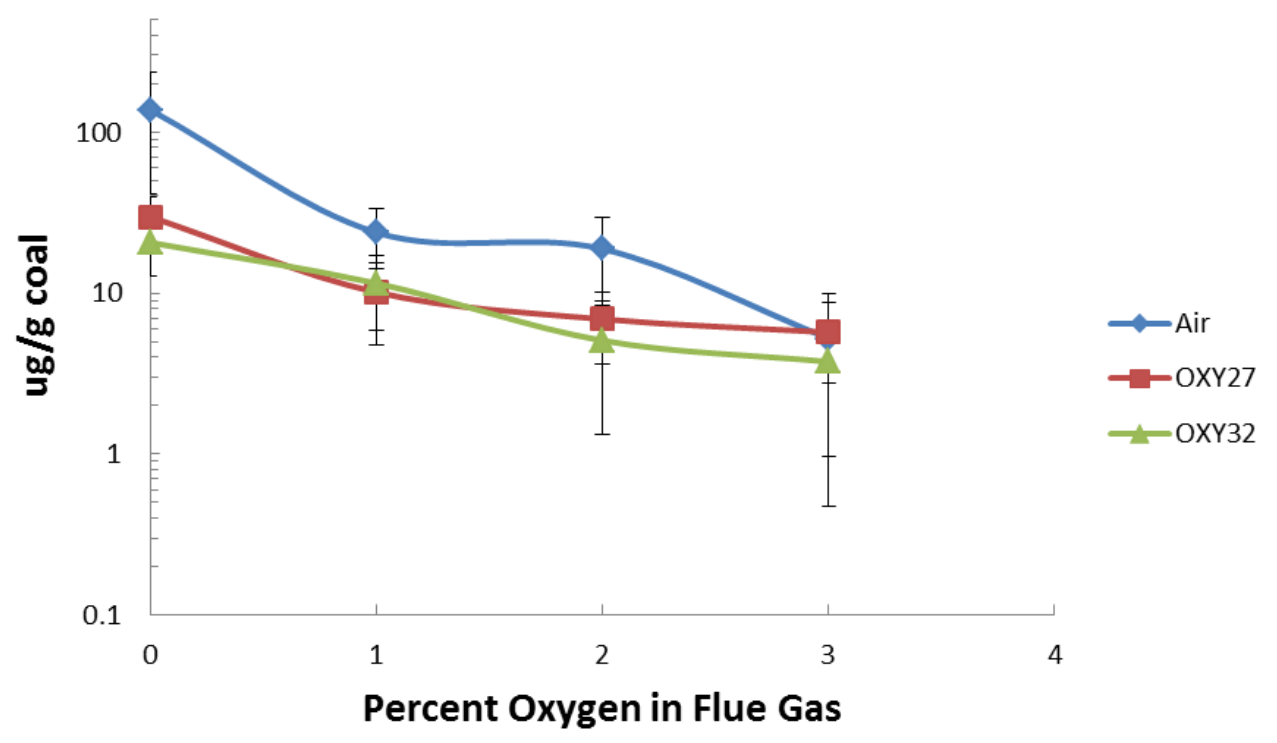

Figure 4.7-16: Illinois black carbon emissions on a $\mu \mathrm{g} / \mathrm{g}$ coal basis.

While the $3 \% \mathrm{O}_{2}$ cases were very similar among the three firing conditions, it was still evident that the lower excess oxygen oxy-fired cases had reductions in soot formation when compared to air firing. This was the same trend observed with the Utah and PRB coals. 
The BYU tests were conducted only under air and once through conditions. When running untreated FGR tests with the high sulfur Illinois coal, $\mathrm{SO}_{2}$ concentrations of nearly 20,000 ppm were measured. This level was not only hazardous to people who may be operating the equipment, but it was also very destructive to instruments which were sampling the flue gas. As a result, FGR conditions were not examined for the Illinois coal. The tests between air-fired and oxy-fired again showed that switching from air to oxy-firing did reduce the sooting behavior of the flame across a wide range of stoichiometric ratios as illustrated in Figure 4.7-17.

\section{Illinois Black Carbon Concentration}

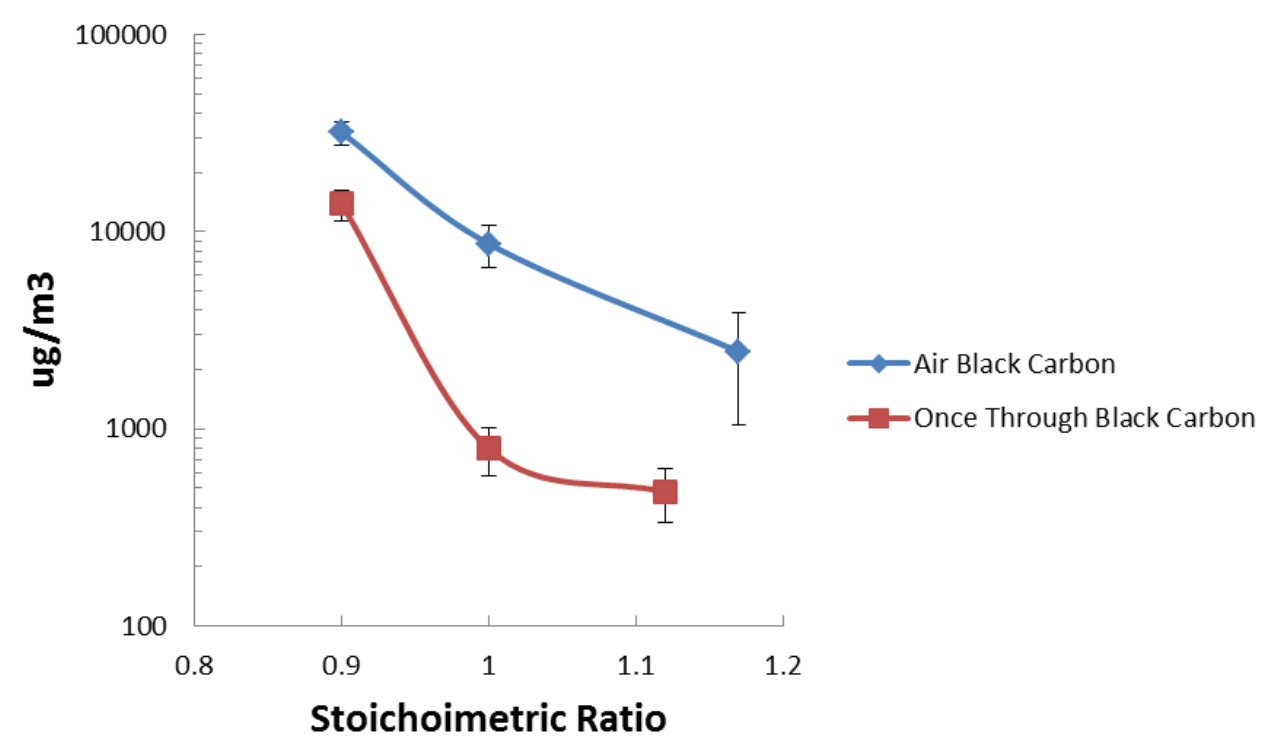

Figure 4.7-17: Illinois black carbon comparison between air-fired and 27\% oxy once through fired experiments.

\subsection{Effect of Coal Composition on Black Carbon Aerosols}

Soot or black carbon emissions were also strongly affected by coal rank and chemical composition. For this reason, it was useful to compare the results of emissions between coals of the same firing condition as opposed to just examining the comparisons of the same coal under different firing conditions.

In order to keep redundancy to a minimum, the coals were compared to each other under the BYU joint soot testing conditions rather than every condition that was previously examined. Also, due to greater experience with the instruments and sampling systems, this data set has been deemed the best and most accurate for comparison. These data show that the higher rank Utah and Illinois bituminous coals produced more black carbon emissions than the lower rank and lower volatile yielding PRB coal under air-fired conditions as shown in Figure 4.7-18. 


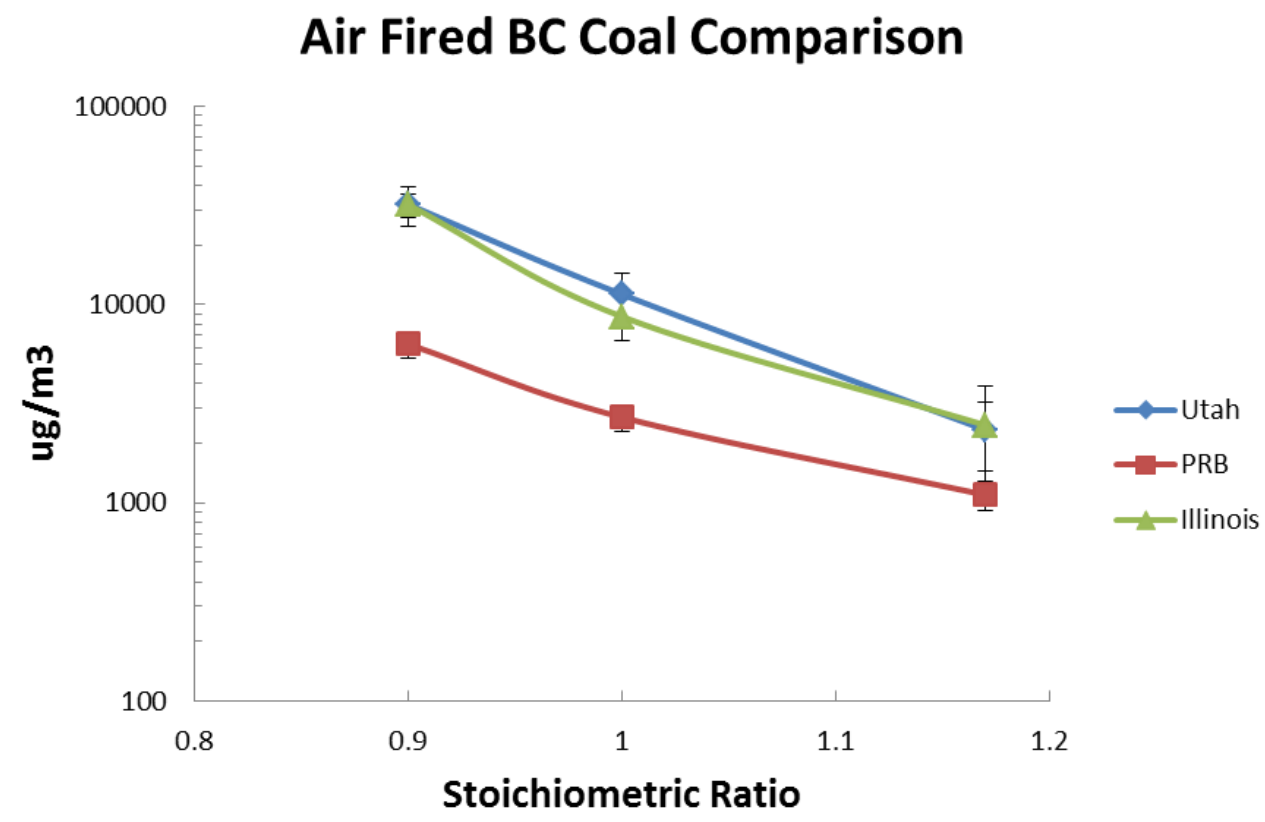

Figure 4.7-18: Black carbon emissions comparisons of the Utah, PRB, and Illinois coals under airfired conditions. Error bars for PRB are less than the point size.

In addition to comparing the coals under air-fired conditions, it was also useful to see if the reductions of soot under oxy-fired conditions were dependent upon coal rank or whether they are affected equally by switching to oxy-fired conditions. While the Utah and Illinois coals were not as closely matched in terms of their soot emissions under the OXY27 case as they were under air firing, they were still at very similar levels and produced greater soot concentrations than the PRB coal under oxy-firing as shown in Figure 4.7-19.

However, the OXY27 represented clean flue gas that had been treated to a high level of purity and then recycled. For this reason, it was also useful to examine the difference between the higher rank Utah bituminous and the sub-bituminous PRB coal. There were no recycle data for the Illinois coal due to issues with recycling such highly concentrated $\mathrm{SO}_{2}$ flue gas. However, as has been shown previously, the black carbon emissions of the Utah coal were very similar to the Illinois coal.

When recycling completely untreated flue gas, the difference between the higher volatile yielding Utah coal and the lower rank PRB coal became less pronounced than when the differences between air and once through oxy-fired conditions were examined. In the untreated FGR comparison, the black carbon emissions from the Utah and PRB coals were nearly equivalent as shown in Figure 4.7-20 at the highest stoichiometric ratios. However, at lower stoichiometric ratios, there still existed a difference in the emissions of black carbon between the two coals. At the lower ratios, the Utah coal still produced significantly more emissions than the PRB under the same firing conditions. 


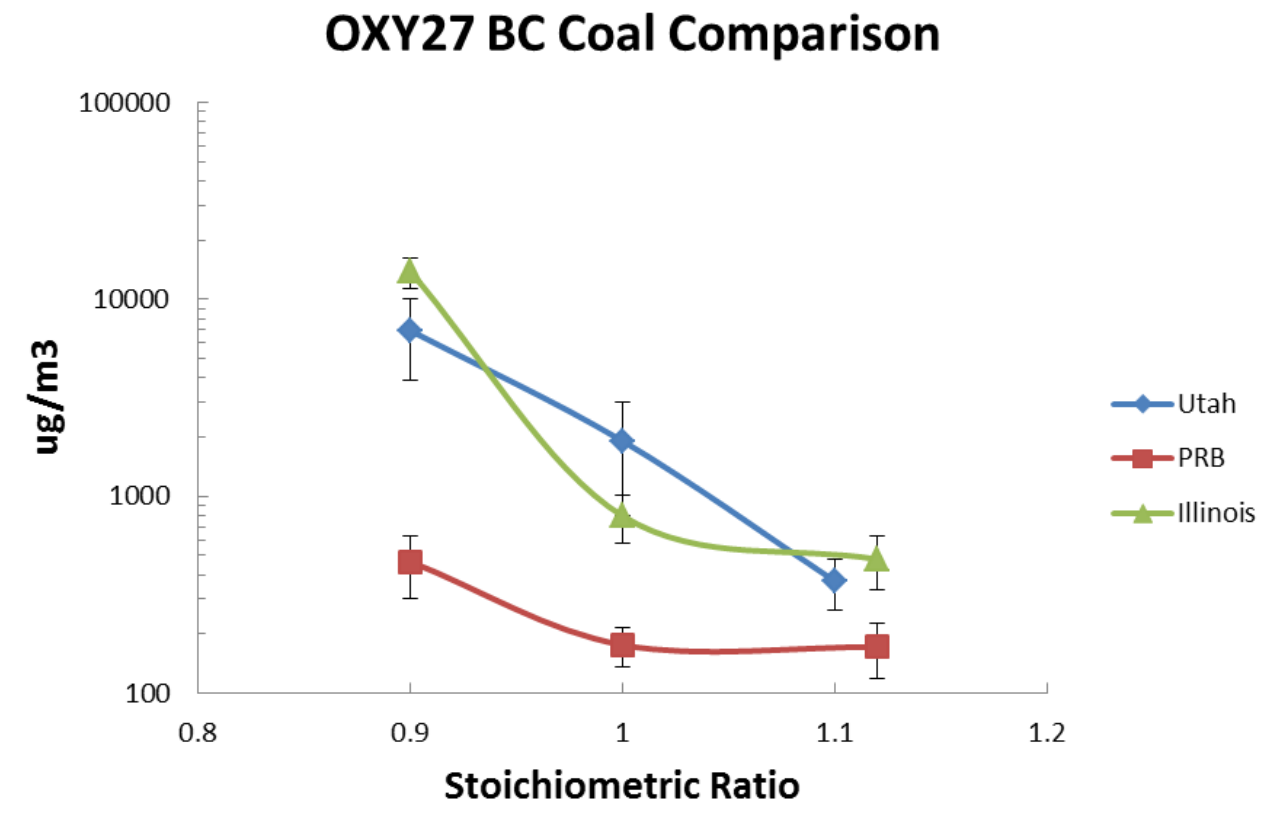

Figure 4.7-19: OXY 27 black carbon emission comparison of the Utah, PRB, and Illinois coals.

\section{Untreated FGR BC Coal Comparison}

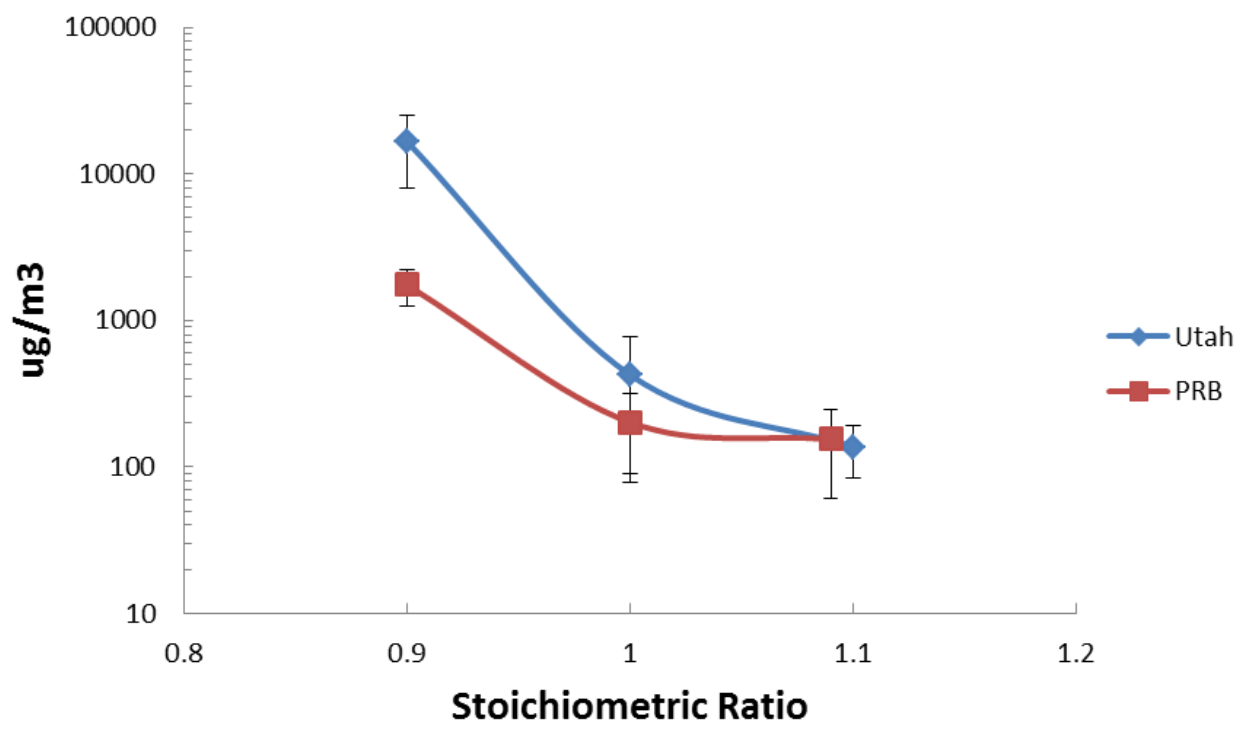

Figure 4.7-20: Untreated recycled flue gas comparison of black carbon emissions between Utah and PRB coals. 


\subsubsection{Particle Size Distribution}

Particle size distributions were important for understanding how the ash and other aerosols partitioned during the combustion process. Particle size distributions (PSDs) were collected for each coal using a variety of different methods. An SMPS was used to record PSDs for a range of particles approximately 15-670 nm in diameter. A Berner low pressure impactor (BLPI) was used to collect PSDs ranging from $32 \mathrm{~nm}$ to $15.7 \mu \mathrm{m}$. An aerosol particle sizer was purchased halfway through the research campaign, and when available, it measured PSDs from 0.5 to $20 \mu \mathrm{m}$.

First, PSDs for each individual coal are presented. Each coal was examined under different firing conditions. Then the effects of coal composition are presented and compared. The PSDs are plotted on a $\log$ vs. $\log$ scale and occasionally on a semi-log scale in order to allow identification of particle size modes. These data include BLPI, SMPS, and APS measurements. Ash composition data follow in the subsequent section.

PSDs were collected for each of the three coals under a wide variety of combustion conditions including air, oxy-fired, and oxy-fired with flue gas recycle. Many of these conditions were also examined under multiple stoichiometric ratios as well to determine how any excess oxygen would affect partitioning of the aerosols in the furnace.

\subsection{Utah Skyline}

The Utah Skyline particle size distributions were collected over a wide range of combustion conditions. Samples were collected with the BLPI at $3 \% \mathrm{O}_{2}$ in the flue gas under air-firing, oxy-firing with once through $\mathrm{CO}_{2}$ at $27 \%$ and $32 \% \mathrm{O}_{2}$, oxy-firing at $32 \% \mathrm{O}_{2}$ under flue gas recycle conditions with a bag house for particle removal, and $32 \% \mathrm{O}_{2}$ oxy-firing with untreated flue gas recycle.

Each condition produced results with the expected trimodal behavior of a fume, fine fragmentation, and coarse modes (W. Seames 2001). However, there were differences in the relative contributions of each mode when comparing air-fired to the oxy-fired conditions. The oxy-fired conditions typically had a greater concentration of ultrafines than the air-fired condition. Furthermore the recycled flue gas conditions had a lower concentration of coarse particles than the air and once through cases as shown in Figure 4.7-21 and Figure 4.7-22 which is semi-log to show greater definition of particle modes.

Also, the once through $\mathrm{CO}_{2}$ conditions seemed to be more similar to the air-fired PSDs rather than the FGR PSDs. Furthermore, the untreated FGR condition also had noticeably more fine particulate $(\sim 1 \mu \mathrm{m})$ than the FGR condition where the flue gas was cleaned with a bag house, but this difference was less pronounced on larger supermicron particles. 


\section{Utah BLPI PSDs}

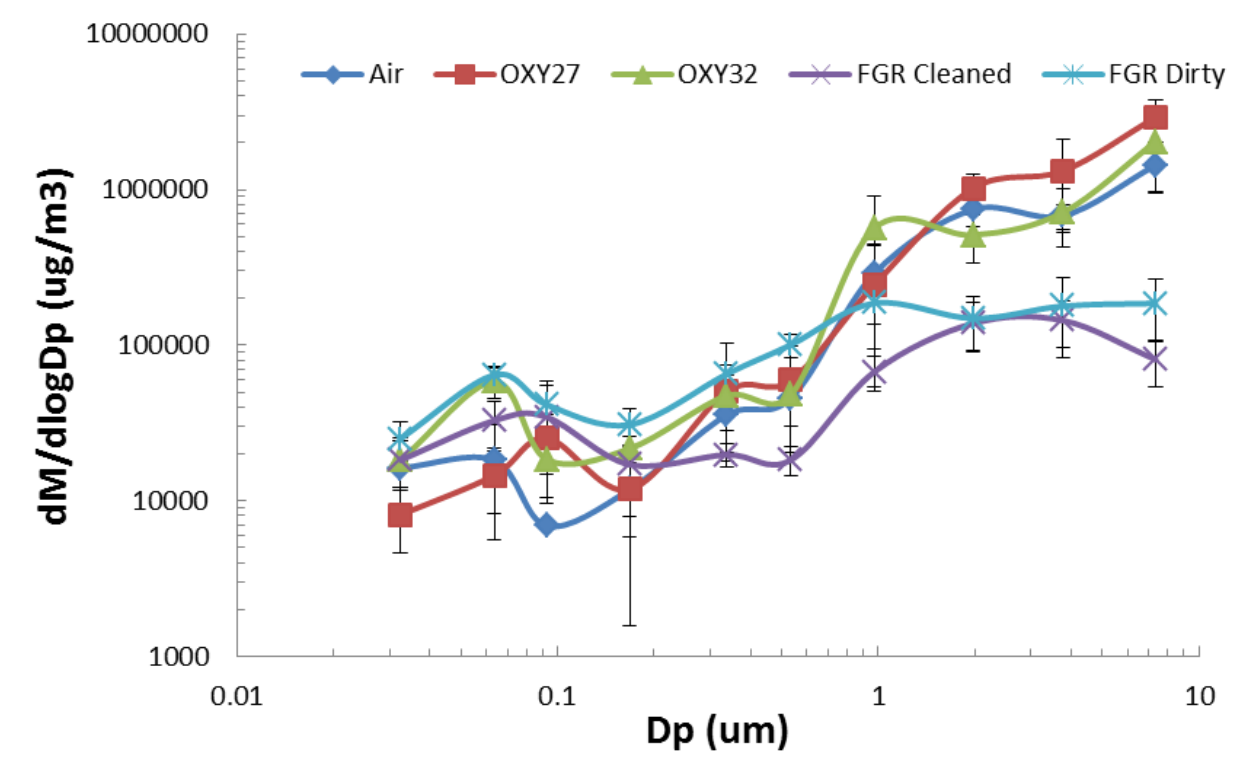

Figure 4.7-21: Utah coal particle size distributions recorded with the Berner low pressure impactor and $3 \% \mathrm{O}_{2}$ in the flue gas.

\section{Utah BLPI PSDs}

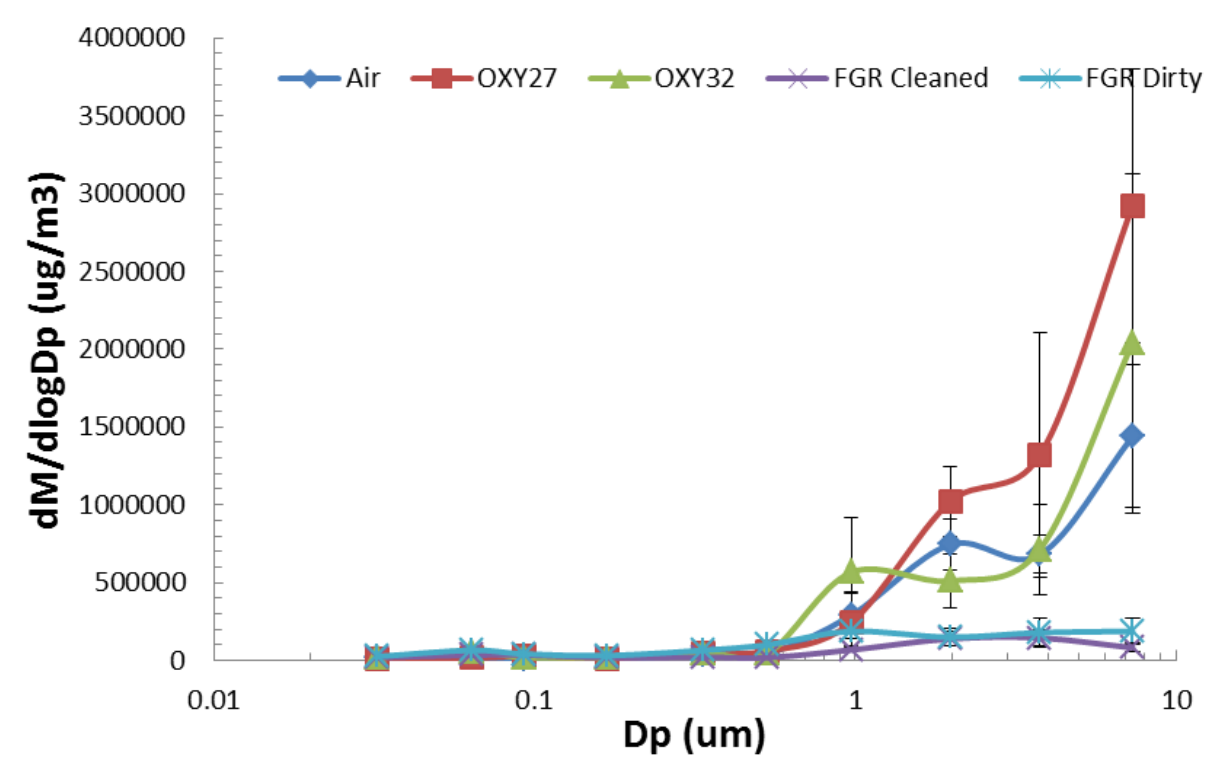

Figure 4.7-22: Particle size distribution for the Utah coal on a semi-log scale. 
In addition to the data collected with the BLPI, significant amounts of data were collected for the Utah coal in the ultrafine range of less than $670 \mathrm{~nm}$. These data sets were collected over a wide range of stoichiometric ratios as well as firing conditions.

Air-fired data were collected as a baseline dropping the percent oxygen in the flue gas from $3 \% \mathrm{O}_{2}$ to $0 \%$ $\mathrm{O}_{2}$ one percent at a time. The four resulting PSDs that were recorded by the SMPS are shown in Figure 4.7-23.

\section{Utah Skyline Air Fired Cases}

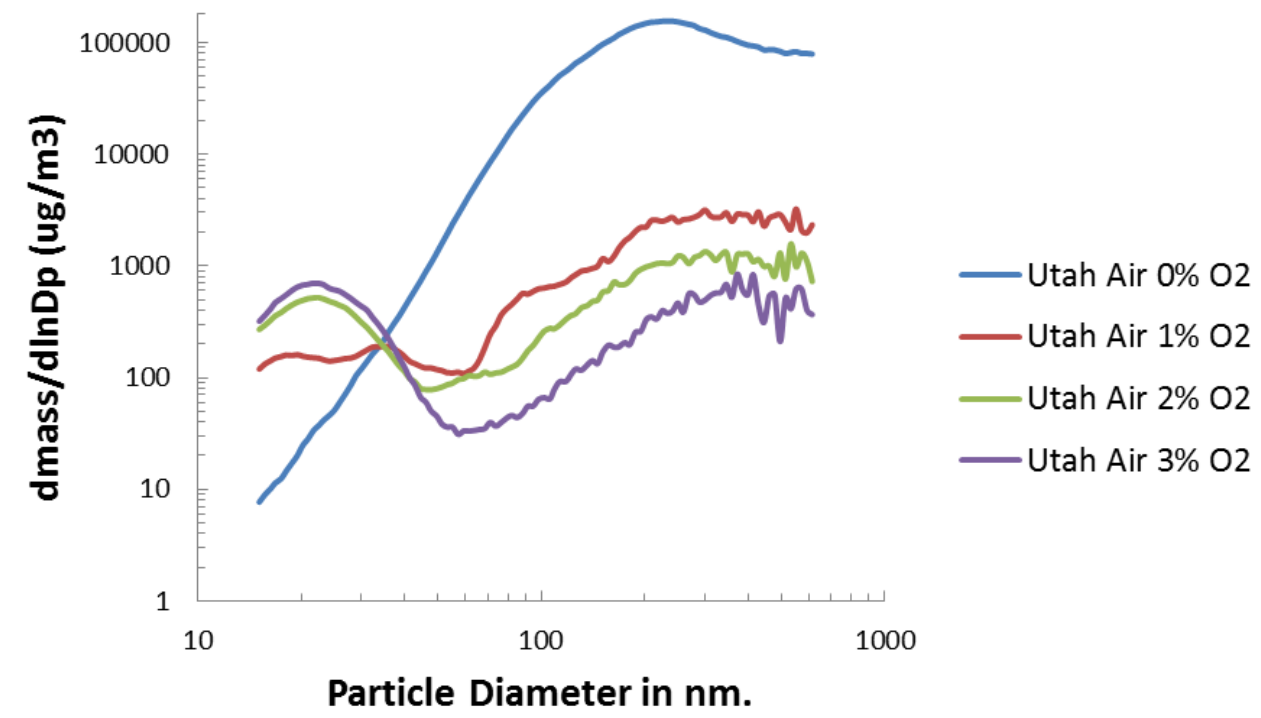

Figure 4.7-23: Utah coal ultrafine particle size distributions at varying stoichiometric ratios as measured by an SMPS under air-fired conditions.

The PSDs for the air-fired Utah coal tests had two modes. The first mode was below approximately $100 \mathrm{~nm}$, and the other was above 100nm and extended beyond the range of the instrument. The exception is the $0 \% \mathrm{O}_{2}$ case which appeared to have only one mode which was of a significantly greater particle concentration than the other cases.

Also, the first mode below 100nm decreased as the excess air was reduced, while the second mode increased, in some cases dramatically, when the excess air was increased. The two modes moved opposite of one another as excess air was either increased or decreased.

This same general trend was also observed in once through $\mathrm{CO}_{2}$ applications. The difference was a lack of dramatic shift at the $0 \% \mathrm{O}_{2}$ condition for OXY27 shown in Figure 4.7-24. 


\section{Utah Skyline 27\% Oxy Fired Cases}

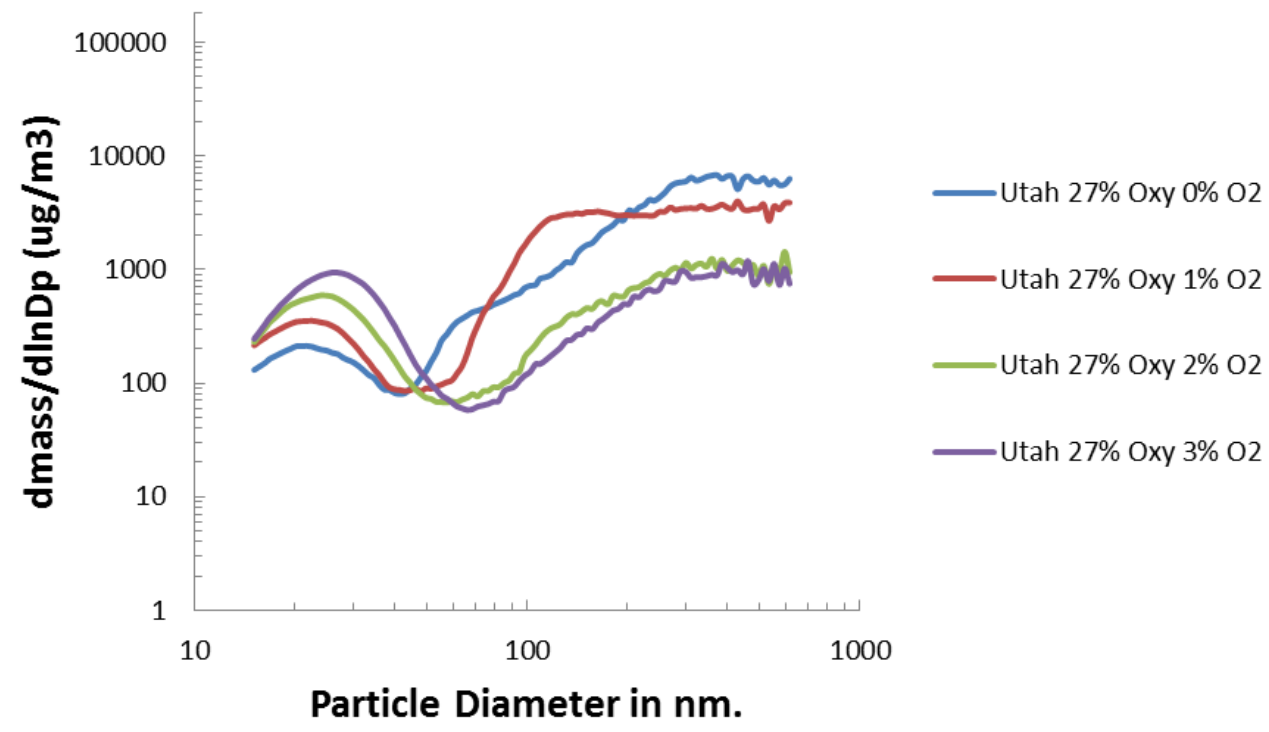

Figure 4.7-24: Utah coal ultrafine particle size distributions at varying stoichiometric ratios as measured by an SMPS under OXY27 conditions.

The OXY32 case also exhibited the same PSD behavior where the two ultrafine modes moved in opposite directions as excess oxygen was added or removed from the combustion process. There was one notable exception, which was that under the OXY32 case, rather than having the order of the super 100nm mode from smallest to largest being $3 \%, 2 \%, 1 \%$, and $0 \%$ as was the case with the air firing and OXY27 conditions, under OXY32 the order was 2\%, 3\%, 1\%, 0\% as shown in Figure 4.7-25.

In addition to the data collected with the SMPS under air-fired and once through oxy-fired conditions, PSDs were also collected at $3 \% \mathrm{O}_{2}$ in the flue gas under FGR conditions. When compared to the once through $\mathrm{CO}_{2}$ case at the equivalent 32\% oxy-firing concentration, the recycled flue gas conditions had more ultrafine particles present than the once through case as shown in Figure 4.7-26. 


\section{Utah Skyline 32\% Oxy Fired Cases}

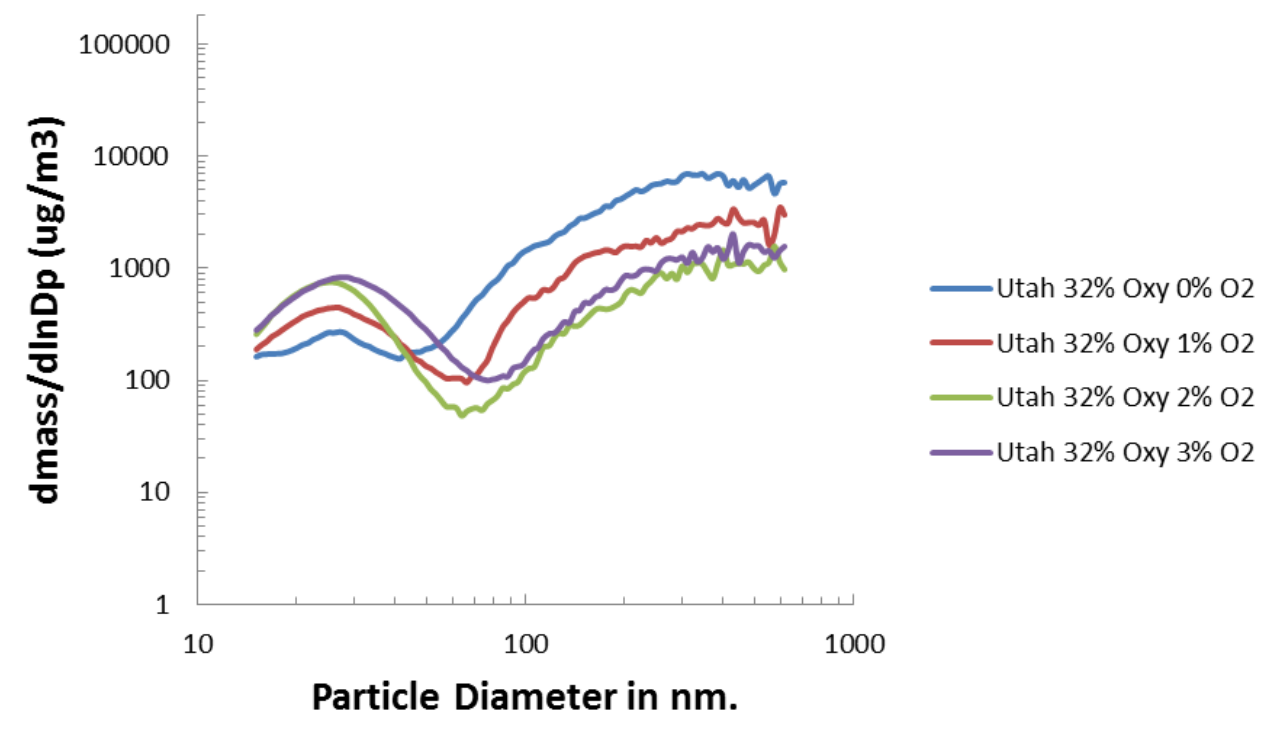

Figure 4.7-25: Utah coal ultrafine particle size distributions at varying stoichiometric ratios as measured by an SMPS under OXY27 conditions.

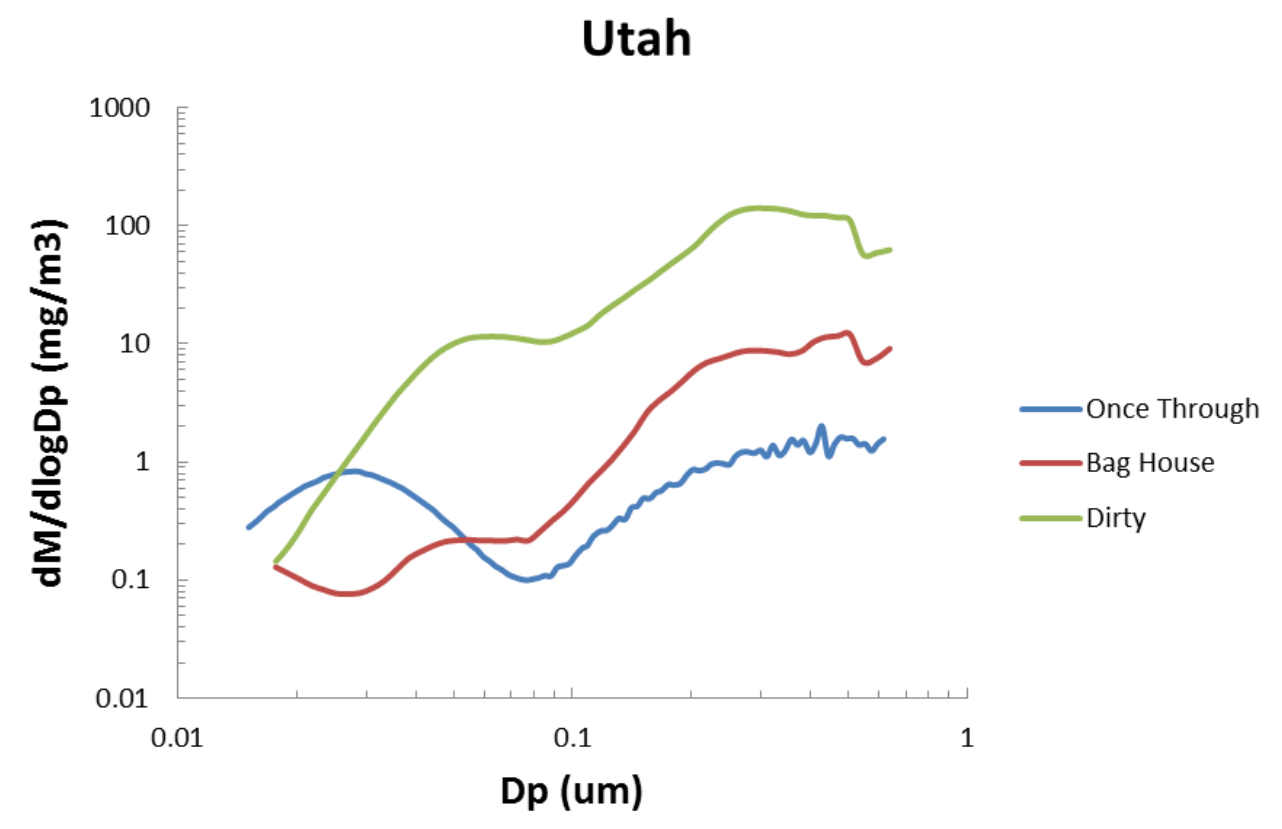

Figure 4.7-26: SMPS comparison of once through OXY32 with corresponding $32 \% \mathrm{O}_{2}$ oxy- fired FGR conditions.

The last series of PSDs were collected during the BYU soot experiments. In these tests, the primary purpose was to determine the overall concentration of the ultrafines measured by the SMPS. As a result, curves of the overall PSDs are not presented, but rather the integrated value under the curve which gives the total concentration of the particles have been recorded. This was done in order to compare values between the ultrafine concentration as measured by the SMPS and the concentration of the soot or black 
carbon particles measured by the PA. The SMPS values followed similar trends as the PA values reported in section Utah Skyline with the air firing having the highest concentration followed by the OXY27 oxy-fired case, and the untreated FGR oxy-case having the lowest concentration as shown in Figure 4.7-27.

\section{Utah Integrated SMPS Concentration}

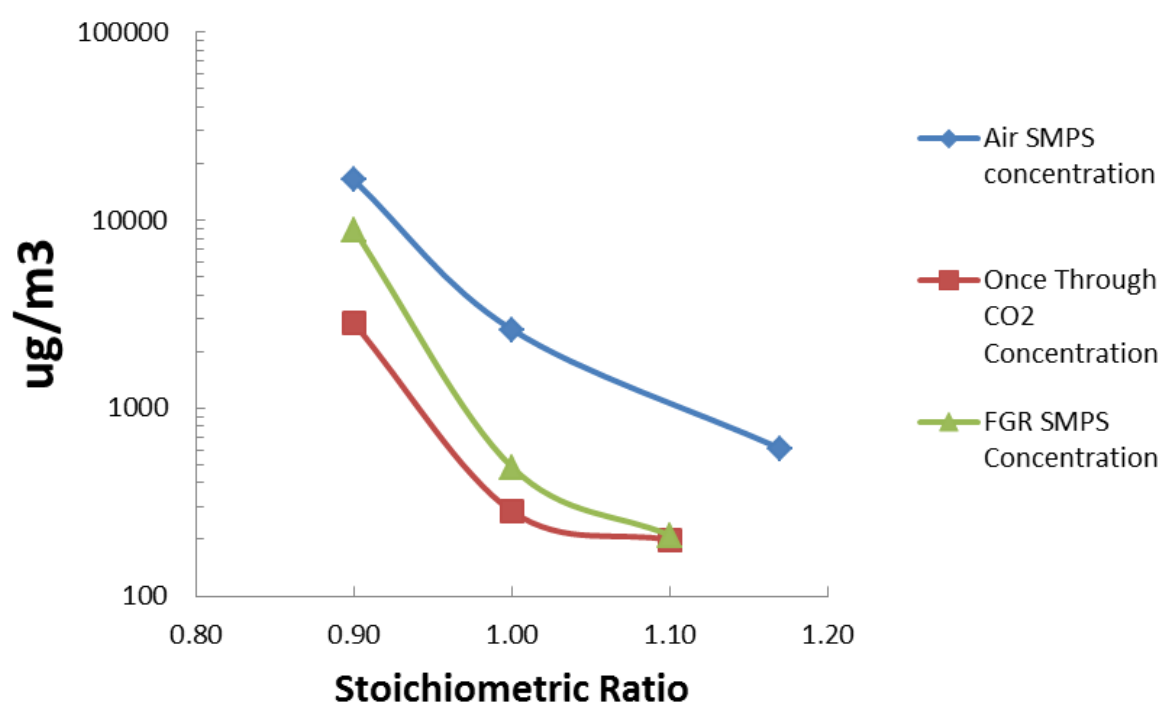

\section{Figure 4.7-27: Utah SMPS concentration of ultrafine particles less than $670 \mathrm{~nm}$ as measured by SMPS during the BYU soot tests.}

\subsubsection{2 $P R B$}

Particle size distributions were also collected for the PRB coal in order to observe the changes in PSDs as a function of coal composition when compared to the Utah Skyline bituminous as well as the Illinois high sulfur bituminous coal. PSDs were collected for the PRB coal under the same firing conditions and equivalent oxygen flue gas concentrations as the Utah coal reported in section 4.7.3.3.1.

As with the Utah coal, three replicates were performed with each BLPI collection, and error bars represent standard deviation for three replicates unless otherwise noted. Unlike the Utah coal samples, there was no need for a cyclone to be inserted in front of the BLPI in order to collect ash for extended periods of time to gather sufficient mass on the lower stages.

The PRB results showed that, in general, there was a higher concentration of fine particles from the oxyfired conditions when compared to the air-fired conditions. Furthermore, the recycled flue gas conditions tended to have greater concentrations of fine particles than did the oxy-fired conditions. Additionally, the shoulder of the coarse ash mode of 10 micron and larger particles is present for all of the oxy-fired cases, but is not obvious for the air-fired case. A semi-log arithmetic plot also did not provide an obvious indication of the coarse mode. These results are shown in Figure 4.7-28 and Figure 4.7-29.

In addition to BLPI samples, SMPS and APS data were also collected for the PRB coal. The data collected with the online particle instruments showed that as the amount of excess air was reduced under air-fired conditions, there was a corresponding increase in the concentration of ultrafine particles as measured by the SMPS. Results have been plotted here with the SMPS and APS data together using 
TSI's proprietary data merge software to combine the data collected by the two instruments as shown in Figure 4.7-30.

While differences were noted for the ultrafine particles under air-fired conditions, very little difference was noted with the fine particle mode of approximately one micron and larger measured by the APS. The results in Figure 4.7-30 did not indicate any significant differences in the supermicron range as a result of changing stoichiometric ratios.

The label in the figure refers to the coal fired, the combustion atmosphere, and the amount of oxygen in the flue gas. Thus PRB Air 0 refers to the PRB coal being fired under air-fired conditions with $0 \% \mathrm{O}_{2}$ in the flue gas. PRB Air $1 \% \mathrm{O}_{2}$ in the flue gas refers to firing the PRB coal in air at $1 \% \mathrm{O}_{2}$ in the flue gas and so on and so forth.

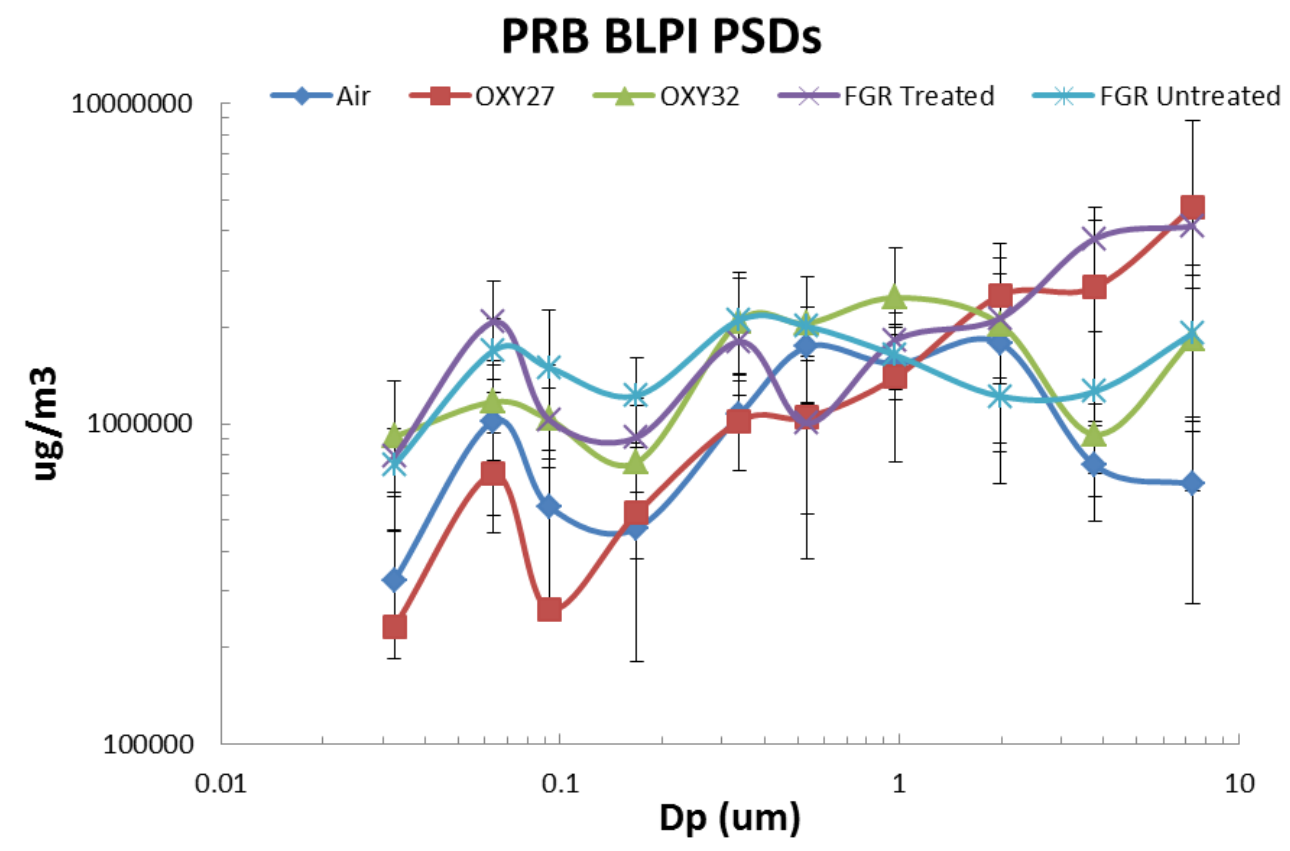

Figure 4.7-28: PRB PSDs collected with the BLPI for all combustion conditions including air, OXY27, OXY32, treated FGR, and untreated FGR. 


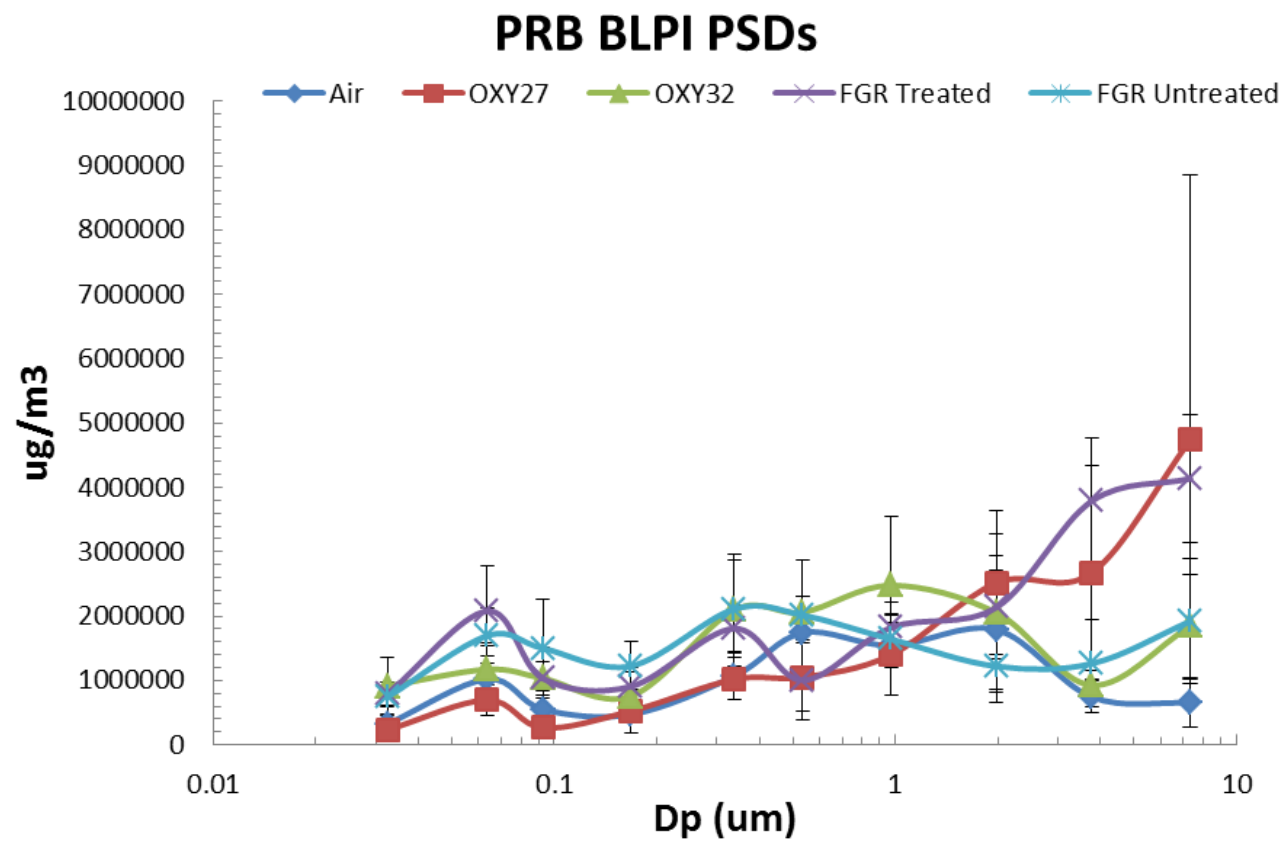

Figure 4.7-29: Semi-log plot of PRB particle size distributions to highlight particle modes.

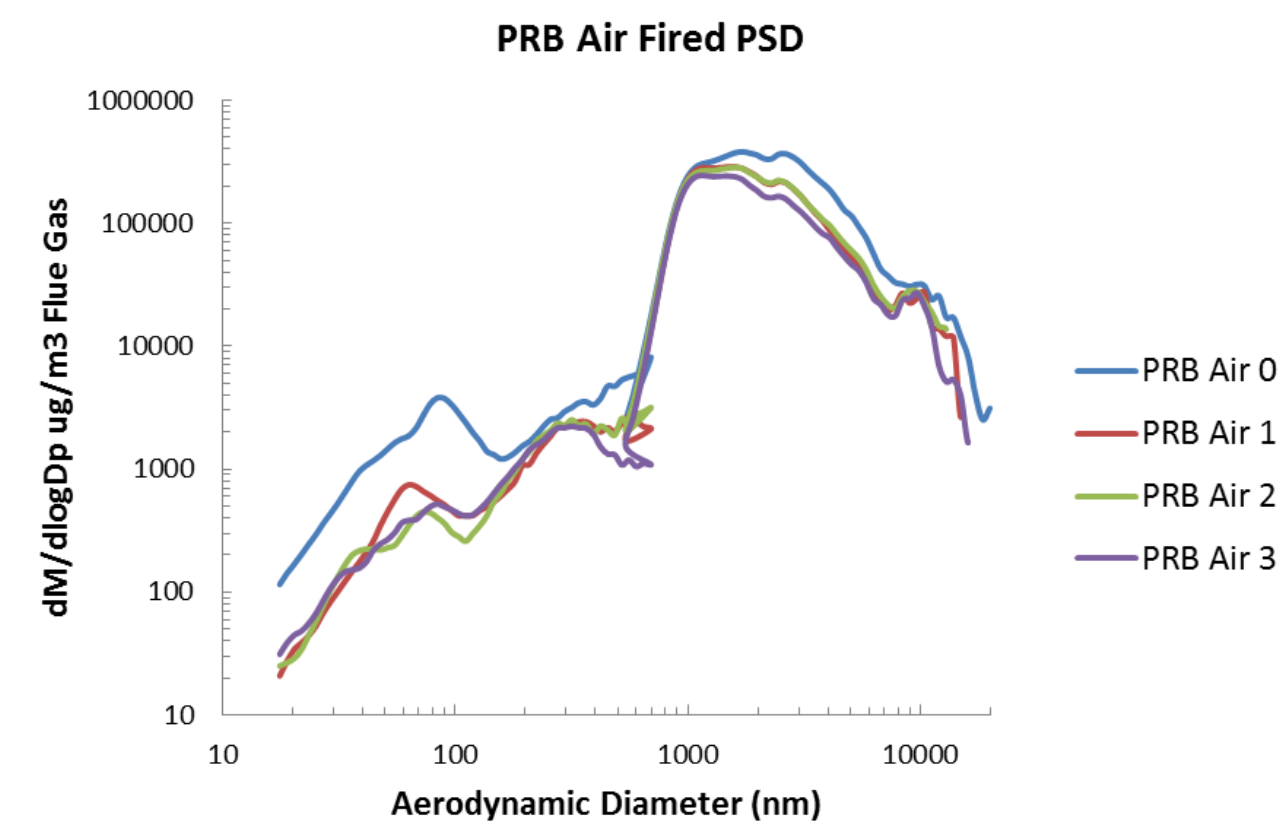

Figure 4.7-30: Air-fired PSD results for the PRB coal using SMPS and APS instruments with 0\%, $1 \%, 2 \%$, and $3 \% \mathrm{O}_{2}$ in the flue gas.

In addition to the air-fired data, data were also collected for the OXY27 combustion condition. In this condition, like air, the supermicron range of particles exhibited similar behavior under all stoichiometric ratios. However, unlike the air-fired cases, there was not a significant difference from the $0 \% \mathrm{O}_{2}$ in the flue gas case and the other cases. Also, it was more difficult to discern overall trends. While it was clear that the particle concentration sub $100 \mathrm{~nm}$ goes in order from greatest to lowest concentration following 
each case as excess oxygen is added, the results were considerably more muddled for the rest of the ultrafine range without clearly defined trends in Figure 4.7-31.

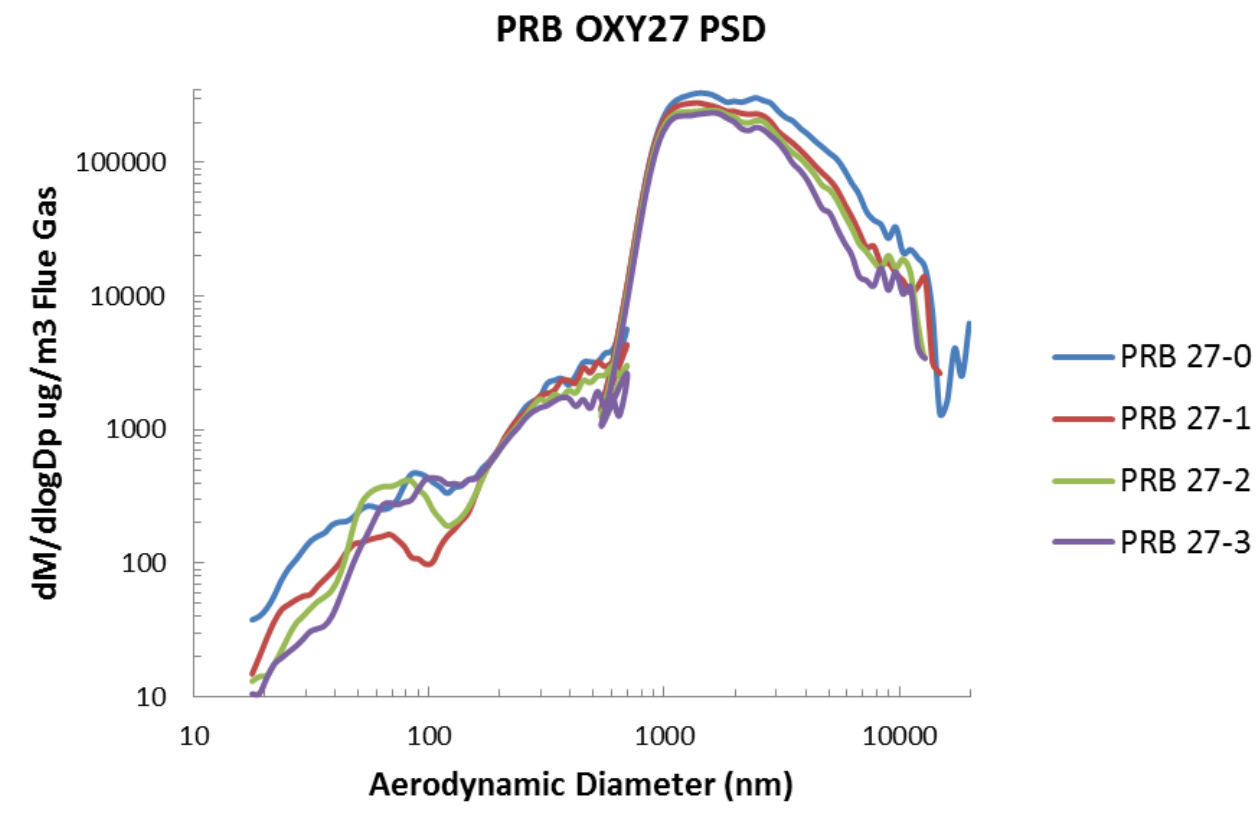

Figure 4.7-31: OXY27 PSD results for the PRB coal using SMPS and APS instruments with 0\%, $1 \%, 2 \%$, and $3 \% \mathrm{O}_{2}$ in the flue gas.

As was the case with the air-fired conditions, the labels in Figure 4.7-31 refer to the coal fired, the once through oxy condition firing atmosphere, and the percentage of oxygen on a dry basis present in the flue gas. As a result, the label PRB 27-0 refers to the PRB coal being fired at $27 \% \mathrm{O}_{2}$ in the once through oxy-fired condition with $0 \% \mathrm{O}_{2}$ in the flue gas. Thus, the label PRB 32-1 refers to the PRB coal being fired using a 27\% O2 oxy-fired condition with once through $\mathrm{CO}_{2}$ and $1 \% \mathrm{O}_{2}$ in the flue gas and so on and so forth for the data presented in Figure 4.7-32.

The OXY32 data was more similar to the OXY27 data for the PRB coal than the air-fired data for the PRB. As with the OXY27 cases, it was harder to see a trend in terms of increasing or decreasing modes as excess oxygen was added or removed from the system. Instead, for the OXY32 cases, the concentrations of all modes seemed to be less dependent upon the stoichiometric ratios for the OXY32 condition when compared to the air-fired conditions. 


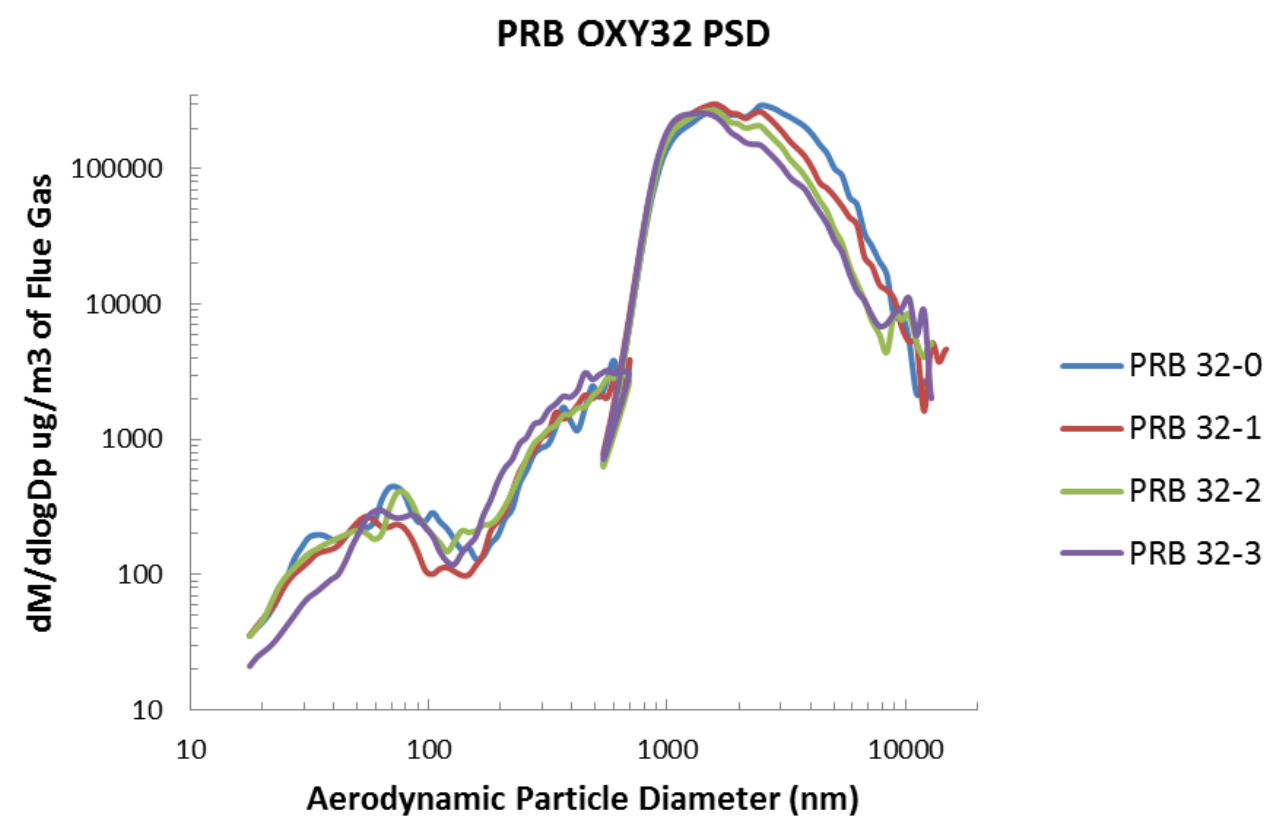

Figure 4.7-32: OXY32 PSD results for the PRB coal using SMPS and APS instruments with 0\%, $1 \%, 2 \%$, and $3 \% \mathrm{O}_{2}$ in the flue gas.

Also, while the Utah coal showed definite increases in ultrafine particle concentrations when comparing once through oxy-fired conditions to FGR conditions, the PRB results showed the same trend, but with more scatter in the data resulting in a less smooth PSD curve. Results of a $3 \% \mathrm{O}_{2}$ in the flue gas and a $32 \% \mathrm{O}_{2}$ firing condition comparison between once through, treated, and untreated FGR have been presented in Figure 4.7-33.

\section{PRB}

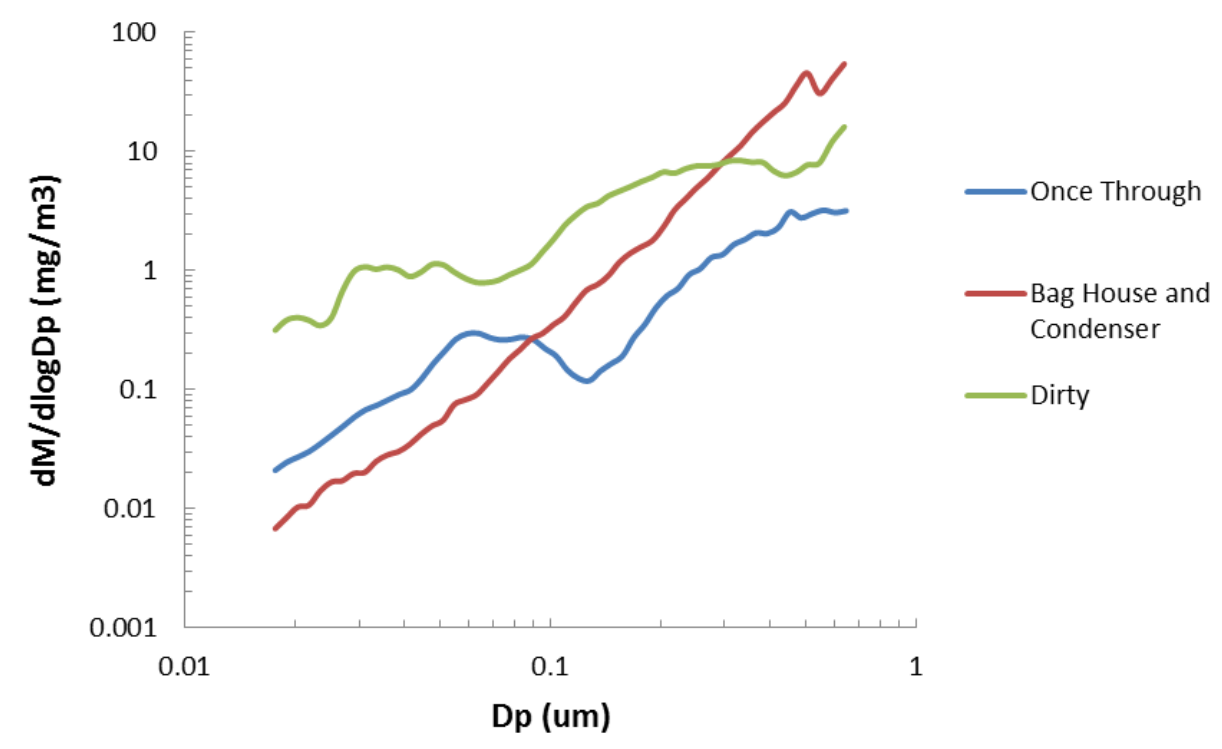

Figure 4.7-33: SMPS comparison of once through OXY32 with corresponding $32 \% \mathrm{O}_{2}$ oxy- fired FGR conditions. 
In addition to the PSDs collected with the SMPS under FGR conditions for comparison with the PSDs collected under a once through condition, data were collected simultaneously with black carbon measurements under air, and once through oxy-fired conditions. An untreated FGR condition was also examined. However due to SMPS malfunction, data could not be collected for the FGR conditions in the time and budget allowed for the project, so data for that condition cannot be presented. All tests were performed with $3 \% \mathrm{O}_{2}$ in the flue gas.

These tests showed that air firing had a higher ultrafine particle concentration than the once through OXY27 condition. Furthermore, the concentration of ultrafine particles in both cases decreased as stoichiometric ratio was increased. Results are shown in Figure 4.7-34.

\section{PRB Integrated SMPS Concentration}

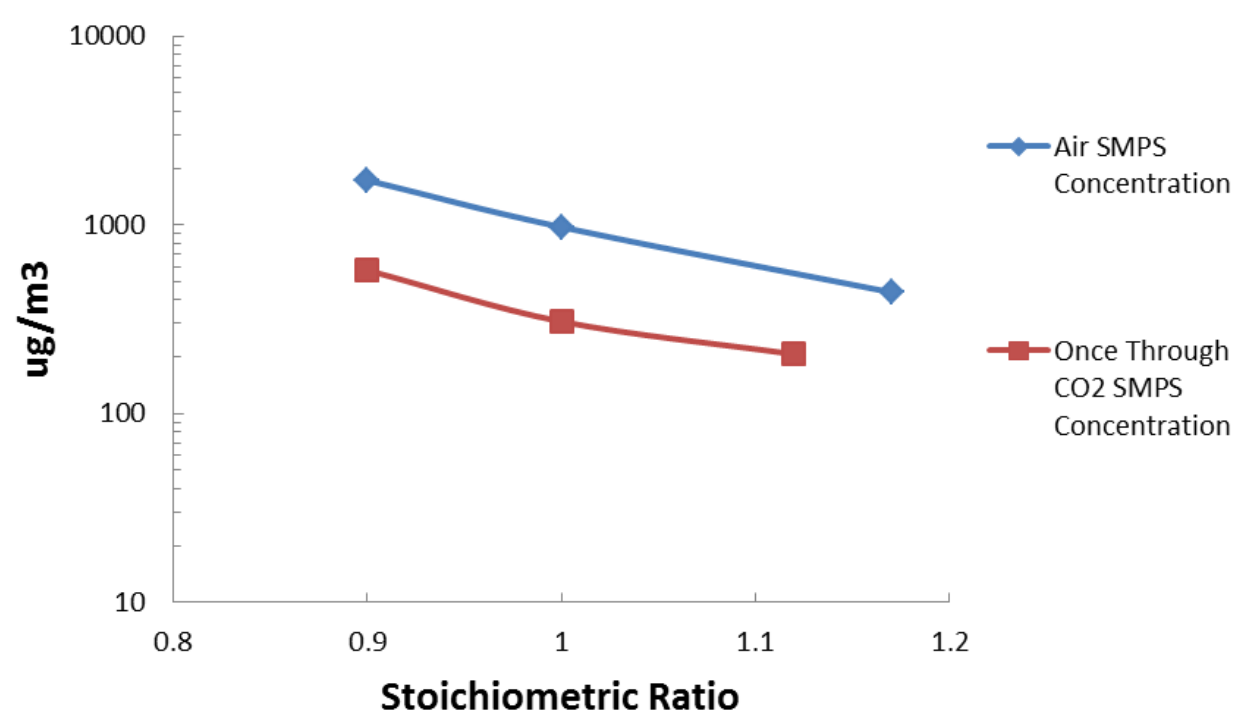

\section{Figure 4.7-34: Measured total concentration of ultrafines by SMPS of air and once through $\mathrm{CO}_{2}$ conditions during the BYU soot tests.}

\subsection{Illinois}

The same tests for the PRB and Utah coal were conducted for the high sulfur bituminous Illinois coal. Due to the high sulfur content of the Illinois coal, collecting PSDs for the untreated FGR cases proved to be difficult to impossible due to the very high $\mathrm{SO}_{2}$ concentrations that built up under recycle conditions. Furthermore, even in the air-fired and once through oxy-fired conditions, due to nearly $4 \%$ total sulfur in the coal, a large amount of sulfuric acid aerosol existed in the ultrafine particle region. This proved to be very corrosive and caused damage to the substrates in the smallest particle stages of the BLPI during each of three replicates. As a result, this excessive acid aerosol during the recycle conditions proved to be very difficult to capture.

The particle size distributions collected with the BLPI for the Illinois coal showed a clear trimodal behavior. However, due to the very high sulfur concentration, the first mode in the submicron range was proportionally very large when compared to the rest of the modes. Also, while there appeared to be very minor differences in the PSDs for air and once through oxy-fired, the FGR conditions actually had lower sub 100nm modes than the air and once through cases while they also had a fourth mode centered 
between 100nm and 1 micron. The behavior above 1 micron for all scenarios though appeared to be quite similar. These observations are clearly illustrated in Figure 4.7-35 and Figure 4.7-36.

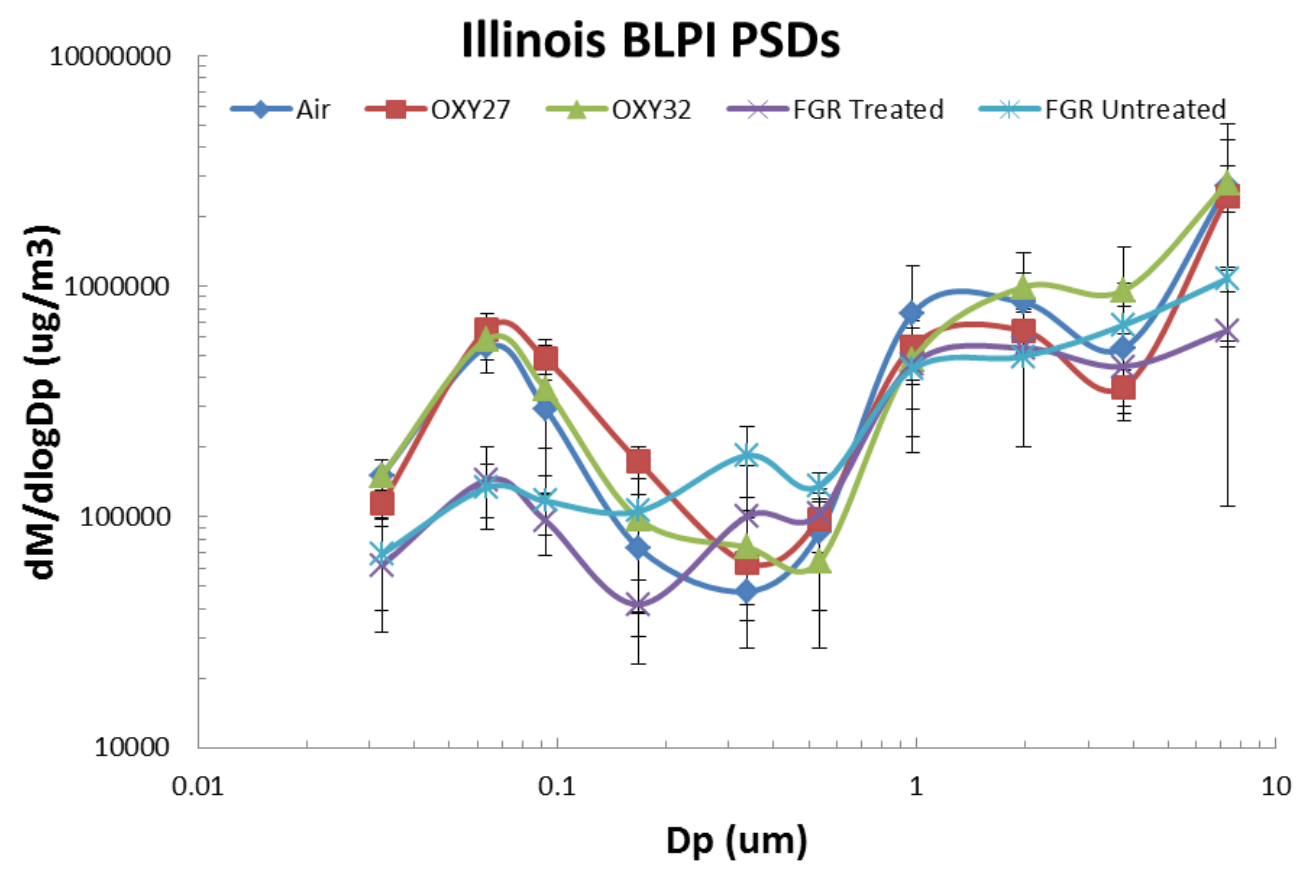

Figure 4.7-35: Particle size distribution collected across air, once through oxy-fired, and flue gas recycled oxy-fired conditions with a BLPI for the Illinois coal.

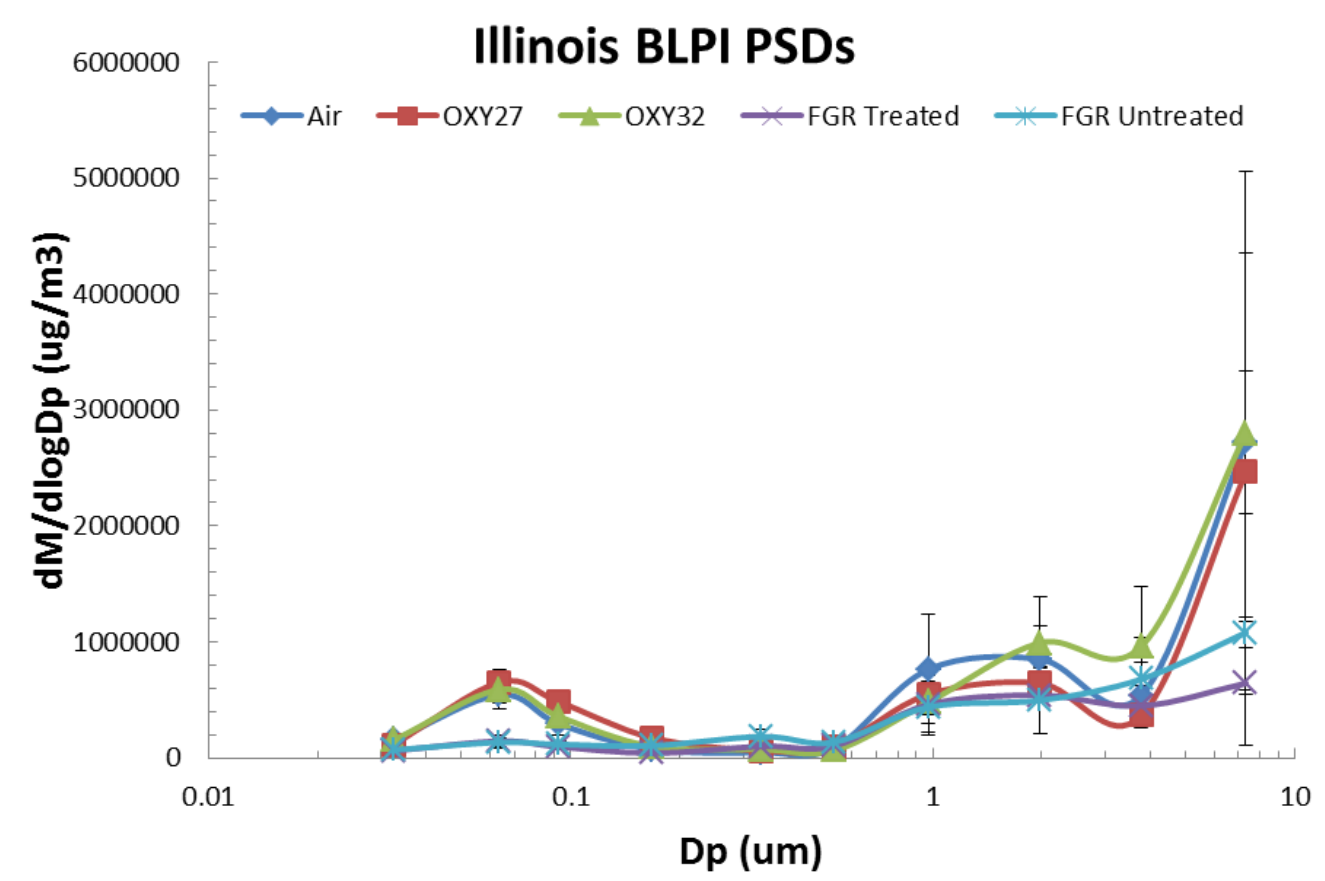

Figure 4.7-36: Semi-log particle size distribution for the Illinois coal. 
In addition to the BLPI comparisons at 3\% $\mathrm{O}_{2}$ in the flue gas, data were also collected with an SMPS and APS. These data were collected at varying stoichiometric ratios with $0 \%, 1 \%, 2 \%$, and $3 \% \mathrm{O}_{2}$ in the flue gas.

The Illinois coal had a very significant sub 100nm mode under air-fired conditions. As with the Utah coal, the Illinois coal's sub 100nm mode decreased as the excess air was decreased. Unlike the Utah coal, the Illinois coal's next mode above $100 \mathrm{~nm}$ did not follow a clear pattern with varying stoichiometry except for the fact that the $100 \mathrm{~nm}-1 \mu \mathrm{m}$ mode at SR 1 was clearly much higher than the other air-fired combustion conditions. Also, the supermicron mode exhibited similar behavior with much greater concentration under SR1 conditions as compared to the excess air-fired conditions shown in Figure 4.7-37.

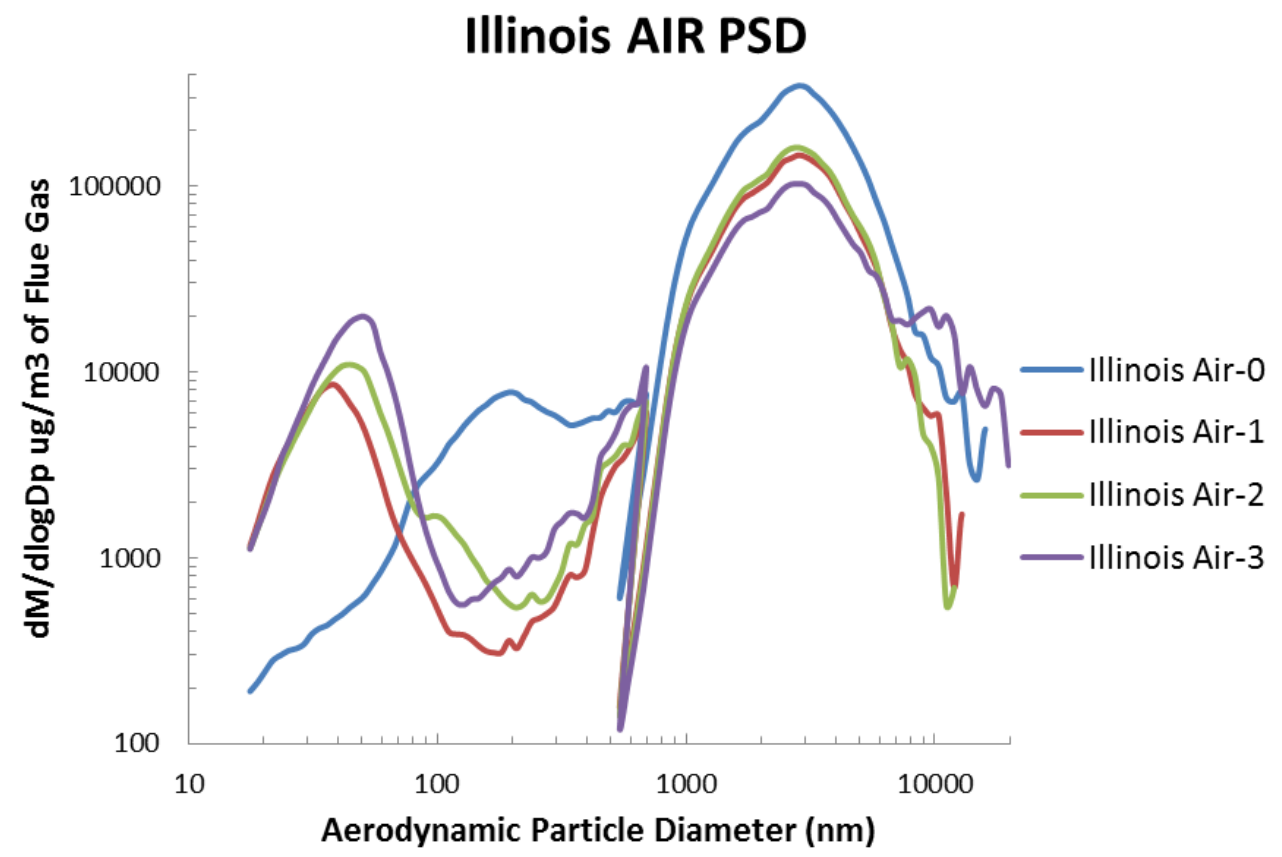

Figure 4.7-37: Illinois air-fired PSDs as measured by SMPS and APS.

Under OXY27 firing conditions, the same trend was observed for the sub 100nm mode, which decreased as the amount of excess oxygen decreased. Also, like the air-fired conditions, the differences in the mode greater than $100 \mathrm{~nm}$ are difficult to characterize and are not smooth curves. In addition, the mesh of the APS and SMPS data near 0.5 microns was not continuous. Unlike the air-fired results, there was not as significant a difference between the sub $100 \mathrm{~nm}$ and super $100 \mathrm{~nm}$ modes at low stoichiometric ratios, and the amount of excess oxygen appeared to have less of an effect on particle size distributions for the OXY 27 case compared to the air-fired cases. The OXY27 data were reported in Figure 4.7-38. 


\section{Illinois OXY 27 PSD}

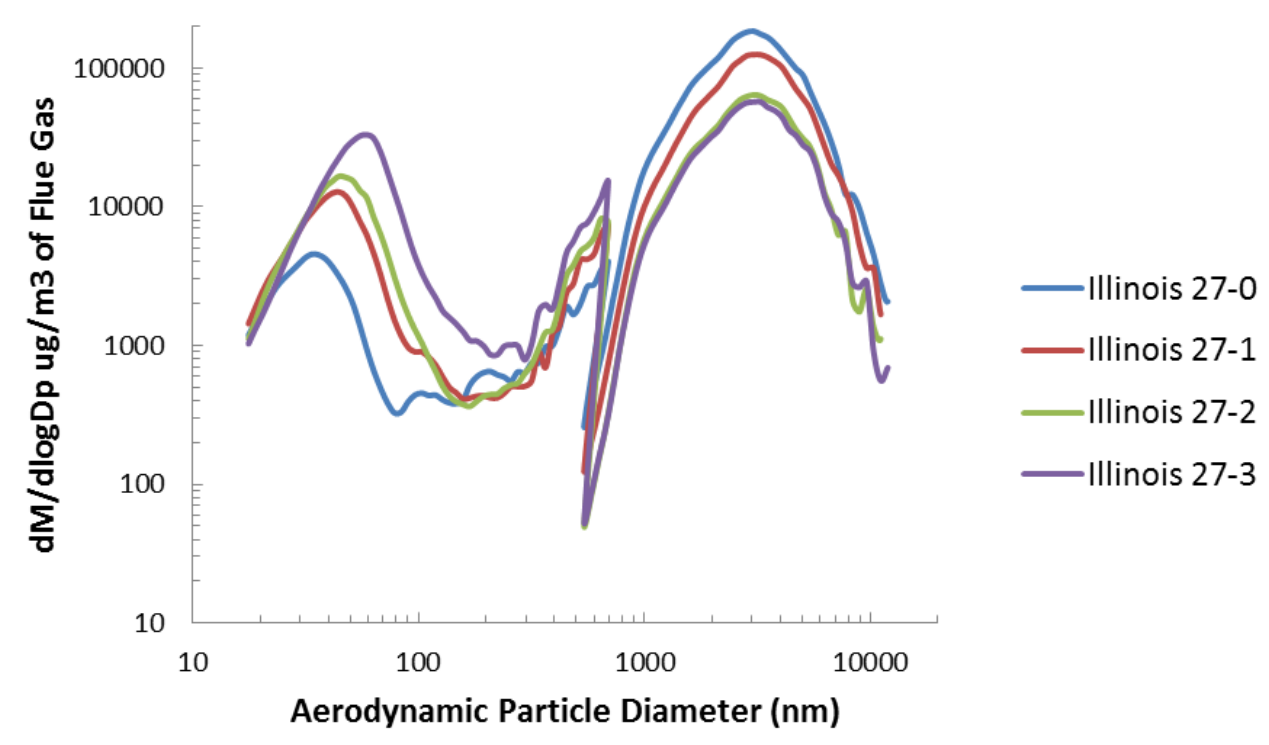

Figure 4.7-38: Illinois PSDs collected by SMPS and APS for once through OXY27 firing condition.

This pattern was also repeated in Figure 4.7-39 which illustrated the OXY32 results. The main exception for the OXY32 PSD results was that at $0 \%$ excess oxygen, the first sub $100 \mathrm{~nm}$ mode disappeared which was similar to the air-fired results. However the super $100 \mathrm{~nm}$ mode at the $0 \% \mathrm{O}_{2}$ level did not greatly increase as was seen in the air-fired case. This mode followed the pattern of the OXY27 case where the trend for the super $100 \mathrm{~nm}$ mode was not as clear. Finally, there were not dramatic changes as the stoichiometric ratios changed under OXY32 conditions.

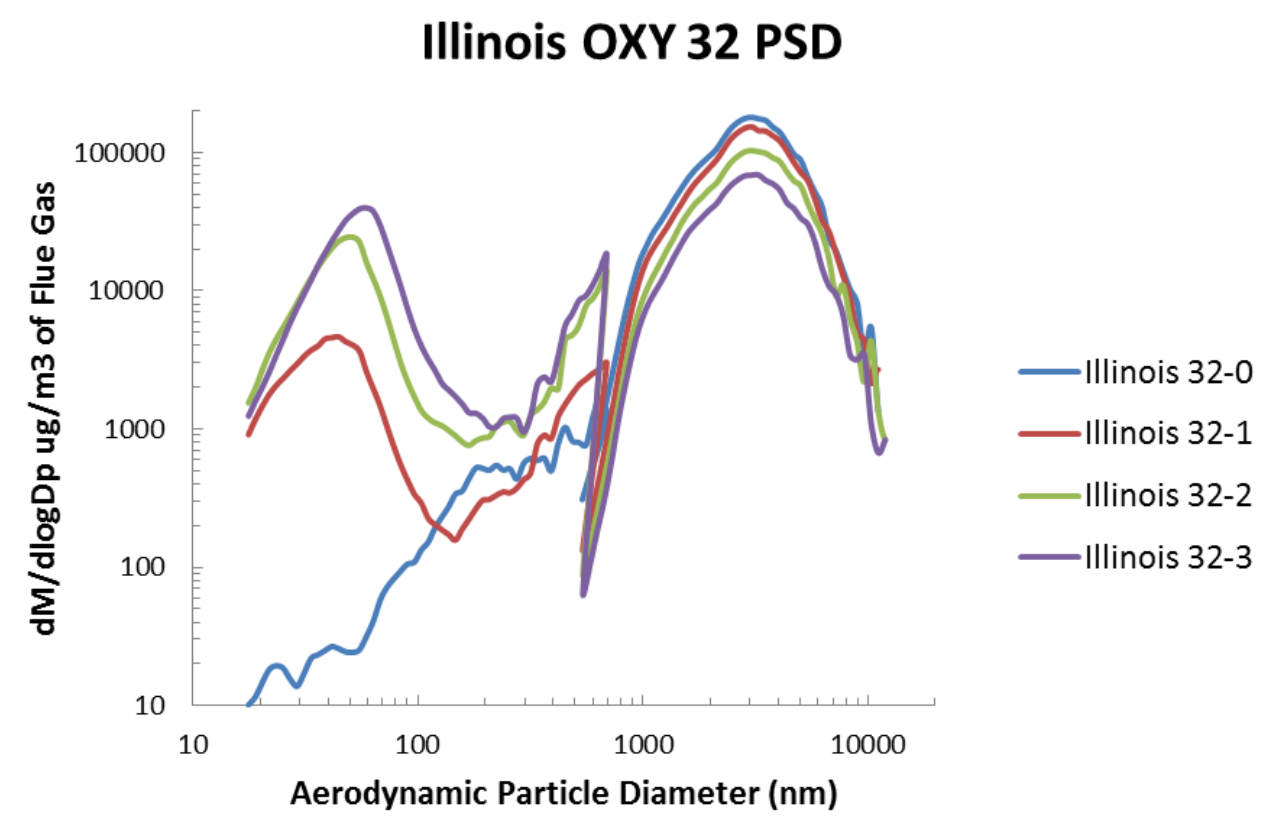

Figure 4.7-39: Illinois PSDs collected by SMPS and APS for once through OXY32 firing condition. 
The particle data for the FGR conditions were very challenging to collect and interpret due to dangerously high levels of $\mathrm{SO}_{2}$ that exceeded 20,000 ppm at times during untreated FGR operation. Particle size distributions were collected at these conditions, though the data were questionable for the untreated FGR condition.

The treated FGR condition PSD was very similar to the equivalent OXY32 3\% $\mathrm{O}_{2}$ in the flue gas combustion scenario. However, the untreated FGR scenario did not have a smooth PSD curve which clearly indicated that proper data collection did not occur in the incredibly acidic flue gas environment. The treated FGR case did have greater concentrations for each mode when compared to the once through cases which was similar behavior to the Utah coal. This comparison was clearly evident in Figure 4.7-40.

Due to the aforementioned difficulty and health hazards of sampling such acidic flue gas, an untreated FGR condition was not examined during the BYU cooperative soot experiments. Rather, an air-fired and once through oxy-fired $27 \% \mathrm{O}_{2}$ case was examined. The SMPS data were collected for the purposes of comparison with the soot data that were collected by the PA. As a result, instead of reporting the PSD, the data were compiled for the total concentration of the ultrafine aerosol in the measurement range of the SMPS.

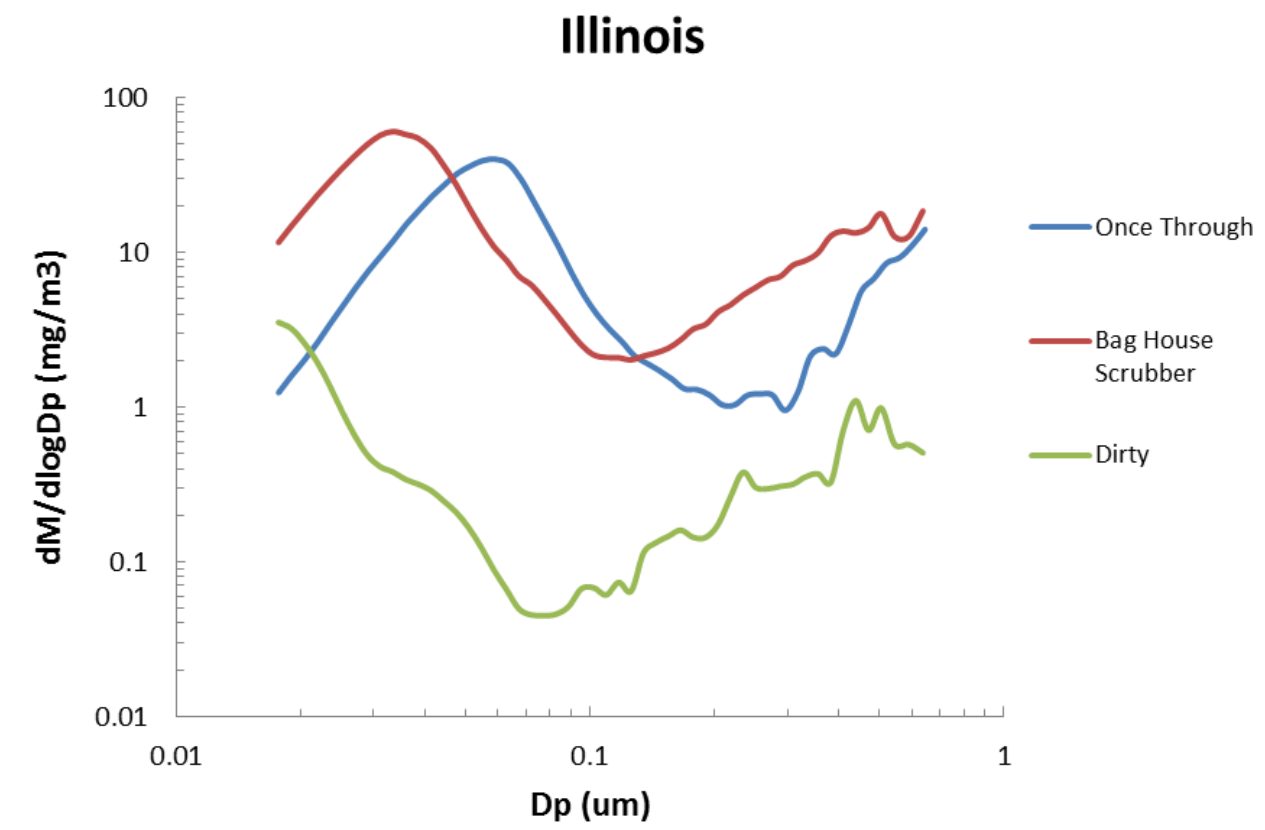

Figure 4.7-40: Comparison of once through OXY32, treated FGR, and untreated FGR ultrafine PSDs by SMPS for the Illinois coal.

The data showed that decreasing the stoichiometric ratio clearly increased the total concentration of ultrafine aerosols. Furthermore, the air-fired results tended to be of higher concentration than the once through OXY27 results. The only exception appeared to be at $3 \% \mathrm{O}_{2}$ in the flue gas which occurred at different stoichiometric ratios due to the difference in the oxygen concentration of the combustion atmosphere. At these conditions, the concentration of ultrafine particles seemed to be equivalent, which was unlike the PRB or Utah results. The concentrations have been plotted in Figure 4.7-41. 


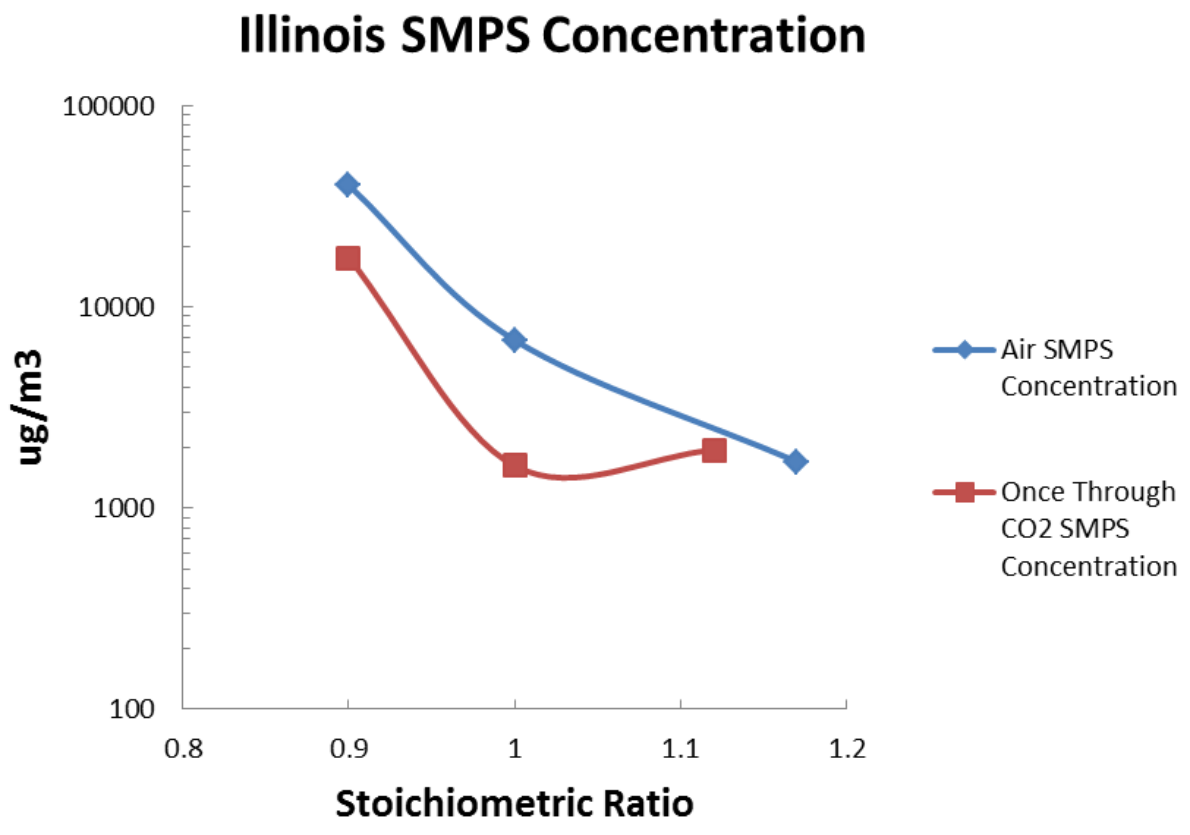

Figure 4.7-41: Total ultrafine concentration by SMPS for air and OXY27 combustion at $3 \% \mathrm{O}_{2}$ in the flue gas for the Illinois coal during cooperative BYU soot experiments.

\subsection{Effect of Coal Composition on Particle Size Distribution}

Coal composition as well as combustion condition could play an important role in the formation of aerosols and their subsequent particle size distribution. The chemical composition of the three coals examined was considerably different. The bituminous coals were of the same rank, but the Illinois coal had much higher sulfur content and a different ash composition. The PRB was a lower rank, very low sulfur coal with much different ash characteristics.

It was therefore useful to see how the differences in coal composition affected the particle size distributions and whether the coals were affected equally as the combustion environment changed from conventional air-fired to once through oxy-fired and oxy-fired with flue gas recycle.

Results for all three coal ash aerosols collected with the BLPI have been presented in Figure 4.7-42. The Illinois had a dramatic ultrafine peak shown below 100nm with the Utah coal's corresponding ultrafine peak considerably smaller in magnitude. Above one micron all three coals showed similar particle distributions, but interestingly the particle mass for the PRB coal seemed to be relatively evenly distributed but still consisted of a multimodal distribution. The bituminous coals had a much greater difference in concentration for the supermicron and submicron particles by comparison.

These trends were also illustrated in the once through OXY32 case for all three coals. No significant differences were observed in the PSDs for the coals when switching from air-fired to the once through oxy-fired condition, and the relative ordering of the coals' PSDs did not change as a result of the change in combustion condition. The comparison of the PSDs for the once through oxy-fired conditions have been plotted in Figure 4.7-43. 


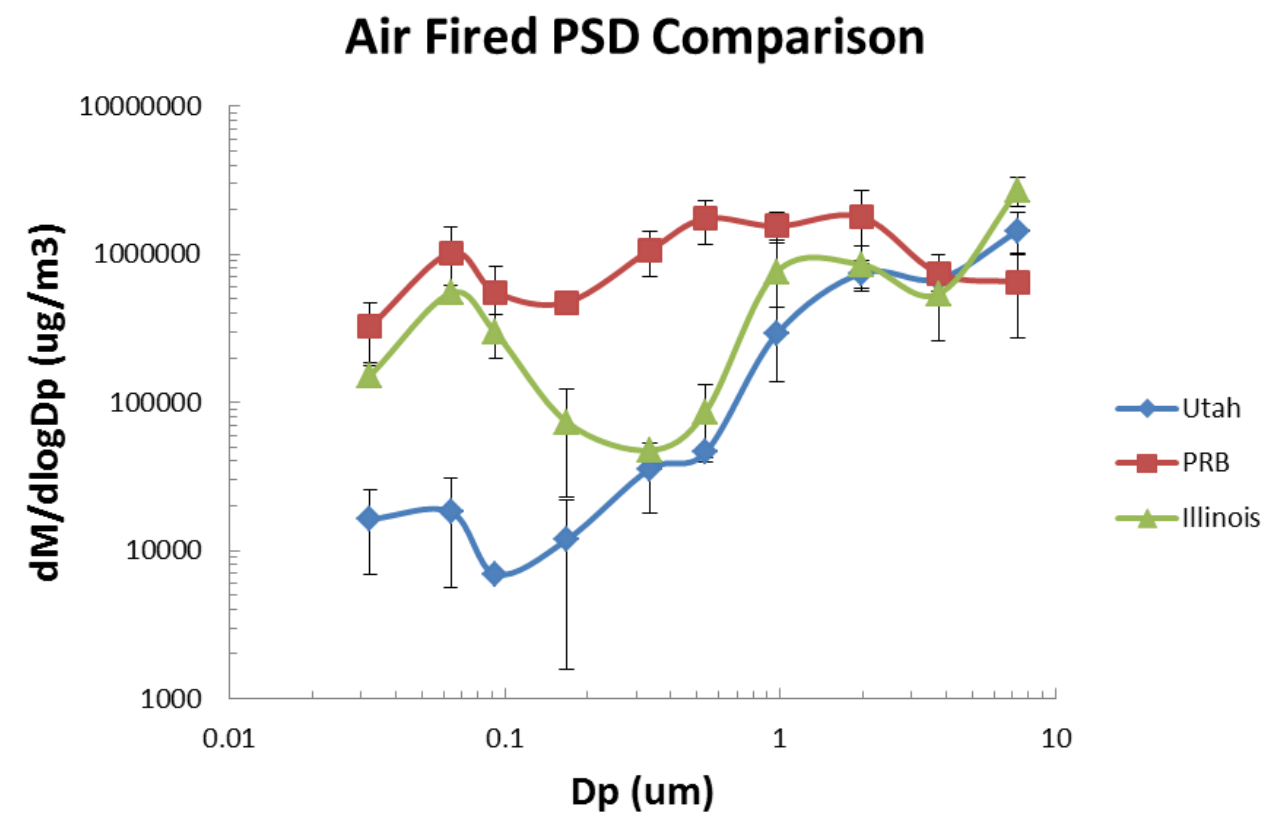

Figure 4.7-42: A comparison of the air-fired particle size distributions as collected by the BLPI for the Utah, PRB, and Illinois coals.

\section{OXY32 PSD Comparison}

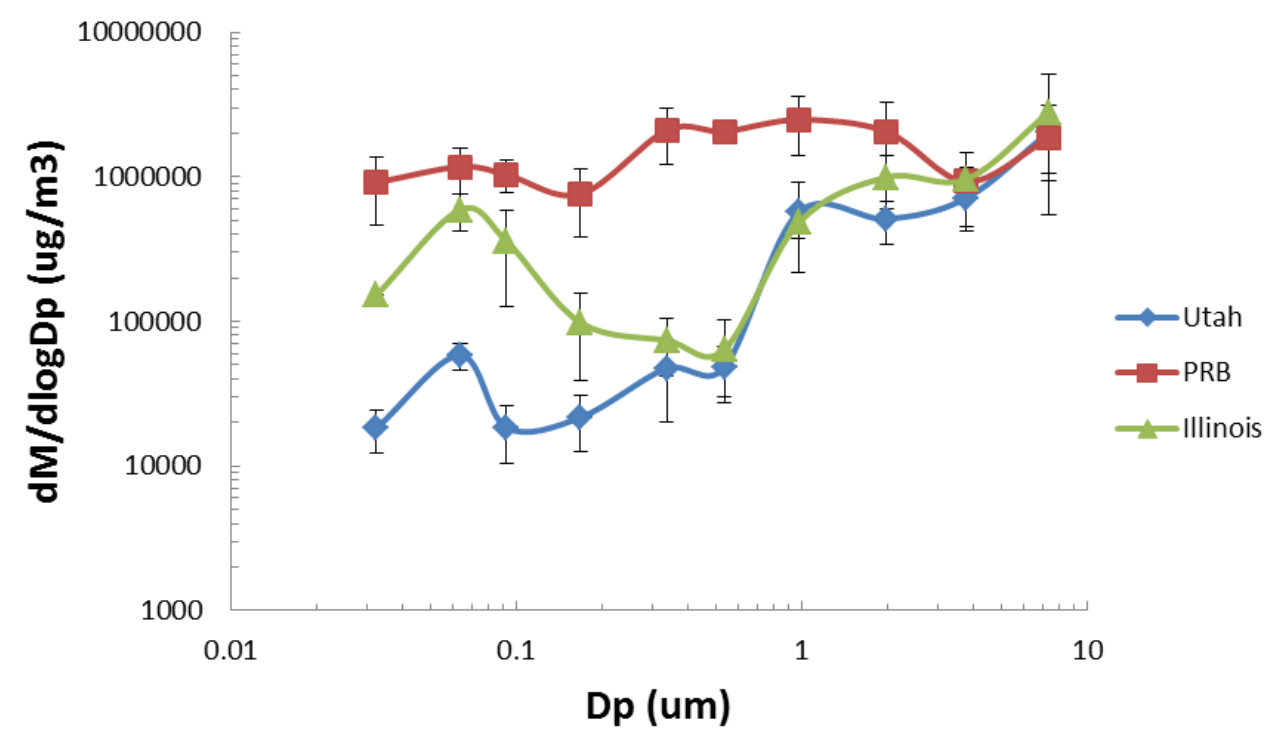

Figure 4.7-43: A comparison of the once through OXY32 fired particle size distributions as collected by the BLPI for the Utah, PRB, and Illinois coals.

There were some differences noted with the BLPI PSDs under the untreated FGR condition. Under this condition, the Illinois coal no longer had as prominent an ultrafine sub $100 \mathrm{~nm}$ peak. Also, there was a greater spread in the supermicron range of the PSDs. In the air and once through oxy-fired conditions, 
there were only minor differences in particle concentrations for the supermicron particles among the three different coals. Under the untreated FGR conditions, the PRB had the highest concentration of supermicron particles followed by the Illinois and then Utah coals.

Also, the PSDs were much flatter without as sharply defined modes for the bituminous coals under the recycled flue gas condition. The differences in modal behavior between the coals was less under the untreated condition than the air and once-through conditions. Less of a difference in the submicron concentration of the PRB coal versus the bituminous coals was evident in Figure 4.7-44.

\section{Untreated FGR PSD Comparison}

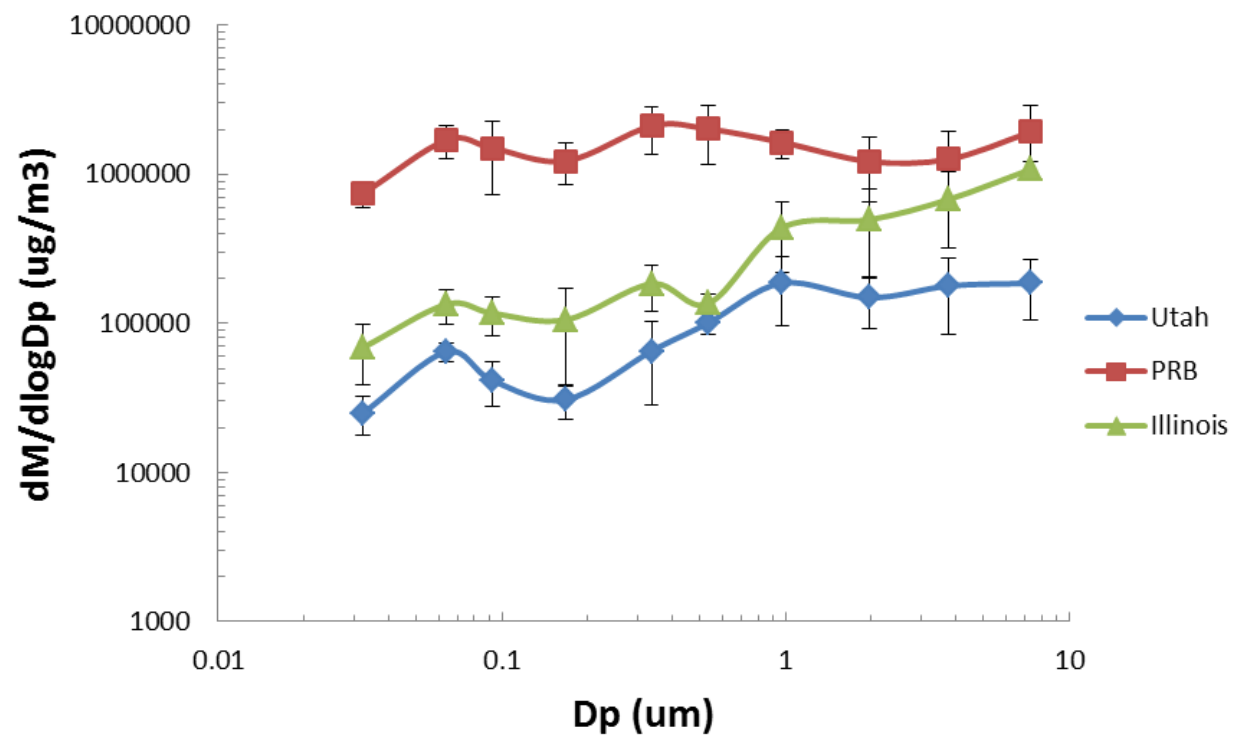

Figure 4.7-44: A comparison of the untreated FGR $32 \% \mathrm{O}_{2}$ fired particle size distributions as collected by the BLPI for the Utah, PRB, and Illinois coals.

When comparing the ultrafine PSDs by SMPS, the PRB ultrafine concentrations are no longer the greatest in magnitude. However, under air-fired conditions, the same relationship exists for the Utah Skyline and Illinois bituminous coals. The Illinois coal still has a much greater ultrafine concentration than the Utah coal with a far more prominent sub 100nm mode. These results have been reported in Figure 4.7-45.

The same relationships were also observed when comparing SMPS data across the coals under once through oxy-firing at $32 \% \mathrm{O}_{2}$. There was less of a difference between the coal PSDs at the upper limit of the instrument under the oxy-fired condition than the air-fired condition. Also, the PRB distribution was similar to the Utah and Illinois coals when the SMPS data for oxy-firing was examined. This was not the case when the samples were collected with the BLPI. The comparison of the coals under the OXY32 condition has been plotted in Figure 4.7-46. 


\section{Air Fired Coal Comparison}

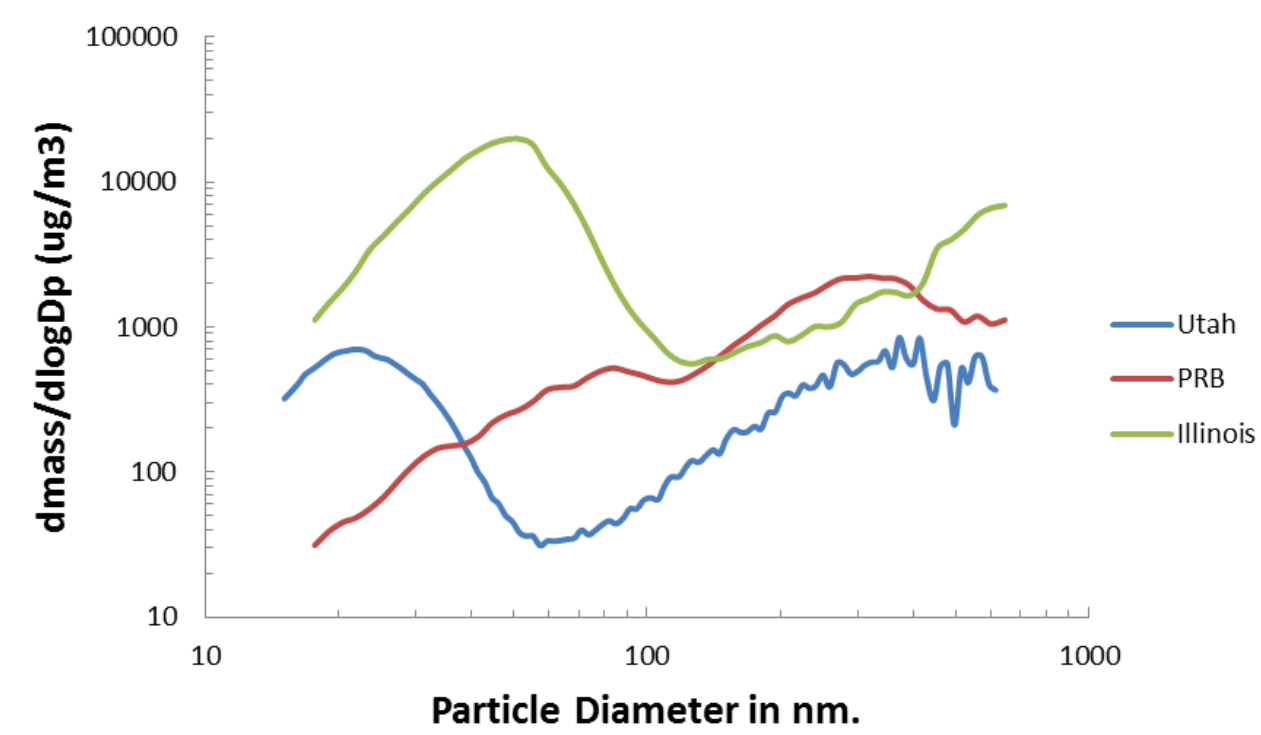

Figure 4.7-45: A comparison of SMPS ultrafine particle distribution at the air-fired condition for the Utah, PRB, and Illinois coals.

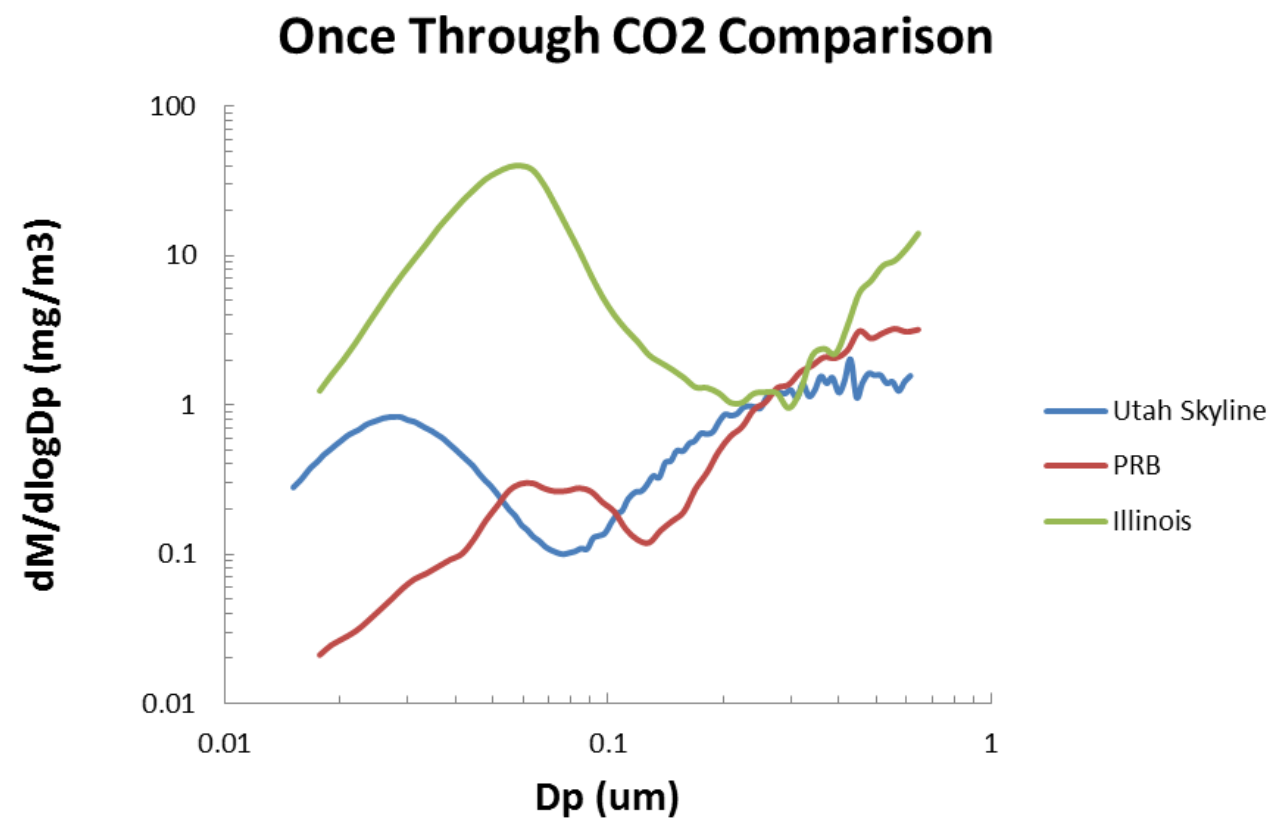

Figure 4.7-46: A comparison of SMPS ultrafine particle distribution at the once through OXY32 condition for the Utah, PRB, and Illinois coals.

For the recycled flue gas conditions, shown in Figure 4.7-47, there was not much difference in the coal comparison between the treated FGR data and the once through OXY32 data. A significant difference in the relative distributions was observed in the untreated FGR conditions. The untreated FGR comparison 
showed that the Utah coal had the highest ultrafine concentrations followed by the PRB and then the Illinois. The treated FGR case was significantly different. The Utah coal was the highest concentration with PRB in the middle and the Illinois coal being the lowest. It should be noted that there were issues sampling the high sulfur Illinois flue gas during the untreated conditions reported in Figure 4.7-48 as discussed previously.

FGR w/ treatment

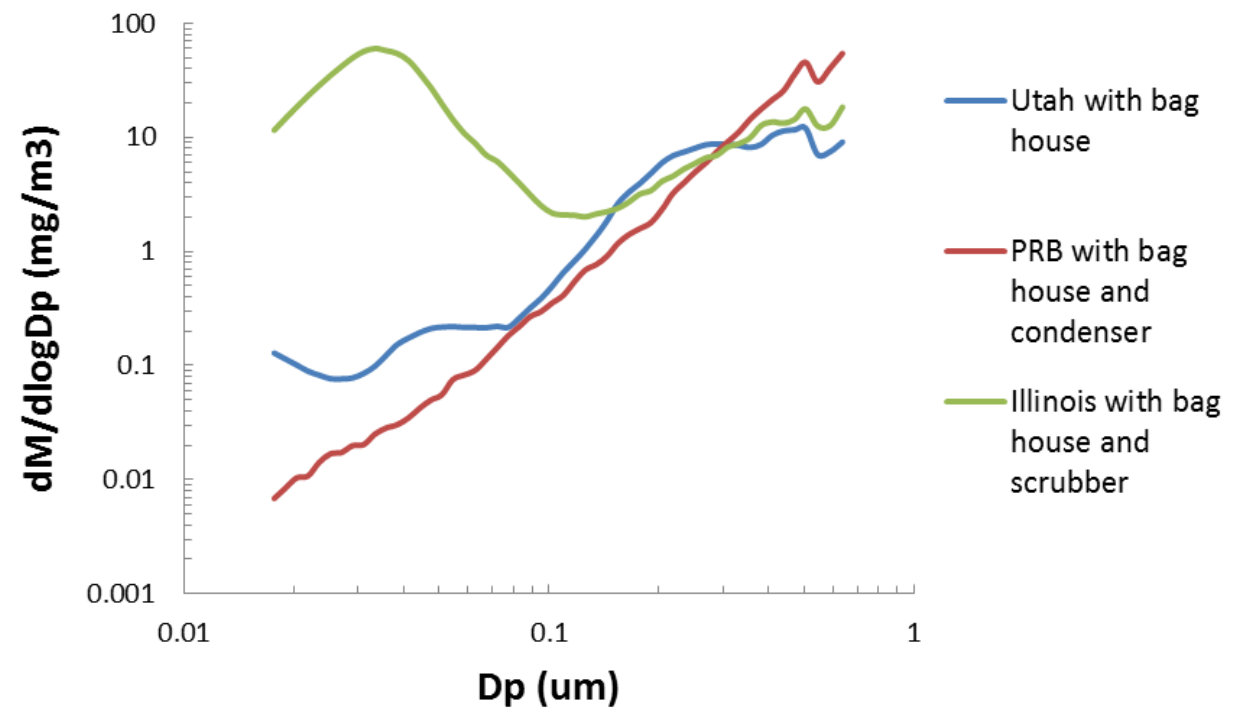

Figure 4.7-47: A comparison of SMPS ultrafine particle distribution at the treated FGR condition at $32 \% \mathrm{O}_{2}$ for the Utah, PRB, and Illinois coals.

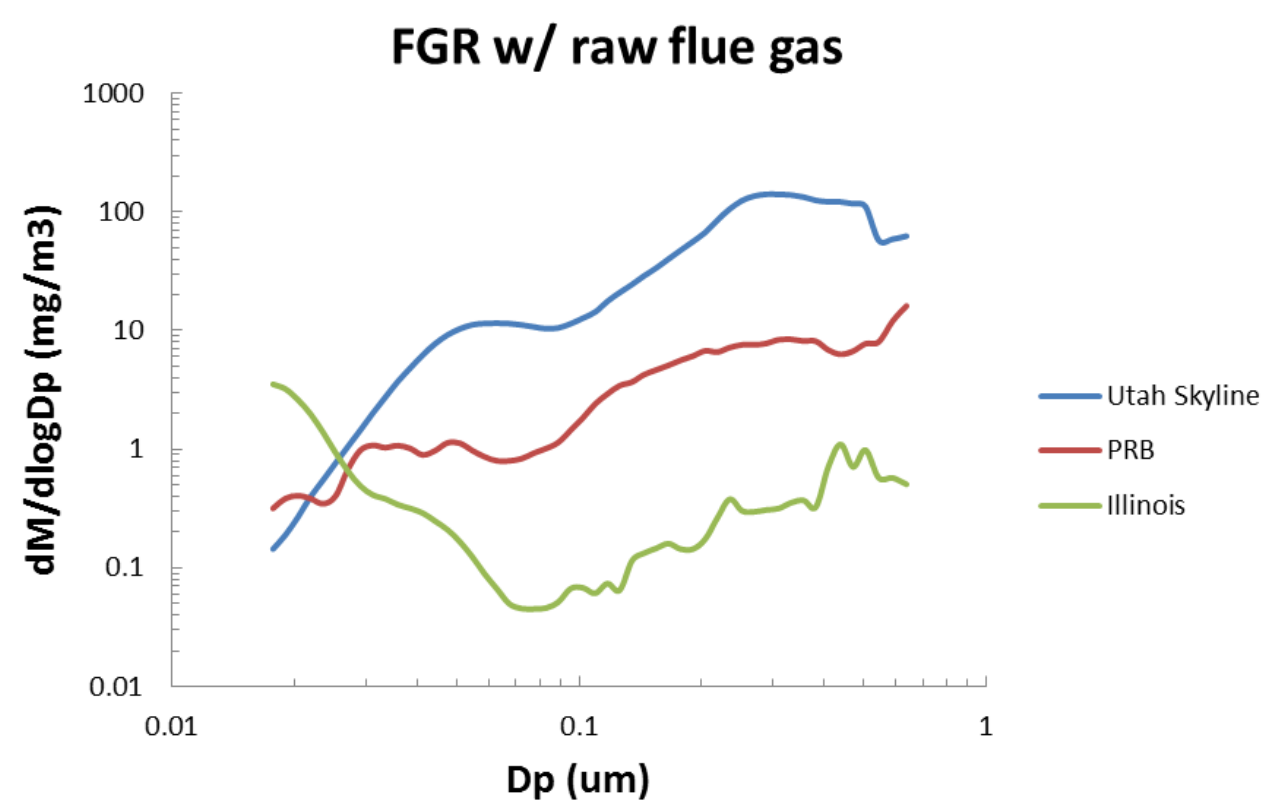

Figure 4.7-48: A comparison of SMPS ultrafine particle distribution at the untreated FGR condition at $32 \% \mathrm{O}_{2}$ for the Utah, PRB, and Illinois coals. 
The comparison of the total ultrafine particle concentrations by SMPS of the coals across a wide range of stoichiometric ratios has been plotted in Figure 4.7-49. The trend of the Illinois coal having higher concentrations than the Utah coal was observed. However the PRB total concentration oddly was less than the bituminous coals. The same trend was illustrated for the OXY27 SMPS total concentrations in Figure 4.7-50. For the once through condition, the Illinois had greater ultrafine concentrations than the Utah coal which was similar to the PRB concentrations at higher stoichiometric ratios.

\section{Air Fired Concentration Comparison}

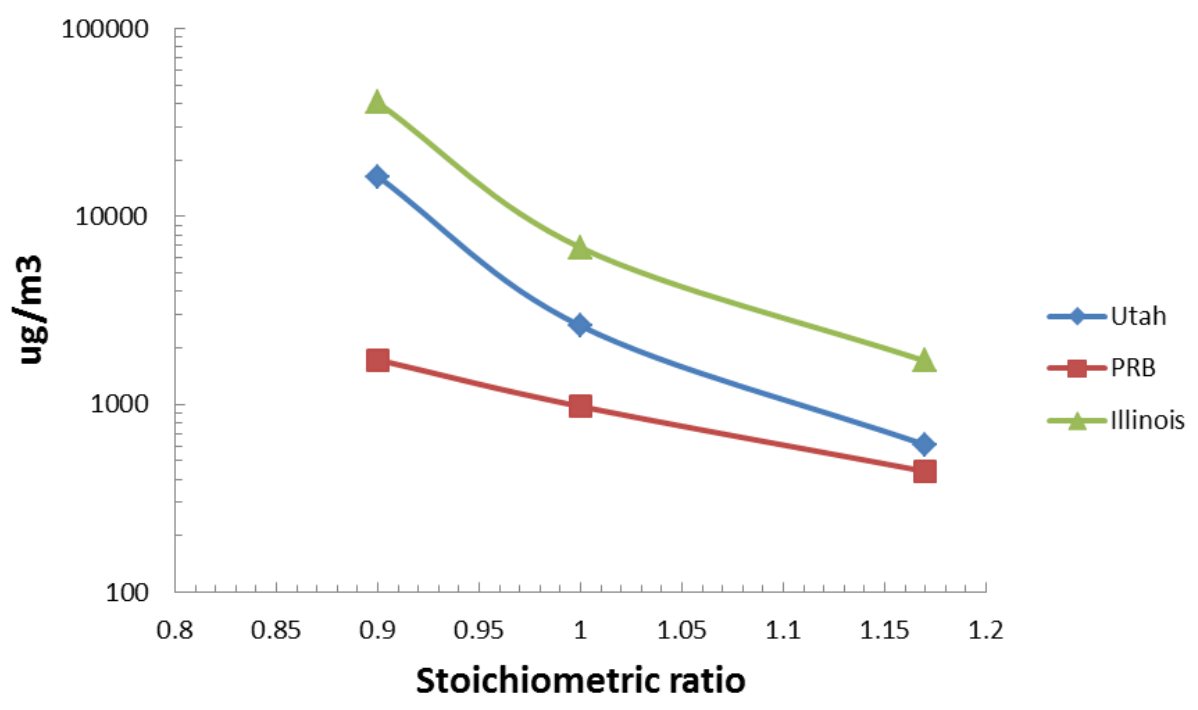

Figure 4.7-49: Comparison of total particle concentration versus stoichiometric ratio measured by SMPS under air-fired conditions for the Utah, PRB, and Illinois coals.

\section{OXY27 Concentration Comparison}

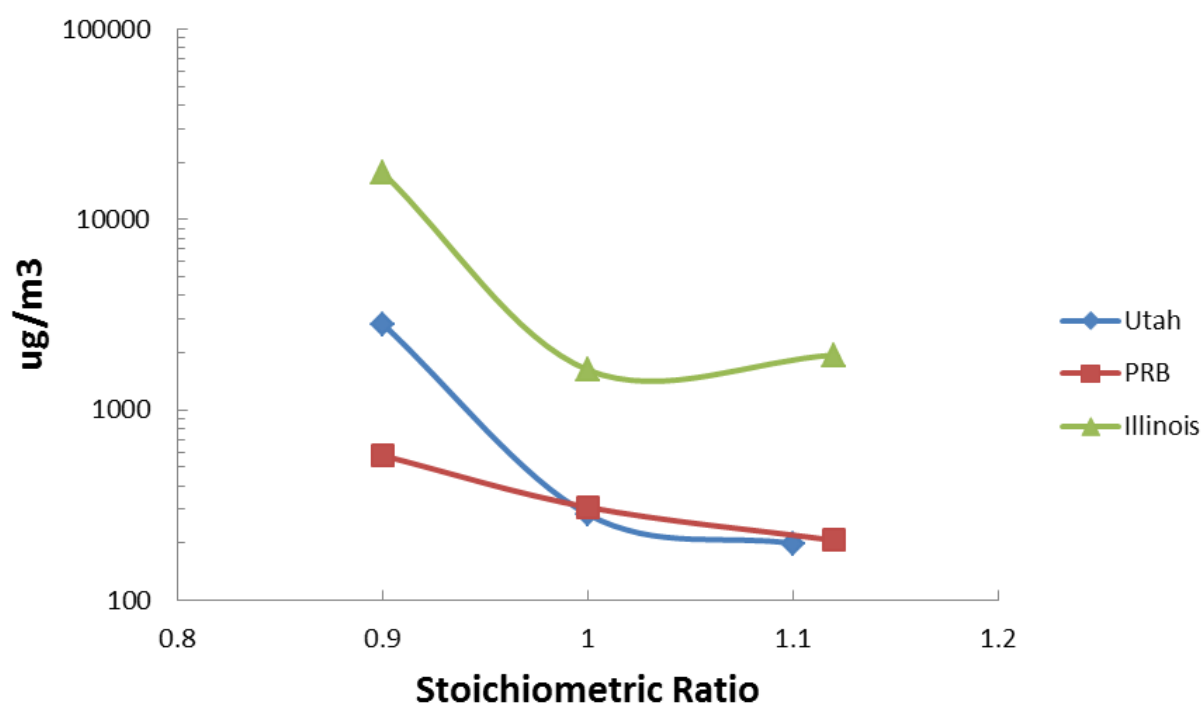

Figure 4.7-50: Comparison of total particle concentration versus stoichiometric ratio measured by SMPS under OXY27 conditions for the Utah, PRB, and Illinois coals. 


\subsubsection{Size Segregated Ash Chemistry}

The size segregated ash chemistry provided information regarding how elements partition through the three particle modes of ultrafine, fine fragmentation, and coarse modes. It was not known how, or if, a change in combustion environment would affect the partitioning of the mineral matter and whether it would affect coals of different type equally. For this reason, size segregated ash samples were collected with a BLPI and then subjected to EDS and ICP-MS analysis for chemical composition. The results have been presented with both EDS data, which were used to analyze 1 micron and larger particles, and with the ICP-MS data which were used to analyze the 1 micron and smaller particles so there are two data points for the one micron particle diameter where the two analytical methods merged. Due to budget constraints, only one replicate could be analyzed for each combustion case. However two sets of samples were collected.

Results were reported for major ash components for each coal. All combustion conditions were compared so that difference between air, once through oxy-fired, and FGR oxy-fired could be observed. Furthermore, elements were assumed and reported as oxides. While other species certainly exist, a basis for comparison had to be selected to examine results between coals, combustion conditions, and size ranges. Finally, all combustion conditions analyzed occurred at $3 \% \mathrm{O}_{2}$ in the flue gas on a dry basis and on a $\mu \mathrm{g}$ of element per gram of coal combusted basis rather than the traditional mass $/ \mathrm{m}^{3}$ basis so that results were not skewed by the differences in flue gas volumes of the different combustion conditions. Calculations regarding how to transfer from the mass collected on the impactor plate to $\mu \mathrm{g} / \mathrm{g}$ coal basis are shown in Appendix A.

\subsection{Utah Skyline}

The first element reported was sodium for the Utah coal, which is important for fouling and deposition because it is easily vaporized and can condense on boiler tubes which would create a sticky surface for particles to accumulate. In the case of the Utah bituminous coal, a submicron mode of sodium appears greater in the once through oxy cases than the air-fired cases, while the air-fired case had one data point in the ultrafines indicating a significantly higher concentration than the oxy-fired cases. Also the once through and air-fired cases appeared to have a higher concentration of fine and ultrafine sodium than the recycled conditions. This corresponded to a greater concentration of sodium in the larger supermicron mode for air-fired and once through oxy-fired combustion as opposed to FGR oxy-fired conditions.

The untreated FGR condition appeared to have an increasing sodium concentration at less than one micron particle diameter, but then suddenly dropped below the detectable limits of the instrument. In addition, the once through oxy-fired cases showed very little difference between the $27 \%$ and $32 \% \mathrm{O}_{2}$ concentrations as both PSDs for the once through conditions tracked each other closely. The results for all combustion conditions for sodium were plotted in Figure 4.7-51.

The results for magnesium have been plotted in Figure 4.7-52. As with sodium, the magnesium concentrations in the submicron range appeared greater for the air and once through oxy-fired conditions than the FGR conditions. The air and once through oxy-fired concentration appeared higher for the supermicron range as well.

As with sodium, the magnesium concentrations were similar between the two once through oxy-fired conditions. However the oxy-fired conditions displayed a more prominent mode less than one micron in diameter, while the air-fired condition was a smoother curve without a sharply peaked mode. Finally, the untreated flue gas recycle condition had similar issues where the ultrafine particles tended to be below the detectable limits of the instrument. 


\section{Utah $\mathrm{Na}_{2} \mathrm{O}$}

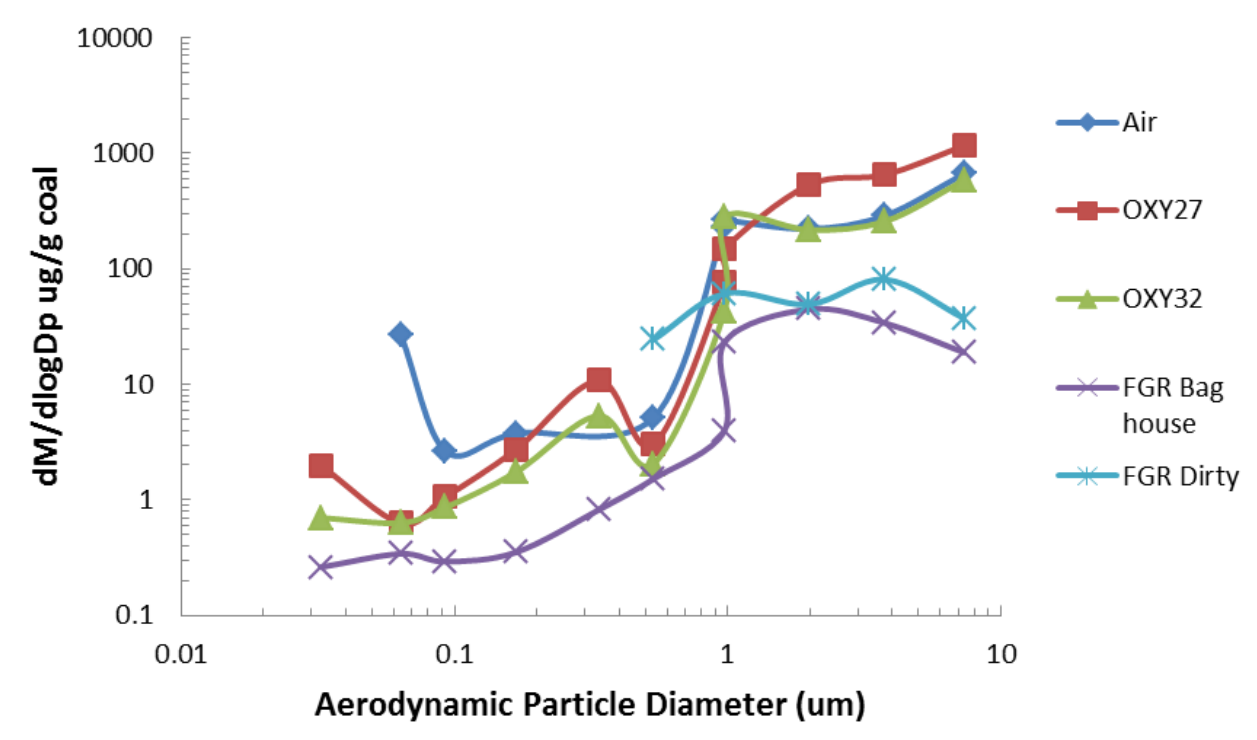

Figure 4.7-51: Sodium oxide aerosol comparison of Utah coal fired experiments.

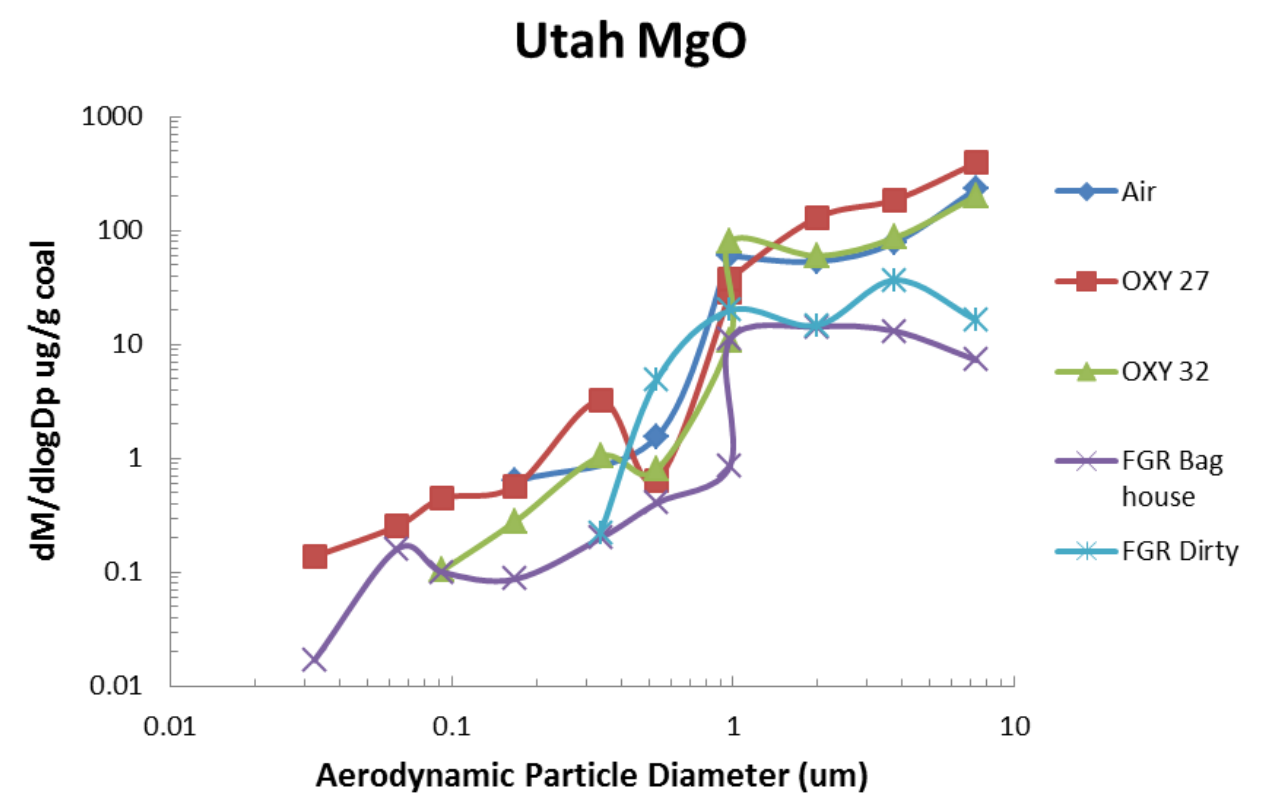

Figure 4.7-52: Magnesium oxide aerosol comparison of Utah coal fired experiments.

The aluminum results in Figure 4.7-53 also showed a unique submicron mode that was present in the untreated FGR condition, but was not observed in the air-fired conditions and was observed at smaller particle diameters for the once through oxy-fired conditions. The sharp submicron peak was absent in the treated FGR condition while the two once through conditions tracked each other very closely once again. 
In general, the air-fired and once through oxy-fired conditions produced a greater concentration of aluminum in the large supermicron range compared to the FGR conditions. Unlike sodium and magnesium, the aluminum did not appear as washed out in the untreated FGR case. The untreated flue gas recycle condition in this case actually had a noticeably higher concentration in the submicron mode peak than the other conditions.

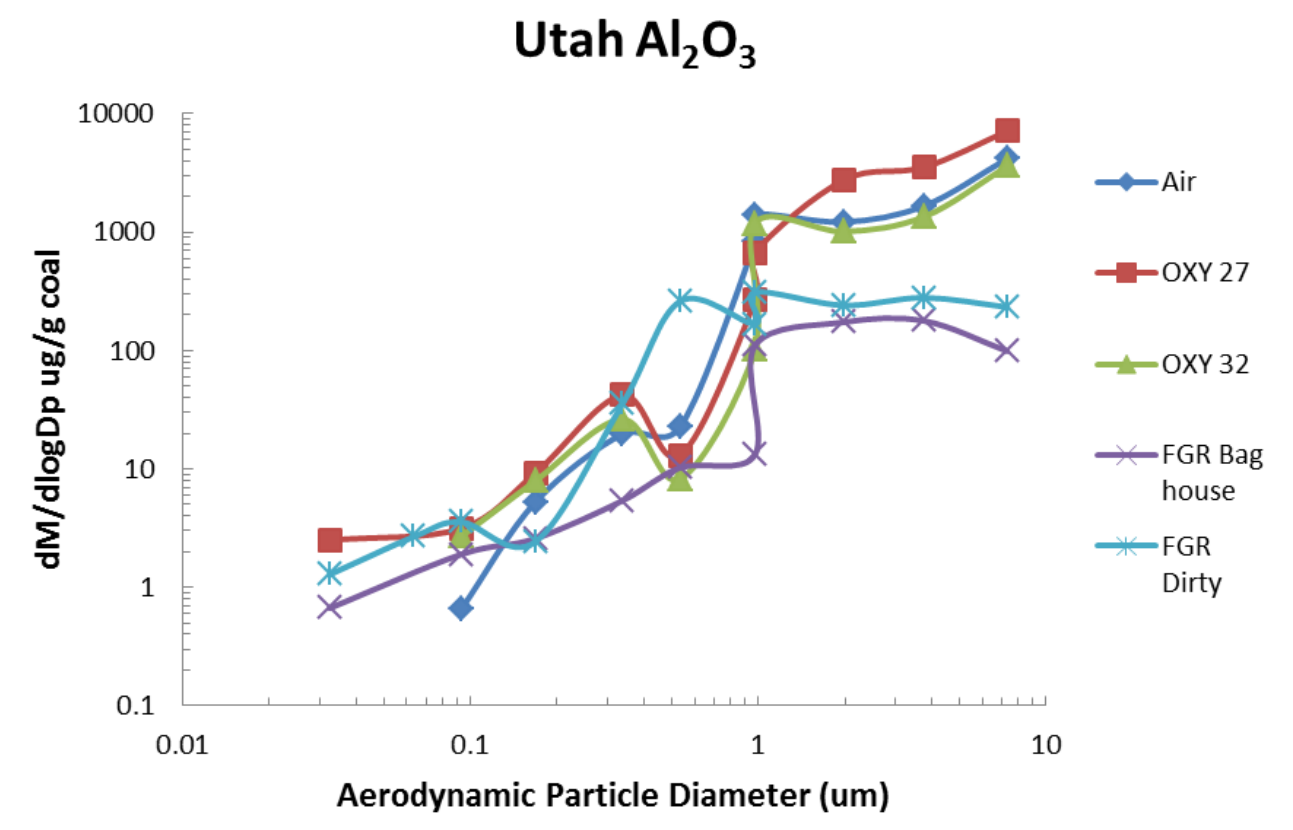

Figure 4.7-53: Aluminum oxide aerosol comparison for Utah coal fired experiments.

Silicon was a very difficult element to measure accurately due to the need to digest the samples with HF. However over digestion with $\mathrm{HF}$ created $\mathrm{SiF}_{3}$ and $\mathrm{SiF}_{4}$, which were volatile species and could evaporate during the high temperature acid digestion process leading to under reporting of silicon.

The results for silicon once again showed very similar behavior between the two once through oxy-fired conditions and the air-fired condition, but there was more scatter with the FGR conditions and large discontinuities at the one micron merge points for the ICP-MS and EDS data for the untreated FGR condition.

For the once through oxy-fired conditions, it was possible to see that there was a greater submicron concentration of silicon for the oxy-fired conditions compared to the air-fired condition. However, the air-fired condition had a similar concentration of super micron silicon as was observed for the once through oxy-fired conditions. The untreated FGR condition had lower supermicron concentrations than both the air and once through oxy-fired concentrations. The silicon results were plotted in Figure 4.7-54.

The phosphorus partitioning also exhibited the same general trend of greater concentrations in the submicron range for once through oxy-fired conditions as opposed to the air-fired condition. The air-fired condition and the once through oxy-fired conditions had higher concentrations of phosphorus in the submicron particles than the FGR conditions.

The once through oxy-fired conditions were very similar to each other with little difference observed between OXY27 and OXY32. The differences between the untreated FGR conditions were greater. 


\section{Utah $\mathrm{SiO}_{2}$}

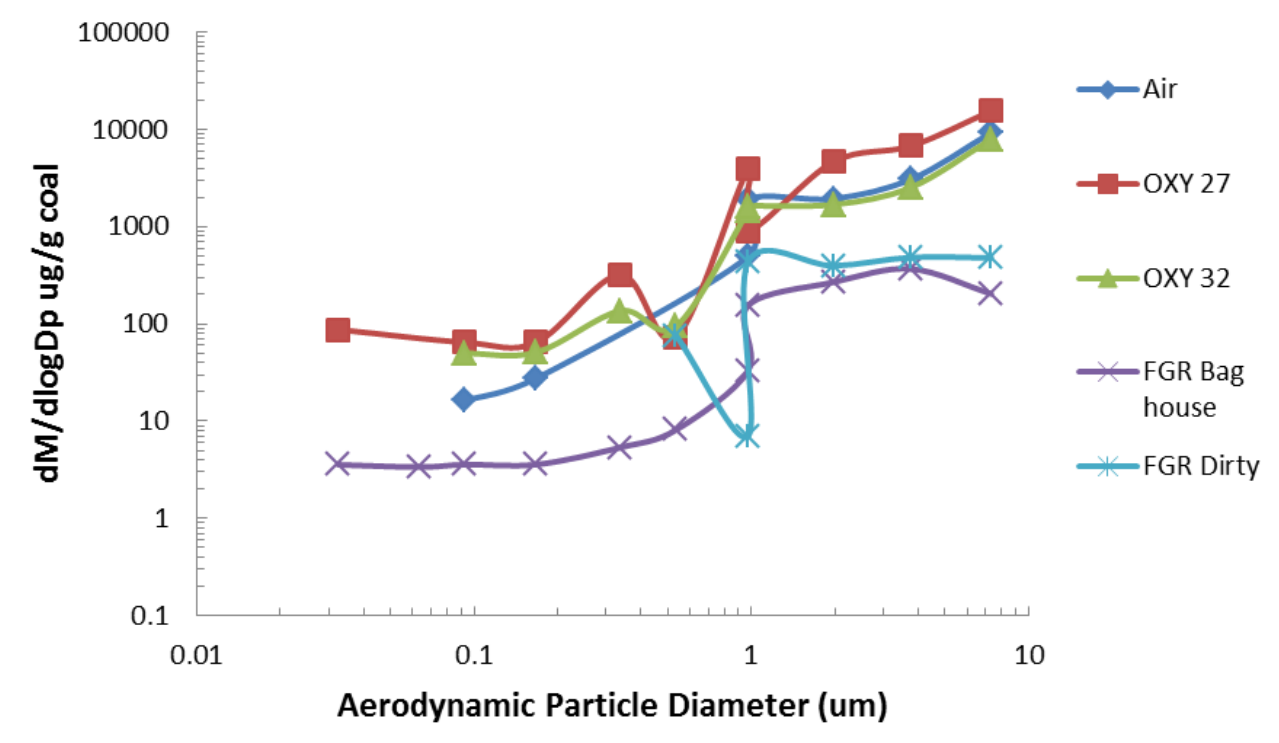

Figure 4.7-54: Silicon oxide aerosol comparison for Utah coal fired experiments.

The most notable of these trends is that once again, a very sharp and distinct sub-micron peak was present in the submicron range for untreated FGR condition that was not present in the air-fired phosphorus distribution. These results were plotted in Figure 4.7-55.

The potassium distribution for the Utah coal also continued the trend observed with the Utah coal of having greater similarity between the oxy-fired and air-fired conditions than the FGR conditions. As a result, under the air, OXY27, and OXY32 fired conditions, there was a greater concentration of potassium in the supermicron range than the FGR conditions. 


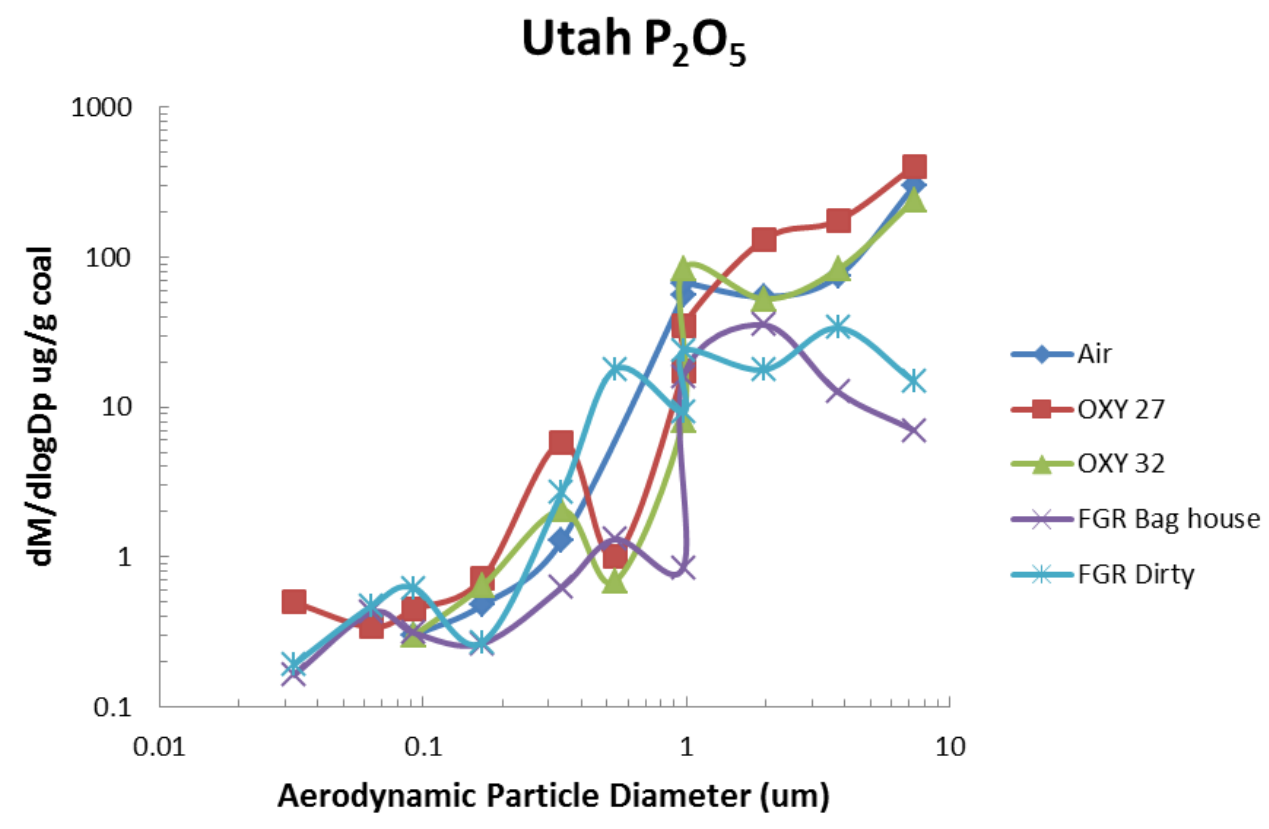

Figure 4.7-55: Phosphorus oxide aerosol comparison of Utah coal fired experiments.

While differences were noticeable in the distribution of potassium between the OXY27 and OXY32 cases, overall they were still closely matched distributions for potassium. Also, the FGR oxy-fired results showed smaller submicron concentrations than the once through oxy-fired and air cases. Finally, at the smaller particle diameters for each case, the mass of potassium was often insufficient to achieve a detectable result with the ICP-MS, and thus data were not able to be plotted in the smaller particle diameter range as shown in Figure 4.7-56.

\section{Utah $\mathrm{K}_{2} \mathrm{O}$}

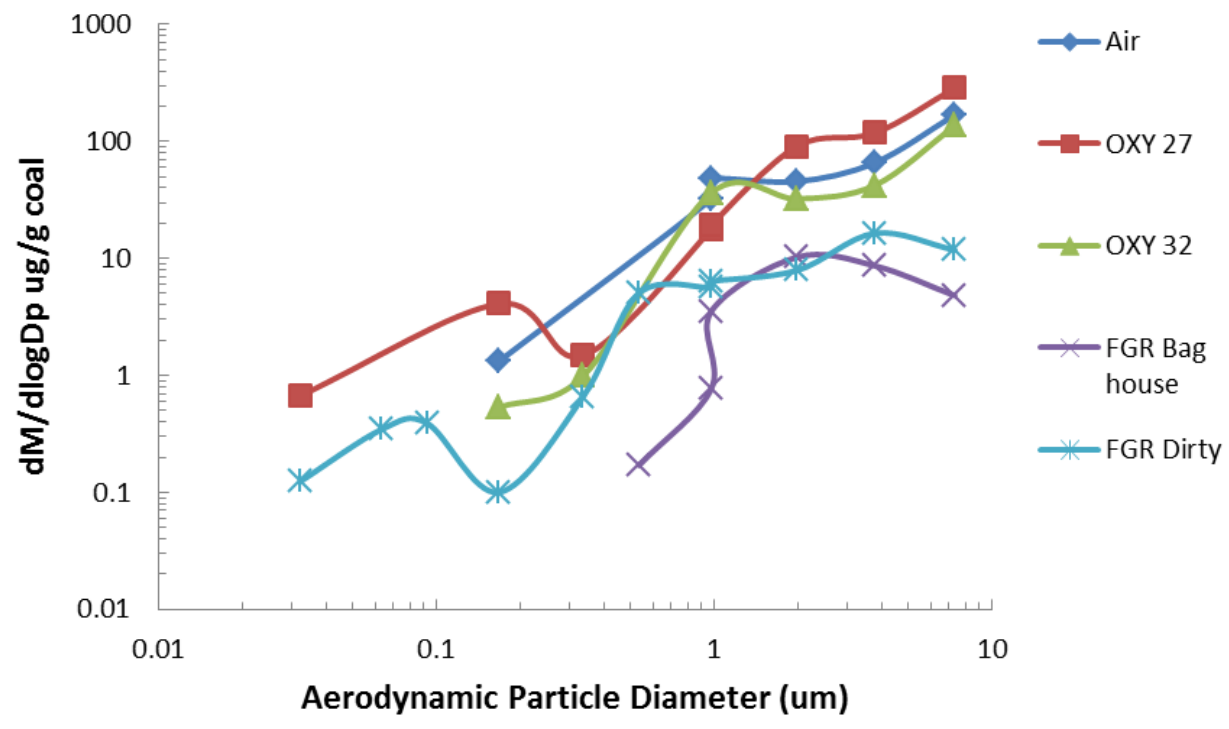

Figure 4.7-56: Potassium oxide aerosol comparison for Utah coal fired experiments. 
The results for the calcium distributions also followed the same trends. It was clear that there was a similar concentration of calcium in the ash aerosol in the sub-micron range under air and oxy-fired conditions, while in the supermicron range, air-fired and once through oxy-fired combustion had a higher concentration than the FGR cases.

It was also clear that the OXY27 and OXY32 calcium distributions were very similar with little noticeable difference between the two once through conditions. The FGR conditions show a difference in the height of the submicron mode peak with the untreated FGR condition having a considerably greater submicron mode peak than the treated FGR. However, the treated FGR had detectable results for calcium in the ultrafine range while the untreated FGR condition was once again apparently washed out in this case.

The results for the calcium distributions for all combustion conditions have been plotted in Figure 4.7-57.

\section{Utah $\mathrm{CaO}$}

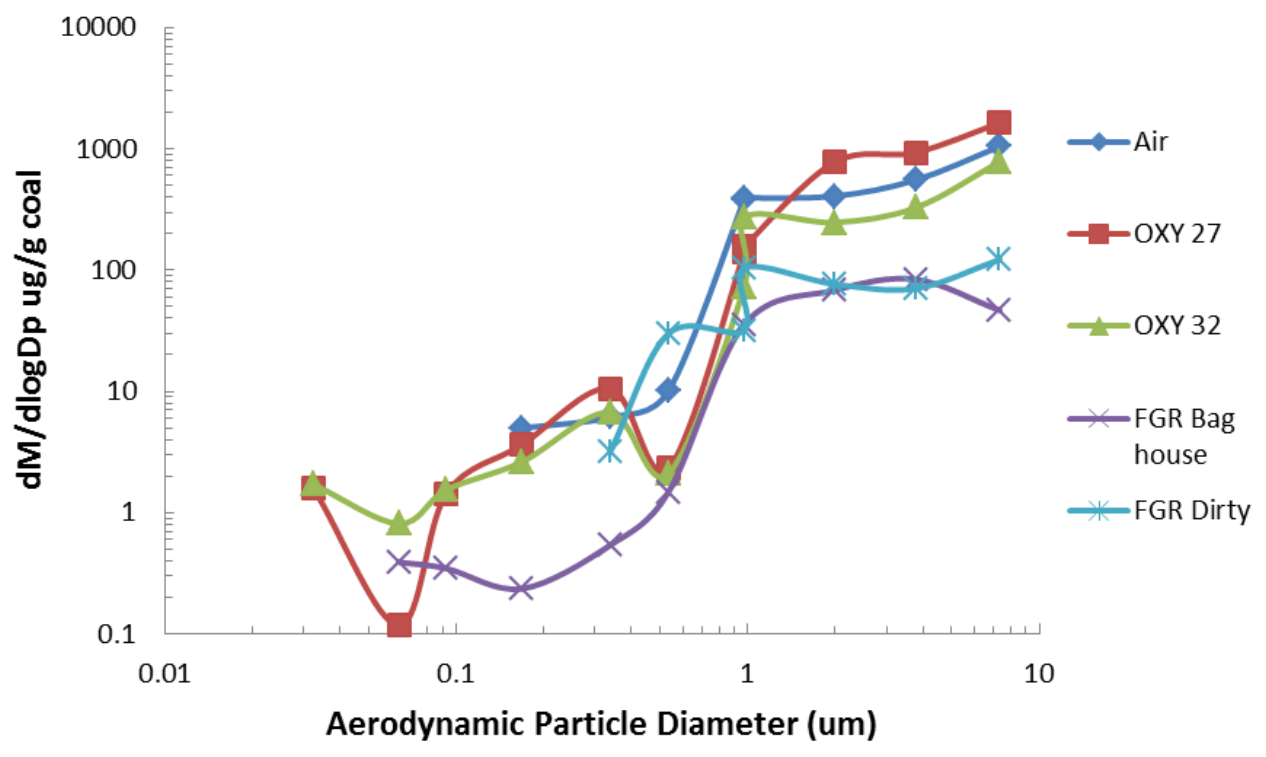

Figure 4.7-57: Calcium oxide aerosol comparison of Utah coal fired experiments.

The results for the titanium distribution also followed the same trends observed for phosphorus, iron, and aluminum for the Utah coal. Titanium once again showed that there was a similar concentration of titanium in the supermicron range of particles under air-fired conditions and once through oxy-fired conditions. Once again the concentration of the air and once through oxy-fired titanium appeared greater than the FGR conditions in the submicron range.

There were no major differences in the results between the once through oxy-fired cases of OXY27 and OXY32. However, there was a significant difference in the magnitude of the submicron mode peak between the treated and untreated FGR oxy-fired conditions. The untreated FGR condition had a much greater concentration of sub-micron titanium than the treated FGR condition in which particles were not recycled. The results for the titanium distributions across all combustion conditions have been plotted in Figure 4.7-58. 


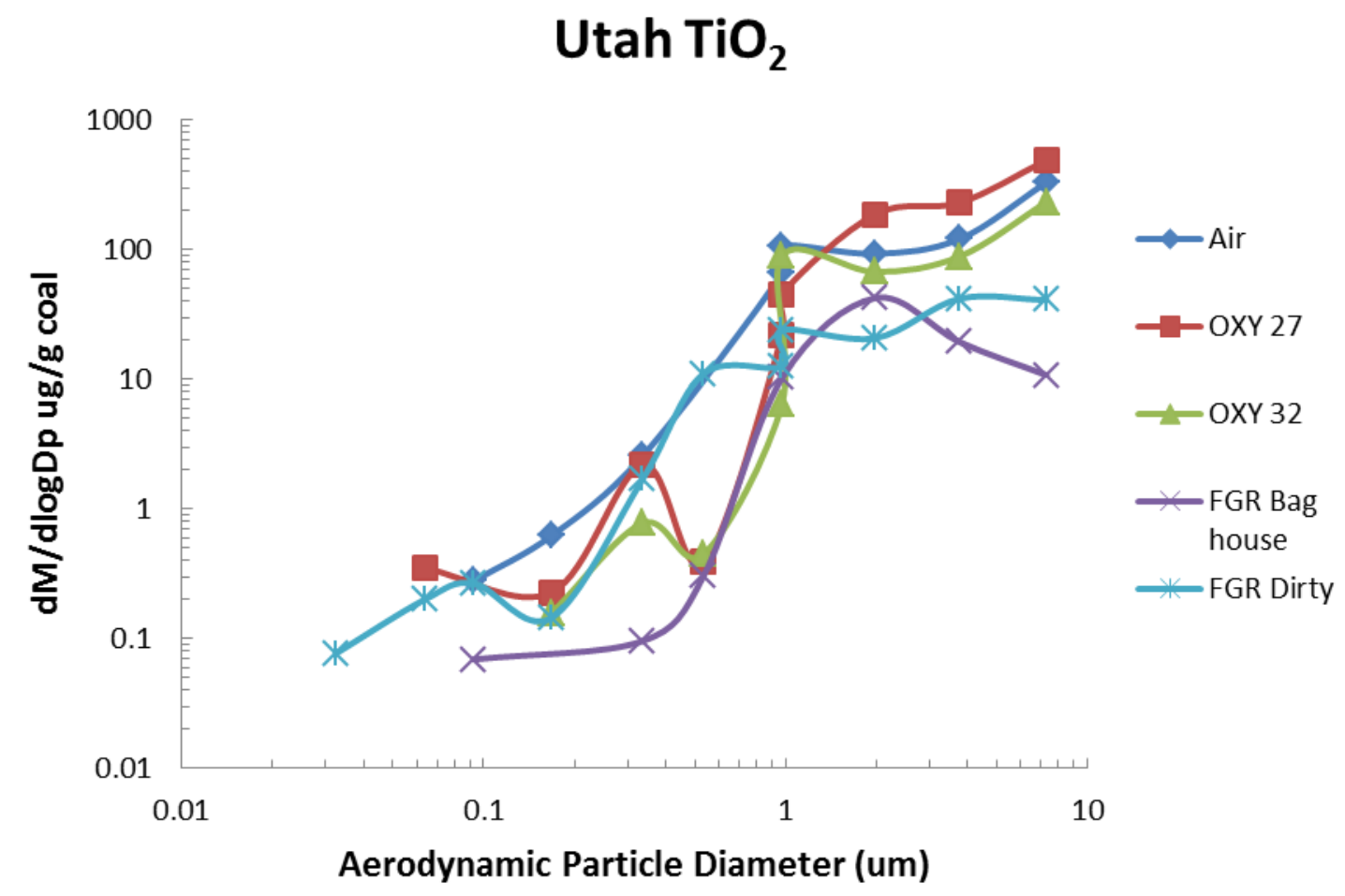

Figure 4.7-58: Titanium oxide aerosol comparison of Utah coal fired experiments.

Iron, an important element for deposition due to the high inertia of particles enriched in iron, followed the same trends as titanium, aluminum, and phosphorus of having a very noticeable and sharp submicron peak in the untreated FGR condition as compared to the air-fired and once through oxy-fired conditions.

In addition, the iron distributions followed the broader trends for the Utah coal of having similar concentrations of iron particles in all particle ranges for the oxy-fired conditions and the air-fired condition. However, the air-fired condition and the oxy-fired conditions had more iron present in the supermicron range than the FGR conditions.

The once through oxy-fired conditions also followed the trends for the Utah coal of having no significant differences in the distribution of iron between OXY27 and OXY32 combustion conditions. The untreated FGR oxy-fired condition once again had the highest magnitude submicron peak of all of the oxy-fired conditions, with the FGR treated with a bag house having the lowest concentration as illustrated in Figure 4.7-59. 


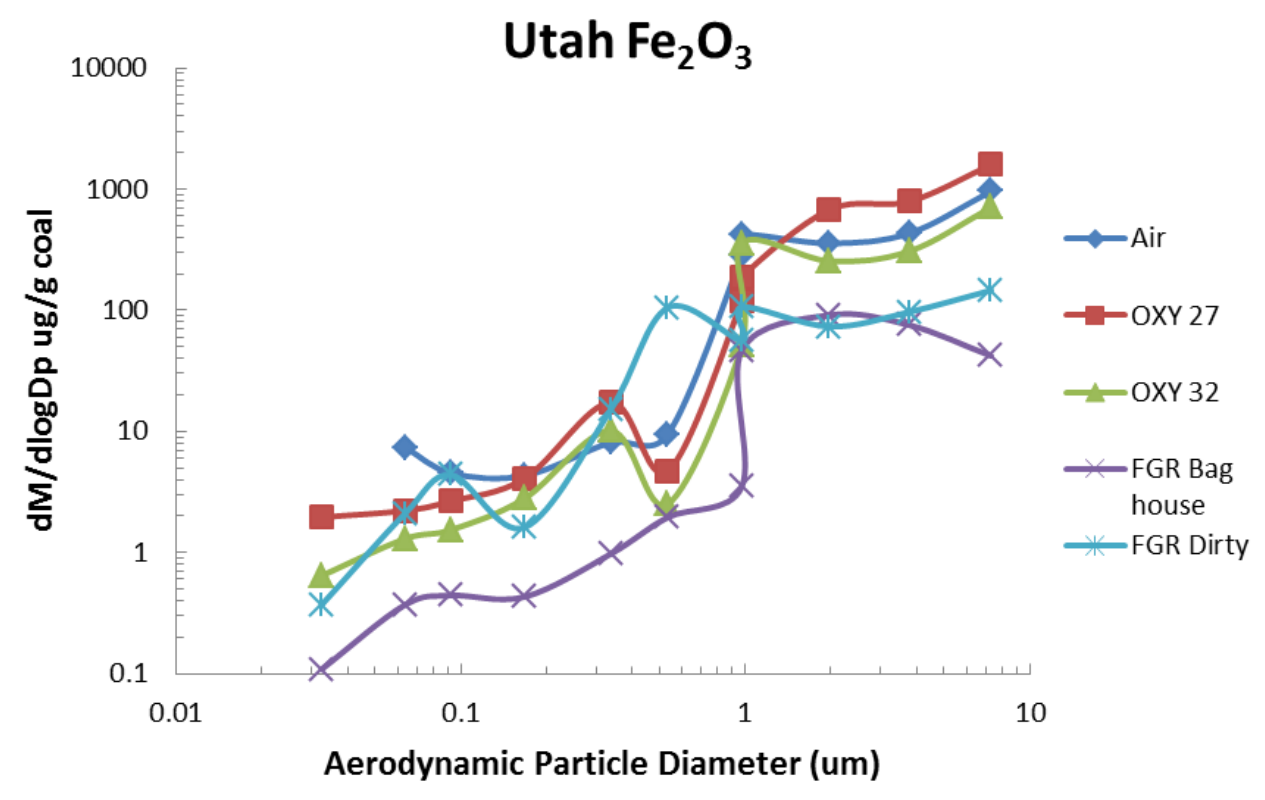

Figure 4.7-59: Iron oxide aerosol comparison of Utah coal fired experiments.

In addition to major species present in the ash, the ICP-MS was also used to analyze trace elements such as arsenic and selenium. While ICP-MS instruments tend to have a large range across which they can be calibrated, it was still a challenge to analyze ash samples which are made up of a percentage of some elements, while others are only found in trace amounts. As a result, it was very difficult to determine specific trends from the data plotted for arsenic and selenium; however they have been presented here for completeness.

The data for the arsenic for the Utah coal showed that there was a submicron mode; however it was very difficult to observe meaningful differences in behavior between oxy-fired conditions. Also, due to the small amounts of arsenic collected in the impactor samples, this was one of the few cases where the OXY27 and OXY32 conditions did not track each other closely. The data for arsenic were plotted in Figure 4.7-60.

The once through OXY27 and OXY32 cases for selenium were more closely matched than the OXY27 and OXY32 cases for arsenic. Also, the untreated FGR case produced a very unusual submicron selenium distribution compared to the once through cases, while the results for selenium were below detection for the treated FGR case.

Unfortunately, these results cannot be visually compared to air-fired results because there were few data points for the air case that were above the detectable limits for selenium and they were not recorded by the lab performing the work due to an unfortunate miscommunication. The results for the oxy-fired cases have been plotted in Figure 4.7-61. 


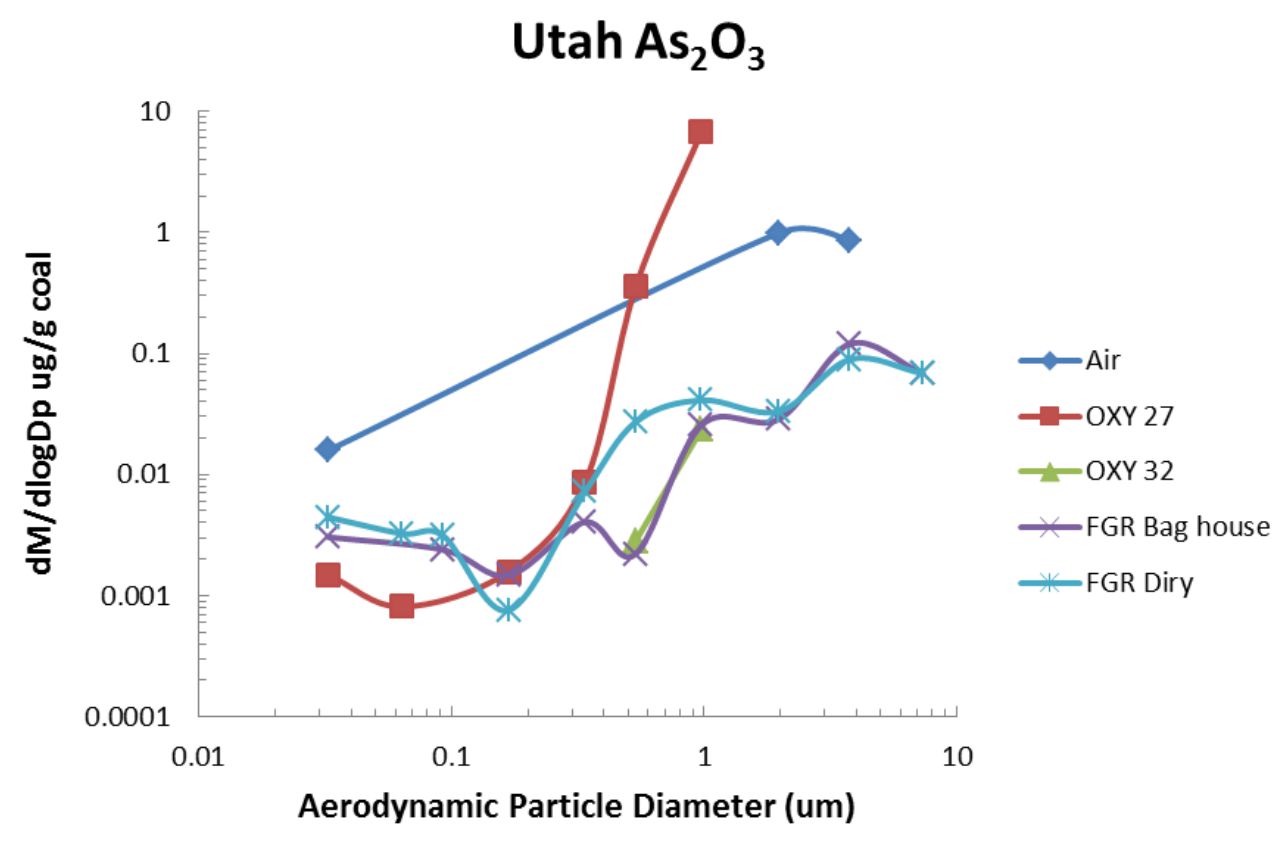

Figure 4.7-60: Arsenic oxide aerosol comparison of Utah coal fired experiments.

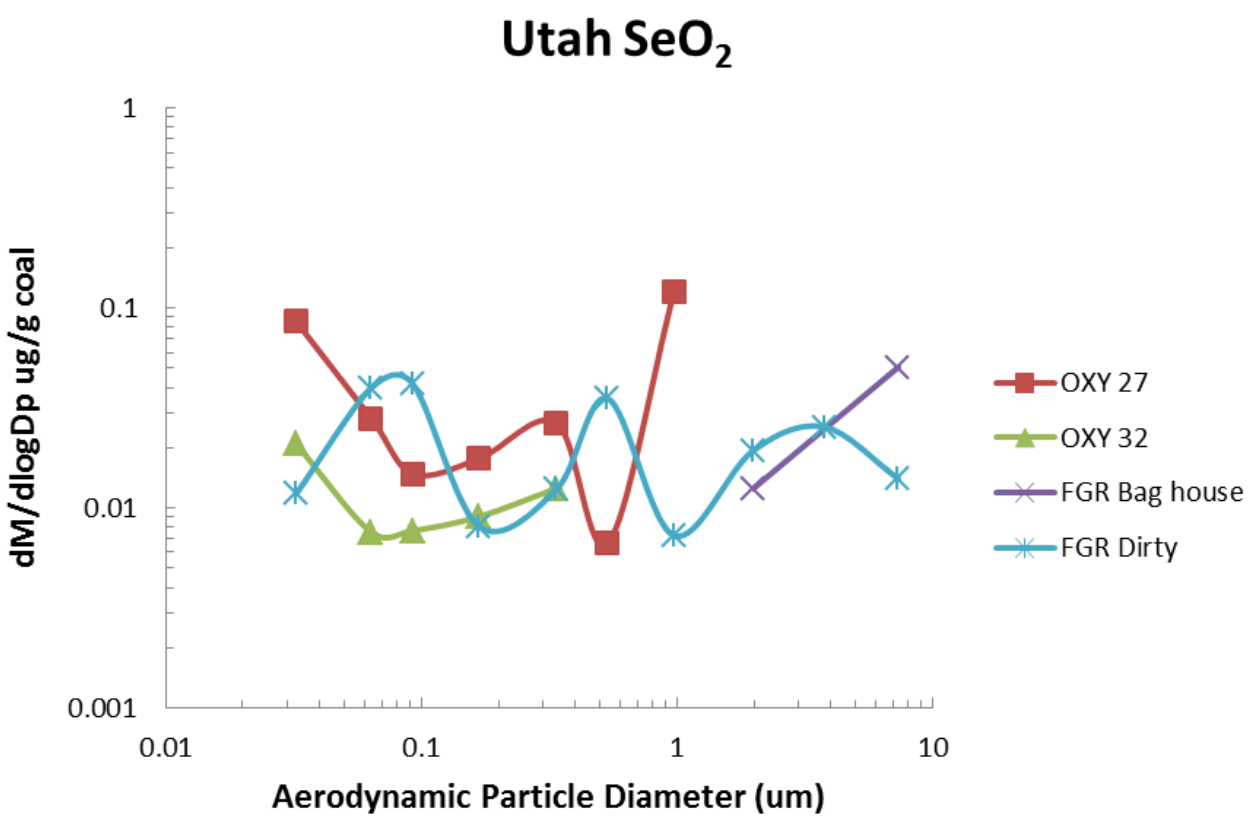

Figure 4.7-61: Selenium oxide aerosol comparison of Utah coal fired experiments.

\subsubsection{2 $P R B$}

The results for PRB coals did not have many significant overarching trends that were observed across a wide variety of elements studied in the size segregated ash. There was actually only one trend. The PRB size segregated ash chemistry results indicated that there were only modest differences between the combustion conditions. As a result, the trend that the once through conditions of OXY27 and OXY32 were very similar in the partitioning of elements also holds for the PRB coal, and there was not a 
significant difference in the partitioning of submicron and supermicron particles in air versus oxy-fired combustion comparison.

The results for sodium indicated that the once through oxy-fired conditions exhibited very similar behavior for the partitioning of sodium. In addition, the differences between FGR oxy-firing and once through oxy-firing were small except in the supermicron range. In the submicron range, there was a dearth of data points for the FGR conditions due to results being below the detectable limits. Also, airfired data indicated that there were no significant differences in behavior of sodium distributions when compared to the oxy-fired data for sodium in Figure 4.7-62.

\section{PRB $\mathrm{Na}_{2} \mathrm{O}$}

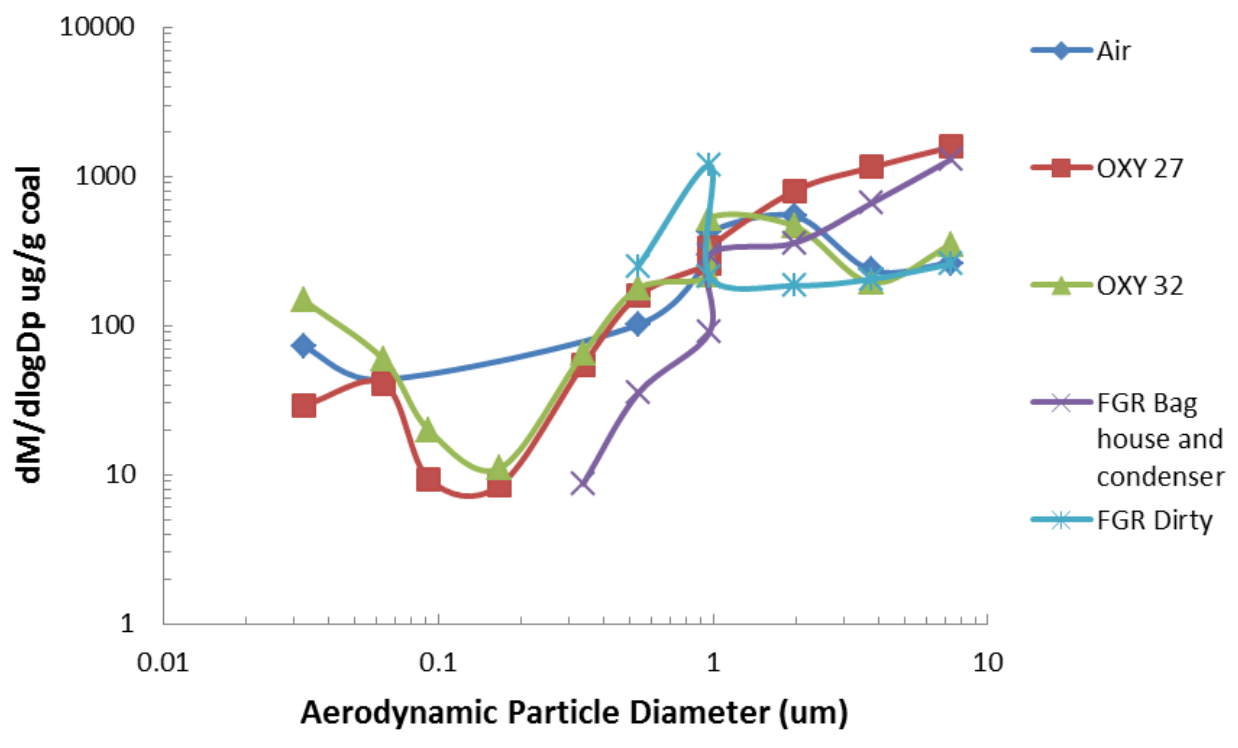

Figure 4.7-62: Sodium oxide aerosol comparison for PRB coal fired experiments.

The differences in the magnesium distribution in the ash aerosol of air and oxy-fired conditions were even smaller for the PRB coal than the differences in sodium. There were no significant differences between the air and oxy-fired conditions. The oxy-fired conditions, whether once through or FGR, produced fairly similar magnesium distributions with some departures below 100nm as shown in Figure 4.7-63.

The distribution of aluminum was also very similar across all combustion conditions. While there were some significant differences at the 32nm particle diameter between the FGR and once through OXY27 the overall distribution of aluminum from the PRB ash was very similar other than the difference in these two points.

Also, there appeared to be very little difference between the air and oxy-fired conditions. There was a slight increase in the submicron range of aluminum for the oxy-fired conditions compared to the air, but overall the differences between air and oxy-fired distributions appeared to be small. The results for the aluminum distributions were plotted in Figure 4.7-64. 


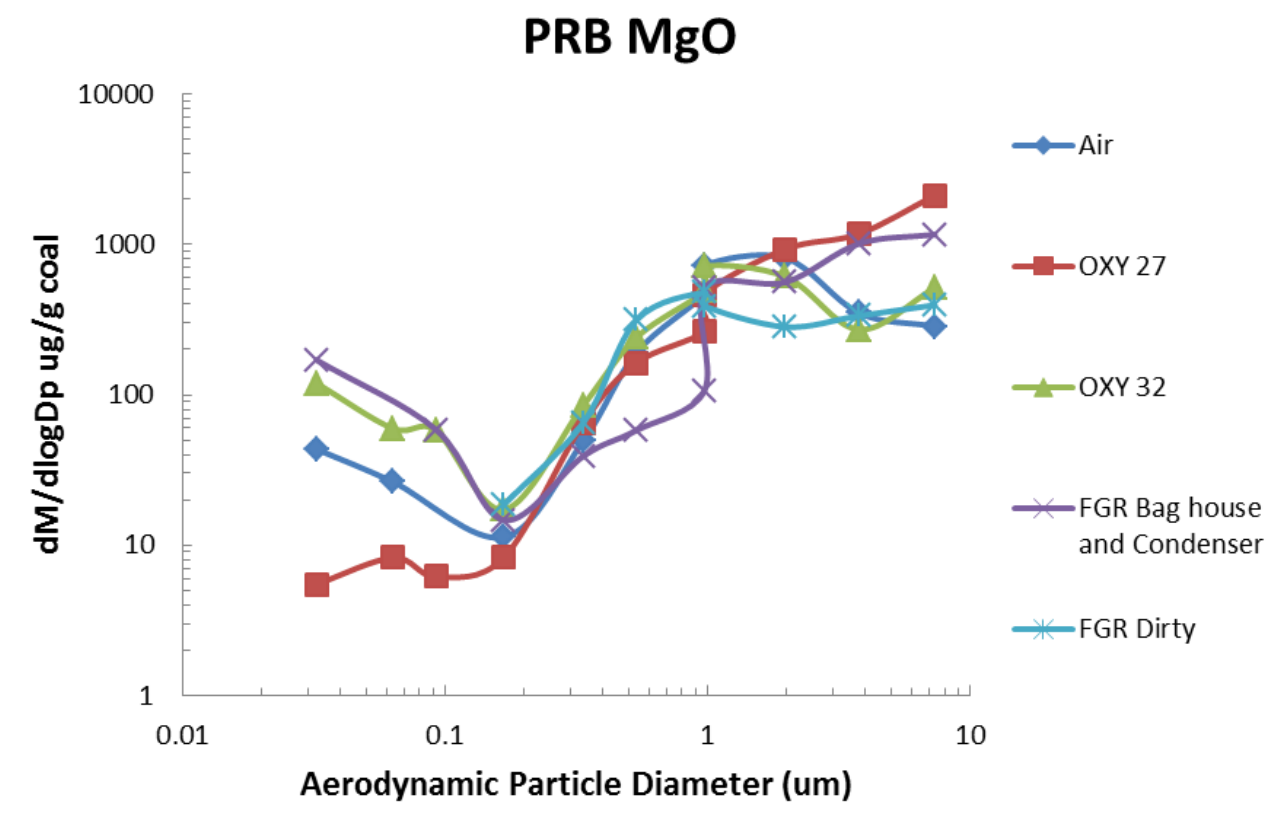

Figure 4.7-63: Magnesium oxide aerosol comparison for PRB coal fired experiments.

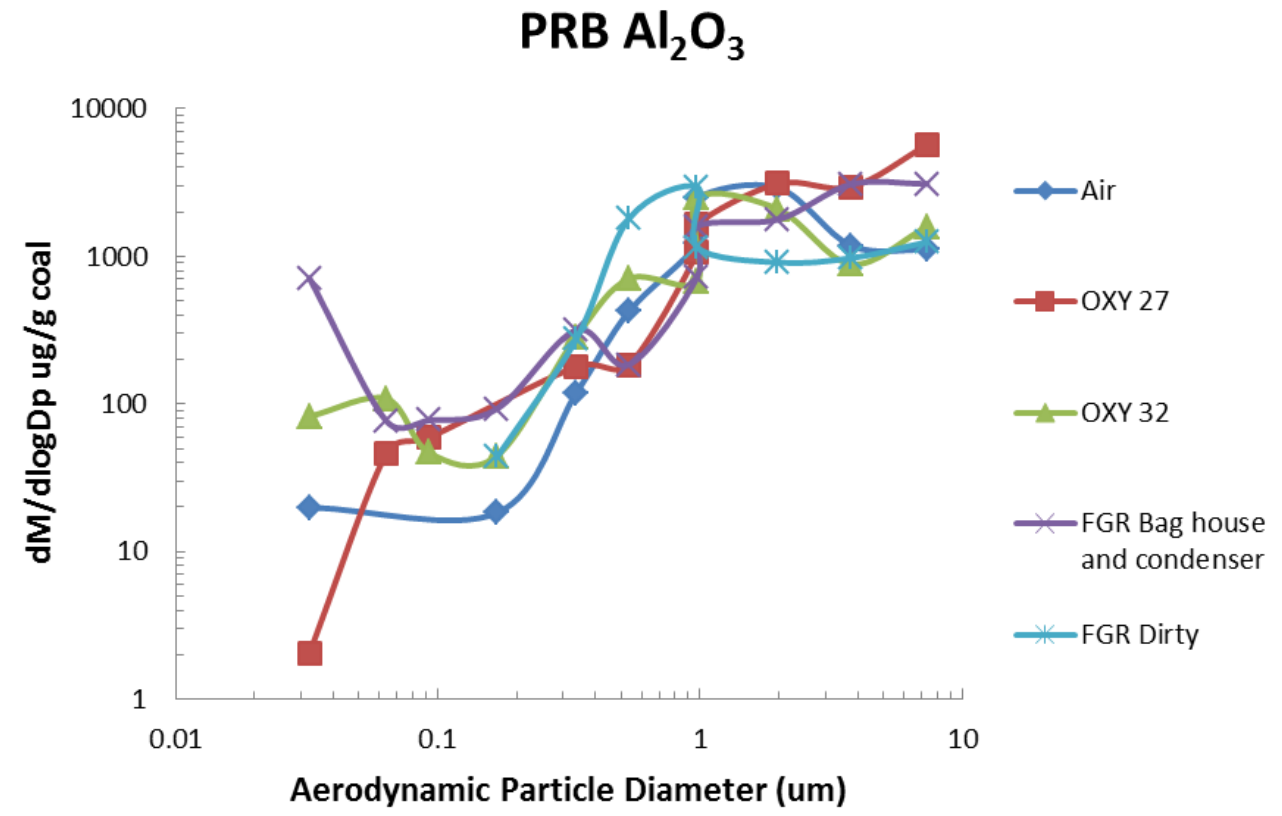

Figure 4.7-64: Aluminum oxide aerosol comparison for PRB coal fired experiments.

There were differences in the silicon distributions for the PRB coal from air to oxy-fired. Among the oxy-fired conditions there were significant differences between the once through and FGR conditions. The data did not show a smooth multimodal distribution for any of the conditions. The results here have been shown for completeness in Figure 4.7-65, but clearly the data plotted did not match the behavior expected of the silicon distributions for the PRB ash chemistry distributions. 


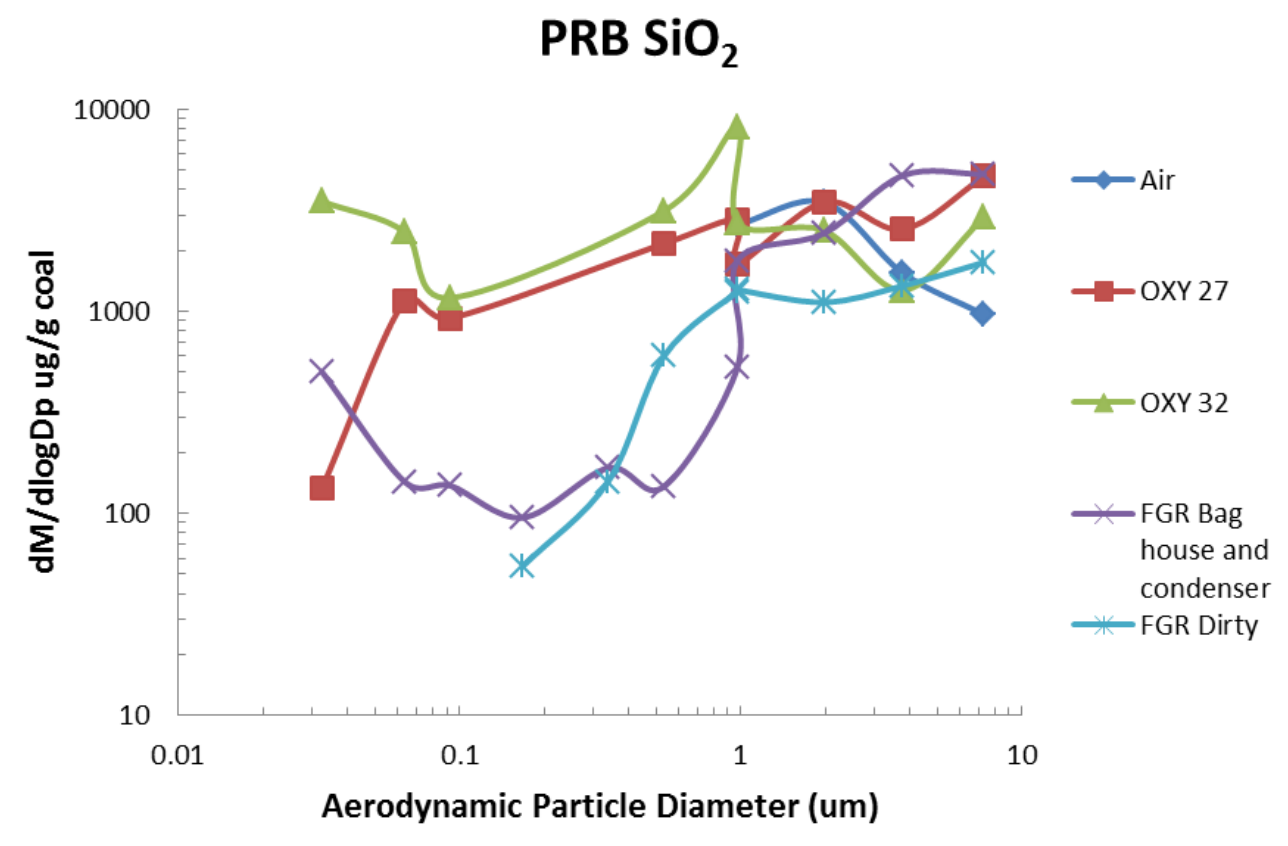

Figure 4.7-65: Silicon oxide aerosol comparison for PRB coal fired experiments.

The phosphorus distribution tracked the distributions for the rest of the major ash elements found in the PRB coal such as calcium, iron, magnesium, and aluminum as well as some minor species such as titanium. As a result there was a similar multimodal behavior for phosphorus in the PRB ash under airfired and oxy-fired conditions without significant differences between the air-fired, once through oxyfired, and FGR oxy-fired conditions. However, the coarse mode did appear to begin at different particle diameters for some combustion conditions which, at times, led to some digression between distribution curves. The phosphorus distributions for the PRB coal were plotted in Figure 4.7-66.

Potassium, which was present in much lower quantities than sodium in the PRB ash, was presented in Figure 4.7-67. While the potassium distribution does generally follow the other elemental distributions, there were impactor stages that did not have enough potassium present to be above the detectable limit of the instrument. As a result, there were more data points missing for the potassium distributions which did affect the smoothness of the multimodal distribution.

However, when examining only the plotted data points there appeared to be no tremendous differences between any of the combustion conditions. As with sulfur, the particle diameter at which modes began and ended was occasionally shifted from one impactor plate to another leading to some differences in the distribution of potassium, but overall the partitioning was similar for all conditions. This was similar to the behavior of the other elements in the PRB ash aerosol. 


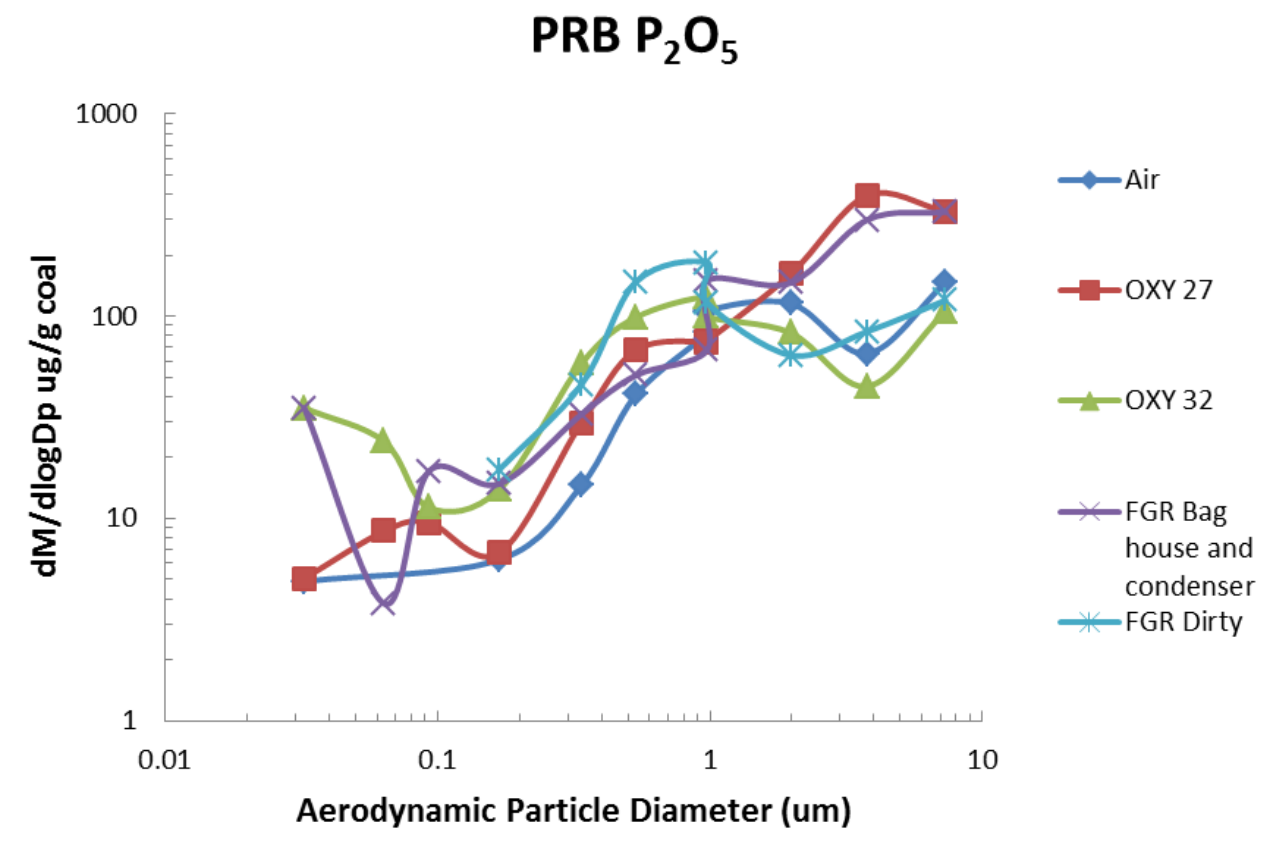

Figure 4.7-66: Phosphorus oxide aerosol comparison for PRB coal fired experiments.

PRB $K_{2} \mathrm{O}$

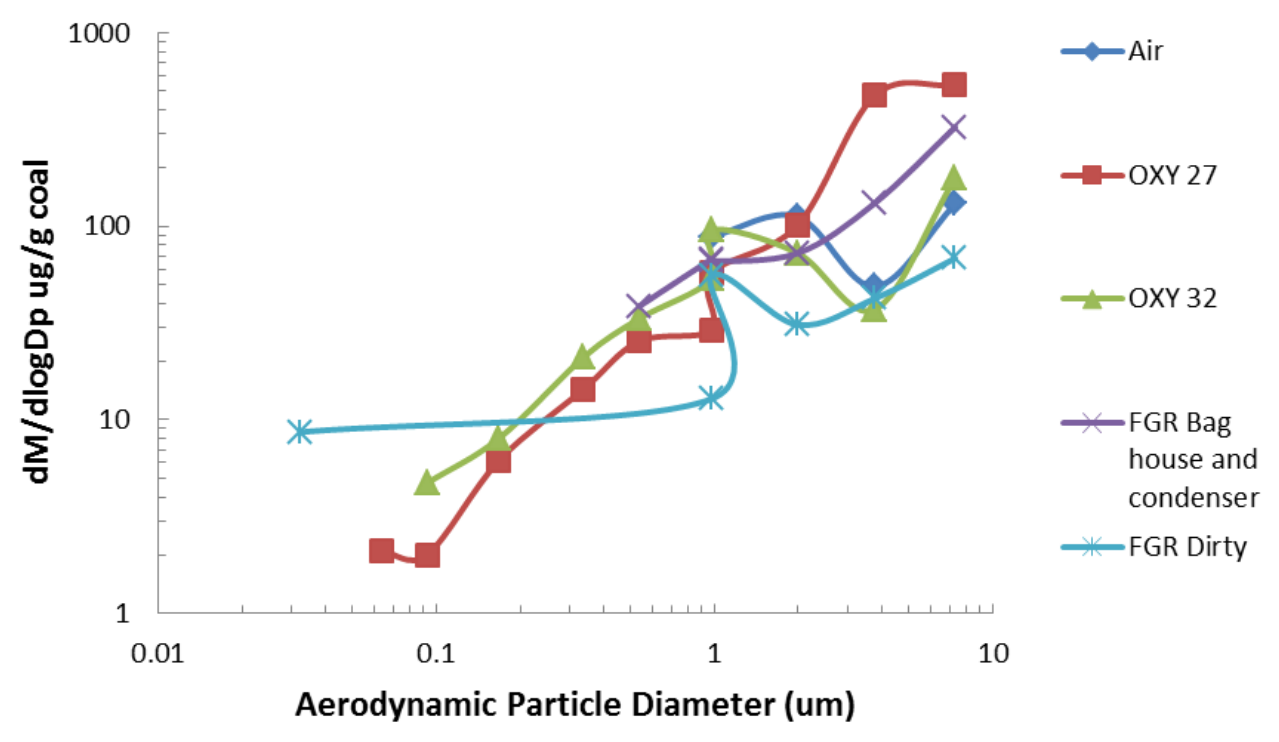

Figure 4.7-67: Potassium oxide aerosol comparison for PRB coal fired experiments.

Calcium was a very significant constituent in the PRB ash. The distribution of calcium, shown in Figure 4.7-68, for the PRB coal indicated no significant difference between any of the combustion conditions. There was certainly some scatter, but in general, the distributions generally overlapped for all combustion conditions. 
The air-fired scenario appeared to match the oxy-fired conditions with minor differences between the once through and FGR conditions, which corresponded to the results of many of the other major ash species in the PRB coal.

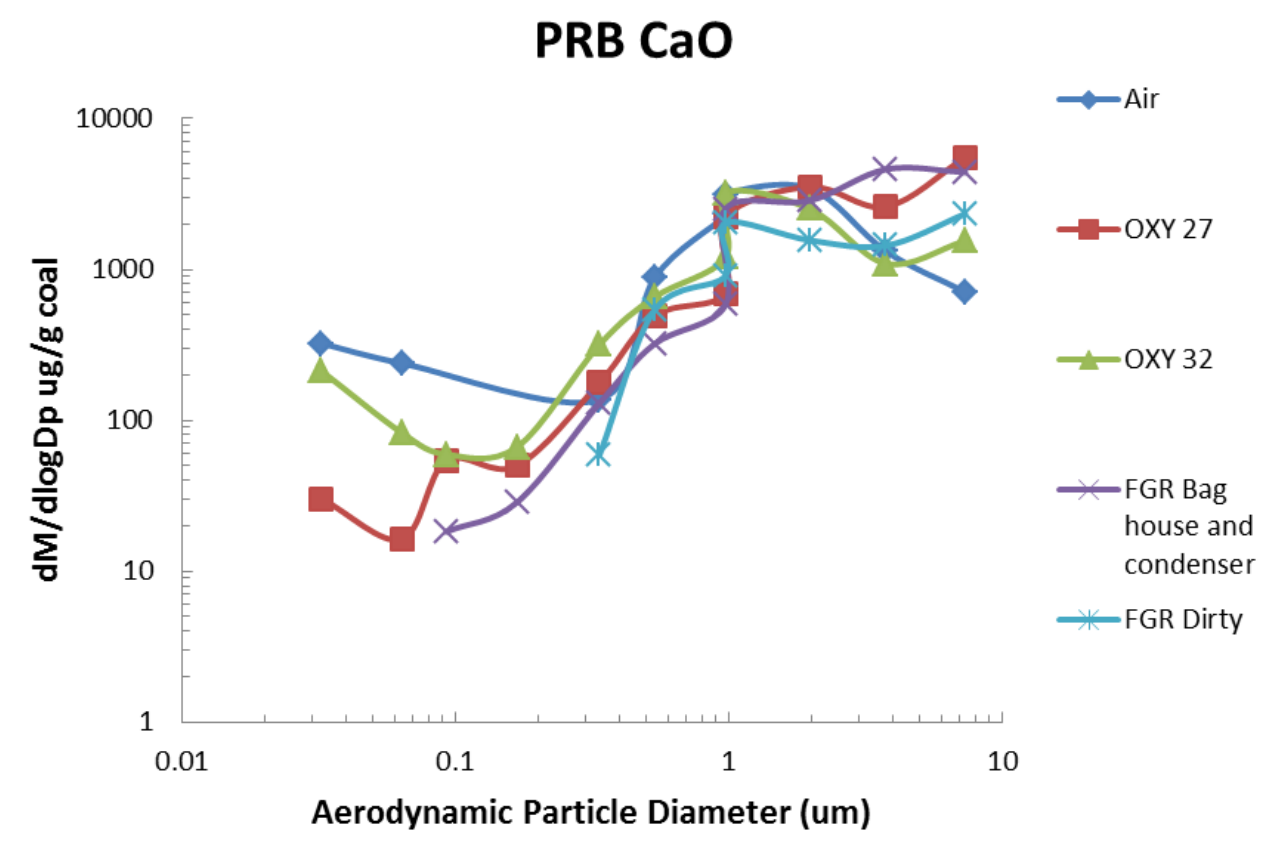

Figure 4.7-68: Calcium oxide aerosol comparison for PRB coal fired experiments.

The titanium distribution also showed very good agreement between the air-fired, once through oxy-fired, and FGR oxy-fired conditions. The data showed a multimodal distribution for titanium with a slight discontinuity at the one micron particle mode where the ICP-MS and EDS data merged. Otherwise, the behavior of titanium was consistent with most of the other chemical compounds present in the PRB fly ash such as aluminum, calcium, phosphorus, and iron. The distributions for all combustion conditions for titanium were plotted in Figure 4.7-69.

The iron distributions for the PRB coal were also consistent with the other distributions for major elements. These elements did not show significant difference in partitioning behavior when changing from air-fired to once through oxy-fired to FGR oxy-fired conditions. The only discontinuities observed in the multimodal distribution of iron occurred when merging the EDS and ICP-MS data at the particle diameter of one micron. There were some differences regarding the particle diameter in which one mode began or ended, but there was not a significant difference in the distribution of iron under the varying combustion conditions presented in Figure 4.7-70. 


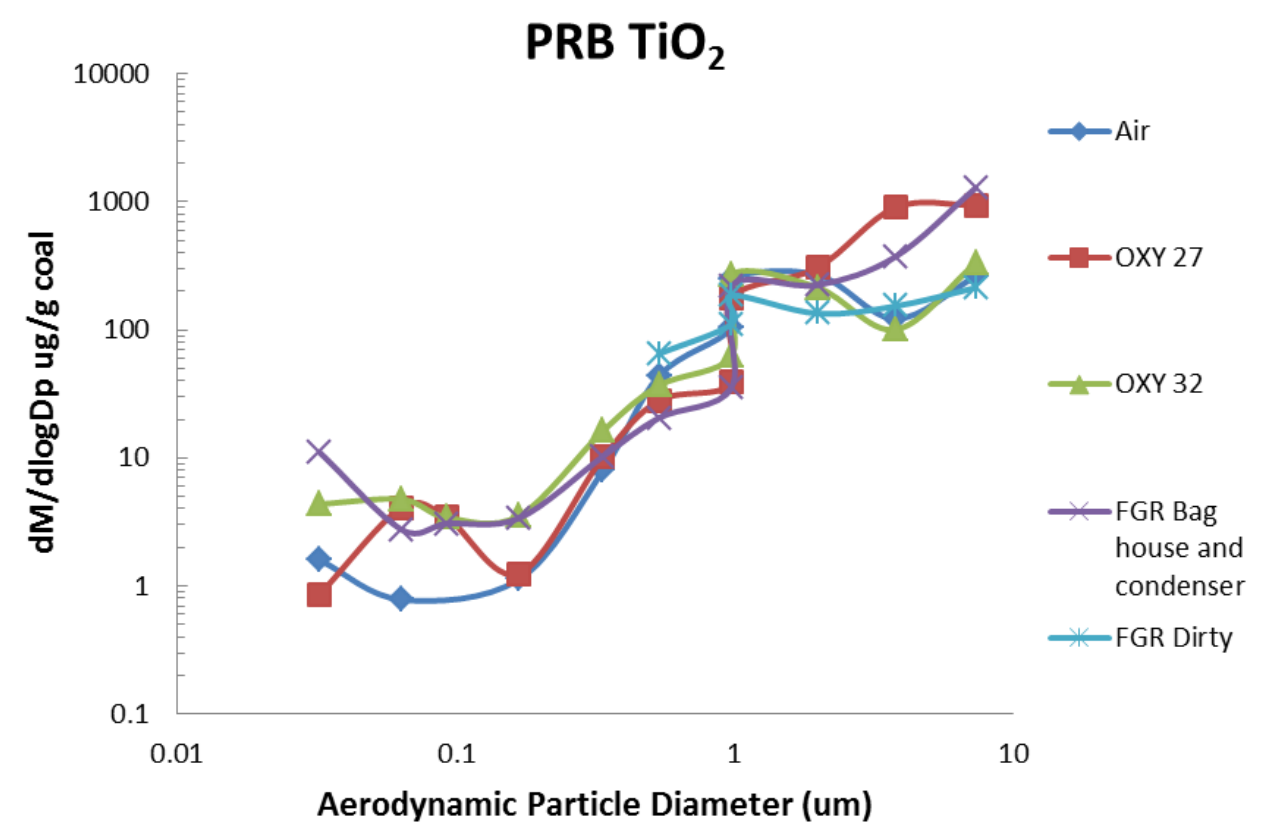

Figure 4.7-69: Titanium oxide aerosol comparison for PRB coal fired experiments.

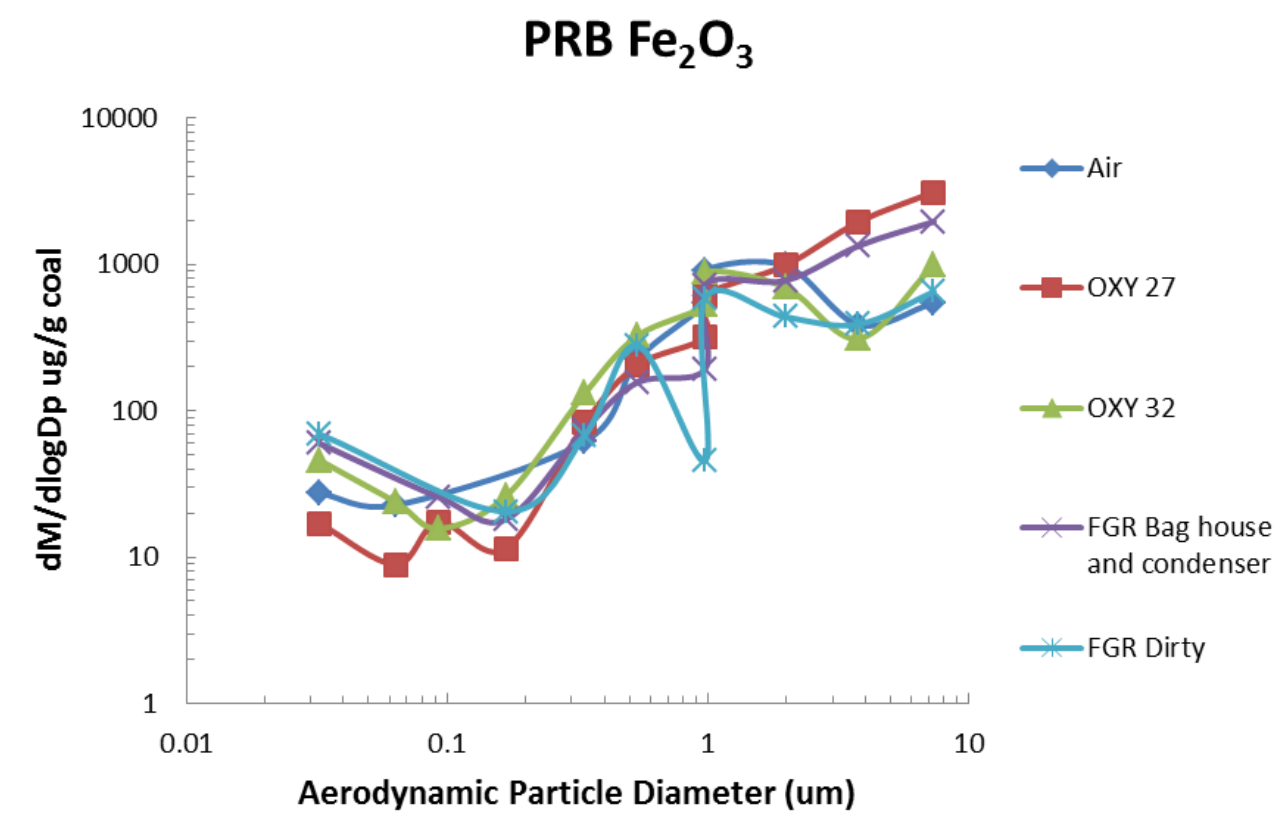

Figure 4.7-70: Iron oxide aerosol comparison of PRB coal fired experiments.

The trace metals arsenic and selenium were also examined by ICP-MS for the PRB coal. The selenium results were all less than the detectable limit for the PRB. The arsenic data were plotted in Figure 4.7-71. It is obvious that there is a great deal of uncertainty and scatter in the data that were collected for arsenic due to the very small amounts of arsenic present in the ash aerosol collected with the BLPI. 
As a result, it is difficult to determine any sort of pattern by examining the data presented for the arsenic distribution. A weak correlation exists between the OXY27 and OXY32 case, but the excessive number of modes for the treated FGR condition and lack of a significant number of data points makes it difficult to observe any meaningful pattern in the data.

\section{$\operatorname{PRB~} \mathrm{As}_{2} \mathrm{O}_{3}$}

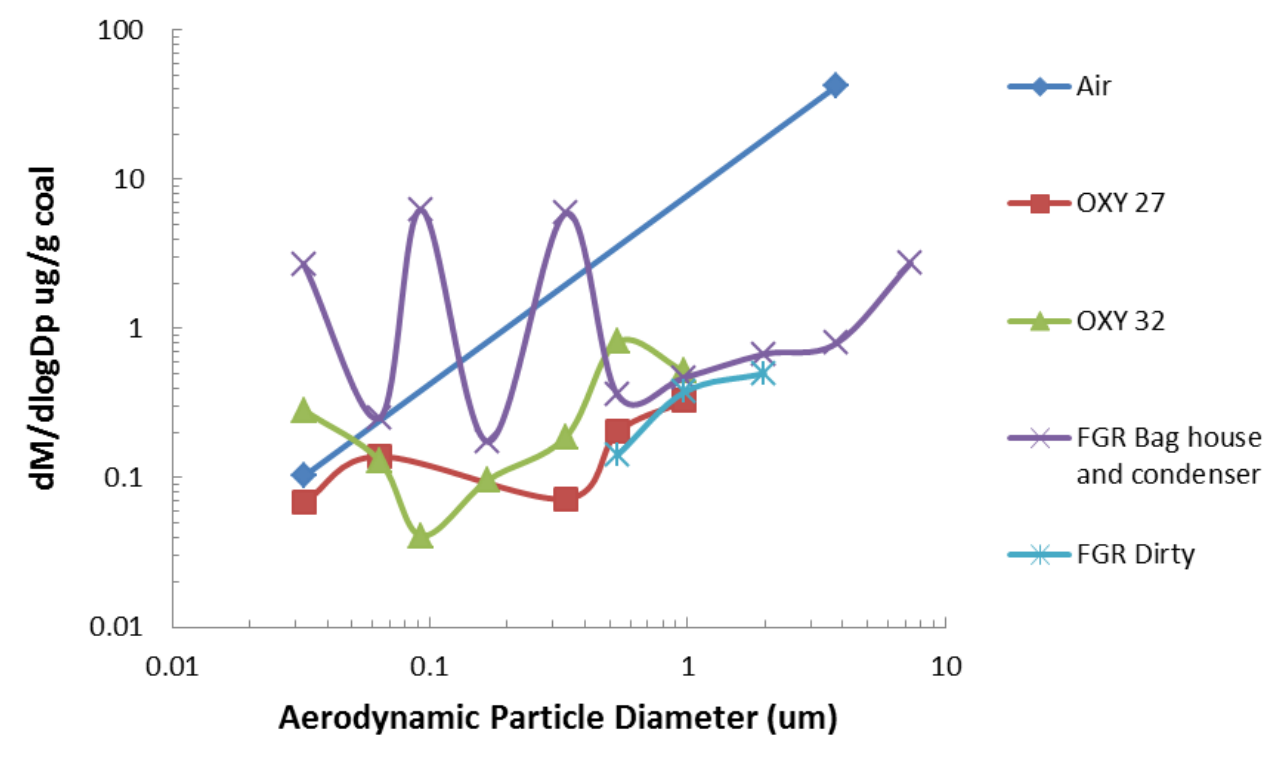

Figure 4.7-71: Arsenic oxide aerosol comparison of PRB coal fired experiments.

\subsection{Illinois}

The same elements were analyzed in the size segregated ash aerosol for the Illinois coal. The Illinois coal did share somewhat similar behavior to the Utah coal regarding a tendency to have a greater concentration of a given element in the super micron particles under air-fired conditions and once through oxy-fired than the FGR conditions. However, this tendency did not always result in a reduction in the amount of submicron particle concentration of a particular element under the air-fired condition as compared to the FGR oxy-fired conditions.

Another observation throughout all of the data was the lack of data points for the untreated FGR condition below one micron. The very high $\mathrm{SO}_{2}$ concentration in the untreated recycled flue gas recycle scenario resulted in a significant amount of sulfuric acid aerosol. This created extreme difficulties in sampling the flue gas as well as being able to accurately analyze any ash samples in the submicron range which were covered with condensed acid particles in the impactor. This often left visual damage to the impactor substrates indicating that material was lost.

These observations can be applied readily to the sodium distribution for the Illinois coal. It was evident that there was more sodium in the super micron range of particle diameters for the air-fired condition compared to all of the oxy-fired conditions. In addition, there was a more prominent ultrafine submicron fume mode in the oxy-fired conditions whereas this mode had not appeared in the ultrafine submicron range for the air-fired combustion condition. This gave the appearance of more sodium in the ultrafine range for the oxy-fired conditions. 
The oxy-fired conditions did show significant differences between the once through and treated FGR conditions. The once through OXY27 and OXY32 conditions were nearly identical, but the untreated FGR condition did not have detectable sodium on many of the submicron collector plates in the impactor. As a result the distribution was only available for the supermicron particles. The sodium distribution for the Illinois coal has been presented in Figure 4.7-72.

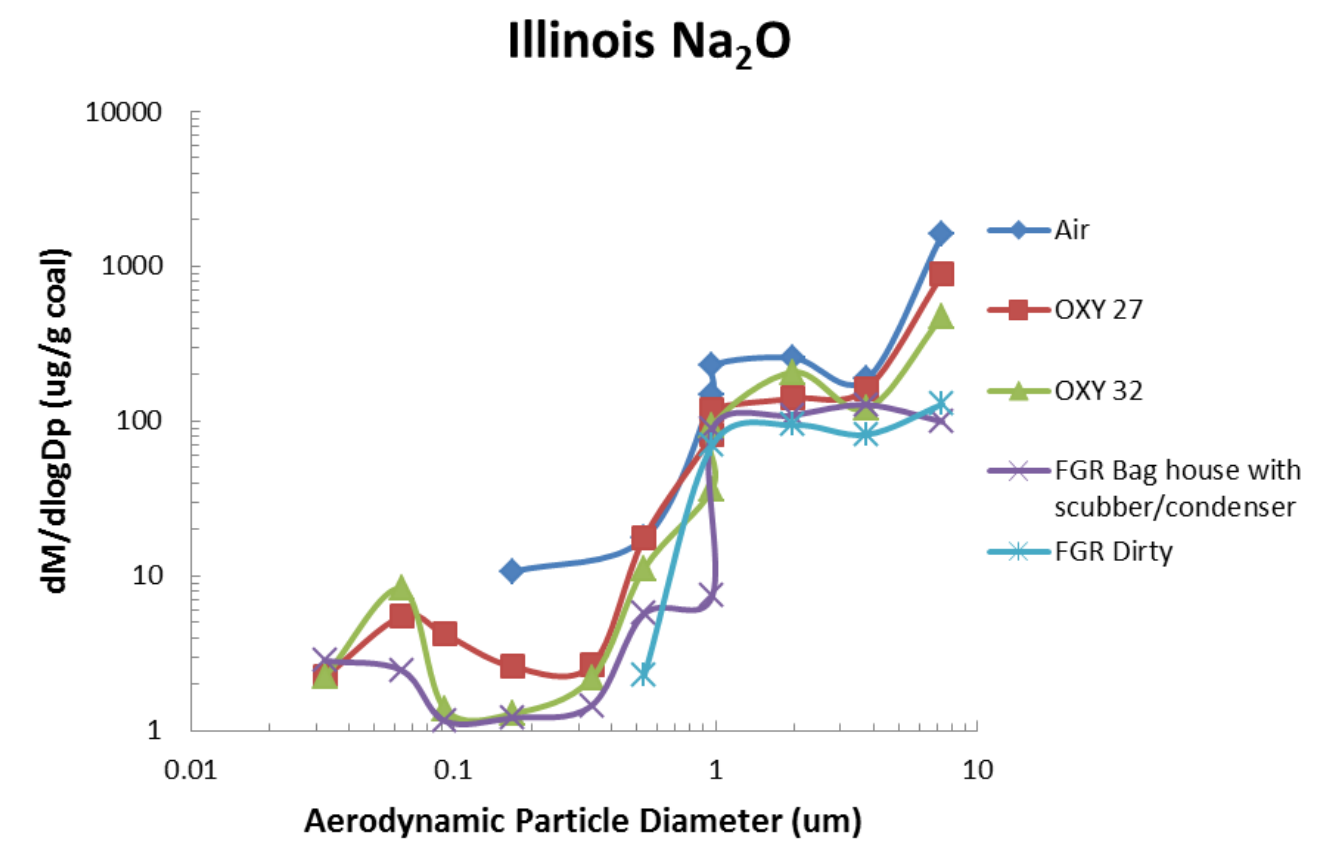

Figure 4.7-72: Sodium oxide aerosol comparison for Illinois coal fired experiments.

Magnesium data for all combustion conditions are plotted in Figure 4.7-73. The data show that there was an ultrafine submicron peak for the oxy-fired results while there were no detectable results for the airfired condition in the ultrafine range.

The oxy-fired FGR conditions, on the other hand, track each other closely, and magnesium was one of the few elements which had a complete distribution for the untreated FGR condition. The FGR conditions did not show significant differences, and were relatively closely matched to the once through conditions. The air-fired results show better integration of the EDS data with the ICP-MS data at one micron than the FGR oxy-fired results as well as a greater concentration of magnesium in the one micron fragmentation mode.

As expected, the OXY27 and OXY32 conditions were very closely matched and tracked each other with only slight differences in the ultrafine range. They also tracked the FGR oxy-fired conditions very closely in the supermicron range, but had greater concentrations of magnesium reported in the ultrafine sub $100 \mathrm{~nm}$ range.

The aluminum distributions for the Illinois coal exhibited many of the trends reported for other elements analyzed in the size segregated ash from Illinois coal combustion. As shown in Figure 4.7-74, the airfired results had a greater concentration in the supermicron range than the oxy-fired conditions; however this did not correspond to a decrease in the concentration of aluminum in the submicron range when compared to the oxy-fired conditions. 


\section{Illinois MgO}

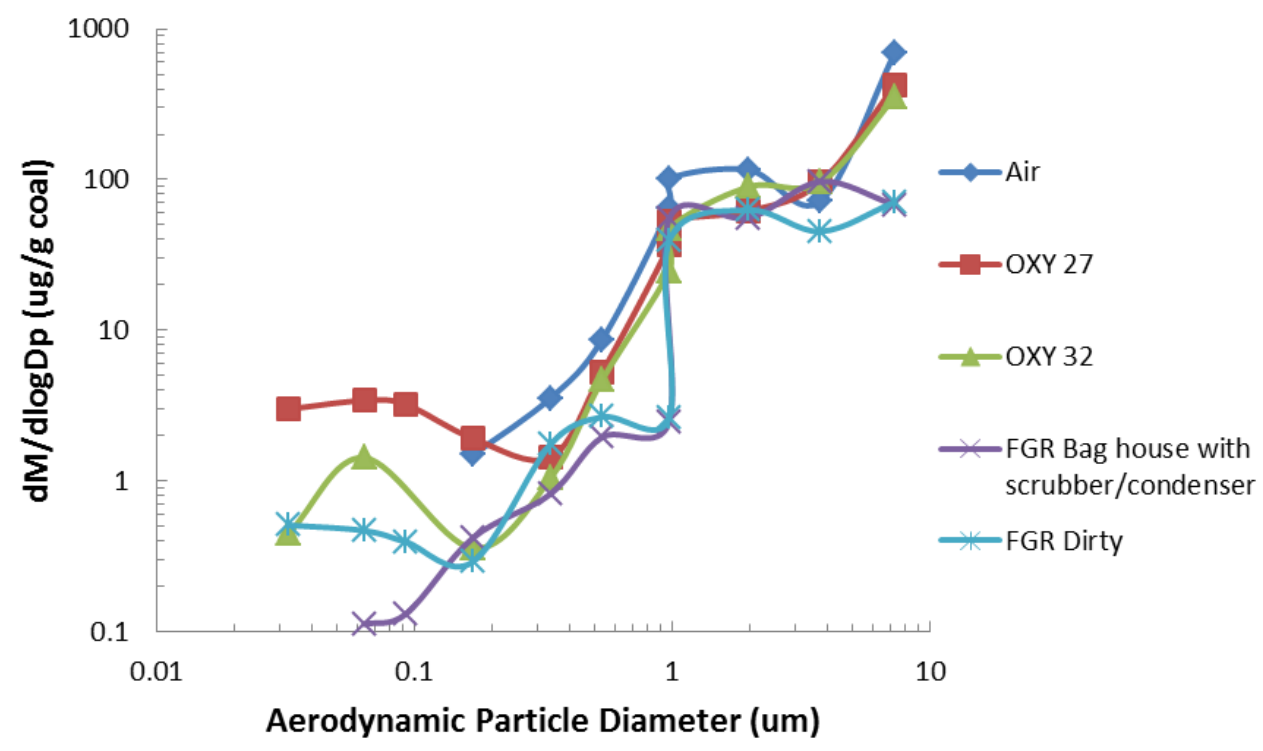

Figure 4.7-73: Magnesium oxide aerosol comparison for Illinois coal fired experiments.

\section{Illinois $\mathrm{Al}_{2} \mathrm{O}_{3}$}

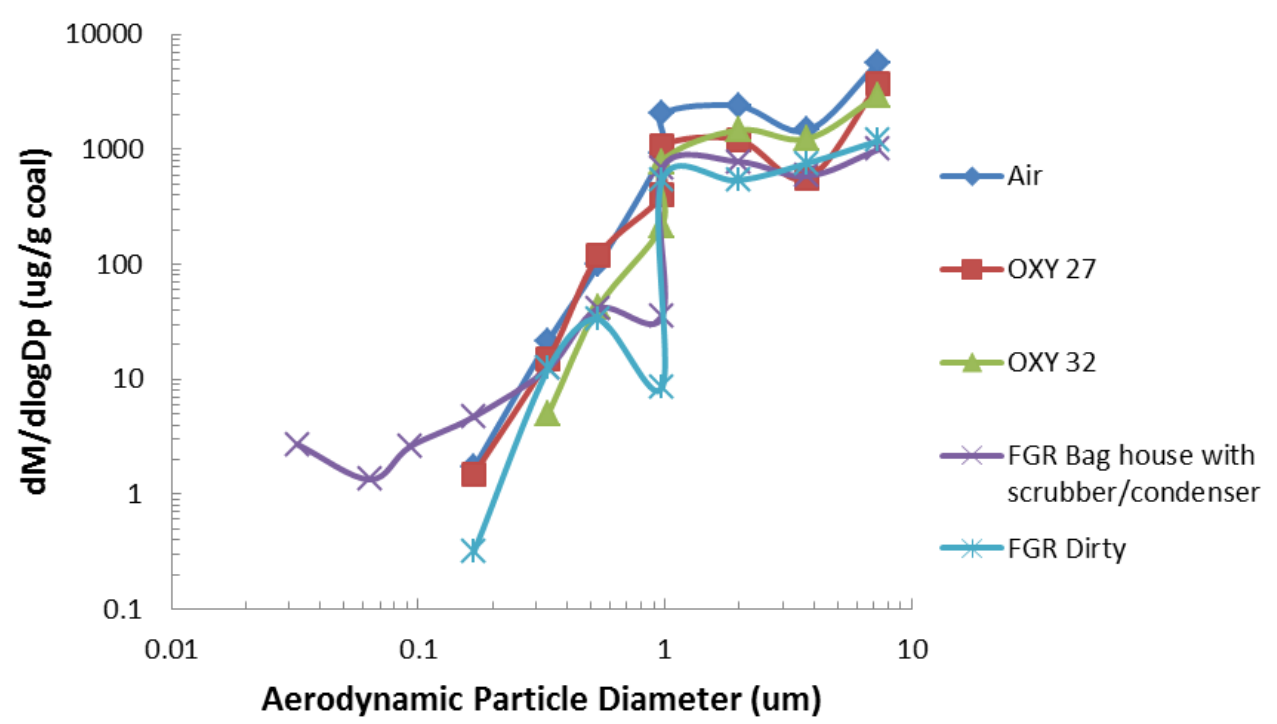

Figure 4.7-74: Aluminum oxide aerosol comparison for Illinois coal fired experiments.

Once again, the air-fired data have better integration between the ICP-MS and EDS data, while there was a larger noticeable discontinuity in the oxy-fired results under FGR conditions. The once through oxyfired conditions had better data integration and tracked each other closely with minimal differences between the OXY27 and OXY32 distributions as expected. Finally, the FGR oxy-fired results tended to have a sharper sub-micron mode peak compared to a smoother curve for the air-fired condition. 
Also, the oxy-fired conditions again appeared to have had more detectable results for impactor plates in the ultrafine the range below 500nm when compared to the air-fired results for $\mathrm{SiO}_{2}$ in Figure 4.7-75; however $\mathrm{SiO}_{2}$ was subjected to error as discussed previously. The once through oxy-fired results and the treated FGR results illustrated this the most clearly. Finally, the OXY27 and OXY32 distributions were very similar while the untreated FGR oxy-fired condition did not have enough recoverable material on many of the submicron plates to have a detectable result with the ICP-MS analysis.

\section{Illinois $\mathrm{SiO}_{2}$}

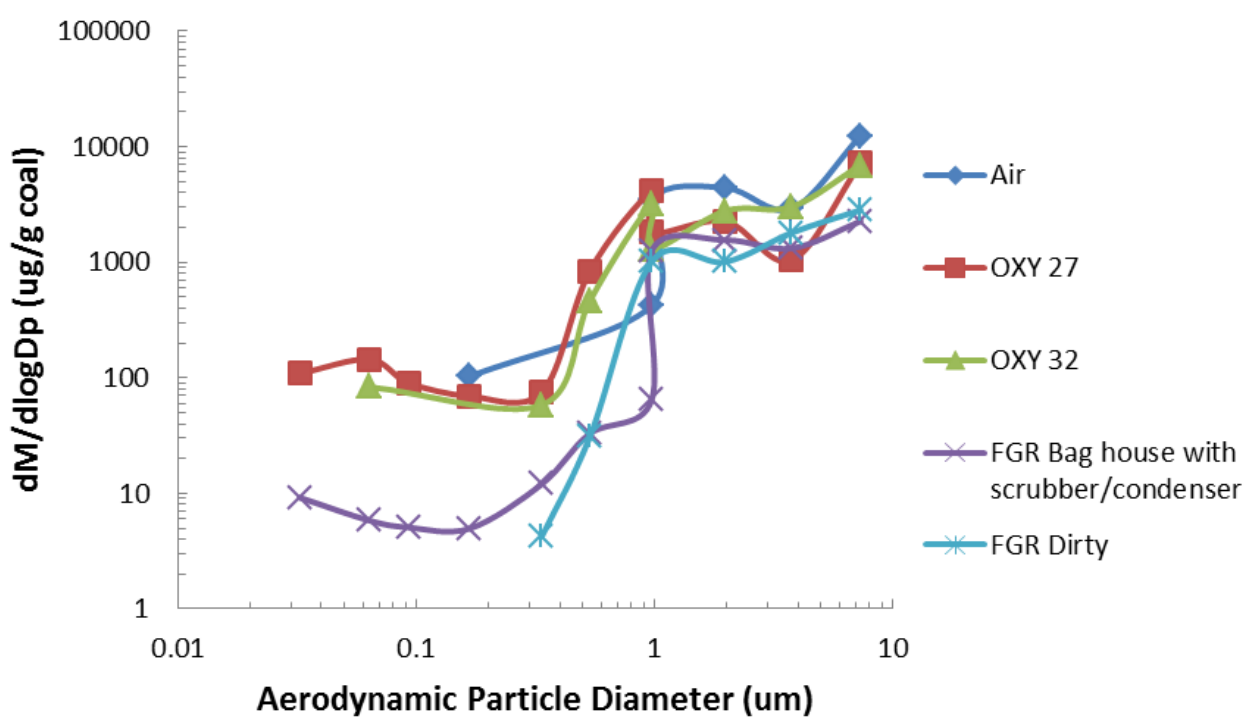

Figure 4.7-75: Silicon oxide aerosol comparison for Illinois fired coal experiments.

The phosphorus data presented in Figure 4.7-76 did not have as clear trends. The oxy-fired results had more reportable data for the submicron range compared to the air-fired condition. The air-fired condition also had a greater concentration of the larger particles greater than 5 microns than the oxy-fired conditions.

Aside from the scatter which was evident in the data, the oxy-fired conditions appeared relatively consistent. However once again there were not many data points above the detectable limits for the untreated FGR condition. The oxy-fired conditions did tend to track each other relatively well, and the once through oxy-fired conditions OXY27 an OXY32 tracked each other the most closely of all of the conditions.

The potassium results once again showed that there was a higher concentration of the element of interest in the air-fired supermicron range than the oxy-fired conditions in the supermicron range. While there are more data points above the detectable limits for the once through oxy-fired and the treated FGR conditions, overall the air-fired results did not show a corresponding decrease compared to the oxy-fired results in the sub-micron range. Also, the oxy-fired results tended to have a prominent peak in the ultrafine region below 100nm, while the air distribution did not have data points above the detectable limits as shown in Figure 4.7-77. 


\section{Illinois $\mathbf{P}_{2} \mathbf{O}_{5}$}

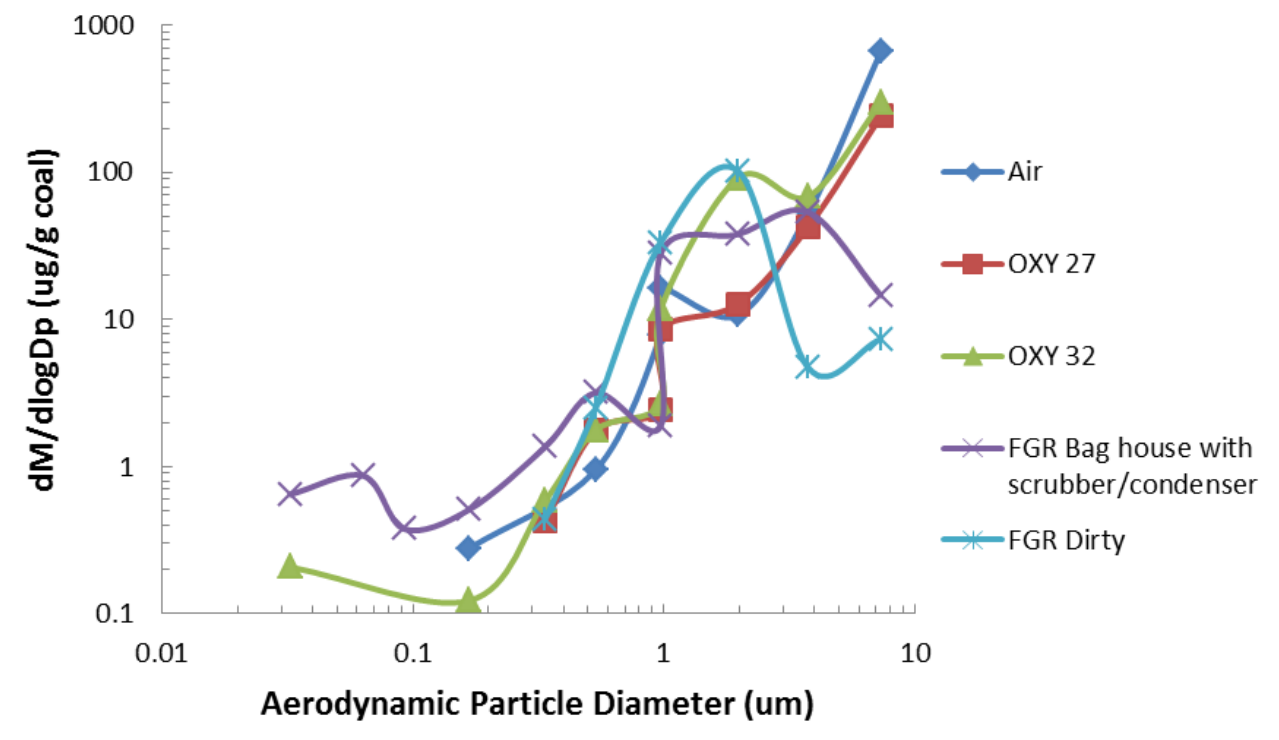

Figure 4.7-76: Phosphorus oxide aerosol comparison for Illinois fired coal experiments.

The untreated FGR oxy-fired case lacked data points to plot in the submicron range; however the treated FGR condition did track the once through oxy-fired results. Although, the once through oxy-fired results of OXY27 and OXY32 showed the most similar behavior of all combustion conditions examined.

The calcium results showed that the air-fired combustion condition had a higher concentration of calcium throughout the particle range collected by the impactor except at the sub $100 \mathrm{~nm}$ range.

\section{Illinois $\mathrm{K}_{2} \mathrm{O}$}

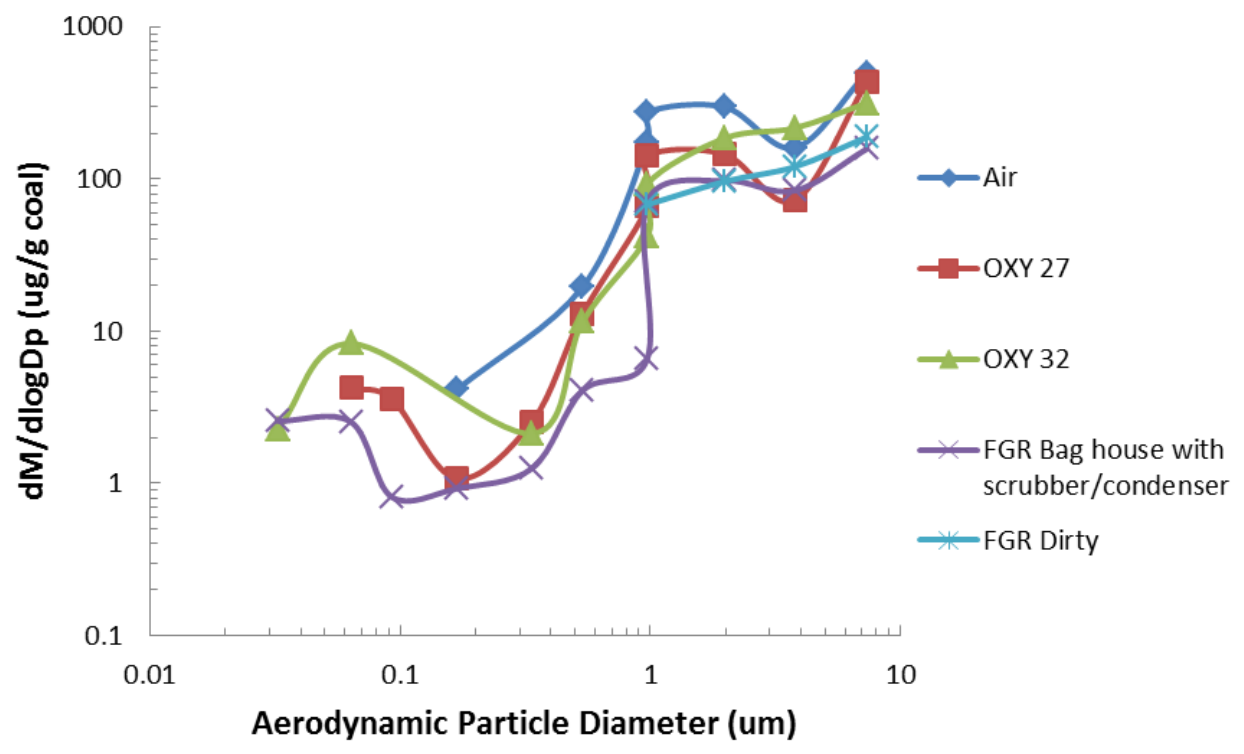

Figure 4.7-77: Potassium oxide aerosol comparison for Illinois coal fired experiments. 
Also, the oxy-fired conditions were very consistent. The untreated FGR oxy-fired condition once again was without many submicron data points, but otherwise the treated FGR and the once through OXY27 and OXY32 conditions were similar, with the once through conditions being the most similar of all conditions in Figure 4.7-78.

\section{Illinois $\mathrm{CaO}$}

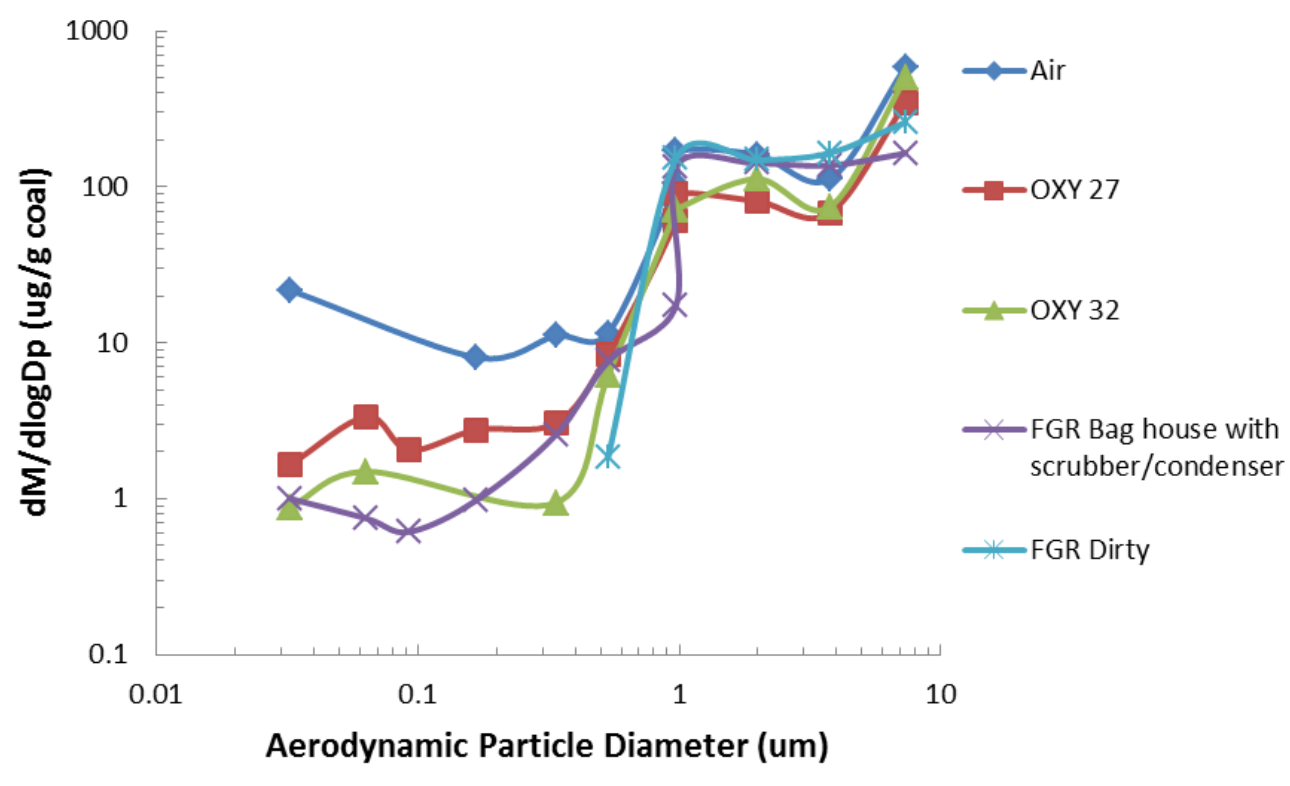

Figure 4.7-78: Calcium oxide aerosol comparison for Illinois coal fired experiments.

Results for titanium have been presented in Figure 4.7-79. While the once through oxy-fired cases were very similar and closely matched to the treated FGR case, the air-fired concentrations for titanium appeared to be greater across nearly all particle diameters than the all of the oxy-fired conditions. The untreated FGR condition was more closely aligned with other once through oxy-fired cases than with other elements.

Also, titanium was one of the few elements with reportable data in the ultrafine range for the untreated FGR conditions, but no data points were above the detectable limit for the air-fired results in the ultrafine range. 


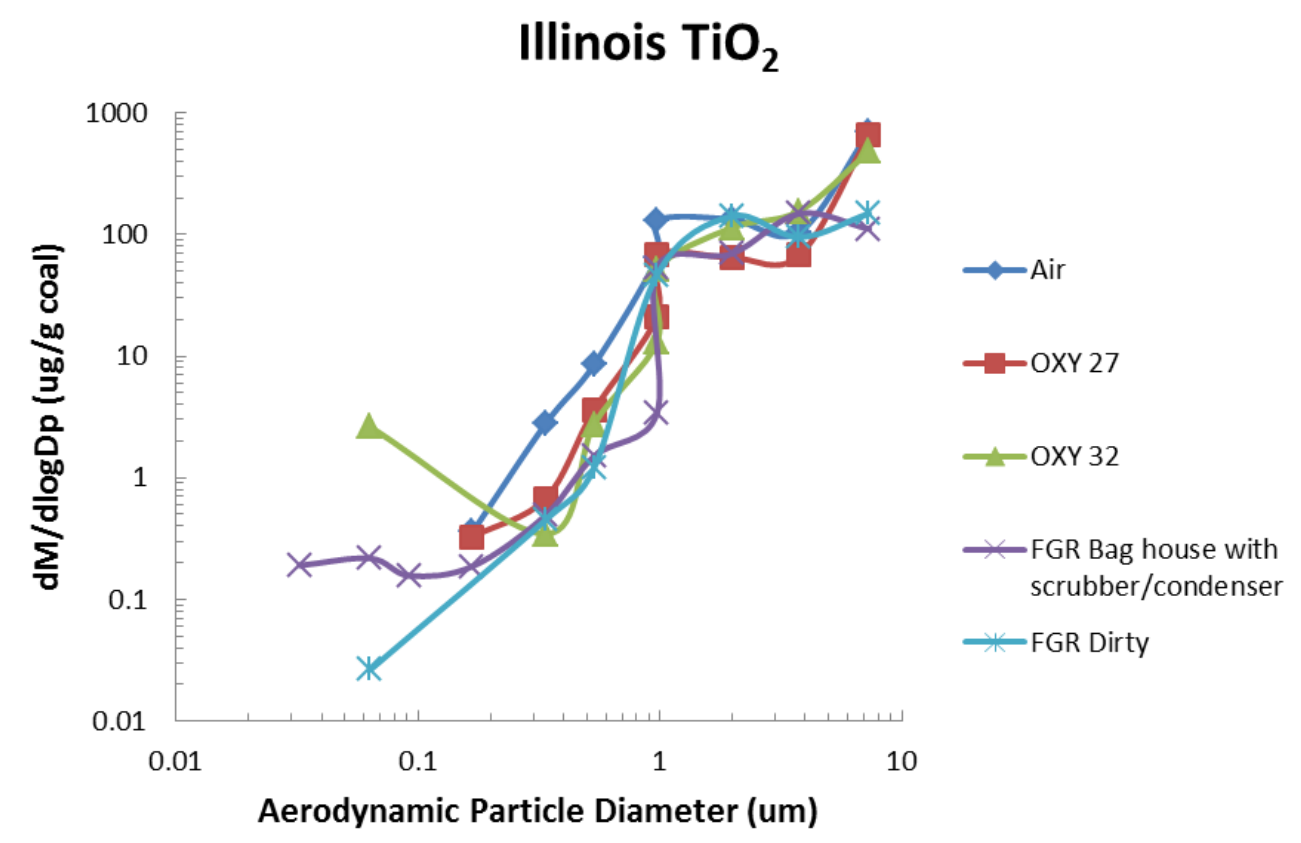

Figure 4.7-79: Titanium oxide aerosol comparison for Illinois coal fired experiments.

In general, the supermicron distribution of titanium was very similar for the air, once through, and FGR conditions. However, the air-fired condition produced higher concentrations of titanium from 100nm to 1 micron than any of the oxy-fired conditions. Finally, the once through OXY27 and OXY32 conditions once again showed only slight differences.

Iron was one of the major elements of Illinois coal ash. As was the case for most elements examined, the air-fired distribution appeared greater than the oxy-fired distributions across nearly all particle diameters though this was more apparent for the submicron range than the supermicron range. Meanwhile, the once through oxy-fired conditions OXY27 and OXY32 were nearly identical.

The FGR oxy-fired results were also very similar to the once through oxy-fired results. The main difference was less smooth coupling of the EDS and ICP-MS data for the FGR conditions. Otherwise, all oxy-fired conditions tracked each other very closely according to Figure 4.7-80.

Results were also obtained for the trace metals arsenic and selenium. Air-fired data were available for arsenic, and showed that the arsenic concentrations were higher once again for the submicron range across all conditions. Considering the incredibly low amounts, the oxy-fired data appeared very similar across all combustion conditions. Supermicron range data were not available for the once through oxyfired cases, and it should not be inferred that they are below the detectable limit. The diameters that seemed to be the most enriched with arsenic were in the ultrafine range of less than $100 \mathrm{~nm}$. Results for available arsenic data have been plotted in Figure 4.7-81. 


\section{Illinois $\mathrm{Fe}_{2} \mathrm{O}_{3}$}

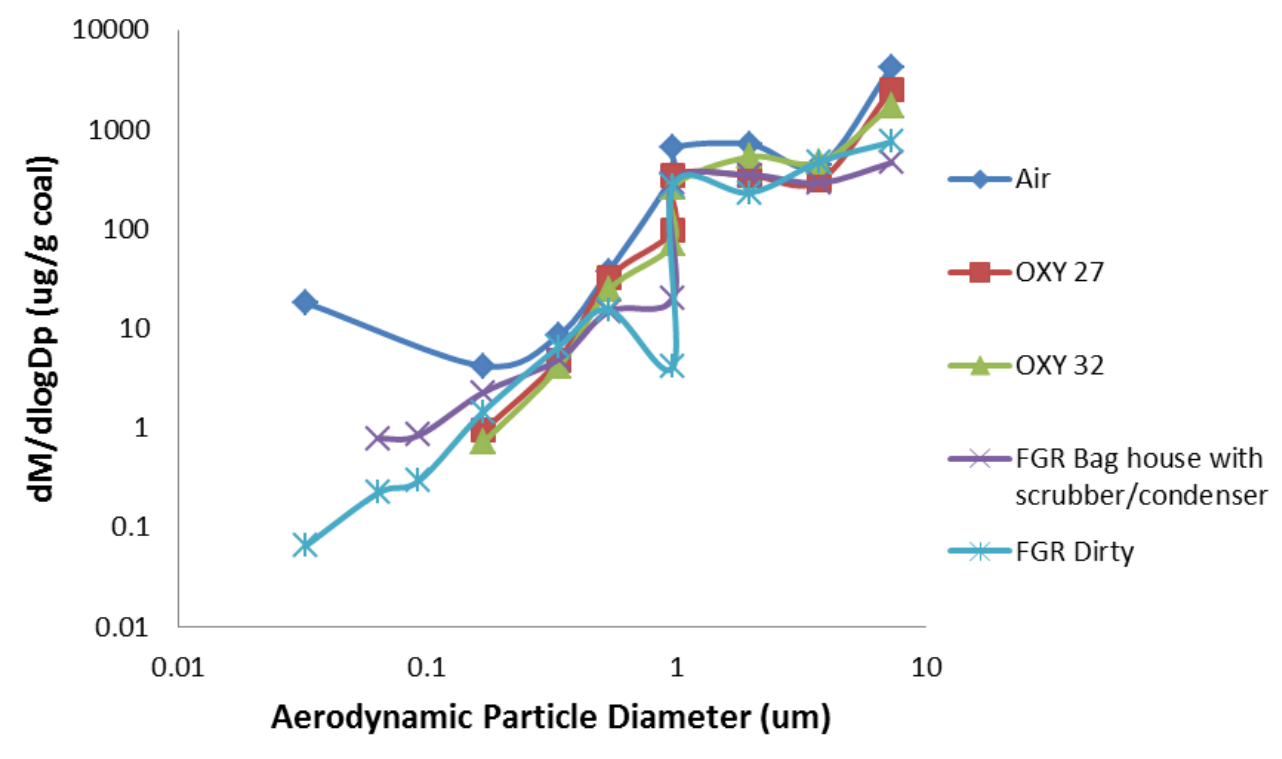

Figure 4.7-80: Iron oxide aerosol comparison for Illinois coal fired experiments.

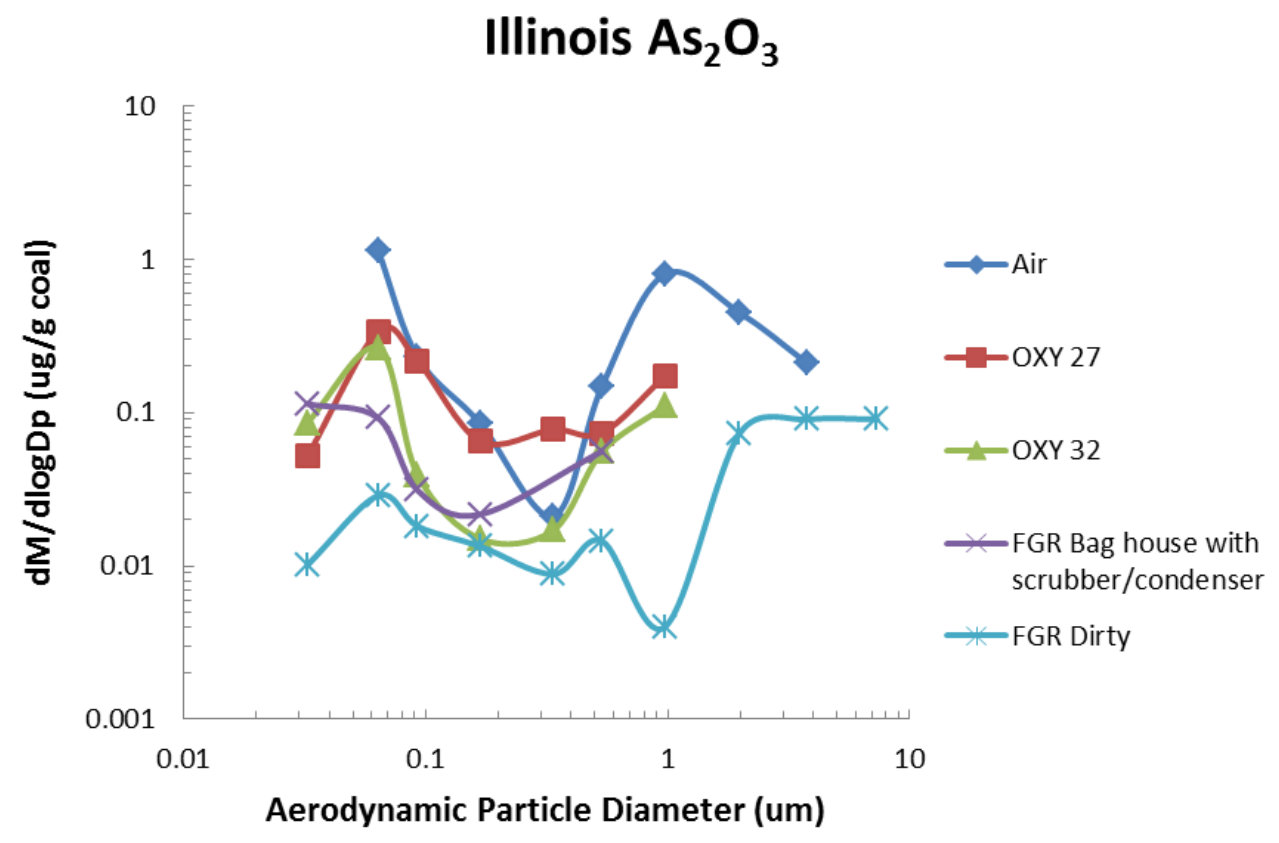

Figure 4.7-81: Arsenic oxide aerosol comparison for Illinois coal fired experiments.

In addition to arsenic, selenium was also analyzed. Unfortunately, the selenium data for the air-fired conditions were not recorded, and thus only the oxy-fired data have been reported in Figure 4.7-82. Oxyfired data were collected up to a particle diameter of 1 micron. 
The data showed that selenium was enriched in the ultrafine region of particles smaller than $100 \mathrm{~nm}$ in diameter as was observed for arsenic. In addition, there did not seem to be significant differences between the once through and FGR conditions.

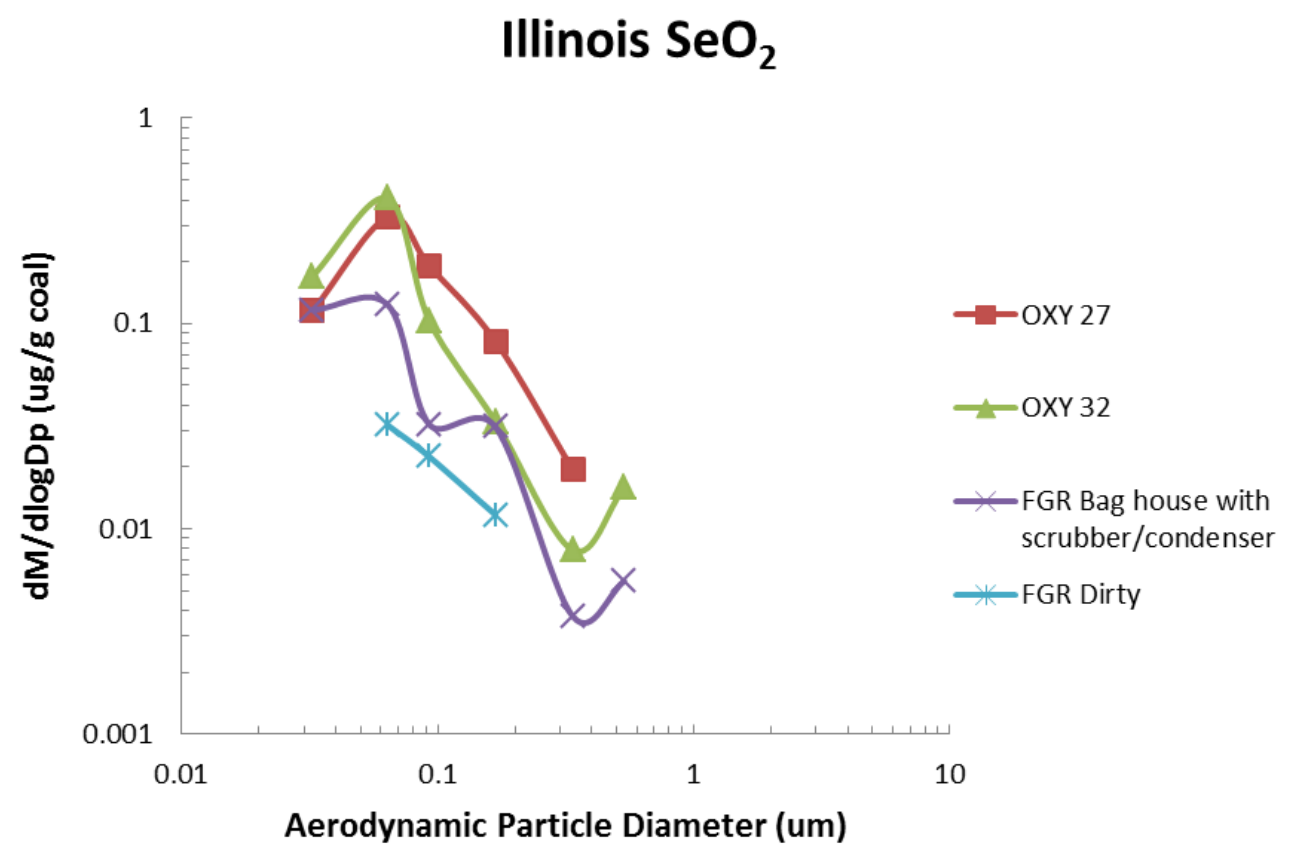

Figure 4.7-82: Selenium oxide aerosol comparison for Illinois coal fired experiments.

\subsection{Effect of Coal Composition on Size Segregated Ash Chemistry}

It was also useful to examine the differences of ash partitioning as a function of coal type and chemistry. For this reason, results were plotted comparing specific elemental oxides at a given firing condition for the three coals to see how the coal type affected the partitioning of the elements. In order to keep redundancy to a minimum, results have been compiled for specific elements of interest.

The PRB coal ash was notably high in calcium, while the Illinois coal ash was very high in iron, and the Utah coal ash was high in silicon. In addition to these elements, results have been compiled to compare the distribution of sodium, which has been important for deposits, and arsenic due to its toxicity. A range of conditions including air-fired, once through oxy-fired at $32 \% \mathrm{O}_{2}$, and untreated FGR oxy-fired have been compiled to display any changes specific to coal type and combustion condition.

Sodium was the first element compared. All three coals had similar concentrations of sodium in the supermicron range. However, there were almost no data points above the detectable limit for PRB in the submicron range. Furthermore, no significant differences appeared for the sodium concentration in the submicron range for the two bituminous coals. The results for the air-fired combustion have been plotted in Figure 4.7-83.

For the once through and FGR oxy-fired results, the supermicron range of particles showed similar concentrations for all coals and combustion conditions. However, the once through conditions showed considerably more detectable sodium than the untreated FGR conditions. For the once through cases, the PRB had the highest concentrations of sodium followed by the Illinois and the Utah bituminous coals. The results have been plotted in Figure 4.7-84. 


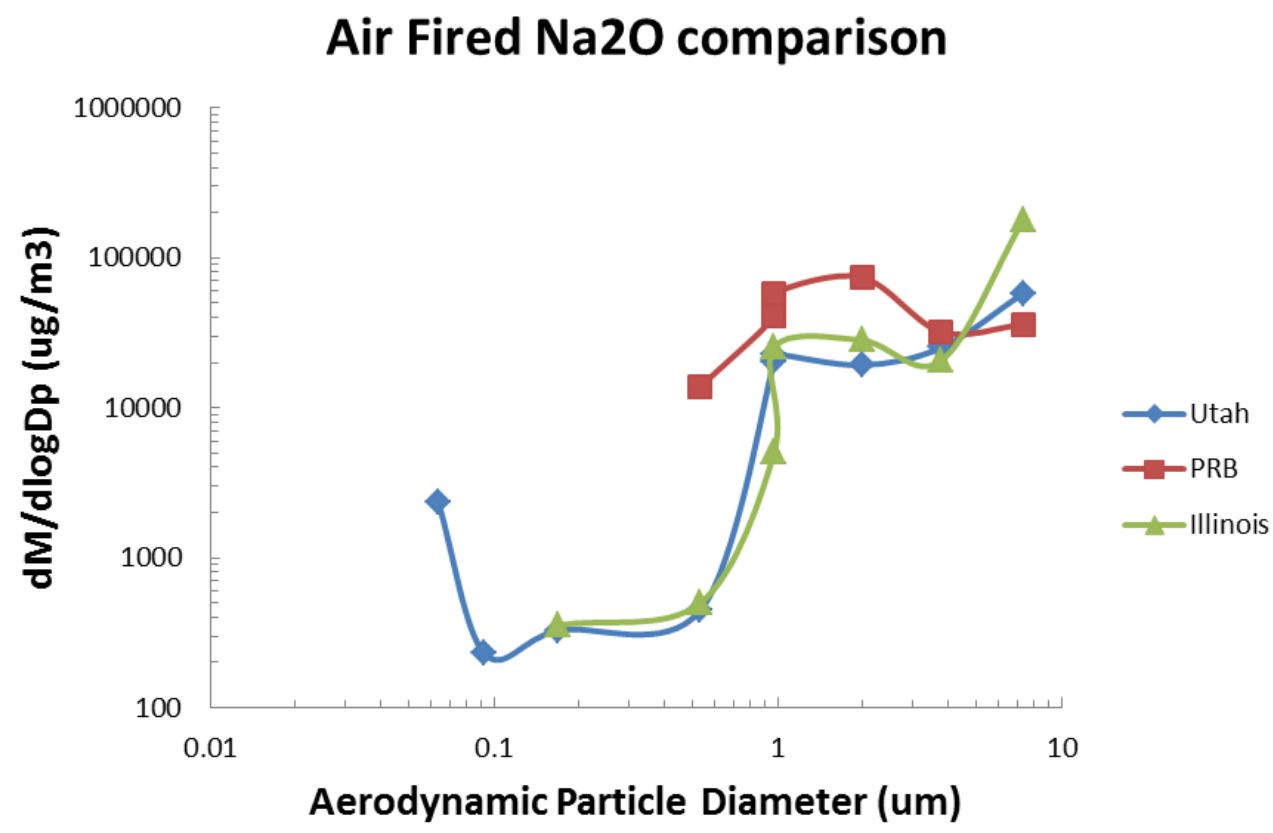

Figure 4.7-83: Sodium emissions comparison under air-fired conditions for the Utah, PRB, and Illinois coals.

\section{Oxy-Fired Na20 Coal Comparison}

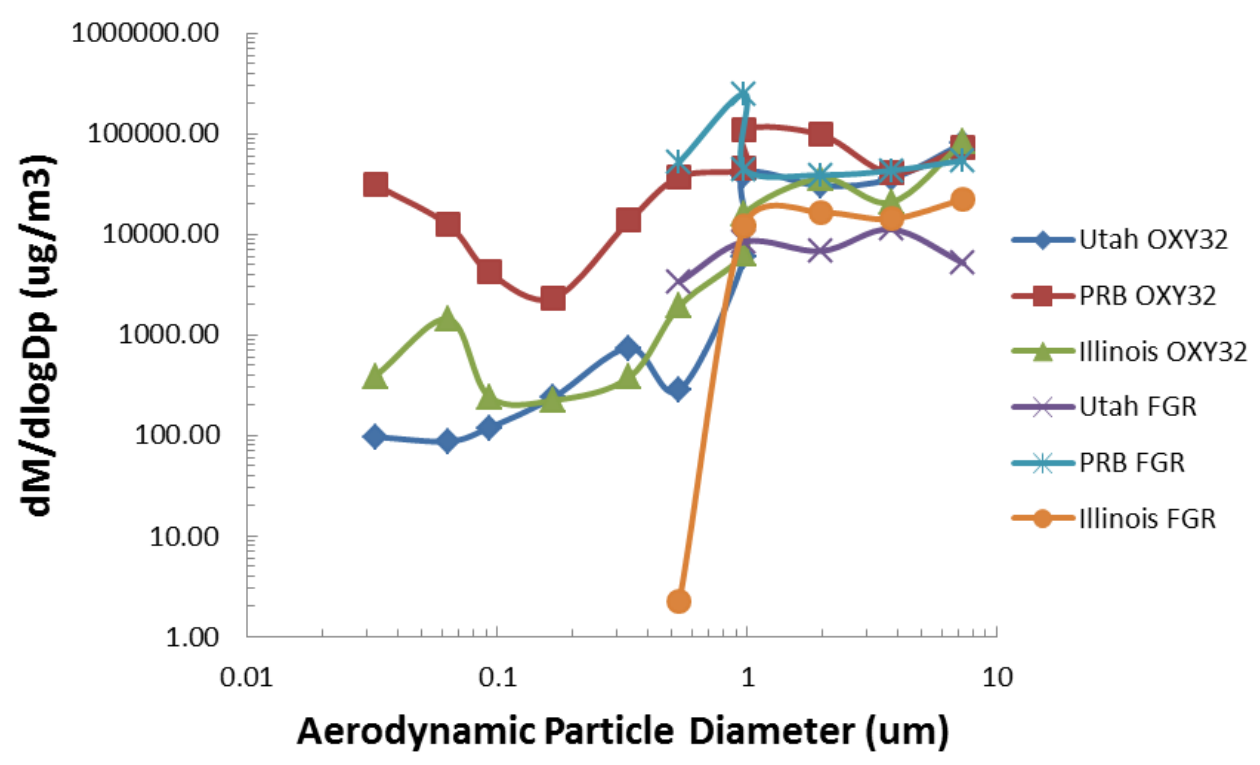

Figure 4.7-84: Sodium emissions comparison under once through and FGR oxy-fired conditions at $32 \% \mathrm{O}_{2}$ for the Utah, PRB, and Illinois coals.

The air-fired silicon results showed that there were similar concentrations of silicon in the supermicron range of particles for all three coals. However, the only sub-micron reportable results are for the bituminous coals, which had considerably higher silicon content in the ash than the PRB. The bulk mode is not completely captured with the BLPI, but the shoulder of this peak is evident, and it showed that 
more silicon in the bulk ash could be expected for the Utah and Illinois coals rather than the PRB coal. These results were reported in Figure 4.7-85.

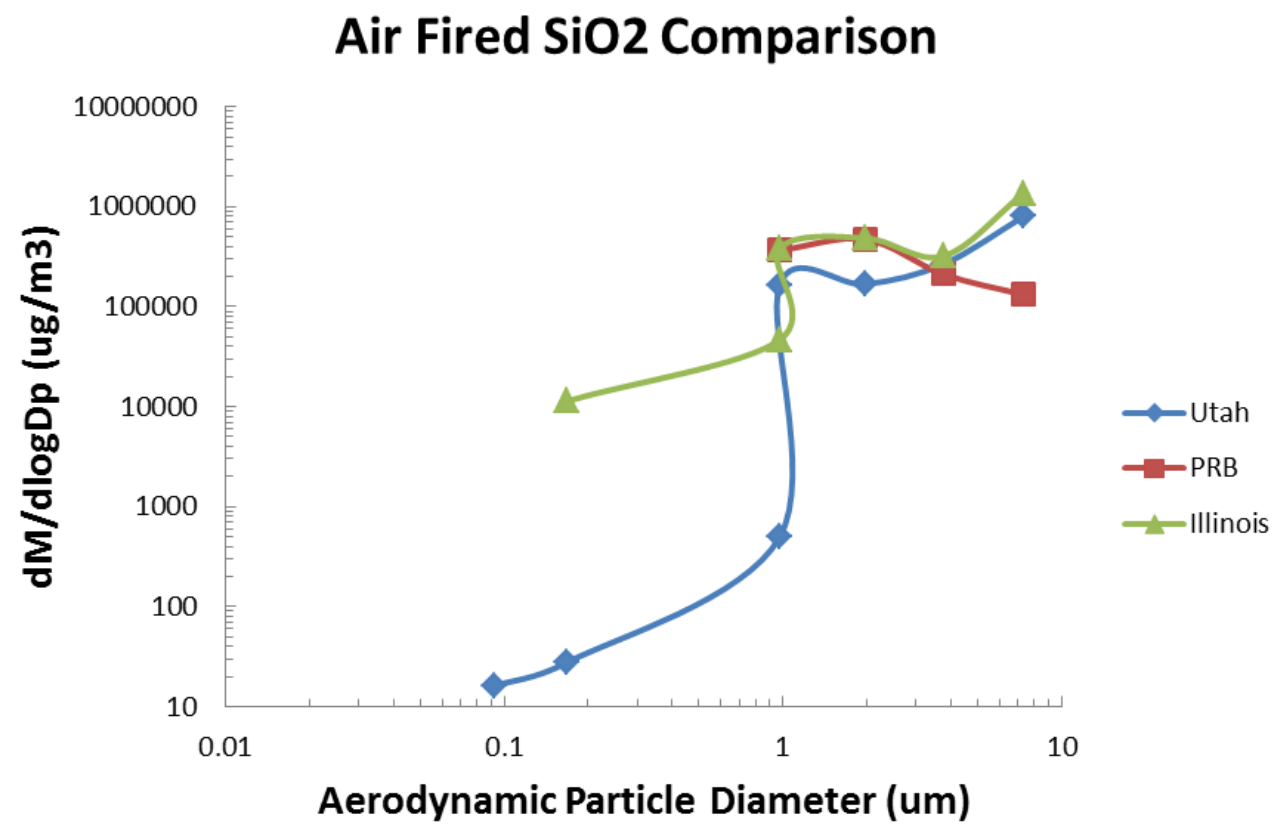

Figure 4.7-85: Silicon emissions comparison under air-fired conditions for the Utah, PRB, and Illinois coals.

The supermicron results for all coals and oxy-fired conditions were similar for silicon as well. The untreated FGR case for the Utah coal was slightly below the concentrations observed for the other coals and conditions however. Otherwise the once through cases also reported more results above the instruments detectable limits in the ultrafine range. Finally, the silicon results for the PRB coal were highest in the sub-micron range. The results have been plotted in Figure 4.7-86.

Results were also compiled for calcium under air-fired conditions. The calcium content of the PRB ash is much higher than the calcium content for either the Illinois or Utah coals. As a result, the concentration of calcium in the ash aerosol is much greater for the PRB coal compared to the Utah or Illinois as shown in Figure 4.7-87. 


\section{Oxy-Fired SiO2 Coal Comparison}

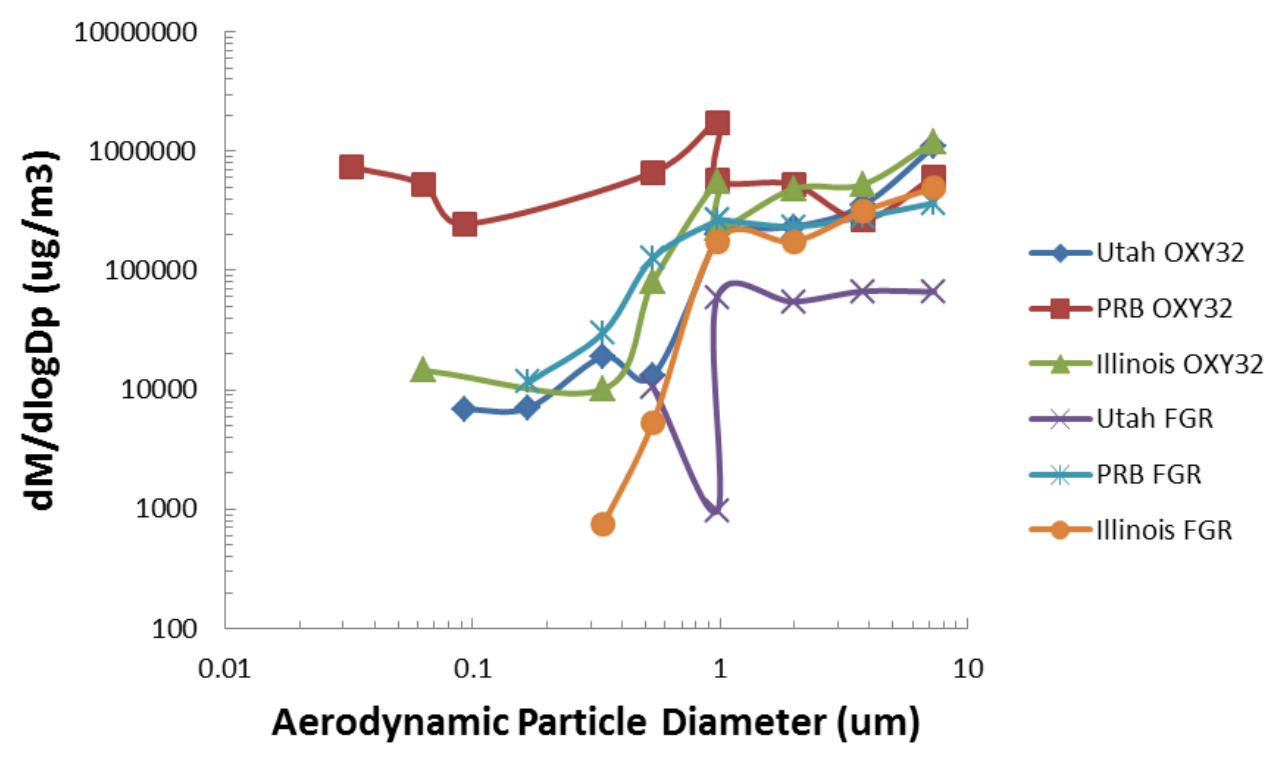

Figure 4.7-86: Silicon emissions comparison under OXY32 and untreated FGR conditions for the Utah, PRB, and Illinois coals.

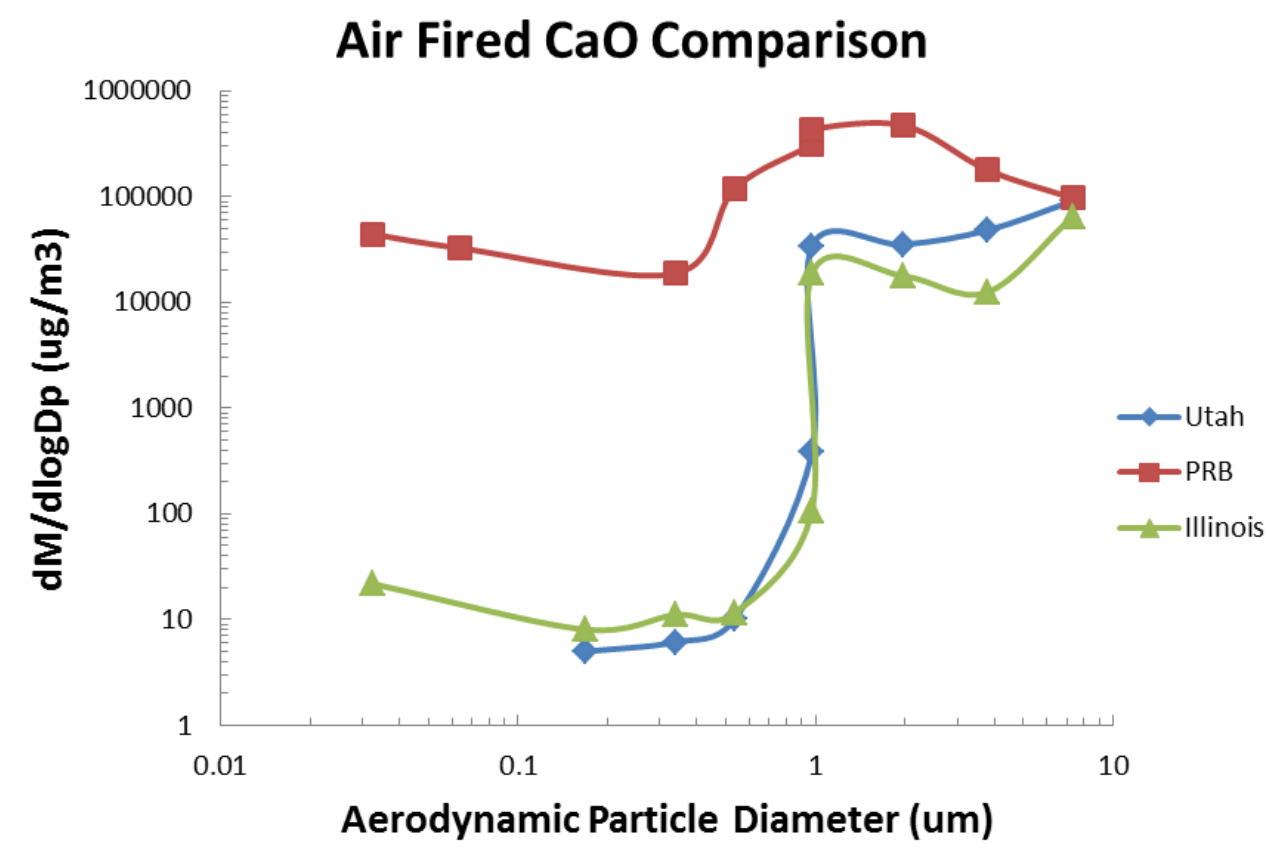

Figure 4.7-87: Calcium emissions comparison for the air-fired condition and the Utah, PRB, and Illinois coals.

These trends were also observed for the once through and FGR conditions as well. The FGR conditions did not record detectable results for most of the submicron range, but the once through conditions indicated far more calcium across the entire particle diameter range for the PRB coal than the bituminous coals according to Figure 4.7-88. 
The content of the iron in the Illinois ash was considerably higher than the iron in the ash of the other coals. However this did not necessarily manifest in huge differences of iron concentration in the flue gas. Under air-fired conditions, the amount of sub-micron iron was similar between the Illinois and PRB coals, which were considerably more than the concentration of iron in submicron particles for the Utah coal. However, at the largest particle diameter collected by the impactor, there was considerably more iron reported for the Illinois coal than the other coals as illustrated in Figure 4.7-89.

\section{Oxy-fired CaO Comparison}

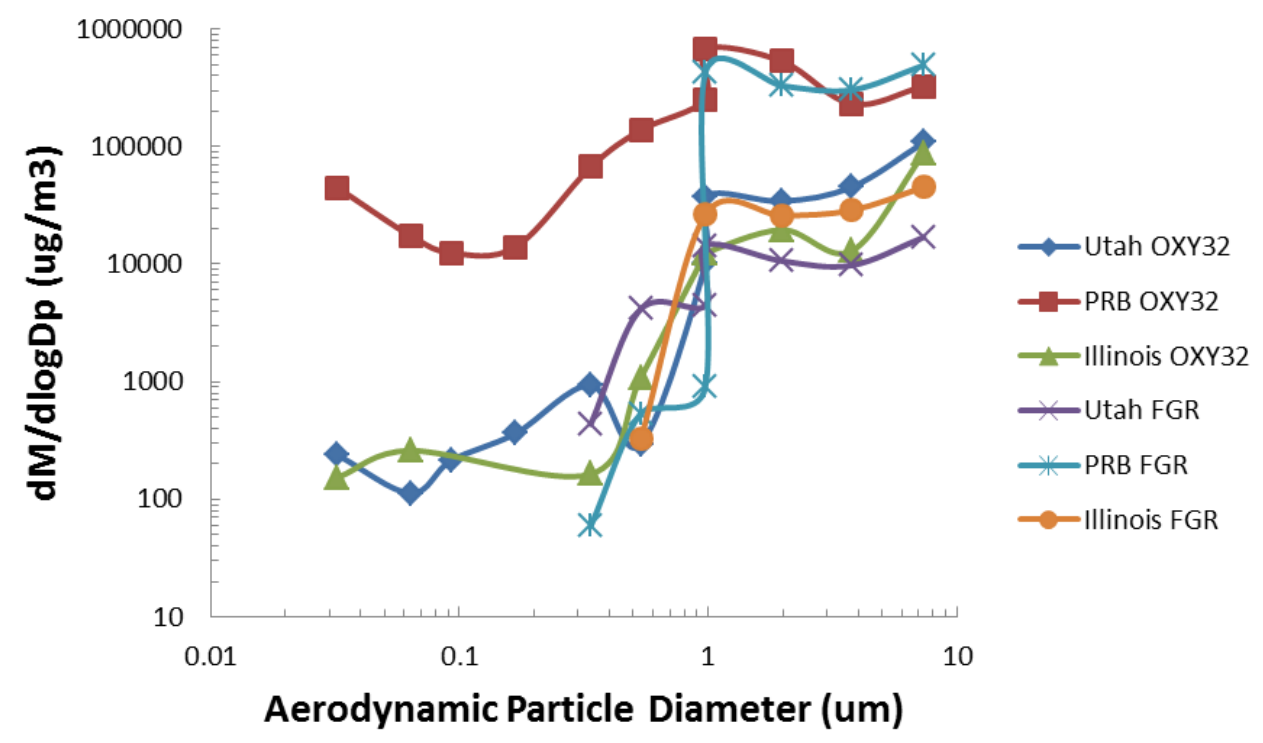

Figure 4.7-88: Calcium emissions comparison for the oxy-fired and FGR cases of the Utah, PRB, and Illinois coals.

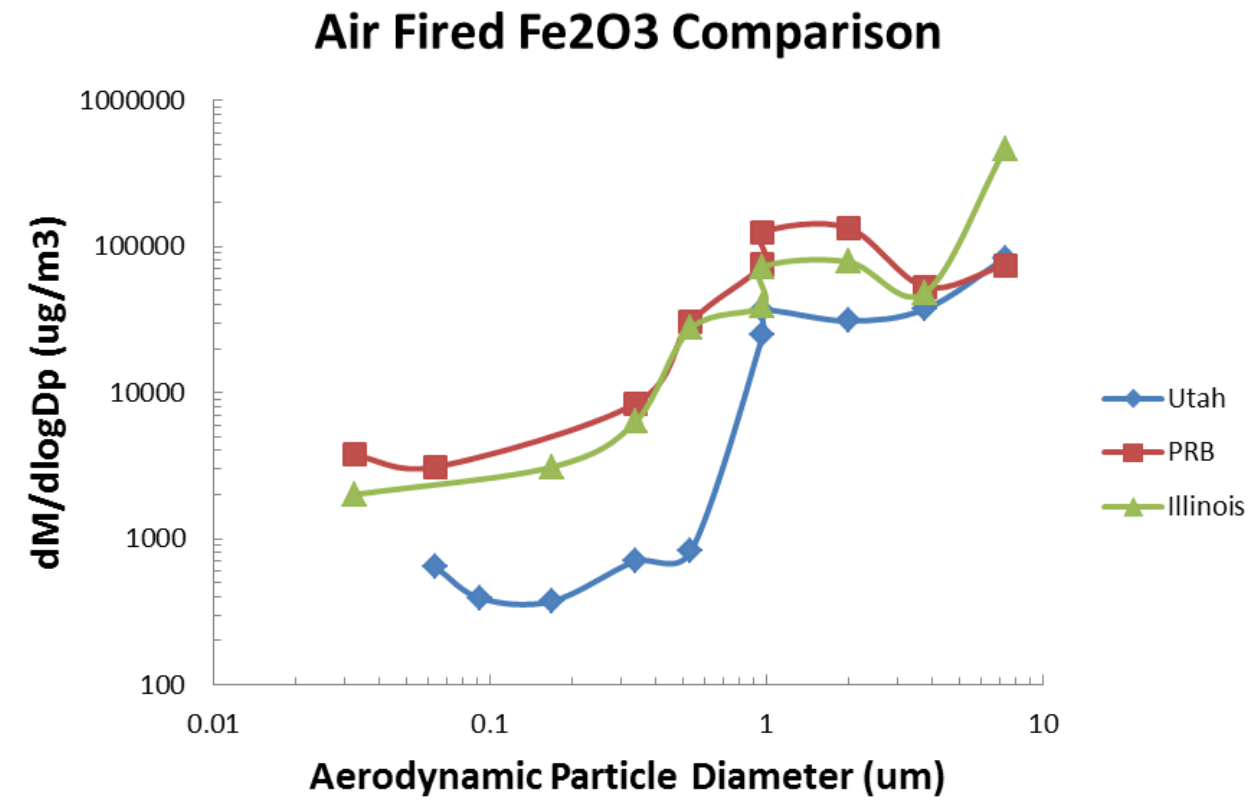

Figure 4.7-89: Air-fired comparison of iron emission of the Utah, PRB, and Illinois coals. 
Under once through oxy-fired and FGR conditions, the PRB showed the greatest concentrations of iron in the submicron range and there was a greater similarity in the emissions concentrations of the Utah and Illinois coals in the submicron range. In the supermicron range, the Utah coal was once again the lowest, but the Illinois was similar to the PRB coal rather than being considerably greater as was the case under air-fired conditions as shown in Figure 4.7-90.

The Illinois coal was the only one that had enough detectable data points to produce a curve for arsenic emissions under air-fired conditions. The other coals only had two impactor stages where arsenic was above the detectable limit for the ICP-MS. However, it was clear that the Illinois coal had a much higher concentration of arsenic in the ultrafine particle range as shown in Figure 4.7-91.

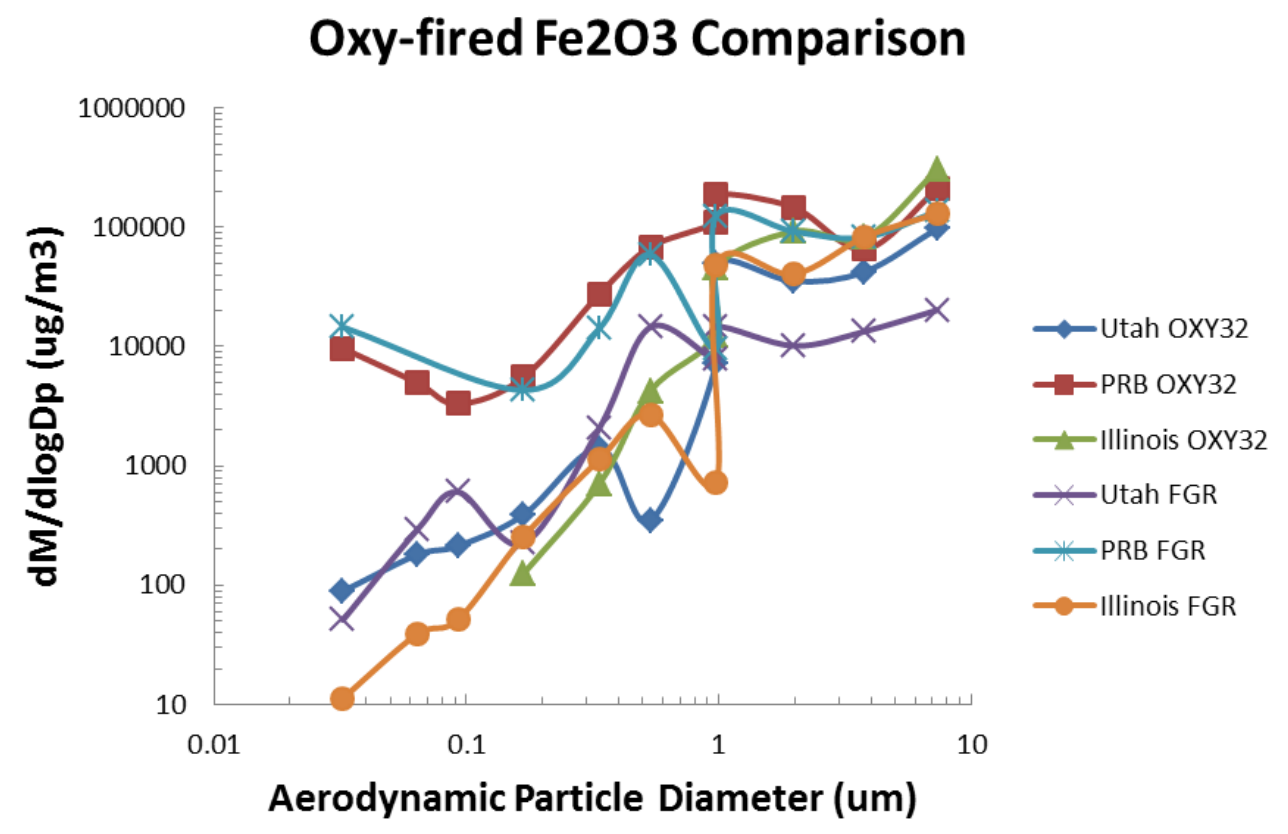

Figure 4.7-90: Oxy-fired and FGR comparison of iron emissions from the Utah, PRB, and Illinois coals. 


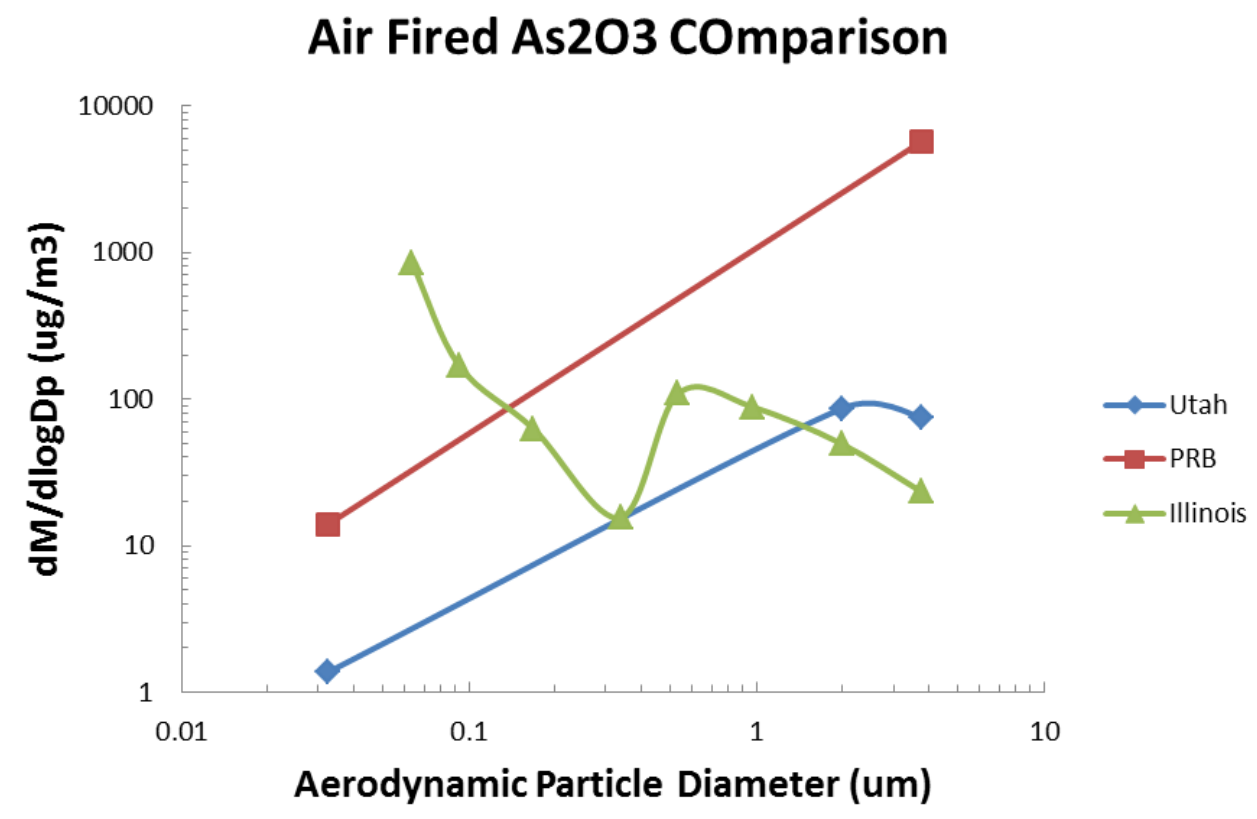

Figure 4.7-91: Air-fired emissions comparison of arsenic for the Utah, PRB, and Illinois coals.

Under oxy-fired conditions, the PRB once again became the most enriched coal compared to the others in the compound of interest. The PRB coal emissions, shown in Figure 4.7-92, had the greatest concentrations for arsenic. The Illinois coal concentrations were still greater than those for the Utah coal. Also, the Illinois coal still had a very high concentration of arsenic found in the ultrafine particle region. The concentration of arsenic in the ultrafine region was similar to that of the concentration found for the $\mathrm{PRB}$ in the sub $100 \mathrm{~nm}$ region.

\section{Oxy-fired As203 Comparison}

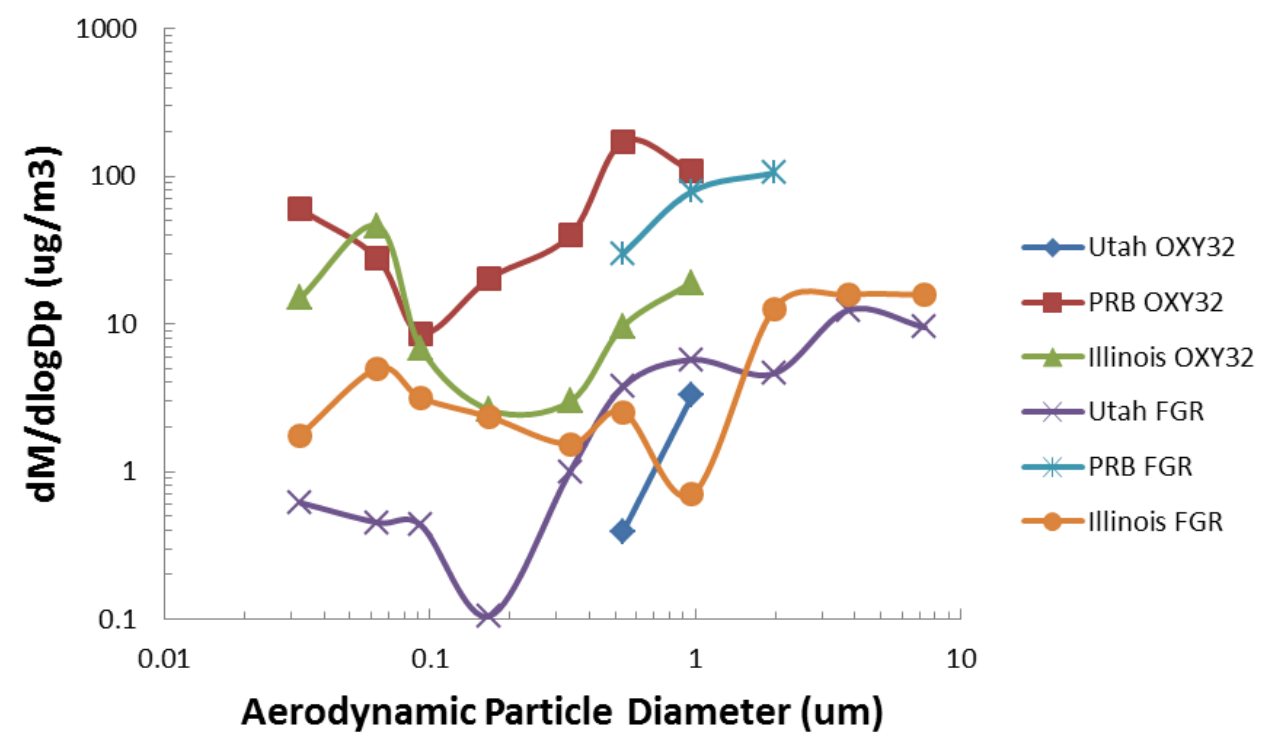

Figure 4.7-92: Once through and FGR oxy-fired arsenic emissions comparison for the Utah, PRB, and Illinois coals. 


\subsubsection{Discussion}

\subsubsection{Loss on Ignition}

The LOI results generally showed that the once through oxy-fired conditions had a lower amount of carbon in the ash (LOI) than the air-fired cases. There are likely three primary reasons for this behavior. The first is that the OXY27 and OXY32 cases have a higher percentage of oxygen in the furnace which would facilitate greater burnout of the char particles. The second is that under OXY27 and OXY32 conditions there is less flue gas volume, and therefore a longer residence time within the furnace allowing a longer time for char oxidation to occur. Finally, gasification of the char by $\mathrm{CO}_{2}$ and $\mathrm{H}_{2} \mathrm{O}$ which are present in high concentrations under wet oxy-fired recycle conditions may also further oxidize the char particles.

However, there was one case which was clearly unusual. For the case of the Utah OXY32 at the $3 \% \mathrm{O}_{2}$ in the flue gas scenario, there was a sharp increase in the LOI from the $2 \% \mathrm{O}_{2}$ in the flue gas scenario. As a result, the $3 \% \mathrm{O}_{2}$ OXY32 case had greater LOI than the OXY27 and air-fired case as was shown in Figure 4.7-7. This anomalous behavior was also seen in an increase in the black carbon or soot concentration for the OXY32 case from $2 \%$ to $3 \% \mathrm{O}_{2}$ in the flue gas as measured by the PA on different days as was shown in Figure 4.7-10.

If greater soot was produced, as was indicated by the PA measurements, this would lead to a corresponding increase in the carbon found in the ash for the Utah coal at the OXY32 $3 \% \mathrm{O}_{2}$ condition and thus an increase in LOI. However, this specific data point seemed to say more about unusual perturbations of a specific condition in a specific furnace than fundamental behaviors of combustion conditions.

All coals had decreasing or stable LOI as the amount of $\mathrm{O}_{2}$ in the flue gas increased except for PRB, which reached a point at which the LOI increased as the amount of excess oxidant was increased, which was observed in Figure 4.7-8. This was clearly a residence time effect. The amount of carbon in the ash decreased as the oxygen concentration in the flue gas increased from $0 \%$ to $2 \% \mathrm{O}_{2}$ in the flue gas. The air-fired case was reduced from approximately $6.5 \%$ to $4.5 \%$ and the oxy-fired cases reduced LOI from approximately $5 \%$ to $3.5 \%$. However, from $2 \%$ to $3 \% \mathrm{O}_{2}$ in the flue gas the air and oxy-fired conditions all increased the LOI at least a full percentage point.

The most logical explanation for this behavior is that the PRB coal was affected by residence time in a fixed geometry furnace. It is common knowledge that PRB has a very reactive char. However, in order to match the same firing rate in the OFC as the bituminous coals, nearly $40 \%$ more coal mass had to be introduced into the furnace as compared with the Utah Skyline coal. As a result, with more mass passing through a fixed geometry, the residence time is decreased. Thus as the oxidant amount fed into the furnace with the coal is increased there is more oxygen to react with the char particles, but as that mass is increased, the residence time decreases until soon the lack of residence time in the furnace dominates the increased amount of available oxygen, and thus the amount of carbon observed in the ash increased.

The data presented in Section 4.1 showed that there were two main factors that influenced the amount of carbon in the ash (LOI). The first is oxygen concentration, both in terms of the amount of oxygen in the oxidant stream and in terms of the amount of excess oxygen in the flue gas. The second critical factor was residence time in the furnace. If the residence time was not sufficient, then increased LOI was the result. 


\subsubsection{Black Carbon Aerosols}

The black carbon aerosol data showed that oxy-firing decreased soot formation across all coals and most stoichiometric ratios and oxy-fired conditions when compared to air firing. This reaffirmed the hypothesis presented by Molina and Shaddix that the high $\mathrm{CO}_{2}$ concentrations of oxy-firing would reduce the diffusion of oxygen to the coal particles which would lead to lower pyrolysis product yields and thus lower concentration of soot formation from the tar yields (Shaddix and Molina, Particle Imaging of Ignition and Devolatilization of Pulverized Coal During Oxy-Fuel Combustion 2009).

The concentration of soot nearly always decreased with the increasing amount of oxygen available in the furnace. As excess oxidant was added and the stoichiometric ratios increased, the soot concentration was reduced as the soot was oxidized as would be expected. As the oxygen increases, the oxidation rate also increases thus eliminating soot particles.

In addition, the results comparing coals showed that coal composition has a very significant impact on the amount of soot produced. Under air and once through oxy-fired conditions, it was very clear that the two bituminous coals produced significantly more soot than the lower rank PRB as was shown in Figure 4.7-18 and Figure 4.7-19. As previously discussed, since soot production is a function of pyrolysis products and volatiles in the coal, it was not surprising that the Utah and Illinois coals, which were 38.6\% and $36.78 \%$ volatiles, respectively, had greater soot production than the PRB coal which was only $33.36 \%$ volatiles as shown in Table 4.7-5.

Under air-fired and once through oxy-fired conditions, these differences were significant since the Utah coal had an average concentration of $2332 \mu \mathrm{g} / \mathrm{m}^{3}$ of soot at $3 \% \mathrm{O}_{2}$ in the flue gas while the PRB coal was $47 \%$ of the concentration at the same condition with a concentration of $1096 \mu \mathrm{g} / \mathrm{m}^{3}$.

This trend was also observed during once through OXY27 conditions where the Utah coal soot emissions were reduced to $370 \mu \mathrm{g} / \mathrm{m}^{3}$ and the PRB emissions were reduced to $171 \mu \mathrm{g} / \mathrm{m}^{3}$, which is $46 \%$ of the concentration of the Utah coal. This suggested that, for once through conditions, a reduction of soot was equivalent across coals of different ranks.

However, this did not hold for the wet untreated FGR conditions which were only analyzed for the Utah and PRB coals. This was due to limitations of both time and the lack of ability to analyze the untreated recycled flue gas of the Illinois coal safely. Under the untreated FGR conditions, the difference between the soot emissions for the PRB and Utah coals disappeared. At $3 \% \mathrm{O}_{2}$ in the flue gas for the untreated FGR condition, average soot measurements of $137 \mu \mathrm{g} / \mathrm{m}^{3}$ for the Utah coal and $155 \mu \mathrm{g} / \mathrm{m}^{3}$ for the PRB coal were recorded.

Under the wet flue gas recycle condition, there was a tremendous difference in the moisture content of the flue gas being recycled into the furnace compared with the dry $\mathrm{CO}_{2}$ from the tank for once through tests. For the Utah coal, this meant that the moisture content increased to $30 \%$ by volume compared with a negligible amount of moisture present in the air and once through cases.

It has been shown that steam can oxidize soot (Stanmore 2001) and this clearly had a very significant impact on the further reduction of soot emissions for the Utah coal. The PRB coal is nearly $24 \%$ moisture, and thus did not see the same significant reductions in soot emissions under the untreated FGR conditions.

As a result, moisture and $\mathrm{CO}_{2}$ both had a very significant effect on reducing soot emissions from coal flames. There were several mechanisms that were responsible for these observations. As previously discussed, $\mathrm{CO}_{2}$ reduces transport of oxygen to the coal particles and thus inhibits pyrolysis as well as 
reducing local temperature. Water vapor, with a high heat capacity, could also reduce local particle temperature and contribute to a further reduction of pyrolysis and tars that form the building blocks for soot. Secondly, moisture also has the ability to oxidize soot and thus cause a further reduction in soot emissions.

It has been shown that by operating under wet flue gas recycle conditions soot emissions can be reduced from an average concentration of 2332 to $137 \mu \mathrm{g} / \mathrm{m}^{3}$ for the Utah bituminous coal. The sub-bituminous PRB coal also showed considerable reduction of soot from 1096 to $155 \mu \mathrm{g} / \mathrm{m}^{3}$. While the relative decrease was certainly more dramatic for the Utah coal, these studies have shown that it is possible to make significant reductions of soot emissions during the retrofit to oxy-firing with wet recycled flue gas.

\subsubsection{Particle Size Distributions}

An important consideration for the particle data is how well the data from different analytical methods matched up. It was noted in the results Section 4.3 that the PRB coal had a higher concentration of particles than the Utah and Illinois coals in the submicron mode when the data were collected with the BLPI; however, when collected with the SMPS, the PRB coal had a lower particle concentration. This indicated that there was not consistent agreement between particle instruments.

In order to understand this further, PSDs have been plotted with both the SMPS/APS and the BLPI data so that a comparison can be made of the particle instruments and the impactor. The particle instruments use different fundamentals such as the SMPS using electronic mobility rather than aerodynamic particle diameter which is how the BLPI was designed. Furthermore, the SMPS has to assume particle densities and spherical geometries, while the BLPI is a gravimetric measurement of captured particles that may have been subject to error in terms of substrate preparation and the potential for particle bounce and improper loading. These sources of error were kept to a minimum, but could still account for disagreement between the two methods.

Sampling effects could also be a concern due to the high moisture content of the PRB ash. However, no water condensation was observed while sampling the PRB coal with the SMPS, so it is highly unlikely that condensation and nucleation caused an underreporting of results.

The comparisons have shown that the BLPI may not have been the most accurate instrument for all aerosols compositions; however it was still a very useful piece of equipment due to its ability to take size segregated samples for chemical analysis.

The data that were collected with the SMPS were collected simultaneously with another instrument, the $\mathrm{PA}$, and a comparison of these data has been very useful and insightful.

While the BLPI may have had limitations regarding its accuracy across all aerosol compositions, it still adequately illustrated different modes that existed for the Utah and Illinois coals. However, when the SMPS data were compared to the PA data, which were collected simultaneously, important patterns emerged.

The Utah coal seemed to have the greatest agreement between the SMPS/APS and the BLPI, although they were not perfectly matched as shown in Figure 4.7-93.

The PRB coal, on the other hand, had very poor agreement between the SMPS in particular and the BLPI data as shown in Figure 4.7-94. This may have been a result of particle bounce giving an erroneously high concentration of particles for the PRB in the submicron range. The PRB coal has much different chemical composition than the ash for the Utah and Illinois coals and sampling was not completed with a 
cyclone to capture large particles and extend sampling time for the submicron particle stages. Thus, larger particles may have traveled further through the impactor and deposited on plates in the submicron region giving an erroneously high concentration of submicron particles with the impactor.

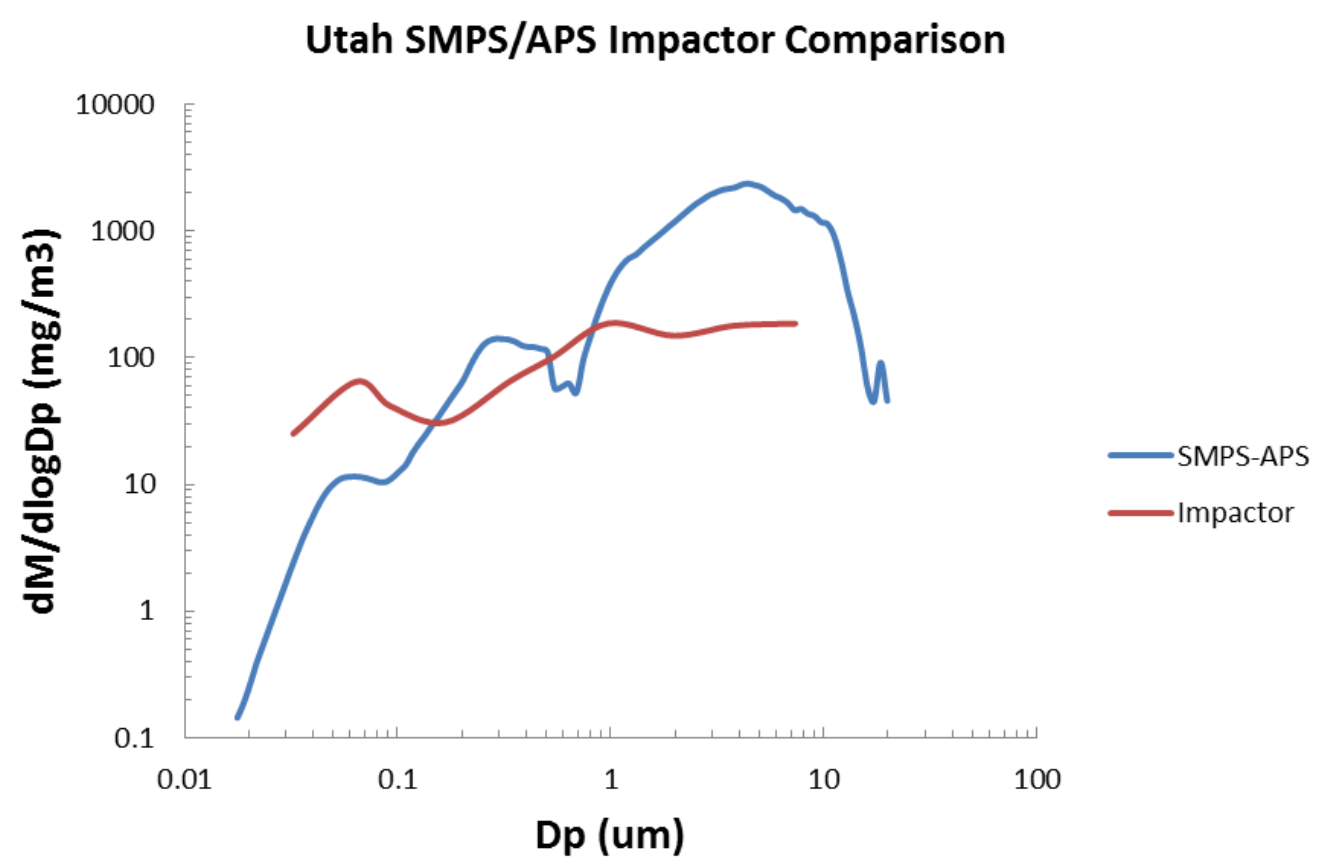

Figure 4.7-93: Comparison of SMPS/APS and BLPI PSDs for the Utah coal.

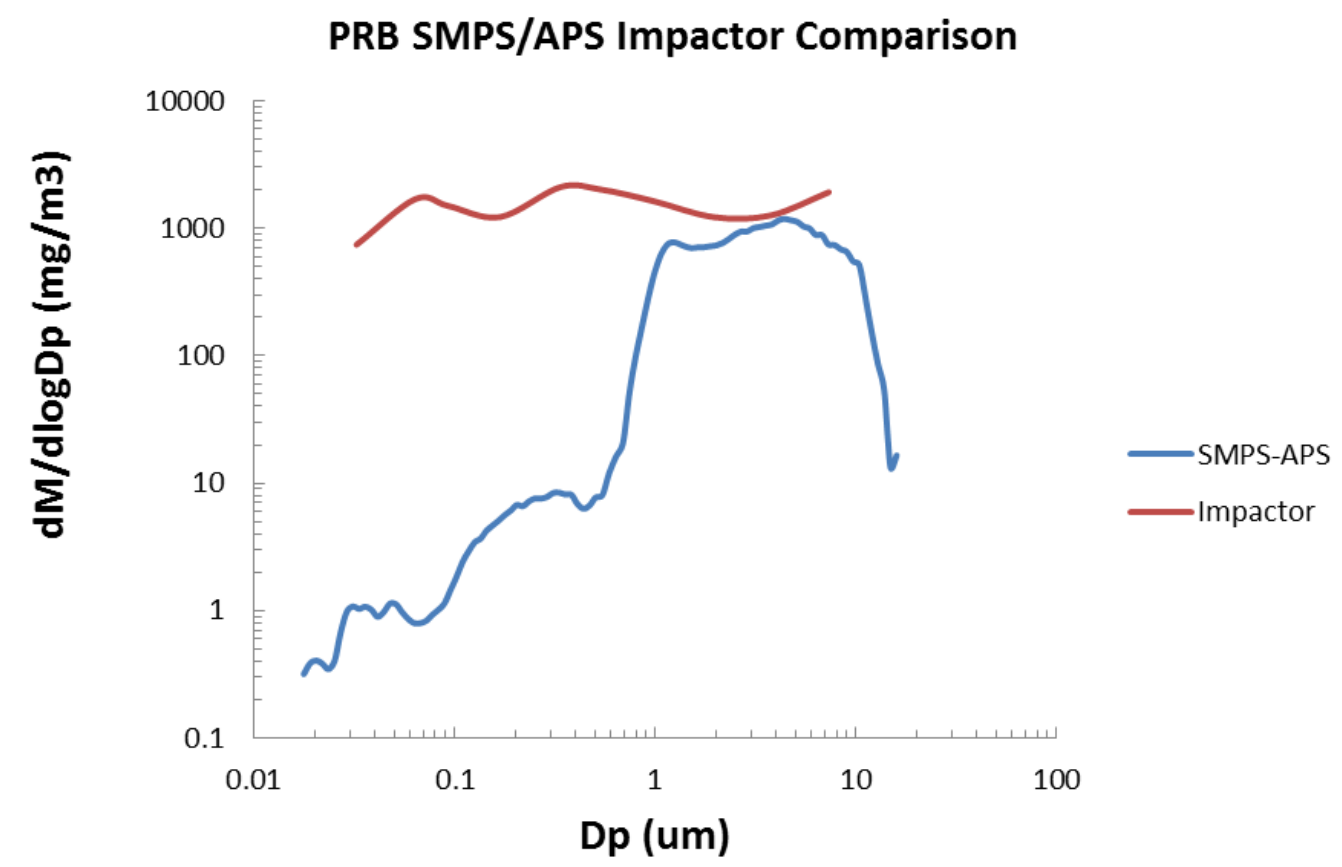

Figure 4.7-94: Comparison of SMPS/APS and BLPI PSDs for the PRB coal. 
The results of the comparison for the Illinois coal, illustrated by Figure 4.7-95, were much more consistent than those of the PRB coal. This further indicated that particle bounce was likely the cause of the difference between the SMPS/APS data and the impactor data for the PRB coal. This suggests that the SMPS/APS is more accurate for particle size distributions than the impactor.

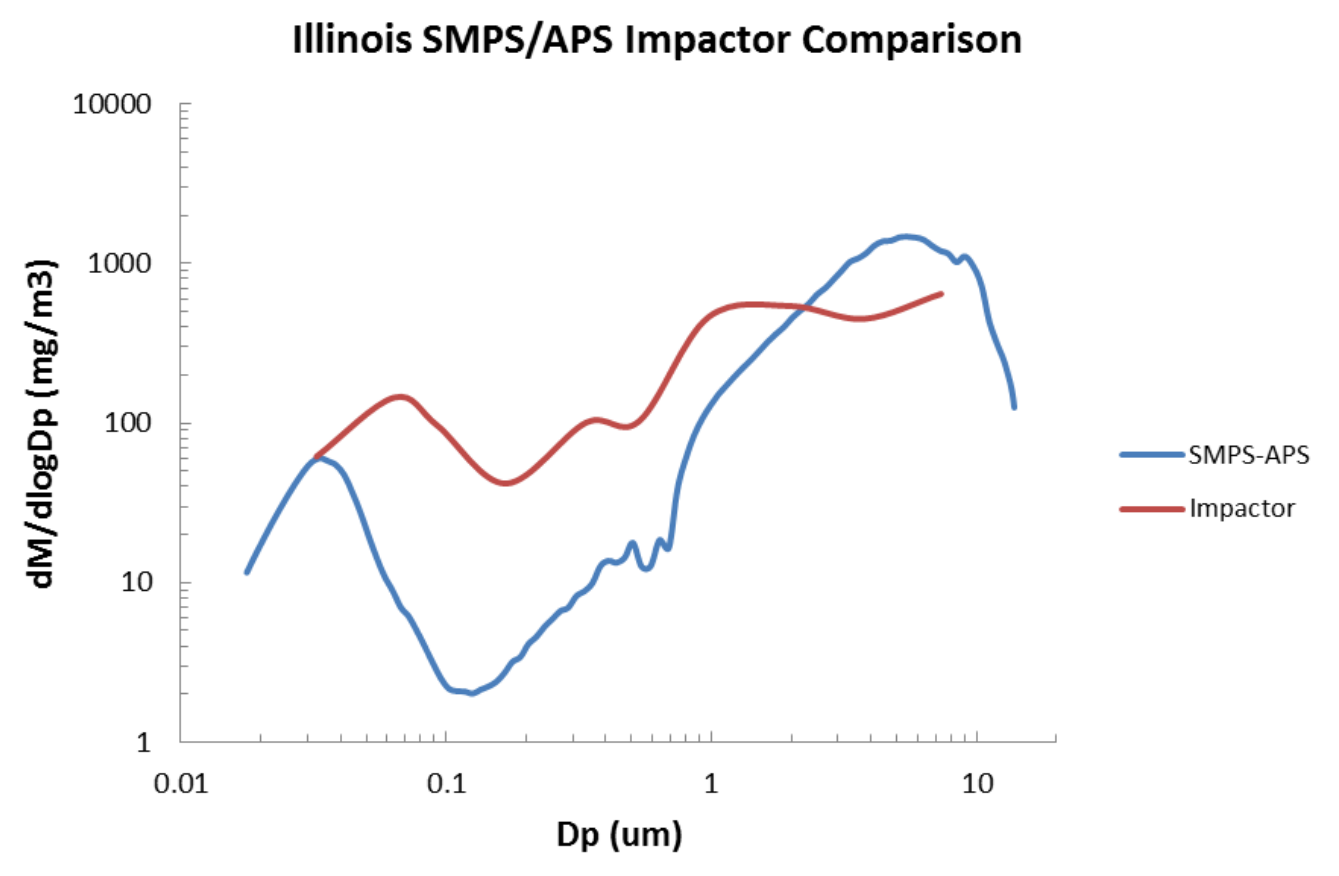

Figure 4.7-95: Comparison of the SMPS/APS and BLPI results for the Illinois coal.

The total concentration of particles measured below $\sim 670 \mathrm{~nm}$ by the SMPS at a given condition was not exactly the same concentration measured by the PA; however the two sets of data are clearly related as shown in Figure 4.7-96. For a given firing condition, the PA and SMPS results tracked each other very well as the stoichiometric ratio varied. Furthermore, in the once through oxy-fired and air-fired cases, the results showed that the black carbon concentration was greater than the ultrafine concentration, which was not completely captured by the SMPS for the second mode of the PSD for the Utah coal. 


\section{Ultrafine and BC Comparison}

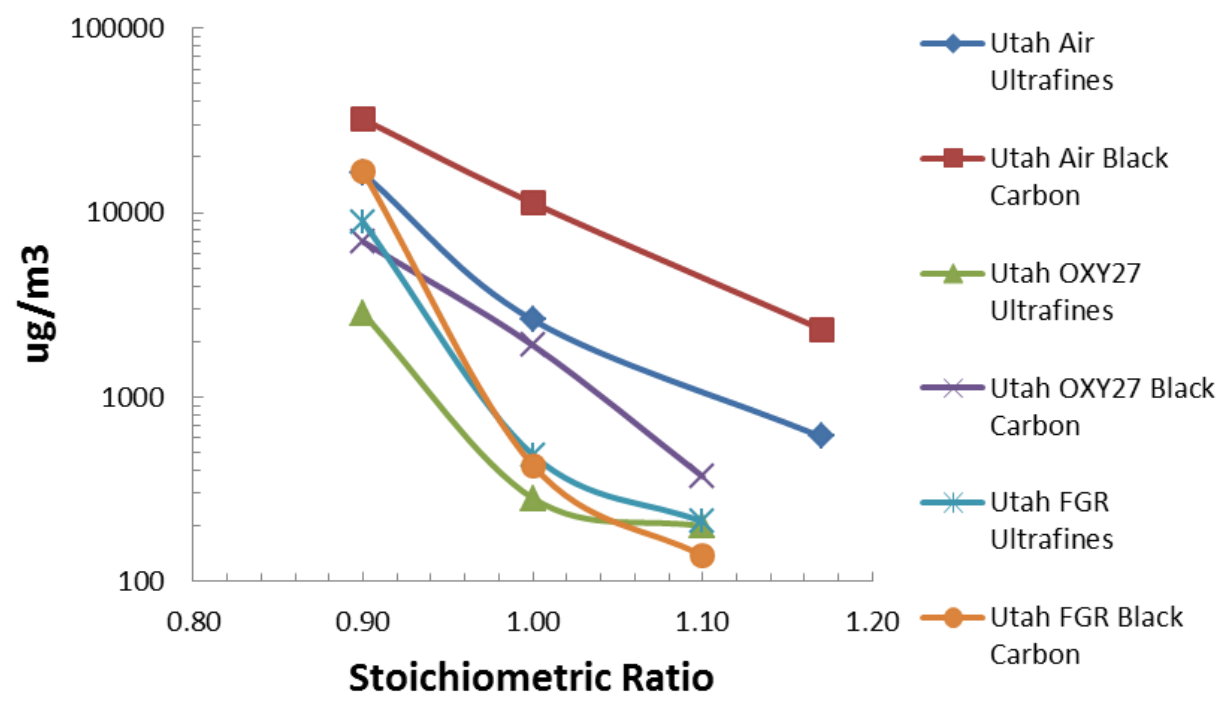

\section{Figure 4.7-96: Comparison of SMPS ultrafine concentration with PA black carbon concentration for the Utah coal.}

This consistency shows that ultrafine concentration and soot concentration are closely related. In the case of the untreated FGR condition for the Utah coal, they were nearly identical. This relationship has shown for the first time that black carbon or soot emissions are very significant contributors to the ultrafine particle concentrations of coal flames across all combustion conditions examined from air-fired to once through oxy-fired to untreated FGR oxy-fired. It would be cavalier to try to have quantified these data using the SMPS data which have been shown to have potential accuracy issues, however the qualitative relationship was still an important realization gained during these sets of experiments.

The PRB results showed that there was a definite correlation between ultrafine emissions measured by the SMPS and black carbon emissions recorded by the PA. Despite the concerns with the PRB SMPS data, this correlation shows that as the excess oxidant was increased, the ultrafine and black carbon emissions decreased as shown in Figure 4.7-97 and Figure 4.7-98. Since the SMPS has been suspected of under reporting the concentration for the PRB, it was no surprise that the ultrafine concentration was found to be greater than the black carbon concentration. Even though the results cannot be fully quantified due to the obvious concerns of the SMPS data, qualitatively it can be concluded that black carbon does make a significant contribution to the ultrafine particle concentration.

The Illinois results also showed a definite correlation between ultrafine emissions and black carbon emissions. However, the Illinois ultrafine emissions were dominated by a significant sulfate mode that was obvious across the SMPS scans that have been reported. As a result, when the excess oxidant was increased, the ultrafine concentration increased as the sulfur in the coal was oxidized to form sulfates. However, at lower excess oxidant levels, it was very clear that the soot was a very significant contributor to the ultrafine particle concentration for both air and oxy-fired conditions. The results for the Illinois coal have been plotted in Figure 4.7-99 and Figure 4.7-100.

These results indicate that black carbon emissions are an important contributor to the ultrafine range of coal combustion emissions across a broad range of combustion conditions. 


\section{PRB Air Fired SMPS and PA Comparison}

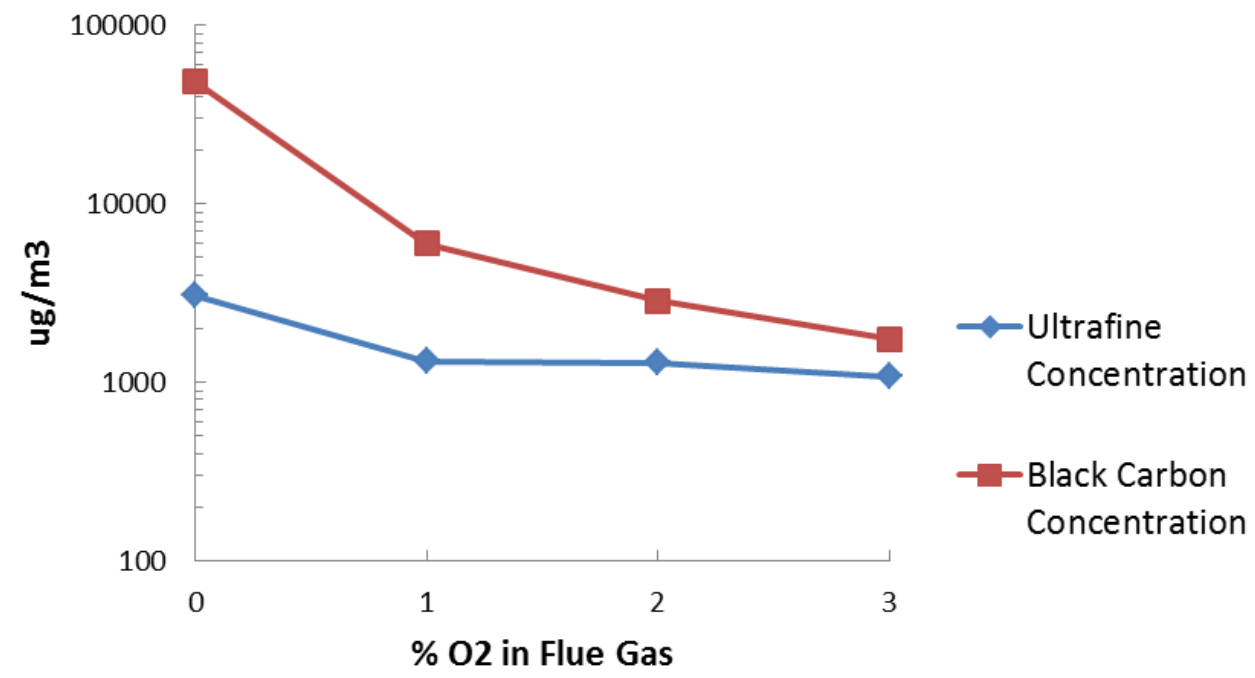

Figure 4.7-97: Comparison of ultrafine and black carbon emissions for the PRB coal under airfired conditions.

\section{PRB OXY27}

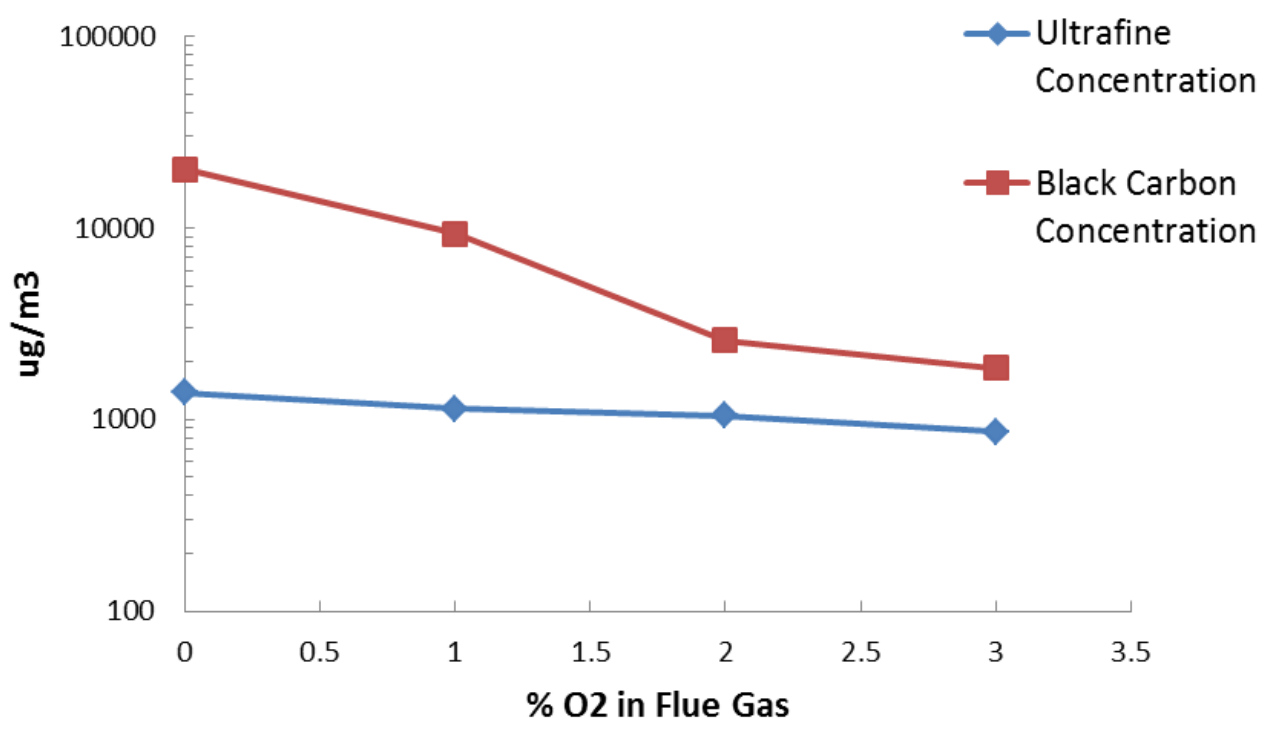

Figure 4.7-98: Comparison of ultrafine and black carbon emissions for the PRB coal under OXY27 conditions. 


\section{Illinois Air}

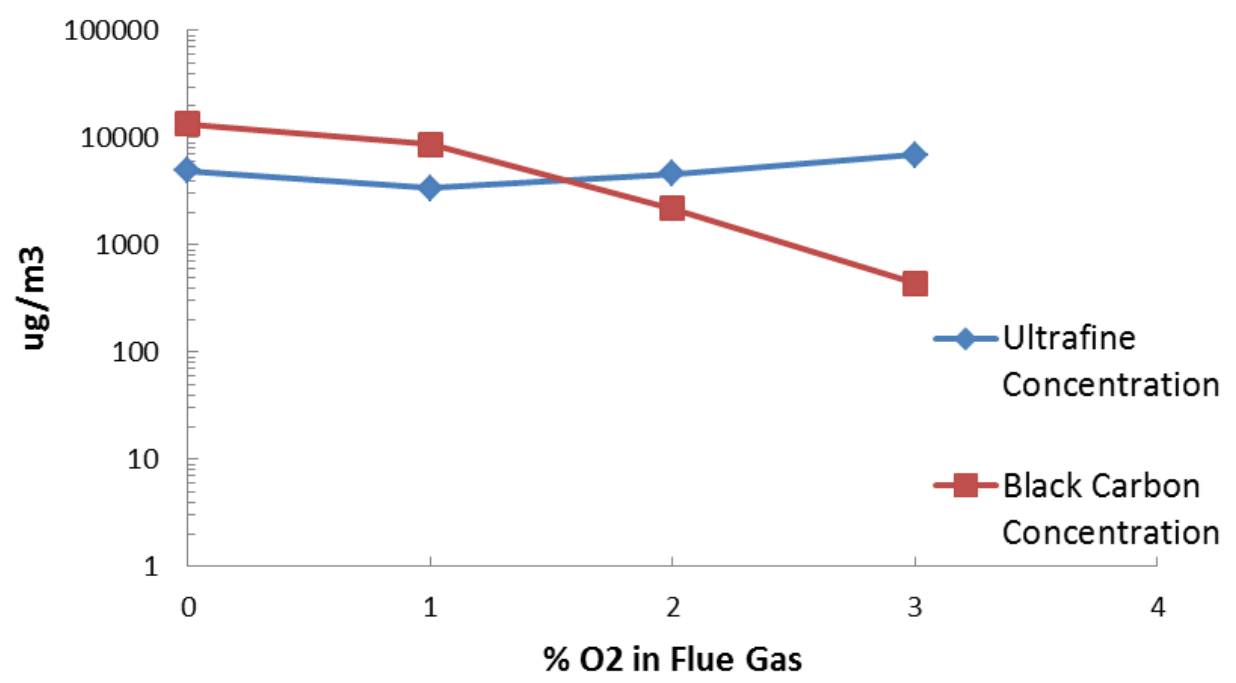

Figure 4.7-99: Comparison of ultrafine and black carbon emissions for the Illinois coal under airfired conditions.

\section{Illinois OXY27}

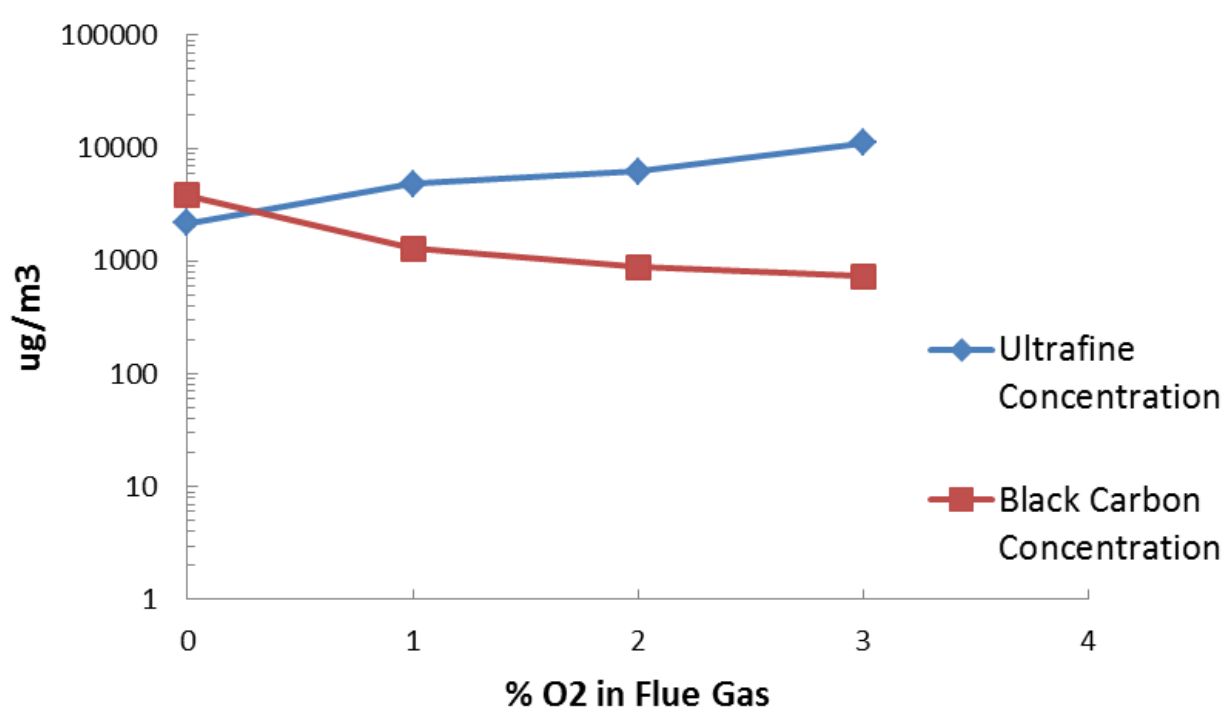

Figure 4.7-100: Comparison of ultrafine and black carbon emissions for the Illinois coal under OXY27 conditions. 


\subsubsection{Size Segregated Ash Chemistry}

A chemistry program, HSC Chemistry 5.0, was used to calculate equilibrium amounts of probable ash species under both air and oxy-fired conditions as a way to understand how the change in combustion atmosphere may change the thermodynamic equilibrium of species formation. This information provided further insight into the governing mechanisms of any changes observed in ash partitioning when changing from an air-fired to an oxy-fired combustion environment.

However, since the budget only allowed for one set of samples to be analyzed for each combustion condition, it was sometimes difficult to discern whether observed changes in partitioning from different combustion conditions were a result of an actual change in mechanism or an individual perturbation.

As discussed in section 1.3, few significant changes were expected in the size segregated ash chemistry. Since the coarse mode was governed by a coalescence of mineral inclusions mechanism, a change in the combustion atmosphere was unlikely to have any major effect on the composition of these particles. This hypothesis was confirmed. The coarse particle chemistry was dominated by the chemical content of the ash of each given coal. Since each coal had significantly different ash compositions, the elemental partitioning of this mode was unique to each coal, but showed little difference as a result of combustion atmosphere.

Furthermore, the fine fragmentation mode centered at one micron was dominated by ash chemistry as well. Since these particles were made up of mineral inclusions that literally were broken to pieces, there was little opportunity for a change in combustion atmosphere to affect the chemistry of this segment of aerosols as well. Once again, their composition was primarily dictated by the chemistry of the mineral inclusions.

These results support the results of Sheng and the results of Wall indicating that a change of combustion environment does not significantly affect ash partitioning (Sheng, et al. 2007) (Wall, et al. 2009) while providing more complete data for modeling. This section provides chemistry across a wide range of ash particle diameters under a self-sustaining coal flame with practical coal to flue gas ratios. Previous work either did not address sufficient conditions, a wide enough range of diameters examined, or were performed using a drop tube furnace and thus did not have realistic coal to gas ratios.

The most likely case for ash partitioning impacts would be on the condensed vapor phase due to higher temperatures and different thermodynamic favorability. Even in this range, differences were minor and consistent with the observations of other investigators which found that at equivalent temperatures only minor differences in partitioning behavior could be expected. The most significant of which was high concentrations of $\mathrm{CO}_{2}$ inhibiting refractory metal vaporization (Sheng, et al. 2007) (Jia 2011).

Thermodynamic models were also constructed and indicated that significant effects in vaporization would not be expected under oxy-fired conditions (Zheng and Furimsky 2003). However, slight variations were noted in the submicron range of several conditions, and thermodynamic calculations were completed in order to better understand these changes which have been discussed for each coal. Inputs for the calculations in gram moles are recorded at the end of Appendix A.

However, the most important finding of ash partitioning work was the collection of ash aerosol data for three very different coals over a wide range of practical self-sustaining oxy-fired combustion conditions. These data were compiled and showed that there is no significant difference in ash aerosol behavior that would warrant sufficient concern to not proceed with an oxy-fired retrofit project from either an operational or emissions perspective. This is the most valuable contribution of the ash aerosol work. 


\subsection{Utah Skyline Ash Chemistry Discussion}

The Utah coal did not show any fundamental changes in ash partitioning behavior when switching from air-fired to oxy-fired conditions. However, there were some subtle differences which thermodynamic data may help to understand.

One of the interesting results was that aluminum appeared in smaller submicron particles under oxy-fired conditions, but was not observed in Figure 4.7-53 for the air-fired condition. In order to understand this observation, equilibrium calculations were made for aluminum species under air and recycled flue gas oxy-fired conditions. The results of these calculations indicated that gas phase species that contained aluminum were more thermodynamically favored at a given temperature for air-fired combustion than for oxy-fired combustion as shown in Figure 4.7-101 and Figure 4.7-102. Thus, the greater vaporization of aluminum, which would be necessary in order to produce aluminum in ash particles of that size must be a result of locally higher temperatures experienced in the furnace as a result of the higher $32 \% \mathrm{O}_{2}$ concentration which would produce more total vaporization and a corresponding increase in aluminum mass in that particle region.

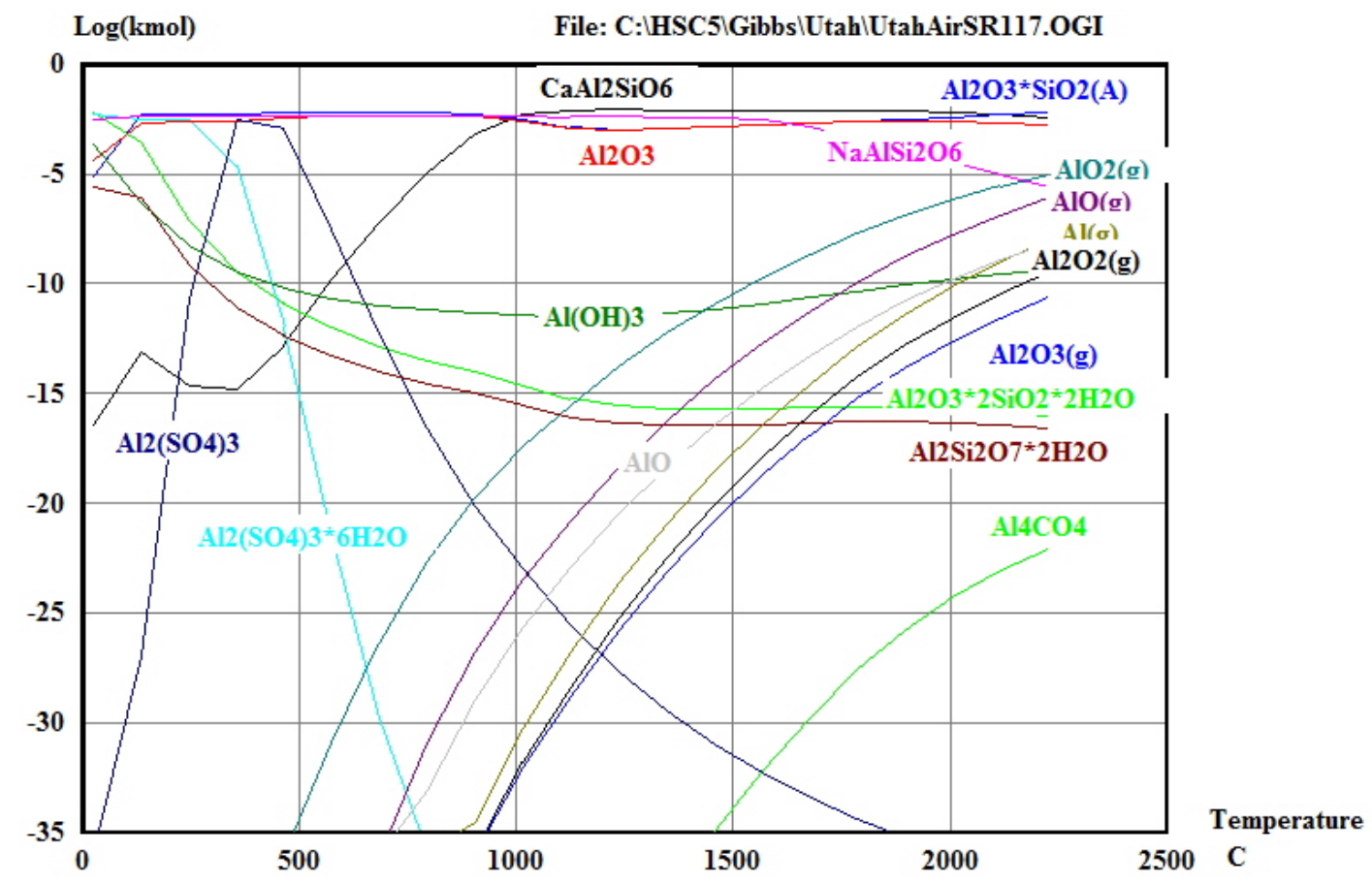

Figure 4.7-101: Air-fired equilibrium results for aluminum species for the Utah coal. 


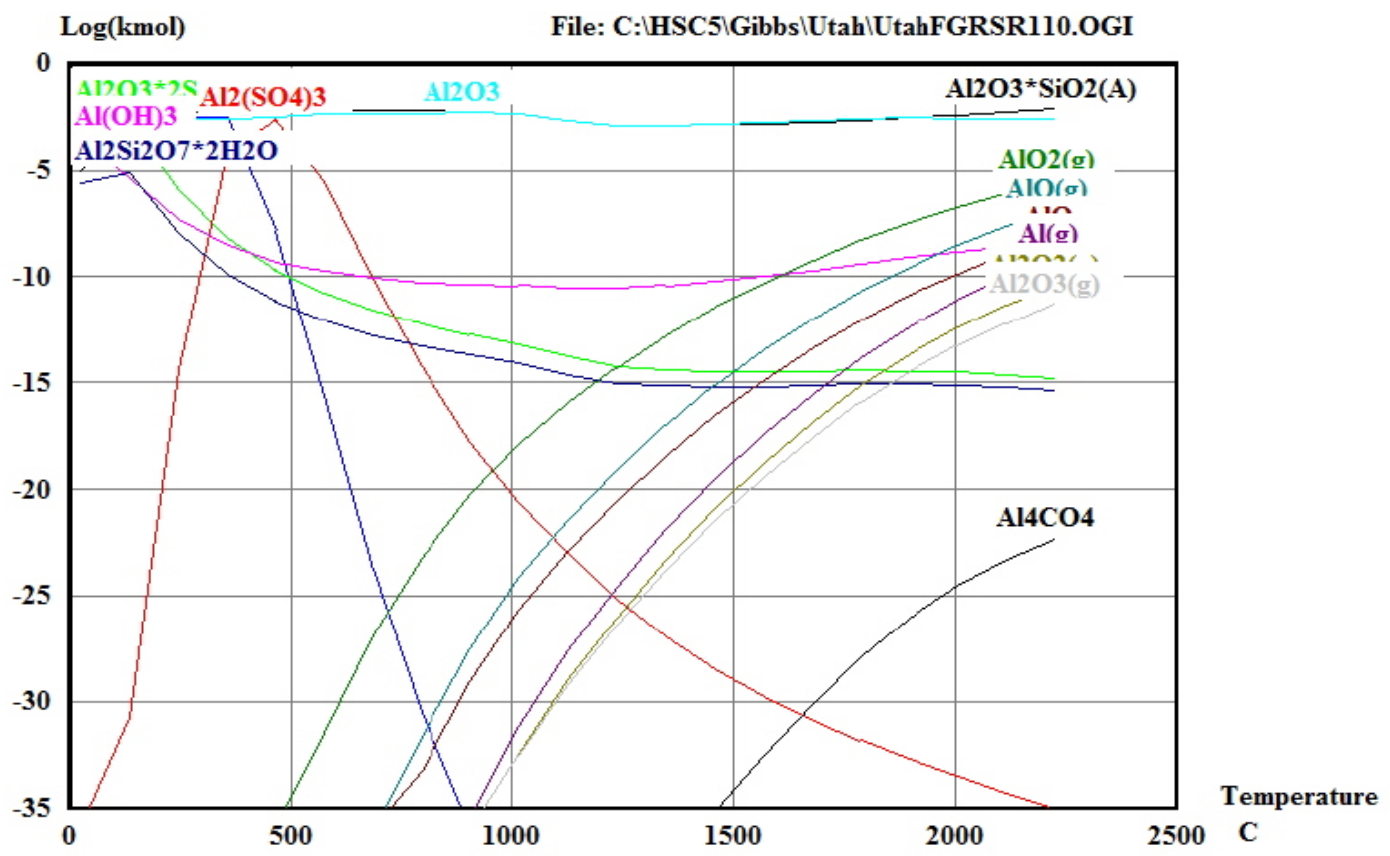

Figure 4.7-102: Thermodynamic equilibrium calculation results for aluminum species under Utah oxy-fired FGR conditions.

The oxy-fired conditions for the Utah coal also showed more calcium in the ultrafine condensed vapor mode. This observation was explained by the higher amount of calcium sulfate in the gas phase created under oxy-fired conditions as opposed to air-fired conditions. This assertion has been illustrated by comparing the results of the thermodynamic calculations in Figure 4.7-103 and Figure 4.7-104.

The greater favorability of the calcium sulfate may also indicate greater deposition rates for the oxy-fired condition as sulfate particles provide a sticky surface as they condense on boiler tubes. This sticky surface traps ash particles as they impact the boiler tubes leading to the buildup of slag in the boiler. 


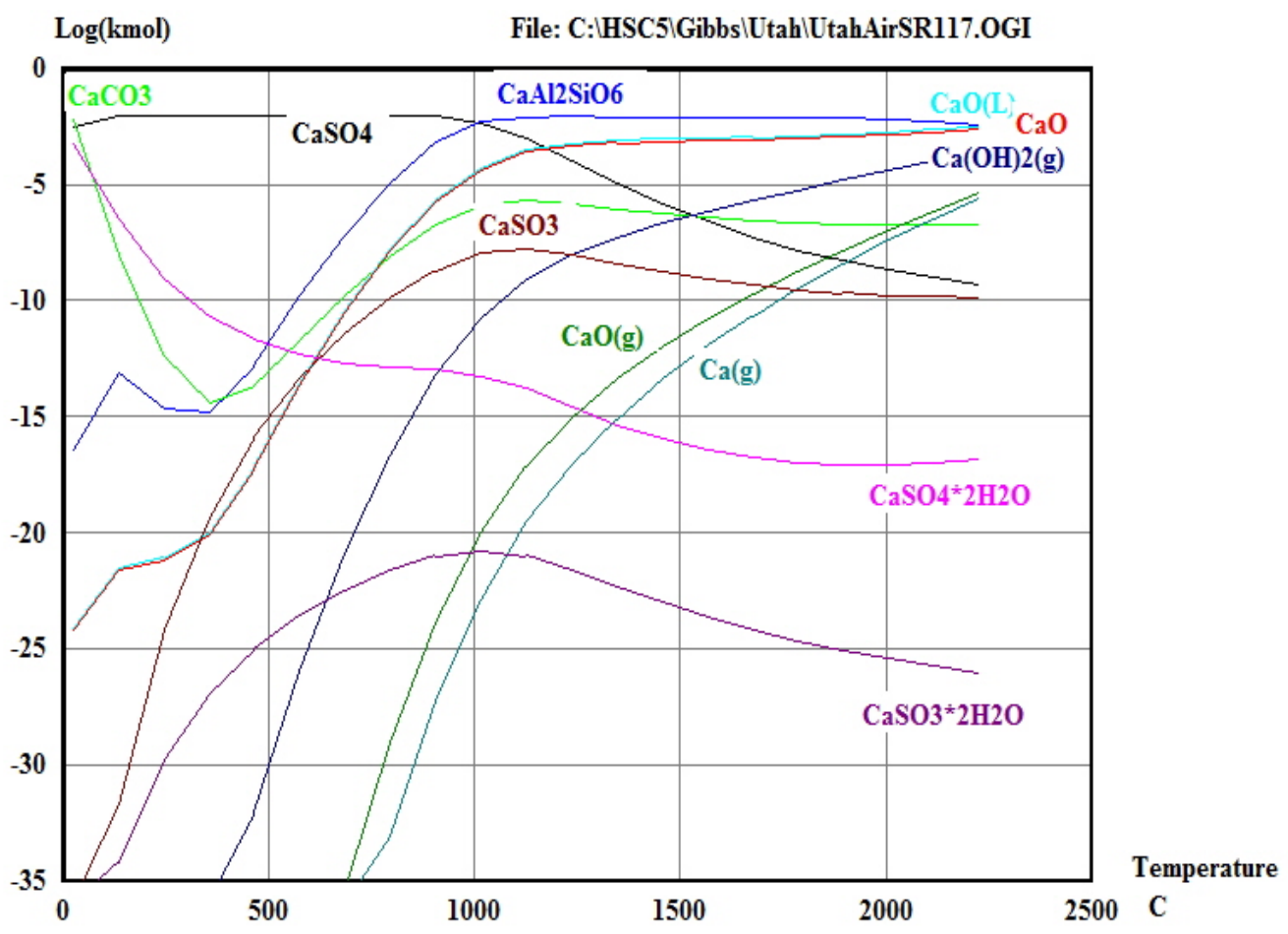

Figure 4.7-103: Utah air-fired equilibrium results for calcium species.

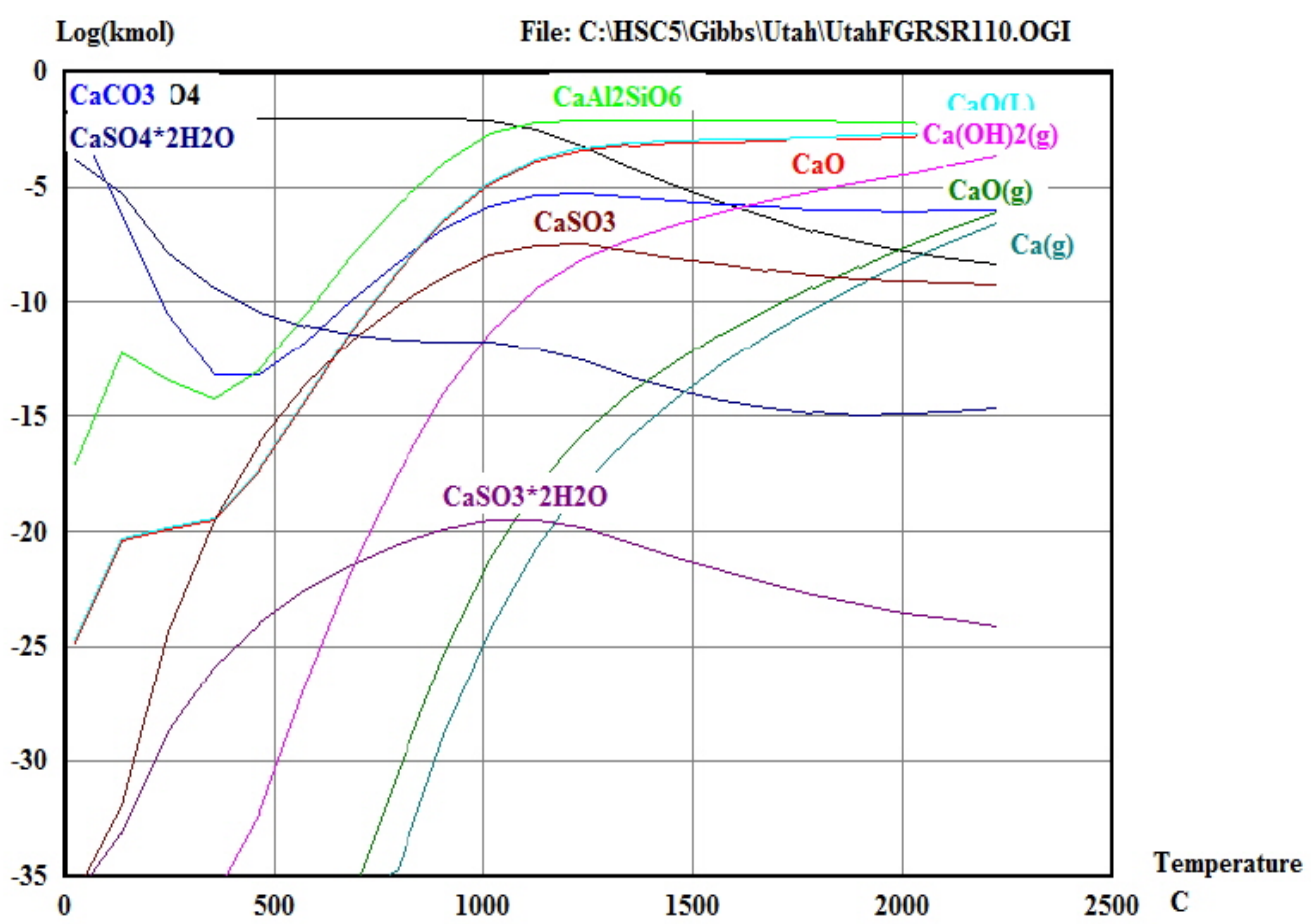

Figure 4.7-104: Thermodynamic equilibrium results for calcium under Utah oxy-fired conditions. 
The iron results, shown in Figure 4.7-59, indicate only minor differences between iron concentrations. The supermicron phase OXY32 and air-fired condition nearly overlap in this region, and as expected, the thermodynamic results for both $\mathrm{Fe}_{2} \mathrm{O}_{3}$ and $\mathrm{FeO}$ under air and oxy-fired conditions were nearly identical. Gas phase species of $\mathrm{Fe}$ and $\mathrm{FeO}$ were more prevalent under air-fired rather than oxy-fired conditions at equivalent temperatures as shown in Figure 4.7-105 and Figure 4.7-106. The oxy-fired conditions had detectable amounts of iron on the smallest $~ 32 \mathrm{~nm}$ diameter cut off plate, while the air did not. However, the air condition data points near 100nm Dp indicated a greater concentration of iron than the oxy-fired conditions as shown in Figure 4.7-59.

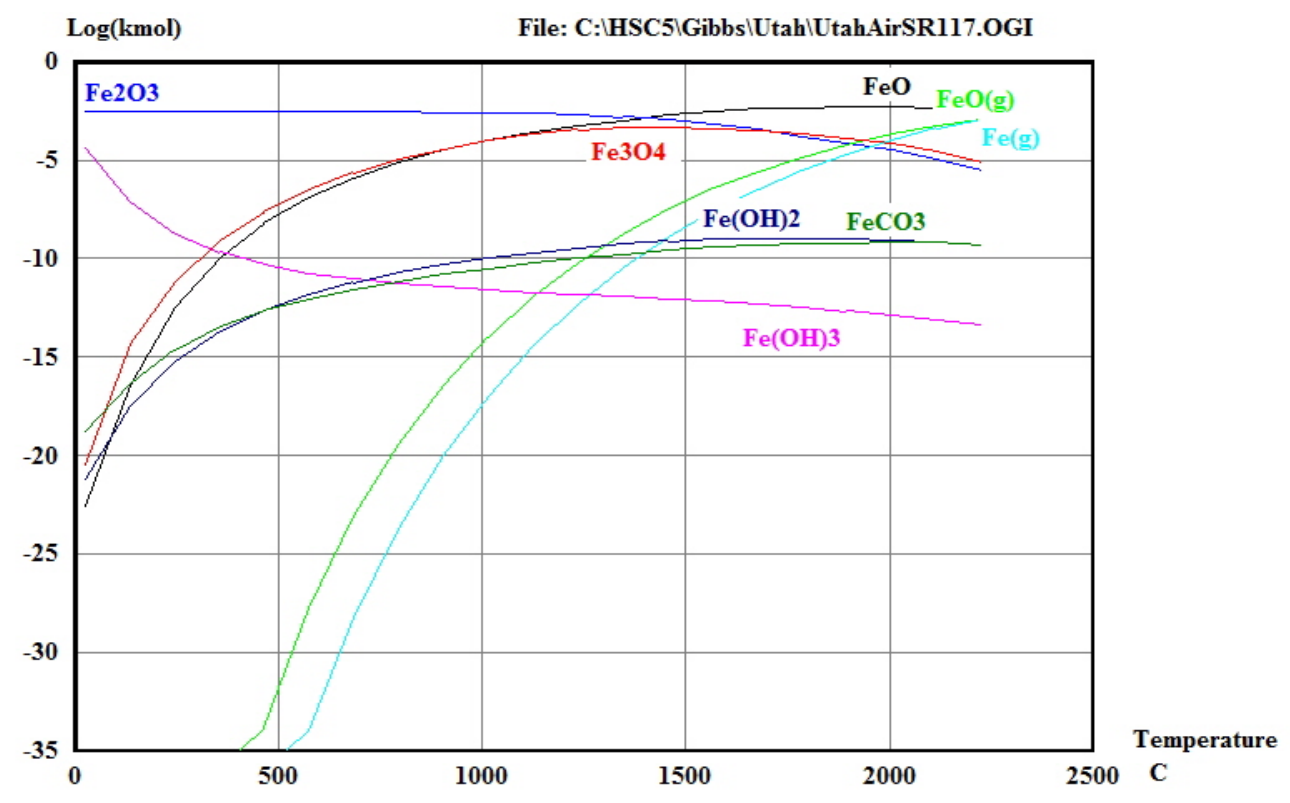

Figure 4.7-105: Thermodynamic calculation results for iron under Utah air-fired conditions.

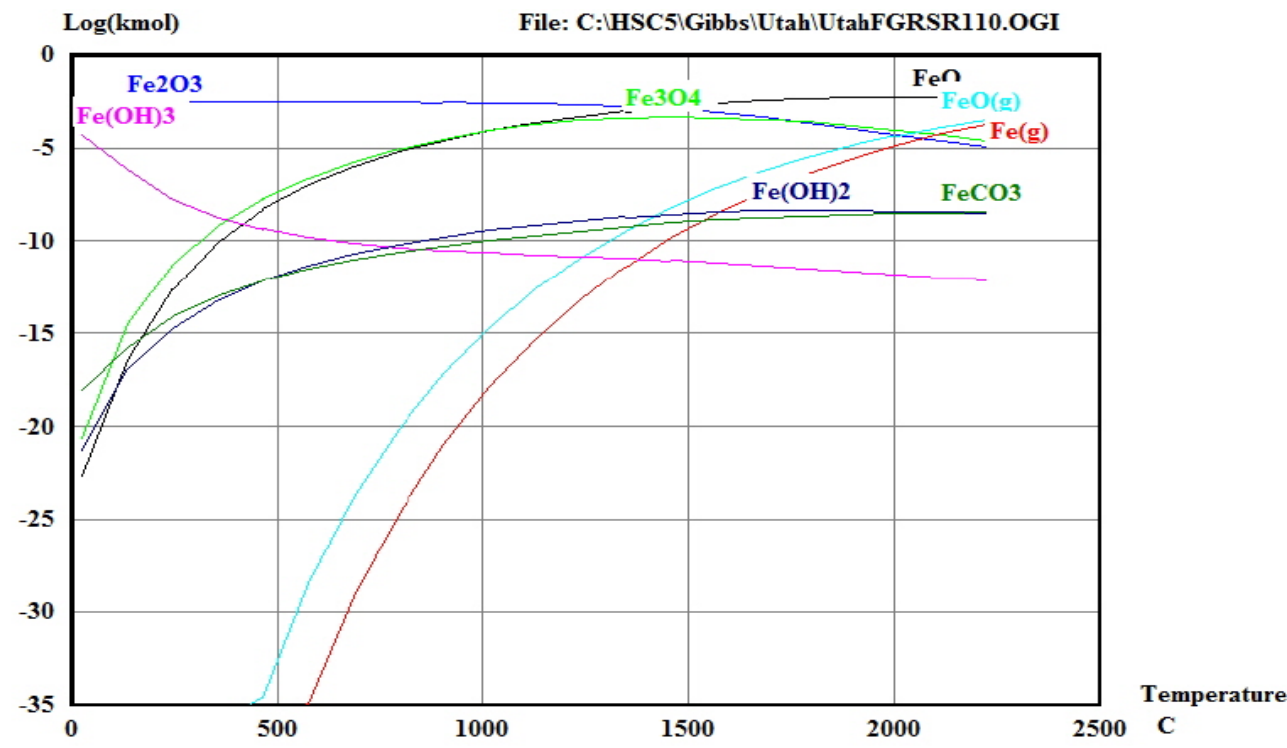

Figure 4.7-106: Thermodynamic equilibrium results for iron under Utah oxy-fired conditions. 
Thus it is possible to conclude that the thermodynamically favored vaporization of iron compounds under air-fired conditions is responsible for this slight increase in iron near $~ 100 \mathrm{~nm}$ and more coagulation has taken place leading to a greater concentration at $100 \mathrm{~nm}$, but insignificant amounts of iron on the 32nm plate. However, locally higher temperatures for the oxy-fired conditions could create equivalent vaporization and result in more iron found in the smallest ultrafine particle region near 32nm Dp.

The potassium results from the ICP-MS were inconclusive due to the small amount of potassium present in the ash. There was often a nondetectable amount captured on the submicron impactor plates used for analysis. However, the thermodynamic simulation results were able to provide useful information to help fill in the gaps.

When the results of the calculations were compared between air and oxy-fired conditions in Figure 4.7-107 and Figure 4.7-108, the gas phase potassium was favored by the air combustion at equivalent temperatures. However, potassium sulfate and potassium carbonate were favored by the oxy-fired conditions which would indicate a potential increase in deposition rate since potassium sulfate is known to be sticky and provide a good surface on boiler tubes for other particles to bond. Consequently, a switch from air to oxy-fired combustion could have impacts on the deposition rates and chemistry that would be observed in a given furnace.

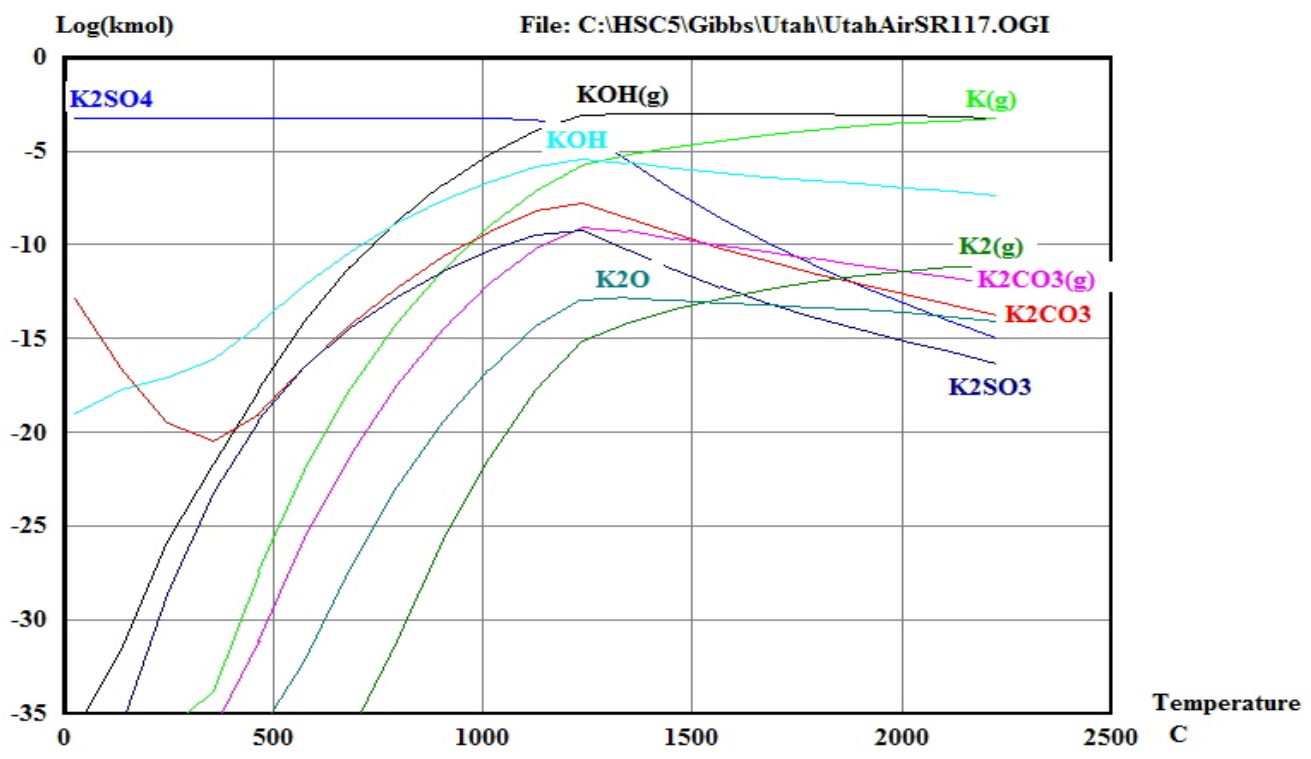

Figure 4.7-107: Thermodynamic equilibrium calculation results for potassium under Utah air-fired conditions. 


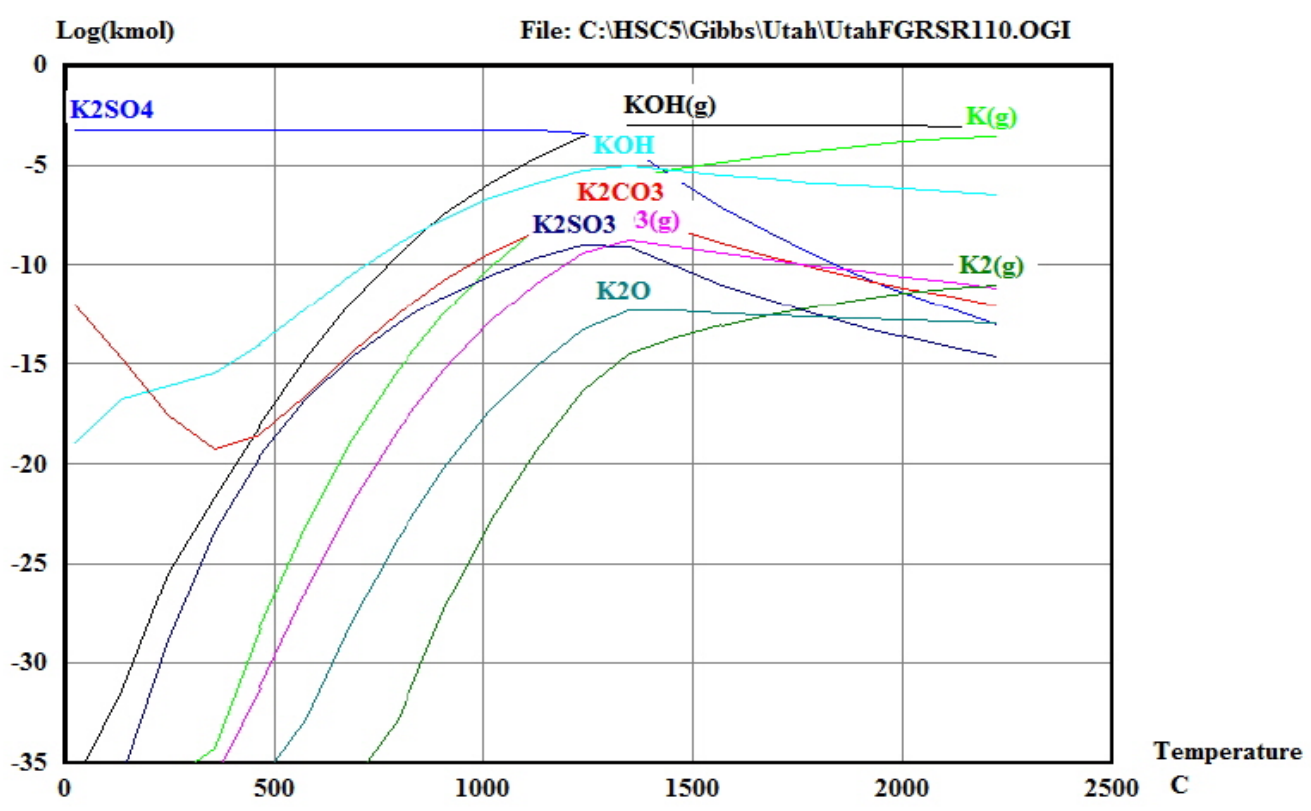

Figure 4.7-108: Thermodynamic equilibrium calculation results for potassium under Utah oxyfired conditions.

Figure 4.7-51 showed that there was a higher concentration of sodium for the Utah coal in the condensed vapor ultrafines for the air-fired condition than the oxy-fired conditions. When the results were compared for the thermodynamic calculations in Figure 4.7-109 and Figure 4.7-110, sodium appeared to be more volatile under air than oxy-fired conditions thus explaining why there was a greater concentration of sodium in the ultrafines for air compared to oxy-firing.

However, like potassium, the thermodynamic equilibrium results showed that sodium carbonate and sodium sulfate were more likely under oxy-fired conditions. This was a very significant result, because of sodium sulfate's importance as a sticky surface that can condense on boiler tubes and provide a bonding surface for deposition formation. 


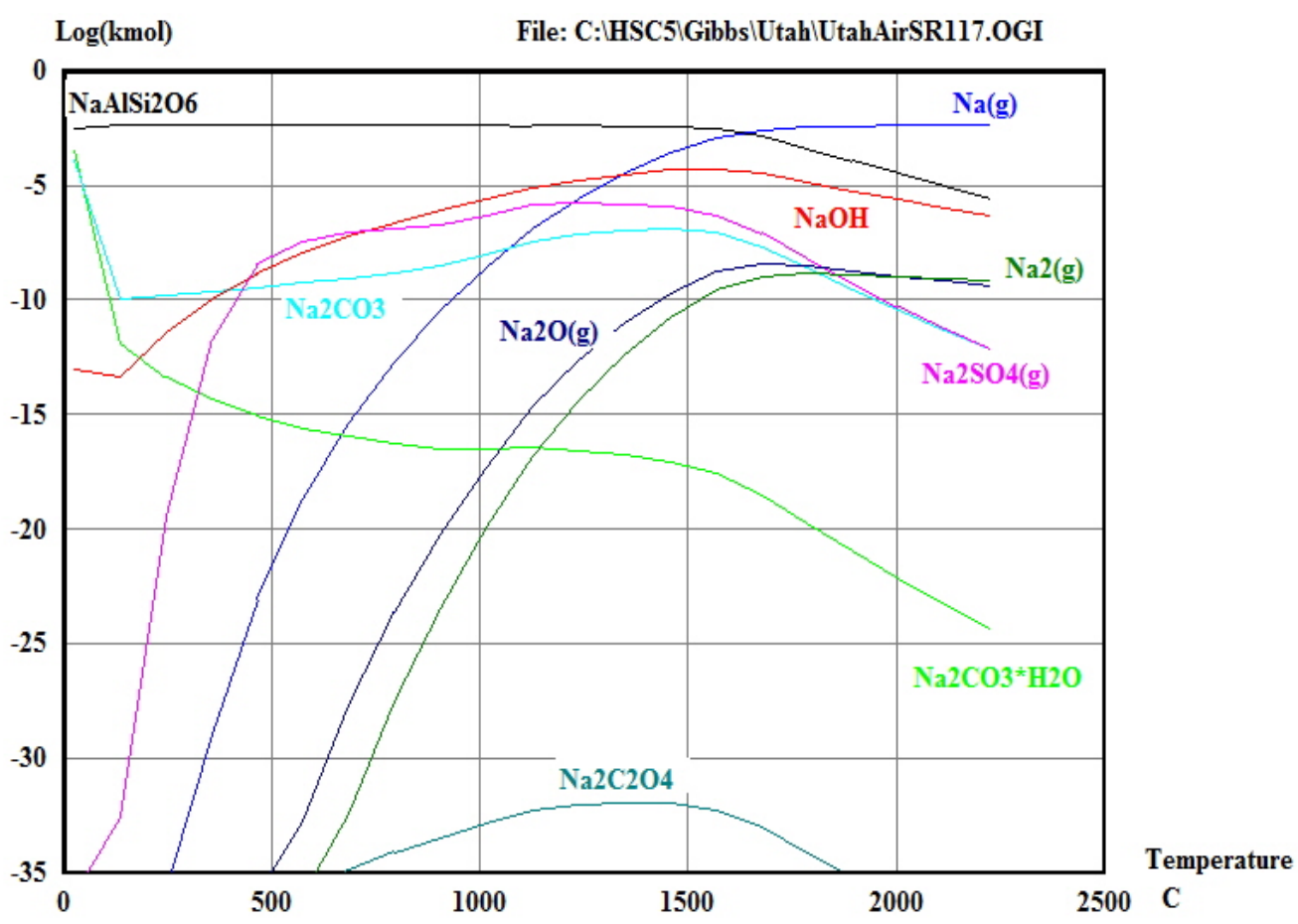

Figure 4.7-109: Thermodynamic equilibrium calculation results for sodium under Utah air-fired conditions.

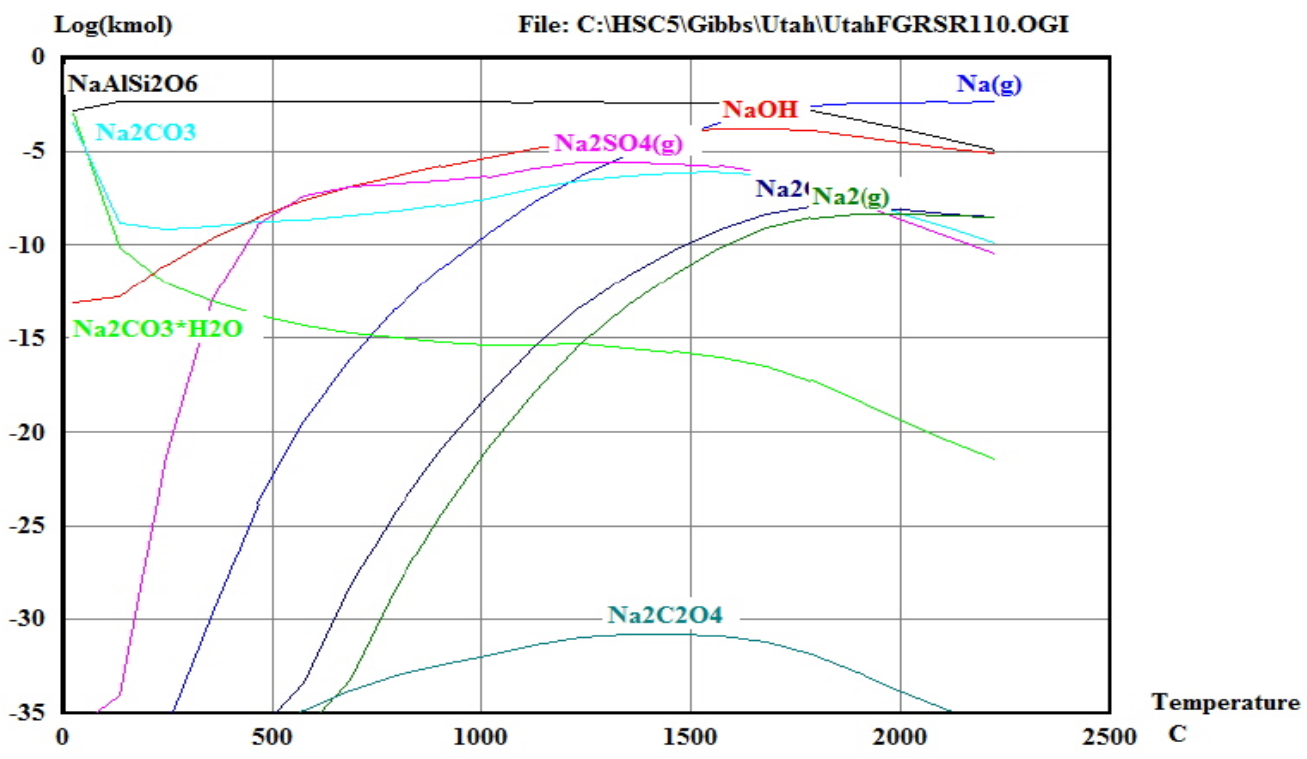

Figure 4.7-110: Thermodynamic equilibrium calculations for sodium under Utah oxy-fired conditions. 
The silicon results in Figure 4.7-54 indicated that there was a greater amount of silicon in the submicron range for the oxy-fired conditions as opposed to the air-fired conditions. The thermodynamic data did not support this result as shown in Figure 4.7-111 and Figure 4.7-112. The thermodynamic calculations suggested greater silicon vaporization under air-fired rather than oxy-fired conditions.

However, silicon in the submicron range had to be measured with ICP-MS. It was necessary to acid digest the samples with HF in order to completely dissolve the silicon. This process could have created $\mathrm{SiF}_{3}$ and $\mathrm{SiF}_{4}$ which are volatile and may be lost during the digestion process. This has been controlled by introducing boric acid to fix the silicon. However boric acid was found to have a large interference for the mass spectrometer for this instrument and its use had to be limited. Therefore, there is greater uncertainty with the silicon measurements.

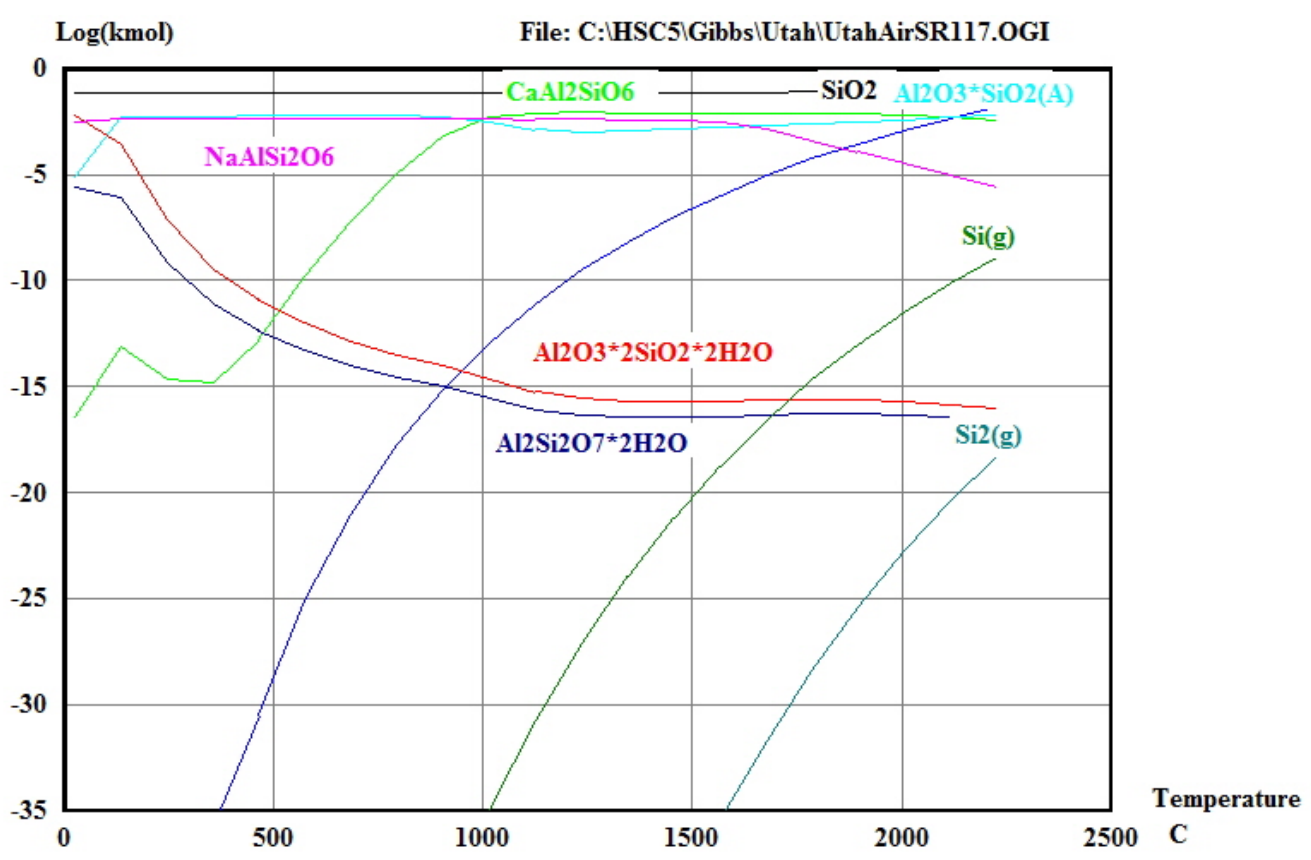

Figure 4.7-111: Thermodynamic equilibrium calculations for silicon under Utah air conditions. 


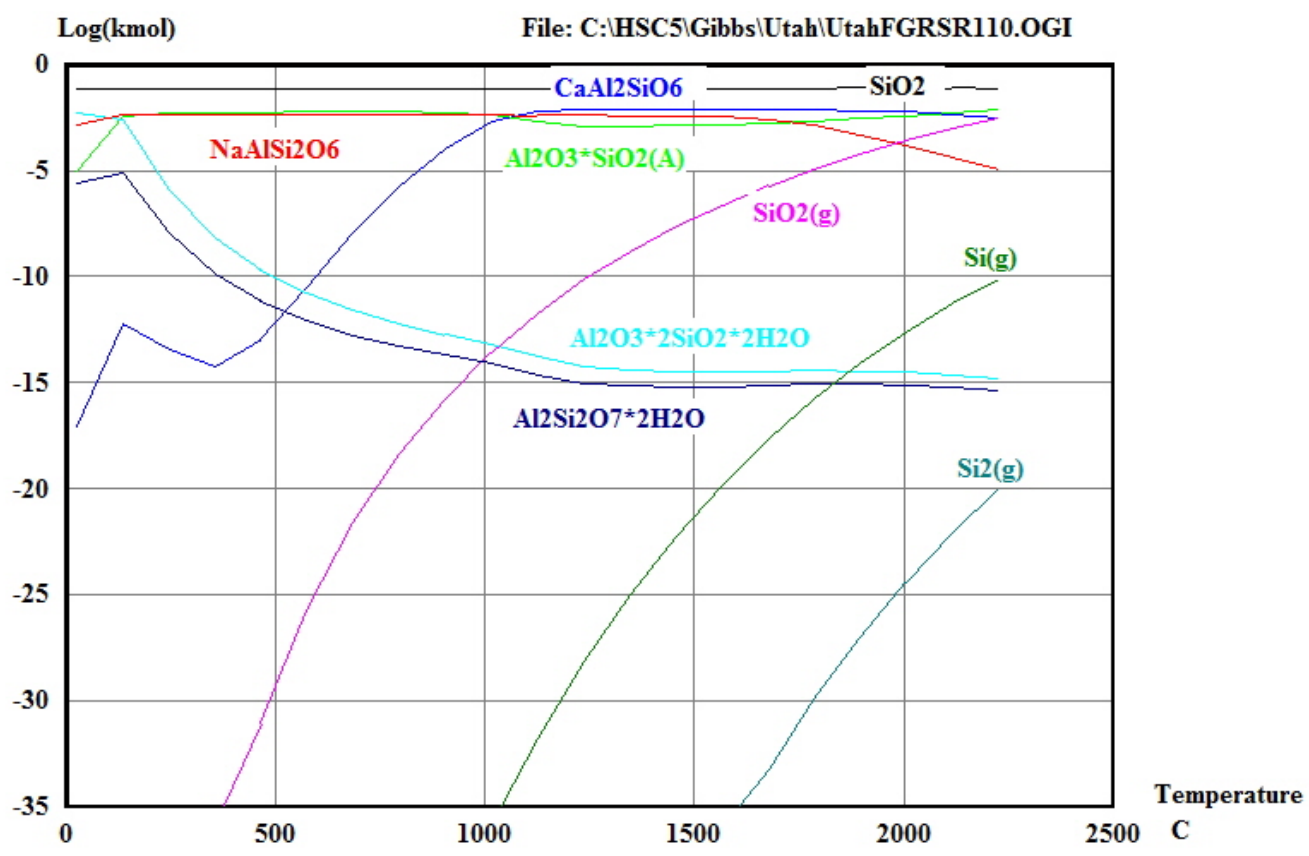

Figure 4.7-112: Thermodynamic equilibrium calculation results for silicon under Utah oxy-fired conditions.

\subsection{PRB Ash Chemistry Discussion}

The PRB coal did not have any major differences in ash partitioning that were observed in section 4.7.3.3.2. However, equilibrium calculations were still performed in order to understand any mechanisms that may be responsible for subtle differences in ash partitioning between the air and oxy-fired conditions.

The results for aluminum partitioning showed that there was more aluminum in the ultrafine region for the PRB coal under oxy-fired conditions rather than air-fired conditions in Figure 4.7-64. However, the calculation results showed that vaporization of aluminum was more favored under air conditions than oxy-fired conditions at equivalent temperatures in Figure 4.7-113 and Figure 4.7-114. Therefore, the mechanism for increased aluminum concentration in the submicron region for the PRB coal is likely not that it is thermodynamically advantageous for aluminum to vaporize.

However, sulfation of aluminum is greater under oxy-fired conditions than air-fired conditions. Thus a greater concentration of aluminum sulfate could be the cause for the greater aluminum concentrations in the fine and ultrafine range for the PRB coal under oxy-fired conditions. Another possible mechanism is that regions of increased temperature exist under oxy-fired conditions due to the higher concentration of oxygen. This would have created more vaporization compared to the air-fired condition causing the concentration of aluminum to be greater under oxy-fired conditions in the submicron range. 


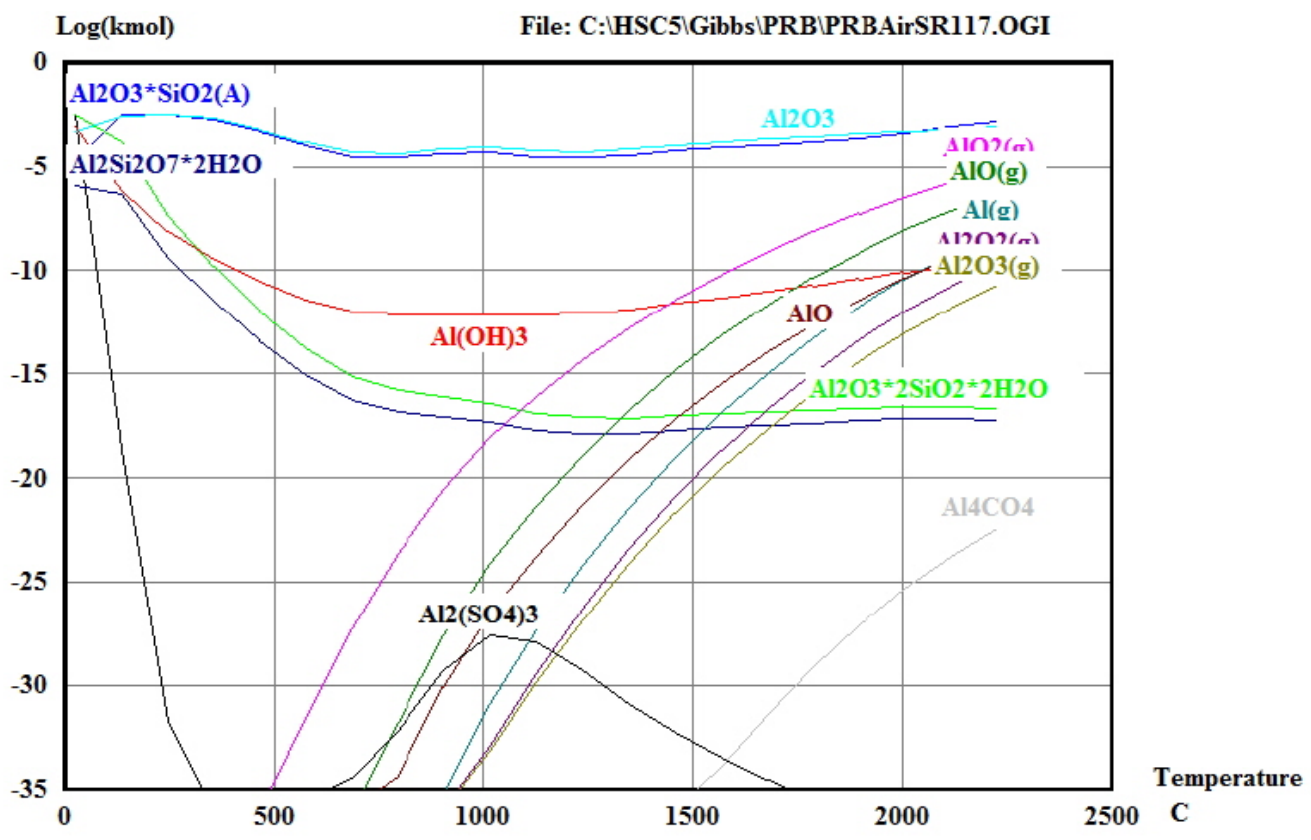

Figure 4.7-113: Thermodynamic equilibrium calculation results for aluminum under PRB air-fired conditions.

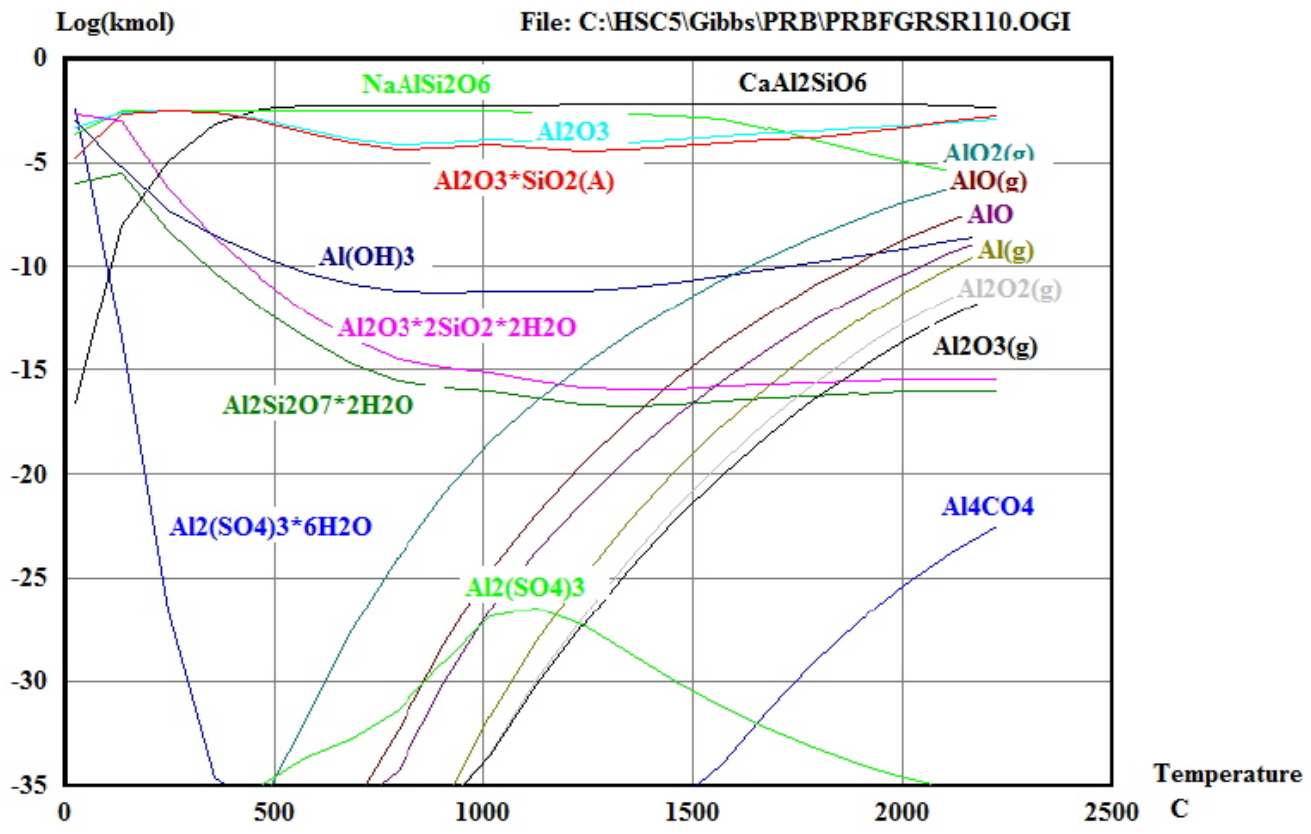

Figure 4.7-114: Thermodynamic equilibrium calculation results for aluminum under PRB oxy-fired conditions. 
Results were reported for size segregated calcium compositions in Figure 4.7-68. This graph showed that there was more calcium in the ultrafine region for air-fired combustion than the oxy-fired scenarios. The thermodynamic data also showed that greater vaporization of calcium at equivalent temperatures would be expected under the air-fired condition rather than oxy-fired as shown in Figure 4.7-115 and Figure 4.7-116 which would lead to a greater concentration of calcium in the submicron range for the air-fired condition.

However, calcium sulfate decomposed at lower temperatures for the air-fired than oxy-fired condition. This would suggest that calcium would be more likely to capture sulfur under oxy-fired than air-fired combustion.

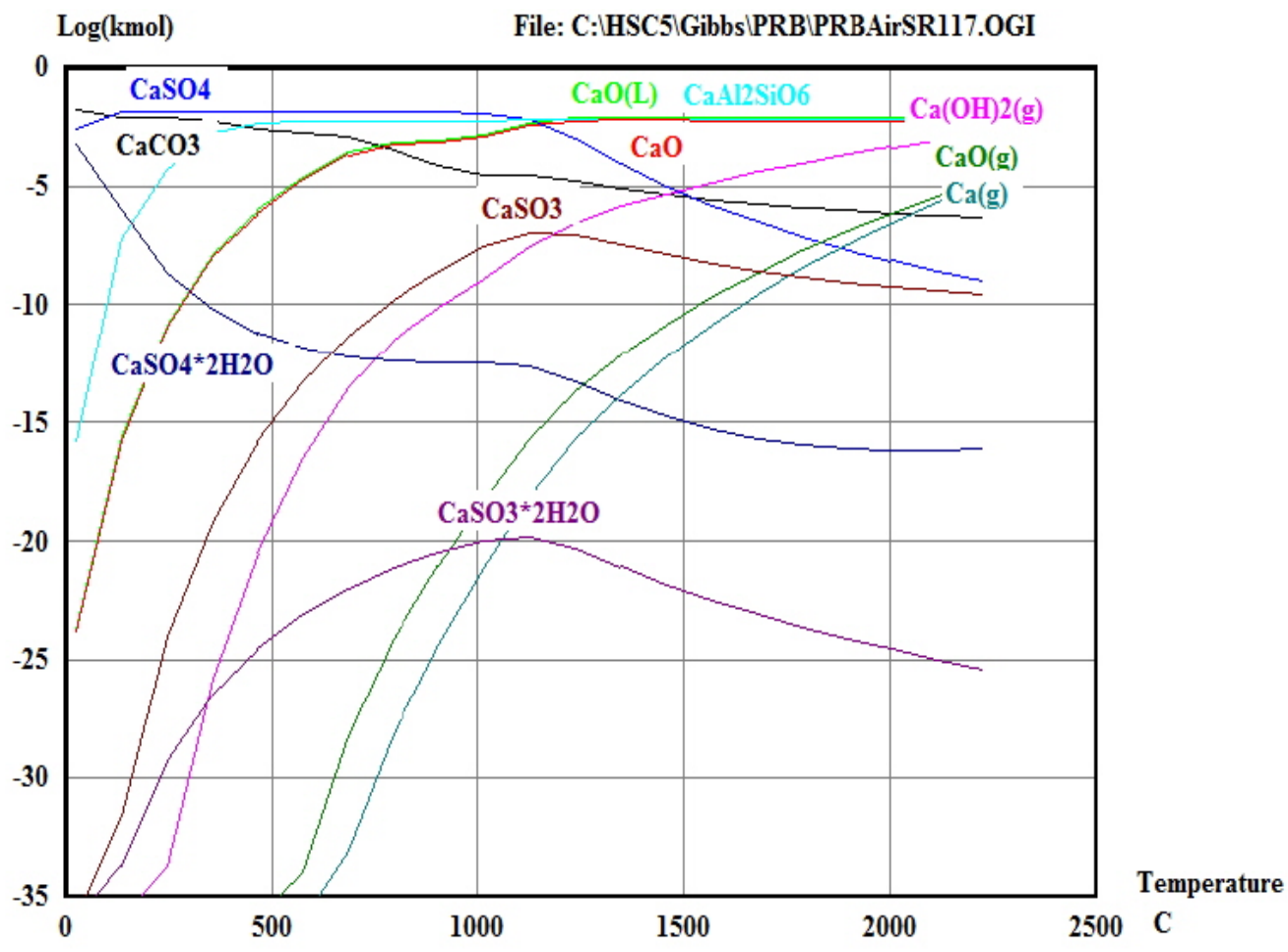

Figure 4.7-115: Thermodynamic equilibrium calculation results for calcium under PRB air-fired conditions. 


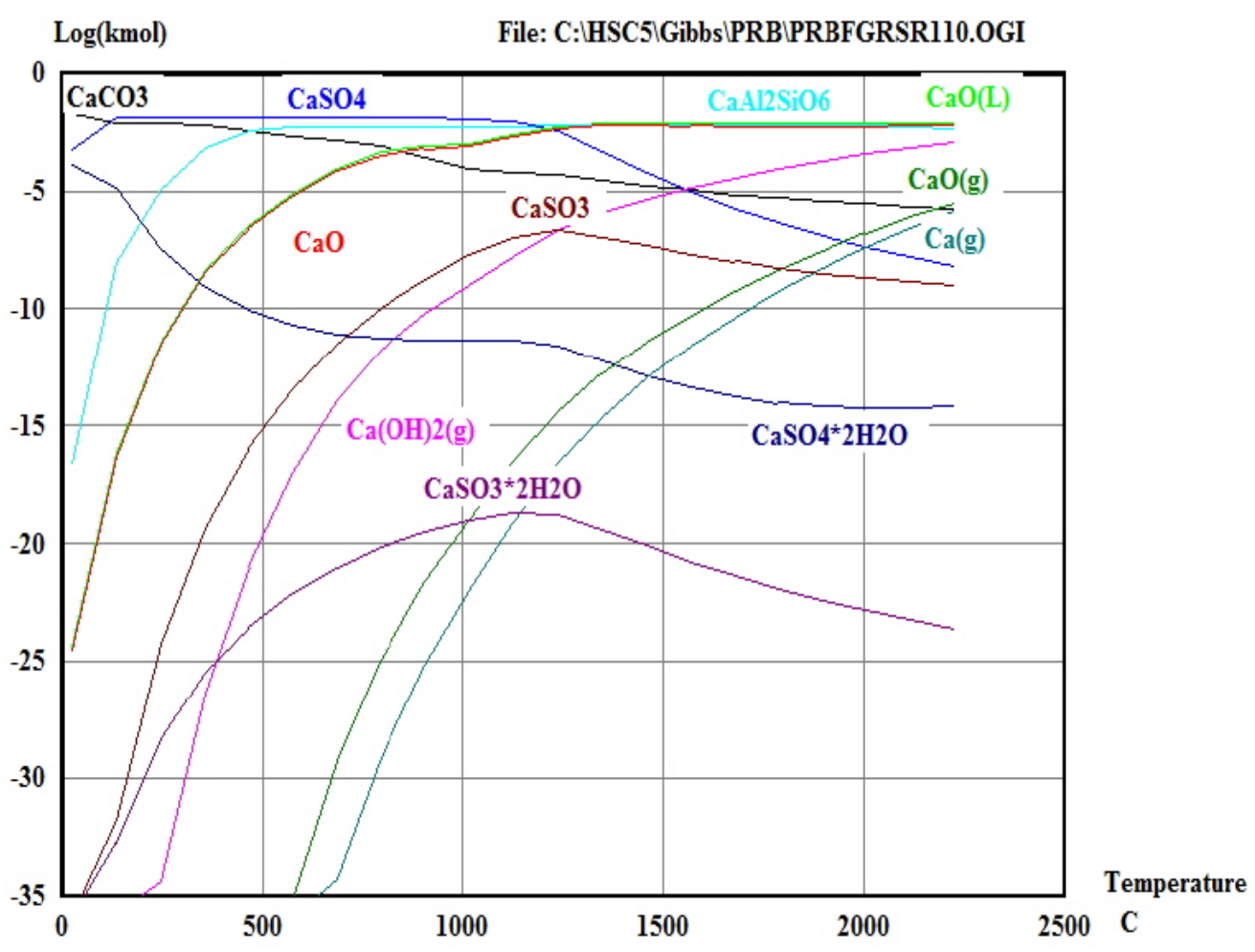

Figure 4.7-116: Thermodynamic equilibrium calculation results for calcium under PRB oxy-fired conditions.

No major differences were noted in the partitioning of iron for the PRB coal when switching from the air to oxy-fired cases in Figure 4.7-70. The thermodynamic equilibrium calculations were performed, and there was almost no difference between the results for the air-fired condition and the oxy-fired conditions in Figure 4.7-117 and Figure 4.7-118. Thus the change of combustion environment has very little effect on the partitioning of iron from coal ash, and this is particularly true for the PRB coal where there were no significant differences. 


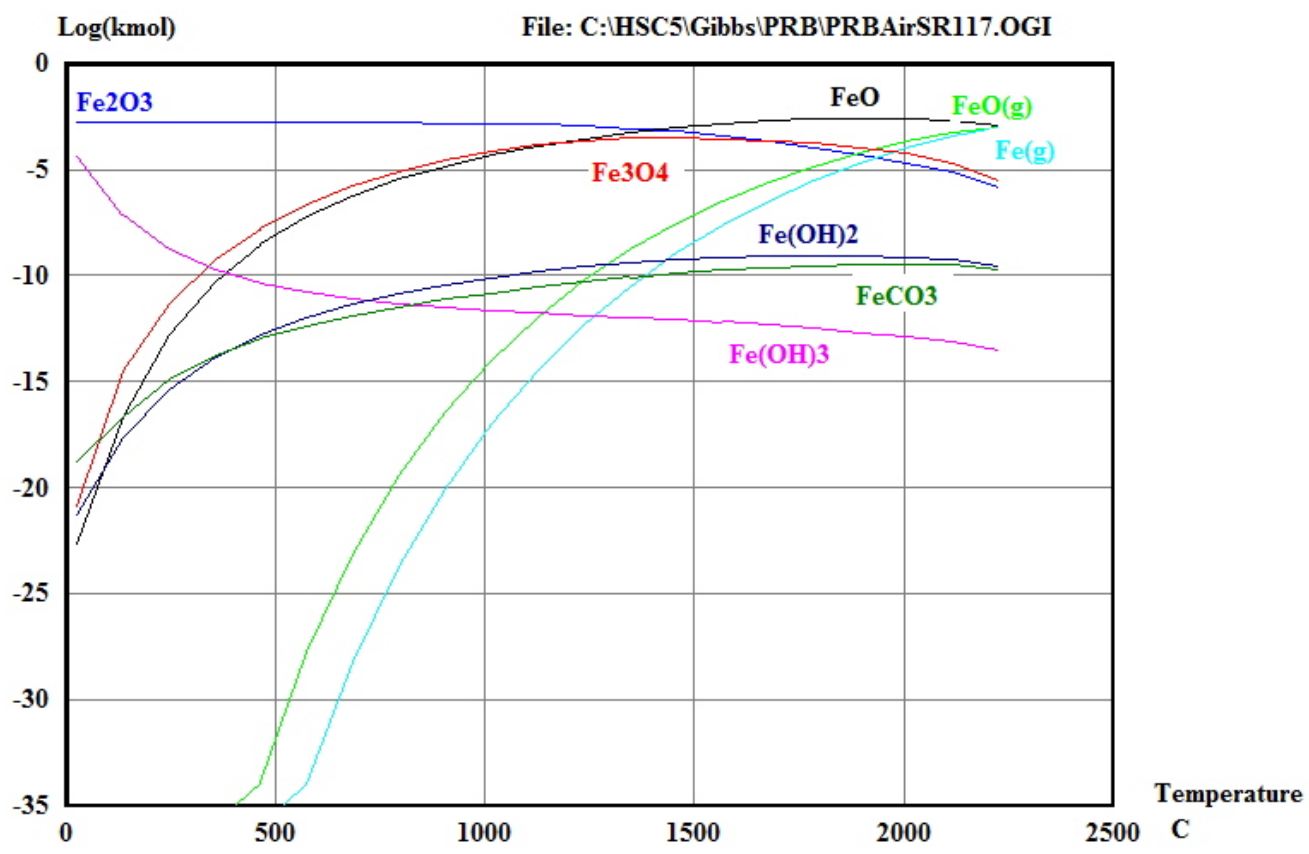

Figure 4.7-117: Thermodynamic equilibrium calculation results for iron under PRB air-fired conditions.

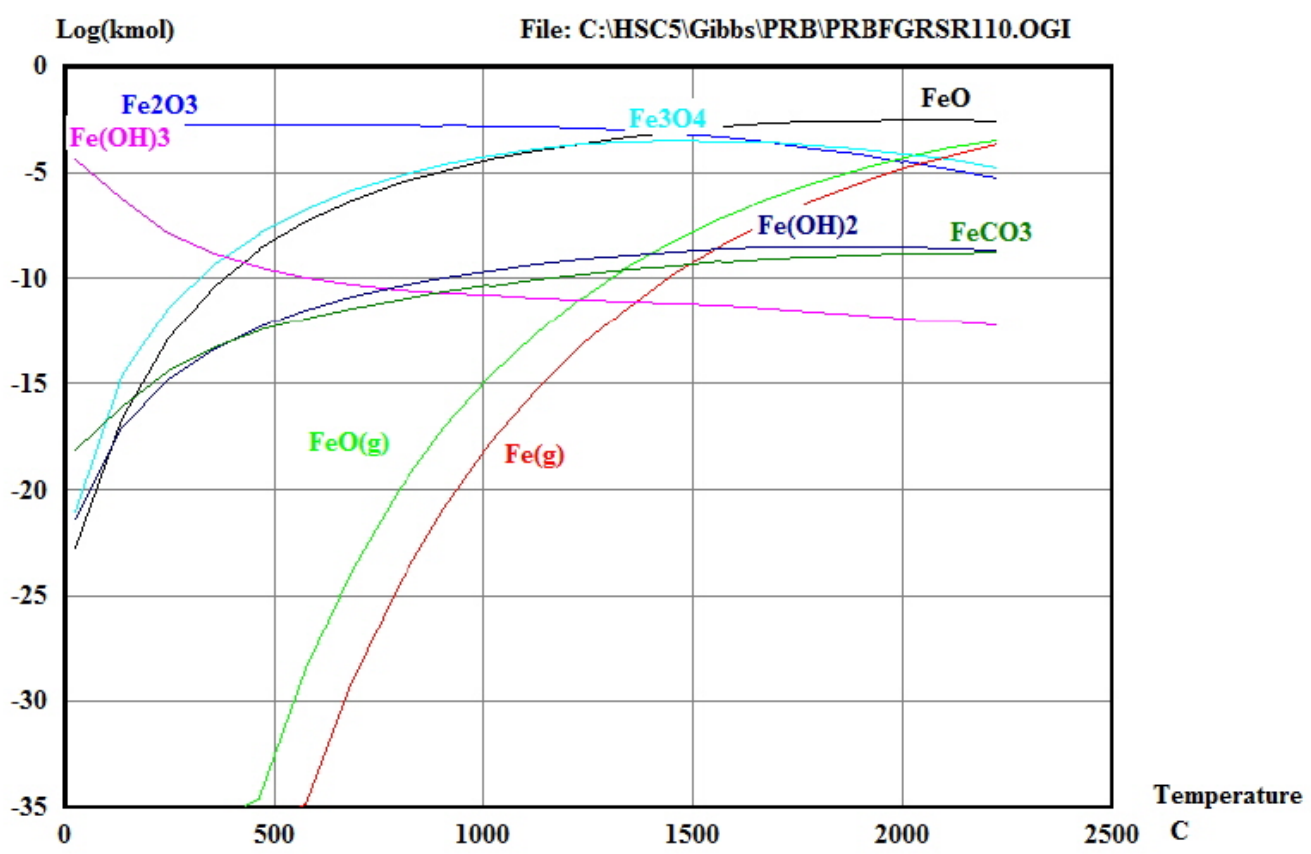

Figure 4.7-118: Thermodynamic equilibrium calculations for iron under PRB oxy-fired conditions. 
The potassium results that were reported for the PRB coal showed that potassium was below the detectable limit in most cases for the air-fired case but results were obtained for the oxy-fired cases in Figure 4.7-67. The thermodynamic equilibrium results shown in Figure 4.7-119 and Figure 4.7-120 showed that vaporization of potassium is more favorable under air-fired conditions while potassium sulfate is more stable under oxy-fired conditions which could explain why potassium was observed in the submicron range for oxy-fired conditions but not air conditions. This result is also important, because it suggests that potassium sulfate may be found in higher concentrations under oxy-fired conditions which could lead to greater deposition due to potassium sulfate forming a sticky surface on boiler tubes.

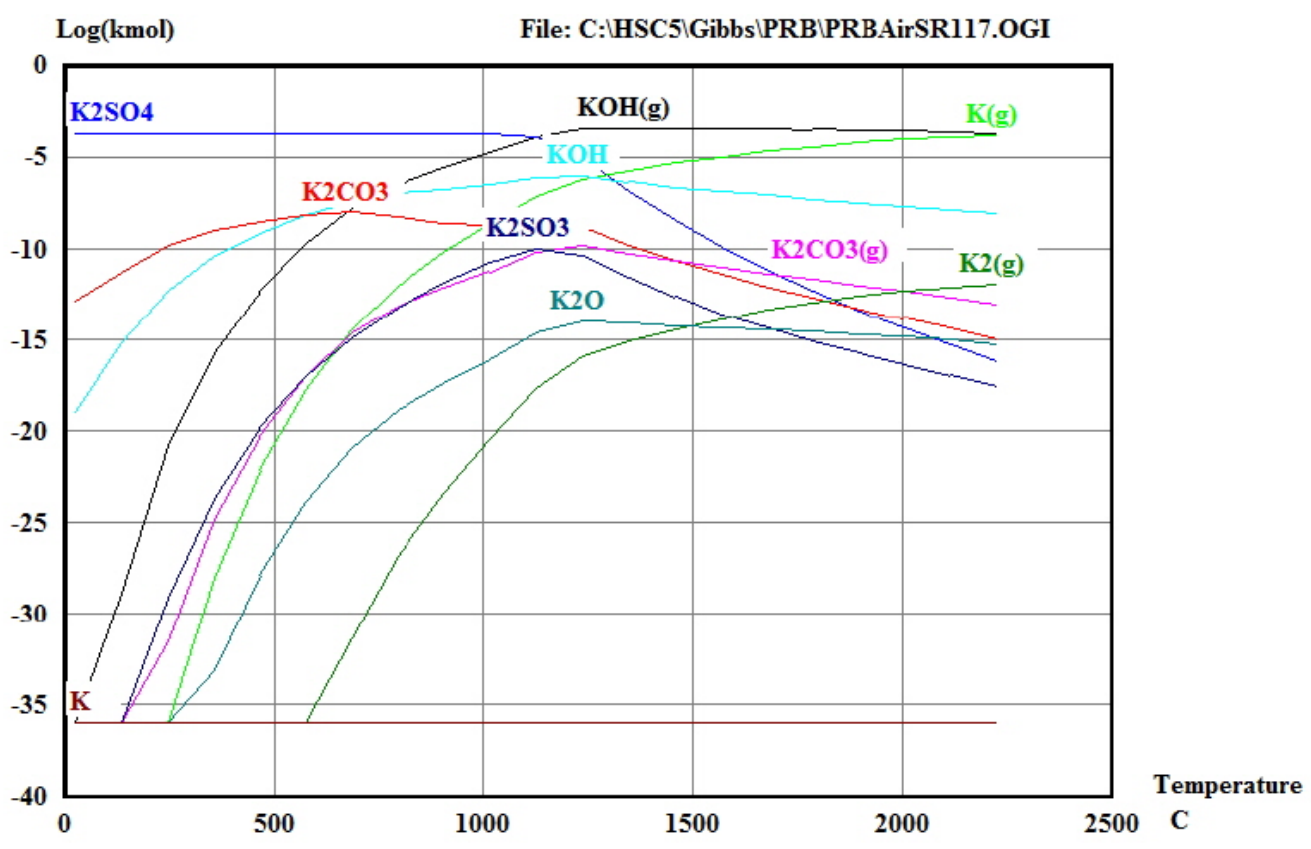

Figure 4.7-119: Thermodynamic equilibrium calculation results for potassium under PRB air-fired conditions. 


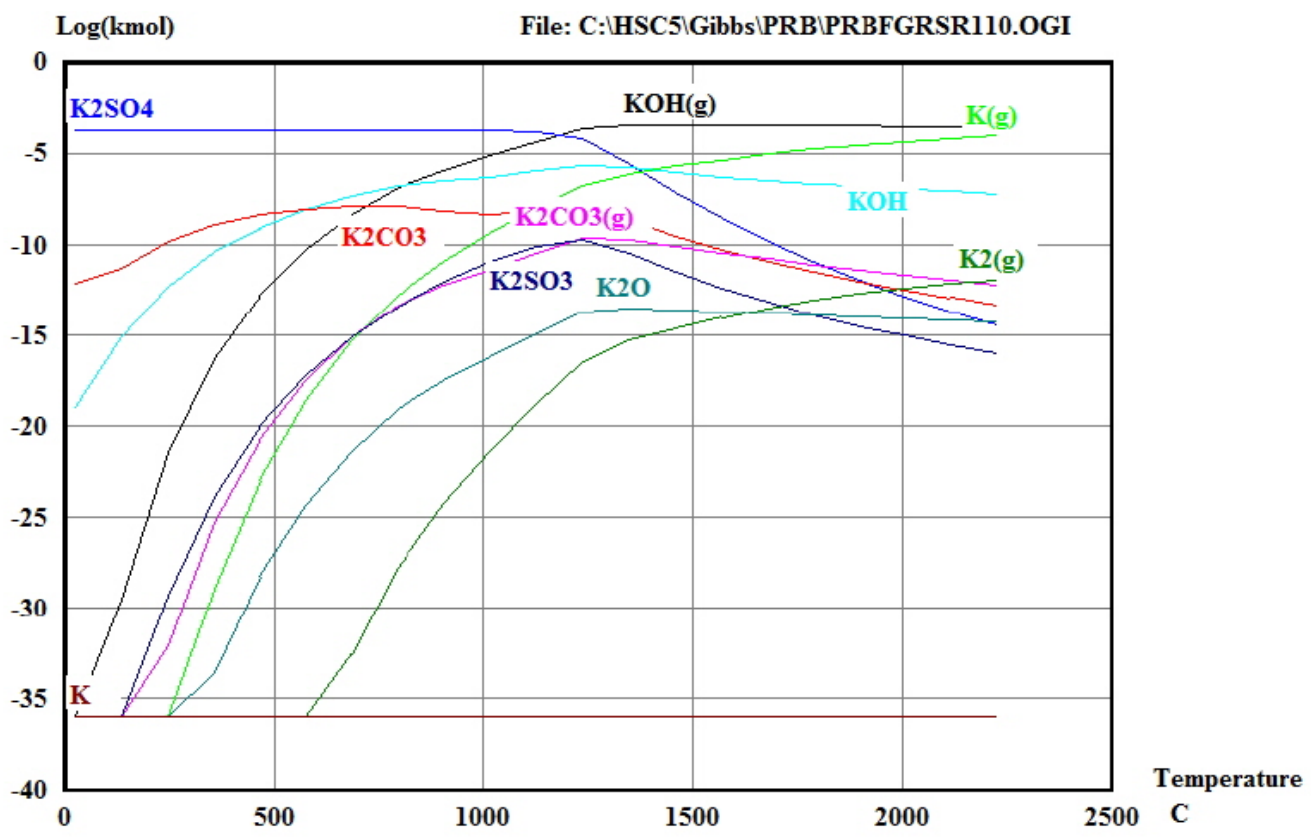

Figure 4.7-120: Thermodynamic equilibrium calculation results for potassium under PRB oxy-fired conditions.

The results for the sodium distribution for PRB coal showed that there was very little difference between the air and oxy-fired conditions in Figure 4.7-62. The FGR conditions had issues with sampling due to the incredibly high concentration of moisture in the flue gas, but the air and once through sodium distributions were very similar. The only difference was in the very low concentrations of sodium present for particles close to $100 \mathrm{~nm}$ in diameter. The oxy-fired samples had sodium very near the detectable limit while the air-fired results were below the detectable limit. However, for most particle diameters, the airfired composition for sodium matched the composition for oxy-fired.

The thermodynamic calculations for sodium indicate that there is nearly no difference in volatility of sodium or in the concentration of sodium sulfate for air and oxy-fired conditions in Figure 4.7-121 and Figure 4.7-122. 


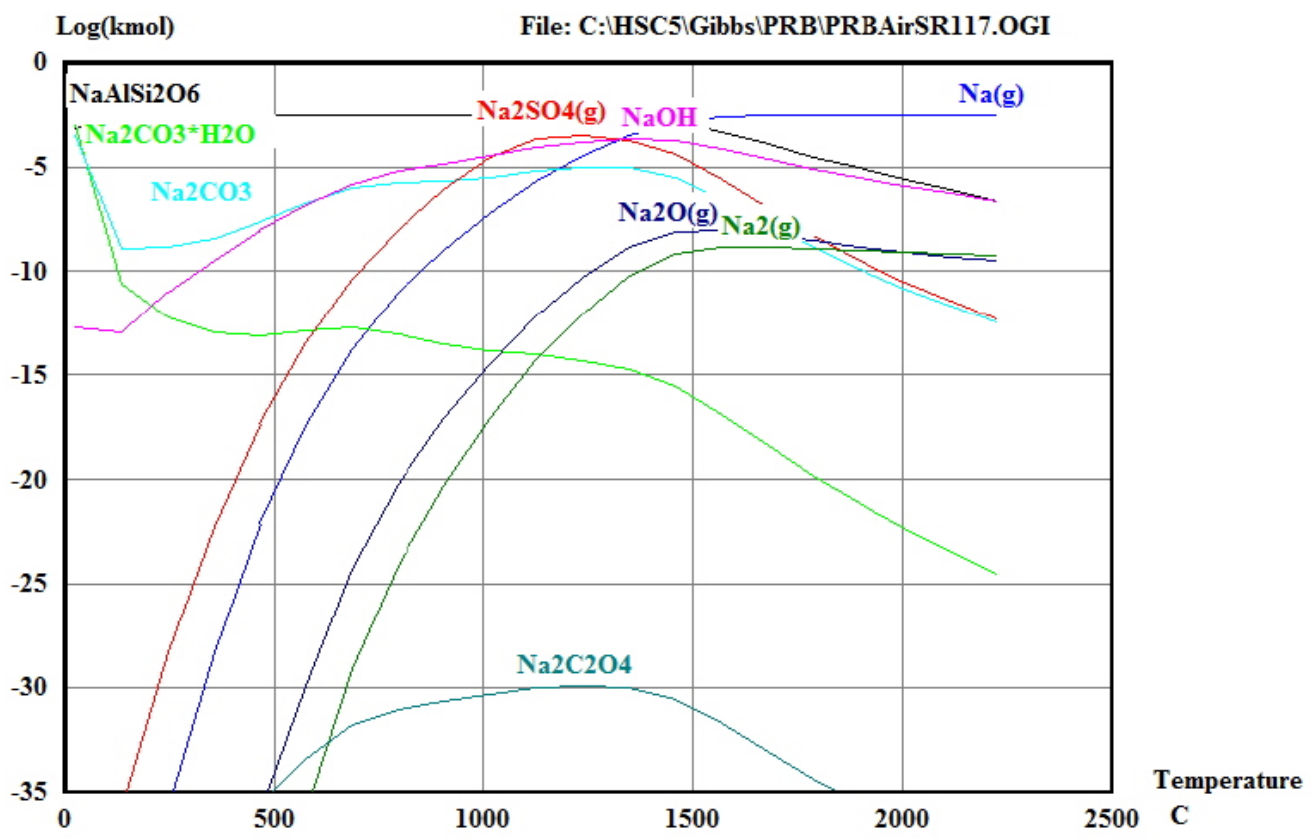

Figure 4.7-121: Thermodynamic equilibrium calculation results for sodium under PRB air-fired conditions.

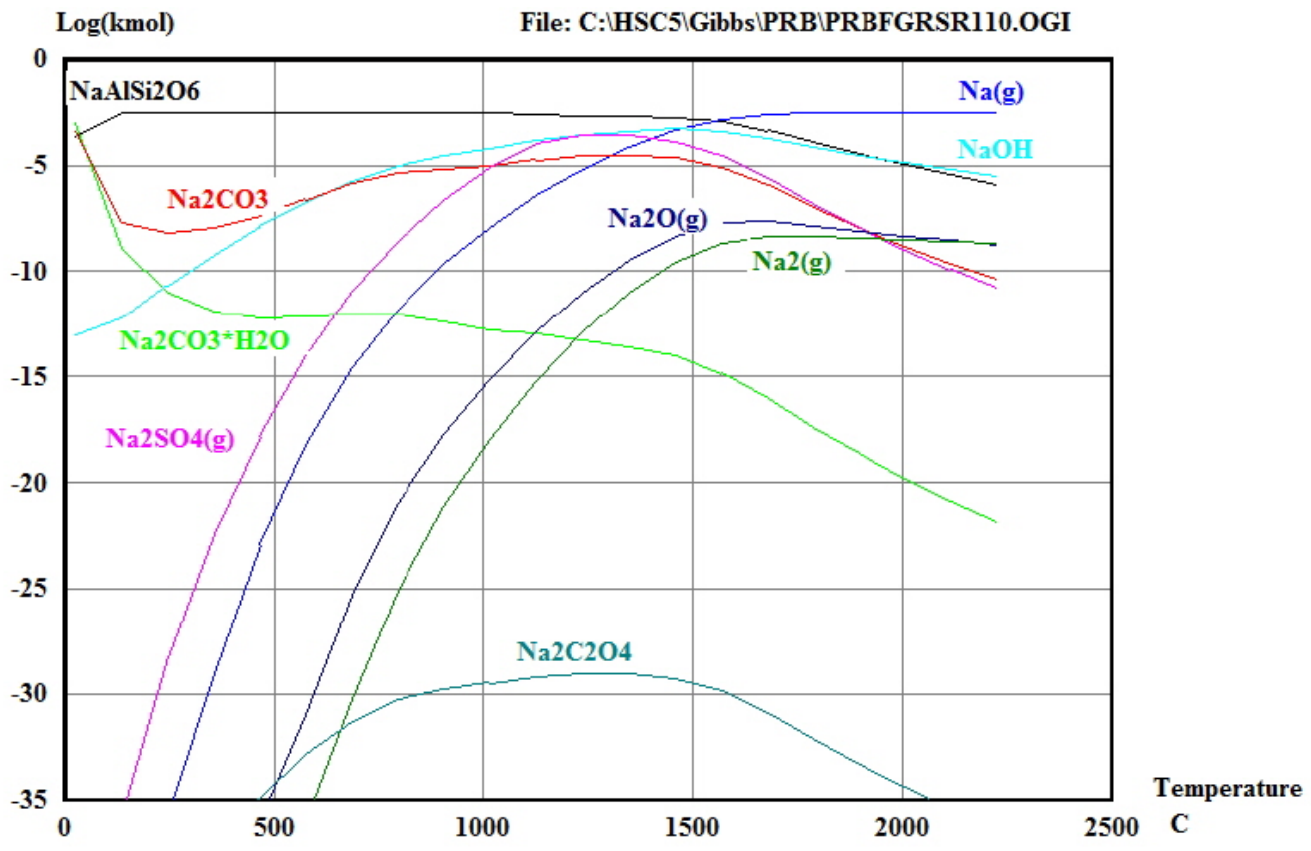

Figure 4.7-122: Thermodynamic equilibrium calculation results for sodium under PRB oxy-fired conditions. 
The results for silicon in the PRB size segregated aerosol were clearly sporadic in Figure 4.7-65. No conclusions about the behavior of silicon could accurately be deduced from the ICP-MS data for PRB due to issues with dissolving silicon with $\mathrm{HF}$ and then having potential evaporative loss due to $\mathrm{SiF}_{3}$ and $\mathrm{SiF}_{4}$. The distributions were clearly not representative enough to determine if there were any differences in silicon partitioning under oxy-fired conditions.

However, the thermodynamic equilibrium calculations indicate no significant differences in gas phase silicon in Figure 4.7-123 and Figure 4.7-124. The air-fired result showed a slight increase $\mathrm{SiO}_{2}$ gas phase, but overall the change to oxy-firing had little effect on silicon for the PRB coal.

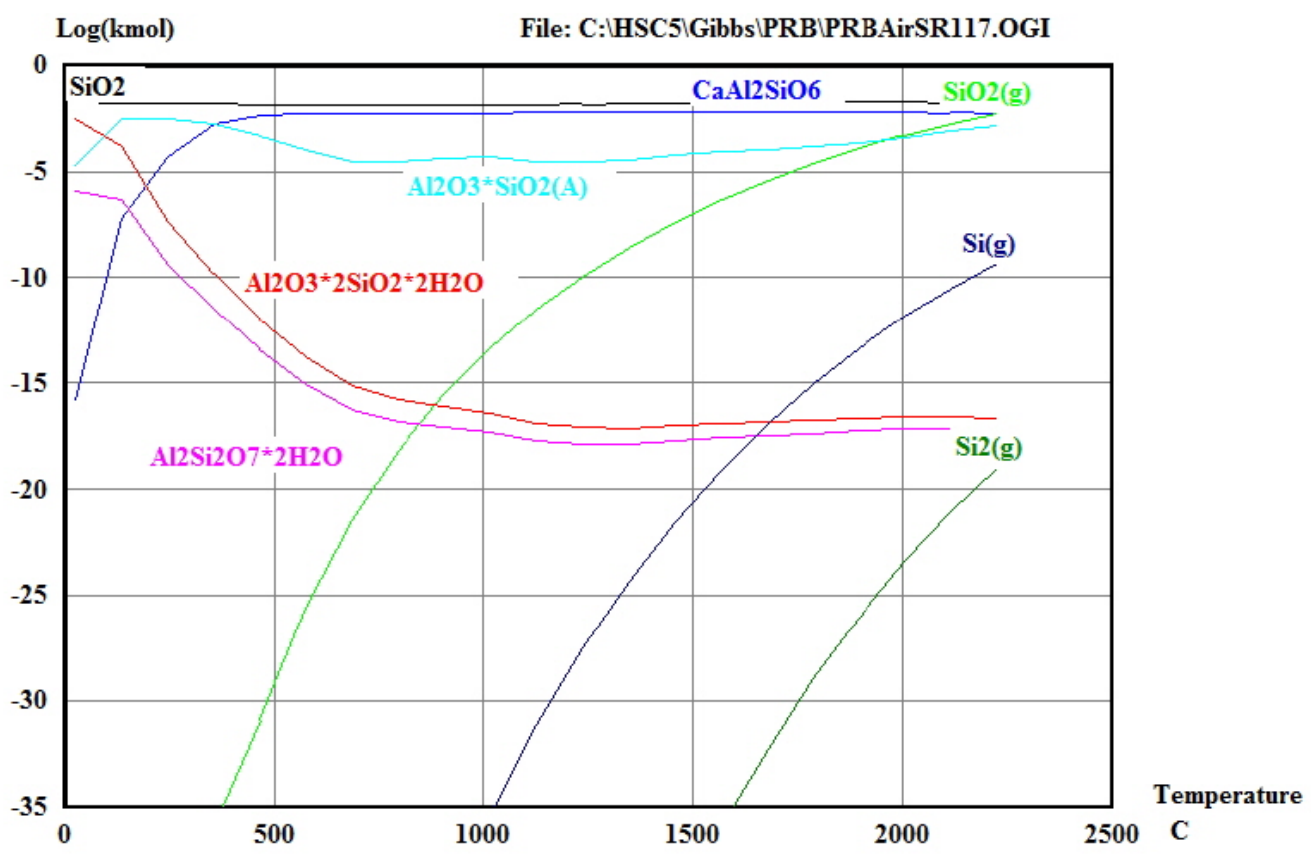

Figure 4.7-123: Thermodynamic equilibrium calculation results for silicon under PRB air-fired conditions. 


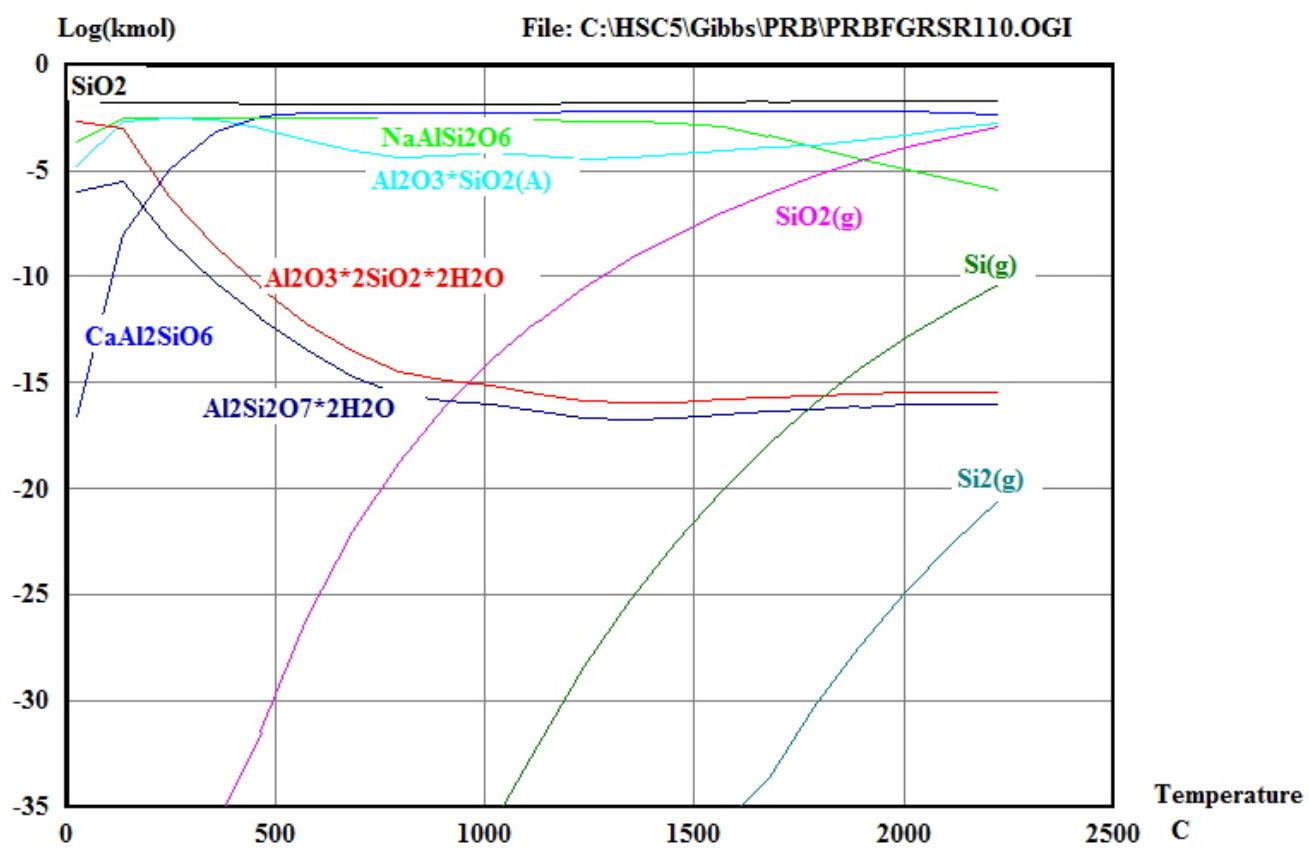

Figure 4.7-124: Thermodynamic equilibrium calculation results for silicon under PRB oxy-fired conditions.

\subsection{Illinois Ash Chemistry Discussion}

The Illinois coal results presented in section 4.7.3.3.3 showed that the oxy-fired conditions had a lower concentration of several elements in the submicron range than the air-fired condition. In order to understand how or why, thermodynamic equilibrium calculations were also completed to help clarify this observation.

The aluminum results for the Illinois coals in Figure 4.7-74 showed that the air-fired condition had slightly greater aluminum concentration for supermicron particle diameters collected by the impactor. The thermodynamic equilibrium calculations indicated that there was very little difference in volatility of aluminum or expected changes in concentration of aluminum oxides or alumina silicates in Figure 4.7-125 and Figure 4.7-126. 


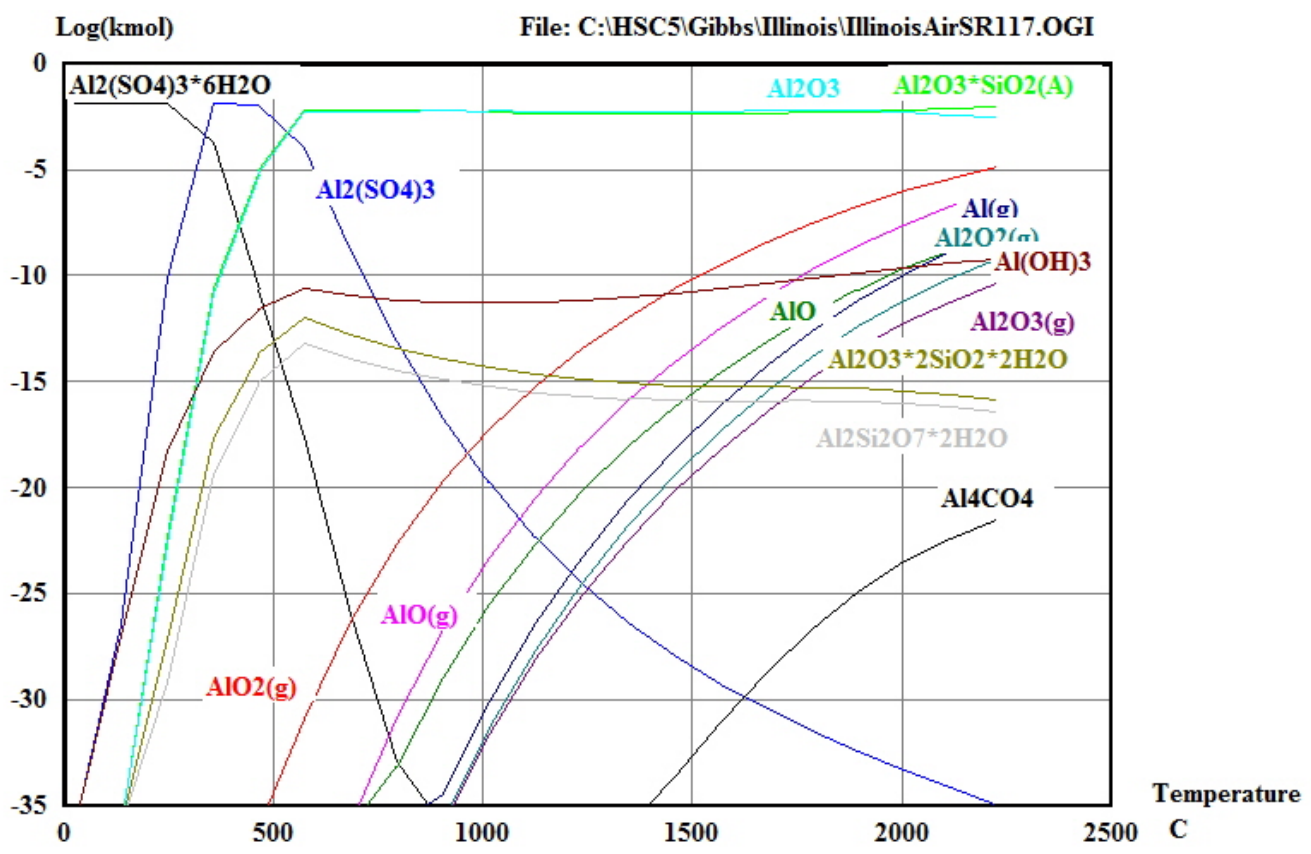

Figure 4.7-125: Thermodynamic equilibrium calculation results for aluminum under Illinois airfired conditions.

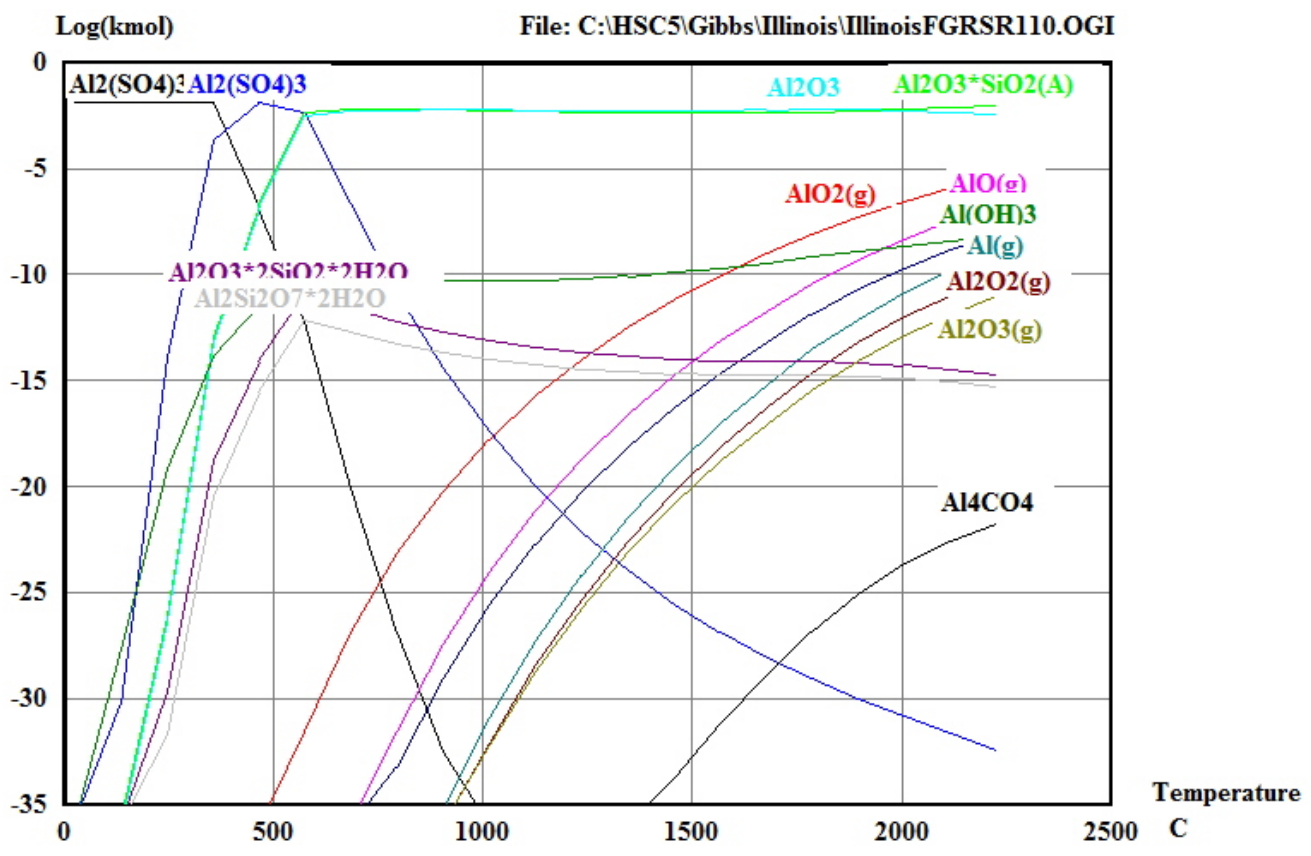

Figure 4.7-126: Thermodynamic equilibrium calculation results for aluminum under Illinois oxyfired conditions. 
The thermodynamic data indicated that aluminum sulfate was more stable and would decompose at higher temperatures for the oxy-fired case rather than the air-fired case. This indicates that under oxy-fired conditions sulfur capture by aerosols is more likely than under air-fired conditions. This was a significant result because it showed that there could be ancillary emissions reductions benefits to oxy-firing beyond the production of a high quality stream of $\mathrm{CO}_{2}$ for capture and storage.

The change in sulfate capture did not translate into a difference in concentration of aluminum in air and oxy-fired conditions since any concentrations of aluminum sulfate would be extremely small according to the calculation. The air case was nearly identical to the oxy-fired cases in the submicron particle diameter range.

The calcium results for the Illinois coal in Figure 4.7-78 indicated a higher concentration of calcium in the air-fired submicron range than in the oxy-fired submicron range. The thermodynamic equilibrium results indicated a very slight increase in the tendency of calcium to vaporize under air-fired conditions compared to oxy-fired conditions in Figure 4.7-127 and Figure 4.7-128. However, this did not indicate enough of a difference to produce the large difference in concentration of the submicron particles between air and oxy-fired conditions again indicating that the one air-fired data set may not be completely representative.

The thermodynamic data also demonstrated the increased stability of calcium sulfates under oxy-fired conditions, which further illustrated the potential reductions of sulfur emissions by retrofitting air to oxyfired.

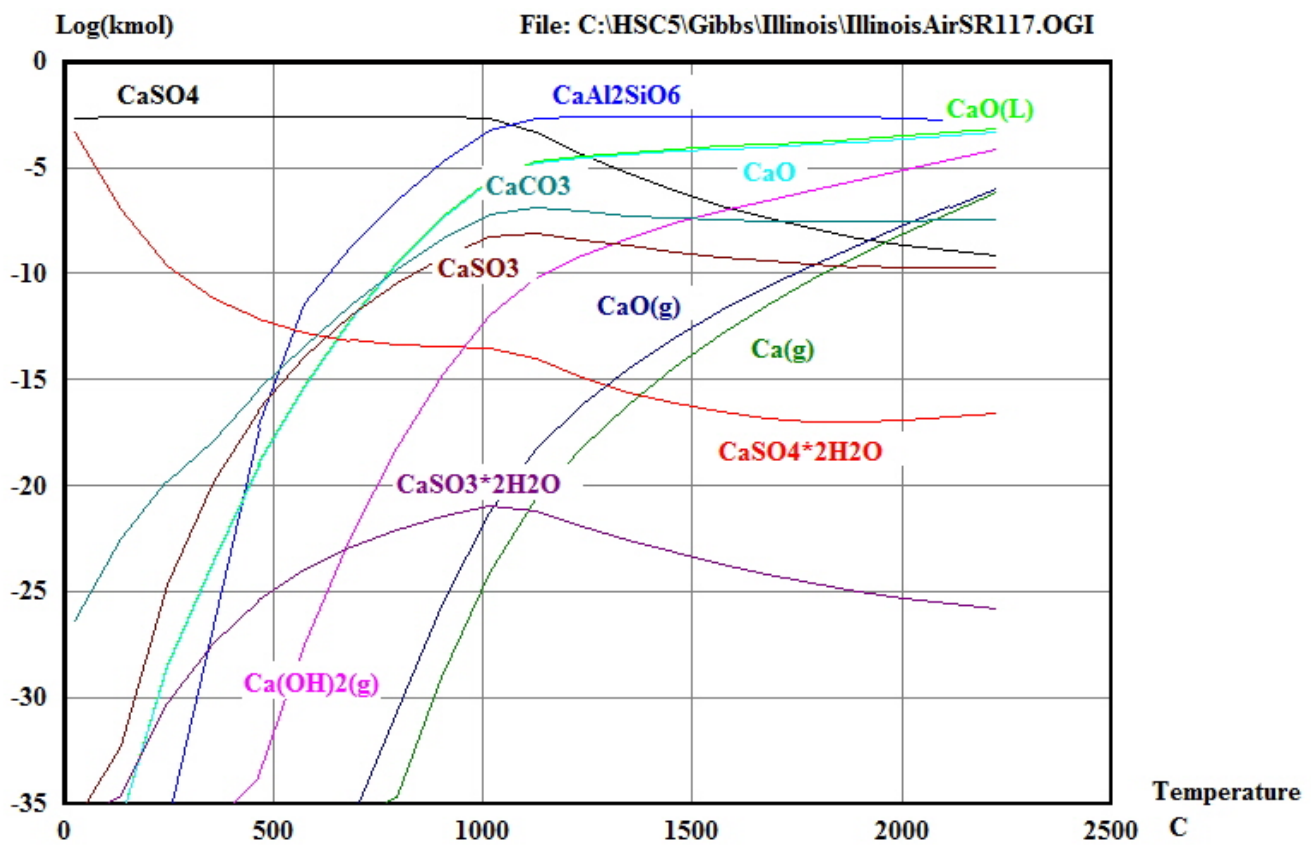

Figure 4.7-127: Thermodynamic equilibrium calculation results for calcium under Illinois air-fired conditions. 


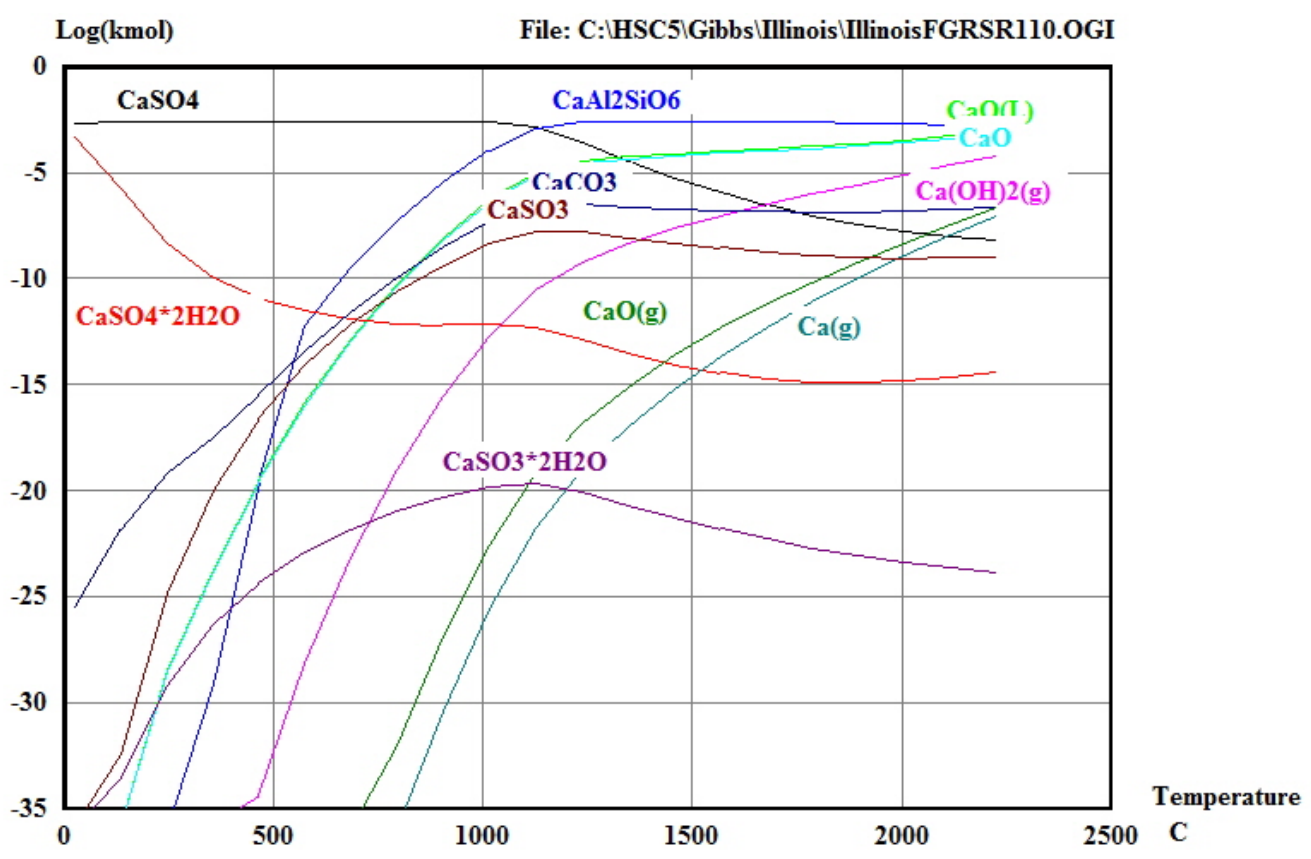

Figure 4.7-128: Thermodynamic equilibrium calculation results for calcium under Illinois oxy-fired conditions.

The results for iron for the Illinois coal in Figure 4.7-80 showed a very similar distribution across nearly the entire particle diameter range. However there was only one air-fired data point which did not agree with the oxy-fired results, and that was at a particle diameter of 32nm. Like calcium, the increase in iron vaporization of air-fired from oxy-fired has been shown to be small in the thermodynamic equilibrium calculations in Figure 4.7-129 and Figure 4.7-130. Thus, it is more likely that this sudden departure from the trend and increase in iron at $32 \mathrm{~nm}$ when iron was nondetectable at $64 \mathrm{~nm}$ was likely due to a very small amount of iron contamination or particle bounce off since even an extremely small amount of iron would still result in a large difference at such as a small particle diameter and corresponding low total particle mass. 


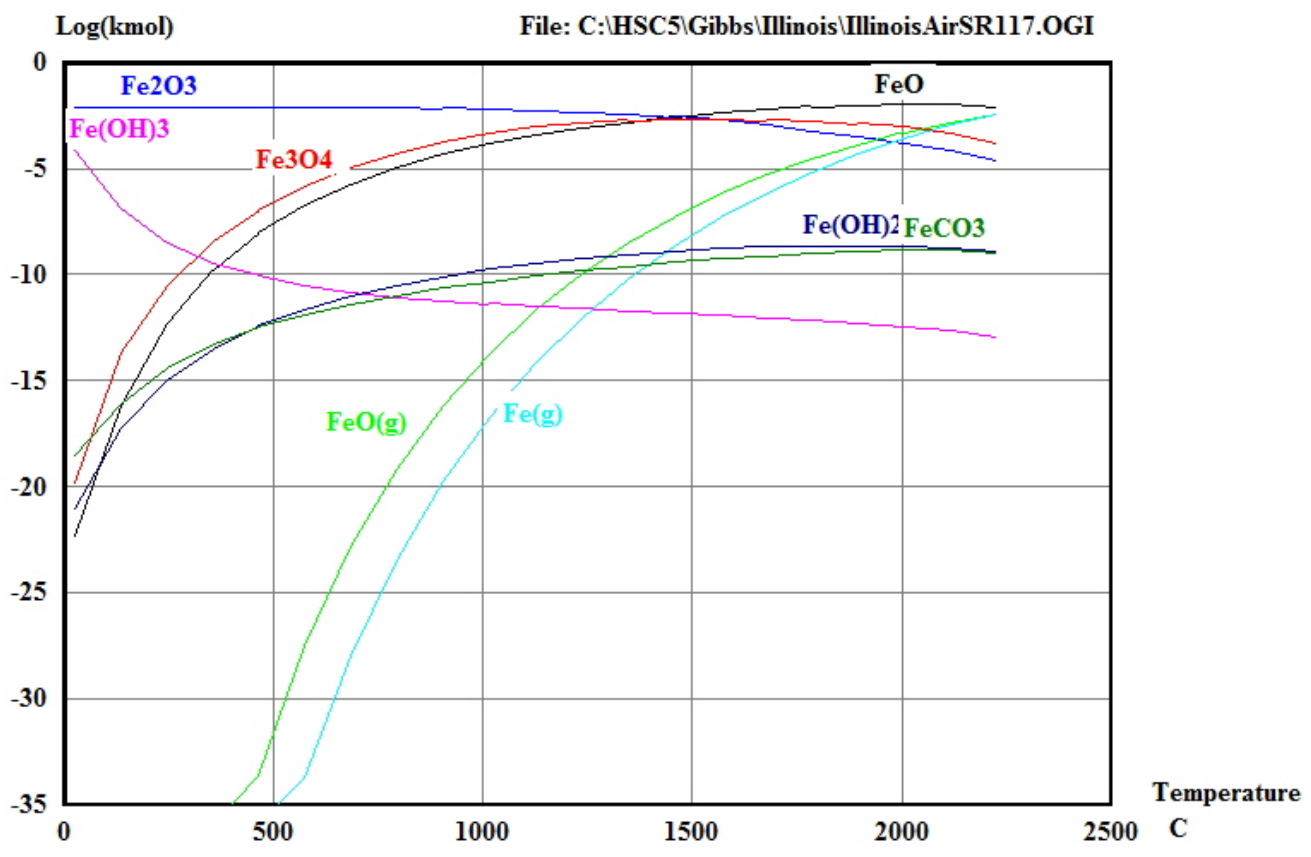

Figure 4.7-129: Thermodynamic equilibrium calculation results for iron under Illinois air-fired conditions.

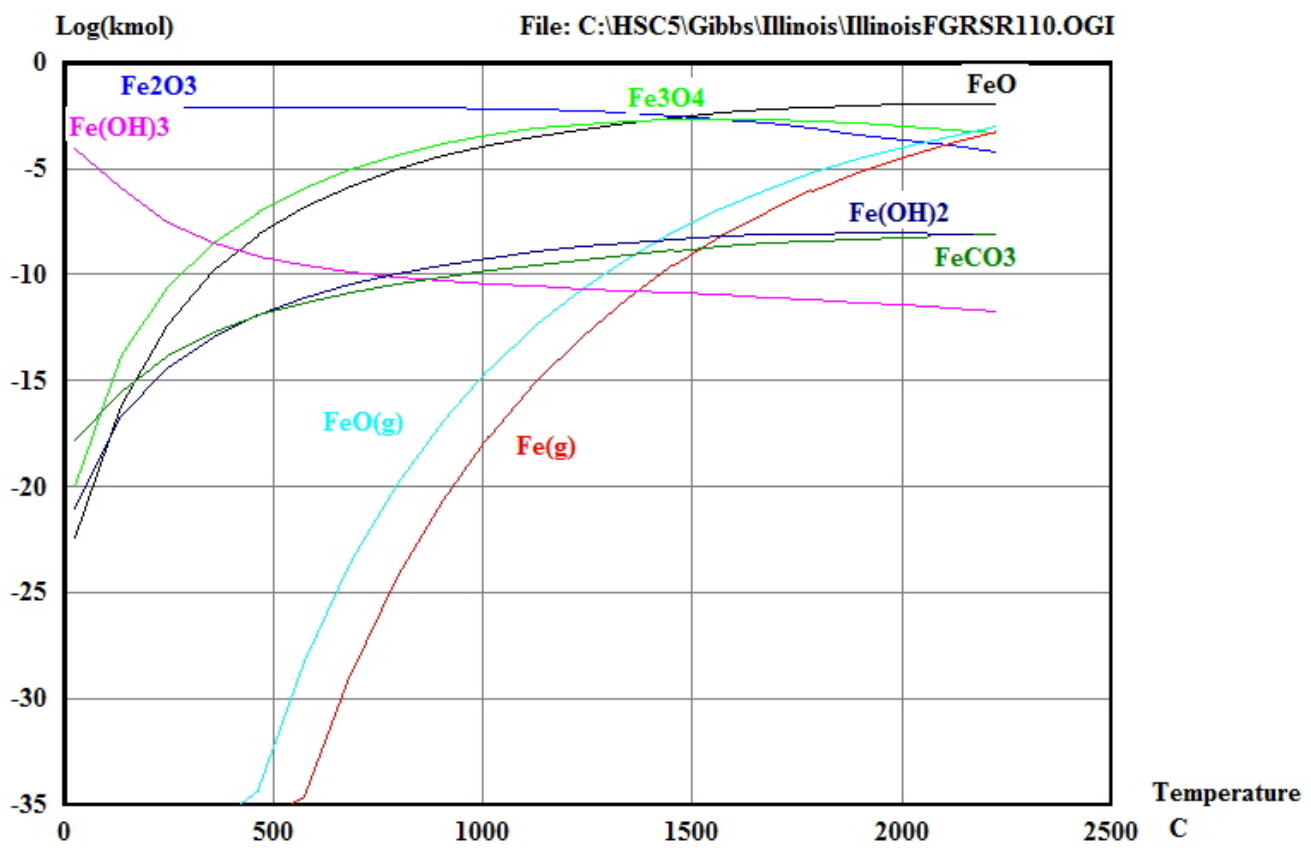

Figure 4.7-130: Thermodynamic equilibrium calculation results for iron under Illinois oxy-fired conditions. 
The results for potassium in the Illinois coal aerosol indicated that there was generally an equivalent distribution of potassium under air and oxy-fired conditions for most particle diameters as previously reported in Figure 4.7-77. The only subtle difference was that small amounts of potassium were detected under oxy-fired conditions in the ultrafine range of less than $100 \mathrm{~nm}$, while no detectable results in this range were recorded for the air-fired case.

The thermodynamic results presented in Figure 4.7-131 and Figure 4.7-132 indicated that potassium sulfate would be found in greater concentrations at higher temperatures under oxy-fired conditions than under air-fired conditions. This could result in a greater concentration of ultrafine potassium particles as well as increasing the deposition rate by condensing sticky sulfate particles on boiler tubes.

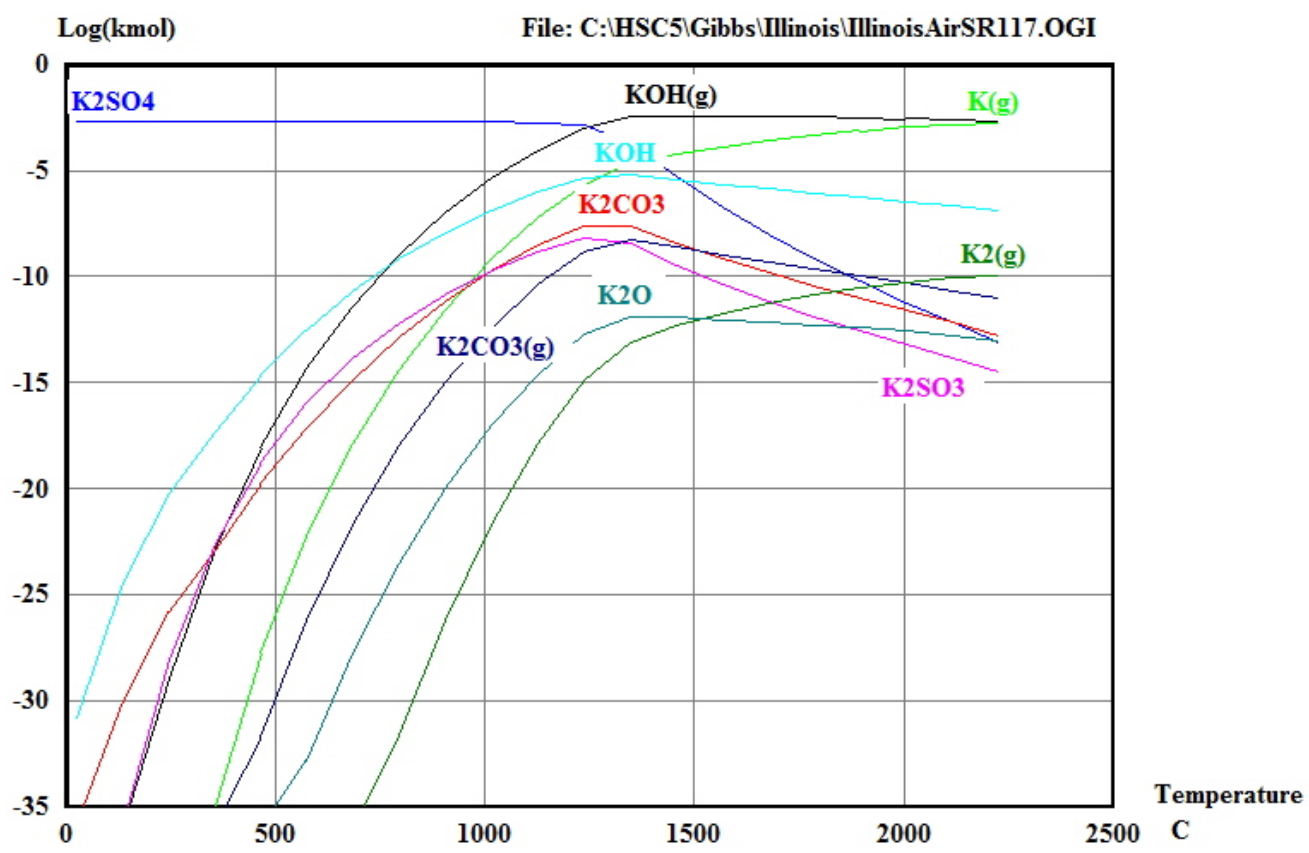

Figure 4.7-131: Thermodynamic equilibrium calculation results for potassium under Illinois airfired conditions. 


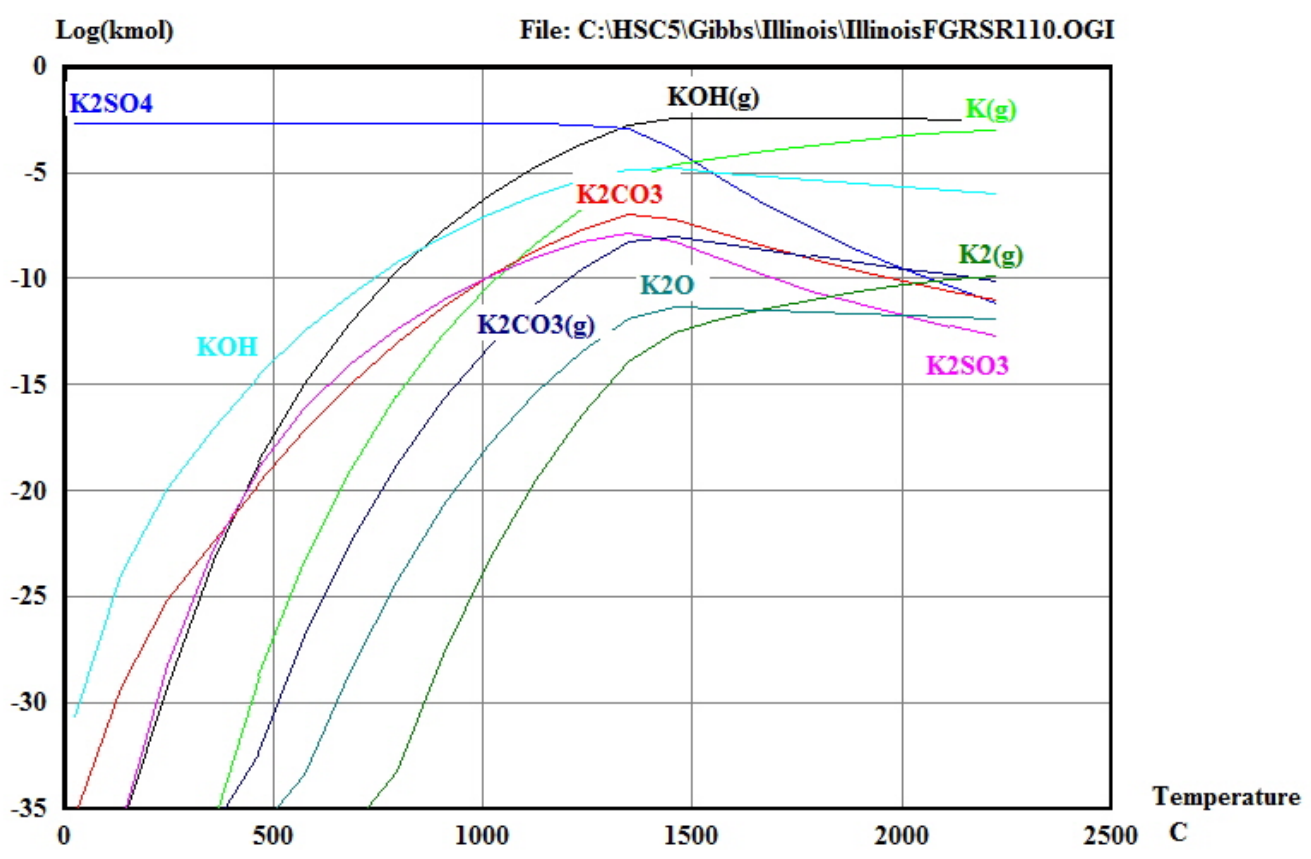

Figure 4.7-132: Thermodynamic equilibrium calculation results for potassium under Illinois oxyfired conditions.

The results for the size segregated ash chemistry for sodium presented in Figure 4.7-72 followed similar trends as the potassium results. For the half micron and larger particles, the air and oxy-fired ash aerosols had very similar concentrations of sodium. However, in the ultrafine range below $100 \mathrm{~nm}$, no sodium was detectable for the air-fired results, but sodium was detected for the oxy-fired results.

Once again, the thermodynamic data indicated a slight increase in gas phase sodium sulfate under oxyfired conditions compared to air-fired conditions in Figure 4.7-133 and Figure 4.7-134. This increase in gas phase sodium sulfate would lead to a greater concentration of sodium in condensed vapor particles below $100 \mathrm{~nm}$ as well as creating a sticky surface on boiler tubes which would increase the rate of ash deposition as sodium sulfate condensed on boiler tubes and bonded with other particles impacting the surface. 


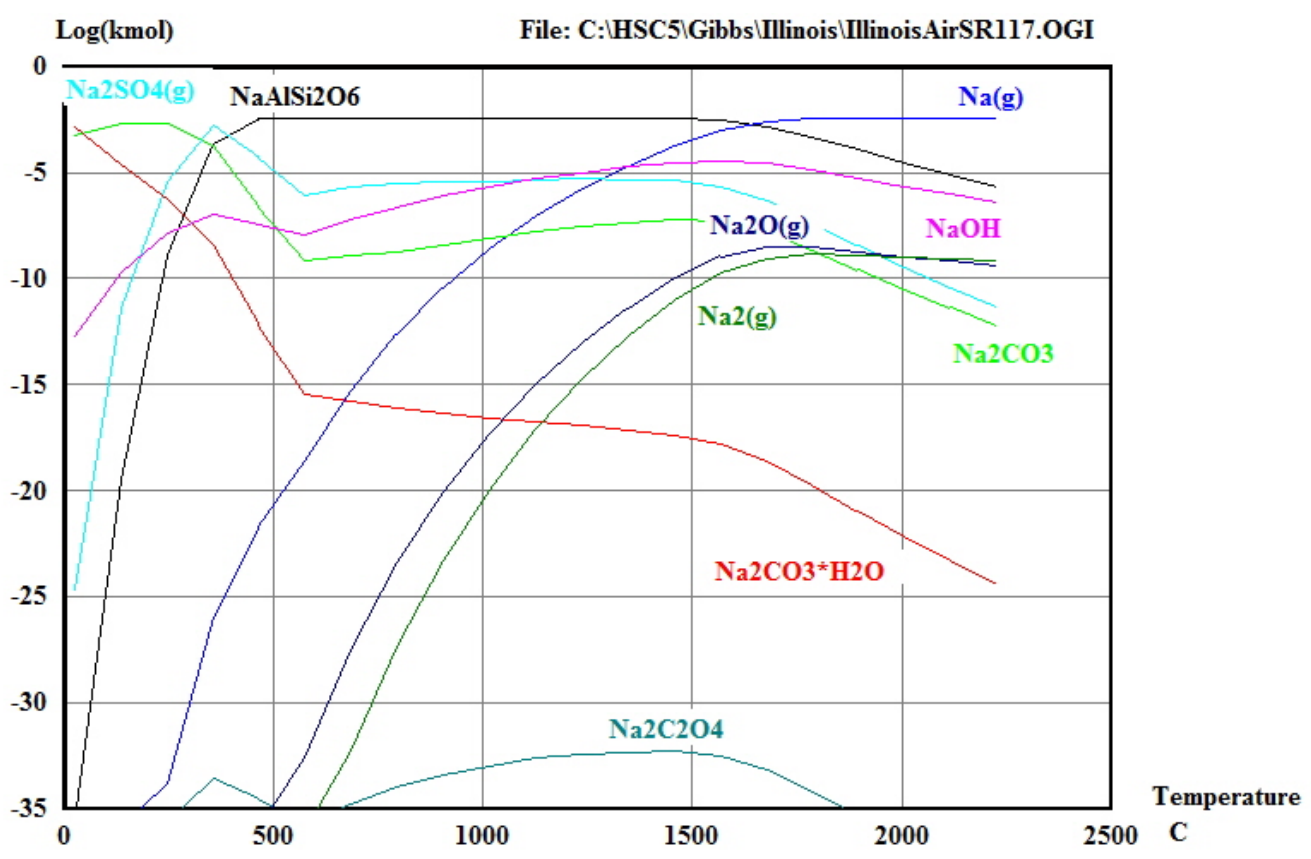

Figure 4.7-133: Thermodynamic equilibrium calculation results for sodium under Illinois air-fired conditions.

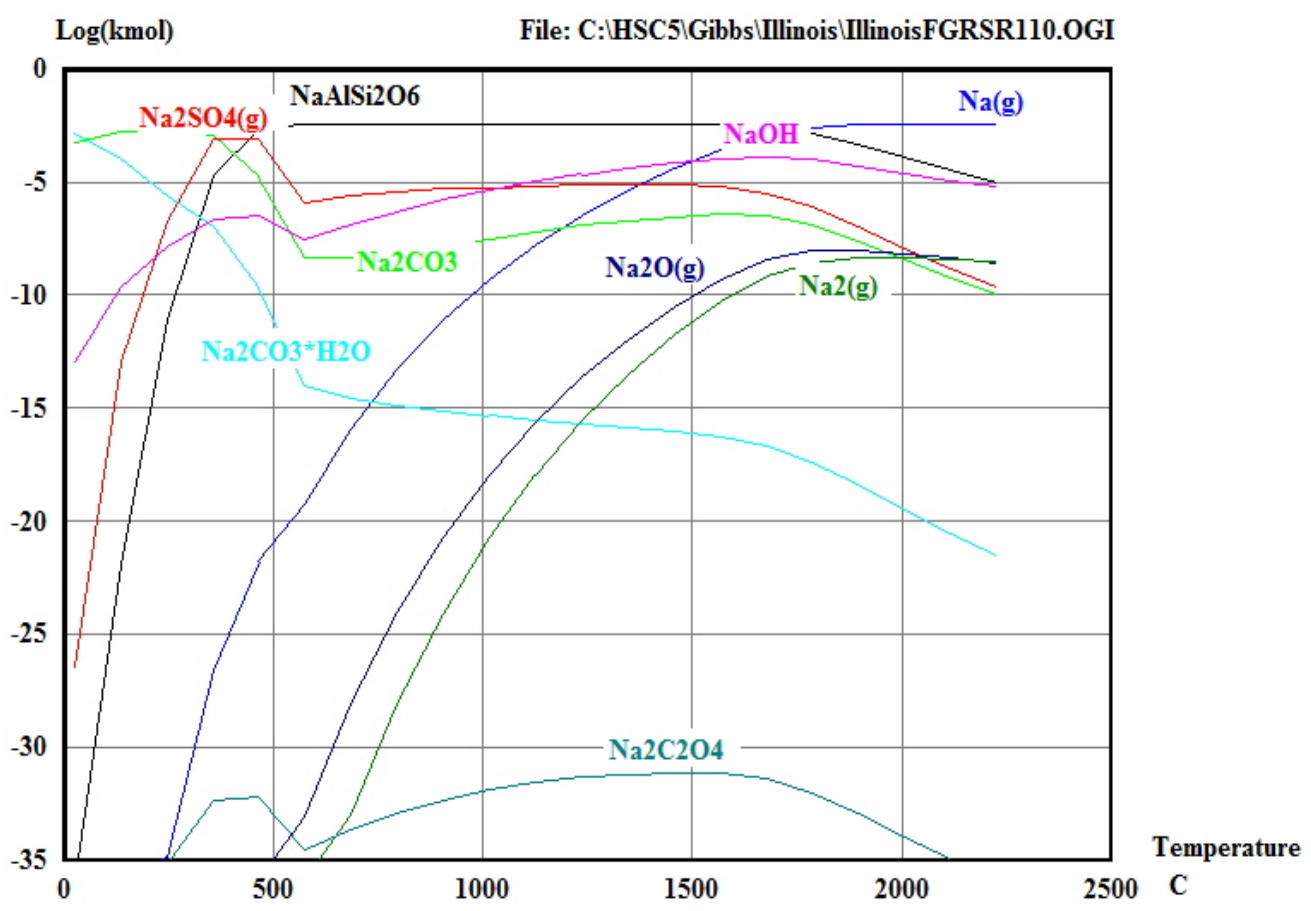

Figure 4.7-134: Thermodynamic equilibrium calculation results for sodium under Illinois oxy-fired conditions. 
No significant differences in the silicon concentration of the Illinois size segregated ash between air and oxy-fired conditions were observed in Figure 4.7-75. The thermodynamic calculation results Figure 4.7-135 and Figure 4.7-136 did not suggest any difference in equilibrium silicon behavior between air and oxy-fired conditions. Minor perturbations and impactor stages that were below detectable limits existed, but these were more likely a result of the difficulty in accurately digesting and measuring the silicon concentration of submicron particles with the ICP-MS. Therefore, it is not possible to make definitive conclusions about any potential difference in silicon distribution under air and oxy-fired conditions for the Illinois coal as a result of this work.

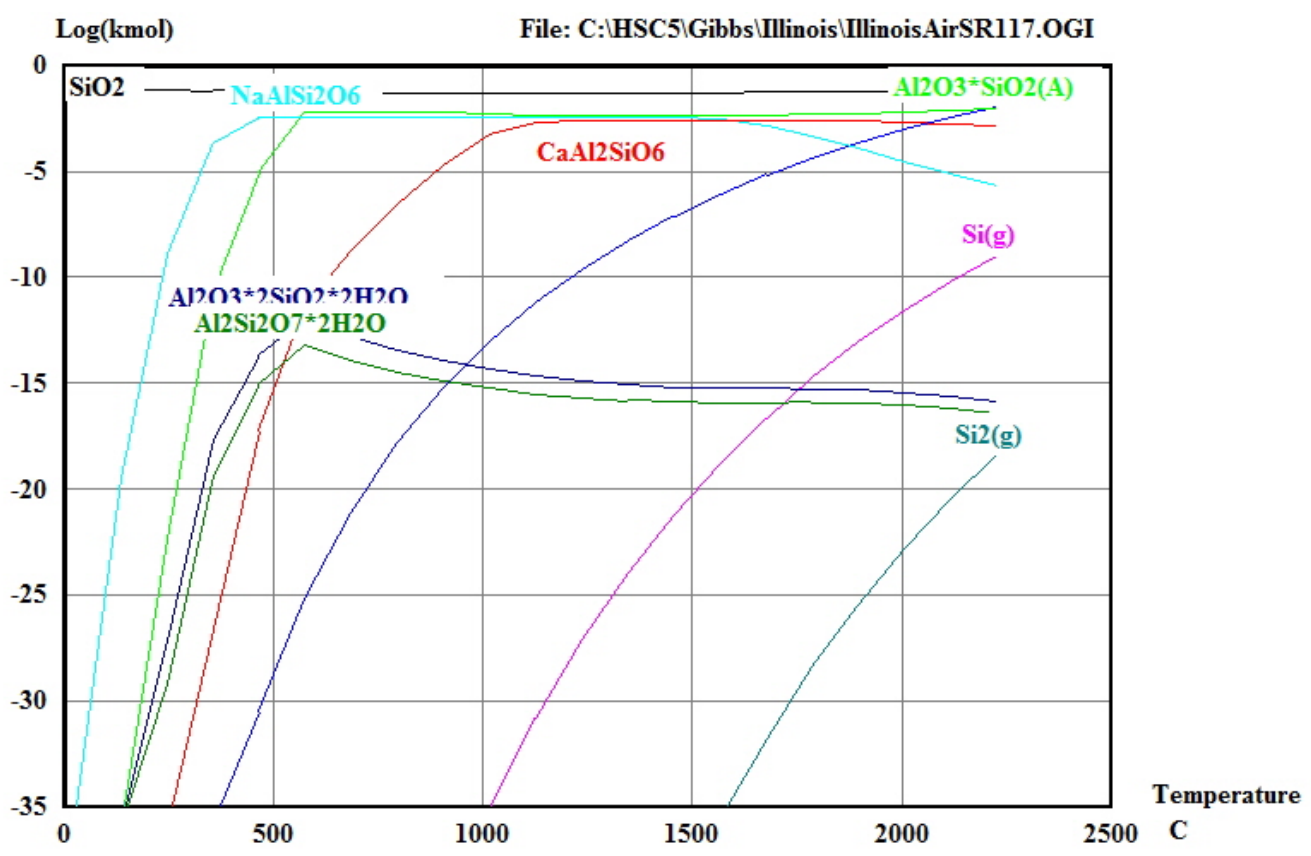

Figure 4.7-135: Thermodynamic equilibrium calculation results for silicon under Illinois air-fired conditions. 


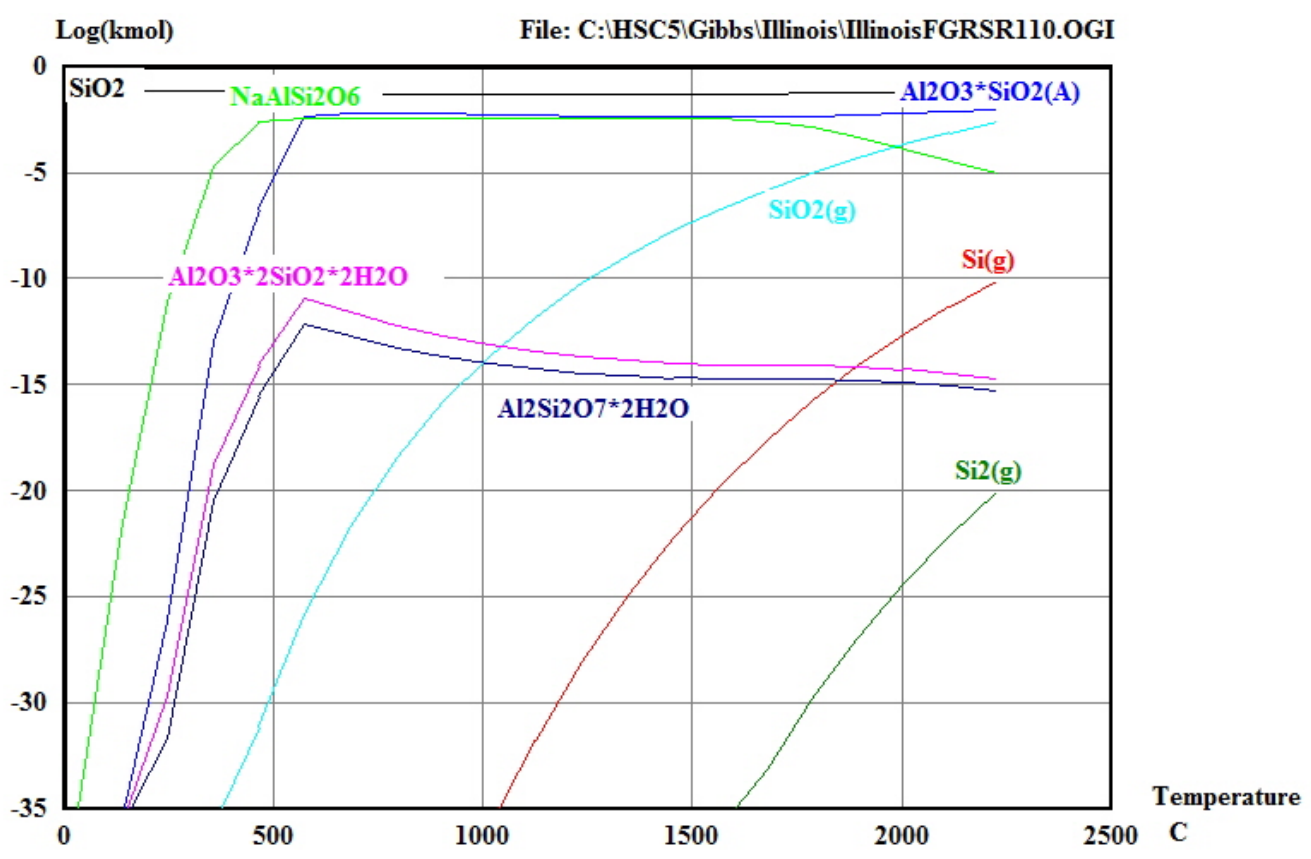

Figure 4.7-136: Thermodynamic equilibrium calculation results for silicon under Illinois oxy-fired conditions.

\subsection{Sodium Vaporization Discussion}

The vaporization of sodium for all coals under all combustion conditions was also of interest due to sodium's potential to create deposits on heat transfer surfaces within a boiler. After the sodium vaporizes, it condenses on the cooler boiler tube surfaces and begins the process of ash deposition on the heat transfer surface thus reducing the efficiency of the boiler.

In order to understand whether the current models used to predict vaporization of sodium under air-fired conditions were sufficient for use with oxy-fired conditions, data were plotted for all coals and combustion conditions assuming that all sodium found in the particle diameter range of less than $0.5 \mu \mathrm{m}$ would be condensed vapor sodium. Thus data for each coal and each condition were plotted along with Gallagher's data to illustrate any potential differences between vaporization of similar coals when transitioning from air to various oxy-fired combustion environments.

The data show that the existing models can likely be utilized effectively for prediction of sodium vaporization for a given coal even under oxy-fired conditions. The data for the oxy-fired conditions plotted in this work showed similar scatter to the data in Gallagher's work for coals with similar ash chemistry. Room for optimization may be available as more data are gathered, but currently the existing air-fired models have been deemed sufficient and should be used with confidence while being refined as more data become available. These results have been presented in Figure 4.7-137. 


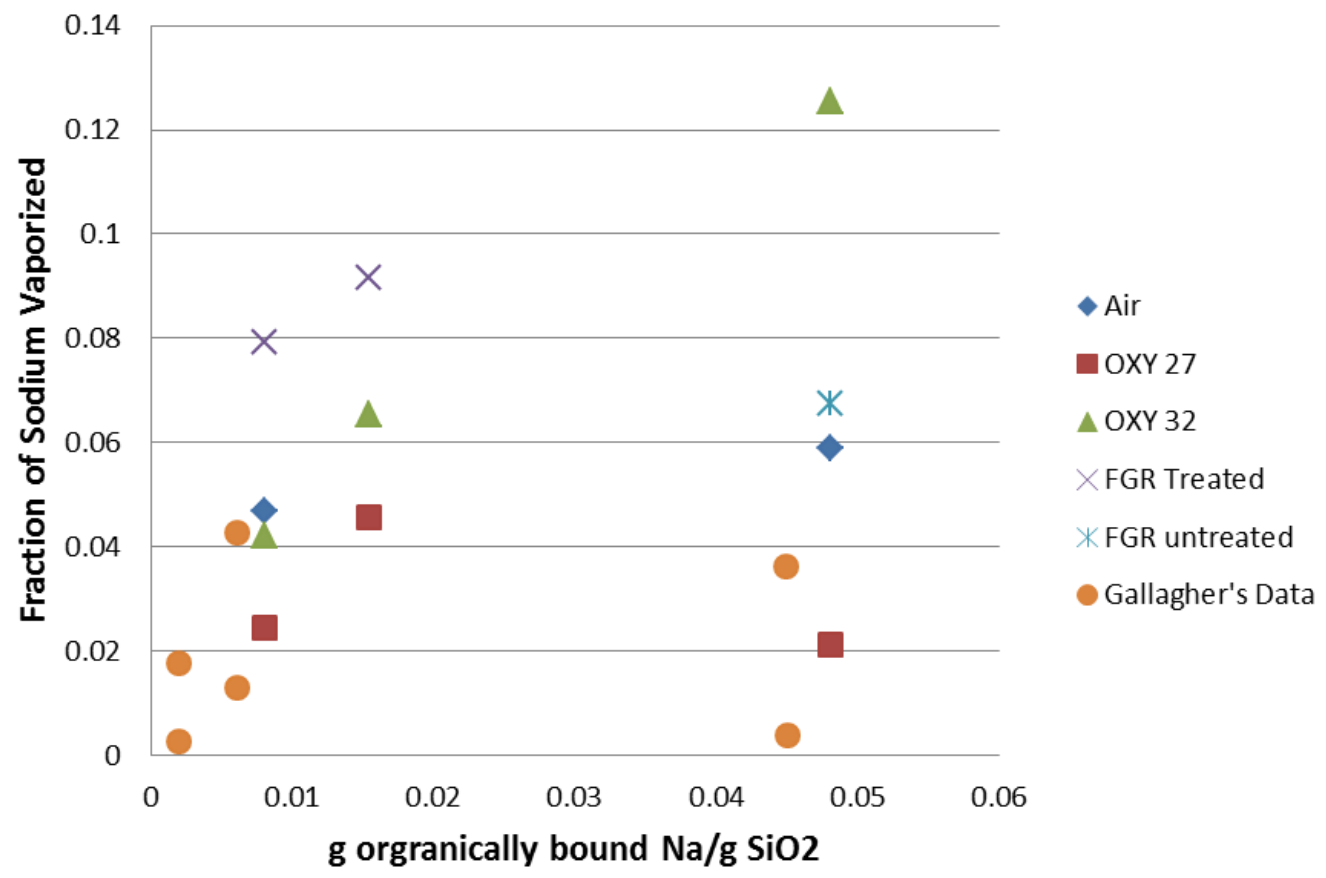

Figure 4.7-137: Sodium vaporization between air and oxy-fired conditions for the Utah, PRB, and Illinois coals when compared with previous data from Gallagher.

\subsubsection{Aerosols Conclusions}

This work was performed in order to answer several questions about the differences in aerosols produced by given coals under air and oxy-fired conditions. The conclusions are presented on a point by point basis to emphasize each unique discovery of this research.

- LOI or carbon in the ash is nearly always reduced under oxy-fired conditions of $27-32 \% \mathrm{O}_{2}$ as a result of increased oxygen and residence time to facilitate greater char oxidation when compared to air-fired combustion. The increased residence time is a result of less flue gas moving through the same furnace under oxy-fired conditions.

- Black carbon or soot is also nearly always reduced when switching from air to oxy-fired conditions in the 27-32\% $\mathrm{O}_{2}$ range. The reduction of pyrolysis products as a result of the more mass transfer resistant $\mathrm{CO}_{2}$ atmosphere seems to be a significant mechanism, however increased residence time in the furnace and increased oxygen concentration could also facilitate greater oxidation under oxy-fired conditions.

- Black carbon or soot is a very significant contributor to the ultrafine particle mode.

- Overall particle size distributions for a given coal are not fundamentally different between air and oxy-fired conditions of similar temperatures, i.e., $27-32 \% \mathrm{O}_{2}$ range.

- Differences in ultrafine particle size distributions exist due to a reduction in the volatility of some elements under oxy-fired conditions as well as a reduction in soot. 
- Particle size distributions are affected by stoichiometric ratio due to differences in soot and sulfate production.

- Fundamental operations and assumptions of the SMPS instrument may lead to erroneous mass based particle size distributions.

- Differences between air and oxy-fired partitioning of elements in the ash are subtle and do not indicate the need for fundamental changes in aerosol handling or potential aerosol toxicity.

- A thermodynamic equilibrium calculation that suggested sodium and potassium sulfates are more stable under oxy-fired conditions was often observed by greater concentrations of sodium and potassium at the sub $100 \mathrm{~nm}$ particle diameter.

- These thermodynamic equilibrium calculations also suggested only a very small increase in carbonates in the mineral matter under oxy-fired conditions.

- The increase in sodium and potassium sulfate under oxy-fired conditions suggests increased deposition rates for oxy-firing over long time scales during extended furnace operation.

- No significant changes occurred for larger supermicron ash particle chemistry when changing from air to oxy-fired conditions.

- No significant changes occurred for the fine fragmentation particles near 1 micron in diameter when changing from air to oxy-fired conditions.

- Coal rank and chemistry dominates the partitioning of ash particles and elements and combustion atmosphere has a comparatively limited mechanistic influence.

- No aerosol data were discovered across a wide range of coal compositions and oxy-fired combustion conditions that would indicate a significant problem or hurdle for retrofitting an existing boiler with oxy-fired technology. 


\subsection{Slagging and Fouling}

\subsubsection{Introduction}

Slagging can be defined as the process by which ash deposits on heat-transfer surfaces in the radiant section of the coal-fired boiler. Slagging creates deposits that decrease heat transfer in the radiant zone, which can result in a reduction in plant output (load). Most boilers have systems in place to remove deposits, soot blowing systems, although not all deposits can be removed successfully. If these deposits become too large, they can cause mechanical damage to the boiler, and that damage can result in an unplanned outage.

Fouling can be defined as the process by which ash deposits on heat-transfer surfaces in the convective section of the coal-fired boiler. The convective section of a boiler consists of banks of tubes containing steam. The flue gases flow across the tubes and inorganic material accumulates by deposition of vapors and by deposition of particles. The mechanisms for deposition by fouling are not entirely the same as those for slagging, but the consequences are similar: loss of heat transfer, unplanned outages due to build-up of large deposits.

Work on the development and validation of REI's slagging and fouling models for oxy-combustion is detailed in this section. Data on ash size and compositions were collected under both air and oxycombustion conditions. The analyses of coal samples were used to generate model inputs and the ash analyses were used for model validation.

In the Oxy-Fuel Combustor (OFC) furnace, the experimental conditions examined were for air-fired combustion, and oxy-coal combustion with inlet concentrations of $32 \% \mathrm{O}_{2}$ and $27 \% \mathrm{O}_{2}$ in once-through $\mathrm{CO}_{2}$. Data have been processed for combustion experiments using Utah bituminous coal, Powder River Basin (PRB) subbituminous coal and Illinois bituminous coal.

\subsubsection{Ash Analysis Results and Discussion}

\subsubsection{Coal Analyses}

The coal analyses, including mineral analysis of ash, for the three coals used in this testing are shown in Table 4.8-1. The Utah bituminous coal is low in sulfur with a moderate ash content (8.8 wt\%). The ash contains a high amount of silica (61 wt $\% \mathrm{SiO}_{2}$ on an ash basis). The ash is also relatively low in iron and calcium. The PRB coal, in contrast to the Utah bituminous coal, has higher calcium content in the ash (22 wt $\% \mathrm{CaO}$ on an ash basis). The sodium content of the PRB ash is almost $2 \mathrm{wt} \% \mathrm{Na}_{2} \mathrm{O}$. Combined with the low silica content of the ash, this sodium content points to the potential for higher fouling with this coal. The Illinois coal, in contrast to the Utah bituminous coal, contains less $\mathrm{Ca}$ (only $1.9 \%$ as $\mathrm{CaO}$ ) and much higher Fe (nearly 15\%). The silica content is slightly lower than that of the Utah bituminous coal, but not as low as that of the PRB. 
Table 4.8-1: Coal analyses (weight percent basis).

\begin{tabular}{|l|l|l|l|}
\hline & Utah & PRB & Illinois \\
\hline Moisture (\%) & 3.18 & 23.69 & 9.65 \\
\hline Ash (\%) & 8.83 & 4.94 & 7.99 \\
\hline $\mathrm{C}(\%)$ & 70.60 & 53.72 & 64.67 \\
\hline $\mathrm{H}(\%)$ & 5.06 & 3.59 & 4.52 \\
\hline $\mathrm{N}(\%)$ & 1.42 & 0.78 & 1.12 \\
\hline $\mathrm{S}(\%)$ & 0.53 & 0.23 & 3.98 \\
\hline $\mathrm{O}(\%)$ & 10.38 & 13.05 & 8.07 \\
\hline Volatile $(\%)$ & 38.60 & 33.36 & 36.78 \\
\hline Fixed $\mathrm{C}(\%)$ & 49.39 & 38.01 & 45.58 \\
\hline $\mathrm{HHV}(\mathrm{Btu} / \mathrm{lb})$ & 12,606 & 9,078 & 11,598 \\
\hline $\mathrm{Minerals}$ & & & \\
\hline $\mathrm{Al}$ as $\mathrm{Al}_{2} \mathrm{O}_{3}(\%)$ & 14.52 & 14.78 & 17.66 \\
\hline $\mathrm{Ca}$ as $\mathrm{CaO}_{(\%)}(6.11$ & 22.19 & 1.87 \\
\hline $\mathrm{Fe}$ as $\mathrm{Fe}_{2} \mathrm{O}_{3}(\%)$ & 5.09 & 5.20 & 14.57 \\
\hline $\mathrm{Mg}$ as $\mathrm{MgO}(\%)^{(\%)}$ & 1.39 & 5.17 & 0.98 \\
\hline $\mathrm{Mn}$ as $\mathrm{MnO}_{(\%)}$ & 0.02 & 0.01 & 0.02 \\
\hline $\mathrm{P}$ as $\mathrm{P}_{2} \mathrm{O}_{5}(\%)$ & 0.59 & 1.07 & 0.11 \\
\hline $\mathrm{K}$ as $\mathrm{K}_{2} \mathrm{O}(\%)$ & 0.57 & 0.35 & 2.26 \\
\hline $\mathrm{Si}$ as $\mathrm{SiO}_{2}(\%)$ & 60.89 & 30.46 & 49.28 \\
\hline $\mathrm{Na}$ as $\mathrm{Na}_{2} \mathrm{O}(\%)$ & 1.41 & 1.94 & 1.51 \\
\hline $\mathrm{S}$ as $\mathrm{SO}_{3}(\%)$ & 2.33 & 8.83 & 2.22 \\
\hline $\mathrm{Ti}$ as $\mathrm{TiO}_{2}(\%)$ & 0.88 & 1.30 & 0.85 \\
\hline
\end{tabular}

Three coal samples (PRB, Utah Bituminous and Illinois bituminous) and nine ash samples (each coal fired under air, 27\% $\mathrm{O}_{2}$ and 32\% $\mathrm{O}_{2}$ ) were analyzed by Computer-Controlled Scanning Electron Microscopy (CCSEM) at Microbeam Technologies. The raw CCSEM analyses of the coal samples were processed to determine the mineral composition (as wt\% oxides) for comparison to the coal ASTM analyses. The coal CCSEM results are compared to the coal minerals analysis in Figure 4.8-1, Figure 4.8-2, and Figure 4.8-3. The comparison between the CCSEM data and the coal minerals analysis is fairly close for the bituminous coals, but the data for the PRB coal show significant differences. This is due to organically bound minerals in the coal. While the ASTM ash analysis of the coal measures total concentration (including organically bound minerals), the CCSEM analysis does not measure any organically bound species. Therefore, the results of processing the CCSEM analysis for the PRB coal were modified to include organically bound $\mathrm{Na}, \mathrm{Mg}$ and $\mathrm{Ca}$. The concentrations of these species were increased to match the coal minerals analysis. This greatly improved the agreement between the coal minerals analysis and the CCSEM data as seen in Figure 4.8-2. 


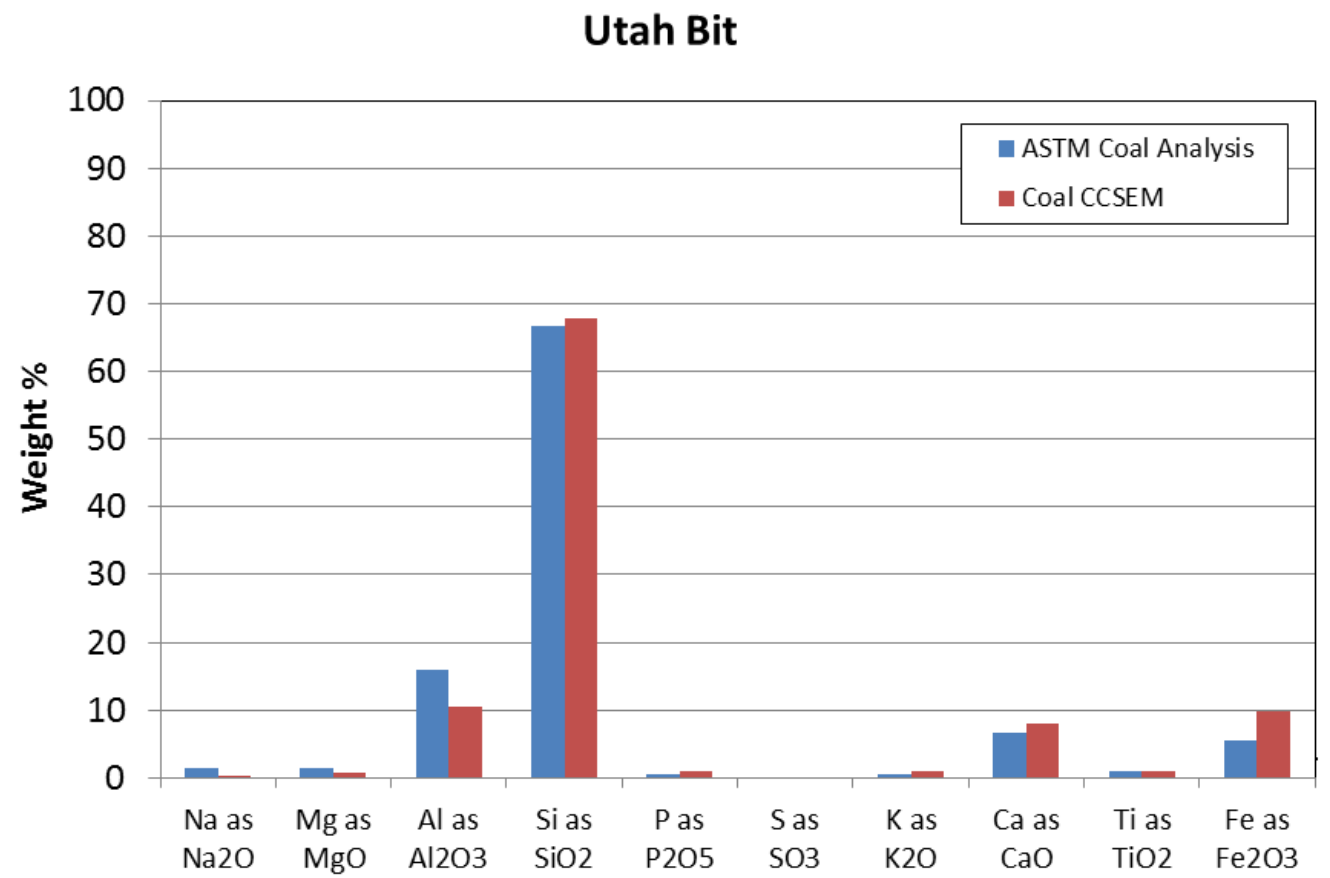

Figure 4.8-1: Comparison of coal ASTM mineral analysis and CCSEM analysis of Utah bituminous coal.

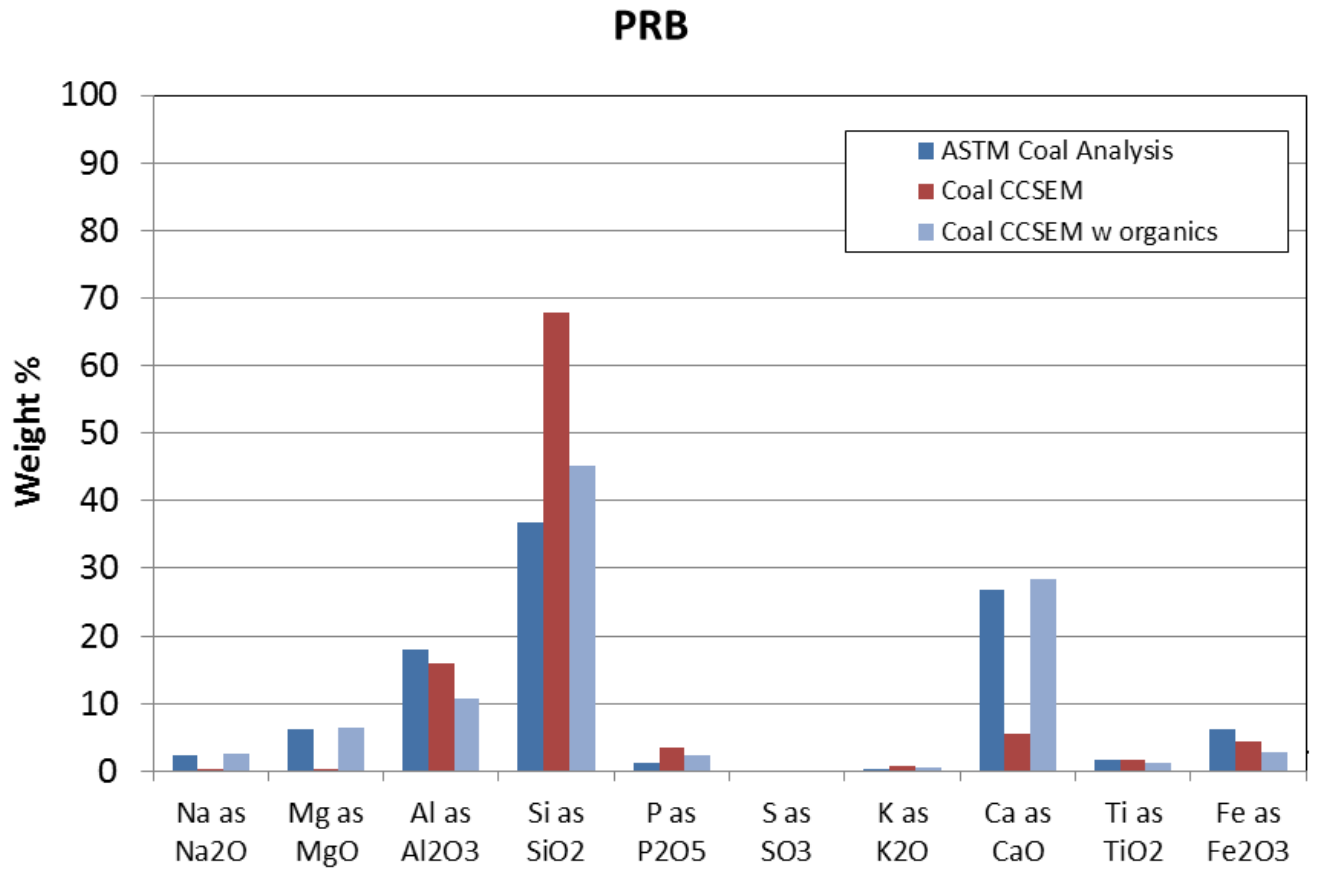

Figure 4.8-2: Comparison of coal ASTM mineral analysis and CCSEM analysis of PRB coal. 


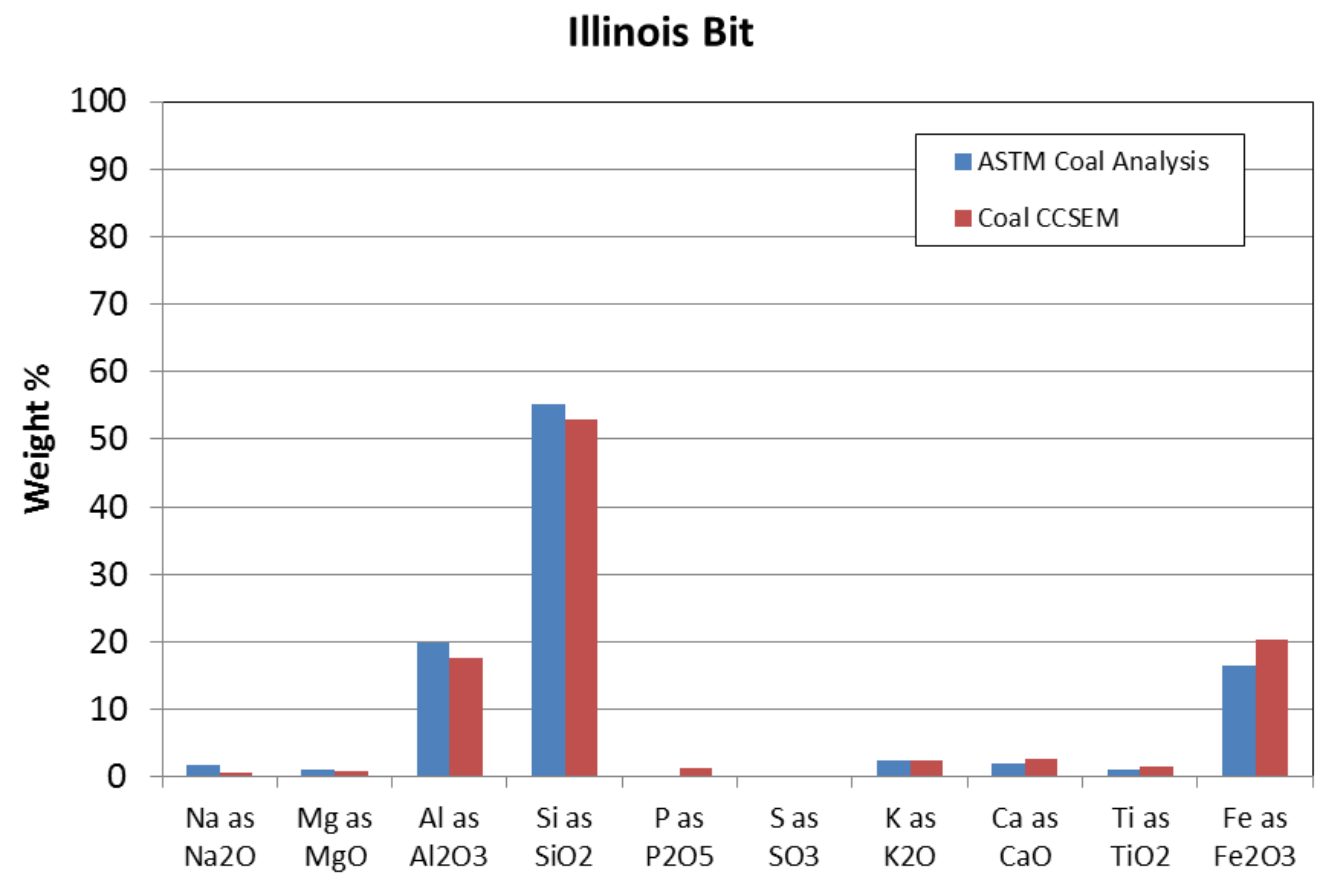

Figure 4.8-3: Comparison of coal ASTM mineral analysis and CCSEM analysis of Illinois bituminous coal.

\subsubsection{Ash from Combustion Process}

CCSEM analysis was also carried out on in-flight ash samples collected from the oxy-furnace. Ash samples were collected using a probe in the vertical section of the furnace. For each coal, the ash samples corresponded to combustion in air, $27 \% \mathrm{O}_{2}$ and $32 \% \mathrm{O}_{2}$, without flue gas recycle.

The ASTM coal minerals analysis and the CCSEM data were also compared to the ash CCSEM analyses that had been processed and converted to wt\% oxides. These comparisons are shown in Figure 4.8-4, Figure 4.8-5, and Figure 4.8-6. There are significant differences between the coal minerals data and the various ash CCSEM data for each coal type. The Utah bituminous ash contains less $\mathrm{SiO}_{2}$ than the coal and more calcium and iron than the coal. The PRB ash also contains less $\mathrm{SiO}_{2}$ than the coal and more iron and calcium than the coal. The Illinois bituminous ash contains less iron than the coal and slightly more $\mathrm{SiO}_{2}$. There are also differences in bulk composition of the ash samples corresponding to difference combustion conditions. 


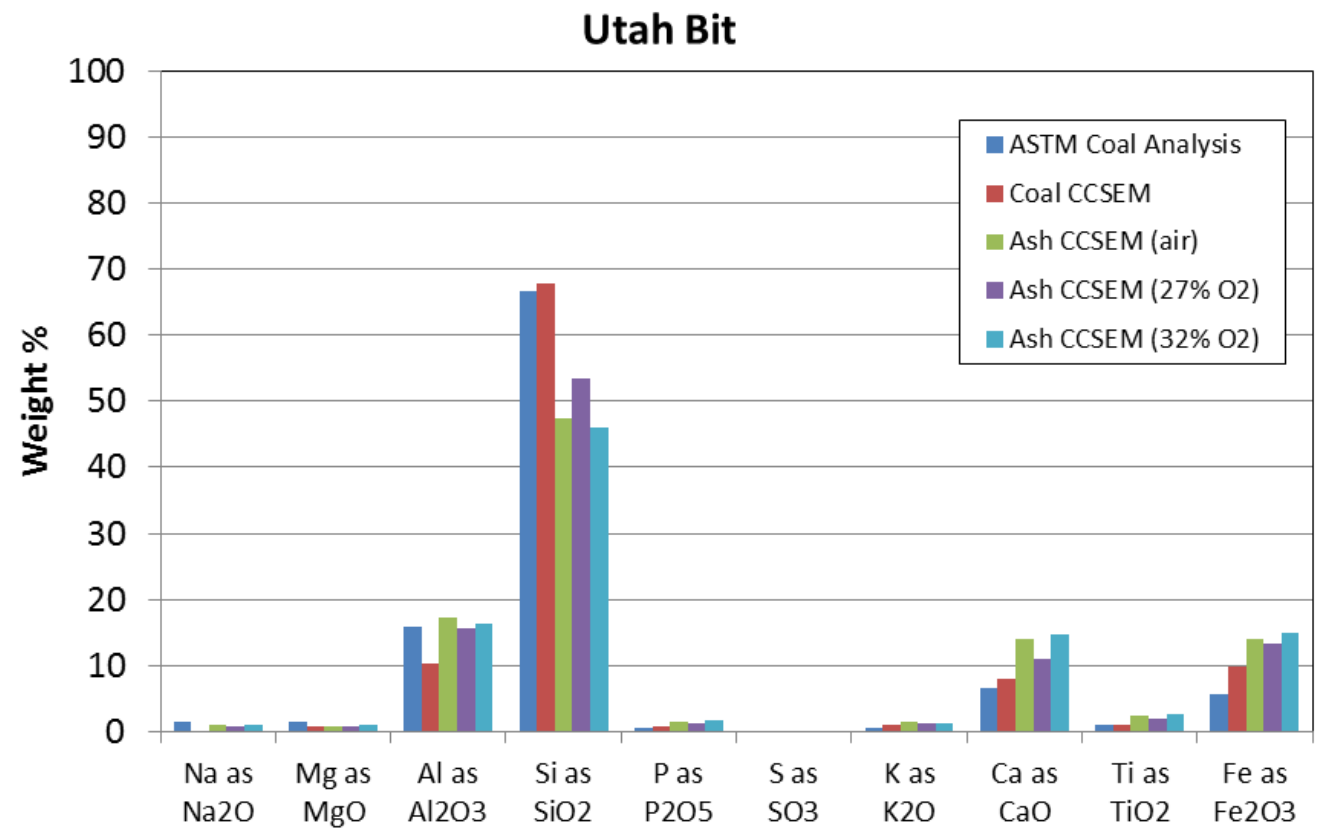

Figure 4.8-4: Comparison of Utah bituminous coal ASTM mineral analysis and CCSEM analysis of Utah bituminous fly ash under three oxygen environments.

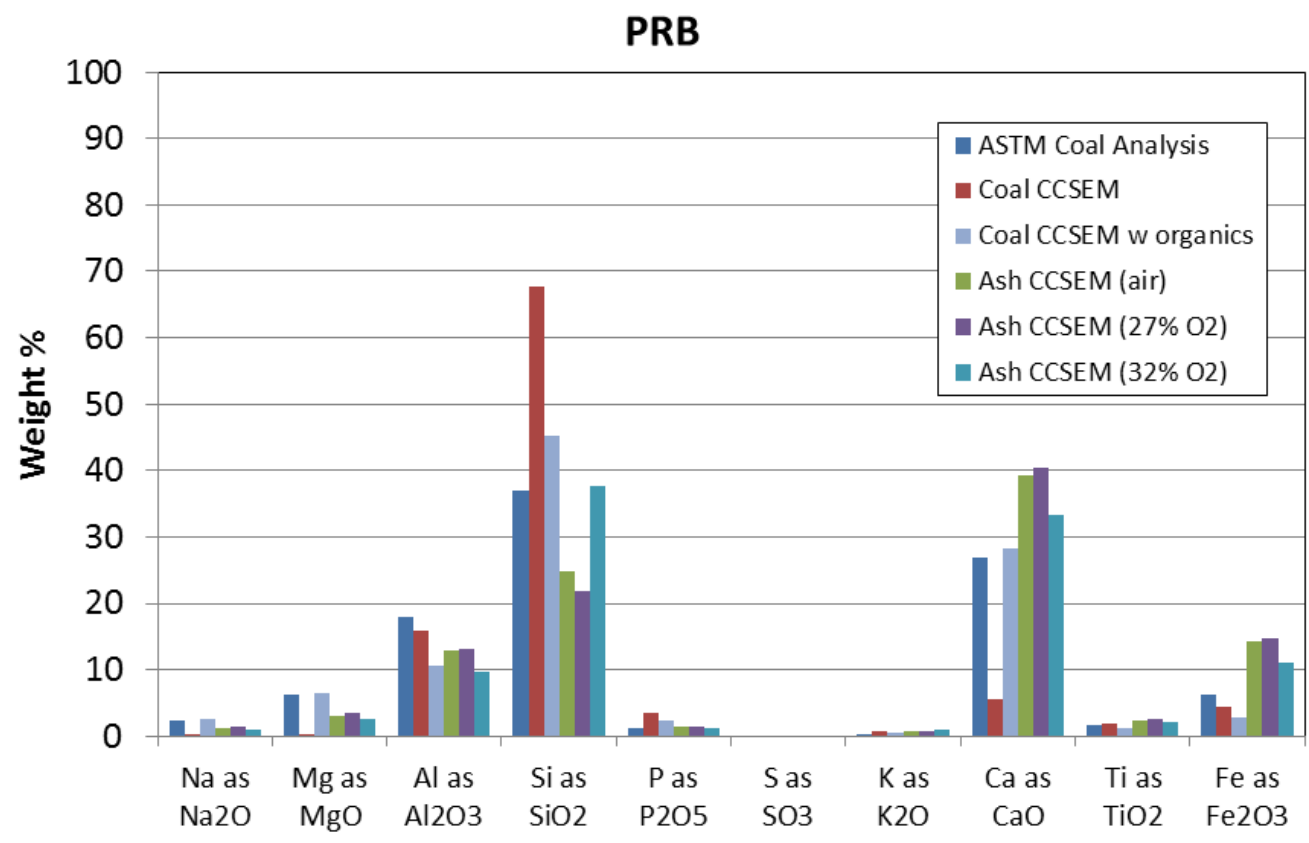

Figure 4.8-5: Comparison of PRB coal ASTM mineral analysis and CCSEM analysis of PRB fly ash under three oxygen environments. 


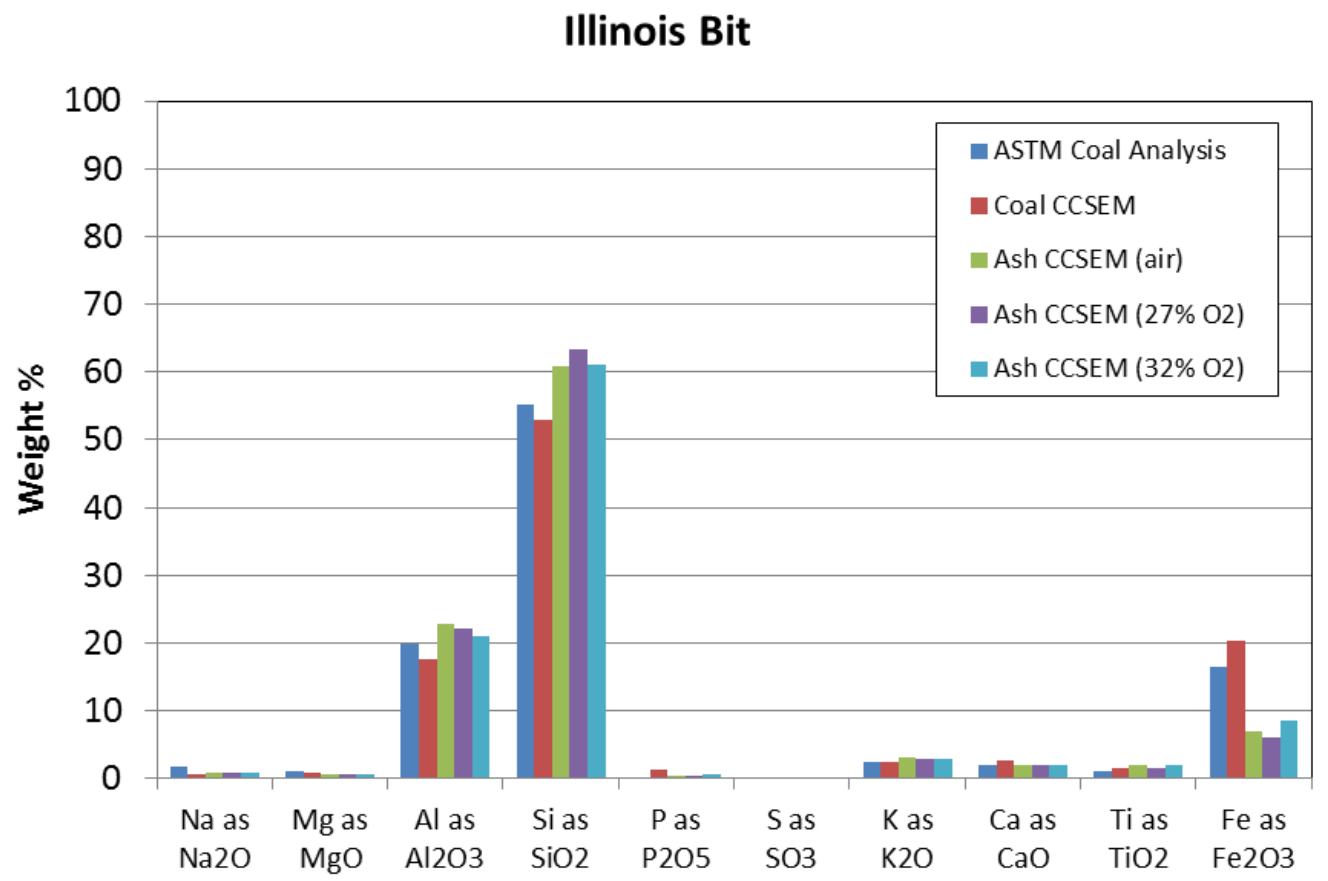

Figure 4.8-6: Comparison of Illinois bituminous coal ASTM mineral analysis and CCSEM analysis of Illinois bituminous fly ash under three oxygen environments.

In addition to minerals composition, the size distributions of the CCSEM data were also compared. Cumulative size distributions for both the coals and ashes are shown in Figure 4.8-7, Figure 4.8-8, and Figure 4.8-9. These plots show that the ash is finer than the coal minerals, especially for the PRB coal. Size distributions taken from CCSEM may be easily biased if the sample analyzed is not representative. It is expected that ash particles will coalesce; hence the ash size distribution is expected to be coarser than the coal mineral size distribution. As this is not the case, there might be a bias in either the sampling or CCSEM analyses. It is possible that large ash particles are dropping out in the furnace, in which case the ash sample is not representative. This hypothesis is supported by the differences between the ash CCSEM oxide composition and the coal ASTM minerals analyses. Another possibility is that the coal CCSEM analyses are biased towards large particles, perhaps large silica and/or aluminosilicate minerals. This hypothesis is supported by the high $\mathrm{SiO}_{2}$ concentrations noted in the Utah bituminous and PRB coals vs. their respective ashes.

For the Utah bituminous coal, the ash from the oxy-fire conditions is finer that the ash from air-fired combustion. The opposite is true for the PRB coal (air-firing produced finer ash than oxy-firing). For the Illinois bituminous coal, there doesn't seem to be a significant difference in the cumulative size distribution of the ash under air- of oxy-combustions conditions. The Illinois coal was finer than the Utah bituminous or PRB coals, leading to finer ash. It must be noted that the PRB coal CCSEM does not include any organically bound minerals. Even though the cumulative distribution has been normalized, the actual total cumulative distribution from the CCSEM analysis is less than $100 \%$. In normalizing the CCSEM cumulative distribution, it is assumed that the organically bound minerals have a similar size distribution to that shown by CCSEM. 


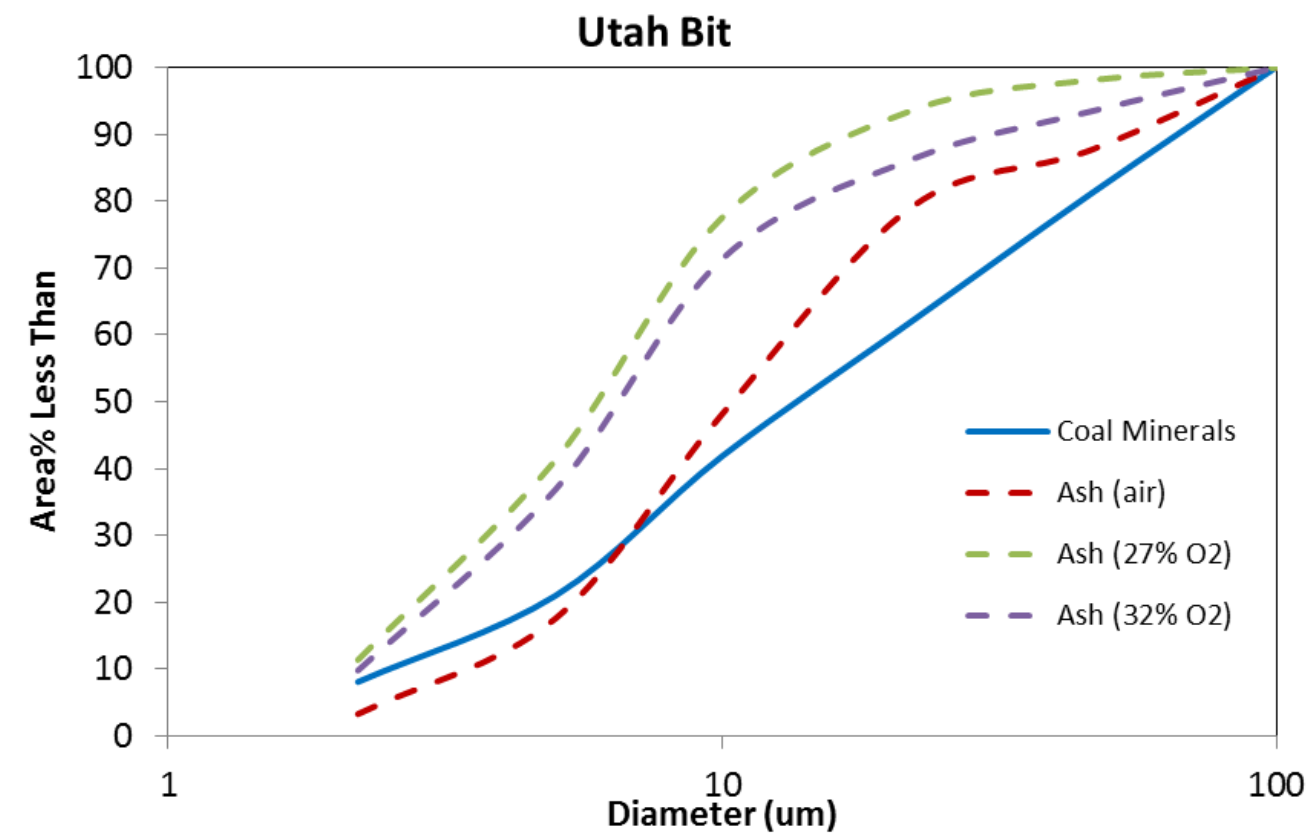

Figure 4.8-7: Cumulative size distributions for the Utah bituminous coal and ash from air, 27\% $\mathrm{O}_{2}$ and $32 \% \mathrm{O}_{2}$ conditions.

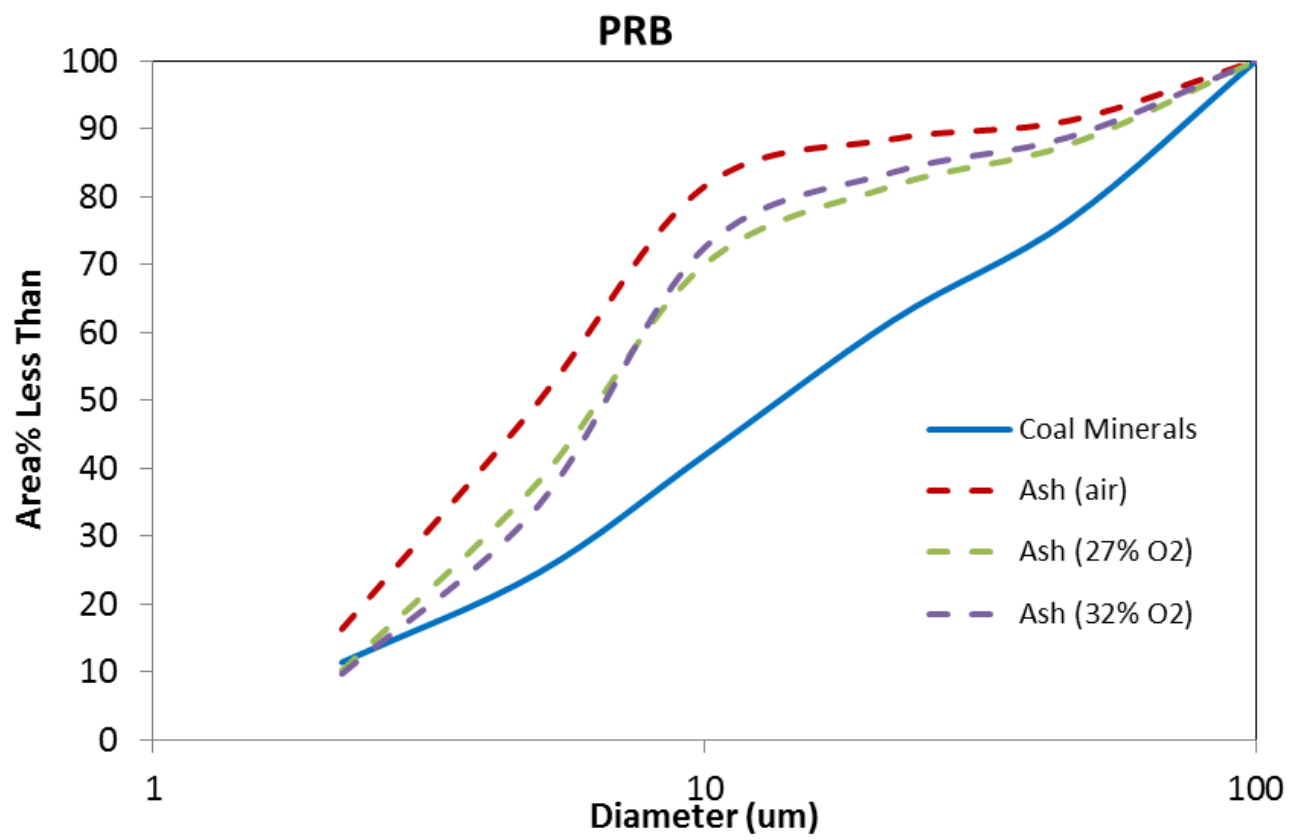

Figure 4.8-8: Cumulative size distributions for the PRB coal and ash from air, $27 \% \mathrm{O}_{2}$ and $32 \% \mathrm{O}_{2}$ conditions. 


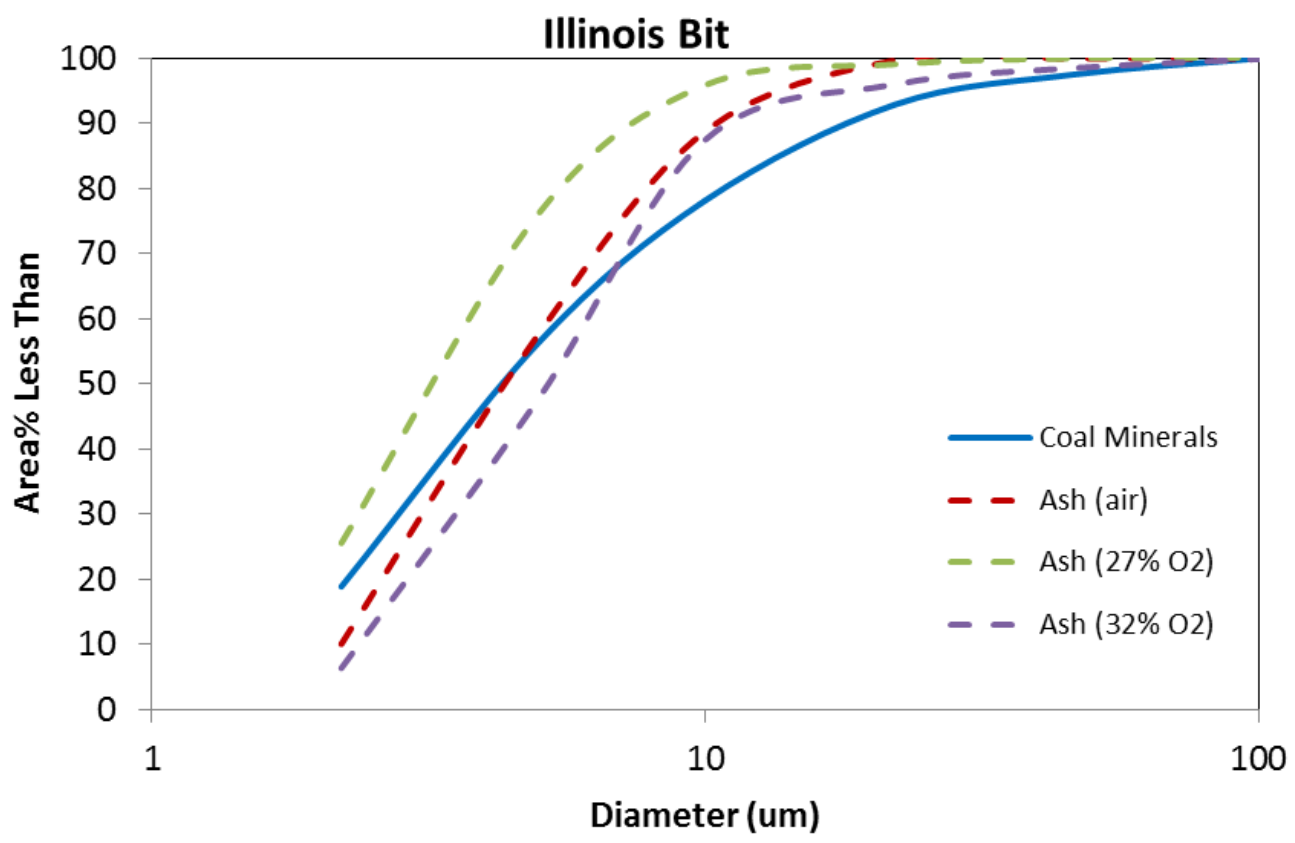

Figure 4.8-9: Cumulative size distributions for the Illinois bituminous coal and ash from air, $27 \%$ $\mathrm{O}_{2}$ and $32 \% \mathrm{O}_{2}$ conditions.

Cumulative size distributions can be misleading if a bias in the large particles exists, so differential distributions were computed, based on the CCSEM analyses. In order to compute differential, log-normal distributions, the areas in the CCSEM raw data files were normalized for the field magnifications. (Three magnifications were used for each CCSEM analysis.) Discrete diameter ranges were chosen and the total area was summed for each diameter range. An average diameter was computed for each range and, from this average diameter, the log-normal distribution was computed. The areas were normalized to the total area. At the diameter boundary between magnifications, the volume distribution was smoothed, since it was noted that discontinuities were present. Even though these distributions should be more reliable than cumulative size distributions, they are still influenced by any inconsistencies in the CCSEM analysis.

In Figure 4.8-10 and Figure 4.8-11, the differential area distribution of the minerals for the Utah bituminous coal is compared with the size distributions of the ash samples. The Utah bituminous coal has large minerals of 20-40 $\mu \mathrm{m}$, many of which are probably excluded from the coal particles. Excluded minerals would not be expected to grow into larger ash particles, since they would not be in contact with other minerals during combustion (as would included minerals). The ash samples show very large particles in the range of 50-100 $\mu \mathrm{m}$ as can be seen in Figure 4.8-10. These particles are probably unburned carbon particles, which have a significant component of ash. Focusing on the ash particles less than $10 \mu \mathrm{m}$ (Figure 4.8-11), the ash from oxy-combustion experiments appears to have a peak at about 4 $\mu \mathrm{m}$, but the air-combustion sample does not. The air-combustion sample shows more evidence of coalescence of minerals to form 10-20 $\mu \mathrm{m}$ ash particles, while the oxy-combustions samples suggest that there was less coalescence of mineral particles during combustion, resulting in a finer ash. 


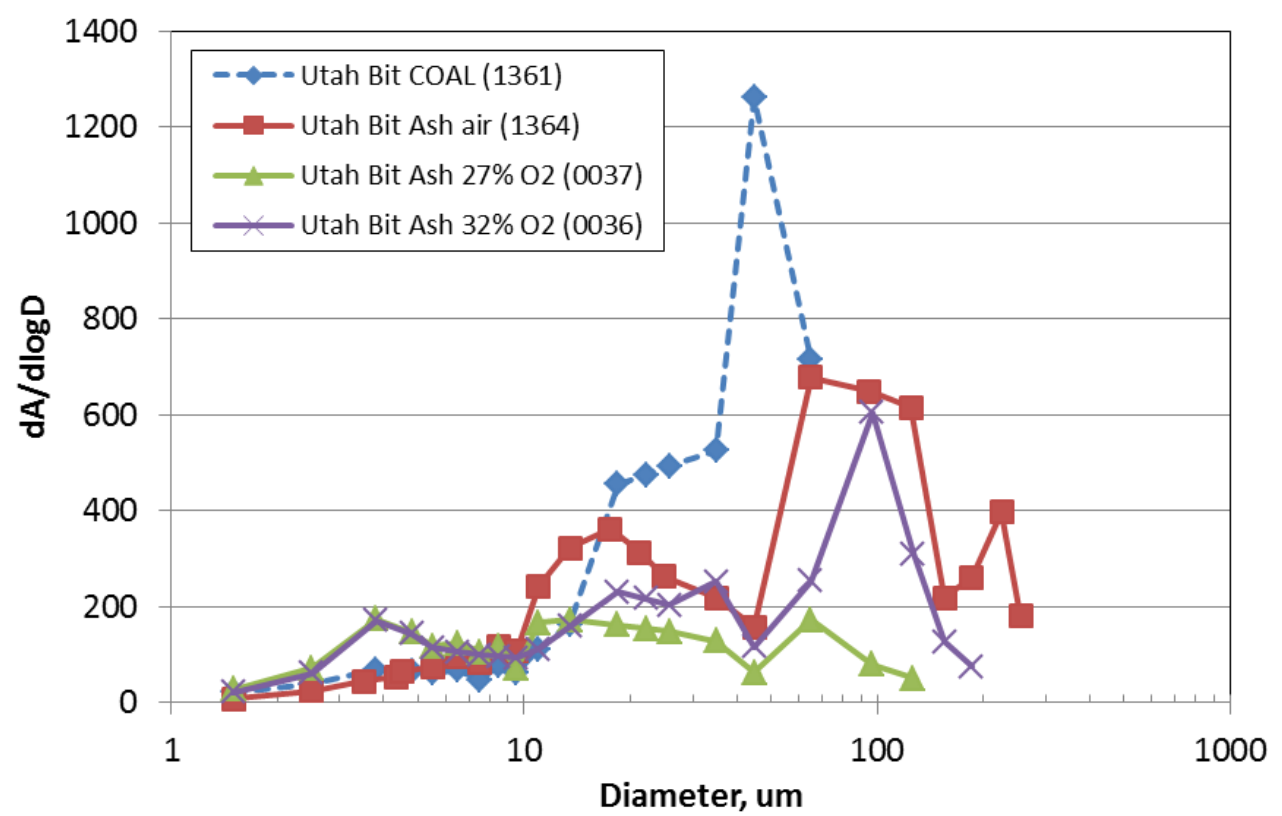

Figure 4.8-10: Differential area distributions of coal minerals and ash (Utah bituminous coal).

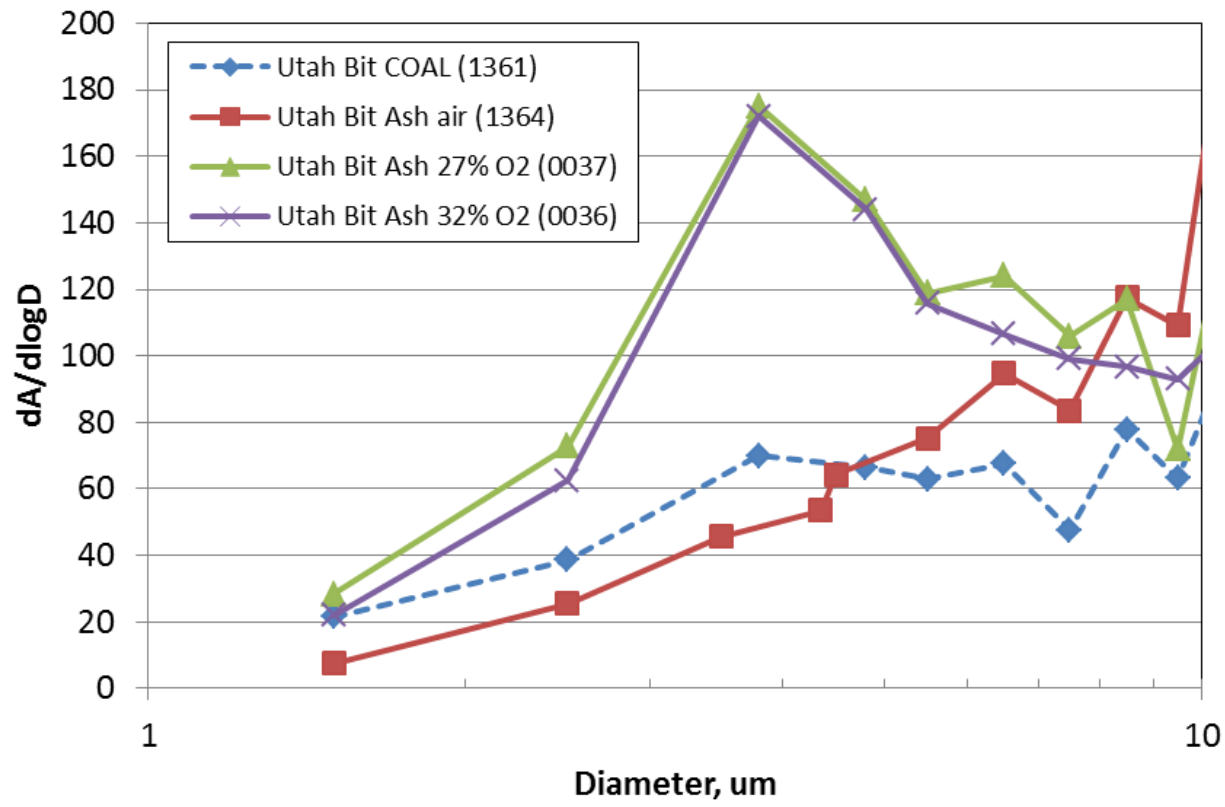

Figure 4.8-11: Differential area distributions of coal minerals and ash (Utah bituminous coal): detail of $<10 \mu \mathrm{m}$.

Figure 4.8-12 and Figure 4.8-13 show the computed differential area distribution for the PRB ash, compared with the coal minerals. The area of the coal minerals has been divided by four in this figure, to reflect the fact that most of the area of the inorganic ash in the PRB coal is not identified by CCSEM, since it does not occur as discrete minerals. The coal minerals have a large mode, from about 50-100 $\mu \mathrm{m}$, which probably correspond to excluded minerals. This same mode can be observed in the fly ash particles, under all combustion conditions. PRB coal is expected to burn out more readily than bituminous coal. Thus, there is less evidence for large, unburned carbon particles in the PRB ash as compared to the Utah bituminous ash. 
As expected, the PRB ash is finer than the Utah bituminous ash, as can be seen in Figure 4.8-13. All three ash samples have area peaks at $\sim 3.5$ microns and 6 microns. (It is also possible that these two peaks are really one peak $\sim 5$ microns and the dip between the two peaks is a computational artifact, the result of combining different magnifications of the CCSEM data.) For this coal, the ash produced during air combustion is similar to the ash produced during oxy-combustion.

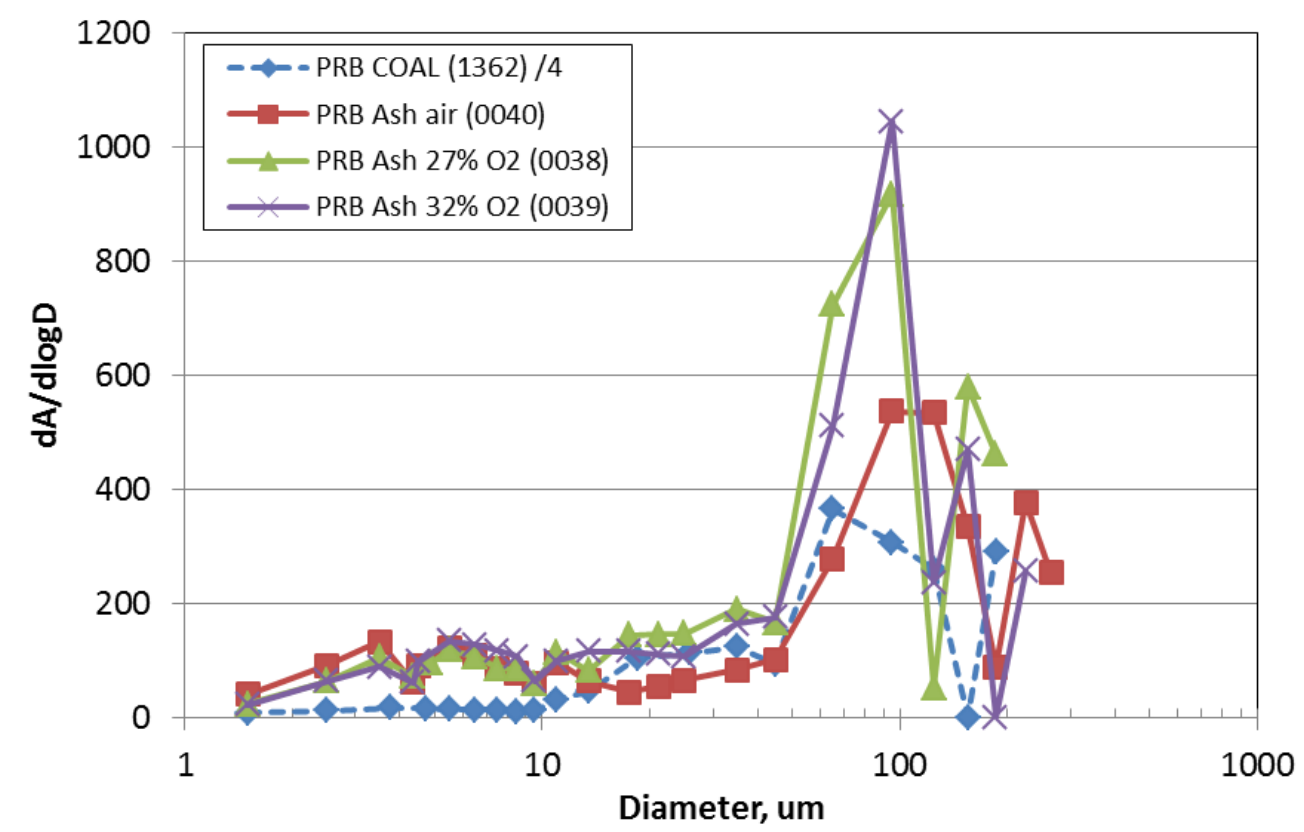

Figure 4.8-12: Differential area distributions of coal minerals and ash (PRB coal); coal volume has been divided by four.

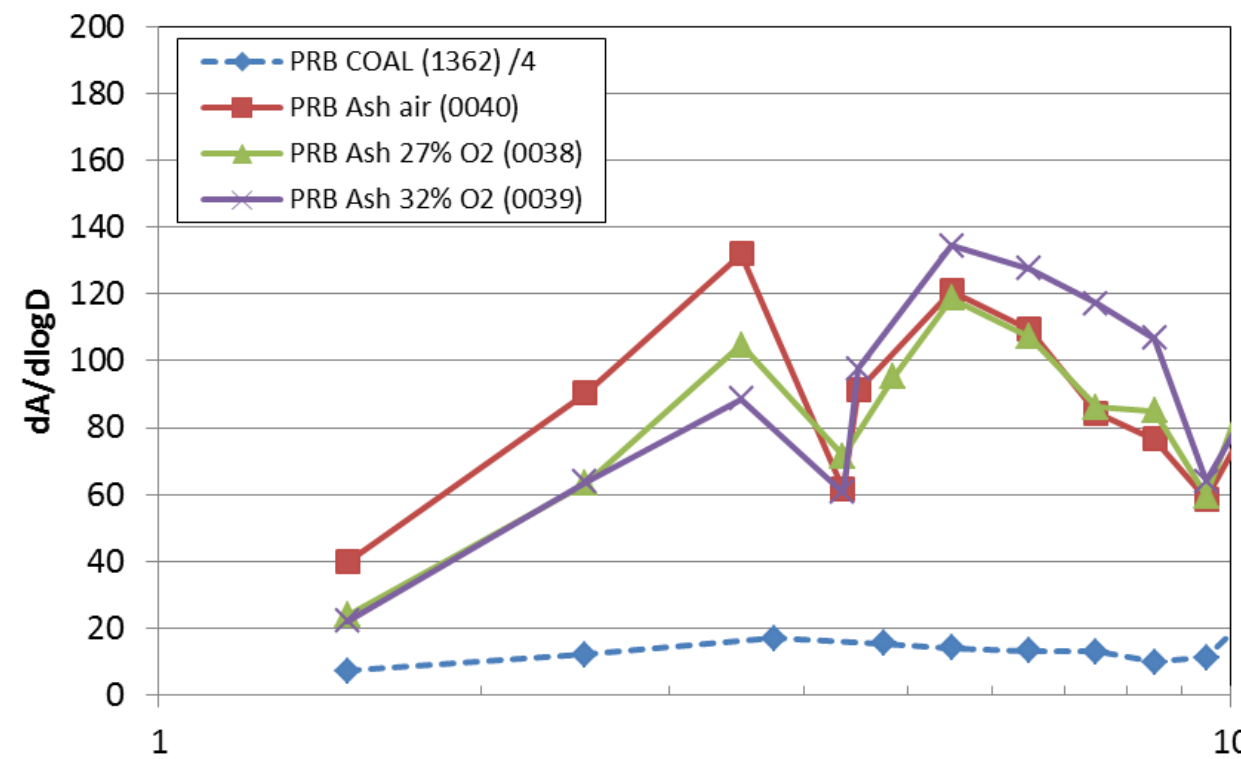

Diameter, um

Figure 4.8-13: Differential area distributions of coal minerals and ash (PRB coal), less than $10 \mu \mathrm{m}$; coal volume has been divided by four. 
In Figure 4.8-14 and Figure 4.8-15, the differential area distributions of the minerals and ash samples for the Illinois bituminous coal are compared. The Illinois bituminous coal does not have the large minerals of 20-40 $\mu \mathrm{m}$, as was seen in the Utah bituminous coal (with the exception of the largest size bin). There is less evidence of excluded particles. The ash samples show a large number of fine particles, as seen in Figure 4.8-15. The ash appears to have a peak at about $4 \mu \mathrm{m}$ for both air and oxy conditions, similar to the PRB ash. For this coal, the ash is similar for all firing conditions.

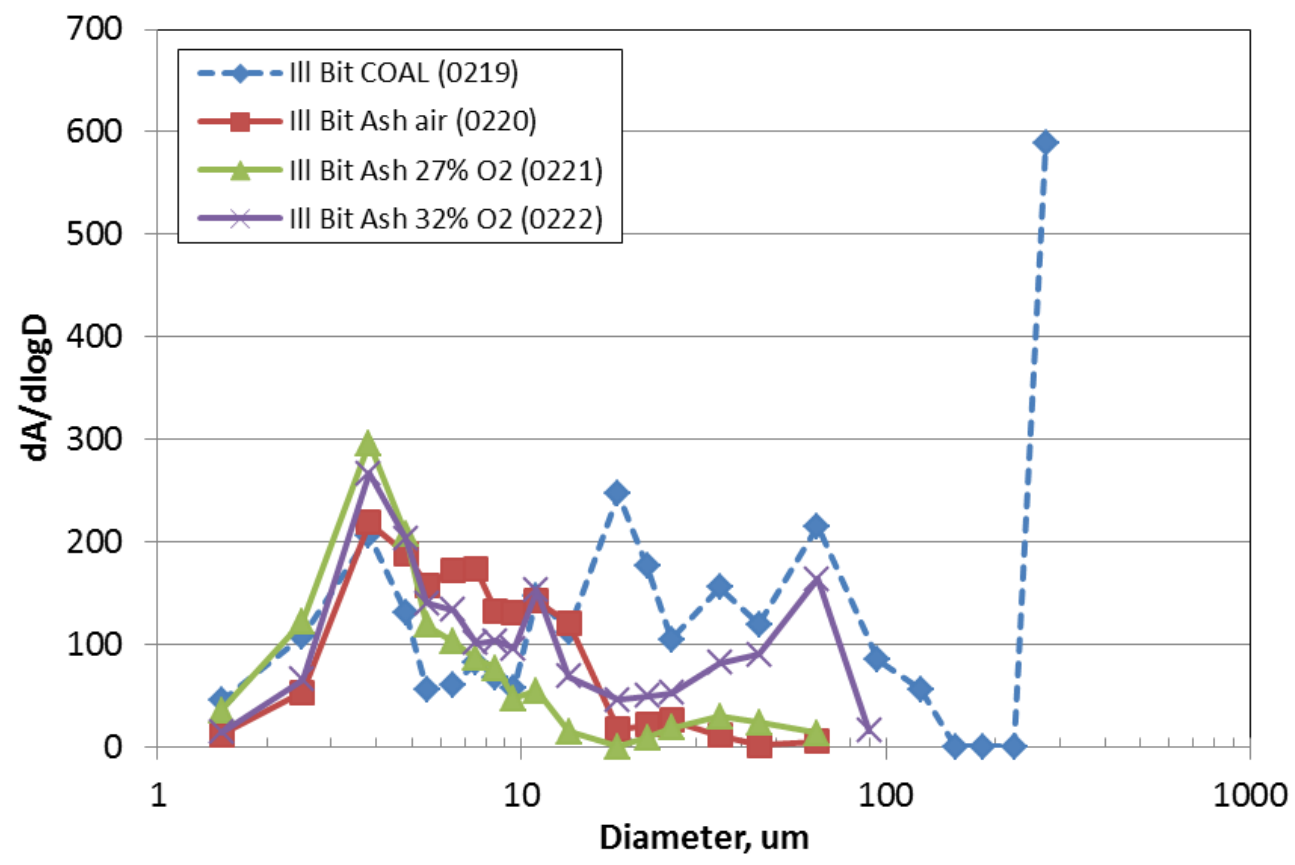

Figure 4.8-14: Differential area distributions of coal minerals and ash (Illinois bituminous coal).

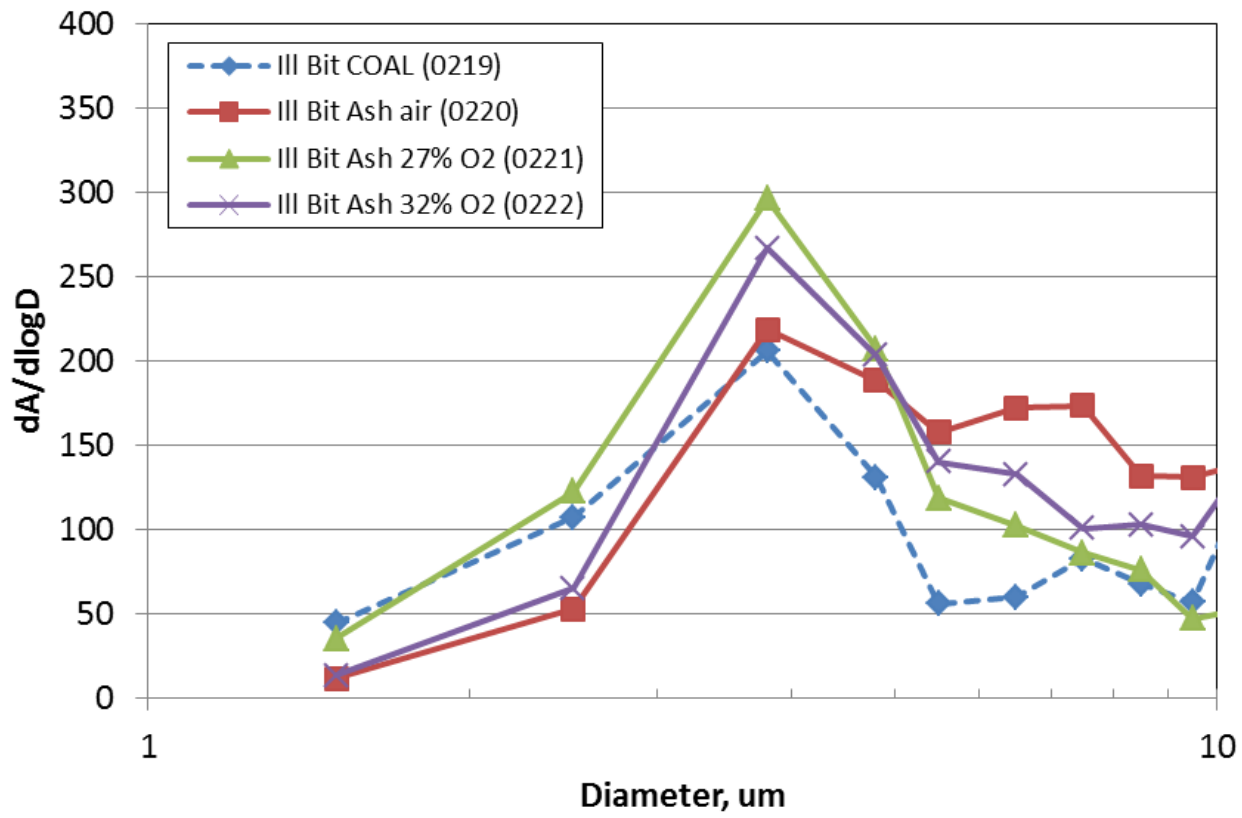

Figure 4.8-15: Differential area distributions of coal minerals and ash (Illinois bituminous coal): detail of $<10 \mu \mathrm{m}$. 


\subsubsection{Mineral Matter Transformation Model}

The mineral matter transformation model (MMT) uses mineral composition and size inputs generated from coal CCSEM to predict ash size and composition. The results of the MMT model are used in the slagging sub-model and the fouling sub-model for CFD calculations. The predictions of the MMT model are compared to size and composition distributions from ash PSD measurements and the ash CCSEM in order to validate the model.

The first step in validating the MMT model is to verify the elemental oxide balance from the inputs to the outputs. A comparison of the coal CCSEM oxide distribution (used as input for the MMT) and the oxide distribution given in the MMT output is show in Figure 4.8-16, Figure 4.8-17, and Figure 4.8-18. These figures show good agreement between the MMT input and output.

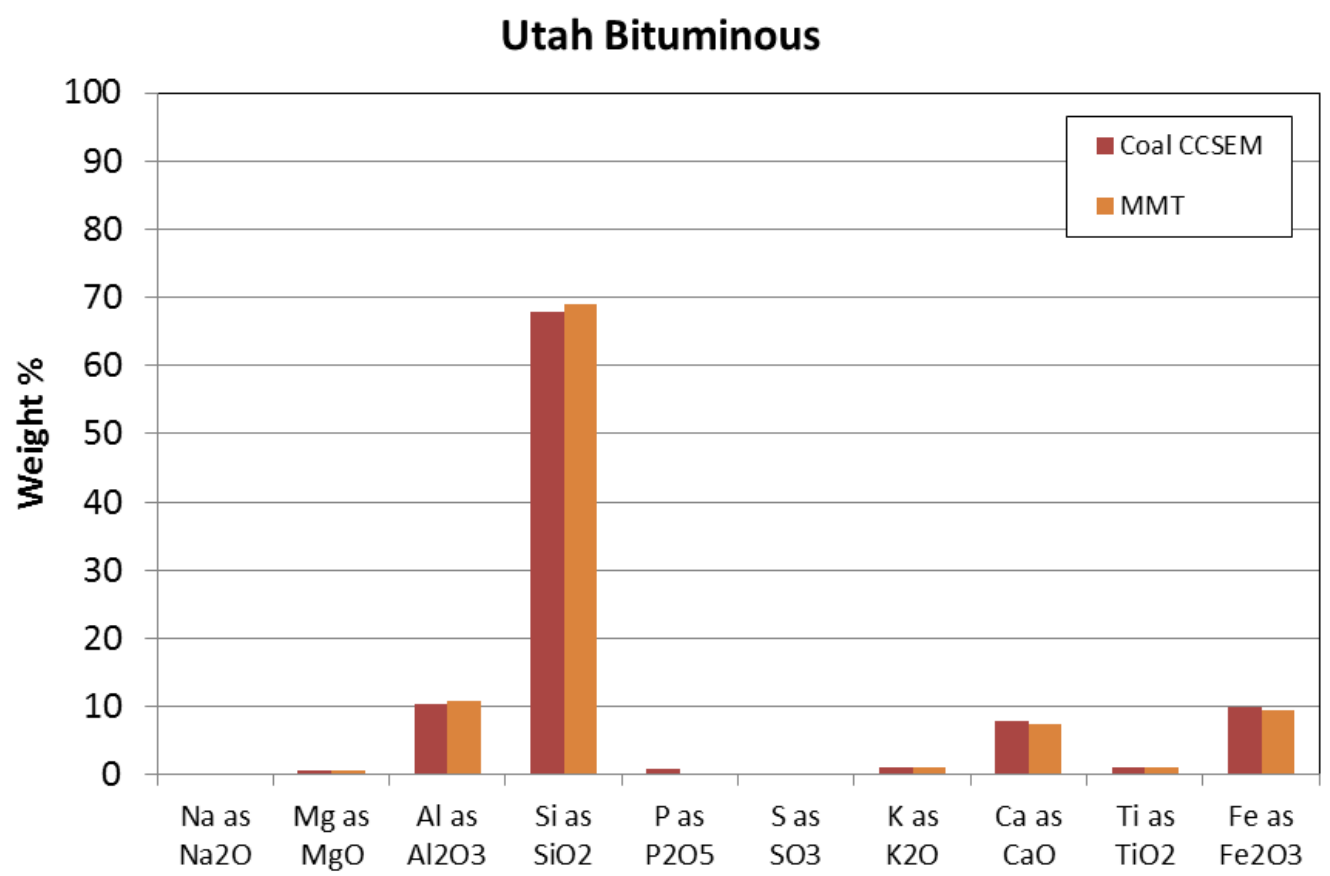

Figure 4.8-16: Comparison of elemental oxide distribution in the Utah bituminous coal CCSEM (MMT input) and the MMT output. 
PRB Sub-bituminous

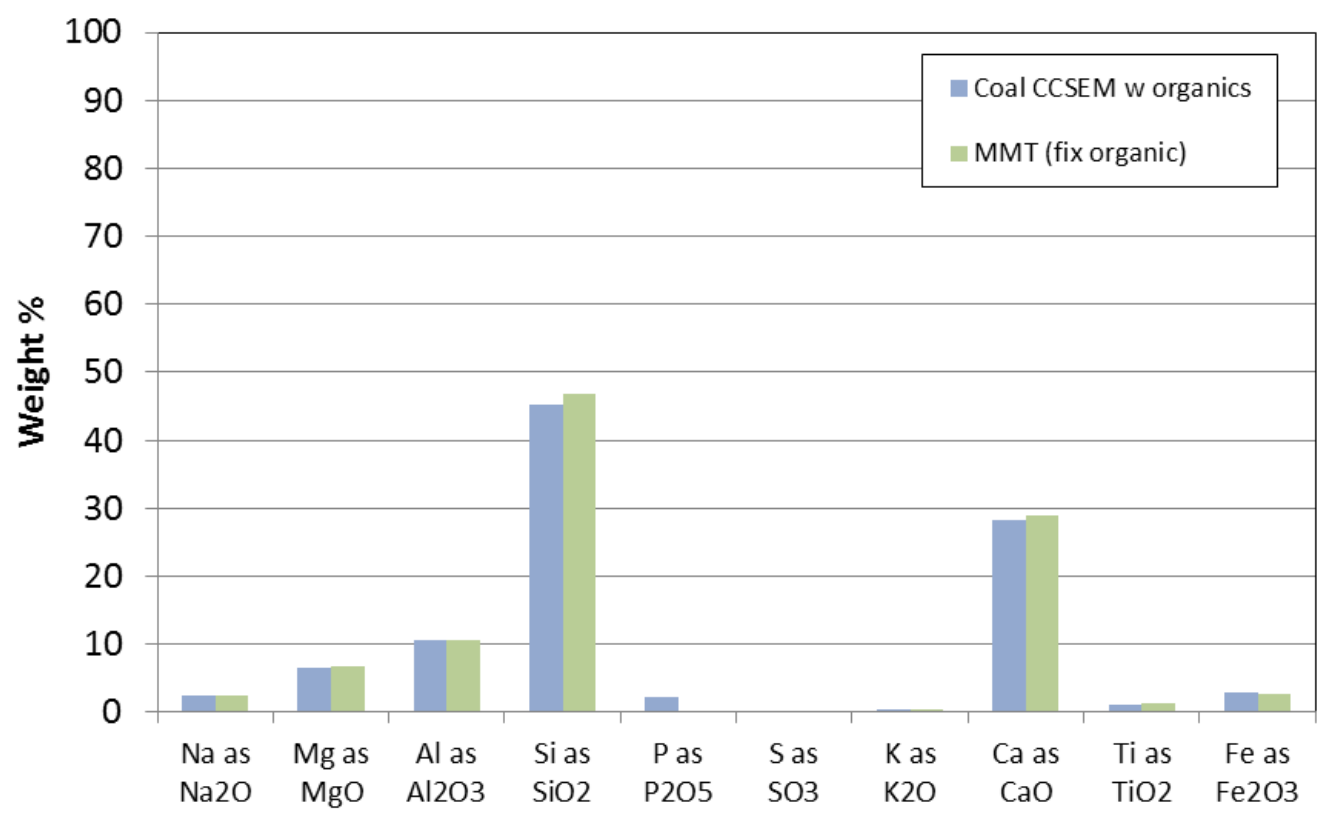

Figure 4.8-17: Comparison of elemental oxide distribution in the PRB coal CCSEM (MMT input) and the MMT output.

\section{Illinois Bituminous}

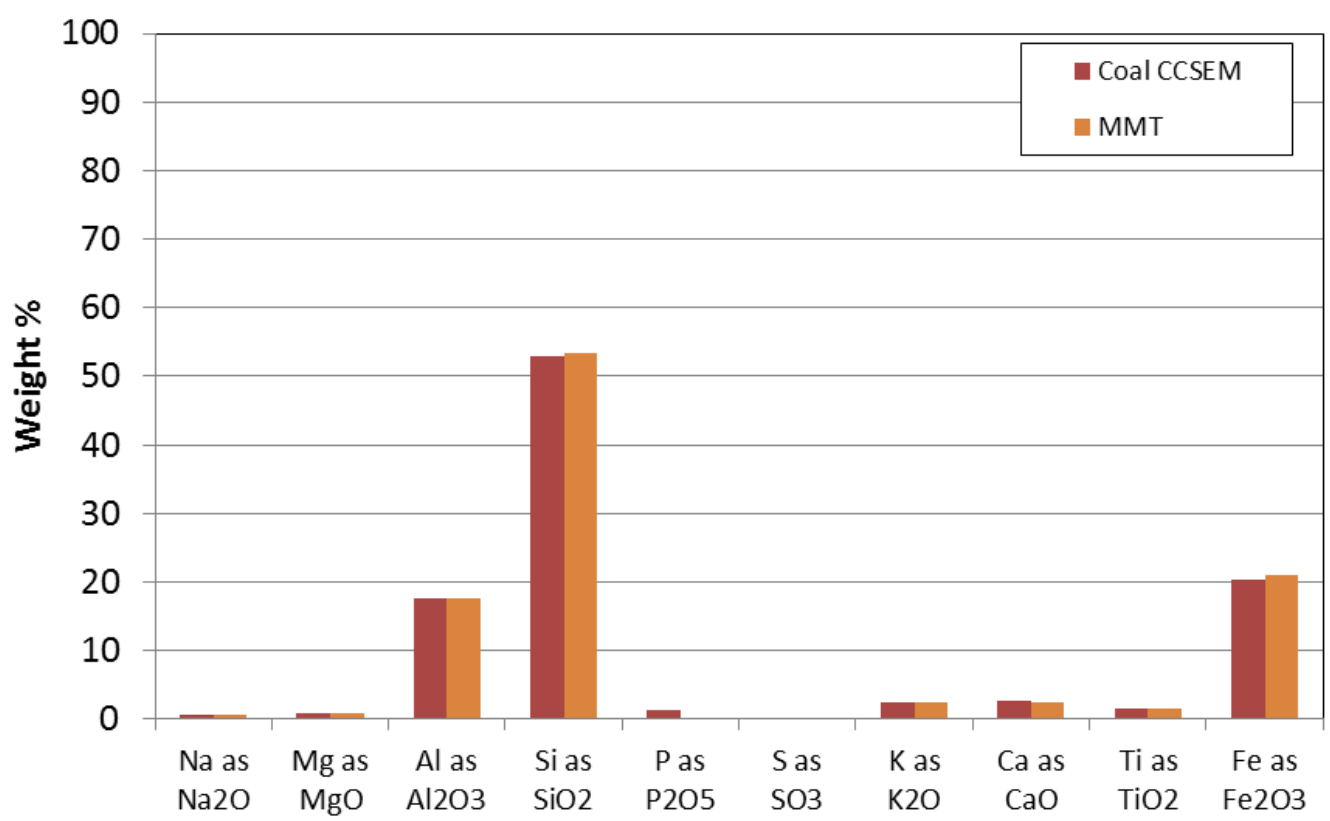

Figure 4.8-18: Comparison of elemental oxide distribution in the Illinois bituminous coal CCSEM (MMT input) and the MMT output. 
The next step in validating the MMT model is comparing the measured and predicted size distributions. Impactor measurements of the particle size distribution are more reliable than those measured by CCSEM, but only the CCSEM data are compared to the MMT predicted distributions below. The size distribution predicted by the MMT model is determined by the input mineral size distribution and the degree of coalescence. The limits of the size distribution are defined by the cases with no coalescence (one ash particle per mineral, finest ash possible) and full coalescence (all minerals in a given coal particle create one ash particle). Figure 4.8-19, Figure 4.8-20, and Figure 4.8-21 compare the size distributions of the coal minerals (CCSEM), the ash produced from firing under three oxidation conditions (CCSEM), and the MMT predictions (default, full, and no coalescence). Each of the ash samples lies within the bounds of the MMT model, which means it is possible to correctly model the size distributions for air- and oxy-firing by adjusting the degree of coalescence.

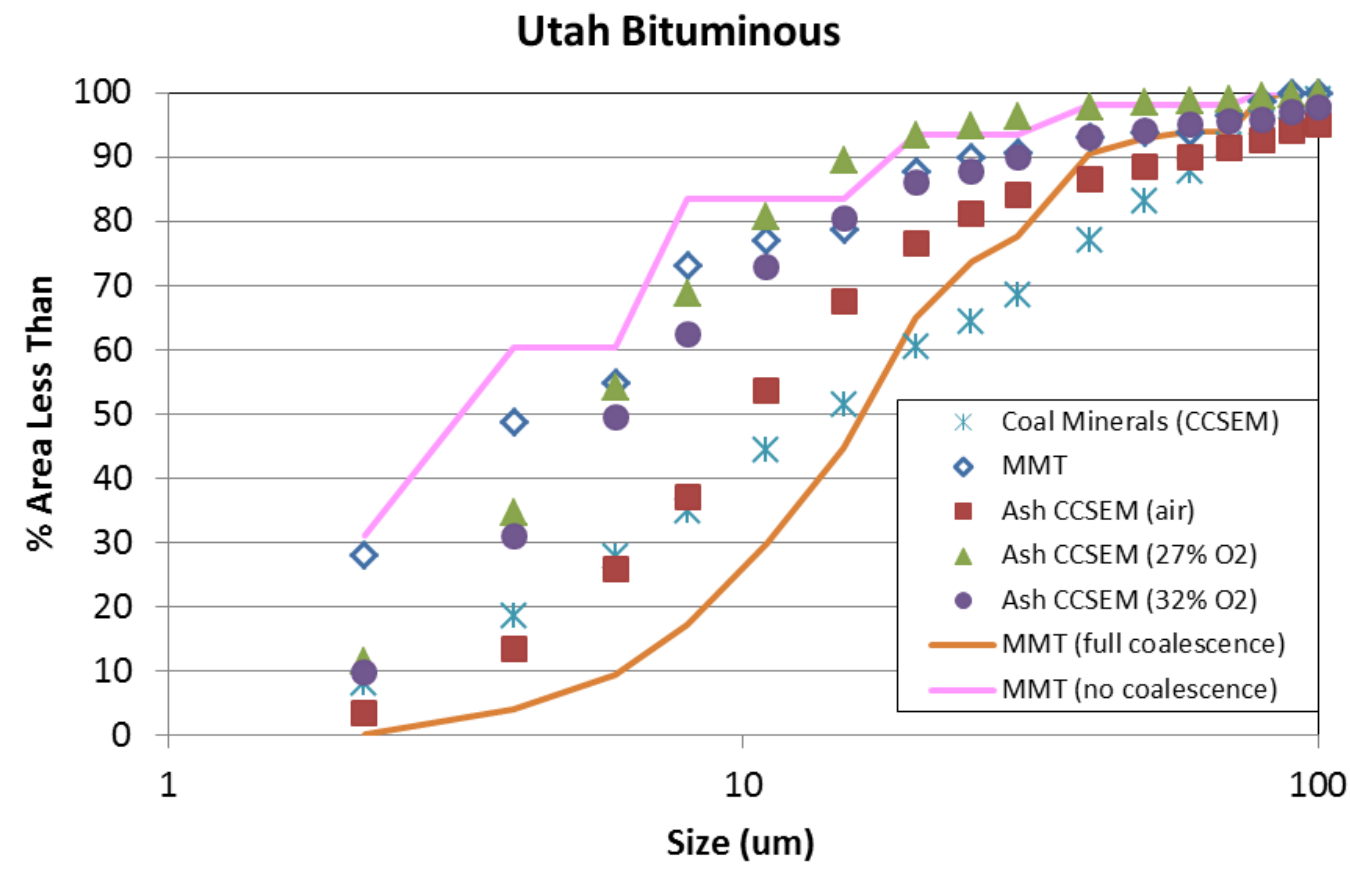

Figure 4.8-19: Cumulative size distributions for the Utah bituminous coal, ash, and MMT predictions. 


\section{PRB Sub-bituminous}

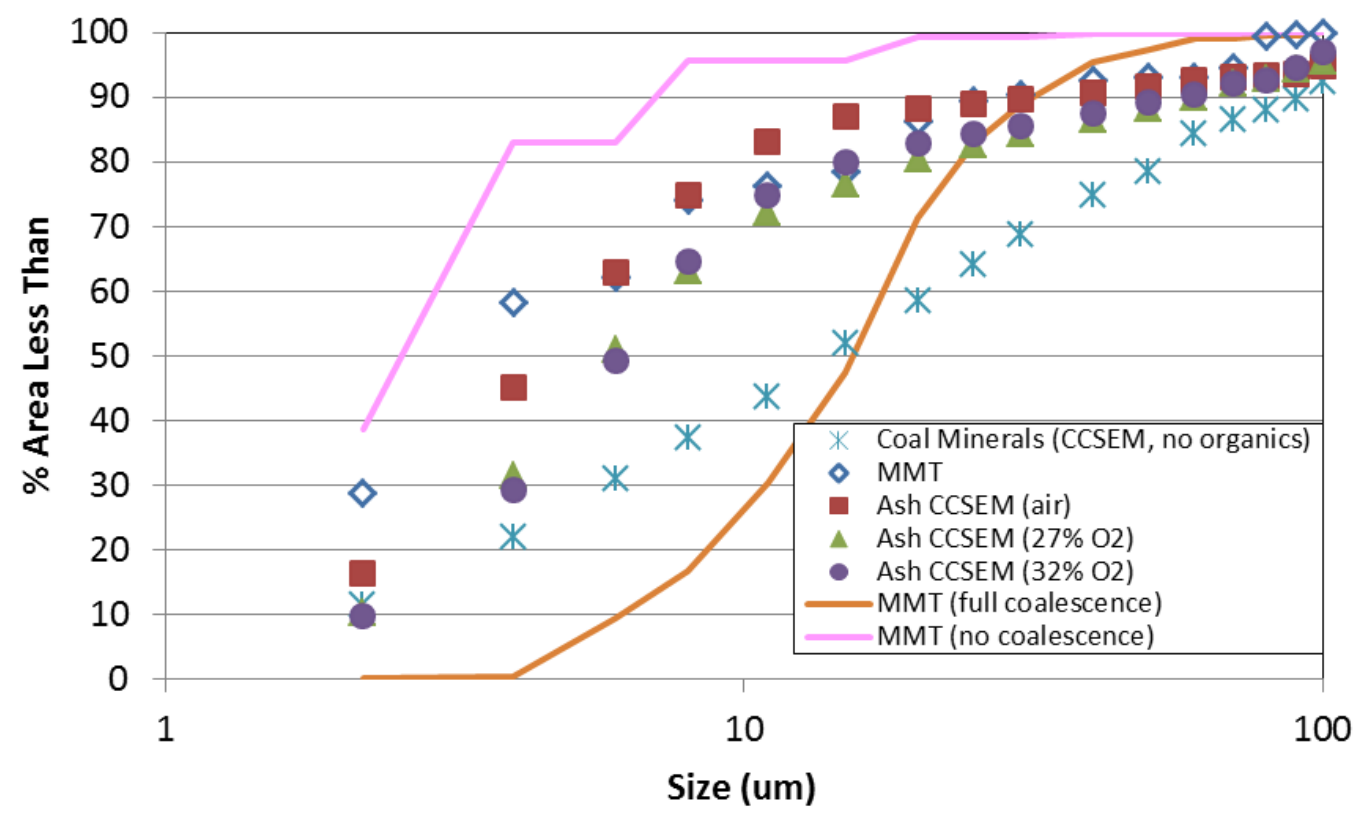

Figure 4.8-20: Cumulative size distributions for the PRB coal, ash, and MMT predictions.

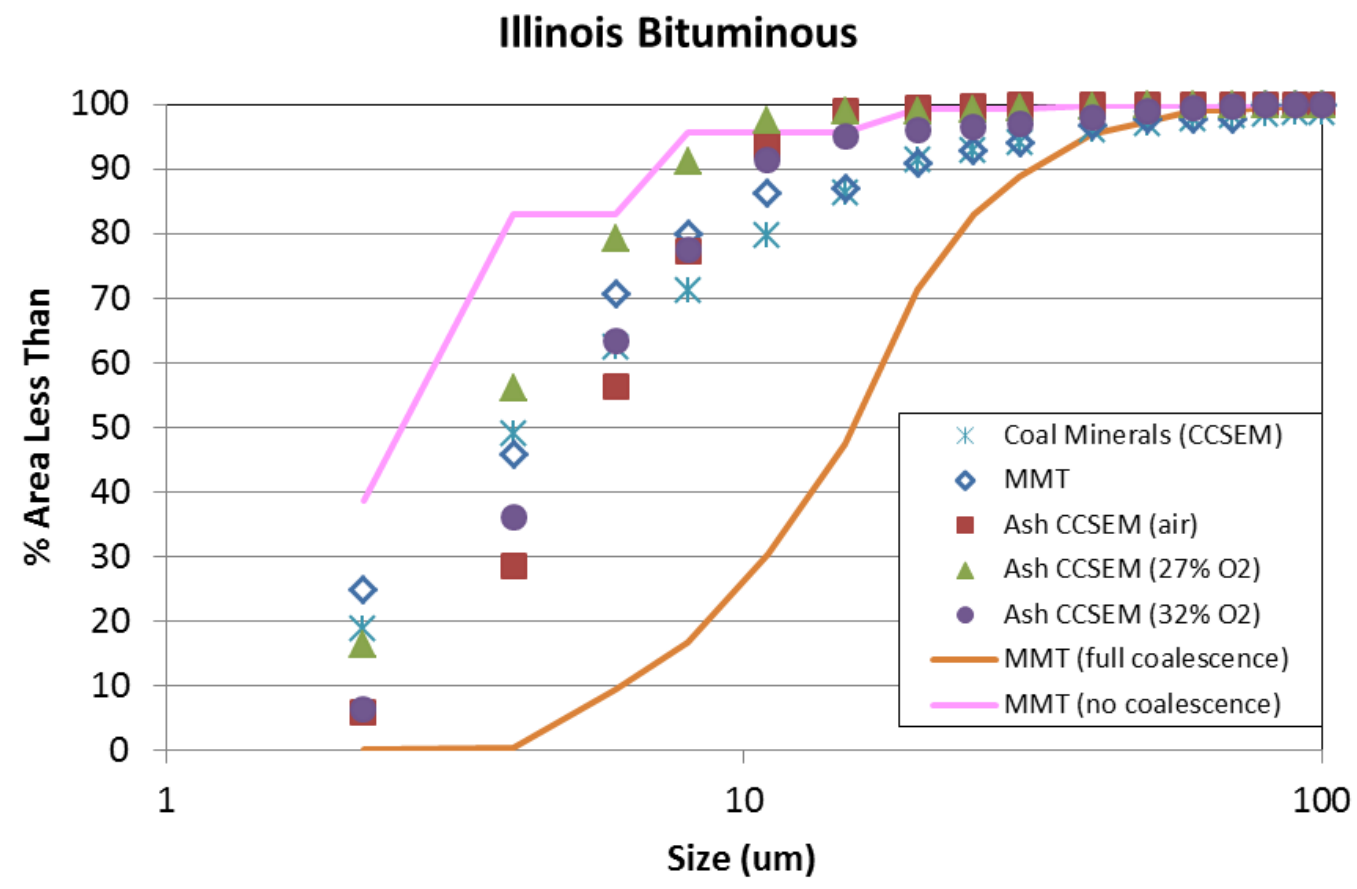

Figure 4.8-21: Cumulative size distributions for the Illinois bituminous coal, ash, and MMT predictions. 
Once the MMT model correctly predicts the size distributions under air- and oxy-fired conditions, the next step is to compare the composition of the ash and the composition distribution. Because the MMT model has not been tuned to predict the size distribution (the degree of coalescence is not accurate), the predicted ash composition will not be completely accurate. However, the current composition predictions (using standard coalescence options) can still give a clue to how the MMT model is behaving. For comparison to CCSEM, both the MMT output and CCSEM ash data were processed to place each ash particle into one of 8 categories: high calcium, high iron, low silica that aren't high calcium or iron, high silica, mixed silicates, mixed aluminosilicates with low iron, mixed aluminosilicates with high iron, and other (Figure 4.8-22, Figure 4.8-24, and Figure 4.8-26). Each of these particles was further categorized by size (Figure 4.8-23, Figure 4.8-25, and Figure 4.8-27).

The MMT comparison the ash CCSEM can only be as good as the comparison of the MMT input (coal CCSEM) to the ash CCSEM. For the Utah bituminous coal, the coal CCSEM showed higher silica and lower calcium and iron compared to the ash CCSEM. This is also reflected in the MMT predictions (the MMT model shows more high Si particles). The PRB coal also showed more silica and less calcium and iron compared to the ash. This is reflected in the MMT predictions as more low-iron particles and fewer high-calcium particles. The coal and ash CCSEM agreed fairly well for the Illinois bituminous coal, but the coal did show higher iron compared to the ash. As a result, the MMT predictions are consistent with the ash CCSEM analyses with the MMT predicting more high-iron particles.

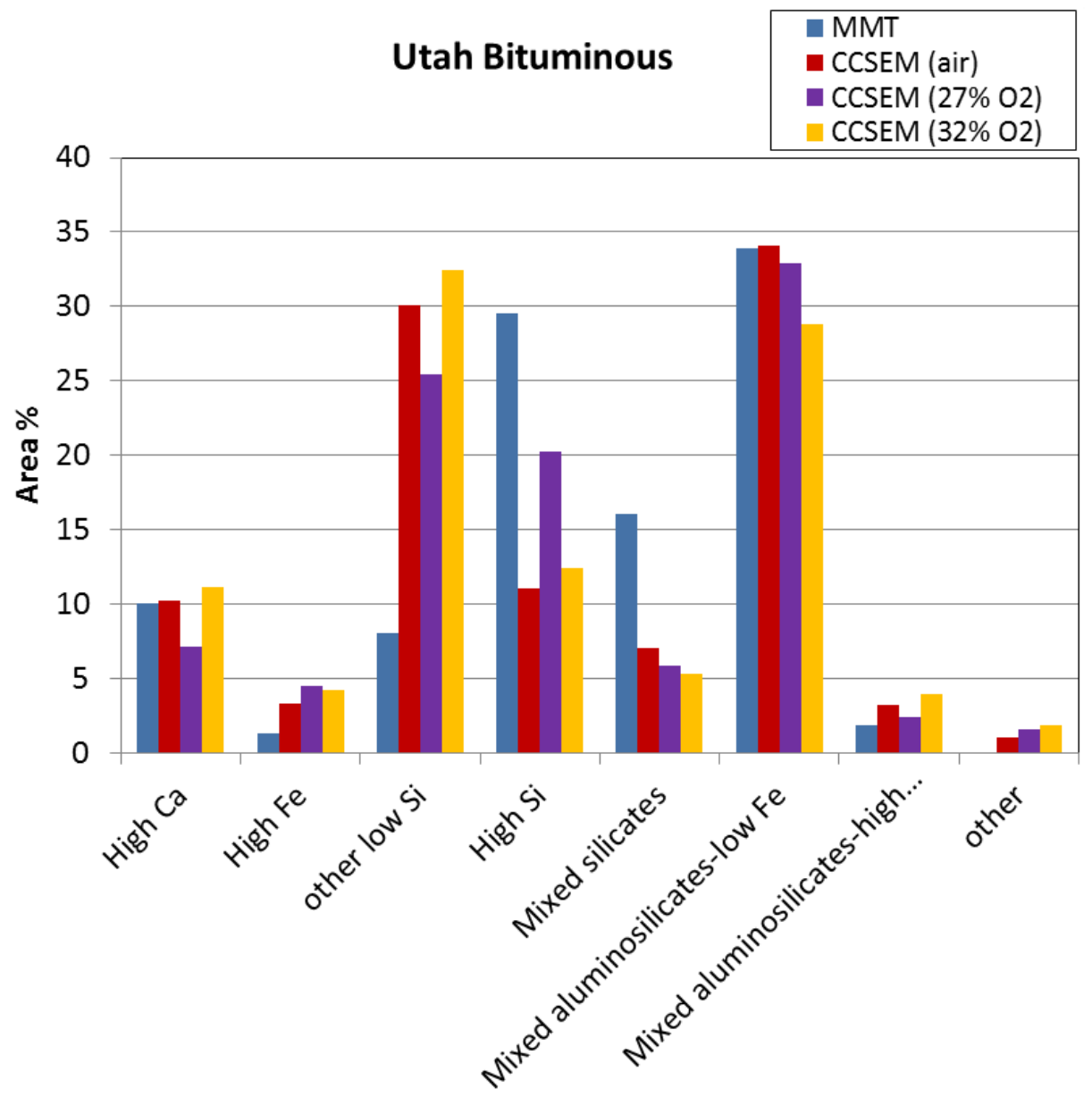

Figure 4.8-22: Comparison of MMT predicted ash composition and CCSEM measured ash composition for Utah bituminous coal. 

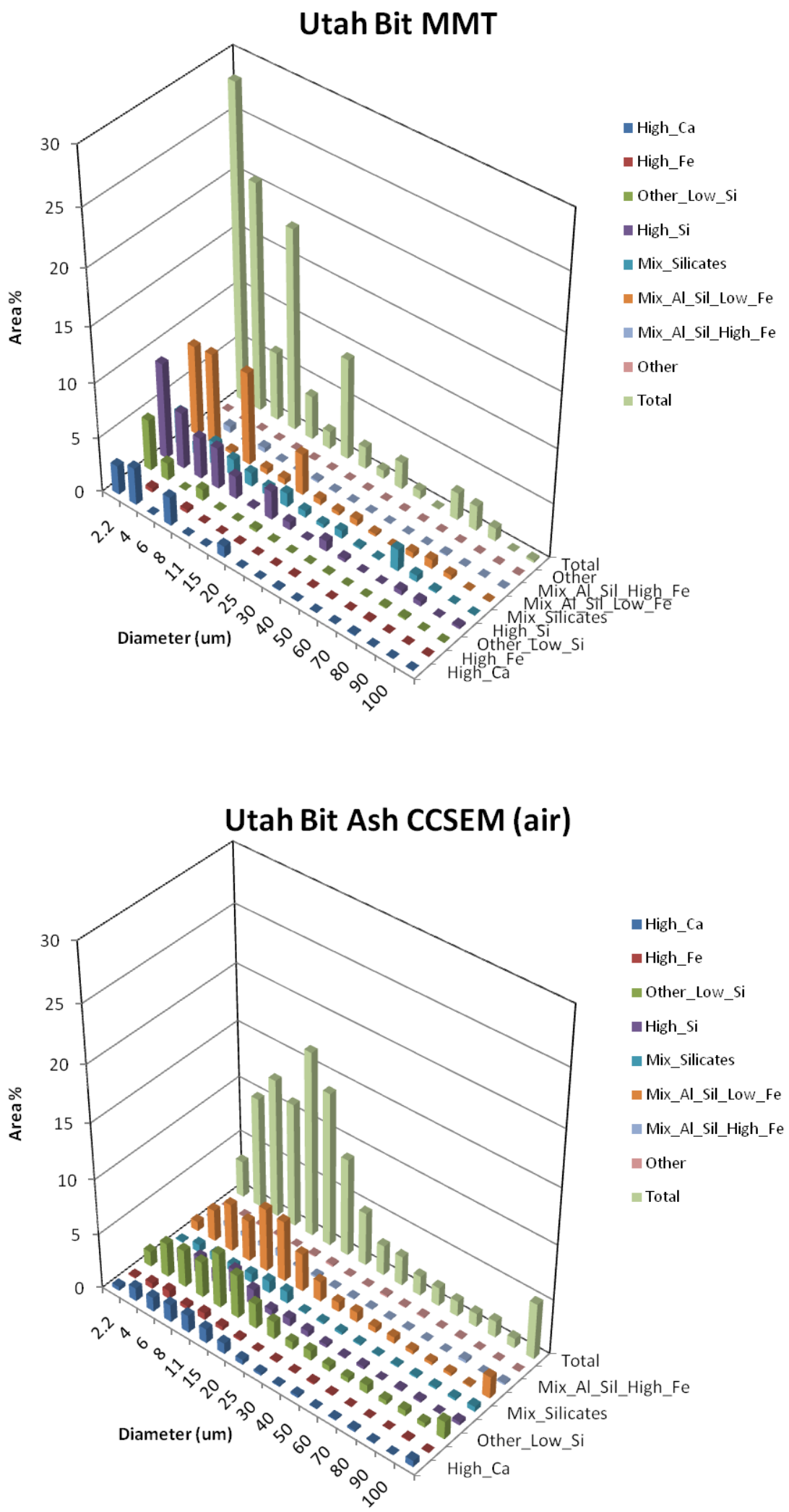

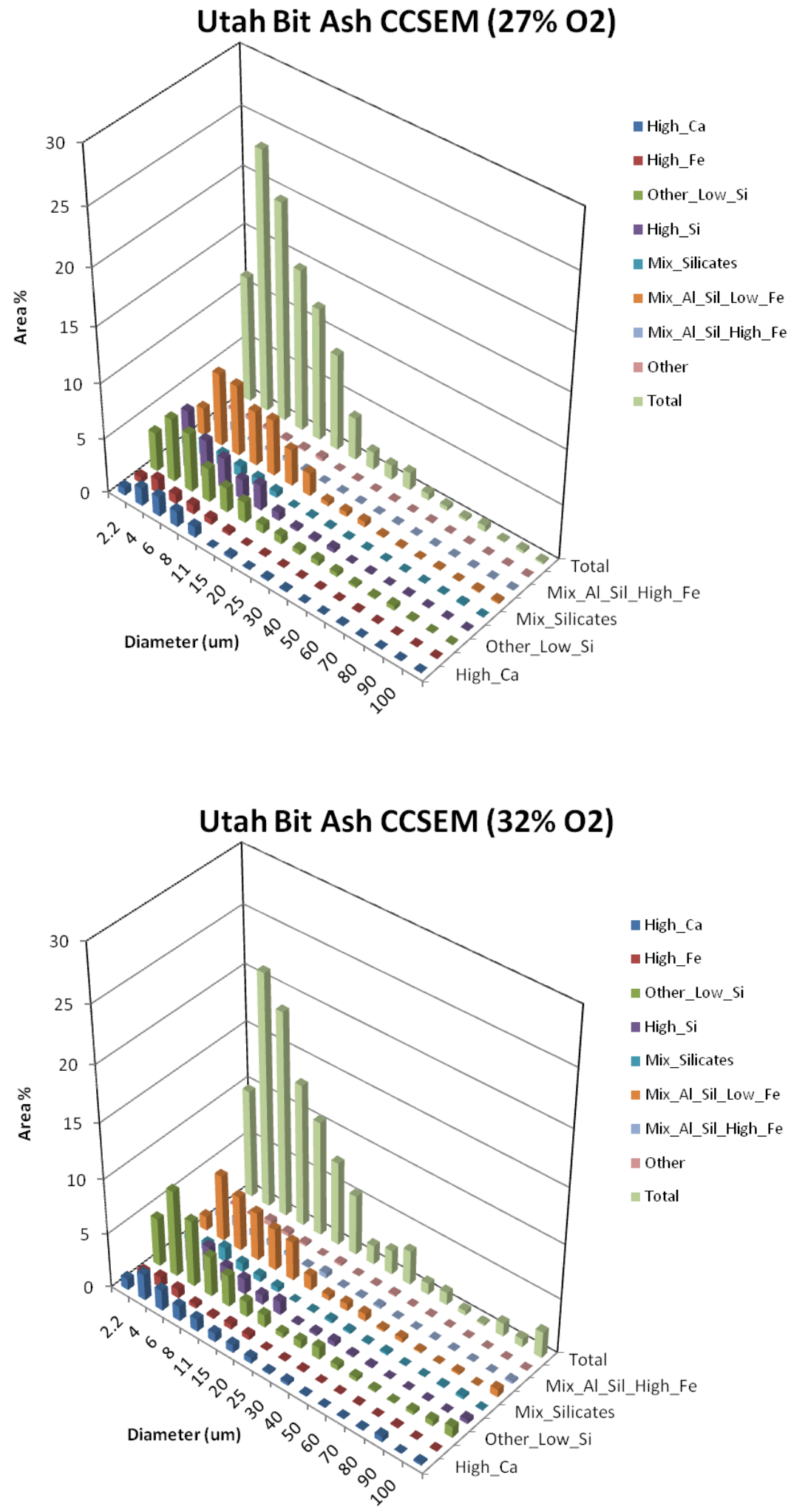

Figure 4.8-23: Comparison of MMT predicted ash composition distribution and CCSEM measured ash composition distribution for Utah bituminous coal. 


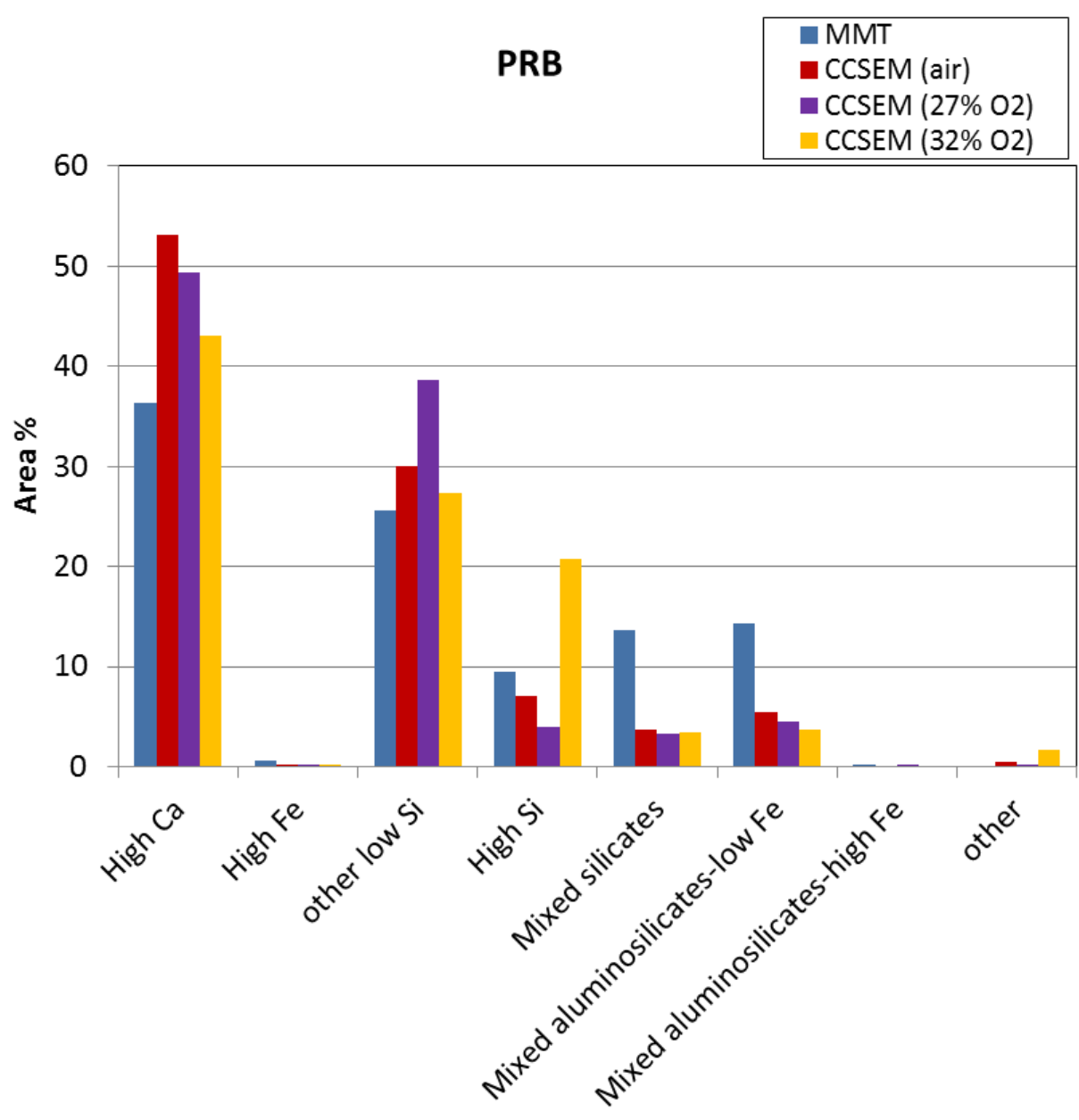

Figure 4.8-24: Comparison of MMT predicted ash composition and CCSEM measured ash composition for PRB coal. 

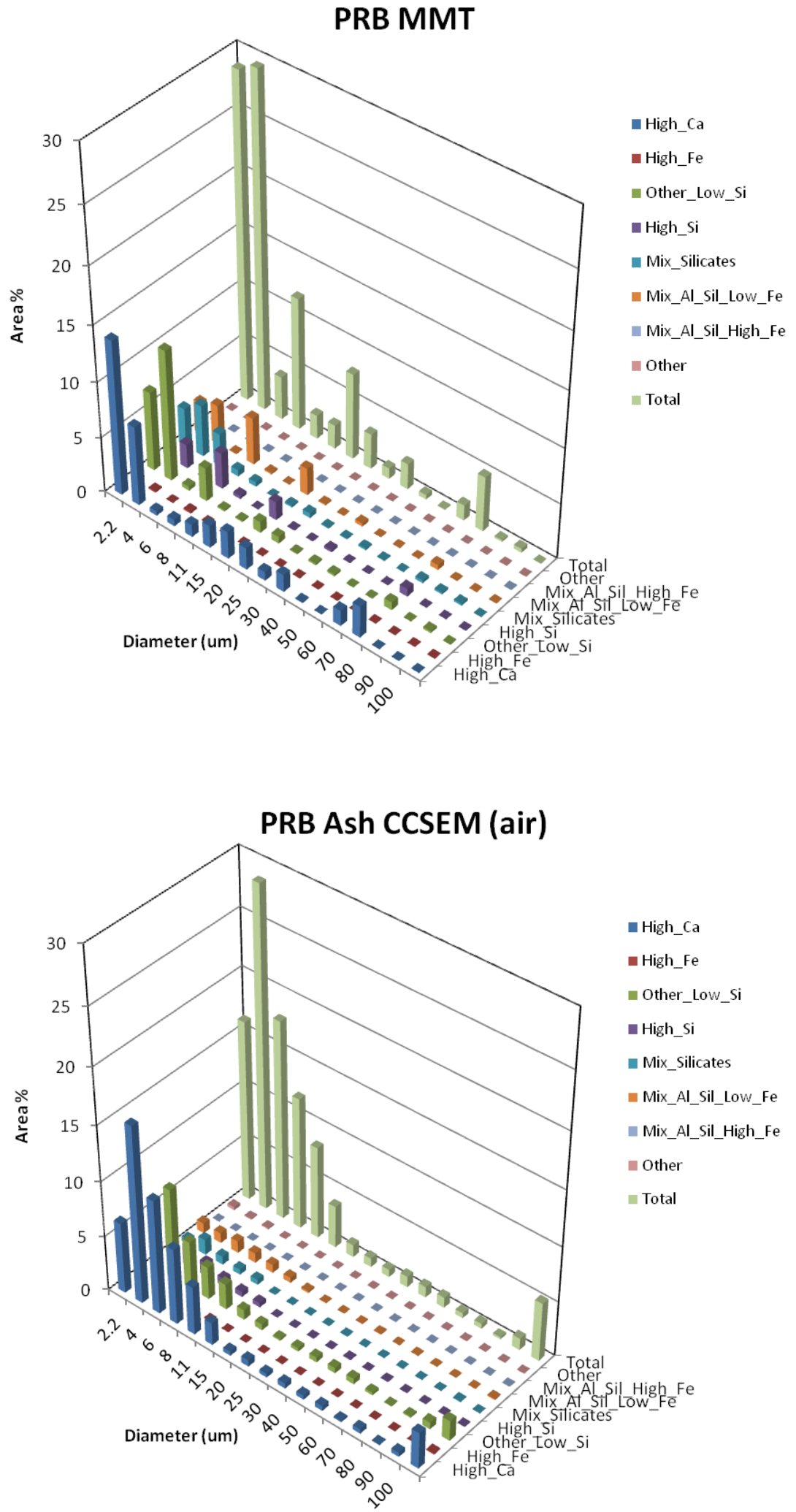

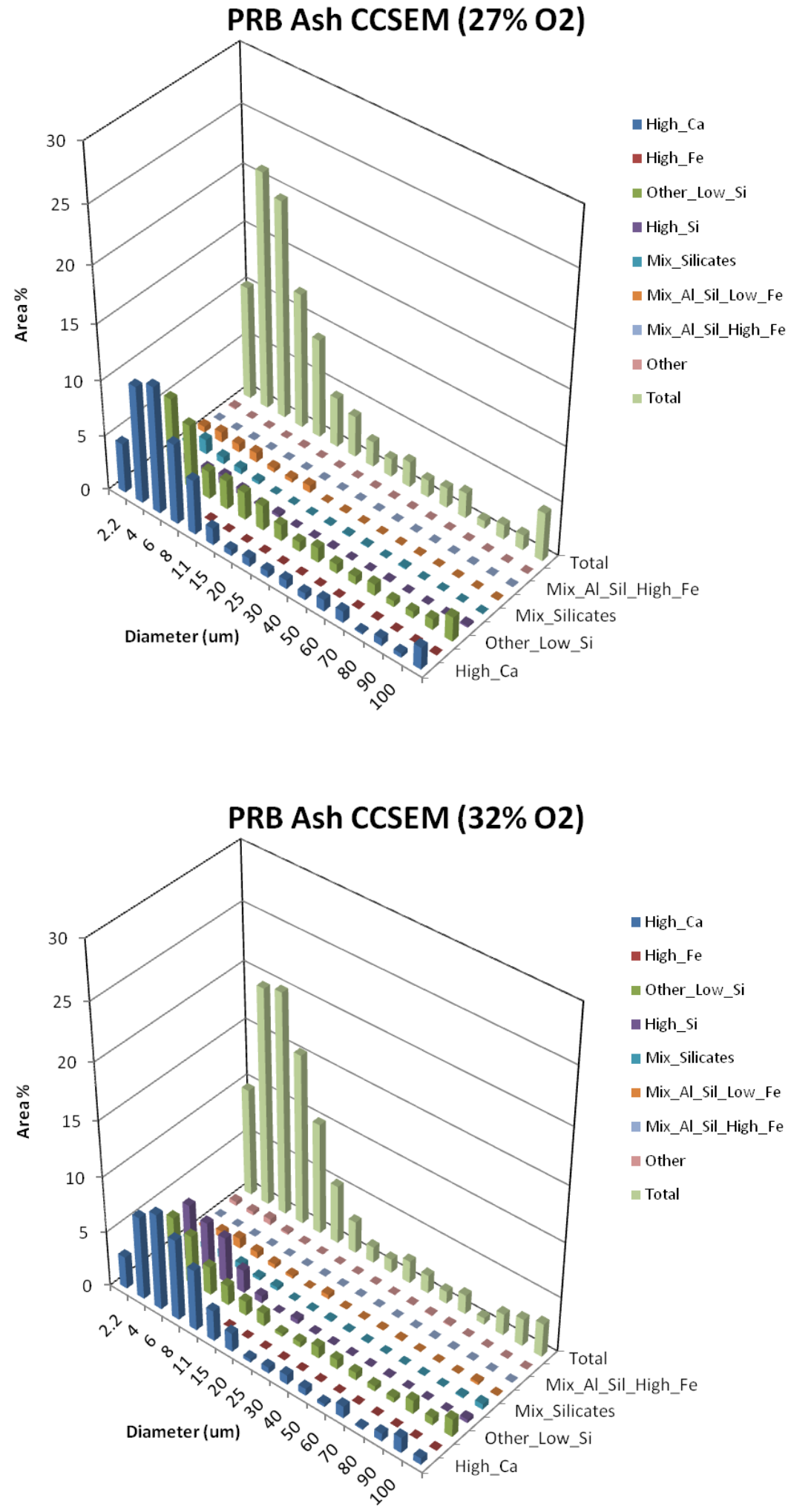

Figure 4.8-25: Comparison of MMT predicted ash composition distribution and CCSEM measured ash composition distribution for PRB coal. 


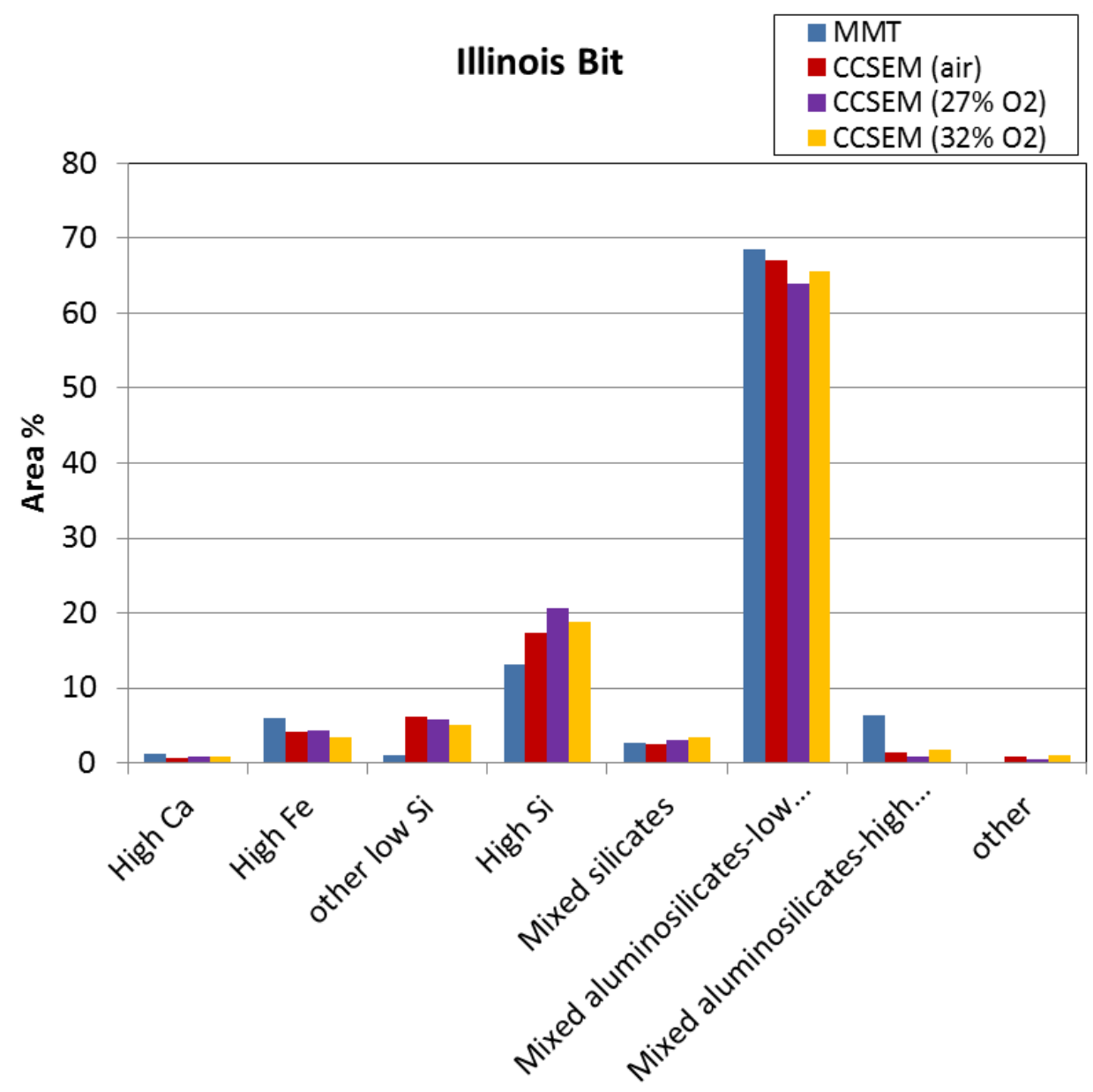

Figure 4.8-26: Comparison of MMT predicted ash composition and CCSEM measured ash composition for Illinois bituminous coal. 

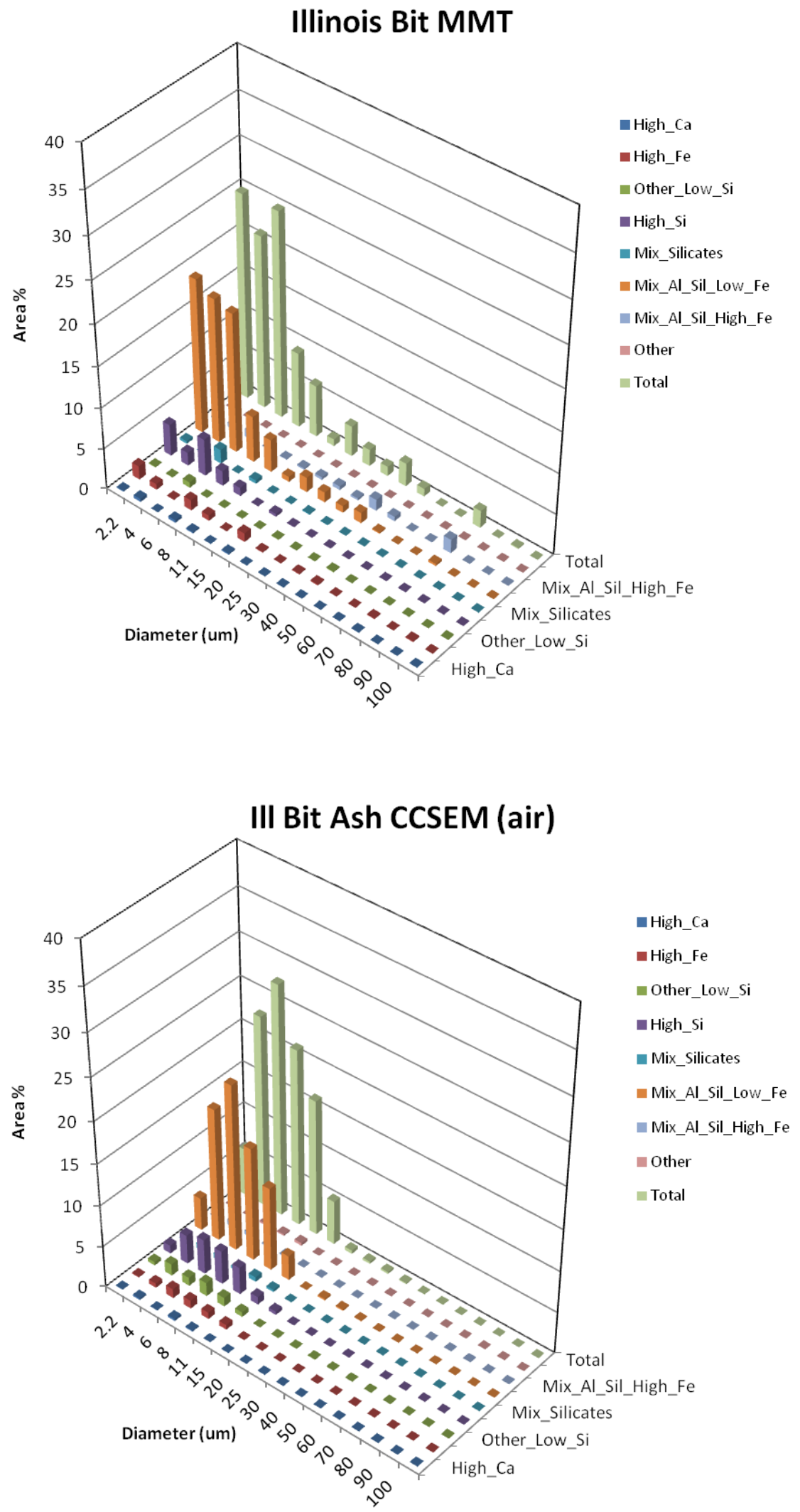

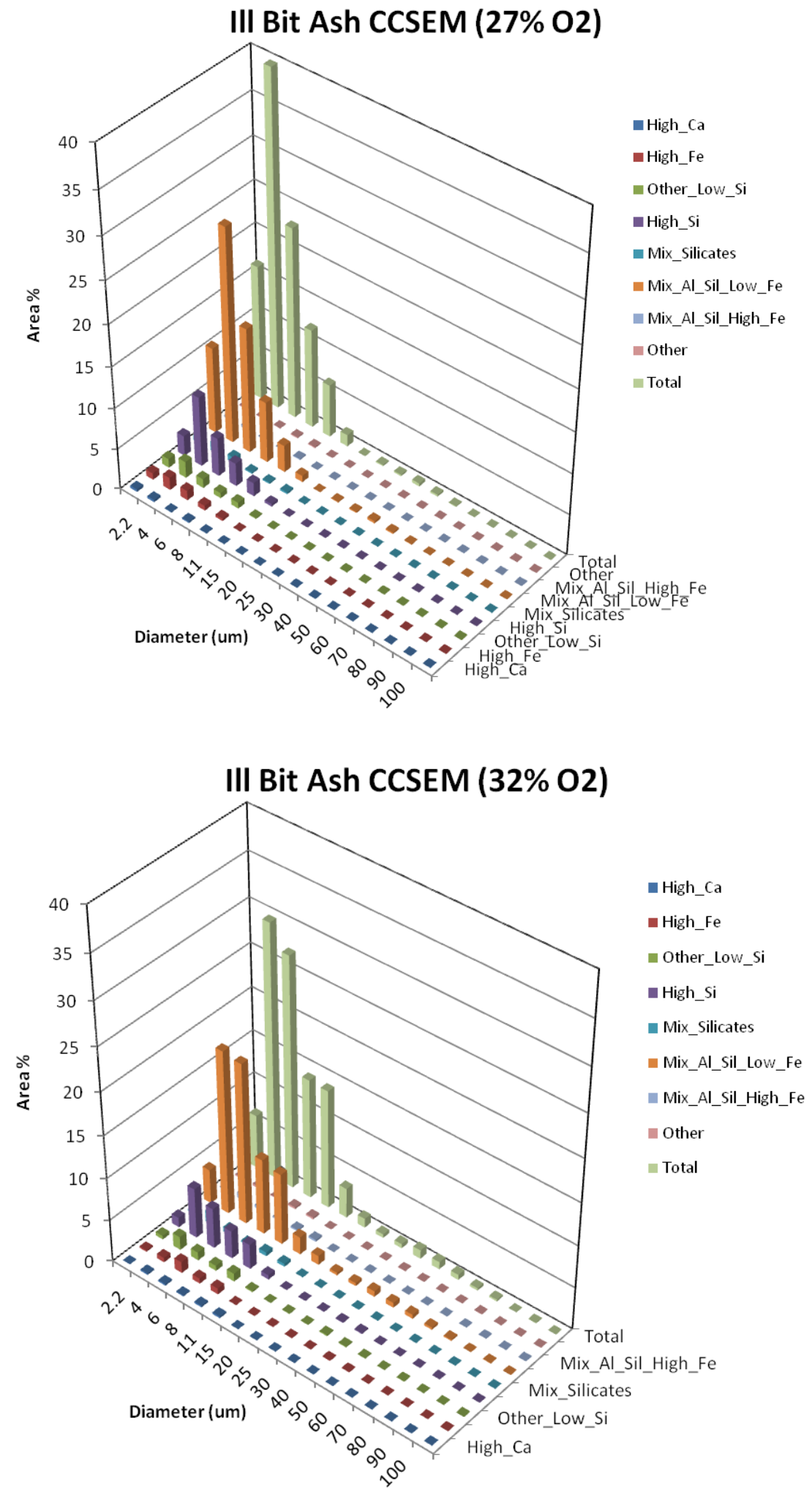

Figure 4.8-27: Comparison of MMT predicted ash composition distribution and CCSEM measured ash composition distribution for Illinois bituminous coal. 


\subsubsection{Slagging Modeling}

The overall approach of slagging modeling is to use the slagging sub-model together with a comprehensive CFD combustion model, as shown in Figure 4.8-28. The comprehensive CFD simulation provides the flame side information and deposition rate. The slagging sub-model performs the deposit growth, sintering and properties calculation and updates the wall boundary condition for comprehensive CFD simulation. Total deposition time is discretized into several time steps during which the deposition rate is assumed to be constant and the steady-state comprehensive CFD model can be used. The transient deposition build up process in the furnace can be addressed with this approach with adequate accuracy and manageable computational time. The two key elements in this approach are how to predict the deposition rate and how to predict the deposit property and growth. The deposition rate calculation is presented in detail first, followed by the discussion of the approach used to predict deposit property and growth.

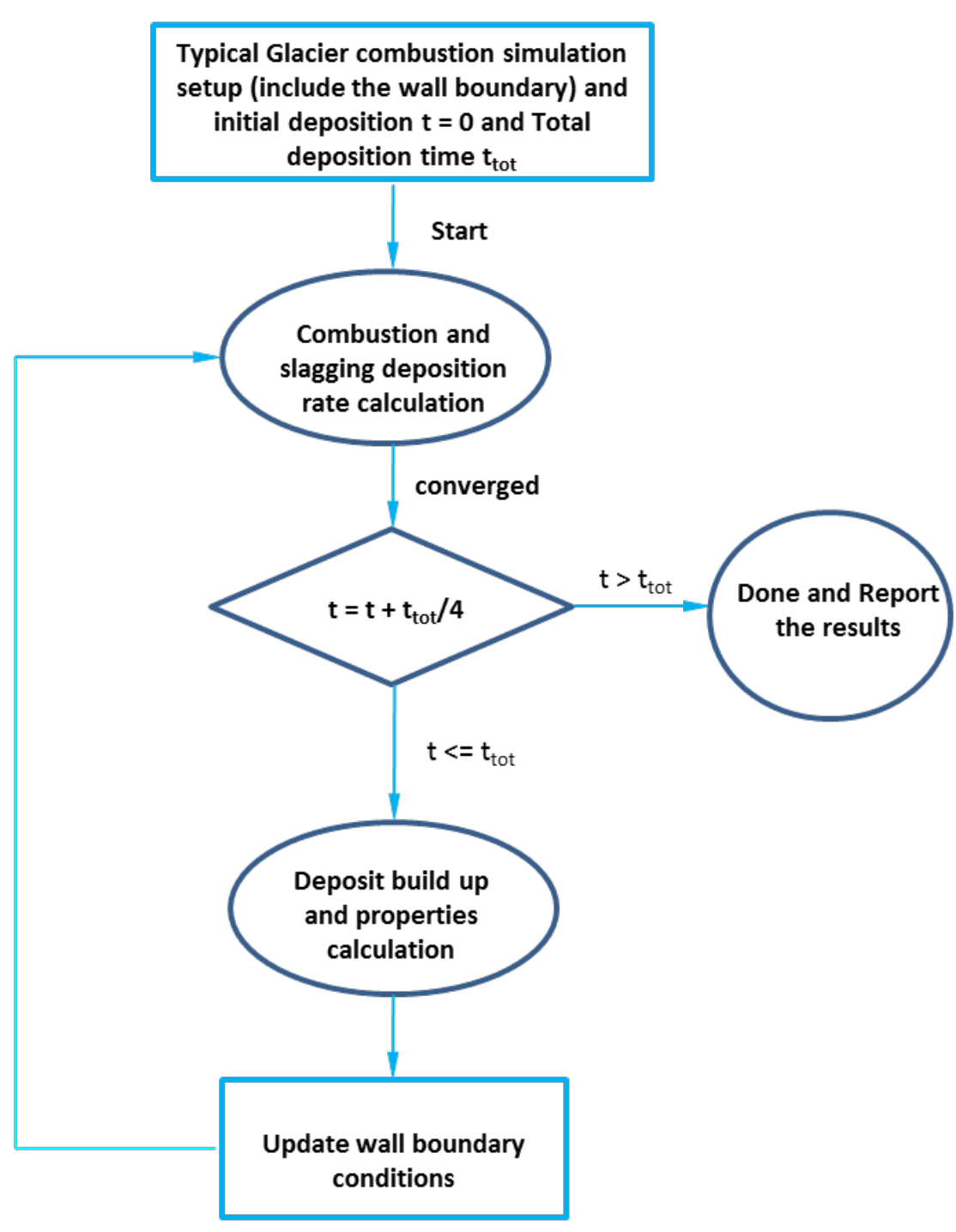

Figure 4.8-28: Overall approach to slagging model. 


\subsubsection{Slagging Deposition Rate}

The initial ash composition distribution of each coal particle is assumed to be known and is estimated by a fly ash transformation model, expressed by $n$ groups of compositions with a weighing factor $w^{i}$ for each group. When the coal particle cloud interacts with wall cells, the fraction that sticks on the wall surface (capture efficiency $f_{d e p}{ }^{i}$ ) for a particle with composition of group $i$ was expressed by (Walsh, Sayre, et al. 1990):

$$
{f_{\text {dep }}}^{i}=p^{i}\left(T_{p}\right)+\left[1-p^{i}\left(T_{p}\right)\right] p_{\text {sur }}\left(T_{s}\right)-k_{e}\left[1-p^{i}\left(T_{p}\right)\right]\left[1-p_{\text {sur }}\left(T_{s}\right)\right]
$$

where, $p^{i}(T)$ is the sticking probability (the probability that an impacting particle will stick on a clean wall surface) for an incoming particle of group $i$ evaluated at temperature $T$, and $T_{p}$ and $T_{s}$ are the incoming particle and deposit surface temperatures, respectively, $k_{e}$ is the erosion coefficient for the particular system and is assumed to be 0 at present, and $p_{\text {sur }}$ is the sticking probability for dry particles on the deposit surface.

Particle viscosity $\mu^{\mathrm{i}}$ has been found to provide a reasonable representation of the particle properties that affect sticking probability as shown:

$$
\begin{array}{ll}
p^{i}(T)=\frac{\mu_{r e f}}{\mu^{i}} & \mu^{i}>\mu_{\text {ref }} \\
p^{i}(T)=1 & \mu^{i} \leq \mu_{\text {ref }}
\end{array}
$$

A value of $10^{5}$ poise for $\mu_{\text {ref }}$ was suggested by (Richards, Slater and Harb 1993), based on the relative deposition rates observed for two different coals in a laminar drop tube furnace and is used here.

A viscosity model developed by (Senior and Srinivasachar 1995) is used to calculate the viscosity of silicate glass particles as a function of both temperature and composition.

The viscosity calculation is based on the ash composition and particle temperature, the influence of unburned carbon on particle viscosity is accounted in such a way that when the particle burnout is larger than a critical burnout, the ash tends to be explored at the outer surface of the particle, thus the viscosity of ash particle is representative of the particle in calculating the sticking probability. When particle burnout is less than a critical burnout, the ash tends to be buried in the carbon matrix, thus, a large viscosity is assigned to the particle in calculating the sticking probability.

The sticking probability of the deposit surface $P_{\text {sur }}\left(T_{s}\right)$ was approximated by the following expression by using the deposit surface temperature and deposit composition:

$$
P_{\text {sur }}\left(T_{s}\right)=\frac{\sum_{i=1}^{N} w^{i} P^{i}\left(T_{s}\right)}{\sum_{i=1}^{N} w^{i}}
$$

where, $P^{i}\left(T_{s}\right)$ is the sticking probability of ash composition $i$ in the deposit at surface temperature $T_{s}, w^{i}$ is the weighting factor associated the composition $i$ in the deposit.

Thus the average capture efficiency of coal particles is expressed as: 


$$
f_{d e p}=\frac{\sum_{i=1}^{N} w^{i} f_{d e p}^{i}}{\sum_{i=1}^{N} w^{i}}
$$

where, $f_{\text {dep }}^{i}$ is the capture efficiency of ash composition $i$ and $w^{i}$ is the weighting factor associated the composition $i$ in the coal particles.

After deposition, the deposit compositions in the wall cells are recorded and the ash composition in the coal particle along the trajectory is adjusted based on the ash composition balance by recalculating the weighting factor $w^{i}$ for ash composition in the coal particles.

The outlined approach is completed for all the coal particle trajectories to calculate the slagging deposition rate and size and composition distribution of deposited particles in the comprehensive CFD combustion simulation.

\subsubsection{Deposit Properties and Growth}

\subsection{Deposit Properties}

A quantitative description of deposition properties is necessary in order to assess the effect of the ash deposition on heat transfer and to assess deposit strength. Key physical properties related to heat transfer are the emissivity, absorptivity, and thermal conductivity. The viscosity, porosity and surface tension of the deposit are related to sintering and deposit strength.

The emissivity and absorptivity of the deposit were found to decrease with temperature and to increase with particle size or iron content prior to sintering. A sintered or fused deposit was found to have high emissivity and absorptivity of approximately 0.9 (Wall, Bhattacharya, et al. 1993). A quantitative method for calculation of deposit emissivity and absorptivity was reported by (Wall, Bhattacharya, et al. 1993). In this method, spectral data for the complex index of refractive of coal slags (Goodwin 1986) was estimated as a function of iron-oxide content. A two-flux model (Bohren 1987) (Brewster 1992) was used to solve the radiative transport equation through the opaque particulate deposit. The spectral emissivity and absorptivity were assumed to be equal and were calculated for the deposit at several wavelengths. The spectral values were then weighted by the relevant Planck distribution and integrated to yield the desired radiative properties. Once the deposit began to sinter, the emissivity and absorptivity were assumed to increase linearly with temperature to a maximum value, for a completely sintered deposit, of 0.9 (Wall, Bhattacharya, et al. 1993). The values of emissivity and absorptivity are also dependent on the structure of the heat transfer surface. For example, a thin deposit on boiler tubes will follow the curvature of the tubes with an emissivity $\varepsilon$ related to the flat emissivity $\varepsilon_{f}$ by Eq. 4.8-5 (Wall, Lowe, et al. 1979):

$$
\varepsilon=\frac{\pi \varepsilon_{f}}{1+(\pi-1) \varepsilon_{f}}
$$

The thermal conductivity of ash deposits was reviewed by (Gupta, Wall and Baxter 1997) who recommended methods for determination of the effective thermal conductivity for different types of deposits as follows. The effective thermal conductivity $K_{e}$ of a particulate deposit can be calculated by Eq. 4.8-6 


$$
K_{e}=K_{c}\left[r \phi_{s}^{2 / 3}+\left(1-\phi_{s}^{2 / 3}\right)\right] /\left[r\left(\phi_{s}^{2 / 3}-\phi_{s}\right)+\left(1-\phi_{s}^{2 / 3}+\phi_{s}\right)\right]
$$

where, $K_{c}$ is thermal conductivity of the continuous phase (gas), $r$ is the ratio of discrete phase conductivity $K_{d}$ to continuous phase conductivity $K_{c}$, and $\phi_{s}$ is the volume fraction of the discrete solid phase.

The thermal conductivity of the partially sintered deposit is more complex, and can be estimated by Eq. 4.3-7

$$
K_{e}=K_{2}\left[\zeta+\left(\zeta^{2}+8 K_{1} / K_{2}\right)^{0.5}\right] / 4.0
$$

where $\zeta=\left(3 \phi_{1}-1\right)\left(K_{1} / K_{2}\right)+\left(3 \phi_{2}-1\right)$. The thermal conductivities $K_{1}$ and $K_{2}$ in Eq. 4.8-7 correspond to the thermal conductivities of gas-continuous-phase and solid-continuous-phase, respectively, and can be determined by Eq. 4.8-6 using gas and solid as continuous phase, respectively. In the expression of $\zeta_{,}, \phi_{1}$ and $\phi_{2}$ are the volume fractions of gas-continuous-phase and solid-continuous-phase. An empirical correlation to estimate the volume fraction of gas-continuous-phase $\phi_{1}$ and solid-continuous-phase $\phi_{2}$ from the volume fraction of gas phase $\phi$ is given by Eq. 4.8-8

$$
\phi_{1}=\phi[\alpha+(1-\alpha) \phi] \quad \phi_{2}=1-\phi
$$

where $\alpha$ is a parameter related to the structure of the deposit.

The thermal conductivity of a completely sintered or molten deposit has a high value, close to the thermal conductivity of the solid deposit. A deposit is characterized by particulate (or partially sintered) deposit layers near the heat transfer surface and highly sintered layers exposed to the flame. Therefore, all the formulas mentioned above need to be used together in order to describe the effective thermal conductivity of a deposit.

The development of deposit strength is due primarily to the viscous flow sintering, which is determined by particle surface tensions and viscosities. Methods for estimating the surface tension of a slag deposit have been summarized by (Mills 1986). A viscosity model developed by (Senior and Srinivasachar 1995) is used to calculate the viscosity of silicate glass particles as a function of both temperature and composition.

Deposit properties (porosity, thermal conductivity, emissivity, absorptivity, etc.), which are determined by the deposit morphology, composition, and temperature, are critical in the prediction of heat transfer and deposit growth. Equilibrium is not reached locally in the deposit, and viscous flow sintering is the main mechanism responsible for the change of deposit morphology and properties. Sintering changes the pore structure of a deposit and causes an increase of deposit cluster size or connectivity. However, the porosity of a deposit appears to decrease significantly only in the outer region of the deposit where the temperature is sufficiently high.

\subsection{Sintering in Deposit}

Viscous flow sintering in the deposit is largely determined by viscous forces and surface tension forces. Surface tension forces cause adjacent particles to sinter together by increasing the width of the neck between particles and by decreasing the distance between the centers of the particles. Viscous forces are required to be low enough not to hinder the sintering from occurring. The extent of sintering is described by the sintering percentage or the densification parameter, $\psi$, as shown in the following expression: 


$$
\psi=\frac{V_{s}-V_{G}}{1-V_{G}}
$$

where $V_{\mathrm{s}}$ is the volume fraction of solid phase (or relative density), and $V_{\mathrm{G}}$ is the initial volume fraction of solid phase. Thus $V_{\mathrm{s}}=\rho / \rho_{\mathrm{s}}$ and $V_{\mathrm{G}}=\rho_{d} / \rho_{\mathrm{s}}$, where, $\rho$ is the deposit density, $\rho_{o}$ is the initial deposit density, and $\rho_{s}$ is the theoretical density for the solid material. The porosity of the deposit $(\phi)$ is related to the relative density through Eq. 4.8-10:

$$
\phi+V_{s}=1
$$

The sintering between particles with uniform size and uniform composition can be predicted by using Frenkel's model (Frenkel 1945) for the initial stage of sintering, Scherer's model (Scherer 1997) for middle and initial stages of sintering, and Mackenzie and Shuttleworth's model (Mackenzie and Shuttleworth 1949) for the final stage of sintering. All these models predict the relative density as a function of particle size, viscosity, surface tension and time. The influence of particle shape and size distribution on the sintering rate has been discussed in the literature (Coble 1973) (Chappell and Ring 1986). The effect of the nonuniform composition on the sintering rate has also been recognized as important, although it has not been discussed quantitatively in the literature (German 1996). Unfortunately, ash deposits are formed from fly ash particles that come in a wide variety of sizes, shapes, and compositions. Thus, accurate prediction of the sintering rate in an ash deposit is a very difficult task. Also, sintering predictions must be simple enough computationally to permit integration with a comprehensive combustion code for the simulation of deposition behavior in large-scale boilers. An attempt has been made here (Wang 1998) to track the sintering in the deposit and to represent the experimental results at a minimal computational cost.

Viscous-flow sintering is the principal mechanism responsible for changing the structure of a deposit. Based on experimental observations (Wang, West and Harb 1999), initial sintering tends to increase the connectivity of the deposit without making significant changes in the deposit porosity. Observations also indicate substantial porosity changes in the later stages of sintering. These observations have been incorporated into the sintering model developed here. Fly ash particles that adhere to the surface and form the ash deposit are assumed to be spherical for the purpose of simplification. This assumption is not expected to have a large effect on the predicted results. Before the calculation of sintering in the deposit, particles that adhere to the surface and form the deposit are divided into a finite number of groups (according to their sizes and compositions) in order to represent the behavior of a large number of particles. Grouping of the particles is required in order to make the sintering calculations computationally feasible. The following key assumptions were made in order to predict overall sintering of the deposit, which is responsible for an increase of deposit connectivity, and to predict the porosity (or relative density) of the deposit:

1) The extent of sintering of a particular particle group depends only on the size and composition of particles in that group.

2) The overall sintering can be calculated as a weighted average of the extent of sintering of individual particle groups.

3) High-viscosity particles will not mix and react with the surrounding species unless other smaller or equally sized particles have completely sintered.

4) The extent of sintering affects the cluster size or connectivity of the deposit, not the deposit porosity, until a critical viscosity is reached. 
5) When the critical viscosity is reached, an increase of sintering will result in a decrease in the deposit porosity or an increase in the relative density of the deposit.

The first two assumptions are key simplifications. As shown in Figure 4.8-29, the contribution of particle A to the sintering is through the movement of flow coming from particle A to the area between particle A and $\mathrm{B}$ or between particle $\mathrm{A}$ and $\mathrm{A}^{\prime}$. In the present implementation, the contribution of particles of a particular size and composition to the overall sintering of a deposit is approximated as that which would be observed from a deposit made up entirely of those particles. The overall sintering of the deposit is then calculated as the weighted average of sintering extent of individual particle groups.

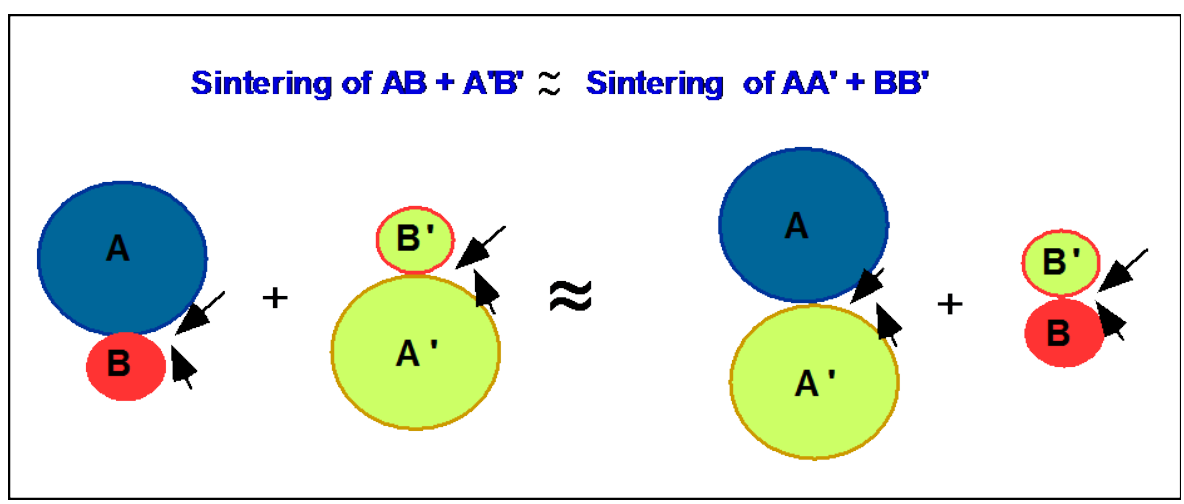

Figure 4.8-29: Movement of viscous flow.

The first two assumptions preclude the need to deal with individual pairs of particles of different size and/or composition. Instead, a combination of Scherer's model (Scherer 1997) and the model of Mackenzie and Shuttleworth (Mackenzie and Shuttleworth 1949) can be used to predict the sintering extent of a particular group of particles, as described in Figure 4.8-30. In other words, overall sintering of the deposit is estimated as the weighted average of the sintering which would occur for groups of monosized particles of a particular composition. 


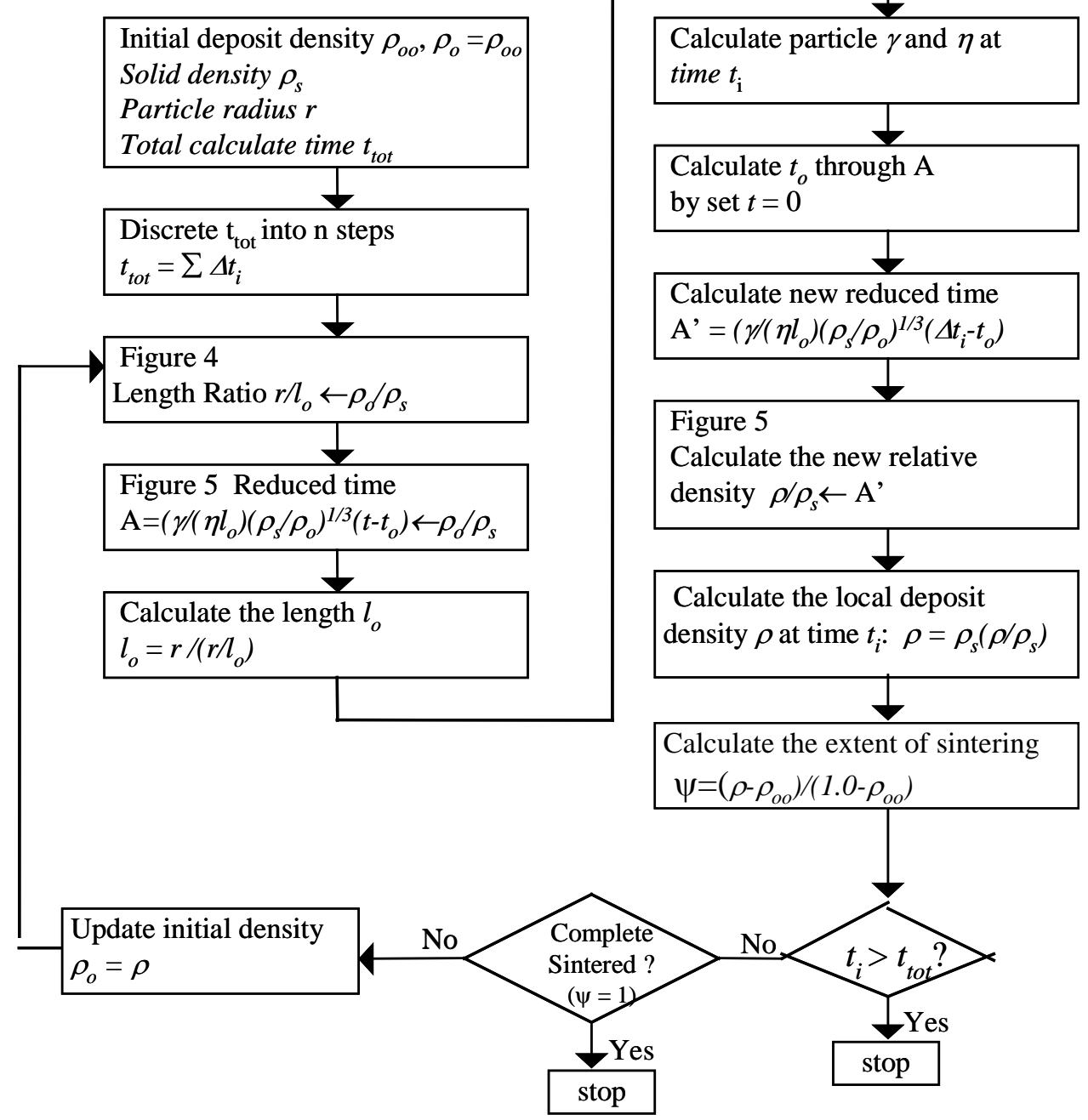

\section{Figure 4.8-30: The procedure to calculate the extent of sintering for a particular group as a function of time.}

It is well known (Frenkel 1945) (Mackenzie and Shuttleworth 1949) (Scherer 1997) that sintering of monosized particles leads to a reduction in porosity and hence a change in relative density. Therefore, a relative density change can be used to characterize the sintering extent of the monosized groups. However, overall porosity of the deposit does not change significantly until well after significant sintering has occurred. This phenomenon was confirmed by experimental observation and was mainly due to the fact that a deposit was formed from fly ash particles with varied size, shape, and compositions. The possible reasons for a deposit to maintain porosity as sintering occurs are explained later in this section together with assumptions 3 and 4 . Therefore, the relative density $(\rho)$ in Figure 4.8-31 is merely a way of quantifying the extent of sintering $(\psi)$ of the monosized groups. The relationship between the relative density $\left(\rho / \rho_{\mathrm{s}}\right)$ and reduced time $\left.\left(\gamma /\left(\eta l_{o}\right)\left(\rho_{\mathrm{s}} / \rho_{o}\right)^{1 / 3}\left(t-t_{0}\right)\right)\right)$ and the relationship between the length ratio $\left(r / l_{o}\right)$ and relative density $\left(\rho / \rho_{s}\right)$ for the monosized groups were developed by Scherer (Scherer 1997) and are plotted in Figure 4.8-31 and Figure 4.8-32. 


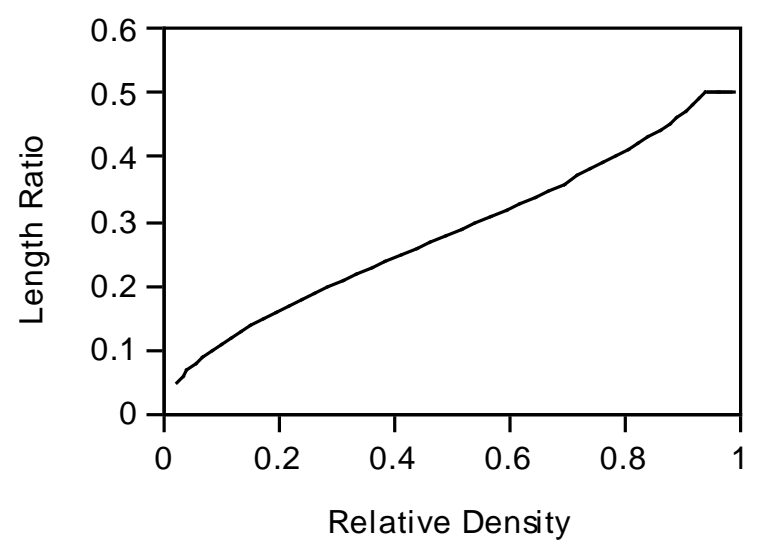

Figure 4.8-31: Length ratio $\left(\mathrm{r} / \mathrm{l}_{0}\right)$ versus relative density $\left(\rho / \rho_{s}\right)$ used to estimate extent of sintering for individual particle groups.

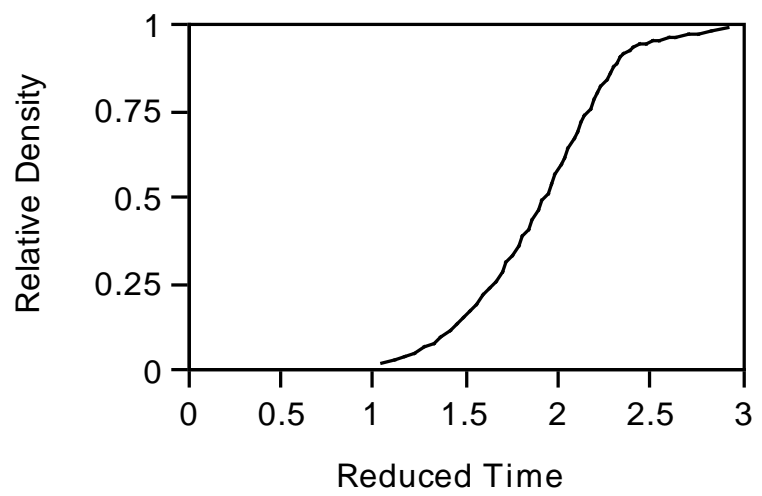

Figure 4.8-32: Relative density $\left(\rho / \rho_{s}\right)$ versus reduced time $\left(\gamma /\left(\eta l_{o}\right)\left(\rho_{s} / \rho_{o}\right)^{1 / 3}\left(t-t_{o}\right)\right)$ used to estimate extent of sintering for individual particle groups.

These two figures provide a simple way to get the deposit length and reduced time when the relative density is known (or vice versa). The corresponding values from these two figures were tabulated in a computer program for the purpose of computer simulation. In Figure 4.8-30 through Figure 4.8-32, $\gamma$ is the surface tension, and $\eta$ is the viscosity of the particle group. The viscosity model of (Senior and Srinivasachar 1995) was used to calculate the viscosity of particles as a function of particle composition and temperature. The surface tension of particles was estimated using the method of (Mills 1986). Once the sintering extent of the individual groups $\left(\psi_{j}\right)$ was calculated, the overall sintering extent of the deposit $(\psi)$ was estimated through Eq. 4.8-11, which is a mass weighted average of the sintering of individual groups:

$$
\psi=\frac{\sum_{j=1}^{N} m_{j} \psi_{j}}{\sum_{j=1}^{N} m_{j}}
$$

where $m_{j}$ is the mass associated with the particle group $j$, and $N$ is the total particle groups in the deposit. 
The third and fourth assumptions recognize that high viscosity particles, due to their relative immobility, play a very important role in maintaining the porosity of the deposit during the sintering of other particles. These high-viscosity particles were assumed to have a viscosity greater than $10^{11}$ poise at a temperature of $1250 \mathrm{~K}$. The high-viscosity particles tend to hold their original positions to maintain the porosity of the deposit during the sintering of other particles until mixing occurs with basic "flux" components that surround them. The mixing between high-viscosity particles and the surrounding basic "flux" components only occurs at high temperature. In the current model, the high-viscosity particles are not allowed to mix with other species and sinter until smaller or equally sized particles have sintered completely.

The fifth assumption recognizes that the deposit porosity begins to decrease in the outer region of the deposit where the temperature is sufficiently high. The viscosity of the bulk deposit at the deposit surface temperature was calculated and compared to a critical value, $10^{5}$ poise, chosen based on the viscosity of formation of non-flowing slag (Raask 1985). The porosity of the deposit was assumed to decrease once the viscosity calculated from the bulk deposit composition reached the critical value. If $\psi_{\text {cri }}$ represented the overall sintering percentage when the viscosity of bulk deposit at the deposit surface temperature reached the critical value, a linear relationship between the extent of sintering and the deposit porosity $\phi$ was assumed as described in Eq. 4.8-12:

$$
\begin{array}{ll}
\phi=\phi_{o} & \psi \leq \psi_{c r i} \\
\frac{\phi_{o}-\phi}{\phi_{o}}=\frac{\psi-\psi_{c r i}}{100 \%-\psi_{c r i}} & \psi>\psi_{c r i}
\end{array}
$$

where, $\phi$, and $\phi_{o}$ are the deposit porosity and initial deposit porosity, respectively; $\psi$ is the overall extent of sintering of the deposit.

The local overall extent of sintering in the deposit as a function of time was calculated by dividing the deposit into discrete layers. The extent of sintering for each layer during the time step $\Delta \mathrm{t}_{\mathrm{i}}$ was approximated by the mass average of the extent of sintering for each of the relevant particle groups. High-viscosity particle groups were not allowed to mix and sinter until other groups of equal or smaller size had completely sintered. Once the sintering of a particular particle group was complete, the mass of this group was distributed among the high-viscosity particle groups. This procedure permitted approximation of the local extent of sintering as a function of time, particle size, and composition, and was used to estimate the deposit properties.

One complication of this approach is the influence of unburned carbon in the deposit on the deposit growth and sintering. The effect of unburned carbon on deposit growth is determined by the release rate of unburned carbon in the deposit, which in turn influences the deposit surface sticking probability. The release rate of deposited unburned carbon is dependent on the local gas environment where the deposit is located. If the local gas is very fuel lean, quick lease of all unburned carbon in the deposit is assumed. If the local gas is very fuel rich, none of unburned carbon in the deposit is released into gas phase. Under normal conditions, the release rate of unburned carbon in the deposit creates a near stoichiometric local gas environment.

Deposited partially-burned carbon particles are treated in a same way as other deposited ash particles in surface sticking probability calculation and in sintering calculation through their viscosity identities. The viscosity of a partially burned-carbon particle is calculated in such a way that when the particle burnout is larger than a critical burnout, the ash tends to be exposed on the outer surface of the particle, thus the 
viscosity of ash particle is representative of the particle. When particle burnout is less than a critical burnout, the ash tends to be buried in the carbon matrix, thus, a high viscosity is assigned to the particle.

Crystallization in the deposit at sufficiently high temperatures was not considered in the current model. Crystal formation would affect deposit properties and deposit strength. However, as a first effort, this sintering model approximated the overall extent of sintering and deposit porosity as a function of time, particle size, and composition in the deposit, which in turn was used to estimate the deposit properties.

Deposit properties include deposit porosity, local thermal conductivity, emissivity, and absorptivity. The porosity $(\phi)$ of the deposit was discussed previously. The initial deposit porosity was assumed to be 0.6 in the model, a typical value for the particulate deposit and consistent with values measured by (Anderson, Viskanta and Incropera 1987).

The local thermal conductivity $\left(K_{e}\right)$ of an ash deposit depends on the extent of sintering, the deposit porosity and the temperature. As discussed previously, the local thermal conductivity of a particulate deposit $\left(K_{e}\right)$ was calculated by Eq. 4.8-6. The local thermal conductivity of a partially or completely sintered deposit was calculated by Eq. 4.8-13.

$$
\begin{aligned}
& K_{e}=\psi K_{s c}+(1-\psi) K_{g c} \\
& K_{s c}=K_{s}\left[r_{s} \phi^{2 / 3}+\left(1-\phi^{2 / 3}\right)\right] /\left[r_{s}\left(\phi^{2 / 3}-\phi\right)+\left(1-\phi^{2 / 3}+\phi\right)\right] \\
& K_{g c}=K_{g}\left[r_{g} \phi_{s}^{2 / 3}+\left(1-\phi_{s}^{2 / 3}\right)\right] /\left[r_{g}\left(\phi_{s}^{2 / 3}-\phi_{s}\right)+\left(1-\phi_{s}^{2 / 3}+\phi_{s}\right)\right]
\end{aligned}
$$

where $K_{g c}$ and $K_{s c}$ correspond to the thermal conductivities of gaseous continuous phase and solid continuous phase, respectively; $r_{s}$ is the ratio of gas conductivity $K_{g}$ to solid conductivity $K_{s}$ and $r_{g}$ is the ratio of solid conductivity $K_{s}$ to gas conductivity $K_{g} ; \phi$ and $\phi_{s}$ are the volume fractions of gas and solid, respectively; $\psi$ is the extent of sintering. The value of thermal conductivity calculated for the completely sintered deposit using Eq. 4.8-13 will be close to the thermal conductivity of the solid deposit phase.

The thermal conductivity of the gas phase (in $\mathrm{W} /(\mathrm{m} \mathrm{K})$ ) was approximated as that of nitrogen at the local deposit temperature, which is expressed in Eq. 4.8-14,

$$
K_{g}=1.14 \times 10^{-2}+5.108 \times 10^{-5} T_{d e p}
$$

where, $T_{\text {dep }}$ is the temperature of the deposit in Kelvin. The thermal conductivity of the solid deposit phase was assumed to be constant at $4 \mathrm{~W} /(\mathrm{m} \mathrm{K})$, a value representative of silica-containing materials at high temperature (Kingery, Bowen and Uhlmann 1976).

The emissivity and absorptivity of the particulate deposit surface were determined by the particle size and composition distribution as per (Harb, Slater and Richards 1993). The method assumed multiple independent scattering and utilized the scattering albedo and the scattering asymmetry factor from single particle calculations performed with the Mie code of (Bohren and Huffman 1983). Once the surface deposit began to sinter, the emissivity was assumed to increase linearly with temperature. These thermal and physical properties of the deposit were then used to predict the deposit growth and heat flux through the deposit as discussed in the next section. 


\subsection{Deposit Growth and Heat Flux}

Deposit growth and the heat flux through the deposit are simulated for a time period in which the deposition rate and the incident heat flux are assumed to remain constant. Figure 4.8-33 illustrates the procedure used for simulation of deposit growth and heat flux through the deposit (Wang and Harb 1997). The simulated time is divided into a finite number of time steps and the amount of deposit, which accumulates during the $i^{\text {th }}$ time step, is referred as the $i^{\text {th }}$ deposit layer.

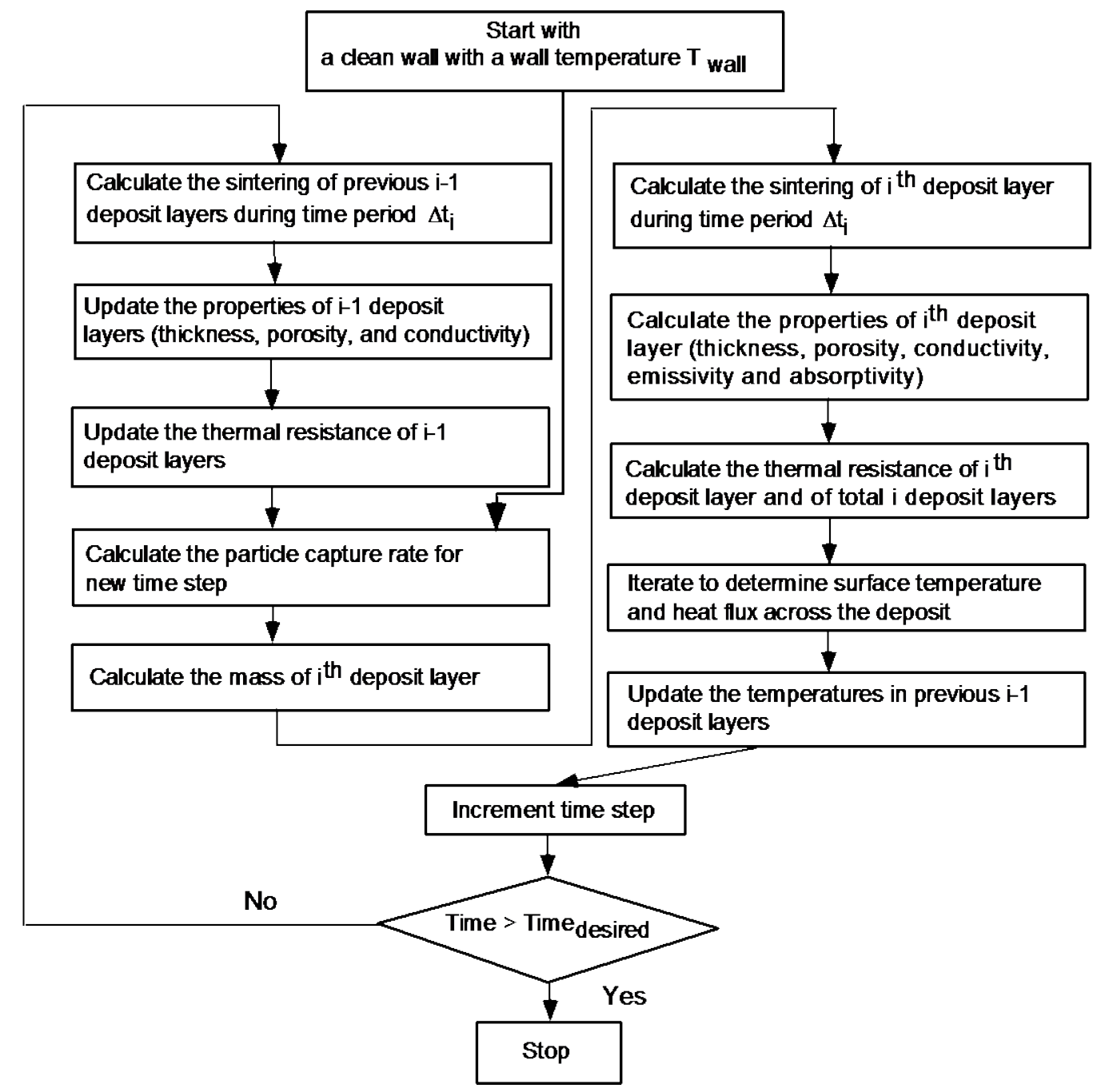

Figure 4.8-33: Flowchart illustrating the procedure used to simulate deposit growth.

First, the extent of sintering that occurs during the time step $i$ is calculated for each layer of the existing deposit (layers 1 to $i-1$ ) and the deposit thermal conductivities for each of these layers are updated. Next, the mass of the deposit, which accumulates during the time step $i$, is determined. The thickness and sintering of the new deposit layer is then calculated and the thermal conductivity, emissivity, and absorptivity of the new deposit layer are approximated as discussed in the previous section.

Once the thermal resistance of the deposit and the emissivity and absorptivity of the deposit surface have been calculated, it is then possible to calculate the deposit surface temperature and the net heat flux through the deposit by solving Eqs. 4.8-15 and 4.8-16 together: 


$$
\begin{gathered}
T_{s}=q_{\text {net }} R_{i}+T_{\text {wall }} \\
q_{\text {net }}=h\left(T_{g}-T_{s}\right)+\alpha q_{\text {inc }}-\varepsilon \sigma T_{s}^{4}
\end{gathered}
$$

where, $T_{S}$ is the deposit surface temperature, $q_{\text {net }}$ is the net heat flux through the deposit, $R_{i}$ is the thermal resistance of the $i^{\text {th }}$ deposit layer, $q_{\text {inc }}$ is the incident radiation heat flux on the deposit surface, $T_{\text {wall }}$ is the wall surface temperature, $T_{g}$ is the near deposit gas temperature, $h$ is the convection coefficient, $\alpha$ is the absorptivity of deposit surface, $\varepsilon$ is the emissivity of deposit surface, and $\sigma$ is the Stefan-Boltzmann constant. In these two equations, $q_{\text {inc }}, h, T_{g}, T_{\text {wall }}$ are provided by the combustion simulation, whereas $\alpha, \varepsilon$, and $R_{i}$ are predicted as discussed previously. Finally, an iterative procedure is performed to solve for the surface temperature $T_{s}$ and heat flux $q_{\text {net }}$. Once the new surface temperature and flux have been determined, the temperatures in the deposit layers are recalculated by Eq. 4.8-17:

$$
T_{k}=T_{\text {wall }}+q_{\text {net }} R_{k}
$$

These temperatures at different layers are saved and used to calculate the sintering in these deposit layers at the next time step. The entire process is repeated until the total time specified for deposit growth has been reached.

\subsubsection{Fouling Modeling}

\subsubsection{Introduction}

This analysis will generally follow the analysis of (Walsh, Sarofim and Beer 1992). The major assumptions used are as follows:

- Alkali species ( $\mathrm{Na}, \mathrm{K}$ ) vaporize during combustion, and some of the vaporized alkali species persist in the gas phase in the convective pass;

- Sodium sulfate condenses on cooled surfaces when the surfaces are below the dew point;

- When the surface temperature of the deposit is between the sodium sulfate dew point and the melting temperature of sodium sulfate $\left(884^{\circ} \mathrm{C}\right.$ or $\left.1623^{\circ} \mathrm{F}\right)$, the surface will be sticky;

- When the gas temperature reaches the sodium sulfate dew point, sodium begins to condense on suspended ash particles;

- Homogeneous nucleation of sodium sulfate is neglected;

- When the gas temperature is between the sodium sulfate dew point and the melting temperature of sodium sulfate $\left(884^{\circ} \mathrm{C}\right)$, the ash particle surface will be sticky (if sodium sulfate has condensed);

- Deposits grow most rapidly when their surfaces are sticky, at surface temperatures between $884^{\circ} \mathrm{C}$ and the dew point;

- Erosion of a dry surface by dry particles competes with deposit growth.

Thus, the region in which significant fouling will occur is that in which the gas temperature lies between the dew point of sodium sulfate and the melting point of sodium sulfate. Local gas temperatures and velocities in the backpass will be calculated by the CFD model. The amount of sodium vaporization will be calculated using a correlation between organically bound sodium and $\mathrm{SiO}_{2}$ in the coal. The size distribution of the ash particles will be calculated by the mineral matter transformation model. 


\subsubsection{Estimation of sodium vaporization in pc-combustion}

Prediction of fouling in the convective pass of a coal-fired boiler requires knowledge of the amount of sodium $(\mathrm{Na})$ and potassium $(\mathrm{K})$ vaporized in the boiler and carried over into the convective pass. In previous work (Gallagher, Bool, et al. 1990) (Gallagher, Peterson and Wendt 1996), the amount of acidsoluble Na (Boni 1990) was found to be an important parameter correlated with vaporization of Na under pulverized coal combustion conditions. The amount of acid-soluble $\mathrm{Na}$ and $\mathrm{K}$ should correspond to the amount of organically-bound element. Published data on chemical fractionation (selective leaching) of calcium (Ca), magnesium (Mg), Na, and K were assembled (Benson and Holm 1985) (Bool 1995) (C. L. Senior 2001) as shown in Table 4.8-2.

Table 4.8-2: Chemical fractionation data (Benson et al., 1985; Bool et al., 1995; Senior et al., 2001).

\begin{tabular}{|c|c|c|c|c|c|c|c|c|}
\hline & $\begin{array}{c}\text { Falkirk } \\
\text { NDL }\end{array}$ & $\begin{array}{l}\text { Beulah, } \\
\text { NDL }\end{array}$ & $\begin{array}{c}\text { Bryan, } \\
\text { TXL }\end{array}$ & $\begin{array}{c}\text { Black } \\
\text { Thunder }\end{array}$ & Wyodak & Rochelle & Rosebud & $\begin{array}{l}\text { Ohio } \\
5 / 6 / 7\end{array}$ \\
\hline \multicolumn{9}{|c|}{ Chemical fractionation results (\% of element) } \\
\hline & $\begin{array}{c}\text { Removed } \\
\text { by } \\
\text { NH4Ac }\end{array}$ & $\begin{array}{l}\text { Removed } \\
\text { by NH4Ac }\end{array}$ & $\begin{array}{c}\text { Removed } \\
\text { by } \\
\text { NH4Ac }\end{array}$ & $\begin{array}{c}\text { Removed } \\
\text { by H2O } \\
+ \\
\text { NH4Ac } \\
\end{array}$ & $\begin{array}{c}\text { Removed } \\
\text { by } \\
\text { NH4Ac }\end{array}$ & $\begin{array}{c}\text { Removed } \\
\text { by H2O } \\
+ \\
\text { NH4Ac } \\
\end{array}$ & $\begin{array}{c}\text { Removed } \\
\text { by } \\
\text { NH4Ac }\end{array}$ & $\begin{array}{c}\text { Removed } \\
\text { by } \\
\text { NH4Ac }\end{array}$ \\
\hline $\mathrm{Ca}$ & 40 & 76 & 62 & 59 & 45 & 67 & 57 & 30 \\
\hline $\mathrm{Mg}$ & 50 & 90 & 94 & 72 & 55 & 64 & 65 & 10 \\
\hline $\mathrm{Na}$ & 85 & 84 & 75 & 86 & 90 & 93 & 81 & 25 \\
\hline $\mathrm{K}$ & 10 & 20 & 9 & 15 & 30 & 49 & 2 & 0 \\
\hline \multicolumn{9}{|l|}{ Coal composition } \\
\hline Coal C, wt\% dry & 60.15 & 64.13 & 53.67 & 69.80 & 69.00 & 69.04 & 70.70 & 72.77 \\
\hline Coal O, wt\% dry & 19.53 & 20.07 & 15.86 & 17.07 & 16.57 & 18.83 & 16.62 & 8.29 \\
\hline Coal Ash, wt \% dry & 14.63 & 9.55 & 24.50 & 5.94 & 8.13 & 5.95 & 4.90 & 9.93 \\
\hline Coal C/O & 3.08 & 3.20 & 3.38 & 4.09 & 4.17 & 3.67 & 4.25 & 8.77 \\
\hline
\end{tabular}

The organically bound elements should be correlated with the oxygen available for ion exchange in the coal. Thus, the more oxygen the coal has, the more organically bound cations the coal should have. In Figure 4.8-34, the $\mathrm{C} / \mathrm{O}$ ratio is plotted against the fraction of organically bound elements. For $\mathrm{Na}$ and $\mathrm{Mg}$, the correlations are good. For Ca, the correlation is not as good, while for $\mathrm{K}$, the correlation is poor. However, the amount of $\mathrm{K}$ associated with organically bound elements is generally low; the poor correlation might be due, in part, to the difficulty in accurately measuring the amount of ion-exchangeable $\mathrm{K}$ in coals.

(Gallagher, Bool, et al. 1990) carried out pilot-scale combustion experiments in which he reported results on vaporization. In particular, vaporization of $\mathrm{Na}$ could be correlated with the ratio of acid-soluble Na to $\mathrm{SiO}_{2}$ in the coal.

Table 4.8-3 gives selective coal composition and acid-soluble Na data reported by (Gallagher, Bool, et al. 1990). The amount of acid-soluble Na was sometimes greater than the amount of $\mathrm{Na}$ in the coal, as calculated from the ash composition and ash content. Thus, the amount of acid-soluble Na reported in (Gallagher, Bool, et al. 1990) (Boni 1990) is suspect. For this reason, the amount of organically bound Na was estimated using the correlation in Figure 4.8-34; this is also shown in Table 4.8-3. 
Table 4.8-3: Sodium in coal and acid-soluble or organically bound forms.

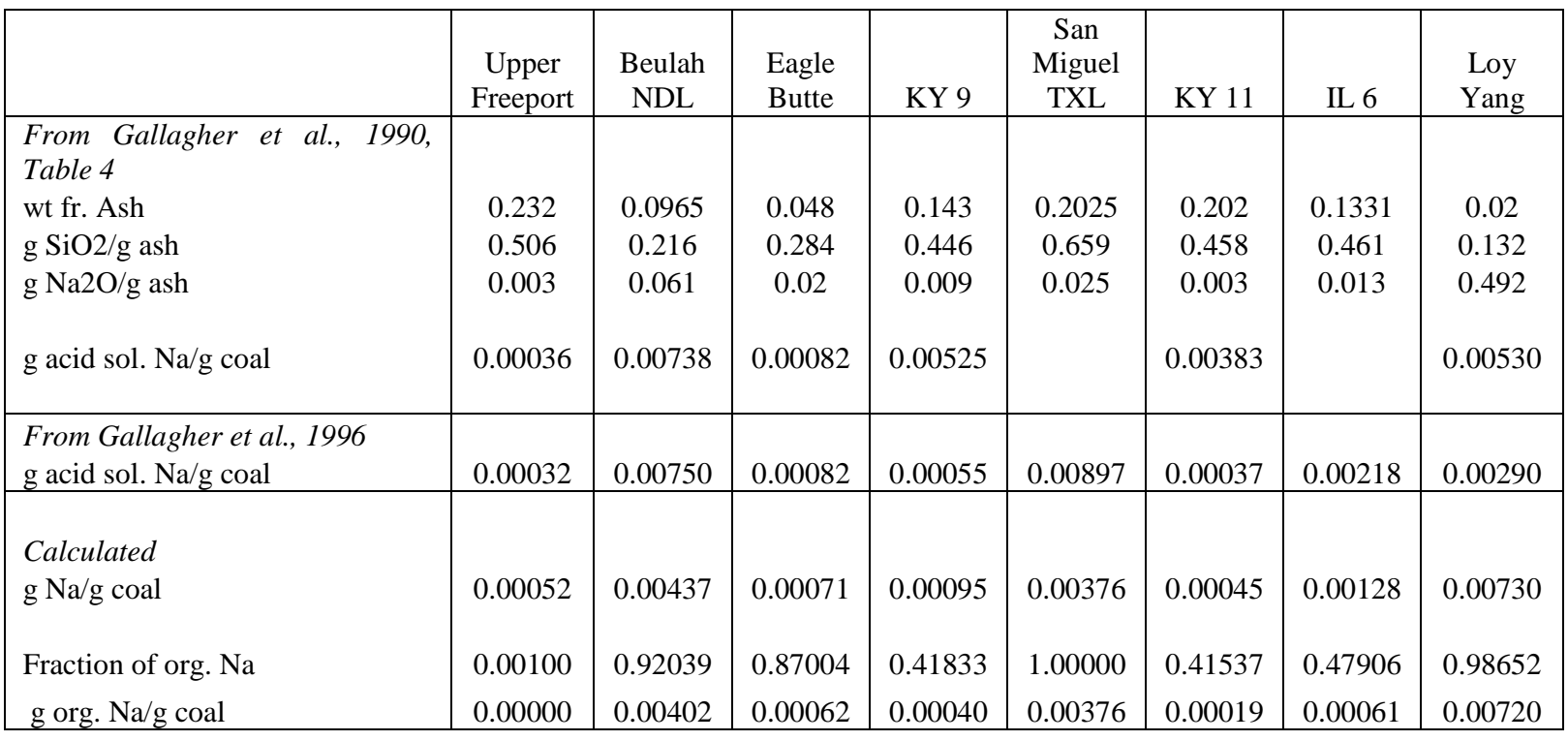

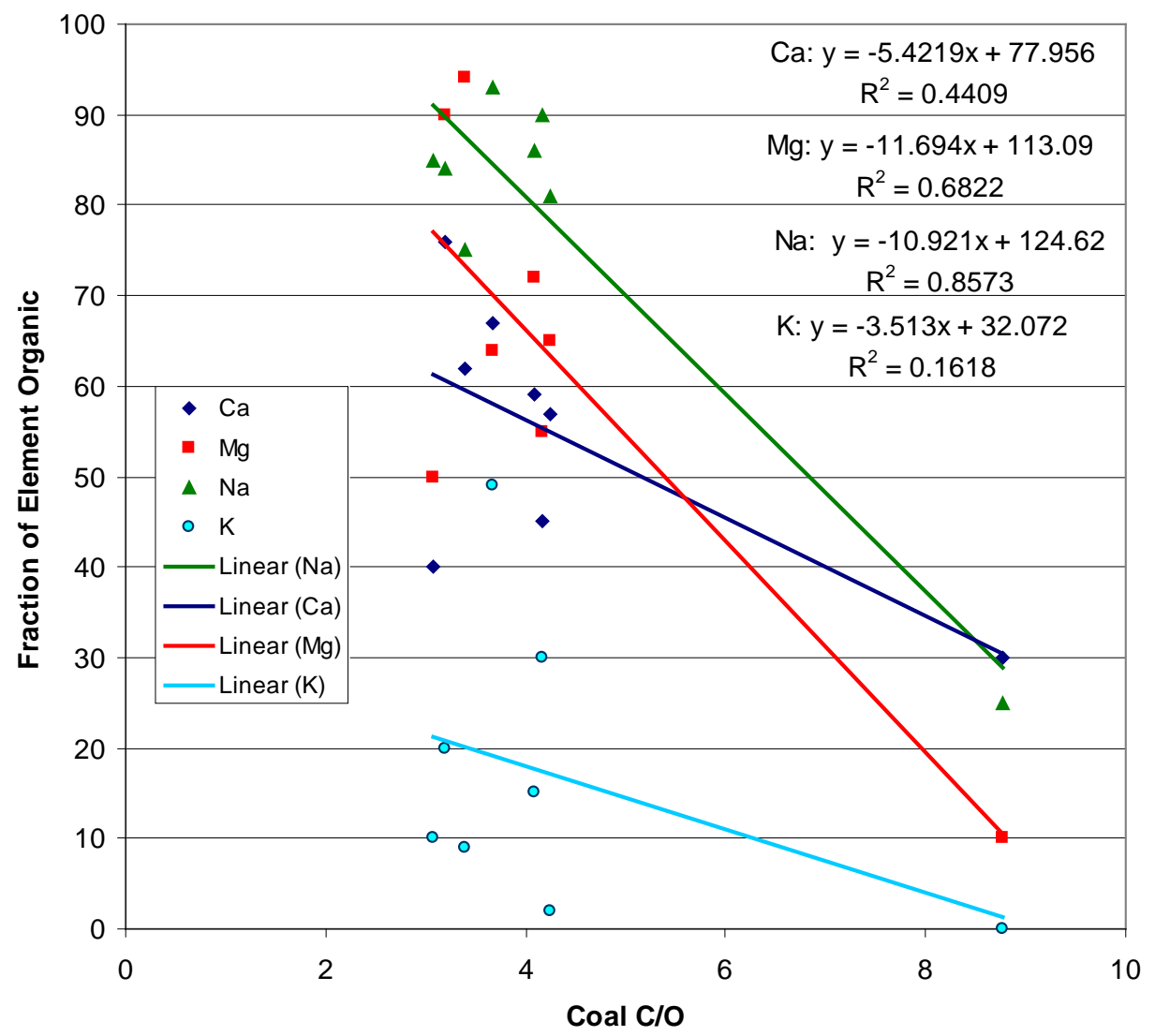

Figure 4.8-34: Fraction of elements that are ion-exchangeable (organically bound) as a function of $\mathrm{C} / \mathrm{O}$ ratio. 
The result is a plot of $\mathrm{g}$ acid-soluble $\mathrm{Na} / \mathrm{g} \mathrm{SiO}_{2}$ versus fraction of $\mathrm{Na}$ vaporized in Figure 4.8-35. The scatter in the data is probably because of different peak temperatures in the experiments. In oxycombustion, there may be a different relationship to express sodium vaporization as a function of $\mathrm{Na} / \mathrm{Si}$ ratio.

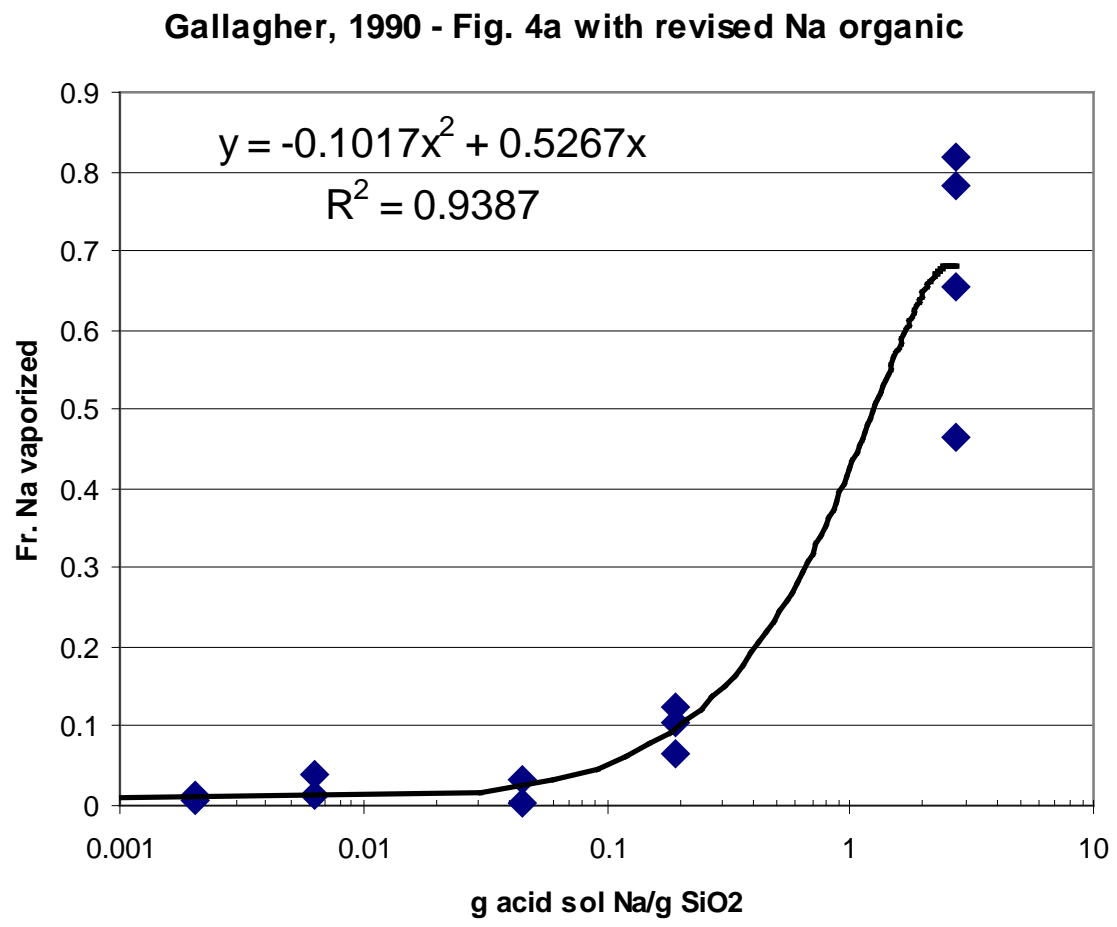

Figure 4.8-35: Na vaporization as a function of acid-soluble (organic) $\mathrm{Na} / \mathrm{SiO}_{2}$, re-interpretation of data of (Gallagher, Bool, et al. 1990) with estimated organic Na fraction.

Gallagher observed a good correlation between the fraction of $\mathrm{Na}$ vaporized and the fraction of $\mathrm{K}$ vaporized, as shown in Figure 4.8-36. This can be used to calculate the fraction of $\mathrm{K}$ vaporized.

The correlations described in Figure 4.8-34, Figure 4.8-35, and Figure 4.8-36 allow prediction of the fractional vaporization of $\mathrm{Na}$ and $\mathrm{K}$ for any coal, given an ultimate analysis and an ash composition. Examples of these calculations are shown in Figure 4.8-37 for many different U.S. coals. 


\section{Data from Gallagher et al., 1996 - Figure 5}

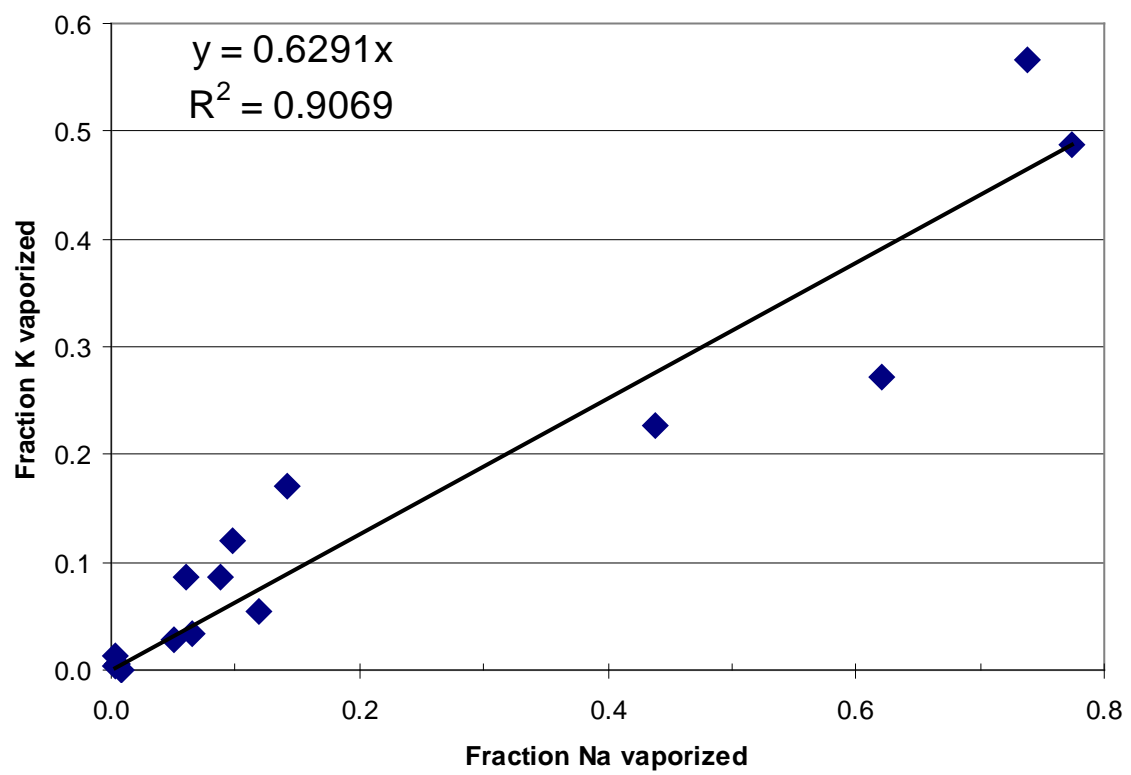

Figure 4.8-36: Fraction of $\mathrm{K}$ vaporized during combustion as a function of fraction of Na vaporized from data of (Gallagher, Peterson and Wendt 1996).

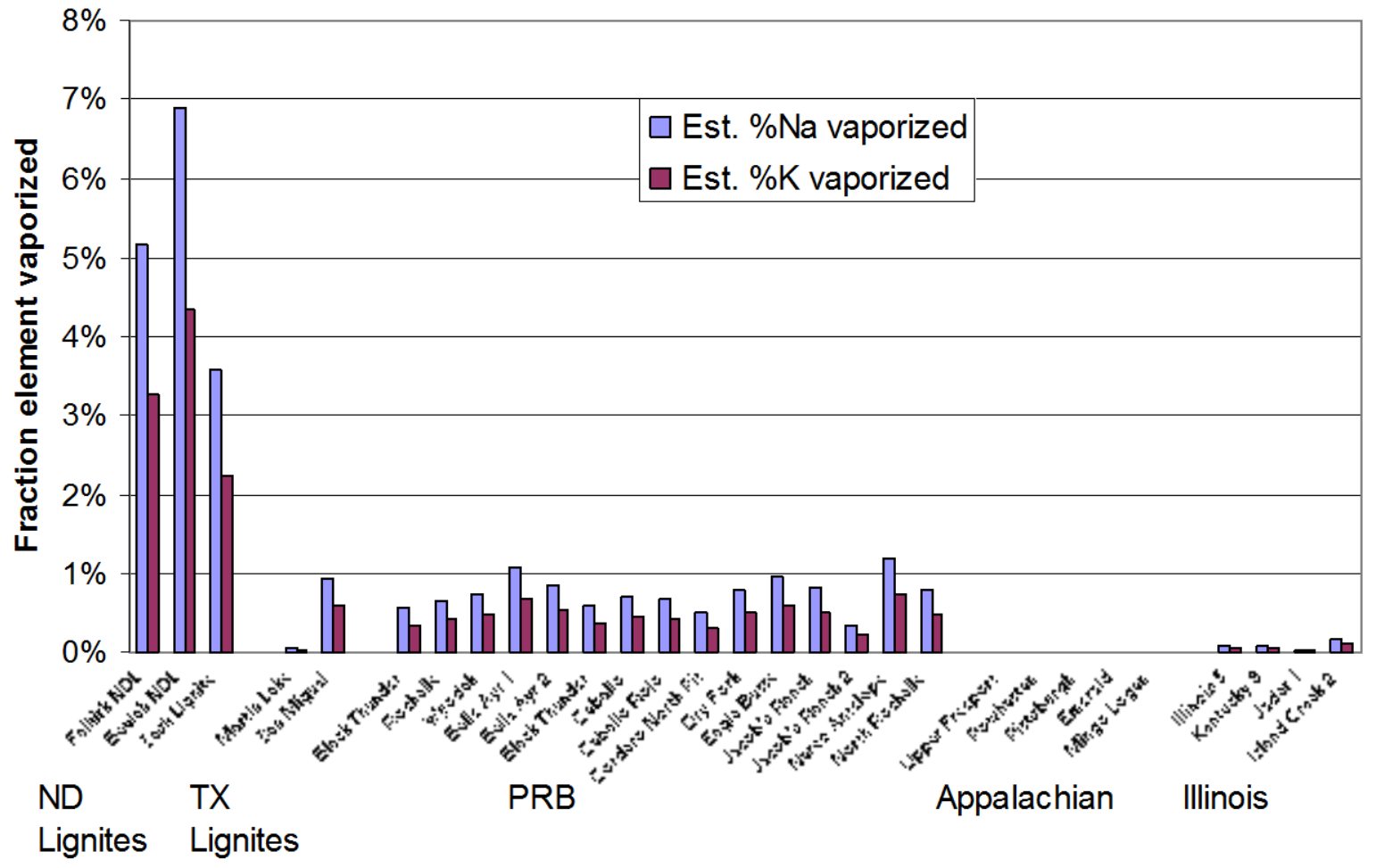

Figure 4.8-37: Calculated vaporization of $\mathrm{Na}$ and $\mathrm{K}$ for different U.S. coals. 
The amount of Na vaporization predicted is $4-7 \%$ for North Dakota lignites and $0.5-1 \%$ for PRB coals. This is much lower than what was observed by (R. J. Quann 1992) in single-particle combustion experiments in a drop tube furnace. Figure 4.8-38 and Figure 4.8-39 show results from Quann's combustion experiments on an Illinois bituminous coal and a Montana lignite, respectively. The fractional vaporization was calculated from the measured amount of the element in a final filter (after an impactor) and the coal composition.

Figure 4.8-38 (Illinois bituminous) suggests that $15 \%$ to $20 \%$ of the Na will vaporize, but the calculations and Gallagher's experiments on bituminous coals (Kentucky and Upper Freeport) suggest less than $1 \%$. Figure 4.8-39 (Montana lignite) shows about 20\% Na vaporization, Gallagher's data shows 5\% to 12\% Na vaporization.

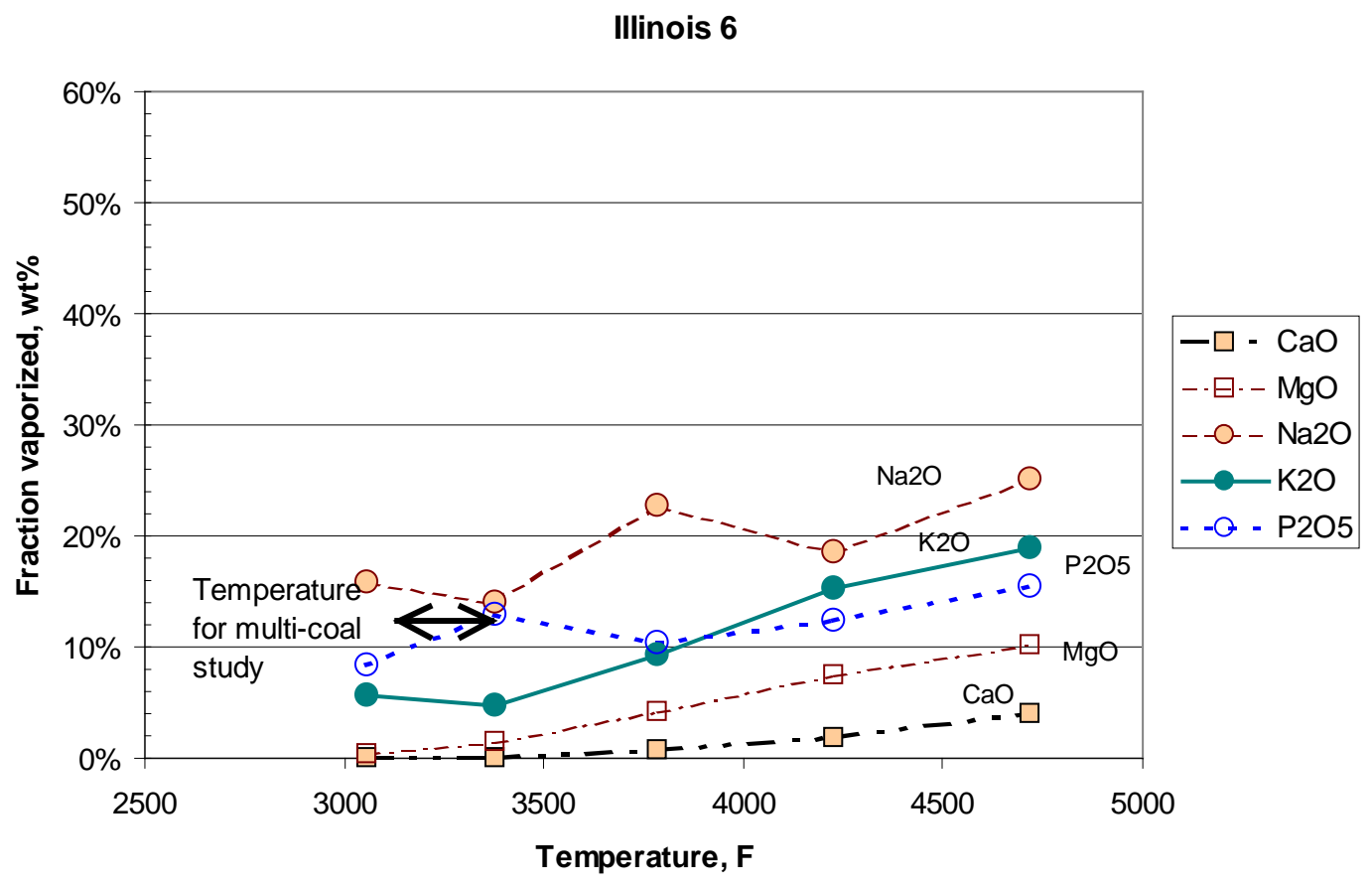

Figure 4.8-38: Fraction of element vaporized as a function of particle temperature for Illinois 6 bituminous coal calculated from data of (R. J. Quann 1992). 


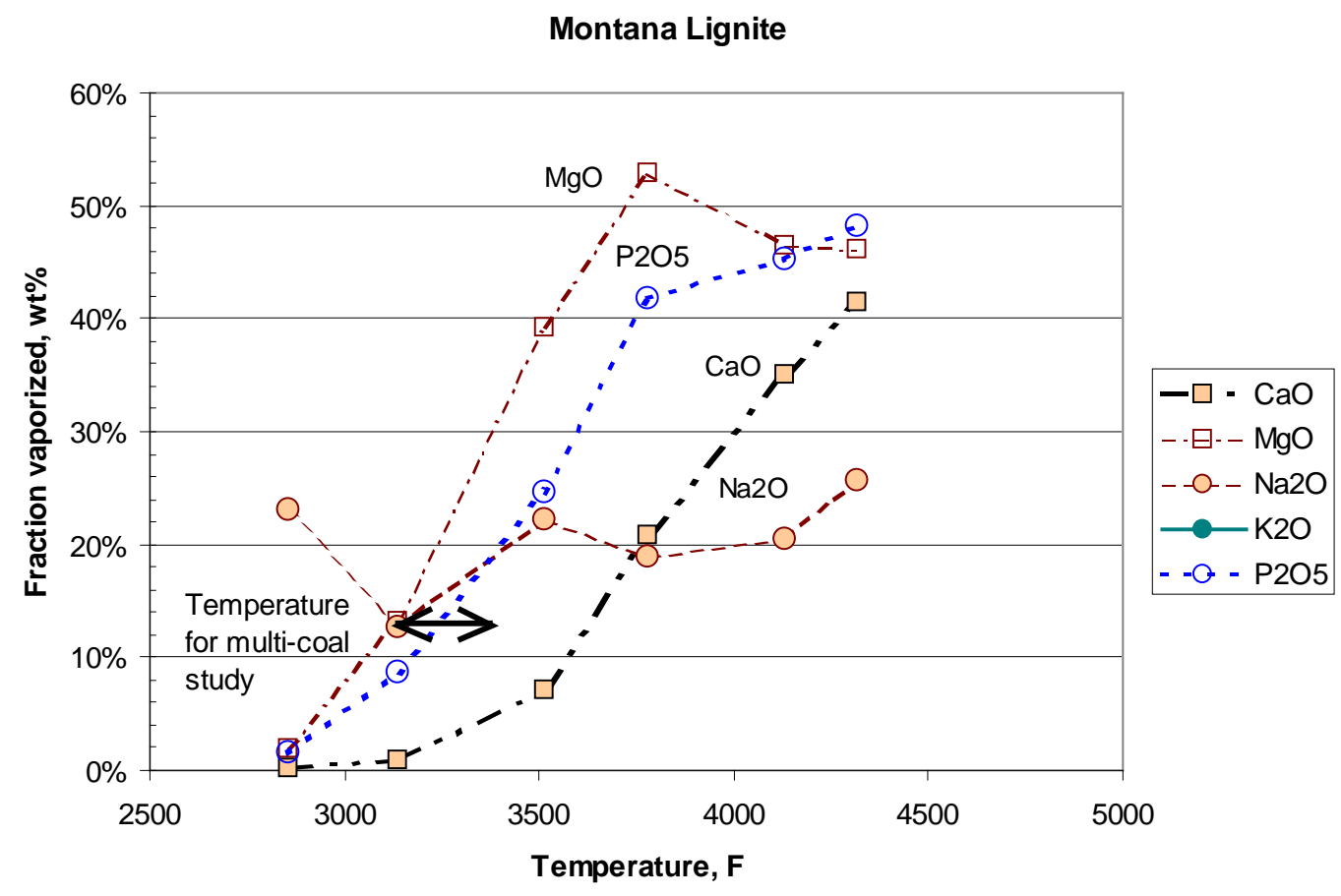

Figure 4.8-39: Fraction of element vaporized as a function of particle temperature for Montana lignite coal calculated from data of (R. J. Quann 1992).

Quann's experiments were very different from Gallagher's. One important difference is that Quann's experiments were dilute in nature, while Gallagher's experiments had a self-sustained flame. In the former experiments, vaporized $\mathrm{Na}$ that escaped the burning char particle would be less likely to interact with ash particles at high temperatures than in the latter experiments. In Gallagher's experiments, Na vapors could be adsorbed on ash particles once the vapors diffused out of the burning char particle.

(Gallagher, Bool, et al. 1990) mixed kaolinite with coal in some of his experiments and he observed a decrease in apparent Na vaporization when he did so. The kaolinite particles are obviously external to the burning char particles. This provides some support for this hypothesis.

The dew point of alkali species in the flue gas can be calculated from equilibrium calculations based on the amount of vaporized alkali. As an example, this calculation was carried out for the Rochelle coal, a subbituminous Powder River Basin coal. Table 4.8-4 summarizes the composition of this coal. 
Table 4.8-4: Coal information for Rochelle-North Antelope coal.

\begin{tabular}{lr}
\hline Composition & Rochelle-North Antelope \\
\hline Ultimate (as-fired) & \\
$\mathrm{C}$ & 51.47 \\
$\mathrm{~S}$ & 0.21 \\
$\mathrm{H}$ & 3.49 \\
Moisture & 27.30 \\
$\mathrm{~N}$ & 0.65 \\
$\mathrm{O}$ & 12.51 \\
Ash & 4.36 \\
Total & 99.99 \\
Proximate & \\
$\mathrm{Moisture}$ & 27.30 \\
$\mathrm{Ash}$ & 4.36 \\
$\mathrm{VM}$ & 32.10 \\
$\mathrm{FC}$ & 36.20 \\
$\mathrm{HHV}_{\mathrm{H}} \mathrm{Btu} / \mathrm{lb}$ & 8,800 \\
$\mathrm{Ash} \mathrm{composition}$ & \\
$\mathrm{SiO}_{2}$ & 33.80 \\
$\mathrm{Al}_{2} \mathrm{O}_{3}$ & 17.40 \\
$\mathrm{Fe}_{2} \mathrm{O}_{3}$ & 5.60 \\
$\mathrm{TiO}_{2}$ & 1.40 \\
$\mathrm{CaO}_{\mathrm{MgO}}$ & 23.80 \\
$\mathrm{Na}_{2} \mathrm{O}$ & 5.60 \\
$\mathrm{~K}_{2} \mathrm{O}$ & 1.90 \\
$\mathrm{P}_{2} \mathrm{O}_{5}$ & 0.30 \\
$\mathrm{SO}_{3}$ & 1.10 \\
$\mathrm{Total}$ & 8.20 \\
&
\end{tabular}

In Table 4.8-5, the concentrations of $\mathrm{Na}_{2} \mathrm{O}$ and $\mathrm{K}_{2} \mathrm{O}$ in the ash have been estimated based on the coal properties of Table 4.8-4, along with the amount of vaporization of $\mathrm{Na}$ and $\mathrm{K}$. Assuming $3 \%$ (dry) $\mathrm{O}_{2}$ in the flue gas, the coal composition was used to create compositions for equilibrium calculations to approximate the sulfate deposition in the backpass.

The results of the equilibrium calculations (using HSC) are shown in Figure 4.8-40. For the RochelleNorth Antelope coal the dew point of sodium sulfate is $990^{\circ} \mathrm{C}\left(1814^{\circ} \mathrm{F}\right)$. This temperature is below the melting point of sodium sulfate of $884^{\circ} \mathrm{C}\left(1623^{\circ} \mathrm{F}\right)$. Thus for this coal, sodium sulfate deposits are expected to be sticky in the convective pass at temperatures between $884^{\circ} \mathrm{C}$ and $990^{\circ} \mathrm{C}$.

The equilibrium calculation for potassium sulfate (not shown) gives a dew point of $850^{\circ} \mathrm{C}\left(1562^{\circ} \mathrm{F}\right)$. The melting point $\mathrm{K}_{2} \mathrm{SO}_{4}$ is $1069^{\circ} \mathrm{C}\left(1955^{\circ} \mathrm{F}\right)$. Potassium sulfate is predicted to deposit at temperatures below the melting point, and therefore would not be expected to be sticky. 
Table 4.8-5: Calculated compositions for equilibrium composition calculation.

\begin{tabular}{|c|c|}
\hline & Rochelle-North Antelope \\
\hline $\mathrm{HHV}$, wet, mineral-matter free & 9,201 \\
\hline C/O Ratio & 4.114 \\
\hline Estimated $\mathrm{Na} / \mathrm{K}$ ratio & 2.745 \\
\hline Fraction of org. $\mathrm{Na}$ & 0.797 \\
\hline Fraction of org. $\mathrm{K}$ & 0.176 \\
\hline $\mathrm{Na}, \mathrm{g} / \mathrm{g}$ coal & 0.000614557 \\
\hline K, g/g coal & 0.000108584 \\
\hline $\mathrm{SiO}_{2}, \mathrm{~g} / \mathrm{gcoal}$ & 0.0147368 \\
\hline Organic $\mathrm{Na} / \mathrm{g} \mathrm{SiO}{ }_{2}$ coal & 0.033231513 \\
\hline Fraction Na vaporized & 0.017390727 \\
\hline Fraction $\mathrm{K}$ vaporized & 0.010940507 \\
\hline g Na vap/g S & 0.005089332 \\
\hline g K vap/g S & 0.000565699 \\
\hline Molar Na/S & 0.007083582 \\
\hline Molar K/S & 0.000462953 \\
\hline \multicolumn{2}{|c|}{ Composition for Equilibrium calculation } \\
\hline $\mathrm{CO}_{2}$ & 0.142346 \\
\hline $\mathrm{SO}_{2}$ & 0.000218 \\
\hline $\mathrm{O}_{2}$ & 0.025911 \\
\hline $\mathrm{N}_{2}$ & 0.695379 \\
\hline $\mathrm{H}_{2} \mathrm{O}$ & 0.136146 \\
\hline $\mathrm{Na}$ & 1.54E-06 \\
\hline $\mathrm{K}$ & 1.01E-07 \\
\hline
\end{tabular}

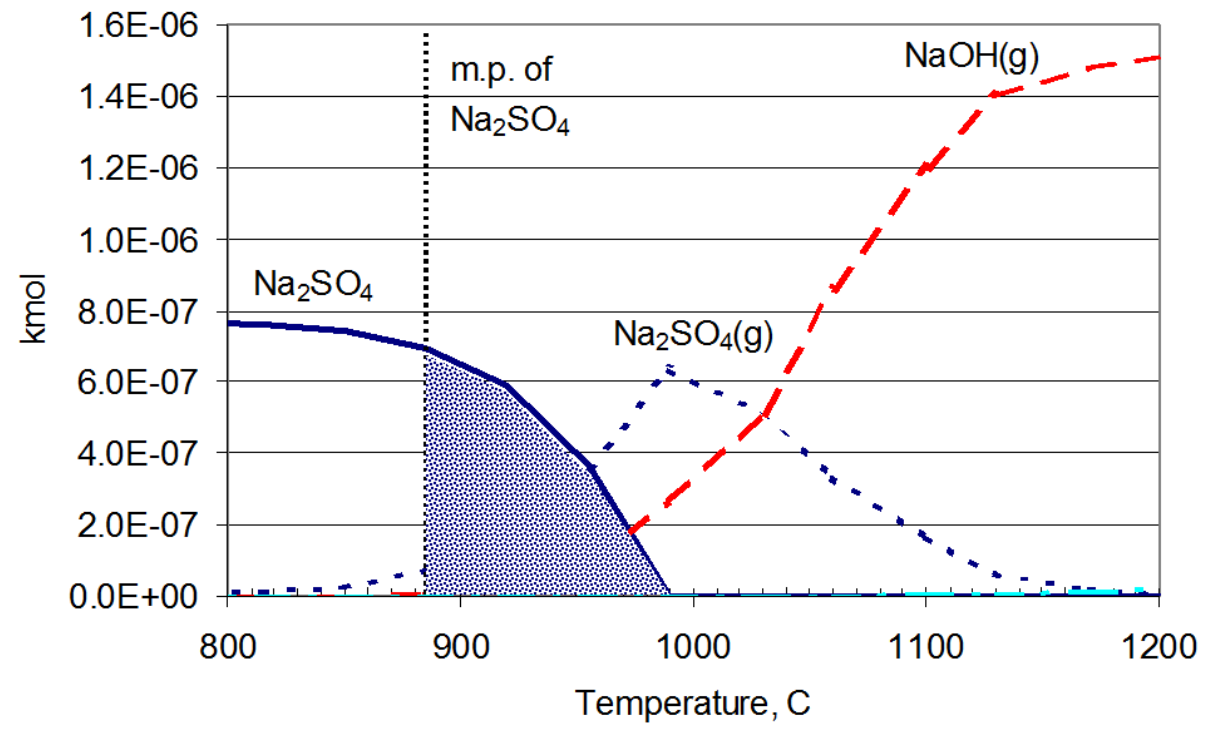

Figure 4.8-40: Sodium equilibrium calculation for Rochelle-North Antelope coal. 


\subsubsection{Ash Particle Size Distribution and Impaction}

The convective pass can be thought of as a series of tubes in cross flow. Much work has been done concerning heat and mass transfer in banks of tubes, which should be investigated at some point in the future. For now, the analysis will be limited to a single tube.

As the flue gas flows across the tube, larger ash particles will impact the tube, while smaller ash particles will flow around the tube. From the mineral matter transformation model, the ash size distribution can be calculated.

When this is implemented in the CFD code, the ash size distribution will be calculated from the mineral matter transformation code. As an example in this section, a simpler (and less accurate estimate) is to use the coal particle size distribution and the coal ash content to calculate the size distribution, assuming one ash particle per coal particle. Given the ash contents of the coals, an ash particle size distribution can be calculated, as follows. First, the volume fraction of fly ash in the coal is calculated from the mass fraction of ash:

$$
f_{\text {vol }}=\frac{1 / \rho_{\text {ash }}}{1 / \rho_{\text {ash }}+\left(1-f_{\text {mass }}\right) / \rho_{\text {carbon }} f_{\text {mass }}}
$$

The ash density was assumed to be $2500 \mathrm{~kg} / \mathrm{m}^{3}$ and the carbon density, $1050 \mathrm{~kg} / \mathrm{m}^{3}$. Assuming one ash particle per coal particle, the ash size distribution can be calculated from the coal particle size distribution and the ash content. For each coal particle diameter, $D_{c i}$, the ash particle diameter, $D_{a i}$, is computed:

$$
D_{a i}=D_{C i}\left(f_{v o l}\right)^{1 / 3}
$$

The results of these calculations are plotted in Figure 4.8-41.

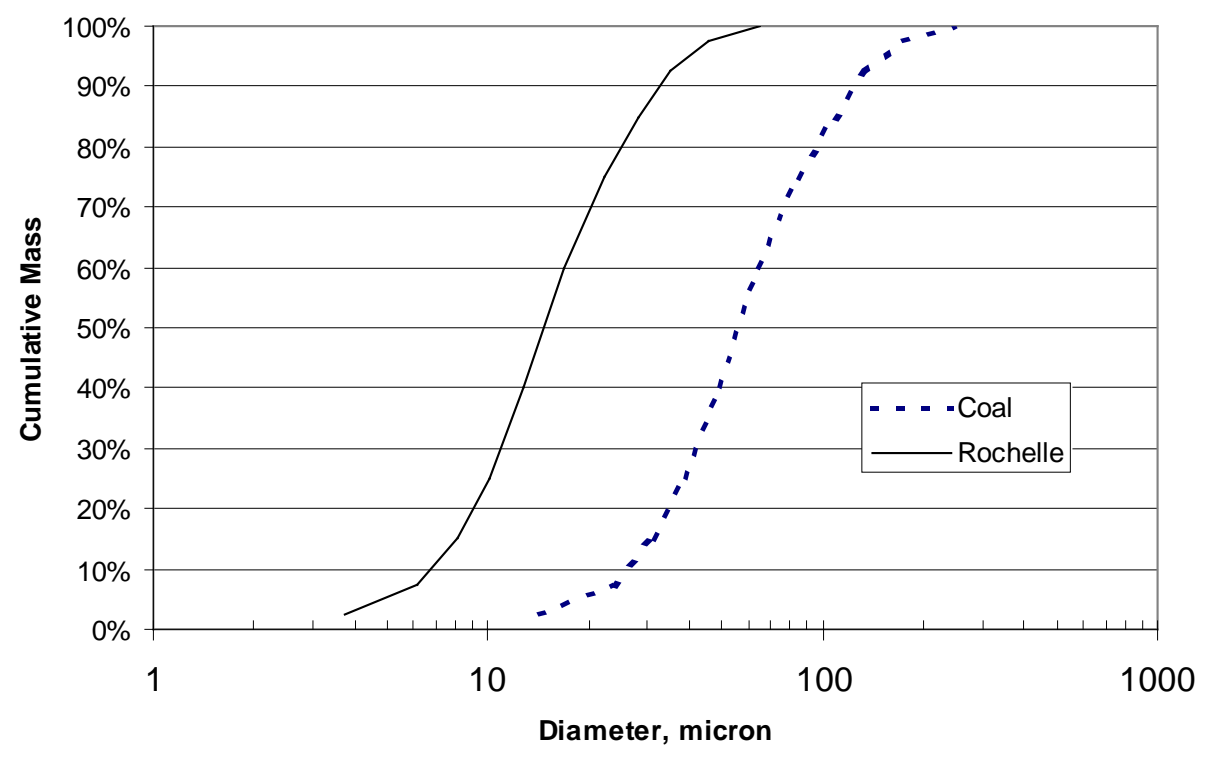

Figure 4.8-41: Predicted ash particle size distributions. 
The impaction efficiency of ash particles on a tube (at $884^{\circ} \mathrm{C}$, the sodium sulfate dew point) is then calculated. The impaction efficiency for a given particle size $i$ can be calculated from the Stokes number $(S t)$ and particle Reynolds number for impaction on tubes in cross flow:

$$
\begin{gathered}
S t_{i}=\frac{\rho_{a s h} V D_{a i}^{2}}{9 \mu D_{\text {tube }}} \\
\operatorname{Re}_{p}=\frac{D_{a i} V \rho}{\mu}
\end{gathered}
$$

The Reynolds number is used to calculate the Stokes correction factor:

$$
\begin{gathered}
\Psi=\frac{18}{\operatorname{Re}_{p}}\left[\operatorname{Re}_{p}^{1 / 3}-\sqrt{6} \tan ^{-1}\left(\frac{\operatorname{Re}_{p}^{1 / 3}}{\sqrt{6}}\right)\right] \\
S t_{\text {eff }}=\Psi S t
\end{gathered}
$$

Using the correlation of Israel and Rosner (1983), the impaction efficiency can be calculated as:

$$
\eta_{i m p}=\left[1+\frac{1.25}{S t_{\text {eff }}-0.125}-\frac{0.014}{\left(S t_{\text {eff }}-0.125\right)^{2}}+\frac{0.000508}{\left(S t_{\text {eff }}-0.125\right)^{3}}\right]^{-1}
$$

This is calculated from a correlation from (Israel and Rosner 1983) and shown in Figure 4.8-42 below.

As Figure 4.8-42 shows, the impaction efficiency depends on the diameter of the tube as well as on the particle size. Figure 4.8-42 also contains the estimated particle size distribution for the Rochelle coal. In general, particles less than 10 microns will not impact on the leading edge of the tubes. Note that this analysis does not take into account thermophoresis or deposition from the turbulent wake behind the tube.

The impaction efficiency is somewhat dependent on temperature, but in most of the convective pass, the impaction efficiency varies little with temperature, except at the lowest temperatures. The dependences on velocity and particle diameter are more pronounced.

The impaction rate $R_{l}\left(\mathrm{~kg} / \mathrm{m}^{2}-\mathrm{s}\right)$ can be calculated from

$$
R_{I}=V M_{a s h}\left(\sum_{i} f_{i} \eta_{i}\right)
$$

where $f_{i}$ is the mass fraction of ash in the ith diameter, $\eta_{i}$ is the impaction efficiency for that diameter, $V$ is the gas velocity, and $M_{\text {ash }}$ is the total ash loading in $\mathrm{kg} / \mathrm{m}^{3}$. 


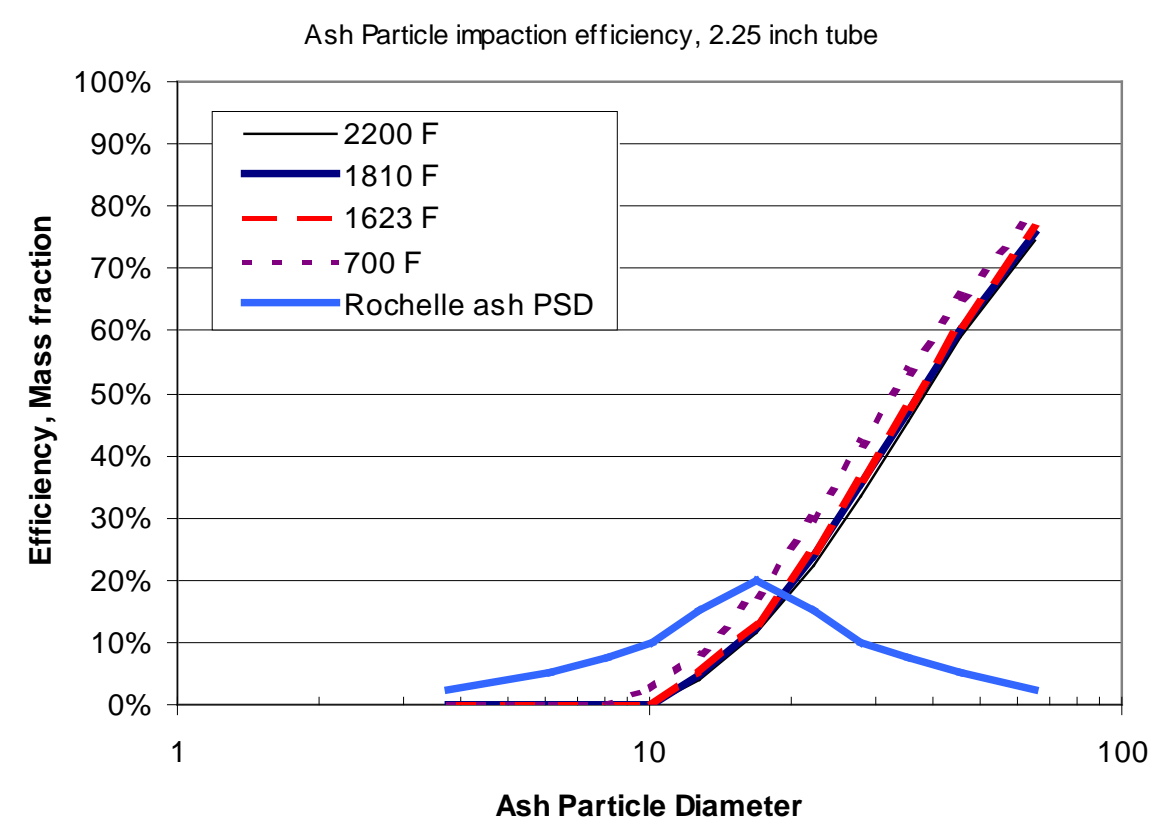

Figure 4.8-42: Impaction efficiency on 2.25 inch tube.

In the CFD simulations conducted with the Glacier code for this project, each "panel" (row of tubes) is modeled as a plate, so that a tube bank is modeled as a series of plates parallel to the flow direction (see Figure 4.8-43). At the leading edge of a tube bank, the velocity and ash loading in the computational cell just before the "plate" or row of tubes can be used to calculate the impaction rate at the leading edge of the "plate." There will be impaction on the tubes within each panel or "plate." Assuming that there is minimal interference with the flow field by upstream tubes, the impaction efficiency for the second, third, etc. tubes can be computed by using the local velocity and ash loading from the leading edge values and the local temperature.

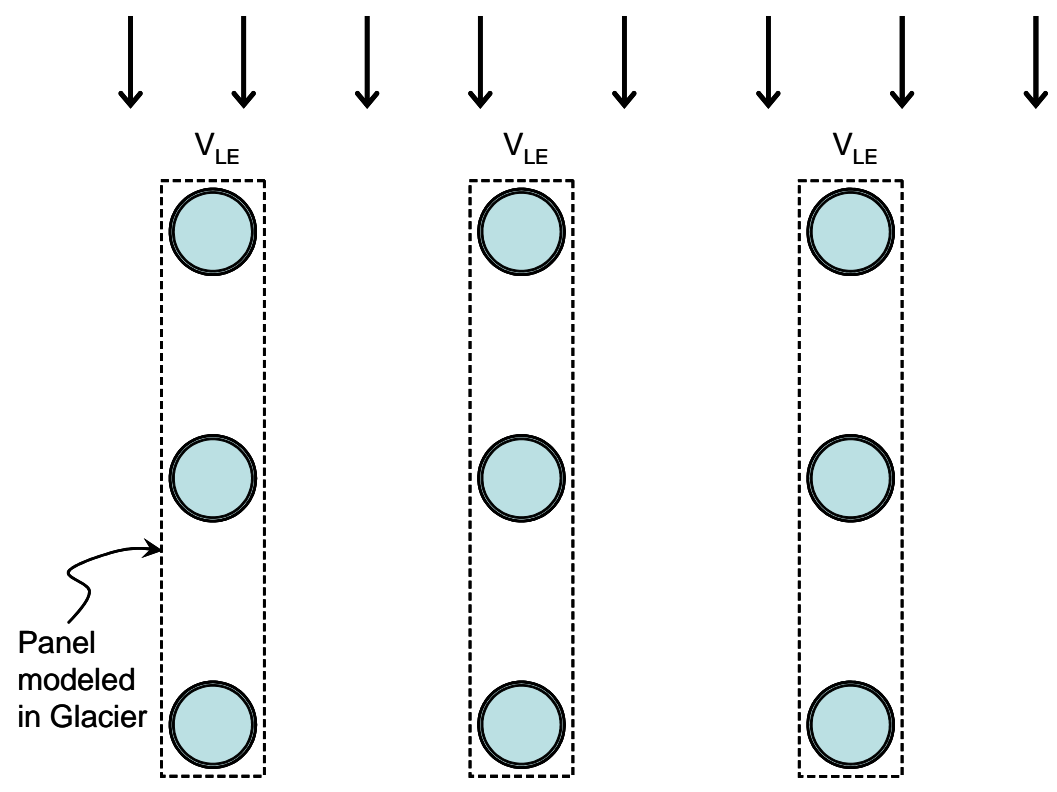

Figure 4.8-43: Representation of tube banks in CFD model. 


\subsubsection{Regions of Deposition}

The deposit surface temperature is related to the thickness of the deposit and the deposit heat transfer coefficient. (Walsh, Sarofim and Beer 1992) assume a Nusselt number of 40 for the tube. Given that and assuming a uniform thickness of ash layer (which is probably not the case), the tube surface temperature can be estimated from

$$
T_{s}=T_{g}-\frac{\left(T_{g}-T_{t}\right)}{0.5 N u \ln \left(r_{2} / r_{1}\right)+1}
$$

where $\mathrm{Nu}$ is the Nusselt number , $r_{2}$ is the radius of the tube plus deposit and $r_{1}$ is the radius of the clean tube. The local gas temperature is calculated assuming a fixed rate of temperature decrease in the convective pass.

Figure 4.8-44 plots results from an example calculation, assuming a dew point temperature of about $990^{\circ} \mathrm{C}$ and a tube metal temperature of $627^{\circ} \mathrm{C}$. The figure shows that the thicker the ash deposit on the tube, the higher the surface temperature. The figure also indicates the region where the gas temperature lies between the dew point and the melting temperature. Sodium sulfate will condense on the ash particles, and therefore the ash particles that impact the deposit in this region will be sticky and thus more likely to stick. Furthermore, as the deposit thickens and accumulates sodium sulfate, the surface temperature will exceed the melting point of sodium sulfate and the surface will become sticky.

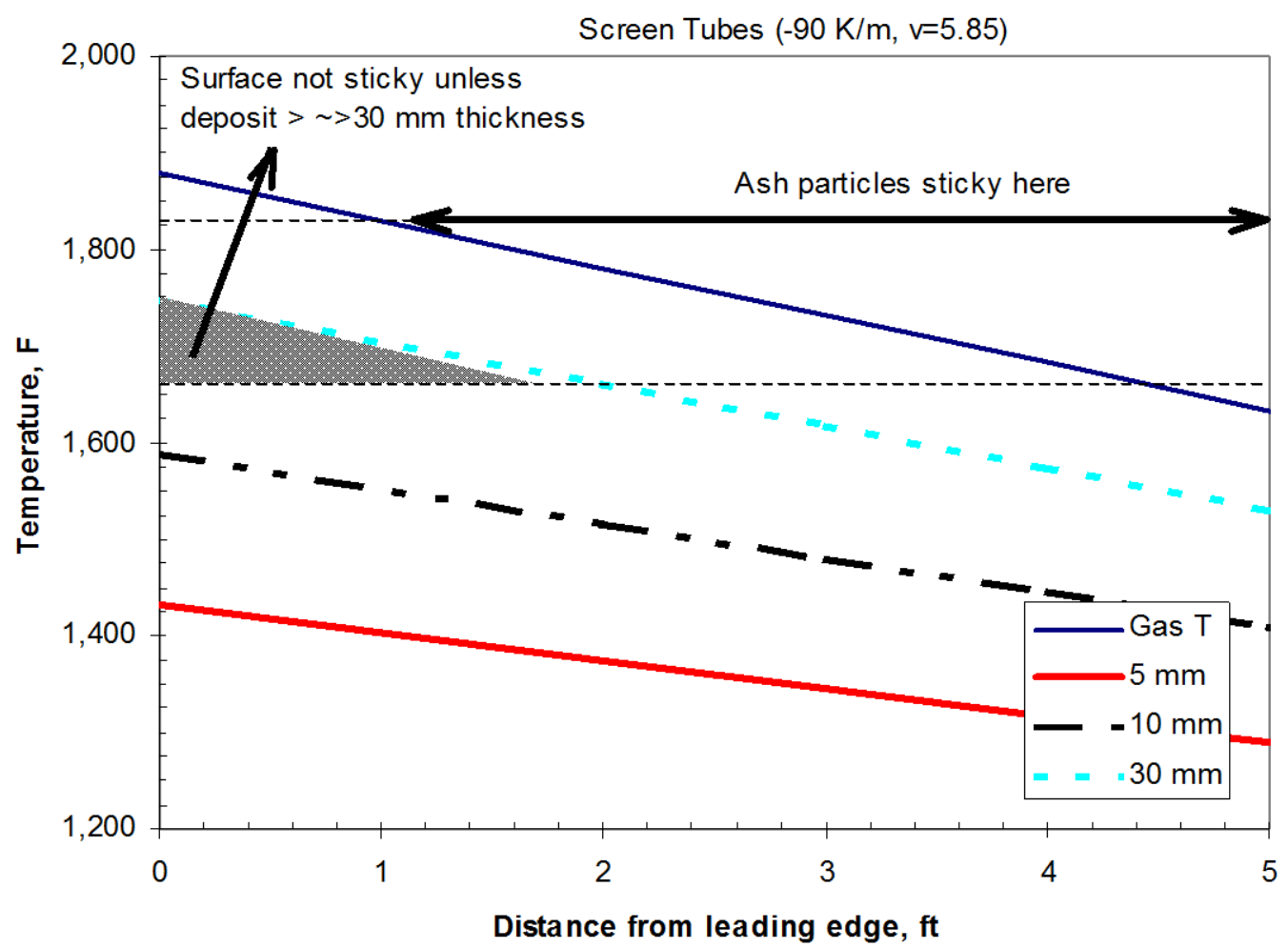

Figure 4.8-44: Gas and surface temperatures as a function of length in convective pass. 
Thus, the fraction of the ash particles likely to impact the surface and the regions in which these particles are more likely to stick can be estimated. More quantitative estimates can be made using the formulae given by (Walsh, Sarofim and Beer 1992).

Walsh assumes that erosion is caused by large quartz particles. Assuming the distribution of both quartz and silicates in the deposit are known, the fraction of particles (of a given size) impacting the surface that will be incorporated into the deposit can be calculated. This is given by the difference between sticking and erosion, and is intended to be for dry deposition (when the surface is not sticky):

$$
f_{\text {deposit }}=\left(1+R_{\mathrm{Na}_{2} \mathrm{SO}_{4}}\right)\left(f_{\text {Silc }}\left(d_{p}\right) P_{\text {Stick }}-f_{Q}\left(d_{p}\right) k_{\text {erosion }}\right)
$$

where $R_{\mathrm{Na2SO} 4}$ is the fraction of $\mathrm{Na}_{2} \mathrm{SO}_{4}$ on the particle, $f_{\text {Silc }}\left(d_{p}\right)$ and $f_{\mathrm{Q}}\left(d_{p}\right)$ are the fractions of the ash size distribution of a given diameter of silicates and quartz, respectively, and $P_{\text {stick }}$ is calculated from Eq. 4 in (Walsh, Sarofim and Beer 1992). $k_{\text {erosion }}$ is an erosion coefficient, i.e., the mass of deposit removed by erosion per unit mass of quartz particles impacting.

The rate of wet deposition (that is, when the surface is above the melting point of sodium sulfate) will be higher, since the probability of sticking is higher on a wet surface. The rate of impaction (in $\mathrm{kg} / \mathrm{m}^{2}-\mathrm{s}$ ) in a given size range can be estimated as

$$
F_{\text {imp }}=U f_{\text {imp }} f_{\text {ash }} C_{\text {ash }}
$$

where $U$ is the gas velocity in $\mathrm{m} / \mathrm{s}, f_{\text {imp }}$ is the impaction efficiency (see Figure 4.8-42), $f_{\text {ash }}$ is the fraction of mass of diameter $d_{p}$, and $C_{a s h}$ is the concentration of ash in the flue gas in $\mathrm{kg} / \mathrm{m}^{3}$. The fraction of mass depositing in a given size range can be calculated from Eq. 4.8-27 and 4.8-28.

The wet deposition rate can be used to calculate the thickness of a triangular deposit on the leading edge of a tube, as shown in Figure 4.8-45. In this calculation, about 5 days are required to produce a deposit thickness of $5 \mathrm{~mm}$.

It is then possible to estimate the fraction of particles that are likely to stick because of sodium sulfate and, thus, the fraction of the ash particles likely to impact the surface and the regions in which these particles are more likely to stick. More quantitative estimates can be made using the formulas given by (Walsh, Sarofim and Beer 1992). 


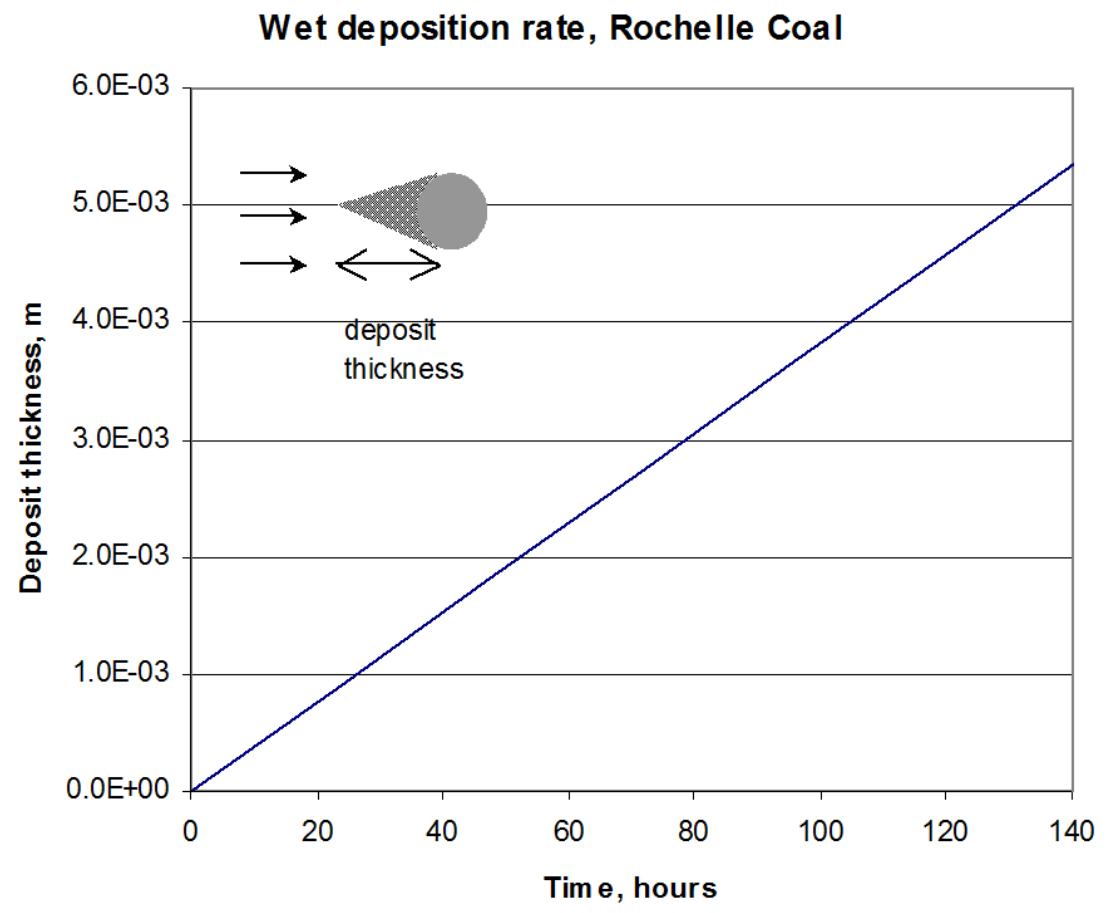

Figure 4.8-45: Estimated thickness of deposit on leading edge of tube as a function of time, Rochelle coal at $988^{\circ} \mathrm{C}$ (after Walsh et al., 1992).

Condensation of sodium sulfate on suspended particles is assumed to begin when the gas has cooled to below the sodium sulfate dew point, which is assumed to be $990^{\circ} \mathrm{C}\left(1814^{\circ} \mathrm{F}\right)$ for the Rochelle coal. Sodium sulfate also deposits on the tubes, but the mass-transfer coefficient for transport to suspended particles is greater than that for transport to the tubes. The partial pressure of sodium sulfate in the gas is assumed to decay exponentially with time following the onset of condensation. The time-constant for condensation of sodium sulfate on particles depends on the specific surface area weighted mean particle size $\left(<d_{s}>\right)$ and the concentration of particles, Mash:

$$
\tau=\frac{\rho_{\mathrm{Na}_{2} \mathrm{SO}_{4}}\left\langle d_{s}\right\rangle^{2}}{6 \mathrm{Sh}_{p} D_{\mathrm{Na}_{2} \mathrm{SO}_{4}} M_{a s h}}
$$

where the Sherwood number $S h_{p}$ of the particles is assumed to be 2, $\rho_{\mathrm{Na}_{2} \mathrm{SO}_{4}}$ is the density of condensed sodium sulfate, and $D_{\mathrm{Na}_{2} \mathrm{SO}_{4}}$ is the diffusivity of sodium sulfate in the gas. For the Rochelle coal the areamean diameter is about 10 microns if just calculated from the one-ash-per-coal particle assumption (Figure 4.8-41); in reality, however, there will be some smaller particles that will shift the area-mean diameter to a smaller size. The area-mean diameter will be assumed to be 5 microns. Using this diameter, the characteristic time is estimated to be $\sim 0.1$ seconds. This suggests that ash particles might not acquire a sticky, sodium sulfate layer immediately after the flue gas temperature drops below the dew point of sodium sulfate, but there might be an induction period of a hundred milliseconds. 
The thickness of the sulfate layer on a particle of diameter $d_{p}$ is calculated as

$$
\delta=Y_{\mathrm{Na}_{2} \mathrm{O}} \frac{M W_{\mathrm{Na}_{2} \mathrm{SO}_{4}} \rho_{a s h}\left\langle d_{s}\right\rangle^{2}}{M W_{\mathrm{Na}_{2} \mathrm{O}} \rho_{\mathrm{Na}_{2} \mathrm{SO}_{4}} 6 d_{p}}\left[1-e^{-t / \tau}\right]
$$

where $Y_{\mathrm{Na}_{2} \mathrm{SO}_{4}}$ is the mass fraction of sodium oxide in the ash and $M W_{i}$ are the molecular weights. For example, the surface layer on a 10 micron particle would be about 0.01 microns.

Walsh, et al. (Walsh, Sayre, et al. 1990) incorporated the analysis of (Wall, Lowe, et al. 1979) to calculate the probability that an ash particle with a condensed sodium sulfate layer (of diameter $d_{p}$ ) would stick (the dry sticking probability) as

$$
\eta_{d r y}=4 \gamma \frac{Y_{\mathrm{Na}_{2} \mathrm{O}} M W_{\mathrm{Na}_{2} \mathrm{SO}_{4}}\left\langle d_{2}\right\rangle^{2}}{\rho_{\mathrm{Na}_{2} \mathrm{SO}_{4}} M W_{\mathrm{Na}_{2} \mathrm{O}} d_{p}^{3} v^{2}}\left[1-e^{-t / \tau}\right]
$$

where $\gamma$ is the surface tension and $v$ is the particle velocity. For the Rochelle coal, the dry sticking probability was estimated at $\mathrm{t}=150$ milliseconds as shown in Figure 4.8-46.

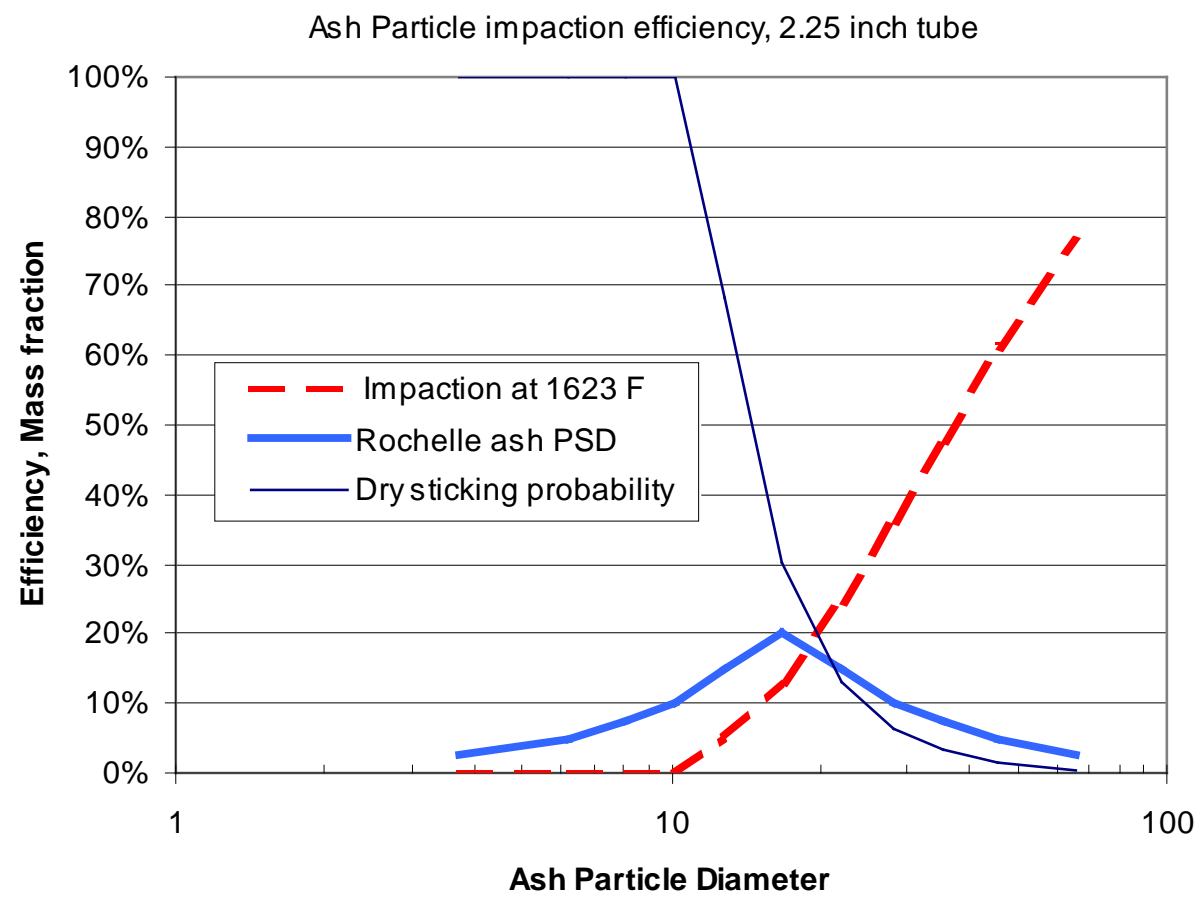

Figure 4.8-46: Impaction efficiency, dry sticking probability, and ash size distribution for Rochelle coal at 150 milliseconds after dew point, $5.85 \mathrm{~m} / \mathrm{s}$ velocity. 
The ratio of the mass of condensed sulfate to the particle mass, for a given particle diameter is

$$
R_{\mathrm{Na}_{2} \mathrm{SO}_{4}}=Y_{\mathrm{Na}_{2} \mathrm{SO}_{4}} \frac{M W_{\mathrm{Na}_{2} \mathrm{SO}_{4}}\left\langle d_{s}\right\rangle^{2}}{M W_{\mathrm{Na}_{2} \mathrm{O}} d_{p}^{2}}\left[1-e^{-t / \tau}\right]
$$

(Walsh, Sarofim and Beer 1992) assume that erosion is caused by large quartz particles. Assuming one knows the distribution of both quartz and silicates in the ash, one can calculate the fraction of particles (of a given size) impacting the surface that will be incorporated into the deposit. This information can be obtained when the mineral matter transformation model is used to calculate the fly ash particle size distribution and composition. This is given by the difference between sticking and erosion, and is intended to be for dry deposition (when the surface is not sticky):

$$
f_{\text {deposit }}=\left(1+R_{\mathrm{Na}_{2} \mathrm{SO}_{4}}\right)\left\lfloor f\left(d_{p} \eta_{d r y}-f_{Q}\left(d_{p}\right) k_{\text {erosion }}\right)\right\rfloor
$$

where $R_{\mathrm{Na}_{2} \mathrm{SO}_{4}}$ is calculated from Eq. 4.8-32, $f\left(d_{p}\right)$ and $f_{\mathrm{Q}}\left(d_{p}\right)$ are the fractions of the ash size distribution of a given diameter of the total ash and quartz, respectively, and $\eta_{\text {dry }}$ is calculated from Eq. 4.8-31. $k_{\text {erosion }}$ is an erosion coefficient, i.e., the mass of deposit removed by erosion per unit mass of quartz particles impacting.

The fraction of the ash particles incorporated into the deposit by dry deposition of sticky particles is estimated in Figure 4.8-47. The erosion term in Eq. 4.8-33 was not included, since nothing is known about the mineralogy of this coal. Figure 4.8-47 shows that the fraction of particles likely to stick because of dry deposition is small and centered around 20-30 microns.

Fraction of particles incorporated into deposit, 2.25 inch tube

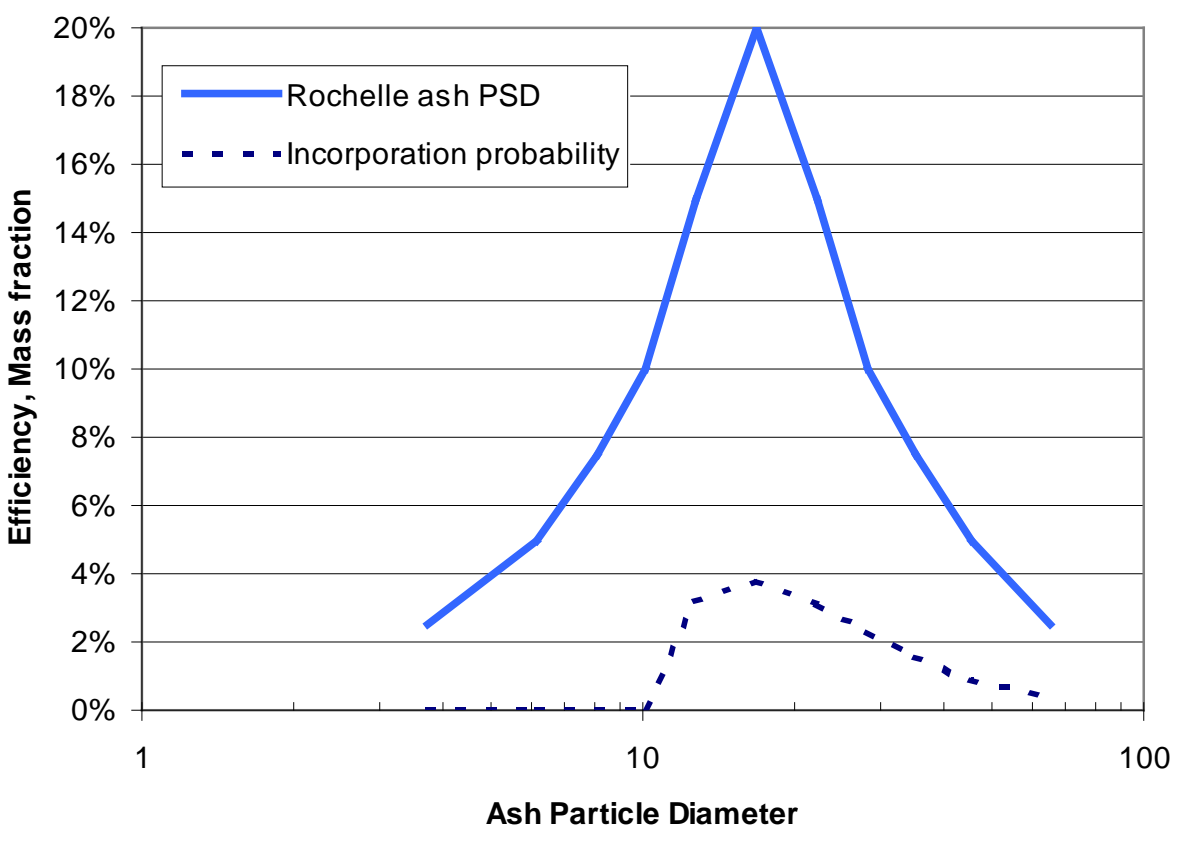

Figure 4.8-47: Fraction of particles sticking by dry deposition (at 150 milliseconds from dew point). 
Sodium sulfate can also deposit directly on the tube, when the gas temperature is below the dew point. This deposition rate (in $\mathrm{kg} / \mathrm{m}^{2}$-s) is given by

$$
F_{\mathrm{Na}_{2} \mathrm{SO}_{4}}=\frac{\mathrm{Sh}_{t} \mathrm{D}_{\mathrm{Na}_{2} \mathrm{SO}_{4}}}{d_{t}} \frac{\pi}{2} M_{a s h} Y_{\mathrm{Na}_{2} \mathrm{O}} \frac{M W_{\mathrm{Na}_{2} \mathrm{SO}_{4}}}{M W_{\mathrm{Na}_{2} \mathrm{O}}} e^{-t / \tau}
$$

where the subscript $t$ denotes the tube. The Sherwood number of the tube is assumed to be 40 .

The rate of direct sodium sulfate deposition on tubes was estimated to be $3 \times 10^{-7} \mathrm{~kg} / \mathrm{m}^{2}$-s at $900^{\circ} \mathrm{C}$ $\left(1650^{\circ} \mathrm{F}\right)$. The sodium sulfate concentration in the flue gas for the Rochelle coal is estimated to be $2 \times 10^{-7}$ $\mathrm{kg} / \mathrm{m}^{3}$. The sodium sulfate would be expected to preferentially deposit on the fly ash, not on the tubes.

The dry ash deposition flux for the Rochelle coal was estimated to be $2 \times 10^{-5} \mathrm{~kg} / \mathrm{m}^{2}$-sec at $900^{\circ} \mathrm{C}\left(1650^{\circ} \mathrm{F}\right)$, without taking into account any erosion by fly ash. This would remove about $0.4 \%$ of the ash from the flue gas and in an eight-hour period result in a wedge of ash at the leading edge of the tube with a maximum thickness of $0.7 \mathrm{~mm}$. This suggests that deposits in areas of the convective pass that are reached by soot blowers can be controlled effectively, but deposits in areas that are not reached by soot blowers would grow.

The preceding example illustrated how fouling calculations would be carried out. In order to integrate these calculations with the CFD model, assumptions must be included as to how often the tubes in the convective pass are cleaned. This will allow the calculation of the steady-state deposit thickness in the convective pass.

\subsubsection{Low Temperature $\mathrm{Na}_{2} \mathrm{SO}_{4}$-based Fouling Model}

\subsection{Introduction}

A low temperature sodium sulfate $\left(\mathrm{Na}_{2} \mathrm{SO}_{4}\right)$-based fouling model has been developed to address two questions:

1) Whether $\mathrm{Na}_{2} \mathrm{SO}_{4}$-based low temperature fouling will cause a potential problem in the boiler convective tubes, and

2) If a potential problem is identified, how quickly will the low temperature fouling cause a problem for the boiler operation?

For the model to address the first question, coal and ash analysis and general combustion condition (such as overall furnace stoichiometric ratio) are needed. Detailed results from furnace CFD simulation are not necessary. For the model to address the second question, information about a) fly ash, b) convective tube, and c) gas velocity and temperature are needed. This information can be estimated, but is better provided through mineral matter transformation model and an upper furnace CFD simulation.

\subsection{Identifying a Potential Problem}

Alkali species ( $\mathrm{Na}, \mathrm{K}$ ) vaporize during combustion, and some of the vaporized alkali species persist in the gas phase in the convective pass. The empirical correlations in the model to estimate the alkali species in the gas phase in the convective pass have been presented earlier in this section on fouling.

An equilibrium calculation is performed in the model to predict the dew point of alkali species in the flue gas. If the predicted $\mathrm{Na}_{2} \mathrm{SO}_{4}$ dew point is higher than the melting point of $884^{\circ} \mathrm{C}\left(1623^{\circ} \mathrm{F}\right)$, a potential 
low temperature fouling problem is identified. If the predicted $\mathrm{Na}_{2} \mathrm{SO}_{4}$ dew point is lower than the melting point, there should not be a low temperature fouling problem in the boiler.

The dew point of potassium sulfate $\left(\mathrm{K}_{2} \mathrm{SO}_{4}\right)$ is also predicted. Unless burning high potassium biomass in the boiler, due to the relatively high melting temperature of $\mathrm{K}_{2} \mathrm{SO}_{4}\left(1069^{\circ} \mathrm{C}, 1955^{\circ} \mathrm{F}\right)$, the predicted dew point of $\mathrm{K}_{2} \mathrm{SO}_{4}$ is usually much lower than the melting temperature. Thus, $\mathrm{K}_{2} \mathrm{SO}_{4}$ is usually not causing the potential low temperature fouling problem in the boiler.

A sample data input file for the model to predict whether or not a potential low temperature fouling problem exists is shown in Figure 4.8-48. The model output is plotted as Figure 4.8-49 and Figure 4.8-50. In summary, the model predicts a $\mathrm{Na}_{2} \mathrm{SO}_{4}$ dew point of $981^{\circ} \mathrm{C}$ (higher than the melting point of $884^{\circ} \mathrm{C}$ ) and a $\mathrm{K}_{2} \mathrm{SO}_{4}$ dew point of $834^{\circ} \mathrm{C}$ (much lower the melting temperature of $1069^{\circ} \mathrm{C}$ ). Thus, with this sample data input, a potential low temperature fouling problem is identified.

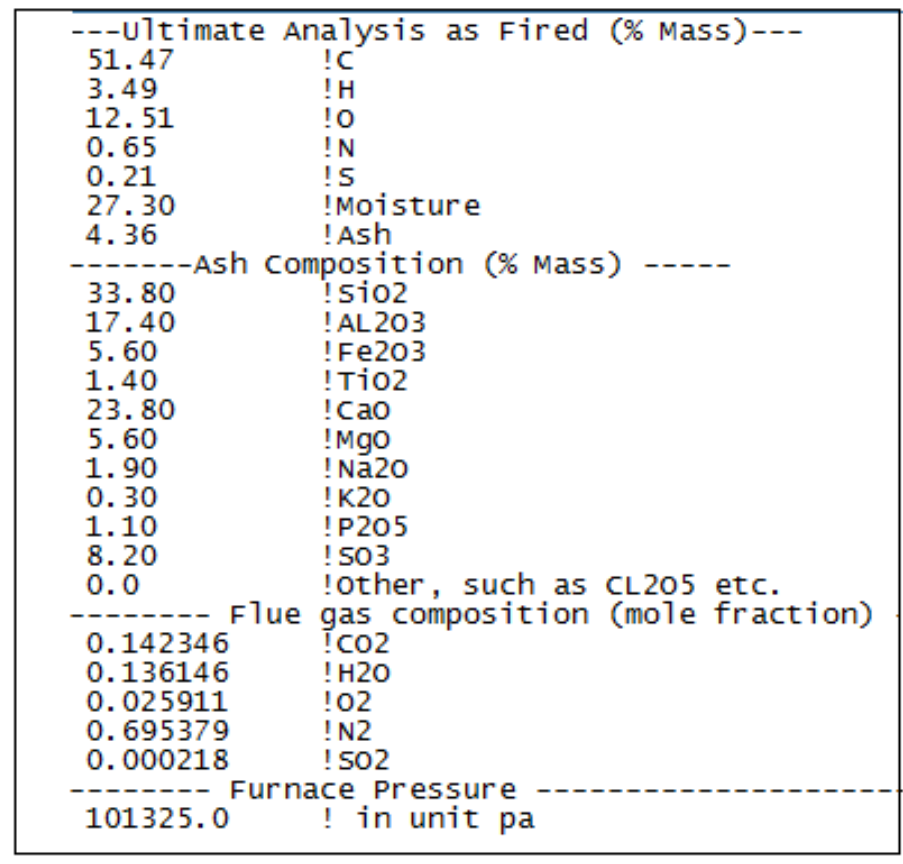

Figure 4.8-48: Sample model data input file for identifying the potential fouling problem. 


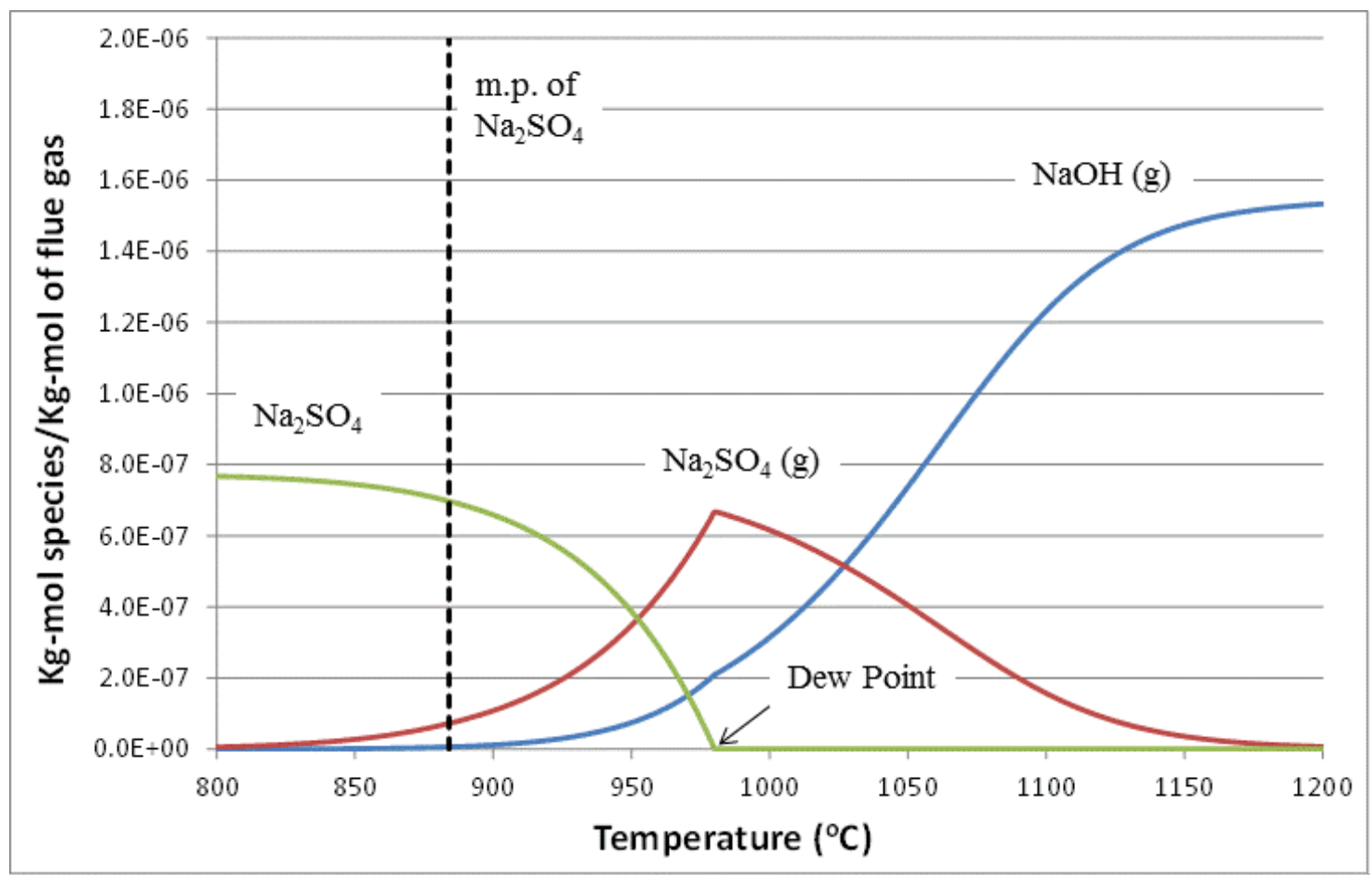

Figure 4.8-49: Sodium equilibrium calculation.

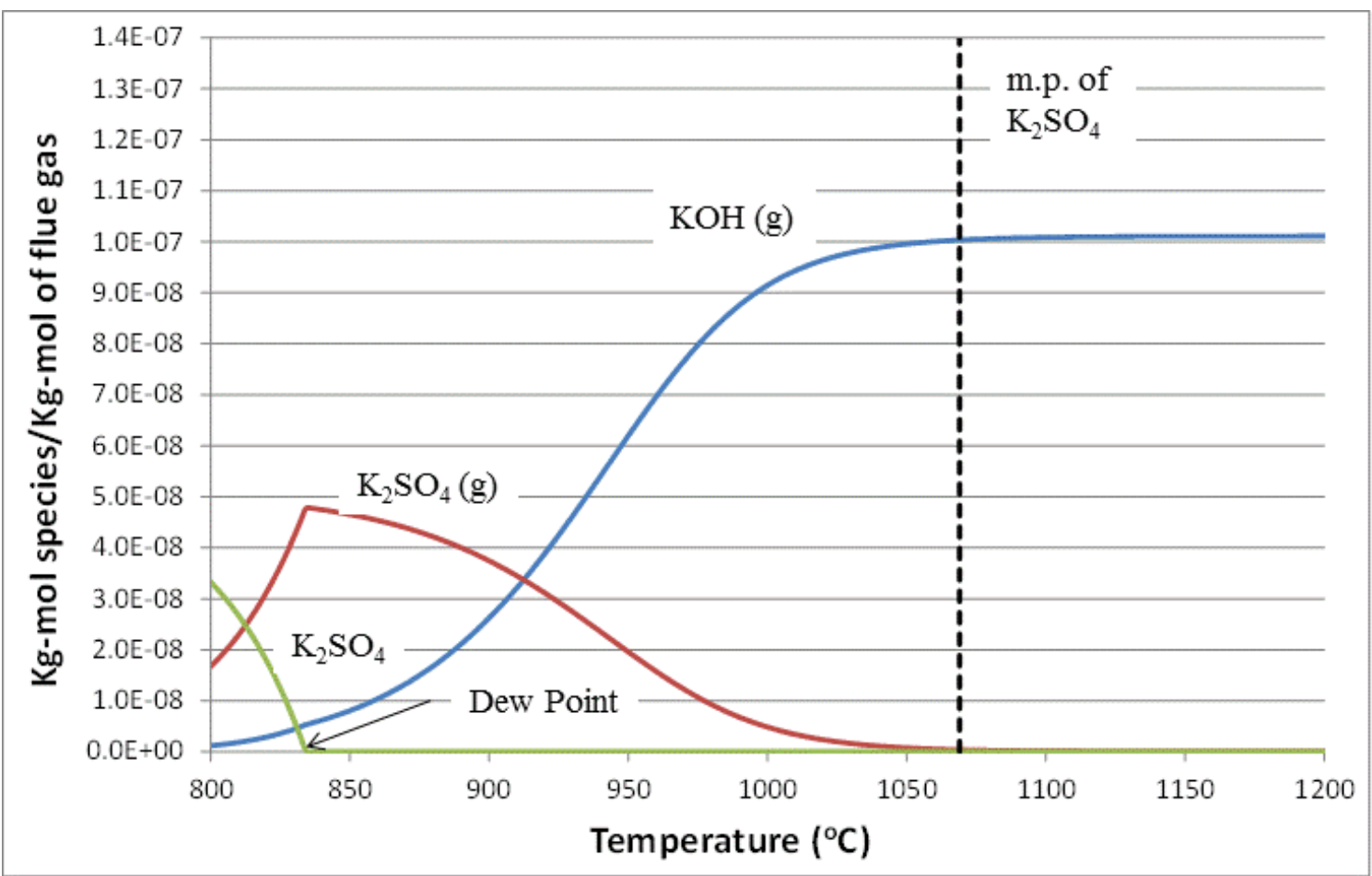

Figure 4.8-50: Potassium equilibrium calculation. 


\subsection{Rate of Fouling Build-up}

Once a potential low temperature fouling problem is identified, the next question will be how fast this fouling problem will show up. In order for the model to address this problem, information about a) fly ash, b) convective tube, and c) gas velocity and temperature, etc. is needed. This information can be estimated, but is better provided through mineral matter transformation model and an upper furnace CFD simulation.

A sample data input file for the model to predict how fast the fouling problem will show up is presented as Figure 4.8-51. The tubes in the gas temperature range $\left(884^{\circ} \mathrm{C} \sim 981^{\circ} \mathrm{C}\right)$ are first identified (in this sample, tubes 4, 5, 6, 7, and 8). Assuming that there is minimal interference with the flow field by upstream tubes, the impaction efficiency and deposit build up etc. of all tubes can be computed by using local gas velocity, ash loading, and condensed amount of $\mathrm{Na}_{2} \mathrm{SO}_{4}$. When the tube deposit surface temperature reaches the $\mathrm{Na}_{2} \mathrm{SO}_{4}$ melting temperature $\left(884^{\circ} \mathrm{C}\right)$, the fouling problem is assumed to be showing up.

The accumulated amount of $\mathrm{Na}_{2} \mathrm{SO}_{4}$ condensed out at the local gas temperature is calculated based on the equilibrium calculation results as shown in Figure 4.8-49. $\mathrm{Na}_{2} \mathrm{SO}_{4}$ can be condensed on the fly ash particles and directly condensed on the deposit surface on the tubes. Neither homogenous nucleation nor condensation of $\mathrm{Na}_{2} \mathrm{SO}_{4}$ on existing particles in the thermal boundary layer of the deposit is considered.

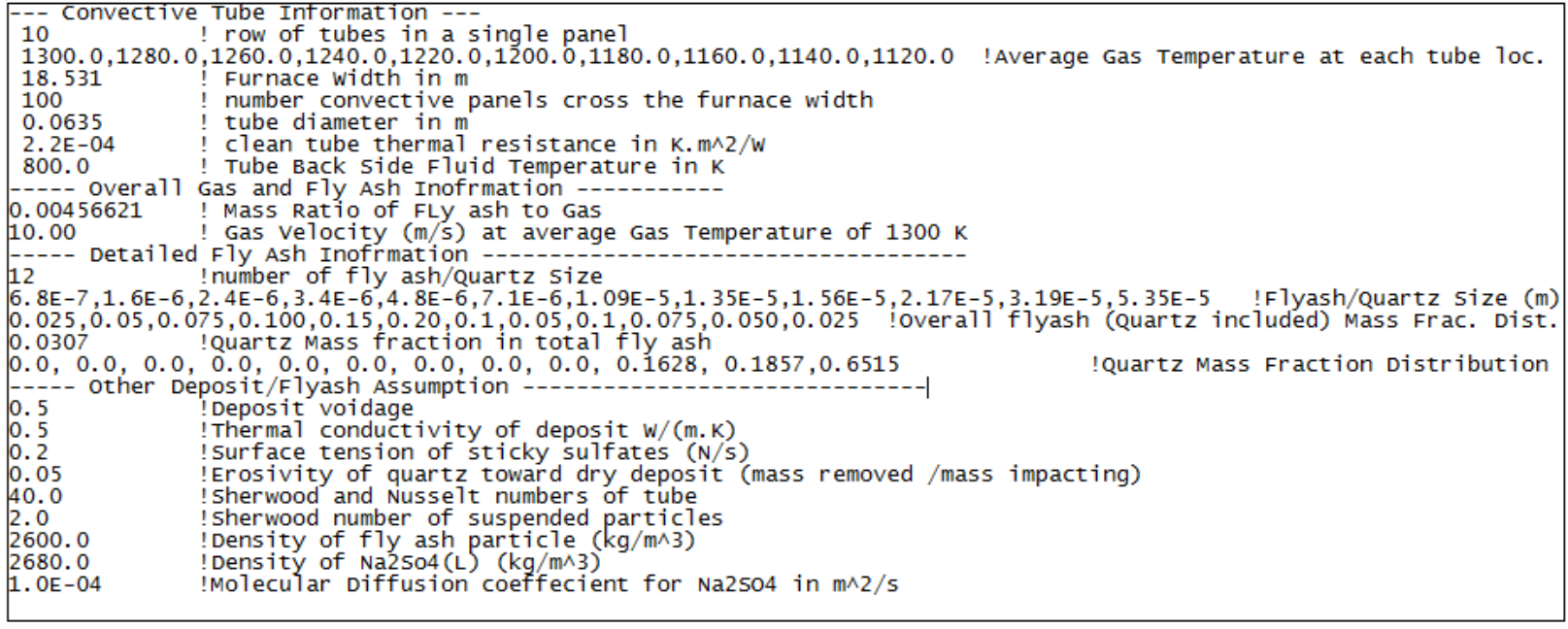

Figure 4.8-51: Sample model input file for predicting how fast a fouling problem grows.

The empirical correlations used in the model to calculate the particle impaction efficiencies, particle velocities approaching tube, mass fractions and thickness of $\mathrm{Na}_{2} \mathrm{SO}_{4}$ layers on the fly ash particles, direct condensation of $\mathrm{Na}_{2} \mathrm{SO}_{4}$ on the deposit surface in the tube, particle sticking probabilities, growth of deposit on dry deposit surface, etc. can be found in previous fouling section. Some model prediction results will be given here using tube 5 as a sample.

Figure 4.8-52 shows the impaction efficiency and sticking probability of sodium sulfate-coated fly ash particle on dry deposit surface on tube 5. The impaction efficiency and sticking probability have a very strong dependence on the particle size, and a weak dependence on gas velocity and gas temperature. The combination effects of sticking probability and impaction efficiency suggest that deposit is formed by particles from a narrow portion of the size distribution. 
Figure 4.8-53 shows the deposit thickness and deposit surface temperature of tube 5 as a function of time. Note that after 9624 hours ( 13 months) of deposit build-up without soot blowing, the deposit surface temperature reaches the melting temperature of $\mathrm{Na}_{2} \mathrm{SO}_{4}\left(884^{\circ} \mathrm{C}\right)$. The deposit surface will start to begin sticky and capture the impacting particle. Then, the deposit will significantly block the gas path and raise the pressure drop in the boiler - fouling problem is assumed to be showing up. For this example, there would not be any concerns about fouling because soot blowing would clean the tubes before the critical deposit build-up is reached.

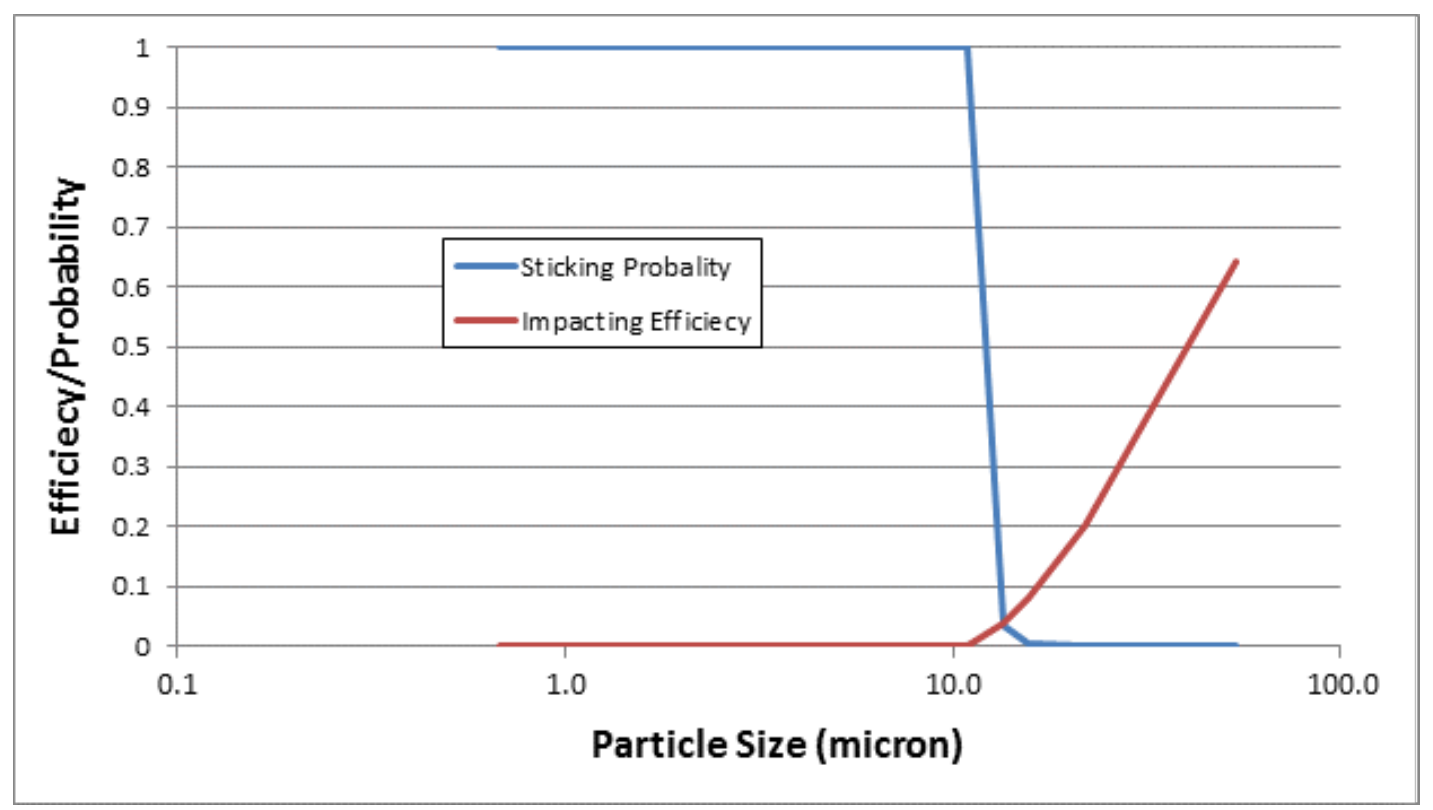

Figure 4.8-52: The impaction efficiency and sticking probability of sodium sulfate-coated fly ash particle on dry deposit surface on tube 7.

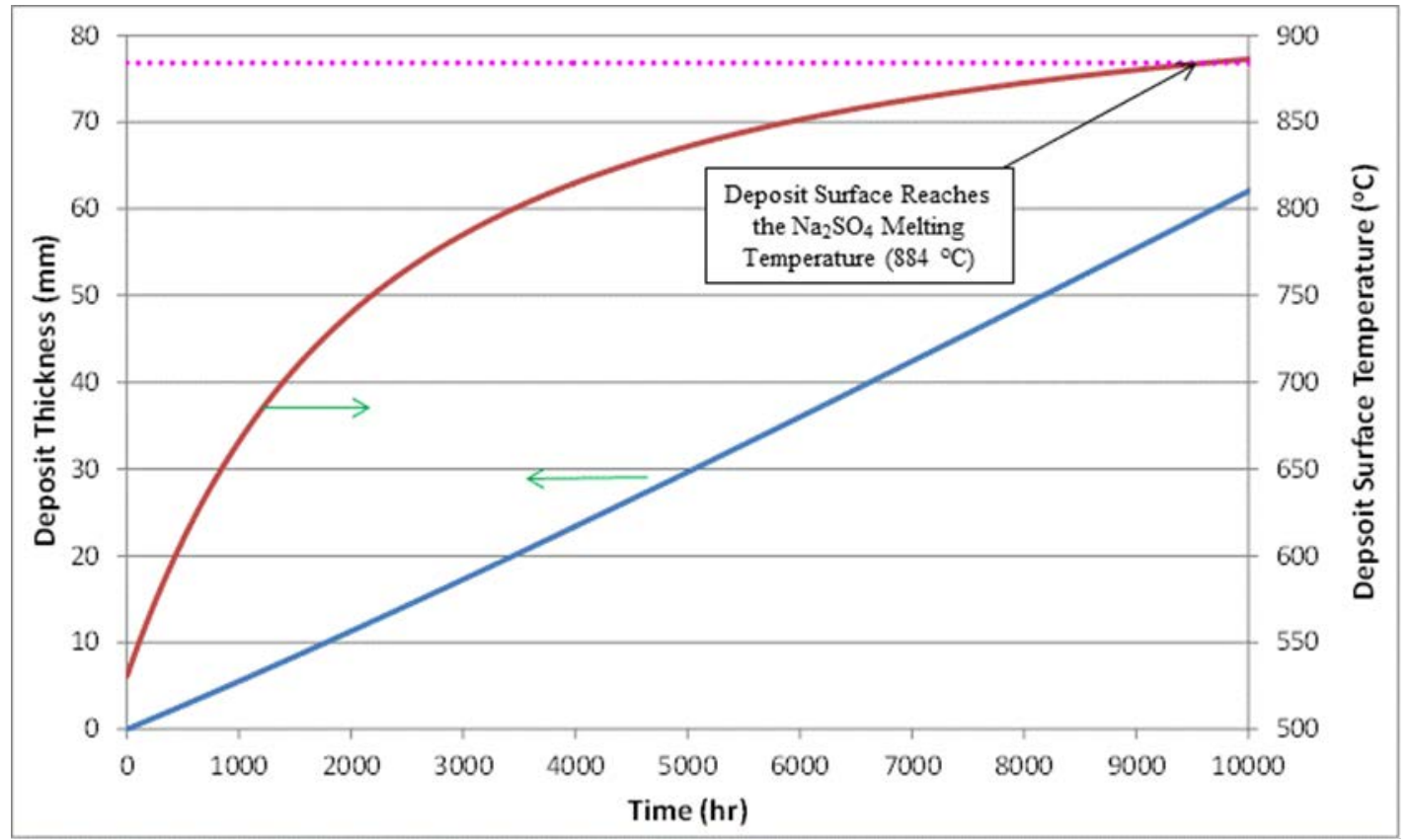

Figure 4.8-53: The deposit thickness and surface temperature in tube 5 as a function of time. 


\subsection{Summary}

A low temperature $\mathrm{Na}_{2} \mathrm{SO}_{4}$-based fouling model has been developed to identify the potential low temperature fouling problem in the boiler and how fast low temperature fouling will cause a problem for the boiler operation.

The empirical correlations, based on the works of Gallager et al. (Gallagher, Bool, et al. 1990), are used to estimate the concentration of alkali species in the gas phase in the convective pass. A thermal equilibrium calculation is performed to calculate the dew point of $\mathrm{Na}_{2} \mathrm{SO}_{4}$. By comparing the melting temperature of $\mathrm{Na}_{2} \mathrm{SO}_{4}$, the potential low temperature fouling problem can be identified. Only coal analysis and general combustion condition are needed for this part of prediction.

Following the analysis of Walsh et al. (Walsh, Sarofim and Beer 1992), the model can predict the time needed to build up the fouling deposit and to raise the deposit surface temperature to the melting temperature of $\mathrm{Na}_{2} \mathrm{SO}_{4}$ - fouling problem shows up. In order to utilize this part of model, information about a) fly ash composition and size, b) convective tube properties, and c) flue gas velocity, temperature, and composition is needed. This information can be estimated, but is better provided through mineral matter transformation model and an upper furnace CFD simulation.

\subsubsection{Slagging and Fouling Conclusions}

\subsubsection{Coal Analyses}

Three coal samples (Utah bituminous, PRB, and Illinois bituminous) and nine ash samples (each coal fired under air and two oxy conditions) were analyzed by CCSEM. The coal mineral composition measured by CCSEM agreed well with the measured ASTM mineral analysis (the PRB CCSEM was modified to include organically bound minerals). The overall elemental composition of the ash measured by CCSEM showed differences from the coal analyses, suggesting there might be biases in the ash samples or the CCSEM analysis. There were minor differences in bulk composition of the ash samples corresponding to difference combustion conditions. Analysis of the ash CCSEM results suggested that oxy-combustion produces slightly finer ash for the Utah bituminous coal and has little effect on the size of the PRB or Illinois bituminous coal. The MMT model was shown to hold a material balance throughout the calculations. The MMT model was run on each coal using standard coalescence options, no coalescence, and full coalescence. The measured ash size distributions for the three firing conditions fall between the full and no coalescence options of the MMT model. This showed the MMT model can be tuned to predict the measured size distributions using coalescence options. Preliminary ash compositions predicted by the MMT model (using standard coalescence options) showed some agreement with the measured CCSEM ash composition. Differences between the coal mineral CCSEM composition (used as MMT input) and measured ash CCSEM composition will be reflected in comparisons between the MMT and ash results.

\subsubsection{Slagging Model}

A slagging modeling approach has been provided here. The approach utilizes both a comprehensive CFD combustion code and a slagging sub-model (which uses MMT model results) to predict the deposit build up and properties in the furnace. The key elements of the proposed slagging approach are (see Figure 4.8-33):

1. Calculate particle capture based on particle deposition rate (from CFD code) and particle viscosity and outermost deposit layer viscosity (based on ash composition, ash and deposit temperature, gas composition).

2. Calculate mass of new deposit layer.

3. Calculate sintering of all deposit layers. 
4. Calculate all deposit layer properties (thickness, porosity, thermal conductivity, emissivity, absorptivity).

5. Calculate deposit layer thermal resistance.

6. Calculate heat flux through all deposit layers and temperature of each deposit layer.

7. Repeat for next time step.

Potential improvements to the proposed approach include, but are not limited to, the following:

1) Coal particle fragmentation

In the Glacier CFD model, an ash composition distribution is assigned to a coal particle size bin based on the fly ash transformation model and the coal particle is tracked along the trajectory with the assumption that one fly ash particle is formed from a coal particle. A more formal coal fragmentation model can be added in the future if it is determined to be necessary in oxy-combustion conditions.

2) Excluded pyrite transformation model

Excluded pyrite transformation is unique in comparison with included mineral matter transformation and other excluded mineral matter. An approach to track excluded pyrite transformation and deposition should be included in the proposed approach when dealing with a coal with an abundance of excluded pyrite. The transformations of excluded pyrite in a combustion environment will depend on the local temperature and oxygen concentration, which may be different in an oxy-combustion environment.

3) Improved sintering and deposit properties calculations

The approach proposed here can be modified if more accurate calculations of sintering and deposit properties have been identified from the literature. In oxy-combustion systems, the local temperature and oxygen concentrations in the combustion zone might differ than in air-combustion systems. Oxygen concentrations will affect the viscosity of the ash particles, particularly for ash with high amounts of iron oxide. The impacts of local oxygen concentrations and temperatures will be accounted for in the existing ash viscosity model.

\subsubsection{Fouling Model}

A low temperature $\mathrm{Na}_{2} \mathrm{SO}_{4}$-based fouling model has been developed to identify potential fouling in the boiler backpass and the rate at which this fouling will cause a problem for the boiler operation. Key elements of the model are:

1) Vaporization of sodium during the combustion process

Empirical correlations are used to estimate the concentration of alkali species in the gas phase in the convective pass.

2) Deposition of sodium sulfate on fly ash particles and tube surfaces

The dew point of sodium sulfate in the flue gas entering the convective pass can be calculated once the net sodium sulfate vaporization is calculated. At temperatures that fall between the dew point of sodium sulfate and the melting temperature of $\mathrm{Na}_{2} \mathrm{SO}_{4}$, condensation of sodium sulfate will result in a sticky surface. The dew point is calculated from an equilibrium calculation, which will take into account any differences in composition of the flue gas between oxy-combustion and air-combustion.

3) Deposit growth rate on convective pass tubes

Once the range of sticking temperatures is calculated as a function of temperature and fly ash particle size, the deposition and erosion rates as a function of location in the backpass can be calculated. The local temperature and velocity in the backpass of the boiler will come from the CFD model. The size distribution of the fly ash will come from the mineral matter transformation model. 


\subsection{Corrosion}

\subsubsection{Introduction}

Fireside tube corrosion is a topic of great concern for US utility boilers. Some furnaces have experienced local tube metal loss rates on the order of $2.5 \mathrm{~mm} / \mathrm{yr}(100 \mathrm{mil} / \mathrm{yr})$ and EPRI has estimated that fireside corrosion costs the U.S. electric power industry up to $\$ 590$ million per year and is responsible for approximately half of unscheduled outages in steam generation units (Syrett and Gorman 2003). During the last twenty years, the introduction of low NOx firing systems (low NOx burners and overfire air) and efforts to improve thermal efficiency through the use of higher pressure/temperature steam conditions have resulted in growing concern with fireside tube corrosion and have led to increasing pressure to improve materials technology. Recent focus has been on the introduction of oxy-fuel combustion, which has the advantage of reducing the volume of exhaust combustion gases, thereby simplifying the approach to reducing $\mathrm{CO}_{2}$ emissions. Oxy-fuel combustion will also change the heat balance within the boiler, especially when applied within existing boiler units. Additionally, the prospect of combusting coal with oxygen and flue gas recycle has the potential to affect corrosion behavior in a number of different ways.

Mechanisms for corrosion are often specific to waterwalls, superheaters, and economizer regions and are affected by fuel properties, boiler design, and operating conditions (see Figure 4.9-1). Waterwall corrosion mechanisms that have been identified include oxidation, chlorine-related reaction, gas-phase sulfur interactions, and the deposition of reduced sulfur material. In the superheat/reheat area oxidation, active oxidation, molten chloride, molten sulfate, carburization, and sulfidation mechanisms have all been indicated as mechanisms for tube attack. The acting corrosion mechanism depends on local environment, determined by various key parameters and can occur through one dominant mechanism or a combination of multiple mechanisms. These mechanisms have been developed for air-fired conditions. The local environment in a furnace retrofit for oxy-combustion is expected to be very different from air-fired boilers. Therefore known corrosion mechanisms need to be re-visited and potentially revised to account for the modified environment. As a part of this effort, the published research studies relevant to oxidation, sulfidation, chloridation, carburization, and the issues related to oxy-firing conditions are summarized in this section.

A simplistic consideration of oxy-coal combustion indicates a number of possible impacts on corrosion tendencies. Thermodynamics indicate that flame temperature is a function of oxygen concentration in the reactant gases. In addition, a difference in peak combustion temperatures will lead to changes in heat flux and temperature gradients. Each of these factors will impact corrosion rates for one or all of the mechanisms indicated above. The removal of the nitrogen diluent and the increased concentration of minor species (especially sulfur and chlorine species) during flue gas recycle provide another potential means for impacting corrosion rates in a boiler. In addition to the thermal and concentration issues noted, deposit chemistry/stability is known to be impacted by the existence of alternating oxidizing and reducing

conditions. The potential existence of larger extremes in oxygen concentration during oxy-firing could further magnify these effects. 


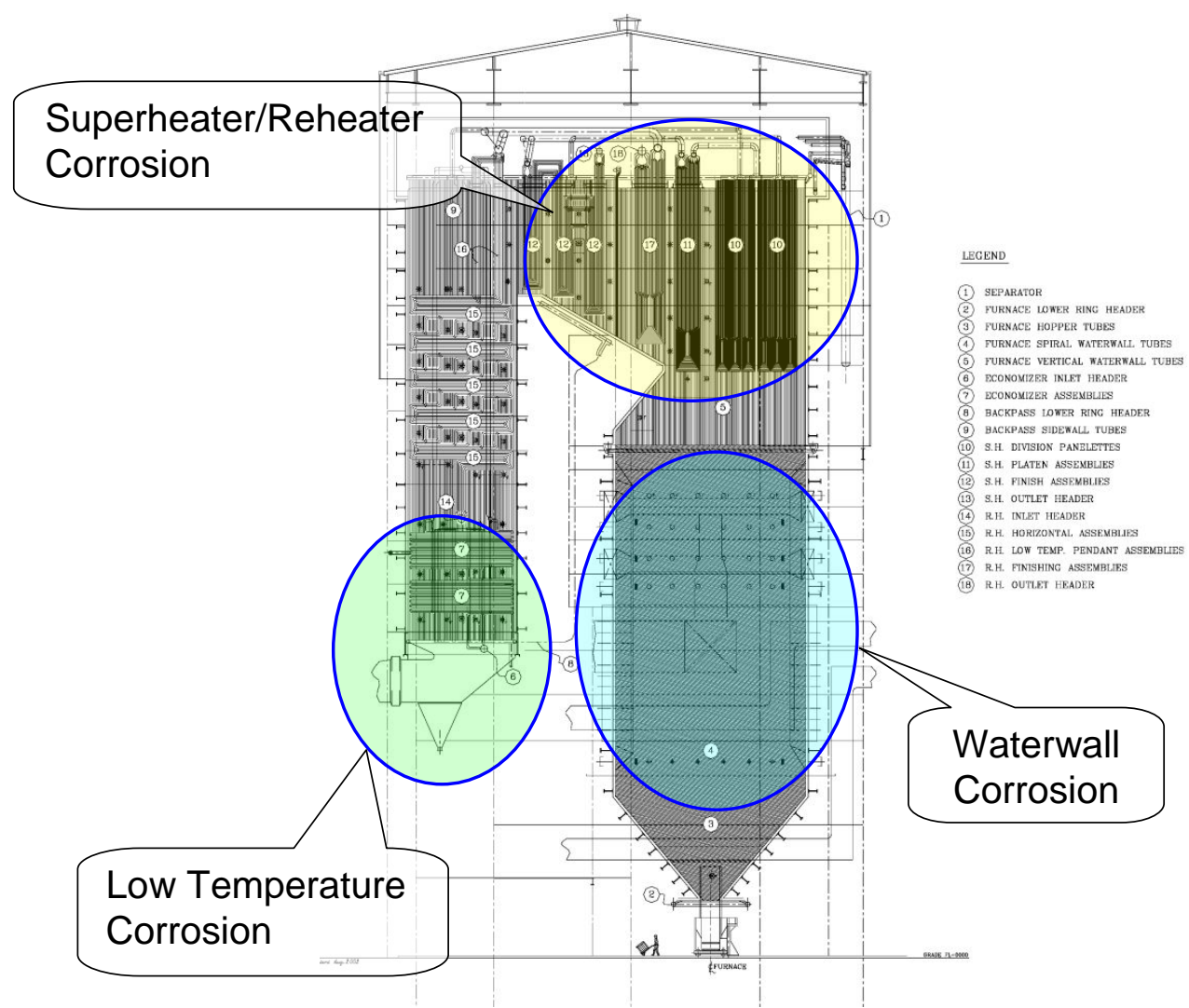

Figure 4.9-1: Fire-side corrosion based on the location in the furnace.

Alternatively, it has been suggested by some researchers that the change in combustion environments might result in carburization of boiler tube materials, in particular superheater tube materials. Were this to occur, the results could be potentially catastrophic. If confirmed, carburization would have a particular impact on retro-conversion of existing boilers, thereby reducing considerably the attractiveness of the technology to improve the $\mathrm{CO}_{2}$ emissions of existing plant capacity.

As a portion of this program, therefore, REI and Corrosion Management Ltd. have performed pilot-scale experimentation to elucidate the potential impacts of oxy-coal combustion retrofit of utility boilers on corrosion. The goals of these tests were two-fold:

1. To demonstrate differences, if any, in corrosion behavior of materials typically implemented in US utility boilers between air-coal and oxy-coal combustion conditions.

2. To develop a data set suitable for validation of mechanisms developed to predict the corrosion rate of heat transfer surfaces under air- and oxy-fired coal combustion conditions.

This section of the report will be devoted to reporting the results of these corrosion experiments and applying those results to the refinement of corrosion mechanisms.

\subsubsection{Mechanism Review and Development}

It is useful to summarize various key corrosion parameters before a discussion of corrosion mechanisms. Fireside corrosion may be induced by combinations of many boiler parameters. These parameters include:

- Sulfur, vanadium, chlorine, alkali and alkaline metal contents in fuel. 
- Local deposition and deposit characteristics including: thermal gradients, chlorine, $\mathrm{SO}_{2}$ and metal species concentrations and deposit physiochemical properties.

- Local stoichiometry and fluctuations in stoichiometry.

- Local flue gas composition.

- Local heat flux.

- Tube metal temperature (determined by steam side temperature).

- Flue gas temperature, temperature fluctuations and flue gas temperature gradient.

These parameters can determine active corrosion mechanism(s) and the extent and rate of corrosion, and should be considered in understanding corrosion in oxy-fired pulverized coal combustion conditions.

The main corrosion phenomena on the fireside of the boiler tubes can be classified as oxidation, sulfidation, and chloridation. In oxy-firing conditions, carburization may also occur due to high concentration of $\mathrm{CO}_{2}$ in flue gas. In the following sections, these mechanisms are discussed in detail.

\subsubsection{Oxidation}

Oxidation is typically the most common high temperature corrosion mechanism in the boiler. Under an oxidizing environment, tube metal (M) can react with gaseous oxidant such as $\mathrm{O}_{2}, \mathrm{CO}_{2}$, or $\mathrm{H}_{2} \mathrm{O}$ to form metal oxides on the bare tube:

$$
\begin{gathered}
M+\frac{1}{2} \mathrm{O}_{2} \rightarrow M O \\
2 \mathrm{MO}+\frac{1}{2} \mathrm{O}_{2} \rightarrow \mathrm{M}_{2} \mathrm{O}_{3}
\end{gathered}
$$

Oxidation is not always detrimental to the metal surface as the oxide scale can provide protection from attacks of corrosive species. Therefore, the tube metal surfaces with oxide scale are more corrosion resistant than those metal surfaces exposed to corrosive gases without oxide scale. Metal temperature is an important parameter in this mechanism, as oxidation rates of the tube metals will increase with increasing temperature. The most common oxide scale that provides corrosion protection is chromium oxide $\left(\mathrm{Cr}_{2} \mathrm{O}_{3}\right)$. Therefore, increasing chromium content in the tube metal is one of the ways to increase corrosion resistance. Other alloy components that can provide corrosion resistance are aluminum, silicon, nickel, and rare-earth metals. However, if the metal is exposed to conditions where continuous oxidation can occur, oxidation can result in metal wastage. To avoid continuous oxidation, the corrosion product, oxide scale, should remain attached to the metal surface without flaking or spalling and have a high melting temperature, a low vapor pressure, similar thermal expansion coefficients as the tube metal, some plasticity at high temperature, and low diffusion coefficients for metal ions and oxygen.

\subsubsection{Sulfidation}

\subsection{Corrosion by Gaseous $\mathrm{H}_{2} \mathrm{~S}$}

Under oxidizing conditions, a protective $\mathrm{Fe}_{3} \mathrm{O}_{4}$ scale forms on tube surfaces and metal wastage generally occurs at extremely low rates. The $\mathrm{Fe}_{3} \mathrm{O}_{4}$ scale adheres strongly to the underlying metal, is impermeable to gases, and inhibits further metal loss. Under oxidizing conditions, fuel sulfur is converted primarily to $\mathrm{SO}_{2}$ which typically has little effect on the tube metal. However, under reducing conditions, existing in the lower furnace when combustion is staged, fuel sulfur is preferentially converted to a reducing sulfur species such as $\mathrm{H}_{2} \mathrm{~S}, \mathrm{CS}_{2}$, or COS. High temperature metal corrosion may occur in the presence of these 
species through sulfidation of the metal surface. FeS forms on the tube surface in addition to or in place of $\mathrm{Fe}_{2} \mathrm{O}_{3}$. The weak FeS or mixed $\mathrm{FeS} / \mathrm{Fe}_{2} \mathrm{O}_{3}$ scale is not as protective as the $\mathrm{Fe}_{2} \mathrm{O}_{3}$ scale, is more permeable to gases, and is subject to spalling, resulting in metal loss. A schematic of this corrosion mechanism is shown in Figure 4.9-2 and this corrosion occurs through the following steps:

1. Under a reducing environment, non-uniform oxide scale is formed on the metal surface

2. Reduced sulfur species such as $\mathrm{H}_{2} \mathrm{~S}$ are formed and diffused to the metal surface

3. Sulfidation occurs and FeS forms on the tube surface

4. FeS scale does not provide any protection against corrosive gas access

Tube material can also affect the sulfidation behavior. The presence of chromium in tube metal results in the formation of a protective chromia rich scale, as chromium can be relatively easily oxidized under even low partial pressure of oxygen compared to iron and nickel. This chromia can inhibit sulfidation.

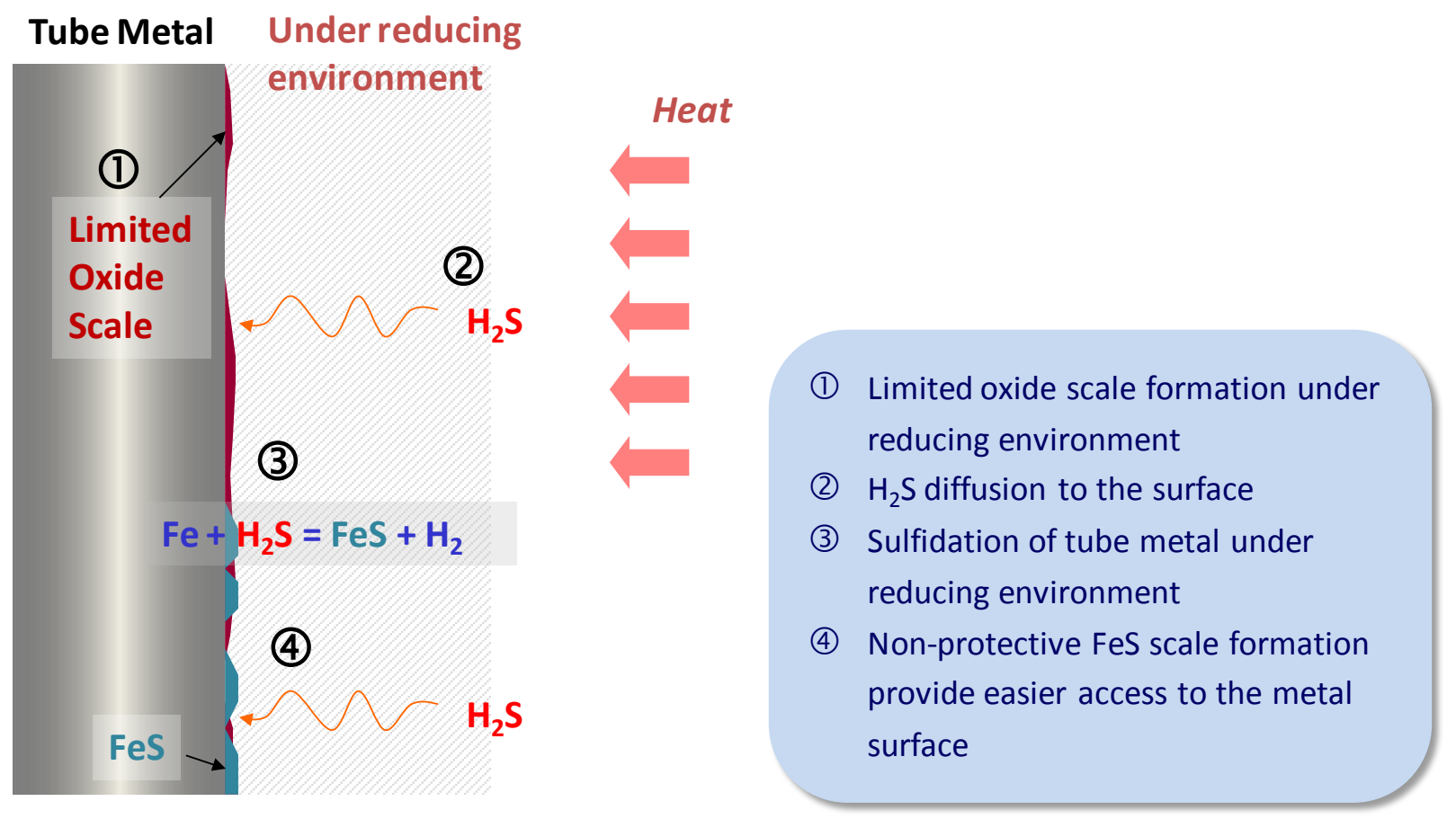

Figure 4.9-2: Schematic of $\mathrm{H}_{2} \mathrm{~S}$ corrosion mechanism.

Kung's (Kung 1997) empirically developed correlations for $\mathrm{H}_{2} \mathrm{~S}$ corrosion for low and high chromium steels are

$$
C R=3.2 \times 10^{5} \exp \left(-\frac{15,818}{1.987 T}\right) \times\left[H_{2} S\right]^{0.574} \times \frac{1}{(C r \%+10.5)^{1.234}} \pm 2.2
$$

for carbon and low-alloy steels with $0 \leq \mathrm{Cr} w \mathrm{t} \% \leq 10$, and

$$
C R=1.04 \times 10^{7} \exp \left(-\frac{19,230}{1.987 T}\right) \times\left[H_{2} S\right]^{0.29} \times \frac{1}{(C r \%+1.40)^{1.37}} \pm 1.2
$$


for high-alloy steels with $10 \leq \mathrm{Cr} w \mathrm{t} \% \leq 16$, where $C R$ is the corrosion rate in mil/yr, $T$ is the tube metal temperature in Kelvin, $\mathrm{H}_{2} \mathrm{~S}$ is the flue gas concentration of $\mathrm{H}_{2} \mathrm{~S}$ in $\mathrm{mg} / \mathrm{kg}$, and $\mathrm{Cr} \%$ is the \% metal $\mathrm{Cr}$ content by weight.

Kung recommends that use of these correlations be limited to tube temperatures up to $482^{\circ} \mathrm{C}$. (755 K), metal $\mathrm{Cr}$ contents up to $25 \%$ by weight, and $\mathrm{H}_{2} \mathrm{~S}$ concentrations of $500 \mathrm{mg} / \mathrm{kg}$ to $5000 \mathrm{mg} / \mathrm{kg}$. According to these correlations, corrosion rate is more dependent on temperature than on $\mathrm{H}_{2} \mathrm{~S}$ concentration.

The $\mathrm{H}_{2} \mathrm{~S}$ corrosion rate, according to Kung's correlation for low alloy steel, is plotted for two metal temperatures in Figure 4.9-3. Corrosion rate increases with increasing temperature and the $\mathrm{H}_{2} \mathrm{~S}$ dependence of corrosion rate increases at higher temperature. However, even at the higher temperature, the predicted corrosion rate is far below the highest rates approaching $100 \mathrm{mil} / \mathrm{yr}$ that have been observed in some utility boilers. This observation has led to examination of other corrosion mechanisms for these cases.

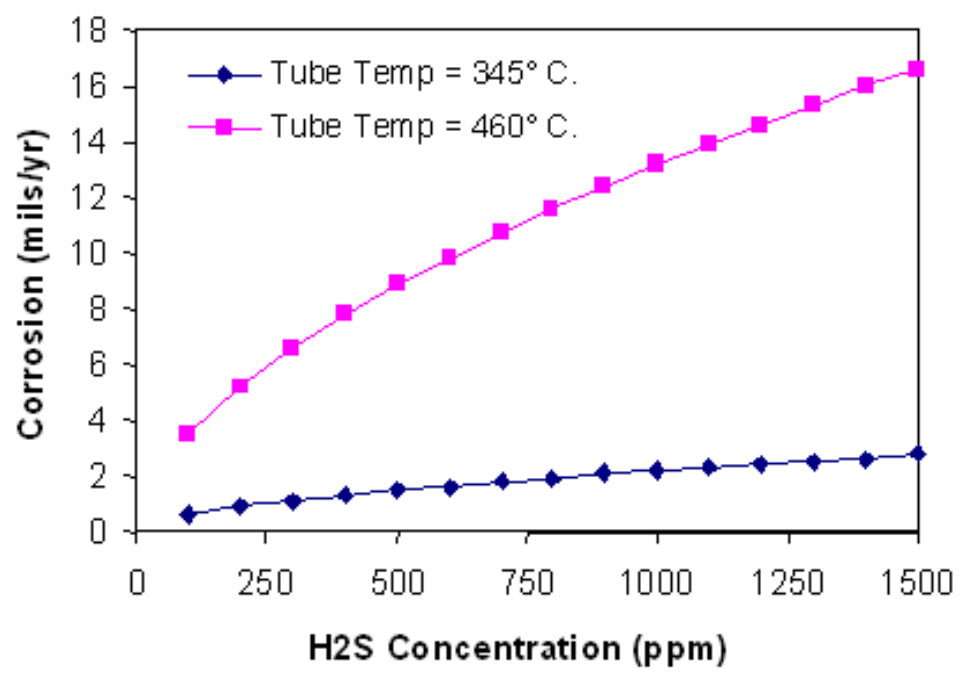

\section{Figure 4.9-3: Plots of Kung's $\mathrm{H}_{2} \mathrm{~S}$ corrosion correlation as a function of temperature and $\mathrm{H}_{2} \mathrm{~S}$} concentration.

(Perkins, et al. 1990) had previously developed an empirical expression for $\mathrm{H}_{2} \mathrm{~S}$ corrosion of carbon steel under conditions simulating those of syngas coolers on coal gasifiers,

$$
C R=2.23 \times 10^{5} \exp \left(-\frac{4,723}{T}\right) \times\left[H_{2} S\right]^{0.23}
$$

where $C R$ is the corrosion rate in mil/yr, $T$ is the tube metal temperature in Kelvin, and $H_{2} S$ is the flue gas concentration of $\mathrm{H}_{2} \mathrm{~S}$ in atm. However, Kung notes that under utility boiler conditions, this expression predicts a corrosion rate approximately four times too high.

(Davis, et al. 2001) have developed an empirical expression for a parabolic corrosion rate constant to describe sulfidation rate under reducing conditions $\left(\mathrm{O}_{2}<0.5 \%\right.$, $\left.\mathrm{CO}>2 . \%\right)$ : 


$$
K_{p r}=B \times(\% C O)^{n} \times \exp \left(-\frac{Q_{r}}{R T}\right)
$$

where $K_{p r}$ is the parabolic sulfidation corrosion rate constant under reducing conditions, $B$ and $m$ are constants, \%CO is the local CO concentration, and $Q_{r}$ is the activation energy for sulfidation. This expression is less useful than the Kung correlation since it does not account for metal composition and, although local concentrations of reducing sulfur species correlate with CO concentration, the expression does not explicitly account for varying fuel sulfur.

(Nava, Plumley and Knodler 1997) developed an empirical expression for low alloy steel weight loss in an $\mathrm{H}_{2} \mathrm{~S}$ environment at $500^{\circ} \mathrm{C}$ :

$$
\text { WeightLoss }=7.74 \times 10^{-3} \times\left(\mathrm{H}_{2} \mathrm{~S}\right)^{0.54} \times(\text { time })^{0.86}
$$

where Weight Loss is the metal loss in $\mathrm{mg} / \mathrm{cm}^{2}, \mathrm{H}_{2} \mathrm{~S}$ is the local $\mathrm{H}_{2} \mathrm{~S}$ concentration in ppmv, and time is the exposure time in hours. This expression is less general than Kung's correlation since it is applicable only at one temperature, but it does indicate that corrosion rate decreases with exposure time, an observation also made by other researchers (John, Thompson and Karakaya 1990) (Huijbregts, Janssen and Rens 1998). Nava also observes that metal corrosion resistance increases with increasing chromium content.

(Huijbregts, Janssen and Rens 1998) used experimental data to determine constants in an expression for a parabolic corrosion rate coefficient:

$$
\log K=a_{0}+a_{1} \frac{1000}{T}+a_{2}\left(\log \left(p S_{s}\right)+0.5 \times \log \left(p C l_{2}\right)-0.75\left(p O_{2}\right)\right)
$$

where, $K$ is corrosion rate coefficient in $\mathrm{mm} / \mathrm{hr}^{0.6}, \mathrm{~T}$ is temperature, and $\mathrm{pS}_{2}, \mathrm{pCl}_{2}$, and $\mathrm{pO}_{2}$ are the partial pressures of $\mathrm{S}_{2}, \mathrm{Cl}_{2}$, and $\mathrm{O}_{2}$, respectively.

In addition to metal loss due to sulfidation, this expression also contains a term for metal loss due to chlorine attack. For $13 \mathrm{CrMo} 4.4$ steel at temperatures varying from $400^{\circ} \mathrm{C}$ to $450^{\circ} \mathrm{C}$, constants $\mathrm{a}_{0}, \mathrm{a}_{1}$, and $\mathrm{a}_{2}$ were determined to be $2.78,-3.56$, and -0.027 , respectively.

(John, Thompson and Karakaya 1990) developed similar correlations for prediction of corrosion rates due to gaseous phase sulfidation. Although attack by gaseous phase reducing sulfur species contributes to corrosion of tube metal surfaces, at typical pulverized coal furnace temperatures this mechanism results in lower corrosion rates than those due either to deposition of sulfur containing material or to fuel chlorine.

\subsection{Deposit based Corrosion (FeS)}

When unreacted fuel is deposited on surfaces, impurities such as unoxidized sulfides may also be deposited. Sulfur present in coal is comprised of both organic and inorganic components. The inorganic component is primarily pyrite, which can be excluded (separate from the coal particles) or included (small particles that are trapped within the hydrocarbon matrix). When coal particles are heated, organic sulfur species evolve with other volatile species and, depending on conditions, some fraction of the included sulfur will remain with char. Sulfur can arrive at furnace heat transfer surfaces through the deposition of incompletely oxidized coal char or excluded pyrite, both of which can lead to sulfidation and material loss. 
The deposit based corrosion mechanism is illustrated in Figure 4.9-4. Limited oxide scale is formed where reducing conditions prevail and where local conditions change from oxidizing to reducing or vice versa (step (1). Then deposit is formed on the surface of the tube metal or the oxide scale (step (2)). A number of reports indicate that either an unburned carbon or an FeS deposit on a metal surface may increase corrosion rates, often significantly (Nava, Plumley and Knodler 1997) (Kung 1997) (Kung and Bakker 1998) (Bakker 2003). It is believed that a fuel rich microclimate develops under the deposit surface and metal loss occurs through sulfidation (steps (3) and (4)). FeS and carbon rich deposits have been observed in furnace high corrosion regions and it has been observed that impacting FeS can interact chemically with an existing protective iron oxide scale (Mayoral, et al. 2002).

Model predictions of sulfur release from pyrite decomposition at three temperatures are compared with experimental data in Figure 4.9-5 (Valentine, et al. 2000). The model included sub-models for pyrite particle tracking, kinetics and decomposition. The model shows an initial rapid sulfur release due to thermal decomposition then a slower oxidation process. Sulfur species released at high temperatures are then involved in sulfidation of metal (step (5)). Sulfide scale formed from iron sulfidation does not provide protection, has higher gas permeability, and is prone to spalling. These characteristics lead to metal wastage.

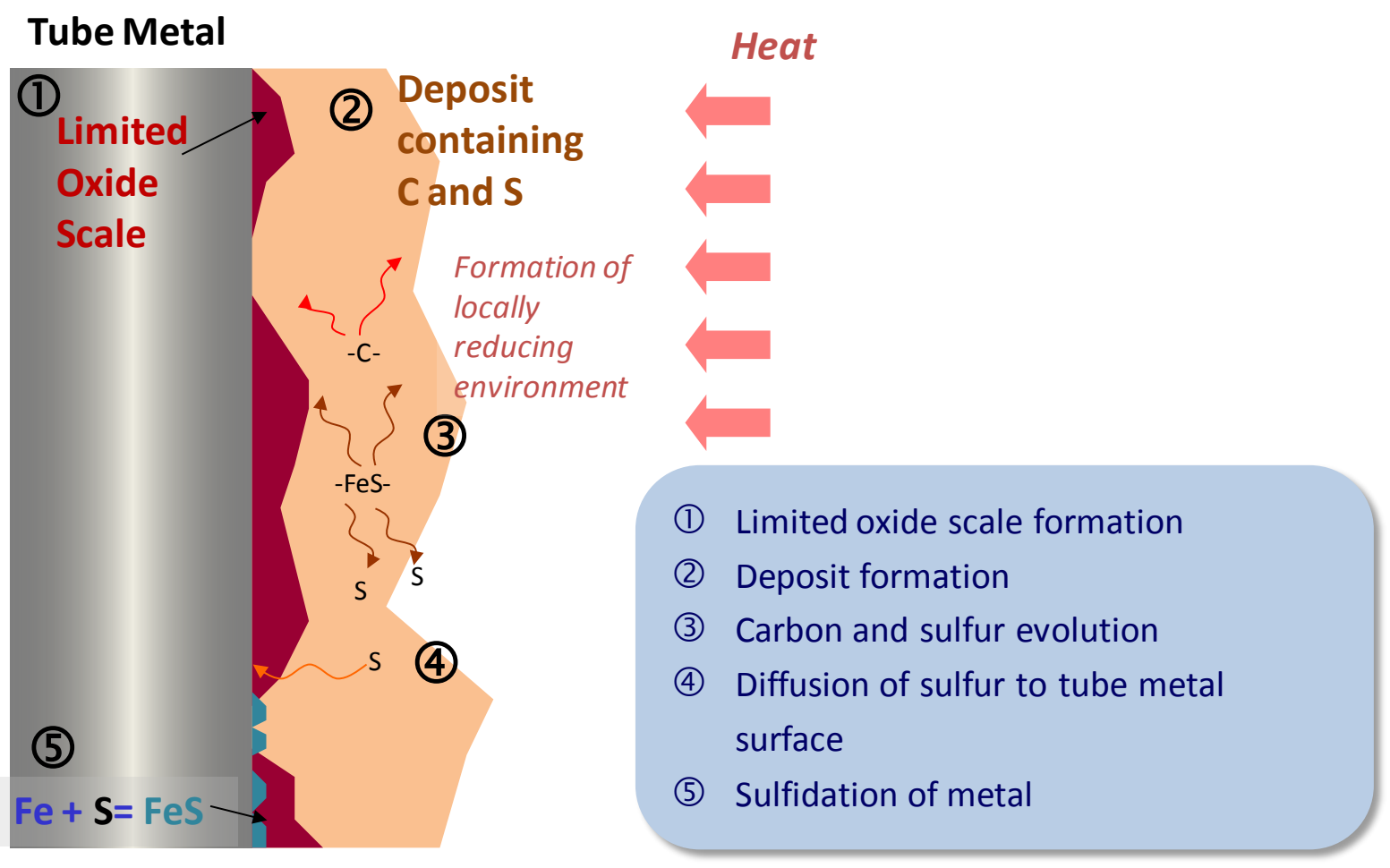

Figure 4.9-4: Schematic of deposit-based corrosion mechanism. 


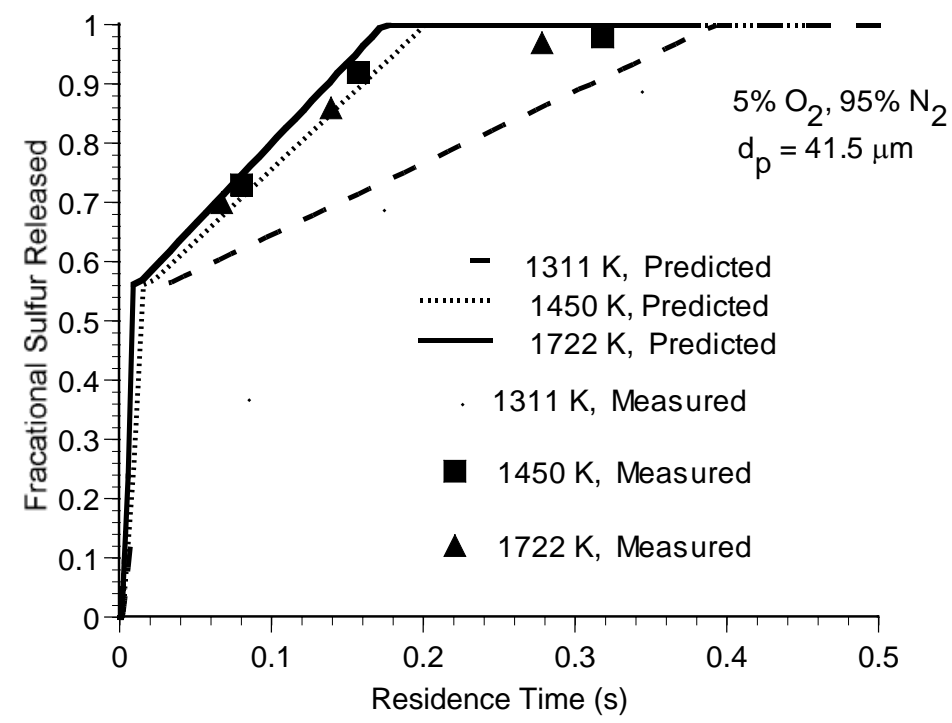

Figure 4.9-5: Comparison of predicted fractional sulfur from pyrite decomposition with laboratory measurements (Valentine, et al. 2000).

Laboratory tests have indicated that metal corrosion rates under an FeS layer can exceed $100 \mathrm{mil} / \mathrm{yr}$ (Bakker 1998). However, under very reducing conditions (CO > 7\%), the FeS deposit was inert and corrosion rates were low. Under mildly reducing conditions $(0 \%<\mathrm{CO}<3 \%)$, corrosion rates increased somewhat, while the highest corrosion rates under an FeS deposit were measured for oxidizing conditions $\left(\mathrm{O}_{2}>1 \%\right)$. This indicates that corrosion may result from cycling of furnace operating conditions when regions go from substoichiometric (when FeS deposits occur) to oxidizing. Figure 4.9-6 shows the effect of local stoichiometry on corrosion rate under an FeS layer; as noted above, corrosion rates are highest under oxidizing gas phase conditions. (Nava-Paz, et al. 2002) report that the microclimate under an unburned carbon layer in the presence of a sulfidizing gas atmosphere is as corrosive as that under an FeS layer.

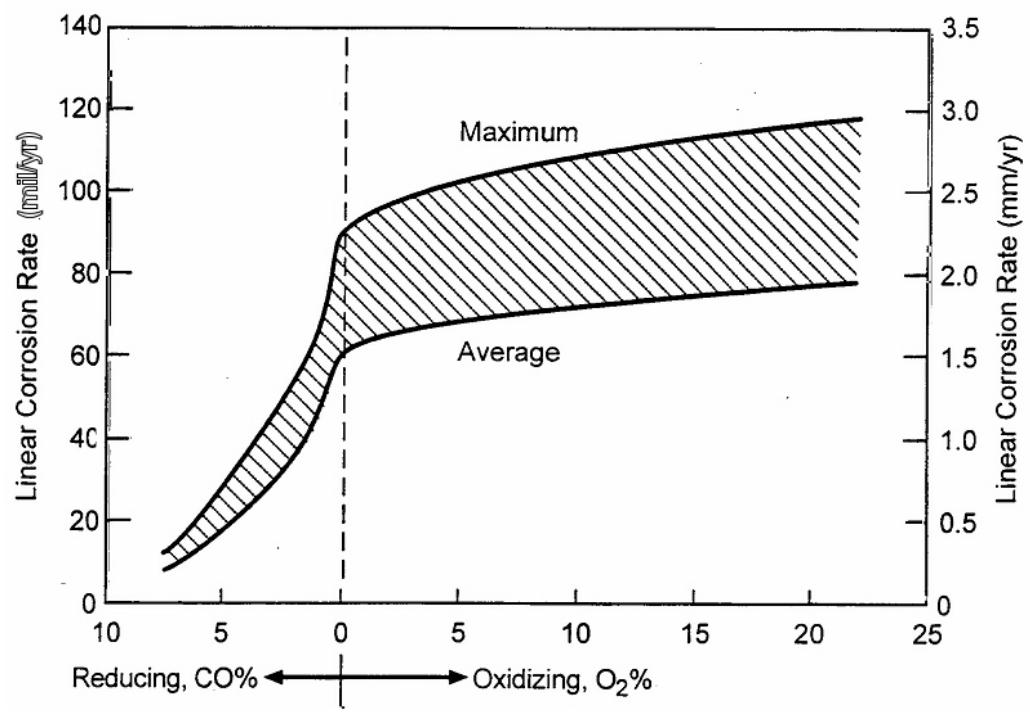

Figure 4.9-6: Corrosion rates predicted for low alloy steels under FeS rich deposits, as a function of $\mathrm{O}_{2}$ and $\mathrm{CO}$ content of flue gas at $450^{\circ} \mathrm{C}$ (Bakker, Kung, et al. 1999). 
Figure 4.9-7 shows predicted corrosion rates under an FeS layer and in a $1 \% \mathrm{O}_{2}$ gas environment as a function of temperature. Corrosion rates increase with temperature, so supercritical boilers with higher tube temperatures frequently suffer greater wastage than do subcritical boilers. (Nava, Plumley and Knodler 1997) observed that metal temperature gradients (as opposed to the isothermal conditions) can accelerate wastage. Such gradients may arise from heat transfer through the surface deposit.

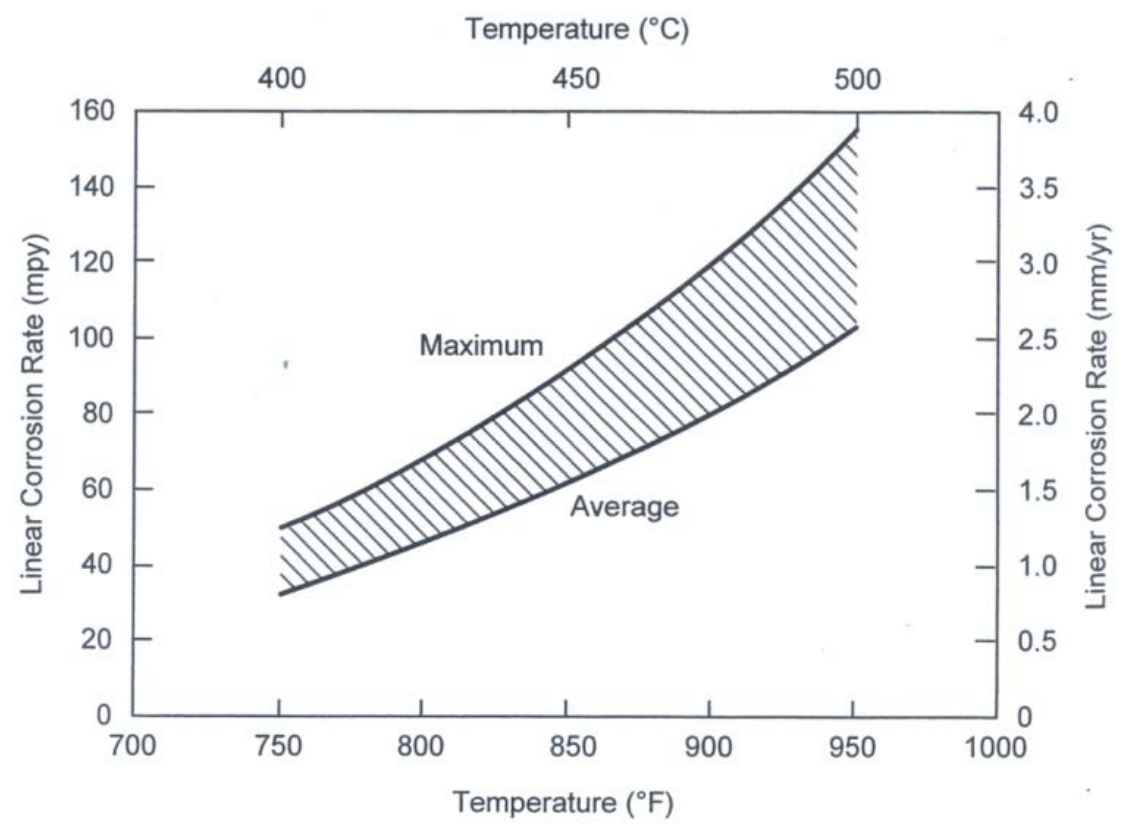

Figure 4.9-7: Corrosion rates as a function of temperature predicted for low alloy steels under FeS rich deposits and in a $1 \% \mathrm{O}_{2}$ gas environment.

\subsection{Molten Sulfate Corrosion}

One of the most common forms of corrosion found in coal-fired boilers is accelerated corrosion by molten alkali metal trisulfate (Harb and Smith 1990) (Raask 1985) (Nielsen, et al. 2000) (James and Pinder 1997) (James and Pinder 1997). Alkali iron trisulfate, $\mathrm{A}_{3} \mathrm{Fe}\left(\mathrm{SO}_{4}\right)_{3}$, has often been found on corroded pendant tubes. There is much discussion on the role of alkali iron trisulfate in this corrosion process. The lowest melting point of Na-K sulfate system is known to be $1513^{\circ} \mathrm{F}\left(823^{\circ} \mathrm{C}\right)$. This temperature would be representative of significantly overheated pendant tubes. However, when iron sulfate is added into the system, alkali iron trisulfate is formed and its melting point is lowered to a typical superheater/reheater pendant tube metal temperatures. In its liquid form, alkali iron trisulfate is known to be highly corrosive. The melting points of $\mathrm{Na}_{3} \mathrm{Fe}\left(\mathrm{SO}_{4}\right)_{3}$ and $\mathrm{K}_{3} \mathrm{Fe}\left(\mathrm{SO}_{4}\right)_{3}$ are $1155^{\circ} \mathrm{F}\left(624^{\circ} \mathrm{C}\right)$ and $1144^{\circ} \mathrm{F}\left(618^{\circ} \mathrm{C}\right)$, respectively, and significant corrosion can occur at tube metal temperature higher than these temperatures. When these two materials are mixed, the melting point of the mixture can be lowered to $1022^{\circ} \mathrm{F}\left(550^{\circ} \mathrm{C}\right)$. Figure $4.9-8$ shows variations in melting points in the alkali iron trisulfate system as a function of $\mathrm{K}$ and Na mole ratios. This figure clearly shows that alkali iron trisulfate can exist in the stable liquid form at the superheater tube temperature ranges. However, the stability of the alkali iron trisulfate in the liquid form decreases with increasing temperature. This is one of the reasons that the rates by molten sulfate corrosion have a bell-shape as a function of tube metal temperature (see Figure 4.9-11). Figure 4.9-9 shows the fire side corrosion of various alloys as a function of temperature (Viswanathan and Bakker 2000). As discussed, most alloys have a bell-shaped temperature dependency of the corrosion rates. 


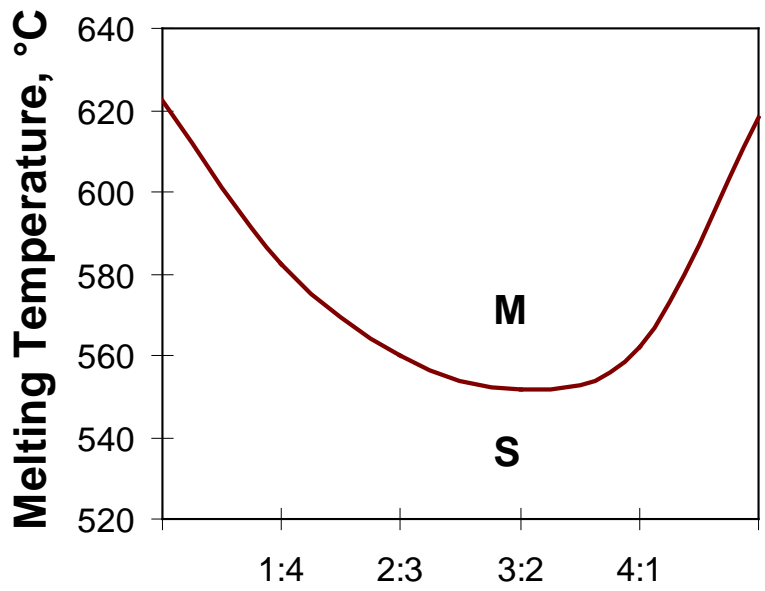

Molar Ratio of $\mathrm{K}$ to $\mathrm{Na}$ in Melt

Figure 4.9-8: Solid/liquid equilibrium of $\mathrm{K}_{3} \mathrm{Fe}\left(\mathrm{SO}_{4}\right)_{3} / \mathrm{Na}_{3} \mathrm{Fe}\left(\mathrm{SO}_{4}\right)_{3}$ system. $\mathrm{M}$, molten phase; $\mathrm{S}$, solid phase (adapted from (Raask 1985)).

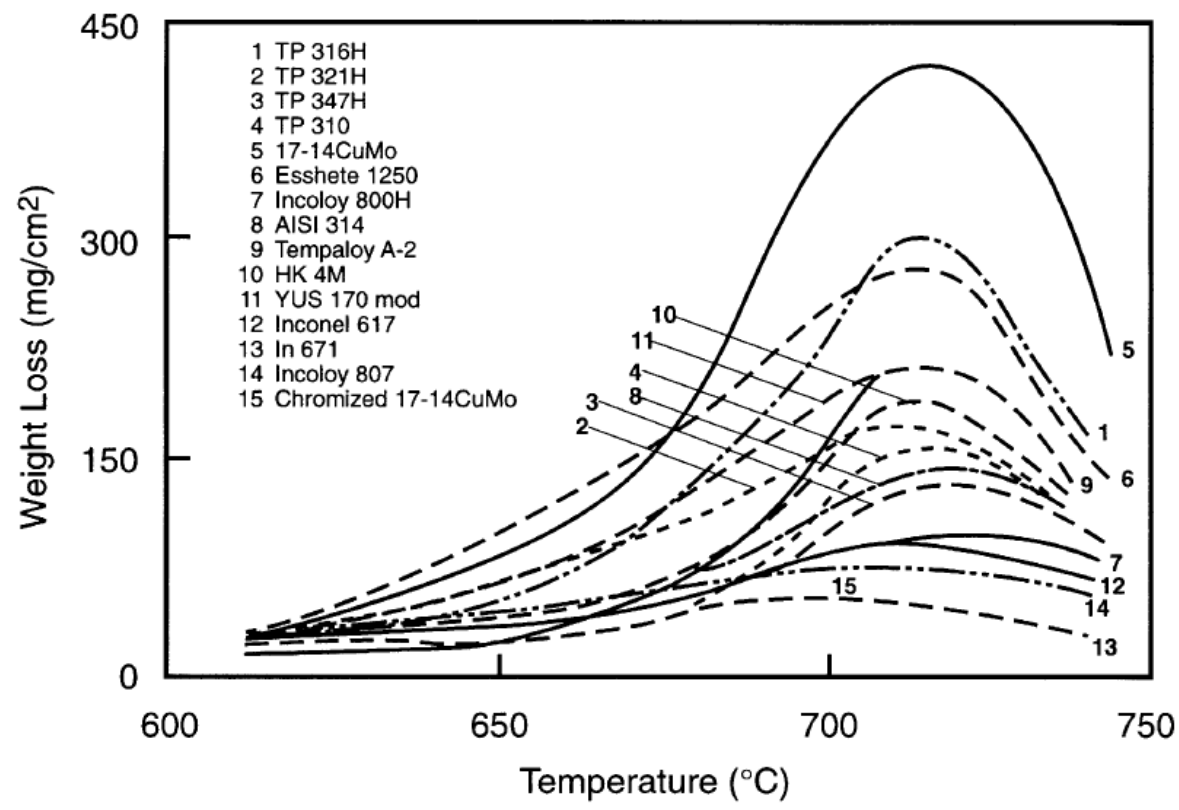

Figure 4.9-9: Weight loss as a function of temperature for various alloys.

Figure 4.9-10 illustrates overall molten sulfate corrosion reaction pathways. In this mechanism generally two surface reactions are considered:

a) Pyrosulfate $\left(\mathrm{A}_{2} \mathrm{~S}_{2} \mathrm{O}_{7}\right)$ formation.

b) Alkali metal trisulfate formation through reactions of alkali sulfate and iron oxide in the presence of $\mathrm{SO}_{2}$ under oxidizing environment. 


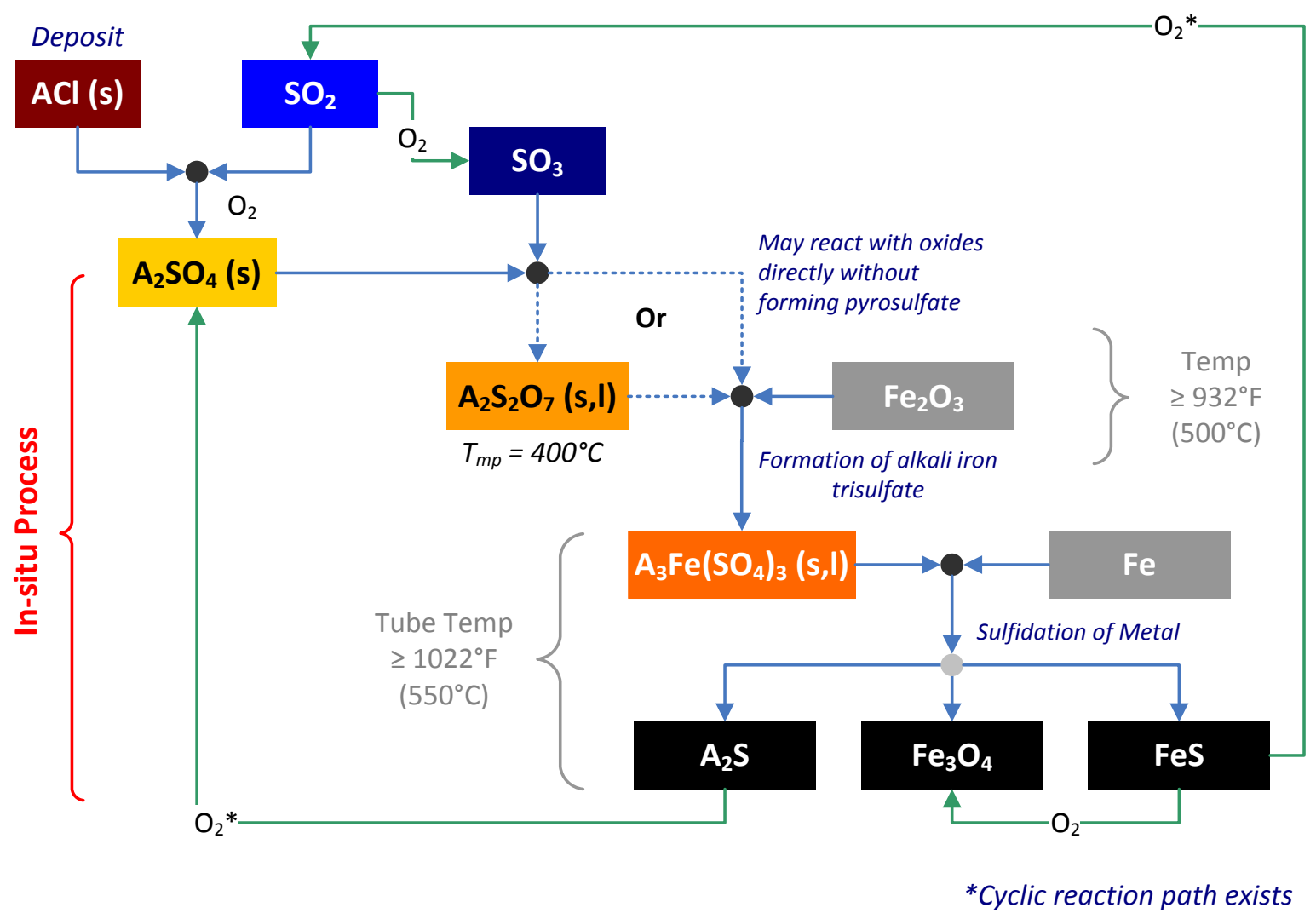

Figure 4.9-10: Overall reaction paths in molten sulfate corrosion mechanism (A: Na or K).

Pyrosulfate formation may start with the deposition of alkali chloride on the oxide scale surface. Then the alkali chloride deposit reacts with $\mathrm{SO}_{2}$ under oxidizing environment to form pyrosulfate:

$$
2(\mathrm{Na}, \mathrm{K}) \mathrm{Cl}(\mathrm{s})+2 \mathrm{SO}_{2}(\mathrm{~g})+\frac{3}{2} \mathrm{O}_{2}(g)=(\mathrm{Na}, \mathrm{K})_{2} \mathrm{~S}_{2} \mathrm{O}_{7}(\mathrm{~s})+\mathrm{Cl}_{2}(\mathrm{~g})
$$

This reaction (9) can be explained by including sulfate and $\mathrm{SO}_{3}$ formation. The alkali chlorides deposited on the boiler tube can react with $\mathrm{SO}_{2}$ and $\mathrm{O}_{2}$ to form alkali sulfates as in the following reaction:

$$
2(\mathrm{Na}, \mathrm{K}) \mathrm{Cl}(\mathrm{s})+\mathrm{SO}_{2}(\mathrm{~g})+\mathrm{O}_{2}(\mathrm{~g})=(\mathrm{Na}, \mathrm{K})_{2} \mathrm{SO}_{4}(\mathrm{~s})+\mathrm{Cl}_{2}(\mathrm{~g})
$$

Then, the alkali sulfates can react with $\mathrm{SO}^{3}$ to form pyrosulfates:

$$
(\mathrm{Na}, \mathrm{K})_{2} \mathrm{SO}_{4}+\mathrm{SO}_{3}=(\mathrm{Na}, \mathrm{K})_{2} \mathrm{~S}_{2} \mathrm{O}_{7}(\mathrm{~s})
$$

However, the formation of pyrosulfates is still in question. (Coats, Dear and Penfold 1968) studied thermal stability of pyrosulfates in the presence of $\mathrm{SO}_{3}$. This study showed that about $150 \mathrm{ppm} \mathrm{of} \mathrm{SO}_{3}(\mathrm{~g})$ would be needed to form molten $\mathrm{K}_{2} \mathrm{~S}_{2} \mathrm{O}_{7}$ at $765^{\circ} \mathrm{F}\left(407^{\circ} \mathrm{C}\right)$. In the case of $\mathrm{Na}_{2} \mathrm{~S}_{2} \mathrm{O}_{7}$, the study reported that more $\mathrm{SO}_{3}$, about 2000 ppm, would be required to form molten phase.

(Reid 1971) studied potential roles of pyrosulfate in high temperature corrosion of furnace walls and superheaters and concluded that there was no direct evidence of $\mathrm{K}_{2} \mathrm{~S}_{2} \mathrm{O}_{7}$ or $\mathrm{Na}_{2} \mathrm{~S}_{2} \mathrm{O}_{7}$ formation in the 
boiler deposits. Therefore, molten sulfate formation through $\mathrm{SO}_{3}$ absorption and its fluxing of protective oxide scale have been more emphasized. For example, at the temperature higher than $932^{\circ} \mathrm{F}\left(500^{\circ} \mathrm{C}\right)$, the following reaction can occur:

$$
3(\mathrm{Na}, \mathrm{K})_{2} \mathrm{SO}_{4}(\mathrm{~s})+\mathrm{Fe}_{2} \mathrm{O}_{3}(\mathrm{~s})+3 \mathrm{SO}_{3}(\mathrm{~g})=2(\mathrm{Na}, \mathrm{K})_{3} \mathrm{Fe}\left(\mathrm{SO}_{4}\right)_{3}(\mathrm{~s}, \mathrm{l})
$$

Pyrosulfate can be stabilized in the $(\mathrm{Na}, \mathrm{K}) \mathrm{Fe}\left(\mathrm{SO}_{4}\right)_{3}$ system and can expand the temperature range of the molten state.

The presence of $\mathrm{SO}_{3}$ is required to form $(\mathrm{Na}, \mathrm{K}) \mathrm{Fe}\left(\mathrm{SO}_{4}\right)_{3}$ as mentioned before. (Corey, Cross and Reid 1945) reported that at least $250 \mathrm{ppm}$ of $\mathrm{SO}_{3}$ would be required to form $\mathrm{K}_{3} \mathrm{Fe}\left(\mathrm{SO}_{4}\right)_{3}$ at $1000^{\circ} \mathrm{F}\left(538^{\circ} \mathrm{C}\right)$ in the mixture of $\mathrm{K}_{2} \mathrm{SO}_{4}$ and $\mathrm{Fe}_{2} \mathrm{O}_{3}$. In the study by (Anderson and Goddard 1968), the required $\mathrm{SO}_{3}$ is about $1000 \mathrm{ppm}$ at $1175^{\circ} \mathrm{F}\left(635^{\circ} \mathrm{C}\right)$ in an equilibrium state. These values are much higher than $10 \mathrm{ppm}$ typical in coal-fired boilers. However, it is reported that the $\mathrm{SO}_{3}$ concentration can be much higher in ash deposits, through $\mathrm{SO}_{2}$ oxidation by iron oxide catalysts on the metal surface (Equation 2.7-13). In this case, $\mathrm{SO}_{3}$ concentration can be 50-100 ppm at $711-1341^{\circ} \mathrm{F}\left(377-727^{\circ} \mathrm{C}\right.$ ) (Hedley 1967). (Levy and Merryman 1965) also reported $\mathrm{SO}_{2}$ oxidation by catalysis of pure $\mathrm{Fe}_{2} \mathrm{O}_{3}$ and (Krause, Levy and Reid 1969) validated the catalytic effect of $\mathrm{Fe}_{2} \mathrm{O}_{3}$. In this study, local $\mathrm{SO}_{3}$ concentration is reported to be as high as $2000 \mathrm{ppm}$ in a radioactive tracer experiment.

$$
\mathrm{SO}_{2}(g)+\frac{1}{2} \mathrm{O}_{2}(g) \stackrel{\mathrm{Fe}_{2} \mathrm{O}_{3}}{\longrightarrow} \mathrm{SO}_{3}(g)
$$

In addition, $\mathrm{SO}_{3}$ can be formed in the deposit exposed to flame through the reaction between sulfate and silicate as shown in the following reaction:

$$
\mathrm{Na}_{2} \mathrm{SO}_{4}+\mathrm{SiO}_{2} \stackrel{k_{1}}{\longrightarrow} \mathrm{Na}_{2} \mathrm{OSiO}_{2}+\mathrm{SO}_{3} \stackrel{k_{2}}{\longrightarrow} \mathrm{SO}_{2}+\frac{1}{2} \mathrm{O}_{2}
$$

$\mathrm{SO}_{3}$ dissociation can be low in these reactions $\left(\mathrm{k}_{1}>\mathrm{k}_{2}\right)$, then $\mathrm{SO}_{3}$ concentration can be higher than 100 ppm on the deposit surface (Hedley 1967).

At the metal temperature of $550^{\circ} \mathrm{C}$ or higher, alkali metal trisulfate can attack metal surface through the following reactions. $\mathrm{SO}_{3}$ evolved in these reactions can react with $(\mathrm{Na}, \mathrm{K})_{2} \mathrm{SO}_{4}$ again and then cyclic reaction path can be established.

$$
\begin{gathered}
2(\mathrm{Na}, \mathrm{K})_{3} \mathrm{Fe}\left(\mathrm{SO}_{4}\right)_{3}(\mathrm{~s}, \mathrm{l})+19 \mathrm{Fe}=6 \mathrm{Fe}_{3} \mathrm{O}_{4}+3 \mathrm{FeS}+3 \mathrm{Na}_{2} \mathrm{~S} \\
\mathrm{Na}_{2} \mathrm{~S}+2 \mathrm{O}_{2}=\mathrm{Na}_{2} \mathrm{SO}_{4} \\
3 \mathrm{FeS}+5 \mathrm{O}_{2}=\mathrm{Fe}_{3} \mathrm{O}_{4}+3 \mathrm{SO}_{2} \\
2 \mathrm{SO}_{2}+\mathrm{O}_{2}=2 \mathrm{SO}_{3}
\end{gathered}
$$


The temperature dependency of the molten sulfate corrosion mechanism is bell-shaped as shown in Figure 4.9-11 (Cutler and Raask 1981). The temperature gradient existing in the deposit and the deposit characteristics are known to induce this bell-shaped temperature dependency. At the temperatures lower than $1022^{\circ} \mathrm{F}\left(550^{\circ} \mathrm{C}\right)$, the deposit is made of porous layers and free gas diffusion is possible through the pores between the flue gas and the metal surface. Then the temperature dependency of the corrosion rate is similar to that of gas phase oxidation. As the metal temperature increases, deposit forms molten alkali metal trisulfates on the tube surface. Then the corrosion rates significantly increase. The melting points of the sulfates are determined by $\mathrm{SO}_{3}$ partial pressure, relative ratio of $\mathrm{Na}$ and $\mathrm{K}$, and the presences of $\mathrm{Ca}$ and $\mathrm{Mg}$. Ca and $\mathrm{Mg}$ can react with $\mathrm{SO}_{3}$ to form the sulfates (Raask 1985):

$$
\begin{gathered}
\mathrm{CaO}+\mathrm{SO}_{3}=\mathrm{CaSO}_{4} \\
\mathrm{MgO}+\mathrm{SO}_{3}=\mathrm{MgSO}_{4}
\end{gathered}
$$

These two sulfates can form more stable $\mathrm{K}_{2} \mathrm{Ca}_{2}\left(\mathrm{SO}_{4}\right)_{3}$ or $\mathrm{K}_{2} \mathrm{Mg}_{2}\left(\mathrm{SO}_{4}\right)_{3}$ and inhibit the formation of alkali iron trisulfate (Borio and Hensel 1972). In addition, $\mathrm{Ca}$ and/or $\mathrm{Mg}$ containing deposits can cover the oxide scale reducing the catalytic effect of $\mathrm{Fe}_{2} \mathrm{O}_{3}$ in $\mathrm{SO}_{2}$ oxidation (Raask 1985).

When the metal temperature further increases, the alkali metal sulfate is not stable and the corrosion rate decreases.

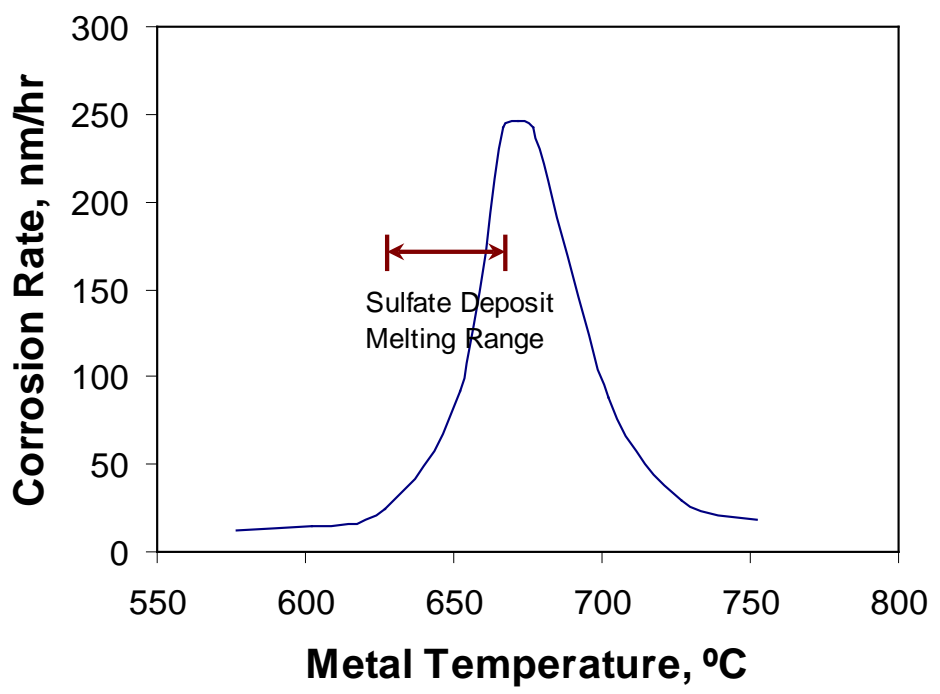

Figure 4.9-11: Bell-shaped curve for the temperature dependence of corrosion on superheater tubes in coal-fired boilers (adapted from (Cutler and Raask 1981)).

If the corrosion products of the tube metal are metal oxides such as $\mathrm{Fe}_{2} \mathrm{O}_{3}$ or $\mathrm{Cr}_{2} \mathrm{O}_{3}$, the protective scale is formed and metal wastage from the molten phase attach can be reduced. On the other hand, if the corrosion product can be dissolved in the molten deposit, then continuous corrosion in liquid form can occur. The solubility of the corrosion products is related to acidity of the molten salts (Rapp 1986). For example, chrome in tube metal can be dissolved in acidic molten phase (high $\mathrm{P}_{\mathrm{SO}}$ ) and generate $\mathrm{Cr}^{3+}$. The layer of the molten salt on the tube metal surface is usually formed under acidic conditions (relatively high $\mathrm{SO}_{3}$ concentration). As the dissolution of the metal progresses, the corrosion product is accumulated in the molten salt layer on the tube metal surface. If there is no driving force to move the corrosion 
product away from the metal surface and precipitate, the accumulation of the corrosion product can be saturated and the molten phase is solidified. (Hendry and Lees 1980) observed the corrosion rate by molten sulfate at isothermal conditions $\left(1112^{\circ} \mathrm{F}\right.$ or $\left.600^{\circ} \mathrm{C}\right)$ decreases significantly due to molten phase saturation. Continuous corrosion can occur when a negative solubility slope exists as shown Figure 4.9-12. This negative solubility slope can move the metal specie dissolved near the tube metal and precipitate away from the tube metal surface, which can avoid saturation near the metal surface. Under isothermal condition, the solubility of the corrosion product such as $\mathrm{Fe}^{3+}$ would increase with increasing $\mathrm{SO}_{3}$ concentration. This implies positive solubility slope as $\mathrm{SO}_{3}$ concentration is low at the interface between metal and molten salt and high at the interface between molten salt and flue gas. Therefore, this positive solubility slope from isothermal condition cannot maintain continuous corrosion.

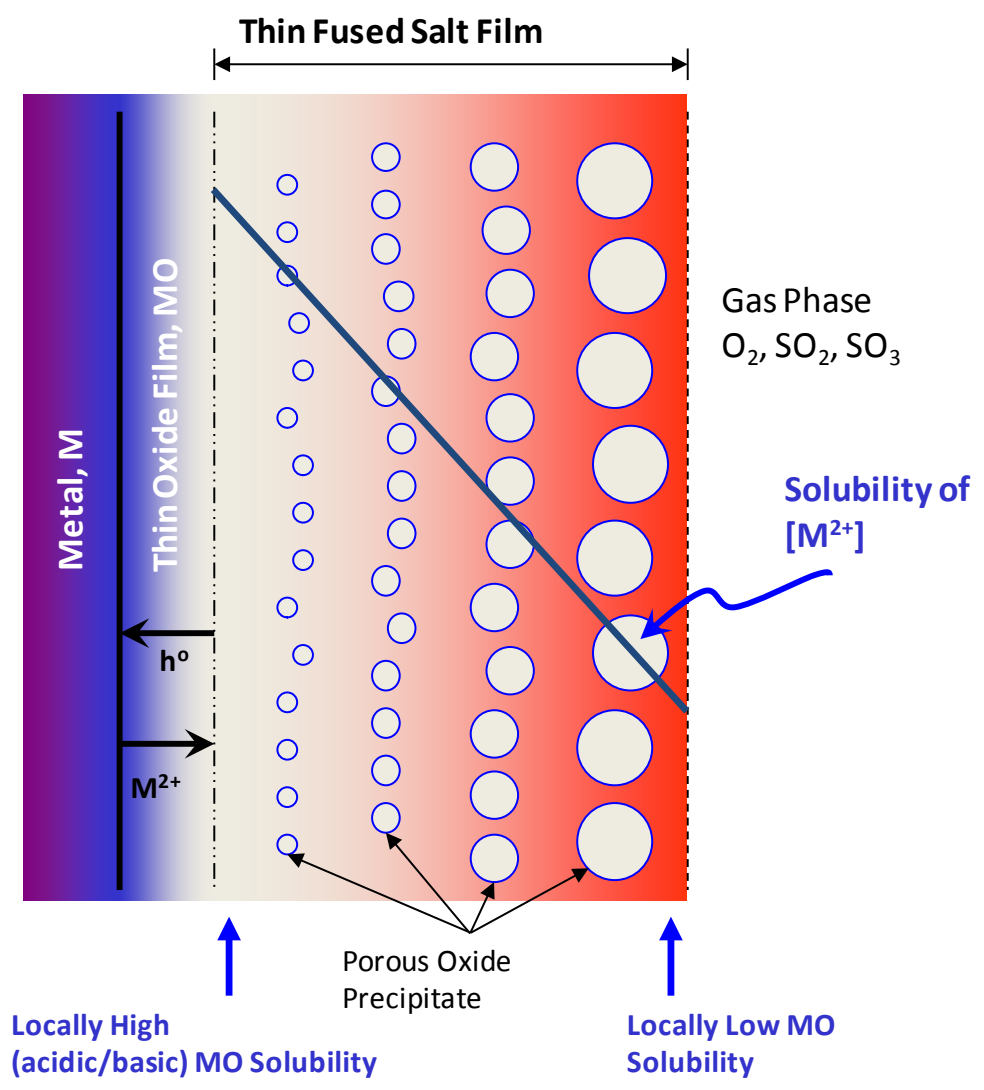

Figure 4.9-12: Precipitation of MO to form porous layer induced by the solubility gradient in a fused salt film (adapted from (Rapp 1986)).

However, actual conditions may be much more complex. A temperature gradient in the molten salt layer acts against the influence of $\mathrm{SO}_{3}$ concentration distribution in the layer (Cutler and Raask 1981) (Hendry and Lees 1980). Thermal gradient increases the solubility at the interface of metal and salt and decreases at the interface of salt and gas, as the corrosion product is more stable at lower temperature. The negative solubility slope from temperature gradient can overcome the positive solubility slope from $\mathrm{SO}_{3}$ concentration gradient, providing conditions suitable for continuous corrosion. Therefore, temperature gradient is very important to have sustained corrosion. However, if there are more than two metal species (products from corrosion), with different stabilities, the situation can be much more complex. For example $\mathrm{Cr}_{2} \mathrm{O}_{3}$ is more stable against acid fluxing than $\mathrm{Fe}_{3} \mathrm{O}_{4}$ or $\mathrm{Co}_{3} \mathrm{O}_{4}$ (Rapp 1986).

Presence of chlorides can affect the molten sulfate corrosion mechanism in the following ways (Nielsen, et al. 2000): 
1. Chloride can disintegrate the protective oxide scale. Normally $\mathrm{SO}_{2}$ and $\mathrm{SO}_{3}$ cannot diffuse through the scale, but, with disrupted oxide scale, $\mathrm{SO}_{2}$ and $\mathrm{SO}_{3}$ can react with tube metal directly.

2. Presence of chlorides in the alkali sulfate can decrease melting point and expand the temperature range that corrosion can occur as shown in Figure 4.9-11.

Many authors report that corrosion rate increases significantly when $\mathrm{NaCl}$ is added to alkali sulfate solution, even with only $1 \mathrm{wt} \%$ (Shirley 1956) (Lucas 1963) (Alexander 1963). The impact of this small increase in chloride concentration is bigger for austenitic metal than ferritic metal.

(McKee, Shores and Luthra 1978) reported experimental results on the role of $\mathrm{NaCl}$ in high temperature corrosion by $\mathrm{Na}_{2} \mathrm{SO}_{4}$ at $1292-1472^{\circ} \mathrm{F}\left(700-800^{\circ} \mathrm{C}\right)$. They observed significant increase in corrosion at about $1382^{\circ} \mathrm{F}\left(750^{\circ} \mathrm{C}\right)$ when $\mathrm{Na}_{2} \mathrm{SO}_{4}$ exists with $\mathrm{SO}_{2}$ and low concentrations of $\mathrm{NaCl}$ under an oxidizing environment. Without $\mathrm{SO}_{2}$ and $\mathrm{NaCl}$, only small corrosion occurred.

(Hancock 1987) reports that $\mathrm{NaCl}$ addition to $\mathrm{Na}_{2} \mathrm{SO}_{4}$ removes incubation time. Normally chrome enrichment in the metal can increase the resistance of alkali sulfate corrosion. However alkali metal chloride can destroy chromia allowing sulfur attack (Alexander 1963).

(Cutler, Grant, et al. 1983) confirmed that addition of $500 \mathrm{ppm} \mathrm{HCl}$ to the flue gas of a pilot-scale furnace could increase corrosion rate. When $\mathrm{HCl}$ is added, the corrosion temperature range was observed to be expanded. Authors report that adding $1 \mathrm{~mol} \% \mathrm{NaCl}$ does not have a large impact on corrosion. This contradicts (Alexander 1963)'s observation. The corrosion increase by $\mathrm{HCl}$ addition at the pilot-scale furnace may be from increased $\mathrm{K}$ release onto the deposit. Generally, the presence of chlorine specie can expand the bell shape temperature dependency shown in Figure 4.9-11.

(James and Pinder 1997) reports corrosion correlations for austenitic tube material:

$$
\text { CRate }=A \cdot B \cdot\left(\frac{T_{g}}{1000}\right)^{\alpha} \cdot\left(\frac{T_{m}-550}{100}\right)^{\beta} \cdot(C l-0.06)
$$

Where CRate is the corrosion rate, $A$ is the tube location, $B$ is chromium content in alloy ( 1 for $18 \%$ CR steel and 0.4 for Type 310$), T_{g}$ is gas temperature $\left(605^{\circ} \mathrm{C}<\mathrm{T}_{\mathrm{g}}<1200^{\circ} \mathrm{C}\right), T_{m}$ is metal temperature $\left(870^{\circ} \mathrm{C}\right.$ $<\mathrm{T}_{\mathrm{m}}<680^{\circ} \mathrm{C}$ ), $\mathrm{Cl}$ represents corrosivity of fuel (chlorine content).

Authors report that the corrosion behavior for low alloy ferritic material is elusive and transition from gaseous to molten corrosion may occur. Generally, $0.1 \%$ increase in chlorine gives $16 \mathrm{~nm} / \mathrm{h}$ increases in corrosion rate.

\subsubsection{Chloridation}

Historically, high fuel chlorine content has been associated with high waterwall corrosion rates in UK pulverized coal furnaces. Recently, a similar problem has developed in US furnaces, although some studies have indicated that burning high chlorine coal does not always lead to accelerated metal corrosion (Ho and Doane 2001). Chlorine corrosion or chloridation may need proper transport mechanism for chlorine to the tube metal surface. Increased understanding of chlorine based corrosion is currently a very active area of research.

(Nielsen, et al. 2000) and (Baxter, et al. 2001) have investigated the mechanisms of chlorine based corrosion. Gaseous phase attack may occur through exposure to gaseous $\mathrm{HCl}$ or $\mathrm{Cl}_{2}$. High rates of metal loss have been associated with the formation of alkali chloride deposits. In general, chlorine corrosion 
occurs in high heat flux, reducing regions when the fuel chlorine content is approximately $0.2 \%$ or higher (James and Pinder 1997) (James and Pinder 1997). Gaseous phase chlorine based corrosion may occur under oxidizing conditions through an “active oxidation” mechanism (Spiegel, Zahs and Grabke 2002).

Sulfur in the presence of chlorine can have different roles in corrosion depending on local environment. Under reducing conditions, metal loss through sulfidation may be accelerated by the presence of chlorine (Uusitalo, Vuoristo and Mantyla 2002). Under reducing conditions alkali chlorides are stable, but under oxidizing conditions the conversion of alkali chlorides to less corrosion alkali sulfates is favored. Thus, the presence of fuel sulfur can provide some protection against chlorine attack under oxidizing conditions, but may enhance sulfidation instead. Chlorine gas forming high temperature gases such as $\mathrm{HCl}, \mathrm{KCl}$, and $\mathrm{NaCl}$ can cause corrosion through different mechanism from molten sulfate corrosion. Condensed chloride on the tube surface can also affect corrosion. Corrosion can occur by gaseous specie, deposit, or the combination of these corrosive materials (Nielsen, et al. 2000).

In the following sections, thermodynamic stabilities of metal oxides and chlorides will be first discussed, followed by discussion on the more details of the chlorine corrosion mechanisms. Understanding thermodynamic stability of metal chlorides and oxides is useful in discussing chlorine related corrosion mechanisms. The corrosion mechanisms by chlorine containing species under various environments are well surveyed by (Nielsen, et al. 2000) and summarized here.

\subsection{Thermodynamic Stability of Metal Oxides and Chlorides}

Thermodynamic stability of the metal oxides and chlorides under a given temperature can be understood through an Ellingham-Pourbaix stability diagram which illustrates the type of corrosion product that would be stable under given oxygen and chlorine partial pressures. Figure 4.9-13 shows the stability of the corrosion products of the alloy with $\mathrm{Fe}, \mathrm{Cr}$, and $\mathrm{Ni}$ as main components at $727^{\circ} \mathrm{C}$. It depends on actual chlorine and oxygen partial pressures, but oxides are more stable than chlorides under low chlorine partial pressure. On the other hand, metal chlorides are more stable at high chlorine and low oxygen partial pressures.

Metal chlorides exist as a solid at normal superheater metal temperatures, but they are known to have high vapor pressure even at relatively low temperature. This can lead to the vaporization of the metal chlorides and rapid metal wastage. It is suggested that when the vapor pressure of corrosion products is higher than $10^{-6} \mathrm{~atm}$, the vaporization can affect corrosion mechanism significantly (McNallan 1998) and many authors agree that when the vapor pressure is higher than $10^{-4} \mathrm{~atm}$, the material's vaporization can be main corrosion mechanism (McNallan 1998) (Grabke 1989). When the chlorides melt due to increase in temperature, oxidation and chloridation can be accelerated. This is due to fluxing of the oxide scale on the metal surface. However, the melting of the metal chlorides occurs at narrow temperature range and the metal chlorides can evaporate when the temperature increases further. 


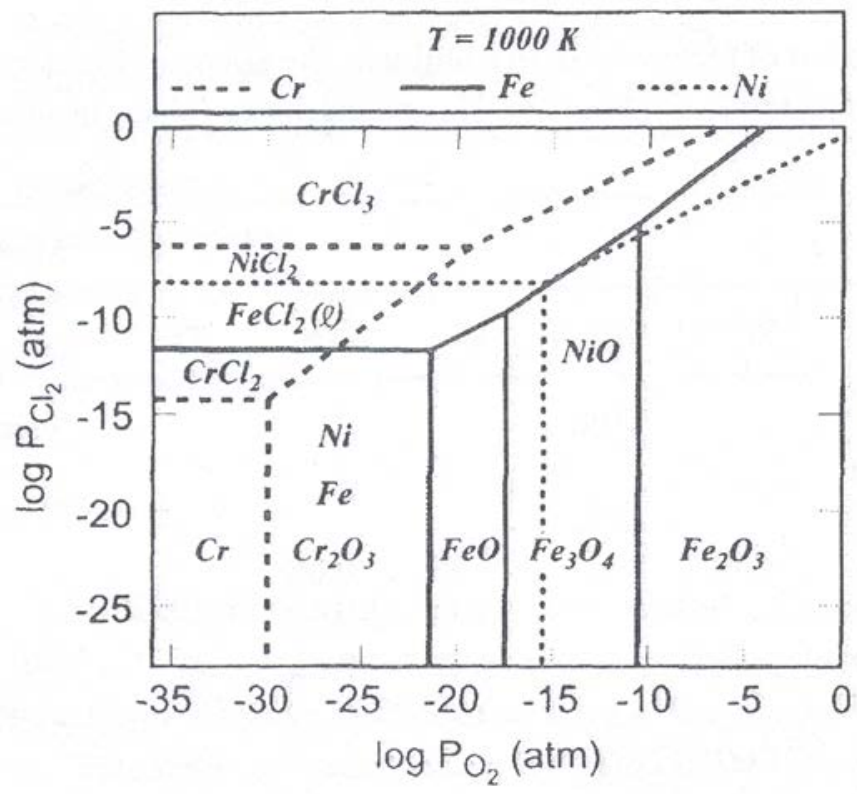

Figure 4.9-13: Stability diagram of $\mathrm{Cr} / \mathrm{Fe} / \mathrm{Ni}-\mathrm{O}-\mathrm{Cl}$ at $727^{\circ} \mathrm{C}$ (adapted from (Grabke 1989))

Table 4.9-1 shows the melting point and the temperature of various metal chlorides when the vapor pressure reaches $10^{-4} \mathrm{~atm}$. Note that the melting temperature of $\mathrm{FeCl}_{3}$ is significantly low. Figure 4.9-14 shows the vapor pressure of the condensed chlorides as a function of temperature. The vapor pressure of the metal chlorides as well as the stability of the oxides under given oxygen partial pressure can determine corrosion propensity. Chromium is usually added into the metal to increase corrosion resistance. Once chromium chloride is formed, however, the metal wastage can be accelerated even with low vapor pressure of chromium chlorides due to highly stable chromia $\left(\mathrm{Cr}_{2} \mathrm{O}_{3}\right)$ formation under even low oxygen partial pressure. This type of enhanced corrosion depends on acting corrosion mechanism and will be discussed later. The stability and the vapor pressure of the metal oxides and chlorides can describe various metals’ vaporization and therefore qualitative corrosion propensities.

Table 4.9-1: Melting point $\left(T_{m}\right)$ and temperature $\left(T_{4}\right)$ at which the chloride vapor pressure is equal to $10^{-4} \mathrm{~atm}$ (adapted from (Grabke 1989)).

\begin{tabular}{lll}
\hline Chloride & $\mathrm{T}_{\mathrm{m}},{ }^{\circ} \mathrm{C}$ & $\mathrm{T}_{4},{ }^{\circ} \mathrm{C}$ \\
\hline $\mathrm{FeCl}_{3}$ & 303 & 167 \\
$\mathrm{FeCl}_{2}$ & 676 & 536 \\
$\mathrm{NiCl}_{2}$ & 1,030 & 607 \\
$\mathrm{CoCl}_{2}$ & 740 & 587 \\
$\mathrm{CrCl}_{2}$ & 820 & 741 \\
$\mathrm{CrCl}_{3}$ & 1,150 & 611 \\
\hline
\end{tabular}




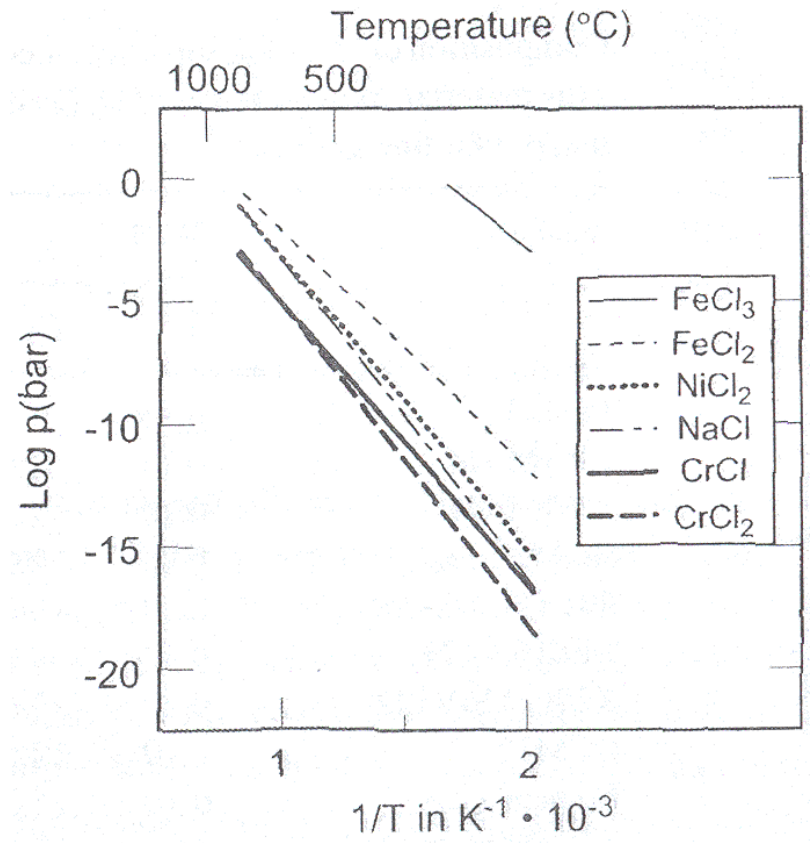

Figure 4.9-14: Vapor pressures of condensed chlorides (adapted from (Grabke 1989)).

\subsection{Corrosion under Oxidizing Environment}

When metal is exposed to high temperature oxidizing environment, the metal will form thermodynamically stable oxides that can provide protection from diffusion of oxygen or other gas species to the metal surface. However, in the presence of chlorine, the formation of protective oxide scale is inhibited and the corrosion of the metal can be accelerated (Nielsen, et al. 2000) (Albina, Millrath and Themelis 2004) (Sander, et al. 2000) (Montgomery, Larsen and Biede 2003) (Spiegel, Zahs and Grabke 2002) (Grabke, Reese and Spiegel 1995). This is called "Active Oxidation.” In this mechanism, the source of chlorine can be in the form of $\mathrm{HCl}$ or $\mathrm{Cl}_{2}$, or in the combined form with $\mathrm{Na}, \mathrm{K}, \mathrm{Zn}, \mathrm{Pb}$, and $\mathrm{Sn}$. Small changes in temperature or partial pressure of oxygen and chlorine are reported to affect the corrosion behavior. This active oxidation mechanism is known to be effective at the metal temperatures above $450^{\circ} \mathrm{C}$. Overall reaction pathway of active oxidation mechanism is shown in Figure 4.9-15. 


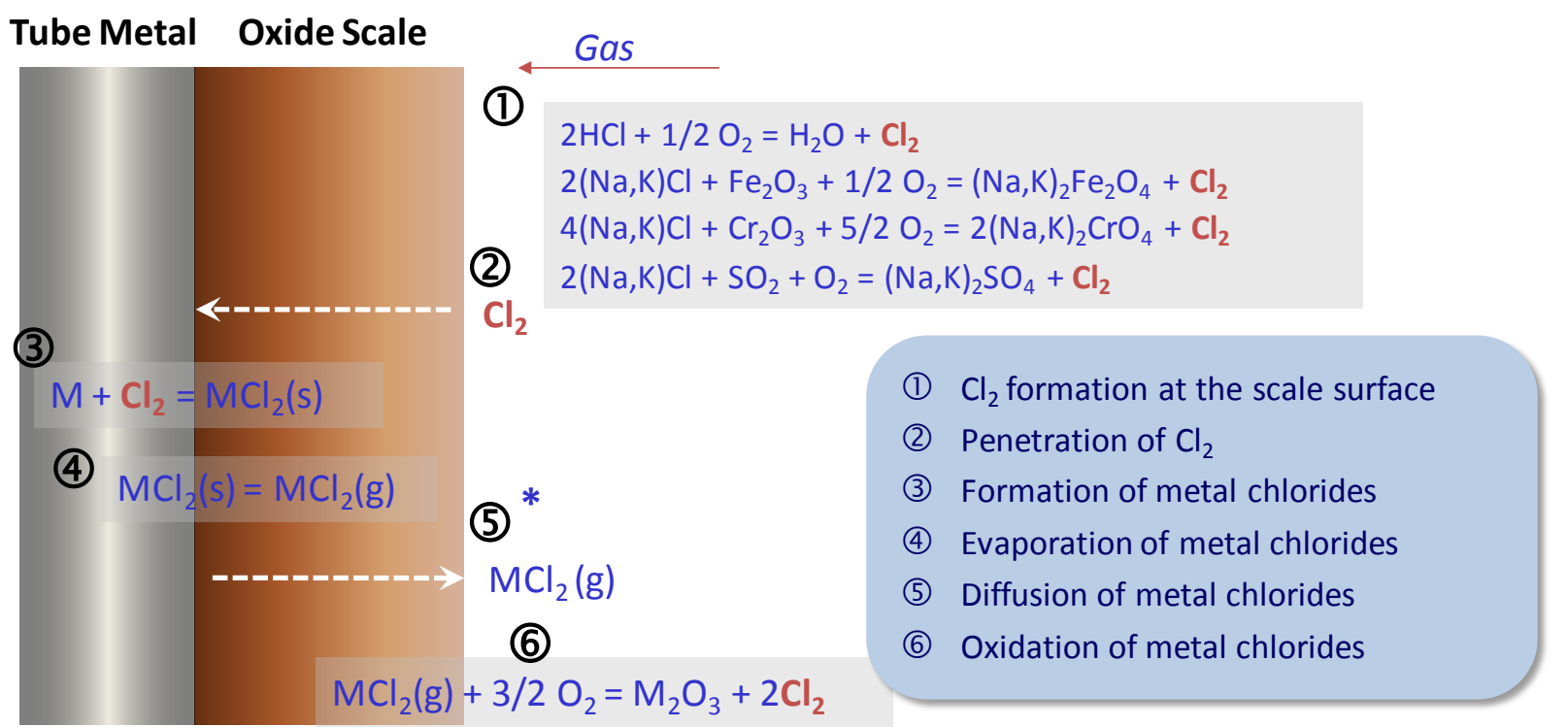

Figure 4.9-15: Overall reaction paths in active oxidation mechanism.

In this mechanism, $\mathrm{Cl}_{2}$ is formed through either the oxidation of $\mathrm{HCl}$ on the oxide scale or the reaction of the oxide scale with $\mathrm{NaCl}$ or $\mathrm{KCl}$ condensed on the scale:

$$
\begin{gathered}
2 \mathrm{HCl}+\frac{1}{2} \mathrm{O}_{2}=\mathrm{H}_{2} \mathrm{O}+\mathrm{Cl}_{2} \\
2(\mathrm{Na}, \mathrm{K}) \mathrm{Cl}+\mathrm{Fe}_{2} \mathrm{O}_{3}+\frac{1}{2} \mathrm{O}_{2}=\left(\mathrm{Na}, \mathrm{K}_{2} \mathrm{Fe}_{2} \mathrm{O}_{4}+\mathrm{Cl}_{2}\right. \\
4(\mathrm{Na}, \mathrm{K}) \mathrm{Cl}+\mathrm{Cr}_{2} \mathrm{O}_{3}+\frac{5}{2} \mathrm{O}_{2}=2\left(\mathrm{Na}, \mathrm{K}_{2} \mathrm{CrO}_{4}+2 \mathrm{Cl}_{2}\right.
\end{gathered}
$$

The $\mathrm{Cl}_{2}$ can access to the metal surface through the cracks or the pores of the oxide scale and react with iron or alloy component such as chromium and nickel to form metal chloride at the tube metal surface. This metal chloride is formed because oxygen partial pressure is low at the metal surface and relatively volatile $\mathrm{FeCl}_{2}$ and $\mathrm{CrCl}_{2}$ are thermodynamically stable (Figure 4.9-13 and Figure 4.9-14). This reaction at the interface of metal and oxide scale can be represented as:

$$
M(s)+C l_{2}(g)=M C l_{2}(s)
$$

where $\mathrm{M}$ is metal component such as $\mathrm{Fe}$, $\mathrm{Cr}$, or Ni. Metal chloride can form through direct reaction between metal and $\mathrm{HCl}$ as in the following reaction:

$$
M(s)+2 H C l(g)=M_{2}(s)+H_{2}(g)
$$


Vapor pressure of metal chlorides at the interface of metal and oxide scale can be very high (ex. $\mathrm{FeCl}_{2}$ vapor pressure is $4 \times 10^{-5} \mathrm{~atm}$ at $500^{\circ} \mathrm{C}$ ) and continuous vaporization can occur.

$$
\mathrm{MCl}_{2}(s)=\mathrm{MCl}_{2}(g)
$$

Vaporized chlorides can diffuse out through crack or pore of the oxide scale and reach a region that has high oxygen partial pressure. Then, the metal chloride is oxidized to from metal oxides $\left(\mathrm{M}_{3} \mathrm{O}_{4}\right.$ or $\left.\mathrm{M}_{2} \mathrm{O}_{3}\right)$ :

$$
\begin{aligned}
& 2 \mathrm{MCl}_{2}(g)+\frac{3}{2} \mathrm{O}_{2}(g)=\mathrm{M}_{2} \mathrm{O}_{3}(s)+2 \mathrm{Cl}_{2}(g) \\
& 3 \mathrm{MCl}_{2}(g)+2 \mathrm{O}_{2}(g)=\mathrm{M}_{3} \mathrm{O}_{4}(s)+3 \mathrm{Cl}_{2}(g)
\end{aligned}
$$

These solid oxides form loose metal oxide layer and do not provide protection against further metal surface attack. The $\mathrm{Cl}_{2}$ formed from these reactions can diffuse out to bulk gas or in to the metal surface to re-iterate the aforementioned reaction steps. This leads to migration of metal component from the metal surface to high partial oxygen pressure region without losing much of $\mathrm{Cl}_{2}$ to bulk gas.

Among the metal chlorides, $\mathrm{FeCl}_{2}$ is the main chloride that is vaporized due to its relatively high vapor pressure. However chromium can also participate in active oxidation mechanism and various studies report that main chloride can be chromium chloride (Harb and Smith 1990) (Montgomery, Larsen and Biede 2003). This is because chromium has more affinity to chlorine than other metal components such as Fe and Ni based on Gibb's free energy calculation and chromium chloride can be oxidized at relatively low oxygen partial pressure due to the chromium oxides' high stability (see Figure 4.9-13). Iron chloride with higher vapor pressure than chromium chloride move more toward outer area and is oxidized at higher oxygen partial pressure. Therefore iron chloride can form oxides near the outer surface of the scale than the chromium oxides. At low temperature, chromium chloride cannot vaporize, but iron chloride can still vaporize and accelerate active oxidation mechanism. At high temperature, high affinity to chlorine can lead to grain boundary corrosion and chromium does not provide protective oxide scale. With decreasing temperature, volatility of the metal chloride can become more important.

According to (Grabke, Reese and Spiegel 1995), the governing reaction of active oxidation mechanism is the outward diffusion of metal chlorides through porous scale (Figure 4.9-15 step (5)). (Grabke, Reese and Spiegel 1995) also argues that the inward diffusion of the chlorine gas through the oxide scale is not clear (Figure 4.9-15 step (2)). The active oxidation mechanism proceeds without any incubation time upon the introduction of the chlorine specie, based on their experiment. The authors said that the solid state diffusion, the grain boundary diffusion, or the molecular diffusion through the cracks or the pores of the oxide scales would not be fast enough to explain this result and concluded that the chlorine species would form a certain fast diffusion pathway such as the grooves and fissures at the grain boundary. (Mayer and Manolescu 1979) and (McNallan 1994) also report similar phenomena. (Mayer and Manolescu 1979) studied how the structure of the oxide scale changed when the $\mathrm{HCl}$ concentration increased in a flue gas. When there was no $\mathrm{HCl}$ in the flue gas, continuous oxide scale without pores was observed. When the $\mathrm{HCl}$ concentration increased to $0.1 \mathrm{vol} \%$, there were some pores in the hematite $\left(\mathrm{Fe}_{2} \mathrm{O}_{3}\right)$ scale, but the scale was still continuous. With 0.2 vol\% of $\mathrm{HCl}$, more pores in the scale were observed and the scale was not continuous anymore. With $0.8 \mathrm{vol} \%$ of $\mathrm{HCl}$, the hematite scale was totally disintegrated and the magnetite $\left(\mathrm{Fe}_{3} \mathrm{O}_{4}\right)$ scale became irregular with many pores. When the $\mathrm{HCl}$ concentration was further increased to $2 \mathrm{vol} \%$, all of the scales were disintegrated and the corrosive gases could access the metal surface freely. Other researchers report the internal attack after the exposure to 
chlorine environment. The internal attack can occur near the grain boundary and can be related to internal chromium carbide formation (McNallan 1994).

Sulfidation of the alkali chloride deposit can accelerate active oxidation (Nielsen, et al. 2000) (Grabke, Reese and Spiegel 1995) (Miler, et al. 1972). The alkali chloride deposit can react with $\mathrm{SO}_{2}$ in oxidizing environment to form $\mathrm{Cl}_{2}$ or $\mathrm{HCl}$ in the presence of $\mathrm{H}_{2} \mathrm{O}$.

$$
\begin{gathered}
2(\mathrm{Na}, \mathrm{K}) \mathrm{Cl}(\mathrm{s})+\mathrm{SO}_{2}(g)+\mathrm{O}_{2}(g)=(\mathrm{Na}, \mathrm{K})_{2} \mathrm{SO}_{4}(\mathrm{~s})+\mathrm{Cl}_{2}(g) \\
2(\mathrm{Na}, \mathrm{K}) \mathrm{Cl}(\mathrm{s})+\mathrm{SO}_{2}(g)+\frac{1}{2} \mathrm{O}_{2}(g)+\mathrm{H}_{2} \mathrm{O}(\mathrm{g})=\left(\mathrm{Na}, \mathrm{K}_{2} \mathrm{SO}_{4}(\mathrm{~s})+2 \mathrm{HCl}(\mathrm{g})\right.
\end{gathered}
$$

$\mathrm{Cl}_{2}$ and $\mathrm{HCl}$ can diffuse in toward the metal surface and form volatile metal chlorides $\left(\mathrm{FeCl}_{2}\right.$ or $\left.\mathrm{CrCl}_{2}\right)$, and then corrosion reaction similar to active oxidation can occur. Then, some of the metal chlorides $\left(\mathrm{FeCl}_{2}\right.$ or $\left.\mathrm{CrCl}_{2}\right)$ can diffuse out toward the high oxygen partial pressure region and be oxidized to form metal oxides and $\mathrm{Cl}_{2}$ or $\mathrm{HCl}$ in the presence of $\mathrm{H}_{2} \mathrm{O}$ :

$$
4 \mathrm{MCl}_{2}(g)+4 \mathrm{H}_{2} \mathrm{O}(g)+\mathrm{O}_{2}(g)=2 \mathrm{M}_{2} \mathrm{O}_{3}(s)+8 \mathrm{HCl}(g)
$$

Here, $\mathrm{HCl}$ can react with $\mathrm{O}_{2}$ to form $\mathrm{Cl}_{2}$ :

$$
2 \mathrm{HCl}(g)+\frac{1}{2} \mathrm{O}_{2}(g)=\mathrm{Cl}_{2}(g)+\mathrm{H}_{2} \mathrm{O}(g)
$$

In the presence of $\mathrm{HCl}$, the following reaction can occur in the sulfate mixture in the deposit:

$$
\begin{aligned}
& (\mathrm{Na}, \mathrm{K})_{2} \mathrm{Ca}_{2}\left(\mathrm{SO}_{4}\right)_{3}(\mathrm{~s})+2 \mathrm{HCl}(\mathrm{g})= \\
& 2(\mathrm{Na}, \mathrm{K}) \mathrm{Cl}+2 \mathrm{CaSO}_{4}+\mathrm{SO}_{2}(\mathrm{~g})+\frac{1}{2} \mathrm{O}_{2}(g)+\mathrm{H}_{2} \mathrm{O}(\mathrm{g})
\end{aligned}
$$

This reaction can form metal chlorides at the interface of the scale and the deposit and the metal chloride can react with the scale to form $\mathrm{Cl}_{2}$. Then, "Active Oxidation" can be accelerated. Sulfates and $\mathrm{SO}_{2}$ from the aforementioned reactions can diffuse toward the interface of the metal and the scale and cause corrosion through "Molten Sulfate" corrosion mechanism. This pathway has been validated through identification of FeS after the experiment. (Grabke, Reese and Spiegel 1995) says that the sulfidation of the metal chloride occurs at the outer surface of the deposit and therefore $\mathrm{Cl}_{2}$ and $\mathrm{HCl}$ are lost in the outer environment and only small parts diffuse toward the metal surface. Sulfidation in solid state can occur by $\mathrm{SO}_{2}$ or $\mathrm{SO}_{3}$ (much faster with $\mathrm{SO}_{3}$ ). Small concentration of $\mathrm{SO}_{3}$ can exist in the bulk, but can increase due to catalytic reaction with $\mathrm{Fe}_{2} \mathrm{O}_{3}$ in the deposit as discussed in the molten sulfate mechanism.

\subsection{Corrosion under Reducing Environment}

Schematic of the chlorine related corrosion under reducing environment is shown in Figure 4.9-16. Under reducing environment, the oxide scale does not exist or exists non-uniformly (step (1)). Chlorine can diffuse in and access the metal surface easily under this environment (step (2)) and react with the metal surface to form metal chloride (step (3): 


$$
\begin{gathered}
M(s)+\mathrm{Cl}_{2}(g)=\mathrm{MCl}_{2}(s) \\
M(s)+\mathrm{HCl}(g)=\mathrm{MCl}_{2}(s)+\mathrm{H}_{2}(g)
\end{gathered}
$$

The metal chloride formed on the metal surface can act as protective scale under stable condition, but mostly can lead to metal wastage due to relatively high vapor pressure of the metal chloride. Corrosion rate by chlorine specie is governed by the volatilization of the metal chloride (see Figure 4.9-14) and, therefore, has high dependency on the temperature (step (4) in Figure 4.9-16).

$$
\mathrm{MCl}_{2}(s)=\mathrm{MCl}_{2}(g)
$$

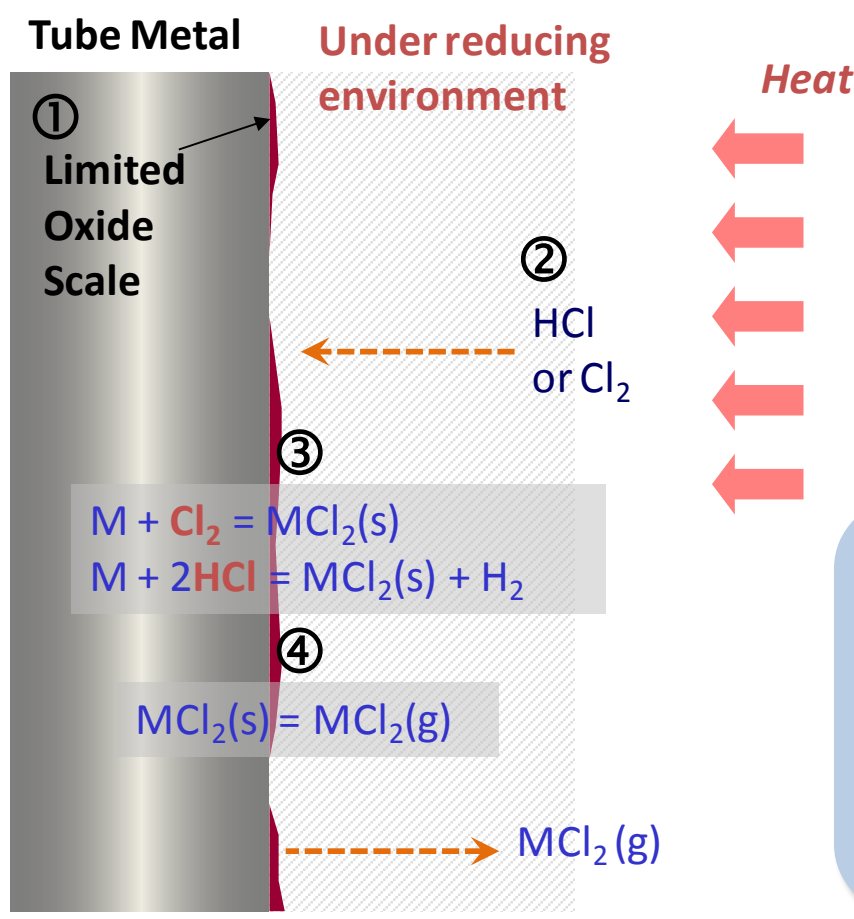
(1) Limited oxide scale formation under reducing environment
(2) $\mathrm{Cl}_{2}$ diffusion to the surface
(3) Formation of metal chlorides
(4) Evaporation of metal chlorides
(5) Diffusion of metal chlorides

Figure 4.9-16: Schematic of $\mathrm{Cl}$ corrosion mechanism under reducing environment.

Chlorine corrosion correlation has been developed to predict waterwall corrosion rate. One of the rate correlations developed in U.K. is (James and Pinder 1997):

$$
C R=1350 \times(\% C l)+780 \times(H F)+413 \times(D F)-743
$$

$C R:$ corrosion rate $(\mathrm{nm} / \mathrm{hr})$

$\% \mathrm{Cl}$ : chlorine content in fuel (weight \%)

$H F$ : heat flux factor related to burner level heat transfer area

$D F$ : deposit factor related to burner operating conditions, coal particle size, distance between burner and side wall. 
(Davis, et al. 2001) have developed empirical correlations for chlorine corrosion rate under reducing environment. When oxygen concentration is less than $0.5 \%$ and $\mathrm{CO}$ higher than $2 \%$, the chlorine corrosion rate is a function of chlorine content in fuel and can be expressed as the following equation:

$$
A C R=(C \times \% C l) \times(H F)^{m} \times \exp \left(-\frac{Q_{c l}}{R T}\right)-d
$$

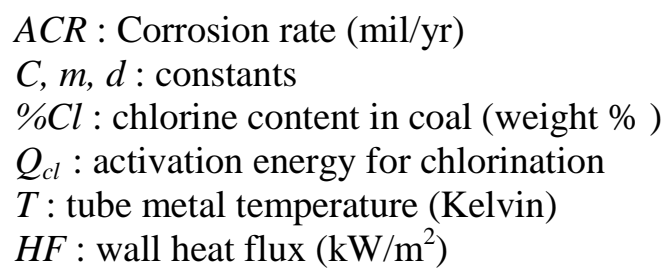

The rate correlations discussed above assume uniform distribution of chlorine gas specie in the furnace and do not consider local variations.

Whether or not chloride scale growth rate can provide enough amounts for volatilization can determine corrosion rate behavior (Chang and Wei 1991). At temperatures below $500^{\circ} \mathrm{C}$, metal chloride formed on the metal surface can provide protective scale and show parabolic corrosion behavior as a function of time. At higher temperature, weight initially shows parabolic increase, but becomes linear as a function of time. When this transition occurs, the scale does not grow anymore and the scale thickness at the transition point is called critical thickness. This point depends on temperature, environment and nature of chlorides. At temperatures higher than $800^{\circ} \mathrm{C}$, the growth rate of chlorides is not fast enough to be able to provide enough amounts for volatilization and corrosion rate shows linear weight loss as a function of time. (Ihara, et al. 1981) reports that when oxygen is added in $\mathrm{HCl}$ gas, ferric chloride, $\mathrm{FeCl}_{3}$ is formed from oxidation and chloridation. Ferric chloride with low melting point can show sublimation and the corrosion of iron metal can be significantly accelerated.

$$
\mathrm{FeCl}_{2}+\mathrm{HCl}+\frac{1}{4} \mathrm{O}_{2}=\mathrm{FeCl}_{3}+\frac{1}{2} \mathrm{H}_{2} \mathrm{O}
$$

(Hupa, et al. 1989) report the high corrosion rate by $\mathrm{HCl}$ under reducing environment due to limited formation of metal oxide scale. They also reports that the corrosion rate increases by a factor of 2.5 when about $2 \%$ CO concentration is added. When CO is added further up to $10 \%$, the corrosion rates don't change much. Under reducing environments, destruction of oxide scale by $\mathrm{HCl}$ increases synergistically in the presence of $\mathrm{CO}$ and $\mathrm{H}_{2}$ (Harb and Smith 1990). In addition, the destruction of the oxide scale by $\mathrm{HCl}$ can accelerate the corrosion rates by other corrosion mechanisms. (Haanappel, et al. 1992) exposed various metals to $500 \mathrm{ppmv} \mathrm{HCl}$ in an environment similar to a coal gasifier. They report that the addition of $500 \mathrm{ppmv} \mathrm{HCl}$ in oxidizing-sulfidizing environment increases corrosion rate significantly and forms thick sulfide scale. The sulfide scale formed here cannot provide protection because the sulfide scale is porous and does not stick to the metal surface.

\subsection{Corrosion by Molten Chlorides}

Chloride mixture in chloride-chloride or chloride-sulfate system forms eutectic point and has relatively low melting point. Examples of the melting temperatures of pure material and mixtures of two materials are shown in Table 4.9-2. 
Table 4.9-2: Melting temperatures of eutectic temperatures for different pure species and binary mixtures (adapted from (Nielsen, et al. 2000)).

\begin{tabular}{|c|c|c|}
\hline System & $\begin{array}{l}\text { Melting/ eutectic } \\
\text { temperature, }{ }^{\circ} \mathrm{C}\end{array}$ & $\begin{array}{l}\text { Composition at } \\
\text { eutectic point } \\
\text { (mol\% alkali) }\end{array}$ \\
\hline $\mathrm{NaCl}$ & 801 & \\
\hline $\mathrm{KCl}$ & 772 & \\
\hline $\mathrm{FeCl}_{2}$ & 677 & \\
\hline $\mathrm{FeCl}_{3}$ & 300 & \\
\hline $\mathrm{NaCl}-\mathrm{FeCl}_{2}$ & $370-374$ & $\sim 56$ \\
\hline $\mathrm{NaCl}-\mathrm{FeCl}_{3}$ & 151 & 45.3 \\
\hline $\mathrm{KCl}-\mathrm{FeCl}_{2}$ & $340-393$ & $45.8-91.8$ \\
\hline $\mathrm{KCl}-\mathrm{FeCl}_{3}$ & 202 & $24-47$ \\
\hline $\mathrm{CrCl}_{2}$ & 845 & \\
\hline $\mathrm{CrCl}_{3}$ & 947 & \\
\hline $\mathrm{NaCl}-\mathrm{CrCl}_{2}$ & 437 & 53.7 \\
\hline $\mathrm{NaCl}-\mathrm{CrCl}_{3}$ & 544-593 & $68-95$ \\
\hline $\mathrm{KCl}-\mathrm{CrCl}_{2}$ & $462-475$ & $36-70$ \\
\hline $\mathrm{KCl}-\mathrm{CrCl}_{3}$ & 700-795 & $54-89$ \\
\hline $\mathrm{Na}_{2} \mathrm{CrO}_{4}$ & 792 & \\
\hline $\mathrm{K}_{2} \mathrm{CrO}_{4}$ & 980 & \\
\hline $\mathrm{NaCl}-\mathrm{Na}_{2} \mathrm{CrO}_{4}$ & 557 & \\
\hline $\mathrm{KCl}-\mathrm{K}_{2} \mathrm{CrO}_{4}$ & 650 & 68.4 \\
\hline $\mathrm{Na}_{2} \mathrm{Cr}_{2} \mathrm{O}_{7}$ & 356.7 & \\
\hline $\mathrm{K}_{2} \mathrm{Cr}_{2} \mathrm{O}_{7}$ & 398 & \\
\hline $\mathrm{NaCl}-\mathrm{Na}_{2} \mathrm{Cr}_{2} \mathrm{O}$ & 592 & 30 \\
\hline $\mathrm{KCl}-\mathrm{K}_{2} \mathrm{Cr}_{2} \mathrm{O}_{7}$ & $366-368$ & $25-27.5$ \\
\hline
\end{tabular}

When corrosive material exists on the metal surface in liquid form, the corrosion rate can be significantly enhanced by the following reasons (Kofstad 1988):

1) Chemical reaction is generally faster in liquid state than in solid state ,

2) Liquid state act as electrolyte and provide ion transfer path for electrochemical attack.

Overall reaction paths of the corrosion by molten chlorides are shown in Figure 4.9-17 using $\mathrm{KCl}-\mathrm{ZnCl}_{2}$ system as an example (Spiegel, Zahs and Grabke 2002). Corrosion reaction starts with the formation of $\mathrm{ZnFe}_{2} \mathrm{O}_{4}$ on the scale, which leads to higher $\mathrm{KCl}$ concentration in molten chloride due to consumption of $\mathrm{ZnCl}_{2}$. Large amount of $\mathrm{K}$ and small amount of $\mathrm{Zn}$ have been identified at the interface of metal and the scale, which means that molten material with high $\mathrm{K}$ diffused through the scale, reached to the metal surface, and formed metal chloride by dissolving iron and chromium. Oxidant, chlorine gas is formed through the following reaction and resides in molten material.

$$
\mathrm{ZnCl}_{2}(\mathrm{l})+\mathrm{Fe}_{2} \mathrm{O}_{3}+\frac{1}{2} \mathrm{O}_{2}=\mathrm{ZnFe}_{2} \mathrm{O}_{4}+\mathrm{Cl}_{2} \text { (diss.) }
$$

Then, the molten material with chlorine in it moves toward metal surface and react with metal component.

$$
\mathrm{Fe}+\mathrm{Cl}_{2} \text { (diss.) }=\mathrm{FeCl}_{2} \text { (diss.) }
$$




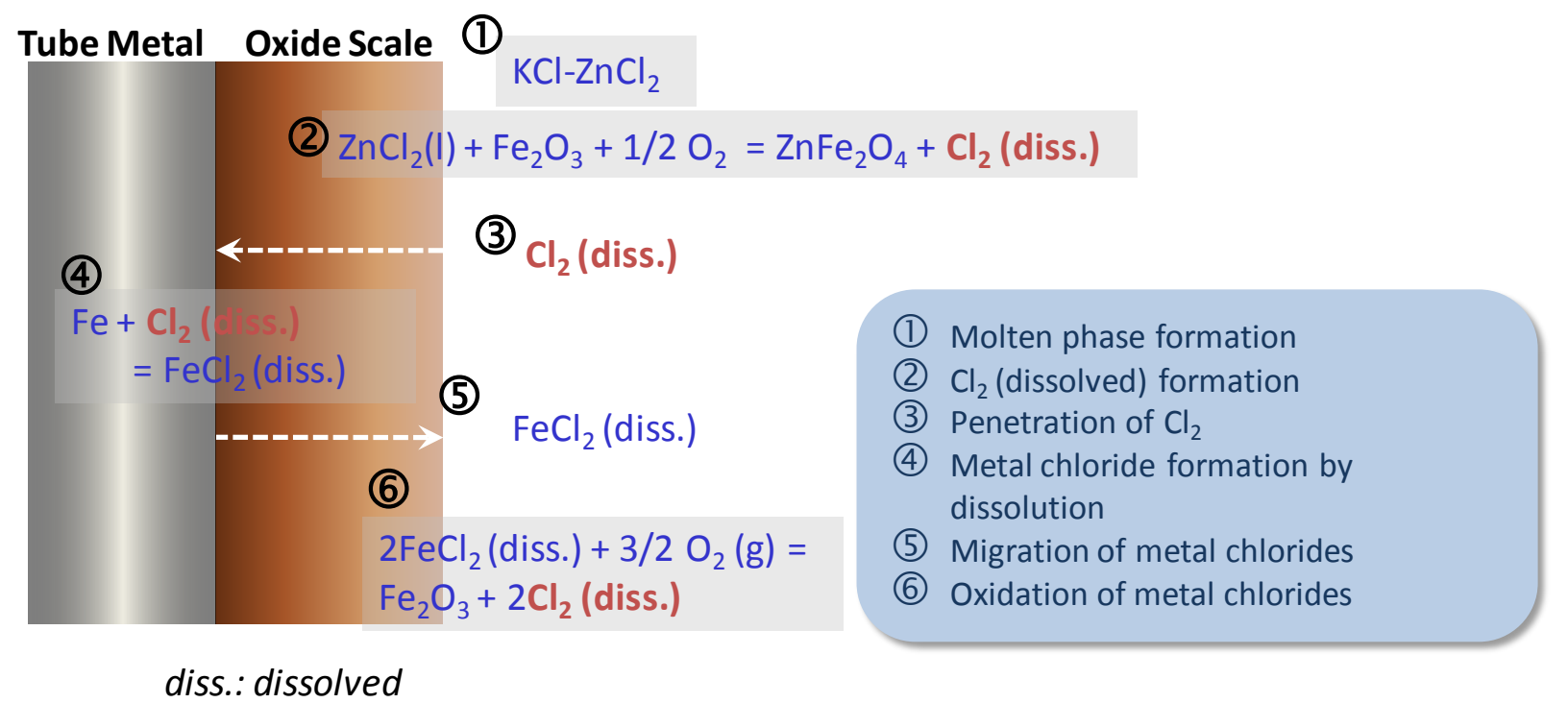

Figure 4.9-17: Overall reaction paths in molten chloride corrosion.

Then, the dissolved $\mathrm{FeCl}_{2}$ diffuses toward outside due to concentration gradient (high at the interface of metal and scale and low at the interface of scale and gas) and reacts with oxygen:

$$
2 \mathrm{FeCl}_{2}(\text { diss. })+\frac{3}{2} \mathrm{O}_{2}(g)=\mathrm{Fe}_{2} \mathrm{O}_{3}+2 \mathrm{Cl}_{2} \text { (diss.) }
$$

Then, precipitation of $\mathrm{Fe}_{2} \mathrm{O}_{3}$ can occur in the oxide scale near the outside surface. Oxygen can diffuse through cracks and pores in the oxide scale toward the interface between the scale and the metal surface. Then solid oxide forms more at the interface and the corrosion rate can eventually decrease.

\subsection{Reaction between Chromium Carbide and $\mathrm{NaCl}$}

When $\mathrm{NaCl}$ deposits on the superheater, the corrosion rate of the alloy is accelerated at the temperature over $550^{\circ} \mathrm{C}$ (Fjujikawa and Maruyama 1987). This was reported to be due to general metal wastage and deeper internal penetration. This internal attack was assumed to be related to grain boundary carbide and was increased with increasing carbon content in the metal. Chromium in the metal increased corrosion at the temperature lower than $\mathrm{NaCl}$ melting temperature $\left(801^{\circ} \mathrm{C}\right)$, but reduced internal penetration attack. This was explained by the reaction of $\mathrm{NaCl}$ vapor and chromium carbide (Fjujikawa and Maruyama 1987) (Hiramatsu, et al. 1989):

$$
\mathrm{Cr}_{23} \mathrm{C}_{6}(s)+46 \mathrm{NaCl}(g)+52 \mathrm{O}_{2}(g)=23 \mathrm{Na}_{2} \mathrm{CrO}_{4}(s, l)+6 \mathrm{CO}_{2}(g)+23 \mathrm{Cl}_{2}(g)
$$

However, the chromium in the metal was reported to be an alloying component that increased corrosion resistance when the temperature was higher than $\mathrm{NaCl}$ melting point.

Reactions between $\mathrm{NaCl}$ and various metal chlorides have been studied by (Mobin and Malik 1992). TGA (Thermogravimetric Analyzer) was used in this study and the temperature ranges were $627-927^{\circ} \mathrm{C}$. The weights of iron and chromium carbide showed initial decrease then increase afterward. Initial weight loss was reported to be from $\mathrm{Cl}_{2}$ and $\mathrm{CO}_{2}$ release (Mobin and Malik 1992): 


$$
\mathrm{MC}(\mathrm{s})+2 \mathrm{NaCl}(s)+2 \mathrm{O}_{2}(g)=\mathrm{MO}(s)+\mathrm{Na}_{2} \mathrm{O}(\mathrm{s})+\mathrm{CO}_{2}(g)+\mathrm{Cl}_{2}(g)
$$

$\mathrm{Na}_{2} \mathrm{O}$ dissolves metal oxide and forms $\mathrm{Na}_{2} \mathrm{O}-\mathrm{MO}$ and $\mathrm{Cl}_{2}$ reacts with metal oxide to form metal chloride:

$$
\begin{gathered}
\mathrm{MO}(s)+\mathrm{Na}_{2} \mathrm{O}(s, l)=\mathrm{Na}_{2} \mathrm{O} \cdot \mathrm{MO}(s, l) \\
M O(s)+\frac{1}{2} \mathrm{Cl}_{2}(g)=\mathrm{MCl}(s, l, g)+\frac{1}{2} \mathrm{O}_{2}(g)
\end{gathered}
$$

Some metal chloride can volatilize and show less weight increase.

\subsubsection{Carburization}

When the metal contains the component that can form carbide and is exposed to high temperature where thermodynamic activity coefficient $\left(\mathrm{a}_{\mathrm{C}}\right)$ is high, then the metal can be carburized (John, Thompson and Karakaya 1990). Flue gas mixture in many systems consists of $\mathrm{CO}, \mathrm{CO}_{2}, \mathrm{CH}_{4}$, and $\mathrm{H}_{2}$. In oxy-firing system, high $\mathrm{CO}_{2}$ concentrations are expected due to flue gas recirculation. Carbide can form at or under the alloy metal surface. Carburization rate is often determined by the carbon transfer rate in the metal. Several possible reactions are:

$$
\begin{gathered}
7 \mathrm{Cr}+3 \mathrm{CH}_{4}=\mathrm{Cr}_{7} \mathrm{C}_{3}+6 \mathrm{H}_{2} \\
23 \mathrm{Cr}+6 \mathrm{CH}_{4}=\mathrm{Cr}_{23} \mathrm{C}_{6}+12 \mathrm{H}_{2} \\
3 \mathrm{Cr}+2 \mathrm{CH}_{4}=\mathrm{Cr}_{3} \mathrm{C}_{2}+4 \mathrm{H}_{2} \\
2 \mathrm{Mo}+2 \mathrm{CO}=\mathrm{Mo}_{2} \mathrm{C}+\mathrm{CO}_{2} \\
W+2 \mathrm{CO}=\mathrm{WC}+\mathrm{CO}_{2}
\end{gathered}
$$

The stability of the carbide is determined by carbon activity coefficient, $a_{C}$, that is defined by various gas species' relative amount, such as $\mathrm{H}_{2} / \mathrm{CH}_{4}$ or $\mathrm{CO} / \mathrm{CO}_{2}$ ratios. Based on the alloy composition, various carbide compositions are possible. Carburization rate is expected to increase with increasing $a_{C}$ and temperature. However, when $\mathrm{P}_{\mathrm{H} 2 \mathrm{~S}}$ becomes about $1 \times 10^{-4}$ atm, the carburization rate decreases. When $\mathrm{H}_{2} \mathrm{~S}$ concentration gets higher, then the major corrosion mechanism is changed to sulfidation.

\subsubsection{Dewpoint Corrosion}

Air heaters are typically operated at temperatures high enough to avoid condensation of acid gases in the flue gas; the species of primary concern in coal-fired boilers being $\mathrm{SO}_{3}$. However, other acid gases that should also be considered for potential involvement in dewpoint corrosion include $\mathrm{NO}_{2}, \mathrm{HCl}$, and $\mathrm{HBr}$. These acid gases will react/condense into acidic compounds such as $\mathrm{H}_{2} \mathrm{SO}_{4}, \mathrm{HNO}_{3}, \mathrm{HCl}$, and $\mathrm{HBr}$. Straightforward calculations of dewpoints based on fuel properties, assumptions related to $\mathrm{SO}_{2}$-to- $\mathrm{SO}_{3}$ 
conversion and temperatures encountered in air heaters or back-end ductwork of coal-fired boilers result in the behavior illustrated in Figure 4.9-18 (Meadowcroft and Cox 1985).

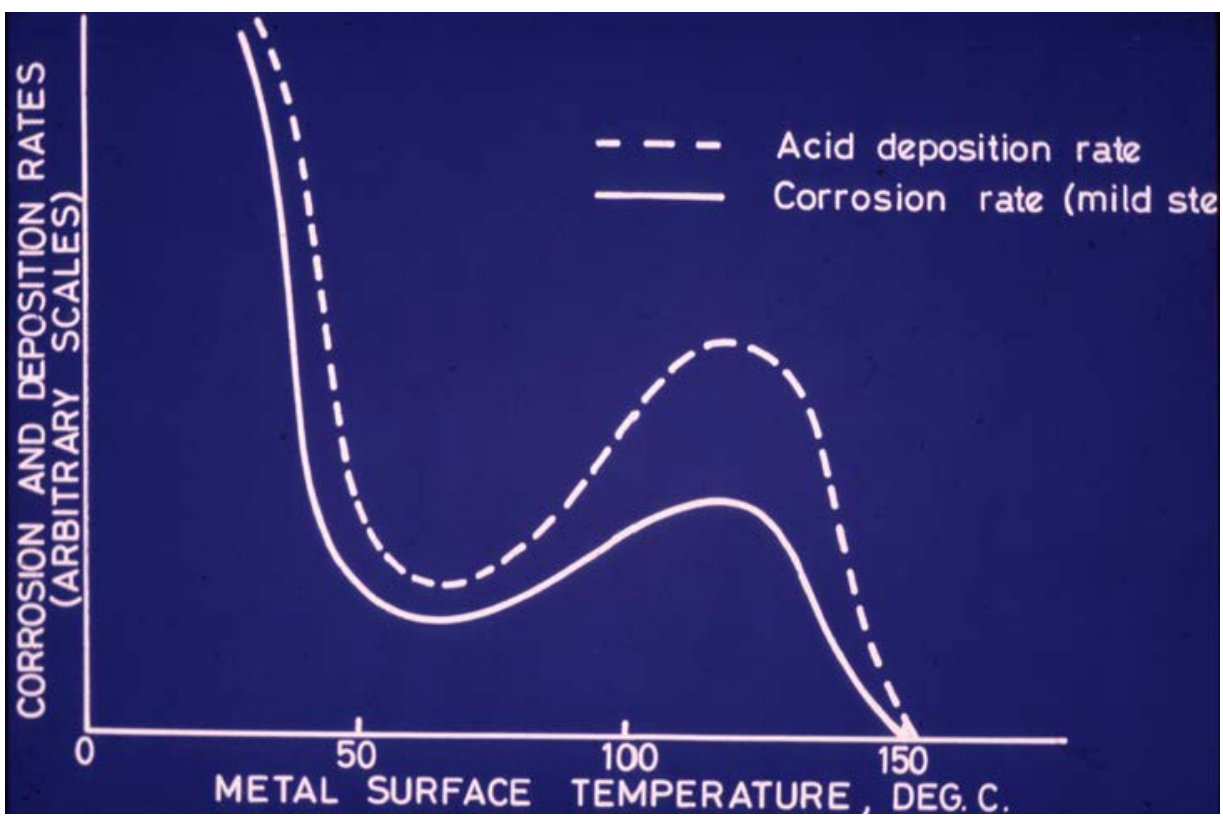

Figure 4.9-18: Classical acid deposition and corrosion rate behavior in a coal-fired boiler.

This behavior can be reproduced in laboratory environments. However, as observed in Figure 4.9-19 (Meadowcroft and Cox 1985) acid dewpoint behavior from field tests results in lower rates and requires lower temperatures.

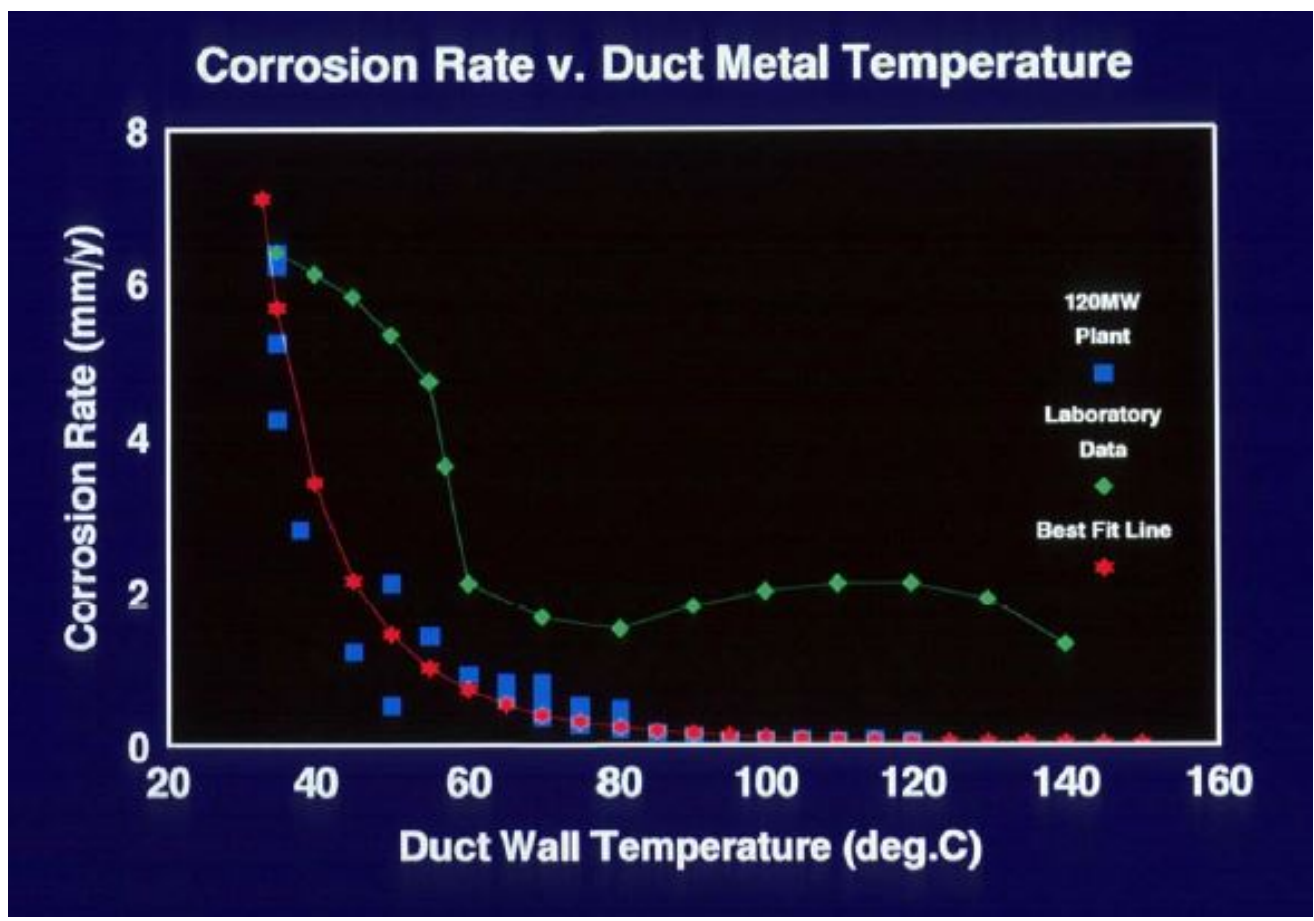

Figure 4.9-19: Comparison of laboratory and field corrosion rate data. 
The difference between plant and laboratory data is likely due to the presence of ash. Raask (Raask 1985) has used an air cooled probe in the air heater duct of two coal-fired boilers to measure the rate of deposition of sulfuric acid as a function of temperature. Boiler A burned a $0.9 \%$ sulfur coal with a low calcium ash, while Boiler B burned a 1.5\% sulfur coal with a high calcium ash. Figure 4.9-20 presents a selection of data from this testing which illustrates one aspect of the interaction between ash and $\mathrm{SO}_{3}$.

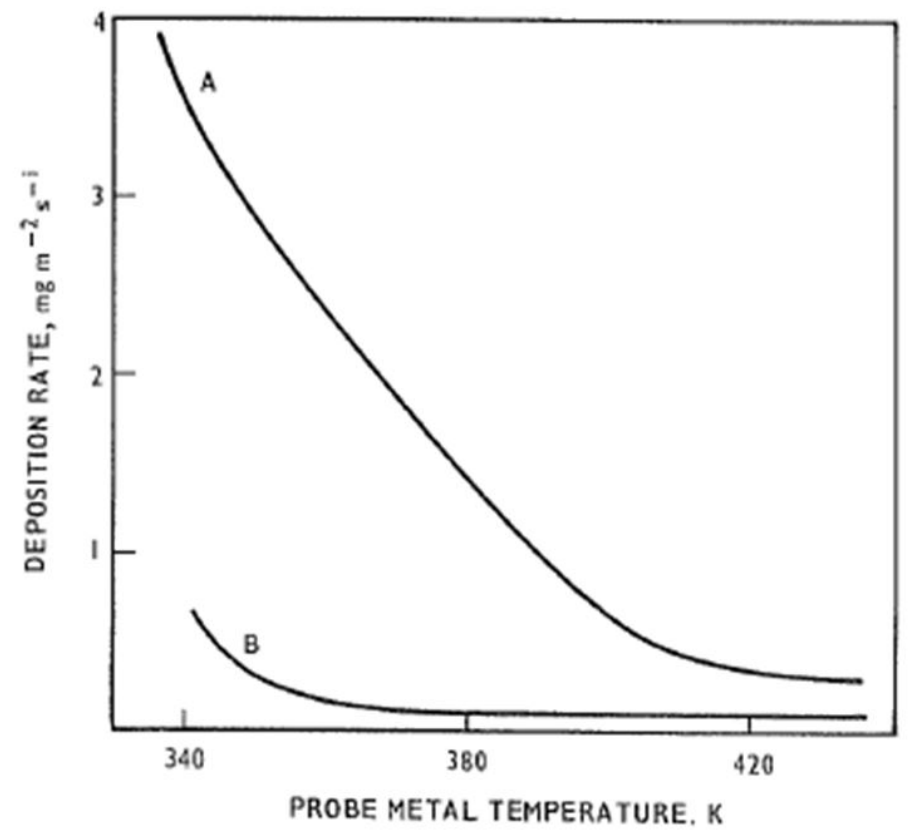

Figure 4.9-20: Acid deposition rate for two coals as a function of temperature.

This data points out an important aspect of the potential interactions between coal flyash and acid gases in that dewpoint corrosion in air heaters can require significantly lower temperatures than simple calculations might suggest. Under certain conditions these low acid dewpoints can result in conditions where the dewpoint of the acid gas will merge with that of water (Huijbregts and Leferink 2004).

The role of sulfur in air heater corrosion has been discussed for many years. Air heater corrosion involving halogens has been of lesser concern until recent regulations led to increasing utilization of halogen-containing compounds for oxidation and subsequent capture of mercury. In addition, tax credits associated with "refined coal" have led to relatively widespread use of halide fuel additives. The most common additive currently in use is calcium bromide and is emphasized in this project. In a recent survey funded by EPRI (Srinivasan and Dombroski 2013), 25 of 65 units that have been using bromine for mercury control for one year or longer have reported issues with air heater corrosion. The conditions that appear to be the most problematic are calcium bromide, PRB, and frequency of low load firing.

\subsubsection{Corrosion Under Oxy-firing Conditions}

The flue gas environment in oxy-firing conditions contains high concentrations of $\mathrm{CO}_{2}$ and $\mathrm{H}_{2} \mathrm{O}$ compared to conventional air-firing conditions and these conditions can affect the corrosion behavior of the metal. (Piron Abellan, et al. 2009) studied the oxidation behavior of martensitic 9-12\%Cr steels under simulated gas mixture containing $70 \% \mathrm{CO}_{2}-30 \% \mathrm{H}_{2} \mathrm{O}$ at the temperatures of $550-700^{\circ} \mathrm{C}$ in a laboratory. In their study, the iron-rich scales were formed at the metal surface instead of the more corrosion resistant $\mathrm{Cr}$-rich scale under the simulated environment. They report enhanced internal oxidation of chromium in the $\mathrm{H}_{2} \mathrm{O}$-containing gases and carbide formation in the $\mathrm{CO}_{2}$-rich gases caused a decreased flux of 
chromium toward the metal surface. The iron oxide scales formed in the simulated environment were reported to be permeable to $\mathrm{CO}_{2}$ resulting in substantial carburization of the steel (Piron Abellan, et al. 2009). In addition, $\mathrm{H}_{2} \mathrm{O}$-rich environment has been reported to form wüstite $(\mathrm{FeO})$ that does not provide protecting scale (Huenert and Kranzmann 2008) and exposes the metal surface for other corrosion attacks as well. On the other hand, in a 500kW oxy-fuel test rig study (Montgomery, Hjomhede and Gerhardt, Short-term Corrosion Testing in a burner rig with oxyfuel and conventional firing 2009) where solid fuels were actually fired under oxy-firing condition and the comparison between the oxy- and air-firing modes were performed, the difference in corrosion behavior between two different operating modes was not significant. This implies that gaseous attack by enhanced $\mathrm{CO}_{2}$ and/or $\mathrm{H}_{2} \mathrm{O}$ concentrations may not be significant and the corrosion may be dominated by other corrosion mechanisms. Further study is needed to clarify the importance of the changed flue gas environment in oxy-firing mode on corrosion.

\subsubsection{Experimental Setup}

In order to obtain a real-time indication of corrosion, a measurement system based on electrochemical noise sensing was utilized. The principle of operation of this corrosion sensing technique is that spontaneous fluctuations in the measured electrical potential and current signals are generated during electrochemical corrosion activity. These spontaneous transients are monitored and converted to digital signals and supplied to a computerized data acquisition unit. An estimate of the rate of corrosion can be made using the corrosion current density $I_{\text {corr }}$, which is obtained by replacing the polarization resistance $\left(R_{p}\right)$ with the noise resistance $\left(R_{n}\right)$ in the standard Stern-Geary equation (see Eq. 4.9-53) and converting the corrosion current value so obtained to an equivalent metal loss rate by application of Faraday's Law (Bakker, Mok and Cox, TR-101799 1992).

$$
I_{\text {corr }}=\frac{B}{R_{n}}
$$

where: $\mathrm{I}_{\text {corr }}$ - Corrosion current density

B - Stern-Geary coefficient

$\mathrm{R}_{\mathrm{n}}-$ Noise resistance

Corrosion rate is computed as a product of the corrosion current density and the material constant. The material constant is a term encompassing the atomic mass of the sensor electrode material, Faraday's constant, the number of electrons produced in the anodic reaction (2 electrons in this case), and the density of the material. This sensing technique was performed on corrosion elements fabricated from materials representative of heat transfer surfaces in high temperature combustion applications.

For this program, one waterwall material and three superheater tube materials were chosen that are typical of those used in US utility boilers. These materials were used for fabrication of the sensor elements in four separate sensor probes. The specifications of the materials chosen are presented in Table 4.9-3.

The materials shown in Table 4.9-3 are arranged in order of increasing alloy content from left to right. The SA210 material is a low-carbon steel that is commonly used to fabricate waterwall tubes in utility boilers and was used for the waterwall corrosion sensor in this investigation. The remaining three materials, T22, P91 and 347H, are commonly used in the construction of superheater tubing and each of these was used to create the sensor elements for superheater probes. The waterwall and superheater sensors differ in their physical construction. The sensor elements of the waterwall probe are at the tip of the probe on the flat surface of the probe. When installed in a furnace, the probe is positioned so that the front face of the probe is flush with the plane as the wall of the furnace. The elements of the superheater probe are rings of tubing that are cut from actual boiler tube. The corrosion surface of these elements has the standard mill finish. The superheater sensor elements are situated at the end of a long, cooled 
stainless steel lance. When inserted into the furnace, the orientation of the sensor elements is that of a tube in cross flow, precisely simulating the condition of a typical superheater tube in a utility boiler. The four probes used for this investigation are pictured in Figure 4.9-21.

Table 4.9-3: Specification of the Materials Used for Corrosion Sensor Elements.

\begin{tabular}{|c|c|c|c|c|}
\hline Material & SA 210 & T22 & P91 & 347H \\
\hline HT Surface & Waterwall & Superheat & Superheat & Superheat \\
\hline $\mathrm{C}, \%$ & 0.07 & 0.11 & 0.10 & 0.048 \\
\hline $\mathrm{Si} \%$ \% & 0.23 & 0.2 & 0.32 & 0.40 \\
\hline $\mathrm{Mn} \%$ \% & 0.42 & 0.44 & 0.47 & 1.32 \\
\hline $\mathrm{Ni} \%$ & - & - & 0.15 & 9.73 \\
\hline $\mathrm{Cr}, \%$ & - & 2.21 & 8.52 & 17.45 \\
\hline $\mathrm{Mo} \%$ & - & 0.95 & 0.93 & - \\
\hline $\mathrm{S}, \%$ & 0.002 & 0.003 & 0.002 & 0.008 \\
\hline $\mathrm{P}, \%$ & 0.009 & 0.01 & 0.018 & 0.026 \\
\hline $\mathrm{Cu}, \%$ & - & - & 0.11 & - \\
\hline $\mathrm{Al} \% \%$ & - & - & 0.01 & 0.005 \\
\hline $\mathrm{Nb} / \mathrm{Cb}, \%$ & - & - & 0.07 & 0.63 \\
\hline $\mathrm{V}, \%$ & - & - & 0.22 & 0.078 \\
\hline $\mathrm{N}, \%$ & - & - & 0.044 & - \\
\hline $\mathrm{Ta}, \%$ & - & - & - & 0.02 \\
\hline
\end{tabular}

\section{Superheat Probes}

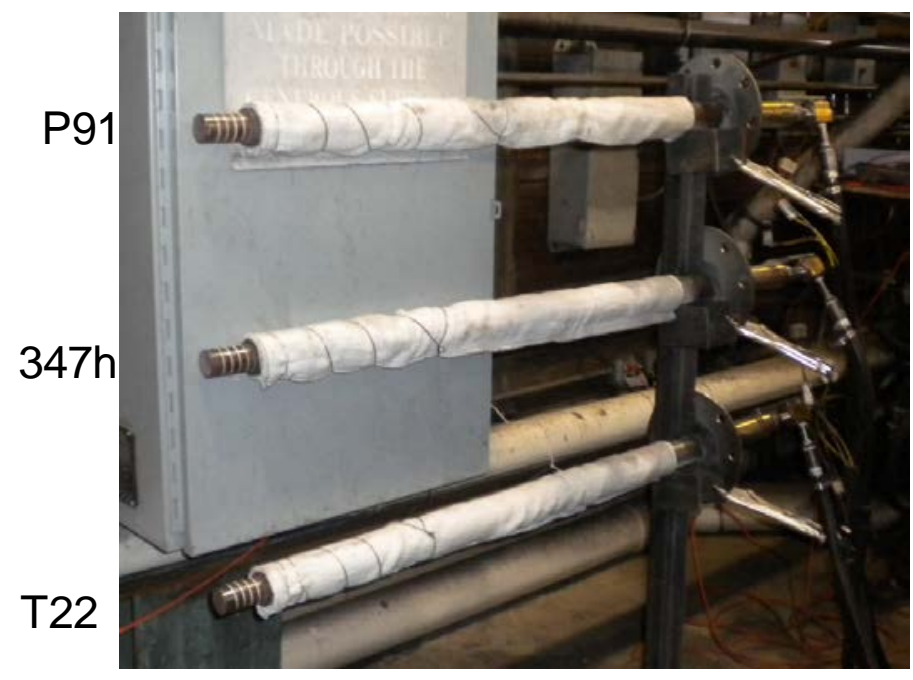

Water Wall Probe

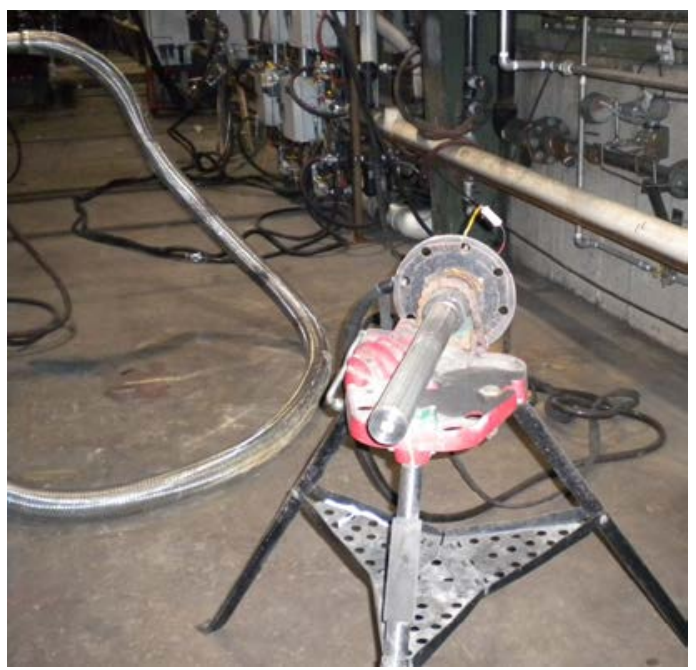

Figure 4.9-21: Waterwall and superheater sensor probes used for corrosion monitoring on this project.

In addition to the four temperature-controlled sensors, the corrosion monitoring system included signal conditioning and data acquisition modules, temperature controllers, a cooling air supply and a computer for data collection, processing and trending. Dry pressurized air for cooling of the sensors was provided 
by a Sullair 375 Instrument air compressor. Cooling the probes with air enables the sensor elements to be controlled at operating temperatures that are representative of conventional boiler tubes.

The platform for this corrosion investigation was the University of Utah's pilot-scale L1500 test furnace. This furnace has been described in detail in previous sections of this report. The corrosion sensor probe and furnace configuration for these tests is presented in Figure 4.9-22.

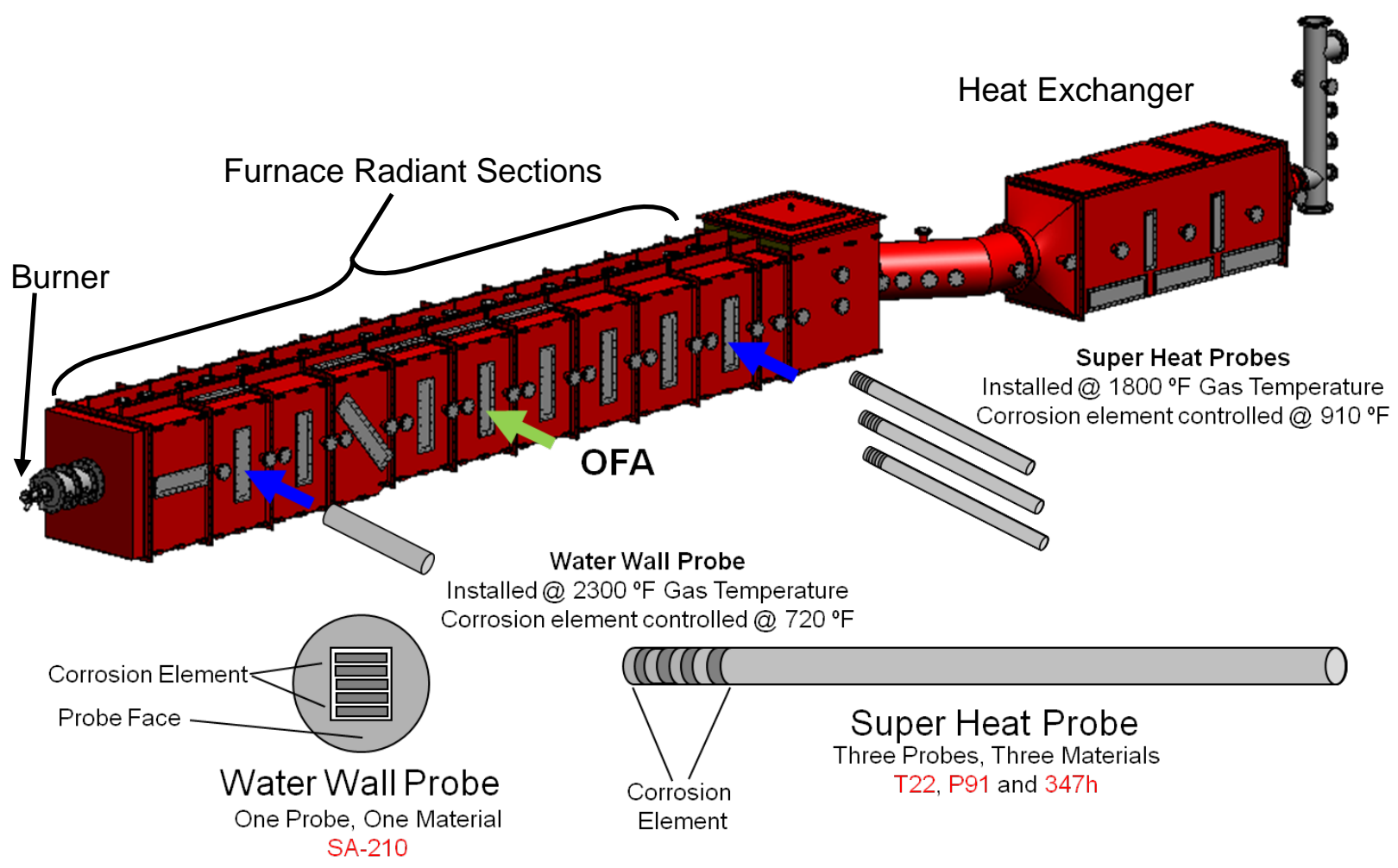

Figure 4.9-22: Pilot-scale furnace and corrosion sensor probe configuration.

The sensor elements of the waterwall probe were typically maintained at $720^{\circ} \mathrm{F}$ and the probe was installed in section 2 of the L1500 with gas temperatures about $2300^{\circ} \mathrm{F}$. The sensor elements on the superheater probes typically were controlled at $910^{\circ} \mathrm{F}$ and were installed at a gas temperature of about $1800^{\circ} \mathrm{F}$. To target this gas temperature, the superheater sensor probes were installed in section 10 of the L1500. The superheater probes were typically installed with the $\mathrm{P} 91$ probe on top, the $347 \mathrm{H}$ probe in the center and the T22 probe on bottom. For all of these tests, the firing rate was $3.5 \mathrm{MBtu} / \mathrm{hr}$. For the majority of these tests, the burner was staged with a stoichiometric ratio of 0.9 . The overall stoichiometric ratio was sufficient to produce $3.0 \% \mathrm{O}_{2}$ (dry) in the flue gas and the concentration is dependent on air or oxy-fired conditions. The over-fire air was introduced in section 6 of the furnace. This configuration and typical operating conditions result in reducing conditions at the waterwall probe and oxidizing conditions at the superheater probes. A picture of the $347 \mathrm{H}$ probe, while installed in the hot furnace, is included as Figure 4.9-23. This picture was taken through the center sample port in section 10 of the L1500, directly across from the $347 \mathrm{H}$ probe. 


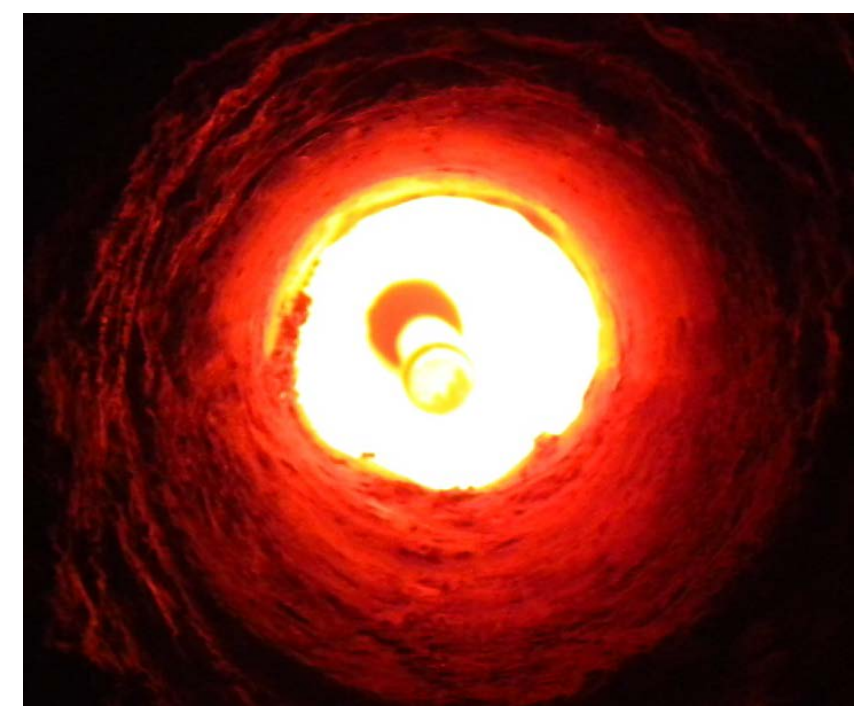

Figure 4.9-23: Alloy 347H corrosion sensor probe while in the hot furnace.

Samples of the deposited mineral matter were collected under conditions that were representative of the $347 \mathrm{H}$ superheater probe. The probe used to collect these samples was a modified corrosion sensor probe on which the sensor elements had been removed and replaced with a single deposition element fabricated from carbon steel. The deposition element was temperature-controlled in the same manner as the corrosion sensor elements and always was installed in the port opposite the $347 \mathrm{H}$ superheat probe. The proximity of the corrosion sensor elements and the deposition element was of the order of inches when both were installed. The deposition element on this probe was easy to replace and a new element was installed for each set of operating conditions and fuel. Concurrent with all periods of deposit collection, measurements of the flue gas temperature and major gas species were performed in the port directly upstream of the $347 \mathrm{H}$ probe. Samples of the entrained ash also were collected. The deposition probe and the location where it is installed on the furnace are shown in Figure 4.9-24.

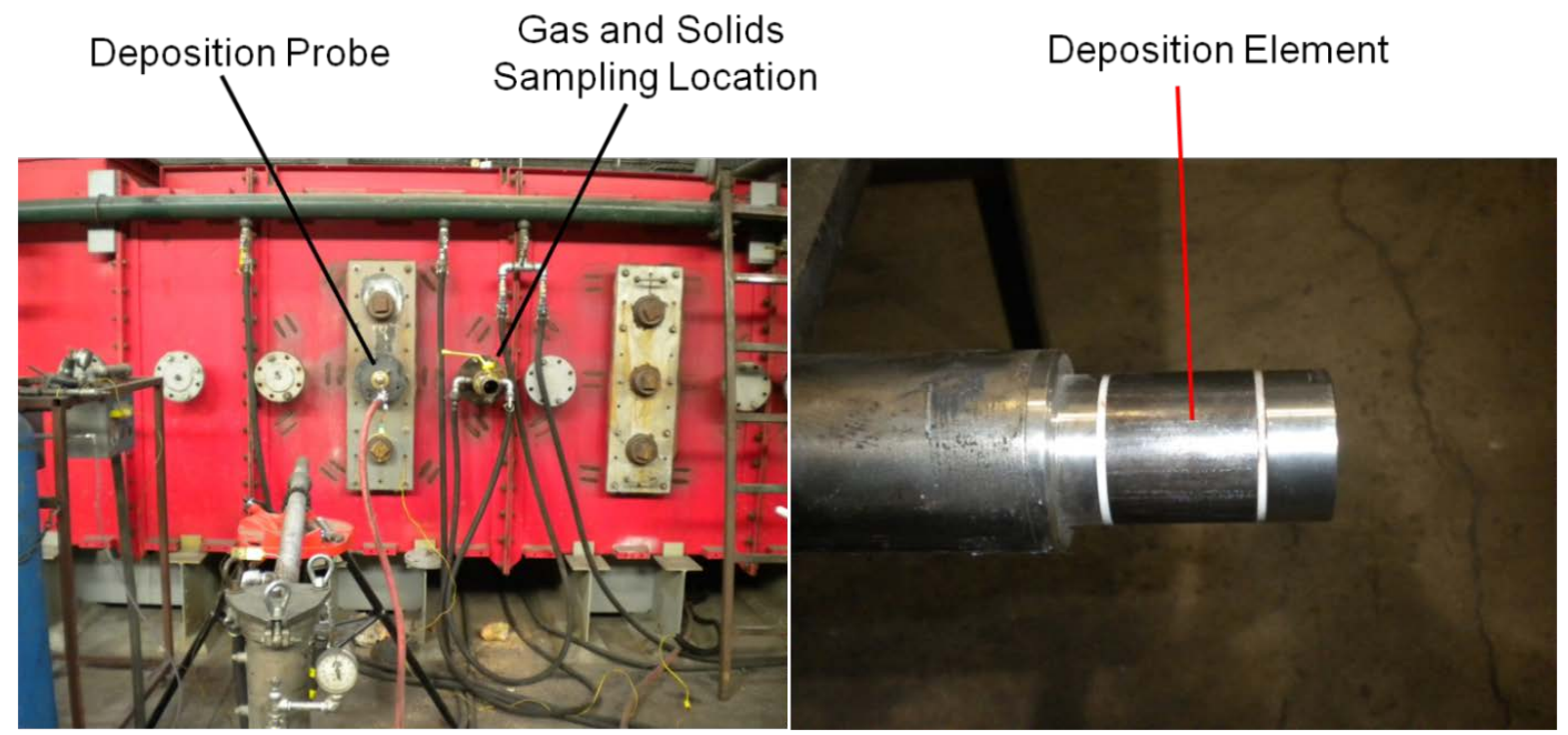

Figure 4.9-24: Deposition element and the location of the deposition probe and gas and solids sampling. 
During two test campaigns performed in May and June of 2013, corrosion monitoring was performed upstream of the baghouse during the testing of calcium bromide additive $\left(\mathrm{CaBr}_{2}\right)$ and activated carbon injection (ACI). Monitoring was performed simultaneously in two locations near the upstream and downstream ends of the duct between the post-furnace heat exchanger and the baghouse as shown in Figure 4.9-25.

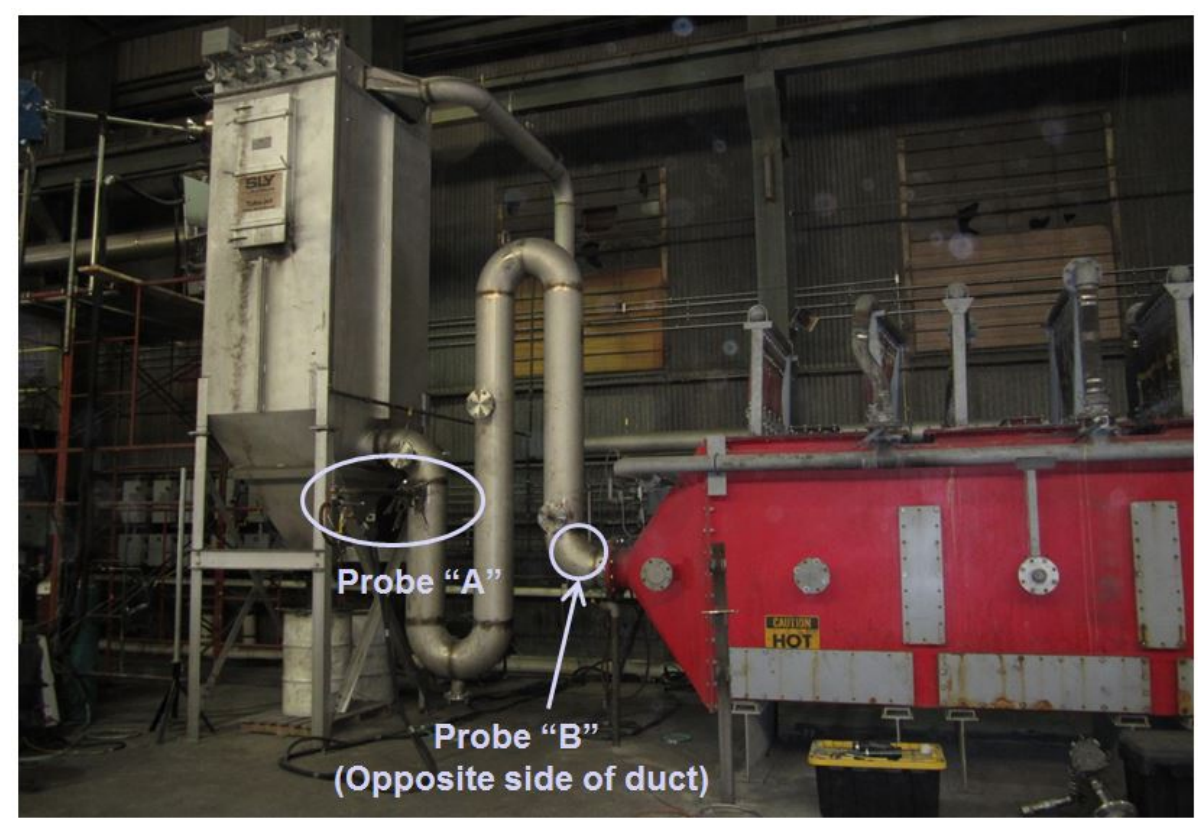

Figure 4.9-25: Two locations of corrosion probes under conditions representative of air heaters.

Three different coals were used for this experimental program. The Utah coal was from the Skyline mine and is a western bituminous, low-sulfur coal. The Powder River Basin (PRB) coal was from the North Antelope mine and is a low sulfur sub-bituminous coal. The Illinois bituminous coal was from the Shay \#1 mine and has very high sulfur content. The analyses of the coals and of the mineral matter are presented in Table 4.9-4.

Table 4.9-4: Coal and Mineral Matter Analyses.

\begin{tabular}{|c|c|c|c|c|c|c|c|}
\hline & Skyline & PRB & Illinois & & Skyline & PRB & Illinois \\
\hline \multicolumn{4}{|c|}{ Coal Analyses } & \multicolumn{4}{|c|}{ Mineral Matter Analyses } \\
\hline $\mathbf{C}$ & 70.60 & 53.72 & 64.67 & Al & 14.52 & 14.78 & 17.66 \\
\hline $\mathbf{H}$ & 5.05 & 3.57 & 4.51 & $\mathbf{C a}$ & 6.11 & 22.19 & 1.87 \\
\hline $\mathbf{N}$ & 1.42 & 0.78 & 1.12 & $\mathbf{F e}$ & 5.09 & 5.20 & 14.57 \\
\hline $\mathrm{S}$ & 0.53 & 0.23 & 3.98 & $\mathrm{Mg}$ & 1.39 & 5.17 & 0.98 \\
\hline $\mathbf{O}$ & 10.39 & 13.07 & 8.08 & Mn & 0.02 & 0.01 & 0.02 \\
\hline Ash & 8.38 & 4.94 & 7.99 & $\mathbf{P}$ & 0.59 & 1.07 & 0.11 \\
\hline Moisture & 3.18 & 23.69 & 9.65 & $\mathbf{K}$ & 0.57 & 0.35 & 2.26 \\
\hline Volatile Matter & 38.60 & 33.36 & 36.78 & Si & 60.89 & 30.46 & 49.28 \\
\hline Fixed Carbon & 49.39 & 38.01 & 45.58 & $\mathrm{Na}$ & 1.41 & 1.94 & 1.51 \\
\hline \multirow[t]{2}{*}{ HHV, Btu/lb } & 12,606 & 9,078 & 11,598 & $\mathrm{~S}$ & 2.33 & 8.83 & 2.22 \\
\hline & & & & $\mathbf{T i}$ & 0.88 & 1.30 & 0.85 \\
\hline
\end{tabular}


In order to determine the dependence of corrosion rate, several parameters were varied in these experiments. These parameters included air- vs. oxy-fired conditions, coal sulfur concentration, corrosion sensor element temperatures and oxidizing vs. reducing conditions. These variables are discussed in more depth in the next section of this report, where the results are presented.

For the second phase of the program (May and June 2013 test campaigns), a similar PRB and a moderate sulfur Bituminous were used (Table 4.9-5).

Table 4.9-5: Coal and Mineral Matter Analyses (Phase 2)

\begin{tabular}{|c|c|c|c|}
\hline \multicolumn{4}{|c|}{ Black Thunder PRB } \\
\hline \multicolumn{2}{|c|}{ Coal Analyses } & \multicolumn{2}{c|}{ Mineral Matter Analyses } \\
\hline C & 54.04 & Al & 14.19 \\
\hline H & 3.74 & Ca & 16.13 \\
\hline N & 0.82 & Fe & 5.99 \\
\hline S & 0.38 & Mg & 3.33 \\
\hline O & 13.69 & Mn & 0.04 \\
\hline Ash & 5.66 & P & 0.71 \\
\hline Moisture & 21.67 & K & 0.47 \\
\hline Volatile Matter & 36.77 & Si & 36.76 \\
\hline Fixed Carbon & 35.91 & Na & 0.93 \\
\hline HHV, Btu/lb & 9320 & S & 10.11 \\
\hline
\end{tabular}

\begin{tabular}{|c|c|c|c|}
\hline \multicolumn{4}{|c|}{ Pratt Bituminous } \\
\hline \multicolumn{2}{|c|}{ Coal Analyses } & \multicolumn{2}{c|}{ Mineral Matter Analyses } \\
\hline C & 69.23 & Al & 25.91 \\
\hline H & 4.82 & Ca & 3.41 \\
\hline N & 1.69 & Fe & 13.20 \\
\hline S & 2.22 & Mg & 1.18 \\
\hline O & 6.54 & Mn & 0.04 \\
\hline Ash & 13.14 & P & 0.83 \\
\hline Moisture & 2.38 & K & 2.33 \\
\hline Volatile Matter & 35.64 & Si & 44.78 \\
\hline Fixed Carbon & 48.85 & Na & 0.47 \\
\hline HHV, Btu/lb & 12659 & S & 3.72 \\
\hline
\end{tabular}

\subsubsection{Results and Discussion}

Corrosion experiments were performed for a total of six weeks of operation in the L1500 during spring 2010. These experiments consisted of many days where the furnace was operated as consistently as possible to produce corrosion data under steady-state conditions. These conditions included $3.5 \mathrm{MBtu} / \mathrm{hr}$ firing rate, staged combustion with a burner stoichiometric ratio (BSR) of 0.9 , over-fire air introduced in section 6 of the furnace, waterwall corrosion probe (SA210 tube material) installed in section 2 of the furnace, superheater corrosion probes (T22, P91 and 347H tube materials) installed in section 10 of the furnace and $3 \% \mathrm{O}_{2}$, dry, in the emitted flue gas. The base temperatures for the corrosion sensor elements were: $720^{\circ} \mathrm{F}$ for the waterwall probe and $910^{\circ} \mathrm{F}$ for the superheater probes. These conditions may be assumed for all results presented in this section of the report, unless otherwise specified.

\subsubsection{Sulfur Effects}

One of the key parameters found to be associated with higher corrosion rate is the sulfur content of a coal, which influences the flue gas concentrations of $\mathrm{SO}_{2}, \mathrm{SO}_{3}$ and $\mathrm{H}_{2} \mathrm{~S}$. As is evident from Table 4.9-4, there was a great difference between the sulfur concentration of the Illinois coal and the PRB and Skyline coals. It is necessary to understand the impact each of these coals had on the flue gas $\mathrm{SO}_{2}$ concentration before discussing the corrosion results because the sulfur dependence is integrated into all of the results. During the experimental program, the flue gas $\mathrm{SO}_{2}$ concentration was shown to be a function of coal sulfur content and firing condition. When firing with oxygen, the nitrogen dilution is not included in the flue gas and the concentrations of the minor species increase drastically. In effect, corrosion behavior was investigated in six different gas-phase sulfur concentrations, resulting from the three coals and the air- and 
oxy-fired conditions. The average measured, and expected $\mathrm{SO}_{2}$ concentrations, for each of these conditions are detailed in Table 4.9-6.

Table 4.9-6: Flue Gas $\mathrm{SO}_{2}$ Concentrations.

\begin{tabular}{|c|c|c|c|c|}
\hline Coal & $\begin{array}{c}\text { Firing } \\
\text { Condition }\end{array}$ & $\begin{array}{c}\text { Measured } \\
\text { SO }_{2} \text { Conc., } \\
\text { ppmv } \\
\text { (Average) }\end{array}$ & $\begin{array}{c}\text { Expected } \\
\text { SO }_{2} \text { Conc., } \\
\text { ppmv }\end{array}$ & $\begin{array}{c}\text { Difference } \\
\text { Between } \\
\text { Measured \& } \\
\text { Expected }\end{array}$ \\
\hline PRB & Air & 128 & 266 & $52 \%$ \\
\hline PRB & Oxy & 289 & 1,374 & $79 \%$ \\
\hline Skyline & Air & 445 & 448 & $1 \%$ \\
\hline Skyline & Oxy & 1,737 & 2,405 & $28 \%$ \\
\hline Illinois & Air & 3,219 & 3,603 & $11 \%$ \\
\hline Illinois & Oxy & 17,642 & 19,552 & $10 \%$ \\
\hline
\end{tabular}

The reported measured value of the $\mathrm{SO}_{2}$ concentration represents the average value for all tests during the corrosion experiments. The reported expected value of the $\mathrm{SO}_{2}$ concentration was calculated by material balance. For these calculations, the exit flue gas $\mathrm{O}_{2}$ concentrations were set at $3 \%$ and the contribution of the $\mathrm{CO}_{2}$ purge gas on the camera and optical viewports was included. Air infiltration also was included at a rate resulting in a $\mathrm{CO}_{2}$ concentration of $90 \%$. The high $\mathrm{SO}_{2}$ concentrations (expected and measured) during oxy-firing suggest that the flue gas recycle stream may need to be treated in order to avoid potential corrosion and mercury capture interference issues.

The measured gas-phase $\mathrm{SO}_{2}$ concentrations were lower than were those calculated by material balance, with the exception of the air-fired Skyline coal condition. This indicates that sulfur was being removed in the system, either with condensed moisture or on the removed ash particles. These possibilities were evaluated by plotting the difference between expected and measured $\mathrm{SO}_{2}$ concentrations from Table 4.9-6 (furnace $\mathrm{SO}_{2}$ removal) against the mass percent of calcium in the coal. This plot is included as Figure 4.9-26.

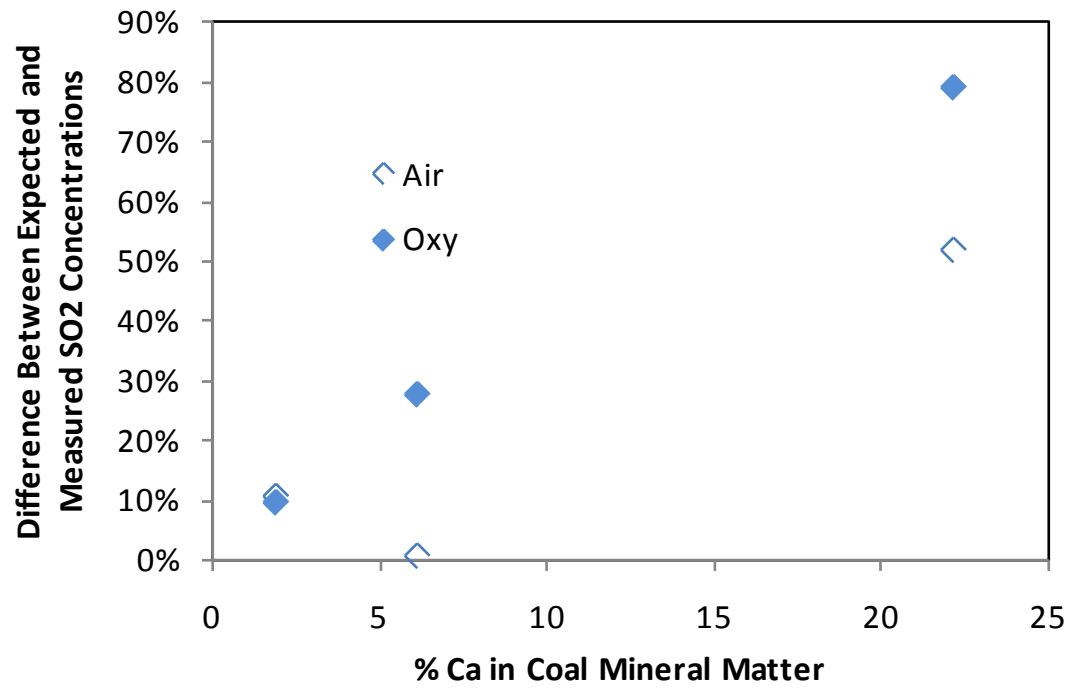

Figure 4.9-26: $\mathrm{SO}_{2}$ removal in the furnace as a function of coal calcium content. 
Figure 4.9-26 shows a strong dependence of $\mathrm{SO}_{2}$ removal in the furnace on calcium in the mineral matter of the coal. In fact, the relationship is linear for the oxy conditions. The air-fired Skyline coal condition precludes a linear relationship for the air conditions. These data suggest that the primary mode of $\mathrm{SO}_{2}$ removal in the furnace is likely on the ash particles. The plotted data also suggest that the dependence of furnace $\mathrm{SO}_{2}$ removal is stronger for the oxy-fired conditions than for air. The lack of linearity for the airfired condition and the stronger dependence on calcium for the oxy-fired conditions may have been related to the flue gas recycle. The $\mathrm{SO}_{2}$ measurement location in the $\mathrm{L} 1500$ was just upstream of the heat exchange section in Figure 4.9-22. Downstream of the heat exchange section, a baghouse was used for particulate removal. Flue gas recycle for the oxy-fired conditions was taken at the baghouse exit. In the air-fired case, the mode of sulfur removal may only include capture on entrained ash particles. In contrast, for the oxy-fired conditions, the FGR, being $65 \%$ of the mass of all reactants, passed through the baghouse filter cake. This provided an additional, stronger mechanism for $\mathrm{SO}_{2}$ sorption. Figure 4.9-27 shows the sulfur balance when the gas phase, condensate and particulate sulfur are considered. The balance is quite good. For the purposes of digesting and interpreting the corrosion data, the $\mathrm{SO}_{2}$ concentrations in Table 4.9-6 should be considered.

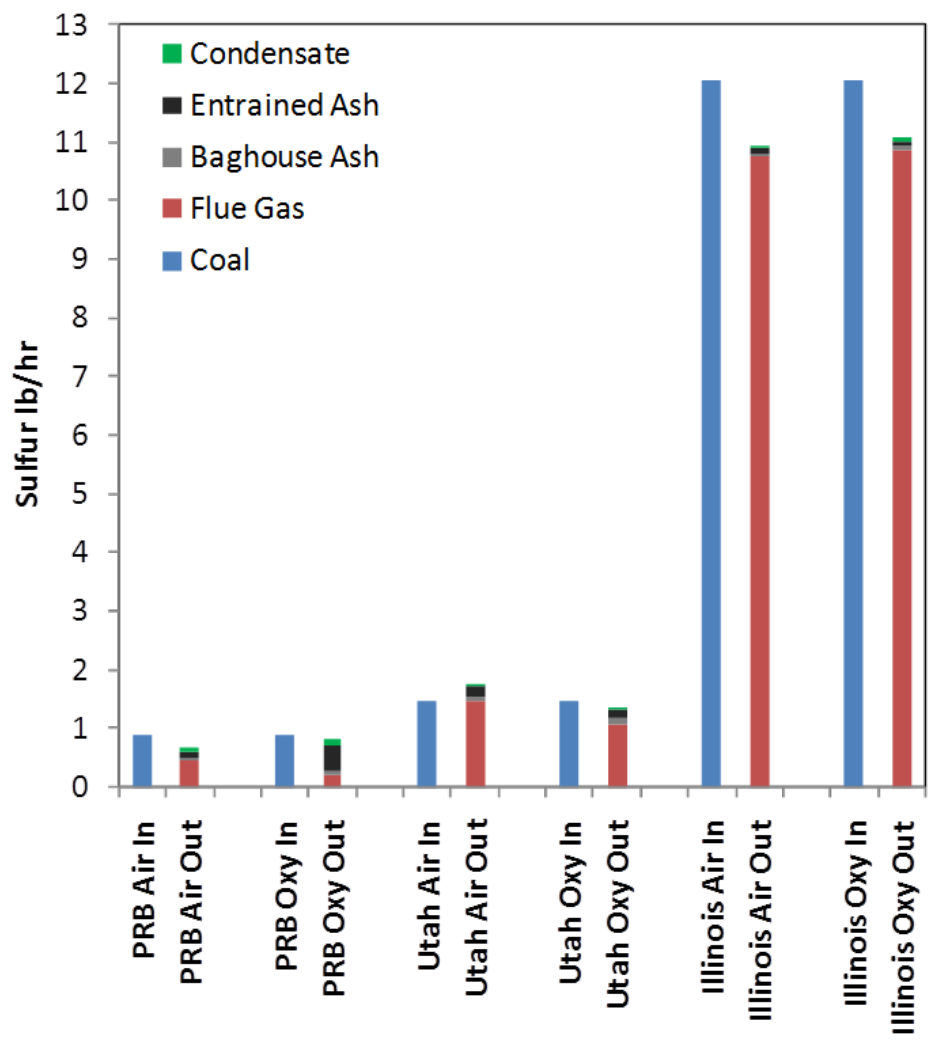

Figure 4.9-27: Sulfur balance for L1500 measurements.

\subsubsection{Corrosion - Air vs. Oxy Conditions}

Before reviewing corrosion results, a brief discussion of corrosion data processing is warranted. Unlike conditions in low-temperature aqueous environments, the instantaneous potential and current transient responses in high temperature combustion environments tend to exhibit greater fluctuations in corrosion signal. In part, this is because phenomena such as changes in the equilibrium potential value of a material in the environment tends to fluctuate (for example) due to the arrival of radiant heat as well as from electrochemical transients that are generated by the electrochemical dissolution of the metal. Such signal fluctuation is an inherent feature of high temperature systems and are a relevant component of the overall 
electrochemical cell. Therefore, plotting and analysis of the data are more easily performed by looking at a smoothed signal (in much the same way that commercial polarization instrumentation contains circuitry to produce a smooth output response). Smoothing of the raw data is performed by windowing a rolling average. Care must be taken in the method of averaging of the data so that real peaks and fluctuations in the data remain in their actual temporal location. This allows the data to be compared with specific changes in furnace operating conditions and measurements. Sample plots of raw and smoothed corrosion signal from the $347 \mathrm{H}$ superheater probe for two of the initial test days are shown in Figure 4.9-28.
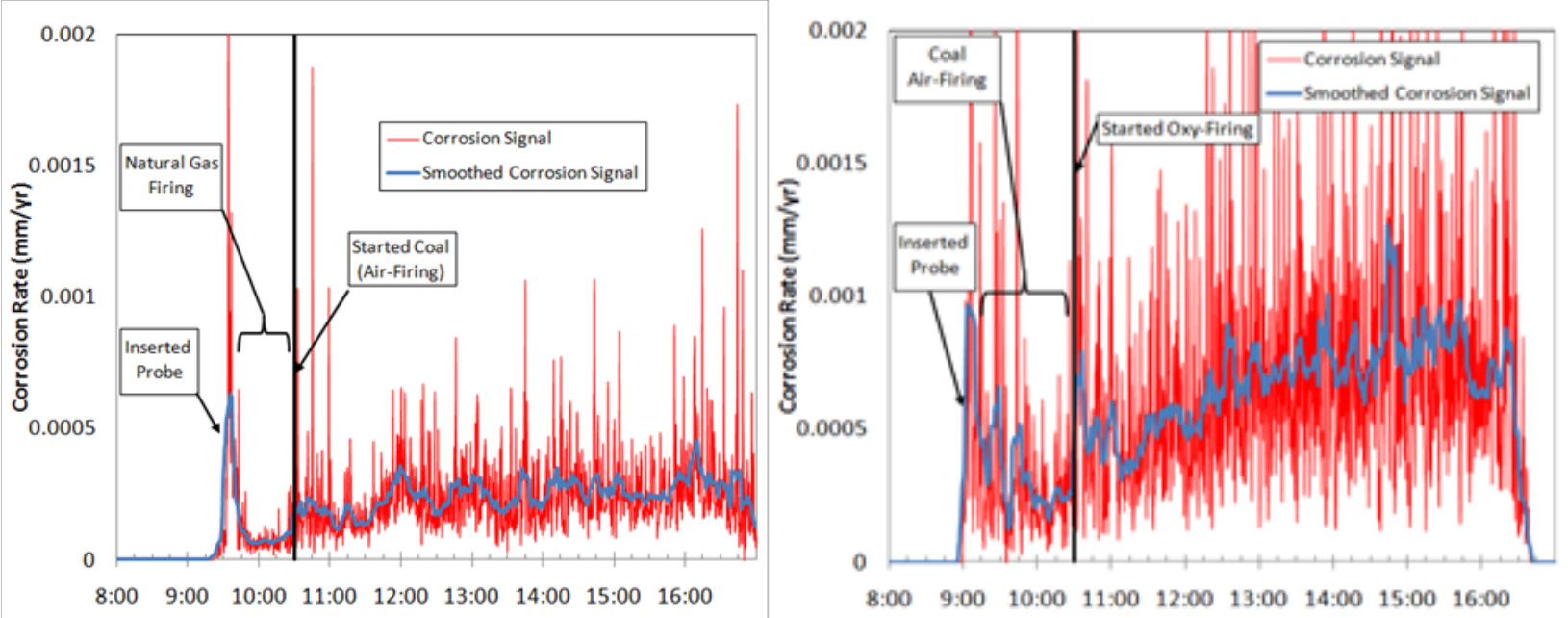

Figure 4.9-28: Noisy and smoothed corrosion data from the $347 \mathrm{H}$ superheater probe with a comparison of air- and oxy-firing of PRB coal.

Figure 4.9-28 shows data collected on two days of testing with each day's data on a separate plot. The data on the left was collected first and it details the insertion of the probe into the furnace while firing with natural gas, a period of natural gas firing, initiation of air firing of PRB coal and then stable operation of the furnace under air-fired conditions for the remainder of the day. The data presented in the plot on the right was collected two days later. These data show insertion of the probe into the furnace while already firing PRB with air, a short period of air-firing, initiation of oxy-firing and then stable operation of the furnace under oxy-fired conditions for the remainder of the day.

There are several aspects to this figure that are noteworthy. Each time the corrosion probe is inserted into the furnace, whether firing coal or natural gas, there is a short period where the corrosion rate is high and then it settles down. In these plots this period is short, but depending on the conditions it may last for an hour or two. The corrosion rate following a conversion from air- to oxy-fired conditions also takes some time to come to steady state. This is partly due to the fact that it takes 30 minutes to an hour to completely convert to oxy-firing and build up the $\mathrm{CO}_{2}$ concentration to $90 \%$, dry. Finally, it is apparent from these plots that the corrosion rate, although very low, appears to be higher for oxy-firing than for airfiring for this material and these conditions. This will be discussed later in more detail.

Data were collected over six weeks of in-furnace testing. During this period, the furnace was operated across a wide range of operating conditions including: three different coals, air- and oxy-fired conditions, variation of burner stoichiometric ratio, variation of corrosion sensor element temperatures and variation of burner operating conditions. Efforts were made to hold a set of conditions for long periods of time in order to collect corrosion data representative of stable operation. Despite these efforts, transient perturbations in the electrochemical response could be observed due to disruptions in the fuel feed rate, transients in corrosion sensor temperature control, deposit thickness and composition and other short-term 
operational excursions. As a result, two independent methods of data reduction were used and compared. These two methods are reviewed below.

As the L1500 is operated, data is periodically logged independent of the automatic data acquisition system. Logging of data always occurs at periods where the furnace is operating stably, at prescribed conditions. The manually logged data provides discrete snapshots of furnace operation at times where there is high confidence in the operating conditions and furnace behavior. As many as 25 of these snapshots where collected in an eight hour period. However, if there were problems with the furnace or desired operating conditions were difficult to obtain, only a few manually logged data points might be collected in a day. These data usually are used for primary evaluation of the experiment, with supplemental information coming from the automatically logged data. The manually logged data were used as the basis for the first method of data reduction, which will be referred to as the "Statistical Method.”

For this method, the corrosion rates for each of the sensors were averaged for periods of five and fifteen minutes prior to the manually logged data point. These averages were considered to be representative of the corrosion rate for each of the materials and the associated operating conditions. The five and fifteen minute averages were compared to determine if there was any influence of the size of the averaging window on the result. These data were gathered into groups of similar operating conditions. The average and standard deviation of the corrosion rate were calculated for each condition. Outlying data points were scrutinized for anomalies. The operating conditions, test log notes and behavior of the corrosion probes were evaluated in the temporal vicinity of the data in question. If there were anomalies in any of the operating conditions that would impact the measured corrosion rate, the data were excluded from the averages. Some of these anomalies included shorting of the corrosion sensor element on the deposition probe, sensor element temperature transients and resurfacing of the corrosion element sensors, the latter of which causes a transient signal as representative deposits are accumulated on the elements.

The second method of data reduction began with plotting key furnace operational parameters along with corrosion sensor element temperatures and corrosion rate for the entire test program. These plots were carefully evaluated for periods where the furnace and probe operation were stable. The corrosion rates during these "windows" were averaged and associated with representative operational conditions. The periods of similar operating conditions were grouped and the time weighted average of the corrosion rate was calculated. This method of data reduction will be referred to as the "Operational Method" and was the more insightful, but tedious, method of the two. In our opinion, this method is preferred and all results presented in this section of the report will be from this method of data reduction, unless otherwise indicated.

The average corrosion rates calculated and reported here assume that the metal loss occurs uniformly over the surface of the corrosion sensor element. In reality, the loss of material is more likely to occur in discrete locations on the sensor element associated with deposit and flow characteristics. For the superheater probes this discrete area is probably limited to about a third of the overall surface on the leading and trailing sides of the tube in cross flow. Peak corrosion rates therefore are likely to be approximately 3 times higher than the overall average rates reported here. However, as this is a pilotscale facility which was operated only during an eight to ten hour period each day, and the corrosion probes were removed each night, the relative corrosion rate values were more relevant for comparison purposes than were the absolute rate values.

The average corrosion rates measured for the baseline conditions described in Section 4.9.3 are presented in Figure 4.9-29 on a large scale and in Figure 4.9-30 on a small scale. 


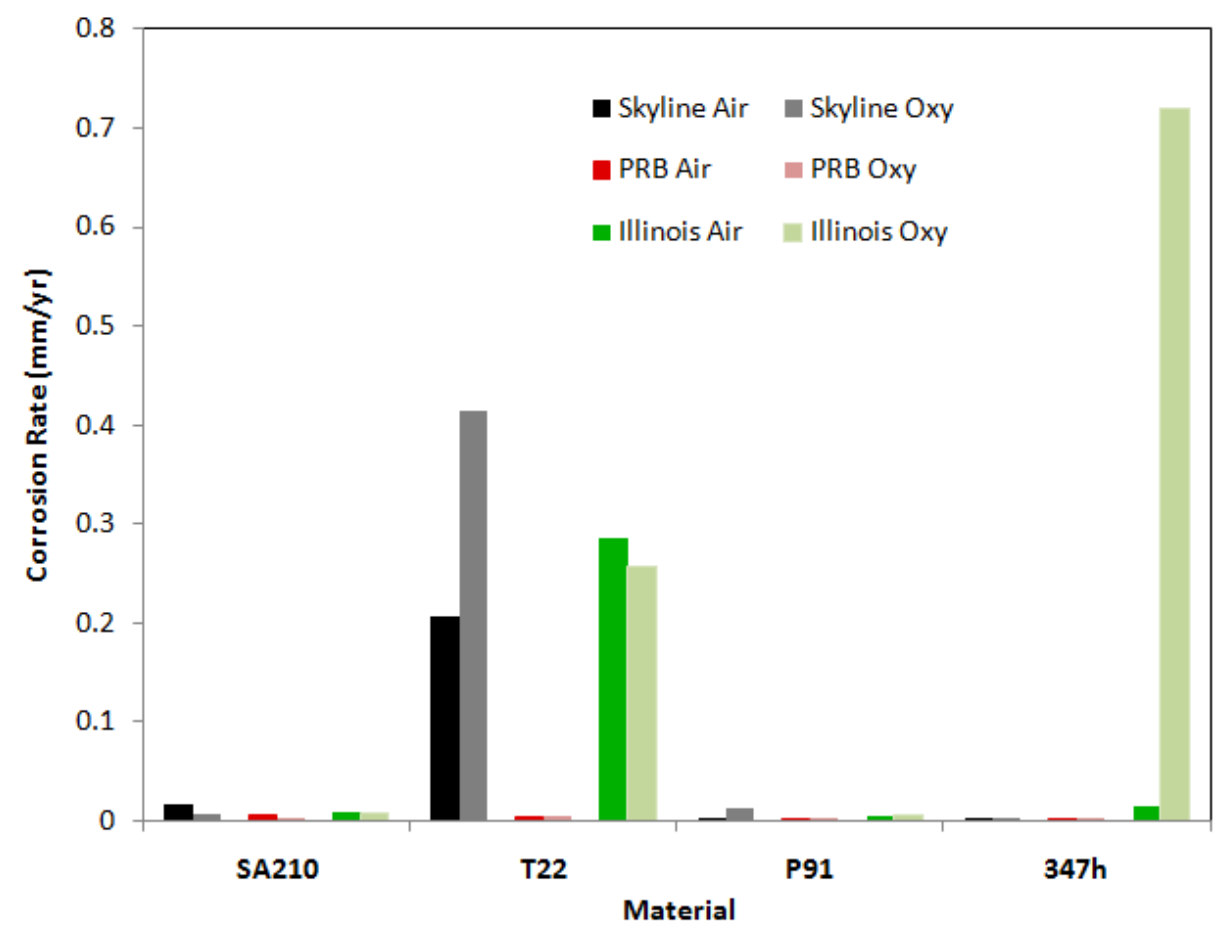

Figure 4.9-29: Summary of average corrosion rates for the baseline sensor element temperatures, probe locations and staging conditions (large scale).

Figure 4.9-29 shows comparative rates under air and oxy-fuel firing for each of the materials under test. As is evident from the figure, very low corrosion rates were evident for all of the materials, coals and air and oxy-firing, with the exception of five conditions. These conditions included the T22 material with Skyline and Illinois coals and for both air and oxy-fired conditions and the $347 \mathrm{H}$ material under Illinois/Oxy conditions. These five condition and material combinations gave indicated rates on the order of 0.21 to $0.72 \mathrm{~mm} / \mathrm{yr}$ ( 8.3 to $28.3 \mathrm{mils} / \mathrm{year}$ ). These corrosion rates are significant and the data were reviewed in greater detail for these conditions. More important than the specific corrosion rate was the relationship between the corrosion rates recorded for the same material and fuel combinations under airand oxy-fired conditions. Additional information for this comparison is provided in Figure 4.9-30, which is a plot of the same data presented in Figure 4.9-29, but using a revised (i.e. smaller) rate axis scale. 


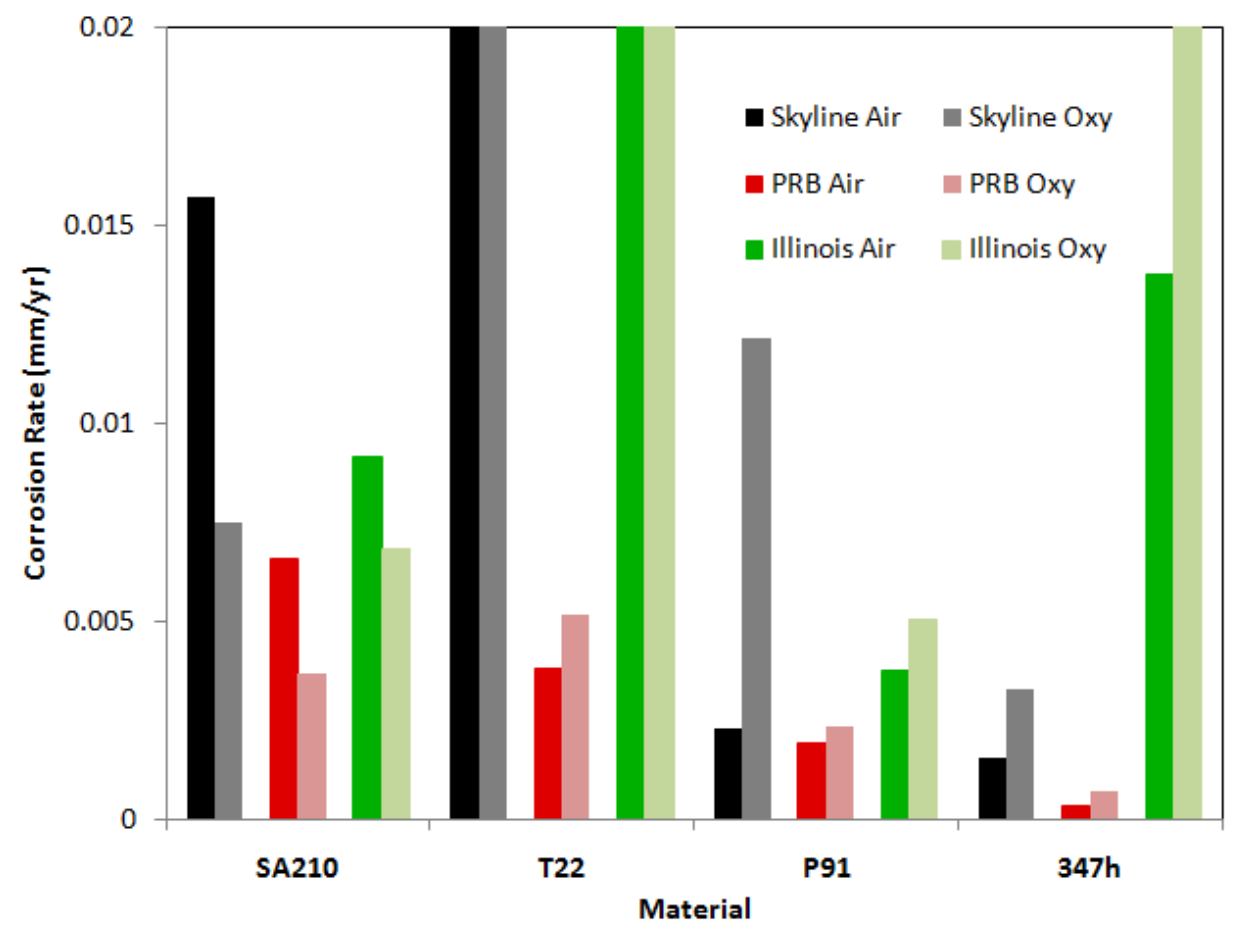

Figure 4.9-30: Summary of average corrosion rates for the baseline sensor element temperatures, probe locations and staging conditions (small scale).

The corrosion rates resolved in Figure 4.9-30 are much lower than the peaks already discussed in Figure 4.9-29. These rates range from 0.0034 to $0.016 \mathrm{~mm} / \mathrm{yr}(0.13$ to $0.62 \mathrm{mils} / \mathrm{yr})$. Figure $4.9-29$ and Figure 4.9-30 detail a significant trend between the air and oxy-fired conditions. For the waterwall probe (SA210), the corrosion rate decreased when the combustion conditions were changed from air- to oxyfiring for all conditions tested. By contrast, for all of the superheater probes (T22, P91 and 347H) the corrosion rate increased when combustion conditions in the furnace were changed from air- to oxy-firing for all but one condition tested.

To examine these trends in more detail it is useful to look at the plot of the increase in corrosion rate when converting from air- to oxy-firing for all materials and conditions. This plot is presented in Figure 4.9-31 on a large scale and in Figure 4.9-32 on a small scale. 


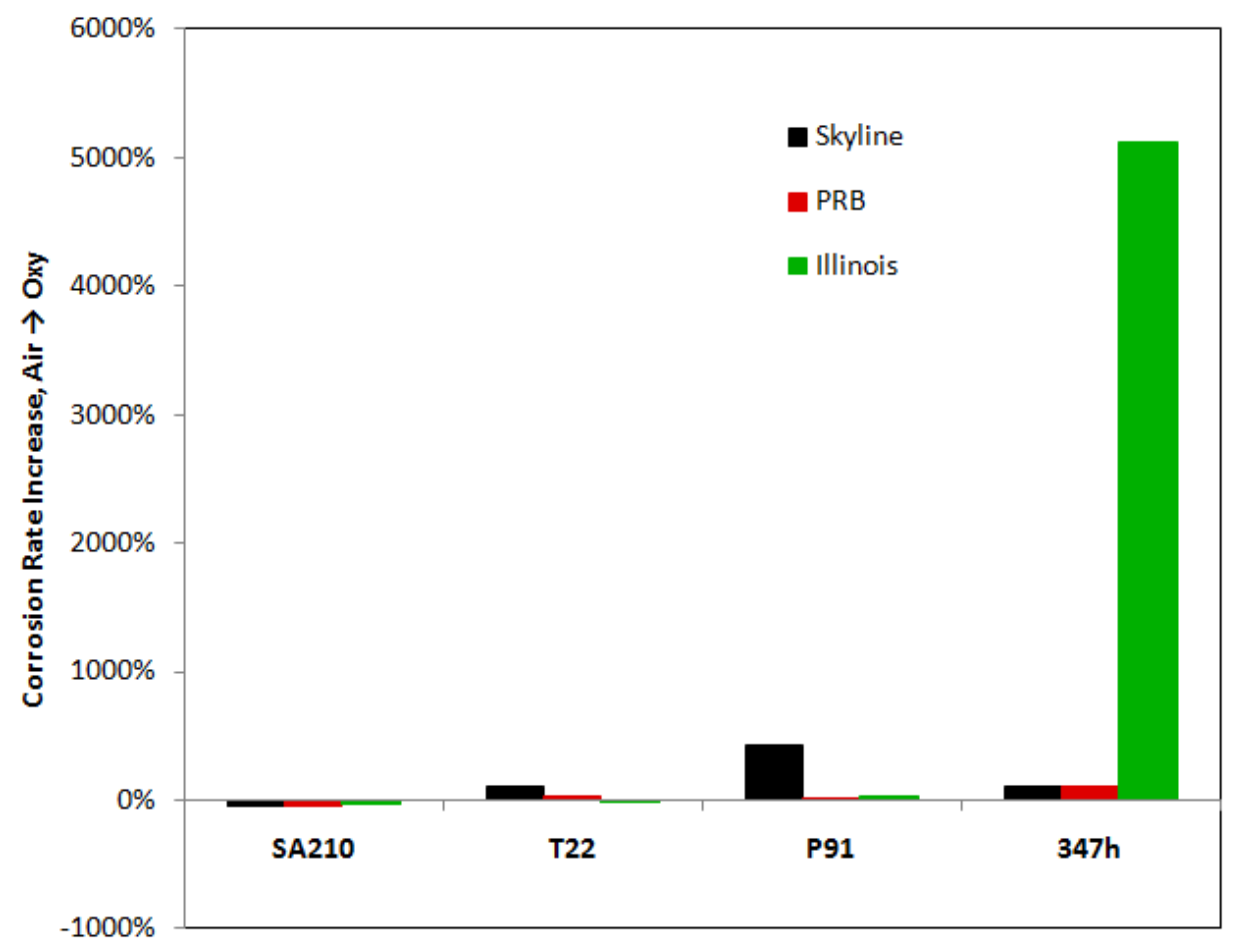

Figure 4.9-31: Measured increase in corrosion rate when converting from air- to oxy-firing.

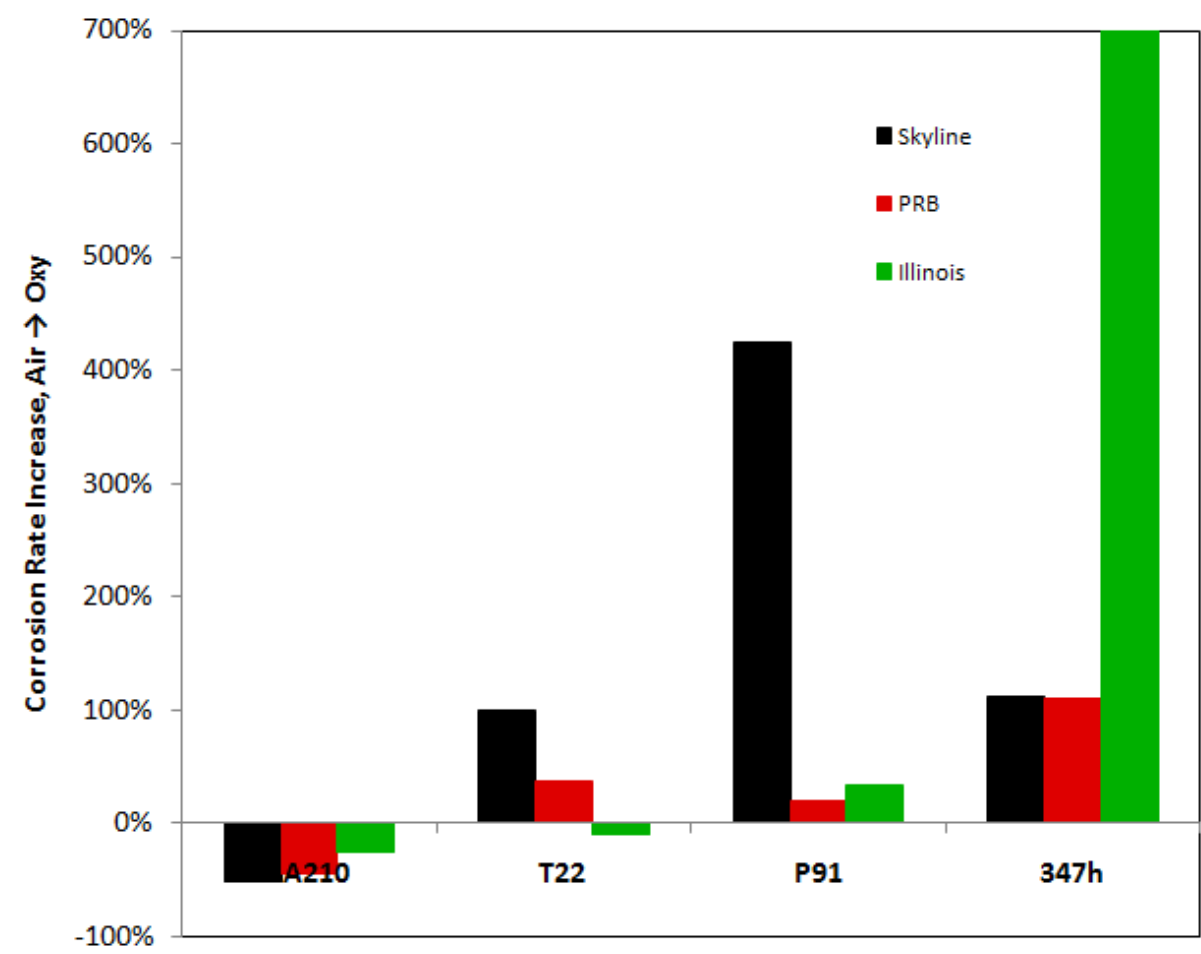

Figure 4.9-32: Measured increase in corrosion rate when converting from air- to oxy-firing (small scale). 
Figure 4.9-31 and Figure 4.9-32 clearly indicate the difference in behavior between the waterwall and the superheater probes. The only material and coal that exhibited behavior that was contrary to the general trend was the T22 material with Illinois coal. The decrease in waterwall corrosion rate when converting from air to oxy-fired conditions, although involving minor corrosion rates, could be a significant circumstance. An expected decrease in corrosion rate to these heat transfer surfaces when retrofitting for oxy-combustion could be a facilitating result for the technology. The difference in behavior between the waterwall and superheater probes may be explained by the difference between oxidizing and reducing conditions. For these data, the waterwall probe was installed in a region with stoichiometry of 0.9, whereas the superheater probes experienced superstoichiometric conditions. The behavior of the superheater probes was not concerning for most of the materials and coals tested. The increase in corrosion rates was small, compounding an already small corrosion rate. The results here that may be concerning and warrant further investigation are the P91 material with Skyline coal and again the 347H material with Illinois coal.

The next step in building confidence in this corrosion data set was to compare the results obtained independently by the Statistical and Operational methods of data reduction. This comparison is presented in Figure 4.9-33 and Figure 4.9-34.

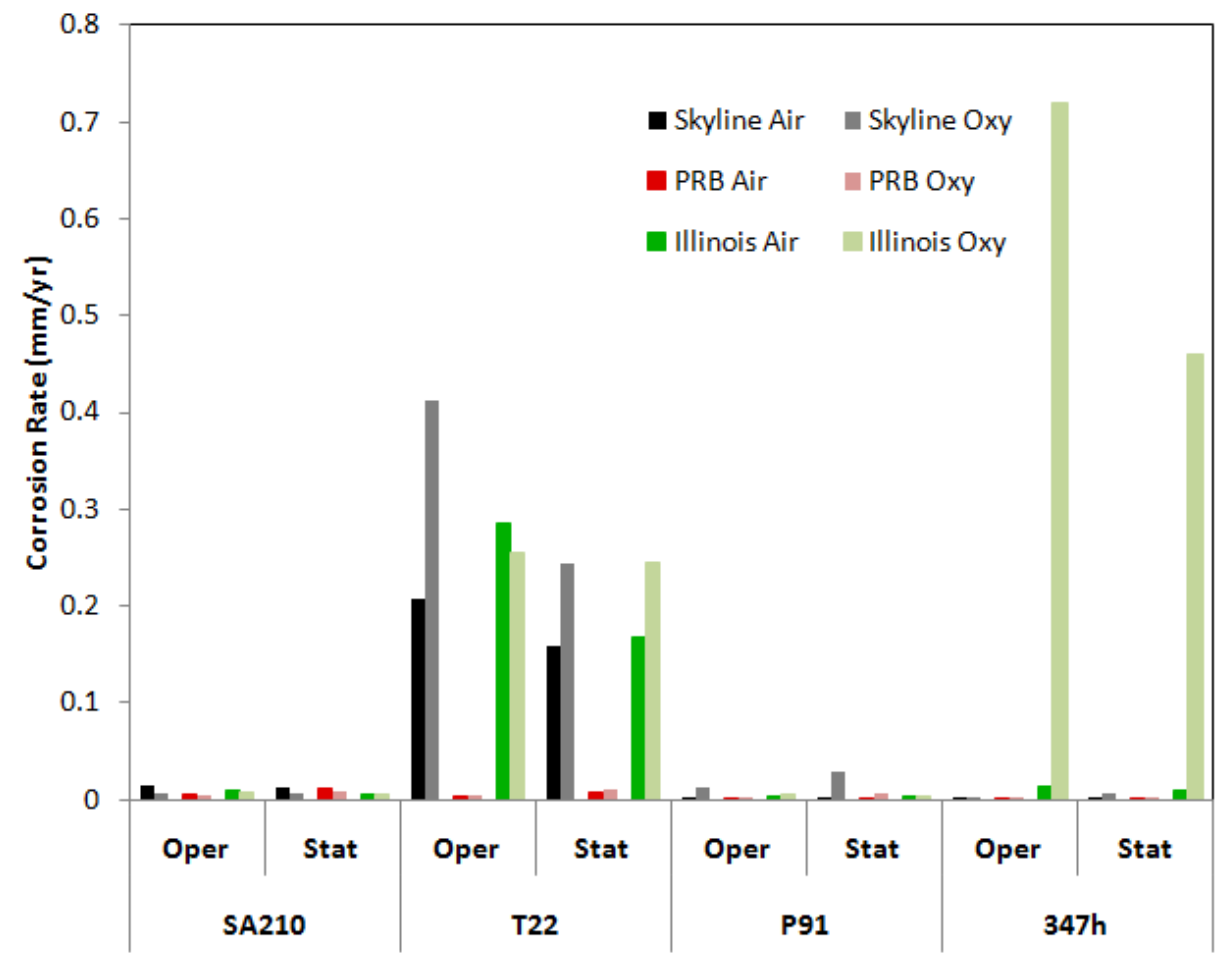

Figure 4.9-33: Comparison of average corrosion rates from both the Operational and Statistical evaluation of the data (large scale). 


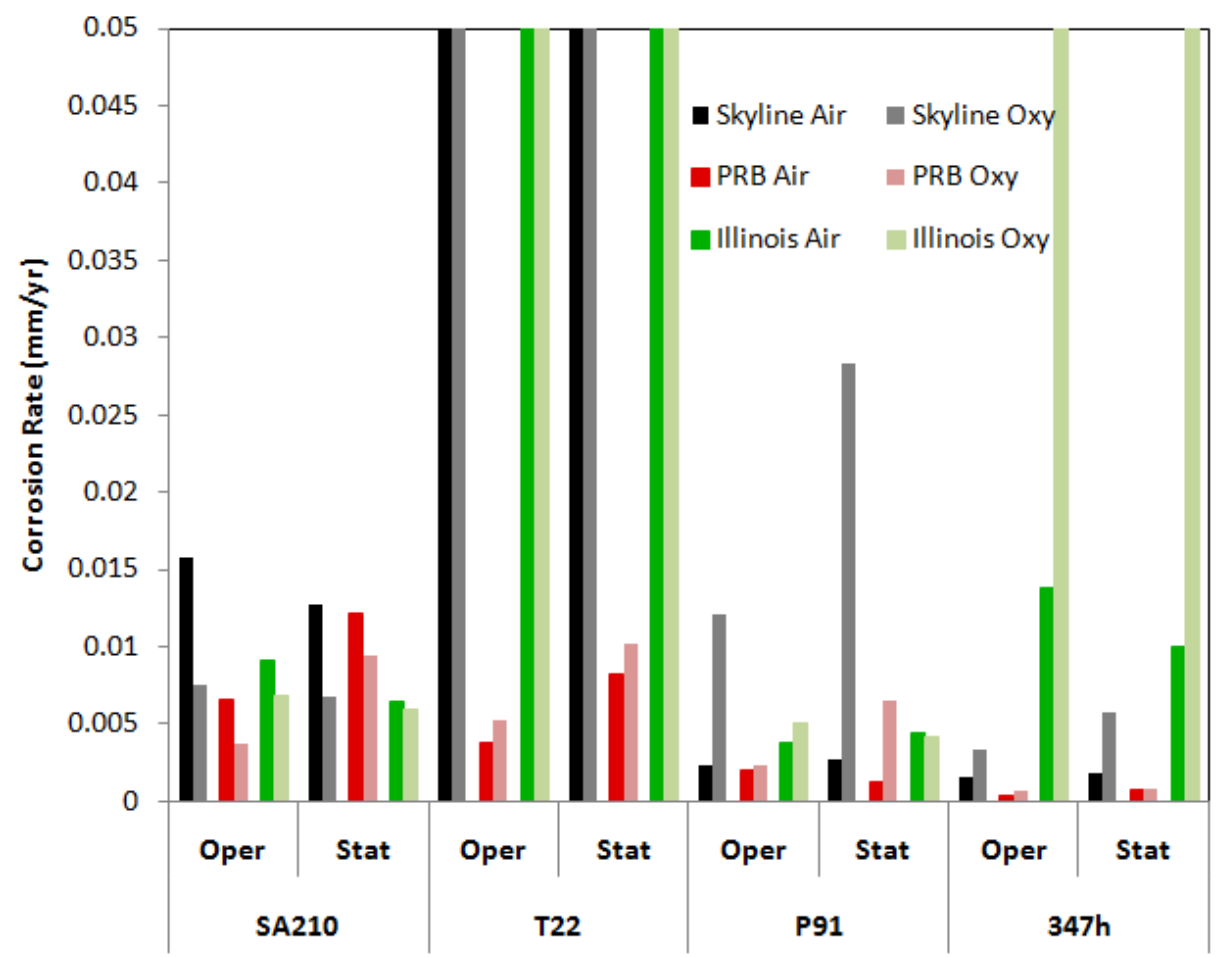

Figure 4.9-34: Comparison of average corrosion rates from both the Operational and Statistical evaluation of the data (small scale).

Figure 4.9-33 and Figure 4.9-34 indicate that there was little difference in the results obtained from each of the data analysis routes, independent of how the data had been analyzed. Notable among the subtle differences were that: the T22 material with Illinois coal gave a higher corrosion rate from air- to oxyfiring with the Statistical Method, the P91 material with Illinois coal gave a lower corrosion rate from airto oxy-firing when the Statistical Method was used and the rate of corrosion was significantly higher from the Operational Method, as compared to Statistical Method, for the P91 material with Skyline coal and oxy-fired conditions. Overall these discrepancies added to the understanding and credibility of the findings from each of the data evaluation methods and therefore to the conclusions drawn from the Operational Method of data reduction.

In order to provide greater confidence in the data and to further investigate the conditions of interest, the data reduced by the Operational Method was further analyzed. Plots were produced for each material, coal and firing condition displaying the data that were used to generate the average rates for that condition. Each discrete window of data used in the Operational Method has been represented by a bar with the height representative of the average corrosion rate for that period and the width representative of the duration of that period. The upper limit of the x-axis is the total duration of all of the tests that were used to produce the average corrosion rate. The average corrosion rate is depicted on theses plots by a horizontal red line. For the purposes of discussion, these plots will be referred to as Duration Plots. It is important to keep in mind while viewing the Duration Plots that each discrete window of data was separated by time (often days) and other corrosion and operating conditions.

Figure 4.9-35 contains Duration Plots for the waterwall probe (SA210 material) while firing Skyline coal under air- and oxy-fired conditions. 


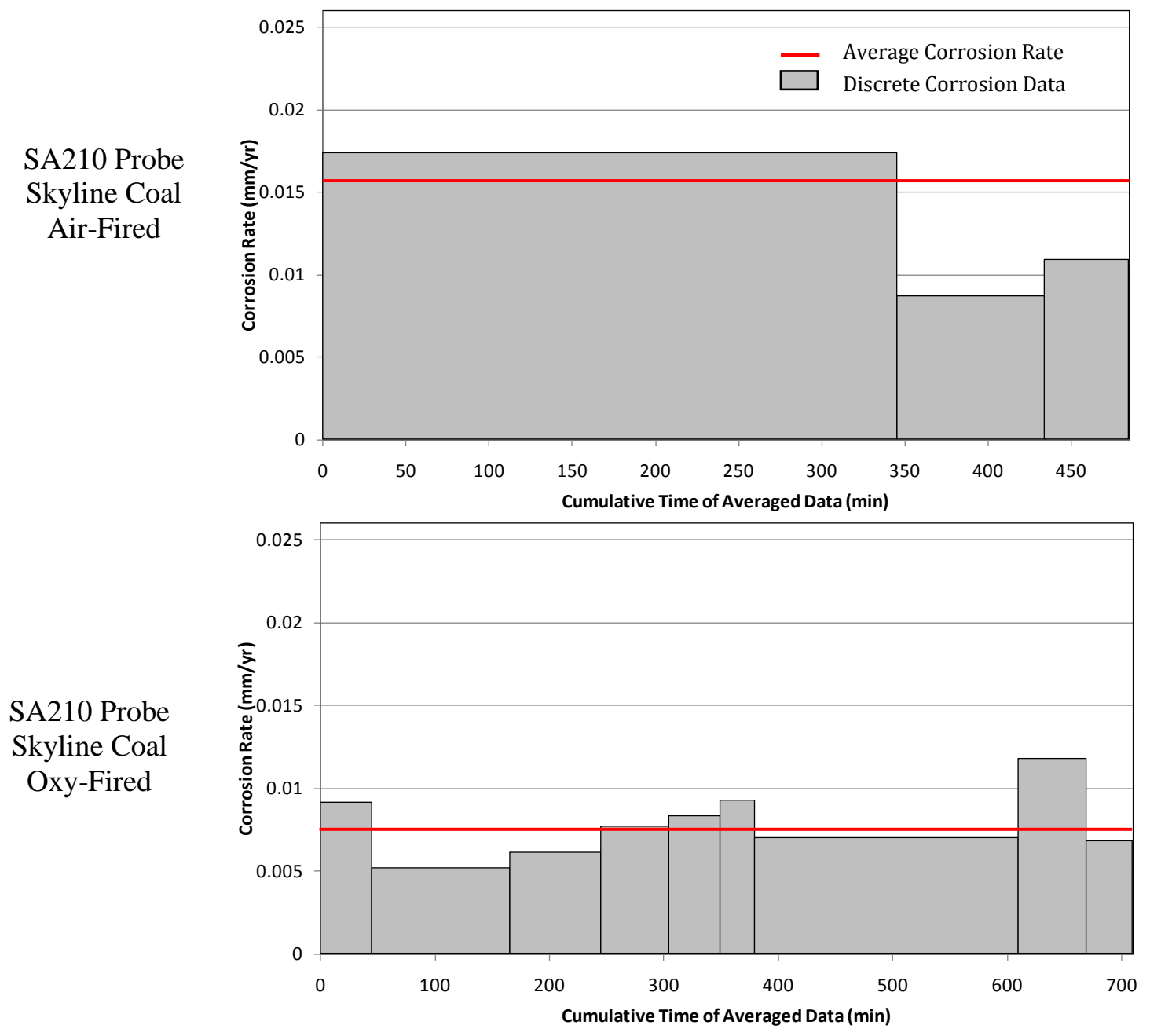

Figure 4.9-35: SA210 waterwall probe corrosion rate data used in the operational evaluation for air and oxy-fired conditions with Skyline coal.

Figure 4.9-35 shows that the average corrosion rate for the air-fired condition was calculated as the time weighted average of three discrete periods of experimentation totaling to 485 minutes while the average rate for the oxy-fired condition was calculated from 9 discrete periods totaling to 710 minutes. The relative lack of variability of the height of each of the discrete periods and the number of periods gave considerable confidence in the consistency of the reported average rate. The Duration Plots in Figure 4.9-35 provide further confidence that the oxy-fired corrosion rate is indeed lower than the air-fired corrosion rate for the waterwall (SA210 material) probe. Each of the duration plots for the waterwall probe showed similar results with a varying, but acceptable, amount of scatter in the discrete periods. Each of these plots supported the conclusions previously drawn.

The Duration Plots were used to investigate the conditions leading to high corrosion rates and to large increases in corrosion rate from air-fired to oxy-fired conditions. Figure 4.9-36 includes Durations Plots for both air- and oxy-fired conditions with the P91 superheat probe while firing the Skyline coal.

Figure 4.9-36 shows some scatter in the corrosion rate from the discrete periods under the oxy-fired conditions. However, the rate in every period in the oxy-fired plot is greater than every period used to 
calculate the air-fired rate. These data support the conclusion that the corrosion rate of the P91 superheat probe was much greater for oxy-fired than for air-fired conditions when firing Skyline coal.
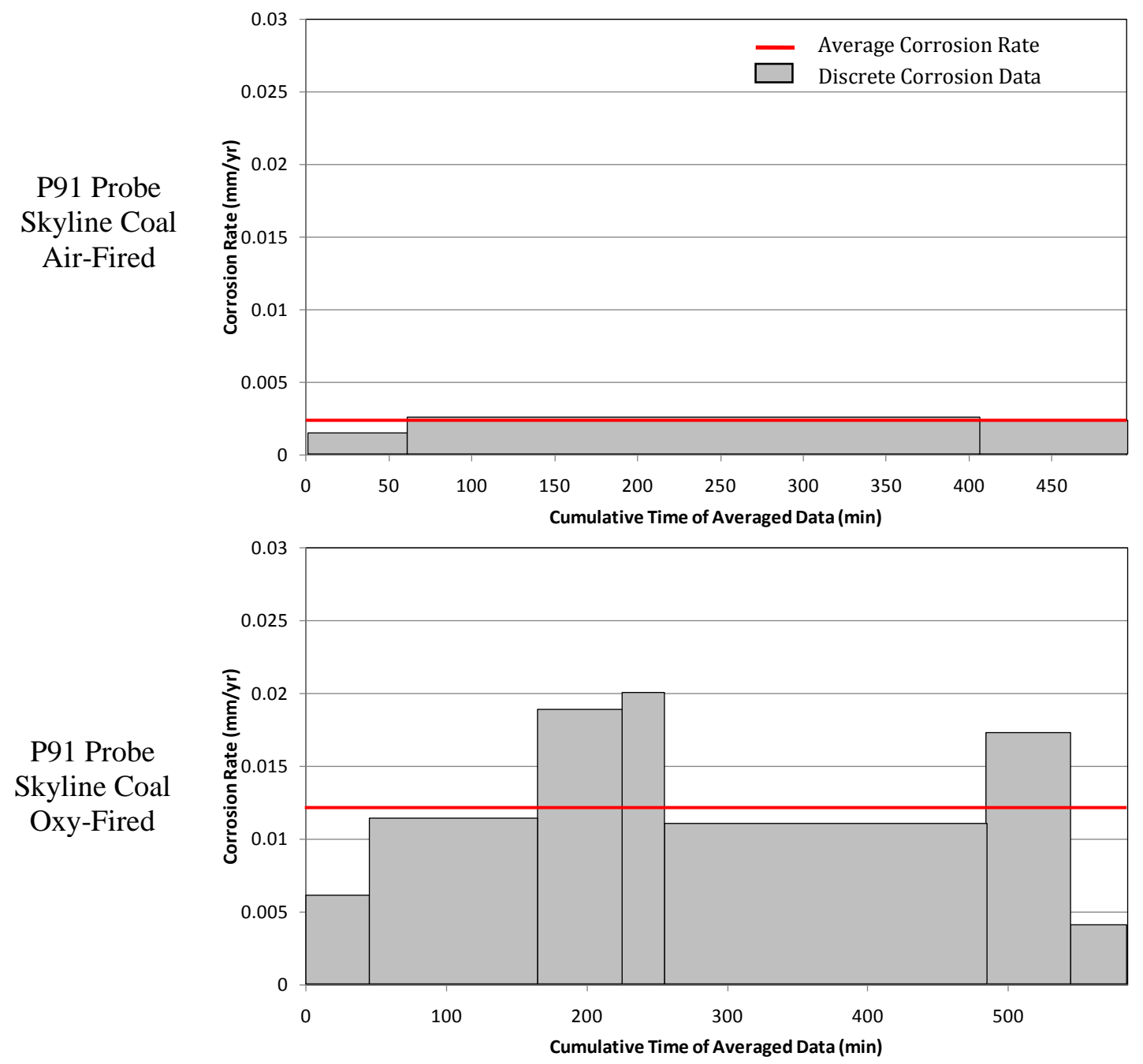

Figure 4.9-36: P91 superheat probe corrosion rate data used in the operational evaluation for air and oxy-fired conditions with Skyline coal.

Other results worthy of additional investigation were the high corrosion rates in Figure 4.9-29. The magnitude of the corrosion rate for the T22 superheat probe while firing Skyline coal under air- and oxyfired conditions was confirmed by the Duration Plots. That information will not be presented here. However, the Duration Plots showed mixed results for the other three high corrosion conditions in Figure 4.9-29. Duration Plots for the T22 and 347H superheater probes while oxy-firing Illinois coal are presented in Figure 4.9-37 and Figure 4.9-38 respectively. 


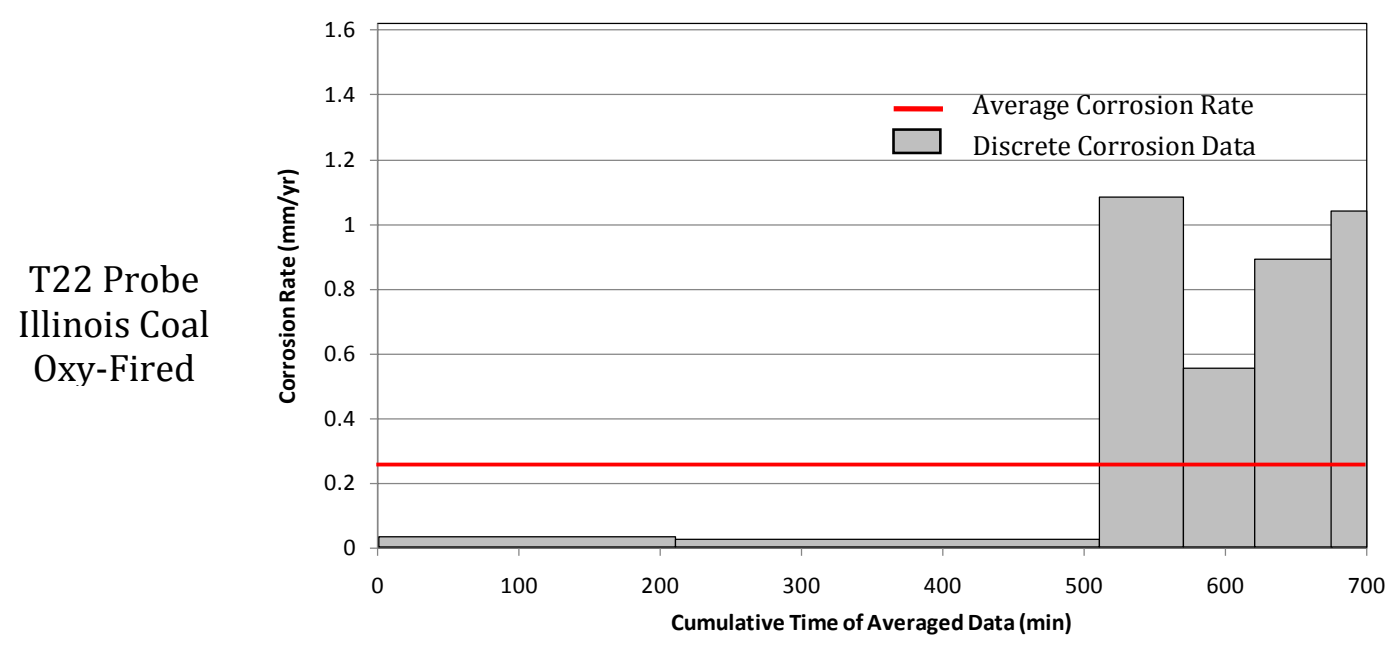

Figure 4.9-37: T22 superheater probe corrosion rated data used in the operational evaluation for oxy-fired conditions with Illinois coal.

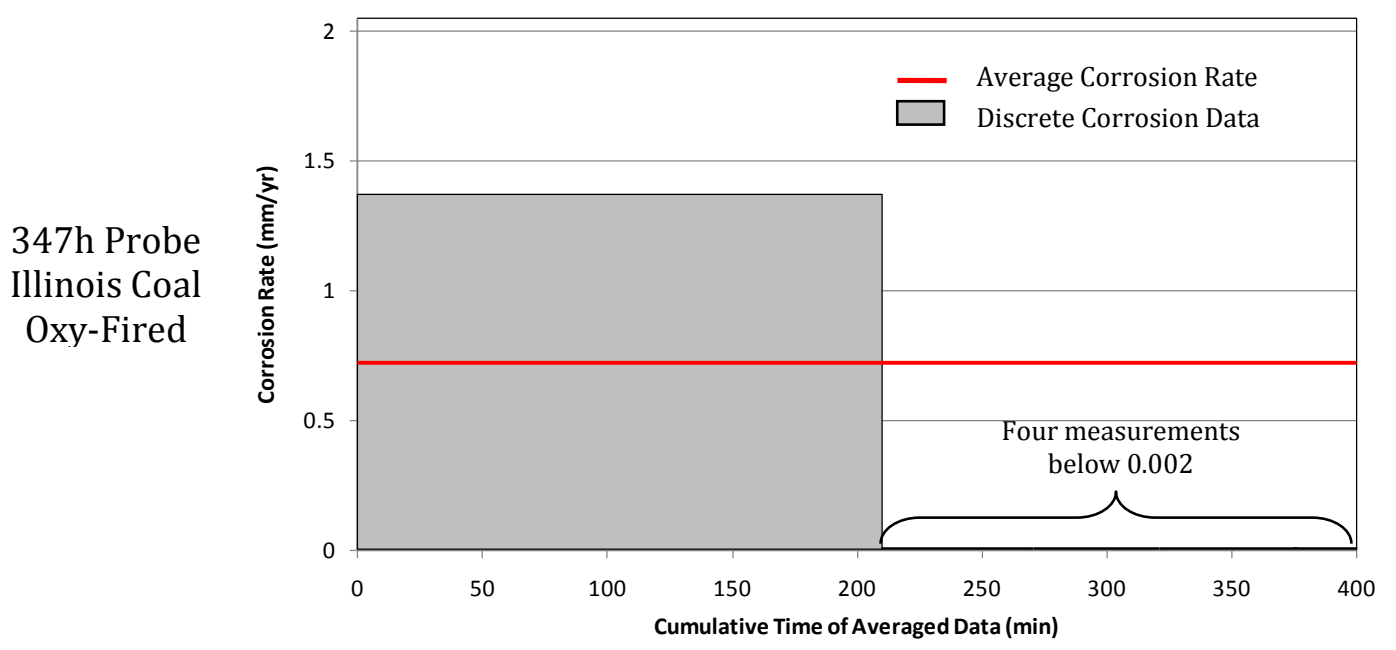

Figure 4.9-38: $347 \mathrm{H}$ superheater probe corrosion rate data used in the operational evaluation for oxy-fired conditions with Illinois coal.

Figure 4.9-37 and Figure 4.9-38 show that there was a dramatic difference in the corrosion rates for these two materials measured early in experimentation and late in experimentation while oxy-firing Illinois coal. This information suggests that there is likely a mechanistic difference between the measured corrosion early and late in these experiments. It is also interesting that the mechanism (if it is the same in both cases) produces opposite effects depending on the material. This observation will be addressed later while discussing temperature dependence.

\subsubsection{Corrosion - Oxidizing vs. Reducing Conditions}

It was identified previously that for the waterwall probe (SA210 material) the rate of corrosion decreased when converting from air- to oxy-fired conditions and this was contrary to the behavior of the superheater probes. It was identified previously also that one of the largest differences between the operating conditions of the waterwall and the superheater probes was the prevailing stoichiometric ratio of the 
combustion gas. The waterwall probe was exposed to flue gases that were at a stoichiometric ratio of 0.9 for the results previously reported. While operating the L1500 test furnace there are often minor perturbations in fuel flow rate. However, if the fuel feed rate decreases significantly for a period of time (for example, due to a pulverized coal hang in the feed hopper) and the flow rate of the oxidizer (air or oxygen) is not compensated, the oxygen concentration in the flue gas will spike and the stoichiometric ratio in the burner region may move from less than unity to greater than unity and back again. This can result in a short-term (perhaps 15 minute) transient from reducing to oxidizing conditions and then back again as the specified coal feed rate is resumed.

Figure 4.9-39 provides a trace of the waterwall probe corrosion rate as one such perturbation occurs. The corrosion rate and the furnace exit oxygen concentration are plotted.

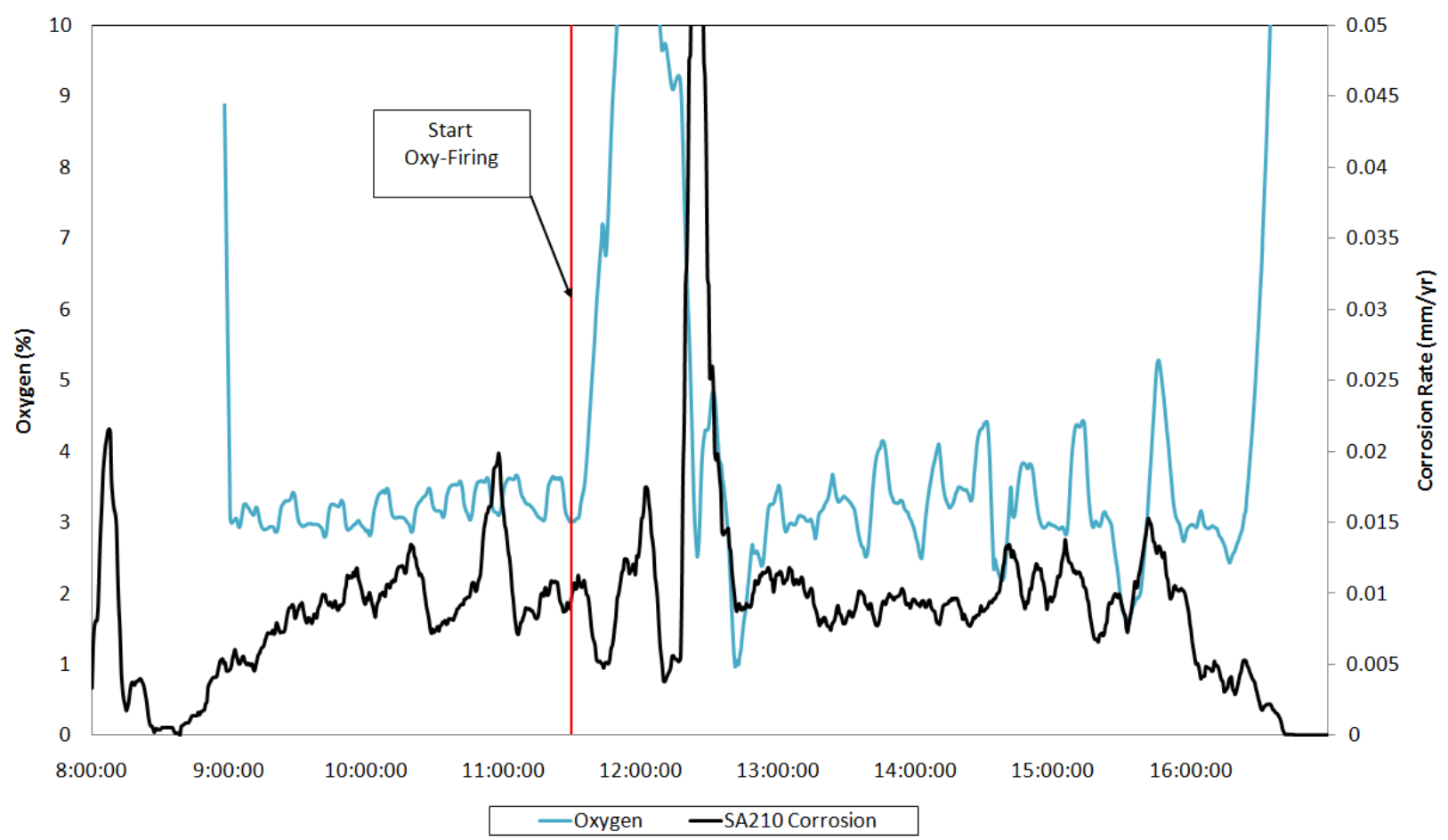

\section{Figure 4.9-39: Corrosion Rate of the SA210 waterwall probe as a function of oxygen concentration while firing Utah coal.}

Shortly after the conversion from air- to oxy-firing is initiated, the oxygen concentration in the furnace increases dramatically. This oxygen transient was undoubtedly due to the manner in which the furnace was converted from air- to oxy-fired conditions. The desired burner stoichiometric ratio throughout this period was 0.9. However, during the conversion from air- to oxy-firing, the conditions in the near burner region were superstoichiometric for a short period. At the point when the furnace exit oxygen concentration began to come back down to 3\%, there would have been a transient from oxidizing to reducing conditions in the vicinity of the waterwall probe. Associated with this transient is a sharp spike in the corrosion rate of the waterwall probe. These findings are important from a practical standpoint because they indicate that locations within a boiler that are susceptible to transient oxidizing/reducing changes are likely to be at risk from much higher rates of corrosion attack than is the case elsewhere under constant oxidizing or reducing conditions. 
For the last two days of corrosion experiments, changes were made to the installation configuration of the superheater probes in the furnace. The three superheater probes were moved from section ten to section five, one section upstream of the over-fire air ports. This change enabled further investigation of oxidizing vs. reducing conditions on corrosion rate. The new configuration of the superheater probes in the furnace is detailed in Figure 4.9-40 and can be compared to the old configuration in Figure 4.9-22.

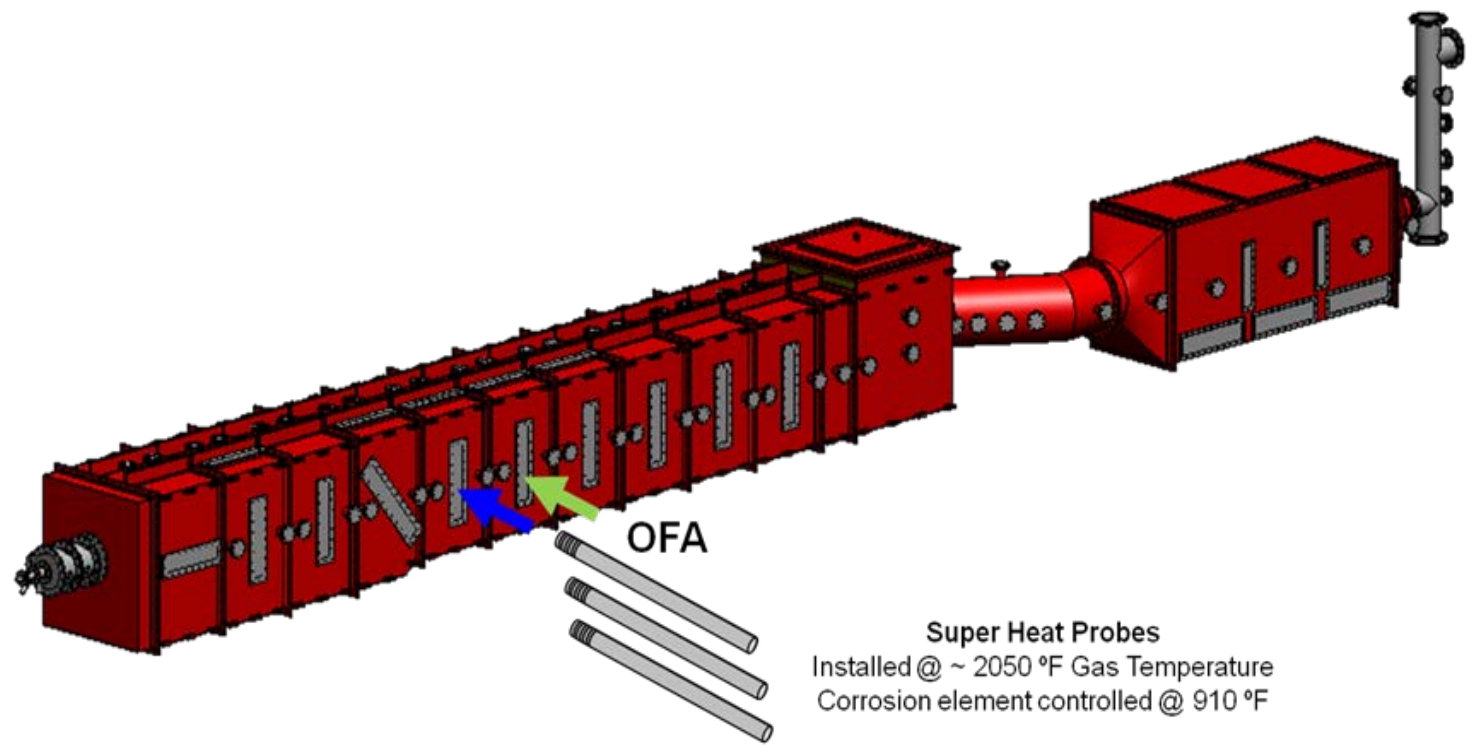

Figure 4.9-40: Alternative location of the superheat probes, upstream of the over-fire air ports.

Experiments were performed with the probe configuration detailed in Figure 4.9-40 where the burner stoichiometric ratio was varied between 0.9 and either 1.16 and 1.09 for air- and oxy-fired conditions respectively. The upper limit of the variation was designed to produce $3 \% \mathrm{O}_{2}$, dry, in the furnace exit flue gas. As the furnace was varied between staged and unstaged conditions, air, or $\mathrm{O}_{2}$ and FGR, moved between the burner secondary and the air ports. A good indicator of transitions between staged and unstaged conditions was the flow rate of the outer secondary air register. This value along with superheater probe corrosion rates are plotted in Figure 4.9-41 for the staging experiments described above.

For the initial hour and a half, the corrosion rates seem to be coming to steady state after being installed in the furnace. This was probably because the deposit characteristics were different for this probe location and the surface condition on the probes required a longer-than-normal period to equilibrate to the new flue gas environment. During the first half of the day, air-fired conditions were tested. At this time, two variations from reducing to oxidizing operation were tested. The first variation occurred while the probes were still equilibrating. The second variation showed a strong impact on corrosion rate for the T22 material right as the conditions are varied from reducing to oxidizing.

For the second half of the day, oxy-fired conditions were tested. Conditions were varied from oxidizing to reducing two times. Under oxy-fired conditions, the T22 corrosion rate spiked during the transient from oxidizing to reducing conditions, which was the opposite behavior to that observed under the airfired conditions. It appeared that the higher alloy materials were unaffected by transients between oxidizing and reducing conditions. The behavior of the T22 corrosion rate displayed in Figure 4.9-41 under oxy-fired conditions is consistent with that displayed in Figure 4.9-39 for oxidizing conditions. 


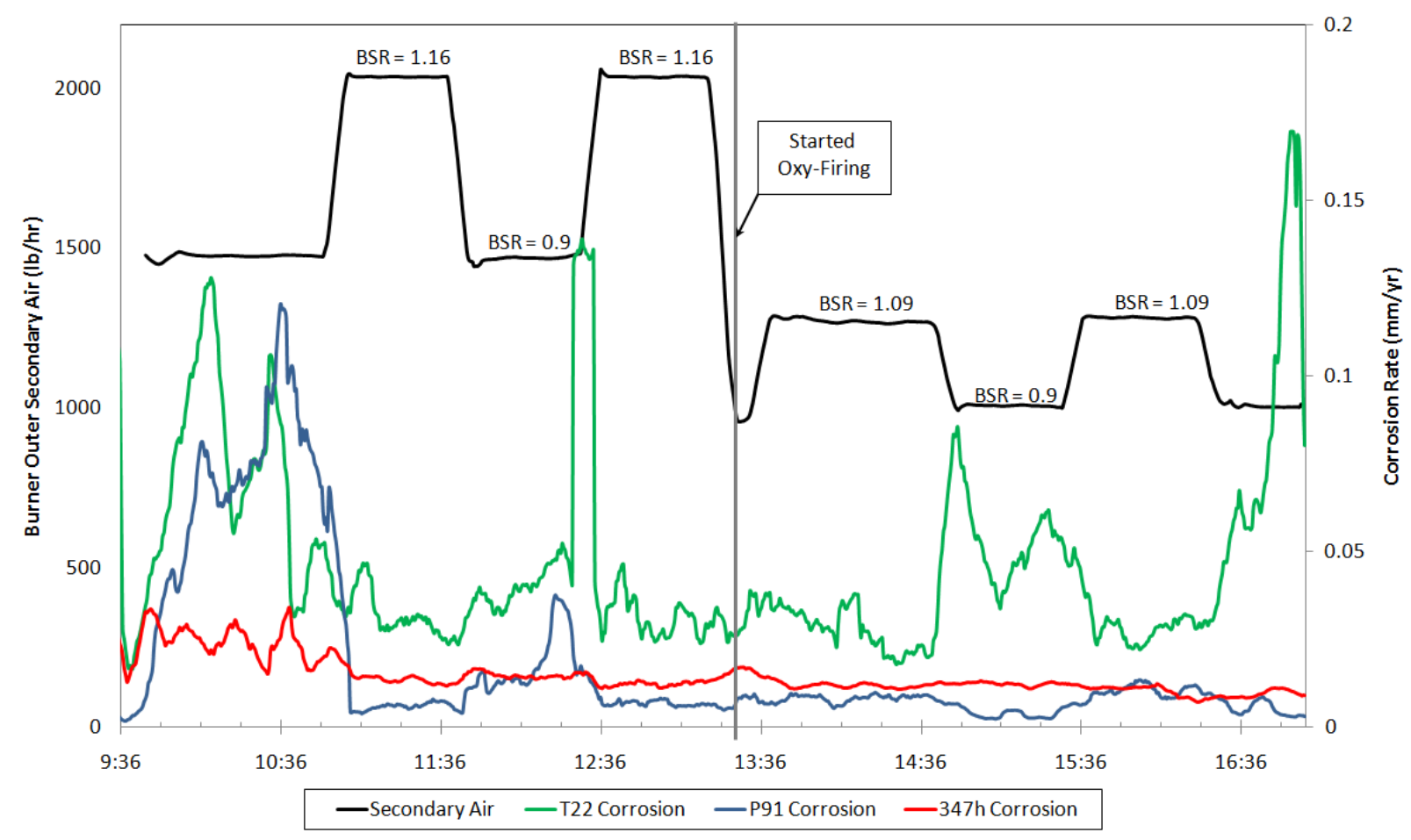

Figure 4.9-41: Superheater probe corrosion rates for oxidizing and reducing conditions while oxyand air-firing Illinois coal.

These are results that coupon tests with synthesized gas and deposits cannot resolve. The results are expected also to have a strong relationship to elevated corrosion rates in regions of fluctuating stoichiometry such as in the near-burner zone and around over-fire air ports. Data such as these can be used in advanced combustion modeling to develop and tune corrosion mechanisms for predicting accurately the impacts of fluctuations between oxidizing and reducing conditions.

\subsubsection{Corrosion - Temperature Dependence}

For all of the previously reported and discussed results, the temperatures of the corrosion sensor elements were controlled at $720^{\circ} \mathrm{F}$ for the waterwall probe (SA210 material) and $910^{\circ} \mathrm{F}$ for the superheater probes (T22, P91 and 347H). These temperatures were chosen because they are typical of sub-critical boilers and are representative of the majority of US power generation boiler installations. One of the goals of this program was to produce a data set that is useful for corrosion mechanism development and validation. The dependence of corrosion rate on metal temperature should be included in these mechanisms. It was noted also that for the high sulfur conditions, molten trisulfates in the deposit could have a large impact on corrosion. To determine whether trisulfates were participating in the corrosion rate it was necessary to operate with tube metal/deposit temperatures below and above the vaporization temperature. According to the literature, this could happen at temperatures as high as $1300^{\circ} \mathrm{F}$ (Viswanathan and Bakker 2000). It was determined that $1300^{\circ} \mathrm{F}$ is above the maximum operating temperature for all of the materials except $347 \mathrm{H}$. Therefore, a decision was made to vary the corrosion monitoring temperature for each material up to the maximum operating temperature for that material, as published in the literature (French 1991) (Viswanathan and Bakker 2000). The upper temperature limit of each of the test materials is shown in Table 4.9-7. 
Table 4.9-7: Maximum Operating Temperatures of the Tested Corrosion Materials.

\begin{tabular}{|l|l|}
\hline SA210 & $850^{\circ} \mathrm{F}$ \\
\hline T22 & $1050^{\circ} \mathrm{F}$ \\
\hline P91 & $1100^{\circ} \mathrm{F}$ \\
\hline $347 \mathrm{~h}$ & $1300^{\circ} \mathrm{F}$ \\
\hline
\end{tabular}

During the first experiments, when the Illinois coal was oxy-fired, the corrosion rate of the 347H material increased drastically. This high rate is represented by the first discrete period presented in the Duration Plot of Figure 4.9-38. Following that experiment, the corrosion rate of the $347 \mathrm{H}$ probe remained high even under air-fired conditions with Illinois coal. These data were considered to be unrepresentative of typical service conditions and therefore were excluded from the calculated rate average under air firing conditions. Shortly after that experiment, an investigation was launched to establish the effect of varying the operating temperature of the $347 \mathrm{H}$ corrosion probe. During the transition to the upper temperature condition, the corrosion rate of the $347 \mathrm{H}$ superheater probe reduced drastically and unexpectedly, even while oxy-firing the Illinois coal. A plot of the corrosion rate of the superheater probes and the temperatures of their sensor elements during this event is included in Figure 4.9-42.

Figure 4.9-42 shows that at 11:23 the temperature set points of the corrosion elements were increased. As the temperature of the $347 \mathrm{H}$ probe increased, the corrosion rate began to fall dramatically, and it resumed a corrosion rate that was similar to that observed previously under the air-fired condition. It was concluded that this behavior was due to decomposition and volatilization of the trisulfate species. This decomposition occurred at a sensor element temperature that was lower than had been expected. However the surface of the deposit would be at a higher temperature than would the metal of the sensor element itself and thus this decomposition behavior was consistent with the deposit condition at the specific deposit temperature.

Most of the remaining corrosion experiments performed while oxy-firing the Illinois coal were carried out with stepped temperature variations between the lower and upper sensor element temperatures. The observed temperature dependence of the $347 \mathrm{H}$ corrosion rate in the presence of high sulfur concentrations and the operating conditions of the $347 \mathrm{H}$ probe across the lifetime of the program explain the discontinuous behavior in Figure 4.9-38. All of the data presented for the $347 \mathrm{H}$ probe that were presented in Figure 4.9-38 were collected during periods when the sensor element temperature was controlled at $910^{\circ} \mathrm{F}$. However, data collected in the latter portion of the program were collected in between oscillations to higher probe temperatures, leaving no time for the trisulfate concentration to build up in the deposit. Therefore, the behavior of the $347 \mathrm{H}$ material under oxy-fired Illinois coal combustion that was reported in Figure 4.9-38 is probably low for continuous operation at $910^{\circ} \mathrm{F}$. However, it is representative of corrosion in the presence of trisulfates and the rate of corrosion will be orders of magnitude lower at elevated temperatures. 


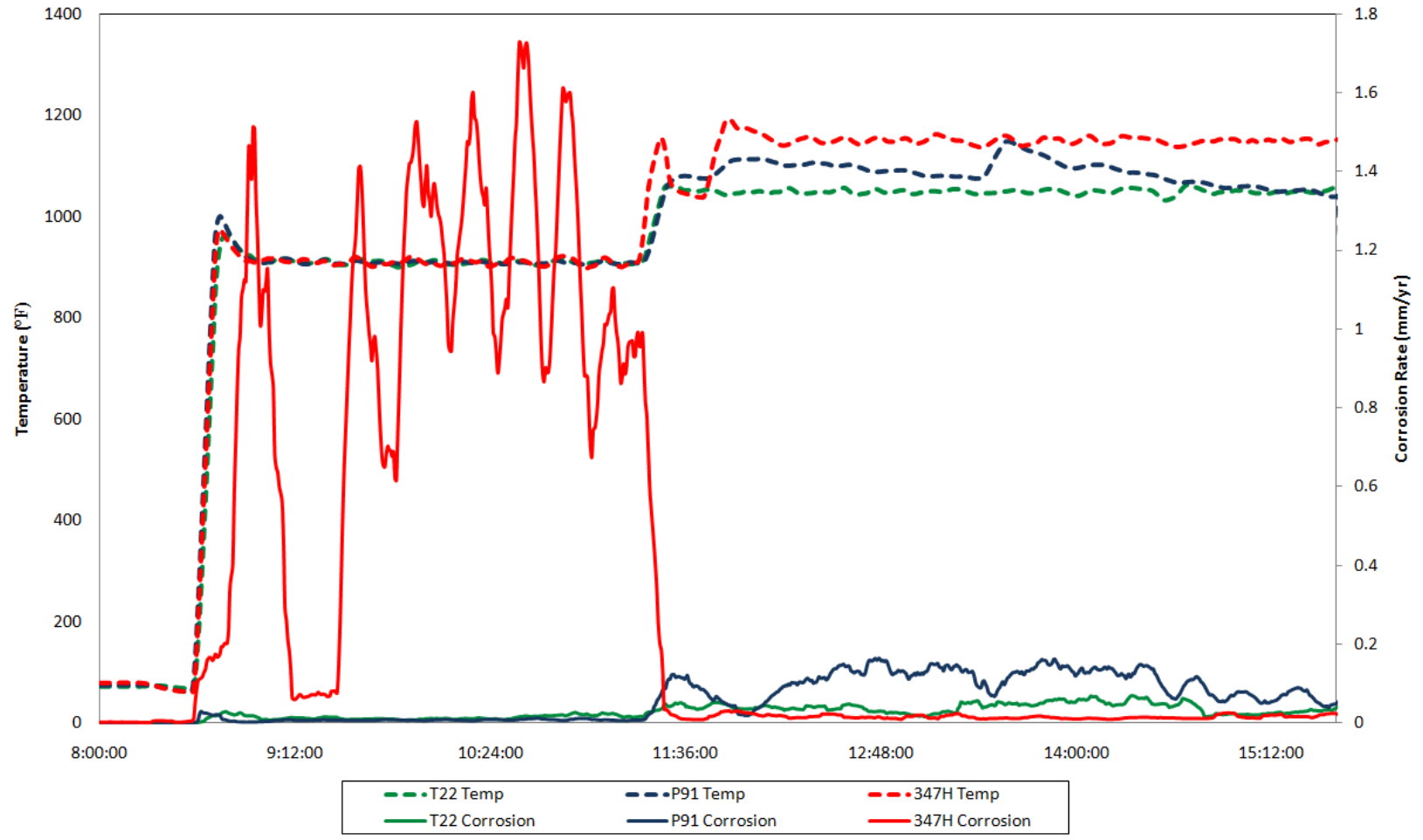

Figure 4.9-42: Inverse temperature dependence of $347 \mathrm{H}$ superheat probe corrosion rate on temperature while oxy-firing Illinois coal.

Further experiments to determine the dependence of corrosion rate on temperature were performed. These experiments are expected to provide the data necessary to tune the temperature dependence, by material, in the mechanism. Some of these data are presented in Figure 4.9-43 and Figure 4.9-44.

In Figure 4.9-43 and Figure 4.9-44 the operating temperatures and corrosion rates of each of the superheat probes are presented. The gray areas on each plot indicate a time periods when the data were averaged and used in the overall average for that condition. The average values for each of the corrosion rates are also included at the top of each of the grey areas. These data not only indicate the temperature dependence of the data, but also demonstrate the excellent repeatability and consistency of the rate estimates. 


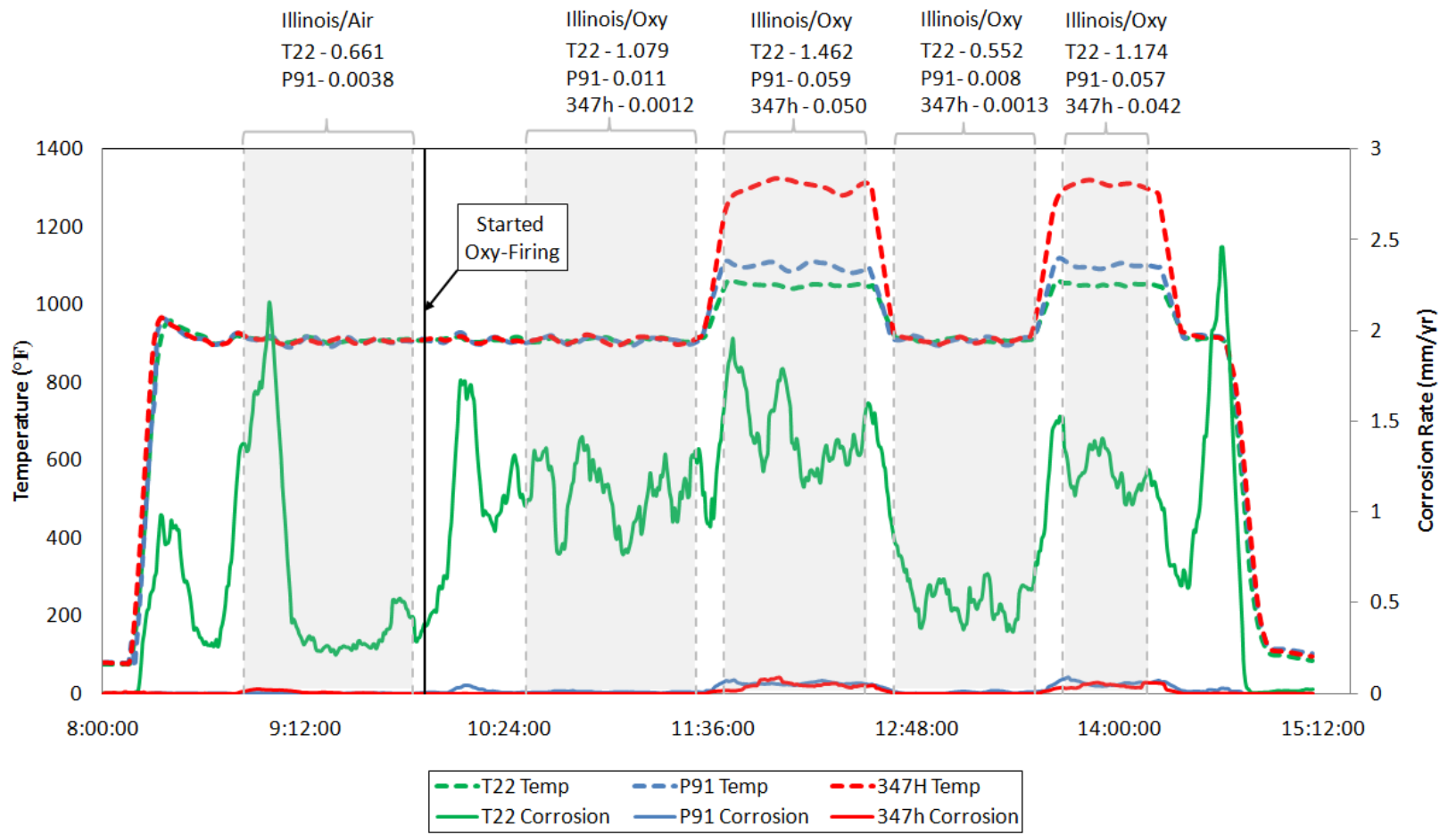

Figure 4.9-43: Plot showing the temperature dependence of the superheater corrosion probes while oxy-firing Illinois coal (large scale).

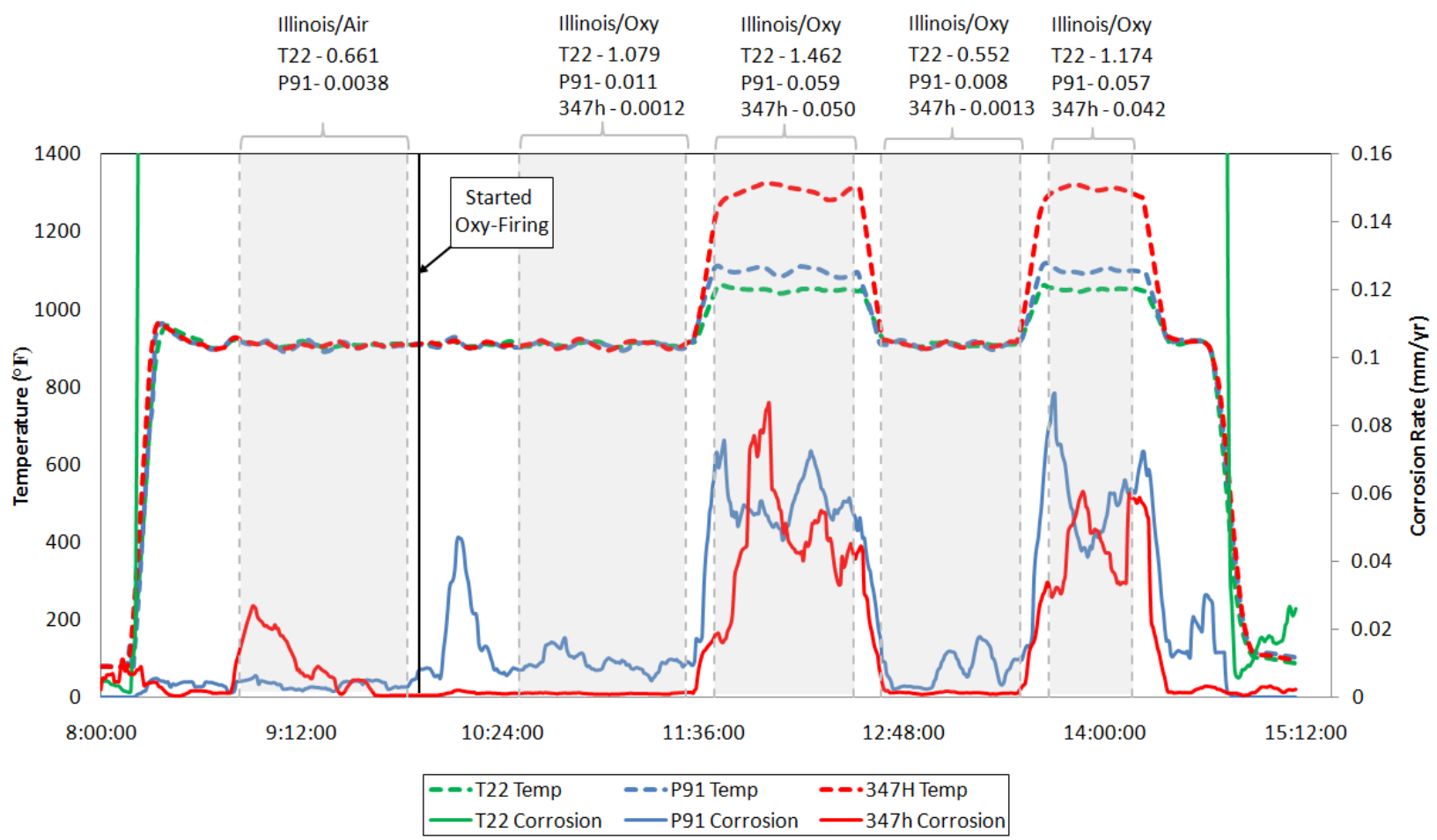

Figure 4.9-44: Plot showing the temperature dependence of the superheater corrosion probes while oxy-firing Illinois coal (small scale). 
The corrosion rate of the T22 probe while operated at $910^{\circ} \mathrm{F}$ (detailed in Figure 4.9-37) was higher prior to the first oscillation to the higher temperature than was the case after it was cycled back to $910^{\circ} \mathrm{F}$. This indicates that there may be some similar effect of trisulfates on corrosion rate as with the $347 \mathrm{H}$ material. However the average corrosion rate for the period beginning at 12:40, after the temperature was cycled back to $910^{\circ} \mathrm{F}$, was still about 20 times higher than the corrosion rates measured for these conditions before the temperature experiments were performed. It appears that the temperature oscillations may have impacted this material in a more permanent manner than had occurred with the other test materials. This would explain the discontinuous behavior in Figure 4.9-37.

\subsubsection{Corrosion Element Metallography}

At the conclusion of the pilot-scale testing, the elements were removed from the corrosion probes and sent to Microbeam Technologies, Inc. for metallographic analysis along with samples of the as received materials from which the elements were fabricated. These analyses were expected to show whether carburization of the metals occurred under oxy-fired conditions. Metallography analyses were performed using scanning electron microscopy with energy-dispersive x-ray area analysis. This method of analysis will not detect carbon at concentrations of $1 \%$ of less and quantification of carbon is not the goal. However these tests may be used qualitatively to determine whether any significant carbon penetration has occurred indicative of carburization.

For our program, one waterwall and three superheater probes were used with elements fabricated from SA210 and T22, P91 and 347H respectively. The specification of each of these materials is presented in Table 4.9-8.

A selection of backscattered electron images and SEM metallography results for each of the pre- and post-test materials will be presented in the following sections. General observations and conclusions from these data will be presented together in a section following the analyses.

Table 4.9-8. Specification of the materials used for corrosion sensor elements.

\begin{tabular}{|c|c|c|c|c|}
\hline Material & SA 210 & T22 & P91 & 347H \\
\hline HT Surface & Waterwall & Superheat & Superheat & Superheat \\
\hline $\mathrm{C}, \%$ & 0.07 & 0.11 & 0.10 & 0.048 \\
\hline $\mathrm{Si}, \%$ & 0.23 & 0.2 & 0.32 & 0.40 \\
\hline $\mathrm{Mn} \%$ \% & 0.42 & 0.44 & 0.47 & 1.32 \\
\hline $\mathrm{Ni} \%$ \% & - & - & 0.15 & 9.73 \\
\hline $\mathrm{Cr} \%$ & - & 2.21 & 8.52 & 17.45 \\
\hline $\mathrm{Mo} \%$ & - & 0.95 & 0.93 & - \\
\hline $\mathrm{S}, \%$ & 0.002 & 0.003 & 0.002 & 0.008 \\
\hline $\mathrm{P}, \%$ & 0.009 & 0.01 & 0.018 & 0.026 \\
\hline $\mathrm{Cu} \%$ & - & - & 0.11 & - \\
\hline $\mathrm{Al} \% \%$ & - & - & 0.01 & 0.005 \\
\hline $\mathrm{Nb} / \mathrm{Cb} \% \%$ & - & - & 0.07 & 0.63 \\
\hline $\mathrm{V}, \%$ & - & - & 0.22 & 0.078 \\
\hline $\mathrm{N}, \%$ & - & - & 0.044 & - \\
\hline $\mathrm{Ta}, \%$ & - & - & - & 0.02 \\
\hline
\end{tabular}




\subsubsection{Metallographic Results - SA210}

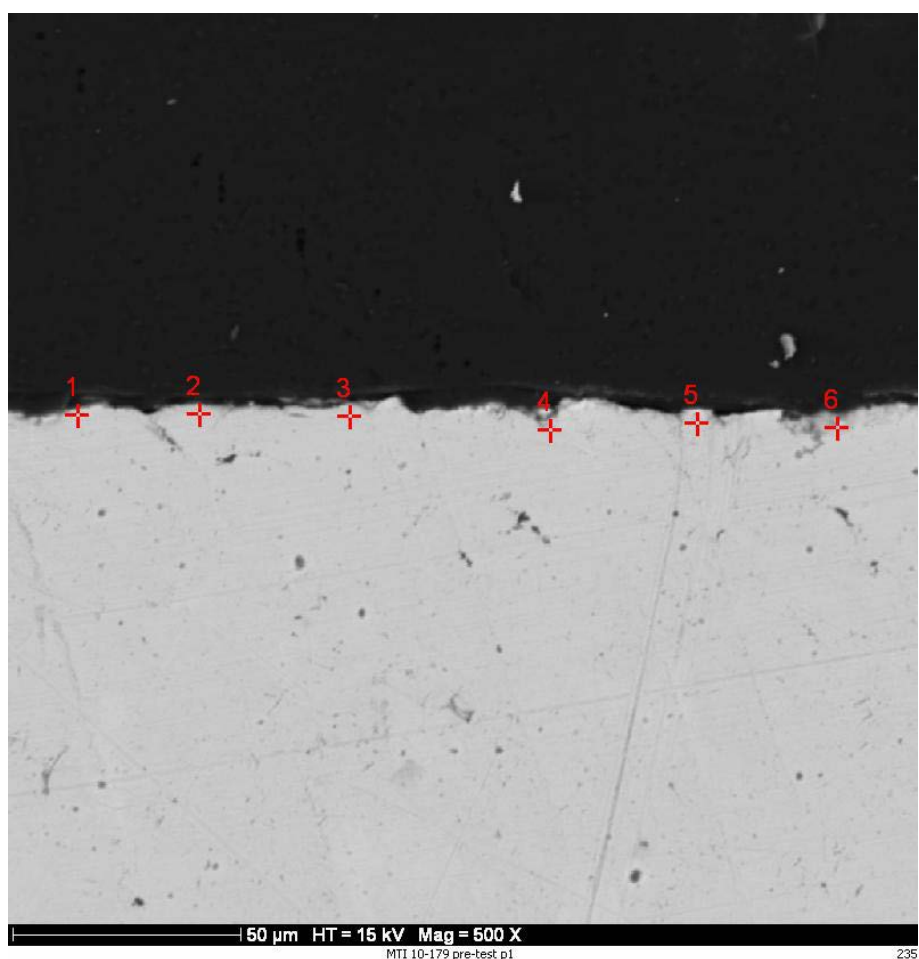

Figure 4.9-45. Backscattered electron image of SA210 pre-test surface.

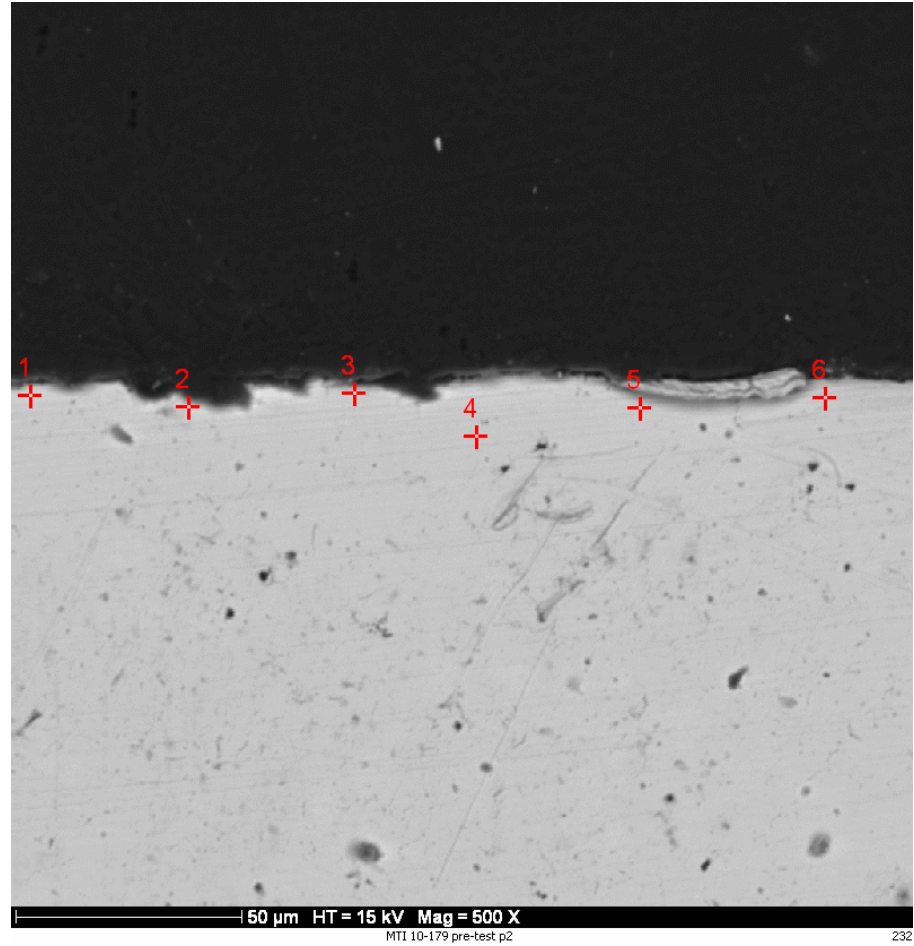

Figure 4.9-46. Backscattered electron image of SA210 pre-test surface. 
Table 4.9-9. SEM metallography results for SA210 pre-test surface.

\begin{tabular}{|l|c|l|c|c|c|c|c|c|c|}
\hline & Point & Description & Na & Al & Si & S & Ca & Fe & O \\
\hline Figure 4.9-45 & 1 & Steel surface & 4.4 & 1.4 & 1.4 & 0.4 & 0.1 & 89.5 & 2.8 \\
\hline Figure 4.9-45 & 2 & Steel surface & 5.7 & 1.7 & 2.0 & 0.6 & 0.1 & 87.6 & 2.4 \\
\hline Figure 4.9-45 & 3 & Steel surface & 3.7 & 1.2 & 1.4 & 0.5 & 0.0 & 90.8 & 2.5 \\
\hline Figure 4.9-45 & 4 & Steel surface & 2.3 & 0.3 & 0.6 & 0.1 & 0.5 & 94.5 & 1.7 \\
\hline Figure 4.9-45 & 5 & Steel surface & 1.5 & 0.9 & 1.2 & 0.5 & 0.1 & 94.5 & 1.3 \\
\hline Figure 4.9-45 & 6 & Steel surface-pit & 9.6 & 1.3 & 2.4 & 1.5 & 0.2 & 78.9 & 6.1 \\
\hline Figure 4.9-46 & 1 & Steel surface & 1.9 & 1.2 & 1.5 & 0.4 & 0.1 & 92.8 & 2.0 \\
\hline Figure 4.9-46 & 2 & Steel surface & 1.5 & 1.0 & 1.2 & 0.4 & 0.1 & 93.8 & 2.0 \\
\hline Figure 4.9-46 & 3 & Steel surface & 0.9 & 0.9 & 1.6 & 0.5 & 0.1 & 95.3 & 0.8 \\
\hline Figure 4.9-46 & 4 & Steel & 0.9 & 1.4 & 1.1 & 0.3 & 0.0 & 94.3 & 2.0 \\
\hline Figure 4.9-46 & 5 & Steel surface & 1.1 & 1.2 & 1.1 & 0.3 & 0.0 & 94.3 & 2.0 \\
\hline Figure 4.9-46 & 6 & Steel surface & 1.1 & 1.1 & 1.2 & 0.3 & 0.0 & 94.5 & 1.8 \\
\hline & Average & All & $\mathbf{2 . 9}$ & $\mathbf{1 . 1}$ & $\mathbf{1 . 4}$ & $\mathbf{0 . 5}$ & $\mathbf{0 . 1}$ & $\mathbf{9 1 . 7}$ & $\mathbf{2 . 3}$ \\
\hline
\end{tabular}

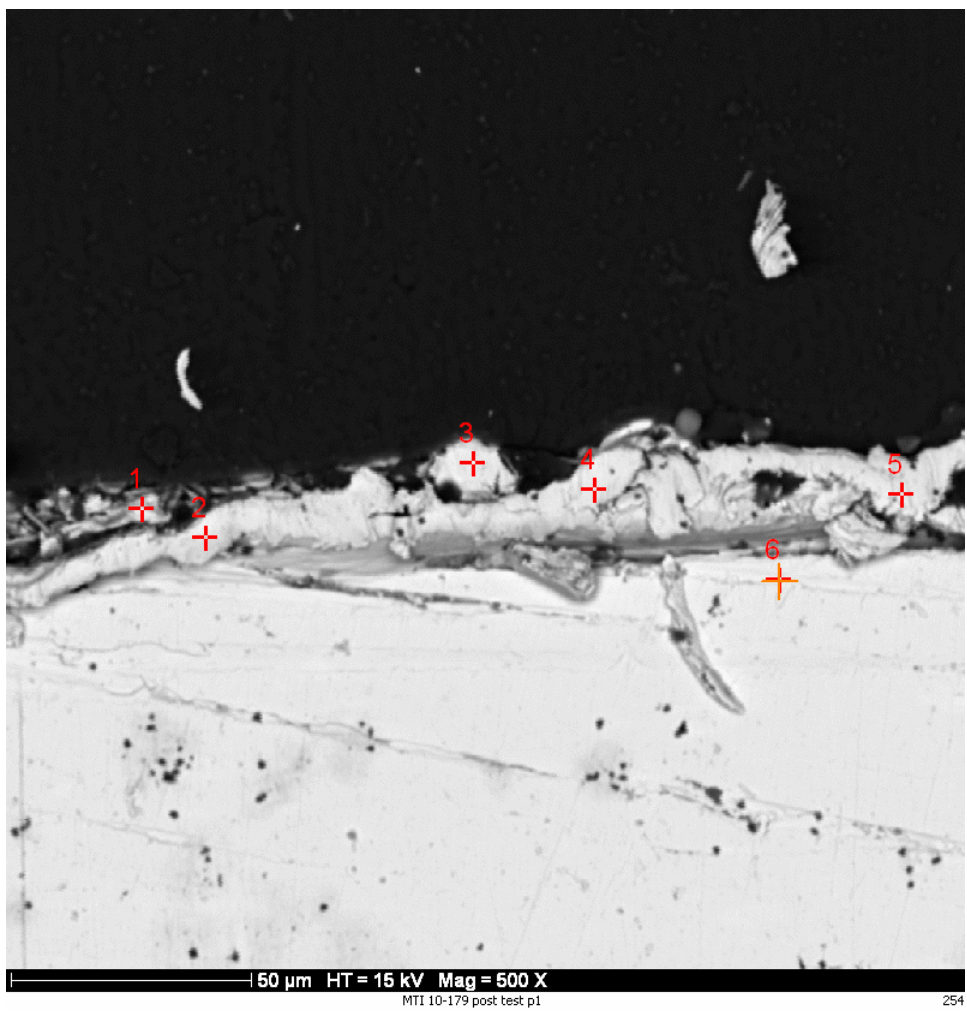

Figure 4.9-47. Backscattered electron image of SA210 post-test surface. 


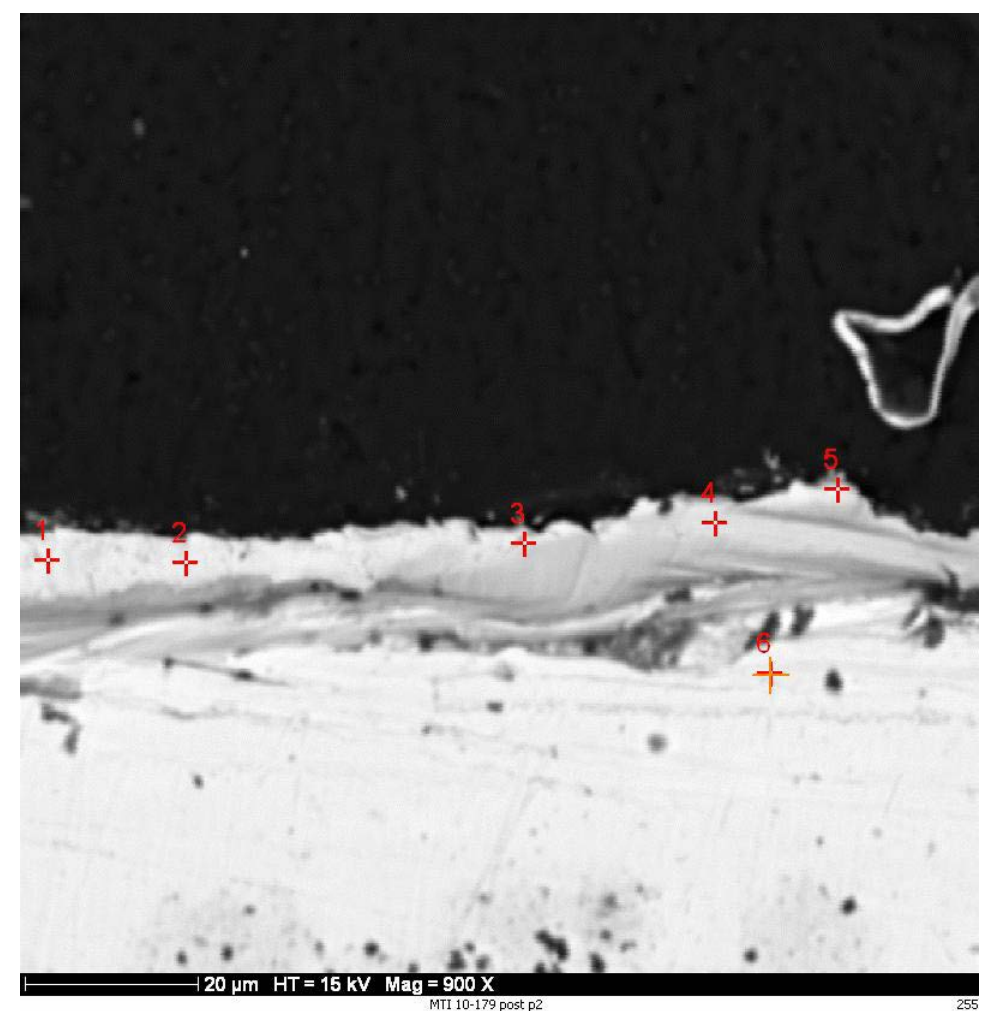

Figure 4.9-48. Backscattered electron image of SA210 post-test surface.

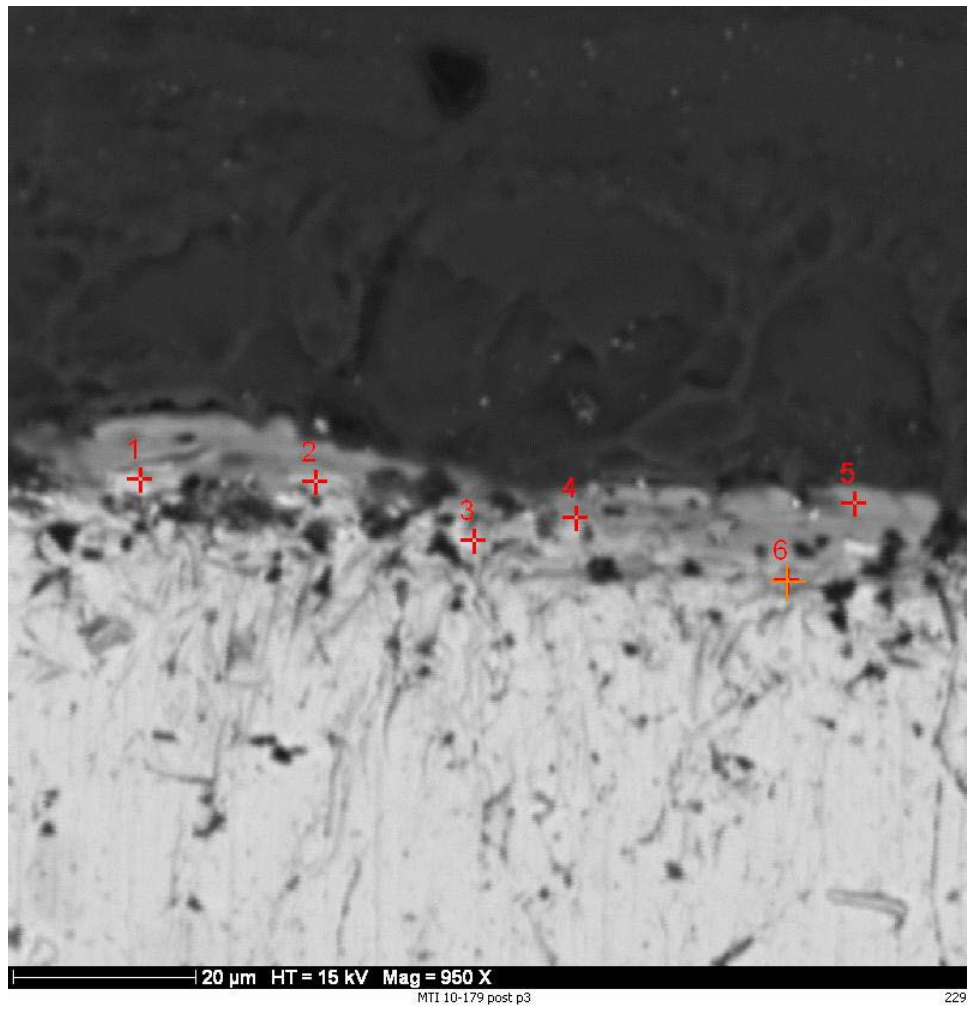

Figure 4.9-49. Backscattered electron image of SA210 post-test surface. 
Table 4.9-10. SEM metallography results for SA210 post-test surface.

\begin{tabular}{|l|l|l|l|l|l|l|l|}
\hline & Point & Description & Al & Si & Mn & Fe & O \\
\hline Figure 4.9-47 & 1 & Outer scale & 1.6 & 2.0 & 0.1 & 92.3 & 4.0 \\
\hline Figure 4.9-47 & 2 & Inner scale & 0.7 & 1.0 & 0.5 & 96.4 & 1.4 \\
\hline Figure 4.9-47 & 3 & Outer scale & 0.3 & 0.9 & 0.3 & 98.5 & 0.0 \\
\hline Figure 4.9-47 & 4 & Scale & 1.1 & 1.0 & 0.5 & 95.0 & 2.5 \\
\hline Figure 4.9-47 & 5 & Scale & 3.4 & 2.1 & 0.2 & 89.2 & 5.0 \\
\hline Figure 4.9-47 & 6 & Steel & 0.1 & 0.1 & 1.2 & 98.6 & 0.1 \\
\hline Figure 4.9-48 & 1 & Scale & 0.0 & 0.0 & 0.5 & 99.5 & 0.0 \\
\hline Figure 4.9-48 & 2 & Scale & 0.4 & 0.9 & 0.5 & 97.5 & 0.7 \\
\hline Figure 4.9-48 & 3 & Scale & 0.6 & 0.7 & 0.6 & 97.2 & 0.9 \\
\hline Figure 4.9-48 & 4 & Scale & 1.1 & 1.1 & 0.2 & 95.5 & 2.0 \\
\hline Figure 4.9-48 & 5 & Scale & 0.9 & 0.8 & 0.4 & 94.3 & 3.6 \\
\hline Figure 4.9-48 & 6 & Steel & 0.8 & 1.0 & 0.4 & 96.5 & 1.3 \\
\hline Figure 4.9-49 & 1 & Scale & 0.1 & 2.8 & 0.8 & 96.1 & 0.3 \\
\hline Figure 4.9-49 & 2 & Scale & 0.1 & 3.0 & 0.9 & 95.5 & 0.5 \\
\hline Figure 4.9-49 & 3 & Scale & 0.0 & 1.7 & 0.5 & 97.8 & 0.1 \\
\hline Figure 4.9-49 & 4 & Scale & 0.0 & 5.4 & 0.4 & 93.9 & 0.3 \\
\hline Figure 4.9-49 & 5 & Scale & 0.1 & 8.3 & 0.6 & 90.7 & 0.4 \\
\hline Figure 4.9-49 & 6 & Scale & 0.1 & 2.6 & 0.8 & 95.3 & 1.3 \\
\hline & Average & All scale & $\mathbf{0 . 7}$ & $\mathbf{2 . 1}$ & $\mathbf{0 . 5}$ & $\mathbf{9 5 . 3}$ & $\mathbf{1 . 4}$ \\
\hline & Average & Steel only & $\mathbf{0 . 4}$ & $\mathbf{0 . 6}$ & $\mathbf{0 . 8}$ & $\mathbf{9 7 . 5}$ & $\mathbf{0 . 7}$ \\
\hline
\end{tabular}

\subsubsection{Metallographic Results - T22}

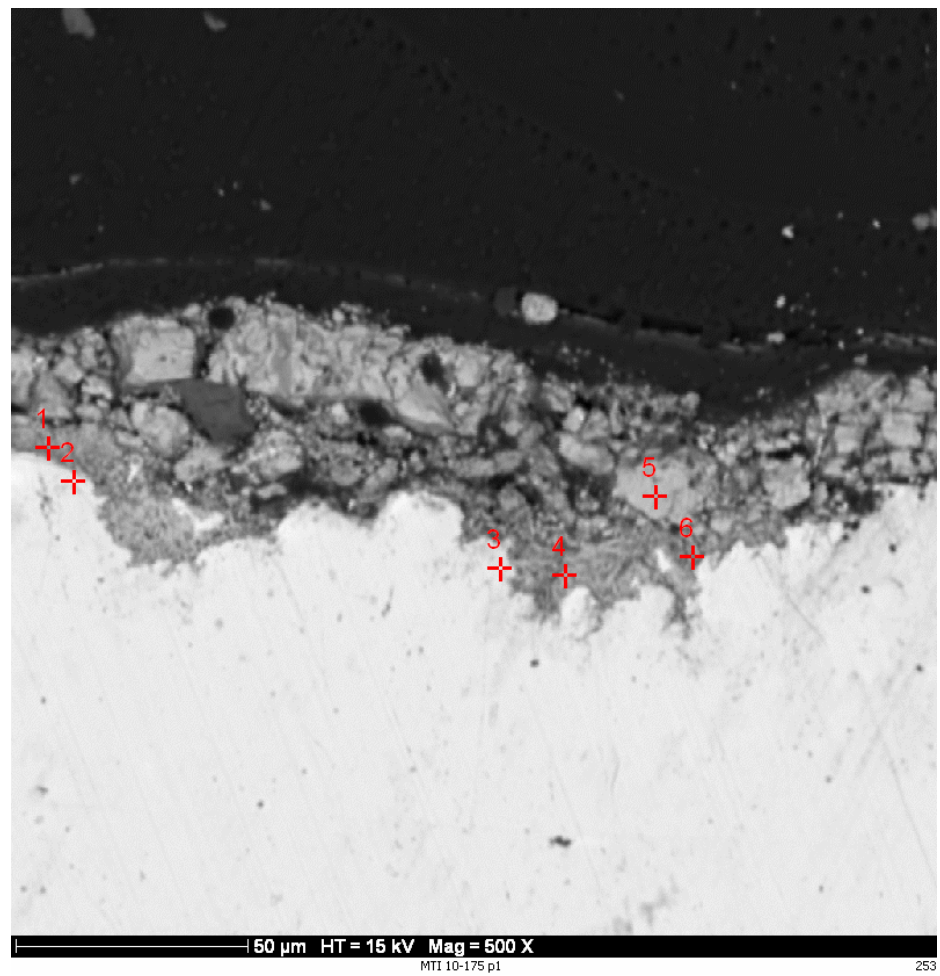

Figure 4.9-50. Backscattered electron image of T22 pre-test surface. 


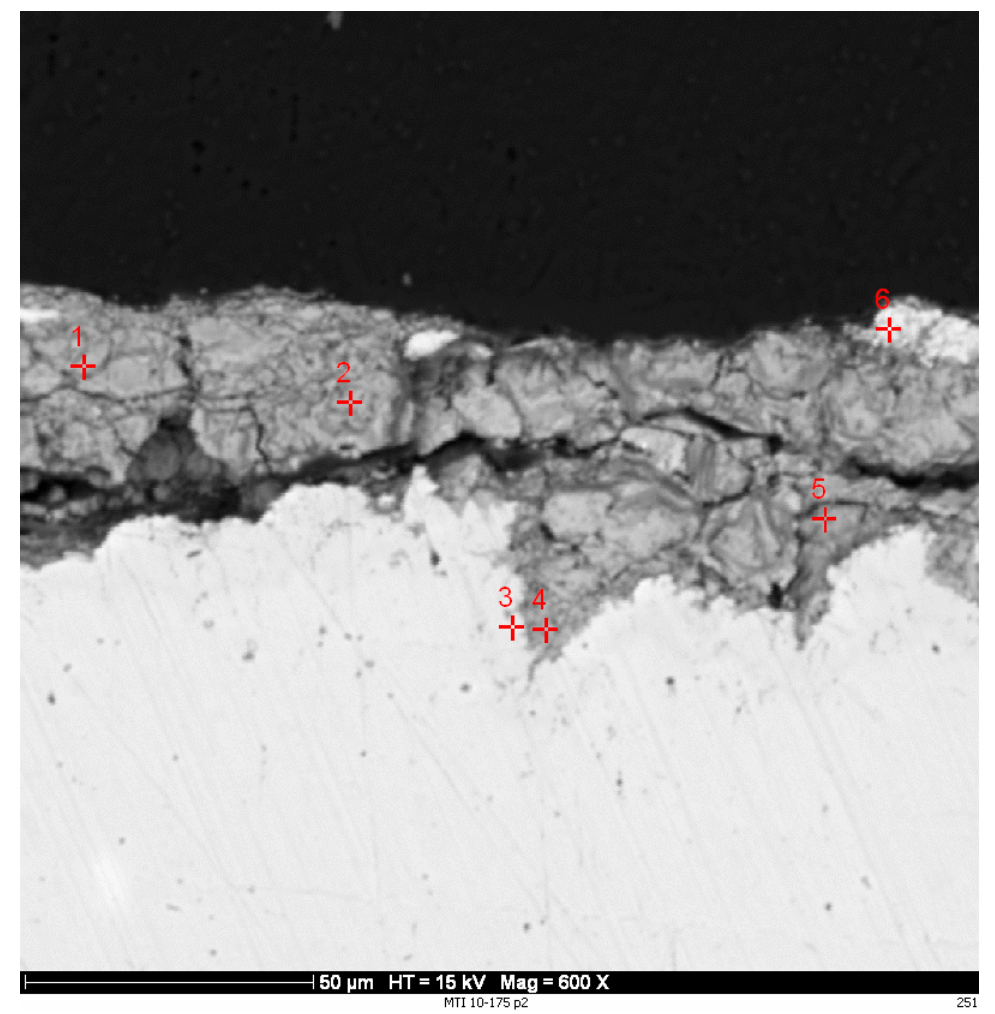

Figure 4.9-51. Backscattered electron image of T22 pre-test surface.

Table 4.9-11. SEM metallography results for T22 pre-test surface.

\begin{tabular}{|l|c|l|c|c|c|c|c|c|}
\hline & Point & Description & Al & Si & $\mathbf{C r}$ & $\mathbf{F e}$ & Mo & $\mathbf{0}$ \\
\hline Figure 4.9-50 & 1 & Inner scale & 1.9 & 2.0 & 1.9 & 91.8 & 2.4 & 0.0 \\
\hline Figure 4.9-50 & 2 & Steel & 0.7 & 1.2 & 1.6 & 95.6 & 1.0 & 0.0 \\
\hline Figure 4.9-50 & 3 & Steel & 1.1 & 1.6 & 2.2 & 93.4 & 1.7 & 0.0 \\
\hline Figure 4.9-50 & 4 & Scale - pit & 0.0 & 0.0 & 4.0 & 95.9 & 0.1 & 0.0 \\
\hline Figure 4.9-50 & 5 & Outer scale & 0.0 & 0.0 & 6.8 & 92.0 & 0.1 & 1.1 \\
\hline Figure 4.9-50 & 6 & Inner scale & 0.8 & 0.9 & 3.2 & 91.3 & 0.9 & 2.9 \\
\hline Figure 4.9-51 & 1 & Outer scale & 1.4 & 1.2 & 0.1 & 82.7 & 1.3 & 13.3 \\
\hline Figure 4.9-51 & 2 & Outer scale & 0.5 & 0.7 & 0.2 & 92.2 & 0.6 & 5.8 \\
\hline Figure 4.9-51 & 3 & Steel & 1.1 & 1.4 & 1.6 & 93.3 & 2.6 & 0.0 \\
\hline Figure 4.9-51 & 4 & Scale - pit & 1.0 & 1.7 & 4.2 & 79.4 & 1.9 & 11.9 \\
\hline Figure 4.9-51 & 5 & OD scale & 2.7 & 1.6 & 1.1 & 70.8 & 1.9 & 21.9 \\
\hline Figure 4.9-51 & 6 & Outer scale & 1.8 & 1.4 & 0.0 & 91.5 & 1.5 & 3.9 \\
\hline & Average & All scale & $\mathbf{1 . 1}$ & $\mathbf{1 . 1}$ & $\mathbf{2 . 4}$ & $\mathbf{8 7 . 5}$ & $\mathbf{1 . 2}$ & $\mathbf{6 . 7}$ \\
\hline & & Steel only & $\mathbf{1 . 0}$ & $\mathbf{1 . 4}$ & $\mathbf{1 . 8}$ & $\mathbf{9 4 . 1}$ & $\mathbf{1 . 8}$ & $\mathbf{0 . 0}$ \\
\hline
\end{tabular}




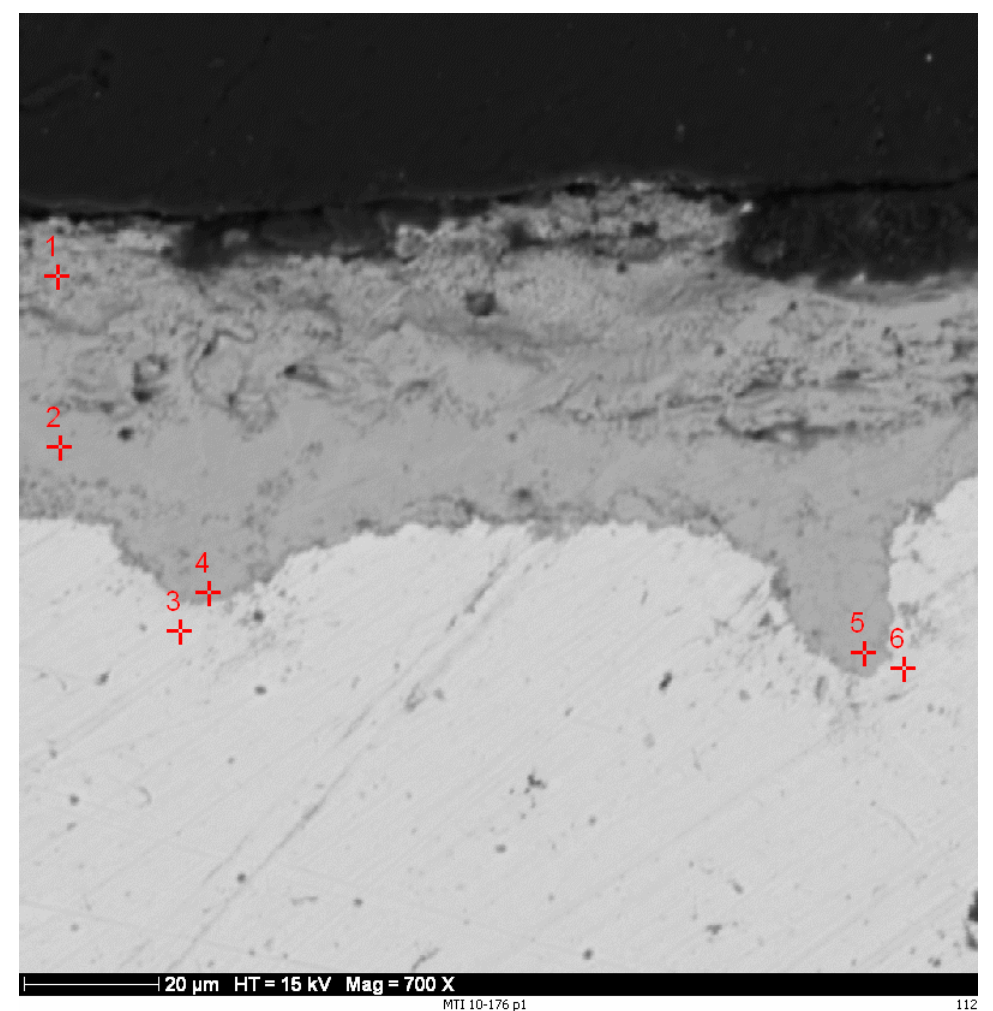

Figure 4.9-52. Backscattered electron image of T22 post-test surface.

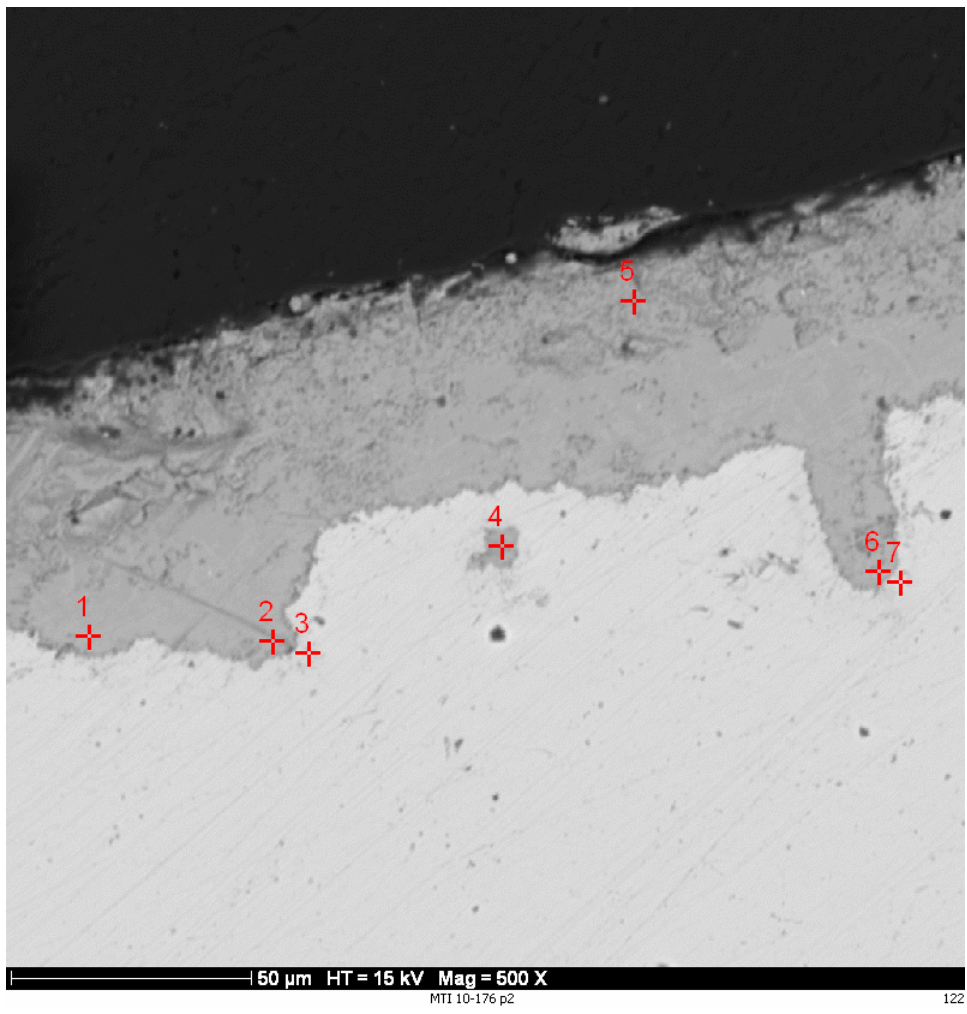

Figure 4.9-53. Backscattered electron image of T22 post-test surface. 
Table 4.9-12. SEM metallography results for T22 post-test surface.

\begin{tabular}{|l|c|l|c|c|c|c|c|c|c|}
\hline & Point & Description & Al & $\mathbf{S i}$ & $\mathbf{C r}$ & $\mathbf{F e}$ & $\mathbf{Z r}$ & $\mathbf{M o}$ & $\mathbf{0}$ \\
\hline Figure 4.9-52 & 1 & Outer scale & 2.0 & 1.7 & 0.3 & 81.3 & 1.3 & 1.8 & 11.7 \\
\hline Figure 4.9-52 & 2 & Scale & 0.8 & 1.4 & 3.5 & 84.4 & 0.7 & 2.1 & 7.2 \\
\hline Figure 4.9-52 & 3 & Steel - by pit & 0.4 & 0.6 & 1.8 & 96.2 & 0.2 & 0.9 & 0.0 \\
\hline Figure 4.9-52 & 4 & Scale in pit & 0.9 & 1.4 & 0.9 & 88.7 & 0.6 & 2.1 & 5.5 \\
\hline Figure 4.9-52 & 5 & Scale in pit & 1.0 & 1.6 & 3.1 & 84.7 & 0.8 & 2.6 & 6.3 \\
\hline Figure 4.9-52 & 6 & Steel - by pit & 0.7 & 1.2 & 1.7 & 94.6 & 0.4 & 1.3 & 0.0 \\
\hline Figure 4.9-53 & 1 & Scale in pit & 0.9 & 1.0 & 1.7 & 88.6 & 0.6 & 1.8 & 5.3 \\
\hline Figure 4.9-53 & 2 & Scale & 0.8 & 1.4 & 2.7 & 85.5 & 0.6 & 2.5 & 6.4 \\
\hline Figure 4.9-53 & 3 & Steel - by pit & 0.9 & 1.1 & 6.9 & 85.0 & 0.5 & 3.8 & 1.8 \\
\hline Figure 4.9-53 & 4 & Pit/void in steel & 1.3 & 3.7 & 16.9 & 60.2 & 0.9 & 5.5 & 11.5 \\
\hline Figure 4.9-53 & 5 & Outer scale & 0.9 & 1.8 & 2.6 & 83.1 & 0.7 & 2.0 & 9.0 \\
\hline Figure 4.9-53 & 6 & Scale in pit & 0.8 & 1.7 & 7.0 & 73.1 & 1.1 & 10.3 & 6.1 \\
\hline Figure 4.9-53 & $\mathbf{7}$ & Steel - by pit & 0.8 & 1.1 & 1.3 & 95.3 & 0.3 & 1.1 & 0.0 \\
\hline & Average & All scale & $\mathbf{1 . 0}$ & $\mathbf{1 . 5}$ & $\mathbf{2 . 7}$ & $\mathbf{8 3 . 7}$ & $\mathbf{0 . 8}$ & $\mathbf{3 . 1}$ & $\mathbf{7 . 2}$ \\
\hline & & Steel only & $\mathbf{0 . 7}$ & $\mathbf{1 . 0}$ & $\mathbf{2 . 9}$ & $\mathbf{9 2 . 8}$ & $\mathbf{0 . 4}$ & $\mathbf{1 . 8}$ & $\mathbf{0 . 5}$ \\
\hline
\end{tabular}

\subsubsection{Metallographic Results - P91}

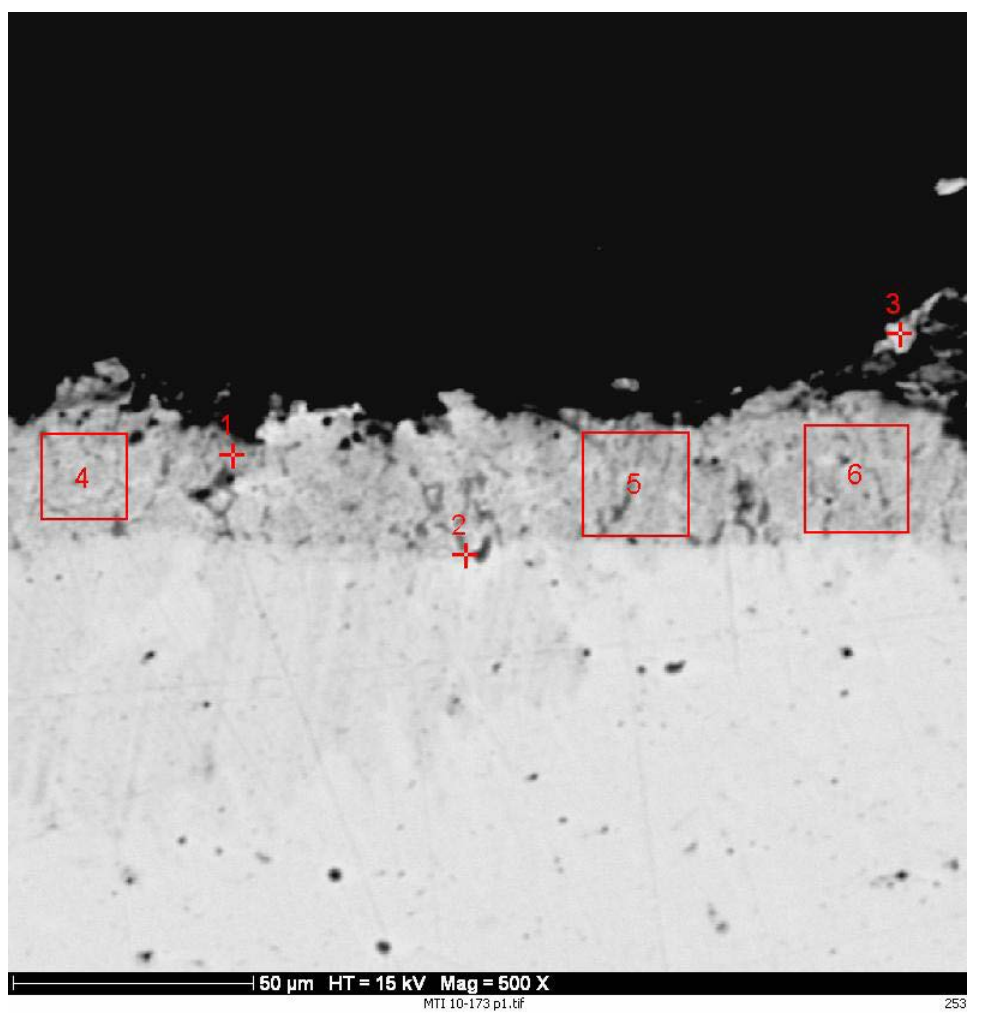

Figure 4.9-54. Backscattered electron image of P91 pre-test surface. 


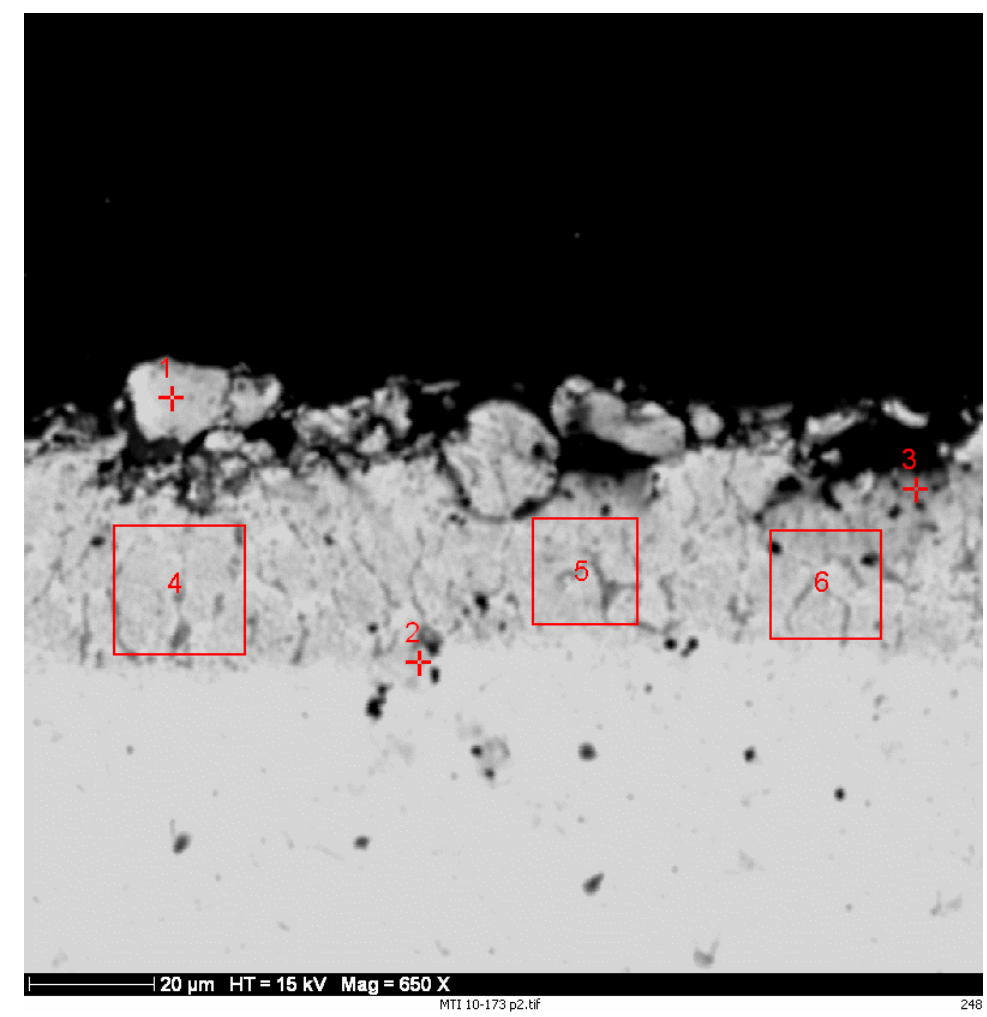

Figure 4.9-55. Backscattered electron image of P91 pre-test surface.

Table 4.9-13. SEM metallography results for P91 pre-test surface.

\begin{tabular}{|l|c|l|l|l|l|l|l|l|l|l|}
\hline & Point & Description & Na & Mg & Al & Si & Cr & Fe & Mo & $\mathbf{0}$ \\
\hline Figure 4.9-54 & 1 & OD scale & 2.6 & 0.9 & 0.9 & 3.9 & 9.5 & 78.6 & 1.7 & 1.9 \\
\hline Figure 4.9-54 & 2 & Inner scale & 0.1 & 0.0 & 0.1 & 1.9 & 11.1 & 85.7 & 1.1 & 0.0 \\
\hline Figure 4.9-54 & 3 & Outer scale & 2.7 & 2.2 & 2.7 & 3.3 & 4.2 & 76.2 & 2.1 & 6.6 \\
\hline Figure 4.9-54 & 4 & OD scale & 1.9 & 0.6 & 0.9 & 3.0 & 6.8 & 83.9 & 1.5 & 1.5 \\
\hline Figure 4.9-54 & 5 & OD scale & 1.7 & 0.8 & 1.1 & 2.8 & 8.2 & 81.6 & 1.7 & 2.1 \\
\hline Figure 4.9-54 & 6 & OD scale & 1.8 & 0.7 & 0.9 & 3.0 & 7.4 & 82.2 & 1.6 & 2.4 \\
\hline Figure 4.9-55 & 1 & Outer scale & 1.3 & 0.7 & 1.0 & 2.3 & 7.2 & 83.6 & 1.5 & 2.5 \\
\hline Figure 4.9-55 & 2 & Inner scale & 2.0 & 0.5 & 0.8 & 2.9 & 4.6 & 86.9 & 1.6 & 0.6 \\
\hline Figure 4.9-55 & 3 & OD scale & 3.7 & 1.0 & 1.0 & 6.3 & 6.6 & 75.3 & 1.7 & 4.4 \\
\hline Figure 4.9-55 & 4 & OD scale & 1.0 & 0.7 & 1.0 & 2.4 & 8.7 & 82.0 & 1.4 & 2.7 \\
\hline Figure 4.9-55 & 5 & OD scale & 2.0 & 0.7 & 0.9 & 3.1 & 9.1 & 79.7 & 1.5 & 3.0 \\
\hline Figure 4.9-55 & 6 & OD scale & 1.9 & 0.9 & 1.0 & 3.2 & 9.6 & 78.9 & 1.4 & 3.1 \\
\hline & Average & All & $\mathbf{1 . 9}$ & $\mathbf{0 . 8}$ & $\mathbf{1 . 0}$ & $\mathbf{3 . 2}$ & $\mathbf{7 . 7}$ & $\mathbf{8 1 . 2}$ & $\mathbf{1 . 6}$ & $\mathbf{2 . 6}$ \\
\hline
\end{tabular}




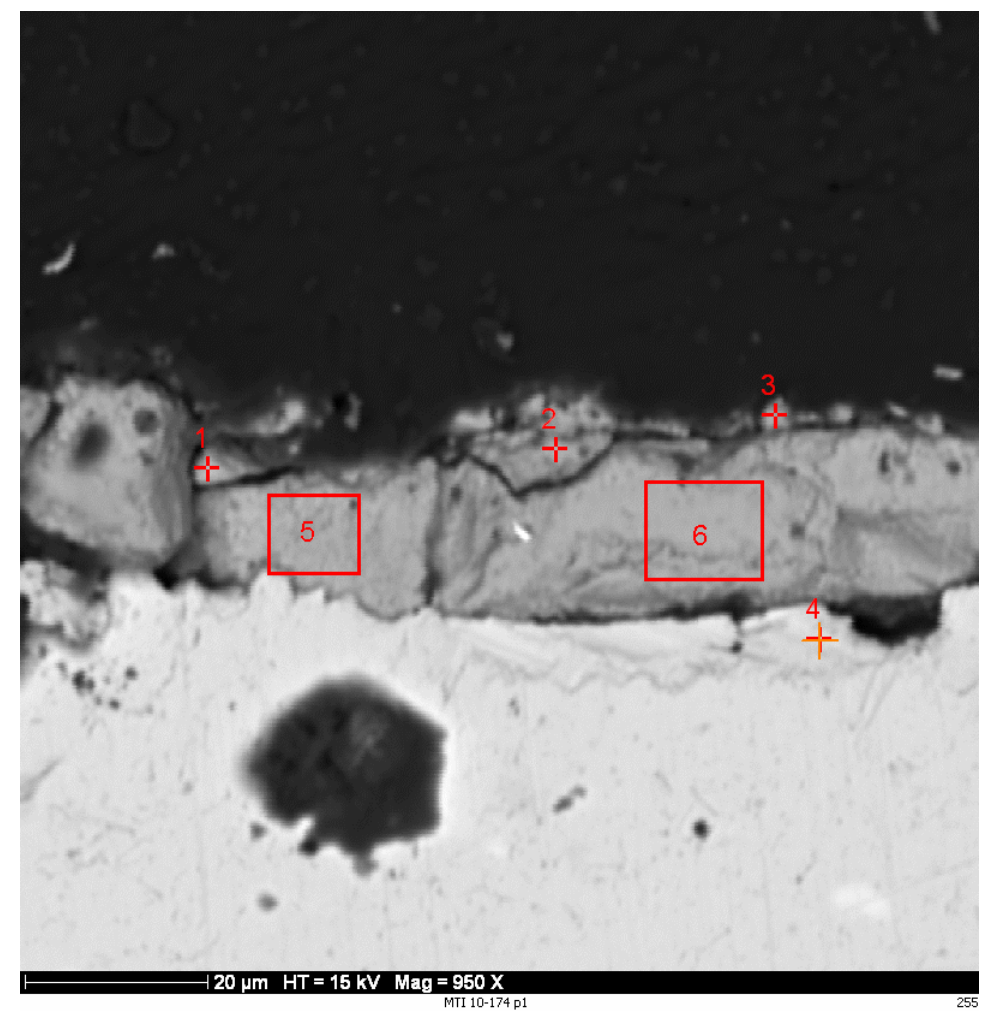

Figure 4.9-56. Backscattered electron image of P91 post-test surface.

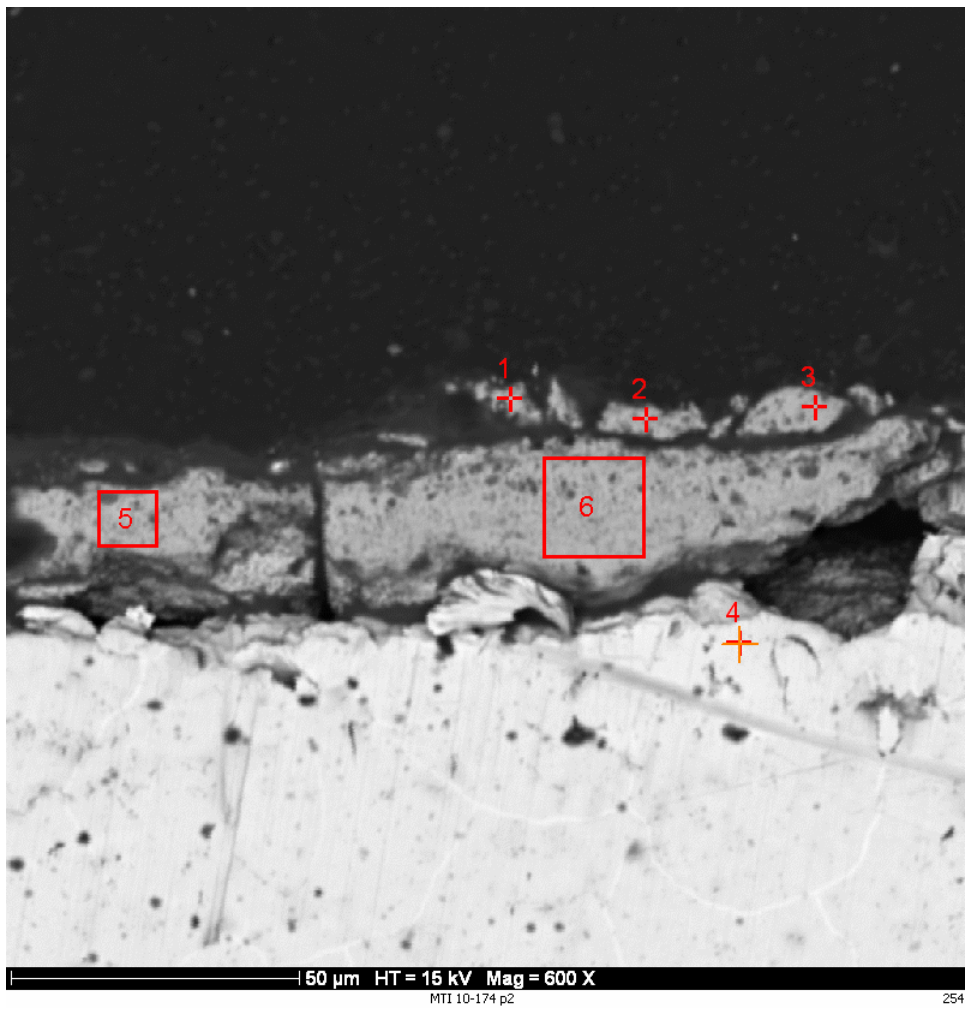

Figure 4.9-57. Backscattered electron image of P91 post-test surface. 
Table 4.9-14. SEM metallography results for $P 91$ post-test surface.

\begin{tabular}{|l|c|l|c|c|c|c|c|c|c|c|c|}
\hline & Point & Description & Na & $\mathbf{M g}$ & $\mathbf{A l}$ & $\mathbf{S i}$ & $\mathbf{C a}$ & $\mathbf{C r}$ & $\mathbf{F e}$ & $\mathbf{M o}$ & $\mathbf{0}$ \\
\hline Figure 4.9-56 & 1 & Outer scale & 0.3 & 0.3 & 1.2 & 1.8 & 0.1 & 0.4 & 91.6 & 2.7 & 1.6 \\
\hline Figure 4.9-56 & 2 & Outer scale & 2.1 & 1.6 & 2.1 & 1.5 & 0.1 & 0.2 & 75.5 & 1.0 & 15.9 \\
\hline Figure 4.9-56 & 3 & Outer scale & 3.4 & 2.6 & 4.1 & 3.7 & 0.8 & 0.3 & 64.8 & 3.8 & 16.6 \\
\hline Figure 4.9-56 & 4 & Steel & 0.9 & 0.7 & 0.7 & 1.2 & 0.0 & 7.8 & 87.1 & 0.8 & 0.8 \\
\hline Figure 4.9-56 & 5 & Inner scale & 0.9 & 0.5 & 0.7 & 0.9 & 0.1 & 5.8 & 84.6 & 1.0 & 5.5 \\
\hline Figure 4.9-56 & 6 & Inner scale & 1.8 & 1.0 & 1.8 & 2.0 & 0.1 & 4.7 & 73.3 & 1.8 & 13.6 \\
\hline Figure 4.9-57 & 1 & Outer scale & 3.8 & 2.5 & 2.3 & 2.6 & 0.1 & 0.1 & 67.8 & 1.8 & 18.9 \\
\hline Figure 4.9-57 & 2 & Outer scale & 1.4 & 0.4 & 0.4 & 3.9 & 1.3 & 0.1 & 86.8 & 1.6 & 4.2 \\
\hline Figure 4.9-57 & 3 & Outer scale & 2.8 & 2.1 & 2.8 & 4.1 & 0.0 & 0.1 & 67.7 & 1.7 & 18.7 \\
\hline Figure 4.9-57 & 4 & Steel & 0.9 & 0.7 & 0.7 & 3.1 & 0.1 & 7.2 & 84.9 & 0.7 & 1.7 \\
\hline Figure 4.9-57 & 5 & Inner scale & 1.1 & 0.7 & 1.3 & 5.1 & 0.1 & 0.3 & 82.8 & 0.7 & 8.0 \\
\hline Figure 4.9-57 & 6 & Inner scale & 0.8 & 0.6 & 1.0 & 3.9 & 0.1 & 5.6 & 83.6 & 0.4 & 4.0 \\
\hline & Average & All scale & $\mathbf{1 . 8}$ & $\mathbf{1 . 2}$ & $\mathbf{1 . 8}$ & $\mathbf{3 . 0}$ & $\mathbf{0 . 3}$ & $\mathbf{1 . 8}$ & $\mathbf{7 7 . 9}$ & $\mathbf{1 . 7}$ & $\mathbf{1 0 . 7}$ \\
\hline & & Steel only & $\mathbf{0 . 9}$ & $\mathbf{0 . 7}$ & $\mathbf{0 . 7}$ & $\mathbf{2 . 1}$ & $\mathbf{0 . 0}$ & $\mathbf{7 . 5}$ & $\mathbf{8 6 . 0}$ & $\mathbf{0 . 8}$ & $\mathbf{1 . 3}$ \\
\hline
\end{tabular}

\subsubsection{Metallographic Results - 347H}

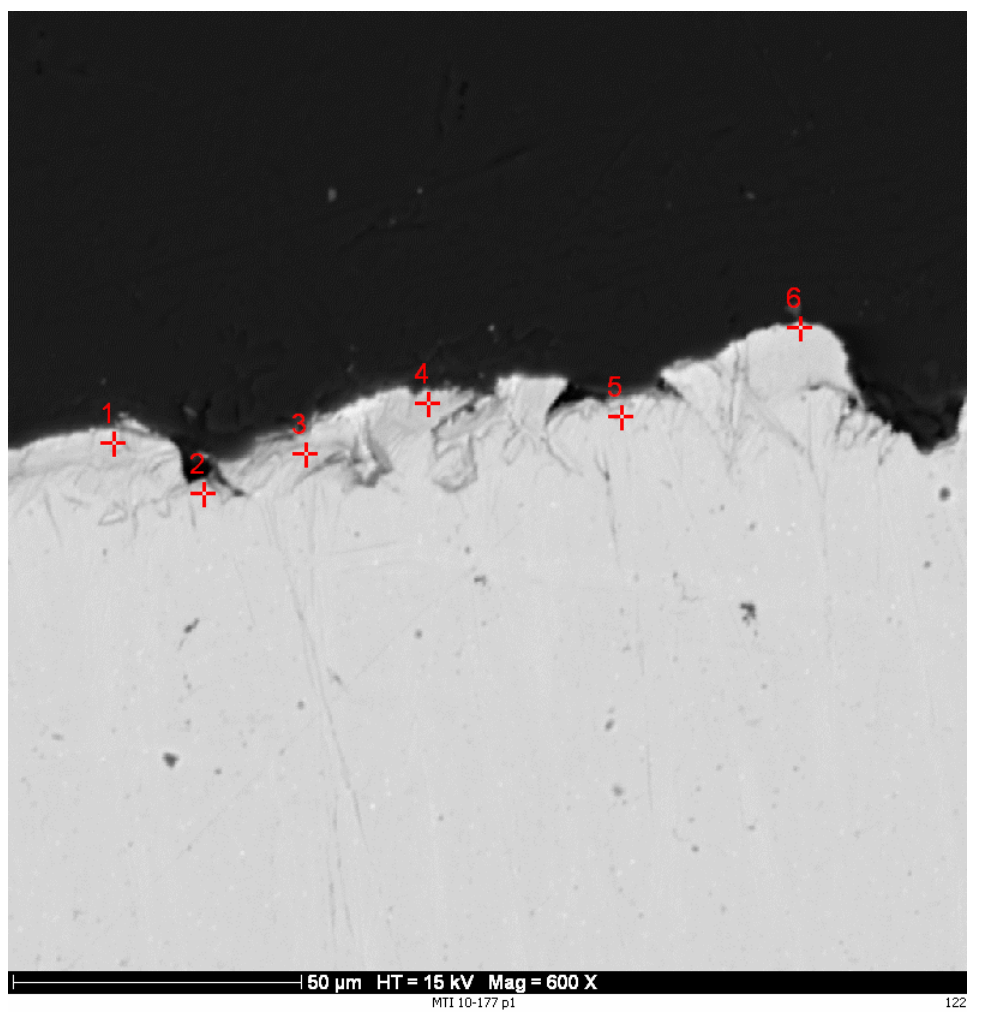

Figure 4.9-58. Backscattered electron image of $347 \mathrm{H}$ pre-test surface. 


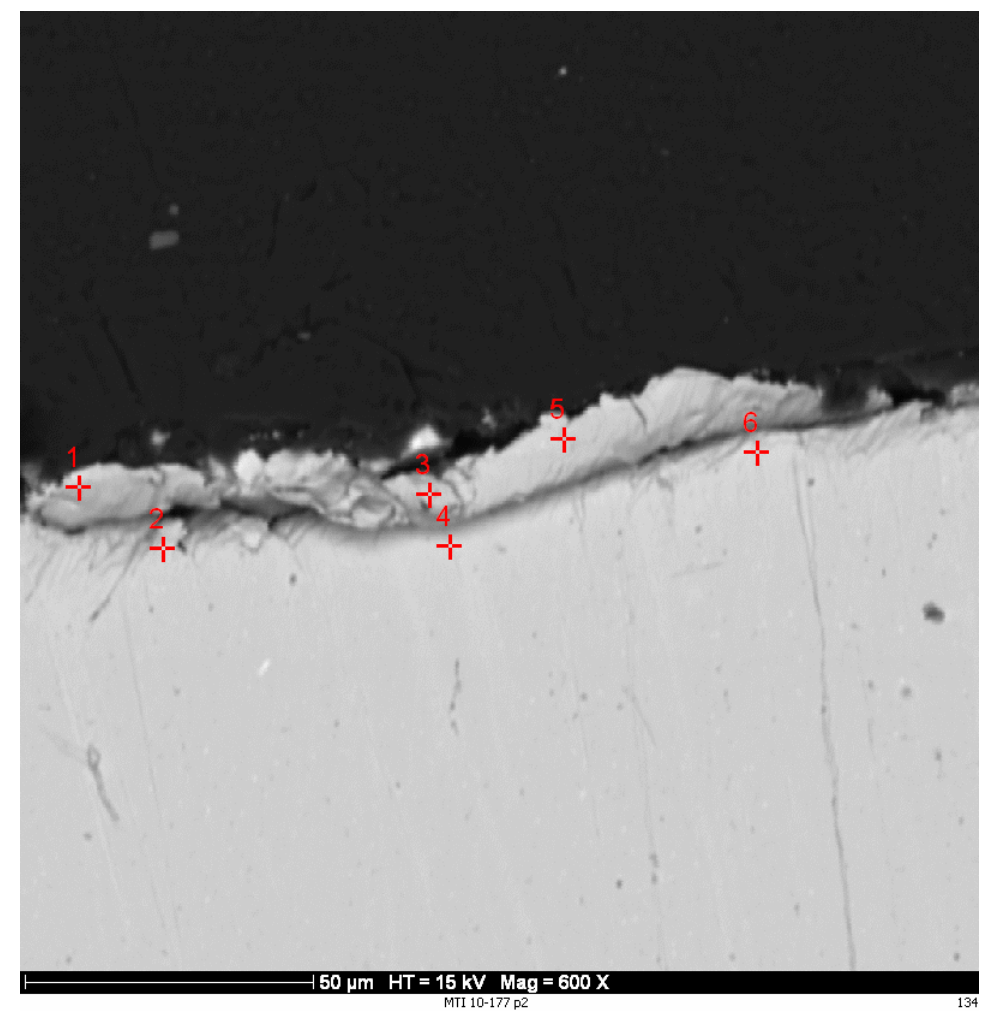

Figure 4.9-59. Backscattered electron image of $347 \mathrm{H}$ pre-test surface.

Table 4.9-15. SEM metallography results for $347 \mathrm{H}$ pre-test surface.

\begin{tabular}{|l|c|l|c|c|c|c|c|c|c|}
\hline & Point & Description & $\mathbf{A l}$ & $\mathbf{S i}$ & $\mathbf{C r}$ & $\mathbf{F e}$ & $\mathbf{N i}$ & $\mathbf{N b}$ & $\mathbf{0}$ \\
\hline Figure 4.9-58 & 1 & Steel surface & 0.8 & 1.2 & 15.7 & 64.8 & 8.7 & 7.1 & 1.7 \\
\hline Figure 4.9-58 & 2 & Steel surface & 0.1 & 0.6 & 16.6 & 73.3 & 8.9 & 0.4 & 0.0 \\
\hline Figure 4.9-58 & 3 & Steel surface & 0.8 & 1.0 & 16.6 & 70.6 & 10.1 & 0.9 & 0.0 \\
\hline Figure 4.9-58 & 4 & Steel surface & 0.0 & 0.0 & 19.7 & 74.1 & 5.9 & 0.0 & 0.1 \\
\hline Figure 4.9-58 & 5 & Steel surface & 1.1 & 1.5 & 15.9 & 69.7 & 10.5 & 1.2 & 0.0 \\
\hline Figure 4.9-58 & 6 & Steel surface & 0.3 & 1.1 & 16.3 & 69.0 & 10.0 & 2.7 & 0.6 \\
\hline Figure 4.9-59 & 1 & Steel surface & 1.3 & 1.4 & 15.7 & 68.6 & 10.1 & 1.1 & 1.8 \\
\hline Figure 4.9-59 & 2 & Inner steel & 0.5 & 1.0 & 16.6 & 71.2 & 9.2 & 0.9 & 0.6 \\
\hline Figure 4.9-59 & 3 & Steel surface & 1.6 & 1.7 & 16.3 & 68.9 & 10.1 & 1.4 & 0.0 \\
\hline Figure 4.9-59 & 4 & Inner steel & 1.8 & 1.5 & 15.8 & 68.3 & 9.9 & 1.1 & 1.5 \\
\hline Figure 4.9-59 & 5 & Steel surface & 1.0 & 1.7 & 16.2 & 68.6 & 10.2 & 1.2 & 1.2 \\
\hline Figure 4.9-59 & 6 & Inner steel & 0.0 & 0.1 & 17.8 & $\mathbf{7 2 . 9}$ & 9.1 & 0.1 & 0.0 \\
\hline & Average & Steel surface only & $\mathbf{0 . 8}$ & $\mathbf{1 . 1}$ & $\mathbf{1 6 . 6}$ & $\mathbf{6 9 . 7}$ & $\mathbf{9 . 4}$ & $\mathbf{1 . 8}$ & $\mathbf{0 . 6}$ \\
\hline & & Inner steel only & $\mathbf{0 . 7}$ & $\mathbf{0 . 9}$ & $\mathbf{1 6 . 8}$ & $\mathbf{7 0 . 8}$ & $\mathbf{9 . 4}$ & $\mathbf{0 . 7}$ & $\mathbf{0 . 7}$ \\
\hline
\end{tabular}




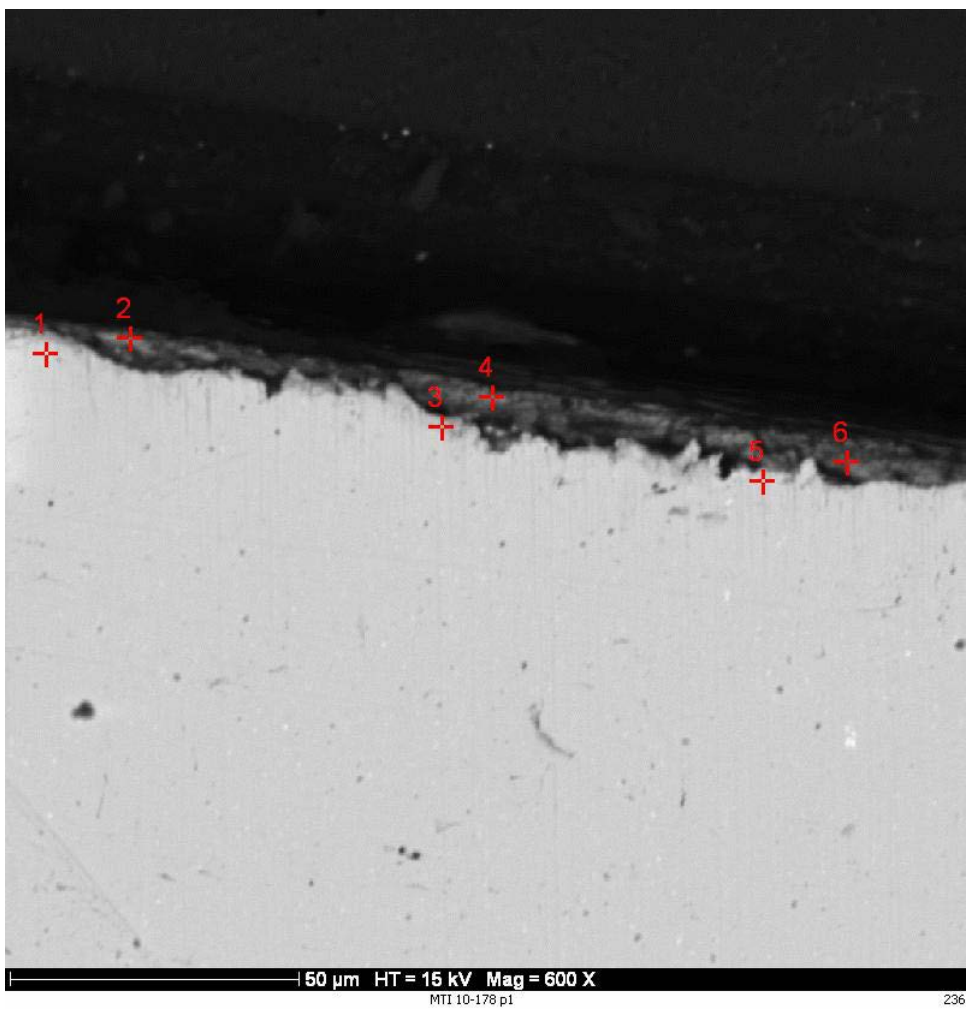

Figure 4.9-60. Backscattered electron image of $347 \mathrm{H}$ post-test surface.

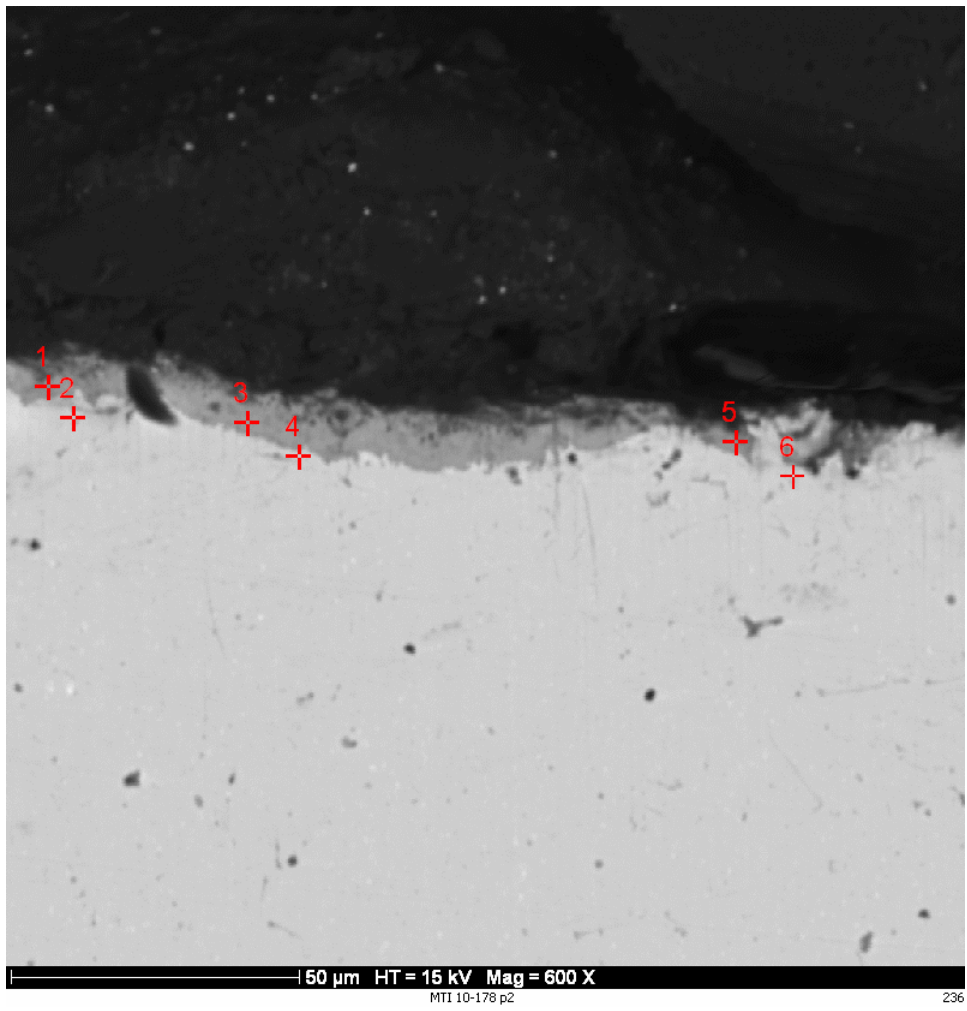

Figure 4.9-61. Backscattered electron image of $347 \mathrm{H}$ post-test surface. 
Table 4.9-16. SEM metallography results for $347 \mathrm{H}$ post-test surface.

\begin{tabular}{|c|c|c|c|c|c|c|c|c|c|c|c|c|}
\hline & Point & Description & $\mathrm{Na}$ & $\mathrm{Mg}$ & Al & Si & S & $\mathrm{Ca}$ & $\mathrm{Cr}$ & $\mathrm{Fe}$ & $\mathrm{Ni}$ & 0 \\
\hline Figure 4.9-60 & 1 & Steel & 1.3 & 0.7 & 1.1 & 1.2 & 0.6 & 0.1 & 16.2 & 69.6 & 8.0 & 1.4 \\
\hline Figure 4.9-60 & 2 & Scale & 5.1 & 2.0 & 3.0 & 1.6 & 0.7 & 0.1 & 1.8 & 66.8 & 0.2 & 18.8 \\
\hline Figure 4.9-60 & 3 & Steel & 3.0 & 2.4 & 2.6 & 1.7 & 1.3 & 0.0 & 11.6 & 56.7 & 17.4 & 3.3 \\
\hline Figure 4.9-60 & 4 & Scale & 6.7 & 2.3 & 5.5 & 4.2 & 2.3 & 1.5 & 0.6 & 50.5 & 0.3 & 26.1 \\
\hline Figure 4.9-60 & 5 & Steel & 1.1 & 0.5 & 0.7 & 1.0 & 0.5 & 0.1 & 16.9 & 70.9 & 7.7 & 0.7 \\
\hline Figure 4.9-60 & 6 & Scale & 4.5 & 1.2 & 2.6 & 2.3 & 1.0 & 0.2 & 14.7 & 58.8 & 2.1 & 12.7 \\
\hline Figure 4.9-61 & 1 & Scale & 3.6 & 1.4 & 2.2 & 2.1 & 1.4 & 0.2 & 16.1 & 59.5 & 2.7 & 10.8 \\
\hline Figure 4.9-61 & 2 & Steel & 1.5 & 0.8 & 1.1 & 3.7 & 0.7 & 0.1 & 15.7 & 66.3 & 8.5 & 1.6 \\
\hline Figure 4.9-61 & 3 & Scale & 1.7 & 0.9 & 1.3 & 2.1 & 1.7 & 0.1 & 29.2 & 48.2 & 1.8 & 13.0 \\
\hline Figure 4.9-61 & 4 & Steel & 1.4 & 0.8 & 1.2 & 1.2 & 0.6 & 0.0 & 16.4 & 68.1 & 8.7 & 1.5 \\
\hline Figure 4.9-61 & 5 & Scale-pit & 2.2 & 1.0 & 3.5 & 6.9 & 1.8 & 0.0 & 19.8 & 52.5 & 0.9 & 11.5 \\
\hline \multirow[t]{3}{*}{ Figure 4.9-61 } & 6 & Steel & 2.1 & 0.9 & 1.2 & 1.5 & 0.8 & 0.1 & 16.0 & 67.8 & 7.9 & 1.8 \\
\hline & Average & All scale & 4.0 & 1.5 & 3.0 & 3.2 & 1.5 & 0.3 & 13.7 & 56.0 & 1.3 & 15.5 \\
\hline & & Steel only & 1.7 & 1.0 & 1.3 & 1.7 & 0.7 & 0.1 & 15.5 & 66.6 & 9.7 & 1.7 \\
\hline
\end{tabular}

\subsubsection{Corrosion Element Metallography Analysis}

Carbon was not present in any of the samples in quantities that would register in the SEM metallography. Analysis of the backscattered electron images shows no indication of carbon inclusions. These data provide no evidence supporting carburization of the materials due to oxy-combustion conditions. However, these data do not refute the possibility that carburization may occur under oxy-combustion conditions.

A plot comparing the waterwall corrosion probe metal, SA210, composition pre- and post-test is presented in Figure 4.9-62. Figure 4.9-62 indicates that the oxygen, sulfur, aluminum and sodium concentration of the SA210 metal decreased during the testing campaign. This material was subject to primarily reducing conditions throughout the testing which may account for the reduction in oxygen. The silicon concentration of the surface scale increased, likely from ash deposition.

Figure 4.9-63 contains a plot comparing the superheater corrosion probe metal, T22, composition pre- and post-test. Figure 4.9-63 indicates that the oxygen concentration in the scale and the steel increased. This is expected as the superheat probes were subject to primarily oxidizing conditions. The post-test analysis of this material shows that there is zirconium present, probably from the ceramic insulators used to isolate the corrosion probe elements. Again, the silicon in the scale has increased.

Figure 4.9-64 contains a plot comparing the superheater corrosion probe metal, P91, composition pre- and post-test. Figure 4.9-64 indicates a large increase in oxygen concentration for the scale. This is also consistent with the oxidizing condition that the probe experienced. This material did not show an increase in silicon in the post-test scale. The chromium concentration of the post-test scale decreased significantly.

Figure 4.9-65 contains a plot comparing the superheater corrosion probe metal, 347H, composition preand post-test. Figure 4.9-65 shows that the post-test scale oxygen behaved in a similar manner to the other superheater probes with a large increase. The $347 \mathrm{H}$ material is the only metal tested with appreciable nickel content. These data indicate that the nickel is removed from the scale and replaced by sulfur. This trend is consistent with sulfur attack of nickel and the high $347 \mathrm{H}$ corrosion rates observed when firing Illinois coal. 


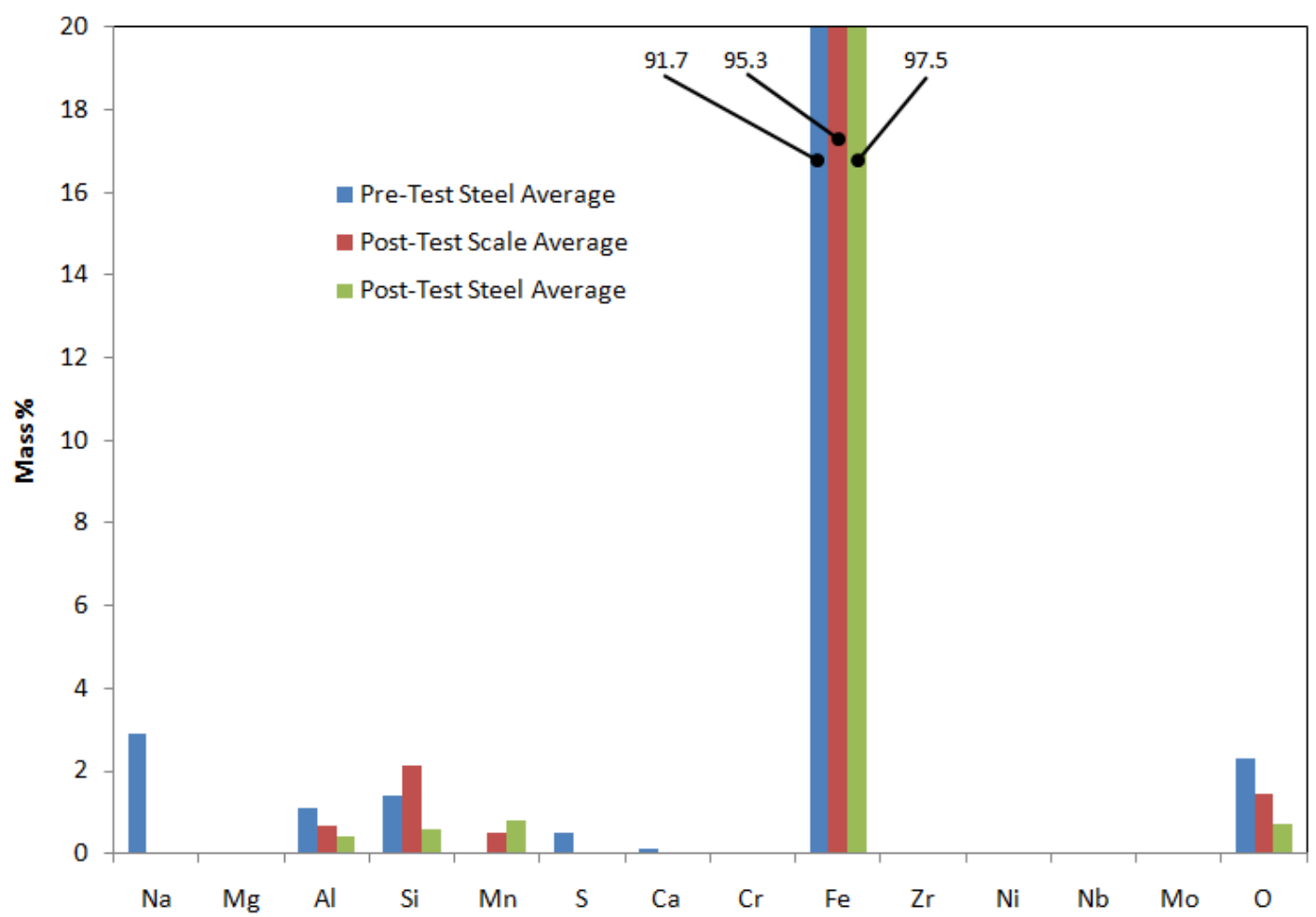

Figure 4.9-62. Comparison of SA210 composition pre- and post-test.

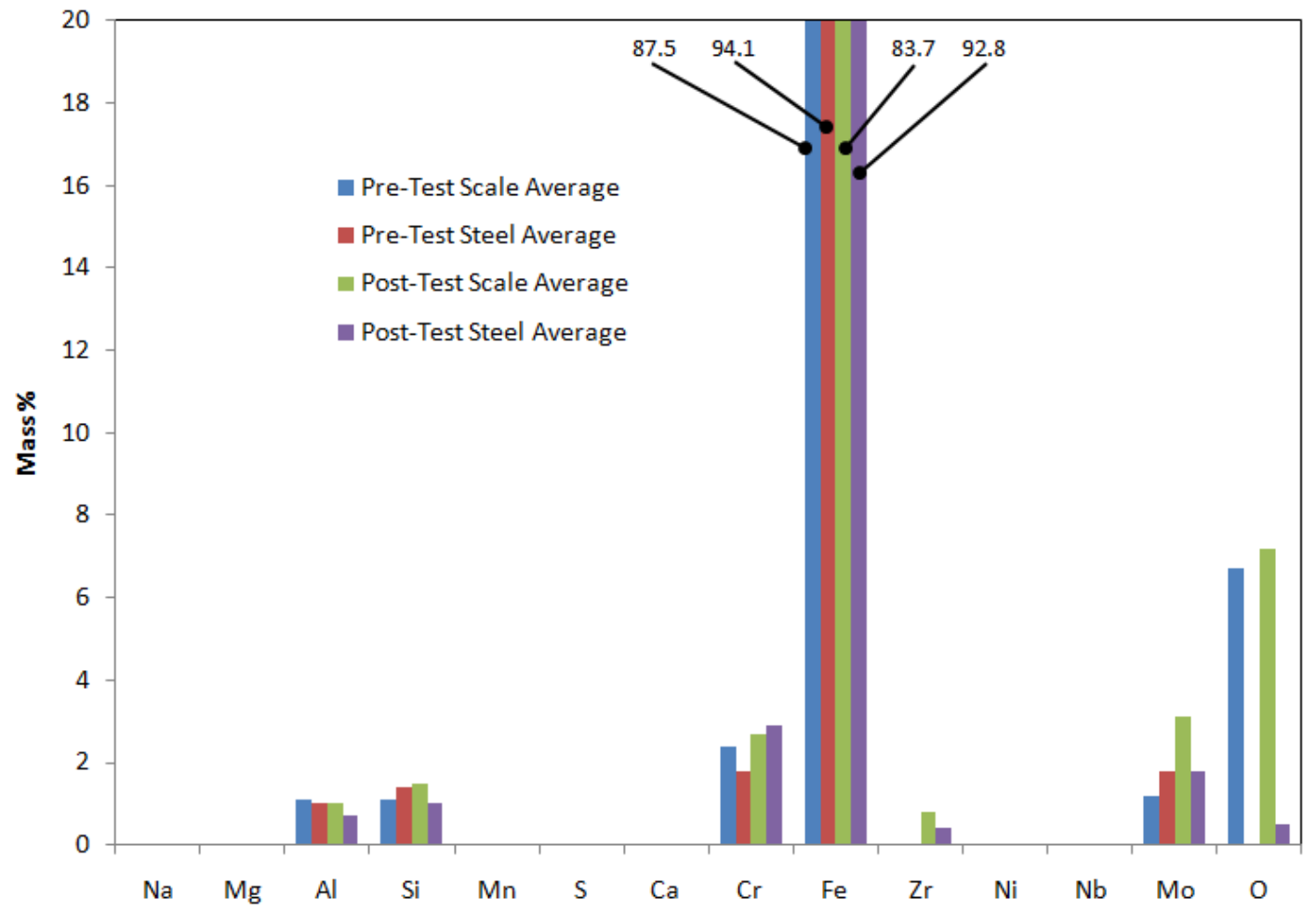

Figure 4.9-63. Comparison of T22 composition pre- and post-test. 


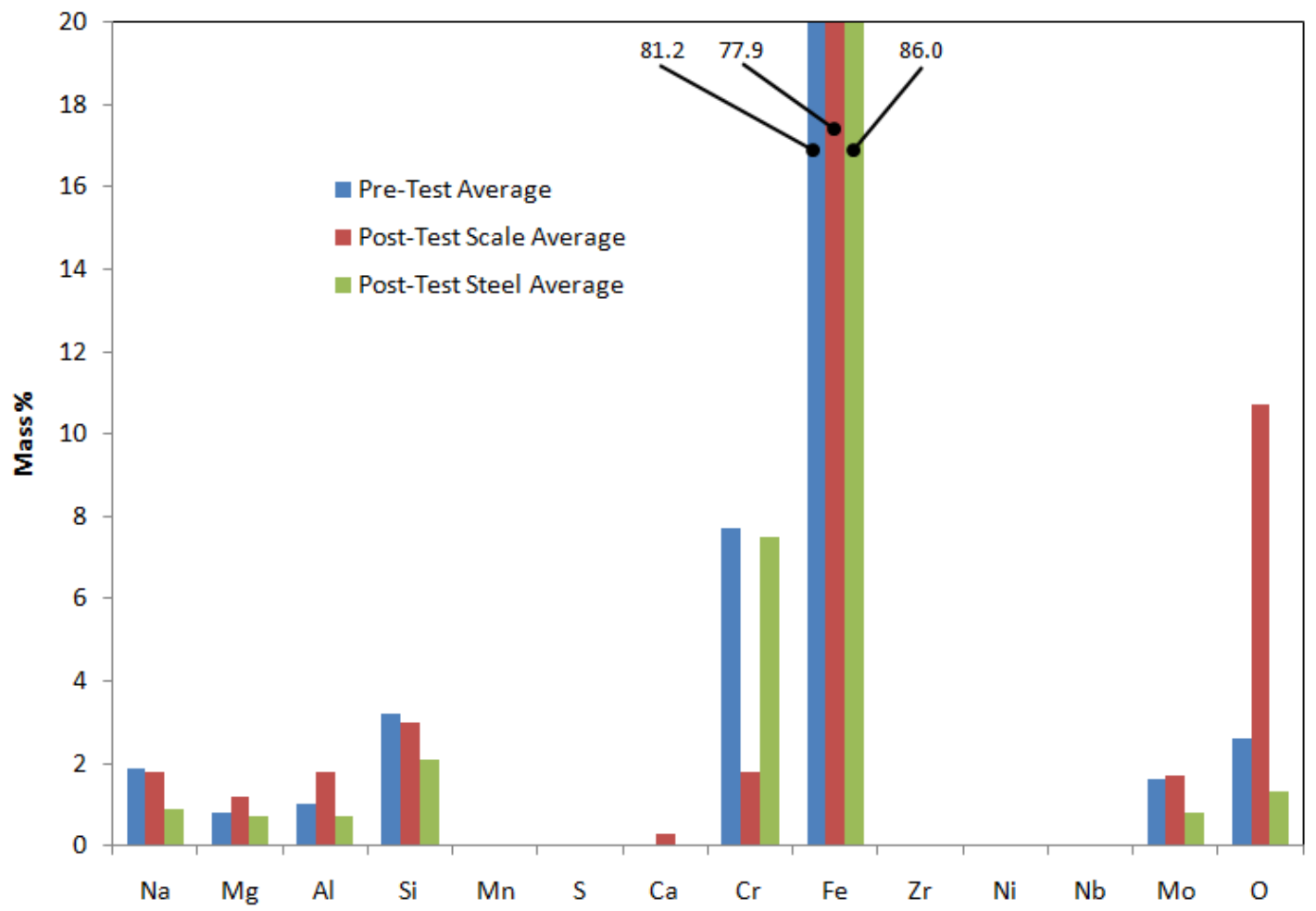

Figure 4.9-64. Comparison of P91 composition pre- and post-test.

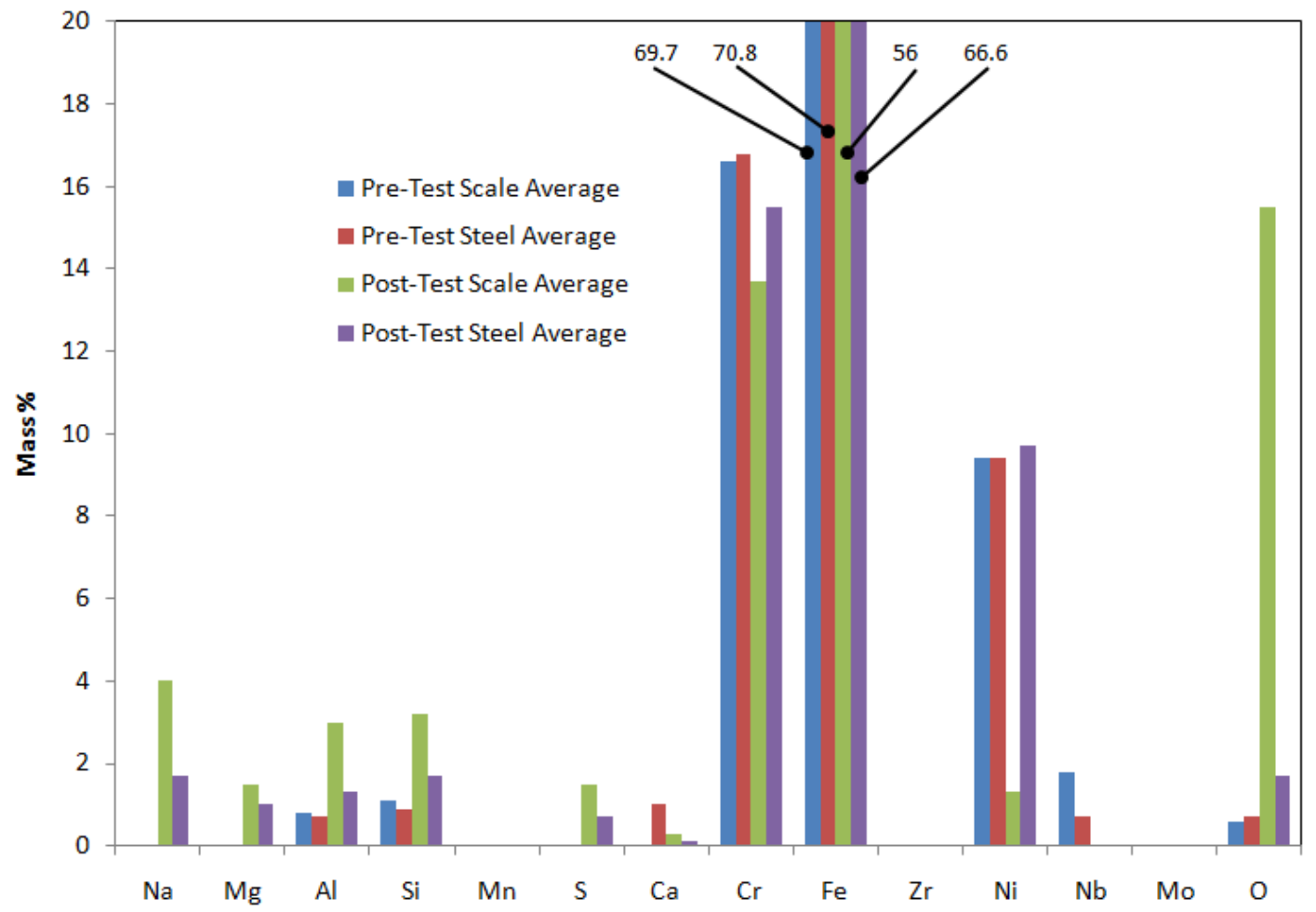

Figure 4.9-65. Comparison of $347 \mathrm{H}$ composition pre- and post-test. 


\subsubsection{Corrosion Element Metallography Summary}

The elements from the one waterwall and three superheater corrosion probes were removed from the probes and metallography analyses were performed the post-test elements and the as-received metal that was used to fabricate the elements. Metallography analyses were performed using scanning electron microscopy with energy-dispersive x-ray area analysis.

There was no indication from the SEM metallography or the backscattered electron images to support carburization as a mechanism for corrosion under oxy-combustion conditions. However, the data were not sufficient to disprove carburization as a potential mechanism.

The oxygen content of the scale and near surface metal decreased from pre- to post-test for the waterwall corrosion element, which was subject to primarily reducing conditions. The oxygen content of the scale and near surface metal for the superheater probes increased. These elements experienced mostly oxidizing conditions during the testing.

The $347 \mathrm{H}$ probe displayed sensitivity of corrosion rate to the sulfur concentration in the flue gas. The metallography analysis showed that for this material the nickel content of the scale decreased while the sulfur content increased. These observations are consistent with a mechanism for sulfur attack on nickel.

\subsubsection{Effect of Mercury Additive on Dew-point Corrosion}

Regulations on mercury emissions from industrial boilers have recently been implemented and are included in the 2013 Mercury and Air Toxics Standards (MATS). Mercury control is of particular interest in oxy-fired combustion systems because it can amalgamate with aluminum surfaces in gas processing units slated for use in $\mathrm{CO}_{2}$ separation processes. Many utilities have implemented control technologies that include some form of bromine additive, whether pre-applied with the coal or injected downstream of the furnace as brominated-activated carbon. Activated carbon injection is also a common mercury control technology.

Some research groups (Senior, et al. 2012) have reported the potential for enhanced corrosion when mercury control additives are used when air, or oxy-firing coal. EPRI (Srinivasan and Dombroski 2013) has reported that a large fraction of plants using bromine for mercury control have issues with air heater corrosion. As significantly enhanced corrosion rates could impact the design and maintenance of oxyretrofit systems, measurements are needed to establish the impact of $\mathrm{CaBr}_{2}$ additive or brominated ACI on corrosion rates under air and oxy-fired conditions.

Phase 2 of this project included corrosion monitoring in May and June 2013. This phase of the project also included mercury measurement recalibration to determine/correct measurement bias in oxy-fired environments. Pilot-scale mercury testing was performed in the University of Utah's $1500 \mathrm{~kW}$ pulverized coal (L1500) furnace. Corrosion monitoring was performed in correlation with these tests. Both a PRB (Black Thunder) and a bituminous coal (Pratt - North River mine) were used and each combusted in an air-fired and oxy-fired environment. Some small modifications to the L1500 were performed to improve its back-end temperature profile and residence time (extend the length of the ductwork). Two mercury control technologies were tested, including injection of solid $\mathrm{CaBr}_{2}$ into the flame and injection of Norit Darco HG activated carbon into the low-temperature flue-gas.

Corrosion monitoring was performed under two different modes. During the first two weeks, corrosion element temperatures were cycled in an attempt to mimic the transient temperature behavior of air heater surfaces. This will be referred to as cycling mode. Throughout the last two weeks, temperatures were held for longer periods and changed in step changes to investigate acid dew-points. This will be referred to as the detection mode. Testing was completed according to the test matrix below in Table 4.9-17. $\mathrm{CaBr}_{2}$ was 
injected at 0 , 20, and $50 \mathrm{ppm}$, nominally. ACI was less stable but the medium and high levels were approximately 1 and 2-4 lbs/MMacf, respectively.

Table 4.9-17: Final mercury and corrosion pilot-scale test matrix

\begin{tabular}{|c|c|c|c|c|}
\hline Day & Condition & Coal & $\mathrm{ACl}$ (lb/MMacf) & $\mathrm{CaBr2}$ (ppmw coal) \\
\hline 1 & \multicolumn{4}{|c|}{ Furnace start-up } \\
\hline 2 & \multicolumn{4}{|c|}{ Furnace feeding system preparation } \\
\hline 3 & \multicolumn{4}{|c|}{ Heat-up and stabilization } \\
\hline 4 & Air & PRB & 0 & 0, med, high \\
\hline 5 & Air & PRB & 0 & 0 \\
\hline 6 & Air & PRB & med, high & 0 \\
\hline 7 & Air & PRB & 0 & 0, med, high \\
\hline 8 & Oxy & PRB & 0 , high & 0, med, high \\
\hline 9 & Air/Oxy & PRB & med, high & 0 \\
\hline 10 & Oxy & PRB & 0 , high & 0, med, high \\
\hline 11 & Air & Bit & 0 & 0, med \\
\hline 12 & Air & Bit & 0, med, high & 0 , high \\
\hline 13 & Oxy & Bit & 0 & 0, med, high \\
\hline 14 & Oxy & Bit & med, high & 0 \\
\hline 15 & Air & Bit & 0 & 0, med \\
\hline 16 & Air & Bit & 0, med & 0 , high \\
\hline 17 & Air/Oxy & Bit & 0 , high & 0, med \\
\hline 18 & Oxy & Bit & 0 & 0 , high \\
\hline 19 & Oxy & Bit & 0, med, high & 0 \\
\hline 20 & Air & PRB & 0 & 0, med, high \\
\hline
\end{tabular}

The overall goal of corrosion monitoring during phase 2 is to qualitatively and quantitatively determine the effect of $\mathrm{CaBr}_{2}$ injection and activated carbon injection on dew-point corrosion rates. The purpose of detection mode operation was to determine ("detect") the specific dewpoints that may be attributable to each acid. Comparing data from test with $\mathrm{CaBr}_{2}$ injection to that without injection can indicate at what temperatures bromine became a corrosion concern and the relative effect of bromine on corrosion rates.

During cycling mode, corrosion probes were only removed from the furnace at night. Ash deposit buildup of 5-10mm was observed during this week and was left undisturbed even when probes were removed at night. When operating in detection mode, corrosion probes were pulled from the furnace and cleaned before any change in condition (i.e., change in $\mathrm{CaBr}_{2}$ or ACI injection rate, change between oxy- and airfiring mode). Figure 4.9-66 shows the probes before and after cleaning. Cleaning involve removing the ash layer and oxide layer with emery cloth. It was hypothesized that different oxide scales may form under differing conditions that could bias results in consecutive tests. Also acid buildup in the ash or oxide layer could also bias results in following tests. Cleaning was done to minimize this bias. 


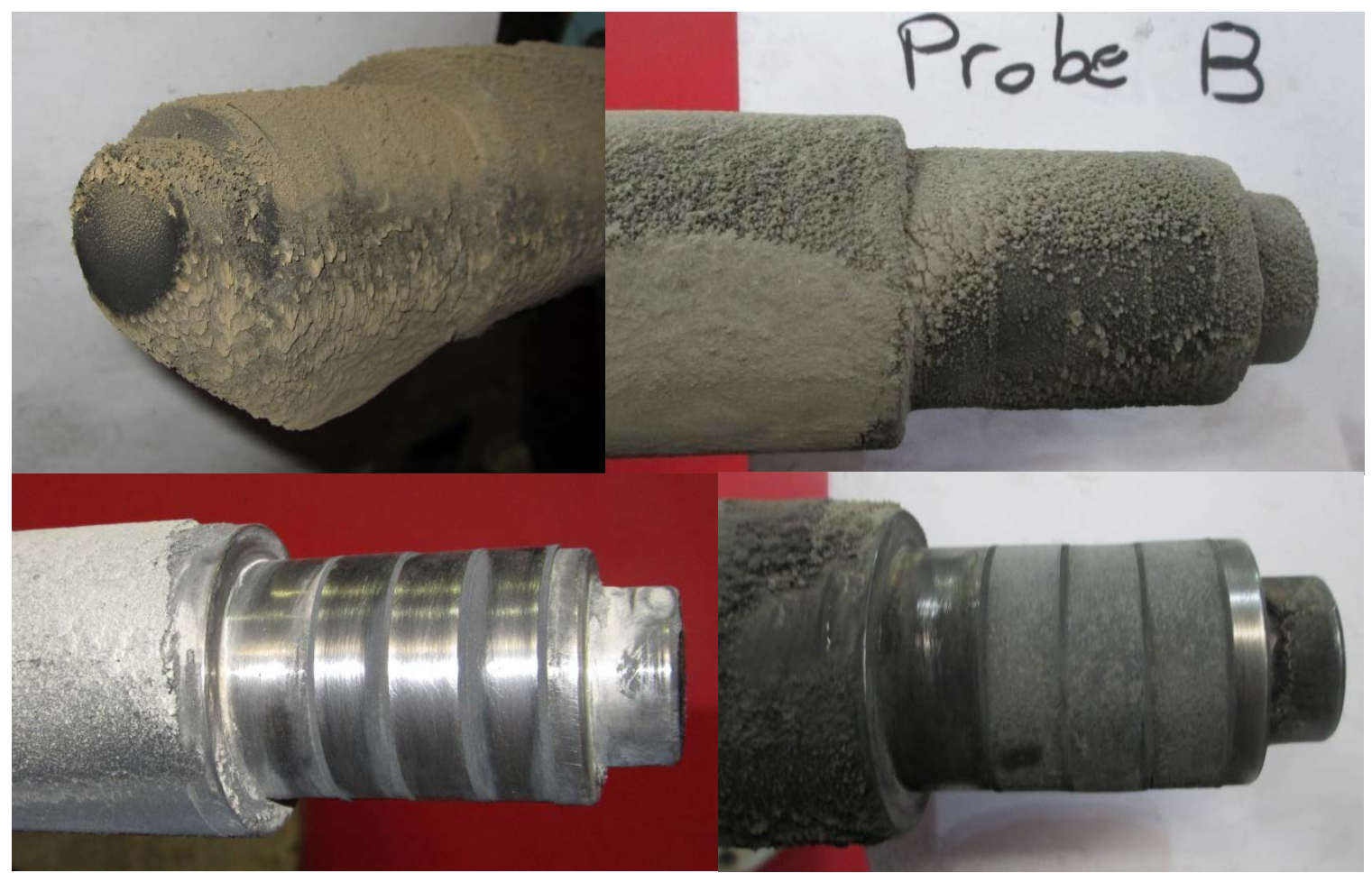

Figure 4.9-66: Images showing deposit buildup on probes after 3-6 hours of operation (top) and after probe cleaning (bottom).

\subsubsection{Effect of $\mathrm{HBr}$ on Corrosion Rates}

Injection of brominated compounds to mitigate $\mathrm{Hg}$ emission has contributed to corrosion issues in air heaters and low-temperature ducting. Results from this study verify that addition of $\mathrm{CaBr}_{2}$ can significantly increase corrosion rate. However the extent of effect of $\mathrm{Br}$ is dependent on metal temperatures and $\mathrm{HBr}$ concentrations in the flue gas.

Figure 4.9-67 displays corrosion results from air-fired combustion of bituminous coal with and without $\mathrm{CaBr}_{2}$ addition. Both data sets are consistent in showing a small increase in corrosion when the element temperature is stepped down to $\sim 125^{\circ} \mathrm{F}$. As temperatures are further stepped down to $\sim 105^{\circ} \mathrm{F}$, no change in corrosion rate is observed in the data set without bromine addition. The data set that includes $\mathrm{CaBr}_{2}$ injection, however, indicates approximately a substantial increase in corrosion activity. 


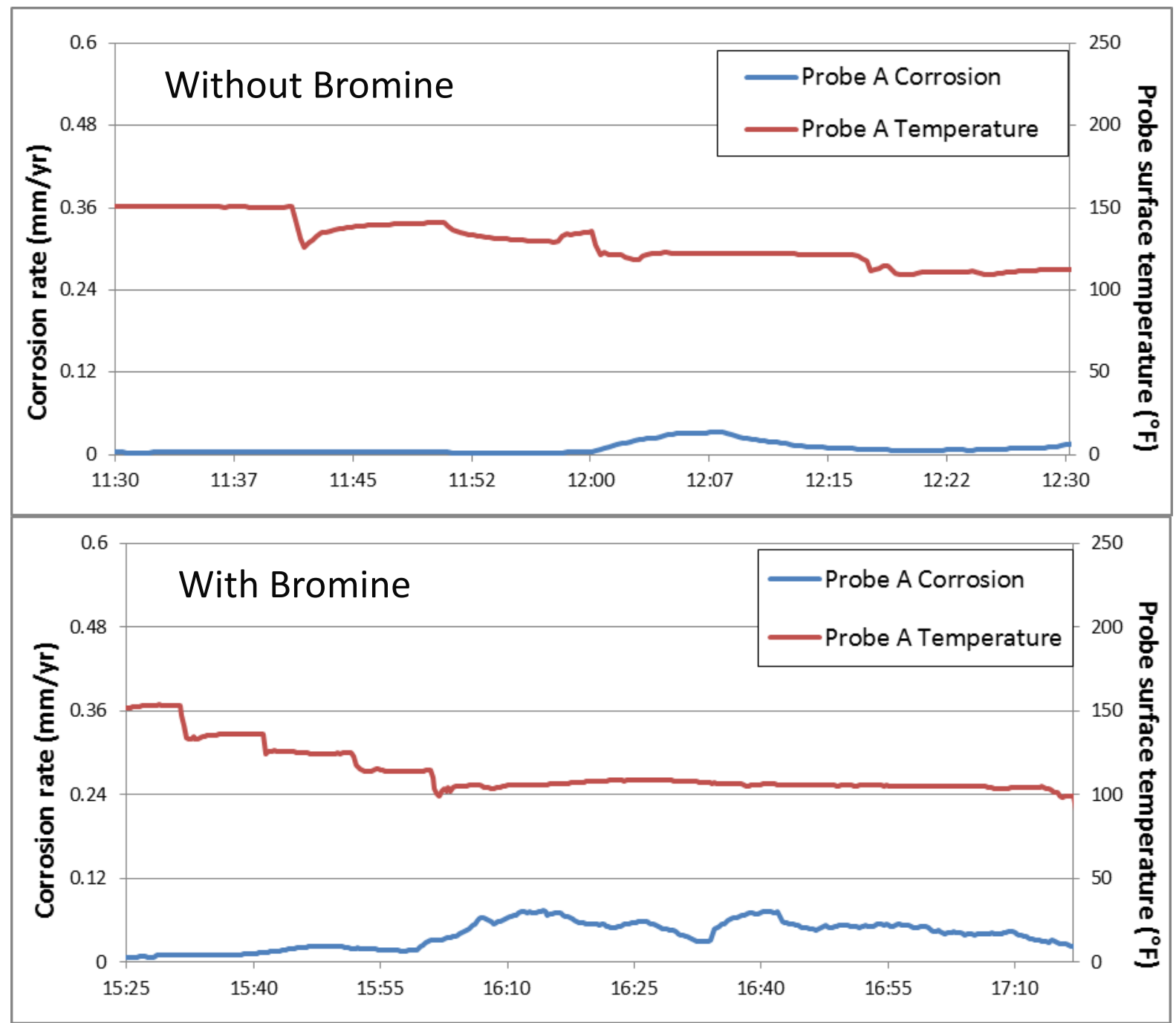

Figure 4.9-67: Corrosion data from air-fired combustion of bituminous coal.

Figure 4.9-68 displays similar data, but the furnace is oxy-fired during these runs. The two data sets are consistent in showing an increase in corrosion as element temperatures decrease. As temperatures reach $\sim 105^{\circ} \mathrm{F}$, with or without bromine injection, corrosion rates are quite high; but with bromine injection a further increase is obvious and results in a nearly three-fold increase in corrosion rates.

It should be noted that data in both these figures, from both an oxy-fired case and air-fired case, came from almost identical $\mathrm{CaBr}_{2}$ injection rates, $18-19 \mathrm{ppm}$. Both cases show that condensation of bromic acid causes a 2-3 fold increase in corrosion rates. The bromine is more detrimental in the oxy-fired case because base rates from sulfuric acid are higher. However, it is noted that the onset of the bromine corrosion effect occur at nearly identical temperatures $\left(100-105^{\circ} \mathrm{F}\right)$. This could indicate that most of the $\mathrm{HBr}$ is removed in the fabric filters and is not recycled.

Figure 4.9-69 shows some general findings from this study. Bromine was seen to increase corrosion rates by a factor of 1.5-3. However this increase in corrosion activity is only seen when metal temperatures drop below the bromine dewpoint. As displayed, no difference in corrosion rate from addition of 18ppm $\mathrm{CaBr}_{2}$ is observed in the $105-106^{\circ} \mathrm{F}$ range; however, decreasing the metal temperature below $100^{\circ} \mathrm{F}$ results in a 3-fold increase in corrosion activity when bromine is present. 


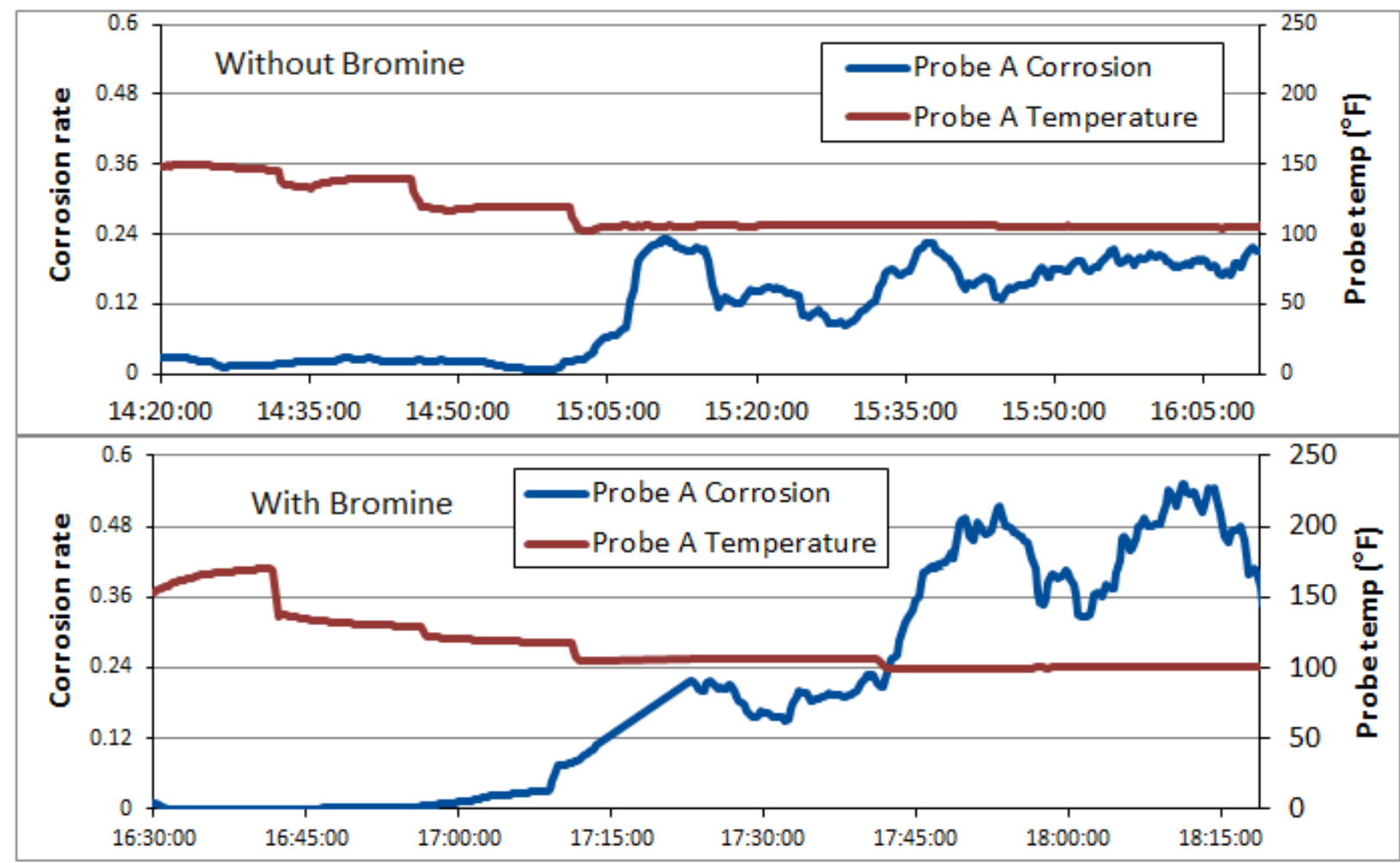

Figure 4.9-68: Effect of $\mathrm{CaBr}_{2}$ addition on acid dew-point corrosion. Oxy-firing of bituminous coal on 6/18/13 with the addition of $18 \mathrm{ppm} \mathrm{CaBr}_{2}$.

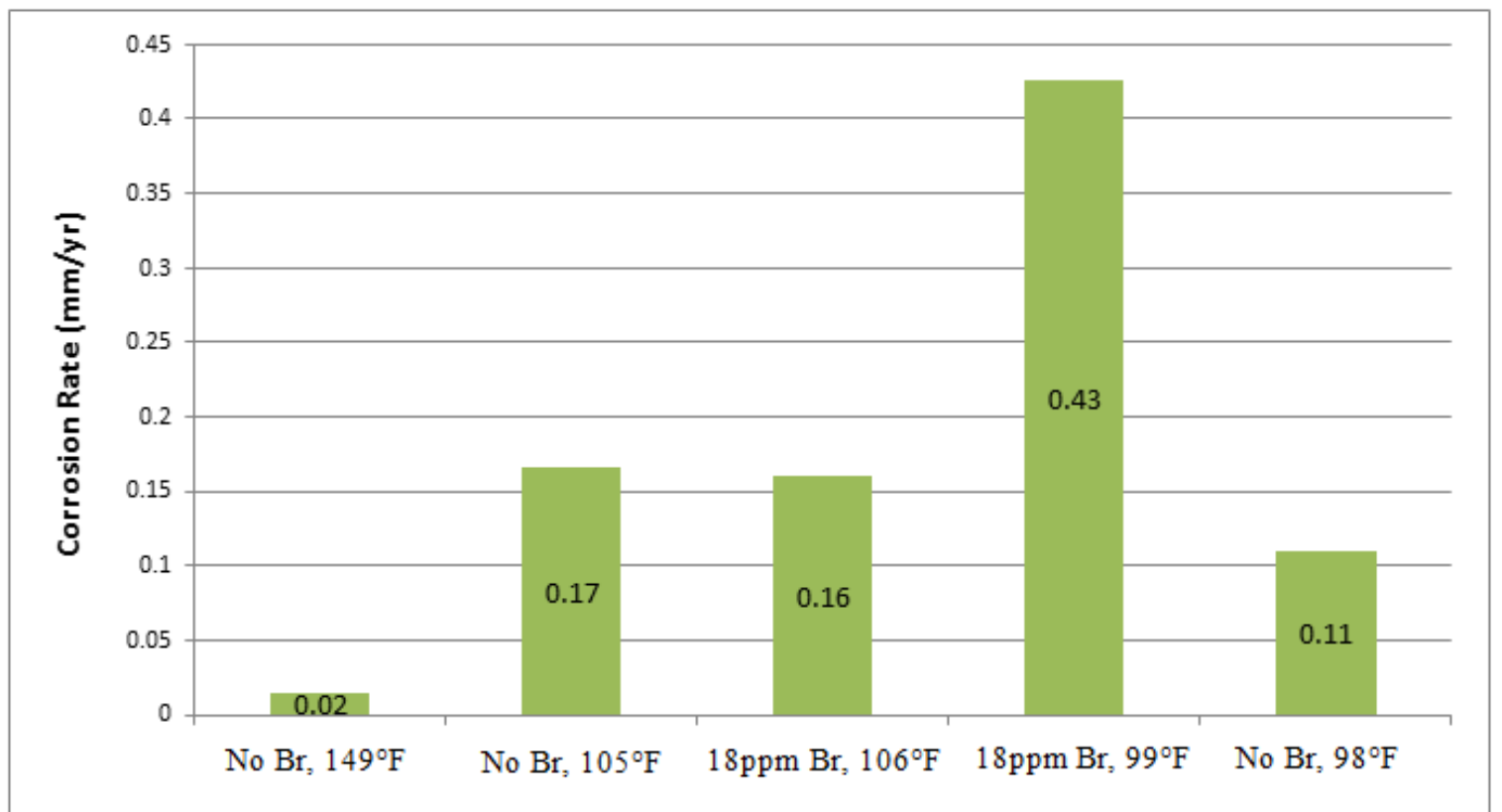

Figure 4.9-69: Effect of Bromine on corrosion rate. Oxy-firing of bituminous coal at $775 \mathrm{~kW}$.

Figure 4.9-70 displays data from air-firing PRB with $42 \mathrm{ppm}$ bromine addition. The sulfur dewpoint was seen at about $135^{\circ} \mathrm{F}$. Because of such a low sulfur content and high Ca content in this coal, the rate at this point is very small $\left(10^{-5} \mathrm{~mm} / \mathrm{yr}\right)$. The effect of bromine is seen between $110-120^{\circ} \mathrm{F}$ increasing the sulfur 
dewpoint corrosion by 3 orders of magnitude. This is significant because most corrosion-related, air heater failures from brominated-compound injection were in boilers burning low-sulfur PRB coal.

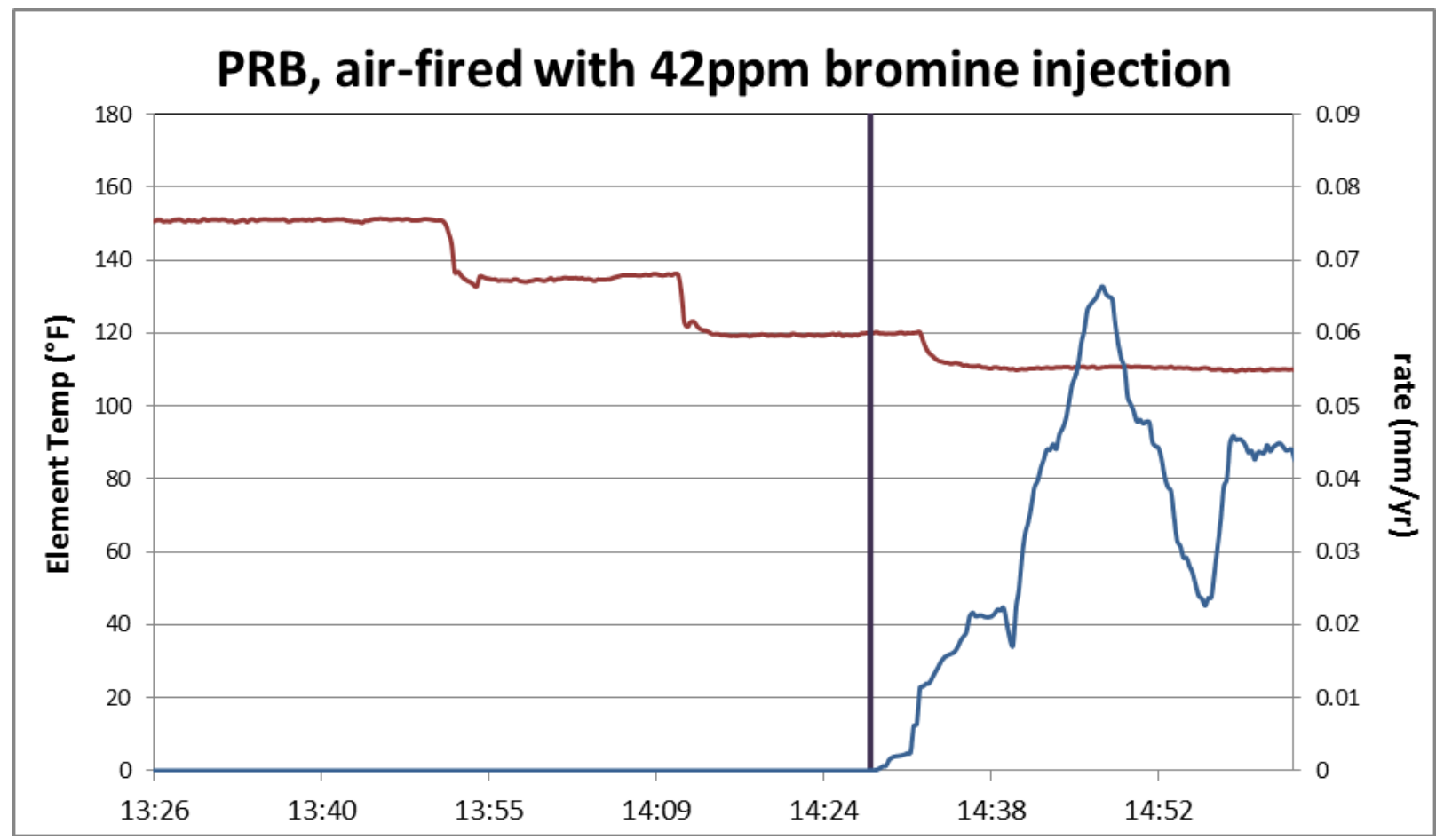

Figure 4.9-70: Effect of Bromine on corrosion rate for air-fired PRB condition.

\subsubsection{Effect of Firing Condition}

As discussed in section 4.9.2.6, other corrosion mechanisms could also contribute to the increase in corrosion rates when oxy-firing. Increased $\mathrm{CO}_{2}$ and $\mathrm{H}_{2} \mathrm{O}$ concentrations could cause iron-rich scales to form on the metal surface instead of the more corrosion resistant $\mathrm{Cr}$-rich scale. This scale is permeable to $\mathrm{CO}_{2}$ resulting in carburization of the steel (Piron Abellan, et al. 2009). Alternatively, $\mathrm{H}_{2} \mathrm{O}$-rich environment has been reported to form wüstite $(\mathrm{FeO})$ that does not provide protecting scale (Huenert and Kranzmann 2008) and exposes the metal surface for other corrosion attacks as well. Analyzing the oxide layer formed on the surface of the elements and attempting to determine the relative effect of each mechanism is beyond the scope of this work. This study did look at the expected increase in acid concentrations on corrosion rate.

A closer look at Figure 4.9-67 and Figure 4.9-69 reveals the effect oxy-firing has on corrosion rate. The data set from Figure 4.9-67 is from an air-fired case and gives corrosion rate of 0.01-0.03 mm/yr with no bromine addition and metal temperatures of $110^{\circ} \mathrm{F}$. At approximately the same temperature and with no bromine addition, the oxy-fired case reveals corrosion rates of $0.1-0.2 \mathrm{~mm} / \mathrm{yr}$.

Corrosion rates from the cycling mode indicate elevated rates under oxy-fired conditions as compared to air-fired conditions as seen in Figure 4.9-71. The data represented by the green line is percent $\mathrm{CO}_{2}$ in the furnace. Furnace gas composition included $12-15 \% \mathrm{CO}_{2}$ under air-fired conditions and normally $>80 \%$ $\mathrm{CO}_{2}$ for oxy-firing conditions. As seen from the $\% \mathrm{CO}_{2}$ trend, the furnace was partially converted to oxyfiring late on 5/6/13 and all day 5/8/13. Corrosion rates increase by at least an order of magnitude under oxy-fired conditions. Because of flue gas recycle, acid and $\mathrm{H}_{2} \mathrm{O}$ concentrations can be 3-4 times higher when oxy-firing. 


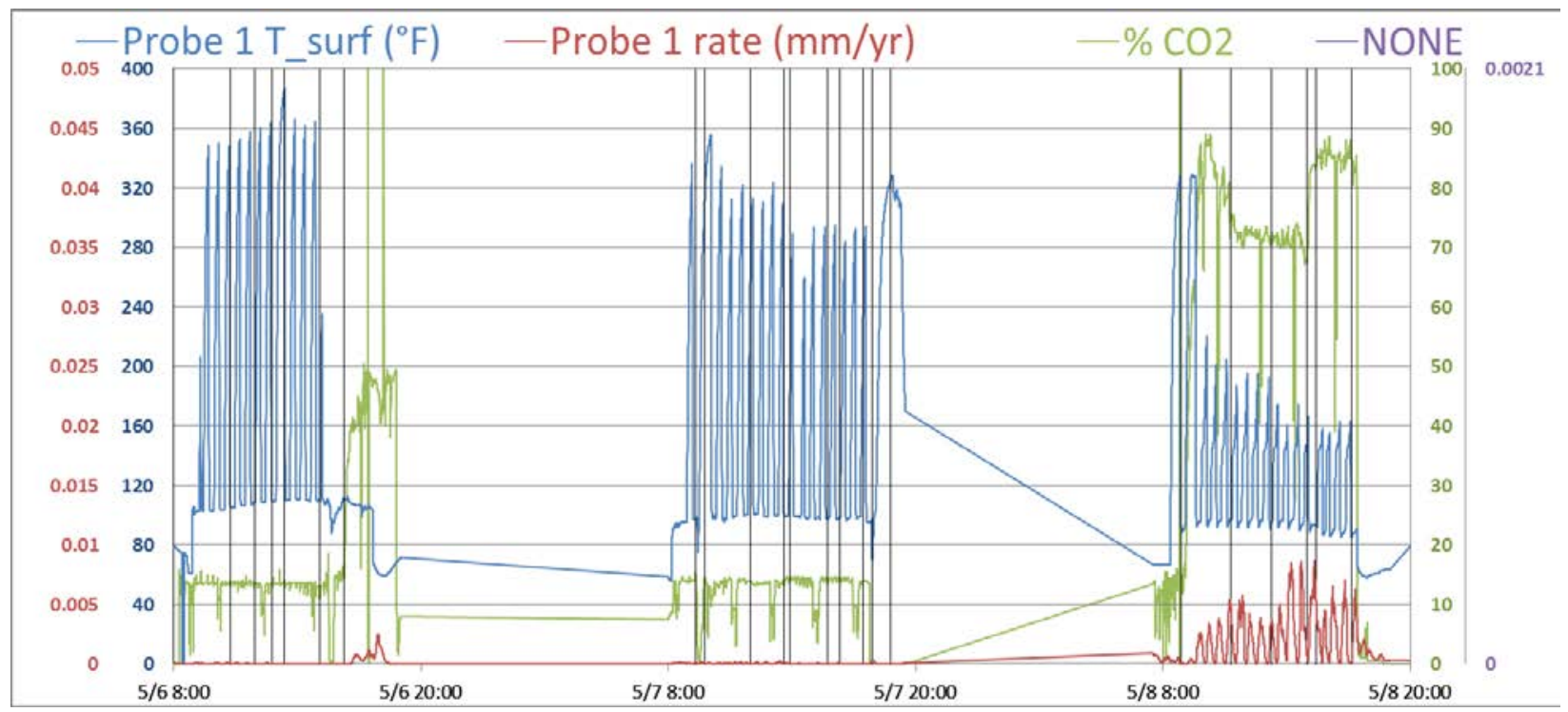

Figure 4.9-71: Data from May 6-8, 2013 including corrosion element temperature, corrosion rate, and $\% \mathrm{CO}_{2}$ in the flue. $\mathrm{CO}_{2}$ percent was $13-15 \%$ under air-fired conditions and near $80 \%$ during oxy-firing.

The increase in corrosion under oxy-firing conditions was an expected result. At least part of the increase in corrosion rate can be attributed to higher acid concentrations. An increase was noticed in the onset of corrosion for the oxy-fired cases which corresponds to the sulfuric acid dewpoint. This occurs because of increased $\mathrm{SO}_{3}$ and $\mathrm{H}_{2} \mathrm{O}$ concentrations in the furnace due to flue gas recycle. An increased dew point temperature also corresponds to a higher equilibrium concentration of sulfuric acid (see Figure 4.9-72).

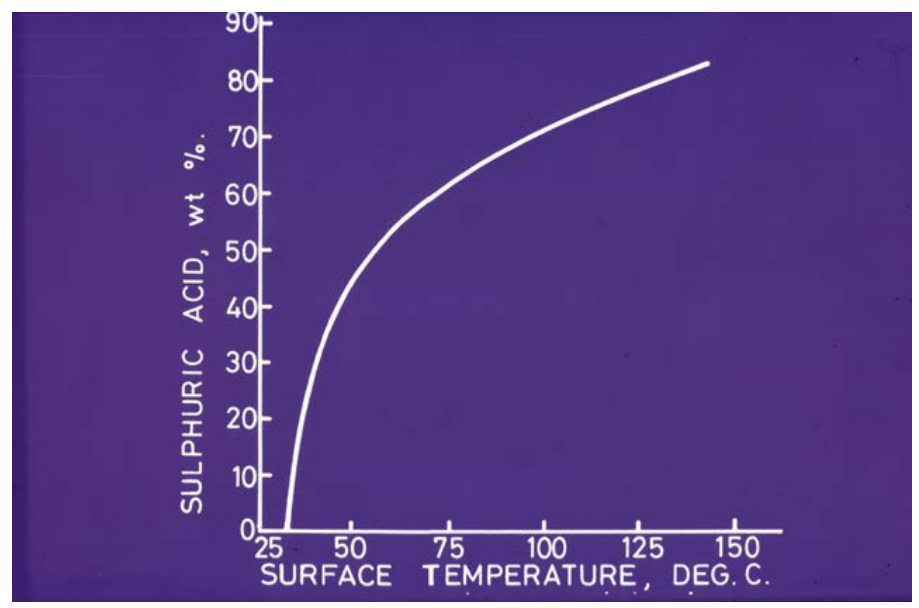

Figure 4.9-72: Equilibrium sulfuric acid concentration (Meadowcroft and Cox 1985)

\subsubsection{Effect of Fuel Type}

Corrosion probes were operated in detection mode during all tests with bituminous coal. The probes were operated in cycling mode during all tests with PRB coal except for one day. Thus a comparison can only be made for conditions from this day. Figure 4.9-73 displays the PRB results and Figure 4.9-74 displays bituminous results from an air-fired test. Both cases display results with injection of a relatively high concentration of $\mathrm{CaBr}_{2}(42-51 \mathrm{ppm})$. The bituminous coal resulted in corrosion rates nearly 10 times that 
of the PRB coal. This is consistent with the higher sulfur content in the bituminous coal and the lower calcium content in the ash (see Table 4.9-18). Both of these factors contribute towards higher SOx concentration in the flue gas and a higher dewpoint temperature.

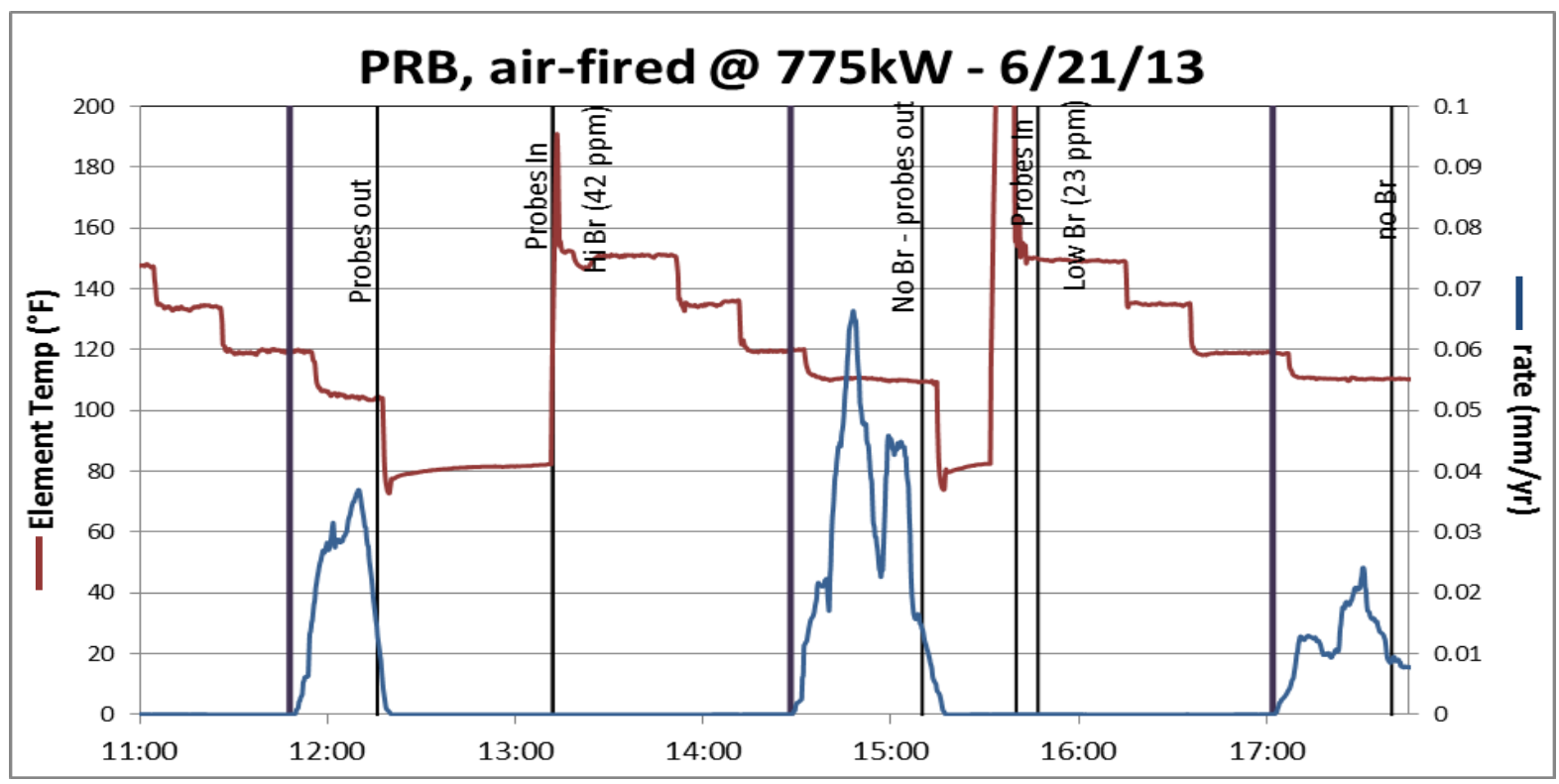

Figure 4.9-73: $\mathrm{PRB}$ coal in air-fired environment. $\mathrm{H}_{2} \mathrm{SO}_{4}$ dewpoint observed at $120^{\circ} \mathrm{F}$ for all 3 instances.

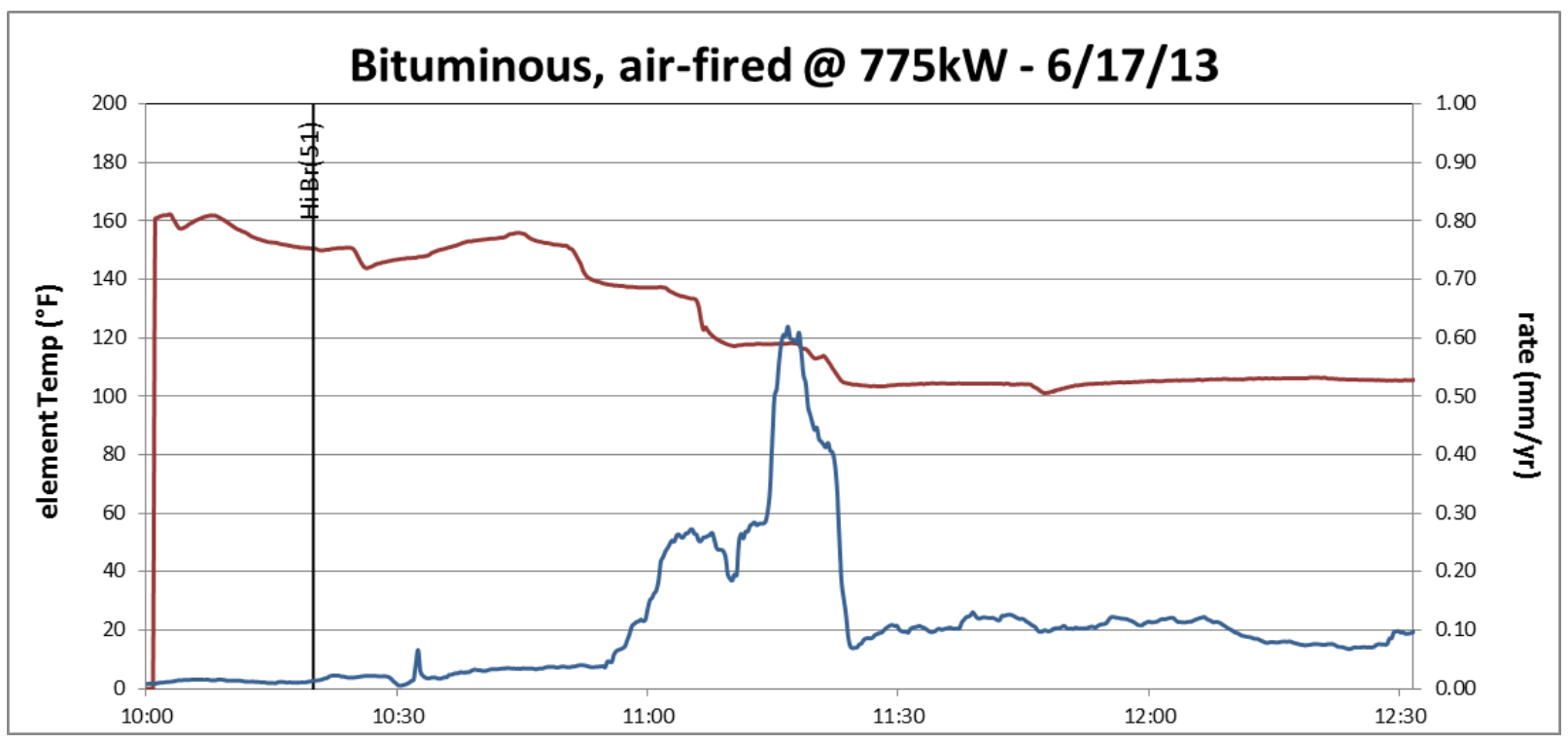

Figure 4.9-74: Surface temperature and corrosion rate during testing; corrosion is evident near $160^{\circ} \mathrm{F}$ and accelerates near $140^{\circ} \mathrm{F}$.

Sulfuric acid is generally the first acid to condense and its dewpoint can be determined from the onset of corrosion. This onset in corrosion (sulfuric acid dewpoint) is observed at $\sim 135^{\circ} \mathrm{F}$ for the PRB coal in an air-fired environment (see Figure 4.9-73). For bituminous coal, some corrosion activity is seen above $160^{\circ} \mathrm{F}$ (see Figure 4.9-74). 
Table 4.9-18 Fuel analysis of coal used during Phase 2.

\begin{tabular}{|c|c|c|c|}
\hline \multicolumn{4}{|c|}{ Black Thunder PRB } \\
\hline \multicolumn{2}{|c|}{ Coal Analyses } & \multicolumn{2}{c|}{ Mineral Matter Analyses } \\
\hline C & 54.04 & Al & 14.19 \\
\hline H & 3.74 & Ca & 16.13 \\
\hline N & 0.82 & Fe & 5.99 \\
\hline S & 0.38 & Mg & 3.33 \\
\hline O & 13.69 & Mn & 0.04 \\
\hline Ash & 5.66 & P & 0.71 \\
\hline Moisture & 21.67 & K & 0.47 \\
\hline Volatile Matter & 36.77 & Si & 36.76 \\
\hline Fixed Carbon & 35.91 & Na & 0.93 \\
\hline HHV, Btu/lb & 9320 & S & 10.11 \\
\hline
\end{tabular}

\begin{tabular}{|c|c|c|c|}
\hline \multicolumn{4}{|c|}{ Pratt Bituminous } \\
\hline \multicolumn{2}{|c|}{ Coal Analyses } & \multicolumn{2}{c|}{ Mineral Matter Analyses } \\
\hline C & 69.23 & Al & 25.91 \\
\hline H & 4.82 & Ca & 3.41 \\
\hline N & 1.69 & Fe & 13.20 \\
\hline S & 2.22 & Mg & 1.18 \\
\hline O & 6.54 & Mn & 0.04 \\
\hline Ash & 13.14 & P & 0.83 \\
\hline Moisture & 2.38 & K & 2.33 \\
\hline Volatile Matter & 35.64 & Si & 44.78 \\
\hline Fixed Carbon & 48.85 & Na & 0.47 \\
\hline HHV, Btu/lb & 12659 & S & 3.72 \\
\hline
\end{tabular}

\subsubsection{Effect of Temperature Cycling}

Corrosion element temperatures were cycled between $100-250^{\circ} \mathrm{F}$ in cycling mode to simulate, to the extent possible given temperature control limitations, the cycling experienced by air heater baskets as they rotate between hot flue gas and cold inlet combustion air. Figure 4.9-75 shows typical data from one of these days. The elements can be cooled relatively quickly since the probe can provide cooling air to the inside of the elements. However, heating is only accomplished by convection from the flue gas and limits the cycling rate. Also, the probes were only cleaned once between the first and second week. An ash layer deposit of 5-10mm was observed throughout this whole campaign. This ash layer thermally insulated the element surface, further inhibiting the cycling frequency.

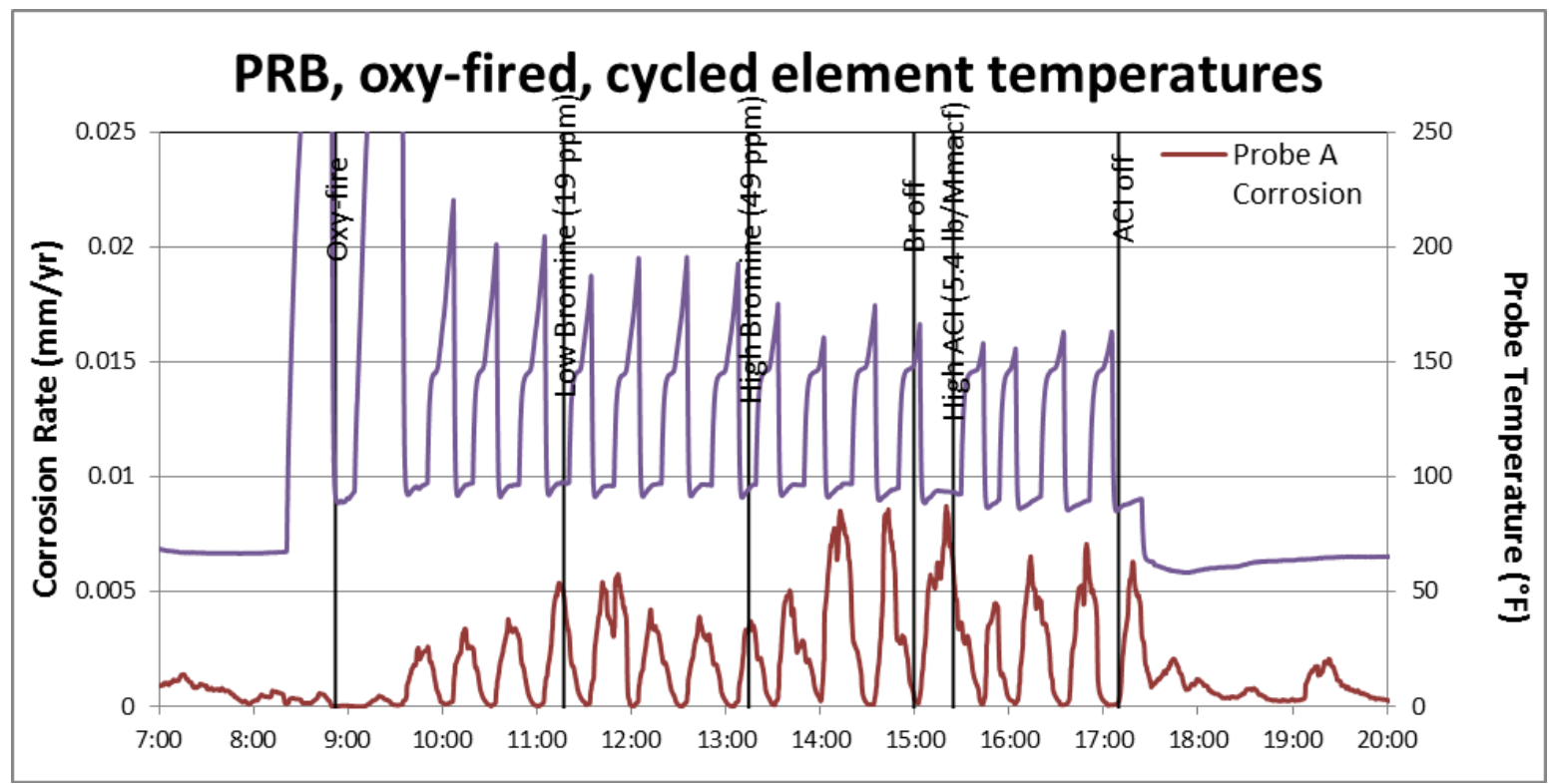

Figure 4.9-75: Typical corrosion data when cycling element temperature. 
The corrosion elements were cooled below $100^{\circ} \mathrm{F}$ and allowed to heat to approximately $200^{\circ} \mathrm{F}$. It is noted that while oxy-firing, back-end temperatures were lower and the probes often did not heat to $200^{\circ} \mathrm{F}$ before cooling again (see Figure 4.9-75). However, corrosion rates fell to near zero even at these relatively cool peak temperatures $\left(160^{\circ} \mathrm{F}\right)$ indicating that acid dewpoints are below this temperature in this flue gas environment. Cooling the probes to $\sim 95^{\circ} \mathrm{F}$ ensured they were below most acid dewpoints: sulfuric acid, hydrochloric acid, hydrobromic acid, and water. Thus corrosion rates were a combined effect from all these acids and should show the effect of $\mathrm{HBr}$ on corrosion rates. Figure 4.9-75 shows a significant increase in corrosion after injection of $49 \mathrm{ppm} \mathrm{CaBr}_{2}$ with the coal at 13:15. The rates increased from an average of $3.8 \times 10^{-3} \mathrm{~mm} / \mathrm{yr}$ before $\mathrm{CaBr}_{2}$ injection to $7.3 \times 10^{-3} \mathrm{~mm} / \mathrm{yr}$ after injection begins. This increase in rate is consistent with data from detection mode, however is not as pronounced.

Injection of low levels of $\mathrm{CaBr}_{2}$ began at 11:17 with no noticeable change in corrosion rates. The theoretical $\mathrm{HBr}$ dewpoint for this condition as calculated using the Kiang correlation (Kiang 1981) is $144^{\circ} \mathrm{F}$. However, within this calculation it has been assumed that there is no interaction with ash and consequently no removal in the baghouse. As explained in section 4.9.6.1, the data shows that a significant fraction of the $\mathrm{HBr}$ must be removed in the fabric filters before recycled since $\mathrm{HBr}$ dewpoints were not changed when switching to oxy-firing. Also, the surface temperature correlates to the surface of the corrosion element.

It was generally seen that corrosion rates were much lower when running in cycling mode as was seen from the one day of detection mode while burning PRB coal. Figure 4.9-75 displays the highest rates observed from the cycling to be approximately $7.3 \times 10^{-3} \mathrm{~mm} / \mathrm{yr}$. Note that this was from a furnace running in oxy-firing mode with high concentration of $\mathrm{CaBr}_{2}$ injection which was shown previously to be the condition causing the greatest corrosion. Figure 4.9-73 displays the only results available for the PRB with probes operating in detection mode. Even though this is from an air-fired case, corrosion rates of $6.7 \times 10^{-2}$ are observed (an order of magnitude greater).

It is likely that the main factor contributing to this apparent discrepancy is the ash deposit layer on the probe during cycling mode. This layer was never removed so the temperature of the surface interacting with the flue gas - that of the ash - was higher than the metal surface temperature reported in the data. Thus temperatures from the cycling mode must be lower than those from detection mode to make a direct comparison. Also this ash layer will interact with the acid and slow its diffusion to the metal surface. Finally the oxide layer that forms from corrosion was never removed and would also act as a barrier of diffusion and further corrosion.

Results from the temperature cycling campaign should not be used to estimate corrosion rates in an air heater. There is no simulated air heater on the L1500 before entering the baghouse, therefore back end temperatures seen by the corrosion probes necessarily were kept much cooler $\left(300-400^{\circ} \mathrm{F}\right)$ than typically seen at air heater inlets in industrial boilers $\left(\sim 700^{\circ} \mathrm{F}\right)$. This limited the temperature cycling to 1 cycle every 15-30 minutes as compared to a cycling rate of 1-3 rpm in a typical Ljungström-style air heater. Also air heater baskets are typically soot blown to remove any ash build-up.

\subsubsection{Corrosion Mechanism Refinement}

The fire-side corrosion correlations for the most commonly encountered corrosion mechanisms were developed based on existing literature and the results from the previous programs that REI performed (Reaction Engineering International 2007) (Reaction Engineering International 2009). Some of these correlations were developed under a limited range of conditions and need further investigation and adjustment. A preliminary adjustment of the fire-side superheater/reheater corrosion correlations was performed to match the measured corrosion rates. Insight toward identifying key corrosion parameters were obtained from CFD simulations and refinements to existing correlations were then developed. 
Corrosion is a complex process and can involve multiple interacting mechanisms. However, corrosion monitoring can only indicate the total corrosion rate at a given location. Therefore it is necessary to develop an approach to make the best use of a given data set. The approach used in this effort was to identify a dominant mechanism at a given location and use the data to fit the corresponding corrosion correlations. Here is the mechanism identification process:

- The key parameter for $\mathrm{H}_{2} \mathrm{~S}$ gas attack is $\mathrm{H}_{2} \mathrm{~S}$ concentration near the metal (see 4.9.2.2.1). However, the superheater region $\mathrm{H}_{2} \mathrm{~S}$ concentration is expected to be low except in those regions where the flow stratification can be significant (e.g., utility boiler upper furnace turning zones). In the L1500 furnace, significant flow stratification near the end of the furnace (superheater probe locations) is not expected, so this corrosion may not be significant for the superheater zone. Therefore the current $\mathrm{H}_{2} \mathrm{~S}$ corrosion correlation should not be adjusted based on the measured corrosion rates. In fact, the calculated $\mathrm{H}_{2} \mathrm{~S}$ concentrations at the probe locations were relatively low resulting in low $\mathrm{H}_{2} \mathrm{~S}$ corrosion rates.

- The key difference between molten sulfate corrosion (see 4.9.2.2.3) and active oxidation (see 4.9.2.3.2) is whether or not deposition occurred. A second factor could also be the formation of $\mathrm{Cl}_{2}$ or the existence of $\mathrm{SO}_{2} / \mathrm{SO}_{3}$ near the surface. However this is hard to measure or predict, so only the deposition is used as the criterion.

- This results in 13 data points that can be considered as molten sulfate corrosion and 5 as active oxidation from L1500 measurements. These data points will be used to tune the parameters of the corresponding correlation.

Based on this mechanism identification process, the coefficients in the correlations were adjusted to match the measured corrosion rates. Due to the difficulty in measuring the detailed local properties, local information, such as heat flux and chemical species concentrations, was calculated from the CFD simulation.

The impact of an independent optimization of both the molten sulfate and active oxidation correlation coefficients using the data considered to be dominated by the individual mechanisms is illustrated in Figure 4.9-76. As indicated the extent of the adjustment to the coefficients of both correlations is significant.

A comparison of the refined predictions with measurements for the combined impact of molten sulfate and active oxidation are shown in Figure 4.9-77. The results show significant improvement after tuning. The corrosion correlations used before tuning were developed based only on the literature survey and some correlations were tuned at relatively low corrosion rates in the previous program (Reaction Engineering International 2007). This may have caused the significant difference after tuning to the new measurements obtained during this program. 
Molten Sulfate Mechanism Tuning
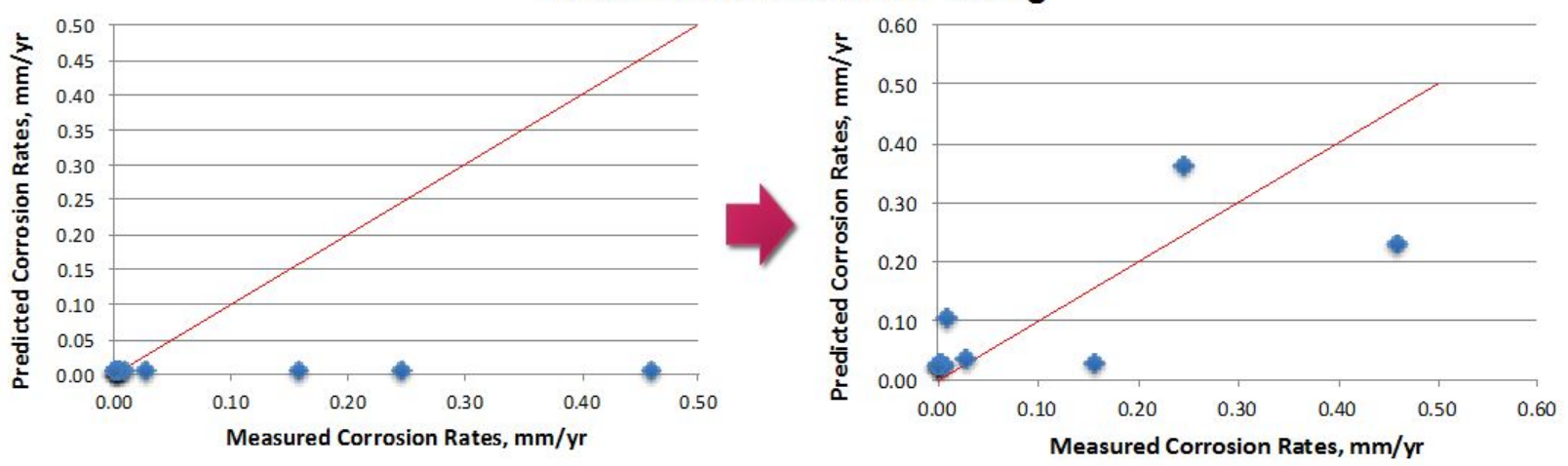

Active Oxidation Mechanism Tuning
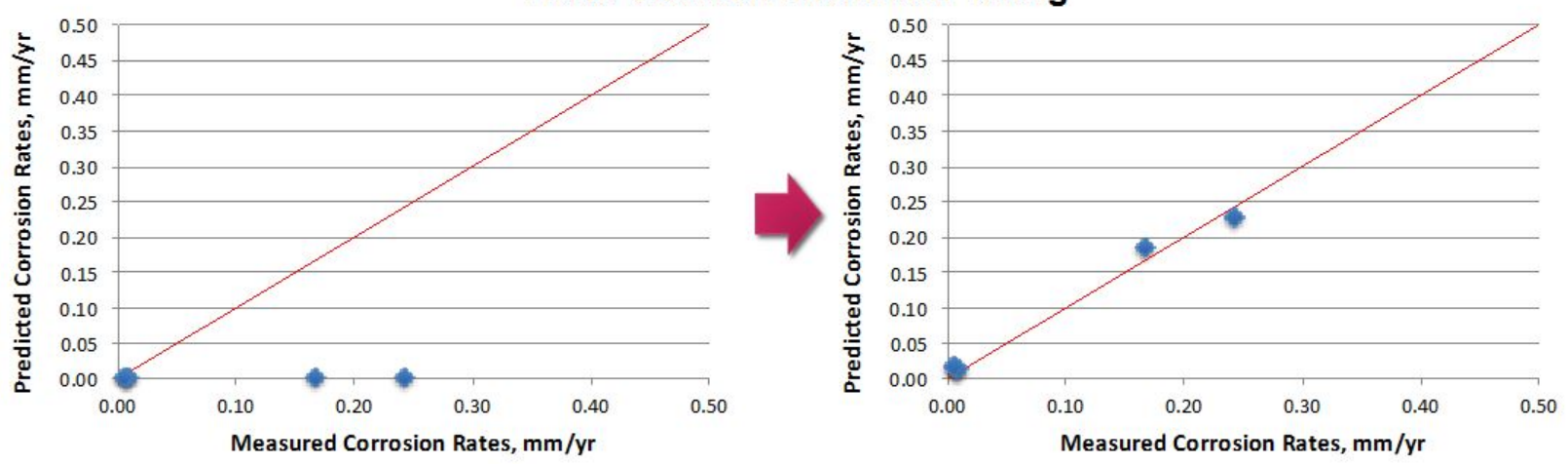

Figure 4.9-76: Independent refinement of corrosion correlations for molten sulfate and active oxidation mechanisms using measurements.
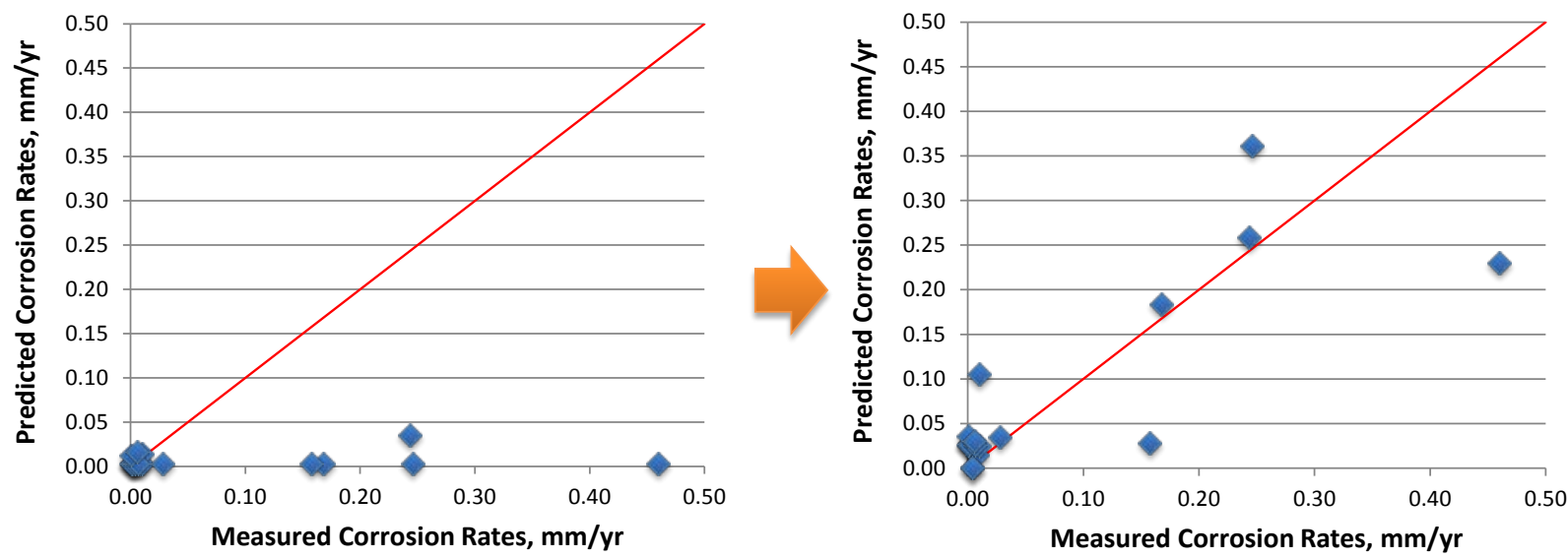

Figure 4.9-77: Predicted corrosion rates as a function of the measured corrosion rates before (left figure) and after (right). 


\subsubsection{Corrosion Conclusions}

Pilot-scale corrosion experiments were performed in the University of Utah's pilot-scale entrained flow furnace. For these corrosion experiments, electrochemical noise corrosion sensing technology was utilized. One waterwall probe employed SA210 low-carbon steel sensor elements and three superheater probes were fabricated that employed T22, P91 and 347H materials, respectively. These materials were selected as being representative of US utility boiler installations. Baseline conditions were used to determine the difference in corrosion rate between air and oxy-fired conditions while firing three coals. The three coals were Powder River Basin (PRB), Utah (Skyline) and Illinois. The baseline operating conditions included: a firing rate of $3.5 \mathrm{MBtu} / \mathrm{hr}$, a burner stoichiometric ratio of 0.9 and $3.0 \%$ excess $\mathrm{O}_{2}$ (dry) with the over-fire air/FGR introduced in section 6 of the furnace. The sensor elements of the waterwall were maintained at $720^{\circ} \mathrm{F}$ and the probe was installed at a gas temperature of about $2300^{\circ} \mathrm{F}$. The sensor elements on the superheater probes were controlled at $910^{\circ} \mathrm{F}$ and the sensors were installed in a region of the furnace where the gas temperature was approximately $1800^{\circ} \mathrm{F}$.

The three coals produced flue gas $\mathrm{SO}_{2}$ concentrations in the range of 128 to 3,219 ppmv (dry) for air-fired conditions and 289 to 17,624 ppmv (dry) for oxy-fired conditions. Removal of gas-phase sulfur dioxide occurred and is likely due to capture on coal mineral matter. The capture rate was shown to have linear dependence on the calcium concentration in the ash.

For baseline conditions, the corrosion rates were in the ranges of 0.21 to $0.72 \mathrm{~mm} / \mathrm{yr}$ (8.3 to 28.3 mils/year) for the T22 material with both Skyline and Illinois coals under air- and oxy-fired conditions and for the $347 \mathrm{H}$ probe when Illinois coal was oxy-fired the corrosion rates were in the range of 0.0034 to $0.016 \mathrm{~mm} / \mathrm{yr}$ ( 0.13 to $0.62 \mathrm{mils} / \mathrm{yr}$ ). These corrosion rates are assuming that the loss of material occurs evenly over the entire sensor element. Actual peak corrosion rates are expected to be on the order of 3 times higher. Waterwall corrosion rates decreased when converting from air to oxy-firing for all coals. Superheater corrosion rates increased when converting from air- to oxy-firing for all conditions with the exception of the T22 material when firing Illinois coal.

Corrosion rates for the lower alloyed materials (SA210 and T22) were shown to increase drastically during transients from reducing to oxidizing conditions when air-firing and from oxidizing to reducing conditions when oxy-firing. Such transients are likely to contribute greatly to practical in-plant corrosion rates in the near-burner and near-OFA port regions. These effects cannot be resolved using coupon tests.

The presence of trisulfates strongly increases the corrosion rate of the $347 \mathrm{H}$ material under high sulfur and low temperature conditions. It was demonstrated conclusively, (and for the first time by real-time corrosion monitoring, and in confirmation of published literature predictions) that these species are decomposed by operating at higher material temperatures, reducing the subsequent corrosion rates to much lower levels.

The dependence of corrosion rate on material temperatures was demonstrated along with the repeatable nature of the results.

It was shown that injection of $\mathrm{CaBr}_{2}$ results in a 1.5-3 fold increase in dew point corrosion rates when metal temperatures are allowed to drop below the $\mathrm{HBr}$ dew point temperature. This result was repeated for both a medium sulfur bituminous coal (Pratt - North River) and a low sulfur sub-bituminous coal (Black Thunder PRB) under both oxy- and air-firing conditions. However for low $\mathrm{CaBr}_{2}$ injection rates, the bromic acid dewpoint may fall below water dewpoints. The relatively high corrosion rates from condensed water may dilute the contribution from bromic acid. 
The data suggests that switching to oxy-firing conditions does not noticeably change the onset of corrosion by $\mathrm{HBr}$. This is likely because most of the $\mathrm{Br}$ is removed with the ash in the fabric filter. More studies are necessary to verify this result. The onset of corrosion by bromine for PRB coal occurs at slightly warmer temperatures than the bituminous coal tested. The elevated moisture created in the flue gas likely causes the increase in $\mathrm{HBr}$ dewpoint which is verified by theoretical dewpoint calculations. While corrosion rates are still lower when burning PRB coal, bromine has a much larger effect for this coal (increasing baseline acid corrosion by 3 orders of magnitude). 


\subsection{Radiation}

\subsubsection{Evaluation of Radiation Property Models}

REI and Vattenfall completed a study which compared methods for calculating radiation property models. The study had two objectives: 1) compare radiative properties calculated from two different modeling approaches, and 2) compare radiative properties for flue gases produced under air-fired and oxy-fired combustion conditions. The property modeling approaches compared were based on REI's CFD code Glacier and Vattenfall's version of the commercial CFD code Fluent. The study compared calculated radiation properties (gas emissivity and absorption coefficient, particle absorption coefficient) for prescribed gas-phase and particle-phase conditions, followed by calculation of radiative heat fluxes and wall temperatures in a simplified utility boiler geometry. The specific steps used in the evaluation were:

1) Comparison of calculated gas-phase radiation properties, i.e., gas emissivity and/or absorptivity.

2) Comparison of predicted gas-phase heat transfer for a simplified enclosure representing a fullscale furnace.

3) Comparison of calculated particle-phase radiation properties, i.e., particle absorption coefficient or absorptivity.

4) Comparison of predicted gas and particle-phase heat transfer for a simplified enclosure representing a full-scale furnace.

\subsubsection{Gas-phase Radiation Properties}

Gas-phase emissivity and/or absorption coefficient were calculated for air-fired and oxy-fired flue gas mixtures $\left(\mathrm{O}_{2}-\mathrm{N}_{2}-\mathrm{CO}_{2}-\mathrm{H}_{2} \mathrm{O}\right)$ at different temperatures and path lengths representative of a full-scale utility boiler. Calculations were based on equations/techniques used in Glacier and Fluent, respectively, and the results compared. Glacier calculations were based on the narrow band (NB) model RADCAL published by the National Institute of Standards and Technology (NIST); Fluent calculations were based on a weighted sum of gray gasses (WSGG) model. Some additional Fluent calculations based on an exponential wide-band model (EWBM) were also completed for some of the scenarios.

Table 4.10-1 shows the assumed flue gas compositions used in the comparisons. Comparisons were made at gas temperatures of $800^{\circ} \mathrm{C}, 1200^{\circ} \mathrm{C}$ and $1600^{\circ} \mathrm{C}\left(1472^{\circ} \mathrm{F}, 2192^{\circ} \mathrm{F}, 2912^{\circ} \mathrm{F}\right)$ and at optical path lengths of $2,5,10$, and $20 \mathrm{~m}$.

Table 4.10-1: Flue Gas Composition for Radiative Property Comparison.

\begin{tabular}{|l|c|c|c|c|}
\hline Flue Gas & $\mathbf{N}_{\mathbf{2}}$ Mole $\%$ & $\mathbf{H}_{\mathbf{2}} \mathbf{O}$ Mole $\%$ & $\mathbf{C O}_{\mathbf{2}}$ Mole $\%$ & $\mathbf{O}_{\mathbf{2}} \mathbf{M o l e} \mathbf{\%}$ \\
\hline Air & $67 \%$ & $15 \%$ & $15 \%$ & $3 \%$ \\
\hline Wet FGR & $7 \%$ & $25 \%$ & $65 \%$ & $3 \%$ \\
\hline Dry FGR & $7 \%$ & $10 \%$ & $80 \%$ & $3 \%$ \\
\hline
\end{tabular}

Figure 4.10-1 plots gas emissivity as a function of path length for the three flue gas compositions at a temperature of $800^{\circ} \mathrm{C}$. Figure $4.10-2$ and Figure $4.10-3$ are similar plots for gas temperatures of $1200^{\circ} \mathrm{C}$ and $1600^{\circ} \mathrm{C}$, respectively. All of these results were calculated using the RADCAL narrow band model as implemented in REI's Glacier CFD code. These results showed that gas emissivities for air and dry FGR compositions were very similar. This was because $\mathrm{H}_{2} \mathrm{O}$ concentrations were the most significant factor in gas emissivity; $\mathrm{CO}_{2}$ concentrations play a secondary role. This was consistent with long established gas emissivity theory and measurements (e.g., (Hottel and Sarofim 1967)). The plots show the air emissivity was slightly higher than dry FGR, even though the $\mathrm{CO}_{2}$ concentration was much higher for dry FGR. This was due to the $\mathrm{H}_{2} \mathrm{O}$ concentration in the assumed air-based flue gas being higher than in the assumed dry 
FGR flue gas. As all three figures show, the wet FGR had the highest gas emissivity due to the high $\mathrm{H}_{2} \mathrm{O}$ concentration.

Figure 4.10-4 shows the impact of changing the air composition from $15 \% \mathrm{H}_{2} \mathrm{O}$ to $10 \% \mathrm{H}_{2} \mathrm{O}$ (and increasing $\mathrm{N}_{2}$ concentration from $67 \%$ to $72 \%$; $\mathrm{CO}_{2}$ concentration remains at $15 \%$ ). In this case, the predicted gas emissivity for the dry air was lower than that for the dry FGR (which had the same $\mathrm{H}_{2} \mathrm{O}$ concentration) because of the (secondary) effect of lower $\mathrm{CO}_{2}$ concentration.

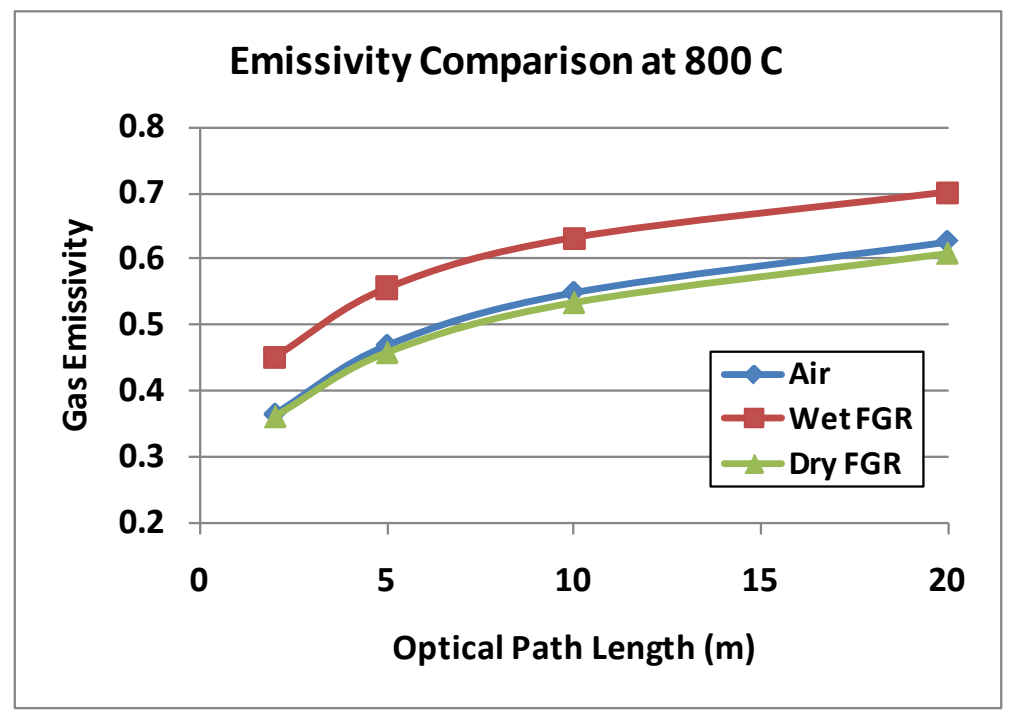

Figure 4.10-1: Gas emissivities as calculated with narrow band model for three different flue gas compositions as a function of optical path length at $800^{\circ} \mathrm{C}$.

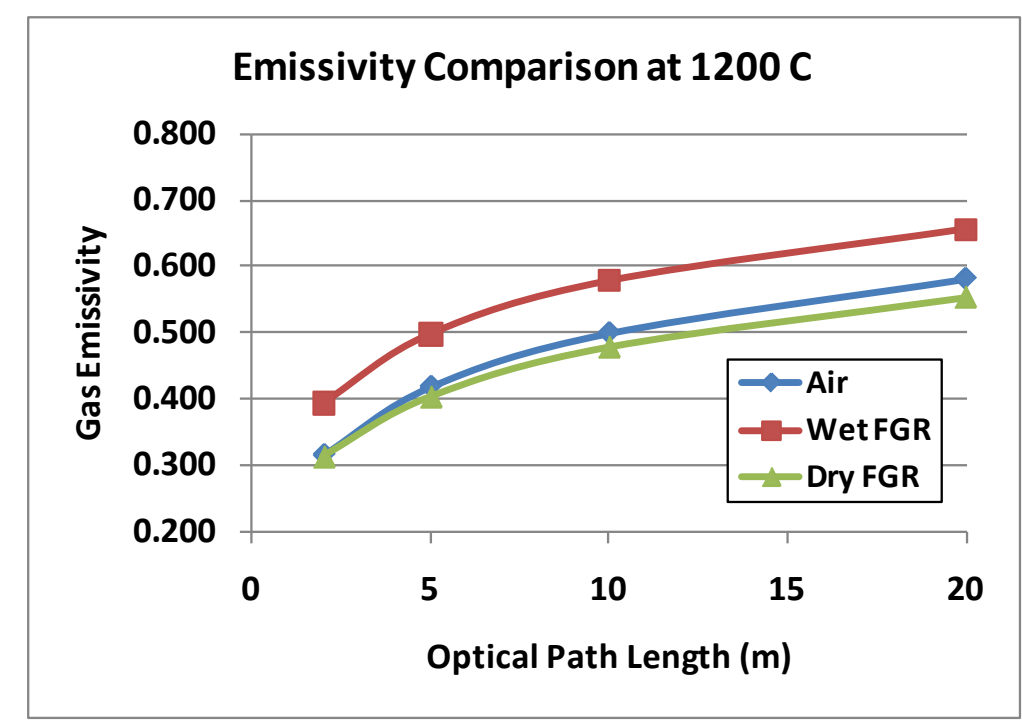

Figure 4.10-2: Gas emissivities as calculated with narrow band model for three different flue gas compositions as a function of optical path length at $1200^{\circ} \mathrm{C}$. 


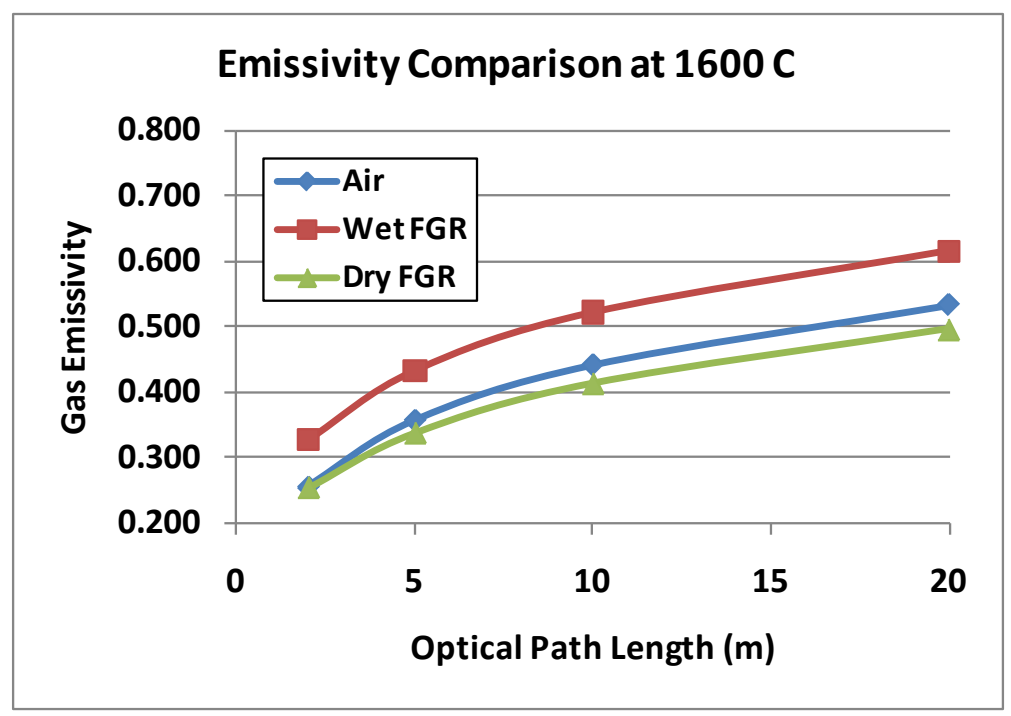

Figure 4.10-3: Gas emissivities as calculated with narrow band model for three different flue gas compositions as a function of optical path length at $1600^{\circ} \mathrm{C}$.

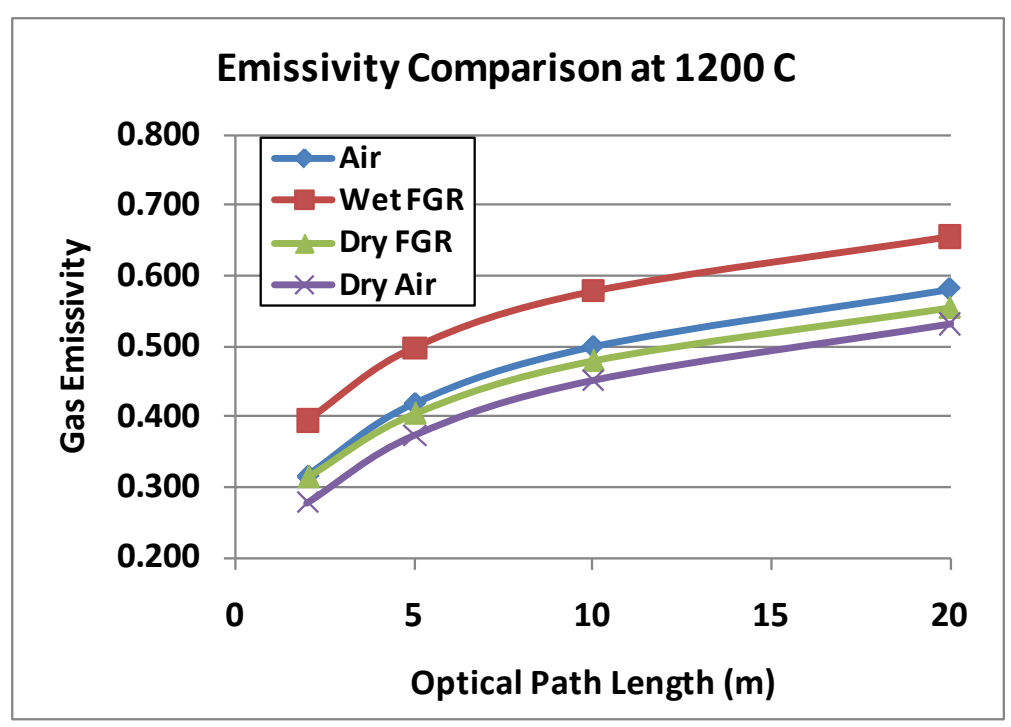

Figure 4.10-4: Gas emissivities as calculated with narrow band model illustrating impact of moisture (dry air vs. wet air vs. dry FGR) at $1200^{\circ} \mathrm{C}$.

Figure 4.10-5 plots the percentage difference between air-fired emissivities and dry FGR and wet FGR emissivities for different gas temperatures at an optical path length of $20 \mathrm{~m}$. There was a slight increase in the difference with increasing temperature for both the wet FGR and dry FGR gases. The relatively small differences between air and dry FGR are again illustrated.

Figure 4.10-6 plots the percentage difference between air-fired emissivities and dry FGR and wet FGR emissivities for different path lengths at a gas temperature of $1200^{\circ} \mathrm{C}$. Interestingly the difference between air and wet FGR emissivities decreased with increasing path length. The difference between air and dry FGR emissivities were small for all path lengths. 


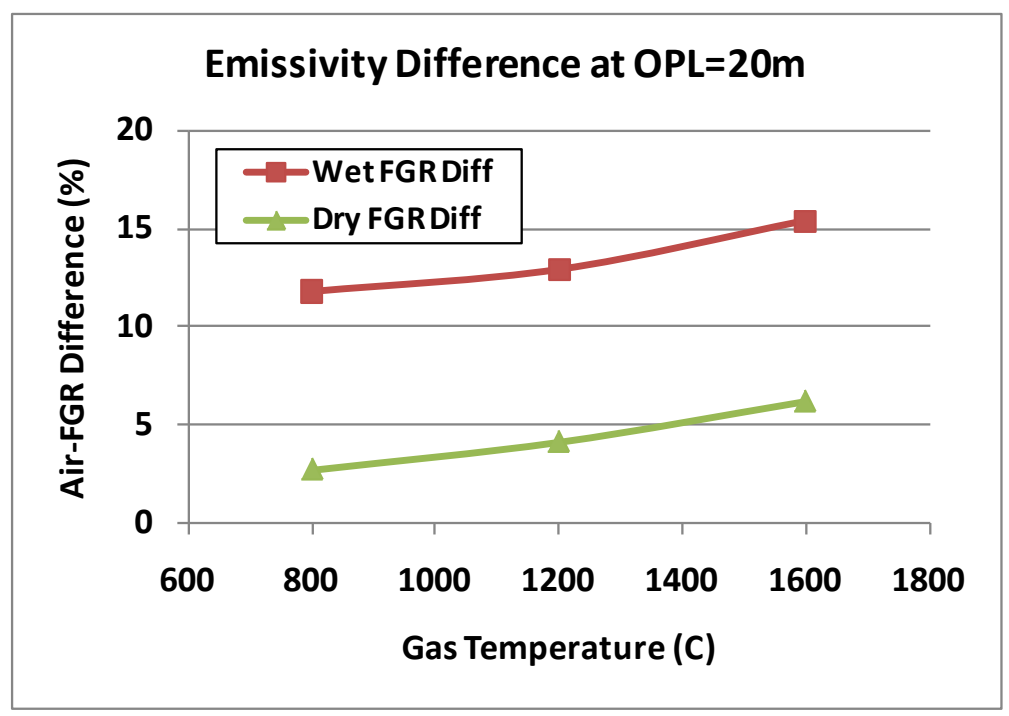

Figure 4.10-5: Gas emissivities as calculated with narrow band model illustrating impact of moisture (dry air vs. wet air vs. dry FGR) at $1200^{\circ} \mathrm{C}$.

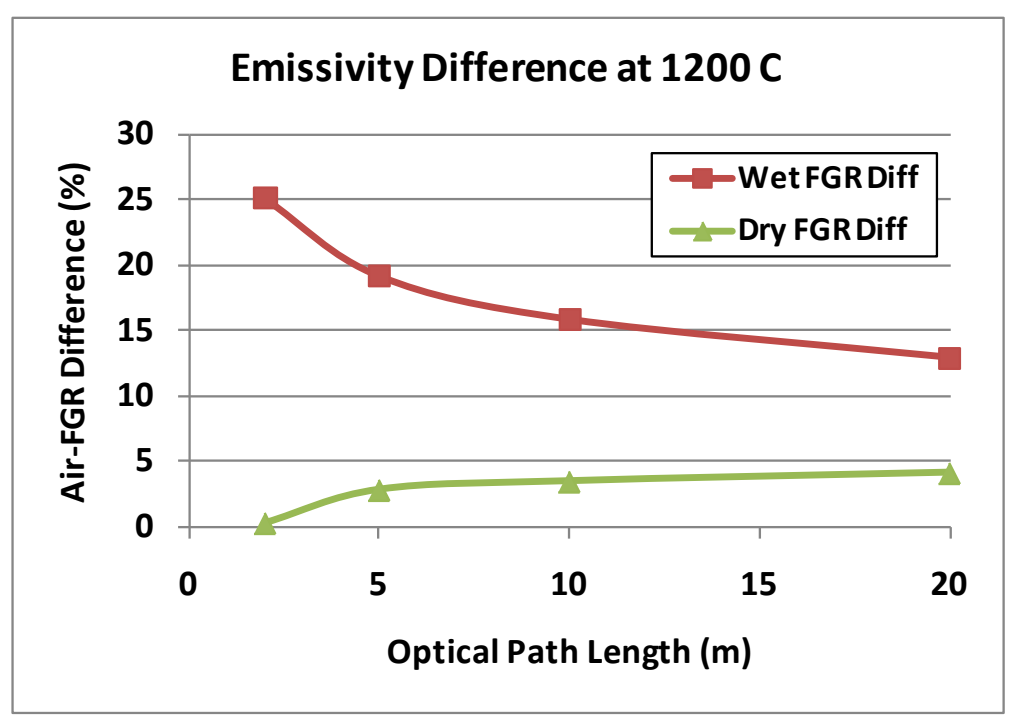

Figure 4.10-6: Gas emissivities as calculated with narrow band model illustrating impact of moisture (dry air vs. wet air vs. dry FGR) at $1200^{\circ} \mathrm{C}$.

In summary, emissivities calculated with a narrow band model for different flue gas compositions at different gas temperatures $\left(800^{\circ} \mathrm{C}\right.$ to $\left.1600^{\circ} \mathrm{C}\right)$ and path lengths $(2 \mathrm{~m}$ to $20 \mathrm{~m})$ showed:

- Wet FGR had $~ 10-20 \%$ higher emissivity than air.

o Magnitude of air and FGR emissivity differences was similar across range of temperature and path length.

o Relative differences between air and FGR increased with temperature (but change was small).

o Relative differences between air and FGR decreased with path length for wet FGR (large) and increased with path length for dry FGR (small).

- Gas emissivity was strongly dependent on $\mathrm{H}_{2} \mathrm{O}$ concentration; $\mathrm{CO}_{2}$ had a lesser effect. 
These results suggest that drying the recycle gas produced during oxy-combustion can produce gas emissivities similar to air emissivities. This in turn suggests that changing operation from air-fired combustion to oxy-fired combustion (with dry FGR) should not result in a significant difference in heat transfer characteristics due to gas phase radiative properties. Also, even with the $10-20 \%$ differences in gas emissivities for wet FGR, these gas property impacts are likely to be secondary to impacts of particle properties and flame temperatures on heat transfer under oxy-fired conditions.

Figure 4.10-7 shows a comparison of gas emissivities for air-fired flue gas at $1600^{\circ} \mathrm{C}$ as calculated with the narrow band model (NBM), weighted sum of gray gas model (WSGGM) and exponential wide band model (EWBM). Results showed the WSGGM compared well with the EWBM model. This was expected as the WSGGM was originally "tuned" to the EWBM model for air properties. The NBM predicted up to 10\% higher emissivities than the WSGGM and EWBM models.

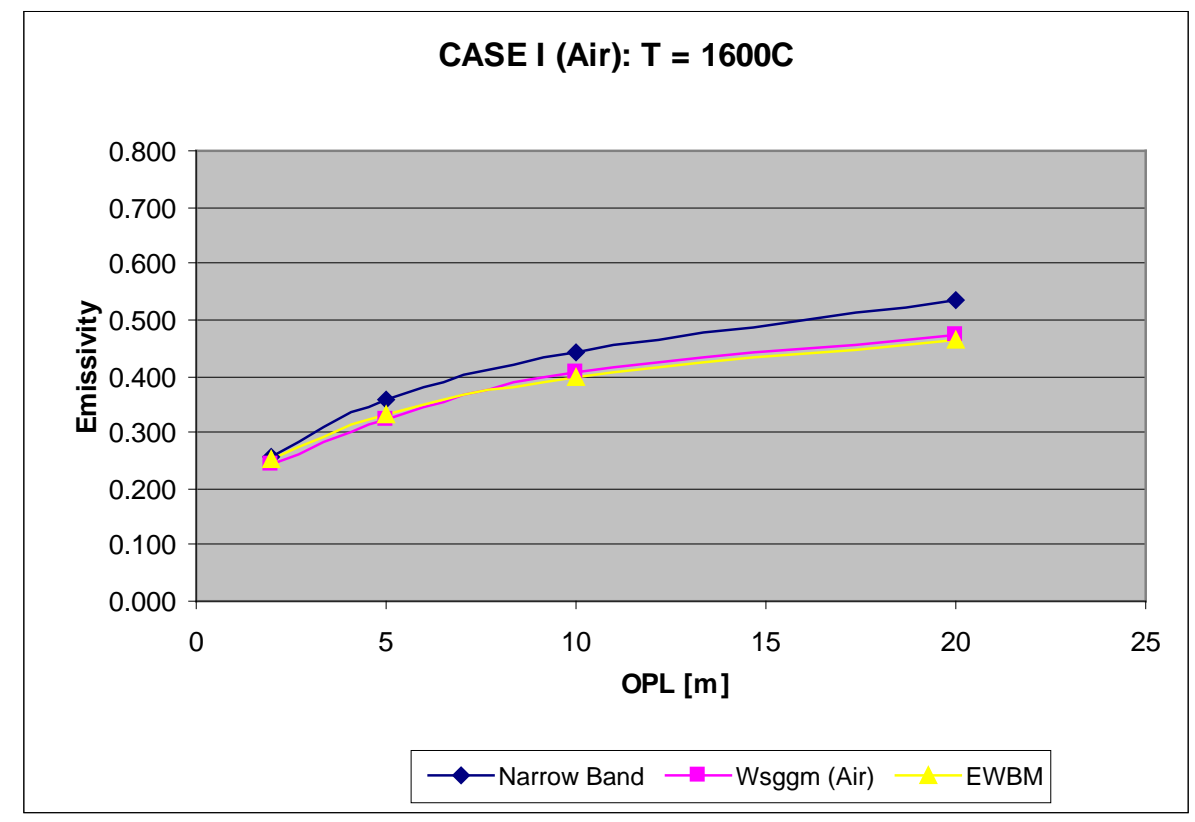

Figure 4.10-7: Comparison of gas emissivities for air-fired flue gas at $1600^{\circ} \mathrm{C}$ as calculated with narrow band model, weighted sum of gray gas model (WSGGM) and exponential wide band model (EWBM).

Figure 4.10-8 shows a comparison of gas emissivities for dry FGR flue gas at $1600^{\circ} \mathrm{C}$. The dry FGR results were very similar to the air-fired results; the NBM produced slightly higher emissivities at long path lengths. Figure 4.10-9 shows a comparison of gas emissivities for wet FGR flue gas at $1600^{\circ} \mathrm{C}$. The wet FGR results were quite different for the three models. The largest difference was between the WSGGM and NBM. There were also notable differences between the WSGGM and EWBM. Since the WSGGM was fitted to air property data, these differences were not unexpected. However it appears that the air-fitted WSGGM is not a good option for use in calculating radiative gas properties under oxy-firing conditions.

The differences between the NBM and EWBM were smaller, particularly at short path lengths. However the predicted results diverged more as the path length increased. Most notably, the slope of the curves changed, with the EWBM emissivity profile flattening out at longer path lengths whereas the NBM profile continued to increase at longer path lengths. It was not clear what caused this difference. Predicted 
emissivities for flue gas mixtures at $800^{\circ} \mathrm{C}$ and $1200^{\circ} \mathrm{C}$ showed similar trends to the $1600^{\circ} \mathrm{C}$ data, although the differences were less pronounced.

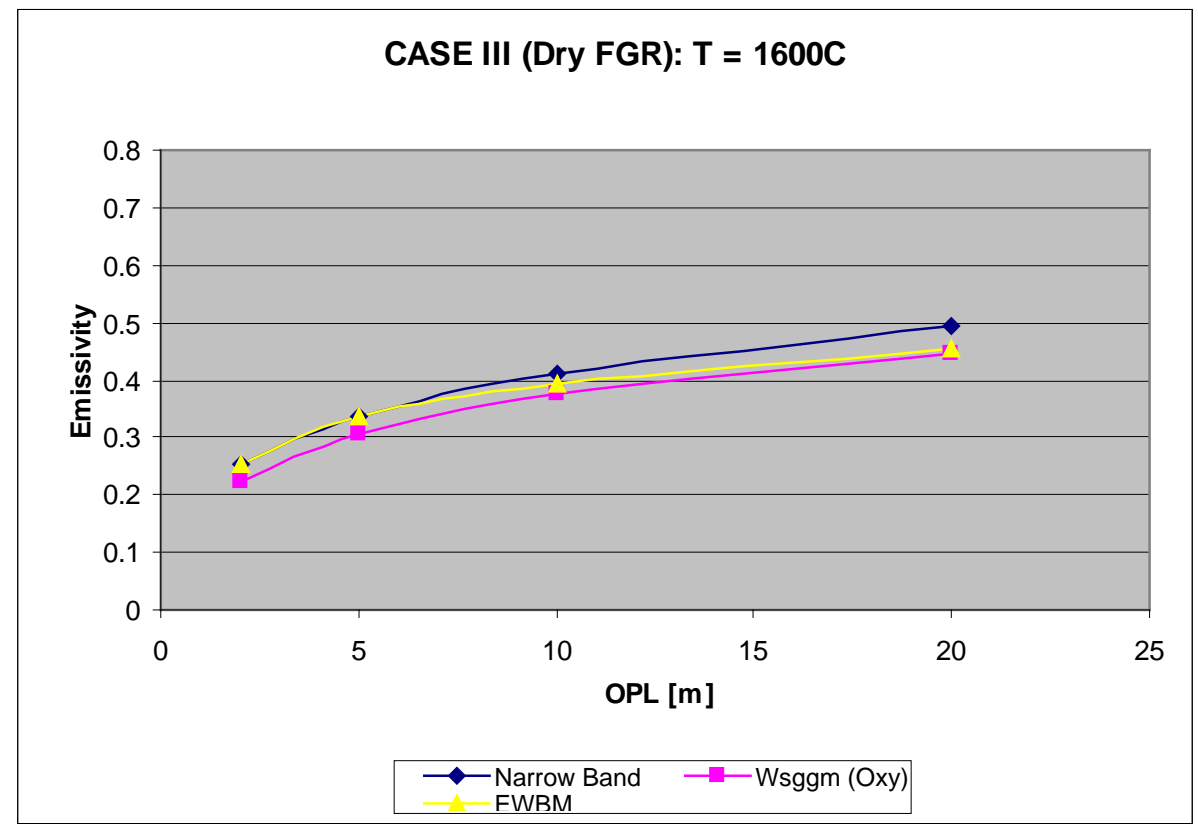

Figure 4.10-8: Comparison of gas emissivities for air-fired flue gas at $1600^{\circ} \mathrm{C}$ as calculated with narrow band model, weighted sum of gray gas model (WSGGM) and exponential wide band model (EWBM).

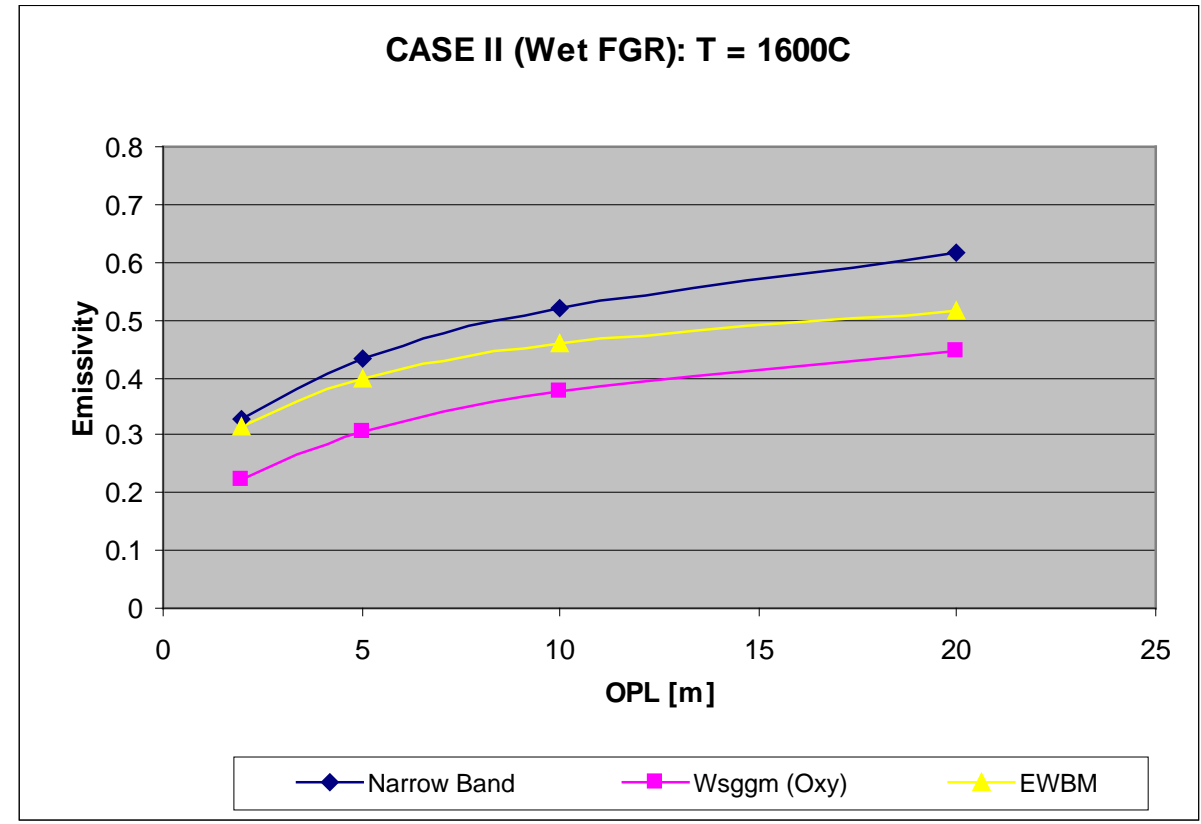

Figure 4.10-9: Comparison of gas emissivities for air-fired flue gas at $1600^{\circ} \mathrm{C}$ as calculated with narrow band model, weighted sum of gray gas model (WSGGM) and exponential wide band model (EWBM). 


\subsubsection{Gas-phase Heat Flux Comparison}

The Glacier (REI) and Fluent (Vattenfall) codes were used to predict incident and net heat fluxes in a three-dimensional "box" with geometry scales similar to a large utility boiler. Predictions were made with the interior (gas-phase) of the enclosure at specified, uniform temperatures and gas compositions representative of air combustion and oxy-combustion. Gas compositions were the same three as previously discussed (air, dry FGR, wet FRG, see Table 4.10-1). Wall boundary conditions (emissivity/absorptivity, temperature) were specified. Figure 4.10-10 shows the geometry of the simplified furnace enclosure and describes the geometry and surface properties. Both codes used the same geometry, computational grid and surface properties. Gas phase radiation properties and radiative heat transfer were calculated based on each code. Both codes used the discrete ordinates method for solving the radiative transfer equation; however the implementation of this method was somewhat different in the two codes. Emissivity coefficients in Glacier were calculated with the narrow band model. Emissivity coefficients in Fluent were calculated with the exponential wide band model for dry FGR and wet FGR cases and with the weighted sum of gray gases model for air-based flue gas. Both codes considered only gas phase radiation (no particulate effects) for this phase of the study.

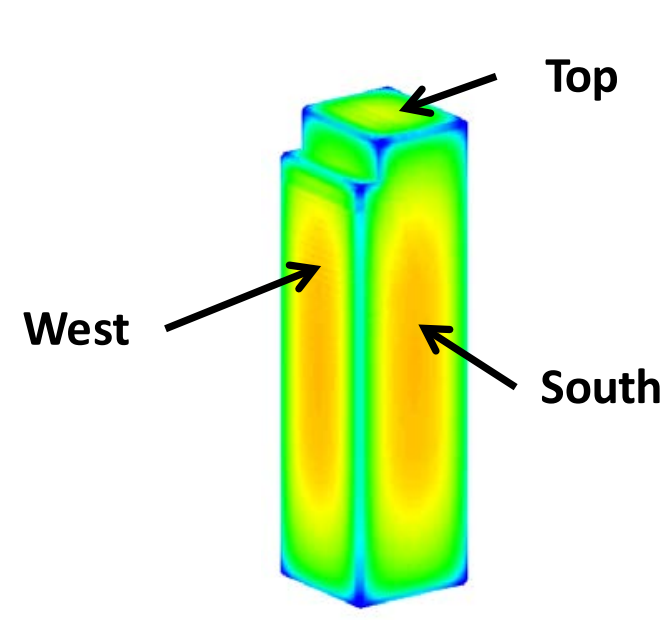

- Furnace "Box" height $55 \mathrm{~m}$

- Cross section $15 \times 15 \mathrm{~m}$

- Superheater "box": 5 meters high, 3 m wide - attached in upper left corner; represent pendants as solid box

- Walls: Emissivity=0.6, Steam temperature $380 \mathrm{C}$, Heat transfer coefficient $=300 \mathrm{~W} / \mathrm{m}^{2}-\mathrm{K}$ $\left(R_{\text {wall }}=0.003333 \mathrm{~m}^{2}-\mathrm{K} / \mathrm{W}\right)$

- SH: Emissivity=0.75, Wall temperature $600 \mathrm{C}$ (fixed)

- Cell size: $0.5 \mathrm{~m} \times 0.5 \mathrm{~m} \times 0.5 \mathrm{~m}$

Figure 4.10-10: Geometry and wall properties of simplified furnace enclosure.

Key results tracked were incident heat flux, net heat flux and wall temperatures. Figure 4.10-11 shows the predicted incident heat flux profiles on the furnace walls calculated with the Glacier code. These heat transfer results are consistent with the gas emissivity calculations, that is, the dry FGR case had the lowest incident heat flux and the lowest calculated gas emissivity (see Figure 4.10-3), and the wet FGR case had the highest incident heat flux and the highest calculated gas emissivity. Net heat flux and wall temperatures for the $1600^{\circ} \mathrm{C}$ flue gas temperature followed these same trends. Similar trends were observed at lower flue gas temperatures $\left(800^{\circ} \mathrm{C}\right.$ and $\left.1200^{\circ} \mathrm{C}\right)$, however the magnitude of the incident flux, net flux and wall temperatures decreased as the flue gas temperatures decreased.

Table 4.10-2 lists the heat transfer to the various furnace surfaces for each of the cases. The heat transfer trends were as expected. Changes to the flue gas composition made small differences in the absorbed heat, whereas changes to the flame temperature caused significant changes to the absorbed heat. This is illustrated in Figure 4.10-12 which plots the total heat absorbed as a function of flue gas temperature and moisture in the flue gas. Figure 4.10-12 shows that the change in flue gas temperature has a much greater impact on heat transfer than the flue gas composition. 

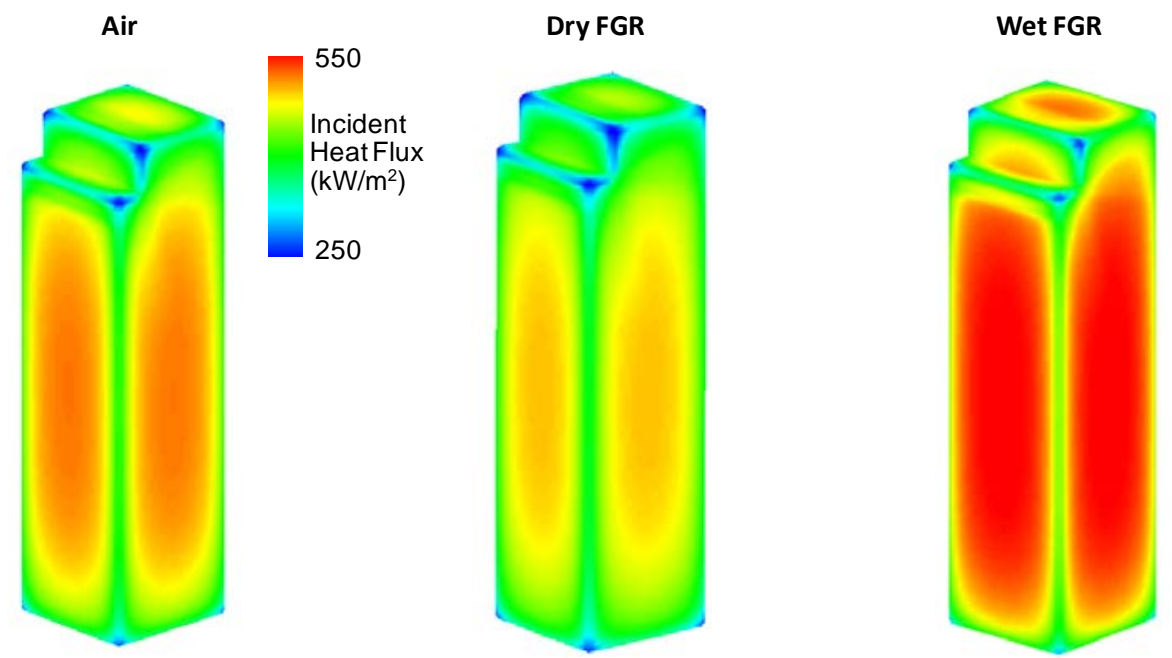

Figure 4.10-11: Incident heat flux profiles calculated by Glacier for the simplified furnace enclosure.

Table 4.10-2: Heat Transfer Values Calculated with Glacier for the Simplified Furnace Enclosure.

\begin{tabular}{|l|c|c|c|c|c|c|c|c|c|}
\hline Parameter & $\begin{array}{c}\mathbf{8 0 0 C} \\
\text { wetFGR }\end{array}$ & $\begin{array}{c}\text { 1200C } \\
\text { wetFGR }\end{array}$ & $\begin{array}{c}\text { 1600C } \\
\text { wetFGR }\end{array}$ & $\begin{array}{c}\mathbf{8 0 0 C} \\
\text { dryFGR }\end{array}$ & $\begin{array}{c}\text { 1200C } \\
\text { dryFGR }\end{array}$ & $\begin{array}{c}\text { 1600C } \\
\text { dryFGR }\end{array}$ & 800C Air & 1200C Air & 1600C Air \\
\hline Gas Emissivity & 0.652 & 0.599 & 0.547 & 0.555 & 0.499 & 0.434 & 0.572 & 0.522 & 0.466 \\
\hline Absorp. Coeff. (1/m) & 0.089 & 0.077 & 0.067 & 0.068 & 0.058 & 0.048 & 0.071 & 0.062 & 0.053 \\
\hline Top Wall HT (MW) & 4.25 & 14.82 & 33.32 & 3.91 & 13.45 & 30.04 & 3.97 & 13.77 & 31.07 \\
\hline Bottom Wall HT (MW) & 5.33 & 19.14 & 43.43 & 4.87 & 17.39 & 39.31 & 4.95 & 17.81 & 40.61 \\
\hline East Wall HT (MW) & 21.04 & 74.78 & 166.5 & 19.29 & 68.08 & 151.05 & 19.61 & 69.69 & 155.96 \\
\hline West Wall HT (MW) & 19.25 & 68.29 & 151.88 & 17.67 & 62.27 & 138.07 & 17.96 & 63.72 & 142.48 \\
\hline North Wall HT (MW) & 20.68 & 73.38 & 163.32 & 18.96 & 66.82 & 148.27 & 19.28 & 68.42 & 153.06 \\
\hline South Wall HT (MW) & 20.68 & 73.38 & 163.32 & 18.96 & 66.82 & 148.27 & 19.28 & 68.42 & 153.06 \\
\hline Superheater HT (MW) & 1.83 & 12.63 & 37.18 & 1.48 & 11.05 & 31.94 & 1.54 & 11.42 & 33.53 \\
\hline Total Heat Absorbed (MW) & 93.06 & 336.42 & 758.95 & 85.14 & 305.88 & 686.95 & 86.59 & 313.25 & 709.77 \\
\hline
\end{tabular}

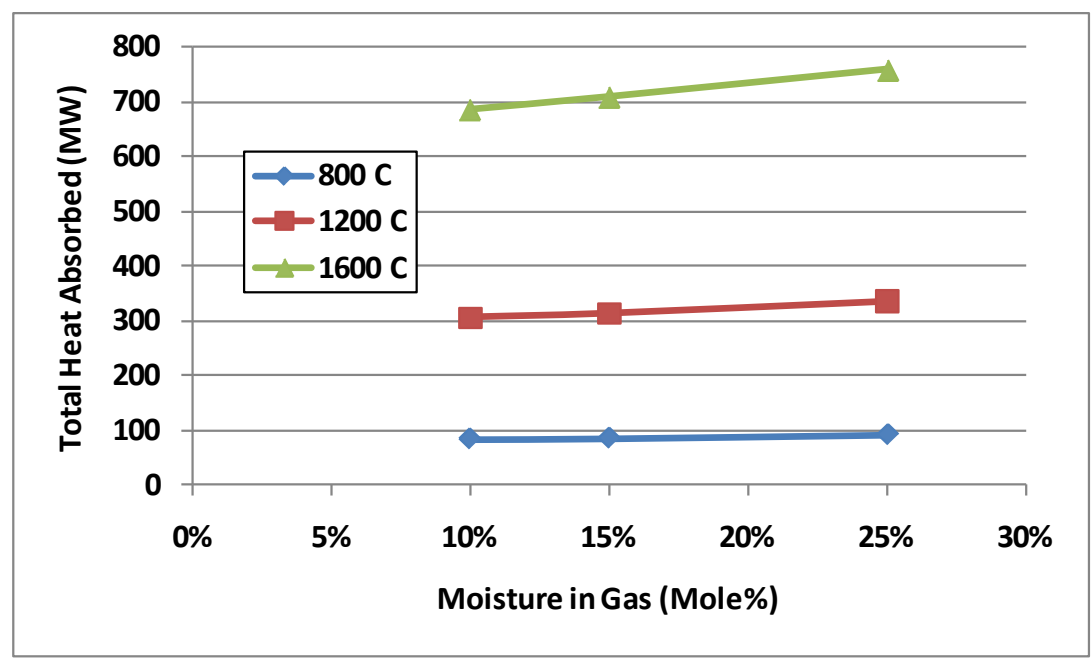

Figure 4.10-12: Calculated heat absorption as a function of flue gas temperature and moisture content. 
This suggests that successful modeling of oxy-combustion retrofits should place a greater emphasis on accurate calculation of flame temperature than gas phase radiative properties. Although there is disagreement in radiative property models, the variation in these properties has much less impact on heat transfer than variation in flame temperature (not surprising given the fourth-order dependence of radiative transfer on temperature).

Table 4.10-3 summarizes the heat transfer calculations from Vattenfall. Similar to the Glacier calculations, the Fluent heat transfer calculations looked reasonable: increased heat transfer when increasing the temperature and keeping the concentration distribution constant. The results for air and dry FGR cases were very similar, whereas the heat transfer of wet FGR was higher than that of dry FGR for the same temperature. The high heat transfer for wet FGR and comparable results of dry FGR/air cases were consistent with the high influence of water and low influence of $\mathrm{CO}_{2}$ on emissivity factor calculation.

Table 4.10-3: Heat Transfer Values Calculated with Fluent for the Simplified Furnace Enclosure.

\begin{tabular}{|l|c|c|c|c|c|c|c|c|c|}
\hline & Wet FGR $t=800 \mathrm{C}$ & Wet FGR $\mathrm{t}=1200 \mathrm{C}$ & Wet FGR $=1600 \mathrm{C}$ & Dry FGR $\mathrm{t}=800 \mathrm{C}$ & Dry FGR $\mathrm{t}=1200 \mathrm{C}$ & Dry FGRt $=1600 \mathrm{C}$ & Air $\mathrm{t}=300 \mathrm{C}$ & Air $t=1200 \mathrm{C}$ & Air $\mathrm{t}=1600 \mathrm{C}$ \\
\hline \hline Top Wall & 4,13 & 14,1 & 31,4 & 3,9 & 13,13 & 29,32 & 3,95 & 13,43 & 29,8 \\
\hline Bottom Wall & 5,16 & 18,26 & 41,1 & 4,88 & 17,07 & 38,45 & 4,93 & 17,39 & 39,1 \\
\hline East Wall & 20,3 & 71 & 157,2 & 19,19 & 66,44 & 147,19 & 19,4 & 67,68 & 149,7 \\
\hline West Wall & 18,58 & 64,9 & 143,6 & 17,6 & 60,73 & 134,6 & 17,77 & 61,9 & 136,85 \\
\hline North Wall & 19,95 & 69,7 & 154,3 & 18,87 & 65,24 & 144,51 & 19,08 & 66,45 & 146,96 \\
\hline South Wall & 19,95 & 69,7 & 154,3 & 18,87 & 65,24 & 144,51 & 19,08 & 66,45 & 146,96 \\
\hline Superheaters & 1,7 & 11,85 & 34,25 & 1,48 & 10,8 & 30,99 & 1,52 & 11,08 & 31,8 \\
\hline Total Heat & 89,77 & 319,51 & 716,15 & 84,79 & 298,75 & 669,57 & 85,73 & 304,38 & 681,17 \\
\hline
\end{tabular}

The difference in predicted heat fluxes and total heat transfer between Glacier and Fluent were consistent with the differences between the calculated emissivities. Glacier predicted higher gas emissivities and higher heat fluxes. The differences in gas-phase heat transfer results between Glacier and Fluent were less than six percent.

In addition to the isothermal calculations, two non-isothermal scenarios were studied. In these cases, the flue gas temperature in the furnace was prescribed such that the lower furnace (below $28 \mathrm{~m}$ elevation) was fixed at $1600^{\circ} \mathrm{C}$ and the upper furnace (above $28 \mathrm{~m}$ elevation) was fixed at $1200^{\circ} \mathrm{C}$. All surface properties remained the same as in the isothermal cases. Two gas compositions were compared, the airbased flue gas and the wet FGR flue gas; gas composition was uniform throughout the furnace.

Figure 4.10-13 shows the resulting heat transfer for the two flue gases as calculated with the Glacier code. As expected the heat transfer in the lower furnace was significantly higher than in the upper furnace. There was an approximately seven percent difference in the heat transfer between the two flue gas cases. The wet FGR case was higher due to the higher calculated emissivities. Fluent results for the same two cases were again slightly lower but within six percent of the Glacier calculations. 


\begin{tabular}{|l|c|c|}
\hline Parameter & $\begin{array}{c}\text { 1600C/1200C } \\
\text { wetFGR }\end{array}$ & $\begin{array}{c}\text { 1600C/1200C } \\
\text { Air }\end{array}$ \\
\hline Gas Emissivity & $0.547 / 0.599$ & $0.466 / 0.522$ \\
\hline Absorp. Coeff. (1/m) & $0.067 / 0.077$ & $0.053 / 0.052$ \\
\hline Top Wall HT (MW) & 15.15 & 14.24 \\
\hline Bottom Wall HT (MW) & 43.05 & 40.06 \\
\hline East Wall HT (MW) & 122.43 & 114.53 \\
\hline West Wall HT (MW) & 115.88 & 108.48 \\
\hline North Wall HT (MW) & 121.02 & 113.24 \\
\hline South Wall HT (MW) & 121.02 & 113.24 \\
\hline Superheater HT (MW) & 12.94 & 11.84 \\
\hline Total Heat Absorbed (MW) & 551.49 & 515.63 \\
\hline
\end{tabular}

Figure 4.10-13: Glacier calculated heat transfer (leaving the domain) for non-isothermal flue gas temperature profile.

\subsubsection{Particle-phase Radiation Properties}

Similar to the gas-phase radiation property study, particle-phase radiation absorption coefficients were calculated based on prescribed particle temperature, diameter, ash mass fraction, and number density using respective techniques from Glacier and Fluent. Absorption coefficients for six different particle conditions were calculated. Results from the Glacier and Fluent techniques were compared, and the relative magnitude of the absorption coefficients will be compared with the gas phase absorption coefficients.

Particle scattering effects could also be calculated with this approach, however, since consideration of particle in-scattering is computationally significant and much of the scattering in coal-fired boilers is forward scattering, evaluation of scattering properties was not included in this study.

The particle absorption coefficient, $k_{a p}$, is calculated in Glacier from the relation:

$$
k_{a p}=\left(\frac{\pi}{4}\right) \sum_{j}\left(Q_{a, j} n_{j} d_{j}^{2}\right)_{p a r t}
$$

where $Q_{a}$ is the particle absorption efficiency, $n$ is the particle number density, $d$ is the particle diameter, and the summation $j$ is over all particle sizes and types (only one size for each case studied here). Absorption efficiency is calculated based on particle diameter, temperature, current and initial ash mass fraction, and coal and ash particle refractive indices. The absorption efficiency is interpolated between efficiencies for coal and ash, respectively, based on the current and initial ash mass fraction.

The particle absorption coefficient, or absorptivity, is calculated in Fluent from the relation:

$$
a_{p}=\frac{3}{2} \cdot \frac{\varepsilon_{p n}}{\rho} \cdot \frac{C}{d}
$$

where $\varepsilon_{p n}$ is the particle emissivity, $C$ is the particle concentration in $\mathrm{kg} / \mathrm{m}^{3}, \rho$ is the particle density and $d$ is the particle diameter.

Particle properties were specified for two combustion conditions, one representing particles in the furnace burner zone where only moisture and volatiles have been released, and the other representing particles in 
the upper furnace where all moisture, volatiles, and char have been released. Three particle diameters (30, $60,90 \mu \mathrm{m}$ ) were studied for each of these conditions. These particle properties are summarized in Table 4.10-4, which also describes the six property configurations calculated.

Table 4.10-4: Specified Particle Properties for Absorption Coefficient Study.

\begin{tabular}{|l|l|l|}
\hline Property & Cases 1-3 (burner zone) & Cases 4-6 (burnout) \\
\hline Particle Temperature (C) & $1800 \mathrm{C}$ & $1100 \mathrm{C}$ \\
\hline $\begin{array}{l}\text { Initial Ash Mass Fraction } \\
\text { (ash mass/total particle mass) }\end{array}$ & 0.047 & 0.047 \\
\hline $\begin{array}{l}\text { Current Ash Mass Fraction } \\
\text { (ash mass /(current particle } \\
\text { mass)) }=\text { (ash/(ash+char)) }\end{array}$ & 0.109 & 1.0 \\
\hline Particle Density & $1300 \mathrm{~kg} / \mathrm{m}^{3}$ & $1300 \mathrm{~kg} / \mathrm{m}^{3}$ \\
\hline Mass Density & $0.1 \mathrm{~kg} / \mathrm{m}^{3}$ & $0.001 \mathrm{~kg} / \mathrm{m}^{3}$ \\
\hline Particle Diameter & $30,60,100 \mu \mathrm{m}$ & $30,60,100 \mu \mathrm{m}$ \\
\hline Number Density & Calculated & Calculated \\
\hline & $\begin{array}{l}\text { Cases } 1-3 \text { represent particles } \\
\text { in the burner zone, where } \\
\text { moisture and volatiles have } \\
\text { been released }\end{array}$ & $\begin{array}{l}\text { Cases } 4-6 \text { represent particles } \\
\text { in the upper furnace, where } \\
\text { all moisture, volatiles and } \\
\text { char have been released }\end{array}$ \\
\hline
\end{tabular}

The particle properties were based on a German lignite coal for which Vattenfall supplied the properties as shown in Table 4.10-5.

Table 4.10-5: Properties of German Lausitz Lignite.

\begin{tabular}{|l|c|}
\hline Proximate Analysis & Weight \% \\
\hline Volatile & 45.1 \\
\hline Fixed Carbon & 38.5 \\
\hline Ash & 4.7 \\
\hline Moisture & 11.7 \\
\hline & \\
\hline Coal Refractive Index & $\mathrm{n}=1.70, \mathrm{k}=0.066$ \\
\hline Ash Refractive Index & $\mathrm{n}=1.50, \mathrm{k}=0.02$ \\
\hline
\end{tabular}

Results from the Glacier calculations are shown in Table 4.10-6. These results showed that the particle absorption coefficient was a strong function of particle mass density (and number density), the particle absorption coefficient was a weaker function of particle diameter, and that the radiative emission from particles is a strong function of absorption coefficient and particle temperature. The strong dependence on mass density resulted in much greater absorption coefficients in the lower furnace (burner zone) than in the upper furnace where the mass density of the burned out particles was two orders of magnitude lower.

The last line of Table 4.10-6 shows that the combined effect of the hotter particle temperature and higher absorption coefficients resulted in particle volumetric emission values that were 500 times greater in the 
lower furnace than in the upper furnace. This was qualitatively consistent with observed boiler operation where the heat transfer in the lower furnace is significantly higher than the upper furnace.

Table 4.10-6: Predicted Particle Absorption Coefficient from Glacier.

\begin{tabular}{|l|c|c|c|c|c|c|}
\hline \multicolumn{1}{|c|}{ Parameter } & Case 1 & Case 2 & Case 3 & Case 4 & Case 5 & Case 6 \\
\hline Particle Temp (C) & 1800 & 1800 & 1800 & 1100 & 1100 & 1100 \\
\hline Initial Ash Mass Fraction (AFRACO) & 0.047 & 0.047 & 0.047 & 0.047 & 0.047 & 0.047 \\
\hline Current Ash Mass Fraction (OMEGAA) & 0.109 & 0.109 & 0.109 & 1 & 1 & 1 \\
\hline Particle Density (kg/m3) & 1300 & 1300 & 1300 & 1300 & 1300 & 1300 \\
\hline Mass Density (kg/m3) & 0.1 & 0.1 & 0.1 & 0.001 & 0.001 & 0.001 \\
\hline Particle Diameter (um) & 30 & 60 & 100 & 30 & 60 & 100 \\
\hline Number density (\# particles/m3) & $5.44 \mathrm{E}+09$ & $6.80 \mathrm{E}+08$ & $1.47 \mathrm{E}+08$ & $5.44 \mathrm{E}+07$ & $6.80 \mathrm{E}+06$ & $1.47 \mathrm{E}+06$ \\
\hline Particle absorption coefficient (1/m) & $\mathbf{3 . 7 4}$ & $\mathbf{1 . 8}$ & $\mathbf{1 . 0 6}$ & $\mathbf{0 . 0 3 5}$ & $\mathbf{0 . 0 1 8}$ & $\mathbf{0 . 0 1 1}$ \\
\hline Particle volumetric emission (W/m3) & 1246504 & 600648 & 352837 & 2256 & 1175 & 704 \\
\hline
\end{tabular}

The results from the Fluent calculations are shown in Table 4.10-7 and Table 4.10-8. Table 4.10-7 results assumed the particle emissivity was set to a constant value of 0.9 . Table $4.10-8$ results assumed the particle emissivity was calculated according to Mie theory.

Table 4.10-7: Predicted Particle Absorption Coefficient from Fluent with Constant Particle Emissivity.

\begin{tabular}{|c|c|c|c|c|c|c|}
\hline Quantity & Case 1 & Case 2 & Case 3 & Case 4 & Case 5 & Case 6 \\
\hline Particle temperature t [C] & 1800 & 1800 & 1800 & 1100 & 1100 & 1100 \\
\hline Volatile [\%] & 0 & 0 & 0 & 0 & 0 & 0 \\
\hline Ash [\%] & 0,109 & 0,109 & 0,109 & 1 & 1 & 1 \\
\hline Char [\%] & 0,891 & 0,891 & 0,891 & 0 & 0 & 0 \\
\hline Particle density [kg/m3] & 1300 & 1300 & 1300 & 1300 & 1300 & 1300 \\
\hline Mass density [kg/m3] & 0,1 & 0,1 & 0,1 & 0,001 & 0,001 & 0,001 \\
\hline Particle diameter [mik.] & 30 & 60 & 100 & 30 & 60 & 100 \\
\hline Absorptivity (FLUENT) & $\mathbf{3 , 4 8}$ & $\mathbf{1 , 7 3}$ & $\mathbf{1 , 0 4}$ & $\mathbf{0 , 0 3 5}$ & $\mathbf{0 , 0 1 7 3}$ & $\mathbf{0 , 0 1}$ \\
\hline
\end{tabular}


Table 4.10-8: Predicted Particle Absorption Coefficient from Fluent with Particle Emissivity from Mie Theory.

\begin{tabular}{|c|c|c|c|c|c|c|}
\hline Quantity & Case 1 & Case 2 & Case 3 & Case 4 & Case 5 & Case 6 \\
\hline Particle temperature t [C] & 1800 & 1800 & 1800 & 1100 & 1100 & 1100 \\
\hline Volatile [\%] & 0 & 0 & 0 & 0 & 0 & 0 \\
\hline Ash [\%] & 0,109 & 0,109 & 0,109 & 1 & 1 & 1 \\
\hline Char [\%] & 0,891 & 0,891 & 0,891 & 0 & 0 & 0 \\
\hline Particle density [kg/m3] & 1300 & 1300 & 1300 & 1300 & 1300 & 1300 \\
\hline Mass density [kg/m3] & 0,1 & 0,1 & 0,1 & 0,001 & 0,001 & 0,001 \\
\hline Particle diameter [mik.] & 30 & 60 & 100 & 30 & 60 & 100 \\
\hline Absorptivity (FLUENT) ** & $\mathbf{3 , 3 3}$ & $\mathbf{1 , 5 5}$ & $\mathbf{0 , 9}$ & $\mathbf{0 , 0 3 5}$ & $\mathbf{0 , 0 1 8}$ & $\mathbf{0 , 0 1 1}$ \\
\hline
\end{tabular}

The values of particle absorptivity or absorption coefficient calculated in Glacier were very similar to those of Fluent default model (based on constant value of particle emissivity). The values of particle absorptivity, calculated with help of Mie theory in Fluent, for high particle temperatures were lower than those of Glacier.

These results suggest that, similar to gas phase radiative property results, accurate simulation of the particle-based heat transfer depends more on accurate prediction of particle temperature, burnout and mass density than on differences in particle property models.

\subsubsection{Combined Particle and Gas-phase Heat Transfer Comparison}

Using the same simplified furnace enclosure (see Figure 4.10-10) as that used for the gas-phase heat flux comparisons, uniform particle temperature, diameter, ash mass fraction, and number density were added to the prescribed gas-phase properties for each computational cell in the furnace enclosure and the radiative transfer calculated using Glacier and Fluent, respectively. Results for heat absorption, incident heat flux profiles and net heat flux profiles were compared.

Four cases (labeled as Cases 7-10) with uniform properties throughout the furnace were studied. The properties used for each case are summarized in Table 4.10-9. All cases assumed a fixed particle diameter of $60 \mu \mathrm{m}, 1300 \mathrm{~kg} / \mathrm{m}^{3}$ particle density and fixed gas composition based on the wet FGR flue gas $\left(7 \% \mathrm{~N}_{2}\right.$, $25 \% \mathrm{H}_{2} \mathrm{O}, 65 \% \mathrm{CO}_{2}, 3 \% \mathrm{O}_{2}$, mole basis). The surface conditions for the simplified enclosure were the same as used for the gas-phase calculations, i.e., wall emissivity of 0.6 , steam temperature of $380^{\circ} \mathrm{C}$, wall resistance of $0.00333 \mathrm{~m}^{2}-\mathrm{K} / \mathrm{W}$, superheat tube emissivity of 0.75 , superheat fixed tube temperature of $600^{\circ} \mathrm{C}$.

Table 4.10-9: Properties used for Combined Particle and Gas-phase Heat Transfer Calculations.

\begin{tabular}{|c|c|c|c|c|}
\hline Case & Part Temp (C) & Ash Mass Fraction & Mass Density $(\mathrm{kg} / \mathrm{m} 3)$ & Gas Temp (C) \\
\hline 7 & 1800 & 0.109 & 0.1 & 1200 \\
\hline 8 & 1800 & 0.109 & 0.1 & 1600 \\
\hline 9 & 1100 & 1.0 & 0.001 & 1200 \\
\hline 10 & 1100 & 1.0 & 0.001 & 1600 \\
\hline
\end{tabular}


Table 4.10-10 summarizes results from the Glacier calculations for the four cases. These results showed:

- For high particle temperatures and mass density, particle emissions were 90x and 40x greater than gas emission for $1200^{\circ} \mathrm{C}$ and $1600^{\circ} \mathrm{C}$ gas, respectively.

- For lower particle temperatures and mass density, particle emissions were 0.18 and 0.08 times gas emission for $1200^{\circ} \mathrm{C}$ and $1600^{\circ} \mathrm{C}$ gas, respectively.

- When particle radiation dominated, gas changes had little impact.

This suggests that particle radiation may dominate in the lower part of the furnace whereas gas radiation may dominate (or at least have a significant impact) in the upper part of the furnace (for the simple example studied here). For very high particle absorption coefficients, wall flux was nearly uniform, which suggests each near wall cell volume was emitting an equal amount of energy to the wall and that emitted energy from the center of the furnace was absorbed (and re-emitted) before reaching furnace walls.

Table 4.10-10: Predicted Particle and Gas-phase Heat Transfer from Glacier.

\begin{tabular}{|l|c|c|c|c|}
\hline Parameter & Case 7 & Case 8 & Case 9 & Case 10 \\
\hline Gas Emissivity & 0.599 & 0.547 & 0.599 & 0.547 \\
\hline Gas Absorp. Coeff. (1/m) & 0.077 & 0.067 & 0.077 & 0.067 \\
\hline Gas volumetric emission (W/m3) & 6538 & 14790 & 6538 & 14790 \\
\hline Particle Absorp. Coeff. (1/m) & 1.8 & 1.8 & 0.018 & 0.018 \\
\hline Particle vol. emission (W/m3) & 600648 & 600648 & 1175 & 1175 \\
\hline Top Wall HT (MW) & 56.57 & 57.2 & 15.06 & 30.97 \\
\hline Bottom Wall HT (MW) & 70.93 & 71.73 & 19.42 & 40.2 \\
\hline East Wall HT (MW) & 260.73 & 263.66 & 75.72 & 154.36 \\
\hline West Wall HT (MW) & 236.88 & 239.54 & 69.05 & 140.65 \\
\hline North Wall HT (MW) & 255.9 & 258.77 & 74.27 & 151.35 \\
\hline South Wall HT (MW) & 255.9 & 258.77 & 74.27 & 151.35 \\
\hline Superheater HT (MW) & 86.7 & 88.42 & 12.97 & 33.65 \\
\hline Total Heat Absorbed (MW) & 1223.61 & 1238.09 & 340.76 & 702.53 \\
\hline
\end{tabular}

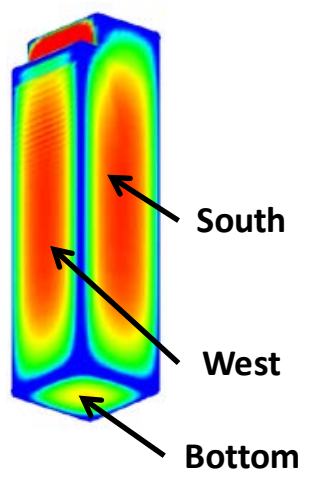

Fluent results are shown in Table 4.10-11, Table 4.10-12 and Table 4.10-13. The differences in these results were the basis for the gas emissivity and particle emissivity calculations. In Table 4.10-11 results, the gas emissivity was calculated with the exponential wide band model and the particle emissivity was set to constant value of 0.9 . Table 4.10-12 results were based on the gas emissivity taken from the Glacier calculations and the particle emissivity was again set to a constant value of 0.9 . Table $4.10-13$ results were based on the gas emissivity calculated with the exponential wide band model and the particle emissivity calculated with Mie theory. All Fluent heat transfer results in the tables have units of MW. 
Table 4.10-11: Predicted Particle and Gas-phase Heat Transfer from Fluent Using EWBM and Constant Particle Emissivity.

\begin{tabular}{|c|c|c|c|c|}
\hline Parameter & Case 7 & Case 8 & Case 9 & Case 10 \\
\hline Top Wall HT & 56,51 & 55,95 & 14,34 & 29,04 \\
\hline Bottom Wall HT & 71,73 & 71,58 & 18,53 & 37,83 \\
\hline East Wall HT & 263,13 & 262,8 & 72,06 & 145,18 \\
\hline West Wall HT & 238,61 & 238,03 & 65,78 & 132,43 \\
\hline North Wall HT & 258,0 & 258,0 & 70,76 & 142,4 \\
\hline South Wall HT & 258,0 & 258,0 & 70,76 & 142,4 \\
\hline Superheater HT & 80,34 & 77,1 & 12,15 & 30,79 \\
\hline Total HT* & 1226,3 & 1221,5 & 324,38 & 660,1 \\
\hline
\end{tabular}

Table 4.10-12: Predicted Particle and Gas-phase Heat Transfer from FLUENT Using Glacier Gas Emissivity and Constant Particle Emissivity.

\begin{tabular}{|c|c|c|c|c|}
\hline Parameter & Case 7 & Case 8 & Case 9 & Case 10 \\
\hline Top Wall HT & 55,34 & 55,97 & 14,96 & 31,05 \\
\hline Bottom Wall HT & 70,67 & 71,5 & 19,32 & 40,35 \\
\hline East Wall HT & 259,57 & 262,6 & 75,02 & 154,5 \\
\hline West Wall HT & 235,1 & 237,83 & 68,42 & 140,77 \\
\hline North Wall HT & 254,5 & 257,5 & 73,60 & 151,5 \\
\hline South Wall HT & 254,5 & 257,5 & 73,60 & 151,5 \\
\hline Superheater HT & 75,6 & 77,2 & 12,88 & 33,86 \\
\hline Total HT & 1205,3 & 1220,1 & 337,8 & 703,5 \\
\hline
\end{tabular}


Table 4.10-13: Predicted Particle and Gas-phase Heat Transfer from Fluent Using EWBM and Mie Theory Particle Emissivity.

\begin{tabular}{|c|c|c|c|c|}
\hline Parameter & Case 7 & Case 8 & Case 9 & Case 10 \\
\hline Top Wall HT & 55,31 & 55,98 & 14,3 & 28,95 \\
\hline Bottom Wall HT & 70,74 & 71,57 & 18,47 & 37,69 \\
\hline East Wall HT & 259,84 & 262,86 & 71,87 & 144,58 \\
\hline West Wall HT & 235,35 & 238,1 & 65,6 & 131,88 \\
\hline North Wall HT & 255,0 & 258,0 & 70,5 & 141,8 \\
\hline South Wall HT & 255,0 & 258,0 & 70,5 & 141,8 \\
\hline Superheater HT & 76,27 & 77,97 & 12,12 & 30,65 \\
\hline Total HT $^{\star}$ & 1207,5 & 1222,5 & 323,4 & 657,4 \\
\hline
\end{tabular}

Fluent results showed that predicted heat transfer values varied less than $10 \%$ across the three property models studied. The largest differences were when the gas emissivity values from Glacier were used in the calculations. The high gas temperature, high particle temperature, high mass density cases gave very similar results for all three cases.

Not surprisingly, Fluent results with Glacier gas emissivity and constant particle emissivity were closest to the Glacier simulations. Since the gas emissivities were the same and the constant particle emissivity model produced absorption coefficients similar to Glacier, the Fluent results for this case were expected to be similar to Glacier. Differences in the results can be attributed to slight variations in particle properties and in the methodologies in which the radiative transfer equations were solved in Glacier and Fluent, respectively. This showed up most notably in the heat transfer to the superheat tubes (or box). Fluent predicted approximately 10\% lower heat transfer at the superheater than predicted by Glacier. This was the most geometrically complex region of the simplified furnace, and would be most susceptible to differences in how the discrete ordinates method was implemented in the two codes (e.g., ordinate directions, ordinate weighting factors, radiation intensity differencing schemes, radiation intensity treatment at surfaces). Predicted heat transfer to surfaces other than the superheater agreed to within 1$2 \%$.

Beyond the comparison between radiation models, the heat transfer results confirmed the large difference in heat transfer between the lower furnace (with hot coal particles) and the upper furnace (with cooler ash particles). Fluent results confirmed the Glacier results that for high particle loadings and hot particles (i.e., lower furnace), particle radiation dominates the heat transfer, and that for lower particle loadings and lower particle temperatures (e.g., upper furnace), gas radiation also plays a significant role (as particle radiation drops off).

In order to better understand radiation behavior between lower and upper furnace, one additional Glacier case was studied in which the furnace was split with hotter burning particles in the lower furnace (Case 8 conditions) and cooler ash particles in the upper furnace (Case 9 conditions). The results of this calculation are shown in Table 4.10-14.

Predicted heat transfer to the furnace walls was between the results for Case 8 and Case 9, with the top wall mimicking Case 9 results (upper furnace properties based on Case 9) and the bottom wall mimicking Case 8 results (lower furnace properties based on Case 8). Superheater heat transfer was also very similar 
to that in Case 9. The other walls which spanned both upper and lower furnace saw heat transfer roughly averaged between the two cases.

Table 4.10-14: Glacier Heat Transfer for Split Furnace Properties.

\begin{tabular}{|c|c|c|}
\hline Parameter & $\begin{array}{l}\text { Case } 11 \text { Lower } \\
\text { furnace }\end{array}$ & $\begin{array}{l}\text { Case } 11 \text { Upper } \\
\text { furnace }\end{array}$ \\
\hline Gas Emissivity & 0.547 & 0.599 \\
\hline Gas Absorp. Coeff. (1/m) & 0.0666 & 0.077 \\
\hline Gas volumetric emission (W/m3) & 14790 & 6538 \\
\hline Particle Absorp. Coeff. $(1 / \mathrm{m})$ & 1.802 & 0.0183 \\
\hline Particle vol. emission (W/m3) & 600648 & 1175 \\
\hline Top Wall HT (MW) & \multicolumn{2}{|c|}{15.58} \\
\hline Bottom Wall HT (MW) & \multicolumn{2}{|c|}{71.74} \\
\hline East Wall HT (MW) & \multicolumn{2}{|c|}{179.9} \\
\hline West Wall HT (MW) & \multicolumn{2}{|c|}{173.16} \\
\hline North Wall HT (MW) & \multicolumn{2}{|c|}{178.44} \\
\hline South Wall HT (MW) & \multicolumn{2}{|c|}{178.44} \\
\hline Superheater HT (MW) & \multicolumn{2}{|c|}{13.46} \\
\hline Total Heat Absorbed (MW) & \multicolumn{2}{|c|}{810.72} \\
\hline
\end{tabular}

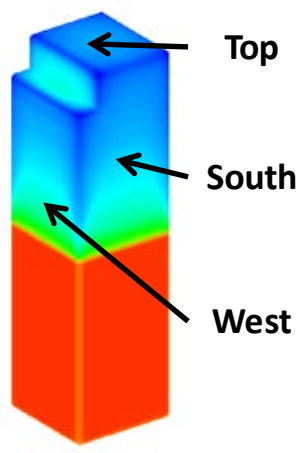

Further analysis of the results showed that the heat transfer in the lower furnace was providing energy to the participating medium (gas and particles) in the upper furnace. This is illustrated in Figure 4.10-14 where the radiative flux divergence (a measure of the radiative energy absorbed or emitted in a local region) is positive in the lower furnace (emitted energy) and negative in the upper furnace (absorbed energy). In a full CFD simulation, this would mean that the medium in the upper furnace would be heated by the radiation from the lower furnace.
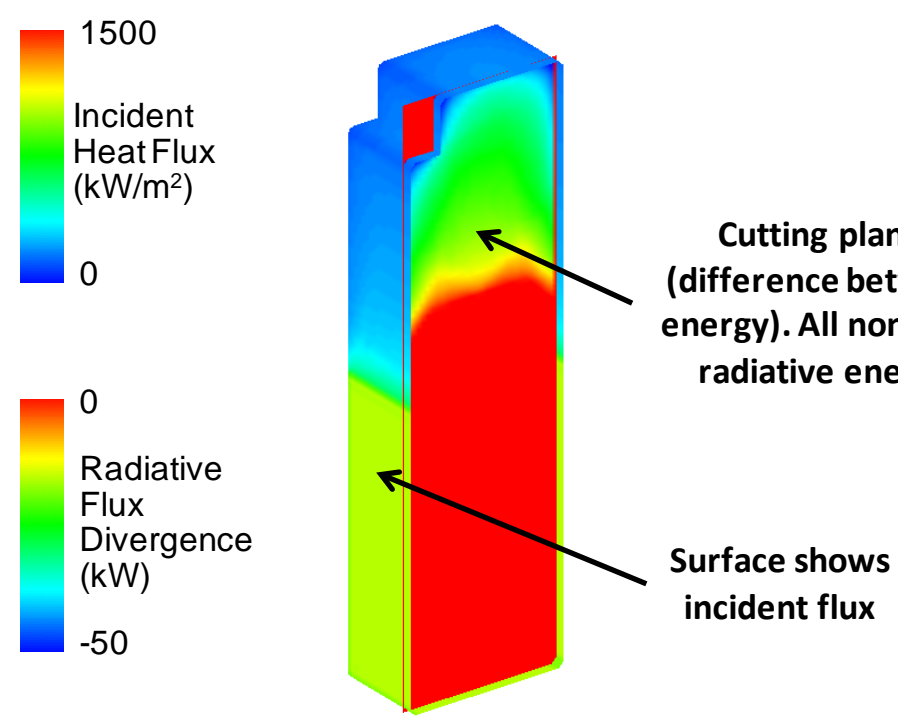

Figure 4.10-14: Predicted incident flux and radiative flux divergence for split furnace case. 


\subsubsection{Radiation Property Comparison Summary}

A series of calculations were performed to compare gas and particle radiative property calculation methods and the impact of these differences on heat transfer predictions. The basis for the comparison was calculations from REI's in-house CFD code Glacier and Vattenfall's version of the commercial CFD code Fluent. The results of this comparison were as follows:

- Fluent exponential wide band model (EWBM) predicted gas emissivities lower than the Glacier RADCAL narrow band model (NBM); the greatest differences of $~ 10 \%$ were for longer path length (20 m) and higher $\mathrm{H}_{2} \mathrm{O}$ concentrations. This was consistent with some earlier work done by REI comparing NBM and REI EWBM. The existing weighted sum of gray gases model (WSGGM) in Fluent predicted consistently lower gas emissivities for oxy-combustion conditions.

- Wet FGR flue gas had $~ 10-20 \%$ higher emissivity than air-based flue gas; the magnitude of air and wet FGR emissivity differences was similar across range of temperature and path length. The differences in gas emissivities for flue gases from air-fired and oxy-fired conditions was due primarily to the moisture content of the gases; $\mathrm{CO}_{2}$ concentration had a secondary effect.

- Dry FGR flue gas had gas emissivity similar to air. This suggests that drying the recycle gas produced during oxy-combustion could produce gas emissivities similar to air emissivities.

- The differences in gas-phase heat transfer results for isothermal and non-isothermal gas cases between Glacier and Fluent were less than 6\%: the largest differences are in case of wet FGR for T $=1600^{\circ} \mathrm{C} / 1200^{\circ} \mathrm{C}$. These differences were due to different methodologies used to calculate the local gas emissivity. When using the emissivity value calculated in Glacier as an input to Fluent, there was almost no difference in calculated wall heat transfer.

- Heat absorption for gas-phase heat transfer was much more dependent on gas temperature than moisture content (gas emissivity).

- The values of particle absorption coefficient calculated in Glacier were similar to those of Fluent default model (based on constant value of particle emissivity of 0.9). The values of particle absorption coefficient for high particle temperatures, calculated with help of Mie theory in Fluent, were lower than those of Glacier.

- Particle absorption coefficient was a strong function of particle mass density (and number density); particle absorption coefficient was a weaker function of particle diameter. Radiative emission from particles was a strong function of absorption coefficient (mass density) and particle temperature.

- In the lower furnace, particle radiation dominated gas radiation due to hot particles and higher mass density (e.g., particle loading). In the upper furnace, the lower particle temperature and lower mass density (e.g., particle loading) allowed gas radiation to play a more significant role.

- For heat transfer predictions with combined gas and particle-phase effects, Fluent and Glacier predicted heat transfer to furnace walls was very similar (1-2\% difference). Fluent predicted $~ 10 \%$ lower heat transfer at the superheaters than Glacier, possibly due to different treatment of boundary conditions or use of different ordinate weightings or coordinates.

- Overall, the radiative properties calculated by Fluent and Glacier were quite similar. This suggests that any differences observed between Fluent and Glacier heat transfer predictions for a full CFD case are likely to be attributable to combustion effects (particle dispersion, mixing, reaction rates, etc.) rather than to radiation calculations. 


\subsection{Mercury Additive Testing}

\subsubsection{Introduction}

Continued research during the course of the program identified that mercury emissions are of particular interest in oxy-fired combustion systems. Mercury can amalgamate with aluminum surfaces in gas processing units (GPU) slated for use in $\mathrm{CO}_{2}$ separation processes at the back end of oxy-coal combustion systems (Coade and Coldham 2006). Such amalgamation can cause premature equipment degradation or failure. Even small amounts of mercury deposits can be significant for low temperature aluminum applications such as cryogenic heat exchangers. The behavior of mercury in oxy-coal systems is not well understood so quantifying the concentration and speciation of mercury as it exits the furnace and enters the GPU under controlled and un-controlled conditions is difficult. The first step in understanding mercury behavior in oxy-fired situations is validating traditional mercury measurement techniques under these different flue gas conditions. The behavior of mercury under various flue gas conditions also needs to be investigated. Traditional mercury control technologies are untested under oxy-fired conditions and mercury speciation/oxidation in high $\mathrm{CO}_{2}$ environments is not well understood. Variations in recycled flue gas properties may also change the effectiveness of different control technologies. Measurements conducted here in the L1500 pilot-scale furnace compare mercury speciation/partitioning and mercury capture effectiveness of different control technologies under air and oxy-fired conditions.

\subsubsection{Mercury Measurement Recalibration}

The purpose of this task was to investigate the potential biases of $\mathrm{Hg}$ measurement techniques, dependent on the nature of the flue-gas composition: air vs. oxy. EERC has performed some experimentation showing that wet-chemical conditioning systems may bias mercury concentration measurements by scrubbing $\mathrm{CO}_{2}$ from the flue gas stream (Pavlish 2011) (Zhuang, et al. 2011). This bias has not been observed in the measurements performed by REI so far. However, EERC uses a much higher concentration of $\mathrm{NaOH}$ in solution than that typically used at REI and a much faster solution refresh rate. To test this potential bias, a simple bench-scale experiment was set up where a synthesized gas of varying composition was sent directly to multiple $\mathrm{Hg}$ analyzers. The concentrations of $\mathrm{CO}_{2}, \mathrm{~N}_{2}, \mathrm{O}_{2}, \mathrm{NO}$, and $\mathrm{SO}_{2}$ were varied to determine the effect on mercury measurements. Either oxidized or elemental mercury (generated by a Hovacal Cal gas generator) was introduced to the synthesized gas stream. Mercury measurement techniques included: method 30B carbon traps, a wet-chemical conditioning system linked to a Tekran Hg analyzer and an Ohio-Lumex (OL) IRM thermal speciating analyzer.

\subsubsection{Introduction}

It is suspected that traditional mercury measurement methods may be adversely impacted by high $\mathrm{CO}_{2}$ in flue gas, such as would exist under oxy-firing conditions. EERC has performed some experimentation showing that wet-chemical conditioning systems may bias mercury concentration measurements by scrubbing $\mathrm{CO}_{2}$ from the flue gas stream (Pavlish 2011) (Zhuang, et al. 2011). In addition, the variability in average molecular weight of the flue gas stream can cause some mercury analyzers to volumize the sampled gas incorrectly. Initial mercury measurements by REI have indicated that these biases may be dependent on the specific conditions and settings of the conditioning system and analyzer. Different mercury measurement techniques such as carbon traps, wet chemical conditioning and thermal speciation need to be calibrated under oxy-coal firing conditions to determine the accuracy of the measurement systems over a range of flue gas and sampling conditions. This is critical to characterizing and controlling mercury behavior in oxy-retrofit systems with $\mathrm{CO}_{2}$ capture.

\subsubsection{Experimental}

Six simulated flue gas mixtures (summarized in Table 4.13-9) were studied in combination with three mercury measurement techniques. The flue gas mixtures were made using bottled gases. Mercury was 
added to the mixtures using a Hovacal Mercury Calibration Gas Generator. The Hovacal creates a mercury laden stream by evaporating a liquid $\mathrm{HgCl}_{2}$ solution into a carrier gas. This creates an oxidized mercury stream, which may be used directly or passed through a redox chamber to produce an elemental mercury stream. For this study, all three mercury measurement techniques were studied with both an elemental and an oxidized mercury stream. The average expected mercury concentration was 15.8 ug/dscm.

Table 4.11-1: Simulated flue gas mixtures.

\begin{tabular}{|c|c|c|c|c|c|c|}
\hline Flue Gas & \multicolumn{7}{|c|}{ Constituents } \\
\hline & $\mathbf{N}_{\mathbf{2}}$ & $\mathbf{O}_{\mathbf{2}}$ & $\mathbf{C O}_{\mathbf{2}}$ & $\mathbf{H}_{\mathbf{2}} \mathbf{O}$ & $\mathbf{S O}_{\mathbf{2}}$ & $\mathbf{N O}$ \\
\hline & $\mathrm{vol} \%$ & $\mathrm{vol} \%$ & $\mathrm{vol} \%$ & $\mathrm{vol} \%$ & $\mathrm{ppm}$ & $\mathrm{ppm}$ \\
\hline $\mathrm{A}$ & 94 & 0 & 0 & 6 & 0 & 0 \\
\hline $\mathrm{B}$ & 89 & 5 & 0 & 6 & 0 & 0 \\
\hline $\mathrm{C}$ & 77 & 5 & 12 & 6 & 0 & 0 \\
\hline $\mathrm{D}$ & 64 & 5 & 25 & 6 & 0 & 0 \\
\hline $\mathrm{E}$ & 9 & 5 & 80 & 6 & 0 & 0 \\
\hline $\mathrm{F}$ & 9 & 5 & 80 & 6 & 420 & 200 \\
\hline
\end{tabular}

The first mercury measurement technique involved a wet conditioning system followed by a Tekran 2537A mercury continuous emissions monitor (CEM). A diagram of this analysis method is shown in Figure 4.13-7. Two sample streams were pulled from the flue gas mixture and passed directly into a wetchemical conditioning system. Two sets of solutions were investigated as shown in Table 4.11-2. For the first set, one sample stream was bubbled through an acidic $2 \% \mathrm{SnCl}_{2}$ solution to reduce all mercury to the elemental form. This stream represented the total mercury concentration present in the system. The other stream was passed through a solution containing $10 \mathrm{wt} \% \mathrm{KCl}$ and $0.5 \mathrm{wt} \% \mathrm{Na}_{2} \mathrm{~S}_{2} \mathrm{O}_{3}$ to capture oxidized mercury. This stream represented the elemental mercury concentration present in the system. A 5wt\% $\mathrm{NaOH}$ solution was used to remove acid gases from each of the sample streams. For the second set of solutions, one stream was passed through a $2 \% \mathrm{SnCl}_{2} / 20 \% \mathrm{NaOH}$ solution (total mercury) and the other stream was passed through $5 \% \mathrm{Na}_{2} \mathrm{~S}_{2} \mathrm{O}_{3} / 20 \% \mathrm{NaOH}$ (elemental mercury). The second impingers on both sides were not used. All the impingers have a flow-through arrangement on the liquid side, so that solutions are continually being refreshed. The two sample streams then passed through a chiller to remove any water. A Tekran 2537A mercury analyzer was used to measure the elemental mercury concentration of each stream. A four-port sampler controlled which stream the Tekran Analyzer sampled. The CEM used a mass flow meter to measure the sample. This mass is then converted to volume using molecular weight (air molecular weight is used). Therefore, mercury concentrations calculated by the CEM will be biased for flue gases with significantly different molecular weight. All mercury readings from the CEM were corrected for the flue gas molecular weight. 


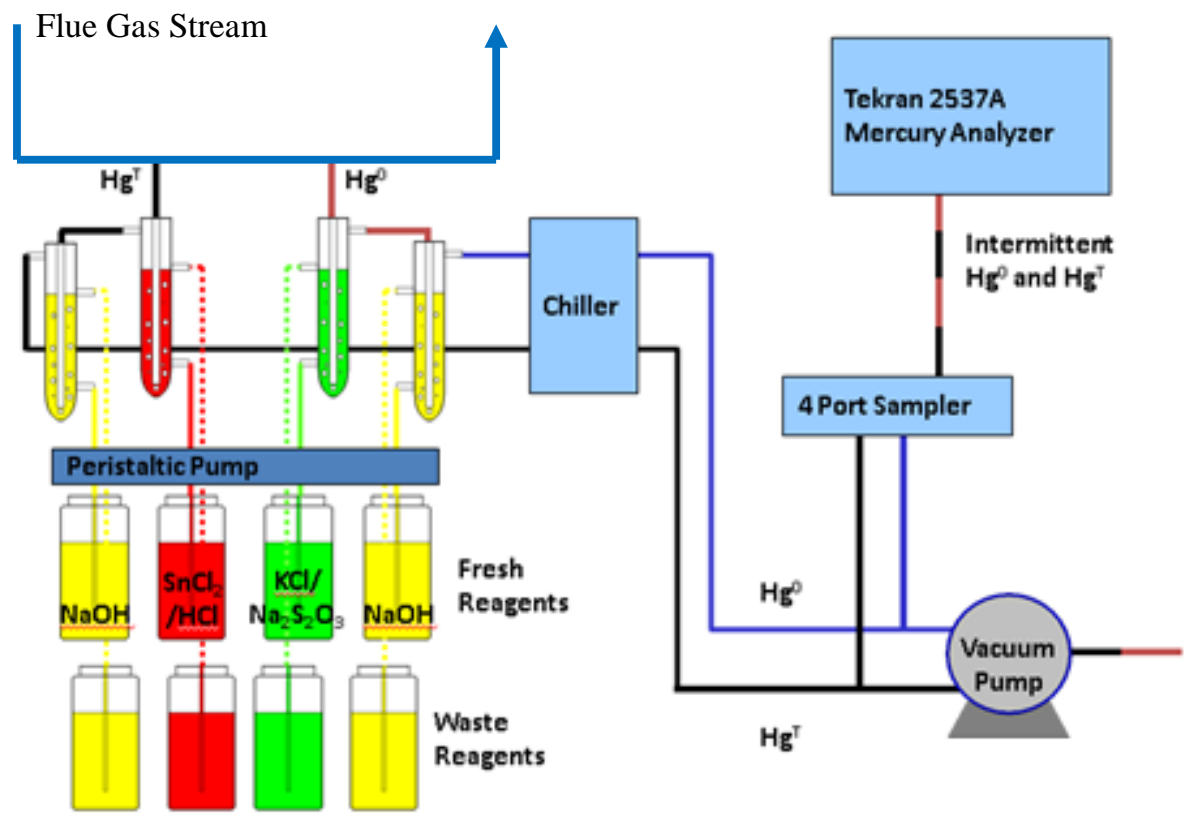

Figure 4.11-1: Wet conditioning system (solutions A) with Tekran CEM mercury measurement system.

Table 4.11-2: Solutions used in wet conditioning system.

\begin{tabular}{|c|c|c|c|c|}
\hline Solutions & \multicolumn{2}{|c|}{$\mathbf{H g}^{\top}$} & \multicolumn{2}{c|}{$\mathrm{Hg}^{\mathbf{0}}$} \\
\hline & First & Second & First & Second \\
\hline $\mathrm{A}$ & $\begin{array}{c}2 \% \mathrm{SnCl}_{2} / \\
3 \% \mathrm{HCl}^{\prime}\end{array}$ & $5 \% \mathrm{NaOH}$ & $\begin{array}{c}10 \% \mathrm{KCL} / \\
0.5 \% \mathrm{Na}_{2} \mathrm{~S}_{2} \mathrm{O}_{3}\end{array}$ & $5 \% \mathrm{NaOH}$ \\
\hline $\mathrm{B}$ & $\begin{array}{c}2 \% \mathrm{SnCl}_{2} / \\
20 \% \mathrm{NaOH}\end{array}$ & Not used & $\begin{array}{c}5 \% \mathrm{Na}_{2} \mathrm{~S}_{2} \mathrm{O}_{3} / \\
20 \% \mathrm{NaOH}\end{array}$ & Not used \\
\hline
\end{tabular}

The second mercury measurement technique studied was carbon traps. Two sample streams were taken from the flue gas mixture and passed into a temperature controlled box $\left(100^{\circ} \mathrm{C}\right)$ containing Ohio-Lumex carbon traps. The flue gas was then passed through a chiller and metered using Method 30B sampling equipment. This Method 30B sampling system is presented in Figure 4.11-2. A total of four carbon traps were taken at each condition: two parallel Ohio Lumex 30B carbon traps (total mercury only) followed by two parallel Ohio Lumex speciating carbon traps (elemental and oxidized mercury species). Traps are run in parallel to quantify error. All traps were analyzed for mercury by Ohio Lumex using their RA 915+ analyzer coupled with the RP-91C pyrolysis furnace. 


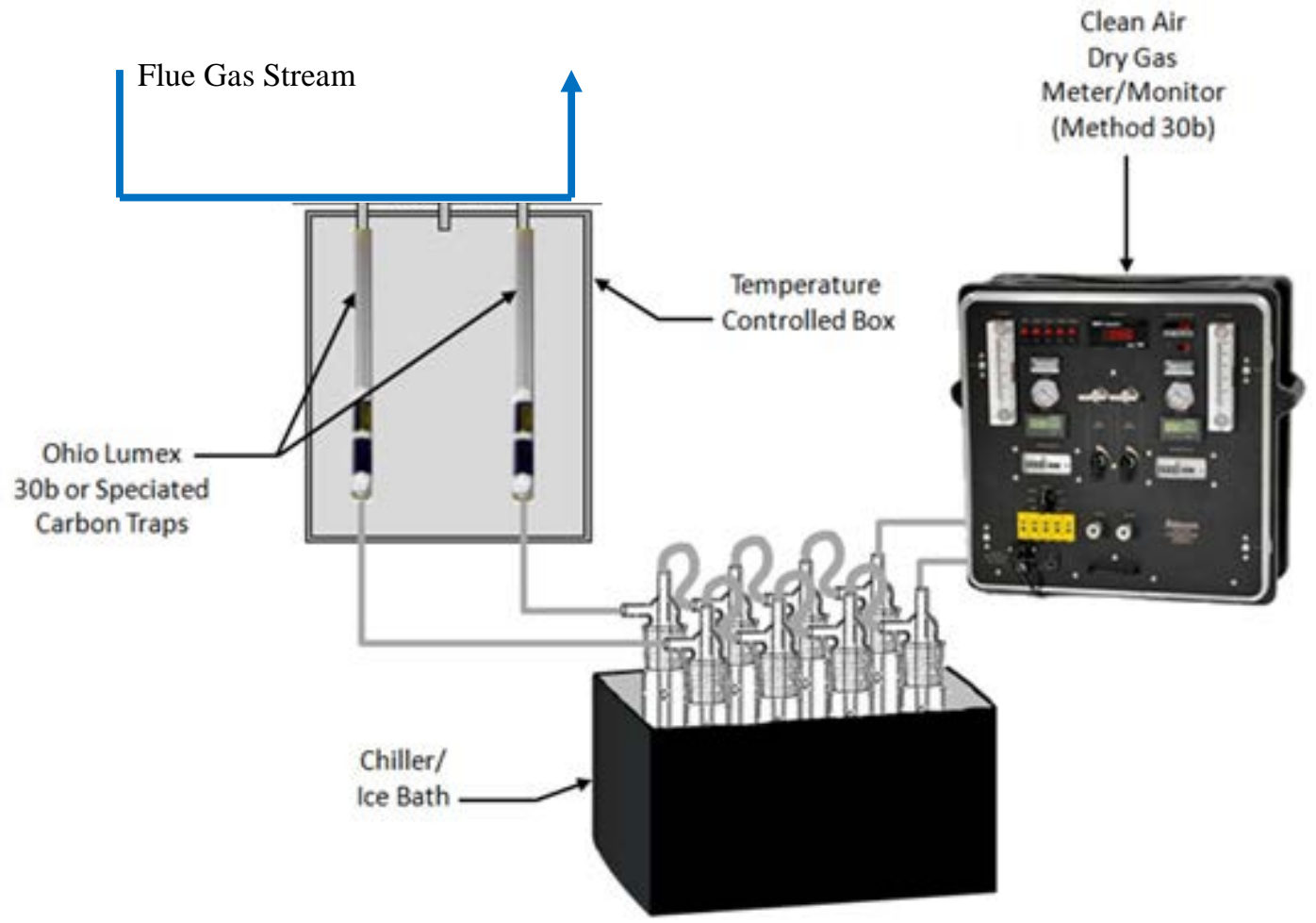

Figure 4.11-2: Method 30B mercury measurement system.

The third mercury measurement technique studied was an Ohio Lumex IRM-915 mercury CEM, shown in Figure 4.11-3. A sample of the flue gas mixture is pulled through a heated, titanium probe into a dilution probe head. The probe head contains a dilution block (where a small sample of flue gas is diluted with clean, dry air) and scrubbers to remove acid gases. Also included in the probe head are an oxidized mercury scrubber and a thermo catalytic conversion unit. If the system is measuring total mercury, the oxidized mercury scrubber is bypassed and the entire diluted stream passes through the thermal conversion unit where all mercury is reduced to an elemental form for analysis. If elemental mercury is being measured, the diluted flue gas stream passes through the oxidized mercury scrubber (where all oxidized mercury is captured) before passing into the thermal conversion unit. The stream is then passed to the atomic absorption analyzer. 


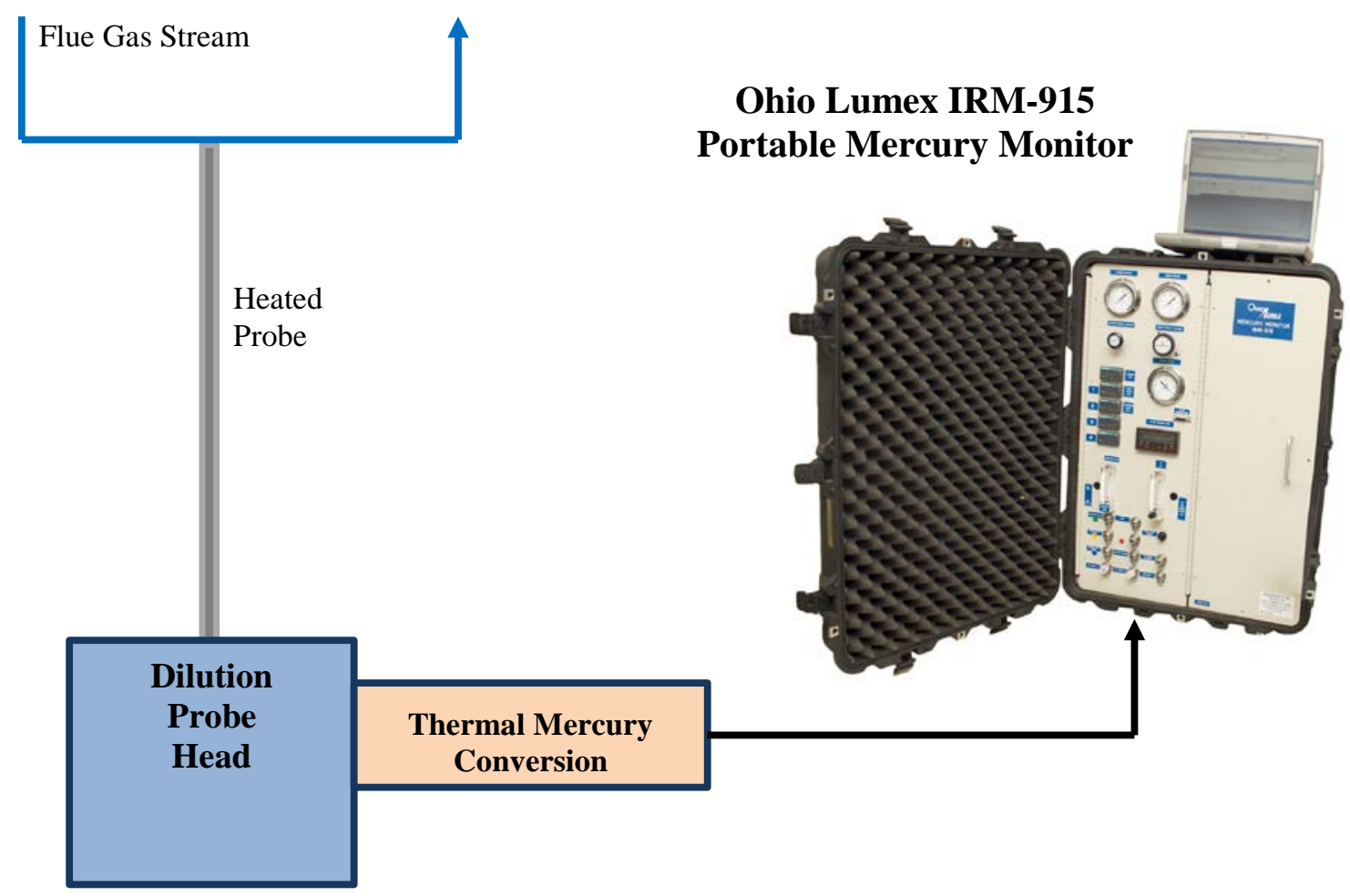

Figure 4.11-3: Ohio Lumex CEM mercury measurement system.

\subsubsection{Results}

A total of five mercury measurement values were compared in this study: wet conditioning system with Tekran CEM (two impinger solutions), carbon trap system (30B and speciating carbon traps), and Ohio Lumex CEM. These five measurements were taken with each of the six simulated flue gas mixtures and with both an elemental and oxidized mercury stream.

Figure 4.11-4 shows measurement comparisons for the elemental mercury stream. All measurements have been normalized to the expected mercury concentration. Both solutions in the wet conditioning system and the Ohio Lumex CEM gave reasonable results for all six flue gas mixtures. Results with the "B" solutions (highest $\mathrm{NaOH}$ concentrations) tended to increase slightly with higher $\mathrm{CO}_{2}$ concentration, suggesting some $\mathrm{CO}_{2}$ may be absorbed by the $\mathrm{NaOH}$ solution. However, the " $\mathrm{A}$ " solutions as well as the Ohio Lumex CEM also showed deviations that reached this level, which seemed independent of $\mathrm{CO}_{2}$ concentration. Both the $30 \mathrm{~B}$ and speciating carbon traps tended to give low mercury measurements; however, no clear trend with increasing $\mathrm{CO}_{2}$ was seen. Overall, no clear bias in high $\mathrm{CO}_{2}$ environments was noted. While other studies have suggested bias (Pavlish 2011) (Zhuang, et al. 2011), difference in the amount of $\mathrm{NaOH}$ solution and the method of contact between the solution and gas stream may account for the apparent lack of bias found in this study.

Figure 4.11-5 shows the mercury oxidation for the four speciating measurements. In theory, oxidation should be zero since this was an elemental mercury stream. The Ohio Lumex CEM consistently showed oxidation levels above 30\% while the wet conditioning system showed slightly lower levels. Overall, the speciating traps gave the lowest levels of oxidation. The flue gas matrix with $\mathrm{NO}$ and $\mathrm{SO}_{2}$ showed the highest deviation for all four measurements. It was unclear why the presence of $\mathrm{NO}$ and $\mathrm{SO}_{2}$ would 
impact speciation measurements. The flue gas $\mathrm{CO}_{2}$ composition did not seem to have an impact on measured oxidation levels.

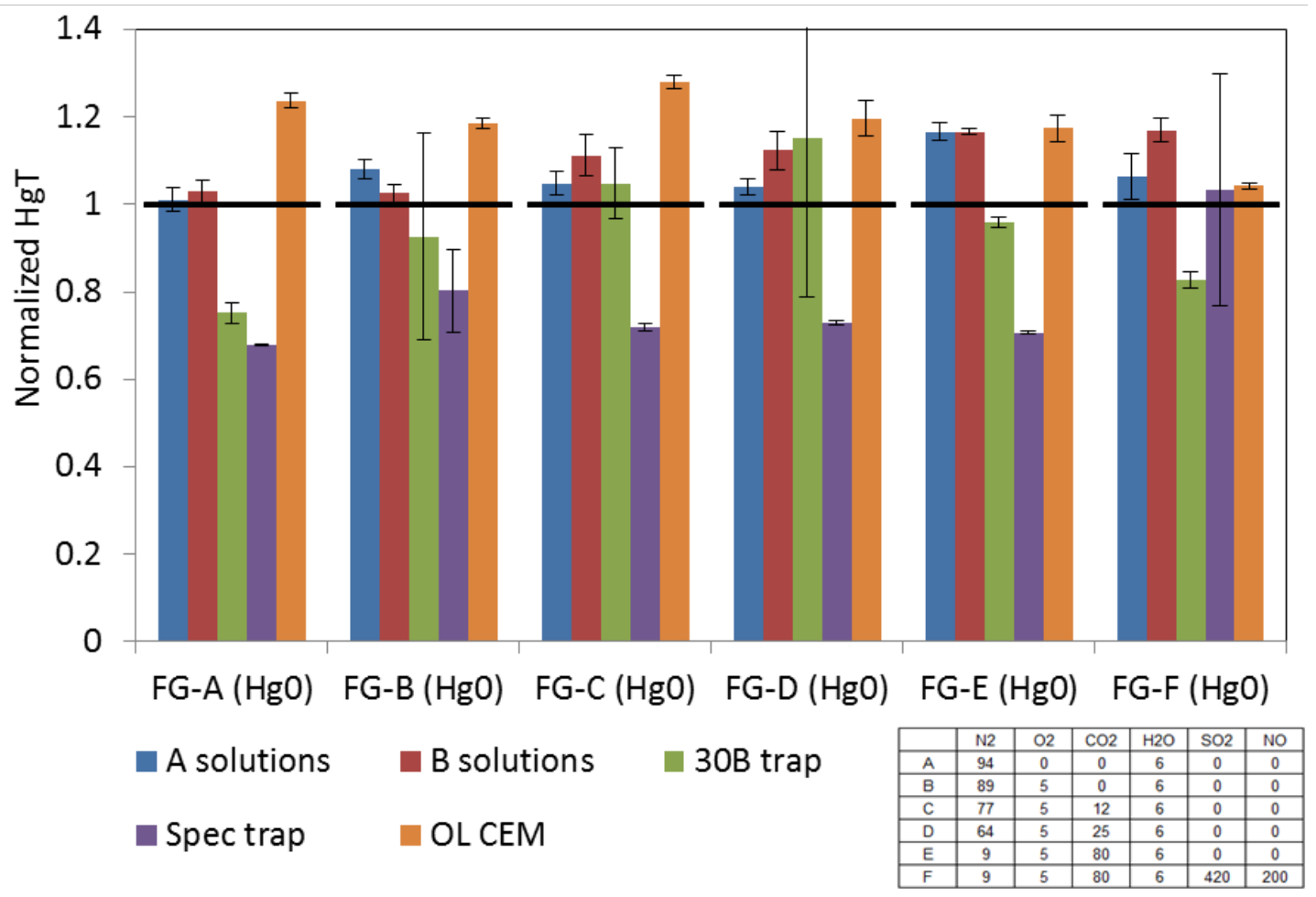

Figure 4.11-4: Comparison of mercury measurement methods with elemental mercury.

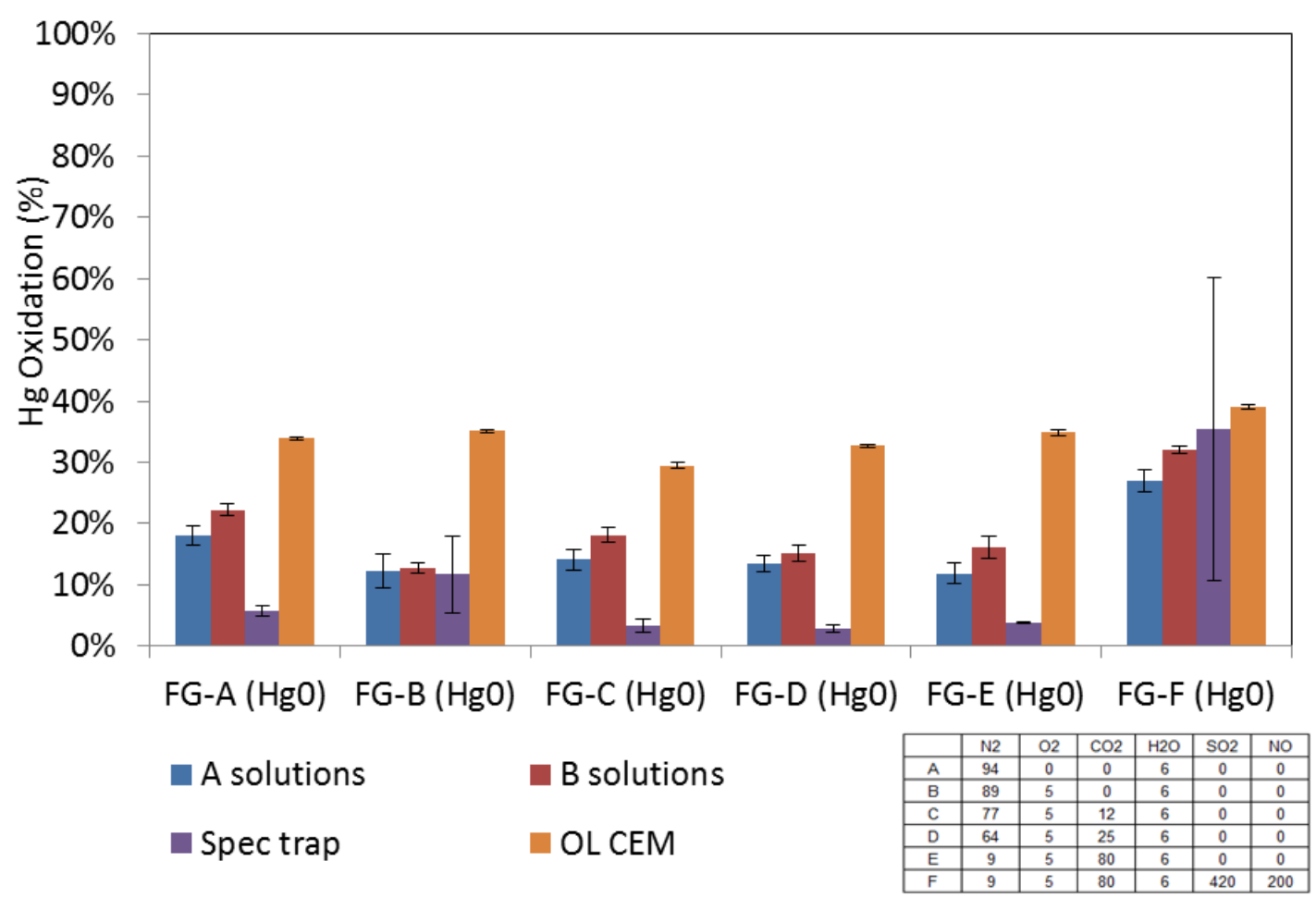

Figure 4.11-5: Comparison of measured mercury oxidation with elemental mercury. 
Figure 4.11-6 shows measurement comparisons for the oxidized mercury stream. All measurements have been normalized to the expected mercury concentration. These data show significantly more scatter than the elemental mercury stream. This is expected due to oxidized mercury's high water solubility and affinity for surfaces. No clear bias with increasing $\mathrm{CO}_{2}$ concentration was observed. The Ohio Lumex CEM in particular seemed to perform better with high $\mathrm{CO}_{2}$ concentrations. The 30B and speciating carbon traps gave the lowest mercury measurements, significantly lower than the expected values. It is unclear why the carbon traps performed so poorly under these conditions. It is possible that the tubing between the mercury injection location and the heated trap box was capturing oxidized mercury. Cool tube surface temperatures could impact mercury transfer through the tube, even though Teflon tubing was used.

Figure 4.11-7 shows the oxidized mercury measurements taken on the oxidized mercury stream. In theory, oxidation should be $100 \%$ since this was an oxidized mercury stream. Both wet conditioning system solutions showed greater than 97\% oxidation while the Ohio Lumex CEM showed slightly lower values between $85-90 \%$. The speciating traps showed the lowest levels of oxidation overall $(<70 \%)$, with the exception of the flue gas containing $\mathrm{NO}$ and $\mathrm{SO}_{2}$. It is unclear why the presence of $\mathrm{NO}$ and $\mathrm{SO}_{2}$ appeared to improve the speciation performance of the traps. Once again, no clear bias with increasing $\mathrm{CO}_{2}$ concentration was observed.

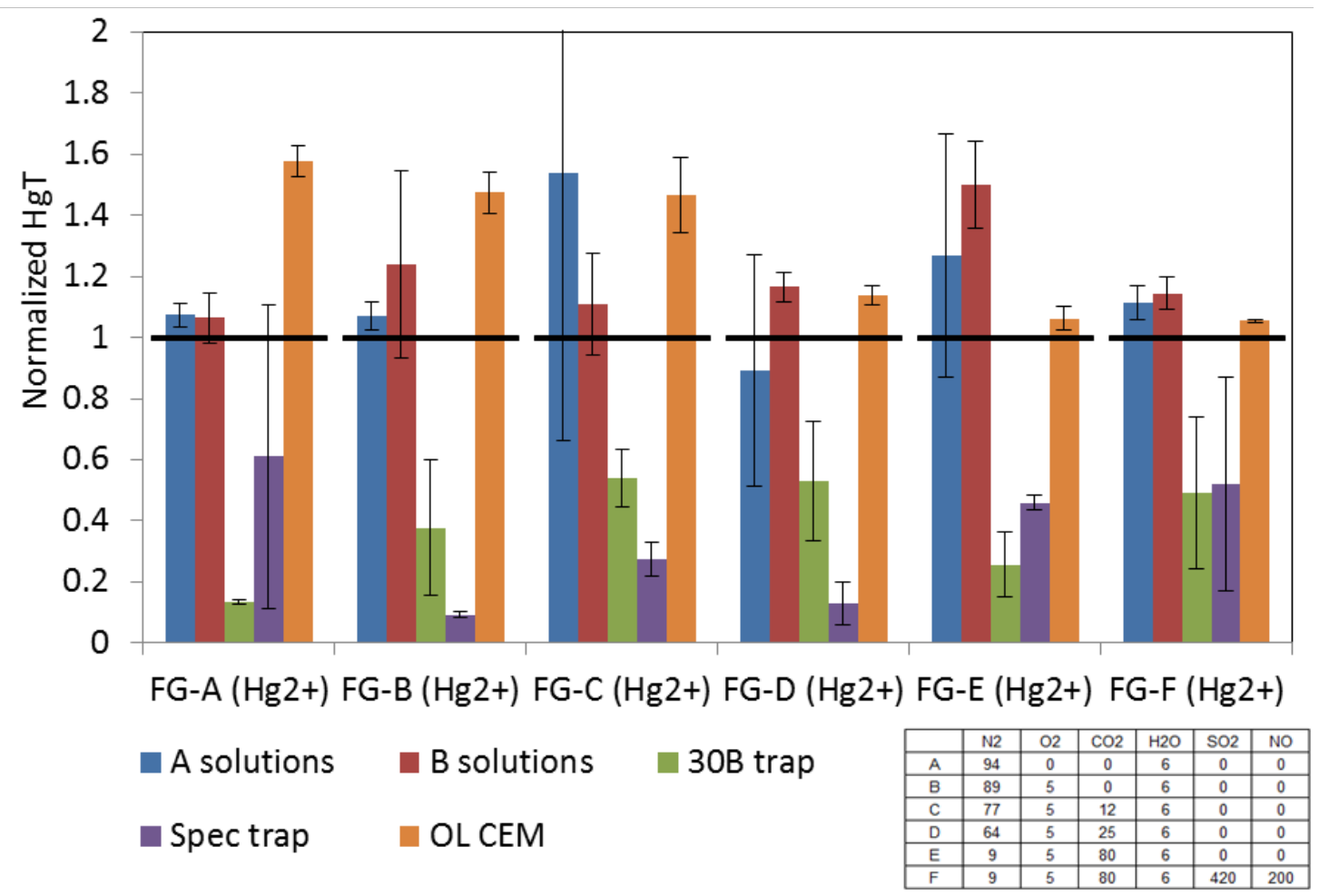

Figure 4.11-6: Comparison of mercury measurement methods with oxidized mercury. 


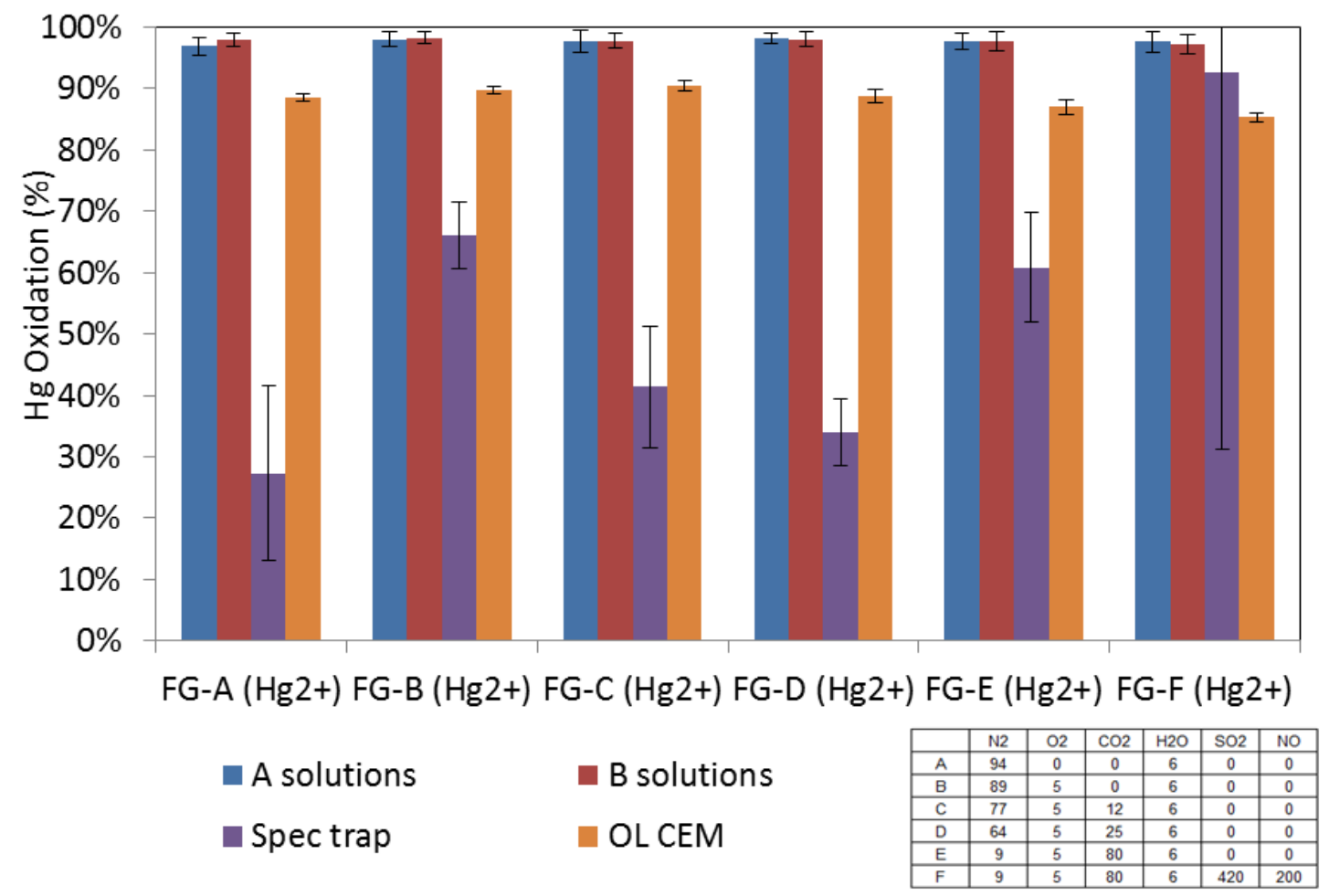

Figure 4.11-7: Comparison of measured mercury oxidation with oxidized mercury.

The flue gas sent to the Tekran CEM was analyzed for $\mathrm{O}_{2}, \mathrm{CO}_{2}$, and $\mathrm{NO}$ (since the impinger solutions were thought to potentially have the most bias). The $\mathrm{O}_{2}$ measurements were consistent among the various flue gas mixtures and the two solutions. However, the $\mathrm{CO}_{2}$ measurements were consistently 2\% lower using the " $\mathrm{B}$ " solutions compared to the " $\mathrm{A}$ " solutions. While this will cause a slight bias in the mercury measurements, this error is within the scatter of the data. This decrease in $\mathrm{CO}_{2}$ is much smaller than other researchers have noted when using this set of impinger solutions (greater than $10 \%$ loss of $\left.\mathrm{CO}_{2}\right)($ Pavlish 2011) (Zhuang, et al. 2011). The smaller $\mathrm{CO}_{2}$ loss observed in this study may be attributed to the volume and method of introduction for the solutions.

\subsubsection{Conclusions}

Six simulated flue gas mixtures were investigated for mercury measurement bias. Elemental and oxidized mercury were tested with each flue gas mixture using three measurement techniques: wet conditioning system with Tekran CEM (two impinger solutions), carbon trap system (30B and speciating carbon traps), and Ohio Lumex CEM. While there was some indication of $\mathrm{CO}_{2}$ absorption in the high concentration $\mathrm{NaOH}$ solutions, the bias this might cause in mercury measurement is small and was within the scatter of the data. The elemental mercury data showed significantly less scatter (as expected given oxidized mercury's high water solubility and affinity for surfaces). The 30B and speciating carbon traps gave the lowest mercury measurements (deviations more severe while introducing oxidized mercury). The Ohio Lumex CEM showed larger deviation in speciation compared to the wet conditioning system with the Tekran CEM. In these bench-scale experiments, the Tekran CEM with wet conditioning systems performed the best of the three techniques. Overall, no clear bias was observed with increasing $\mathrm{CO}_{2}$ concentration for either CEM system or the trap system. 


\subsubsection{Pilot-scale Mercury Test Results and Discussion}

The purpose of this testing was to investigate differences in mercury control technologies under air- and oxy-fired conditions. Experiments were performed in University of Utah's $1500 \mathrm{~kW}$ pulverized coal furnace over four weeks. Both a PRB and a bituminous coal were used. Some small modifications to the L1500 were performed to improve its back-end temperature profile and residence time (extend the length of the ductwork). Mercury measurements were performed on the flue gas using Method 30B (modified to distinguish between gas phase and particle-bound mercury), a CEM with a wet chemical conditioning system, and a CEM with a thermal conditioning system. Two mercury control technologies were tested, including injection of solid $\mathrm{CaBr}_{2}$ into the flame and injection of Norit Darco HG activated carbon into the low-temperature flue-gas. Coal, baghouse ash, and in-flight ash samples were collected to investigate mercury mass balance and gas-solids partitioning.

\subsubsection{Introduction}

Many factors influence mercury emission and speciation from coal-fired furnaces including, mercury content of the coal, coal composition (halogens, sulfur, etc.), operating conditions (temperature, gas composition, etc.), and air pollution control devices for $\mathrm{NO}_{\mathrm{x}}, \mathrm{SO}_{2}, \mathrm{PM}$, and $\mathrm{CO}_{2}$. Mercury exists as the elemental form $\left(\mathrm{Hg}^{0}\right)$ in the high-temperature regions of coal-fired boilers. As the flue gas is cooled, a series of complex reactions begin to convert the $\mathrm{Hg}^{0}$ to gaseous oxidized forms $\left(\mathrm{Hg}^{2+}\right)$ and particulatebound mercury $\left(\mathrm{Hg}^{\mathrm{p}}\right)$. The extent of conversion of $\mathrm{Hg}^{0}$ to $\mathrm{Hg}^{2+}$ and $\mathrm{Hg}_{\mathrm{p}}$ depends on the flue gas composition, the amount and properties of fly ash and the flue gas temperature and quench rate. Under different firing conditions, such as oxy-combustion, the flue gas environment changes which may affect the fate of mercury in the system. Under oxy-combustion, flue gas recycle (FGR) leads to the enrichment of $\mathrm{CO}_{2}, \mathrm{H}_{2} \mathrm{O}, \mathrm{SO}_{\mathrm{x}}, \mathrm{HCl}, \mathrm{CO}$ and possibly reduced concentration of $\mathrm{NO}_{\mathrm{x}}$. The flue gas also experiences longer residence time in the combustion system due to flue gas recycle.

\subsubsection{Experimental Approach}

The L1500 pilot-scale combustor configuration used for these tests is presented in Figure 4.11-8 with some of its features and sample locations detailed. The L1500 combustion test facility has been retrofit with a stainless steel flue gas recycle (FGR) pipe, fan and control system to allow exhaust gas to be returned to the burner. These modifications, along with an $\mathrm{O}_{2}$ and $\mathrm{CO}_{2}$ supply and control system, enabled oxy-combustion experimentation to be undertaken on the unit. As noted above, some modifications to the L1500 were performed to improve its back-end temperature profile and residence time (extend the length of the ductwork) for this work.

The furnace is equipped with CEMs for $\mathrm{O}_{2}, \mathrm{CO}_{2}$, and CO. These major gas species were measured at the inlet to the convective section of the L1500. Mercury was measured at the baghouse inlet and outlet. Coal, in-flight ash samples, and baghouse ash samples were taken and analyzed for mercury content.

The different flue gas environment must be taken into account when taking Hg measurements from an oxy-combustion system and evaluating data. Some mercury measurement techniques may bias mercury readings in high $\mathrm{CO}_{2}$ environments (Pavlish 2011) (Zhuang, et al. 2011). For this reason, multiple mercury measurement techniques were used in this test study and any necessary corrections were made to the raw data. The techniques used in this study have been previously investigated under various flue gas environments in an effort to fully understand any bias (see section 4.11.2 Mercury Measurement Recalibration).

Mercury measurements were performed upstream and downstream of the baghouse using three techniques: Method 30B (modified to distinguish between gas phase and particle bound mercury), a CEM with a wet chemical conditioning system, and a CEM with a thermal conditioning system. An Apogee 
QSIS inertial separation probe was used to pull sample flue gas from the duct for the Method 30B system and the wet conditioning system with CEM. For the Method 30B system, two sample streams were taken from the probe and passed into a temperature controlled box $\left(100^{\circ} \mathrm{C}\right)$ containing Ohio-Lumex carbon traps. Method 30B carbon traps were used. The flue gas was then passed through a chiller and metered using Method 30B sampling equipment. This modified Method 30B sampling system is presented in Figure 4.11-9. All Method 30B carbon traps were analyzed for mercury by Ohio Lumex using their RA 915+ analyzer coupled with the RP-91C pyrolysis furnace.

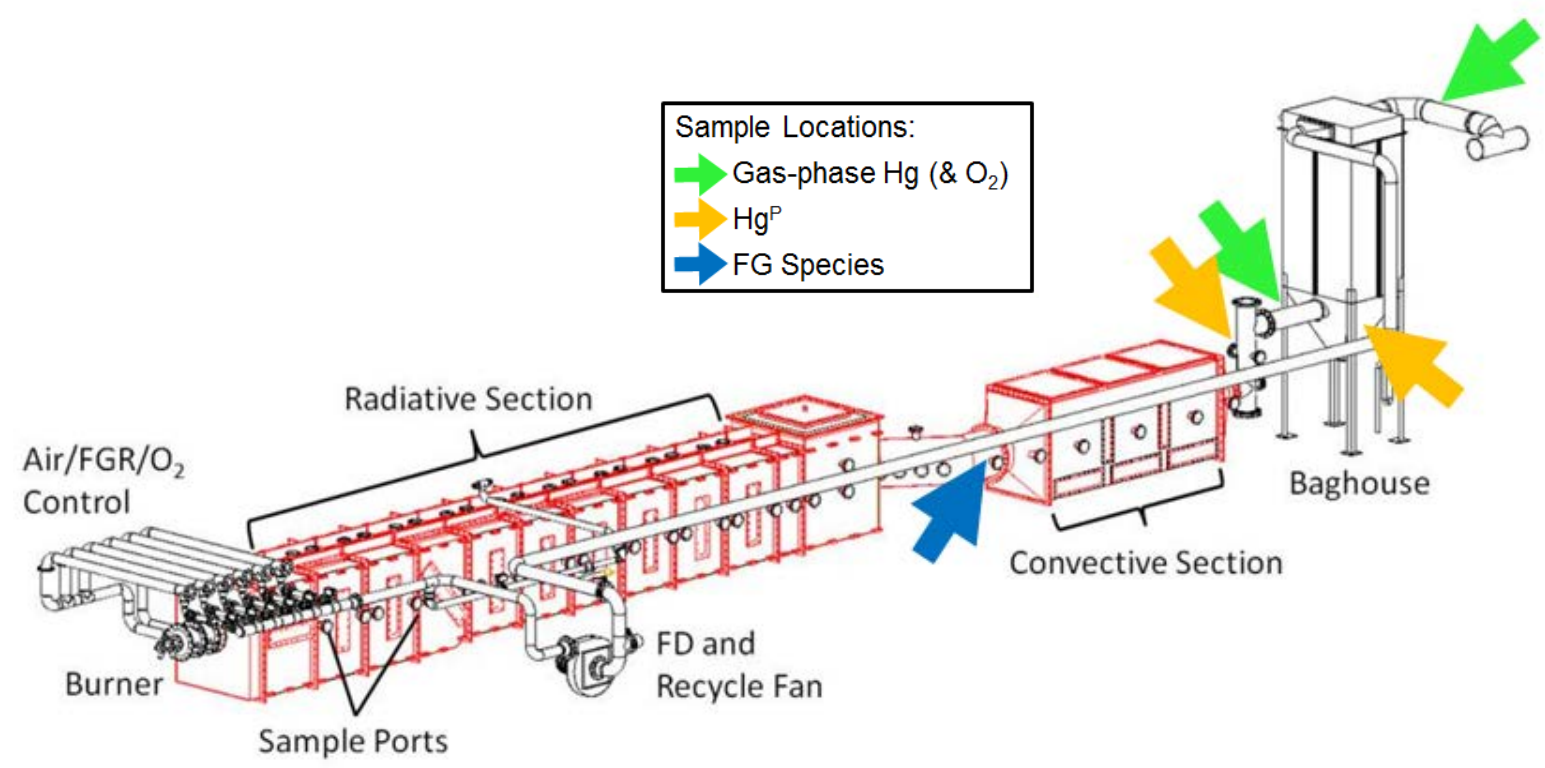

Figure 4.11-8: University of Utah's $1500 \mathrm{~kW}$ pilot-scale pulverized coal furnace (L1500).

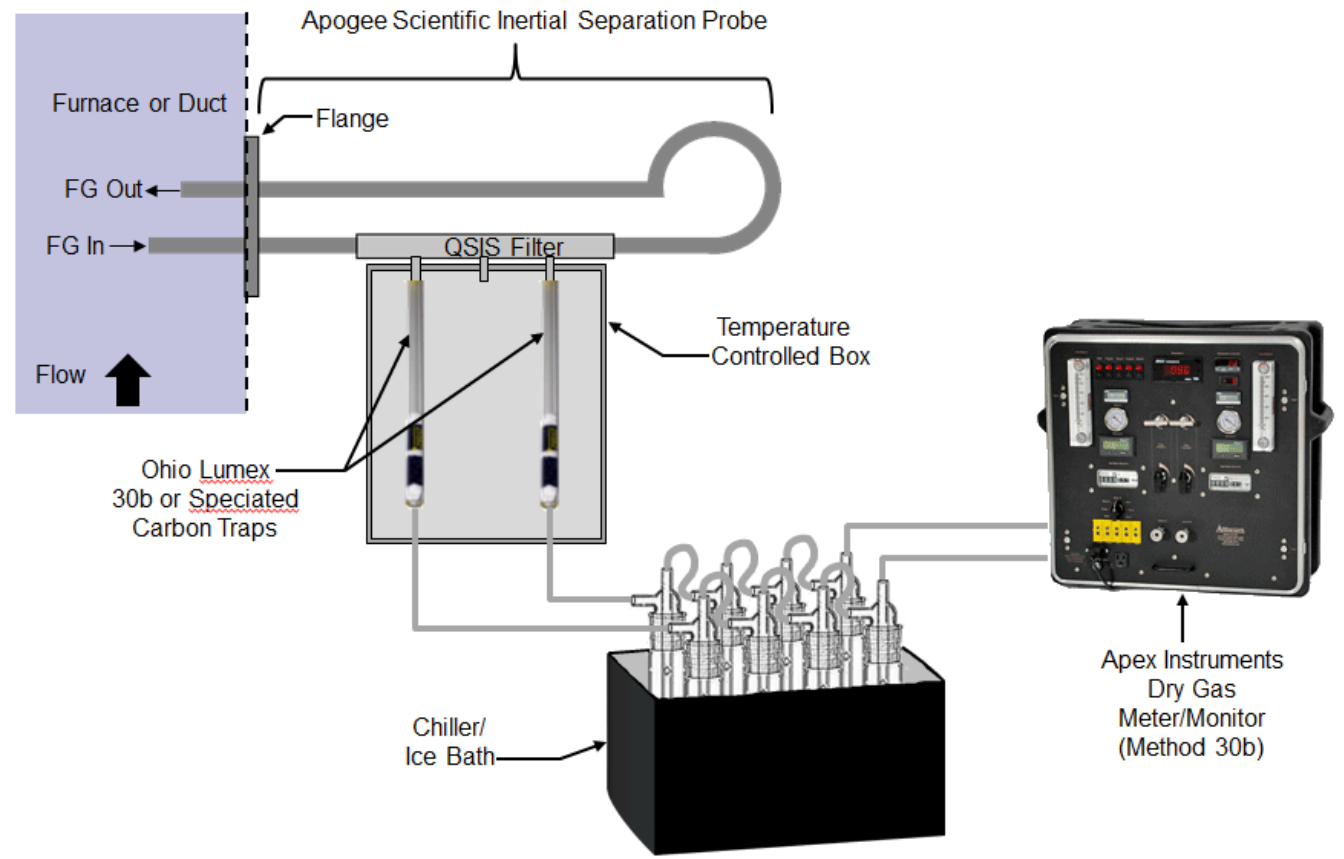

Figure 4.11-9: Modified Method 30B used for mercury measurements. 
The mercury CEM with speciating wet conditioning system is shown in Figure 4.11-10. The two sample streams pulled from the QSIS probe were split (two streams for the trap system and two streams for the CEM system). The two CEM samples passed directly into a wet-chemical conditioning system. One stream was bubbled through an acidic $2 \% \mathrm{SnCl}_{2}$ solution to reduce all mercury to the elemental form. This stream represented the total mercury concentration present in the system. The other stream was passed through a solution containing $10 \mathrm{wt} \% \mathrm{KCl}$ and $0.5 \mathrm{wt} \% \mathrm{Na}_{2} \mathrm{~S}_{2} \mathrm{O}_{3}$ to capture oxidized mercury. This stream represented the elemental mercury concentration present in the system. A $5 \mathrm{wt} \% \mathrm{NaOH}$ solution was used to remove acid gases from each of the sample streams. All the impingers have a flowthrough arrangement on the liquid side, so that solutions are continually being refreshed. The two sample streams then passed through a chiller to remove any water. A Tekran 2537A mercury analyzer was used to measure the elemental mercury concentration of each stream. A four-port sampler controlled which stream the Tekran Analyzer sampled. The CEM uses a mass flow meter to measure the sample. This mass is then converted to volume using molecular weight (air molecular weight is used). While the molecular weight of air-fired flue gas is very similar to air (mostly $\mathrm{N}_{2}$ ), the molecular weight of oxy-fired flue gas is appreciably higher (mostly $\mathrm{CO}_{2}$ ). Therefore, mercury concentrations calculated by the CEM will be biased under oxy-fired conditions. All mercury readings from the CEM were corrected for high flue gas molecular weight during oxy-firing.

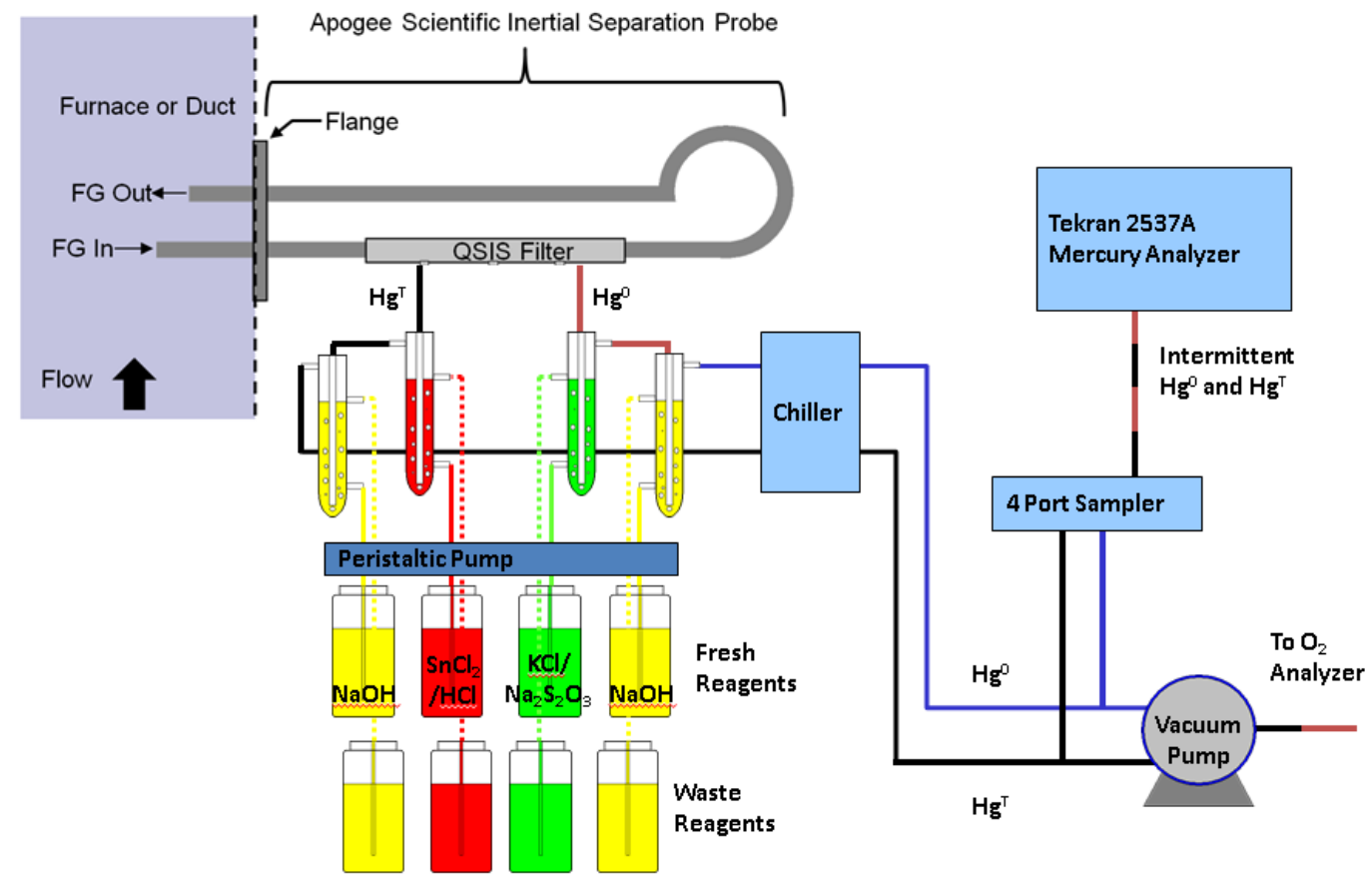

Figure 4.11-10: CEM with wet conditioning system used for mercury measurements.

The third mercury measurement technique used was an Ohio Lumex IRM-915 mercury CEM, shown in Figure 4.11-11. A sample of the flue gas is pulled through a heated, titanium probe into a dilution probe head. The probe head contains a dilution block (where a small sample of flue gas is diluted with clean, dry air) and scrubbers to remove acid gases. Also included in the probe head are an oxidized mercury scrubber and a thermo catalytic conversion unit. If the system is measuring total mercury, the oxidized mercury scrubber is bypassed and the entire diluted stream passes through the thermal conversion unit where all mercury is reduced to an elemental form for analysis. If elemental mercury is being measured, the diluted flue gas stream passes through the oxidized mercury scrubber (where all oxidized mercury is captured) before passing into the thermal conversion unit. The stream is then passed to the atomic absorption analyzer. 


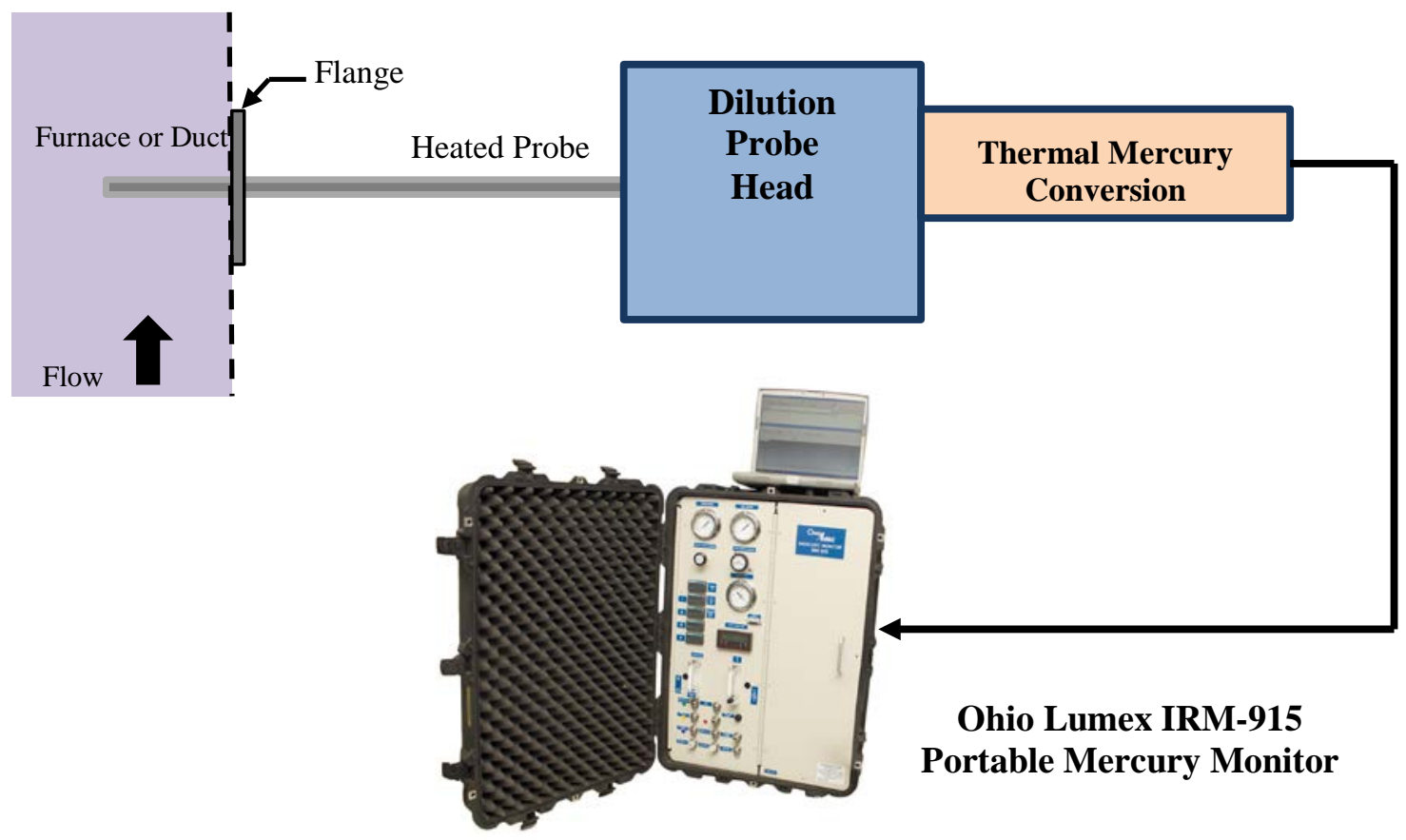

Figure 4.11-11: Ohio Lumex CEM mercury measurement system.

Pictures of the L1500 furnace and mercury measurement equipment are shown in Figure 4.11-12 through Figure 4.11-15.

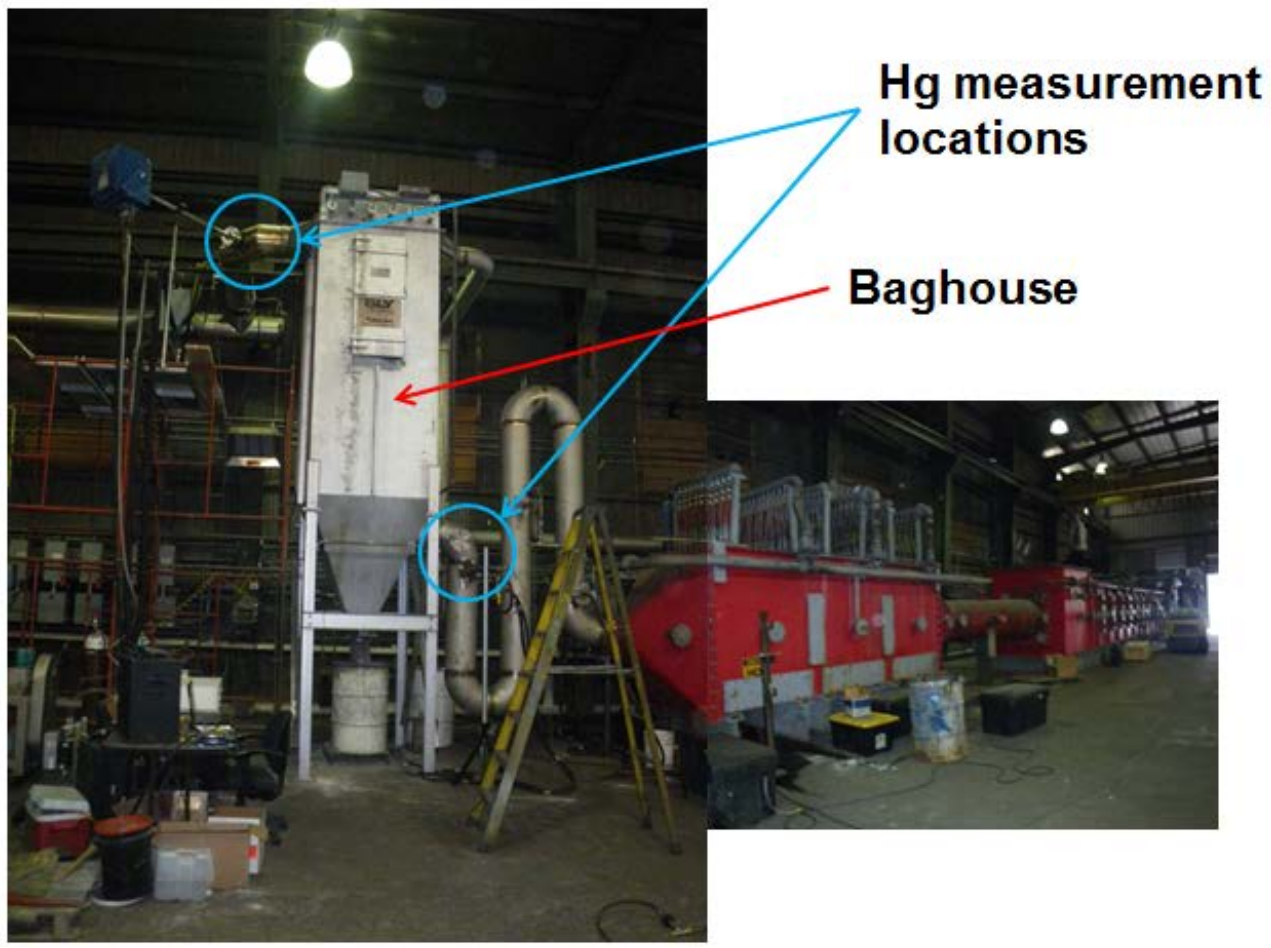

Figure 4.11-12: Picture of University of Utah's $1500 \mathrm{~kW}$ pilot-scale pulverized coal furnace (L1500). 


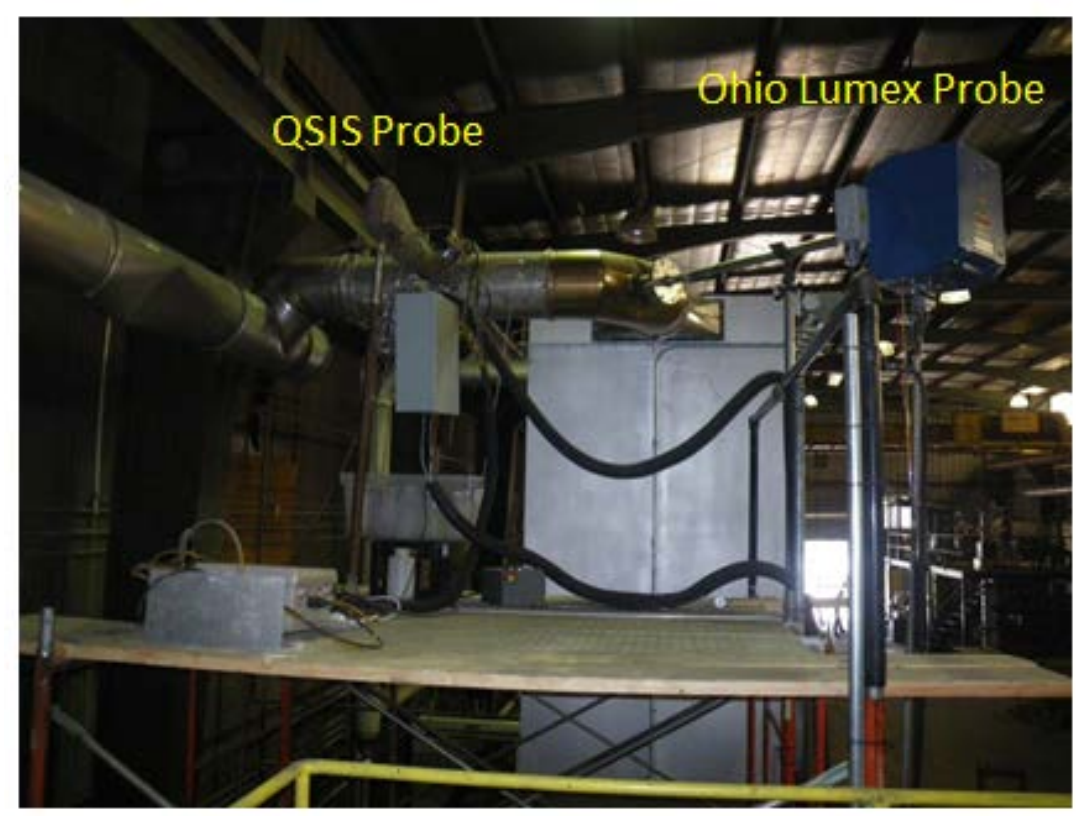

Figure 4.11-13: Picture of mercury sampling probes (after baghouse measurement location).
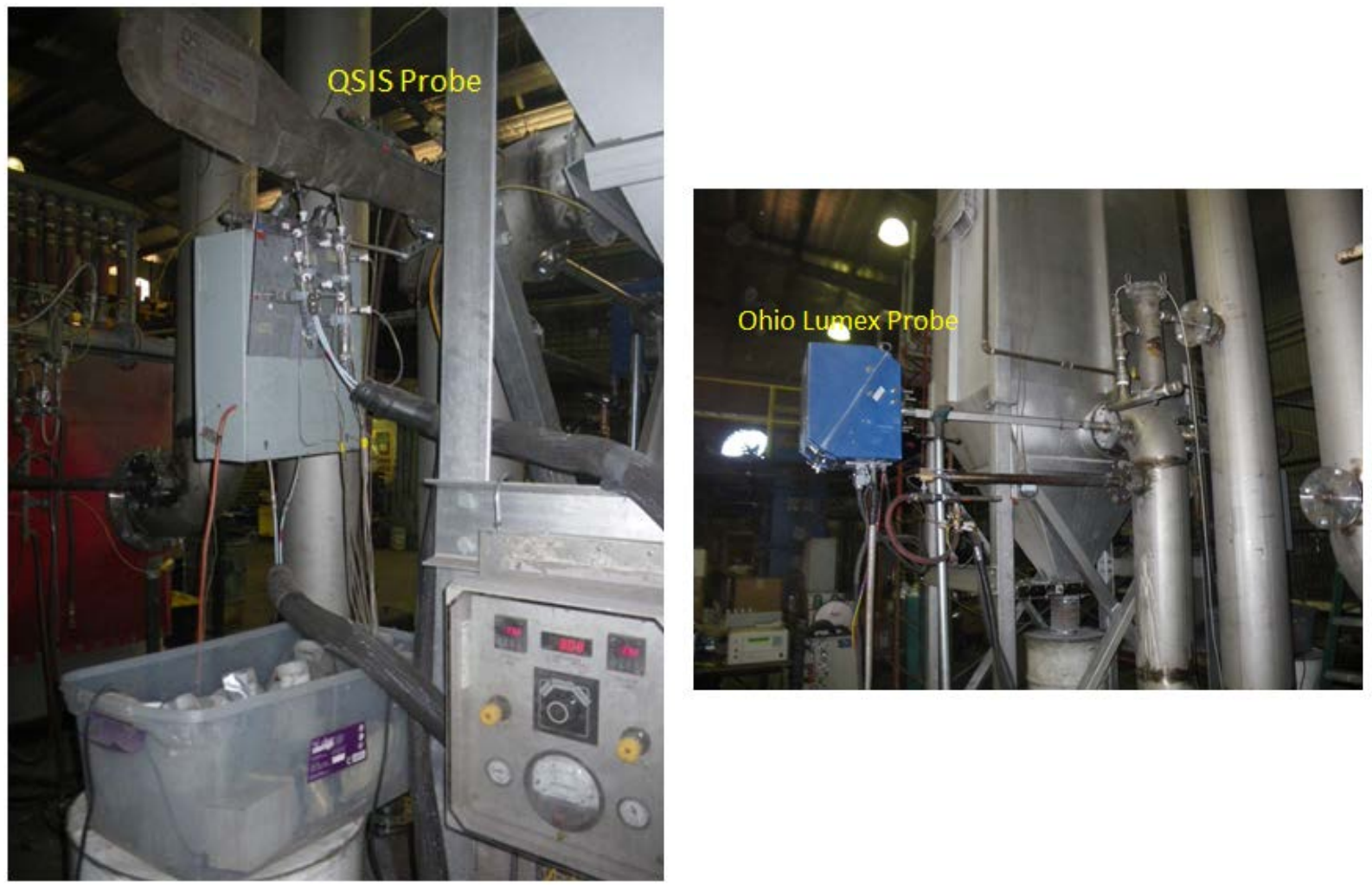

Figure 4.11-14: Picture of mercury sampling probes (before baghouse measurement location). 

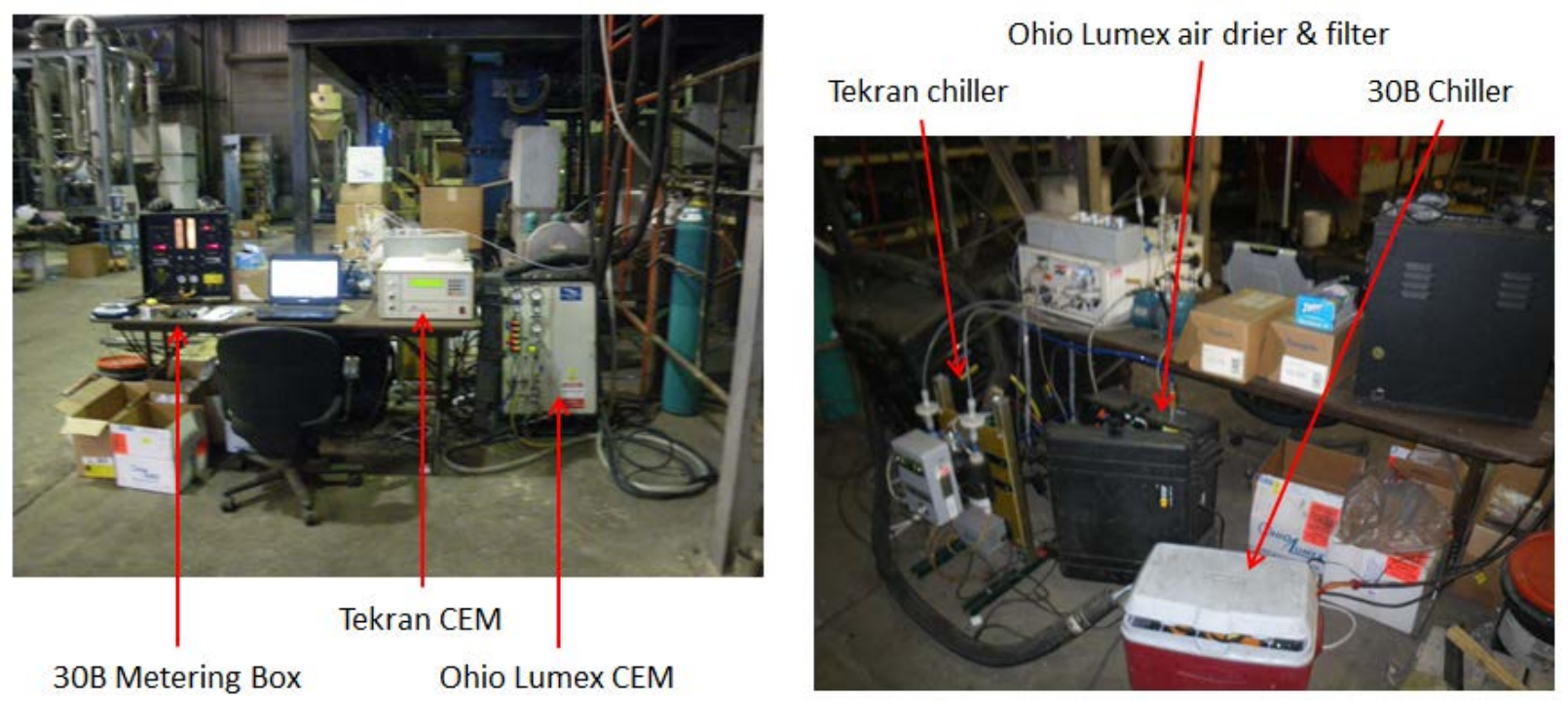

Figure 4.11-15: Picture of mercury analysis equipment.

Bromine or activated carbon was injected into the L1500 to investigate mercury control technologies under air- and oxy-fired conditions. For bromine addition, anhydrous $\mathrm{CaBr}_{2}$ solid was co-injected with the coal at rates ranging from 8 to $75 \mathrm{ppm} \mathrm{Br}$ on coal (wet). Activated carbon was injected into the duct immediately following the convective section of the furnace. The transition ductwork between the convective section and the baghouse was modified to allow for approximately one second residence time. Injection rates ranged from 0.5 to $11 \mathrm{lb} / \mathrm{MMacf}$.

In this pilot-scale system, the only mechanism for mercury capture is on particulate. The system has no wet scrubber, so removal of gas-phase oxidized mercury in solution is not an option. Bromine addition is expected to increase removal through increased oxidation both in the gas-phase (gas-phase oxidized mercury is more easily captured on particulate) and on particulate surfaces (heterogeneous oxidation and retention on the particle surface). Activated carbon injection is expected to increase removal through addition of potential Hg capture sites.

\subsubsection{Results - PRB coal}

The furnace operating conditions for the PRB testing are shown in Table 4.11-3. The excess $\mathrm{O}_{2}$ in the furnace was kept approximately the same for all testing. The $\mathrm{CO}_{2}$ concentration increased from $14 \%$ dry during air-firing to $83 \%$ dry for oxy-firing. The remaining gas composition is largely $\mathrm{N}_{2}$. The flue gas temperatures at the baghouse inlet and outlet dropped significantly during oxy-firing. This can be attributed to the smaller flue gas volume, which results in longer residence time and increased heat transfer.

Table 4.11-3: L1500 operating conditions during PRB testing.

\begin{tabular}{|c|c|c|c|c|c|}
\hline & $\begin{array}{c}\text { Firing Rate } \\
\mathbf{( k W )}\end{array}$ & $\begin{array}{c}\mathbf{O}_{\mathbf{2}} \\
\mathbf{( \% ,} \mathbf{d r y})\end{array}$ & $\begin{array}{c}\mathbf{C O}_{\mathbf{2}} \\
\mathbf{( \% ,} \mathbf{d r y})\end{array}$ & $\begin{array}{c}\text { BH inlet } \\
\mathbf{( F )}\end{array}$ & $\begin{array}{c}\text { BH outlet } \\
\mathbf{( F )}\end{array}$ \\
\hline Air-Fired & $780-860$ & 4.0 & 14 & 380 & 250 \\
\hline Oxy-Fired & 780 & 3.5 & 83 & 300 & 140 \\
\hline
\end{tabular}


A Black Thunder PRB coal was used in this study. The properties of this coal are shown in Table 4.11-4. The mercury content of the Black Thunder PRB coal is low at $0.05 \mu \mathrm{g} / \mathrm{g}$. The expected gas phase mercury concentration from this coal is approximately $8 \mu \mathrm{g} / \mathrm{dscm}$ (air-fired) or $5 \mathrm{lb} / \mathrm{TBtu}$. For oxy-fired conditions, gas phase mercury concentrations could be up to 5 times higher due to the removal of the nitrogen diluents. A complete list of the mercury analyses of each coal sample is shown in Table 4.11-5.

Table 4.11-4: Properties of the Black Thunder PRB coal.

\begin{tabular}{|l|c|l|c|}
\hline \multicolumn{3}{|l|}{} & \multicolumn{3}{|l|}{ Mineral Matter Analyses } \\
\hline Coal Analyses & 54.04 & Al & 14.19 \\
\hline $\mathbf{C}$ & 3.74 & $\mathbf{C a}$ & 16.13 \\
\hline $\mathbf{H}$ & 0.82 & $\mathbf{F e}$ & 5.99 \\
\hline $\mathbf{N}$ & 0.38 & $\mathbf{M g}$ & 3.33 \\
\hline $\mathbf{S}$ & 13.69 & $\mathbf{M n}$ & 0.04 \\
\hline $\mathbf{O}$ & 5.66 & $\mathbf{P}$ & 0.71 \\
\hline Ash & 21.67 & $\mathbf{K}$ & 0.47 \\
\hline Moisture & 36.77 & $\mathbf{S i}$ & 36.76 \\
\hline Volatile Matter & 35.91 & $\mathbf{N a}$ & 0.93 \\
\hline Fixed Carbon & 9320 & $\mathbf{S}$ & 10.11 \\
\hline HHV, Btu/lb & $\mathbf{0 . 0 5} \mathbf{\pm 0 . 0 1}$ & $\mathbf{T i}$ & 1.11 \\
\hline Hg, $\mathbf{\mu g} / \mathbf{g}$ AR & & \multicolumn{2}{|l|}{} \\
\hline
\end{tabular}

Table 4.11-5: Mercury concentration of each PRB coal sample.

\begin{tabular}{|l|c|c|}
\hline Coal & Date & Hg (ng/g AR) \\
\hline Black Thunder PRB & $05 / 02 / 2013$ & 53.49 \\
\hline Black Thunder PRB & $05 / 03 / 2013$ & 44.03 \\
\hline Black Thunder PRB & $05 / 06 / 2013$ & 46.91 \\
\hline Black Thunder PRB & $05 / 08 / 2013$ & 41.40 \\
\hline Black Thunder PRB & $05 / 09 / 2013$ & 47.48 \\
\hline Black Thunder PRB & $05 / 10 / 2013$ & 50.63 \\
\hline Black Thunder PRB & $06 / 21 / 2013$ & 74.13 \\
\hline
\end{tabular}

Baghouse ash samples were taken once during each test and analyzed for mercury content and LOI. Inflight (entrained) ash samples were taken upstream of the baghouse when mercury sampling was being performed upstream of the baghouse and analyzed for mercury content. Results from the ash analyses are shown in Table 4.11-6. As expected, the mercury content of the ash increased when activated carbon was injected (both baghouse ash and entrained ash). The ash mercury did not change significantly when bromine was injected. The baghouse ash is expected to have higher mercury content than the entrained ash samples (more mercury is captured in the ash as it sits on the filters forming a cake), which was the case. The LOI showed variability, which is a reflection of unstable furnace operating conditions. Due to its horizontal arrangement and flue gas velocities, the L1500 furnace has significant ash dropout before the baghouse. It is likely that the fly ash sampled from the baghouse or entrained in the upstream section of duct may not be representative of the entire system. The fly ash spread throughout the furnace will certainly behave differently towards mercury as temperature and composition vary. This will have an impact on mercury mass balance calculations. 
Table 4.11-6: Mercury and LOI analyses of PRB fly ash.

\begin{tabular}{|c|c|c|c|c|c|c|}
\hline & & \multicolumn{2}{|c|}{ Baghouse Ash Samples } & \multicolumn{2}{c|}{ Entrained Ash Samples } \\
\hline Date & Conditions & Time & $\begin{array}{c}\text { Hg } \\
\text { (ug/g AR) }\end{array}$ & $\begin{array}{c}\text { LOI } \\
\text { (\%) }\end{array}$ & Time & $\begin{array}{c}\text { Hg } \\
\text { (ug/g AR) }\end{array}$ \\
\hline 5/2/13 & air, before BH & $14: 00$ & 678.49 & 4.75 & $14: 00$ & 222.25 \\
\hline $5 / 2 / 13$ & air, before BH, low Br & & & & $16: 45$ & 103.42 \\
\hline $5 / 2 / 13$ & air, before BH, high Br & $18: 55$ & 620.09 & 3.42 & $19: 00$ & 80.87 \\
\hline $5 / 3 / 13$ & air, before BH & $12: 00$ & 672.04 & 2.06 & $12: 00$ & 34.82 \\
\hline $5 / 6 / 13$ & air, before BH & $10: 40$ & 694.82 & 0.89 & $10: 15$ & 19.27 \\
\hline $5 / 6 / 13$ & air, before BH, low ACI & & & & $12: 30$ & 441.88 \\
\hline $5 / 6 / 13$ & air, before BH, high ACI & $14: 30$ & 949.22 & 1.52 & $14: 30$ & 680.43 \\
\hline $5 / 7 / 13$ & air, after BH & $11: 40$ & 838.19 & 0.83 & & \\
\hline $5 / 7 / 13$ & air, after BH, low Br & $15: 20$ & 729.09 & 0.77 & & \\
\hline $5 / 7 / 13$ & air, after BH, high Br & $17: 20$ & 643.68 & 0.50 & & \\
\hline $5 / 8 / 13$ & oxy, after BH & $11: 00$ & 709.51 & 1.58 & & \\
\hline $5 / 8 / 13$ & oxy, after BH, low Br & $13: 00$ & 543.20 & 0.48 & & \\
\hline $5 / 8 / 13$ & oxy, after BH, high Br & $14: 30$ & 440.43 & 1.14 & & \\
\hline $5 / 8 / 13$ & oxy, after BH, high ACI & $16: 45$ & 768.28 & 1.30 & & \\
\hline $5 / 9 / 13$ & air, after BH, low ACI & $11: 15$ & 1395.19 & 3.74 & & \\
\hline $5 / 9 / 13$ & air, after BH, high ACI & $14: 40$ & 1686.68 & 1.24 & & \\
\hline $5 / 9 / 13$ & oxy, after BH, low ACI & $16: 45$ & 1371.86 & 1.09 & & \\
\hline $5 / 9 / 13$ & oxy, before BH & $20: 20$ & 1140.60 & 1.91 & $20: 10$ & 171.22 \\
\hline $5 / 10 / 13$ & oxy, before BH, low ACI & $10: 20$ & 1302.81 & 1.79 & $10: 30$ & 267.04 \\
\hline $5 / 10 / 13$ & oxy, before BH, high ACI & $13: 30$ & 1229.48 & 1.11 & $13: 20$ & 1032.66 \\
\hline $5 / 10 / 13$ & oxy, before BH, low Br & $17: 30$ & 1249.42 & 0.97 & $17: 00$ & 93.20 \\
\hline $5 / 10 / 13$ & oxy, before BH, high Br & $18: 40$ & 1238.30 & 1.50 & & \\
\hline $6 / 21 / 13$ & air, before BH & $11: 40$ & 857.47 & 2.31 & $12: 00$ & 227.07 \\
\hline $6 / 21 / 13$ & air, before BH, high Br & $14: 40$ & 680.87 & 1.35 & $14: 45$ & 90.90 \\
\hline $6 / 21 / 13$ & air, before BH, low Br & $17: 10$ & 777.83 & 0.88 & $17: 30$ & 59.83 \\
\hline
\end{tabular}

The three mercury measurement techniques are compared in Figure 4.11-16. The Tekran CEM tended to give slightly higher $\mathrm{Hg}^{\mathrm{T}}$ measurements compared to the 30B traps, but generally these two methods agreed well. There was much more scatter when comparing the OL CEM to either the 30B carbon traps or the Tekran CEM, especially when measuring before the baghouse. The baseline measurements before the baghouse were higher with the OL CEM and lower for additive injection. For these low OL measurements, it is suspected that particles on the filter of the dilution probe head contributed to biased capture readings. More frequent blowback of the probe and washing of the heated filter may help prevent biasing. 
Reaction Engineering International - Characterizing Oxy-combustion Impacts for Coal-fired Boilers

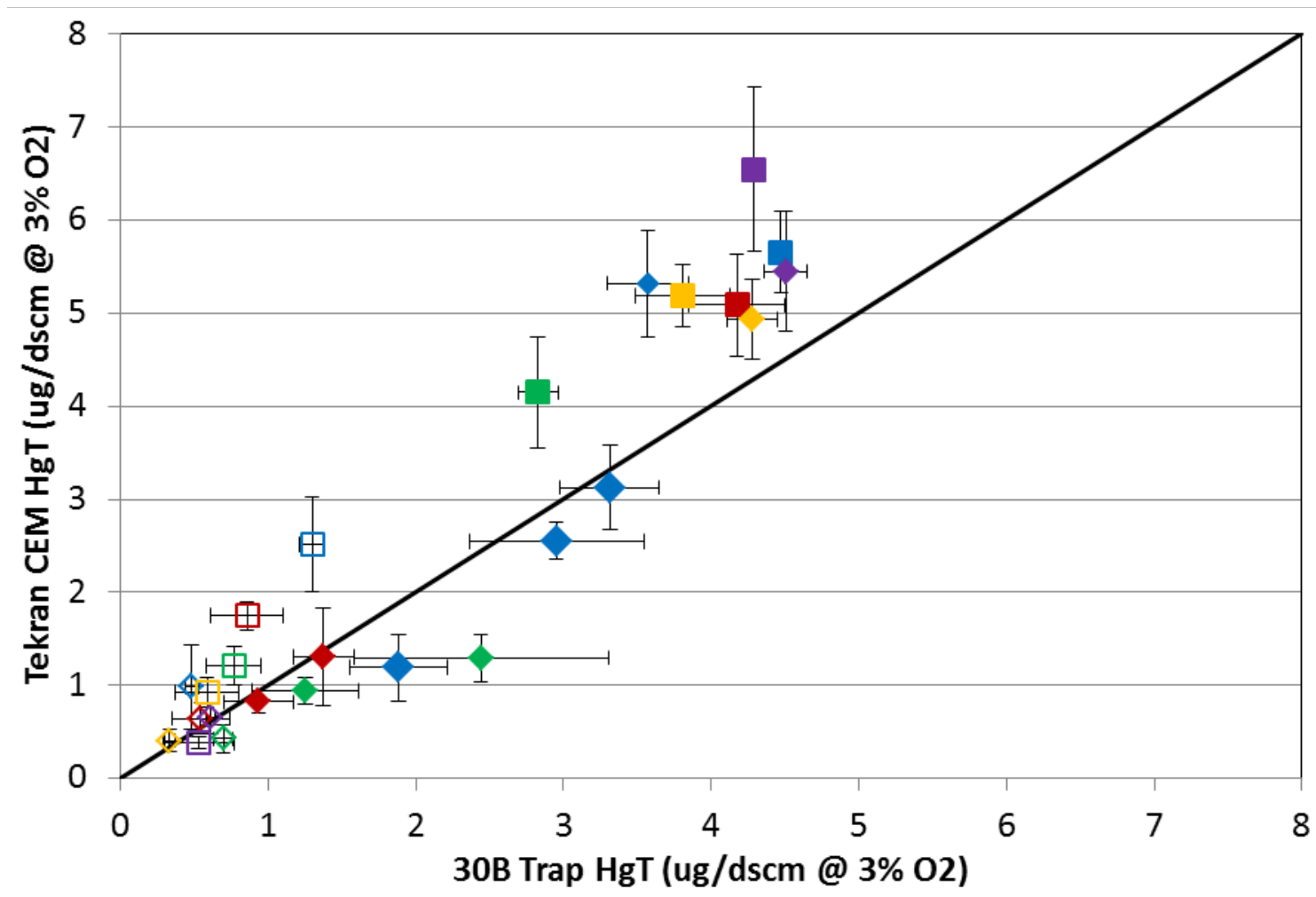

(a)

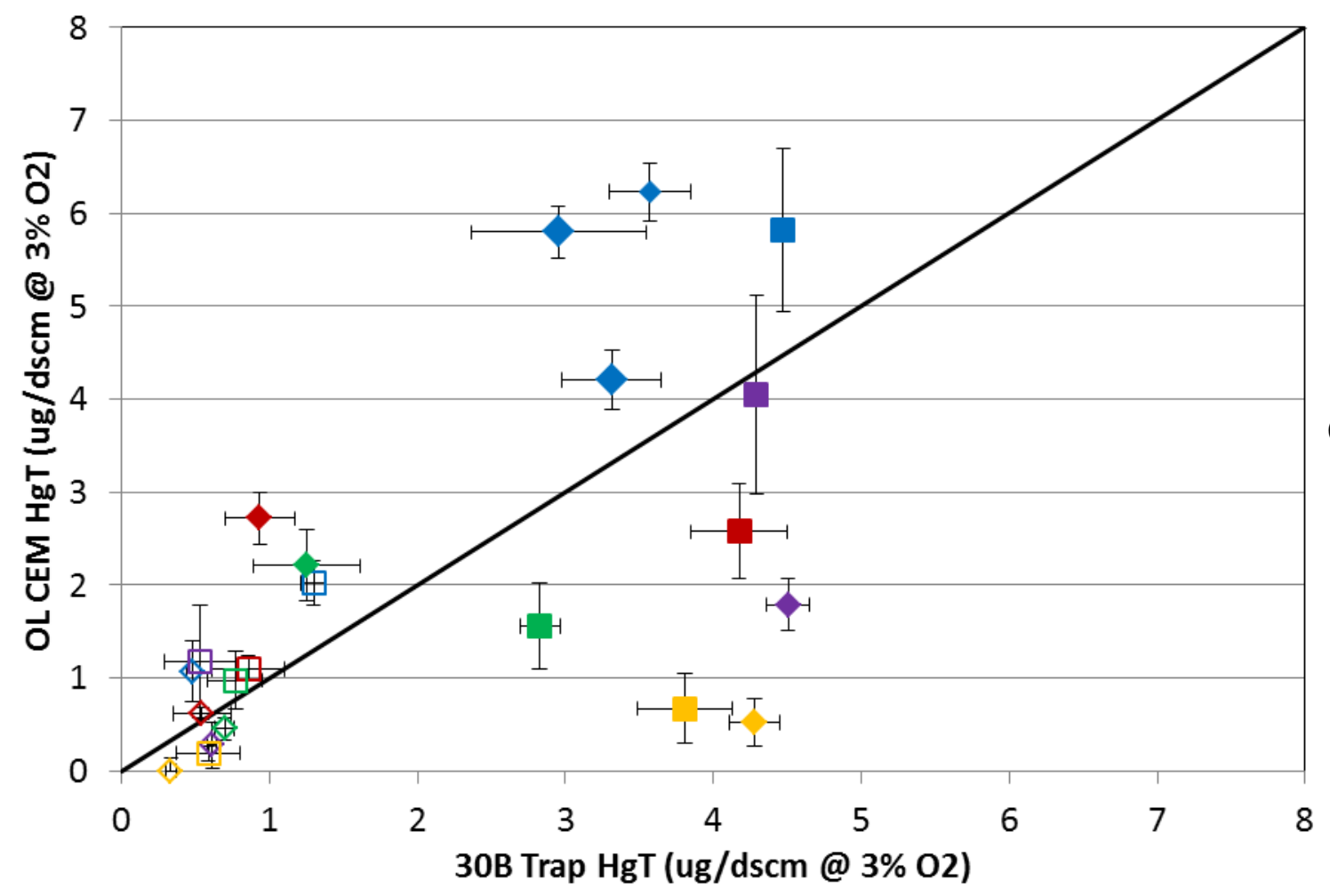

(b) 


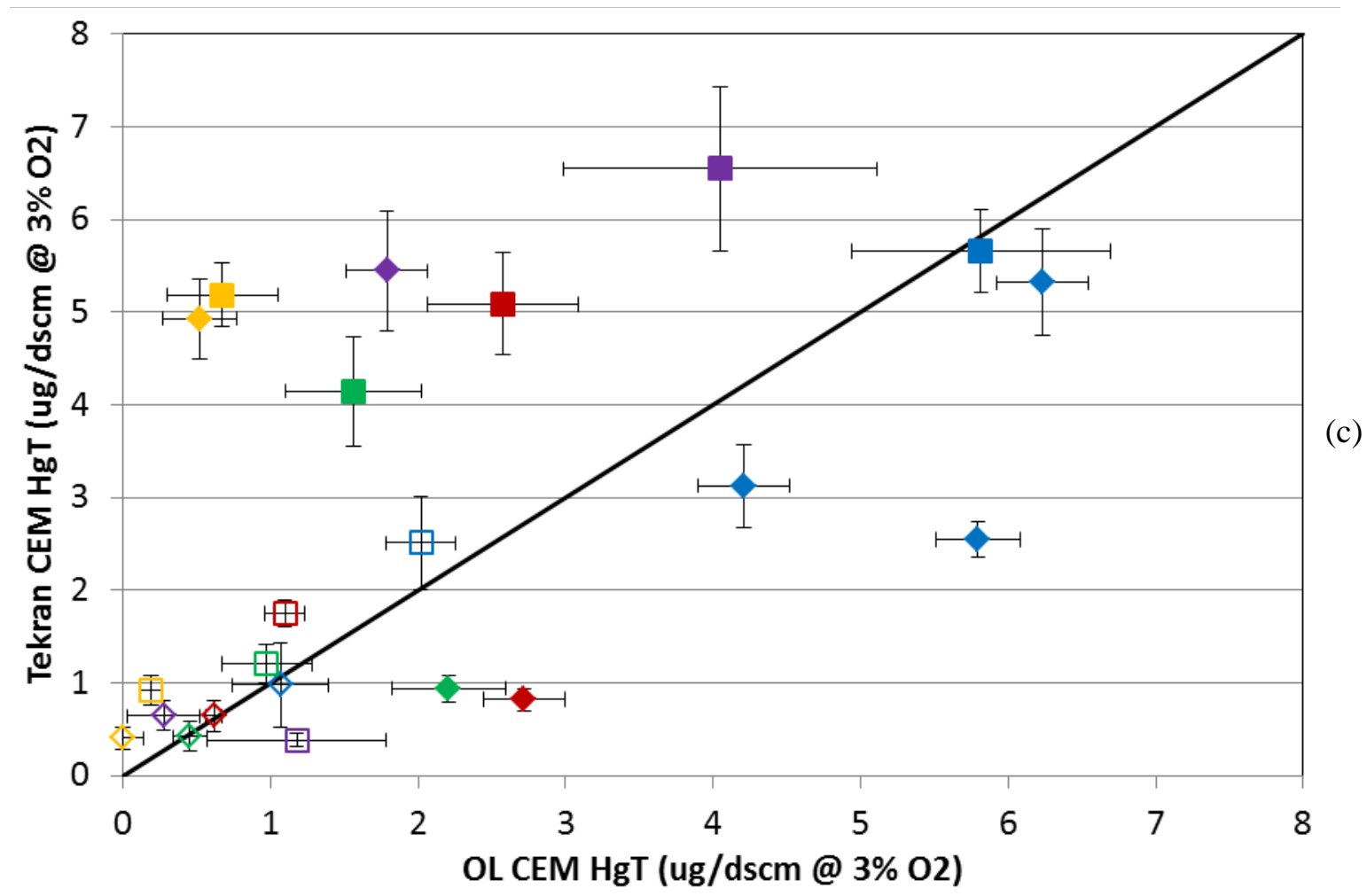

\footnotetext{
- before $\mathrm{BH}$, air

$\diamond$ after $\mathrm{BH}$, air

- before $\mathrm{BH}$, air, low $\mathrm{Br}$

- before $\mathrm{BH}$, air, high $\mathrm{Br}$

- before $\mathrm{BH}$, air, low $\mathrm{ACl}$

- before $\mathrm{BH}$, air, high $\mathrm{ACl}$

$\checkmark$ after $\mathrm{BH}$, air, low $\mathrm{Br}$

$\circ$ after $\mathrm{BH}$, air, high $\mathrm{Br}$

$\diamond$ after $\mathrm{BH}$, air, low $\mathrm{ACl}$

after $\mathrm{BH}$, air, high $\mathrm{ACl}$
}

\author{
- before $\mathrm{BH}$, oxy \\ $\square$ after $\mathrm{BH}, \mathrm{oxy}$ \\ before $\mathrm{BH}$, oxy, low $\mathrm{Br} \quad \square$ after $\mathrm{BH}$, oxy, low $\mathrm{Br}$ \\ before $\mathrm{BH}$, oxy, high $\mathrm{Br} \square$ after $\mathrm{BH}$, oxy, high $\mathrm{Br}$ \\ before $\mathrm{BH}$, oxy, low $\mathrm{ACl} \square$ after $\mathrm{BH}$, oxy, low $\mathrm{ACl}$ \\ before $\mathrm{BH}$, oxy, high $\mathrm{ACl} \square$ after $\mathrm{BH}$, oxy, high $\mathrm{ACl}$
}

\section{Figure 4.11-16: Comparison of (a) trap and Tekran CEM, (b) trap and OL CEM, (c) OL CEM and Tekran CEM total mercury measurements during PRB testing.}

Total gas phase mercury measurements for each test are shown in Figure 4.11-17. The x-axis represents the test conditions, with the additive injection rates in parentheses ( $\mathrm{ppm} \mathrm{Br}$ on coal wet for bromine addition and lb/MMacf for ACI). The tests marked with an asterisk $\left(^{*}\right)$ represent tests where the measured baghouse LOI was high ( $>2$ ). Mercury measurements were lower after the baghouse compared to before the baghouse. This is expected as mercury is captured on the filter cake in the baghouse. Oxyfiring tended to cause an increase in mercury concentrations. This is expected due to the lower flue gas volume and higher moisture content (when correcting to dry conditions). Because mercury emission levels were so low after the baghouse, the flue gas recycle did not cause a dramatic increase in measured mercury concentrations.

Bromine addition caused lower emission levels before the baghouse compare to ACI. This is likely due to increased fraction of oxidized mercury (more easily captured by carbon in ash) and the longer interaction time between $\mathrm{Hg}$, bromine (oxidation mechanism) and ash (capture mechanism). The drop in mercury caused by bromine before the baghouse was larger for air-fired conditions compared to oxy-fired condition. One possible explanation for increased effectiveness during air-firing is increased $\mathrm{SO}_{2}$ concentrations while oxy-firing due to flue gas recycle without any $\mathrm{SO}_{2}$ control. The $\mathrm{L} 1500$ furnace is not equipped with an $\mathrm{SO}_{2}$ scrubber, so the recycle stream during oxy-combustion is very high in $\mathrm{SO}_{2}$. While 
$\mathrm{SO}_{2}$ was not measured during these tests, mass balance calculations suggest that $\mathrm{SO}_{2}$ could increase from $\sim 400 \mathrm{ppmv}$ (wet) during air-firing to $\sim 1500 \mathrm{ppmv}$ (wet) during oxy-firing. It is unlikely that these levels were attained during testing (there are several locations in the furnace where water condenses and $\mathrm{SO}_{2}$ surely condenses as well), but a dramatic increase in $\mathrm{SO}_{2}$ during oxy-firing certainly occurred. Increased $\mathrm{SO}_{2}$ concentrations will lead to higher $\mathrm{SO}_{3}$ levels. $\mathrm{SO}_{3}$ is known in compete with $\mathrm{Hg}$ for capture sites on particulate. It is unclear why mercury concentrations before the baghouse during air-fired conditions seemed to increase during activated carbon injection. One possible explanation could be high LOI levels during baseline testing which resulted in abnormally low concentrations.

After baghouse measurements showed more scatter, with bromine injection causing a decrease in measured mercury for some tests and a slight increase for others. However, mercury concentrations at this location were extremely low. ACI produced the lowest emission levels after the baghouse. Overall, some differences in additive performance were seen when air- or oxy-firing, most likely due to flue gas composition, particularly $\mathrm{SO}_{2} / \mathrm{SO}_{3}$.

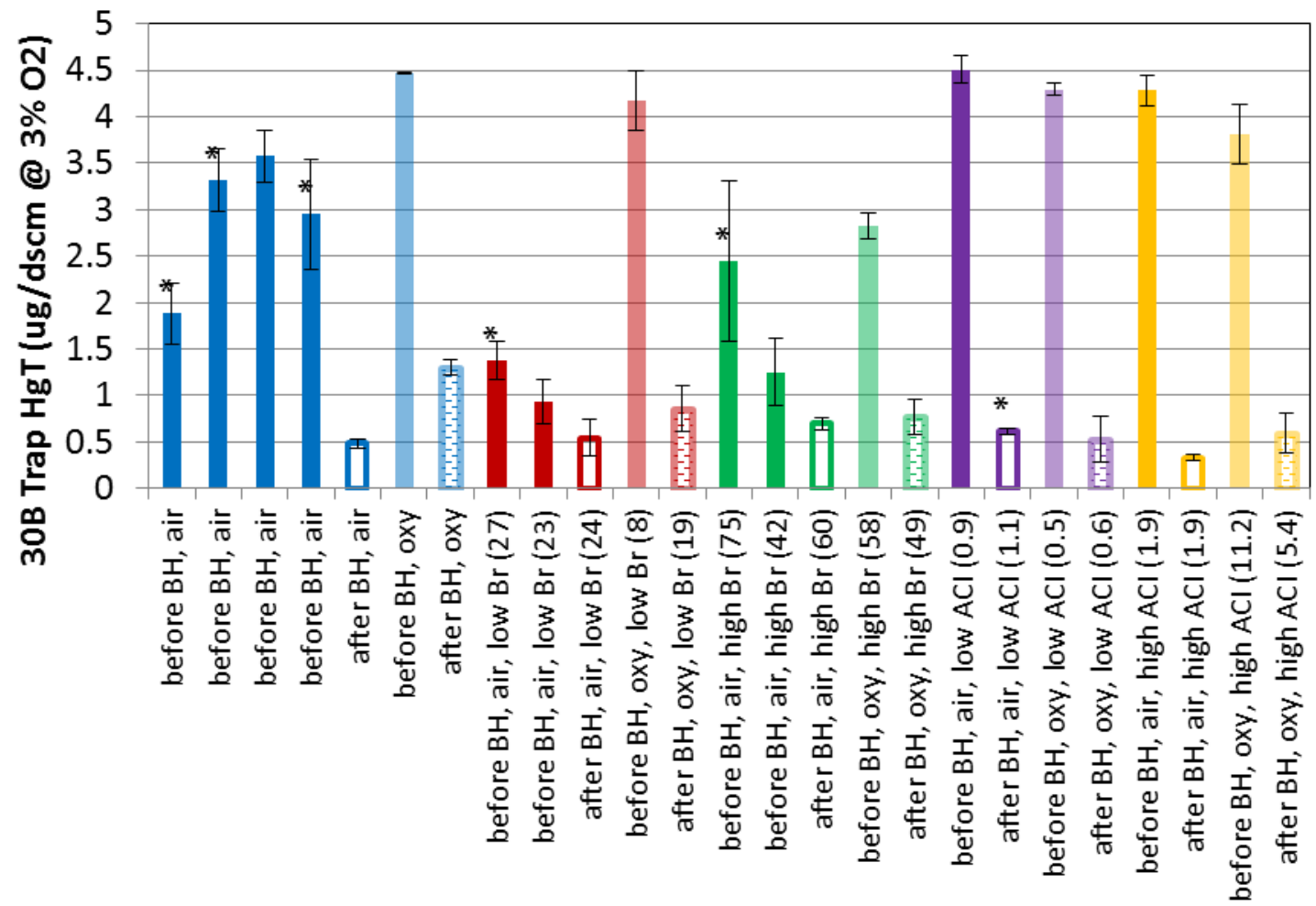

(a) 


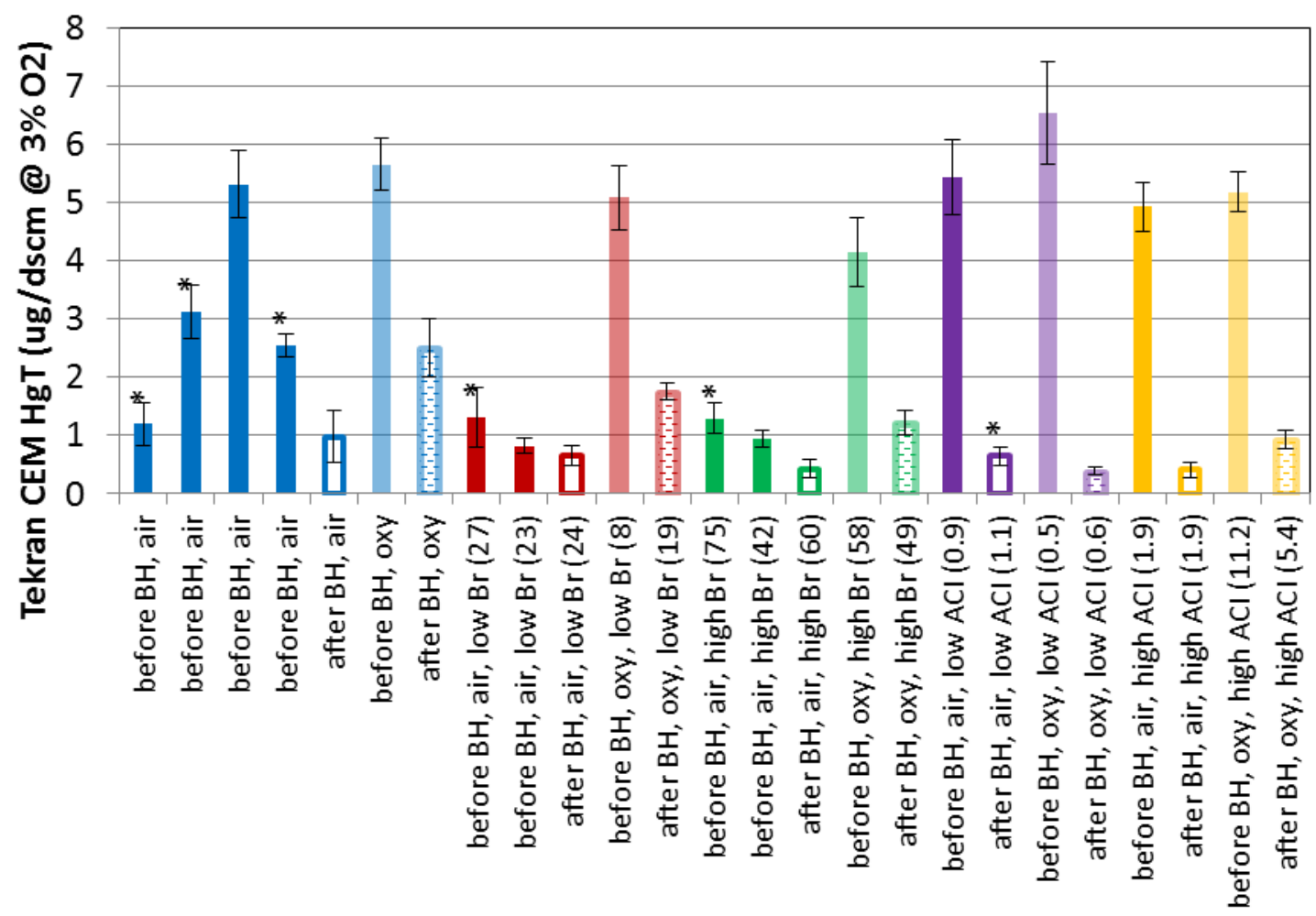

(b)

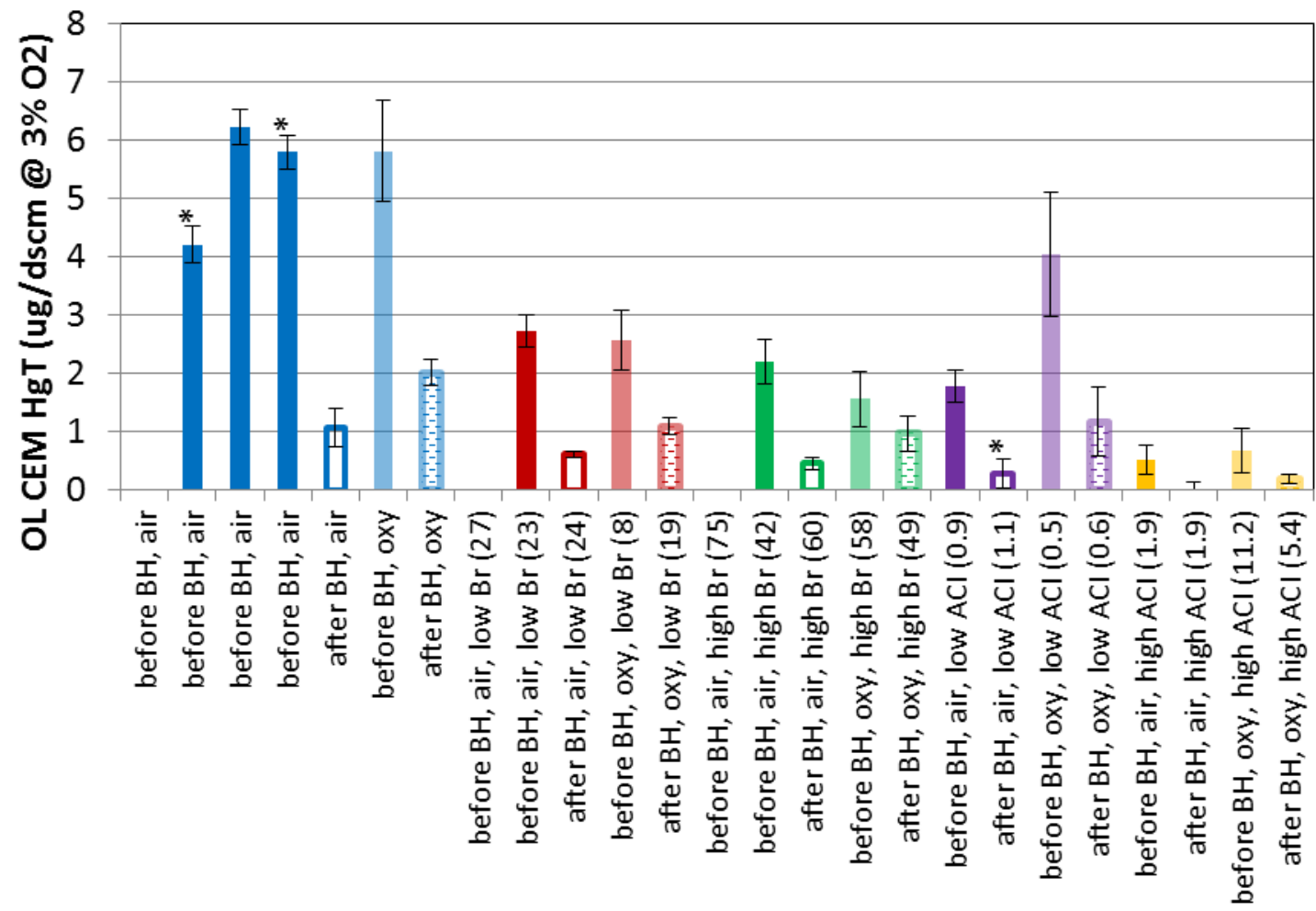

(c)

Figure 4.11-17: Total gas phase mercury measurements from (a) 30B trap, (b) Tekran CEM, or (c) OL CEM (additive feed rate in ppm Br on coal wet or $\mathrm{lb} / \mathrm{MMacf} \mathrm{ACI}$, * LOI >2). 
Mercury oxidation levels reported by the two CEM systems are shown in Figure 4.11-18 and Figure 4.11-19. The oxidation data show significant scatter, with no clear bias when comparing the two measurement techniques. The Tekran CEM showed oxidation was higher during oxy-firing compared to air-firing for most cases, while the OL CEM did not show this trend. Generally, the addition of bromine to the system resulted in increased oxidation as expected. The higher dosage rates of bromine resulted in higher oxidation for most cases.

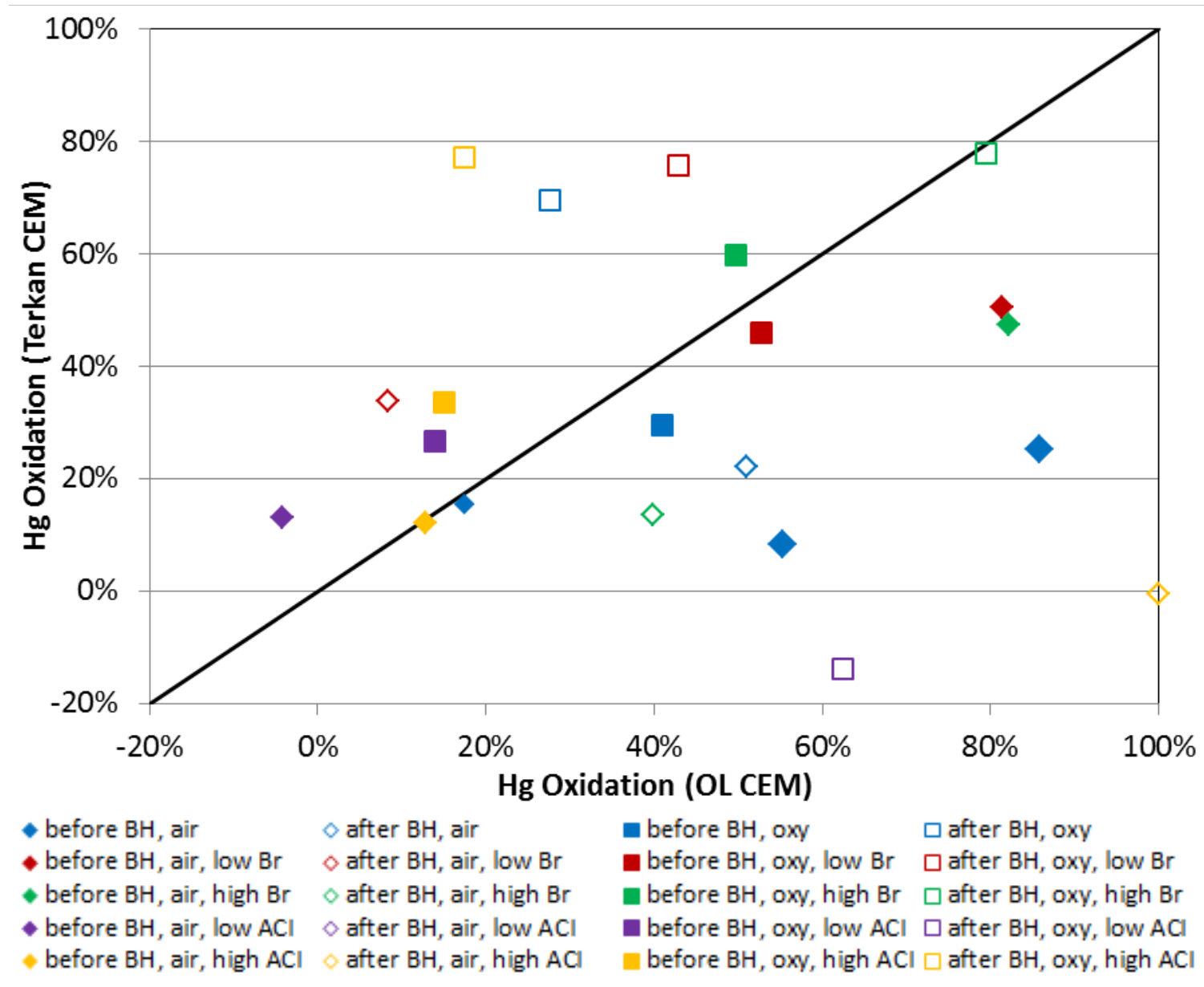

Figure 4.11-18: Comparison of mercury oxidation reported by the Tekran CEM and OL CEM during PRB testing. 


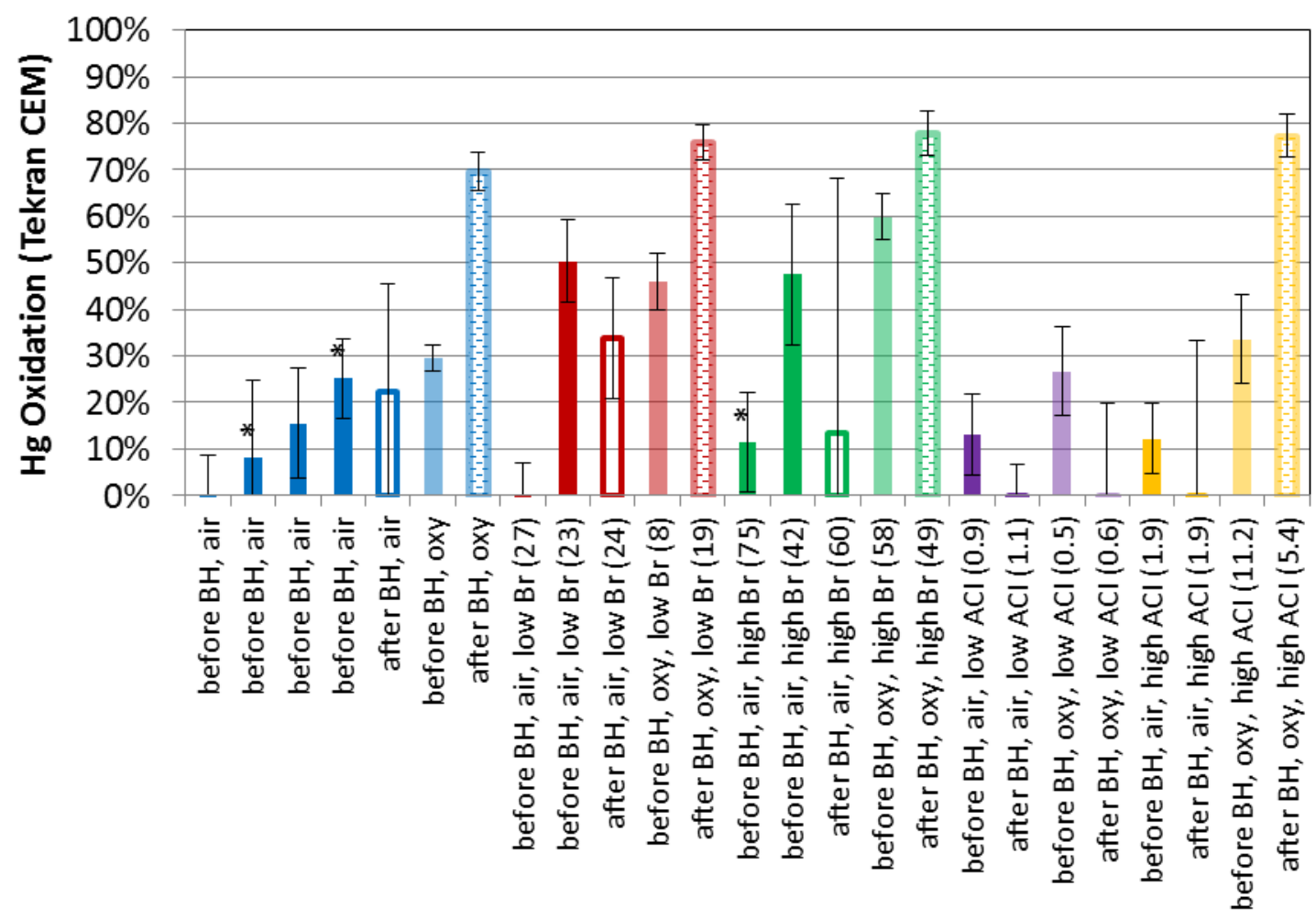

(a)

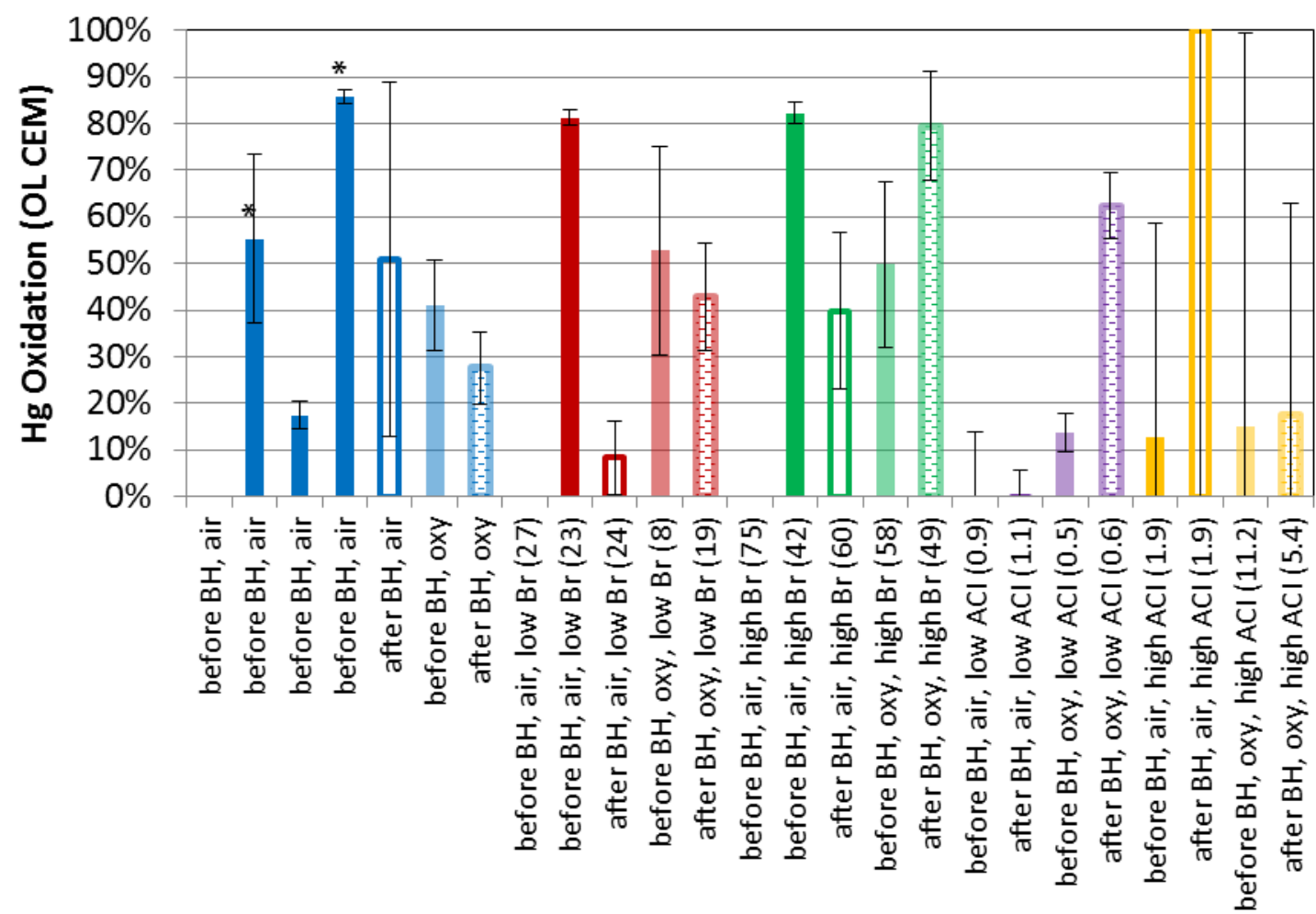

(b)

Figure 4.11-19: Mercury oxidation measurements from (a) Tekran CEM or (b) OL CEM during PRB testing (additive feed rate in ppm Br on coal wet or lb/MMacf ACI, * LOI >2). 
Mercury mass balance closure for the PRB tests is shown in Figure 4.11-20. Here, mass balance is defined as mercury leaving the system (gas phase and ash) divided by mercury entering the system (with coal). An ash carryover of $65 \%$ was assumed. For mercury measurements taken before the baghouse under air-fired conditions, entrained ash mercury content was used to calculate mass balance as this ash most closely represents the gas-solids partitioning corresponding to the gas phase measurement. For all other conditions (after baghouse and before baghouse during oxy-firing), baghouse ash mercury content was used to calculate mass balance. This ash contains additional mercury captured in the baghouse, which must be considered when investigating measurements taken after the baghouse or any measurements that include FGR in which the baghouse is included in the recycle loop. For mercury, mass balance closure between $80 \%$ and $120 \%$ is generally acceptable.

Poor mass balance closure was seen for many of the tests. This is most likely due to unrepresentative ash samples as discussed with Table 4.11-6. Agreement between measurement techniques lends confidence to the gas phase measurements. For many tests mass balance closure was low, suggesting a mercury sink in the system not accounted for or possibly a low assumed ash carryover. Increasing the ash carryover to 90\% did not improve the mass balance closure overall; rather the number of cases outside the acceptable region (above $120 \%$ or below $80 \%$ ) increased. The cases with low mass balance closure remained low and many cases within the acceptable region increased above the acceptable region. The ACI conditions seemed to have the best mass balance closure overall (highest mercury content in ash), suggesting these ash samples more closely represented the mercury content in ash for the entire furnace.

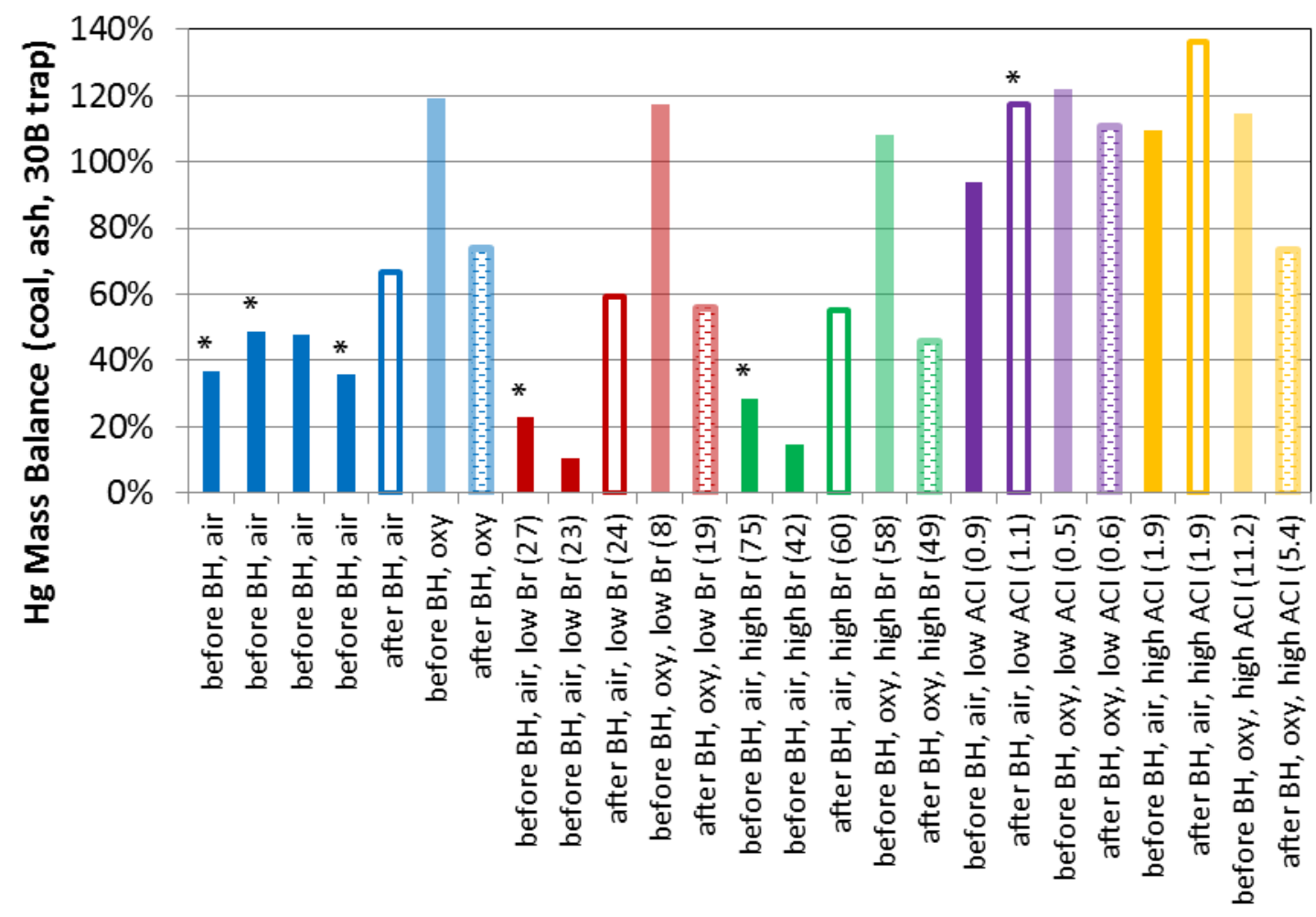

(a) 


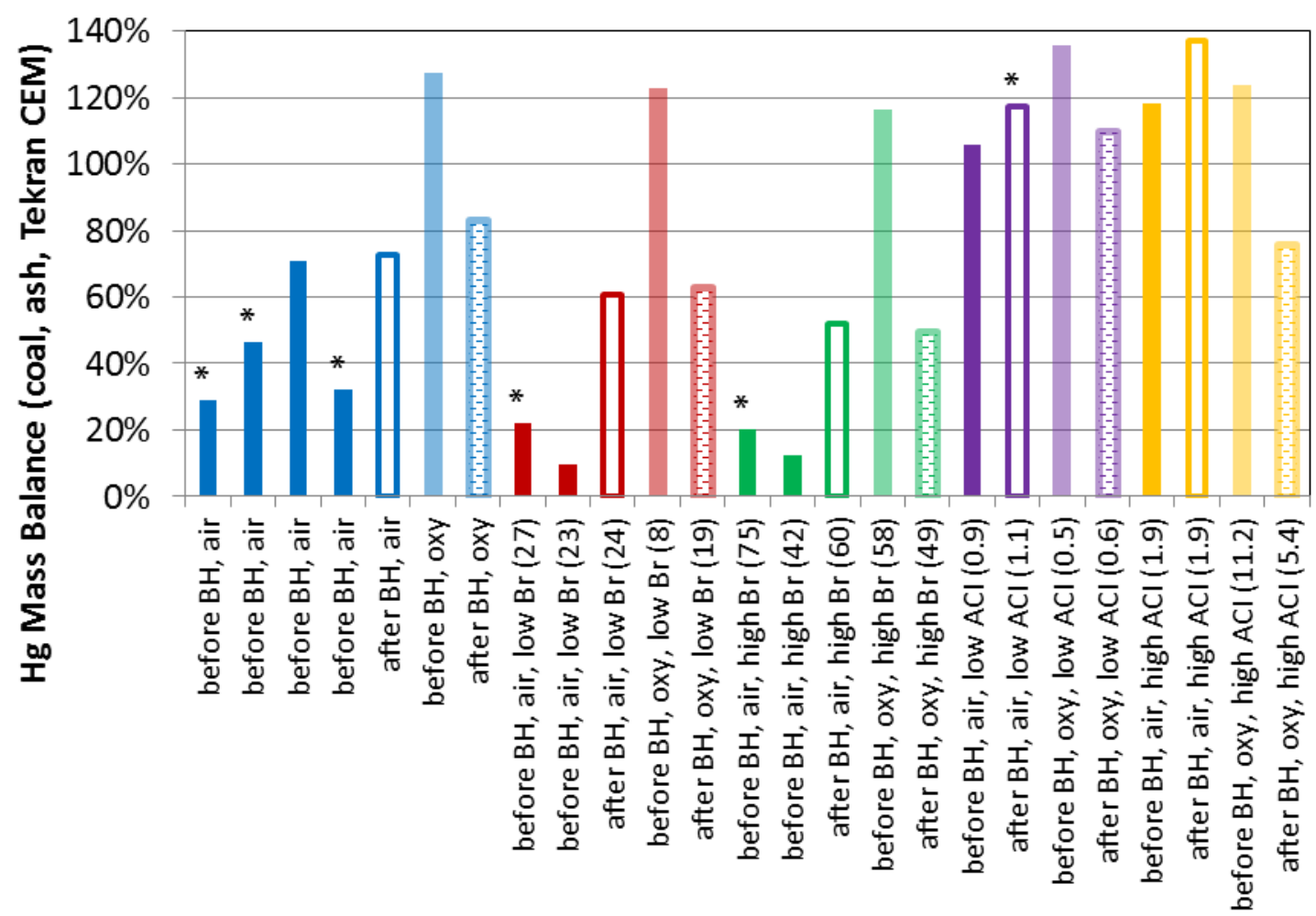

(b)

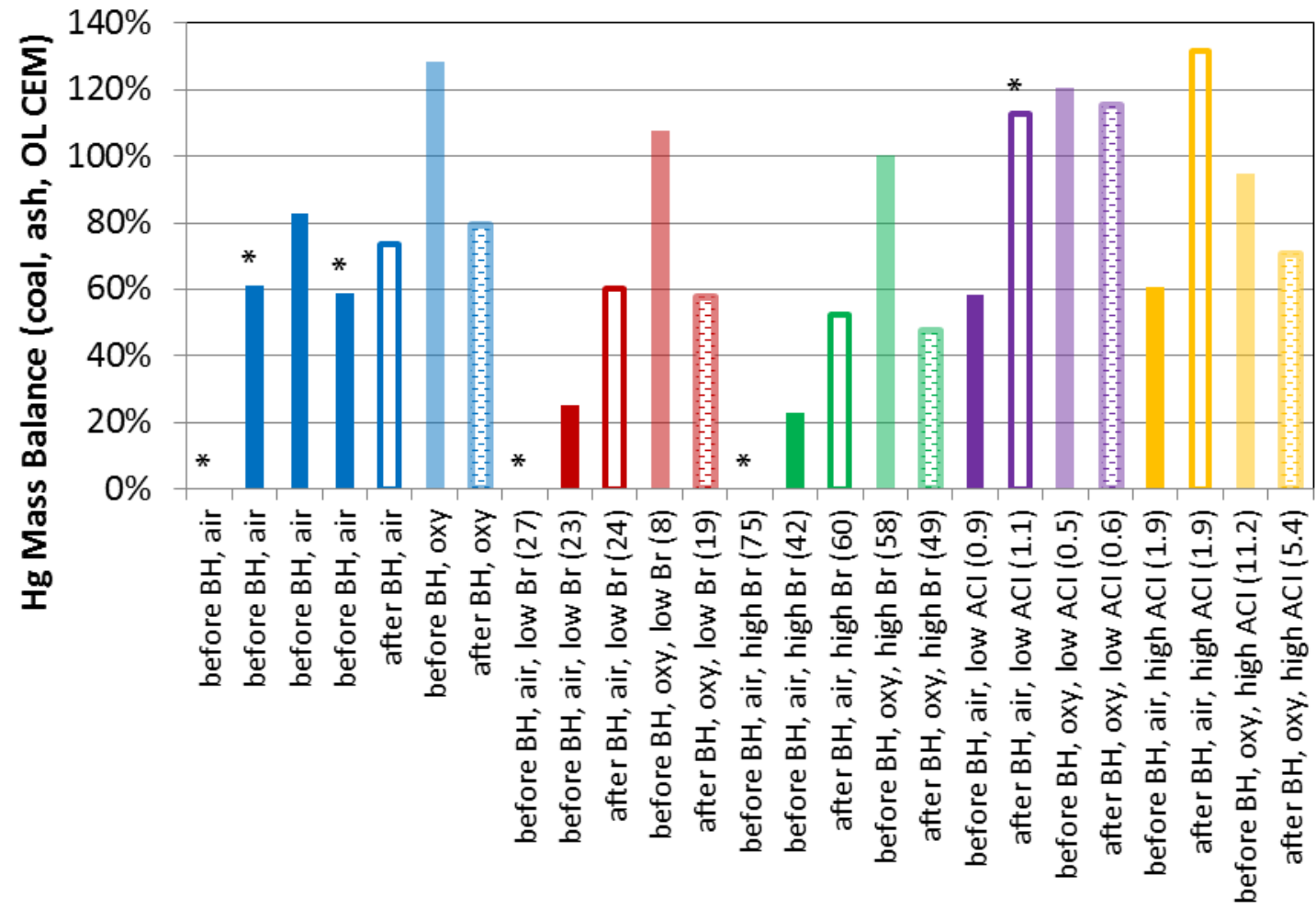

(c)

Figure 4.11-20: Mercury mass balance closure during PRB testing using coal, ash, and (a) 30B trap, (b) Tekran CEM, or (c) OL CEM gas phase mercury measurements (additive feed rate in ppm Br on coal wet or lb/MMacf ACI, * LOI >2). 
Mercury removal is shown in Figure 4.11-21. Mercury removal is higher after the baghouse as expected due to removal across the filter cake. Mercury removal levels after the baghouse were very similar for air- and oxy-fired conditions. The addition of bromine or activated carbon increased removal for most cases. Bromine addition tended to increase removal more before the baghouse compared to carbon injection while removal across the baghouse was higher for carbon injection. Mercury removal increased more before the baghouse with bromine addition for air-fired conditions compared to oxy-fired. It is unclear why ACI seemed to cause a drop in removal for before baghouse measurements during air-firing. It could be that the baseline removal was uncharacteristically high due to higher LOI.
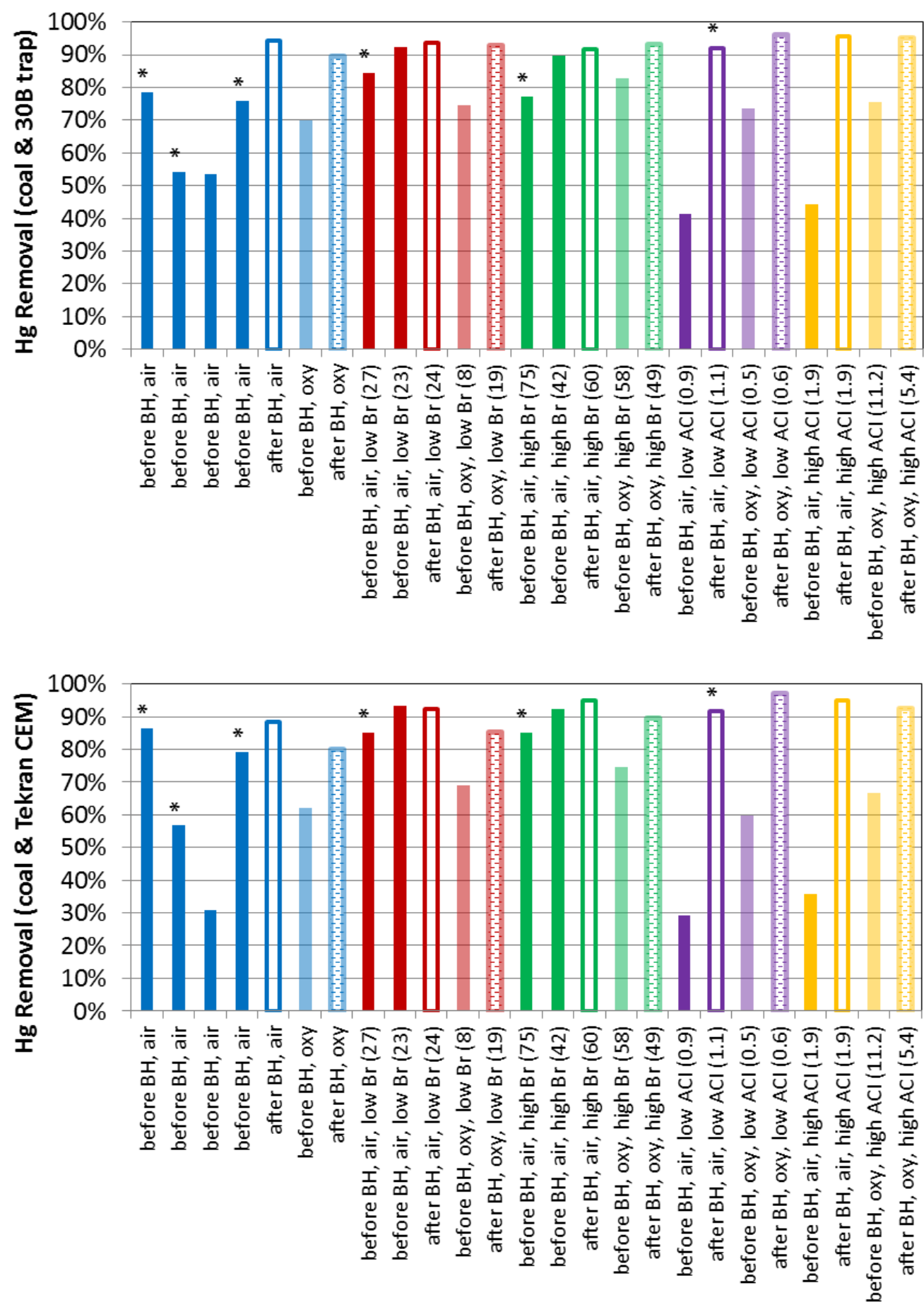


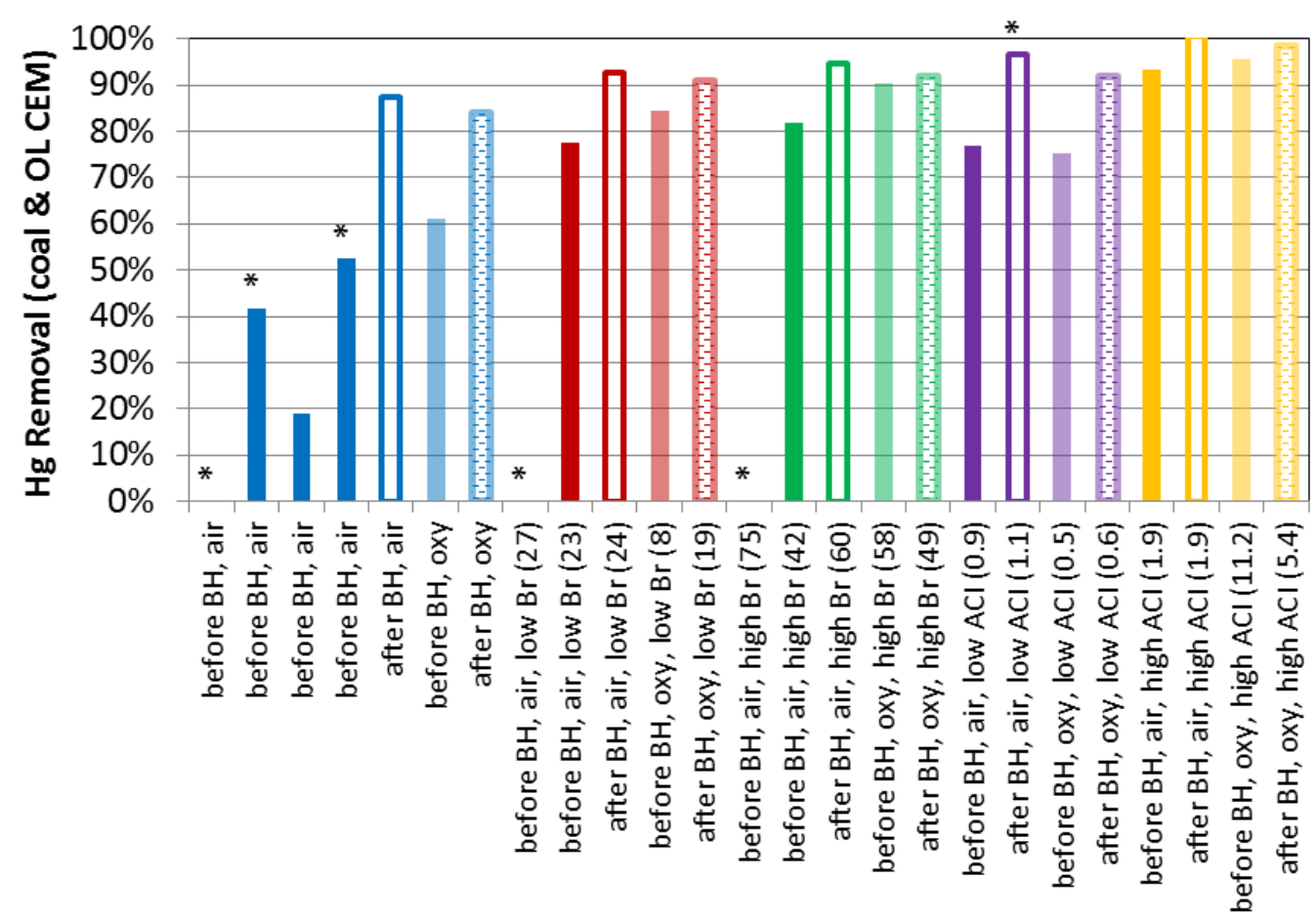

(c)

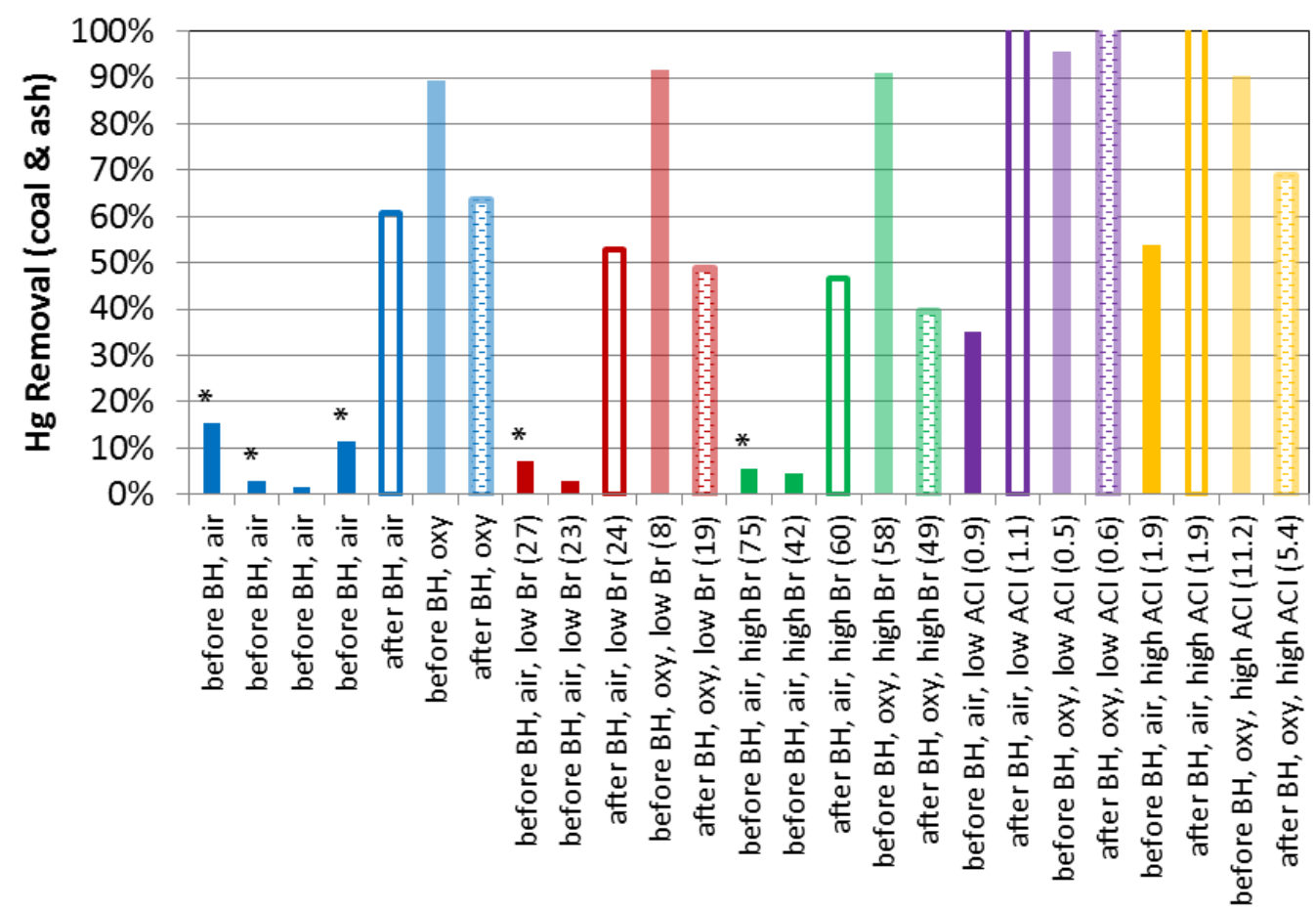

(d)

Figure 4.11-21: Mercury removal for PRB testing calculated using coal input and (a) 30B trap, (b) Tekran CEM, (c) OL CEM gas phase mercury measurements or (d) ash mercury measurement (additive feed rate in ppm Br on coal wet or lb/MMacf ACI, * LOI >2). 
Figure 4.11-22 shows mercury removal above native capture. For these calculations, native capture was defined as the average removal measured either before or after the baghouse during air-firing. These plots show that several additive injection cases did not have improved removal above baseline for certain measurement techniques (those reporting high baseline removal). Bromine addition increased removal before the baghouse while ACI tended to have more of an impact across the baghouse.

While bromine addition showed increased removal before the baghouse for both air- and oxy-firing, higher removal levels were seen for air-firing compared to oxy-firing. This is an unexpected result given oxidation tended to be higher when oxy-firing. One possible explanation is higher $\mathrm{SO}_{2}$ (and therefore $\mathrm{SO}_{3}$ ) concentrations while oxy-firing. $\mathrm{SO}_{3}$ competes with $\mathrm{Hg}$ for capture sites on particulate and will limit the effectiveness of bromine.

Activated carbon was more effective during oxy-firing compared to air-firing. It is unclear why ACI caused a drop in before baghouse removal when air firing. This could be attributed to high baseline removal caused by high LOI. When oxy-firing, an increase in $\mathrm{Hg}$ capture sites provided by activated carbon was able to increase Hg removal.

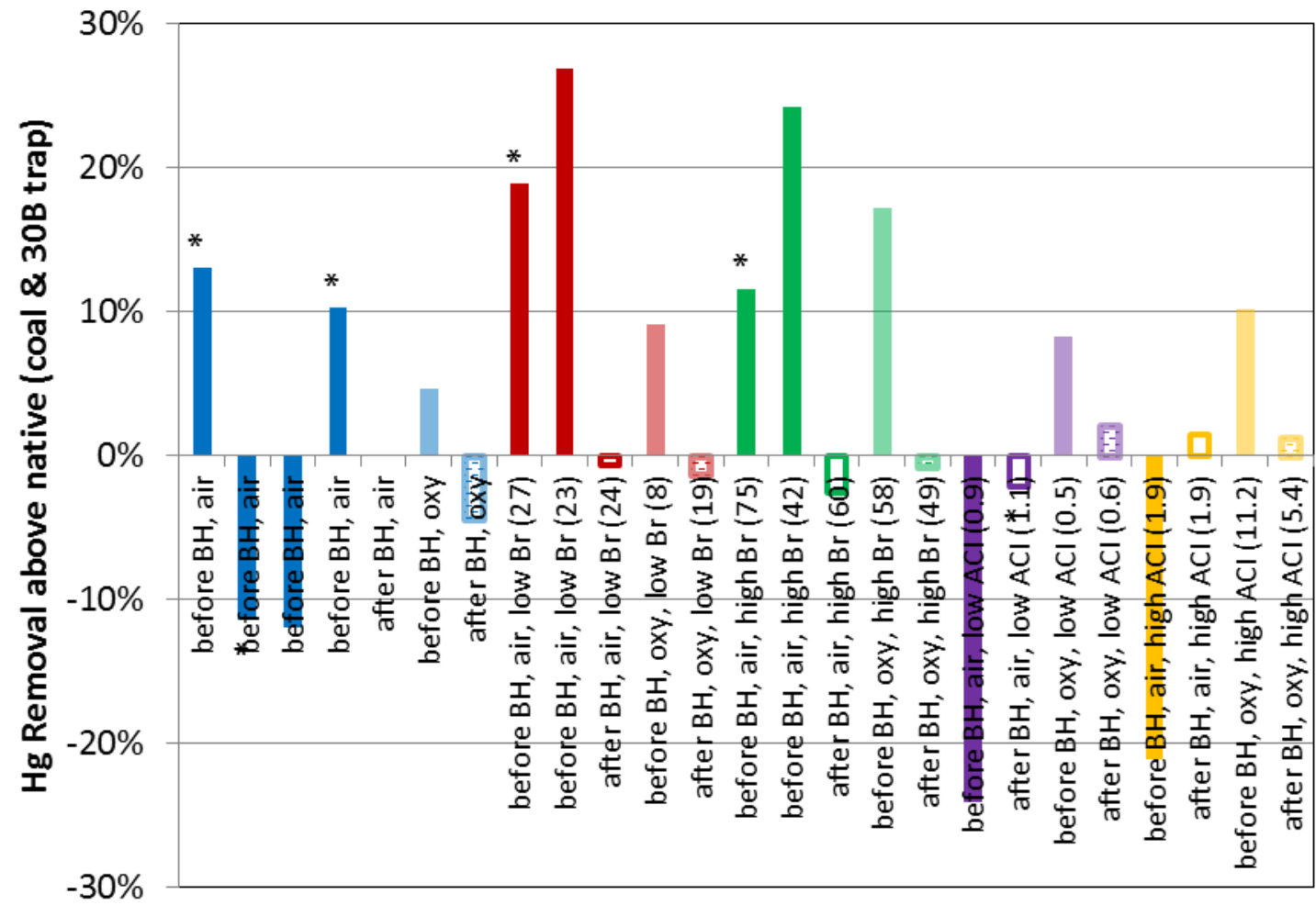

(a) 


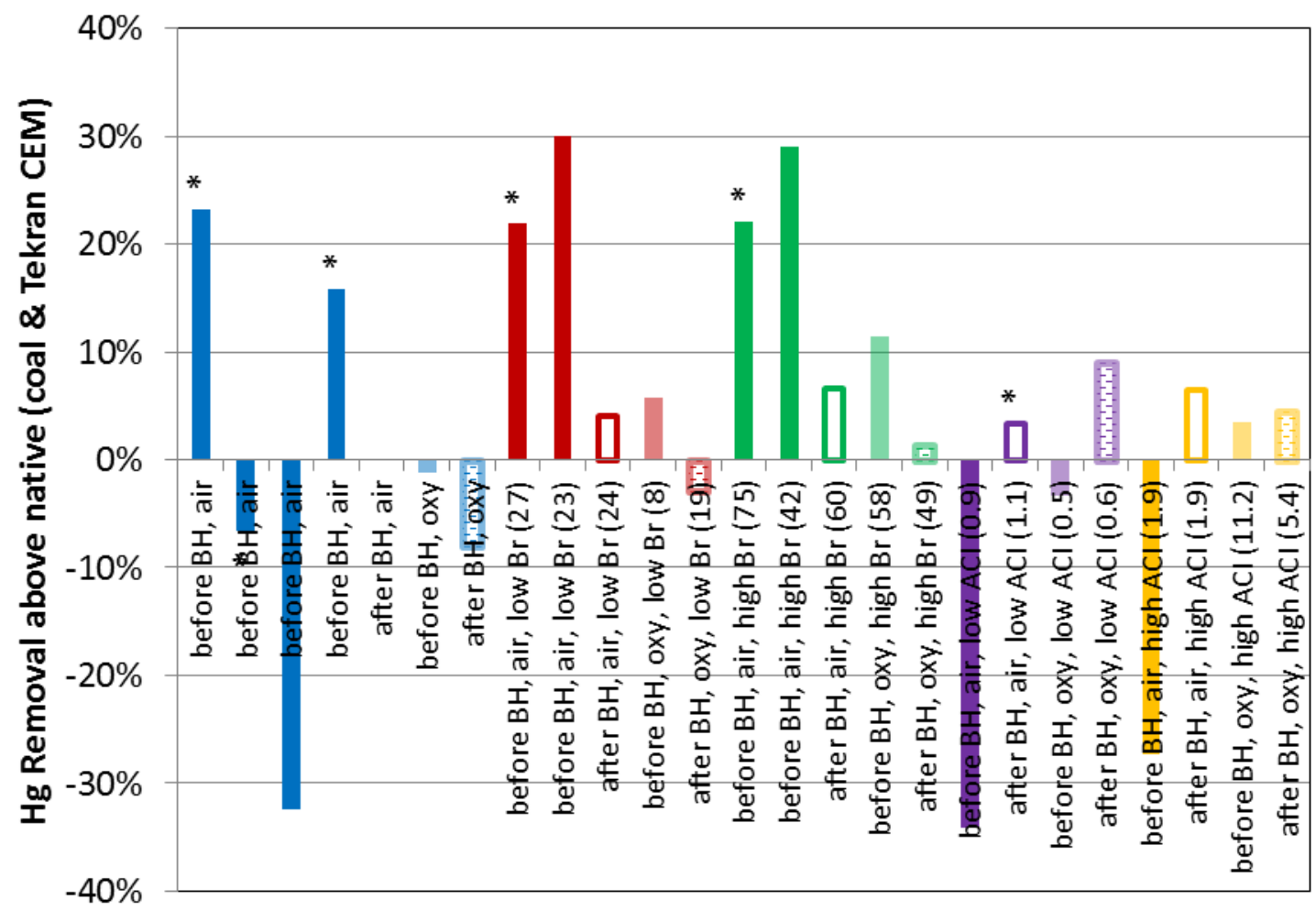

(b)

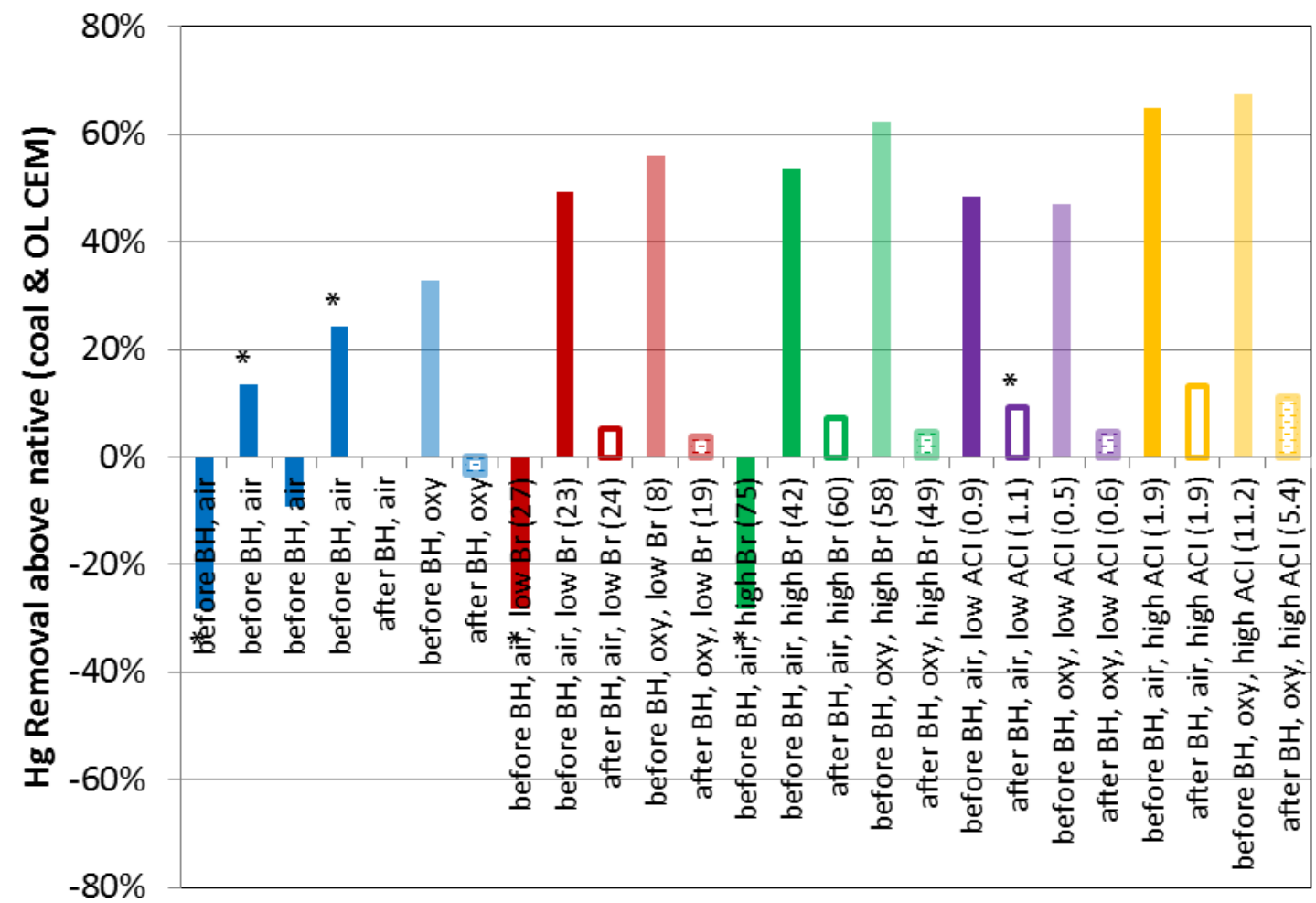

(c) 


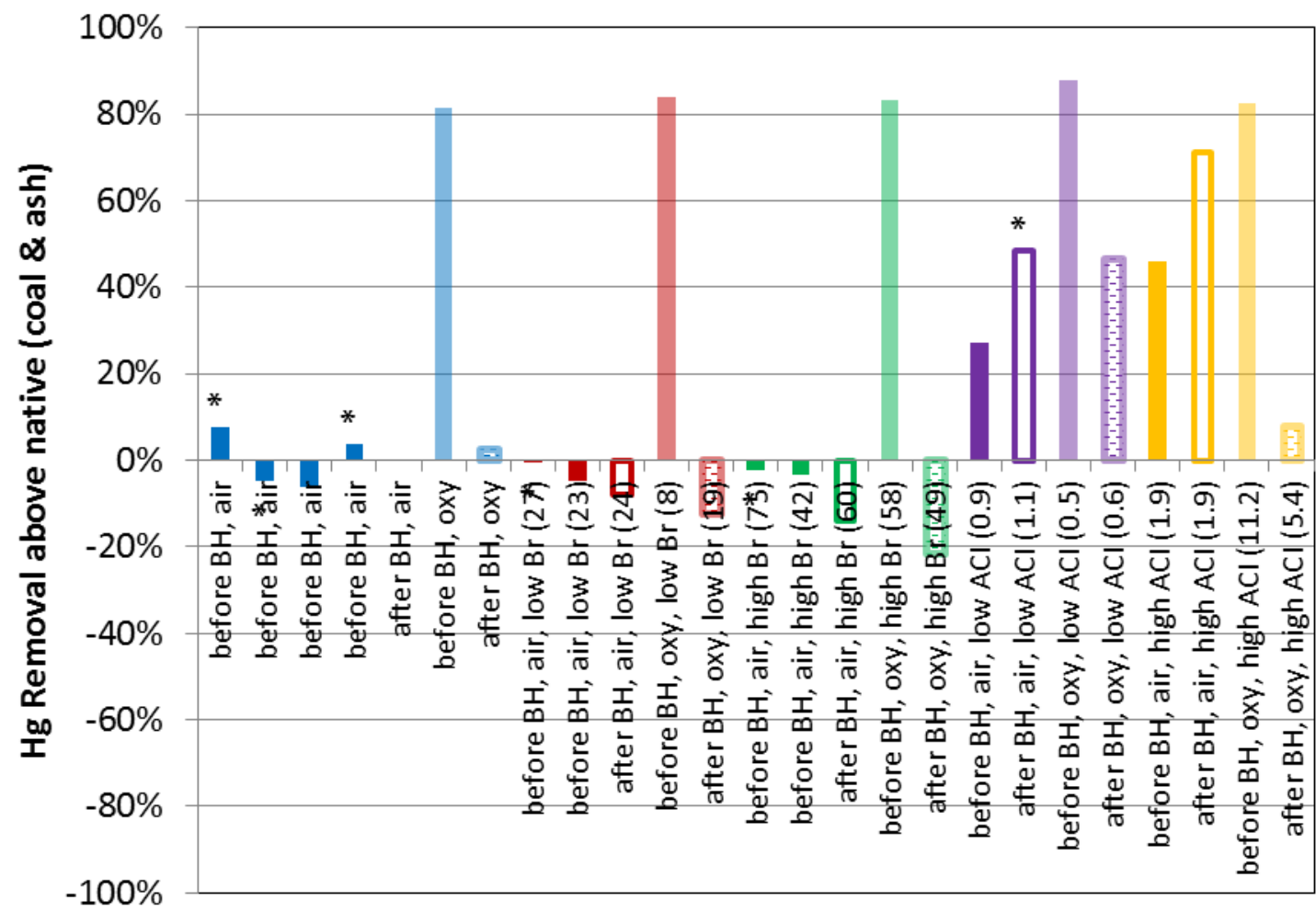

(d)

Figure 4.11-22: Mercury removal above native capture for PRB testing calculated using coal input and (a) 30B trap, (b) Tekran CEM, (c) OL CEM gas phase mercury measurements or (d) ash mercury measurement (additive feed rate in ppm Br on coal wet or lb/MMacf ACI, * LOI >2).

\subsubsection{Results - Bituminous coal}

The furnace operating conditions for the bituminous testing are shown in Table 4.11-7. The excess $\mathrm{O}_{2}$ in the furnace was kept approximately the same for all testing. The $\mathrm{CO}_{2}$ concentration increased from $15 \%$ dry during air-firing to $87 \%$ dry for oxy-firing. The remaining gas composition is largely $\mathrm{N}_{2}$. The flue gas temperatures at the baghouse inlet and outlet dropped during oxy-firing, much more at the outlet location. This can be attributed to the smaller flue gas volume, which results in longer residence time and increased heat transfer.

Table 4.11-7: L1500 operating conditions during Bituminous testing.

\begin{tabular}{|c|c|c|c|c|c|}
\hline & $\begin{array}{c}\text { Firing Rate } \\
(\mathbf{k W})\end{array}$ & $\begin{array}{c}\mathbf{O}_{\mathbf{2}} \\
\mathbf{( \% )} \text { dry) }\end{array}$ & $\begin{array}{c}\mathbf{C O}_{\mathbf{2}} \\
\mathbf{( \% ,} \mathbf{d r y})\end{array}$ & $\begin{array}{c}\text { BH inlet } \\
\mathbf{( F )}\end{array}$ & $\begin{array}{c}\text { BH outlet } \\
\mathbf{( F )}\end{array}$ \\
\hline Air-Fired & $775-1025$ & 3.5 & 15 & 356 & 239 \\
\hline Oxy-Fired & $775-880$ & 3.4 & 87 & 341 & 146 \\
\hline
\end{tabular}

A bituminous coal from the Pratt seam of the North River Mine in Alabama was used in this study. The properties of this coal are shown in Table 4.11-8. The mercury content of the Pratt bituminous coal is $0.21 \mu \mathrm{g} / \mathrm{g}$. The expected gas phase mercury concentration from this coal is approximately $26 \mu \mathrm{g} / \mathrm{dscm}$ (air-fired) or $17 \mathrm{lb} / \mathrm{TBtu}$. For oxy-fired conditions, gas phase mercury concentrations could be up to 5 
times higher due to the removal of the nitrogen diluents. A complete list of the mercury analyses of each coal sample is shown in Table 4.11-9.

Table 4.11-8: Properties of the Pratt Bituminous coal.

\begin{tabular}{|c|c|c|c|}
\hline \multicolumn{4}{|c|}{ Pratt (North River) Bituminous Coal } \\
\hline \multicolumn{2}{|c|}{ Coal Analyses } & \multicolumn{2}{|c|}{ Mineral Matter Analyses } \\
\hline C & 69.23 & Al & 25.91 \\
\hline $\mathbf{H}$ & 4.82 & Ca & 3.41 \\
\hline $\mathbf{N}$ & 1.69 & Fe & 13.20 \\
\hline $\mathbf{S}$ & 2.22 & Mg & 1.18 \\
\hline $\mathbf{O}$ & 6.54 & Mn & 0.04 \\
\hline Ash & 13.14 & $\mathbf{P}$ & 0.83 \\
\hline Moisture & 2.38 & $\mathbf{K}$ & 2.33 \\
\hline Volatile Matter & 35.64 & Si & 44.78 \\
\hline Fixed Carbon & 48.85 & $\mathrm{Na}$ & 0.47 \\
\hline HHV, Btu/lb & 12659 & S & 3.72 \\
\hline Hg, $\mu g / g$ AR & $0.21 \pm 0.01$ & $\mathbf{T i}$ & 1.25 \\
\hline
\end{tabular}

Table 4.11-9: Mercury concentration of each bituminous coal sample.

\begin{tabular}{|l|c|c|}
\hline Coal & Date & Hg (ng/g AR) \\
\hline Pratt Bituminous & $06 / 10 / 2013$ & 200.37 \\
\hline Pratt Bituminous & $06 / 11 / 2013$ & 217.70 \\
\hline Pratt Bituminous & $06 / 12 / 2013$ & 240.70 \\
\hline Pratt Bituminous & $06 / 13 / 2013$ & 208.90 \\
\hline Pratt Bituminous & $06 / 14 / 2013$ & 204.63 \\
\hline Pratt Bituminous & $06 / 17 / 2013$ & 204.93 \\
\hline Pratt Bituminous & $06 / 18 / 2013$ & 217.67 \\
\hline Pratt Bituminous & $06 / 19 / 2013$ & 204.27 \\
\hline Pratt Bituminous & $06 / 20 / 2013$ & 217.07 \\
\hline
\end{tabular}

Baghouse ash samples were taken once during each test and analyzed for mercury content and LOI. Inflight (entrained) ash samples were taken upstream of the baghouse when mercury sampling was being performed upstream of the baghouse and analyzed for mercury content. Results from the ash analyses are shown in Table 4.11-10. Unlike the PRB testing, the mercury content of the ash did not seem to follow any trends. The mercury content of the baghouse ash was relatively constant, whether bromine or activated carbon was injected or not. The entrained ash mercury content also varied widely and no trend was observed. The baghouse ash is expected to have higher mercury content than the entrained ash samples (more mercury is captured in the ash as it sits on the filters forming a cake), which was the case during both PRB and bituminous testing. The LOI showed variability, which is a reflection of unstable furnace operating conditions. As expected, the LOI during bituminous testing was significantly higher than during PRB testing. Due to its horizontal arrangement and flue gas velocities, the L1500 furnace has significant ash dropout before the baghouse. It is likely that the fly ash sampled from the baghouse or entrained in the upstream section of duct may not be representative of the entire system. The fly ash spread throughout the furnace will certainly behave differently towards mercury as temperature and composition vary. This will have an impact on mercury mass balance calculations. 
Figure 4.11-23 shows a photograph of the entrained ash samples taken during bituminous testing. Although the LOI of these samples was not measured, the variability in color reflects the variability in LOI. The measured mercury content of each sample is also shown for comparison. While no clear trend with additive injection was noted with these samples, a clear trend between color and mercury content is seen. The darker samples (higher LOI) tend to have higher mercury content. This illustrates how furnace operation can influence mercury capture by fly ash, even overshadowing additive injection.

Table 4.11-10: Mercury and LOI analyses of bituminous fly ash.

\begin{tabular}{|c|c|c|c|c|c|c|}
\hline & & \multicolumn{2}{|c|}{ Baghouse Ash Samples } & \multicolumn{2}{c|}{ Entrained Ash Samples } \\
\hline Date & Conditions & Time & $\begin{array}{c}\text { Hg } \\
\text { (ug/g AR) }\end{array}$ & $\begin{array}{c}\text { LOI } \\
\mathbf{( \% )}\end{array}$ & Time & $\begin{array}{c}\text { Hg } \\
\text { (ug/g AR) }\end{array}$ \\
\hline 6/10/13 & air, after BH & $14: 30$ & 1041.13 & 5.35 & & \\
\hline 6/10/13 & air, after BH, low Br & $17: 15$ & 1150.10 & 10.67 & & \\
\hline $6 / 11 / 13$ & air, after BH, high Br & $11: 15$ & 1051.43 & 9.10 & & \\
\hline $6 / 11 / 13$ & air, after BH, low ACI & $13: 45$ & 1110.83 & 11.86 & & \\
\hline $6 / 11 / 13$ & air, after BH, high ACI & $17: 00$ & 1318.73 & 11.14 & & \\
\hline $6 / 12 / 13$ & oxy, after BH & $12: 30$ & 1183.73 & 12.20 & & \\
\hline $6 / 12 / 13$ & oxy, after BH, low Br & $14: 45$ & 1383.83 & 6.72 & & \\
\hline $6 / 12 / 13$ & oxy, after BH, high Br & $17: 45$ & 1472.13 & 7.14 & & \\
\hline $6 / 13 / 13$ & oxy, after BH, low ACI & $13: 00$ & 1570.77 & 8.20 & & \\
\hline $6 / 13 / 13$ & oxy, after BH, high ACI & $15: 00$ & 1099.17 & 4.59 & & \\
\hline $6 / 14 / 13$ & air, before BH & $12: 15$ & 1440.97 & 5.20 & $12: 30$ & 689.00 \\
\hline $6 / 14 / 13$ & air, before BH, low Br & $15: 30$ & 1209.37 & 6.02 & $15: 40$ & 1073.23 \\
\hline $6 / 17 / 13$ & air, before BH, high Br & $11: 45$ & 1180.33 & 18.52 & $12: 00$ & 108.87 \\
\hline $6 / 17 / 13$ & air, before BH, low ACI & $17: 00$ & 1144.70 & 12.40 & $17: 15$ & 210.90 \\
\hline $6 / 18 / 13$ & air, before BH, high ACI & $11: 30$ & 1370.37 & 7.75 & $11: 45$ & 442.77 \\
\hline $6 / 18 / 13$ & oxy, before BH & $15: 30$ & 1291.43 & 6.63 & $16: 00$ & 2671.90 \\
\hline $6 / 18 / 13$ & oxy, before BH, low Br & $17: 30$ & 1281.00 & 6.83 & $17: 45$ & 64.47 \\
\hline $6 / 19 / 13$ & oxy, before BH, high Br & $17: 30$ & 1302.87 & 7.69 & $17: 30$ & 1029.23 \\
\hline $6 / 20 / 13$ & oxy, before BH, low ACI & $11: 40$ & 1561.47 & 14.79 & $12: 00$ & 818.57 \\
\hline $6 / 20 / 13$ & oxy, before BH, high ACI & $14: 10$ & 1383.97 & 8.83 & $14: 30$ & 152.60 \\
\hline
\end{tabular}




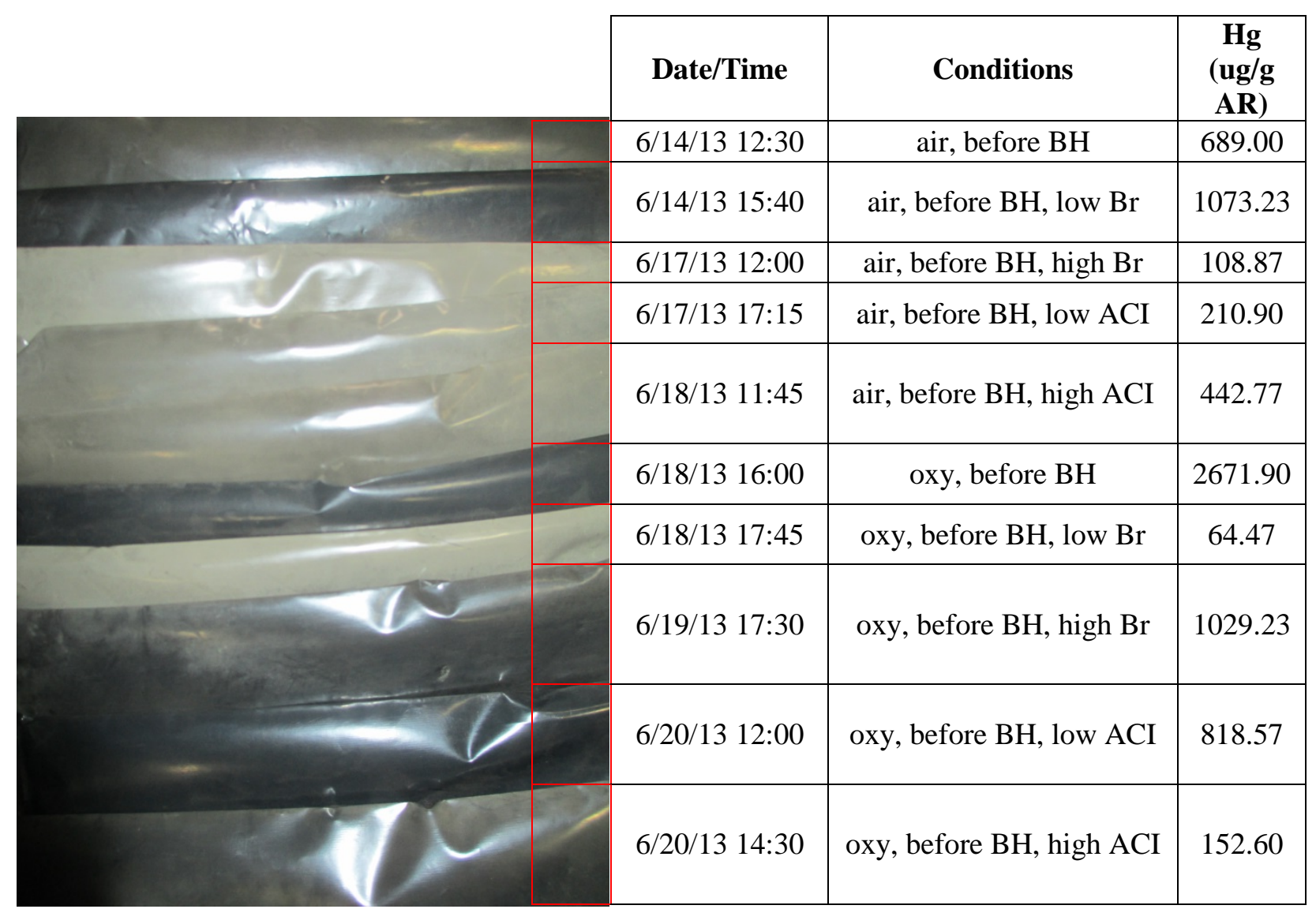

Figure 4.11-23: Picture of entrained ash samples during bituminous testing and the corresponding mercury content. 
The three mercury measurement techniques are compared in Figure 4.11-24. For the bituminous testing, none of the three measurement techniques seemed to agree. The OL CEM gave the highest mercury readings, well above the Tekran CEM or the carbon traps. The Tekran CEM gave the lowest mercury measurements with the 30B carbon traps somewhere between the two CEM systems. One likely explanation is plugging of the QSIS inertial separation probe used to sample flue gas for the Tekran CEM and the 30B carbon traps. The QSIS probe uses an educator to pull sample gas from the duct. The suction capability of the probe is measured using a $\Delta \mathrm{P}$ measurement. During testing, this $\Delta \mathrm{P}$ is maximized to ensure ample flue gas flow is available for the two systems. It was found that when pulling flue gas for carbon trap measurement, the Tekran CEM was unable to pull enough sample gas, even though the QSIS probe showed sufficient $\Delta \mathrm{P}$. On the last day of bituminous testing (following the completion of the test matrix), the $\Delta \mathrm{P}$ measurement on the QSIS probe dropped to zero. This behavior had never been seen before and could not be remedied with blowback. The entire probe was disassembled and it was discovered that the educator had become plugged with ash, which had sufficiently solidified so as to completely restrict sample flow. The educator was cleaned as best as possible and the probe was reassembled. The $\Delta \mathrm{P}$ was restored and suction at the probe tip returned. Because this occurred on the last day of testing, no further experiments were performed with the clean probe. The QSIS probe had never previously been taken apart and cleaned to this degree. It has been in service for nine years, though only used periodically (approximately 2 weeks per year). Most applications are in high-dust environments and it is suspected that ash had been accumulating in the educator for some time. It is likely that the probe was mostly plugged for the duration of the bituminous testing. During previous testing, the restricted flow was not severe enough to impact measurement. The mercury measurement techniques agreed during PRB testing, probe $\Delta \mathrm{P}$ was maintained, and the Tekran CEM and trap system were able to pull sufficient sample gas at the same time. This problem with the QSIS probe likely impacted both the Tekran CEM and carbon trap mercury measurements. For this reason, the OL CEM measurements are expected to be the most representative. Based on findings during the PRB testing (OL CEM tended to have low readings during additive injection when sampling before the baghouse), for bituminous testing the frequency of blowback on the OL probe was increased and the heated probe filter was washed with distilled water prior to each test. 
Reaction Engineering International - Characterizing Oxy-combustion Impacts for Coal-fired Boilers

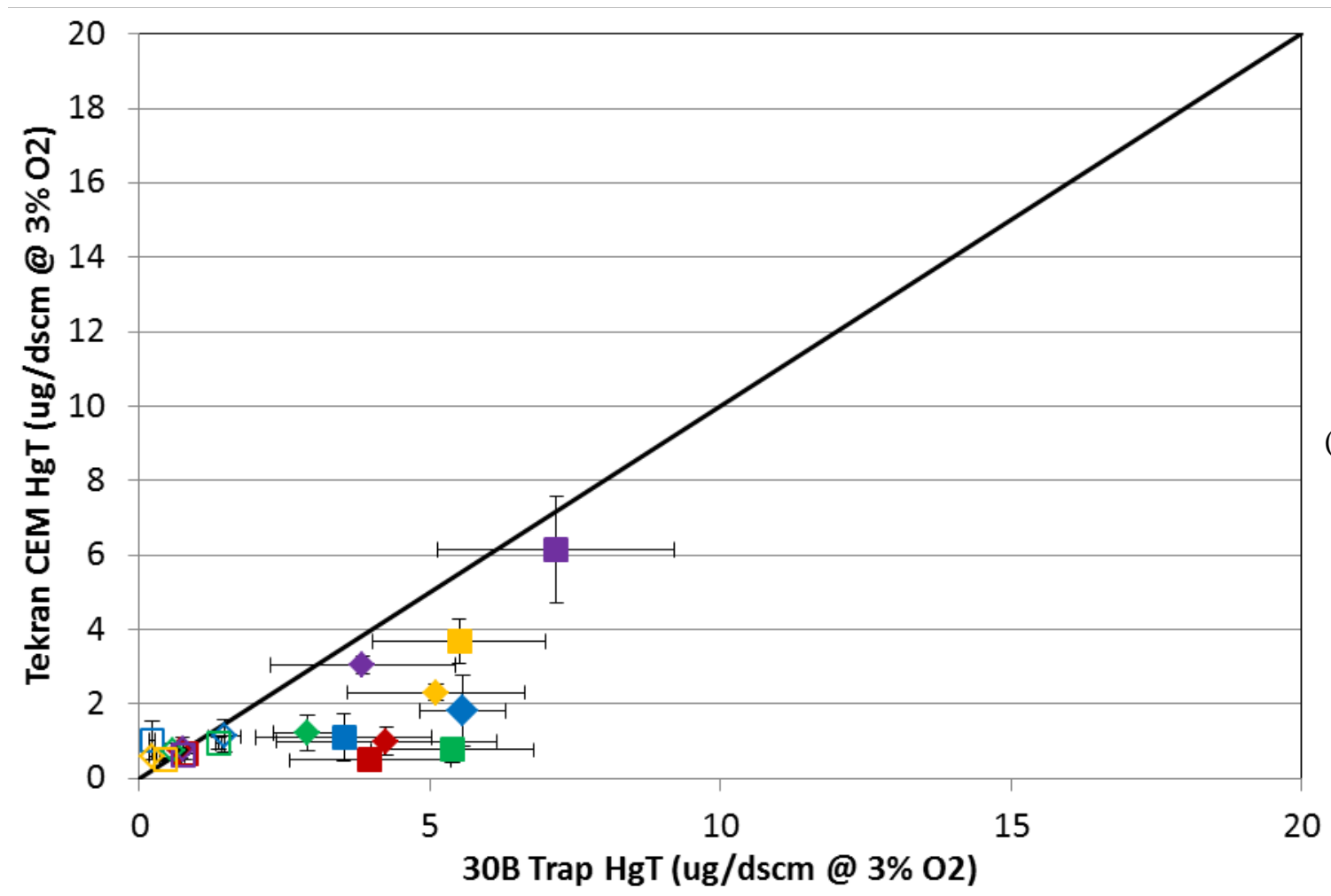

(a)

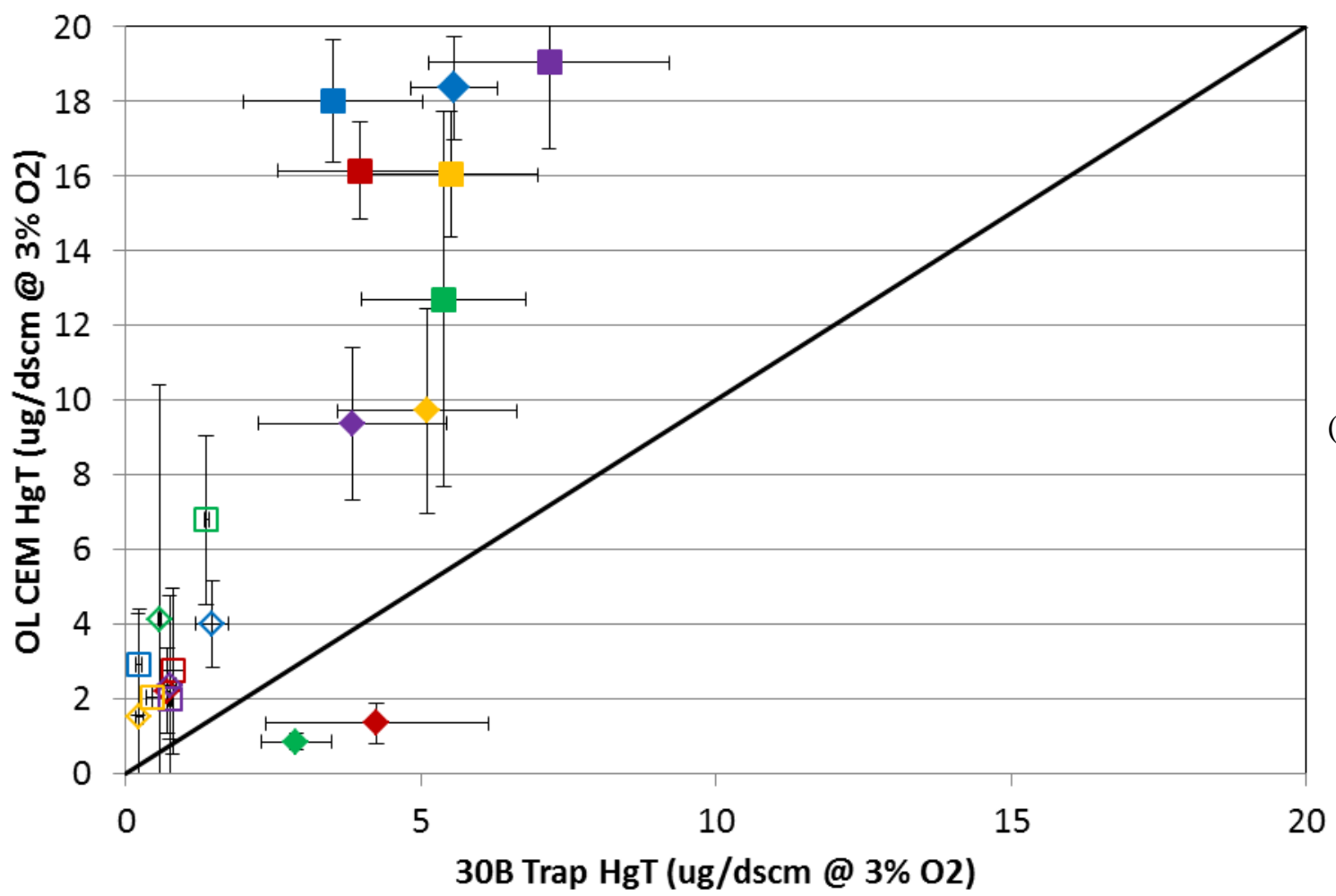




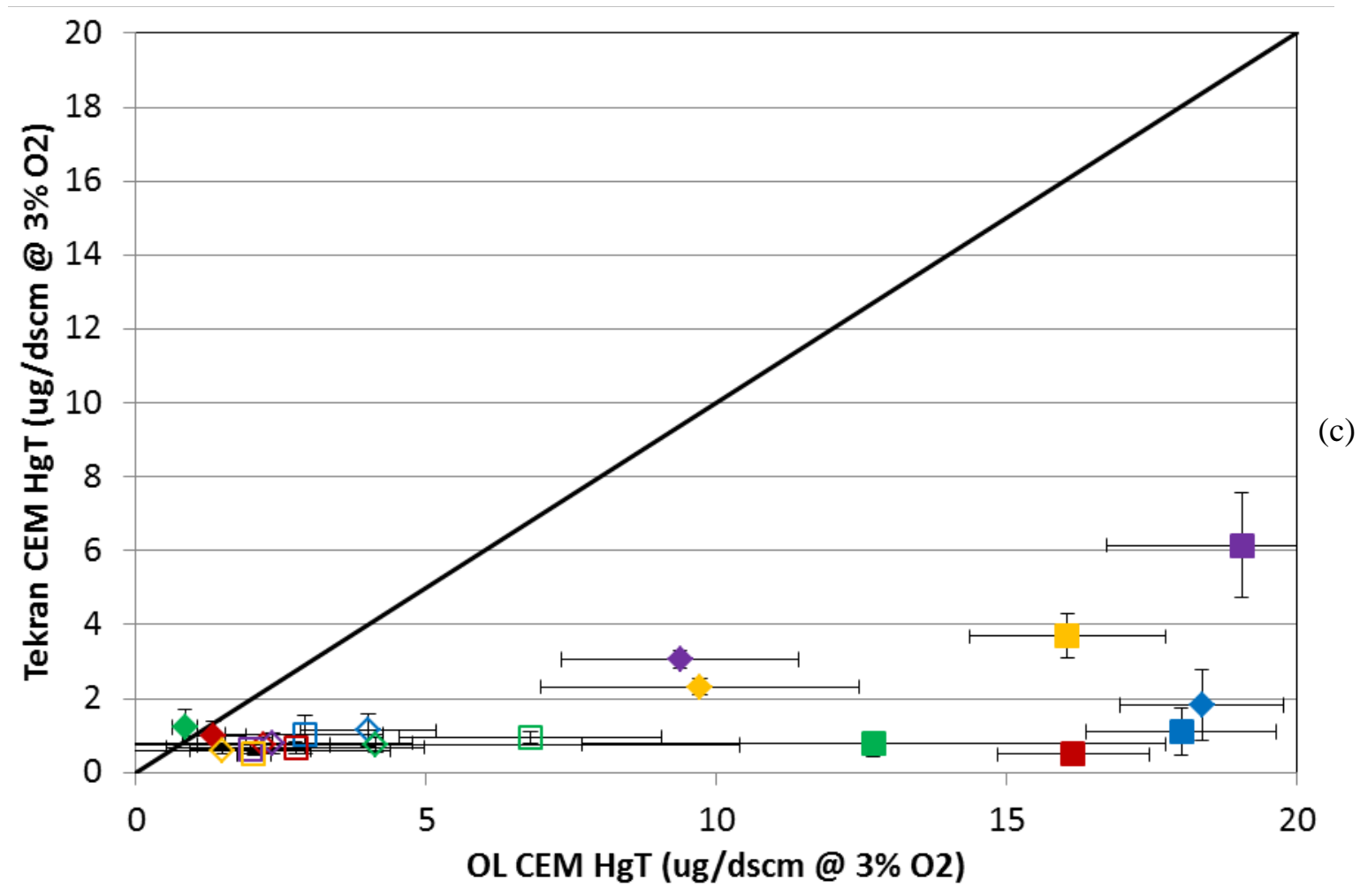

\footnotetext{
- before $\mathrm{BH}$, air $\diamond$ after $\mathrm{BH}$, air

- before $\mathrm{BH}$, air, low $\mathrm{Br} \diamond$ after $\mathrm{BH}$, air, low $\mathrm{Br}$

- before $\mathrm{BH}$, air, high $\mathrm{Br} \diamond$ after $\mathrm{BH}$, air, high $\mathrm{Br}$

- before $\mathrm{BH}$, air, low $\mathrm{ACl} \diamond$ after $\mathrm{BH}$, air, low $\mathrm{ACl}$

before $\mathrm{BH}$, air, high $\mathrm{ACl}$ after $\mathrm{BH}$, air, high $\mathrm{ACl}$
}
- before $\mathrm{BH}$, oxy $\square$ after $\mathrm{BH}$, oxy
before $\mathrm{BH}$, oxy, low $\mathrm{Br} \quad \square$ after $\mathrm{BH}$, oxy, low $\mathrm{Br}$ $\square$ before $\mathrm{BH}$, oxy, high $\mathrm{Br} \square$ after $\mathrm{BH}$, oxy, high $\mathrm{Br}$ $\square$ before $\mathrm{BH}$, oxy, low $\mathrm{ACl} \square$ after $\mathrm{BH}$, oxy, low $\mathrm{ACl}$ $\square$ before $\mathrm{BH}$, oxy, high $\mathrm{ACl} \square$ after $\mathrm{BH}$, oxy, high $\mathrm{ACl}$

Figure 4.11-24: Comparison of (a) trap and Tekran CEM, (b) trap and OL CEM, (c) OL CEM and Tekran CEM total mercury measurements during bituminous testing. 
Total gas phase mercury measurements for each test are shown in Figure 4.11-25. The x-axis represents the test conditions, with the additive injection rates in parentheses ( $\mathrm{ppm} \mathrm{Br}$ on coal wet for bromine addition and lb/MMacf for ACI). The tests marked with an asterisk $(*)$ represent tests where the measured baghouse LOI was high $(>13)$. Looking at the OL CEM results, mercury measurements were generally lower after the baghouse compared to before the baghouse. This is expected as mercury is captured on the filter cake in the baghouse. The exception was bromine injection during air-firing. It is unclear why these before baghouse measurements were so low. The high bromine injection case had an uncharacteristically high LOI of $18.5 \%$, but the low bromine injection case had an LOI of $6.0 \%$, which is lower than average (12.4\% w/o two outliers). However, these two data points are also the only points where the OL CEM did not give measured values above those reported by the 30B traps (these data points may be suspect). It is highly unlikely that mercury concentrations increased across the baghouse.

Similar to PRB testing, oxy-firing tended to increase mercury concentrations for most conditions. Airand oxy-fired baseline measurements were very similar, while additive injection cases showed increased concentrations for oxy-firing. Bromine addition caused lower emission levels before the baghouse compare to ACI (as did the PRB tests). The decrease in measured mercury before the baghouse was much larger during air-firing compared to oxy. This trend was also seen in PRB testing, but to a lesser extent. During PRB testing, air-fired bromine injection still showed a decrease in mercury concentrations across the baghouse, but the bituminous results show an increase. This calls into question the validity of the air-fired measurements. If bromine addition does in fact yield lower before baghouse $\mathrm{Hg}$ concentrations when air-firing compared to oxy-firing, a possible explanation for decreased performance is increased $\mathrm{SO}_{2} / \mathrm{SO}_{3}$ during oxy-firing (as discussed in the PRB results). With the bituminous coal, calculations show that $\mathrm{SO}_{2}$ could increase from $\sim 1700 \mathrm{ppmv}$ (wet) while air-firing to $7900 \mathrm{ppmv}$ (wet) during oxy-firing. While it is unlikely that these levels were reached in the furnace (there are locations where water and $\mathrm{SO}_{2}$ condense) a dramatic increase certainly occurs during oxy-firing. These increased $\mathrm{SO}_{2}$ levels will lead to an increase in $\mathrm{SO}_{3}$ concentrations. $\mathrm{SO}_{3}$ is known to interfere with $\mathrm{Hg}$ capture on particulate, limiting the effectiveness of bromine.

After baghouse measurement showed more scatter, with bromine injection causing a decrease in measured mercury for some tests and an increase for others (similar to PRB testing). ACI caused a significant drop in mercury before the baghouse during air-firing, but not for oxy-firing. This could be due to higher $\mathrm{SO}_{2} / \mathrm{SO}_{3}$ concentrations during oxy-firing. Also similar to PRB testing, ACI produced the lowest emission levels after the baghouse. 


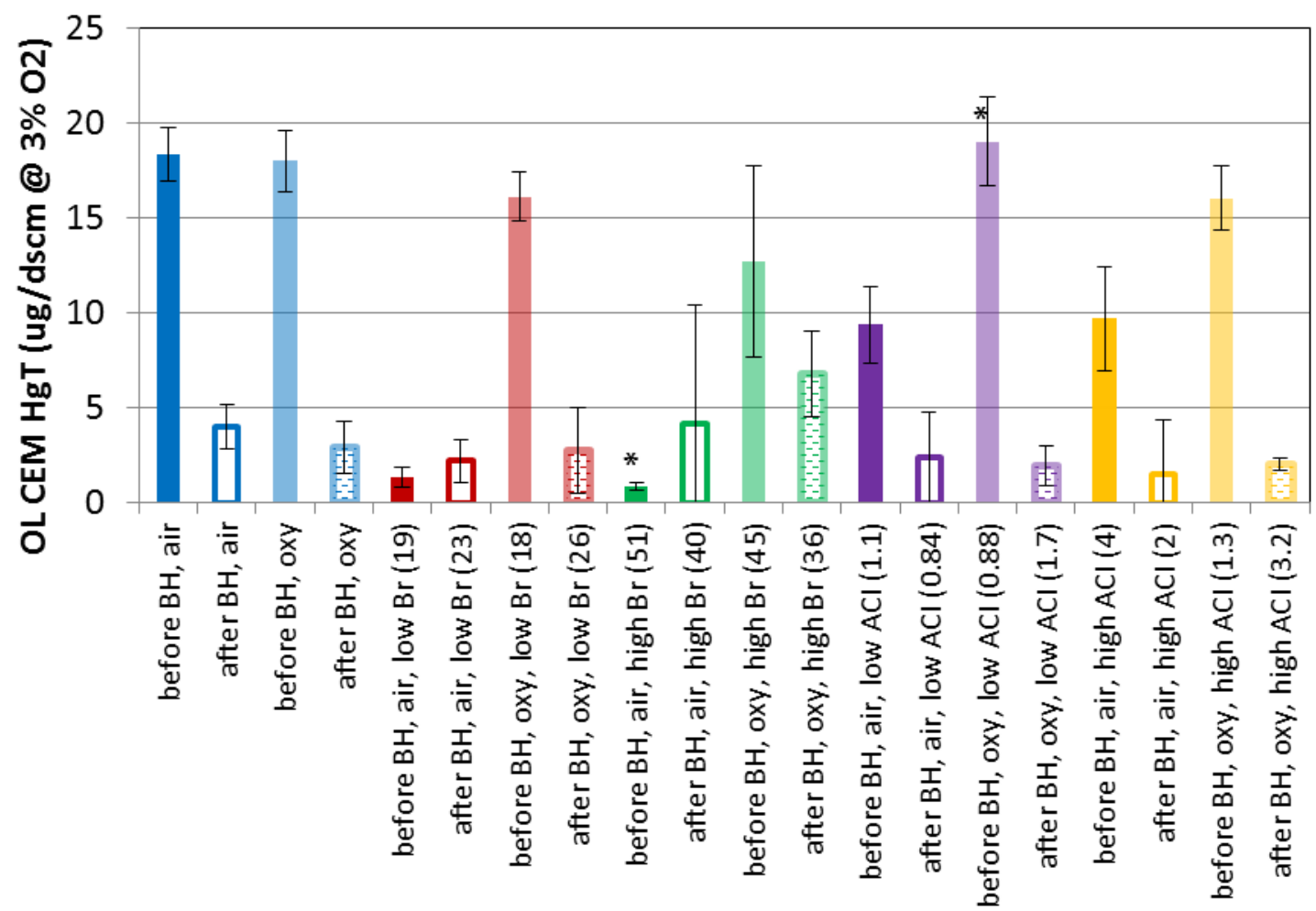

(a)

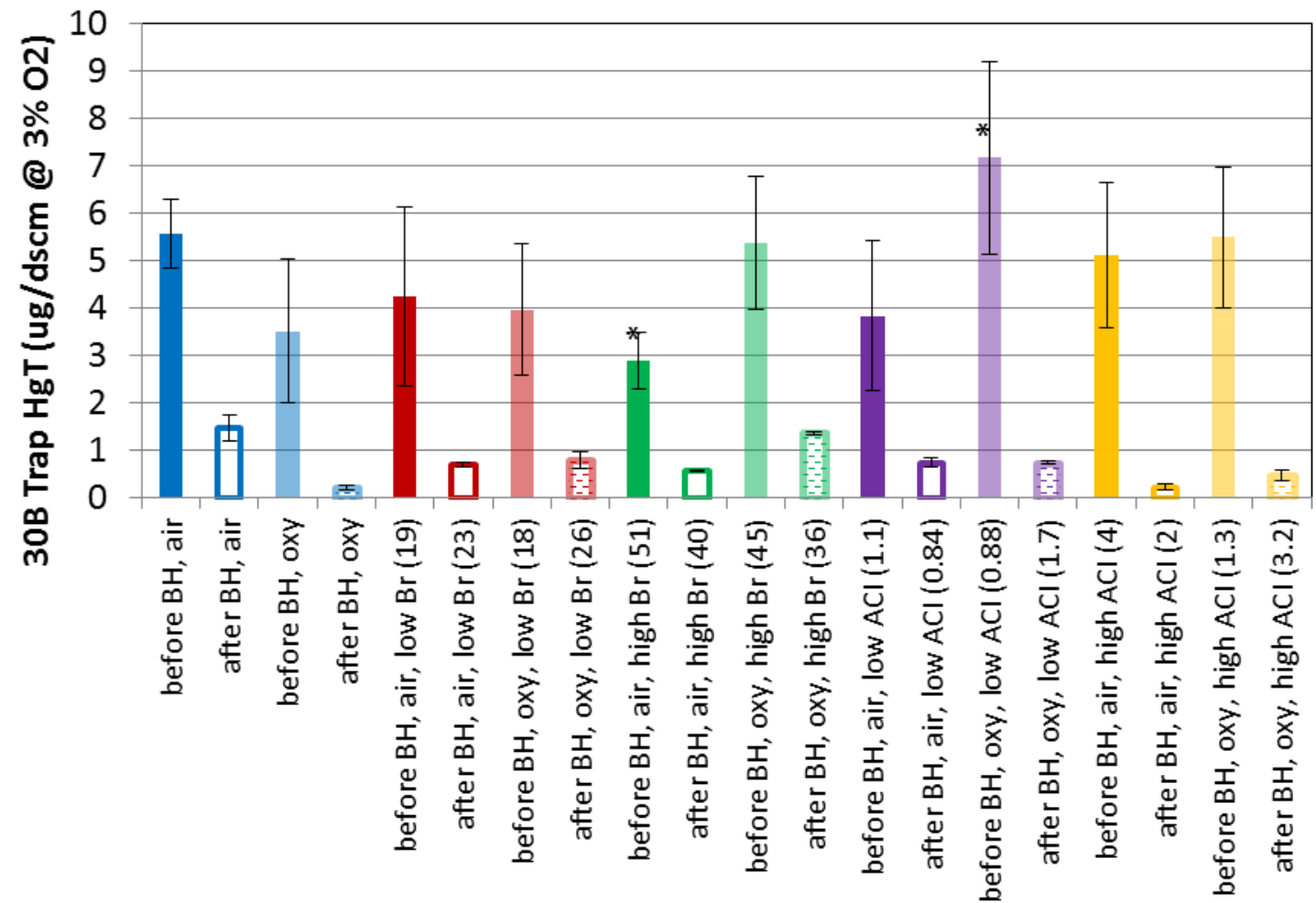

(b) 


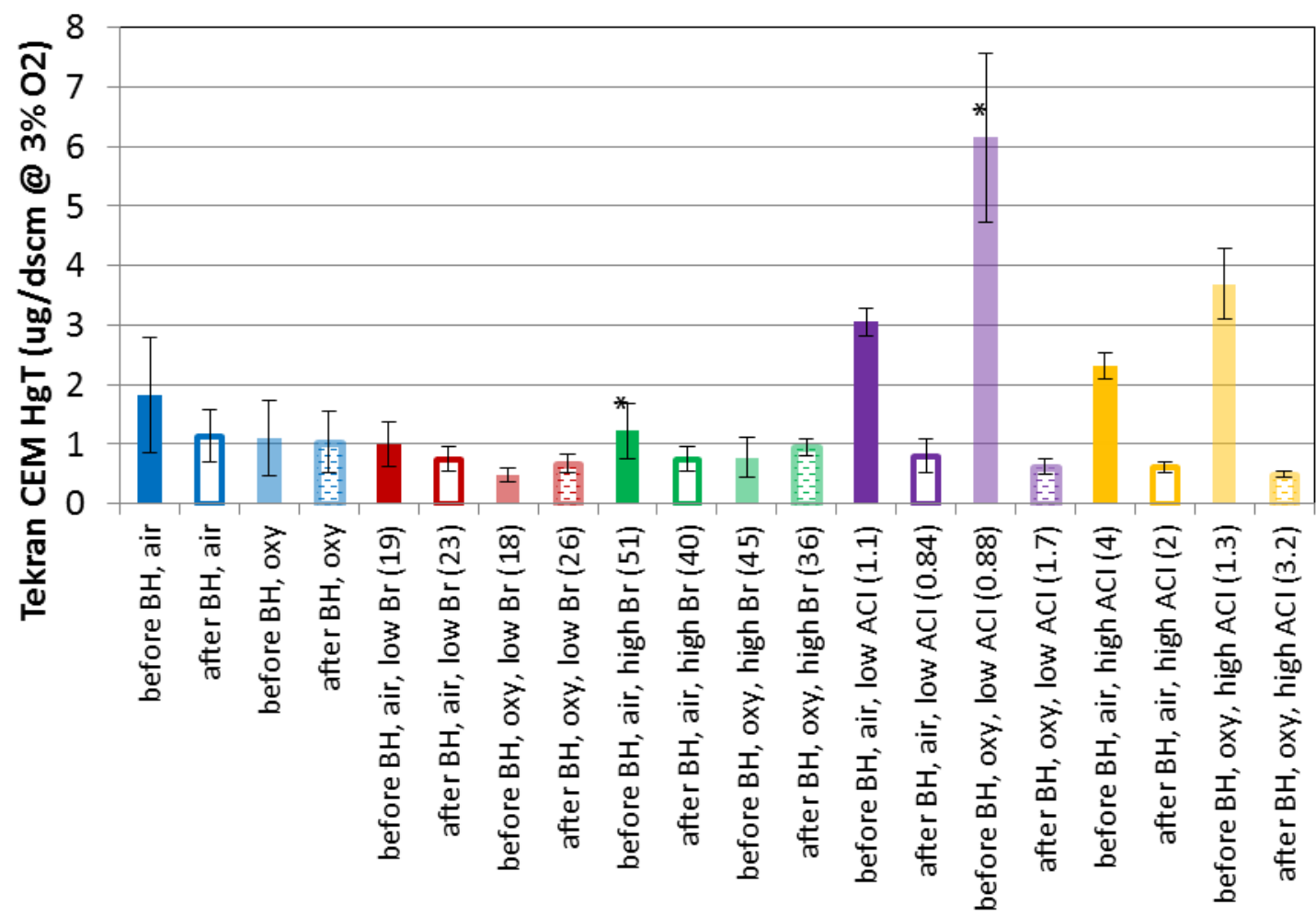

(c)

Figure 4.11-25: Total gas phase mercury measurements from (a) OL CEM, (b) 30B trap, or (c) Tekran CEM (additive feed rate in ppm Br on coal wet or lb/MMacf ACI, * LOI >13).

Mercury oxidation levels reported by the two CEM systems are shown in Figure 4.11-26 and Figure 4.11-27. The oxidation data show significant scatter, with the OL CEM always reporting higher oxidation levels than the Tekran CEM. The OL CEM reported nearly 100\% oxidation for most measurements before the baghouse, higher than measurements after the baghouse. The Tekran CEM in contrast often reported negative oxidation values. This is caused by elemental mercury readings above total mercury readings, which is an unrealistic result and further calls into question the Tekran CEM measurements. Both the OL CEM and Tekran CEM showed oxidation was higher during oxy-firing compared to air-firing for most cases, similar to the Tekran CEM trend during PRB testing. The OL CEM showed the addition of bromine to the system resulted in increased oxidation for oxy-firing, but no clear trend was seen when air-firing. 


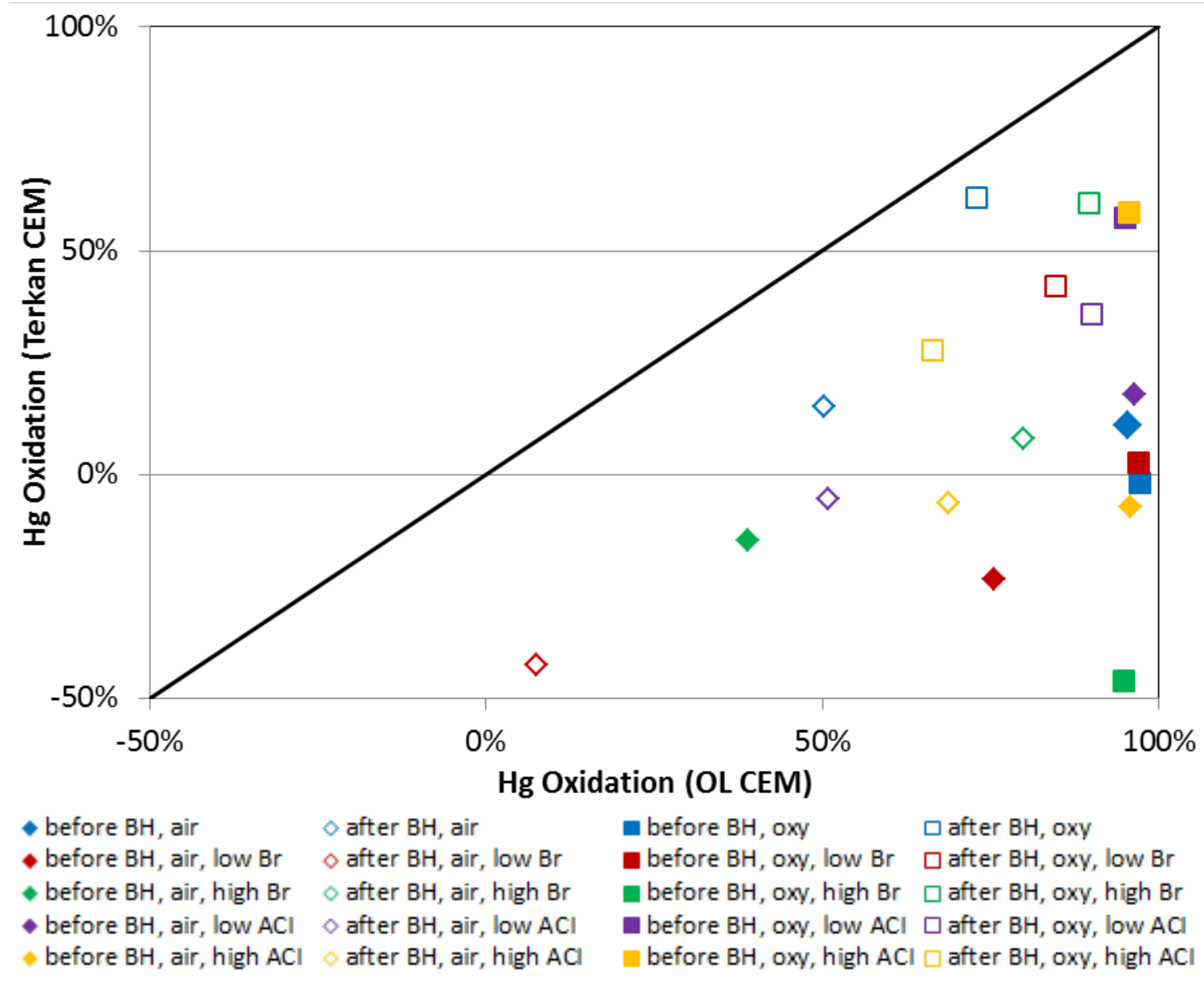

Figure 4.11-26: Comparison of mercury oxidation reported by the Tekran CEM and OL CEM during bituminous testing. 


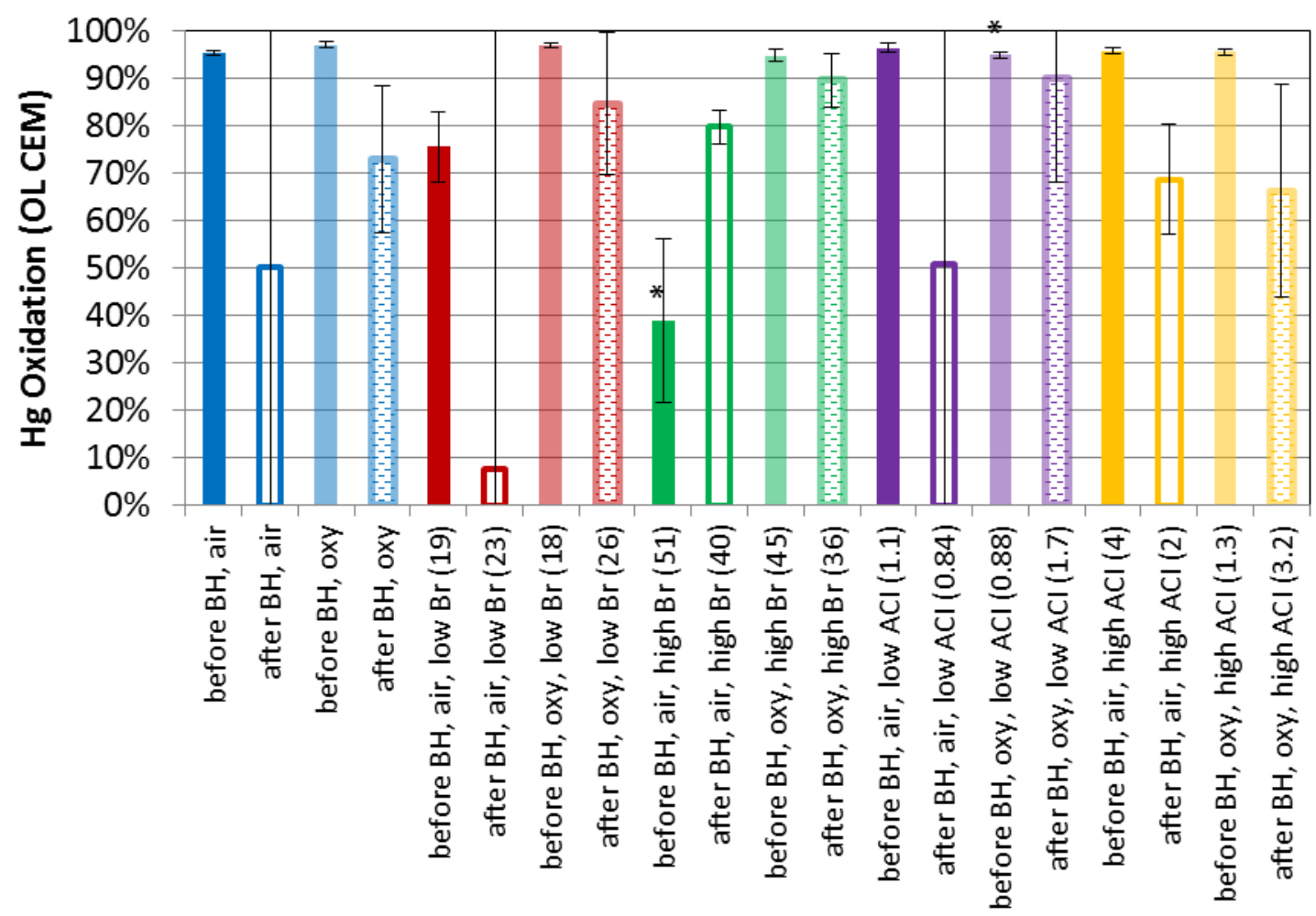

(a)

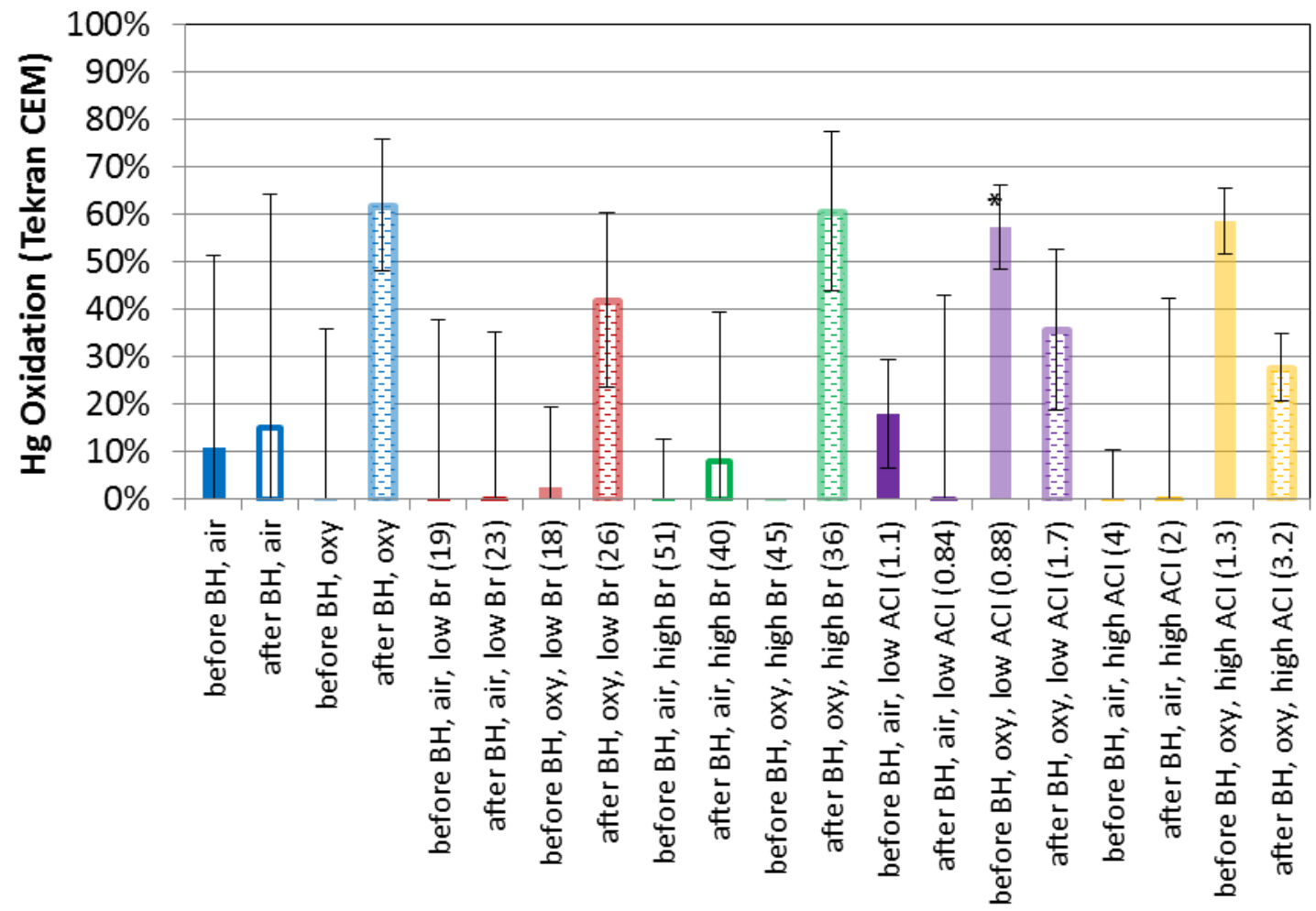

(b)

Figure 4.11-27: Mercury oxidation measurements from (a) OL CEM or (b) Tekran CEM during bituminous testing (additive feed rate in ppm Br on coal wet or lb/MMacf ACI, * LOI >13). 
Mercury mass balance closure for the bituminous tests is shown in Figure 4.11-28. Here, mass balance is defined as mercury leaving the system (gas phase and ash) divided by mercury entering the system (with coal). An ash carryover of 65\% was assumed (same as PRB). For mercury measurements taken before the baghouse under air-fired conditions, entrained ash mercury content was used to calculate mass balance as this ash most closely represents the gas-solids partitioning corresponding to the gas phase measurement. For all other conditions (after baghouse and before baghouse during oxy-firing), baghouse ash mercury content was used to calculate mass balance. This ash contains the addition mercury capture from the baghouse needed when investigating measurements taken after baghouse or any case with flue gas recycle in which the baghouse is included in the recycle loop. For mercury, mass balance closure between $80 \%$ and $120 \%$ is generally acceptable.

Poor mass balance closure was seen for most of the tests, with almost always a low closure. For PRB testing, poor mass balance closure was attributed to unrepresentative ash samples as discussed previously (agreement between measurement techniques lent confidence to the gas phase measurements). During bituminous testing, poor mass balance closure is likely caused by both unrepresentative ash samples and gas phase measurements (poor agreement between pas phase measurements was observed). If the OL CEM gas phase measurements are the most believable as discussed above, the mass balance closure using these measurements should be the closest to $100 \%$. This was the case, but the mass balance closure was still almost always low. Low mass balance closure suggests a mercury sink in the system not accounted for, possibly a low assumed ash carryover, or potentially errors in gas phase measurement (still a possibility since no other gas phase measurement was able to validate the OL CEM). Increasing the ash carryover to $90 \%$ did slightly improve the mass balance closure overall (low mass balance closure numbers were brought closer to the $80 \%$ threshold, but most were still low). It is interesting to note that even using the highest gas phase measurements (produced by the OL CEM opposed to the carbon traps or Tekran CEM), mass balance closure was still low. This further supports the hypothesis that the QSIS probe problems were biasing the carbon trap and Tekran CEM measurements. It is also interesting that mass balance closure was consistently low for the L1500 during both PRB and bituminous testing. This could indicate a systematic error in one or more mercury measurements (gas phase or ash, probably not coal mercury measurement as this is very straight forward). 


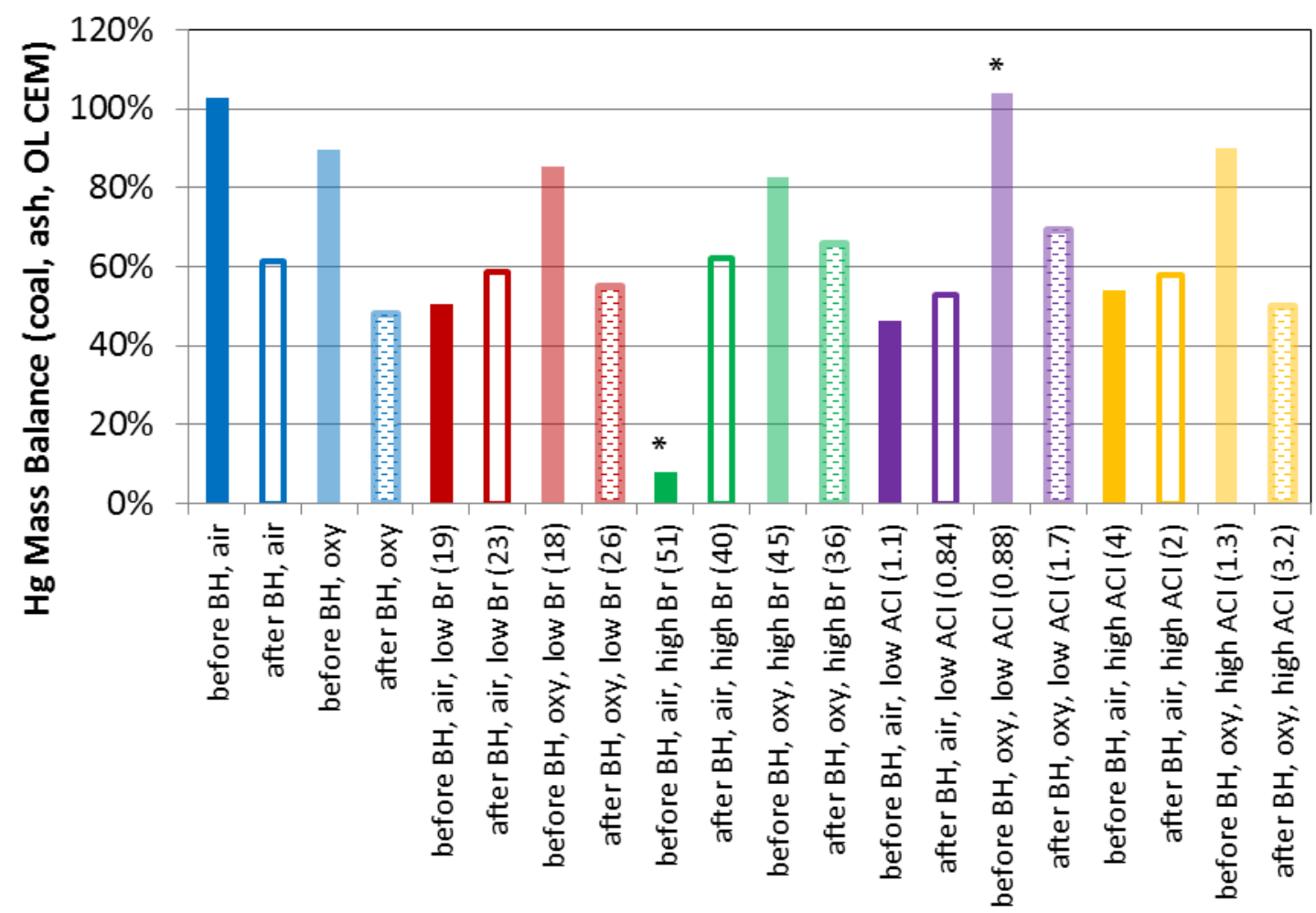

(a)

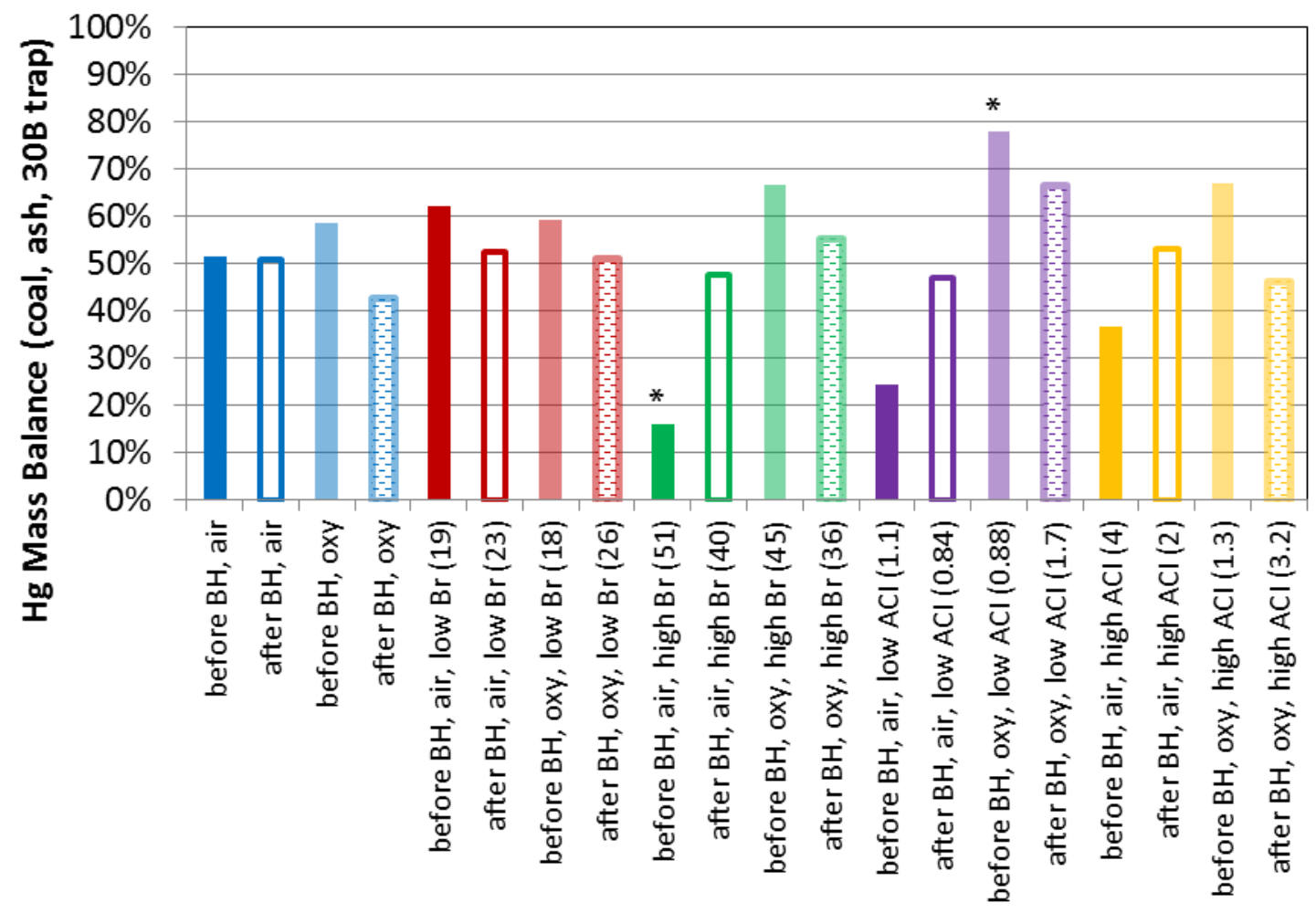

(b) 


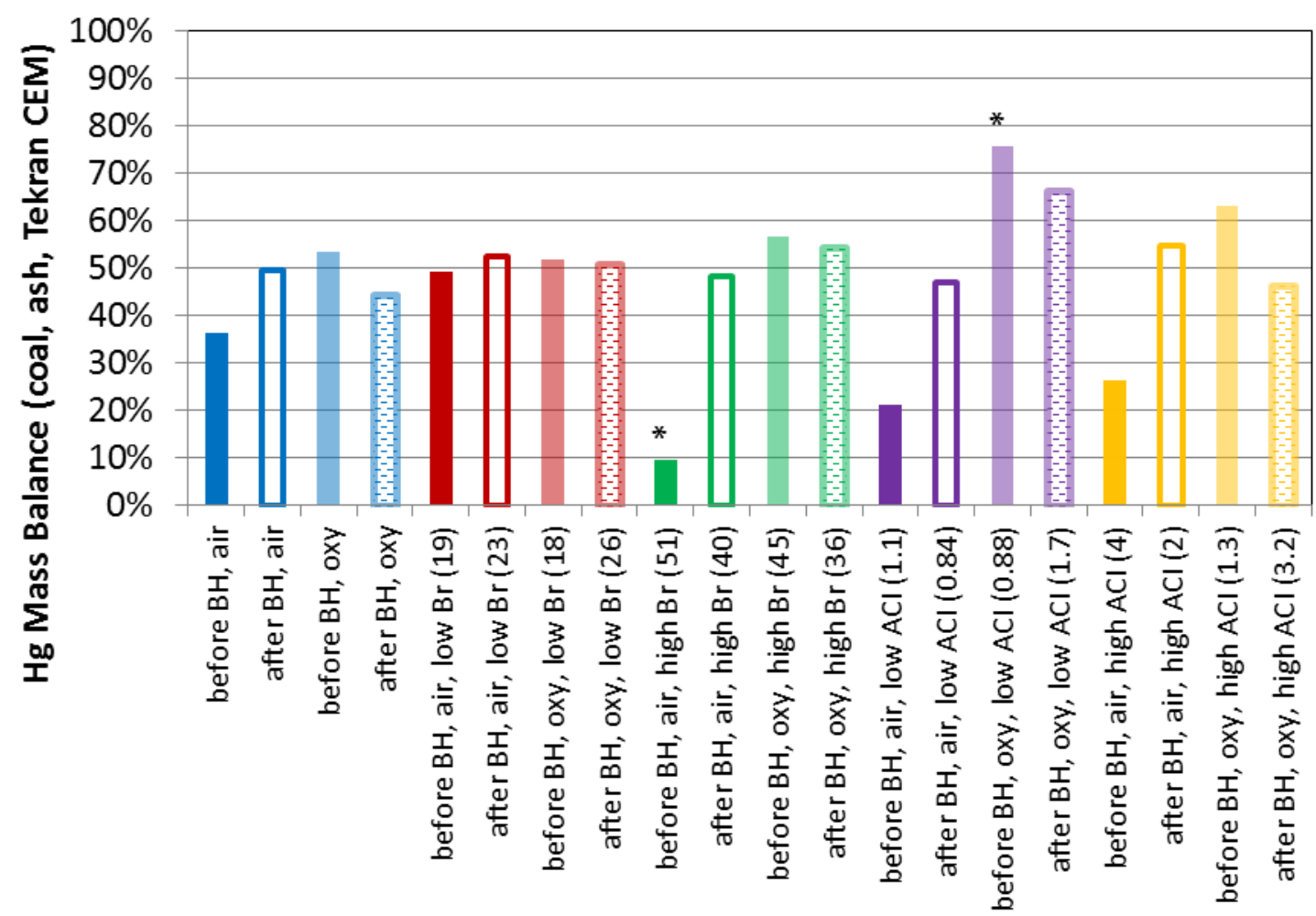

(c)

Figure 4.11-28: Mercury mass balance closure during bituminous testing using coal, ash, and (a) OL CEM, (b) 30B trap, or (c) Tekran CEM gas phase mercury measurements (additive feed rate in ppm Br on coal wet or lb/MMacf ACI, * LOI >13).

Mercury removal is shown in Figure 4.11-29. Looking at the OL CEM results, mercury removal is higher after the baghouse for most cases as expected due to removal across the filter cake. The exception is bromine addition during air-firing. This result is very unlikely and calls into question the validity of the gas-phase measurements. Baseline mercury removal was higher for oxy-fired conditions compared to airfired. The addition of bromine or activated carbon increased removal for most cases. Similar to the PRB tests, bromine addition tended to increase removal more before the baghouse compared to carbon injection while removal across the baghouse was higher for carbon injection. 


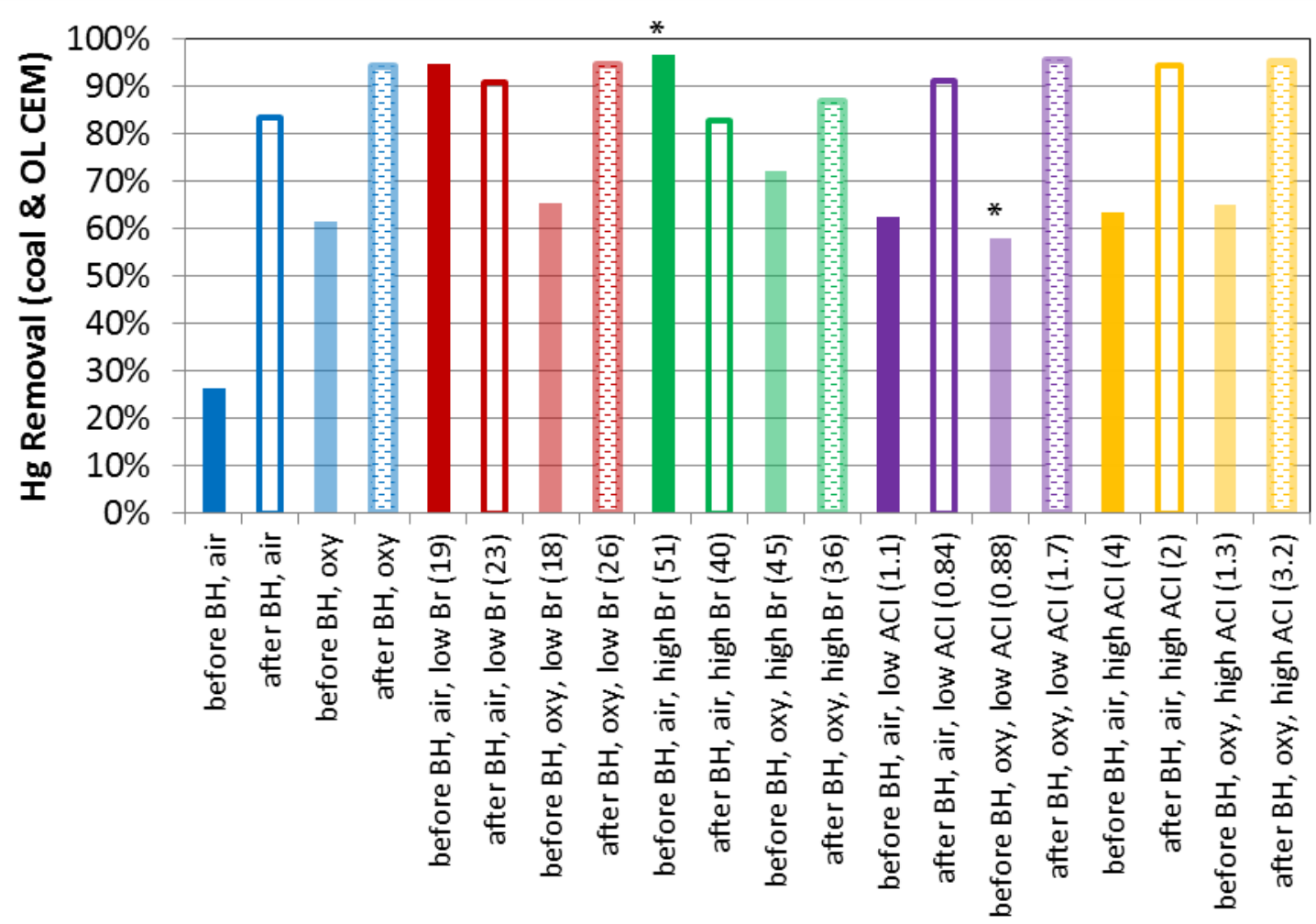

(a)

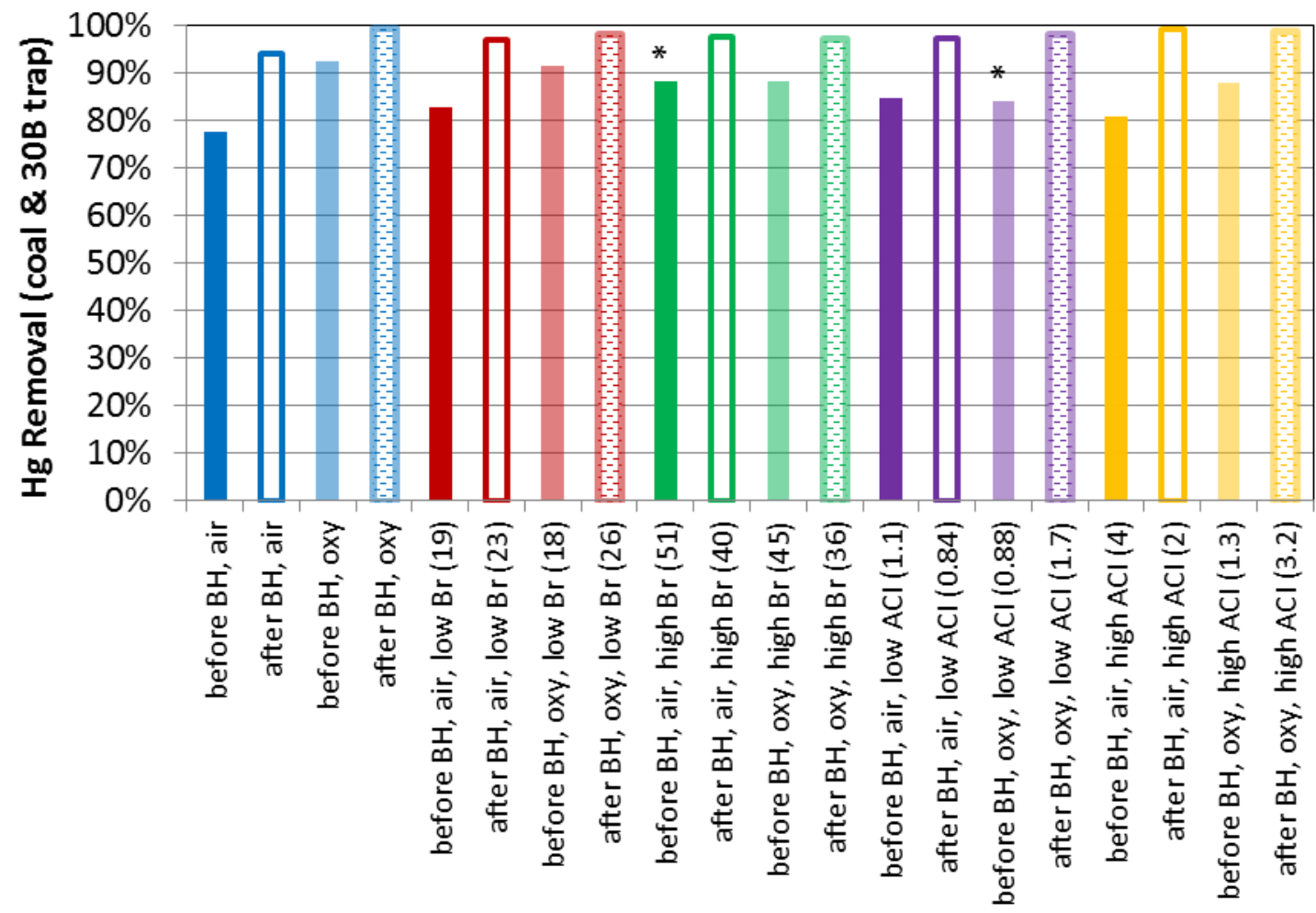

(b) 

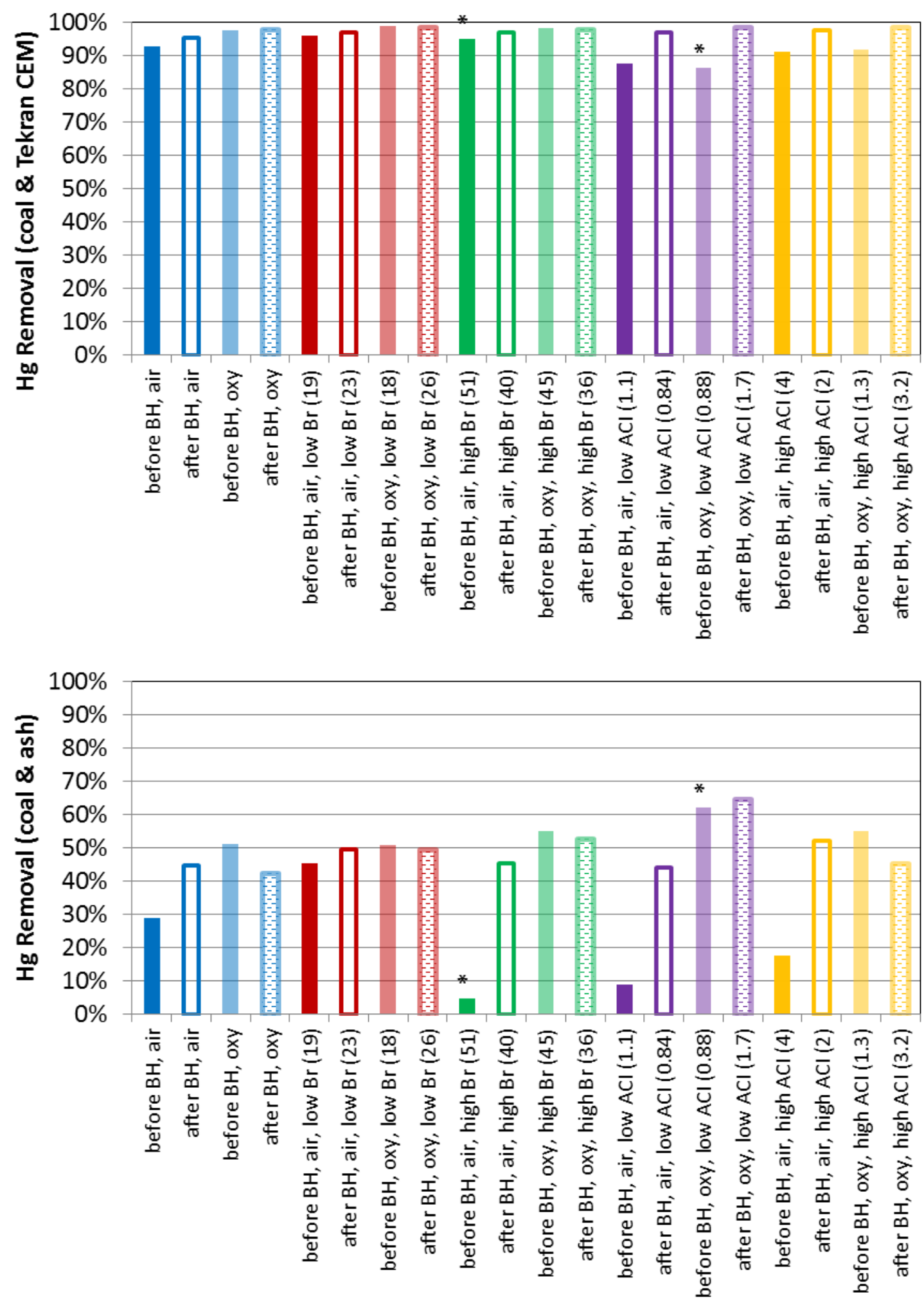

(d)

Figure 4.11-29: Mercury removal for bituminous testing calculated using coal input and (a) OL CEM, (b) 30B trap, (c) Tekran CEM gas phase mercury measurements or (d) ash mercury measurement (additive feed rate in ppm Br on coal wet or lb/MMacf ACI, * LOI >13). 
Figure 4.11-30 shows mercury removal above native capture. For these calculations, native capture was defined as the average removal measured either before or after the baghouse during air-firing. The OL CEM plot show that all additive injection cases had equal or improved removal above baseline. Bromine addition increased removal more before the baghouse compared to ACI (although the air-fired data points are suspect), while ACI tended to have more of an impact across the baghouse.

Bromine addition did show increased removal before the baghouse for both air- and oxy-fired conditions, but was more effective during air-firing. The air-fired results may be erroneous, but if in fact oxy-firing decreased the performance of bromine, one possible explanation is higher $\mathrm{SO}_{2}$ (and therefore $\mathrm{SO}_{3}$ ) concentrations while oxy-firing. $\mathrm{SO}_{3}$ competes with $\mathrm{Hg}$ for capture sites on particulate and will limit the effectiveness of bromine.

Activated carbon also showed limited effectiveness when oxy-firing. Most of the removal above native can be attributed to oxy-firing itself, rather than ACI. Increased $\mathrm{SO}_{2} / \mathrm{SO}_{3}$ when oxy-firing can also explain this poor performance. $\mathrm{SO}_{3}$ competes with $\mathrm{Hg}$ for active capture sites on activated carbon.

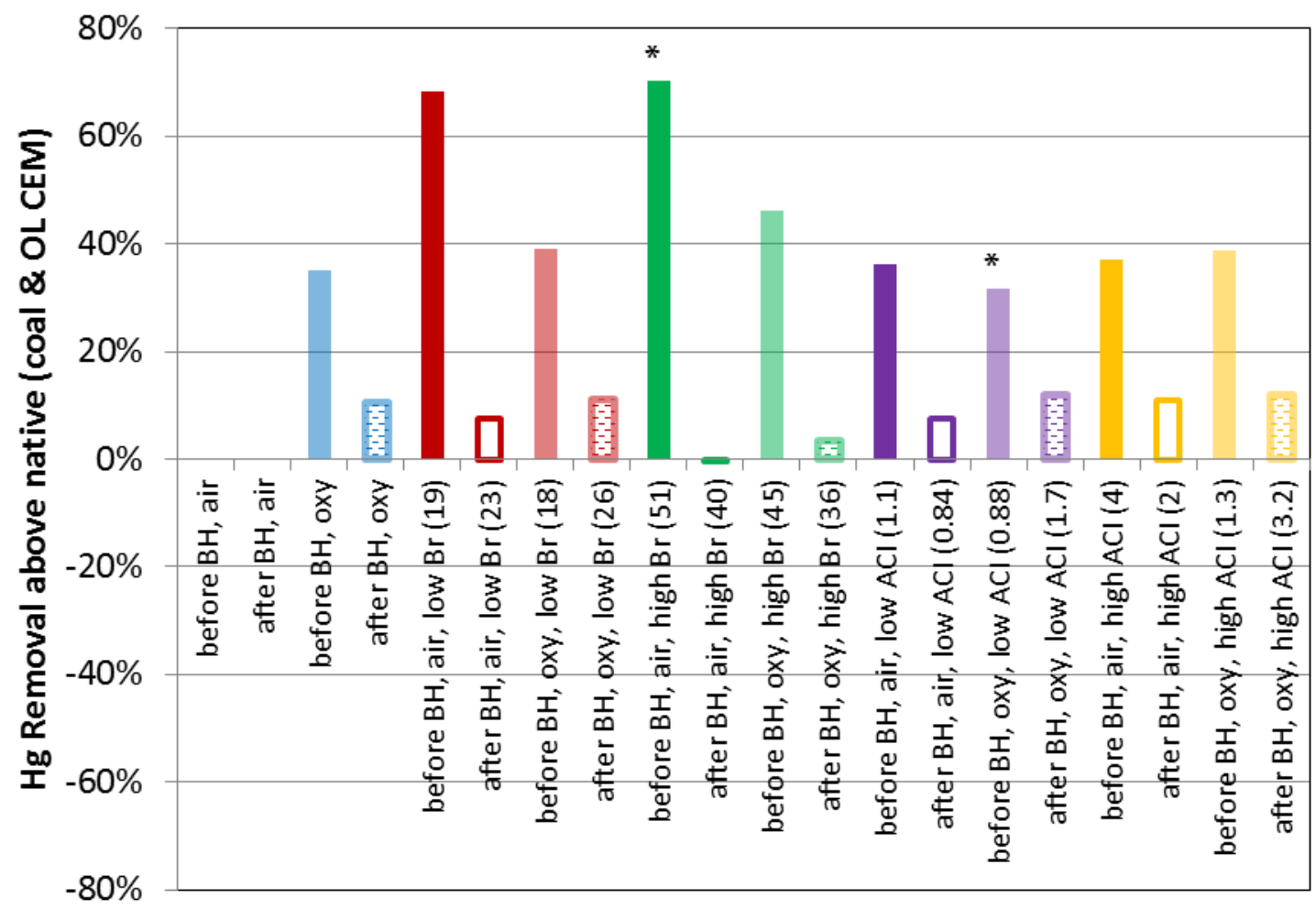

(a) 


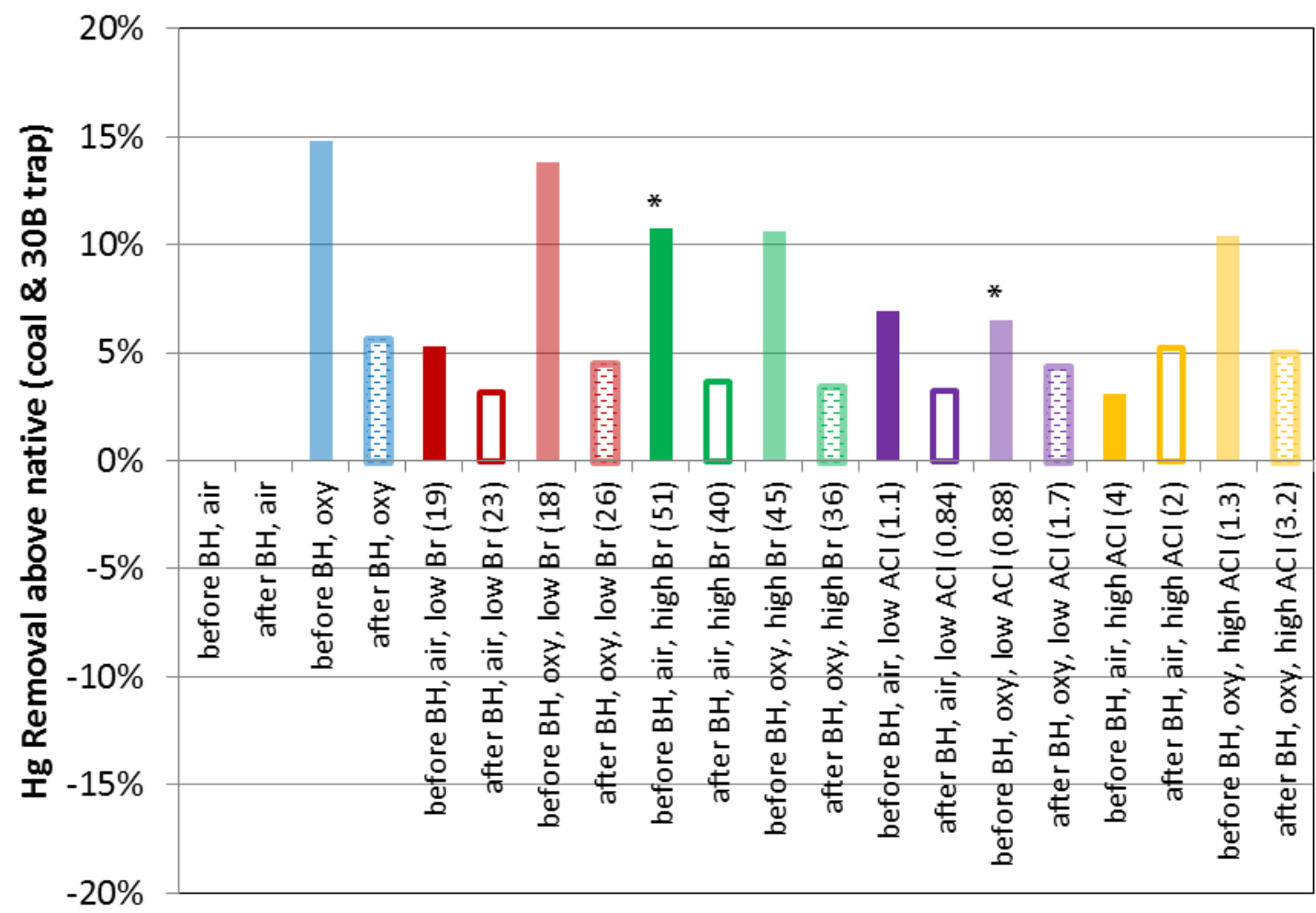

(b)

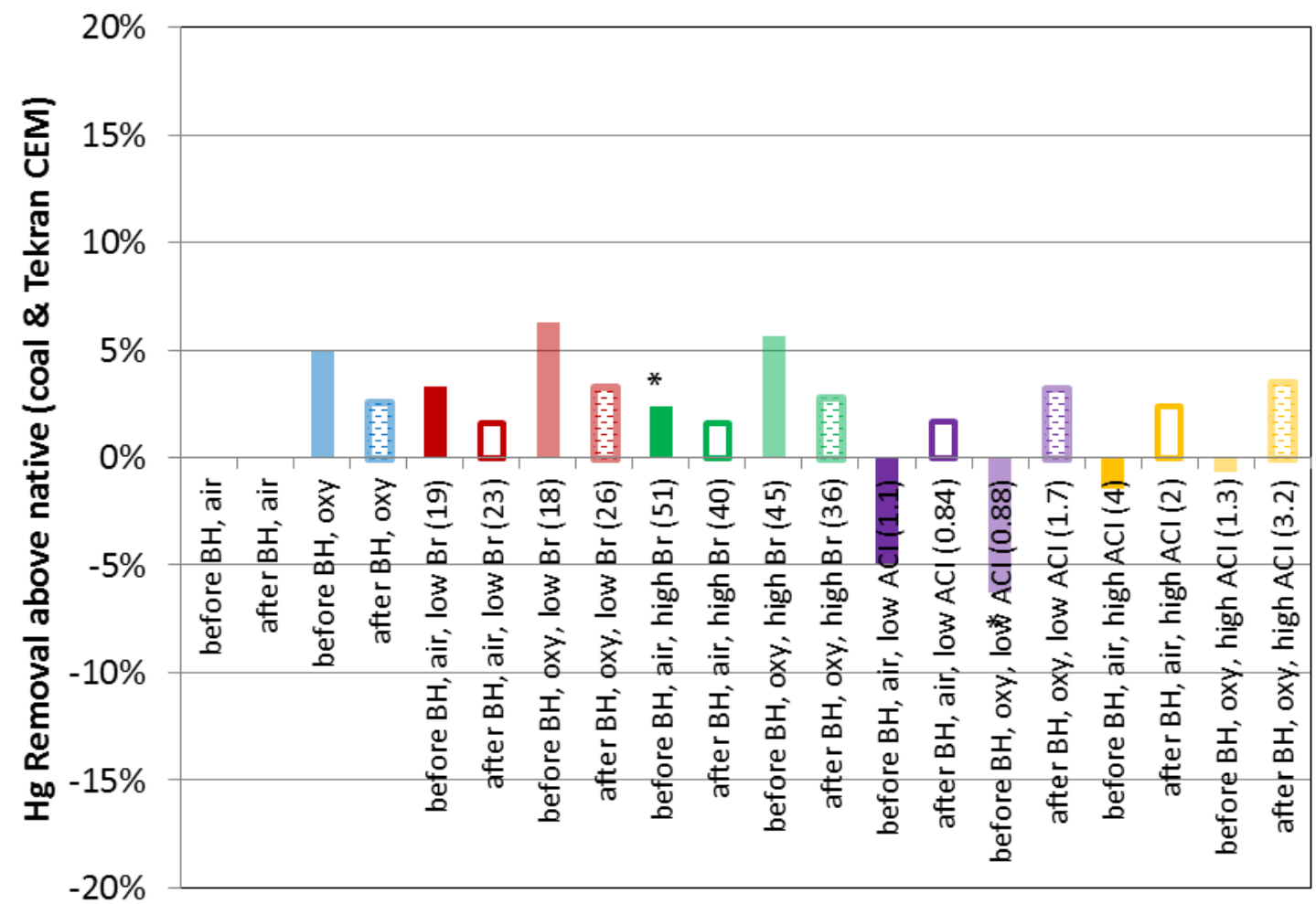

(c) 


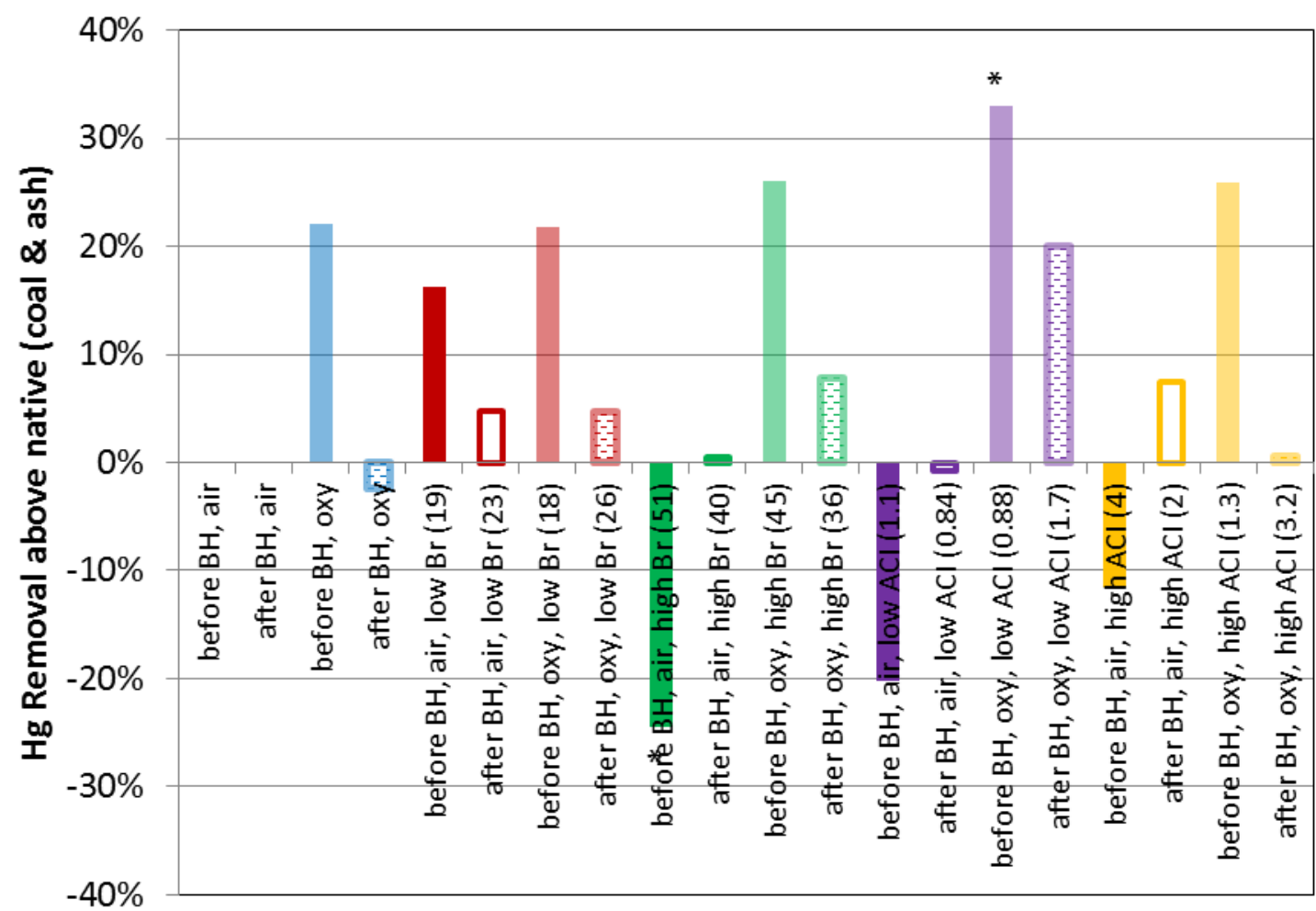

(d)

Figure 4.11-30: Mercury removal above native capture for bituminous testing calculated using coal input and (a) OL CEM, (b) 30B trap, (c) Tekran CEM gas phase mercury measurements or (d) ash mercury measurement (additive feed rate in ppm Br on coal wet or lb/MMacf ACI, * LOI >13).

\subsubsection{Mercury Testing Conclusions}

Experiments were performed in University of Utah's $1500 \mathrm{~kW}$ pulverized coal furnace to investigate differences in mercury control technologies under air- and oxy-fired conditions. Experiments were performed with both a PRB and bituminous coal using either air or $\mathrm{O}_{2} / \mathrm{FGR}$ as the oxidant. Mercury measurements were performed on the flue gas using Method 30B (modified to distinguish between gasphase and particle-bound mercury), a CEM with a wet chemical conditioning system (Tekran CEM system), and a CEM with a thermal conditioning system (OL CEM system). Gas phase mercury was measured both before and after the baghouse. Two mercury control technologies were tested, including injection of solid $\mathrm{CaBr}_{2}$ into the flame and injection of Norit Darco HG activated carbon into the lowtemperature flue-gas. Coal, baghouse ash, and in-flight ash samples were collected to investigate mercury mass balance and gas-solids partitioning.

During PRB testing, the three mercury measurement techniques agreed well with the exception of the OL CEM measurements before the baghouse. It is suspected that during additive injection, particles on the filter of the dilution probe head contributed to biased mercury measurements. More frequent blowback of the probe and washing of the heated filter removed this bias for the bituminous testing. However, during bituminous testing none of the three measurement techniques agreed well. It is likely that ash buildup and clogging of the QSIS probe caused 30B carbon trap and Tekran CEM measurements to be biased low. For this reason, the OL CEM results have the most credibility during bituminous testing.

For both PRB and bituminous testing, gas phase mercury measurements were lower after the baghouse compared to before the baghouse for most cases. This is expected due to mercury capture on the filter 
cake of the baghouse. Oxy-firing tended to increase mercury concentrations for most conditions. Bromine addition caused lower emission levels before the baghouse compare to ACI. ACI produced the lowest concentration levels after the baghouse.

All oxidation data showed significant scatter. During PRB testing, no clear bias between the two CEM systems was apparent. In contrast, during bituminous testing, the OL CEM always showed significantly higher oxidation than the Tekran CEM (which often reported negative erroneous oxidation). There was evidence of higher oxidation levels during oxy-firing (Tekran CEM measurements during PRB testing and OL measurements during bituminous testing). The addition of bromine to the system resulted in increased oxidation as expected for most tests with the exception of air-fired conditions during bituminous testing.

Mercury mass balance closure was poor for many tests during PRB and bituminous testing, usually less than $80 \%$. This is most likely due to unrepresentative ash samples (ash collected for analysis likely interacts differently with mercury compared to the large fraction of ash that drops out before sampling). During PRB testing, consistency among the three measurement techniques lends confidence to the gas phase measurements. Although the gas phase measurements could not be validated during bituminous testing, using the OL CEM measurements (most confidence) which gave the highest values still resulted in low mass balance closure. Consistently low mass balance closure could indicate a systematic error in one or more mercury measurements (gas phase or ash, probably not coal mercury measurement as this is very straight forward).

Mercury removal was higher after the baghouse for almost all cases (as expected due to baghouse filter cake). Mercury removal levels after the baghouse were very similar for air- and oxy-fired conditions. Bromine addition tended to increase removal more before the baghouse compared to carbon injection while removal across the baghouse was higher for carbon injection. Bromine addition was more effective before the baghouse for air-fired conditions. This can be explained by higher $\mathrm{SO}_{2}$ concentrations (and hence higher $\mathrm{SO}_{3}$ ) when oxy-firing. This could also explain why ACI was less effective before and after the baghouse during oxy-firing of bituminous coal. Oxy-firing PRB coal with ACI showed increased prebaghouse Hg removal compared to both baseline oxy-firing and air-firing with ACI. However, it is unclear why air-firing with ACI showed decreased Hg removal before the baghouse compared to baseline. ACI showed equal or slightly increased post-baghouse removal during oxy-firing of PRB coal compared to baseline oxy-firing and air-firing with ACI. 


\subsection{L1500 Modeling and Data Comparison}

CFD models of the L1500 furnace have been developed in order to compare predicted and measured data, both with and without the new or updated mechanisms. Mechanisms evaluated and reported here include gas radiation and char oxidation. Key results comparing gas temperature, CO concentration, gas emissivity and wall heat flux are presented in this section.

This section focuses specifically on comparisons between L1500 data and predictions. Additional mechanism modeling results that are not compared to L1500 measurements are presented in report sections specifically related to those mechanisms. This includes sections for char oxidation (Section 4.5.6), soot (Section 4.6.5) and radiation (Section 4.10.5). Results of mechanism impacts on full-scale systems are presented in the section on full-scale retrofit modeling, Section 4.13. This includes impacts of refined or extended models for char oxidation, soot and slagging.

\subsubsection{L1500 Model Overview}

The radiant section of the L1500 furnace at the University of Utah (see Figure 4.12-1) was modeled using REI's Glacier combustion software. This included the furnace region from the burner to the transition section after furnace section 10 (where the corrosion probes were located). The furnace has a 3.3' x 3.3' square inside cross section and is approximately 43' long. There are serpentine cooling panels in sections S1 - S4 and a single opposed OFA port on each side of the furnace in section S6, about 22' from the burner. The model included approximately 611,000 computational cells. Figure 4.12-2 contains a plot of predicted gas temperatures at the horizontal centerline of the furnace for the air-Skyline condition. In this figure the sample port locations for each of the furnace sections has been labeled, S1 through S10. The location of the burner, over-fire air ports and corrosion probes has also been identified.

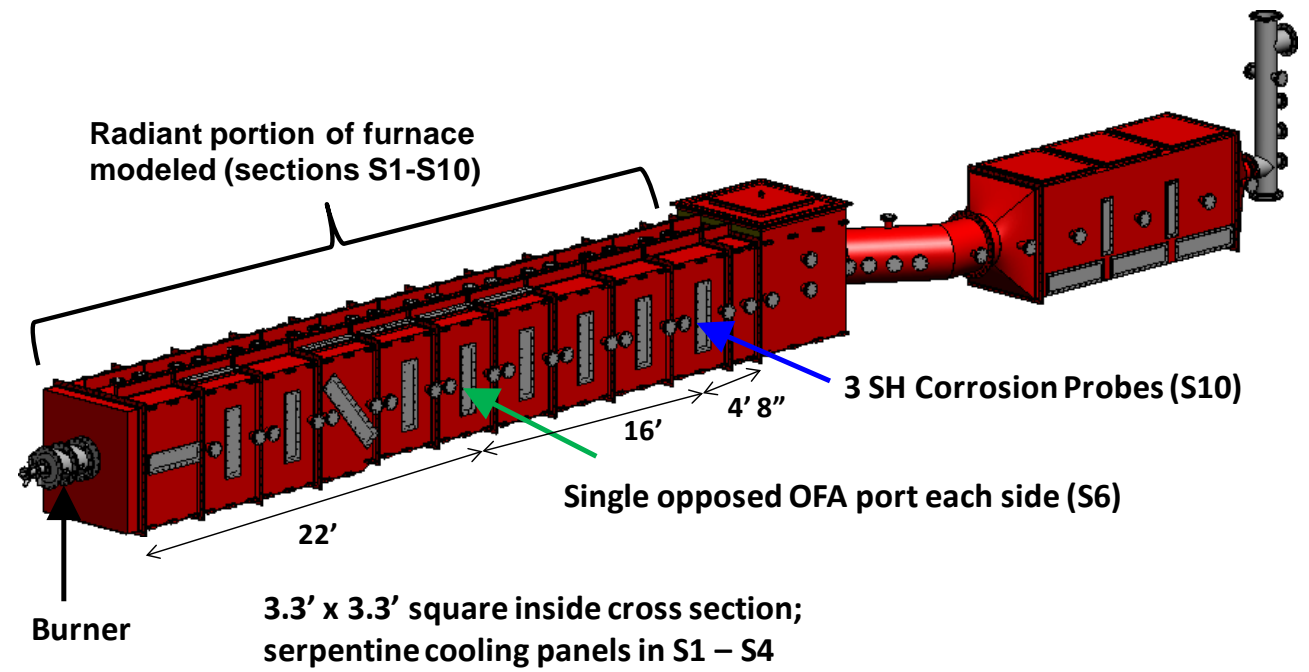

Figure 4.12-1: Schematic of the University of Utah L1500 furnace. 


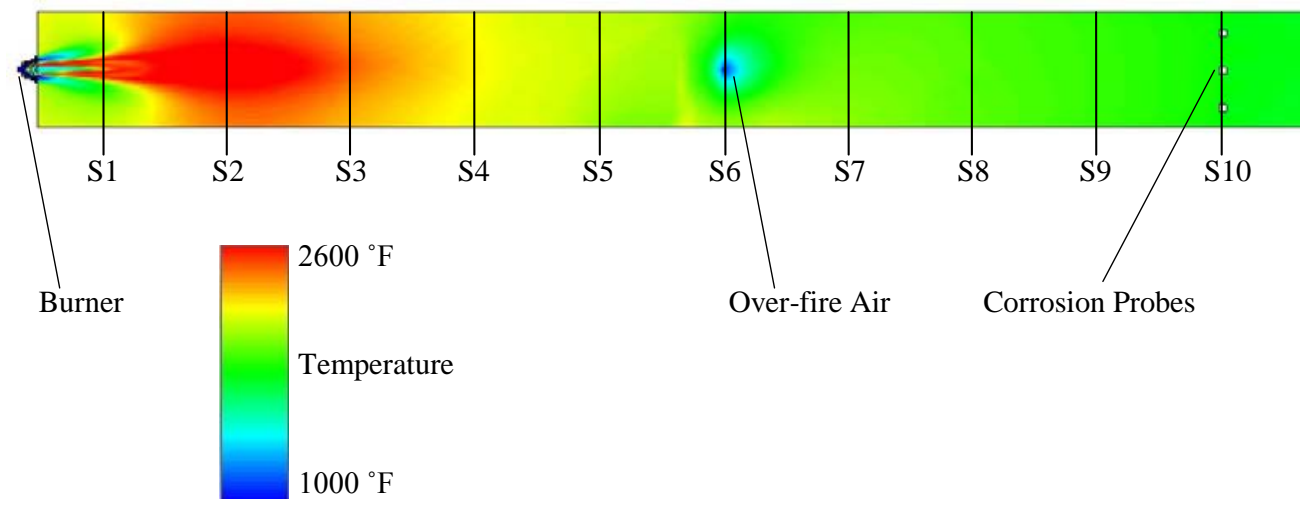

Figure 4.12-2: Predicted temperature profile for the air-fired Skyline condition.

The model inputs for bituminous Utah Skyline coal properties and baseline firing conditions are shown in Table 4.12-1. In both cases the burner stoichiometric ratio (BSR) and primary gas-to-fuel ratio were held constant at 0.9 and 1.8, respectively. The overall oxygen concentration in the oxy-firing case was $27 \%$, wet. Additional cases for PRB coal were also run, but will be reported at a later date.

Table 4.12-1: Skyline Coal Properties and Baseline Firing Conditions.

\begin{tabular}{|l|c|}
\hline Coal Property & $\begin{array}{c}\text { Utah } \\
\text { Skyline }\end{array}$ \\
\hline Moisture (\%) & 3.18 \\
\hline Ash (\%) & 8.83 \\
\hline C (\%) & 70.60 \\
\hline H (\%) & 5.06 \\
\hline N (\%) & 1.42 \\
\hline S (\%) & 0.53 \\
\hline O (\%) & 10.38 \\
\hline Volatile (\%) & 38.60 \\
\hline Fixed C (\%) & 49.39 \\
\hline HHV (Btu/lb) & 12,606 \\
\hline
\end{tabular}

\begin{tabular}{|l|l|c|c|}
\hline Parameter & Units & Air & Oxy \\
\hline Firing Rate & MBtu/hr & 3.5 & 3.5 \\
\hline Excess $\mathrm{O}_{2}$ & \%, dry & 3.14 & 3.07 \\
\hline BSR & & 0.9 & 0.9 \\
\hline Primary Gas/Fuel & & 1.8 & 1.8 \\
\hline Burner IS / OS & & $20 / 80$ & $20 / 80$ \\
\hline Overall $\mathrm{O}_{2}$ & $\%$, wet & 21 & 27 \\
\hline Burner $\mathrm{O}_{2}$ & $\%$, wet & 21 & 27 \\
\hline Primary $\mathrm{O}_{2}$ & $\%$, wet & 21 & 21 \\
\hline IS O & \%, wet & 21 & 28.7 \\
\hline OS O $_{2}$ & $\%$, wet & 21 & 28.7 \\
\hline
\end{tabular}

\subsubsection{Comparison of Predicted and Measured Results}

\subsubsection{Gas Temperature}

Table 4.12-2 summarizes the predicted and measured results for the air and oxy-fired conditions. As expected, the oxy-firing case showed higher exit $\mathrm{SO}_{2}, \mathrm{CO}_{2}$ and $\mathrm{H}_{2} \mathrm{O}$ concentrations. The oxy-firing case also showed higher exit gas temperature, which was consistent with lower wall heat loss. This gas temperature is dependent on the wall boundary conditions prescribed in the model. The wall temperatures were specified based on refractory temperature measurements during testing. 
Table 4.12-2: Summary of Predicted and Measured Results.

\begin{tabular}{|l|c|c|c|c|}
\hline & $\begin{array}{c}\text { Skyline Air } \\
\text { Model }\end{array}$ & $\begin{array}{c}\text { Skyline Air } \\
\text { Ave Measured }\end{array}$ & $\begin{array}{c}\text { Skyline Oxy } \\
\text { Model }\end{array}$ & $\begin{array}{c}\text { Skyline Oxy } \\
\text { Ave Measured }\end{array}$ \\
\hline Exit Temp ( $\left.{ }^{\circ} \mathrm{F}\right)$ & 1743 & & 1872 & \\
\hline Exit $\mathrm{O}_{2}(\%$, dry) & 3.14 & 3.18 & 3.03 & 3.07 \\
\hline Exit CO (ppmv, dry) & 0.16 & 16 & 126 & 90 \\
\hline Exit SO (ppmv, dry) & 444 & 425 & 1,788 & 1754 \\
\hline Exit CO $(\%$, dry) & 15.9 & 15.9 & 89.9 & 89.9 \\
\hline Exit $\mathrm{H}_{2} \mathrm{O}(\%)$ & 6.7 & & 25.6 & \\
\hline Gas Sensible Heat (\%) & 39.7 & & 41.1 & \\
\hline Wall Heat Loss (\%) & 59.6 & & 58.5 & \\
\hline Rad. I Conv. (\%) & $41.4 / 18.2$ & & $46.5 / 12.0$ & \\
\hline
\end{tabular}

Experimental temperature data were collected for these conditions using a suction pyrometer. These data were collected in furnace sections 1 through 5, 7, 8 and 10 at different radial positions in the furnace. All of the experimental data collected at each axial location were averaged and compared with the average gas temperature predicted by the CFD model. Figure 4.12-3 shows the predicted gas temperature profiles for air and oxy-firing conditions for Skyline coal. Figure 4.12-4 shows comparisons of measured and predicted gas temperatures at various axial and radial locations in the furnace for air-fired and oxy-fired conditions.
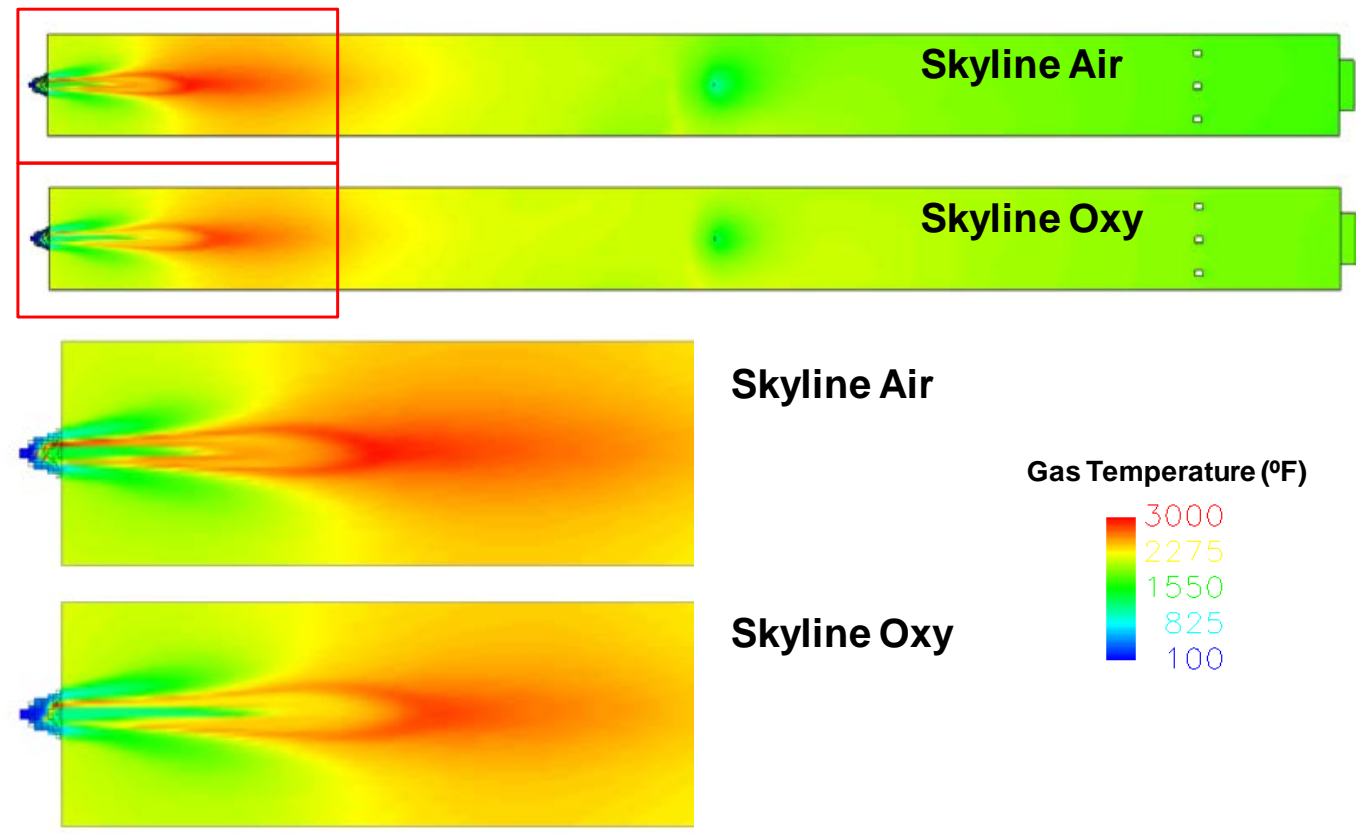

Gas Temperature ( $\left.{ }^{\circ} \mathrm{F}\right)$

Figure 4.12-3: Predicted centerline gas temperature profiles for air and oxy-firing with Skyline coal.

Figure 4.12-4 shows good agreement between the model predictions and the suction pyrometer measurements for the air-fired case. The oxy-fired comparisons showed the predicted temperatures were 
higher than measured temperatures, particularly at the furnace centerline. The largest discrepancy in both firing conditions was the centerline and near centerline temperatures in furnace section 1 . Here the model significantly under predicted the measured data. This may be due in part to temperature averaging which occurred during measurements at this highly stratified temperature region just outside the burner.

Figure 4.12-5 plots the measured and predicted average gas temperatures for air and oxy-fired conditions with Skyline coal as a function of distance from the burner quarl exit. The air-fired predictions and measurements agree fairly well, other than in section S1. There is an expected temperature drop at section S6 where the overfire air enters, but the temperature increases again as the overfire air mixes and reacts with the CO from the staged section preceding S6. The oxy-firing predictions were consistently higher than the measured data (other than at S1), particularly preceding S6. The reason for this is not known.

One interesting trend that occurred in both the predicted and measured data was a temperature "crossover" at the OFA port (section S6), i.e., the gas temperature in the oxy-firing case went from being lower than the air-fired case before the OFA port to higher than the air-fired case after the OFA port. This temperature cross-over effect was likely due to enhanced CO oxidation near OFA ports in the oxy-firing case.

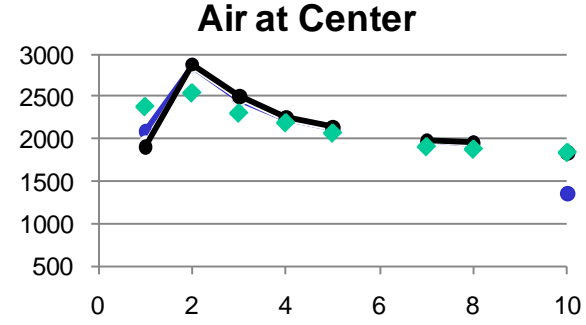

Air at +7.75 in .
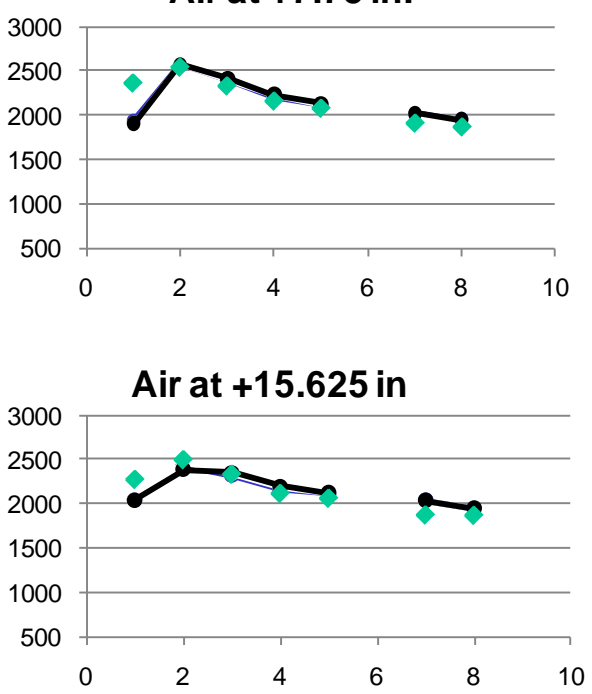
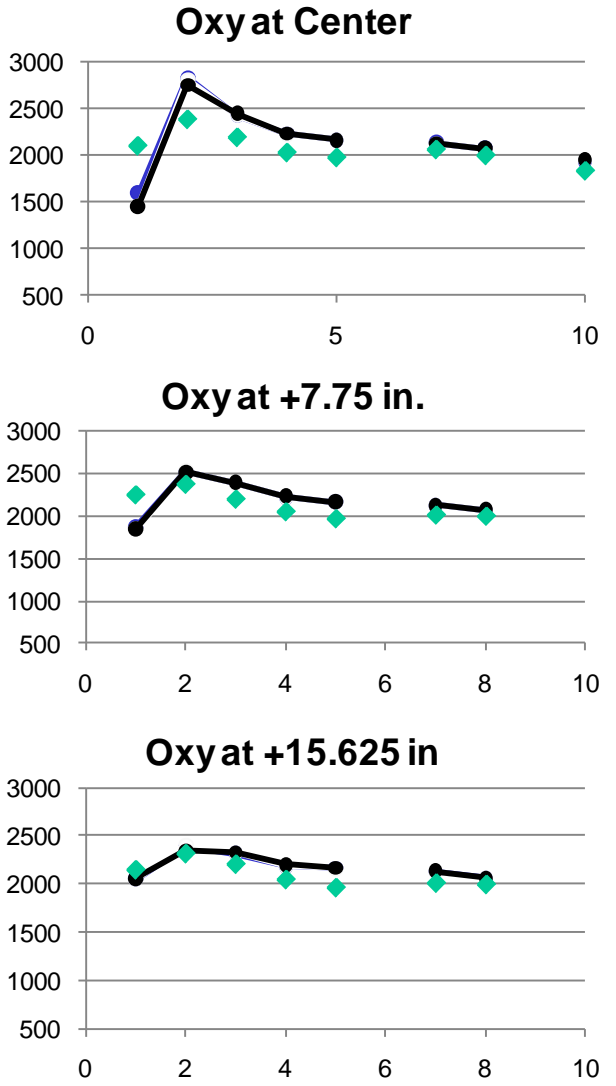

Figure 4.12-4: Comparison of predicted (line) and measured (diamond symbols) axial gas temperature profiles at the furnace centerline and radial distances 7.75" and 15.625" from furnace centerline for air and oxy-firing with Skyline coal. 


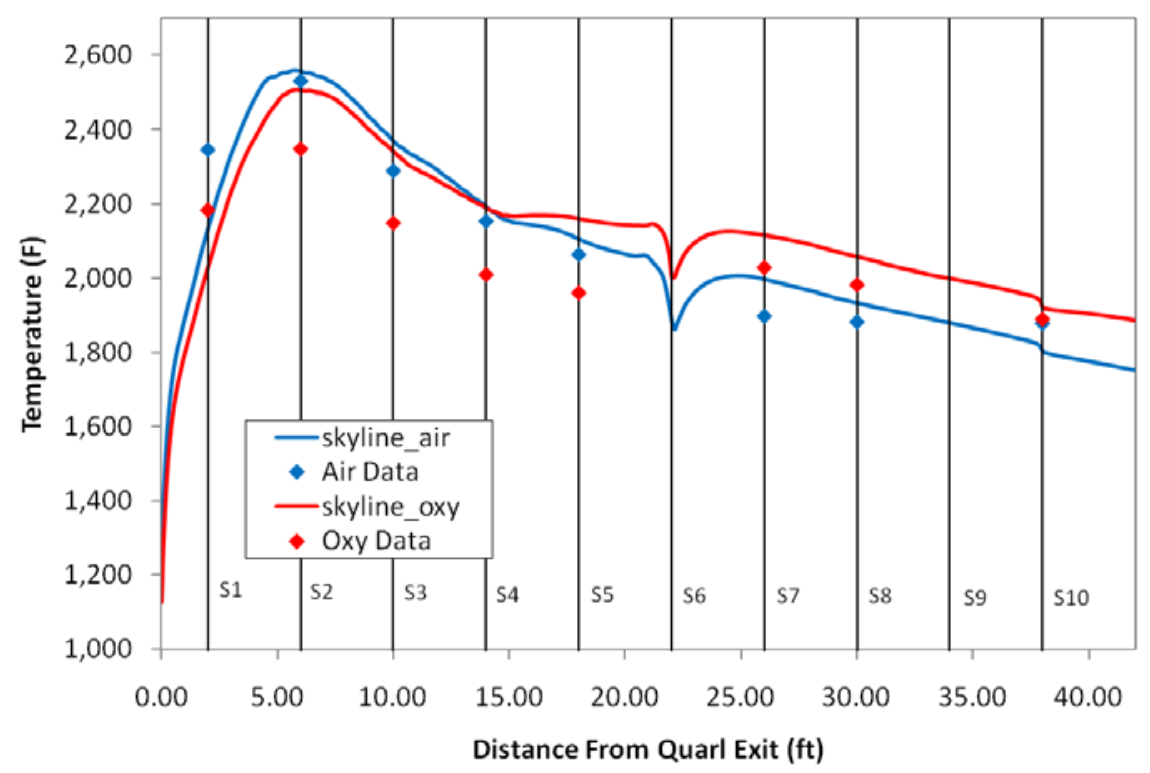

Figure 4.12-5: Predicted and measured average gas temperatures for the air-fired and oxy-fired conditions with Skyline coal.

\subsubsection{CO Concentration}

Figure 4.12-6 shows the predicted and measured average CO concentration for the air and oxy-fired conditions with Skyline coal. Measured data was only available for the air-fired case. Predictions clearly showed a large increase in CO before the OFA port, and showed that the oxy-firing case had higher CO concentrations than the air-fired case. The large increase in CO ahead of the OFA port is likely due to a combination of $\mathrm{CO}$ from continued reaction of the coal particles and the release of volatiles and char from particles deposited on the floor of the furnace. The horizontally-fired furnace has a non-negligible amount of larger diameter particles "drop out" of the gas flow onto the furnace floor. This behavior is exacerbated by the OFA jets pushing the bulk furnace flow toward the roof and floor. Under staged firing conditions, the deposited particles often contain some remaining unburned carbon, which is then released and oxidized from the floor, creating additional CO.

It is the oxidation of these higher concentrations of $\mathrm{CO}$ that are thought to cause the increase in gas temperature after the OFA port for the oxy-firing case (the temperature cross-over effect). The predicted values for air-firing are much lower than the measured values, suggesting that improvements to the particle reaction model and/or gas-phase reaction model may be appropriate. This will be evaluated in the next section with the enhanced char oxidation model.

The differences between $\mathrm{CO}$ concentrations between air and oxy-firing are likely due to the increased amounts of $\mathrm{CO}_{2}$ (and decreased amounts of $\mathrm{N}_{2}$ ) in the oxy-fired case. There is also the potential for additional fuel release in the staged section of the furnace due to increased particle reaction rates under oxy-fired conditions. 


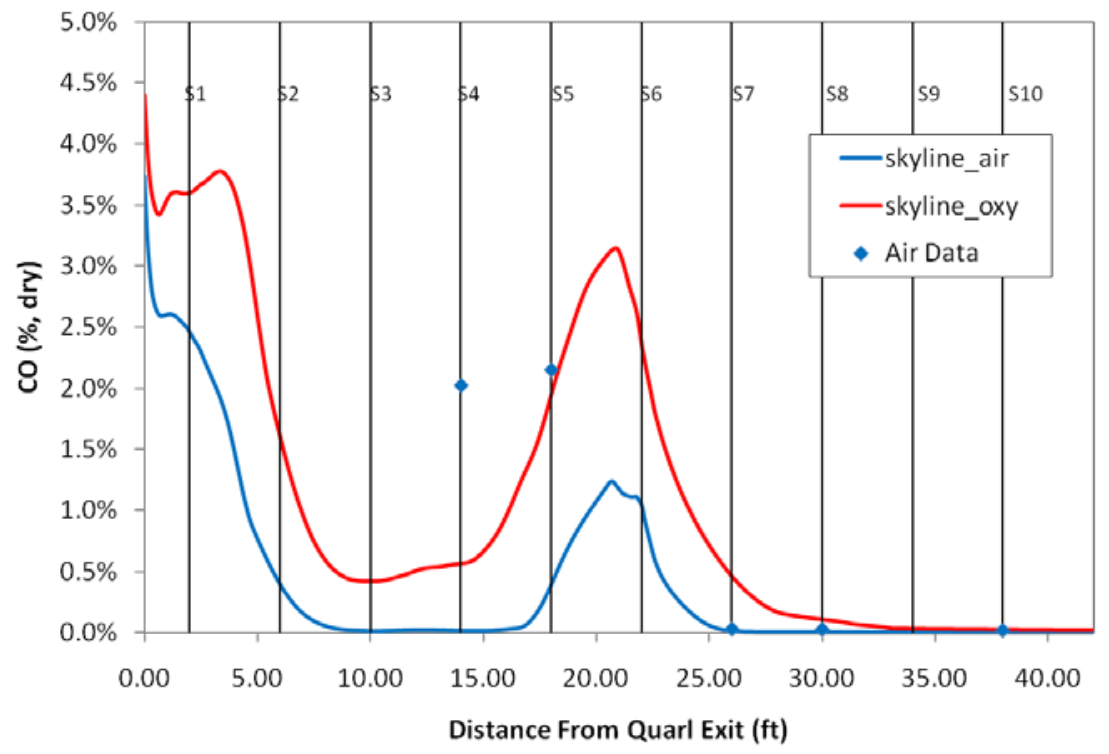

Figure 4.12-6: Predicted and measured average CO concentrations for the air-fired and oxy-fired conditions with Skyline coal.

\subsubsection{Updated Char Oxidation Mechanism}

A noted in Section 4.1, the extended single film char reaction model was successfully implemented into Glacier and could reproduce the Sandia's EFR test results. Glacier with the extended single film model was applied to L1500 simulation and this section discusses the predicted CO concentration along the pilot-scale test furnace. These results are in contrast to the simulation results from the standard Glacier, discussed in the preceding section.

In computational modeling of the coal combustion, $\mathrm{CO}$ can be formed from various sources:

- Coal off gas (volatiles) and their reactions

- Char oxidation: $\mathrm{C}+1 / 2 \mathrm{O}_{2} \rightarrow \mathrm{CO}$ or $\mathrm{C}+\mathrm{O}_{2} \rightarrow \mathrm{CO}_{2}$

- Char gasification: $\mathrm{C}+\mathrm{CO}_{2} \rightarrow 2 \mathrm{CO}$ or $\mathrm{C}+\mathrm{H}_{2} \mathrm{O} \rightarrow \mathrm{CO}+\mathrm{H}_{2}$

Then, further reaction such as $\mathrm{CO}$ to $\mathrm{CO}_{2}$ reaction occurs in as subsequent gas-phase equilibrium calculation.

Figure 4.12-7 shows the CO concentration profiles along the L1500 pilot-scale test furnace from air and oxy combustion cases with char oxidation model (standard) and the extended char reaction model. Two high CO concentration zones could be found: 1) near the burner and its flame zone, and 2) near the bottom of the furnace right at the upstream of OFA port. The first high CO zone could be found in a typical pulverized coal-fired burner, while the second high $\mathrm{CO}$ zone resulted from the combustion characteristics of the given furnace. L1500 furnace is horizontally fired furnace and found some unburned particle deposited on the bottom of the furnace (see Figure 4.12-8). These unburned char particles can react to form CO. Interesting feature is that the predictions with the extended single film model resulted in even higher $\mathrm{CO}$ concentration especially in the second high $\mathrm{CO}$ zone. Although this trend is more consistent with the measurements as compared with the air data in Figure 4.12-9, the explanation is not straightforward. 


\section{Air With Original Char Oxidation}

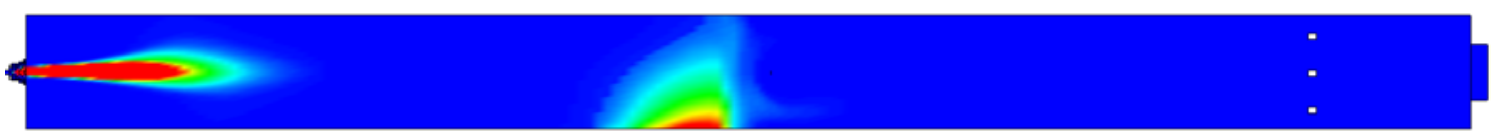

Air With Extended Char Reaction

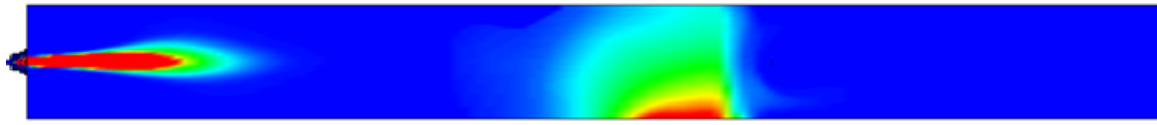

Oxy With Original Char Oxidation

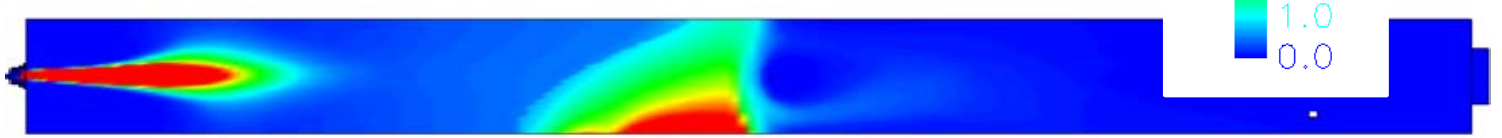

Oxy With Extended Char Reaction

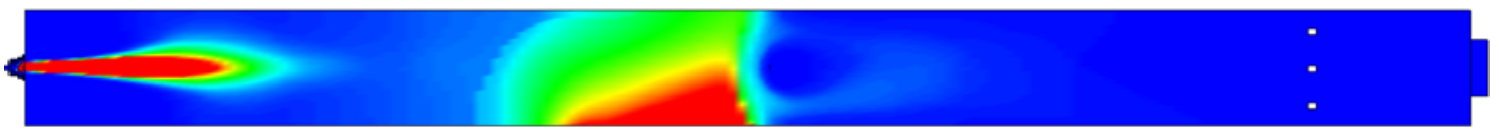

Figure 4.12-7: CO concentration profiles from L1500 simulation firing Utah Skyline coal.

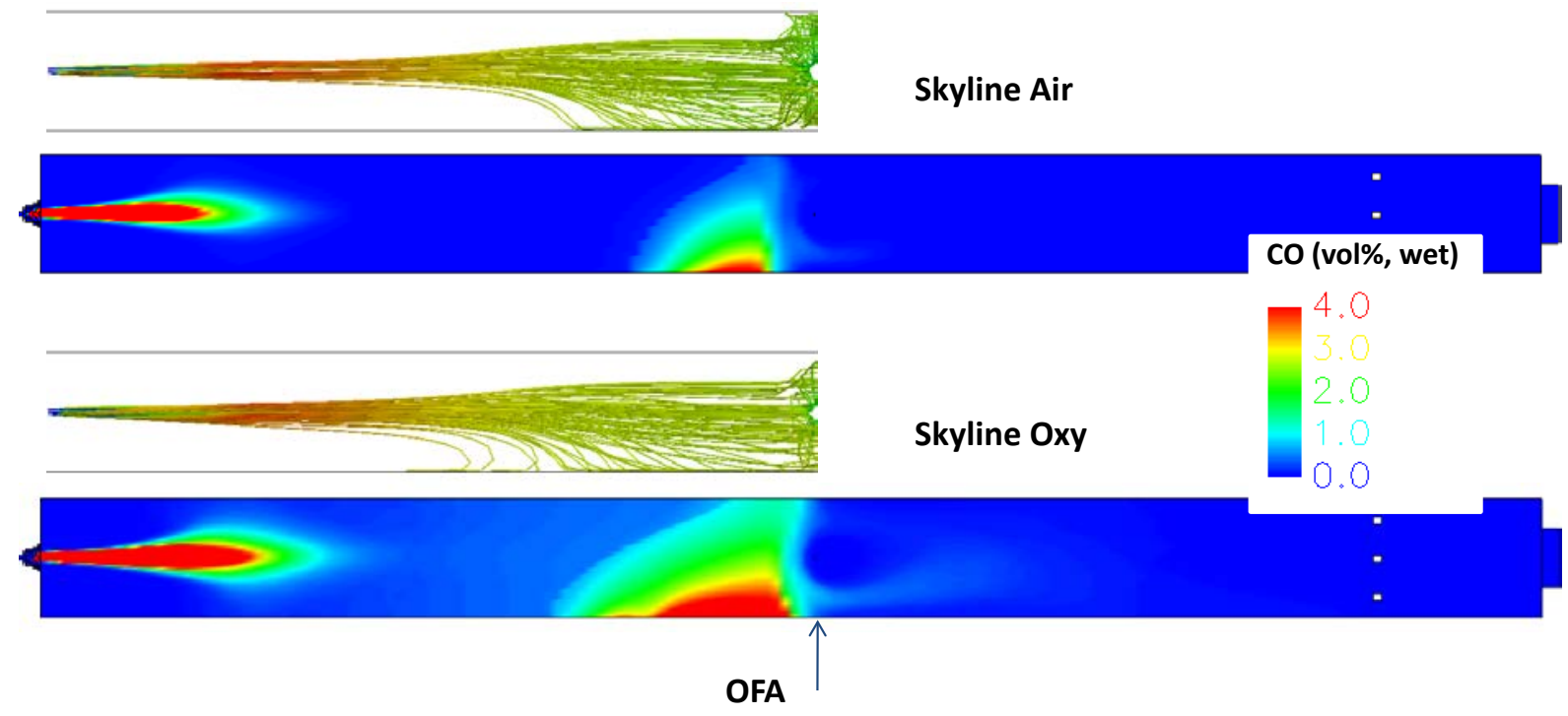

Figure 4.12-8: Particle trajectories and $\mathrm{CO}$ concentration profiles along the furnace from Utah Skyline air and oxy combustion cases. 


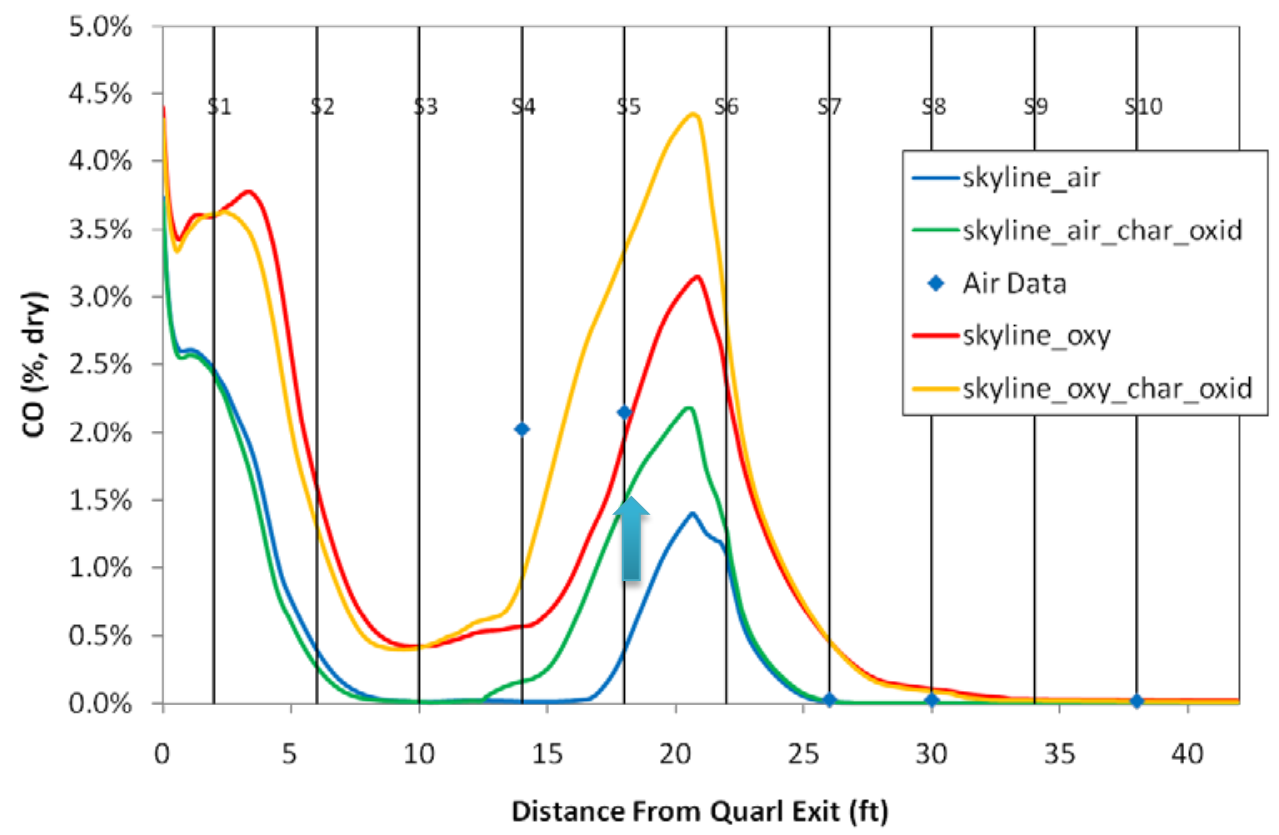

Figure 4.12-9: CO concentration profiles as a function of the distance from the quarl exit.

Figure 4.12-10 and Figure 4.12-11 show the particle deposition flux and the unburned carbon deposition flux, respectively. There is certainly high deposition onto the bottom of the furnace, but the differences between with and without the extended char reaction model are not significant. This can be clearly shown in Figure 4.12-12 and Figure 4.12-13 which plot the average values along the furnace length for air and oxy cases. Based on these plots, the higher $\mathrm{CO}$ in the extended char reaction model is not just from the deposition characteristics in the furnace. The upstream reactions such as added CO generation term (char gasification) in the extended model and the subsequent equilibrium reaction may cause this higher $\mathrm{CO}$ near the OFA in addition to the unburned carbon deposition.

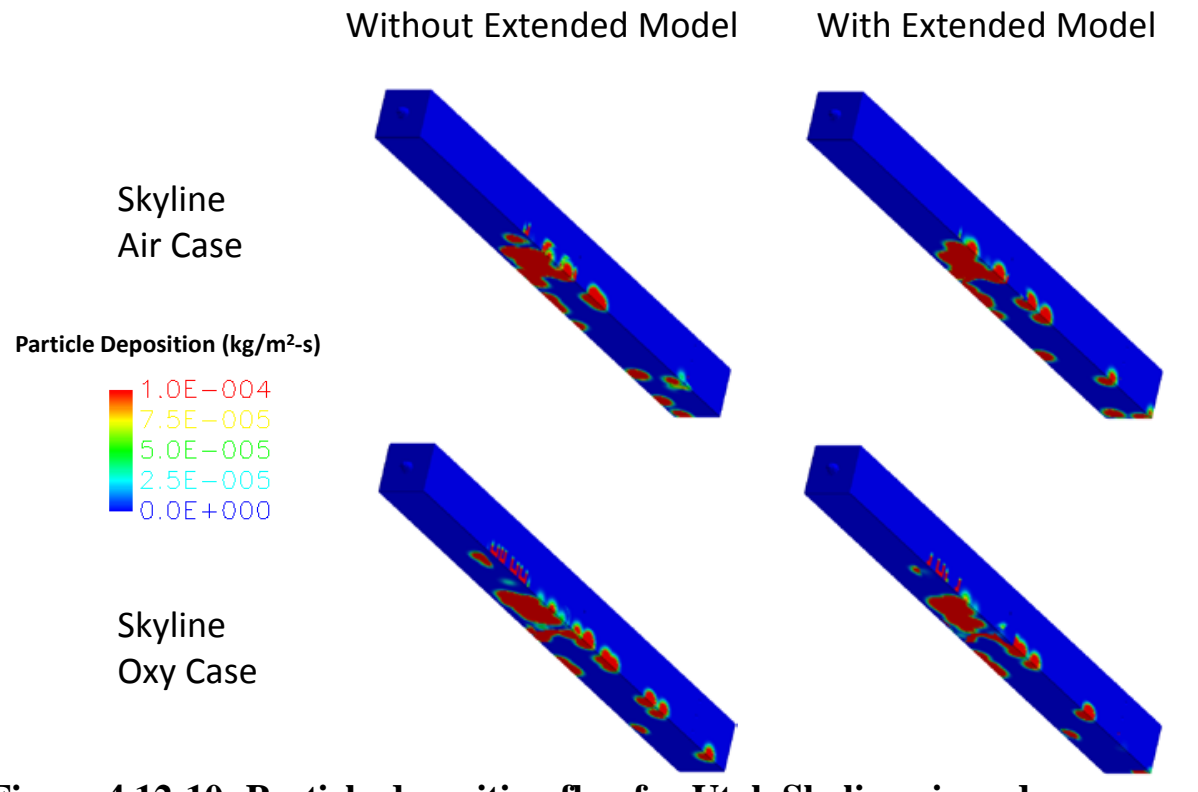

Figure 4.12-10: Particle deposition flux for Utah Skyline air and oxy cases. 


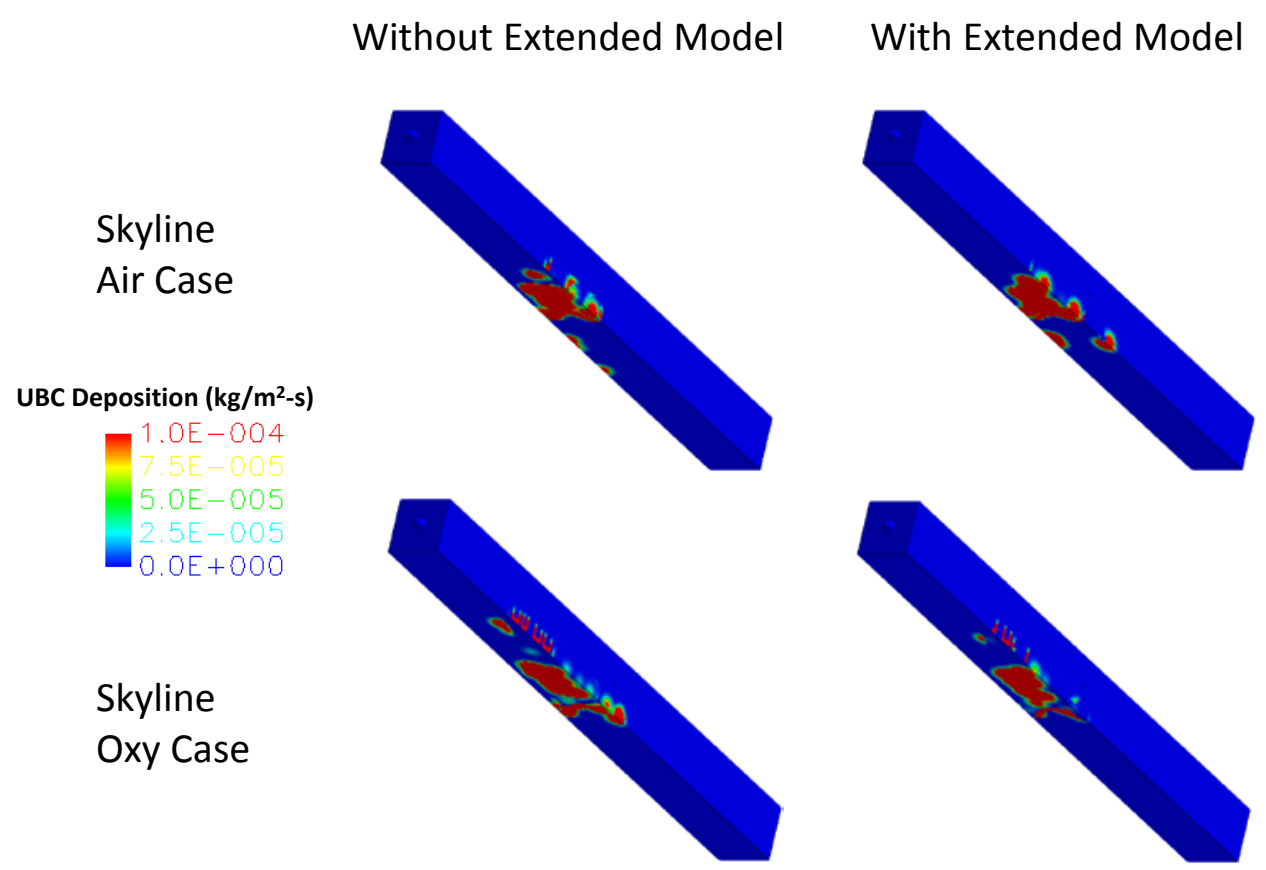

Figure 4.12-11: Unburned carbon deposition flux for Utah Skyline air and oxy cases.

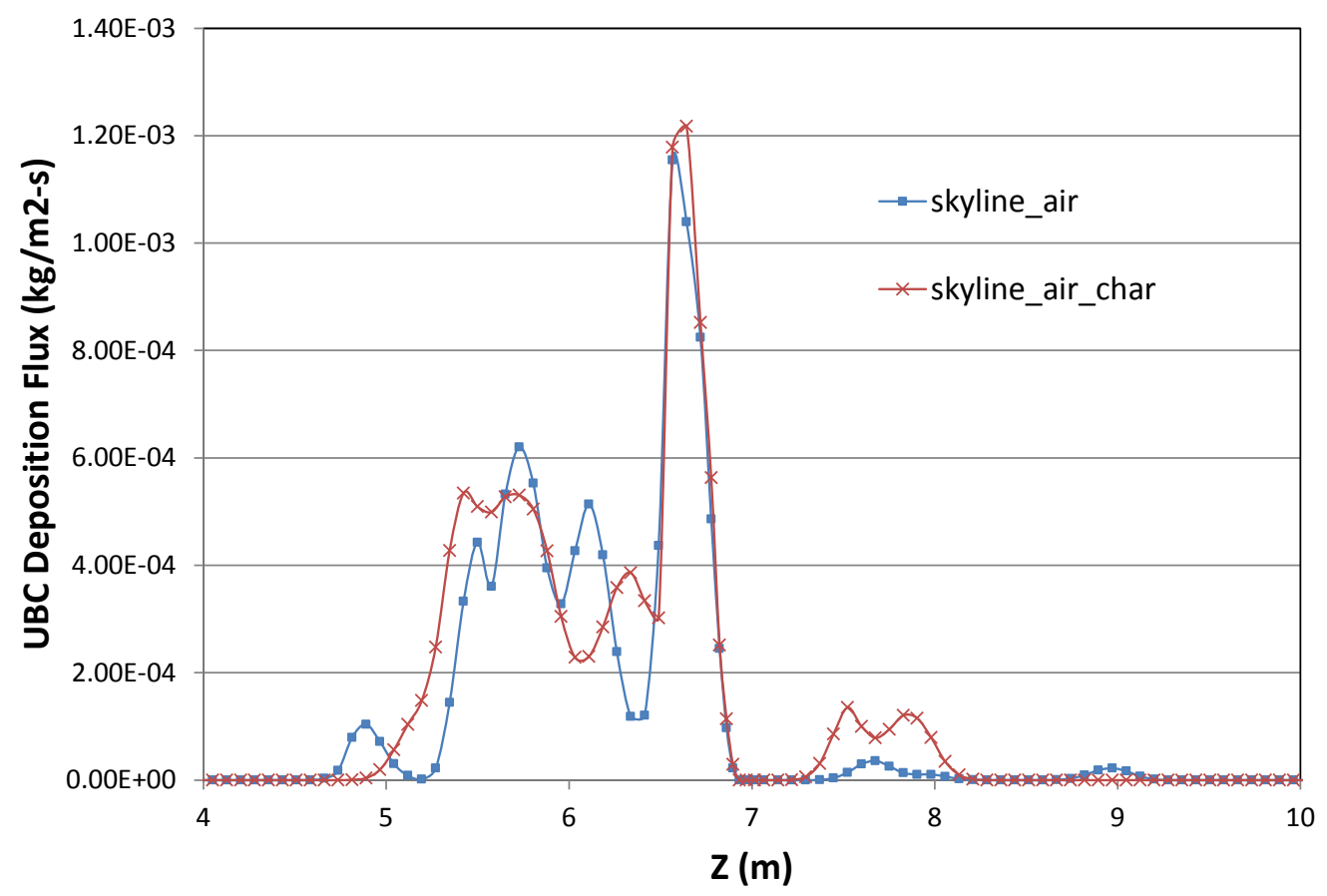

Figure 4.12-12: Unburned carbon deposition flux as a function of furnace section for Utah Skyline air cases without/with the extended char reaction model. 


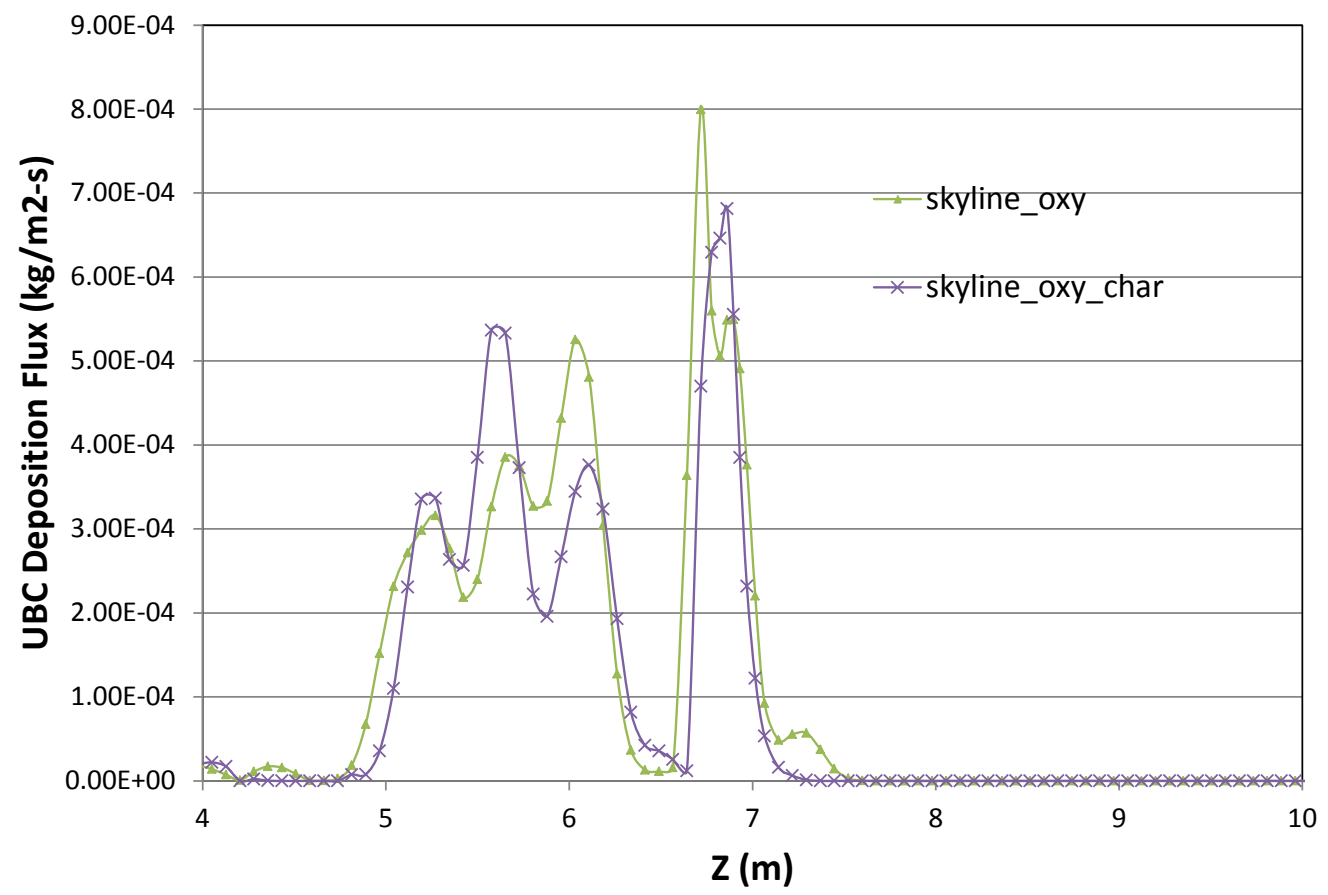

Figure 4.12-13: Unburned carbon deposition flux as a function of furnace section for Utah Skyline oxy cases without/with the extended char reaction model.

\subsubsection{Updated Gas Emissivity Mechanism}

A brief study was conducted with the L1500 model to assess the impact of a narrow band gas emissivity model on heat flux predictions. Baseline Glacier calculations utilize a hybrid Hottel Chart curve-fit and weighted sum of gray gas (WSGG) model to predict gas emissivity. Some research has suggested that predictions from such models are inaccurate in high $\mathrm{CO}_{2}$ and $\mathrm{H}_{2} \mathrm{O}$ environments typical of oxycombustion systems with flue gas recycle. The advanced gas emissivity model is a narrow band model based on the RADCAL code formulated by NIST.

Previous work has suggested that there are minimal emissivity impacts for short path lengths and that particle radiation dominates gas radiation in burner (high heat release) zones. This suggests that comparisons in the pilot-scale L1500 may not be fully representative of differences observed in full-size utility boilers due to limited path lengths in the pilot-scale furnace. Particle radiation may still dominate in the near burner region, but differences in gas emissivity impacts may be limited. Figure 4.12-14 plots a comparison of gas emissivity calculated with the WSGG and narrow band models for air-fired combustion environment $\left(16 \% \mathrm{CO}_{2}, 8 \% \mathrm{H}_{2} \mathrm{O}, 76 \% \mathrm{~N}_{2}\right)$ and oxy-fired environment $\left(64 \% \mathrm{CO}_{2}, 32 \% \mathrm{H}_{2} \mathrm{O}\right.$, $4 \% \mathrm{~N}_{2}$ ) for path lengths from 1 to 20 meters (3.3 to 66 feet). The plot shows little difference between emissivities calculated with the two models for air-fired conditions. Emissivities for oxy-fired conditions are higher due primarily to the higher concentration of $\mathrm{H}_{2} \mathrm{O}$ in the gas $\left(\mathrm{H}_{2} \mathrm{O}\right.$ is a stronger absorber-emitter than $\mathrm{CO}_{2}$ at the wavelengths of interest). The plot shows a divergence in calculated emissivities at longer path lengths (say 10 meters and higher). The L1500 optical path length was $2.96 \mathrm{ft}(0.9 \mathrm{~m})$. As Figure 4.12-14 suggests, there should be no noticeable difference between the calculated emissivities at this short path length. 


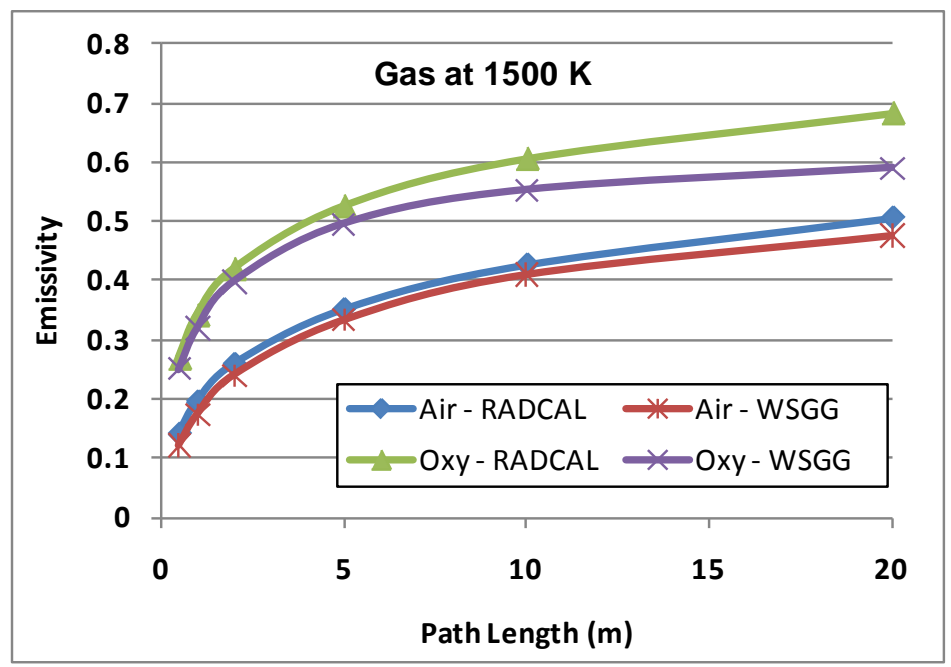

Figure 4.12-14: Predicted gas emissivities calculated with the weighted sum of gray gas (WSGG) and RADCAL narrow band models for air and oxy-fired conditions.

This is confirmed by Figure 4.12-15 which plots the gas emissivity for air and oxy-fired conditions, with the standard WSGG and RADCAL narrow band models. The oxy-fired condition has higher gas emissivity, but there is negligible difference between gas emissivity models for either the air or oxy-fired conditions. Figure 4.12-16, a re-plot of previously shown average gas temperatures in the L1500, also shows negligible impacts on predicted gas temperatures from the different gas emissivity models.

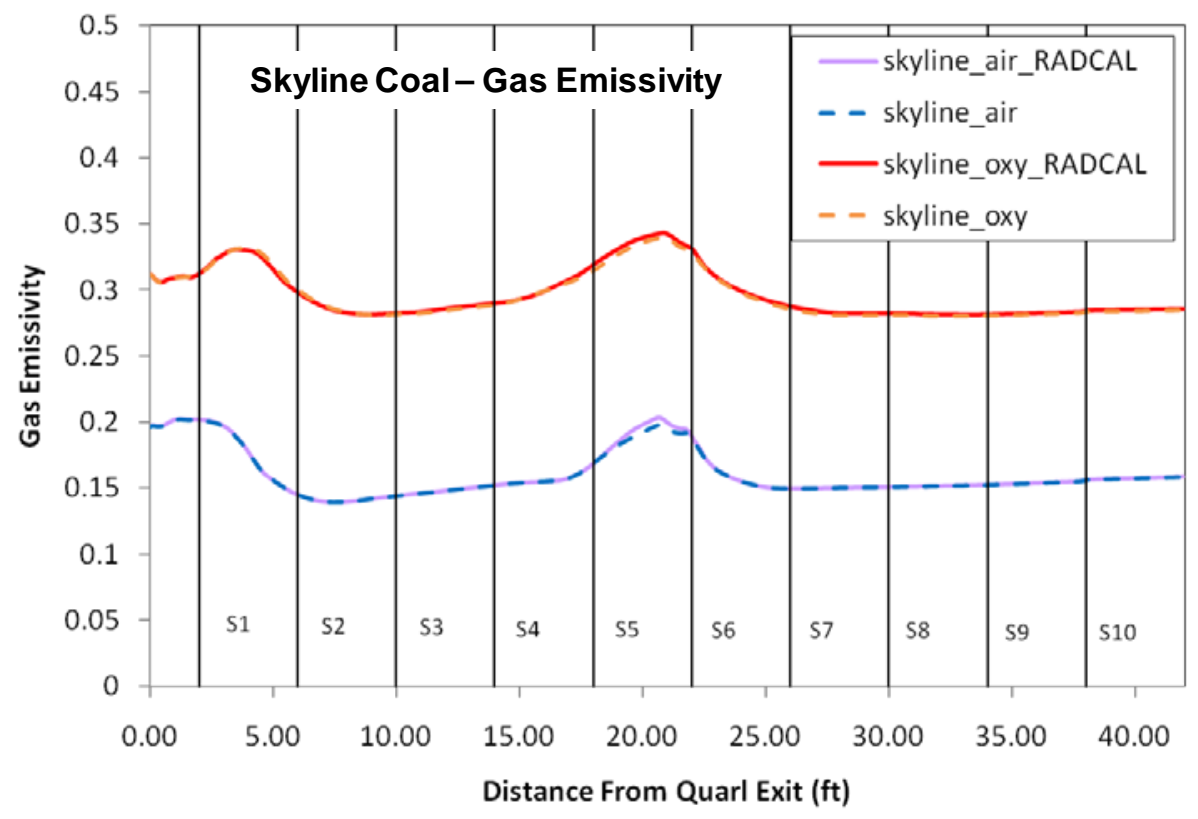

Figure 4.12-15: Calculated gas emissivities for the L1500 pilot-scale furnace with and without the RADCAL narrow band model. 


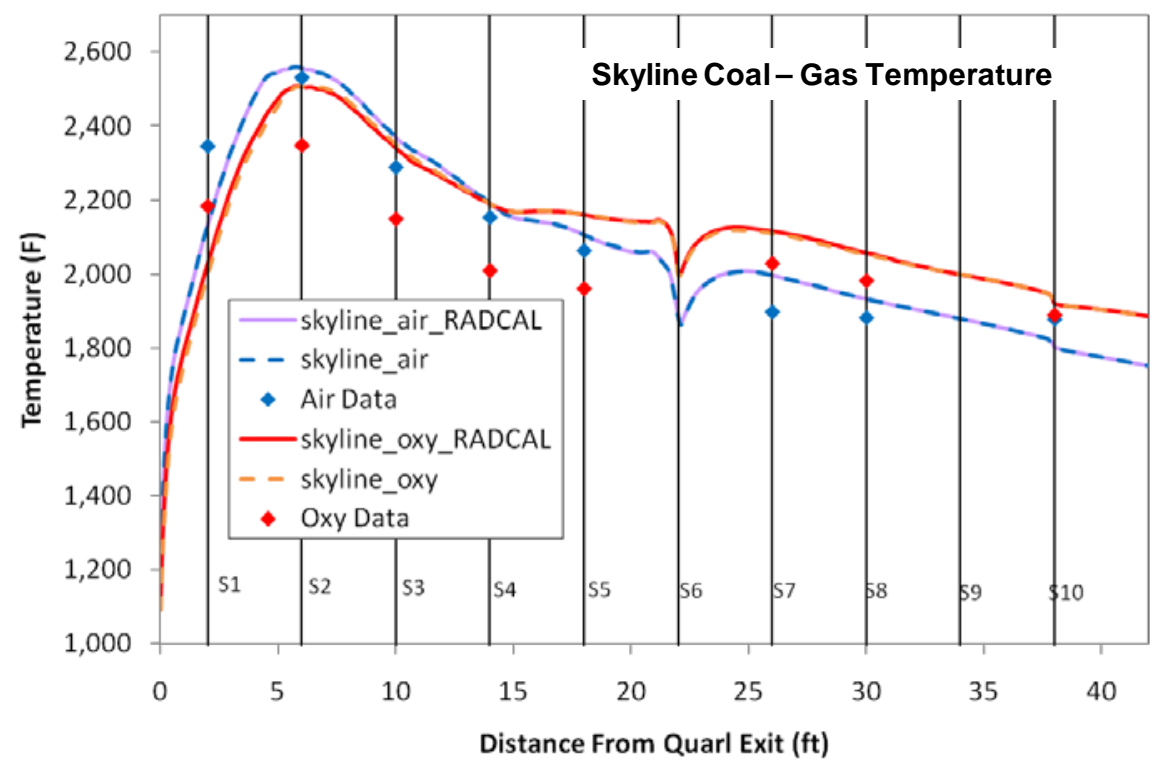

Figure 4.12-16: Calculated gas temperatures for the $\mathbf{L} 1500$ pilot-scale furnace with and without the RADCAL narrow band model.

Figure 4.12-17 plots the calculated incident flux profile averaged on one side wall of the L1500 for air and oxy-fired conditions. The "wiggles" in the profiles in the first four furnace sections are due to the serpentine wall cooling panels in these sections. The predicted flux for the oxy-fired case is higher than the air-fired case. Originally this was believed to be due to the increase in gas temperature and/or gas emissivity in the oxy-fired case, however these effects were secondary. Figure 4.12-18 plots the centerline gas temperature of the furnace, which shows little difference between the air and oxy-fired cases. Similarly the differences in gas plus particle absorption coefficients (i.e., the overall flame emissivity from gas and particles) did not show sufficient differences to account for the incident flux differences. Note that in both plots, the use of the narrow band gas emissivity model made no difference in predicted results. 


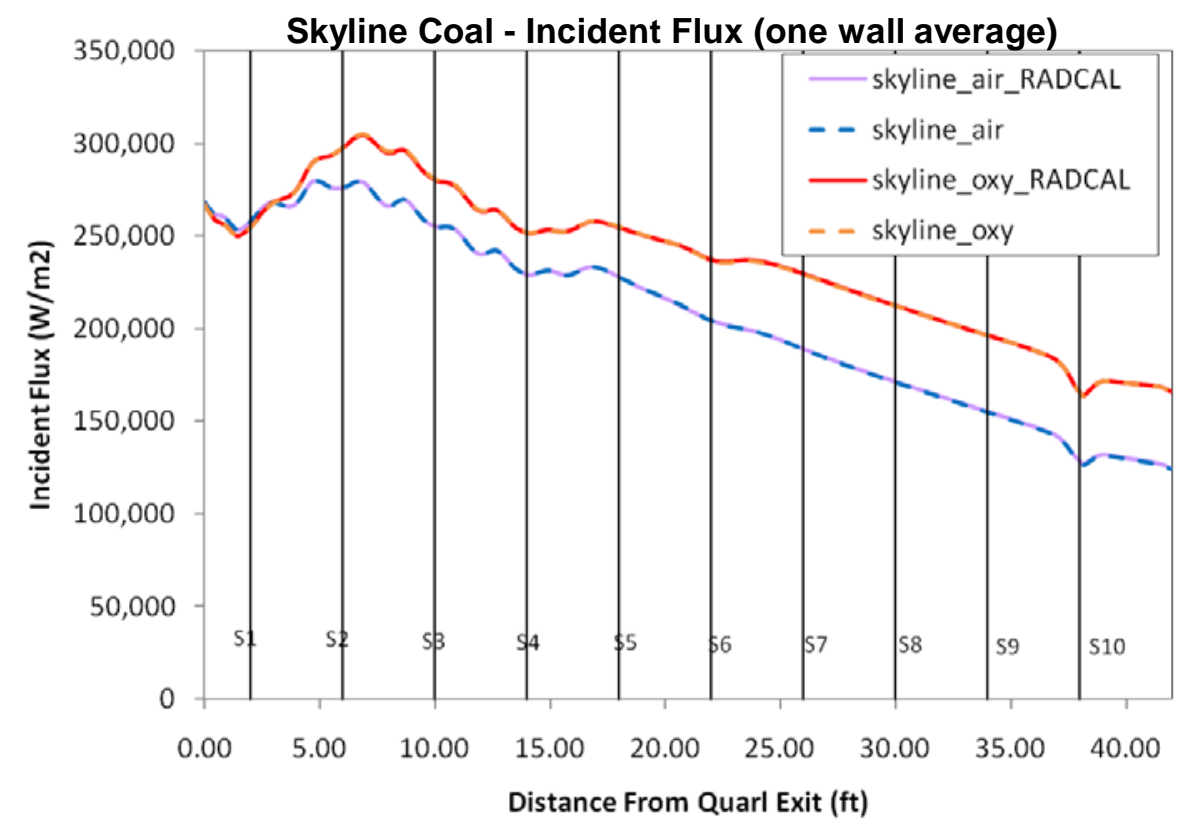

Figure 4.12-17: Predicted average incident flux profile for one wall in the L1500 furnace for air and oxy-fired conditions.

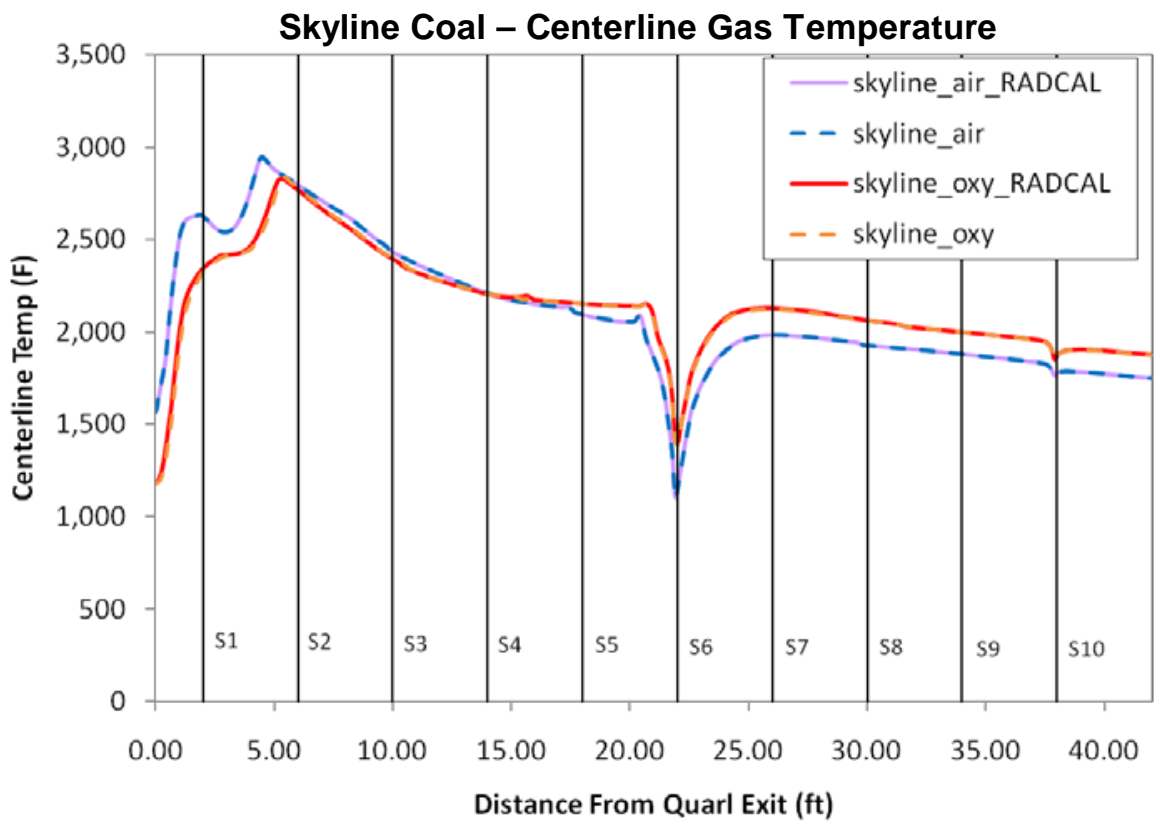

Figure 4.12-18: Predicted centerline gas temperature for L1500 air and oxy-fired conditions.

The parameter which was found to most closely correlate with the incident flux profile was wall temperature. The wall temperature boundary condition was prescribed for these cases based on measured wall temperature data. Figure 4.12-19 plots the measured and modeled wall temperatures for the air and oxy-fired cases. The correlation between wall boundary temperatures and incident wall flux is excellent. This should not be surprising given the small path lengths in the L1500 furnace. This sensitivity of 
surface heat flux to wall boundary conditions illustrates the importance of accurately representing surface properties in full-scale boiler models.

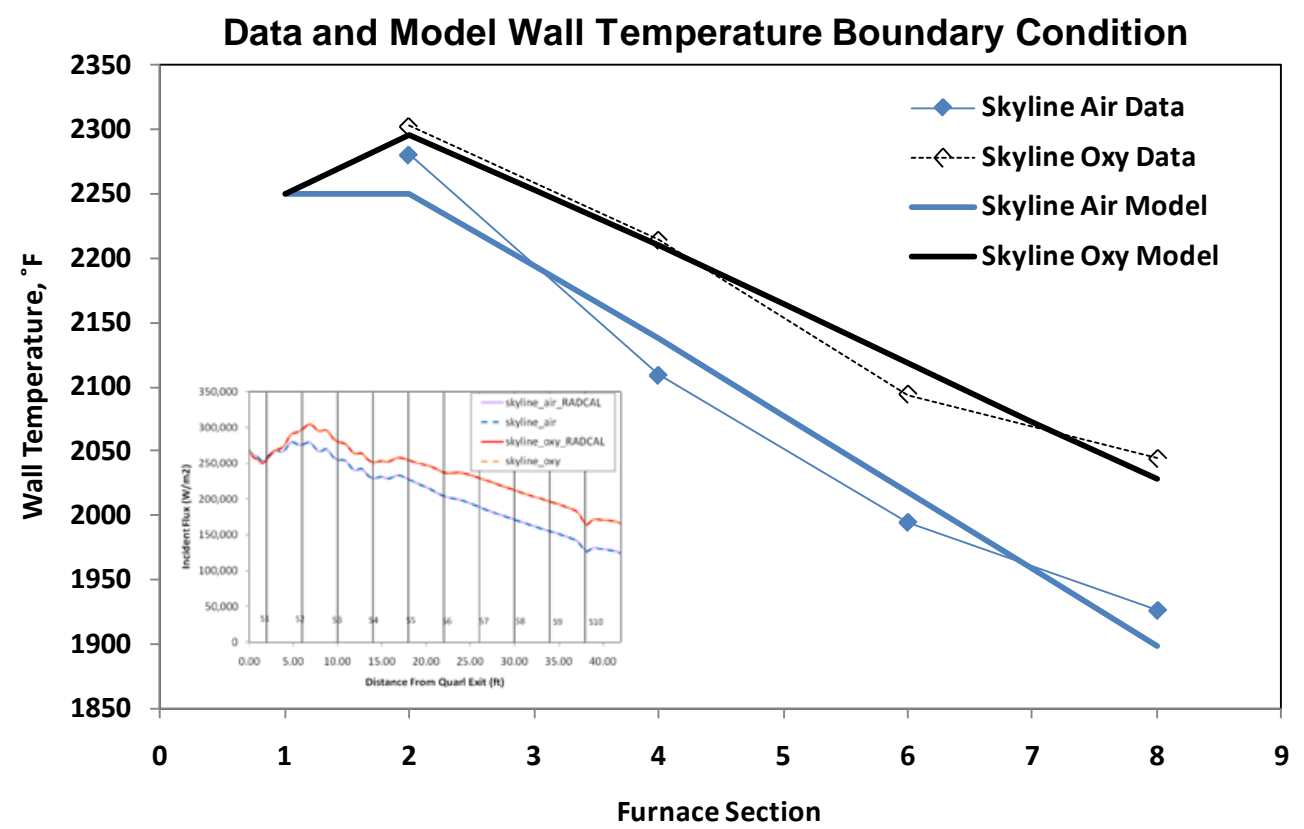

Figure 4.12-19: Measured and modeled L1500 wall temperatures for air and oxy-fired conditions.

\subsubsection{L1500 Comparison Summary}

REI's Glacier CFD code was used to model the L1500 furnace under air and oxy-fired conditions. Comparisons of predicted gas temperatures, $\mathrm{CO}, \mathrm{CO}_{2}, \mathrm{H}_{2} \mathrm{O}, \mathrm{SO}_{2}$ and $\mathrm{O}_{2}$ concentrations, gas emissivity, and wall heat flux have been made. In addition, advanced sub-models for calculating char oxidation and gas emissivity have been evaluated to determine impacts on predicted results. Key conclusions from the comparisons showed:

- Predicted gas temperature trends were correct, including temperature cross-over. Oxy-fired predictions were higher than measured data in staged zone, partly due to prescribed wall temperature boundary conditions.

- The experimentally observed temperature cross-over at the OFA ports was likely due to enhanced CO oxidation near OFA ports. CO concentrations were higher in the oxy-fired case, which could account for a greater temperature increase during oxidation. Predicted results showed the same cross-over behavior and helped explain why this occurred.

- The enhanced char oxidation model developed by Sandia was implemented in the Glacier code. Predictions using this new sub-model showed increased CO production in staged zone and better agreement with air data.

- Using an enhanced gas emissivity sub-model based on narrow band calculations had negligible impact on predicted gas emissivity, temperature or wall flux results. This may in part be due to the small path length of the pilot-scale furnace.

- Wall temperatures based on measured data were prescribed as boundary conditions for the air and oxy-fired cases. These prescribed profiles significantly impacted predicted incident heat flux profiles. Gas centerline temperatures and emissivities had a second-order impact on incident flux profiles. 


\subsection{CFD Modeling of Full-Scale Retrofits}

Two full-scale utility boilers were selected for oxy-retrofit assessment. They were PacifiCorp's Hunter 3 and DTE's River Rouge 3. The unit choices were driven by interest in oxy-combustion technology expressed by the respective utilities. Both utilities provided design, fuel and operating information to REI to facilitate the conceptual design of the oxy-combustion firing systems and simulation of the retrofit configurations.

Figure 4.13-1 describes the approach for the oxy-retrofit process. Because the primary focus of the DOE funded program was on retrofit of existing boilers, the highest priority in the oxy-retrofit design was the matching of heat duties between the air-fired and oxy-fired systems. Once the conceptual designs that provided matching heat transfer were identified (i.e., the firing system development), boiler simulations identified resulting emissions and operational impacts for that firing condition.

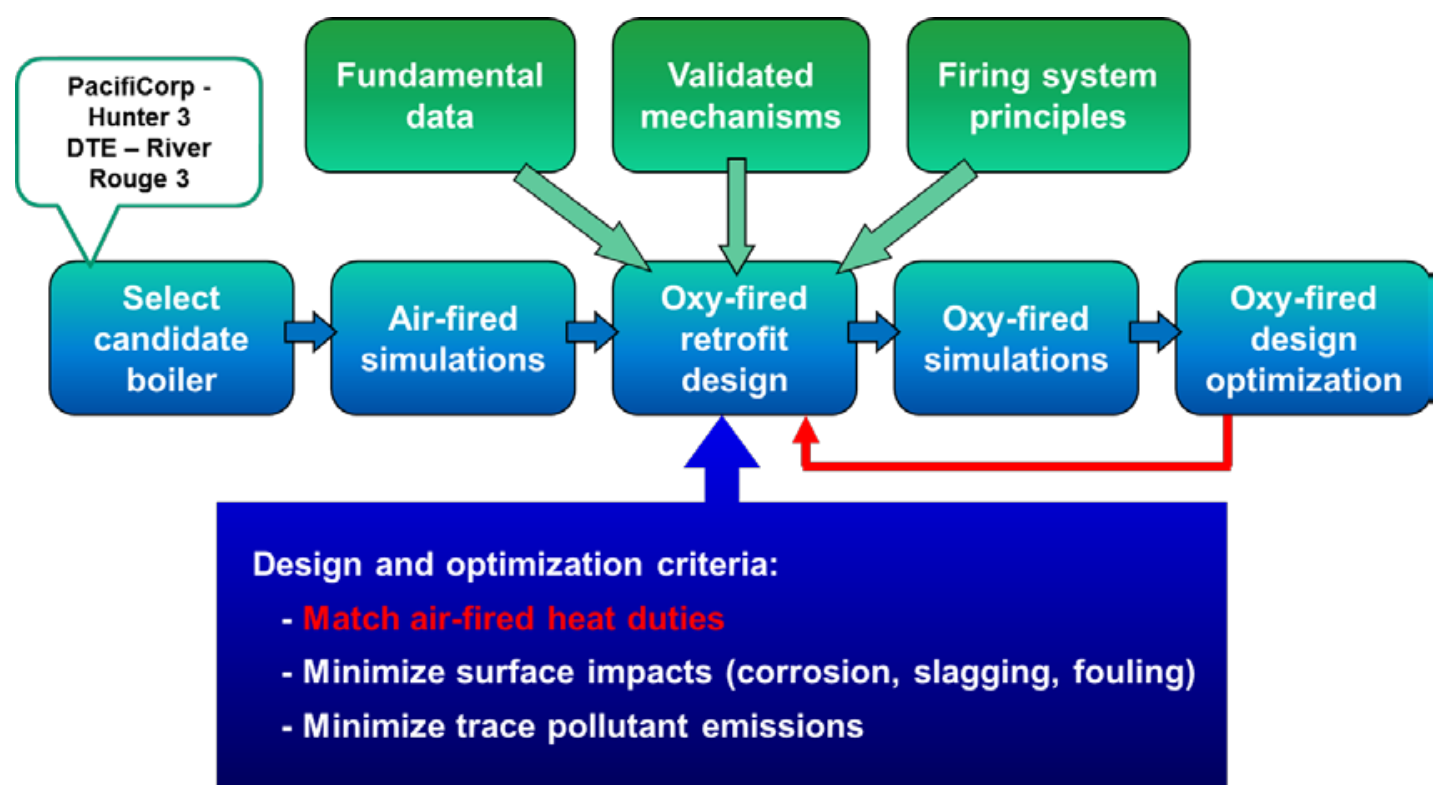

Figure 4.13-1: Oxy-retrofit firing system design approach.

The oxy-retrofit firing system design included two main tasks. First, Siemens Energy developed a conceptual oxy-burner design that could be retrofitted into the existing boiler wall cut-outs. This process to develop the burners is described in the next section for both the Hunter 3 and River Rouge 3 units. These oxy-retrofit burners were used for the oxy-fired CFD simulations.

The second task involved using REI's SteamGen Expert (SGE) process model to determine appropriate firing conditions and FGR properties to best match radiant furnace and backpass heat transfer for the oxyfiring design. Results of this task are described in the respective boiler assessment sections.

\subsubsection{Oxy-Retrofit Burner Development}

\subsubsection{Approach}

Using results from the parametric burner tests performed earlier at the University of Utah (see Sections 4.1 and 4.3), Siemens Energy modified their existing methodology to design full-scale oxy-combustion burners for utility power plants. With this methodology, Siemens developed preliminary burner designs for PacifiCorp's Hunter 3 boiler and DTE’s River Rouge 3 boiler. Both of these burner designs were put 
in a boiler CFD model created by REI. Both models show that the new burner design is an effective means of retrofitting a coal-fired furnace to oxy-combustion firing.

Oxy-combustion burners must be built by considering aerodynamic and thermodynamic principles in order to produce a stable flame with low emissions. The thermodynamic principles are largely governed by the properties of the fuel, the oxidizing medium, and the furnace's capacity to absorb radiant heat. The aerodynamic principles depend on the equipment that introduces the fuel and oxidizing medium into the furnace.

Siemens' approach was to determine the aerodynamic conditions that would create a flame similar to a flame seen in a typical air-fired arrangement. However, if an oxy-fired oxidizer has the same $\mathrm{O}_{2}$ concentration as air, the flame temperature profile decreases due to the increased heat capacity in the burner inlet gases (primarily $\mathrm{CO}_{2}$ from the recycle stream) and potentially slower coal particle reactions. As a result, the furnace sees a decrease in radiative heat transfer, and the boiler loses some ability to produce steam.

To account for this, the $\mathrm{O}_{2}$ concentration in the furnace is raised, which increases the flame temperature and maintains the heat transfer in the radiative section of the boiler. The overall result is an aerodynamic and thermodynamic similitude. In order to produce these results, the following steps were taken (see also Figure 4.13-2):

1) Estimate the total $\mathrm{O}_{2}$ and flue gas used during an oxy-combustion retrofit.

2) Determine the appropriate scaling factors to produce aerodynamic similitude between an air-fired flame and an oxy-fired flame.

3) Account for a burner design that includes heterogeneous mixtures of oxygen and recycled flue gas. For example, the carrier oxy-fuel may be pure flue gas, or may include an injection of pure oxygen.

4) Allocate oxy-fuel to the compartments of the Siemens' burner and overfire gas ports by considering local stoichiometry ratios and aerodynamic proportions.

5) Use the appropriate aerodynamic scaling factors to determine the area of each section of the burner and the overfire gas ports.

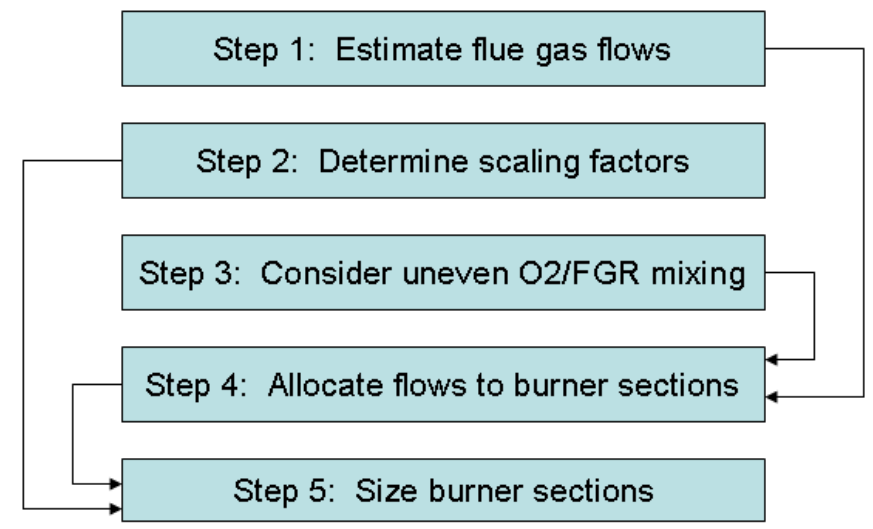

Figure 4.13-2. Process Diagram of oxy-combustion burner sizing. 


\subsubsection{Oxy-combustion Burner Sizing Process}

\subsection{Step 1: Estimate flue gas flows}

The first step was to determine the oxy-fuel flow rates and composition. To do this, Siemens needed to know the following:

- Molar ratio of $\mathrm{O}_{2}$ to FGR, expressed as an $\mathrm{O}_{2} \%$ by volume

- Total excess $\mathrm{O}_{2} \%$ at the stack

- The desired amount of moisture removal from the recycle stream

- The desired amount of moisture removal from the carrier stream

- The coal composition

- $\quad$ The desired $\mathrm{O}_{2} \%$ in the carrier gas

The coal composition and the total excess $\mathrm{O}_{2} \%$ came from the power plants that Siemens modeled. REI provided the desired $\mathrm{O}_{2} \%$ in the $\mathrm{O}_{2} /$ FGR mixture and moisture removal rates based on the principles of combustion and process level simulations. Siemens then expressed this information as a system of equations that includes a material balance of each combustible material and a mathematical representation of each specified operating condition.

These equations were then solved algebraically and put into an Excel program. Depending on the complexity of the operation, these equations were either solved directly or through an iteration process. Solving these equations gives us the composition and the total mass flow rate of both the input streams and the recycle stream.

One key parameter that is unique to oxy-combustion is the flue gas recycle ratio. The recycle ratio dictates the amount of flue gas that re-enters the furnace. In practice, the maintenance of the correct recycle ratio will require a complicated system of controllers, fans and dampers. Although it is outside the scope of this project to design additional equipment for oxy-combustion, future research must consider the costs associated with this recycle ratio.

This recirculation is impacted whenever compounds in the flue gas are removed before it re-enters the furnace. Sulfur dioxide may be removed to avoid corrosion, and excess moisture can negatively impact boiler efficiency and flame propagation. However, it can be energy intensive to remove these chemicals, especially if it requires cooling and reheating a flue gas stream. Again, this is outside of the scope of this project, but the economic impact of these decisions must be taken into account in future research.

Figure 4.13-3 depicts the arrangement of the proposed oxy-combustion furnace at PacifiCorp's Hunter Unit 3. Here, the de-sulfurization system is placed before the recycle loop. This means that either the flue gas desulfurization (FGD) scrubber must be able to withstand high temperature or the flue gas must be cooled and reheated. There is no moisture taken out of the secondary gas system, but there is moisture taken out of the carrier gas stream.

Oxygen is injected into the "windbox gas", that is, the portion of the recycled flue gas that goes to the burner secondary compartments and the over-fire gas system. The carrier gas was enriched to $21 \% \mathrm{O}_{2}$. Preliminary modeling shows that heat transfer characteristics in Hunter 3 will be matched when the $\mathrm{O}_{2}$ concentration is $26 \%$ by volume. 


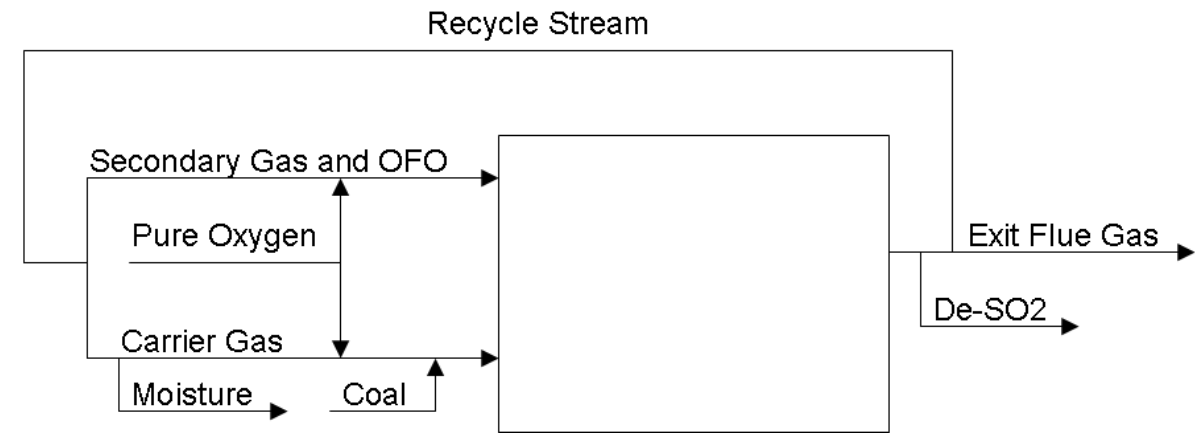

Figure 4.13-3. Block diagram of PacifiCorp's Hunter 3 oxy-combustion arrangement.

In contrast to PacifiCorp's arrangement, DTE's River Rouge Unit 3 is more complicated (see Figure 4.13-4). Oxygen is injected into both the windbox gas and the carrier gas. Moisture is removed in two stages: once immediately after the recycle split, and again in the carrier gas section. This is because the high moisture coal may not burn if it is in a wet atmosphere. $\mathrm{SO}_{2}$ is removed in the flue gas after the recycle split because the sulfur in the coal is low, so recycling a high percentage of the $\mathrm{SO}_{2}$ will not lead to excess corrosion. River Rouge heat transfer will be matched when the $\mathrm{O}_{2}$ is approximately $23 \%$ by volume.

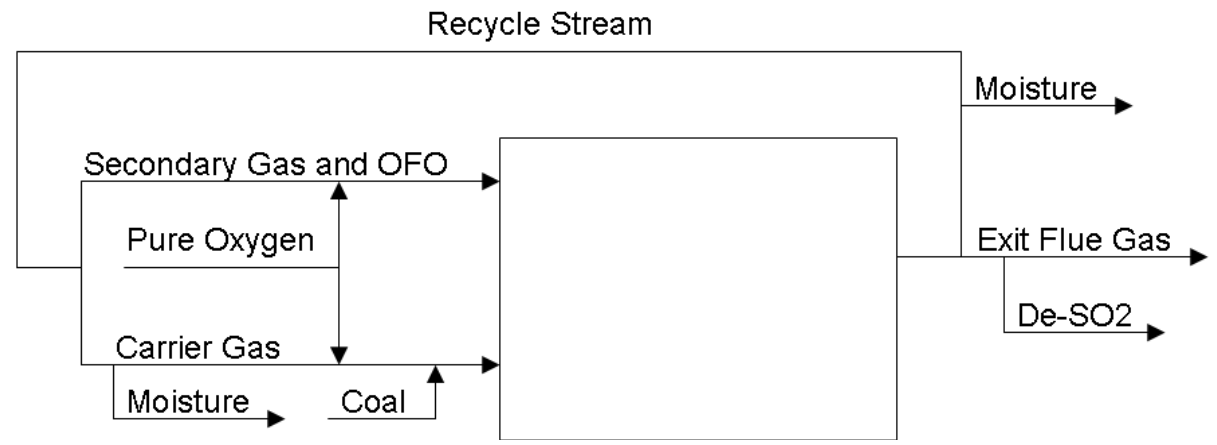

Figure 4.13-4. Block diagram of DTE's River Rouge Unit 3 oxy-combustion arrangement.

These are just two possible arrangements for an oxy-combustion system. Choosing the correct one for a particular power plant requires a full-scale engineering, economic and environmental analysis. These considerations ultimately affect the recycle ratio of the flue gas, thereby changing the composition and total flow rates of the flue gas re-entering the furnace.

\subsection{Step 2: Determine appropriate scaling factors}

As discussed earlier, Siemens' approach was to create aerodynamic similitude between an air-fired burner and an oxy-fired burner. During this step, Siemens determined which scaling factor was most appropriate. In air-fired cases, it is typical to design for certain velocities, so it would seem appropriate to use those velocities for the oxy-combustion case. However, the molecular weight of the flue gas is much higher than that of air, which means the flue gas would have a much greater momentum. This would almost certainly affect flame characteristics.

Testing at the University of Utah confirmed that maintaining primary gas velocities for oxy-fired burners led to extremely poor flames. Maintaining momentum of the carrier gas, conversely, created stable flames. This indicated, at the very least, that the higher density of the flue gas required a corresponding 
decrease in its velocity at the burner. Taking the lessons learned from the University of Utah, Siemens set about determining a scaling factor for all parts of the burners that were to be modeled.

One approach was to size the burner as if it were air-fired, determine the mass flux of each compartment, and resize the burner for an Oxy-fired case such that the mass fluxes were equal. However, sizing a burner requires some detail and has to coincide with the dimensions of the furnace. Designing two burners in that way is time-consuming, and there was no guarantee that this approach would produce an optimal burner; it was only one way of creating a stable burner.

Therefore, it was decided to size the entire burner by reducing the velocity of all the compartments of the Siemens burner by the same proportion as the carrier gas. This approach was later compared with the approach of sizing for momentums, and the results were similar.

Siemens attempted to create a burner that operates optimally under oxy-fired conditions and operates at least satisfactorily under air-fired conditions. However, the oxy-fired burner Siemens designed was typically (though not necessarily) a different size than a burner designed under air-fired conditions. Because of this, it was not always feasible to have one burner design that operated the same way for both the oxy-fired and air-fired condition.

For example, PacifiCorp's Hunter 3 burner was designed to fire at full load with one mill out of service under oxy-fired conditions. However, because the molar percentage of $\mathrm{O}_{2}$ is greater for oxy-fired conditions than that of air-fired, the volumetric flow rate of burner inlet gases will be lower when the unit operates on oxy-firing. Under air-fired conditions, the volumetric flow rate of burner gases (i.e., combustion air) will be greater to provide the desired oxygen concentration for combustion. Therefore, while Hunter 3 is operating under air-fired conditions, the boiler must operate with all mills in service. In this way, Siemens is able to accommodate a furnace that may have to operate under air-fired and oxyfired conditions.

River Rouge 3 was also designed to operate under both oxy-fired and air-fired conditions. However, the River Rouge furnace was significantly different in design and operation than the Hunter 3 furnace. Differences included coal composition, air in-leakage amounts, Coke Oven Gas (COG) burners, and water wall/radiation superheat steam circuits. For these reasons, the oxygen concentration for oxy-firing at River Rouge was lower than Hunter 3 (i.e., closer to $21 \% \mathrm{O}_{2}$ for air-firing) and therefore the oxy-fired burner for River Rouge was approximately the same size as an air-fired burner would be, so it was not necessary to change mill configurations.

\subsection{Step 3: Consider uneven $\mathrm{O}_{2} / \mathrm{FGR}$ mixing}

Oxy-combustion gives burner designers a unique opportunity to control combustion chemistry within the furnace. Because oxygen and FGR diluent are independent flow streams that can be mixed together, it is possible to produce different streams with varying $\mathrm{O}_{2}$ concentrations. This can help burner designers affect local stoichiometries, flame temperatures and emission profiles in ways that are not possible using only air. However, there are dangers to using pure oxygen, especially in the presence of highly combustible material.

For example, an oxy-fired flame can achieve greater stability when oxygen is injected into the carrier gas stream, but oxygen enrichment in the primary stream is bounded by safety concerns. $\mathrm{O}_{2}$ levels of over $23.5 \%$ are deemed to be too high because they may cause explosions within the coal pipe. Even localized areas of high $\mathrm{O}_{2} \%$ can be dangerous in the presence of coal. Therefore, if $\mathrm{O}_{2}$ must be introduced into the carrier stream, it must be done carefully. 
University of Utah testing shows that a flame can propagate without oxygen enrichment in the primary stream. However, the oxy-research burner used at the University of Utah had a small coal nozzle diameter. It is believed that a larger burner with a larger coal nozzle is less stable without $\mathrm{O}_{2}$ enrichment. Hunter 3's burner was not designed for oxygen enrichment in the primary stream while River Rouge 3 was designed for a primary $\mathrm{O}_{2}$ concentration of $21 \%$ by volume. This includes both pure oxygen and oxygen from the flue gas recycle.

There is also an advantage to injecting concentrated pure oxygen along the boundary of the inner secondary fluid zone and the carrier gas zone. The University of Utah accomplished this by having pipes of pure $\mathrm{O}_{2}$ positioned along the coal nozzle of the oxy-research burner. However, for the purposes of burner sizing, it makes little difference if the additional $\mathrm{O}_{2}$ is introduced separately or is mixed into the bulk oxy-fuel stream. Siemens was only concerned with the total flows and average compositions in a given compartment.

Relative to the carrier gas stream and inner secondary gas, testing showed that pure $\mathrm{O}_{2}$ injection in the outer secondary gas and over-fire gas had little effect. Though economic analyses were not a part of this project, it was clear that it was more expensive to increase the number of separate $\mathrm{O}_{2}$ streams. Since there was an obvious cost and little perceived benefit, it was decided not to consider this approach.

Neither Hunter 3 nor River Rouge 3 had additional $\mathrm{O}_{2}$ injection in the inner secondary register, meaning the $\mathrm{O}_{2} \%$ was the same for the inner register, the outer register, and the overfire gas register. Figure 4.13-5 and Figure 4.13-6 show different possible orientations for allocating oxygen and flue gas into the burners and overfire gas system.
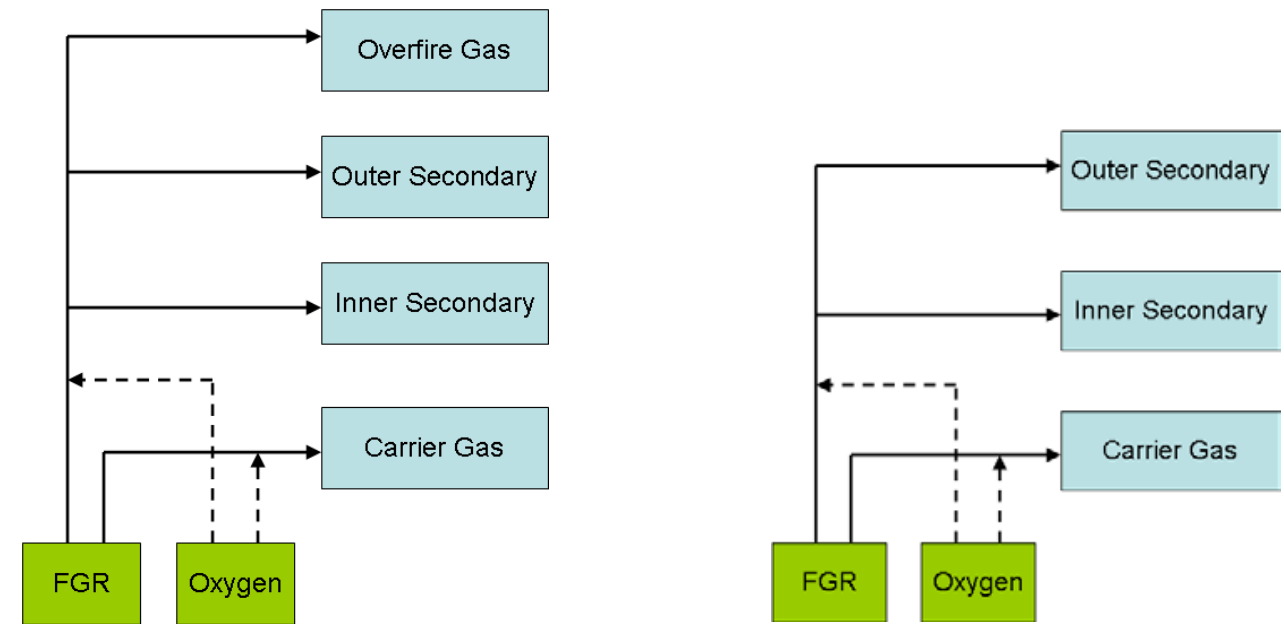

Figure 4.13-5. Block diagrams describing the injection of FGR and oxygen in PacifiCorp's Hunter 3 (left) and DTE's River Rouge 3 (right). 

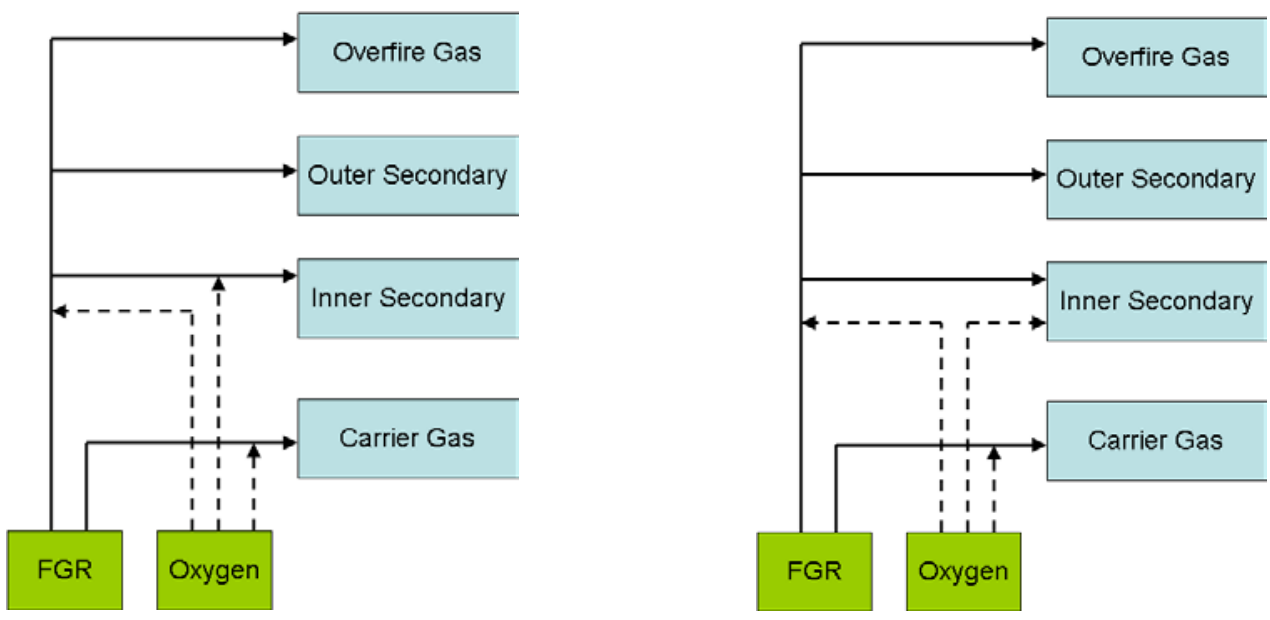

Figure 4.13-6. Block diagrams describing inner secondary $\mathrm{O}_{2}$ injection by additional mixing (left) and by direct injection into the furnace (right).

\subsection{Step 4: Allocate flows to burner sections}

Because the oxidizing fluid entering the furnace is a combination of pure $\mathrm{O}_{2}$ and FGR, it was necessary to create calculations that separately allocate $\mathrm{O}_{2}$ and FGR to these different compartments. The following information was needed for these calculations:

1. Specified $\mathrm{O}_{2} \%$ in the over-fire gas

2. Specified $\mathrm{O}_{2} \%$ in the inner secondary burner compartment

3. Specified $\mathrm{O}_{2} \%$ in the carrier gas

4. Burner Zone Stoichiometry Ratio (BZSR)

5. Specified percent of secondary fluid in the inner secondary burner register (ISF \%)

6. Specified carrier gas required

7. Total FGR flow rate

8. Total pure $\mathrm{O}_{2}$ flow rate (not including $\mathrm{O}_{2}$ present in FGR)

It is easy to see the parallel between the oxy-fired case and the air-fired case. The BZSR, ISF \% and carrier gas flow are important in air-fired cases. The FGR and Pure $\mathrm{O}_{2}$ flow rates combine to create to total mass flow of the oxidizing fluid, which is exactly what the total furnace air is in a current power plant. The only new concepts introduced are the $\mathrm{O}_{2}$ percentages, which can be specified in an oxy-fired case, but remains constant in air.

PacifiCorp's Hunter 3 has an overfire air system and operates with a set BZSR and carrier gas flow rate. Siemens had already determined the total FGR flow rate and the pure $\mathrm{O}_{2}$ flow rate during Step 1 and decided to maintain its ISF\%. The carrier gas $\mathrm{O}_{2} \%$ was already determined in Step 3.

It was also determined in Step 3 that the $\mathrm{O}_{2} \%$ of the inner secondary and over-fire gas is equal to the $\mathrm{O}_{2} \%$ of the outer secondary. The outer secondary $\mathrm{O}_{2} \%$ therefore is a direct function of the primary gas flow rate and $\mathrm{O}_{2} \%$. This satisfies all the information required to allocate FGR and $\mathrm{O}_{2}$ to the different compartments of the Hunter 3 combustion system. 
River Rouge 3 has no overfire air system, so its $\mathrm{O}_{2} \%$ is not included in the calculations, nor is the BZSR. The carrier gas flow rate was dictated by the plant, and its $\mathrm{O}_{2} \%$ was determined in step 3. The secondary gas $\mathrm{O}_{2} \%$ was constant for the inner and outer case. The total FGR flow and the pure $\mathrm{O}_{2}$ flow were decided in Step 1, and the ISF\% was established by Siemens' standard sizing procedure.

\subsection{Step 5: Size burner sections}

The four previous steps provided Siemens with the following information for each section of the combustion system:

- The desired velocity

- The total mass flow rate

- The chemical composition

Designing the burner and overfire gas system sets the area of each section. Siemens was able to calculate the desired area of each section with the following equation,

$$
\mathrm{m}=\rho^{*} \mathrm{~A}^{*} \mathrm{v}
$$

where $\mathrm{m}$ is the mass flow rate, $\rho$ is the density of a given stream, $\mathrm{A}$ is the area of a given burner section, and $\mathrm{v}$ is the desired velocity. The density of the gas stream can be derived from the ideal gas law,

$$
\mathrm{P} * \mathrm{M}=\rho^{*} \mathrm{R} * \mathrm{~T}
$$

where $\mathrm{P}$ is pressure, $\mathrm{M}$ is the molecular weight of a given gas stream, $\rho$ is the density of a given stream, $\mathrm{R}$ is the universal gas constant, and $\mathrm{T}$ is the temperature of a given gas stream. These equations are typically used by Siemens in order to design burners. In most air-fired applications, though, it is sufficient to express the density of the fluid as a function of temperature and pressure. Oxy-fired applications must account for varying molecular weights.

The molecular weight, $\mathrm{M}$, of a gas stream is equal to the arithmetic mean of each constituent chemical's molecular weight. This is expressed mathematically by:

$$
\mathrm{M}:=\frac{\mathrm{m}}{\sum\left(\frac{\mathrm{m}_{\mathrm{x}}}{\mathrm{M}_{\mathrm{x}}}\right)}
$$

where $m_{x}$ and $M_{x}$ represent, respectively, the mass flow rate and molecular weight of each constituent chemical. Combining the three equations above and solving for A produces the following result:

$$
\mathrm{A}:=\frac{\mathrm{R} \cdot \mathrm{T}}{\mathrm{P} \cdot \mathrm{v}} \cdot \Sigma\left(\frac{\mathrm{m}_{\mathrm{x}}}{\mathrm{M}_{\mathrm{x}}}\right)
$$

Note that " $\mathrm{m}_{\mathrm{x}} / \mathrm{M}_{\mathrm{x}}$ " $=\mathrm{N}_{\mathrm{x}}$, that is, the mass flow rate of a chemical divided by its molecular weight is its molar flow rate. Excess $\mathrm{O}_{2} \%$ leaving the furnace and $\mathrm{O}_{2} \%$ entering the furnace are both specified by 
volume, which is the same as a molar concentration. That means the volumetric flow rate is largely independent of the flue gas composition.

In the case of River Rouge, for example, one may expect the size of the burner to be drastically different depending on whether or not moisture was removed. However, removing that moisture means an almost equal molar amount of dry flue gas needs to be introduced into the furnace. Slightly less dry flue gas needs to be used because the concentration of $\mathrm{O}_{2}$ is higher, but this difference should not substantially change the size of the burner.

PacifiCorp Hunter Unit 3 is in Castledale, Utah, which has an elevation of 5,000 feet. This means the atmospheric pressure is about $85 \%$ that of the pressure at sea level, which makes the burner larger. The fuel is a relatively high rank, which raises fluid temperatures and also makes the burner larger. These conditions, however, were true in the air-fired case as well as the oxy-fired case. Conversely, the molecular weight of the Hunter 3 oxy-combustion fluid is about $20 \%$ greater than air, and the mass flow rate is lower by roughly $12 \%$. Both changes make the burner smaller. However, design and testing of the oxy-research burner for the pilot-scale tests revealed that the velocity of an oxy-combustion burner should be reduced by approximately $13 \%$, which increases the size of the burner. The net result is a reduction in burner size by approximately $20 \%$.

DTE River Rouge 3 is in Detroit, which is at sea level, so the pressure is comparatively higher than at Hunter 3. The lower rank of the fuel lowers the primary air temperature, although the secondary air temperatures are still high. This results in a disproportionately larger nozzle, which affects thermodynamic characteristics. The molecular weight is about $30 \%$ greater in the oxy-combustion case, but the mass flow rate was greater by a factor of $13 \%$. Combined with the $13 \%$ reduction of velocity criteria imposed on oxy-combustion burners, the result is a burner that is nearly identical in size compared with an air-fired burner.

\subsubsection{Retrofit Firing System Summary}

Once the appropriate thermodynamic and aerodynamic principles were investigated, Siemens was able to design a burner for oxy-combustion retrofit of a coal-fired boiler without any major difficulty. Furthermore, the five-step approach was shown to be a reasonable methodology for this task. In particular, Siemens was able to identify the following pertinent information required for an oxy-fired retrofit:

- It is critical to know the right $\mathrm{O}_{2}$ concentration in the furnace before starting the design process. This is a parameter that burner designers never had to consider before with air-fired systems and requires some boiler thermal modeling.

- It is not appropriate to match oxy-fired gas velocities with air-fired velocities. It is a better to use lower velocities for oxy-firing than air-fired velocities, particularly in the carrier stream, by a percentage that produces equal momentums between the two conditions. Siemens used $13 \%$, and that value proved to be successful.

- Removing moisture in the recycle stream is necessary for high moisture coals such the fuel used at River Rouge 3, especially in the carrier gas stream. Failure to do so abates coal devolatilization and leads to condensation in the coal pipes.

- There are many oxygen enrichment schemes that have not been considered in this program that could potentially be very useful.

- Oxygen enrichment of the carrier stream poses many safety concerns. 
- When allocating oxygen and FGR to the combustion system compartments, it is advantageous to keep track of total oxygen and total FGR separately.

- Compared with an air-fired design, an oxy-fired burner will need to be adjusted primarily to account for the $\mathrm{O}_{2} \%$ in the furnace, the $\mathrm{O}_{2} \%$ in each compartment, and for the appropriate scaling factors to support combustion.

- A plant that is retrofitted for oxy-combustion can operate at full load for both the air-fired and oxy-fired condition by adjusting mill configurations accordingly (if needed).

\subsubsection{PacifiCorp Hunter 3 Overview}

Hunter 3 is a wall fired unit with 40 B\&W HV-4Z low-NOx burners and 10 over-fired air (OFA) ports. A diagram of the modeled geometry is shown in Figure 4.13-7. The secondary superheater platens and pendants were included in the furnace model. The burner geometry included in the model is shown in Figure 4.13-8. The burner and OFA layout is shown in Figure 4.13-9. The swirl patterns are shown in Figure 4.13-10.

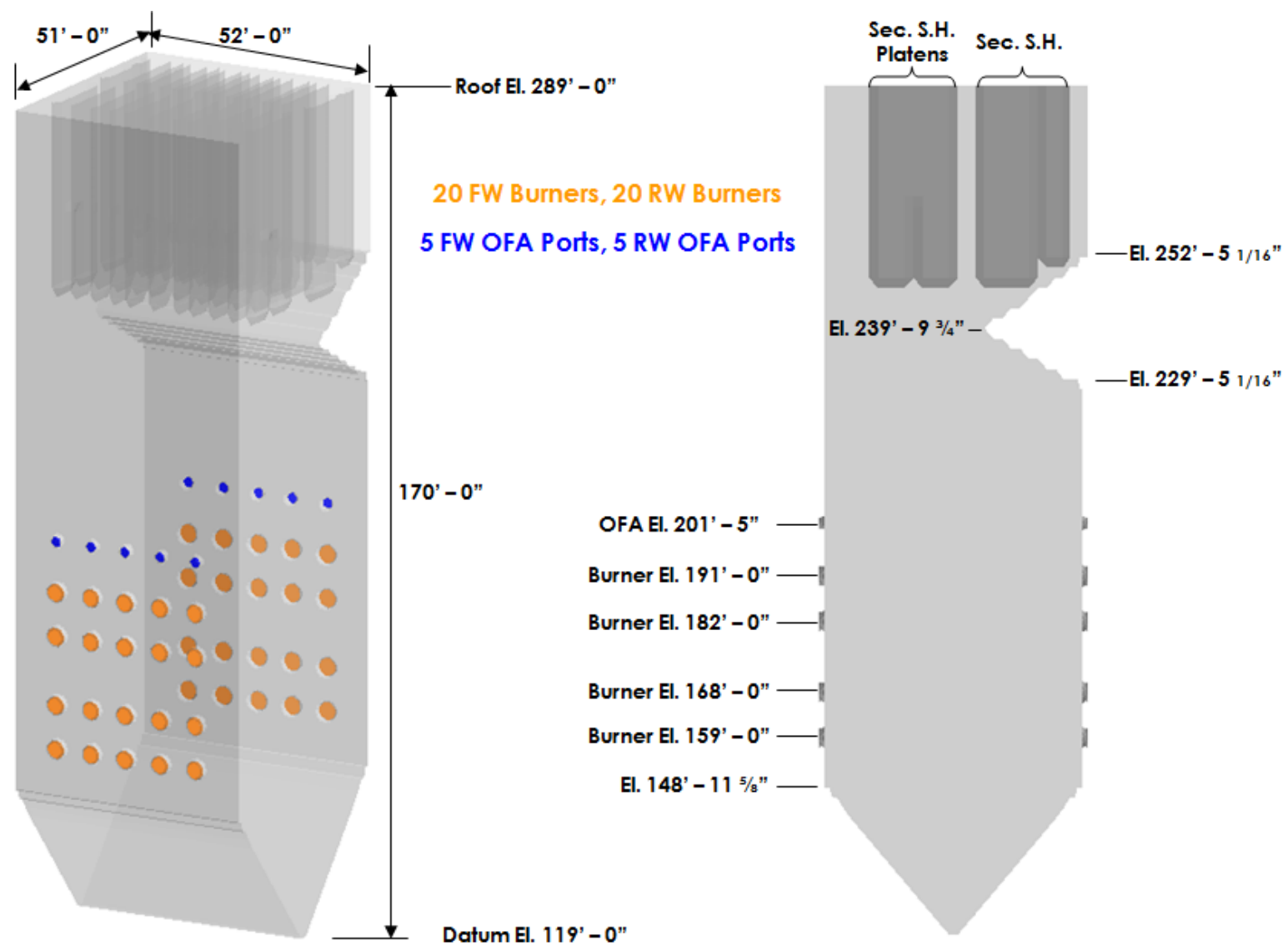

Figure 4.13-7: Hunter Unit 3 modeled geometry. 


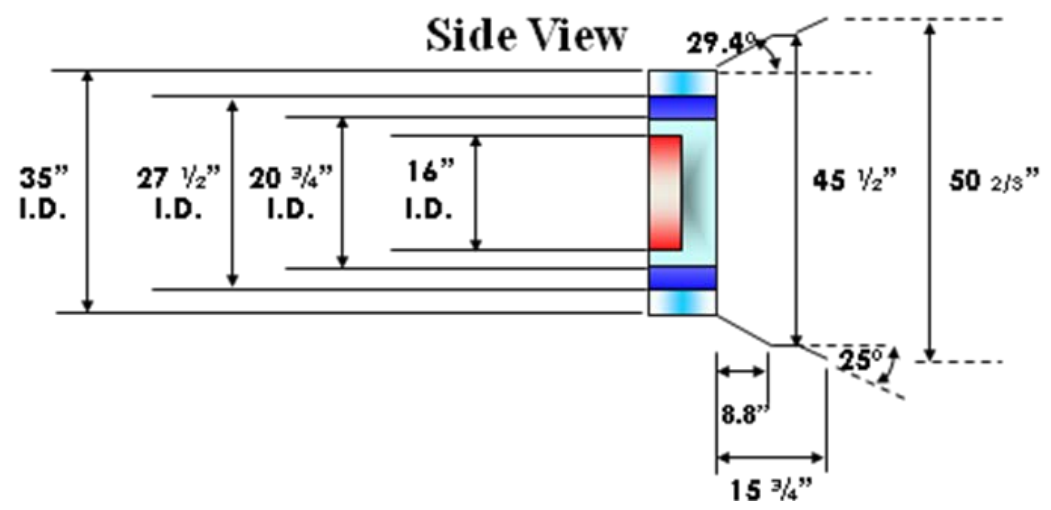

Figure 4.13-8: Air-fired burner geometry included in the model.

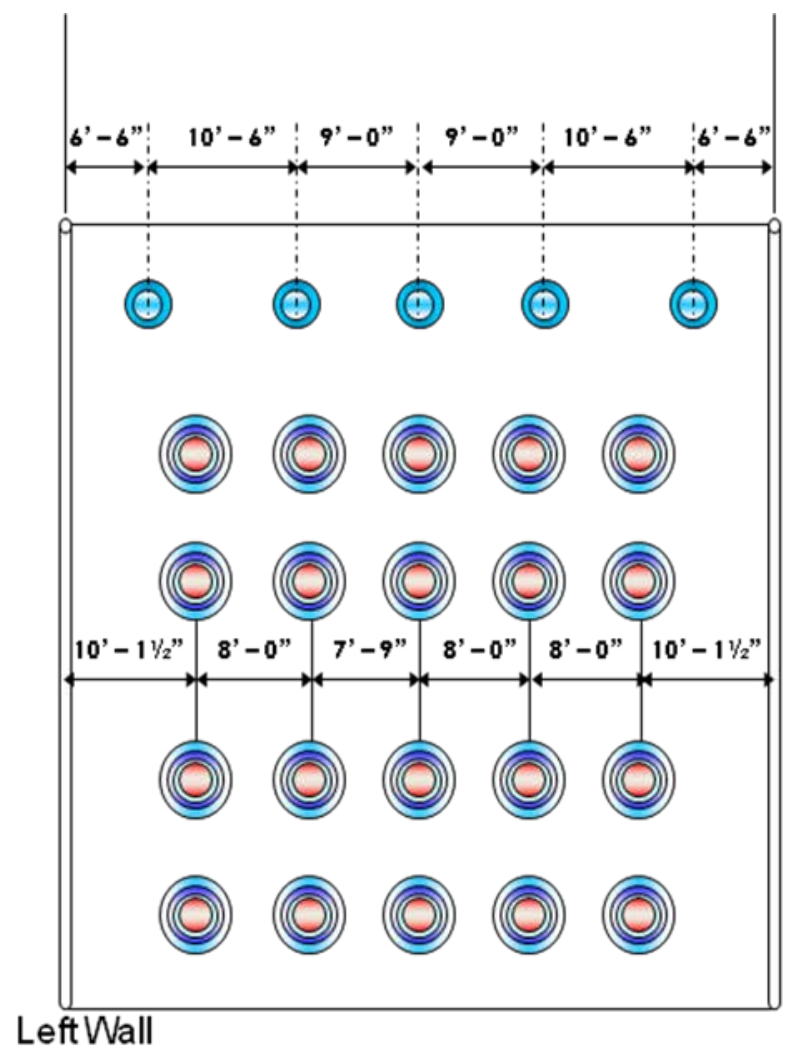

Front Wall (as viewed from outside)

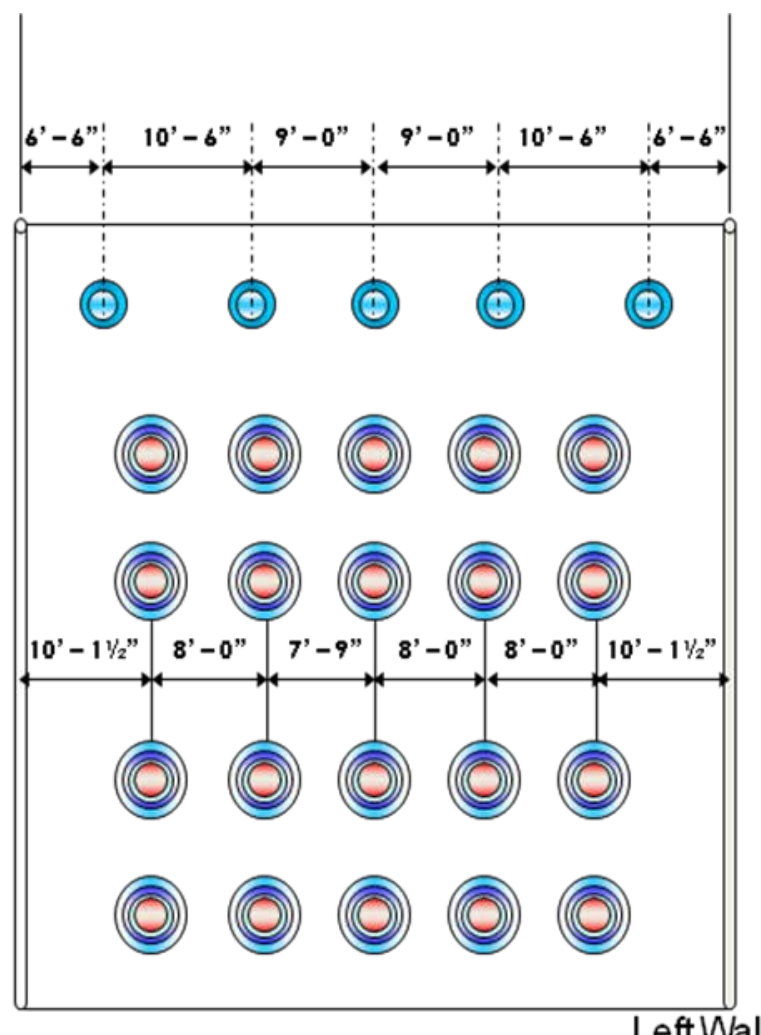

Rear Wall (as viewed from outside)

Figure 4.13-9: Hunter 3 burner and OFA layout. 


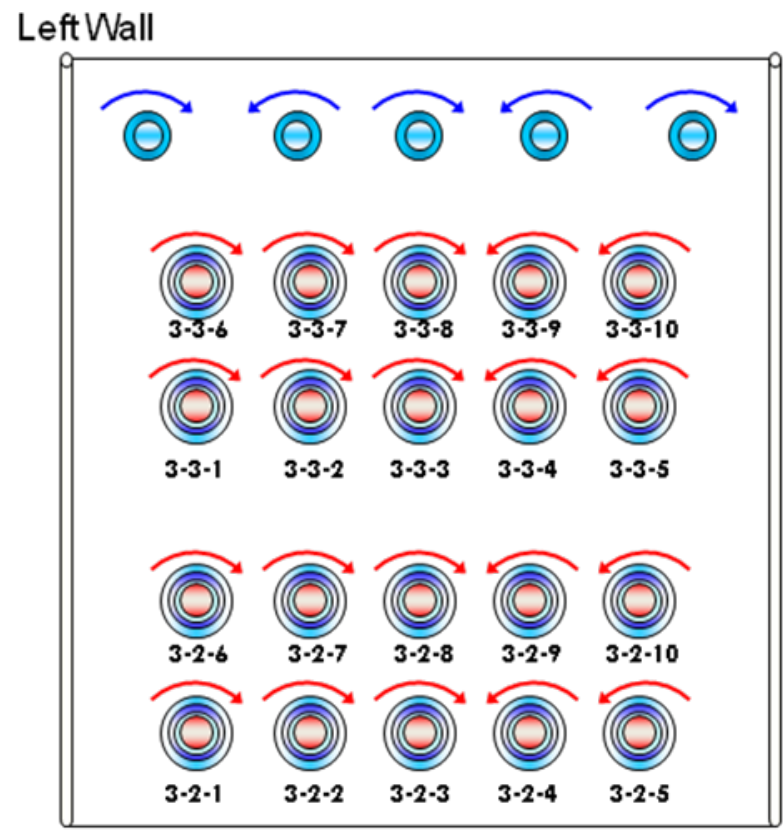

Front Wall (as viewed from outside)

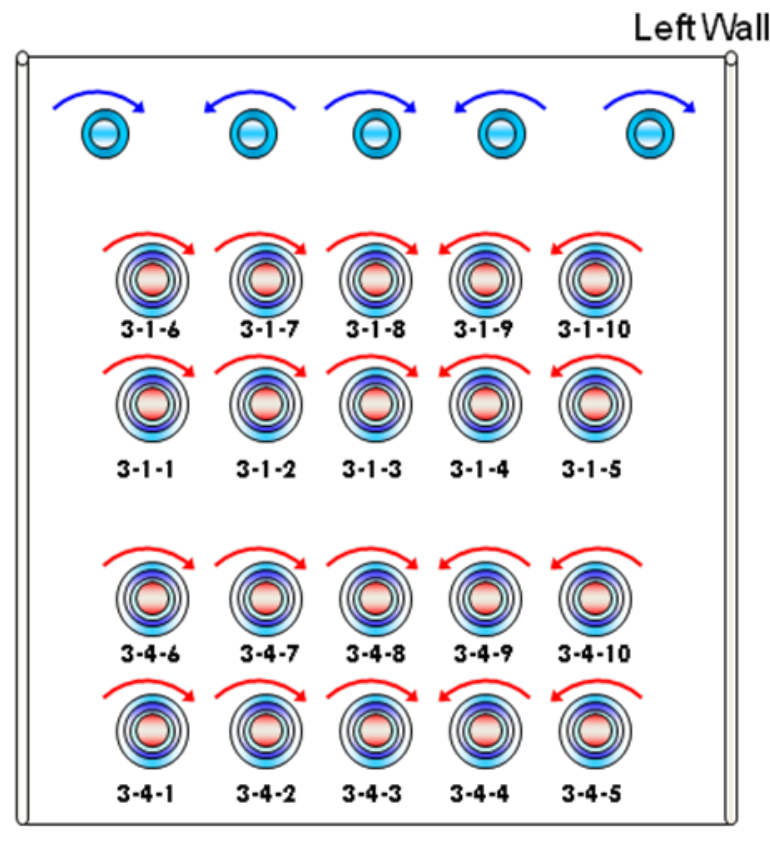

Rear Wall (as viewed from outside)

Figure 4.13-10: Hunter 3 burner and OFA swirl pattern.

\subsubsection{Investigation of Sub-model Impacts}

This section utilizes Glacier CFD simulation results from the Hunter 3 modeling to assess the impact of the soot sub-model extended char oxidation sub-model. These simulations were done in parallel with the Hunter 3 process modeling work described above, so the char oxidation simulations use an earlier estimate of $27 \%$ for the boiler oxygen/FGR mixture. The soot sub-model assessment was completed only for air-fired conditions.

\subsubsection{Soot Sub-model Investigation}

Soot is one of the important elements affecting the radiative heat transfer in a coal combustion system and should be properly accounted for in modeling. The advanced soot sub-model was implemented into the Glacier computational fluid dynamics code and was used to model Hunter Unit 3. The predictions were compared to a case without the new soot calculations to gauge the effects of the enhanced soot sub-model.

For evaluation of the soot sub-model, one air-fired baseline case was run with and without the soot submodel. The furnace operating conditions are shown in Table 4.13-1. The operating conditions were taken from measurements given in the B\&W test report. The coal used in this modeling study was a Utah bituminous (Skyline) with the composition shown in Table 4.13-2 and the size distribution shown in Table 4.13-3. 
Table 4.13-1: Hunter 3 Furnace Operating Conditions.

\begin{tabular}{|c|c|}
\hline Furnace Operational Data & Baseline \\
\hline Firing Rate (MBtu/h) & 4528 \\
\hline Stoichiometric Ratio & 1.18 \\
\hline Lower Furnace Stoichiometric Ratio & 0.9 \\
\hline Coal Flow Rate (klb/h) & 399.1 \\
\hline Total Combustion Air Flow (klb/h) & 4052 \\
\hline Theoretical Excess $\mathrm{O}_{2},(\%, \mathrm{dry})$ & $3.3 \%$ \\
\hline Burner Zone Air Flow (klb/h) & 3085 \\
\hline OFA Flow Air (klb/h) & 967 \\
\hline
\end{tabular}

\begin{tabular}{|c|c|}
\hline & \\
\hline Burner Operational Data (per burner) & 9.98 \\
\hline Coal Flow Rate $(\mathrm{klb} / \mathrm{h})$ & 19.7 \\
\hline Primary Air Flow $(\mathrm{klb} / \mathrm{h})$ & 1.97 \\
\hline Primary Gas/Coal & 150 \\
\hline Primary Air Temperature $\left({ }^{\circ} \mathrm{F}\right)$ & 57.5 \\
\hline Secondary Air Flow $(\mathrm{klb} / \mathrm{h})$ & 4.6 \\
\hline Transition Air Flow $(\mathrm{klb} / \mathrm{h})$ & 15.9 \\
\hline Inner Secondary Air Flow $(\mathrm{klb} / \mathrm{h})$ & 37.0 \\
\hline Outer Secondary Air Flow $(\mathrm{klb} / \mathrm{h})$ & 528 \\
\hline Secondary Air Temperature $\left({ }^{\circ} \mathrm{F}\right)$ & \\
\hline
\end{tabular}

\begin{tabular}{|c|c|}
\hline & \\
\hline OFA Port Operational Data (per port) & 96.7 \\
\hline Air Flow (klb/h) & 58.0 \\
\hline Core Zone Air Flow (klb/h) & 256 \\
\hline Core Zone Velocity (ft/s) & 38.7 \\
\hline Outer Zone Air Flow (klb/h) & 115 \\
\hline Outer Zone Velocity (ft/s) & 528 \\
\hline Temperature $\left({ }^{\circ} \mathrm{F}\right)$ &
\end{tabular}

Table 4.13-2: Utah Skyline Coal Composition.

\begin{tabular}{|c|c|}
\hline & Utah Skyline Bituminous \\
\hline \% Carbon & 64.49 \\
\hline \% Hydrogen & 4.44 \\
\hline \% Nitrogen & 1.18 \\
\hline \% Sulfur & 0.64 \\
\hline \% Oxygen & 9.25 \\
\hline \% Moisture & 8.86 \\
\hline \% Ash & 11.14 \\
\hline HHV (Btu/lb) & 11,344 \\
\hline
\end{tabular}


Table 4.13-3: Coal Particle Size Distribution.

\begin{tabular}{|c|c|c|}
\hline Bin & $\begin{array}{c}\text { Particle } \\
\text { Diameter } \\
\text { [mm] }\end{array}$ & $\begin{array}{c}\text { Mass } \\
\text { Fraction }\end{array}$ \\
\hline 1 & 9.1 & 0.025 \\
\hline 2 & 16.3 & 0.05 \\
\hline 3 & 22.1 & 0.075 \\
\hline 4 & 28.6 & 0.1 \\
\hline 5 & 37.1 & 0.15 \\
\hline 6 & 50.2 & 0.2 \\
\hline 7 & 68.8 & 0.15 \\
\hline 8 & 89.8 & 0.1 \\
\hline 9 & 116 & 0.075 \\
\hline 10 & 155 & 0.05 \\
\hline 11 & 230 & 0.025 \\
\hline
\end{tabular}

Overall model results for the air-fired case with and without the soot sub-model are shown in Table 4.13-4. The addition of the soot sub-model increased CO concentration at the horizontal nose plane and the model exit. The unburned carbon content of the fly ash also slightly increased with the addition of the soot sub-model. A plot of the CO concentration with elevation is shown in Figure 4.13-11. The case with the soot sub-model shows higher CO throughout the furnace. Figure 4.13-12 compares gas temperature and $\mathrm{CO}$ concentration throughout the furnace. The gas temperature profiles look fairly similar with and without the soot sub-model, while more significant differences are seen in the CO profiles. The largest differences occur in the hopper.

Table 4.13-4: Summary of Hunter 3 Model Results for Air-Fired Case With and Without Soot SubModel.

\begin{tabular}{|c|c|c|}
\hline & \multicolumn{2}{|c|}{ Skyline } \\
\hline & Baseline & Baseline w/ soot \\
\hline \multicolumn{3}{|l|}{ Horizontal Nose Plane } \\
\hline Temperature $\left({ }^{\circ} \mathbf{F}\right)$ & 2502 & 2518 \\
\hline CO Concentration, wet (ppm) & 7038 & 8454 \\
\hline $\mathrm{O}_{2}$ Concentration, wet (\%) & $3.6 \%$ & $3.7 \%$ \\
\hline \multicolumn{3}{|l|}{ Vertical Exit Plane } \\
\hline Temperature $\left({ }^{\circ} \mathrm{F}\right)$ & 1785 & 1787 \\
\hline CO Concentration, wet (ppm) & 1745 & 3060 \\
\hline \begin{tabular}{|l|}
$\mathrm{O}_{2}$ Concentration, wet $(\%)$ \\
\end{tabular} & $3.2 \%$ & $3.3 \%$ \\
\hline Unburned Carbon in Fly Ash & $3.3 \%$ & $3.6 \%$ \\
\hline Particle Burnout & $99.4 \%$ & $99.4 \%$ \\
\hline
\end{tabular}

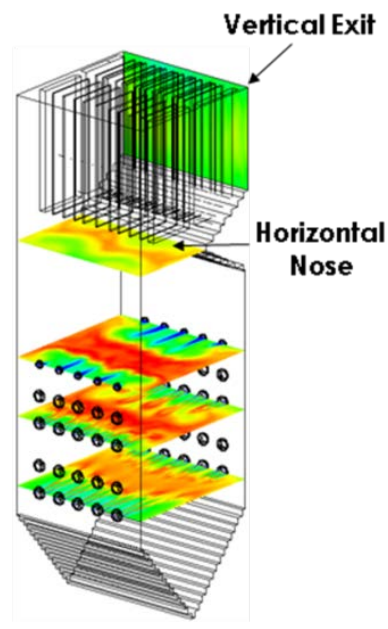




\section{CO Concentration vs. Elevation}

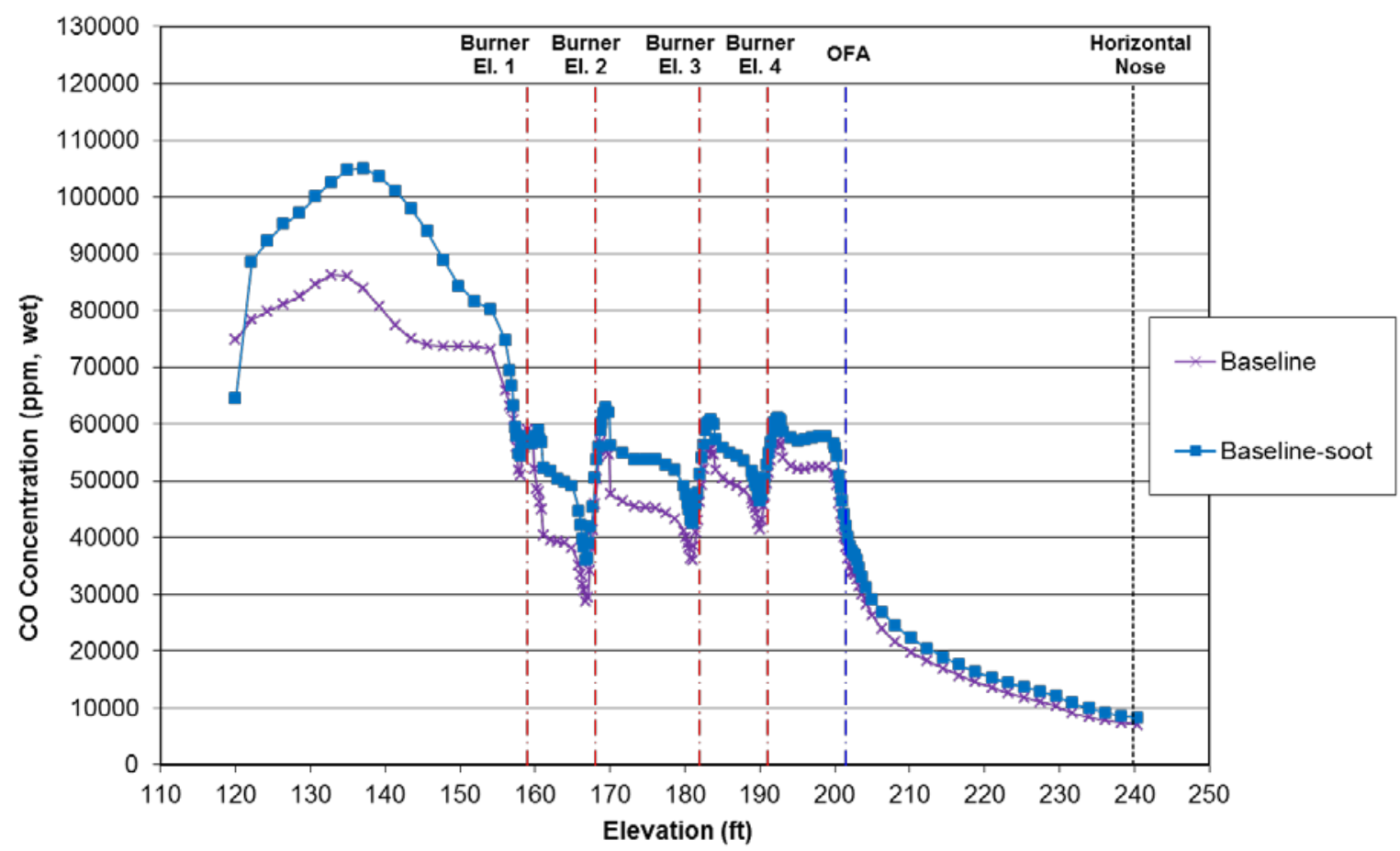

Figure 4.13-11: CO concentration with elevation for air-fired case with and without the soot submodel.

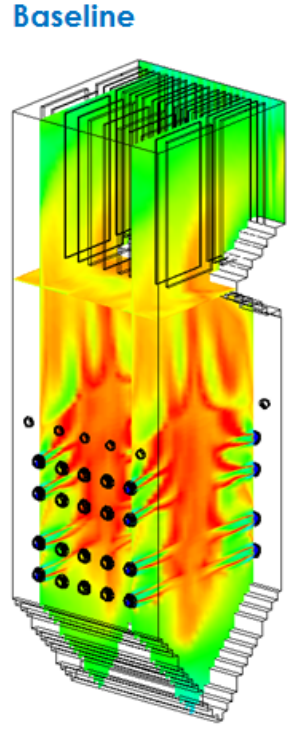

Gas Temperature $\left({ }^{\circ} \mathrm{F}\right)$
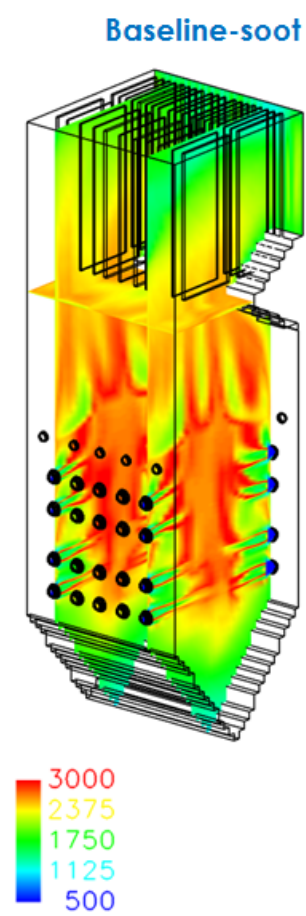

Baseline

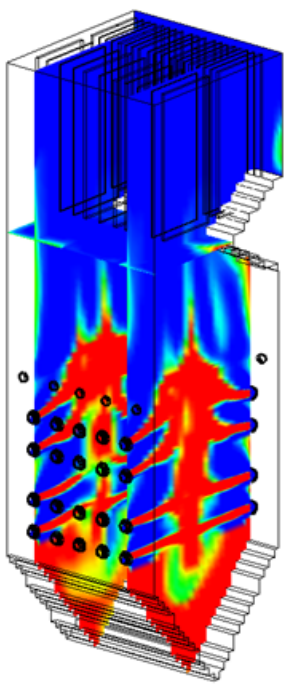

CO Concentration (ppm, wet)
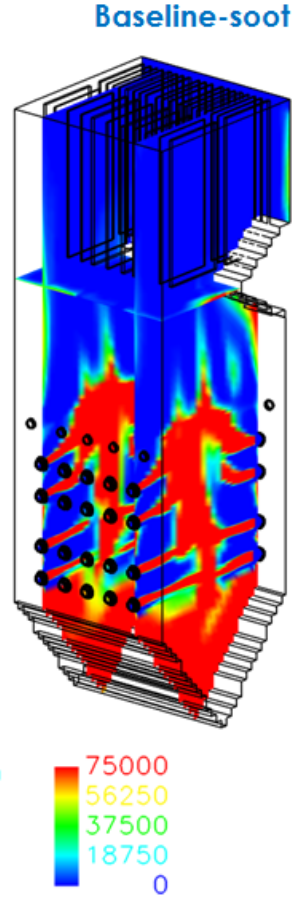

Figure 4.13-12: Comparison of gas temperature and CO concentration with and without the soot sub-model. 
A comparison of wall temperature and incident heat flux in shown in Figure 4.13-13. The case with the soot sub-model shows a slight shift with increased wall temperature and incident heat flux on the front wall and decreased values on the right wall. Overall, the profiles look similar. A more detailed line plot of incident heat flux along the right wall at burner elevation 3 in shown in Figure 4.13-14. This plot also shows a slight difference in the shape of the incident heat flux profile, but the overall incident heat flux is similar. The total net heat flux to various surfaces was unchanged with the addition of the soot sub-model as seen in Figure 4.13-15. This is not too surprising given that coal boiler flame emission is dominated by the coal particles (see Section 4.10.5).
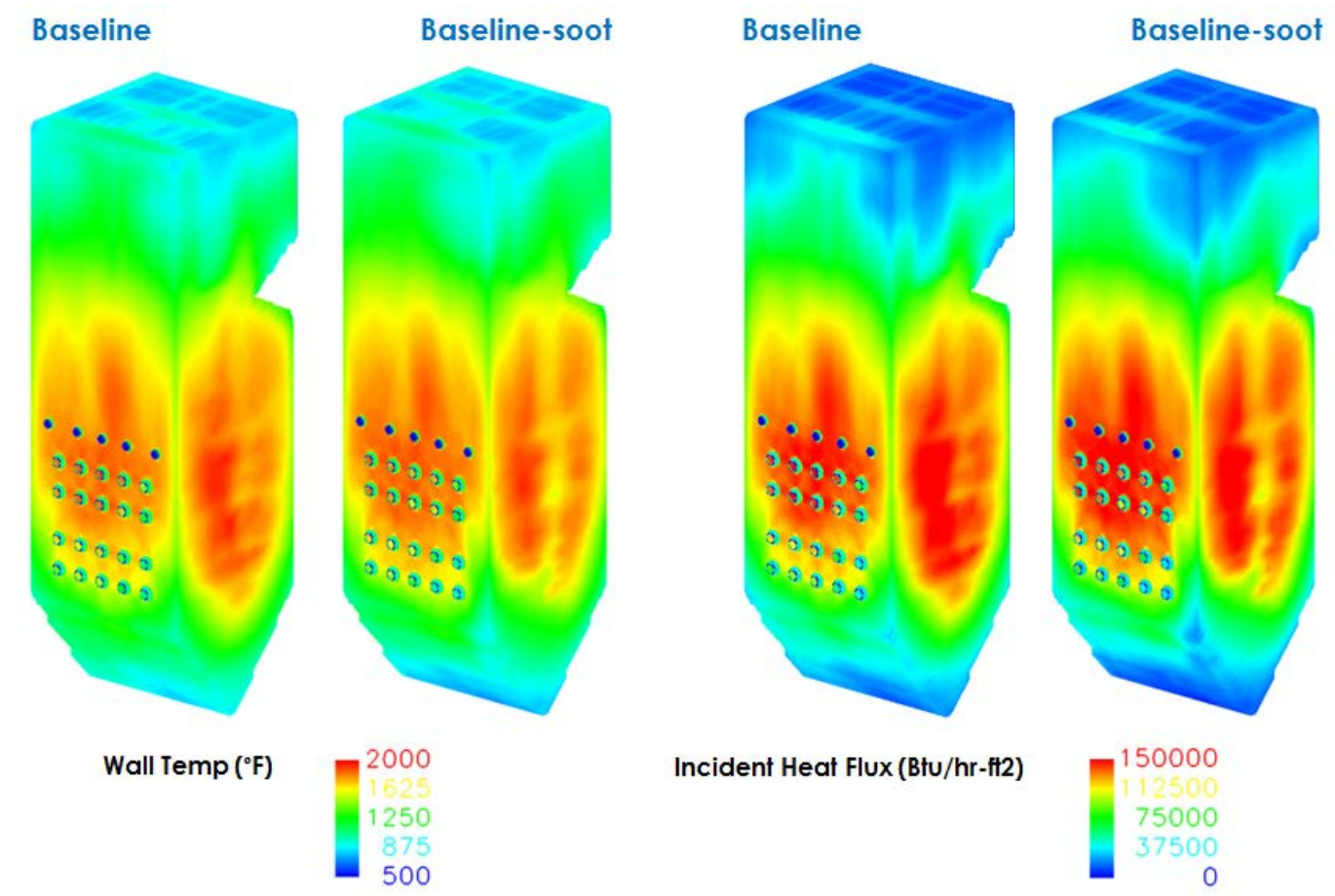

Incident Heat Flux (Btu/hr-ft2)

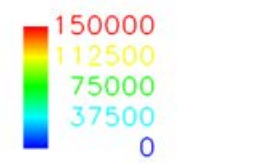

Figure 4.13-13: Comparison of wall temperature and incident heat flux with and without the soot sub-model. 


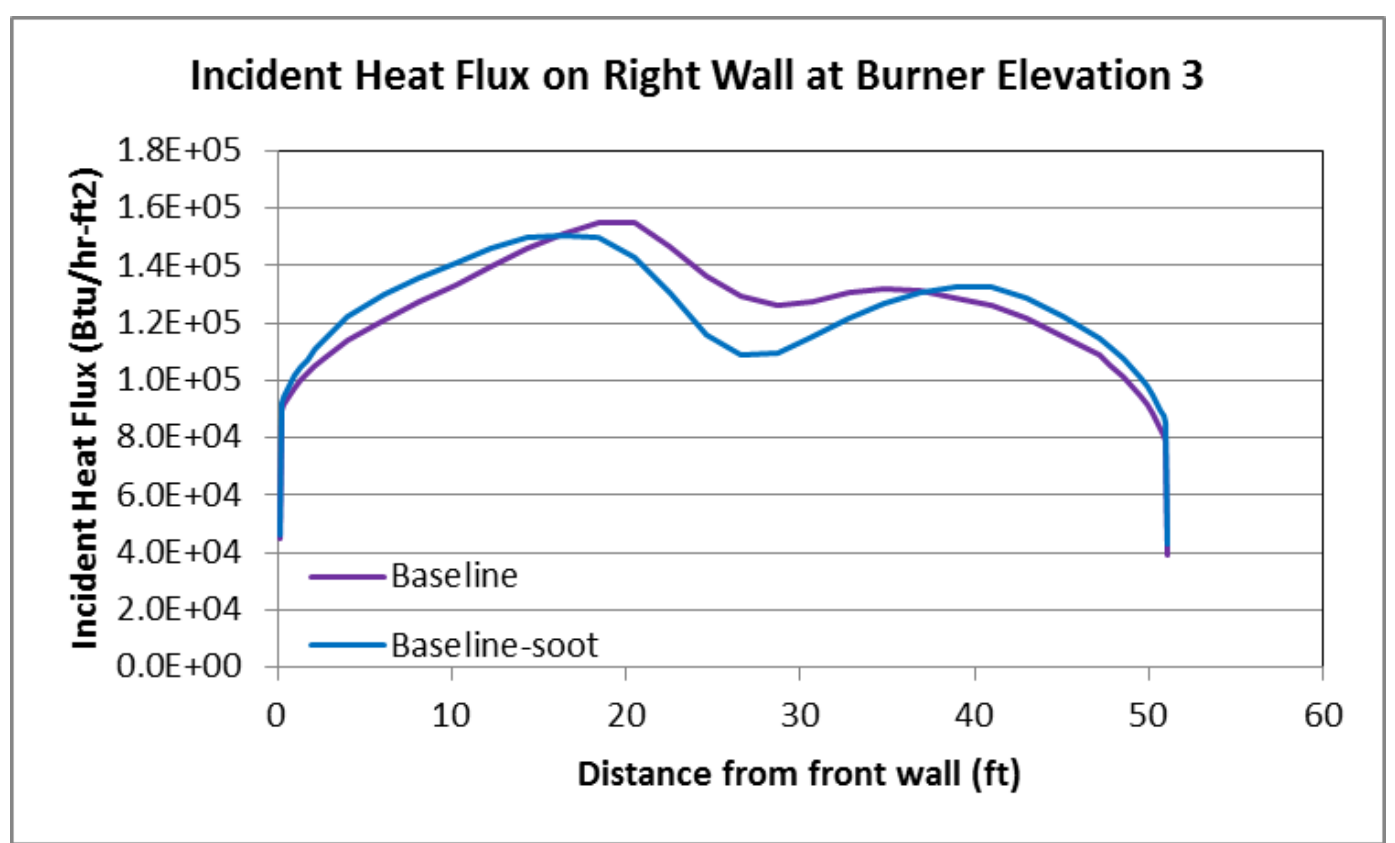

Figure 4.13-14: Incident heat flux profile along right wall at burner elevation 3 with and without the soot sub-model.

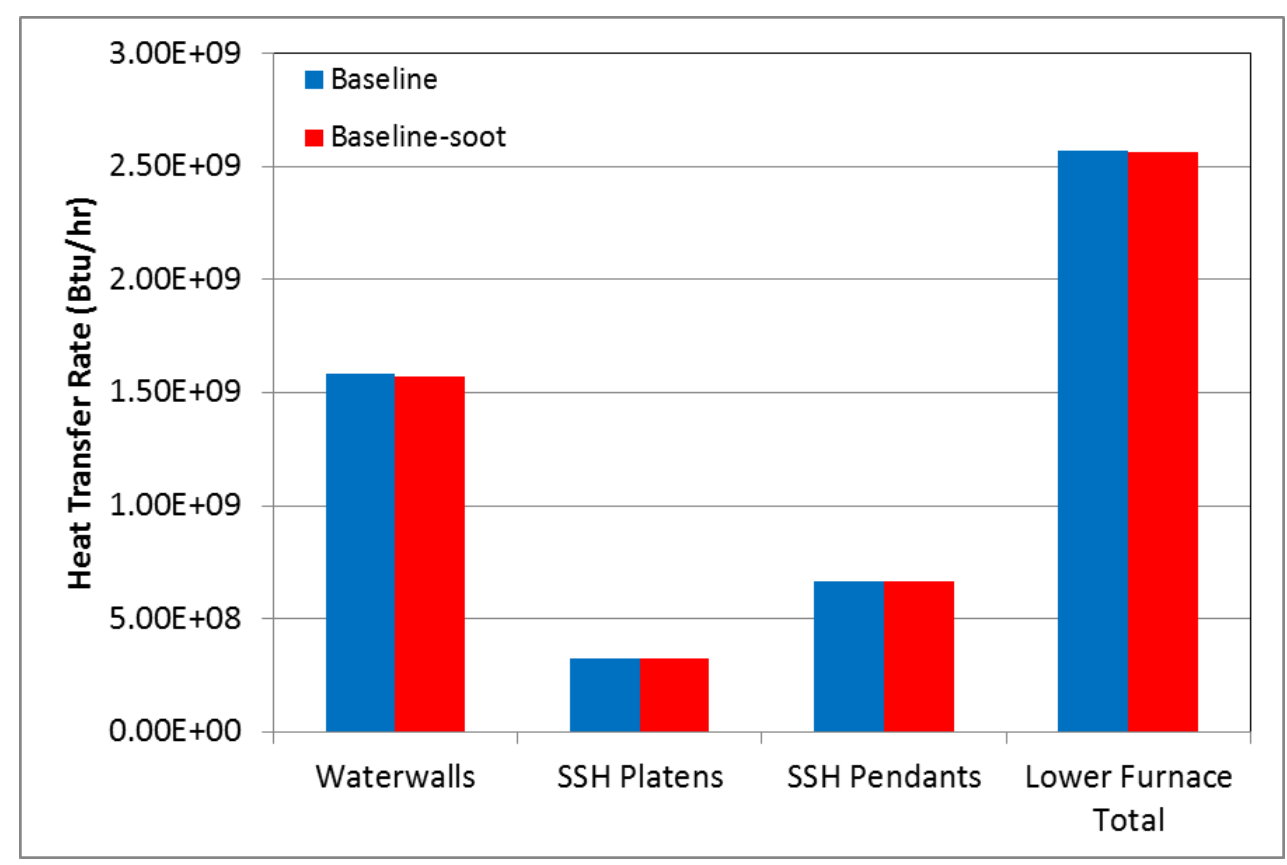

Figure 4.13-15: Net heat flux for various surfaces in the Hunter Unit 3 air-fired case with and without the soot sub-model. 


\subsubsection{Char Oxidation Sub-model Investigation}

CFD modeling of the Hunter 3 unit was conducted to determine impacts of the enhanced char oxidation sub-model. These comparisons are in addition to those conducted with the L1500 modeling in Section 4.12.3. Table 4.13-5 summarizes the modeling results for air-fired and oxy-fired cases with and without the enhanced char oxidation model (the "w/ Char" cases).

The original char oxidation model predicted extremely high unburned carbon in ash (UBC) and increased UBC for oxy-combustion firing. The new, enhanced char oxidation sub-model predicted reasonable UBC concentrations (compared with the 2 to 3\% UBC observed at the Hunter plant) and decreased UBC for oxy-combustion firing. This decrease in UBC level for oxy-firing was consistent with test results from the L1500 (see Figure 4.13-16).

Table 4.13-5: Hunter 3 Predictions With and Without the Enhanced Char Oxidation Sub-Model for Air and Oxy-firing.

\begin{tabular}{rccccc}
\hline & Air & $\begin{array}{c}\text { Air } \\
\text { w/ Char }\end{array}$ & Oxy27 & $\begin{array}{c}\text { Oxy27 } \\
\text { w/ Char }\end{array}$ \\
\hline $\begin{array}{c}\text { Horizontal Nose Plane } \\
\text { Temperature }\left({ }^{\circ} \mathrm{F}\right)\end{array}$ & 2418 & 2417 & 2461 & 2473 \\
$\begin{array}{r}\text { CO Concentration, wet (ppm) } \\
\text { Vertical Exit Plane }\end{array}$ & 4414 & 6168 & 9886 & 15123 \\
$\quad$ Temperature ( $\left.{ }^{\circ} \mathrm{F}\right)$ & 1649 & 1644 & 1622 & 1641 \\
CO Concentration, wet (ppm) & 1032.2 & 1435.7 & 2429.0 & 3815.0 \\
Unburned Carbon in Fly Ash & $7.4 \%$ & $3.8 \%$ & $8.6 \%$ & $2.2 \%$ \\
\hline
\end{tabular}

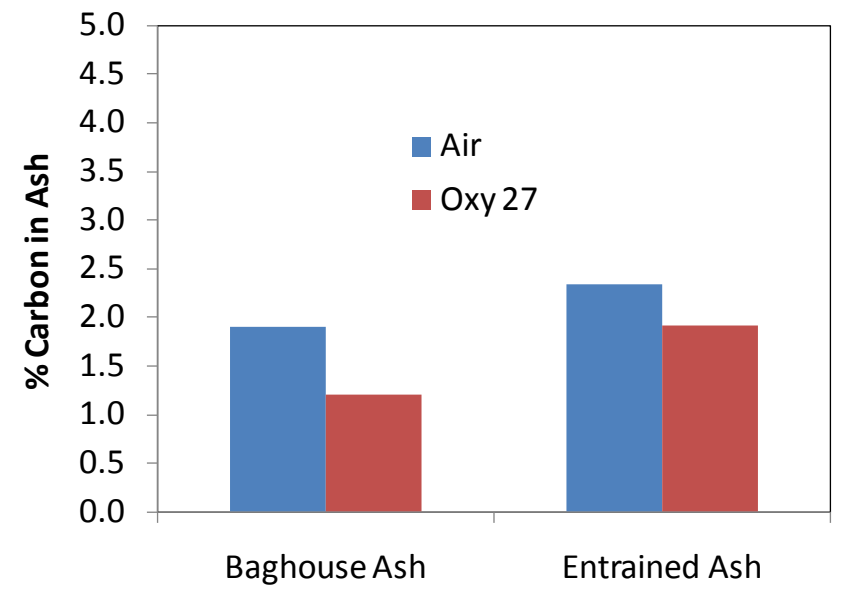

Figure 4.13-16: L1500 measured unburned carbon in ash for air- and oxy-firing.

\subsubsection{Hunter 3 Oxy-Retrofit Process Modeling}

A process model of PaciCorp's Hunter Unit 3 was developed and used to evaluate the impact of different oxygen levels and recycle rates on heat transfer in both the radiant and convective sections of the furnace. This model was created using REI's SteamGen Expert (SGE). The SGE model has the capability to represent furnace combustion and steam-side coupling. SGE is a steady-state flow sheet type application used to simulate steam generating systems firing fossil fuels. It is based on a heat and mass balance approach with extensive steam properties, coal properties, gas properties and heat transfer correlations to 
represent different processes relevant in the combustion and steam-side process. Various modules are available to represent the air streams, air heaters, fuel streams, steam flows, feedwater heaters, coal pulverizers, boilers, flue gas-steam heat exchangers (e.g., primary and secondary superheat, reheat, economizer), steam drum, and attemperators. The SGE model includes a module for the lower furnace which can be configured to represent the actual geometry of the unit where radiation calculations are performed using the emissive properties of mixtures of gases and a predefined heat release profile from the fuel.

The SGE model for Hunter 3 included: coal mills, a lower furnace model which resolved four rows of burners on each the front and rear walls along with OFA, secondary superheat platen and pendants, reheater with both vertical and horizontal tube sections, primary superheater, economizer, attemperation and flue gas recycle. The model configuration is detailed in Figure 4.13-17. Once the process model was configured, the inlet conditions were adjusted to represent an operating data set provided by PacifiCorp, which included both fire and steam-side data. The conditions of the heat transfer surfaces (fouling, resistance) were then adjusted until the heat duty of each surface matched the duty provided in the data set. In this state the SGE model represented the baseline air conditions.

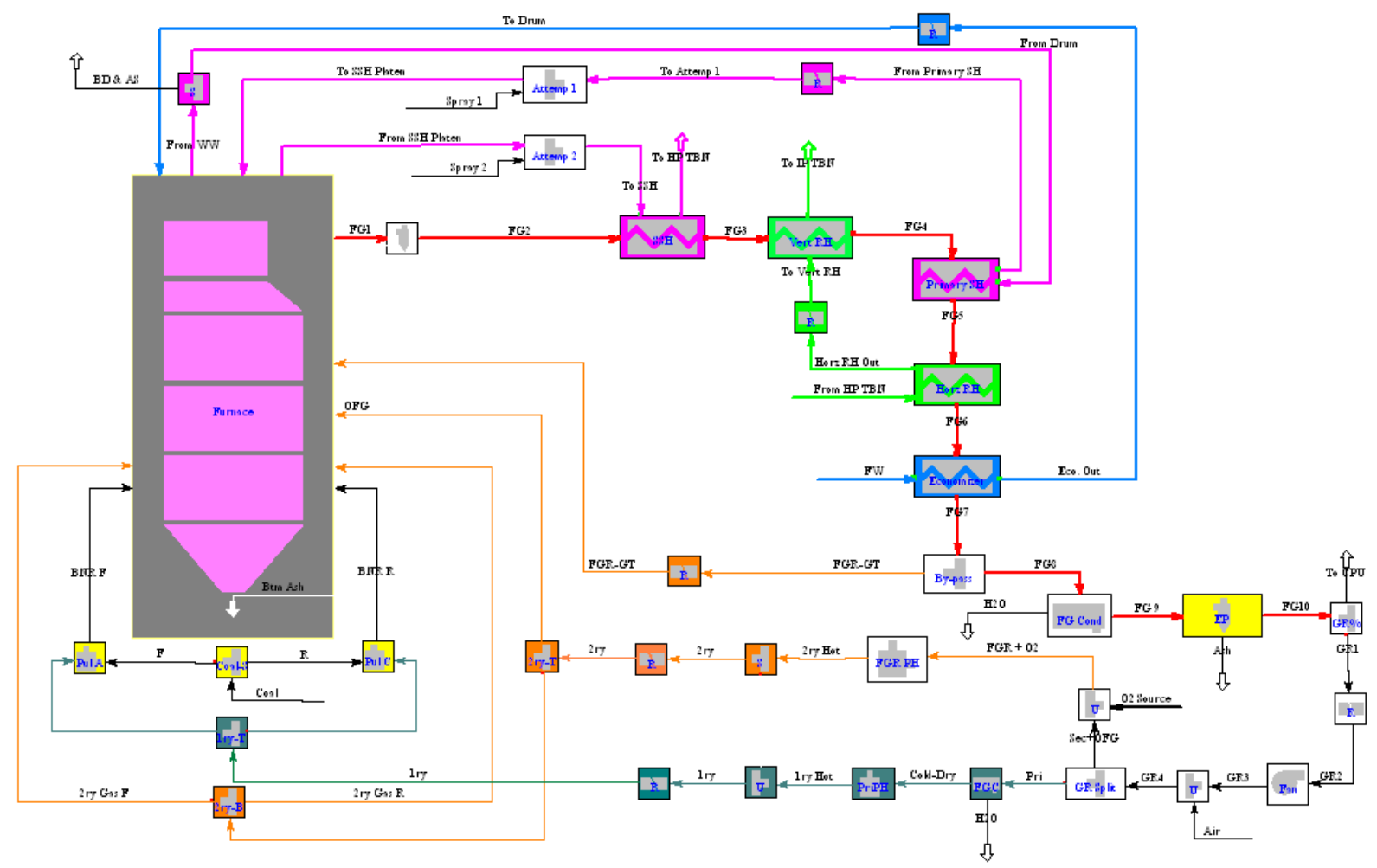

Figure 4.13-17: Process model configuration for Hunter 3 using SGE.

Further process modeling was performed where the inlet conditions were changed to remove air as the oxidant and oxygen was used instead. Various simulations were performed where the amount of flue gas recycled back to the furnace was adjusted. As the flue gas recycle is adjusted, the mass flow of oxygen is only slightly adjusted to maintain $3.0 \% \mathrm{O}_{2}$ (dry) at the boiler exit. However the oxygen concentration in the overall mixture of $\mathrm{O}_{2}$ and FGR (pseudo air) changes greatly. The concentrations selected for this investigation included 21, 25, 27 and $32 \% \mathrm{O}_{2}$ (wet). To achieve greater $\mathrm{O}_{2}$ concentrations in the mixture of $\mathrm{O}_{2}$ and FGR, the FGR rate must be decreased. As the $\mathrm{O}_{2}$ concentration is increased the adiabatic flame temperature is also expected to increase, because there is less dilution gas to heat up. As the flame 
temperature increases, the radiant heat transfer is also expected to increase. However, as the $\mathrm{O}_{2}$ concentration increases, the total volume of gas decreases, reducing velocities and expected heat transfer in the convective heat transfer surfaces. Therefore the heat transfer must be balanced between the radiant and convective heat transfer sections by adjusting the FGR. The range of recycle ratios used here was expected to span the range that would produce a balanced heat transfer.

Figure 4.13-18 details the predicted heat transfer to the water walls in the radiant section of the furnace as a function of furnace elevation and for each of the $\mathrm{O}_{2}$ concentrations. The baseline air case is represented in dark blue. The radiant heat transfer for the $25 \% \mathrm{O}_{2}$ case seems to match fairly well, while the $21 \%$ case is too low and the $27 \%$ and $32 \%$ cases are too high.

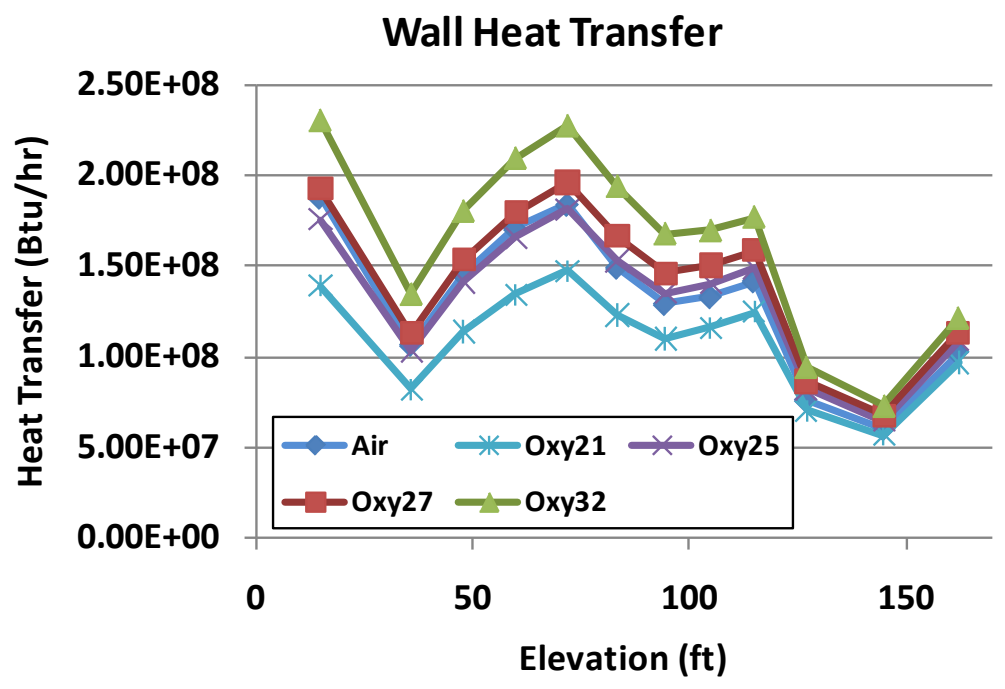

Figure 4.13-18: Predicted water wall heat transfer in Hunter 3 as a function of elevation in the radiant furnace for various mixtures of $\mathrm{O}_{2}$ and FGR.

The overall heat transfer and the heat transfer by heat exchange section are presented in Figure 4.13-19. This figure indicates that both the convective and radiant heat transfer are expected to match with the airfired case when the oxygen concentration is $25 \%$ (wet) in the overall mixture of $\mathrm{O}_{2}$ and FGR. The trends in predicted heat transfer for the convective and radiant sections behave as expected.

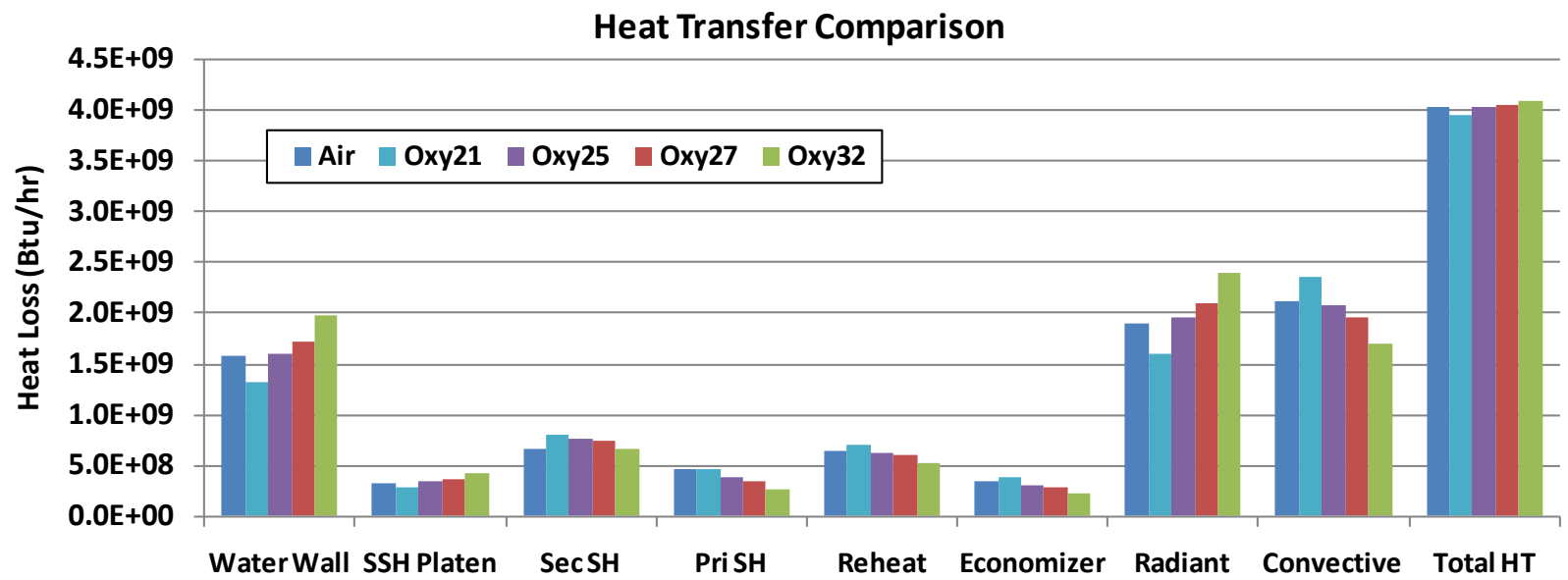

Figure 4.13-19: Overall heat transfer assessment in Hunter 3 for various mixtures of $\mathbf{O}_{2}$ and FGR. 
Following the process modeling, rough CFD models of the radiant furnace were run which suggested that $26 \% \mathrm{O}_{2}$ would match the heat transfer better than $25 \% \mathrm{O}_{2}$. It was decided that all further modeling of oxy combustion conditions would be performed at $26 \% \mathrm{O}_{2}$ (wet) in the $\mathrm{O}_{2}$ / FGR mixture.

\subsubsection{Hunter 3 Oxy-Retrofit CFD Modeling}

\subsubsection{CFD Case Descriptions}

Seven cases have been run for Hunter Unit 3 using REI's standard CFD code with enhanced radiation, char oxidation, and soot sub-models. A summary of these cases is shown in Table 4.13-6. These seven cases were designed to provide information sufficient to evaluate:

1. The behavior of oxy-coal combustion in a full-scale utility boiler compared with the existing airfired behavior including

a. Heat transfer profiles,

b. Corrosion potential of the waterwalls and superheat surfaces,

c. Deposition profiles and rate in the radiant furnace,

d. Combustion Efficiency (CO and UBC),

2. The impact of coal sulfur concentration and flue gas cleaning before recycle.

The geometry used in the furnace model has been previously shown in Figure 4.13-7. Operating conditions for these cases are described in Table 4.13-7. Two coals were investigated: Utah Skyline bituminous and Illinois Shea bituminous (Table 4.13-8). The two coals are very similar with the exception of the sulfur content. For the slagging cases, the corresponding cases without the slagging submodel were restarted using a modeling code in which the slagging sub-model was turned on. The airfired burner geometry and the burner layout are shown in Section 4.13.2. The air-fired burner and OFA operating conditions are shown in Table 4.13-9. For the oxy-fired cases, a different burner designed by Siemens was implemented. The burner layout and swirl pattern were maintained.

Table 4.13-6: Summary of Hunter Unit 3 Modeling Cases.

\begin{tabular}{|l|l|l|c|l|}
\hline Case & Coal & Oxidant & $\begin{array}{l}\text { Slagging } \\
\text { sub-model }\end{array}$ & FGR treatment \\
\hline Baseline & $\begin{array}{l}\text { Utah } \\
\text { Skyline Bit }\end{array}$ & Air & No & NA \\
\hline Baseline-slag & $\begin{array}{l}\text { Utah } \\
\text { Skyline Bit }\end{array}$ & Air & Yes & NA \\
\hline Oxy26 & $\begin{array}{l}\text { Utah } \\
\text { Skyline Bit }\end{array}$ & $\begin{array}{l}26 \% \mathrm{O}_{2} \text { in total } \\
\mathrm{FGR} / \mathrm{O}_{2} \text { mix }\end{array}$ & No & $\begin{array}{l}\text { Primary FGR/ } \mathrm{O}_{2} \text { dried to } 4^{\circ} \mathrm{C} \text { dew } \\
\text { point }\end{array}$ \\
\hline Oxy26-slag & $\begin{array}{l}\text { Utah } \\
\text { Skyline Bit }\end{array}$ & $\begin{array}{l}26 \% \mathrm{O}_{2} \text { in total } \\
\mathrm{FGR} / \mathrm{O}_{2} \text { mix }\end{array}$ & Yes & $\begin{array}{l}\text { Primary FGR/ } \mathrm{O}_{2} \text { dried to } 4^{\circ} \mathrm{C} \text { dew } \\
\text { point }\end{array}$ \\
\hline Baseline-Illinois & Illinois Bit & Air & No & NA \\
\hline Oxy26-Illinois & Illinois Bit & $\begin{array}{l}26 \% \mathrm{O}_{2} \text { in total } \\
\mathrm{FGR} / \mathrm{O}_{2} \text { mix }\end{array}$ & No & $\begin{array}{l}\text { Primary FGR/ } \mathrm{O}_{2} \text { dried to } 4^{\circ} \mathrm{C} \text { dew } \\
\text { point }\end{array}$ \\
\hline $\begin{array}{l}\text { Oxy26-Illinois- } \\
\text { low } \mathrm{SO}_{2}\end{array}$ & Illinois Bit & $\begin{array}{l}26 \% \mathrm{O}_{2} \text { in total } \\
\mathrm{FGR} / \mathrm{O}_{2} \text { mix }\end{array}$ & No & $\begin{array}{l}\text { gas recycle dried to } 135^{\circ} \mathrm{F} \text { dew } \\
\text { point, primary } \mathrm{FGR} / \mathrm{O}_{2} \text { dried to } 4^{\circ} \mathrm{C} \\
\text { dew point }\end{array}$ \\
\hline
\end{tabular}


Table 4.13-7: Operating Conditions for Hunter Unit 3 Cases.

\begin{tabular}{|c|c|c|c|c|c|}
\hline \multirow[t]{2}{*}{ Furnace Operational Data } & \multicolumn{2}{|c|}{ Skyline } & \multicolumn{3}{|c|}{ Illinois } \\
\hline & Baseline & $\mathrm{Oxy}_{26}^{+}$ & Baseline & $\mathrm{Oxy}_{26}^{+}$ & Oxy26-low_SO ${ }_{2}^{\&}$ \\
\hline Firing Rate (MBtu/h) & 4528 & 4528 & 4528 & 4528 & 4528 \\
\hline Stoichiometric Ratio & 1.18 & 1.10 & 1.18 & 1.10 & 1.11 \\
\hline Lower Furnace Stoichiometric Ratio & 0.9 & 0.9 & 0.9 & 0.9 & 0.9 \\
\hline Coal Flow Rate (klb/h) & 399.1 & 399.1 & 390.4 & 390.4 & 390.4 \\
\hline Total Combustion Air/ $\mathrm{O}_{2}$ Flow (klb/h) & 4052 & 813 & 4073 & 818 & 817 \\
\hline Theoretical Excess $\mathrm{O}_{2},(\%$, dry) & $3.3 \%$ & $3.0 \%$ & $3.3 \%$ & $3.0 \%$ & $3.0 \%$ \\
\hline Burner Zone Air $/ \mathrm{O}_{2}$ Flow (klb/h) & 3085 & 663 & 3102 & 666 & 664 \\
\hline OFA Flow Air/O ${ }_{2}(\mathrm{klb} / \mathrm{h})$ & 967 & 151 & 971 & 151 & 154 \\
\hline \multicolumn{6}{|l|}{ Burner Operational Data (per burner) } \\
\hline Coal Flow Rate (klb/h) & 9.98 & 9.98 & 9.76 & 9.76 & 9.76 \\
\hline Primary Air/O $\mathrm{O}_{2}$ Flow (klb/h) & 19.7 & $2.6^{=}$ & 19.2 & $2.5^{=}$ & $2.5^{=}$ \\
\hline Primary Gas/Coal & 1.97 & $1.8^{*}$ & 1.97 & $1.8^{*}$ & $1.8^{*}$ \\
\hline Primary Air Temperature $\left({ }^{\circ} \mathrm{F}\right)$ & 150 & 180 & 150 & 180 & 180 \\
\hline Secondary Air/O $\mathrm{O}_{2}$ Flow (klb/h) & 57.5 & 14.0 & 58.3 & 14.1 & 14.1 \\
\hline Transition Gas Flow (klb/h) & 4.6 & 0.0 & 4.7 & 0.0 & 0.0 \\
\hline Inner Secondary Gas Flow (klb/h) & 15.9 & 9.2 & 16.1 & 9.4 & 9.6 \\
\hline Outer Secondary Gas Flow (klb/h) & 37.0 & 52.4 & 37.6 & 53.3 & 54.4 \\
\hline Secondary Air Temperature $\left({ }^{\circ} \mathrm{F}\right)$ & 528 & 500 & 528 & 500 & 500 \\
\hline \multicolumn{6}{|l|}{ OFA Port Operational Data (per port) } \\
\hline Air/O $\mathrm{O}_{2}$ Flow $(\mathrm{klb} / \mathrm{h})$ & 96.7 & 15.1 & 97.1 & 15.1 & 15.4 \\
\hline Core Zone Gas Flow (klb/h) & 58.0 & 39.9 & 58.3 & 40.3 & 42.0 \\
\hline Core Zone Axial Velocity (ft/s) & 256 & 273 & 258 & 274 & 279 \\
\hline Outer Zone Gas Flow (klb/h) & 38.7 & 26.6 & 38.8 & 26.8 & 28.0 \\
\hline Outer Zone Axial Velocity (ft/s) & 115 & 128 & 115 & 129 & 131 \\
\hline Temperature $\left({ }^{\circ} \mathrm{F}\right)$ & 528 & 500 & 528 & 500 & 500 \\
\hline
\end{tabular}

${ }^{+} 26 \% \mathrm{O}_{2}$ in total $\mathrm{O}_{2} / \mathrm{FGR}$ mixture ${ }^{\circ} 21 \% \mathrm{O}_{2}$ in primary ${ }^{*}$ Primary $\mathrm{FGR} / \mathrm{O}_{2}$ dried to $4^{\circ} \mathrm{C}$

\& $26 \% \mathrm{O}_{2}$ in total $\mathrm{O}_{2}$ /FGR mixture, $90 \% \mathrm{SO} 2$ removal from flue gas before recycle, flue gas moisture removal to $135^{\circ} \mathrm{F}$ dew point before recycle 
Table 4.13-8: Coal Compositions.

\begin{tabular}{|c|c|c|}
\hline & Utah Skyline Bituminous & Illinois Bituminous \\
\hline \% Carbon & 64.49 & 64.67 \\
\hline \% Hydrogen & 4.44 & 4.51 \\
\hline \% Nitrogen & 1.18 & 1.12 \\
\hline \% Sulfur & 0.64 & 3.98 \\
\hline \% Oxygen & 9.25 & 8.08 \\
\hline \% Moisture & 8.86 & 9.65 \\
\hline \% Ash & 11.14 & 7.99 \\
\hline HHV (Btu/lb) & 11,344 & 11,598 \\
\hline
\end{tabular}

Table 4.13-9: Hunter 3 Air-fired Burner and OFA Operating Conditions.

\begin{tabular}{|l|c|c|c|c|}
\hline & $\begin{array}{c}\text { ID } \\
\text { (in) }\end{array}$ & $\begin{array}{c}\text { Open A } \\
\text { (in }^{2} \text { ) }\end{array}$ & $\begin{array}{c}\text { Mass Flow per } \\
\text { Burner (klb/h) }\end{array}$ & v (ft/s) \\
\hline Primary Air & 16.00 & 201.1 & 19.66 & 75.6 \\
\hline Transition Zone Air & 20.75 & 137.1 & 4.60 & 44.0 \\
\hline Inner Secondary Air & 27.50 & 255.8 & 15.86 & 80.3 \\
\hline Outer Secondary Air & 35.00 & 368.2 & 37.01 & 133.9 \\
\hline Core Zone OFA & 19.00 & 283.5 & 58.01 & 256.4 \\
\hline Outer Zone OFA & 30.00 & 423.3 & 38.68 & 114.5 \\
\hline
\end{tabular}

In Table 4.13-7 there are some operating conditions which may appear to result in an apples and oranges comparison between air and oxy-fired conditions. Specifically two of these values are the theoretical excess $\mathrm{O}_{2}$ (3.0\% oxy and 3.3\% air) and primary gas / coal ratio (1.8 oxy and 1.97 air). The air-fired conditions were assigned using plant data, which reflects the way that the boiler is currently being operated. The oxy-fired conditions were assigned to best reflect the way that a boiler would most likely be operated for oxy-fired conditions. The excess $\mathrm{O}_{2}$ would be minimized as much as possible to reduce the cost of air separation. The primary air/fuel ratios are consistent with the burner design criteria that came from the pilot-scale testing and the design philosophy for the Siemens oxy-fired burners to best maintain an attached flame. Additionally primary, secondary and OFA gas temperatures are slightly different for the air and the oxy-fired conditions. For these values, it is understood that there would be necessary modifications to the setup and/or operation and performance of the air heater and mills. Values were chosen that were reasonable and reflected the conditions investigated in the pilot-scale testing.

\subsubsection{CFD Modeling Results - Investigation of Air- and Oxy-firing and the Slagging Sub-model}

The overall model results for cases with the Skyline coal are shown in Table 4.13-10. Flue gas conditions are given at the horizontal nose and the vertical model exit. The oxy-fired case shows increased CO concentrations, lower exit temperature, and lower $\mathrm{O}_{2}$ concentrations (however, the oxy-fired case was run with 3.0\% dry excess $\mathrm{O}_{2}$ and the air-fired case had 3.3\% dry excess $\mathrm{O}_{2}$ ). However, this is consistent with observations from the pilot-scale testing when comparing both air and oxy-combustion at $3.0 \% \mathrm{O}_{2}$. The oxy-fired case also shows lower unburned carbon in fly ash, also consistent with the pilot-scale testing. The addition of the slagging sub-model showed similar gas conditions, but caused a decrease in UBC for both the air- and oxy-fired cases. 
Table 4.13-10: Overall CFD Model Results for Air- and Oxy-Fired Cases With Skyline Coal and With or Without the Slagging Sub-model.

\begin{tabular}{|c|c|c|c|c|c|}
\hline & Baseline & $\begin{array}{c}\text { Baseline } \\
\text { slag }\end{array}$ & Oxy26 & $\begin{array}{c}\text { Oxy26 } \\
\text { slag }\end{array}$ & Vertical Exit \\
\hline \multicolumn{6}{|l|}{ Horizontal Nose Plane } \\
\hline Temperature $\left({ }^{\circ} \mathbf{F}\right)$ & 2518 & 2554 & 2582 & 2522 & \multirow{3}{*}{$\begin{array}{c}\text { Horizontal } \\
\text { Nose }\end{array}$} \\
\hline CO Concentration, wet (ppm) & 8454 & 9415 & 16451 & 15765 & \\
\hline $\mathrm{O}_{2}$ Concentration, wet (\%) & $3.7 \%$ & $3.7 \%$ & $3.5 \%$ & $3.3 \%$ & \\
\hline \multicolumn{5}{|l|}{ Vertical Exit Plane } & \\
\hline Temperature $\left({ }^{\circ} \mathbf{F}\right)$ & 1787 & 1808 & 1765 & 1750 & \\
\hline CO Concentration, wet (ppm) & 3060 & 3404 & 5663 & 5685 & \\
\hline $\mathrm{O}_{2}$ Concentration, wet (\%) & $3.3 \%$ & $3.3 \%$ & $2.9 \%$ & $2.7 \%$ & \\
\hline Unburned Carbon in Fly Ash & $3.6 \%$ & $1.7 \%$ & $2.1 \%$ & $1.1 \%$ & \\
\hline Particle Burnout & $99.4 \%$ & $99.7 \%$ & $99.6 \%$ & $99.8 \%$ & \\
\hline
\end{tabular}

Gas temperature profiles are shown in Figure 4.13-20. A plot of average gas temperature with elevation is shown in Figure 4.13-21. Dips in temperature are seen near the burner and OFA elevations as cooler fuel and air are introduced. The oxy-fired case shows lower temperatures in the burner region compared to the air-fired case and areas of higher temperature above the OFA ports. The addition of the slagging model showed increased gas temperature in the hopper and more matched temperatures above the OFA ports for the air- and oxy-fired cases.
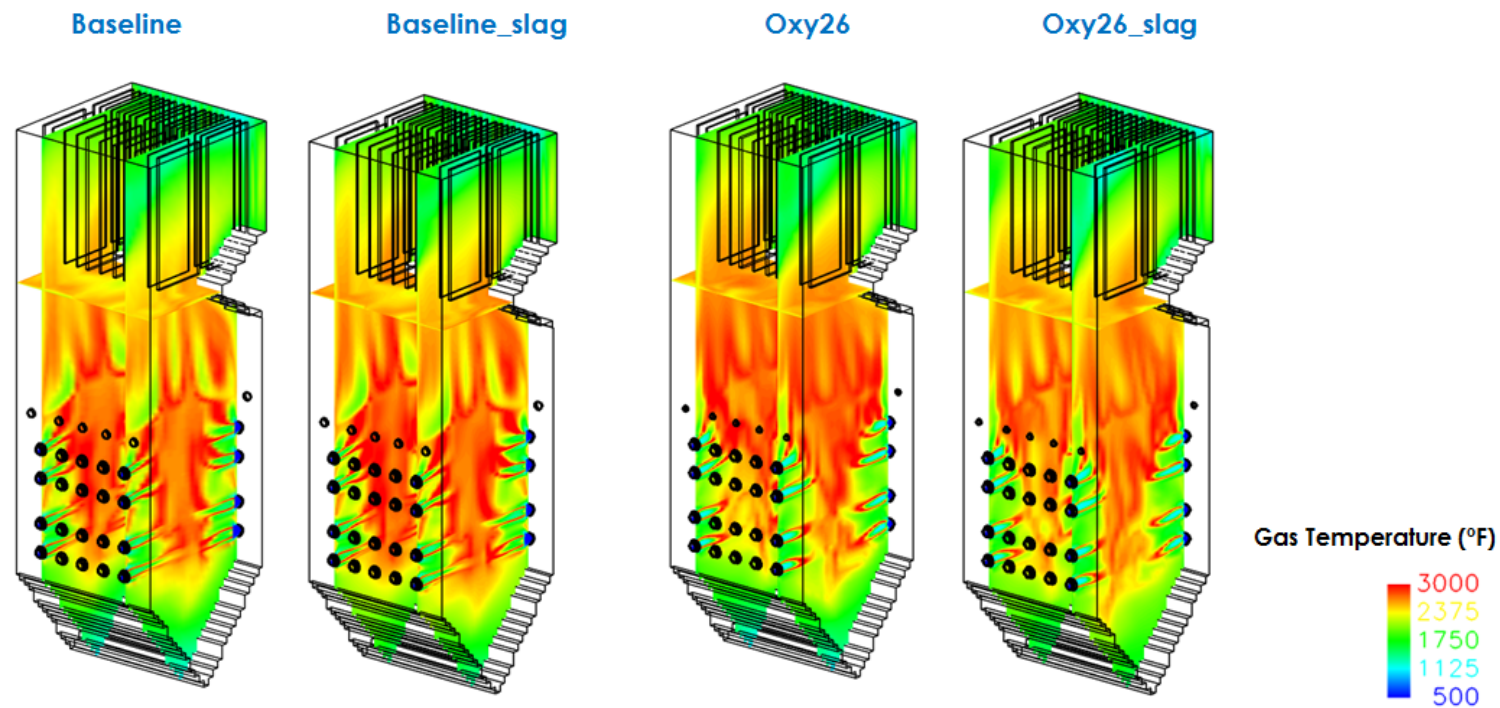

Figure 4.13-20: Model predicted gas temperature profiles, Skyline coal, air- and oxy-fired, with and without the slagging sub-model. 


\section{Gas Temperature vs. Elevation}

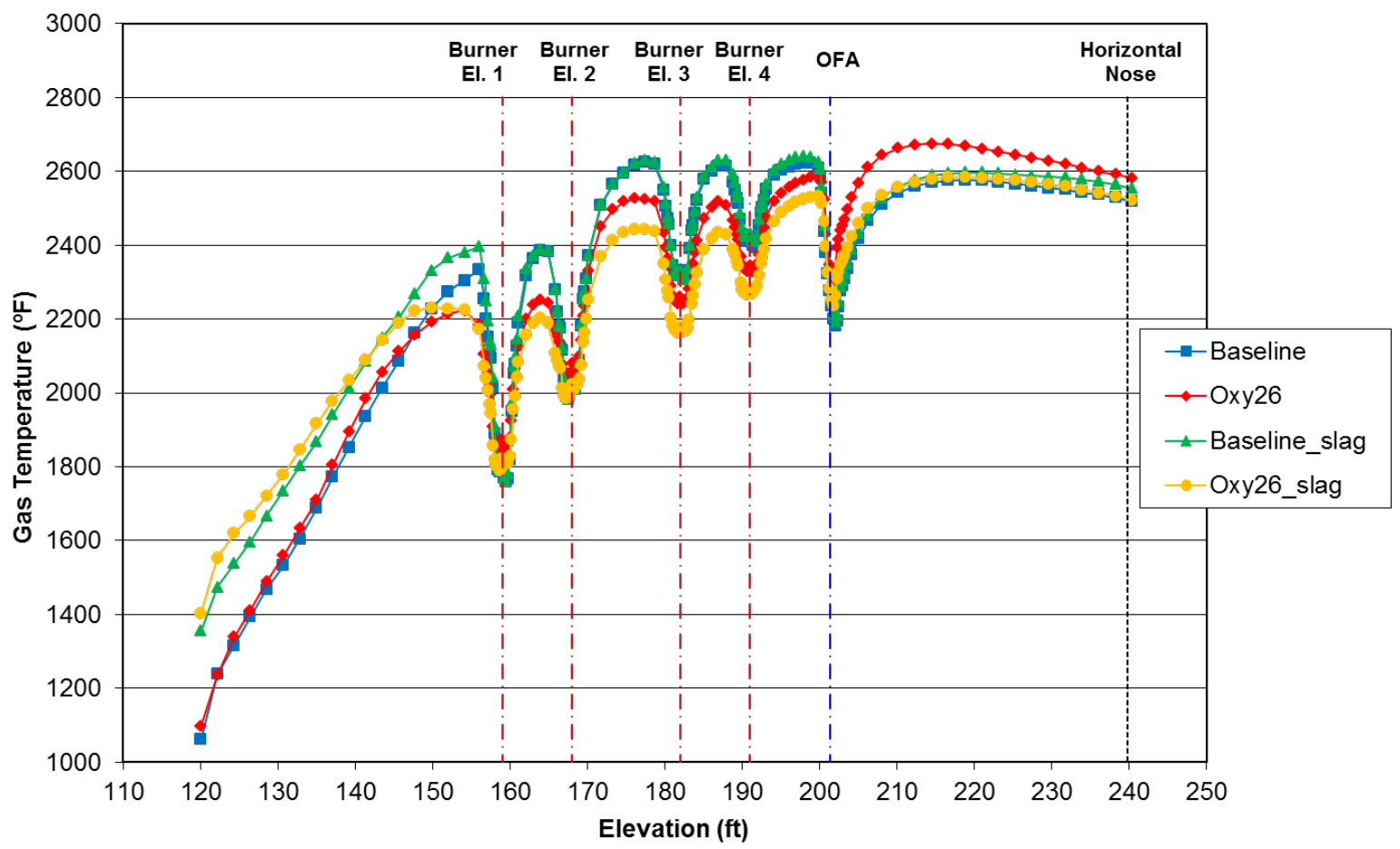

Figure 4.13-21: Model predicted gas temperature with elevation, Skyline coal, air- and oxy-fired, with and without the slagging sub-model.

Predicted CO concentration profiles are shown in Figure 4.13-22 and Figure 4.13-23. Peaks in CO concentration are seen at each burner elevation where fuel-rich (CO generating conditions) are present. A sharp drop in CO is seen at the OFA elevation where excess $\mathrm{O}_{2}$ is available to oxidize some $\mathrm{CO}$ to $\mathrm{CO}_{2}$. The oxy-fired case shows higher CO mass flow throughout the furnace. Regions of higher CO persist above the nose for the oxy-fired case, which results in higher CO concentrations at the model exit. The addition of the slagging sub-model did not have a very large effect on CO concentrations. 

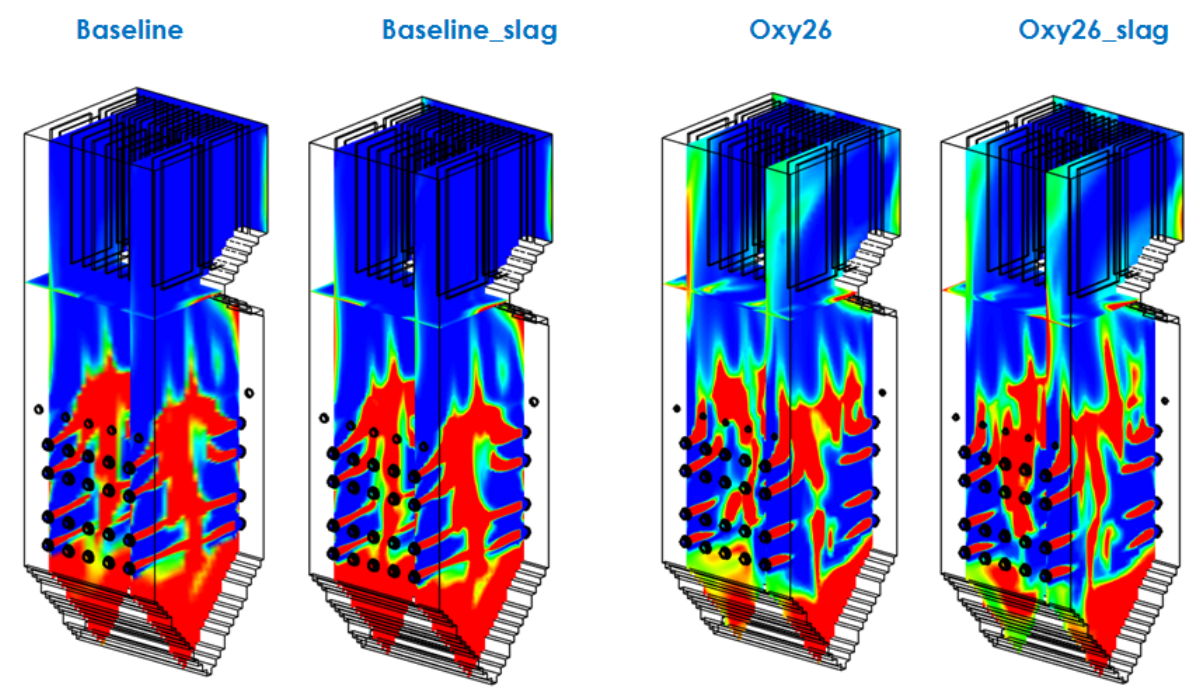

CO Concentration (ppm, wet)

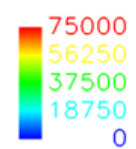

Figure 4.13-22: Model predicted CO concentration profiles, Skyline coal, air- and oxy-fired, with and without the slagging sub-model.

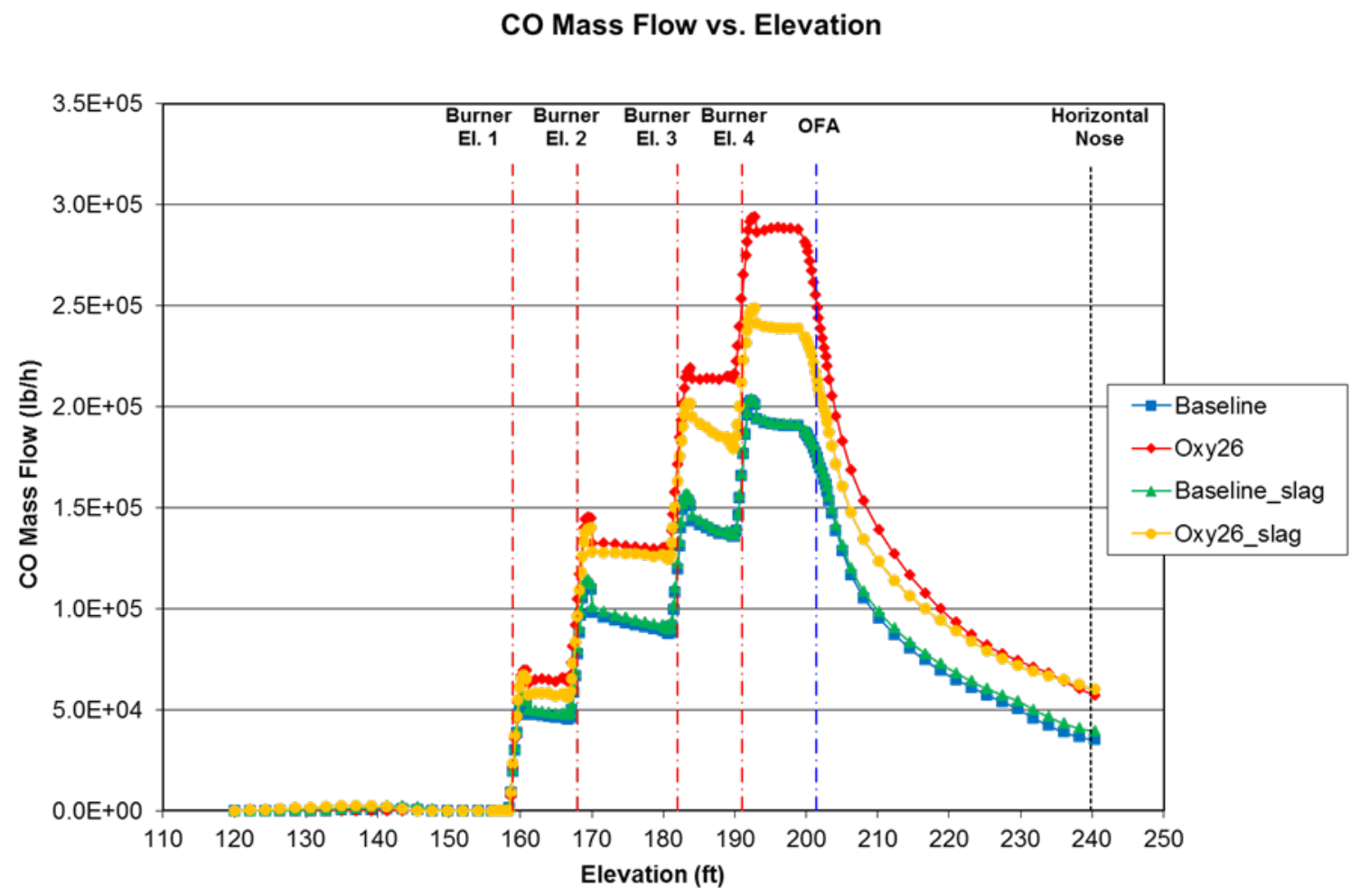

Figure 4.13-23: Model predicted CO flow with elevation, Skyline coal, air- and oxy-fired, with and without the slagging sub-model.

Predicted $\mathrm{O}_{2}$ concentration profiles are shown in Figure 4.13-24 and Figure 4.13-25. Overall, the oxyfired case was run with a lower stoichiometric ratio (3.0\% dry excess $\mathrm{O}_{2}$ versus $3.3 \%$ dry excess $\mathrm{O}_{2}$ in the air-fired case). However, the oxy-fired case shows higher $\mathrm{O}_{2}$ concentrations in the hopper and burner 
regions. This suggests slower burnout of the fuel in the oxy-fired case, which is consistent with the temperature profiles above. The $\mathrm{O}_{2}$ concentration does eventually drop to levels below the air-fired case resulting in lower $\mathrm{O}_{2}$ concentrations at the nose and the model exit for the oxy-fired case. The addition of the slagging model did not affect the air-fired case, but slightly lowered the $\mathrm{O}_{2}$ concentration in the burner region for the oxy-fired case.
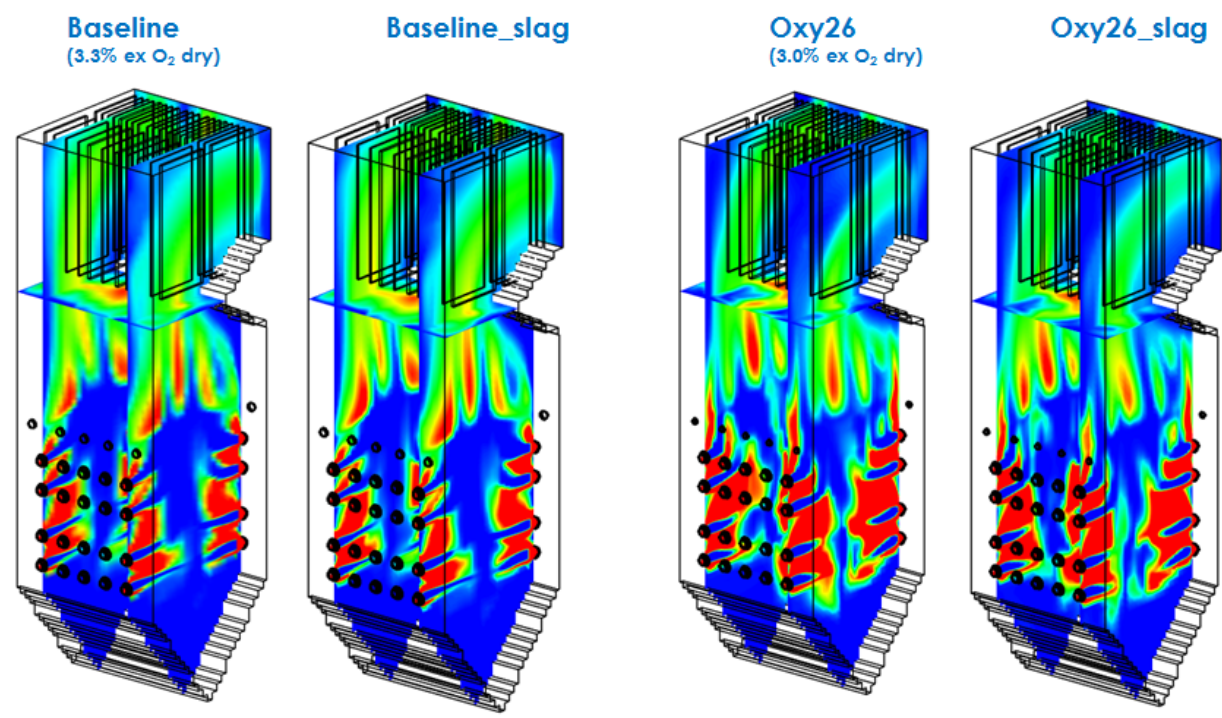

$\mathrm{O}_{2}$ Concentration (ppm, wet)

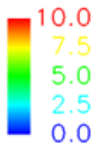

Figure 4.13-24: Model predicted $\mathrm{O}_{2}$ concentration profiles, Skyline coal, air- and oxy-fired, with and without the slagging sub-model.

O2 Concentration vs. Elevation

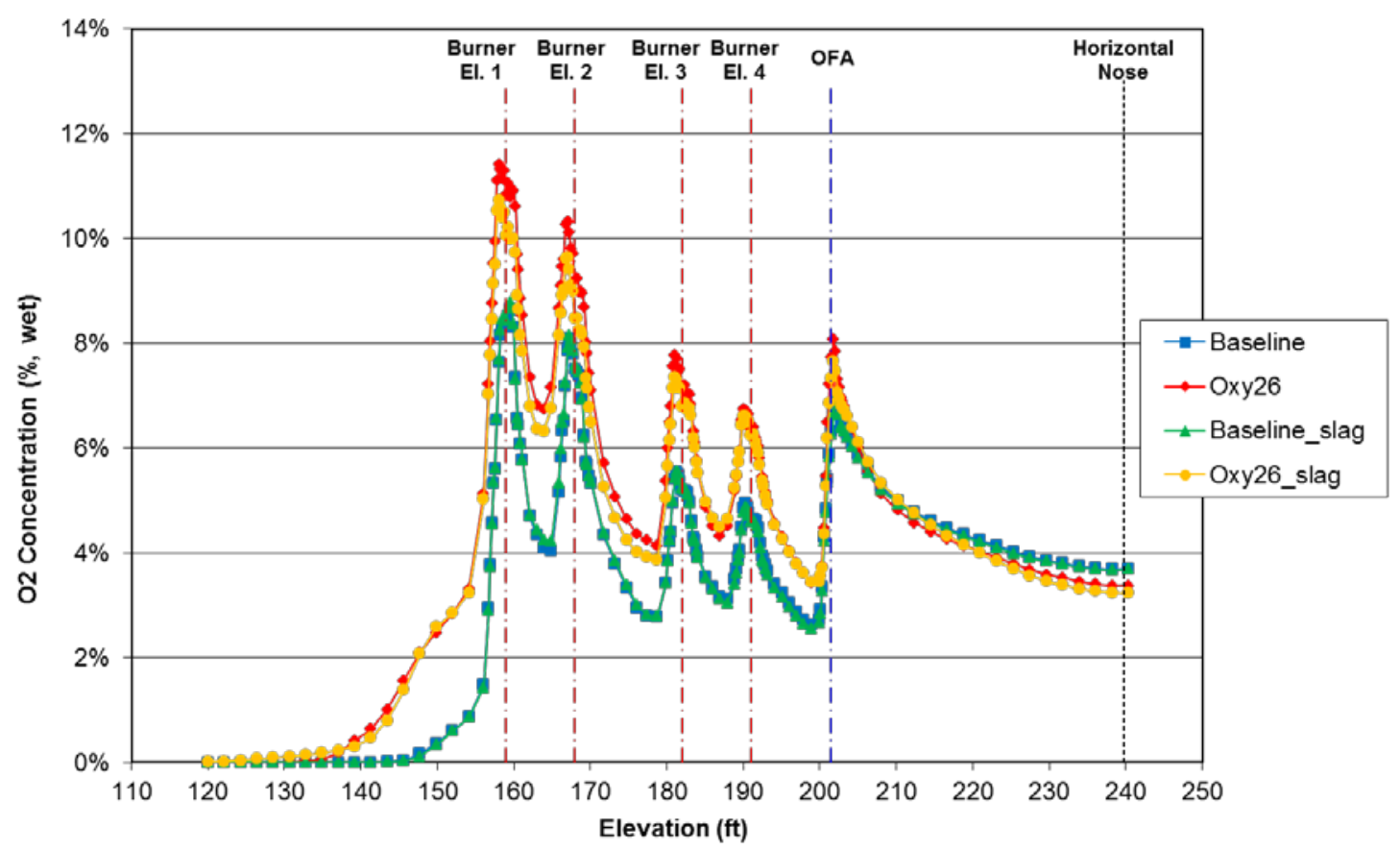

Figure 4.13-25: Model predicted $\mathrm{O}_{2}$ concentration with elevation, Skyline coal, air- and oxy-fired, with and without the slagging sub-model. 
Figure 4.13-26 shows particle burnout profiles. The oxy-fired case shows lower burnout in the burner region and more unevenness. At the model exit, the oxy-fired case shows higher burnout compared to the air-fired case, which results in lower unburned carbon in the fly ash. The addition of the slagging model increases burnout for both the air- and oxy-fired cases.
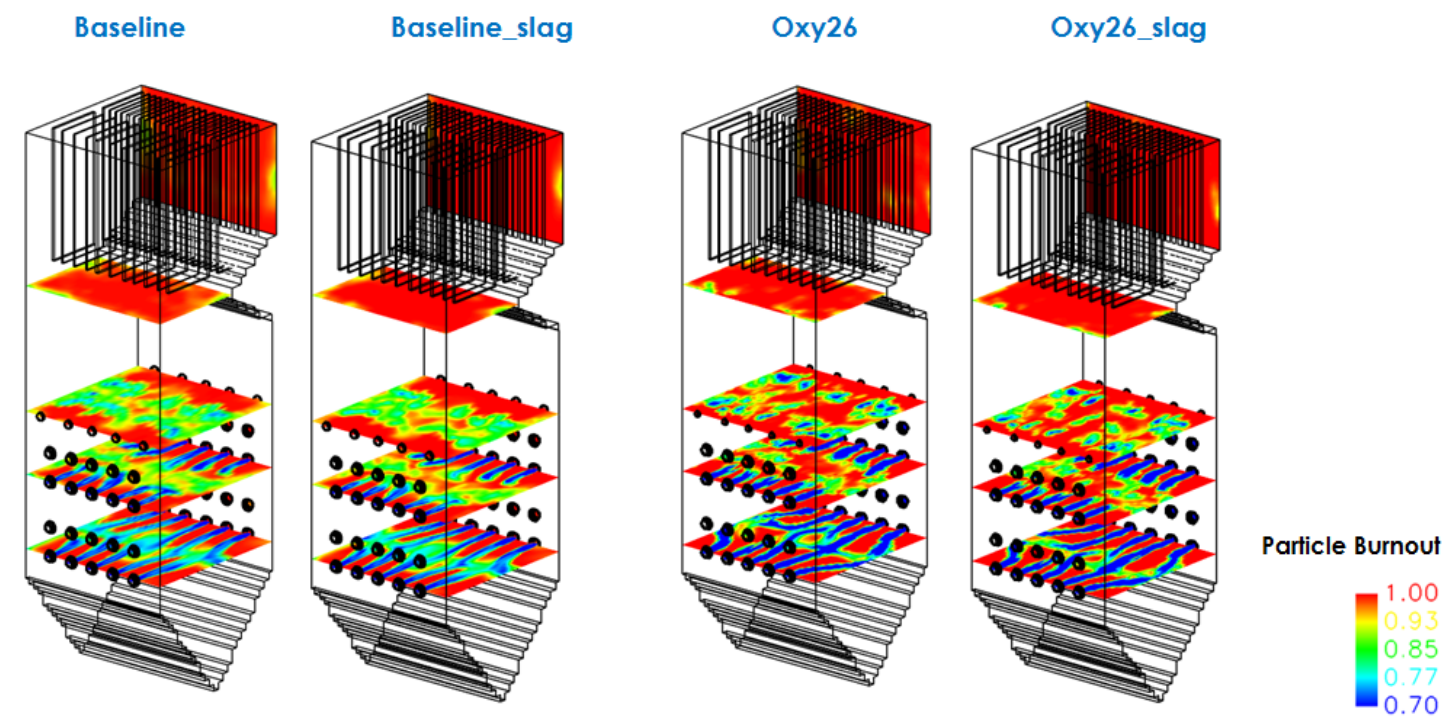

Figure 4.13-26: Model predicted particle burnout profiles, Skyline coal, air- and oxy-fired, with and without the slagging sub-model.

Figure 4.13-27 shows wall deposition profiles. In the air-fired case, $8.1 \%$ of the coal mineral matter deposits on the wall. This increased to $11.4 \%$ with the addition of the slagging sub-model. Deposition was lower in the oxy-fired case: $6.1 \%$ without the slagging sub-model and $6.8 \%$ with the slagging submodel. The slagging sub-model incorporates information learned from earlier tasks in this project which were directed at understanding the behavior of ash in oxy-combustion systems. From that information, little change is expected in the behavior of ash between the two firing conditions. The reduction of deposition predicted here when comparing oxy-combustion with the air-fired case is more likely due to an overall reduction in flue gas volume and reduced velocities in the oxy-fired case. There is an area of high deposition in the center of the front wall above the OFA ports for the air-fired case, which is absent in the oxy-fired case. The hopper and nose regions also show significant deposition. Quantitative deposition flux by zone (Figure 4.13-28) is given in Figure 4.13-29.

The areas of highest particle deposition also show decreased heat flux (Figure 4.13-30). This is due to the increased deposition creating a greater thermal resistance to heat transfer to the water walls. 

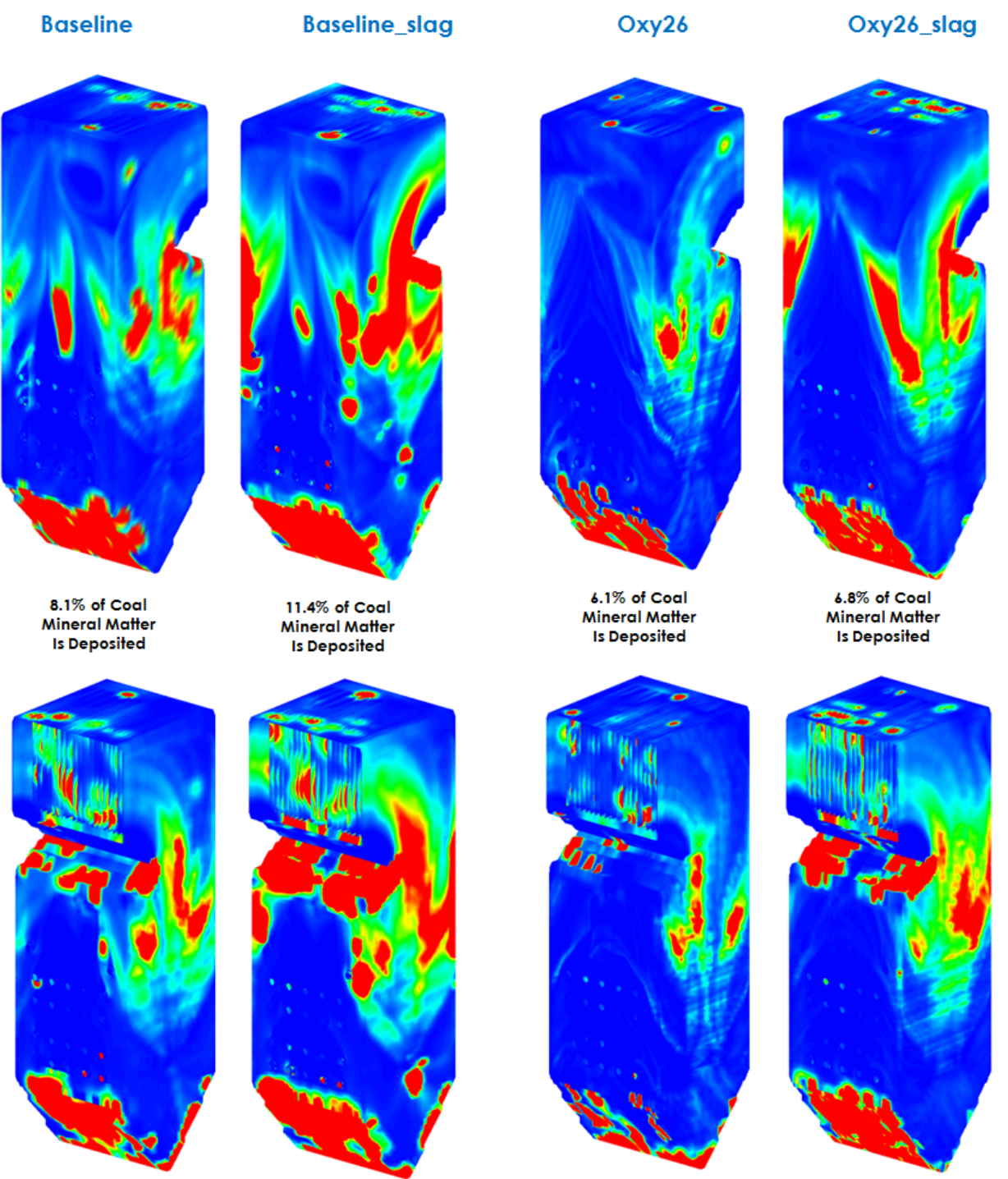

Deposition Flux (lb/ $\left./ \mathrm{ft}^{2} \mathbf{s}\right)$

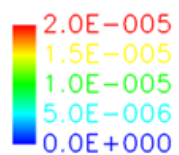

Figure 4.13-27: Model predicted particle deposition profiles, Skyline coal, air- and oxy-fired, with and without the slagging sub-model. 


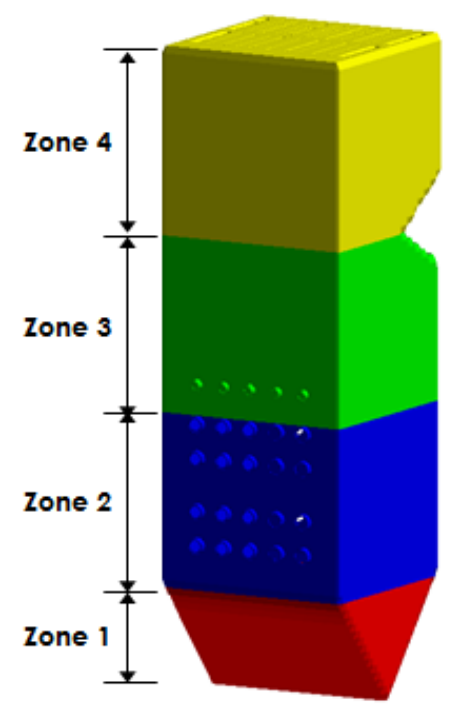

Figure 4.13-28: Four zones of the furnace: hopper, burners, OFA, above nose.

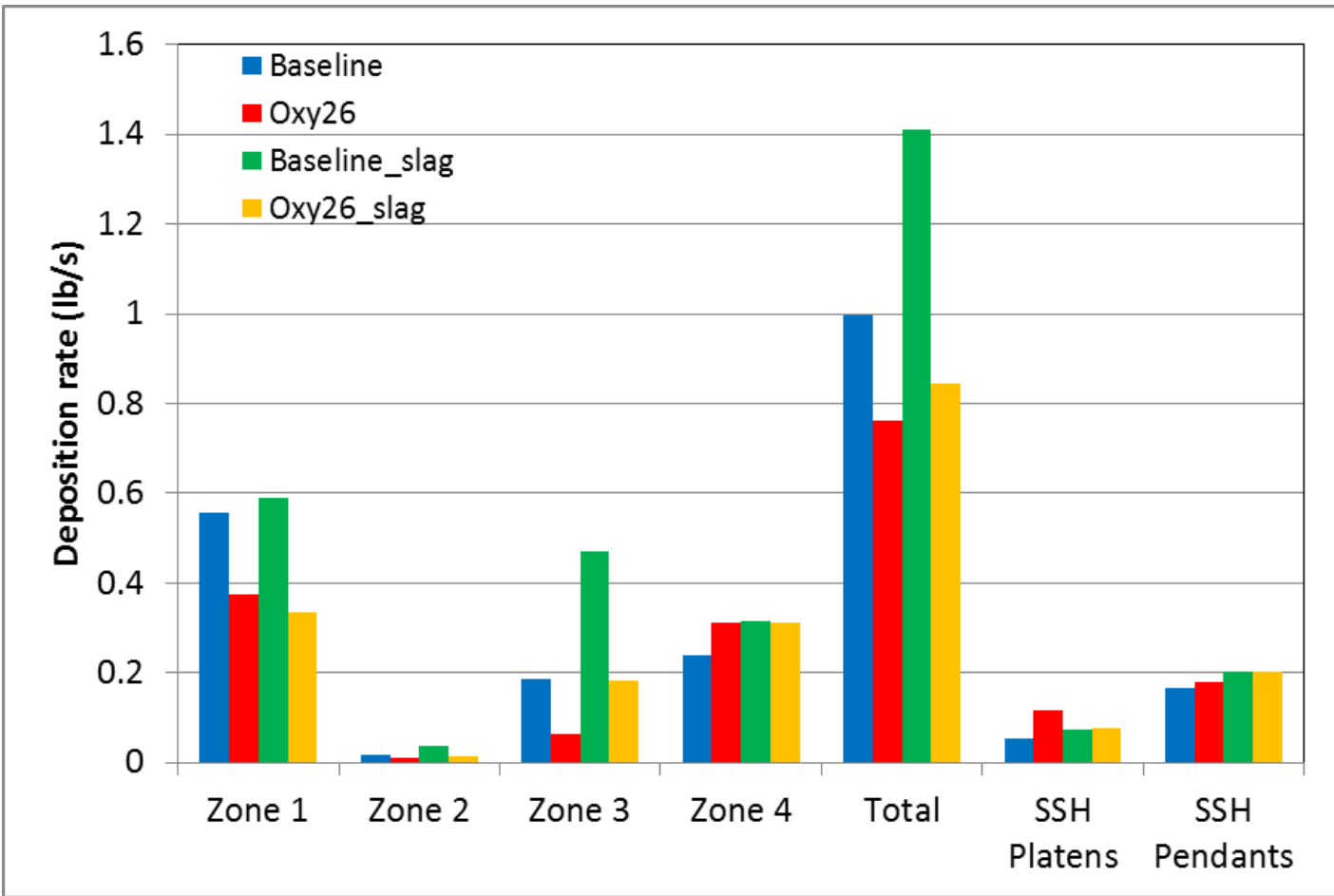

Figure 4.13-29: Deposition flux by zone, Skyline coal, air- and oxy-fired, with and without the slagging sub-model. 


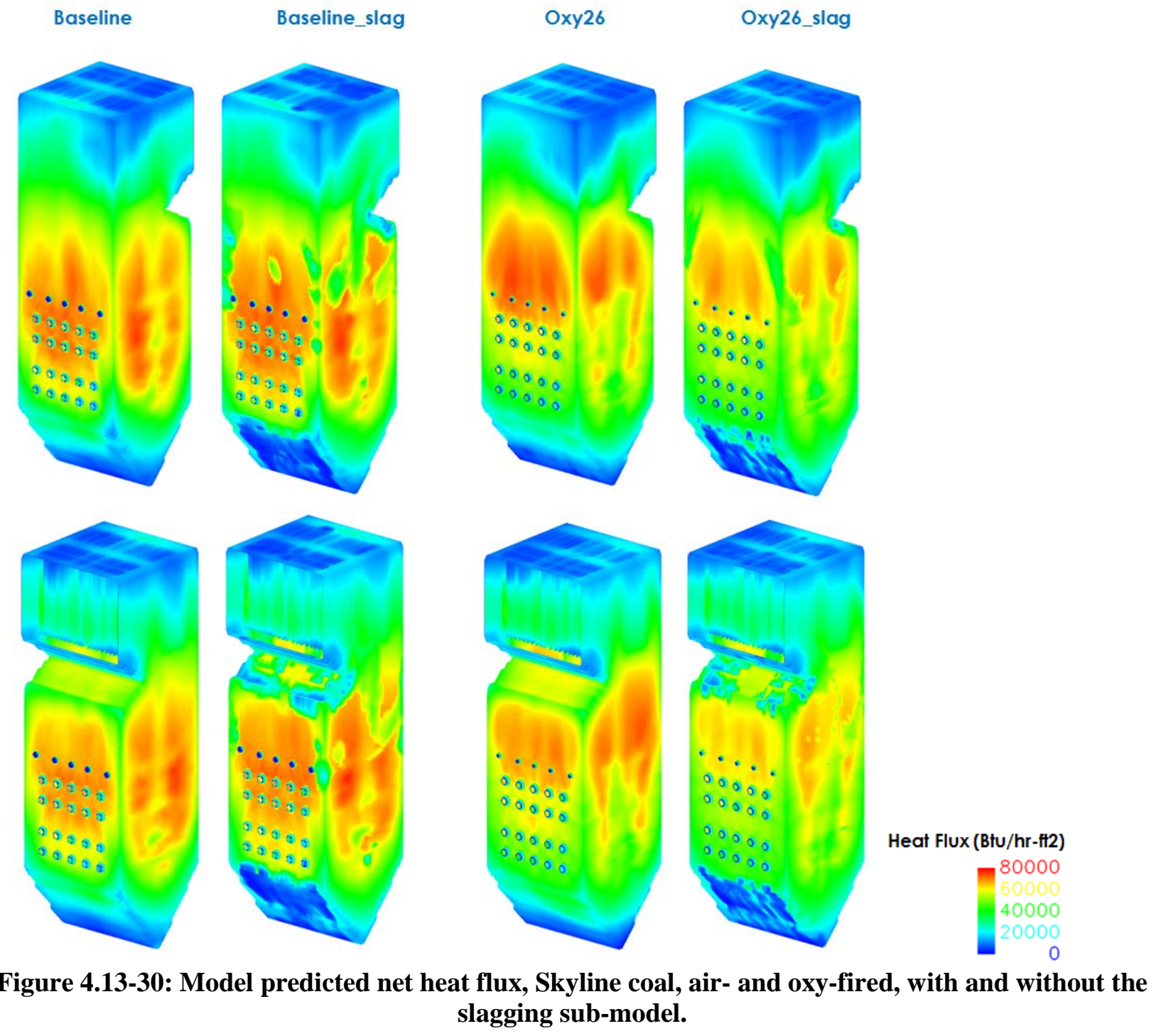

Figure 4.13-31 shows net heat flux by surface and Table 4.13-11 shows net heat flux by zone. The net heat transfer for the air-fired case without the slagging sub-model was tuned to steam side data. The oxyfired case showed 3.5\% higher heat transfer. Heat flux moved to higher elevations in the furnace (less heat transfer in Zone 2 and more in Zone 4 compared to the air-fired case), which is consistent with slower burnout. The addition of the slagging model decreased heat transfer slightly, but brought the airand oxy-fired cases closer in overall heat transfer. 


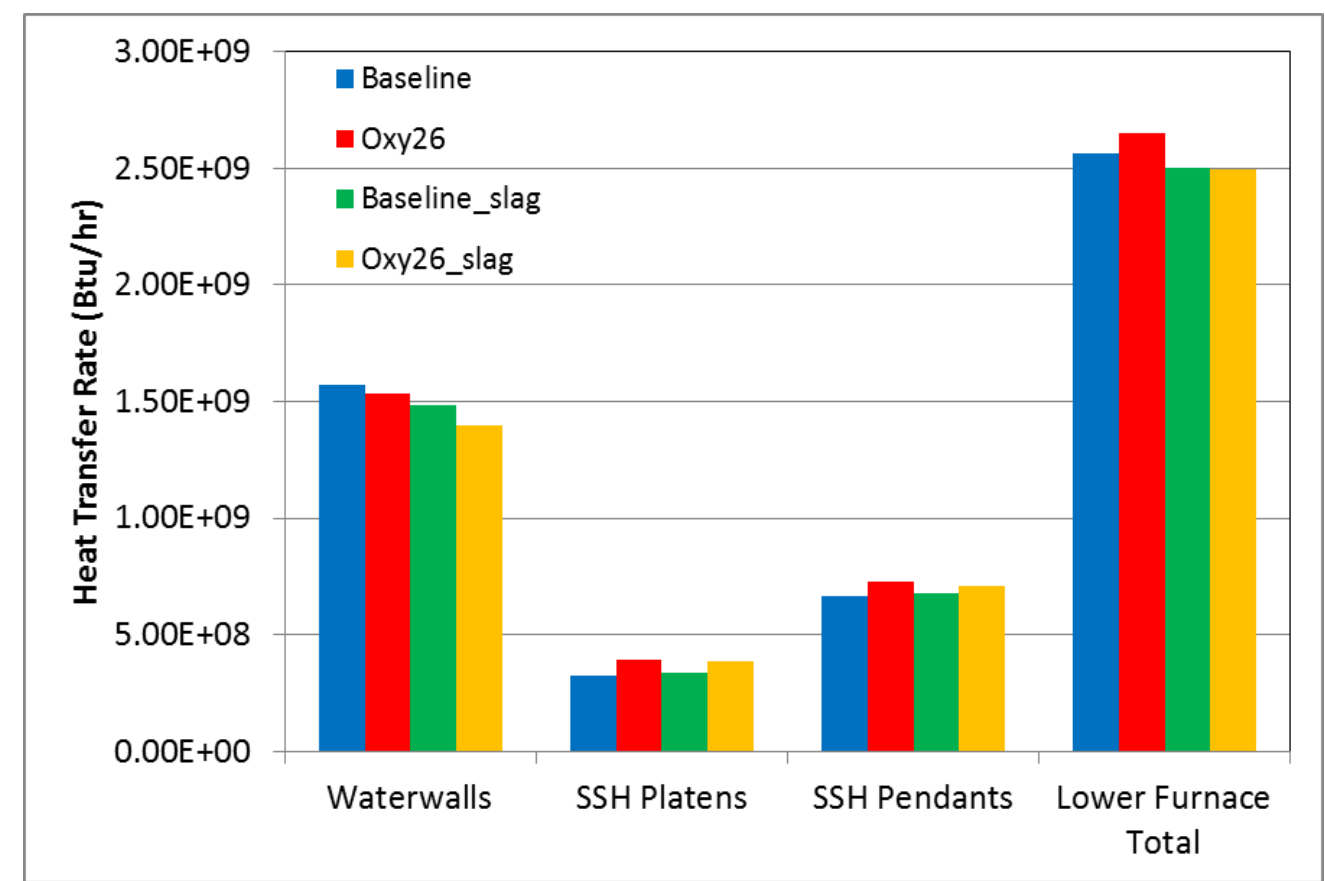

Figure 4.13-31: Net Heat flux by surface, Skyline coal, air- and oxy-fired, with and without the slagging sub-model.

Table 4.13-11: Net Heat Flux by Zone, Skyline Coal, Air- And Oxy-Fired, With and Without the Slagging Sub-model.

Baseline

\begin{tabular}{|l|c|c|}
\hline & $\begin{array}{c}\text { Heat Transfer Rate } \\
\text { (Btu/hr) }\end{array}$ & \% of Total \\
\hline Zone 1 & $1.47 \mathrm{E}+08$ & $6 \%$ \\
\hline Zone 2 & $5.33 \mathrm{E}+08$ & $21 \%$ \\
\hline Zone 3 & $6.40 \mathrm{E}+08$ & $25 \%$ \\
\hline Zone 4 & $1.24 \mathrm{E}+09$ & $48 \%$ \\
\hline Total & $2.56 \mathrm{E}+09$ & \\
\hline
\end{tabular}

Baseline slag

\begin{tabular}{|l|c|c|}
\hline & $\begin{array}{c}\text { Heat Transfer Rate } \\
\text { (Btu/hr) }\end{array}$ & \% of Total \\
\hline Zone 1 & $1.06 \mathrm{E}+08$ & $4 \%$ \\
\hline Zone 2 & $5.40 \mathrm{E}+08$ & $22 \%$ \\
\hline Zone 3 & $5.78 \mathrm{E}+08$ & $23 \%$ \\
\hline Zone 4 & $1.28 \mathrm{E}+09$ & $51 \%$ \\
\hline Total & $2.50 \mathrm{E}+09$ & \\
\hline
\end{tabular}

Oxy26

\begin{tabular}{|l|c|c|}
\hline & $\begin{array}{c}\text { Heat Transfer Rate } \\
\text { (Btu/hr) }\end{array}$ & \% of Total \\
\hline Zone 1 & $1.50 \mathrm{E}+08$ & $6 \%$ \\
\hline Zone 2 & $4.68 \mathrm{E}+08$ & $18 \%$ \\
\hline Zone 3 & $6.57 \mathrm{E}+08$ & $25 \%$ \\
\hline Zone 4 & $1.37 \mathrm{E}+09$ & $52 \%$ \\
\hline Total & $2.65 \mathrm{E}+09$ & \\
\hline
\end{tabular}

\section{Oxy26_slag}

\begin{tabular}{|l|c|c|}
\hline & $\begin{array}{c}\text { Heat Transfer Rate } \\
\text { (Btu/hr) }\end{array}$ & \% of Total \\
\hline Zone 1 & $1.19 \mathrm{E}+08$ & $5 \%$ \\
\hline Zone 2 & $4.44 \mathrm{E}+08$ & $18 \%$ \\
\hline Zone 3 & $5.84 \mathrm{E}+08$ & $23 \%$ \\
\hline Zone 4 & $1.35 \mathrm{E}+09$ & $54 \%$ \\
\hline Total & $2.49 \mathrm{E}+09$ & \\
\hline
\end{tabular}


Calculations were performed with the updated corrosion sub-model to determine the corrosion potential on the waterwalls and secondary superheater. Two corrosion paths were investigated: $\mathrm{H}_{2} \mathrm{~S}$ corrosion is a predominant gas-phase attack (Figure 4.13-32) while FeS corrosion is caused by deposits (Figure 4.13-33). The chlorine content of the coal burned at Hunter 3 during the $\mathrm{B} \& \mathrm{~W}$ testing was negligible; therefore $\mathrm{Cl}$ corrosion was not investigated. The highest peak corrosion areas are caused by deposits (FeS corrosion). Both the air- and oxy-fired cases have regions of high deposit corrosion. The oxy-fired case had much higher gas-phase corrosion, especially in the hopper region. Figure 4.13-34 shows the total predicted corrosion potential of the waterwalls up to the horizontal nose. The highest corrosion potential occurs at locations where deposits developed. This is evident on the front wall above the OFA ports in the air-fired case and around the nose and hopper regions in the oxy-fired case. Even though the air-fired case had more deposits, the oxy-fired case shows higher overall waterwall corrosion potential. This is likely due to the different composition of the deposits and the higher gas-phase $\mathrm{H}_{2} \mathrm{~S}$ concentration.
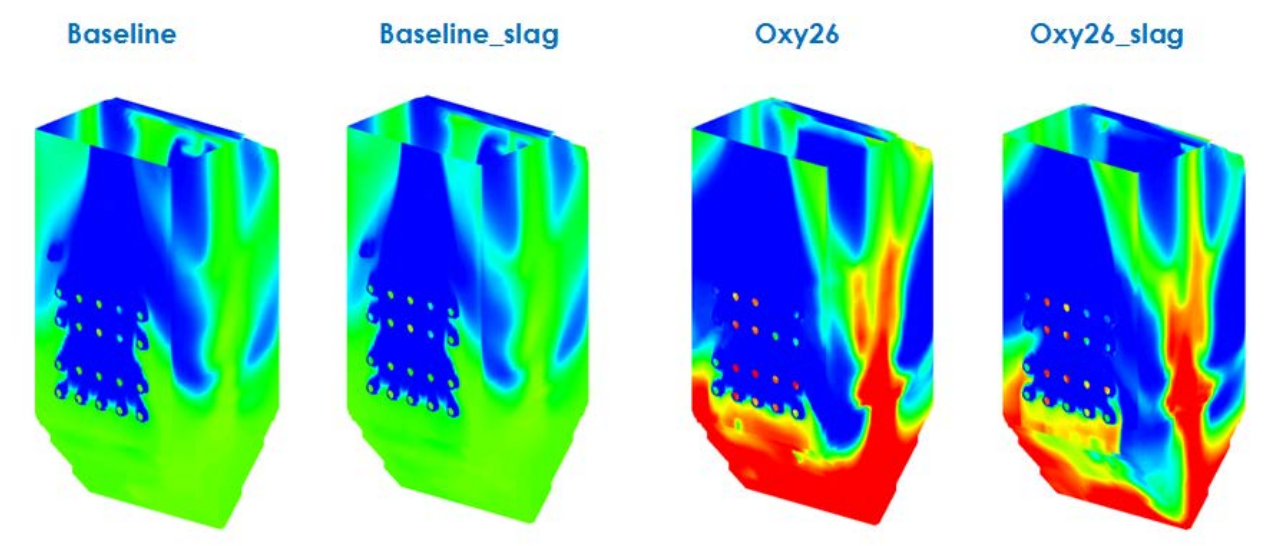

$\mathrm{H}_{2} \mathrm{~S}$ Corrosion (mils/yr)

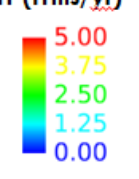

Figure 4.13-32: Model predicted $\mathrm{H}_{2} \mathrm{~S}$ corrosion of the waterwalls, Skyline coal, air- and oxy-fired, with and without the slagging sub-model.
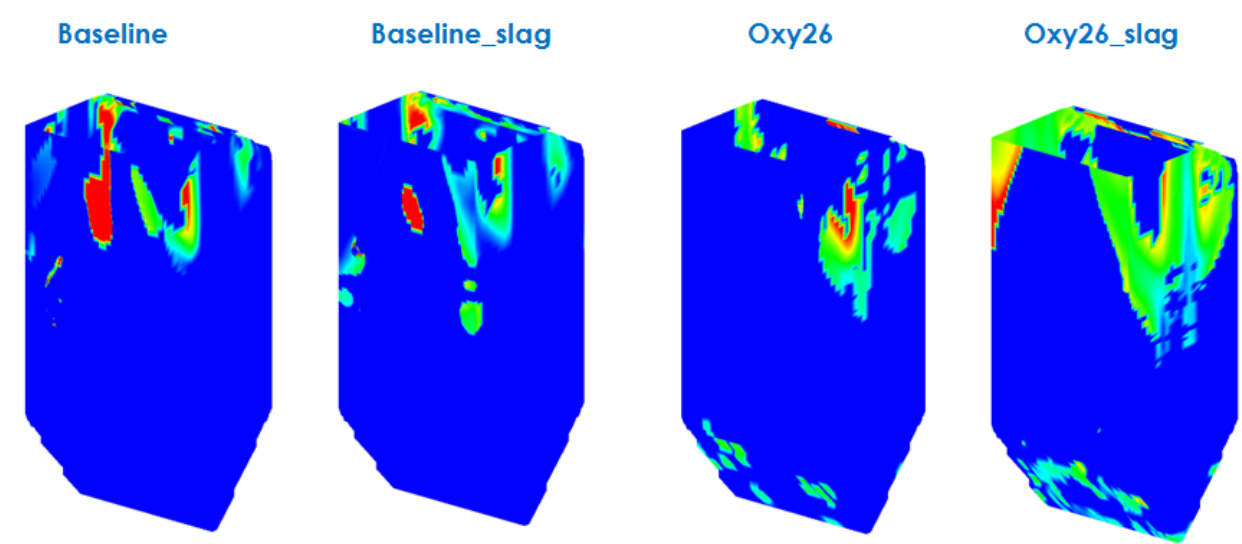

Total WW Corrosion (mils/yr)

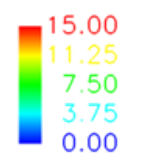

Figure 4.13-33: Model predicted FeS corrosion of the waterwalls, Skyline coal, air- and oxy-fired, with and without the slagging sub-model. 

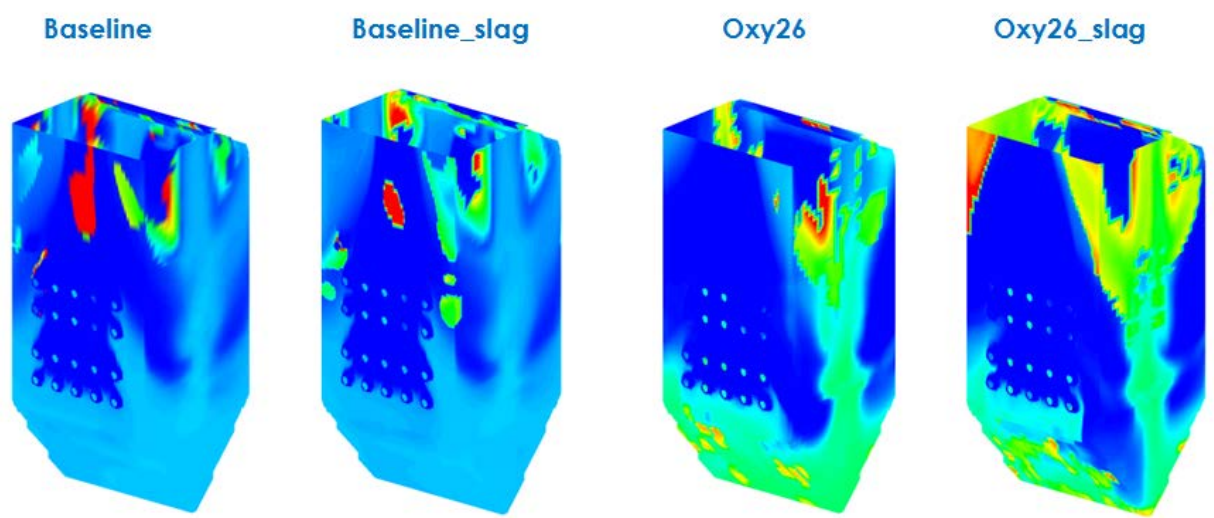

Total WW Corrosion (mils/yr)

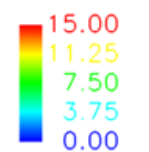

Figure 4.13-34: Model predicted total corrosion of the waterwalls, Skyline coal, air- and oxy-fired, with and without the slagging sub-model.

Figure 4.13-35 shows the predicted secondary superheater corrosion potential. The magnitude of the corrosion potential is much smaller for this region, but the oxy-fired case shows much higher corrosion.

The total corrosion rate (given as a total material loss) for various sections of the furnace is given in Figure 4.13-36. The peak corrosion rates are shown in Figure 4.13-37. The total corrosion rates for the waterwall and superheater surfaces increased in the oxy-fired case. However, the peak corrosion rate on the waterwalls decreased in the oxy-fired case as compared to the air-fired case. This suggests that the increase in total waterwall corrosion is a result of corrosion over a larger surface area. This drop in peak waterwall corrosion is consistent with pilot-scale testing performed in this project. The peak corrosion potential on the superheater surfaces increased drastically in the oxy-fired case, which is also consistent with pilot-scale tests. The addition of the slagging model increased total waterwall corrosion potential and decreased total superheater corrosion. 


\section{Baseline}
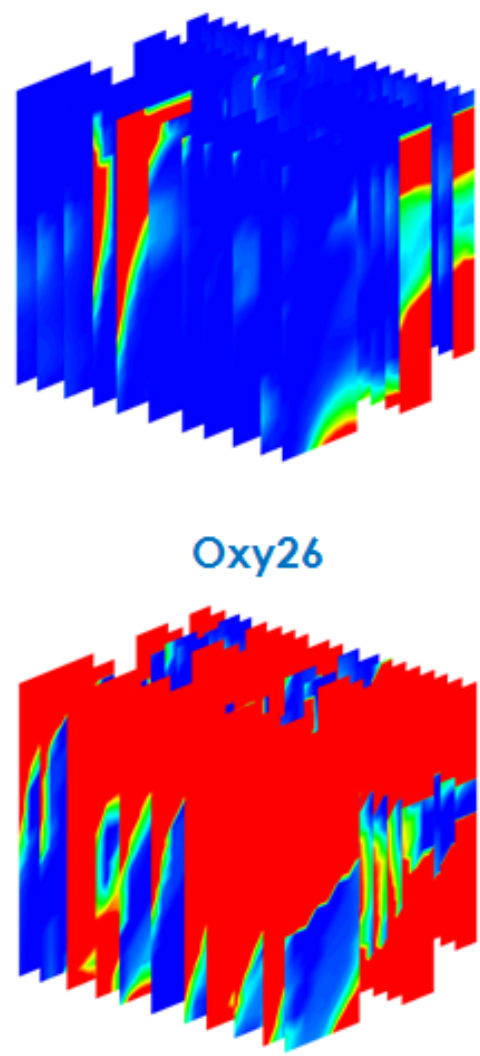

Baseline slag

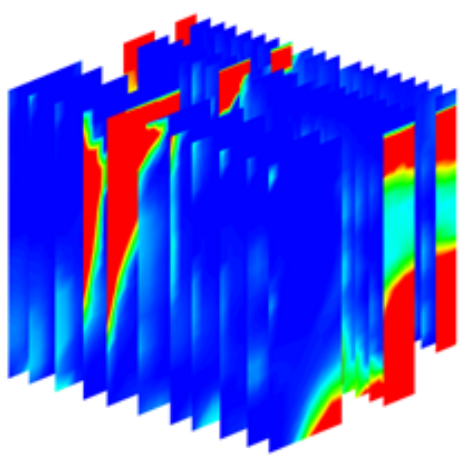

Oxy26_slag

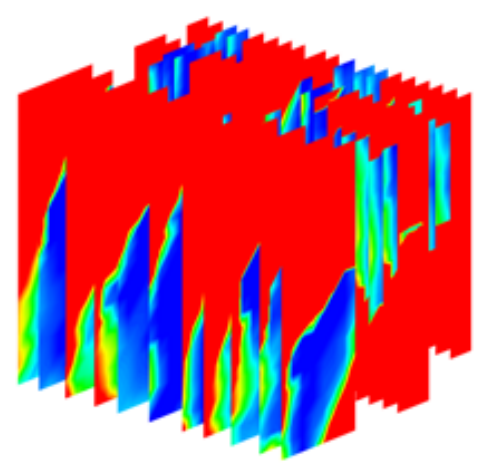

Total SSH Corrosion (mils/yr)

0.16
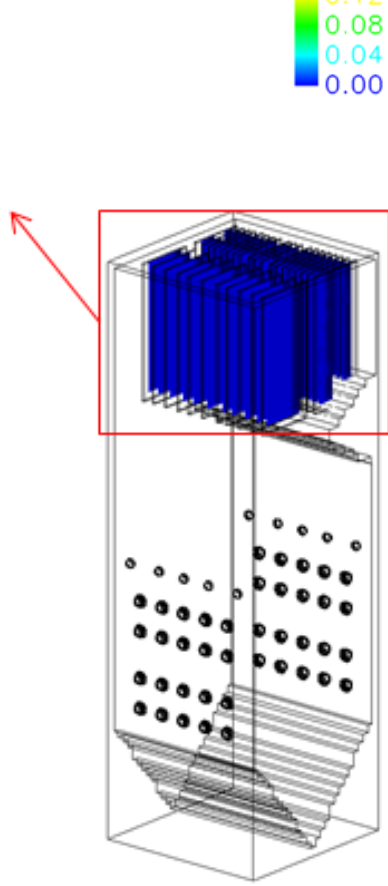

Figure 4.13-35: Model predicted total corrosion of the secondary superheater, Skyline coal, air- and oxy-fired, with and without the slagging sub-model. 


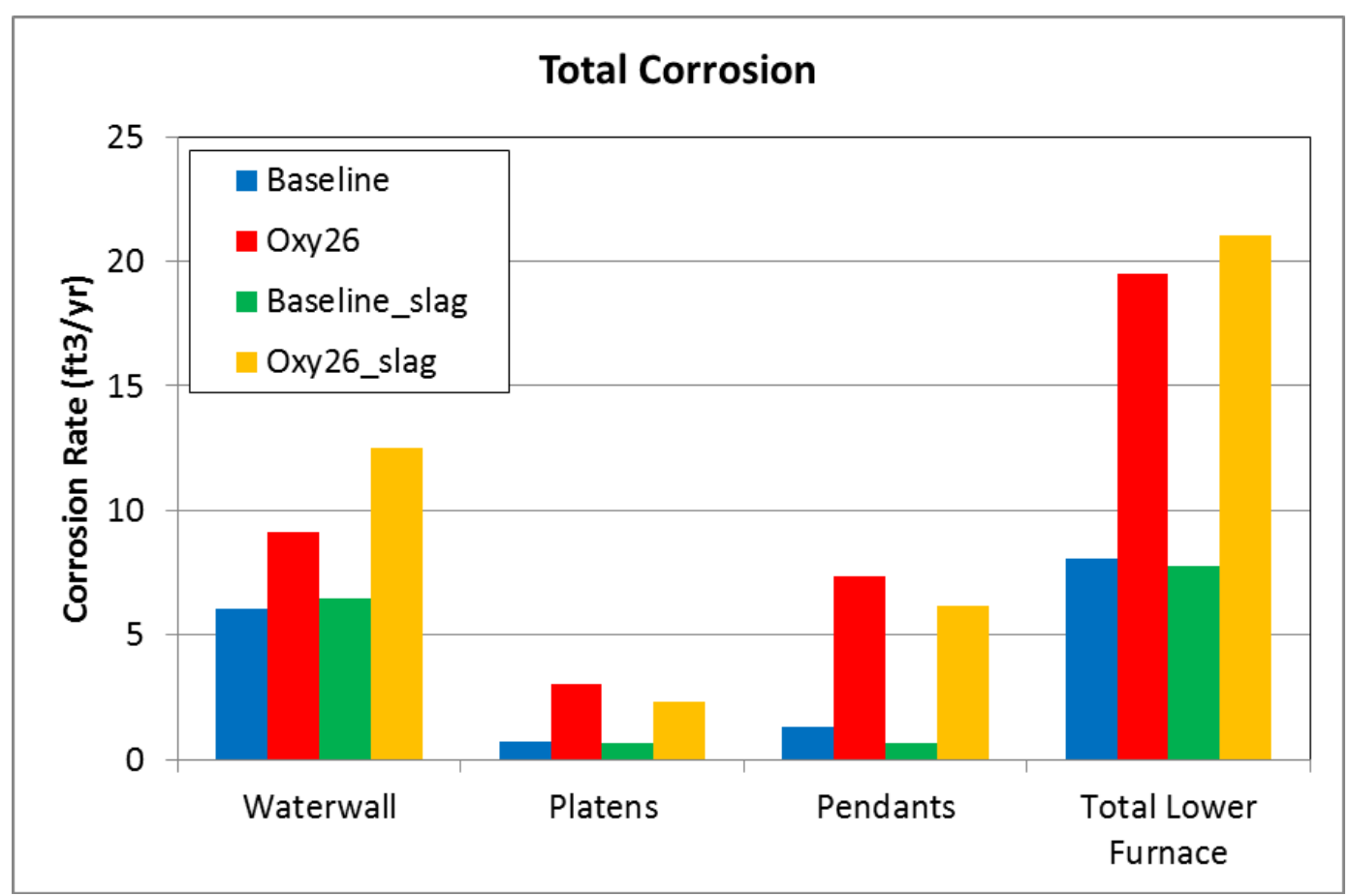

Figure 4.13-36: Model predicted total corrosion rate by furnace section (given as total material loss), Skyline coal, air- and oxy-fired, with and without the slagging sub-model.

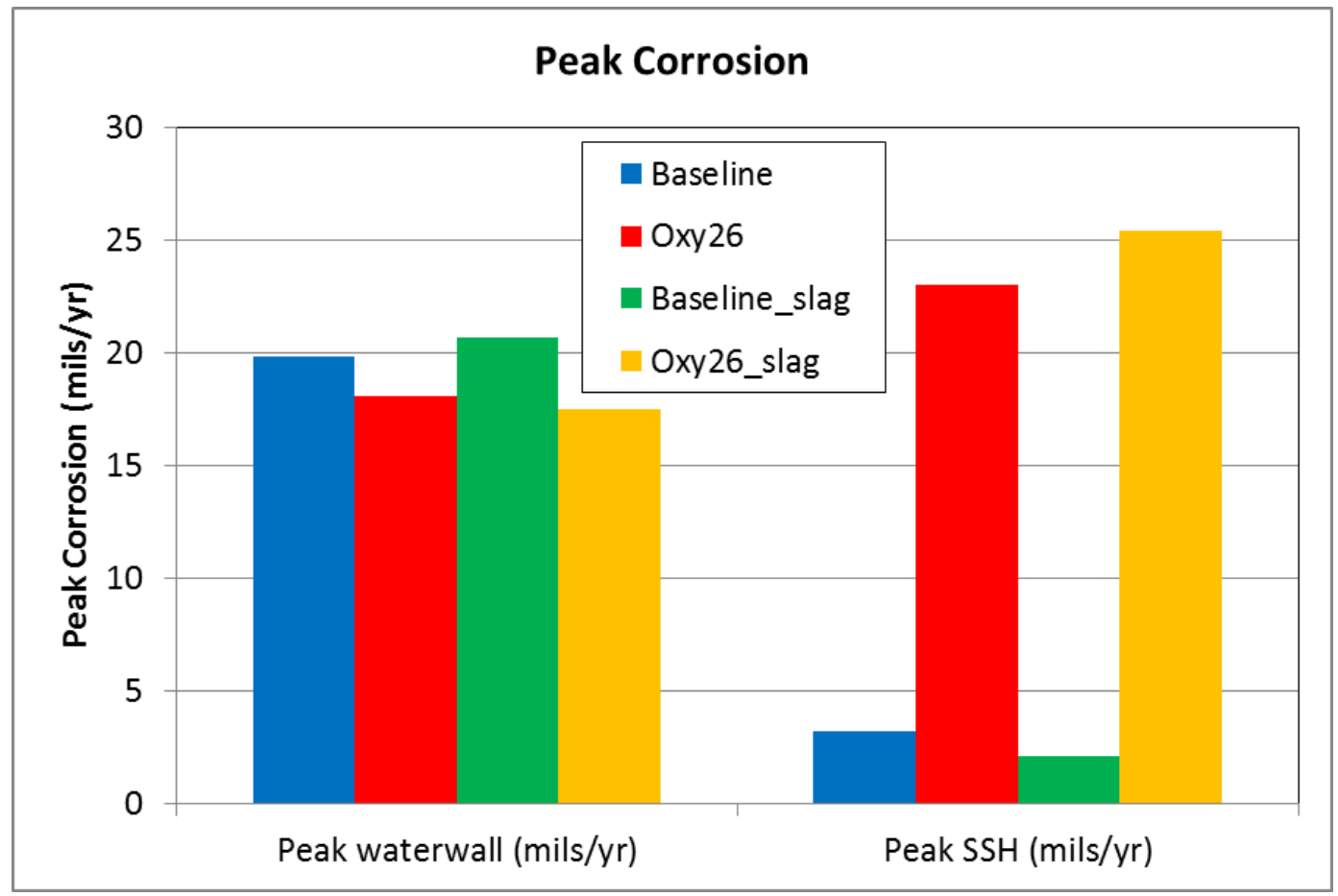

Figure 4.13-37: Model predicted peak corrosion rate by furnace section, Skyline coal, air- and oxyfired, with and without the slagging sub-model. 
Overall, several differences were seen between the air- and oxy-fired cases. CO concentration increased during oxy-firing, which is consistent with pilot-scale tests. $\mathrm{O}_{2}$ is consumed more slowly during oxyfiring suggesting slower burnout. Higher $\mathrm{O}_{2}$ concentrations persist at higher elevations in the furnace. This slower burnout is also reflected in the temperature profile. Higher temperatures also persist to higher elevations. Unburned carbon content of the fly ash is lower for oxy-firing, which is consistent with pilotscale tests. The FGR rate assumed in this modeling (26\% in the total $\mathrm{O}_{2} / \mathrm{FGR}$ mixture) produced results which match the air-fired heat transfer well. This is consistent with previous process modeling. The previous process modeling also suggests that the heat transfer can also be fine-tuned by small adjustments to the recycle ratio. The heat transfer profile in the furnace shifted to higher elevations for oxy-firing, consistent with delayed $\mathrm{O}_{2}$ consumption and current understanding of ignition and char oxidation. The total corrosion potential increased for oxy-firing. The peak waterwall corrosion decreased slightly for oxy-firing, while the peak superheater corrosion increased drastically.

The addition of the slagging model caused several shifts in the modeling:

- Increased exit gas temperature for the air-fired case and decreased exit gas temperature for the oxy-fired case.

- Decreased UBC for both air- and oxy-fired cases.

- Increased particle deposition for both air- and oxy-fired cases.

- Decreased overall heat transfer for both air- and oxy-fired cases.

- Helped the air-fired and oxy-fired overall lower furnace heat transfer agree better.

- Slightly increased total waterwall corrosion and decreased total superheater corrosion for both air- and oxy-fired cases.

\subsubsection{CFD Modeling Results - Investigation of Flue Gas Recycle Composition}

In order to investigate the effect of varied flue gas composition, air- and oxy-fired cases were run with a high sulfur Illinois bituminous coal. The composition of the Illinois coal was very similar to the Utah Skyline bituminous coal, with the exception of the sulfur content. A parametric oxy-fired case was run with the Illinois coal in which the flue gas was modified prior to recycle to simulate flue gas clean-up through a wet FGD. To best approximate the conditions at the wet FGD exit, the flue gas recycle stream had $90 \% \mathrm{SO}_{2}$ removal and was dried to $135^{\circ} \mathrm{F}$ dew point.

Overall model results for the air-fired case and the two oxy-fired cases (as compared to the Skyline cases) are shown in Table 4.13-12. Gas temperatures, $\mathrm{O}_{2}$ concentrations, and CO concentrations were similar for the two coals as expected. $\mathrm{SO}_{2}$ concentrations with the Illinois coal and no flue gas cleaning were significantly higher, also as expected. The unburned carbon levels with the Illinois coal were also higher. Simulating FGR cleanup through a wet FGD brought the $\mathrm{SO}_{2}$ levels down, but they were still higher than the corresponding $\mathrm{SO}_{2}$ levels with the Skyline coal. Removing $\mathrm{SO}_{2}$ also resulted in slightly lower gas temperatures, lower $\mathrm{CO}$ concentrations, and slightly higher unburned carbon levels. These changes brought the Illinois oxy-fired case closer more in-line with the air-fired case. 
Table 4.13-12: Summary of Model Results for Air- And Oxy-Fired Cases With Skyline and Illinois Coals.

\begin{tabular}{|c|c|c|c|c|c|}
\hline & \multicolumn{2}{|c|}{ Skyline } & \multicolumn{3}{|c|}{ Illinois } \\
\hline & Baseline & Oxy26 & Baseline & Oxy26 & $\begin{array}{c}\text { Oxy26 } \\
\text { Low SO }\end{array}$ \\
\hline \multicolumn{6}{|l|}{ Horizontal Nose Plane } \\
\hline Temperature $\left({ }^{\circ} \mathbf{F}\right)$ & 2518 & 2582 & 2499 & 2555 & 2506 \\
\hline CO Concentration, wet (ppm) & 8,454 & 16,451 & 8,230 & 16,125 & 13,625 \\
\hline $\mathrm{O}_{2}$ Concentration, wet (\%) & $3.7 \%$ & $3.5 \%$ & $3.7 \%$ & $3.5 \%$ & $3.4 \%$ \\
\hline \multicolumn{6}{|l|}{ Vertical Exit Plane } \\
\hline Temperature ( $\left.{ }^{\circ} \mathbf{F}\right)$ & 1787 & 1765 & 1782 & 1769 & 1754 \\
\hline CO Concentration, wet (ppm) & 3,060 & 5,663 & 2,881 & 4,509 & 4,042 \\
\hline $\mathrm{O}_{2}$ Concentration, wet (\%) & $3.3 \%$ & $2.9 \%$ & $3.3 \%$ & $2.9 \%$ & $2.8 \%$ \\
\hline $\mathrm{SO}_{2}$ Concentration, wet (ppm) & 504 & 2,615 & 3,030 & 16,483 & 4,450 \\
\hline Unburned Carbon in Fly Ash & $3.6 \%$ & $2.1 \%$ & $5.8 \%$ & $3.2 \%$ & $4.2 \%$ \\
\hline Particle Burnout & $99.4 \%$ & $99.6 \%$ & $99.3 \%$ & $99.6 \%$ & $99.5 \%$ \\
\hline
\end{tabular}

A plot of average gas temperature with elevation is shown in Figure 4.13-38. Dips in temperature are seen near the burner and OFA elevations as cooler fuel and air are introduced. With both coals, the oxyfired cases show lower temperatures in the burner region compared to the air-fired cases and areas of higher temperature above the OFA ports. The removal of $\mathrm{SO}_{2}$ and water from the FGR in the oxy-fired case with Illinois coal resulted in lower temperatures throughout the furnace. 
Gas Temperature vs. Elevation

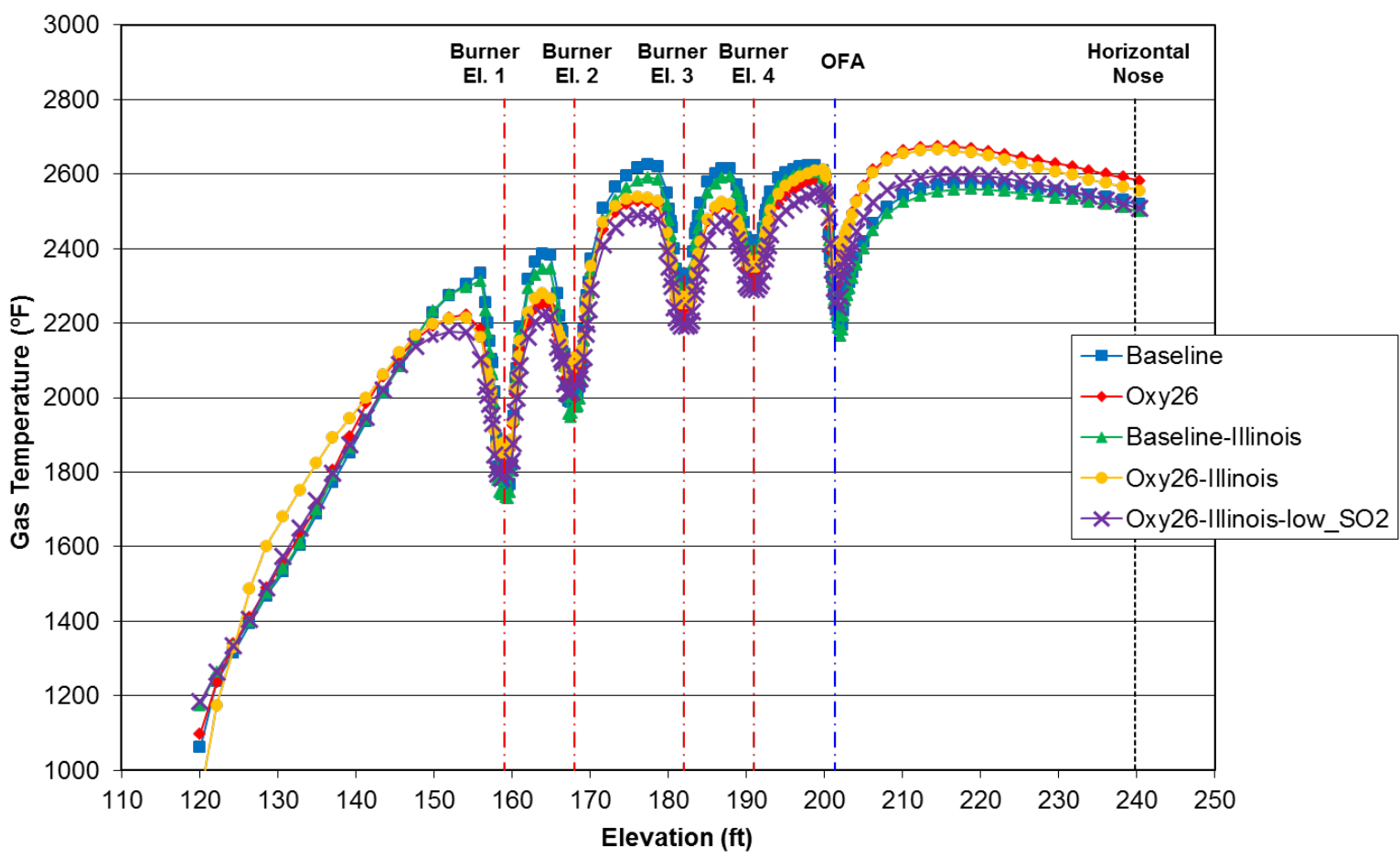

Figure 4.13-38: Model predicted gas temperature with elevation, Skyline and Illinois coal, air- and oxy-fired.

Predicted CO concentration profiles are shown in Figure 4.13-39. Peaks in CO concentration are seen at each burner elevation where fuel-rich (CO generating conditions) are present. A sharp drop in $\mathrm{CO}$ is seen at the OFA elevation where excess $\mathrm{O}_{2}$ is available to oxidize some $\mathrm{CO}$ to $\mathrm{CO}_{2}$. The Skyline oxy-fired case shows higher $\mathrm{CO}$ mass flow above burner elevation 4, but drops below the Illinois oxy-fired case by the nose elevation. All oxy-fired cases showed higher $\mathrm{CO}$ at the model exit. Cleaning the Illinois-coal derived FGR in the oxy-fired case resulted in slightly lower CO concentrations, which is probably related to the temperature. 


\section{CO Mass Flow vs. Elevation}

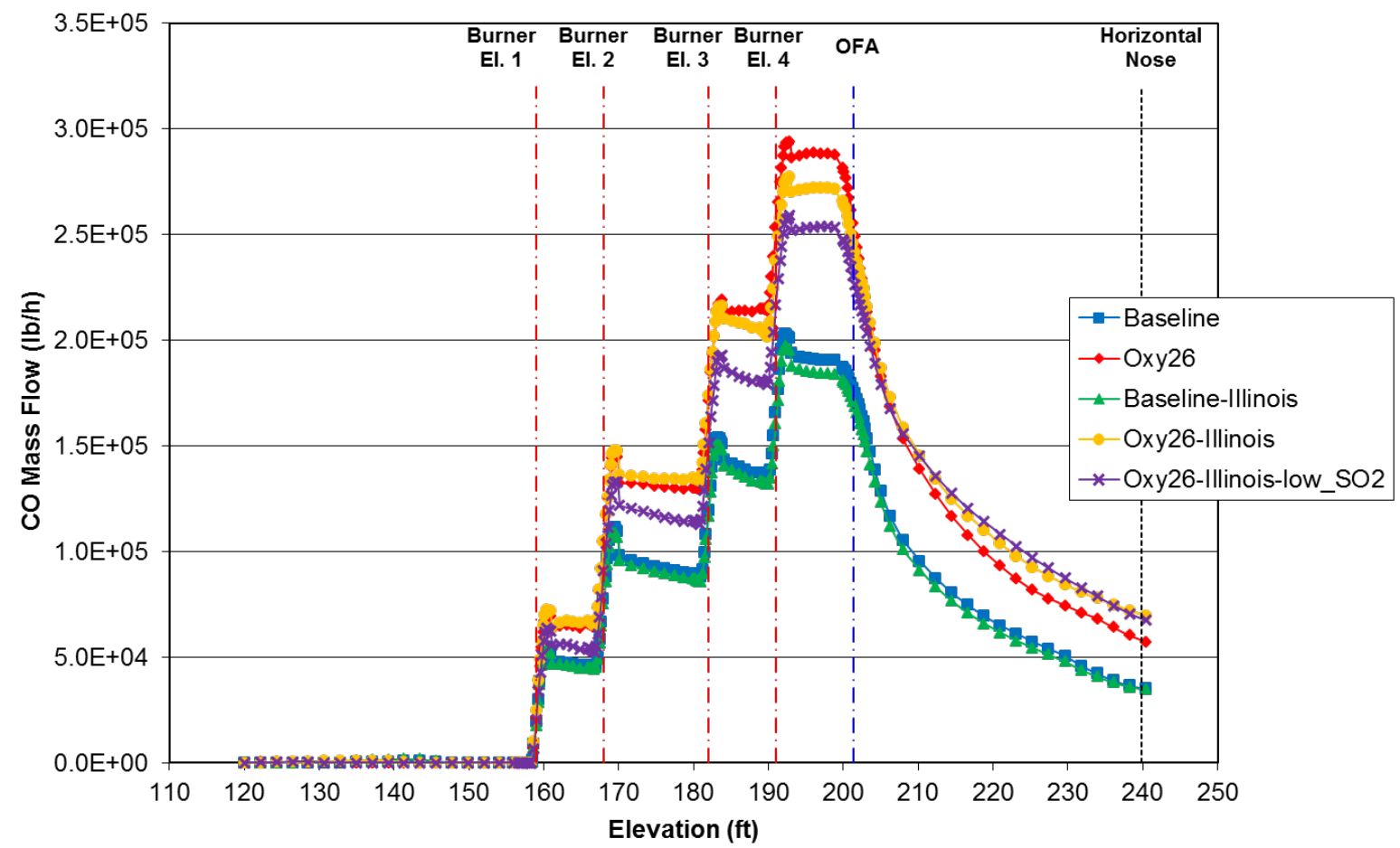

Figure 4.13-39: Model predicted CO flow with elevation, Skyline and Illinois coal, air- and oxyfired.

Predicted $\mathrm{O}_{2}$ concentration profiles are shown in Figure 4.13-40. Overall, the oxy-fired cases were run with a lower stoichiometric ratio (3.0\% dry excess $\mathrm{O}_{2}$ versus $3.3 \%$ dry excess $\mathrm{O}_{2}$ in the air-fired cases). The comparison of air- and oxy-firing is consistent for both the Skyline and Illinois coals. Results suggest slower burnout of the fuel in the oxy-fired cases, which is consistent with the temperature profiles above. The $\mathrm{O}_{2}$ concentrations do eventually drop to levels below the air-fired case resulting in lower $\mathrm{O}_{2}$ concentrations at the nose and the model exit for the oxy-fired cases. Cleaning the FGR in the Illinois oxy-fired case did not have a significant impact on $\mathrm{O}_{2}$ concentration. 


\section{O2 Concentration vs. Elevation}

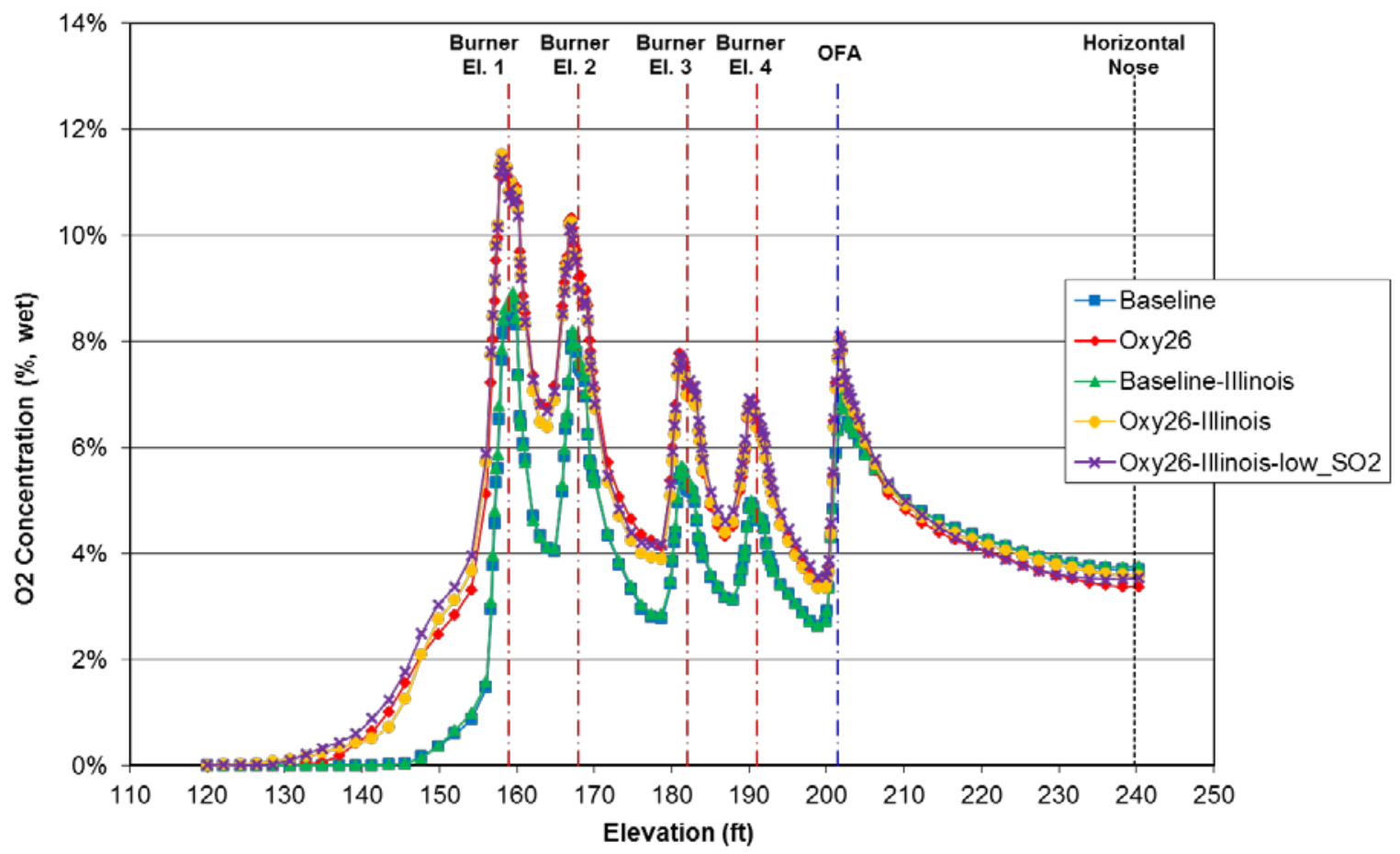

Figure 4.13-40: Model predicted $\mathrm{O}_{2}$ concentration with elevation, Skyline and Illinois coal, air- and oxy-fired.

Figure 4.13-41 shows wall deposition profiles. Consistent with the Skyline cases, for the Illinois coal, deposition was lower in the oxy-fired case (6.7\% deposition versus $9.4 \%$ for the air-fired case). $\mathrm{SO}_{2}$ removal in the Illinois oxy-fired case did not have a significant impact on deposition. The percent of coal mineral matter deposited was slightly higher with the Illinois coal compared to the Skyline coal. However, the total deposition rates were lower for the Illinois coal (Figure 4.13-42). This is a result of the lower ash content of the Illinois coal. The areas of high deposition are similar for the two coals. The areas of highest particle deposition show decreased heat flux (Figure 4.13-43). 
Skyline

Baseline

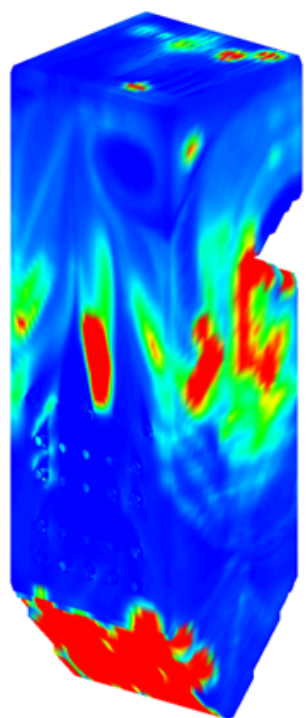

$8.1 \%$ of Coal Mineral Matter Is Deposited
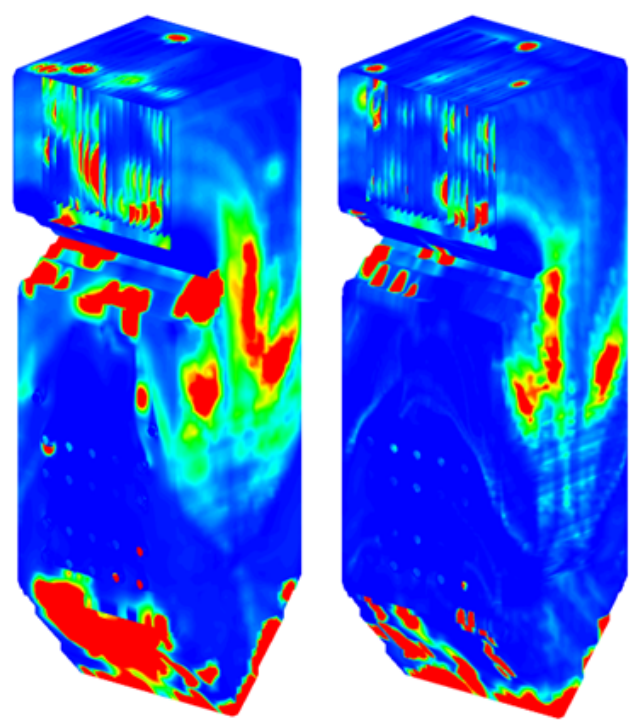

Deposition Flux (lb/tt² s)
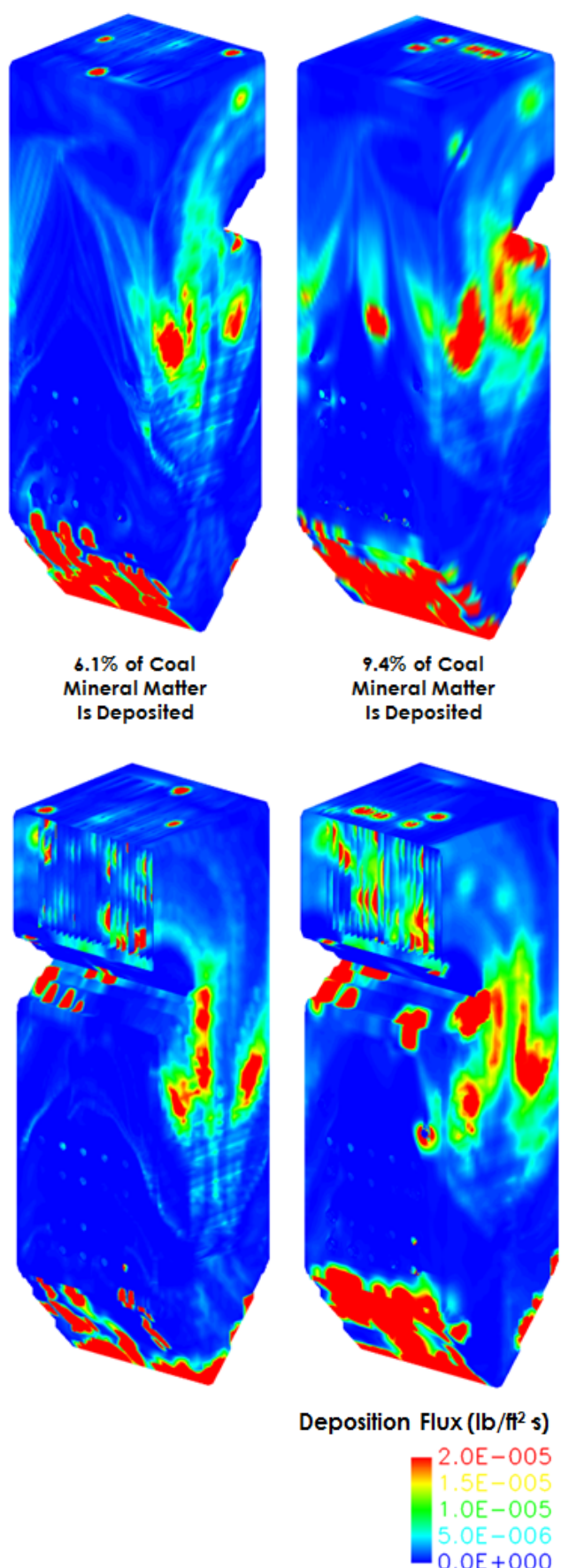

$9.4 \%$ of Coal
Mineral Matter

Is Deposited

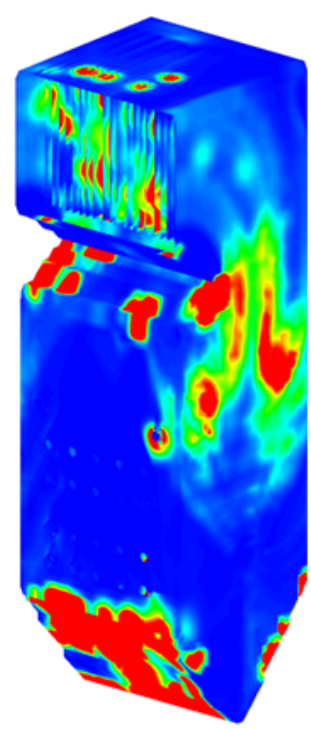

Illinois

Oxy26

Oxy26-low_SO $\mathrm{SO}_{2}$
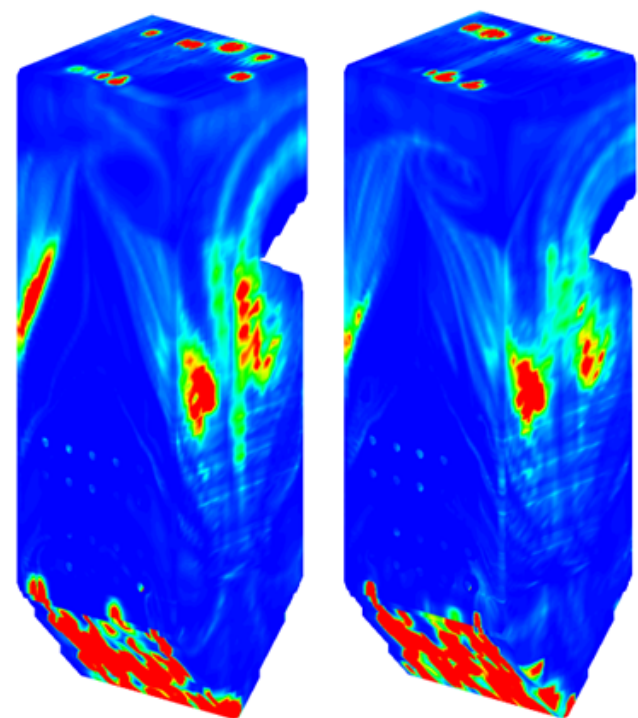

$6.7 \%$ of Coal Mineral Matter

Is Deposited

$6.7 \%$ of Coal

Mineral Matter Is Deposited
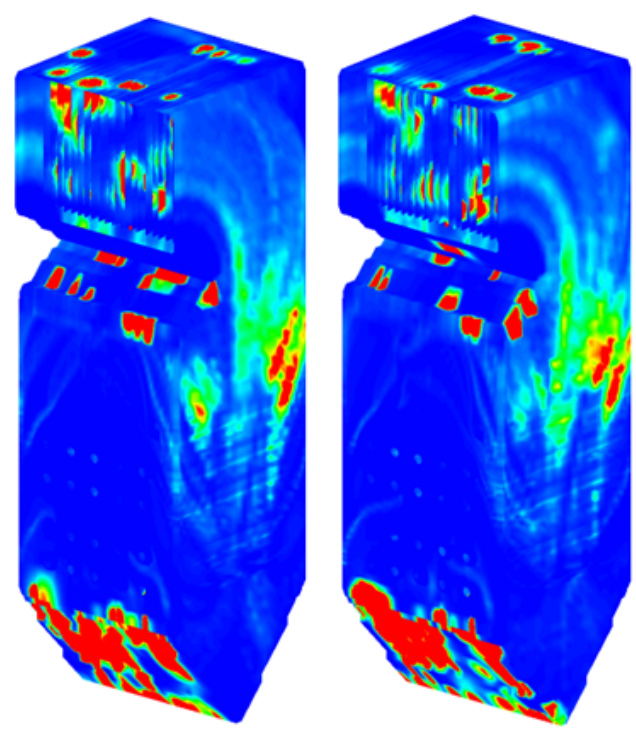

Figure 4.13-41: Model predicted particle deposition profiles, Skyline and Illinois coal, air- and oxyfired. 


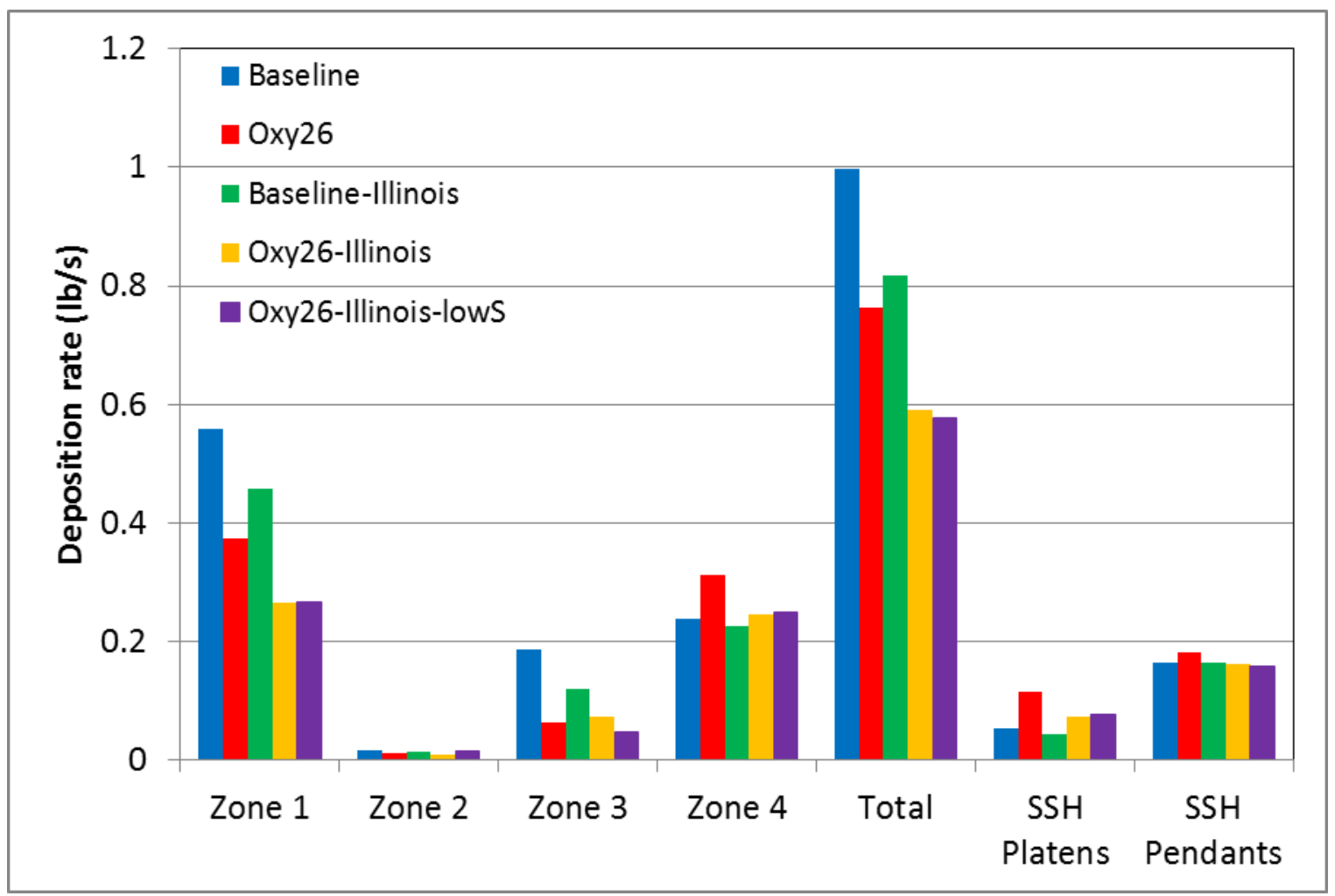

Figure 4.13-42: Deposition flux by zone, Skyline and Illinois coal, air- and oxy-fired. 
Skyline

Baseline
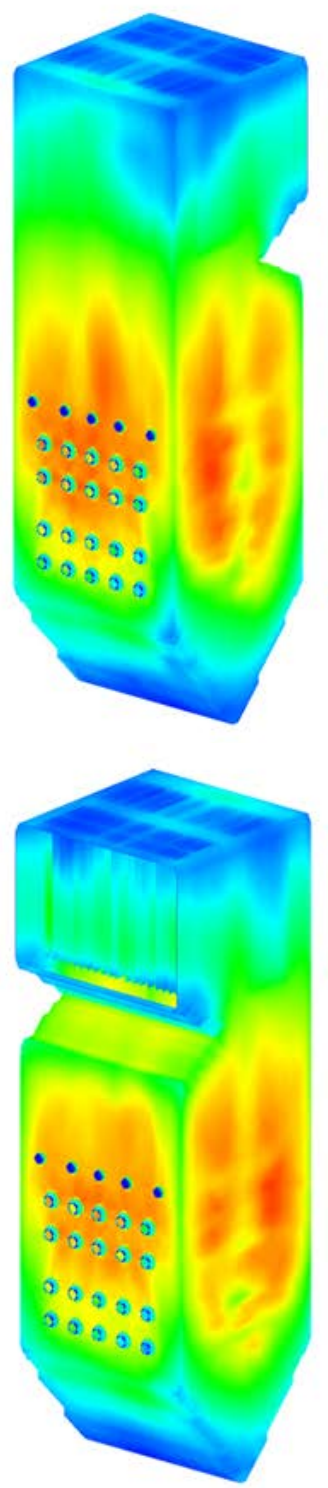

Oxy26
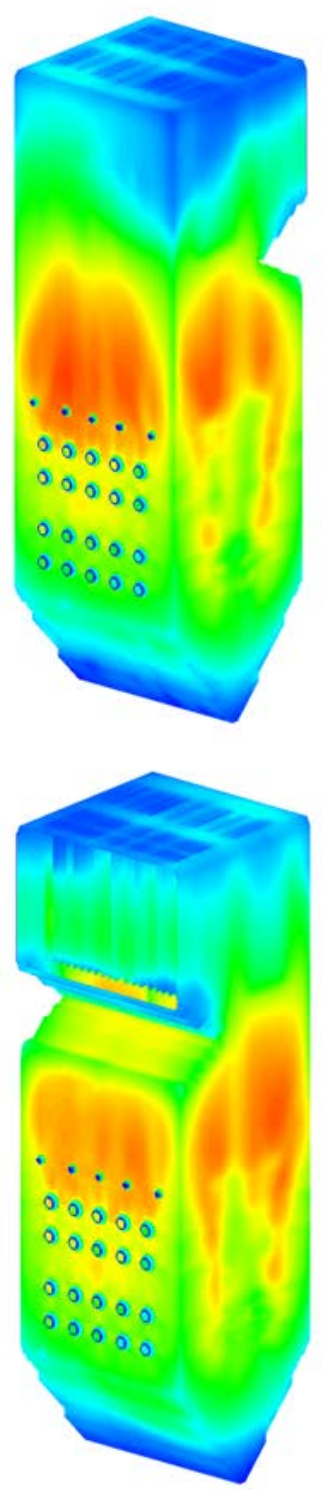

Baseline
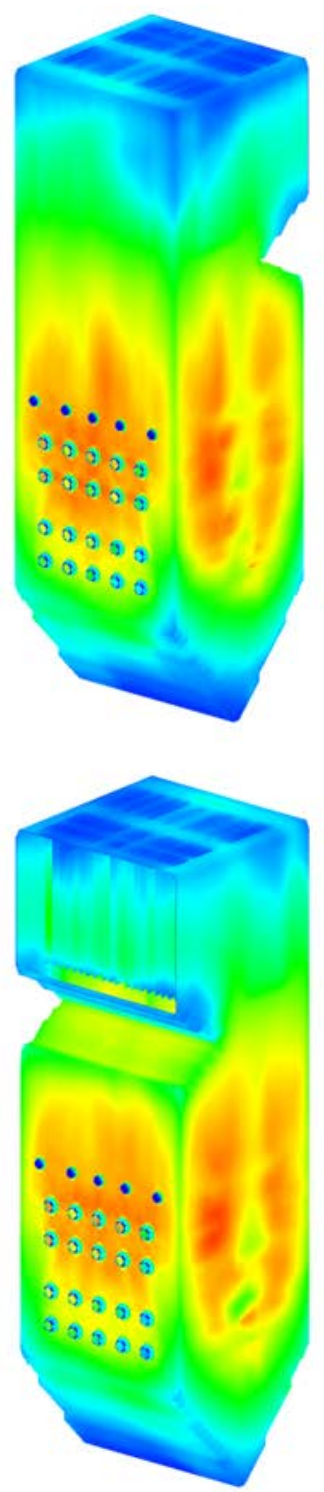

Heat Flux (Btu/hr-ft2)

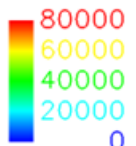

Illinois

Oxy26

Oxy26-low_SO $\mathrm{S}_{2}$
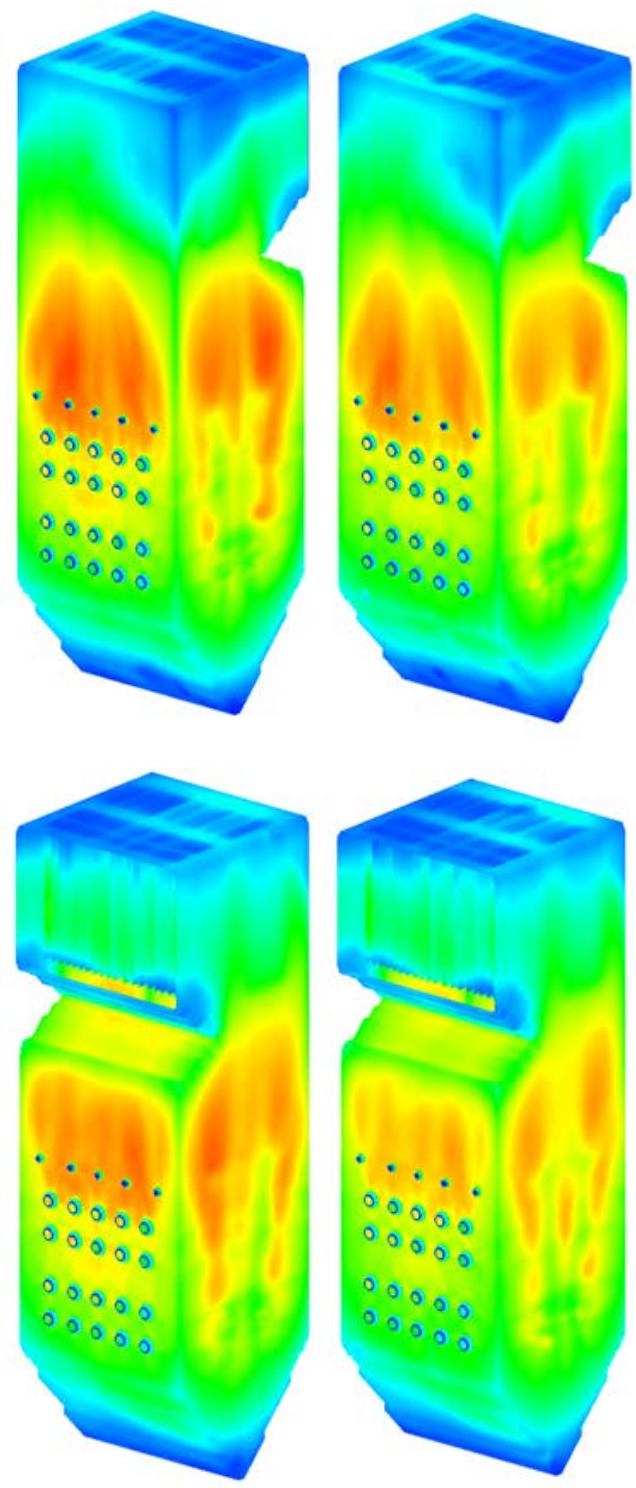

Figure 4.13-43: Model predicted net heat flux, Skyline and Illinois coal, air- and oxy-fired.

Figure 4.13-44 shows net heat flux by surface. Similar to the Skyline coal cases, the Illinois oxy-fired case shows slightly more heat transfer compared to the air-fired case (5.9\% more). The heat transfer is fairly consistent between the two coals. Removing $\mathrm{SO}_{2}$ and water from the FGR in the Illinois oxy-fired case resulted in slightly lower heat transfer, $2.4 \%$ less than the air-fired case. 


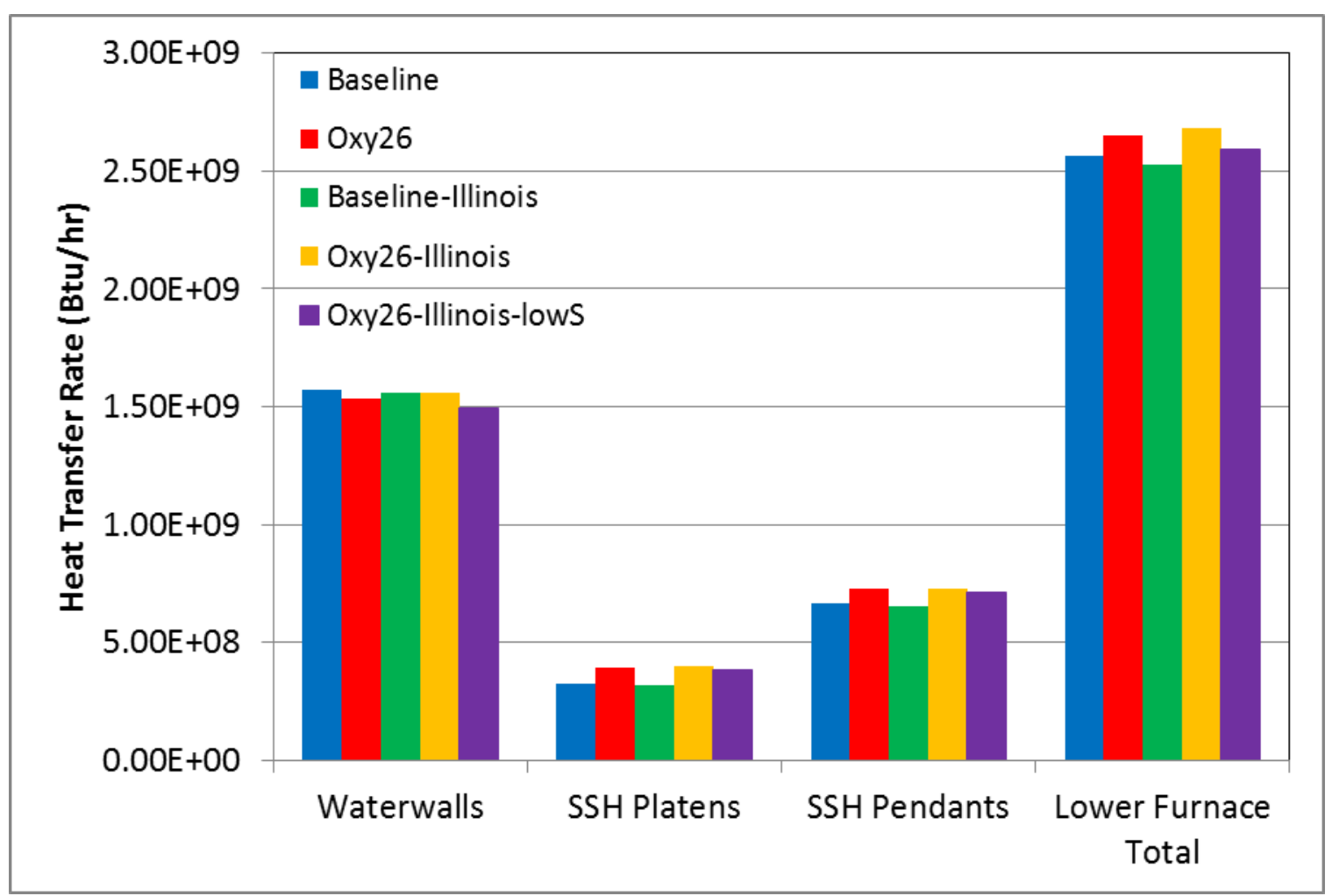

Figure 4.13-44: Net Heat flux by surface, Skyline and Illinois coal, air- and oxy-fired.

Calculations were performed with the new corrosion sub-model to determine the corrosion potential on the waterwalls and secondary superheater. Both $\mathrm{H}_{2} \mathrm{~S}$ corrosion (predominantly gas-phase attack, Figure 4.13-32) and FeS corrosion (deposition attack, Figure 4.13-46) on the waterwalls was investigated. The highest peak corrosion areas are caused by deposits (FeS corrosion). Both the air- and oxy-fired cases for both coals have regions of high deposit corrosion. The oxy-fired cases had much higher gas-phase corrosion compared to the air-fired cases and the Illinois cases have higher gas-phase corrosion than the Skyline cases. This is expected due to the much higher $\mathrm{SO}_{2}$ levels. Figure 4.13-47 shows the total predicted corrosion potential of the waterwalls up to the horizontal nose. The highest corrosion potential occurs at locations where deposits developed. These regions are similar for both coals. Also similar for both coals, oxy-firing shows higher corrosion potential. $\mathrm{SO}_{2}$ removal in the FGR for the Illinois oxy-fired case showed mitigation of corrosion potential. 
Skyline
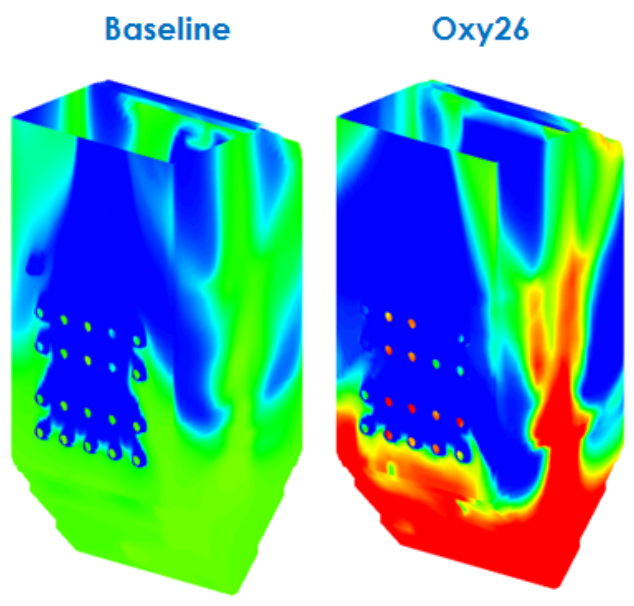

Baseline

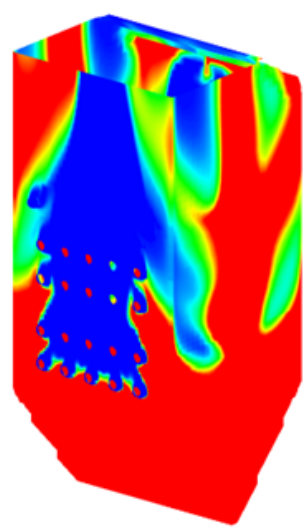

$\mathrm{H}_{2} \mathrm{~S}$ Corrosion (mils/yr)

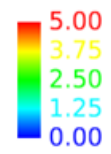

Illinois

Oxy26
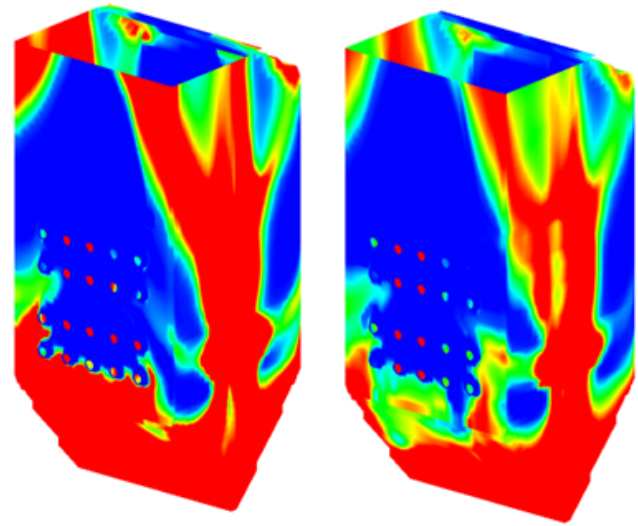

Figure 4.13-45: Model predicted $\mathrm{H}_{2} \mathrm{~S}$ corrosion of the waterwalls, Skyline and Illinois coal, air- and oxy-fired.

Skyline
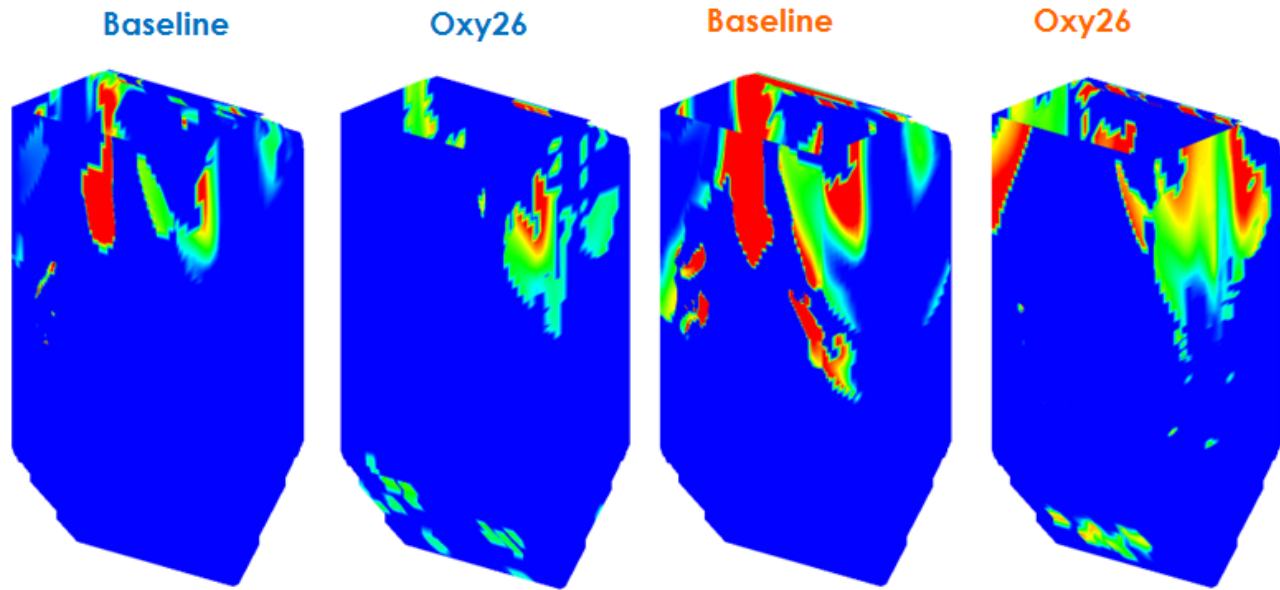

Total WW Corrosion (mils/yr)

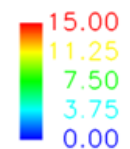

Illinois

Oxy26-low_SO 2

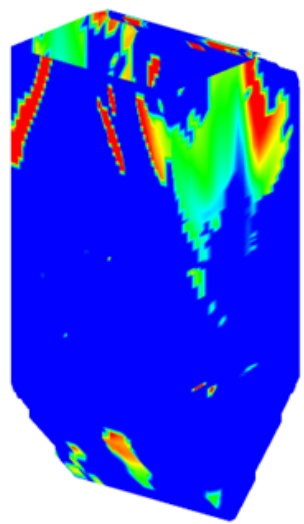

Figure 4.13-46: Model predicted FeS corrosion of the waterwalls, Skyline and Illinois coal, air- and oxy-fired. 


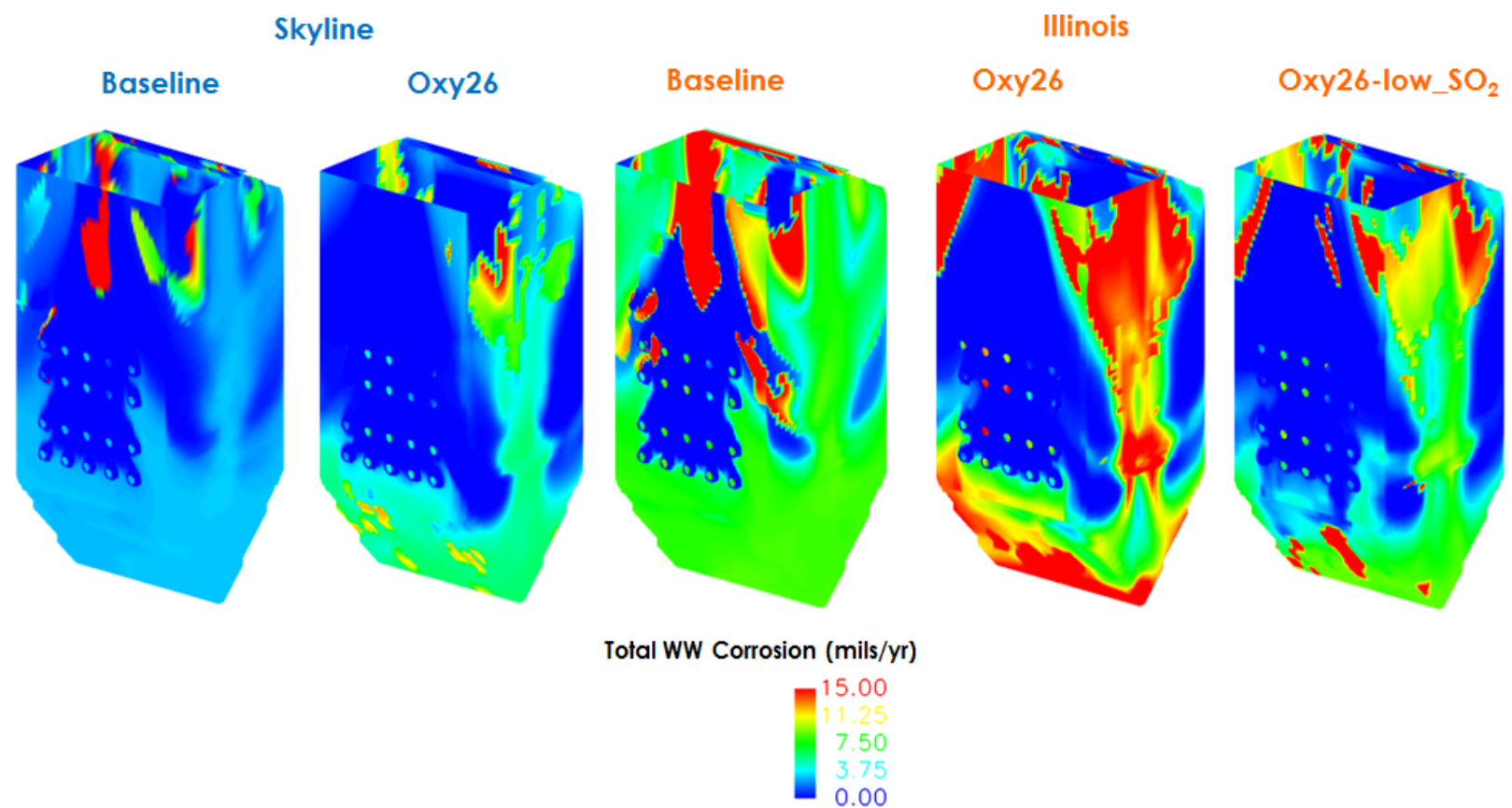

Figure 4.13-47: Model predicted total corrosion of the waterwalls, Skyline and Illinois coal, air- and oxy-fired.

Figure 4.13-48 shows the predicted secondary superheater corrosion potential. The magnitude of the corrosion potential is much smaller for this region, but the oxy-fired cases show much higher corrosion for both coals. Once again, $\mathrm{SO}_{2}$ removal in the FGR mitigates corrosion.

The total corrosion rate (given as a total material loss) for various sections of the furnace is given in Figure 4.13-49. The peak corrosion rates are shown in Figure 4.13-50. The total corrosion rates for the waterwall and superheater surfaces increased for oxy-fired cases compared to air-firing. $\mathrm{SO}_{2}$ removal in the FGR for the Illinois oxy-fired case reduced corrosion potential on all surfaces, especially the waterwalls. The total waterwall corrosion for the low $\mathrm{SO}_{2}$ oxy-fired case with Illinois coal was actually lower than the air-fired baseline. The total furnace corrosion was very similar for the Illinois air-fired and low $\mathrm{SO}_{2}$ oxy-fired cases (and also close to the Skyline oxy-fired case). Different than the Skyline coal, the peak corrosion rate on the waterwalls increased in the Illinois oxy-fired case as compared to the airfired case. With $\mathrm{SO}_{2}$ removal, the peak waterwall corrosion under oxy-firing dropped to levels below the air-fired case. Similar to the Skyline coal, for the Illinois coal, the peak corrosion potential on the superheater surfaces increased drastically in the oxy-fired case. $\mathrm{SO}_{2}$ removal helped to mitigate this sharp increase, but levels were still above both air-fired cases and the Skyline oxy-fired case. 


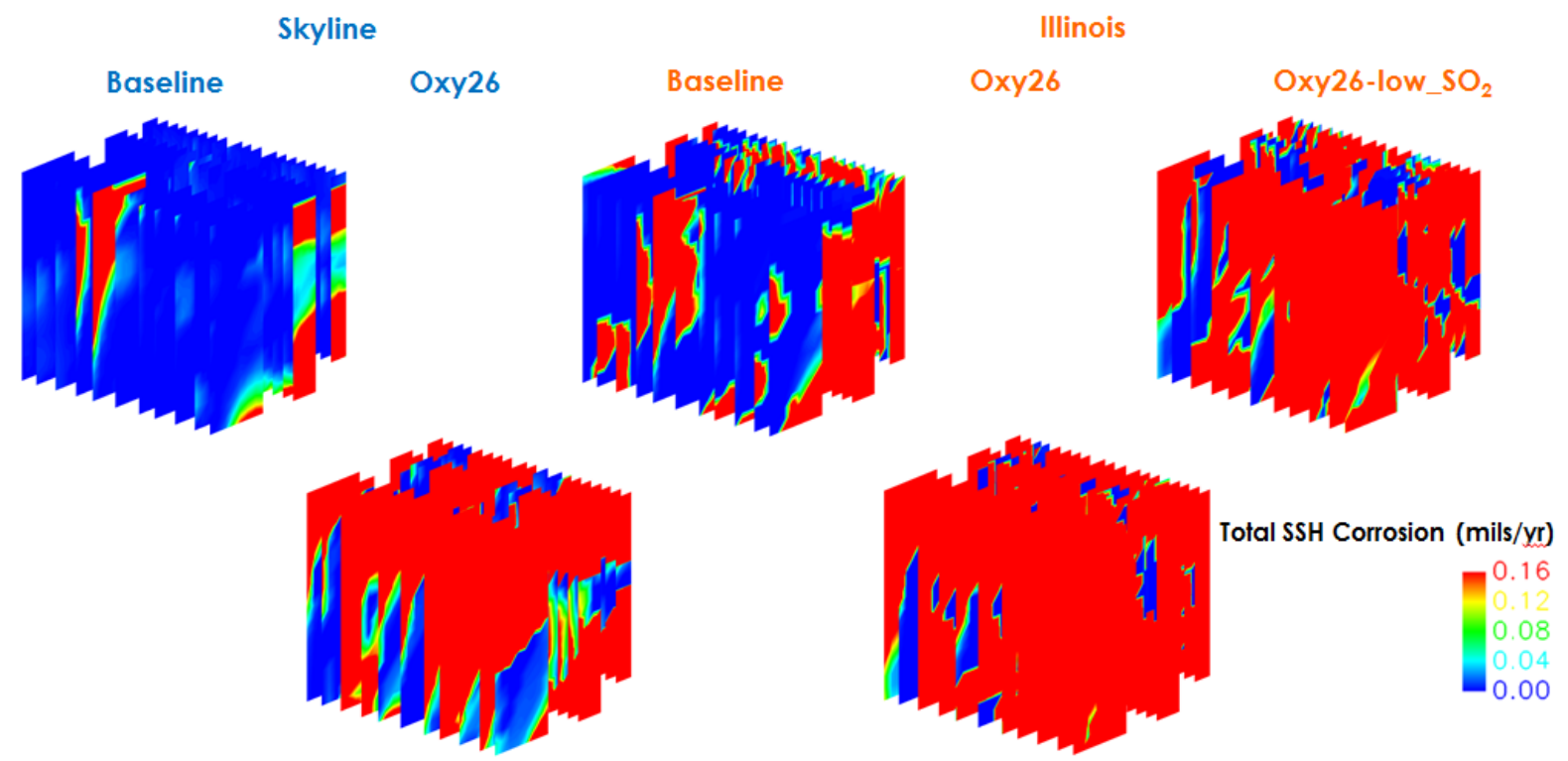

Figure 4.13-48: Model predicted total corrosion of the secondary superheater, Skyline and Illinois coal, air- and oxy-fired.

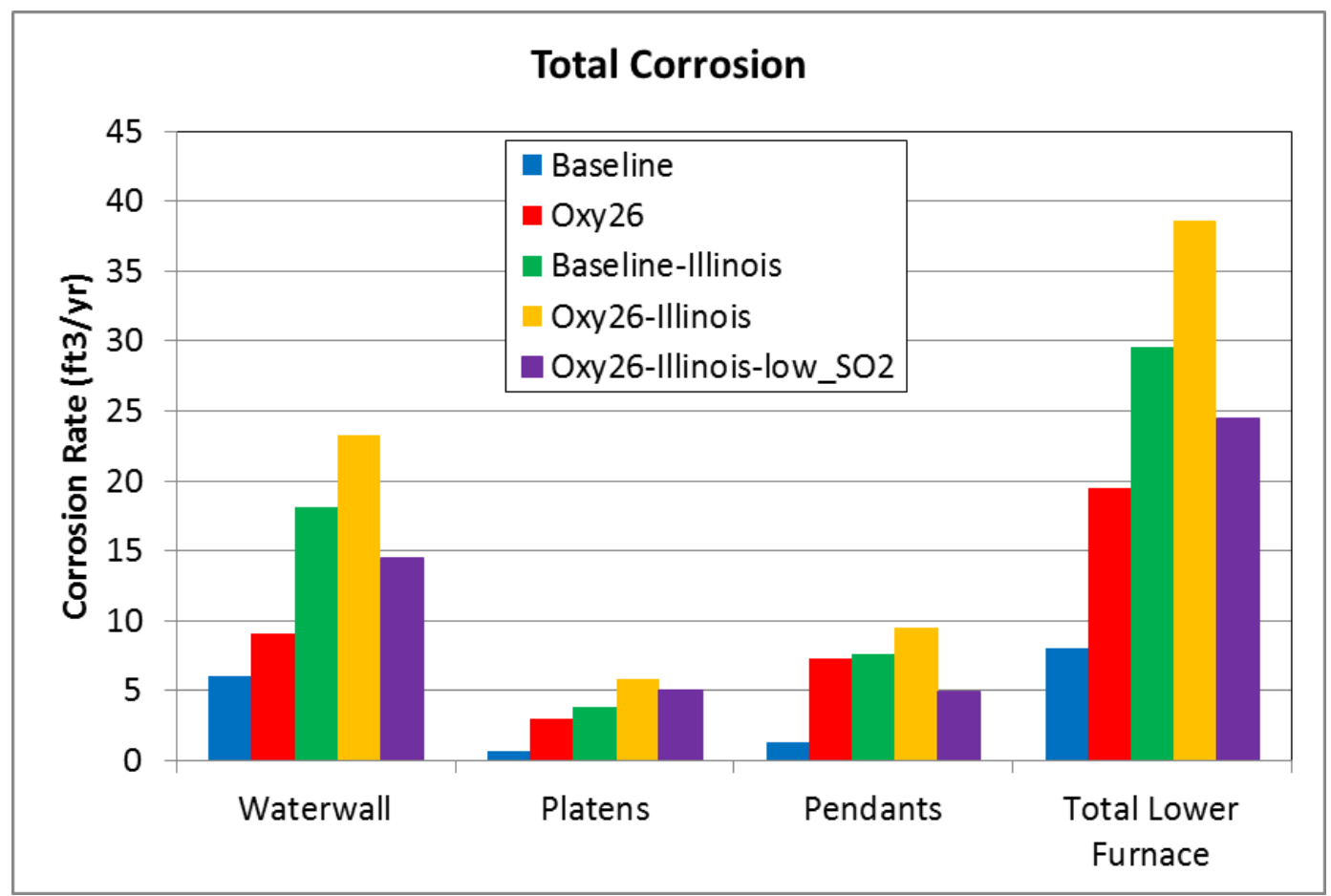

Figure 4.13-49: Model predicted total corrosion rate by furnace section (given as total material loss), Skyline and Illinois coal, air- and oxy-fired. 


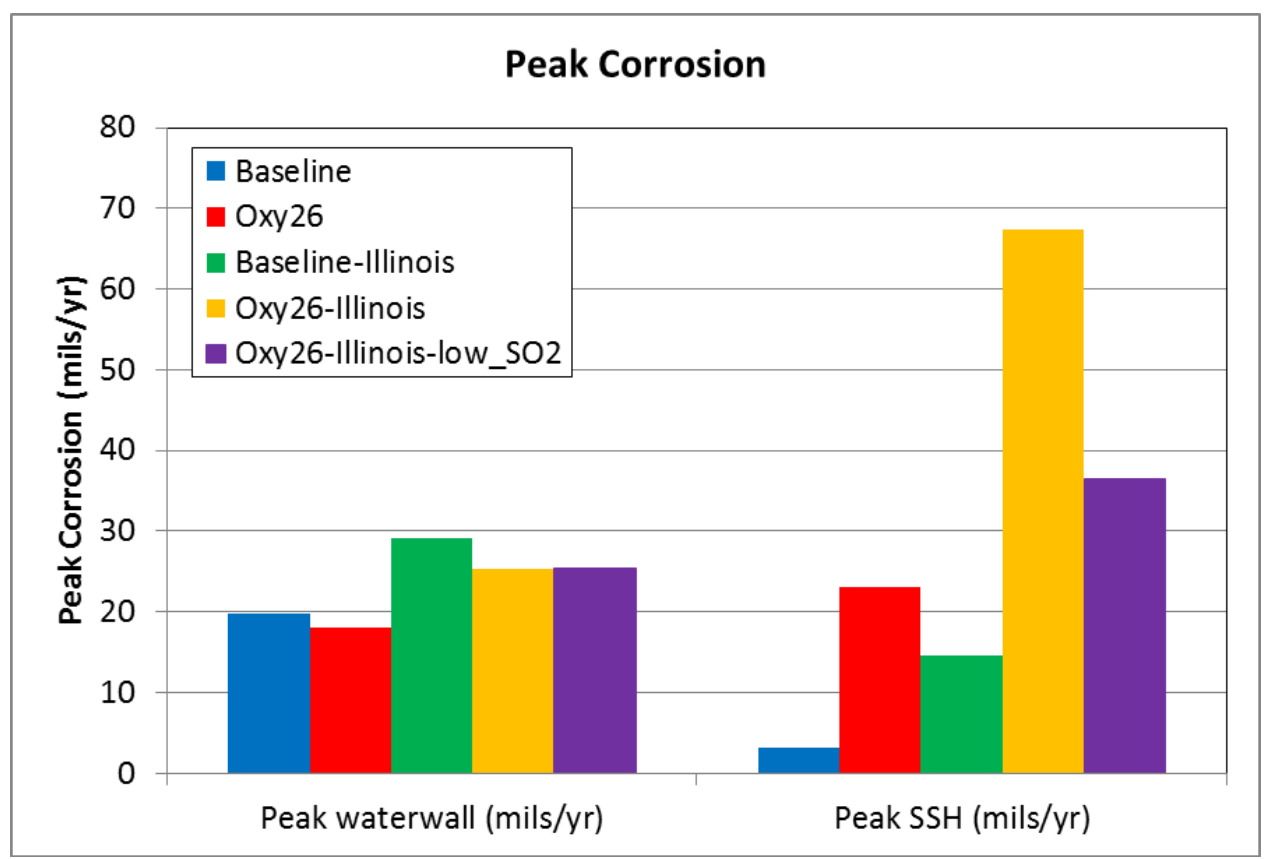

Figure 4.13-50: Model predicted peak corrosion rate by furnace section, Skyline and Illinois coal, air- and oxy-fired.

Variations in flue gas were investigated by modeling an Illinois high sulfur coal. Trends in flue gas temperature, $\mathrm{O}_{2}$ concentration, $\mathrm{CO}$ concentration, and UBC between air-and oxy-fired conditions were the same for both coals. Heat transfer was very similar to the Skyline air- and oxy-fired cases. In comparing corrosion potential between the two coals:

- The same trend of increased total corrosion rate under oxy-firing was observed for both coals

- Consistent with pilot-scale data:

- Peak waterwall corrosion decreased under oxy-fired conditions for the Skyline coal

- Peak SSH corrosion increased under oxy-fired conditions for both coals

- Peak SSH corrosion under oxy-firing conditions with the Illinois coal was extremely high.

This modeling investigation suggests flue gas treatment prior to recycle will be necessary for high sulfur coals. Simulating sulfur removal (FGR conditions approximate to what might exit a wet FGD) showed mitigation of the effects of a high sulfur coal.

\subsubsection{CFD Modeling Results - Backpass}

The results from the lower furnace air and oxy cases while firing Utah Skyline coal were used as inputs to a backpass CFD model. A diagram of the modeled backpass geometry is shown in Figure 4.13-51. Three separate heat transfer surfaces were modeled as shown in Figure 4.13-52: reheat, primary superheat, and economizer. The approach for modeling the backpass involved mapping results from the lower furnace exit plane into the upper furnace model inlet (as shown in Figure 4.13-53) and matching the heat absorption to each section of the convective pass for the air case using existing steam-side data (Table 4.13-13) by adjusting the wall boundary conditions. The convective pass model of the oxy combustion case used the same boundary conditions as the air case and was purely predictive. A non-equilibrium CO oxidation model was used to predict $\mathrm{CO}$ and $\mathrm{O}_{2}$ concentrations through the convective pass. 


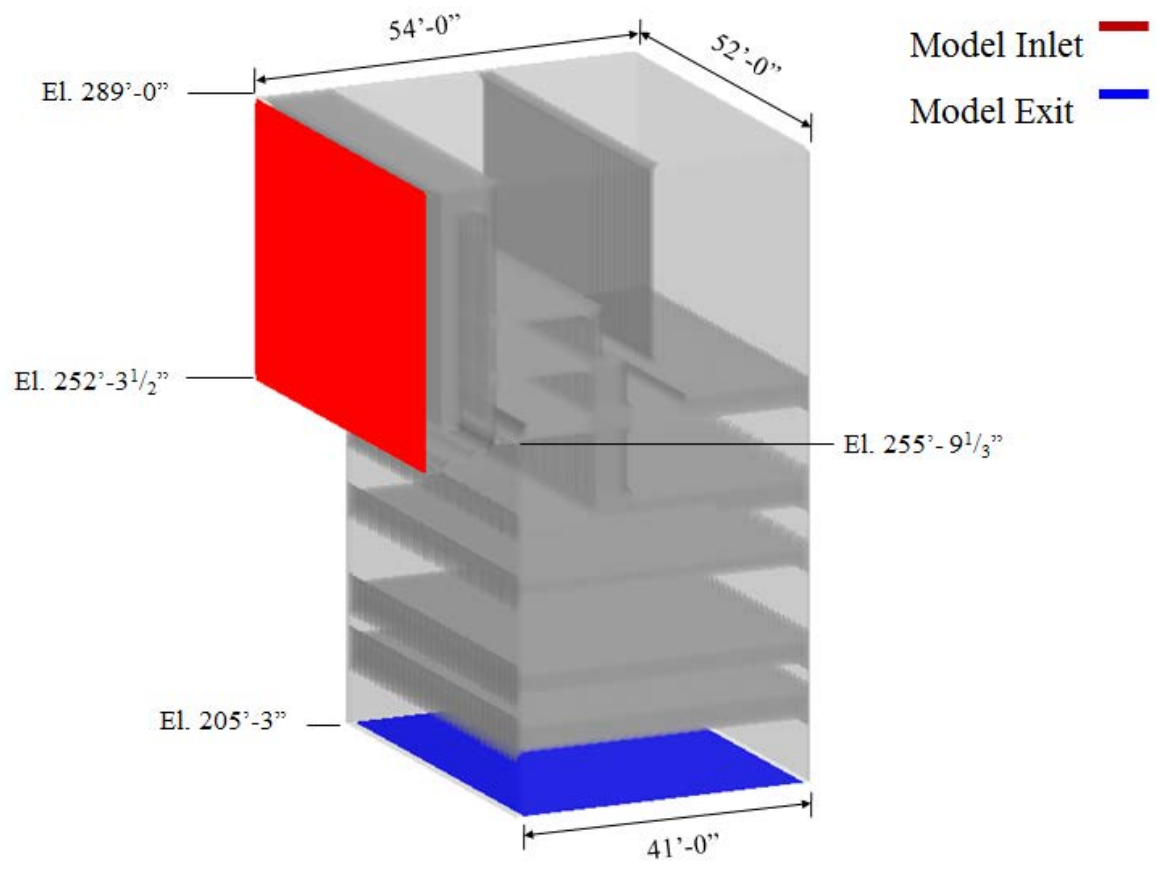

Figure 4.13-51: Hunter Unit 3 modeled backpass geometry.

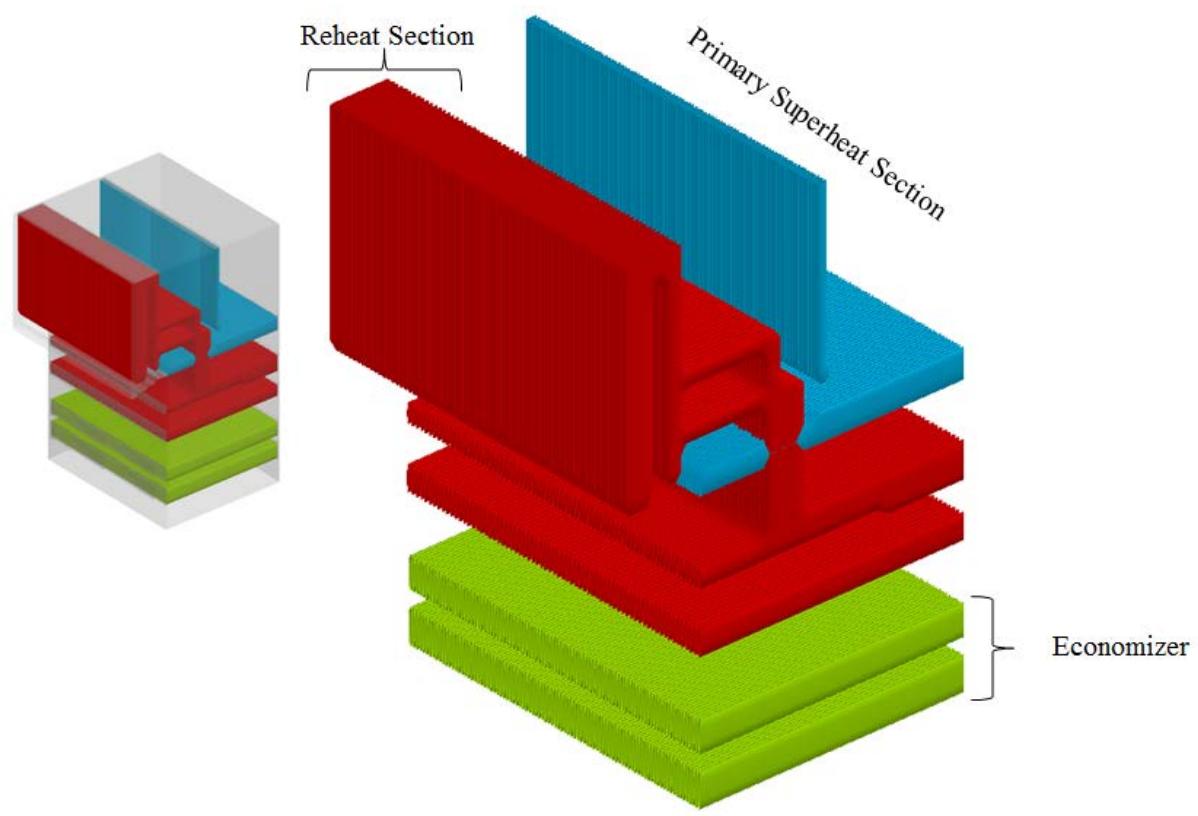

Figure 4.13-52: Convective sections in model. 

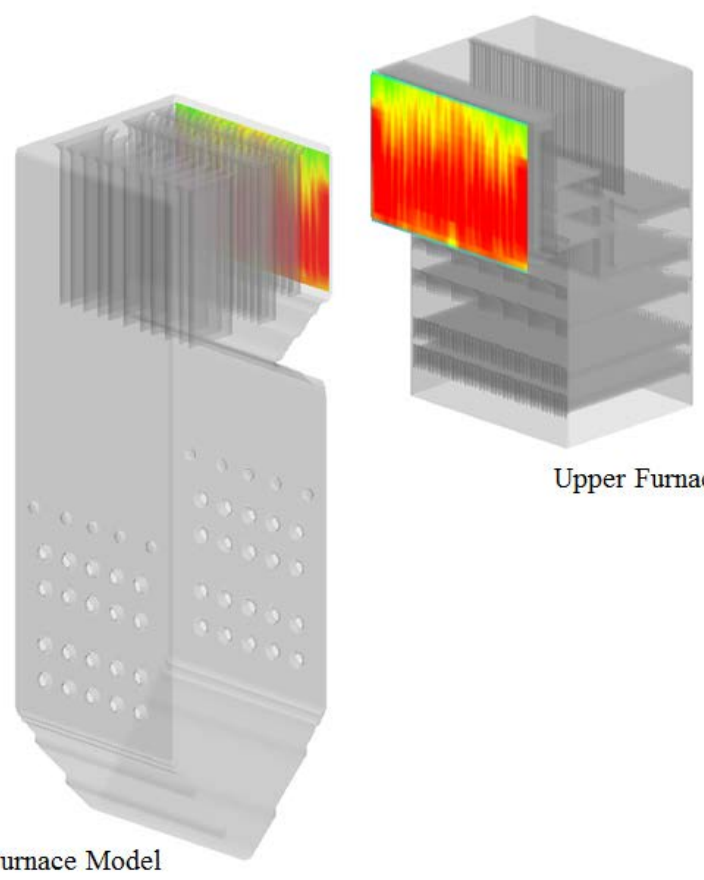

Upper Furnace Model

Lower Furnace Model

Figure 4.13-53: Mapping of lower furnace exit plane to inlet of backpass model.

Table 4.13-13: Steam Side Data Used to Match Predicted Heat Transfer in the Air Backpass Model.

\begin{tabular}{|c|c|}
\hline \multicolumn{2}{|c|}{ Reheat } \\
\hline Steam Temperature In $\left({ }^{\circ} \mathrm{F}\right)$ & Steam Temperature Out $\left({ }^{\circ} \mathrm{F}\right)$ \\
\hline 633.0 & 1000.0 \\
\hline Pressure In (psia) & Pressure Out (psia) \\
\hline 584 & 565 \\
\hline Steam Mass Flow (Mlb/h) & Total Heat Gained by Steam (MBtu/h) \\
\hline 3.096 & 641.2 \\
\hline \multicolumn{2}{|c|}{ Primary Superheat } \\
\hline Steam Temperature In $\left({ }^{\circ} \mathrm{F}\right)$ & Steam Temperature Out $\left({ }^{\circ} \mathrm{F}\right)$ \\
\hline 680.0 & 733.0 \\
\hline Pressure In (psia) & Pressure Out (psia) \\
\hline 2665 & 2658 \\
\hline Steam Mass Flow (Mlb/h) & Total Heat Gained by Steam (MBtu/h) \\
\hline 3.096 & 461.2 \\
\hline \multicolumn{2}{|r|}{ Economizer } \\
\hline Water Temperature In $\left({ }^{\circ} \mathrm{F}\right)$ & Water Temperature Out $\left({ }^{\circ} \mathrm{F}\right)$ \\
\hline 490.0 & 578.0 \\
\hline Pressure In (psia) & Pressure Out (psia) \\
\hline 2710 & 2695 \\
\hline Water Mass Flow (Mlb/h) & Total Heat Gained by Water (MBtu/h) \\
\hline 3.096 & 341.1 \\
\hline
\end{tabular}


The backpass model was run for the Skyline coal air- and oxy-fired cases without the slagging sub-model. The overall backpass model results are shown in Table 4.13-14. Comparing the heat transfer calculated from steam side data (Table 4.13-13) and the air-fired model predictions, convective surface heat transfer is within 1\%. Switching to oxy-firing with an FGR recycle rate producing $26 \% \mathrm{O}_{2}$ (wet) in the $\mathrm{O}_{2} /$ FGR mixture reduces heat transfer by $6.5 \%$ as seen in Figure 4.13-54. From the process model results the heat transfer is expected to increase with increased FGR and the overall heat transfer is expected to be finetuned by slightly adjusting the FGR rate.

Table 4.13-14: Overall CFD Model Results for Backpass Cases, Skyline Coal, Air- and Oxy-Fired.

\begin{tabular}{|l|c|c|}
\hline & Baseline & Oxy26 \\
\hline Model Inlet & & 1765 \\
\hline Temperature ( $\left.{ }^{\circ} \mathrm{F}\right)$ & 1787 & 5663 \\
\hline CO Concentration (ppm, wet) & 3060 & 2.9 \\
\hline $\mathrm{O}_{2}$ Concentration (\%, wet) & 3.3 & \\
\hline Model Outlet & & 625 \\
\hline Temperature ( $\left.{ }^{\circ} \mathrm{F}\right)$ & 672 & 1580 \\
\hline CO Concentration (ppm, wet) & 885 & 2.5 \\
\hline $\mathrm{O}_{2}$ Concentration (\%, wet) & 3.2 & \\
\hline Convective Surfaces $^{\circ}$ & & $6.07 \mathrm{E}+08$ \\
\hline Reheat (Btu/hr) & $6.46 \mathrm{E}+08$ & $4.35 \mathrm{E}+08$ \\
\hline Primary Superheat (Btu/hr) & $4.61 \mathrm{E}+08$ & $3.12 \mathrm{E}+08$ \\
\hline Economizer (Btu/hr) & $3.41 \mathrm{E}+08$ & \\
\hline
\end{tabular}

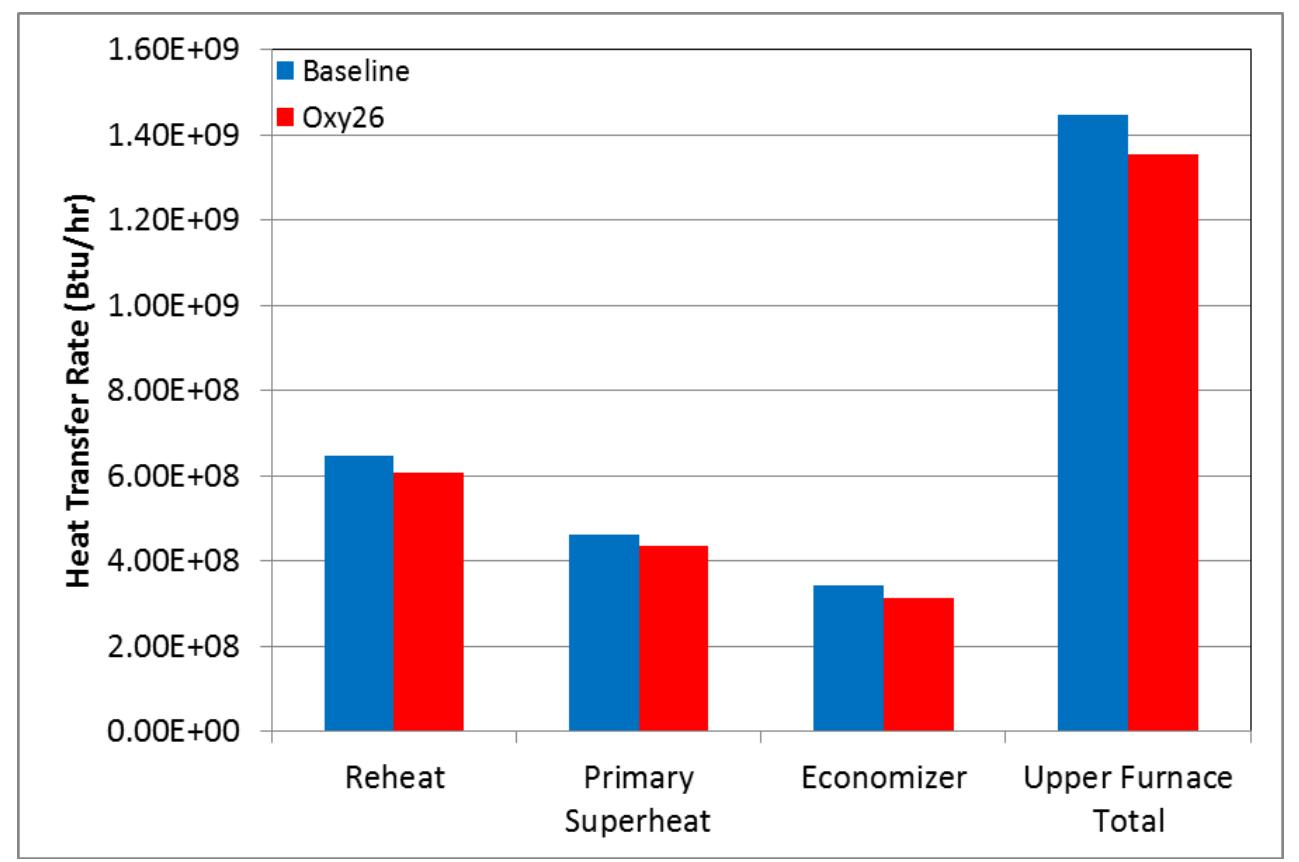

Figure 4.13-54: Backpass heat transfer for air- and oxy-fired cases. 
To aid in visualization, the convective surfaces will not be shown in the plots of model predictions. The locations of the visualization planes in reference to the convective surfaces are shown in Figure 4.13-55.

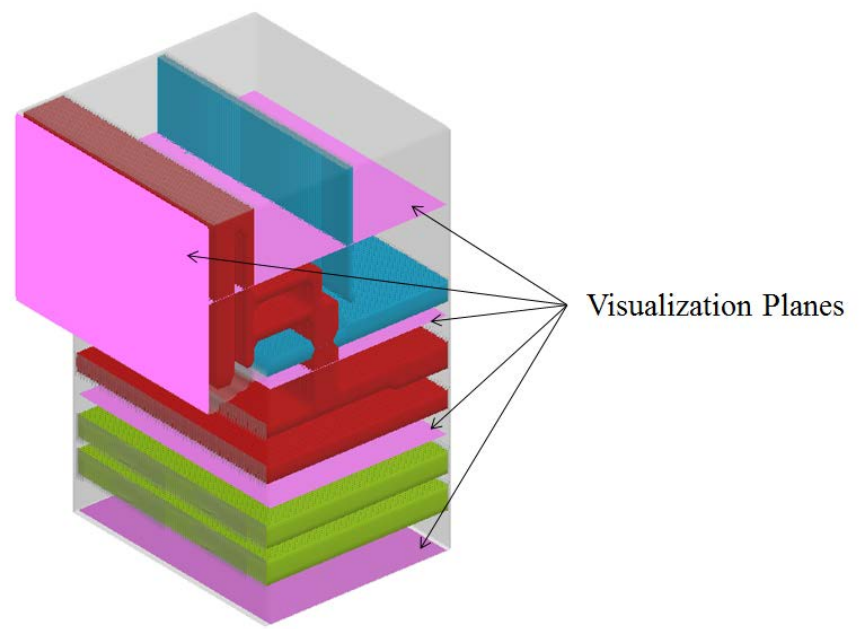

Figure 4.13-55: Location of visualization places for model prediction plots in reference to convective sections.

Plots of gas temperature, $\mathrm{O}_{2}$, and $\mathrm{CO}$ in the backpass are shown in Figure 4.13-56, Figure 4.13-57, and Figure 4.13-58 respectively. Gas temperature decreases quickly. The backpass inlet temperature is slightly higher for the air-fired case, which results in a higher backpass exit temperature as well. The $\mathrm{O}_{2}$ plots show higher concentrations along the centerline of the gas flow, which is more pronounced in the oxy-fired case. The overall $\mathrm{O}_{2}$ concentration doesn't change much in the air-fired case (3.3\% wet at model inlet and 3.2\% wet at outlet), while the change in the oxy-fired case is larger (2.9\% wet at model inlet and $2.5 \%$ wet at outlet) due to CO burnout. CO is concentrated along the right and left walls for both cases. In the air-fired case, the near wall CO concentration stays above 5000 ppm throughout the backpass, while in the oxy-fired case the near wall CO drops below $5000 \mathrm{ppm}$ by the backpass exit. The oxy-fired backpass inlet CO concentration is higher than the air-fired case, as is the backpass outlet. At the outlet, the air-fired case still has regions with CO concentrations of 0 and $>5000 \mathrm{ppm}$, while the oxyfired case is more evenly distributed. 


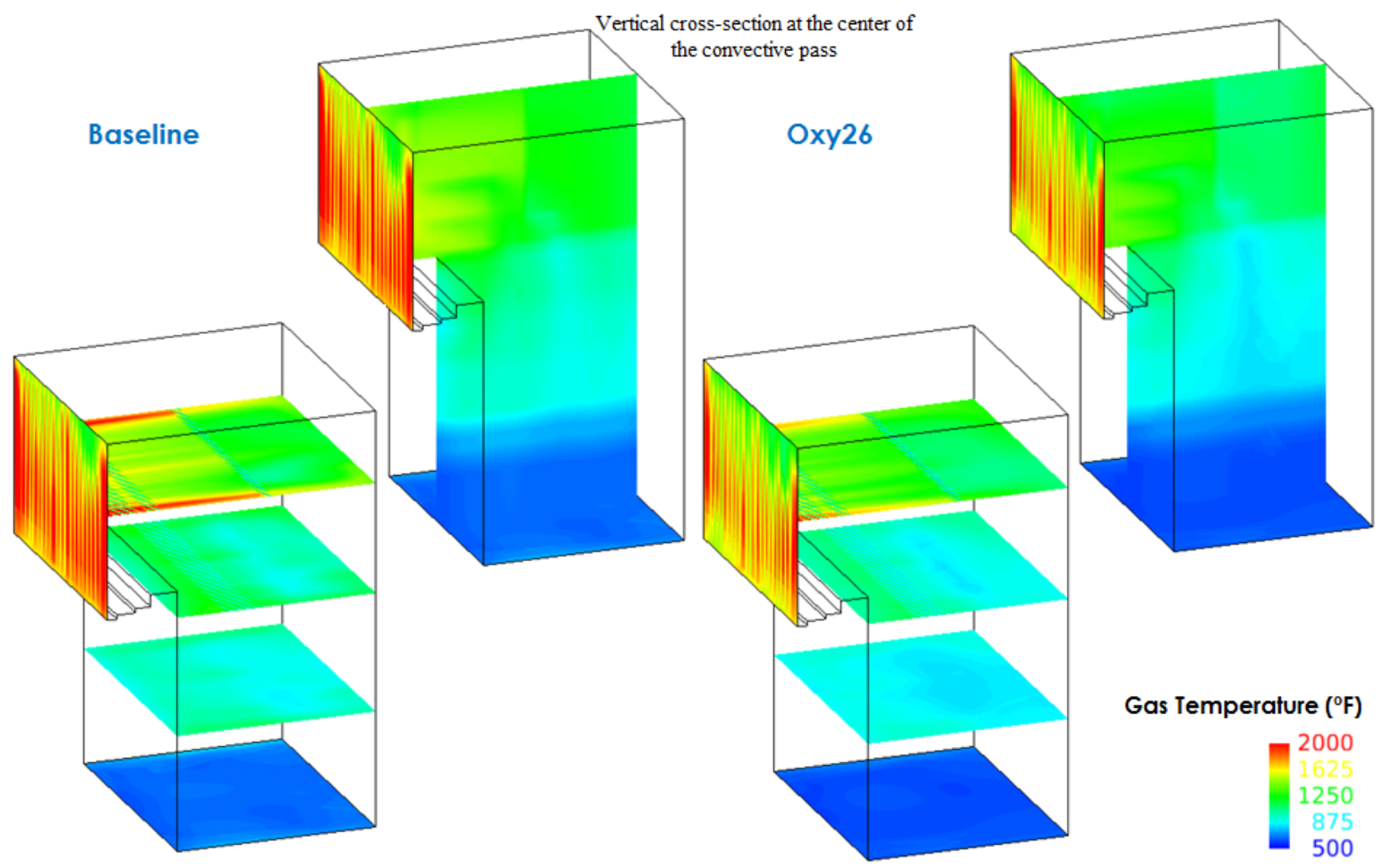

Figure 4.13-56: Model predicted gas temperature profiles in the backpass.

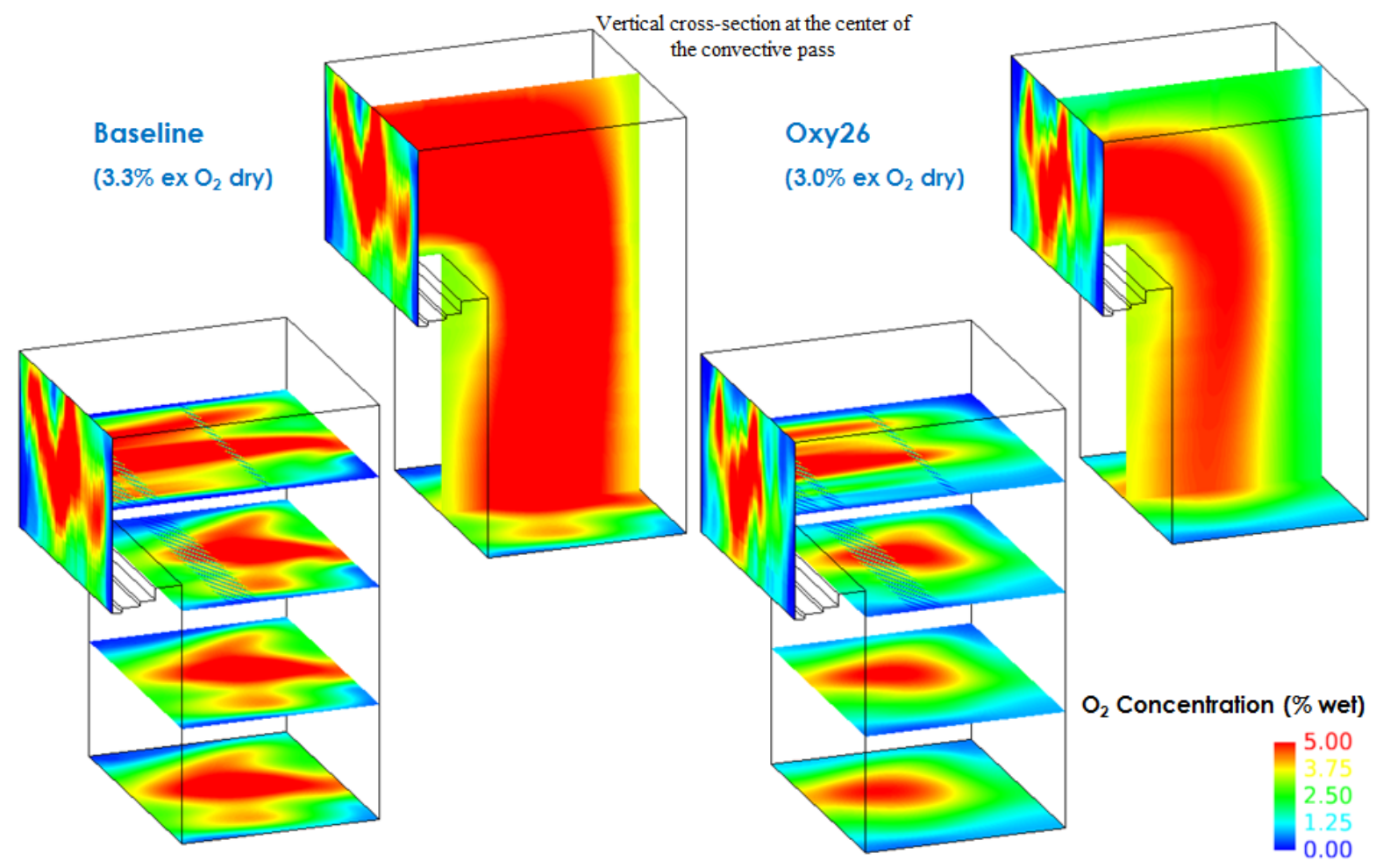

Figure 4.13-57: Model predicted $\mathrm{O}_{2}$ concentration profiles in the backpass. 


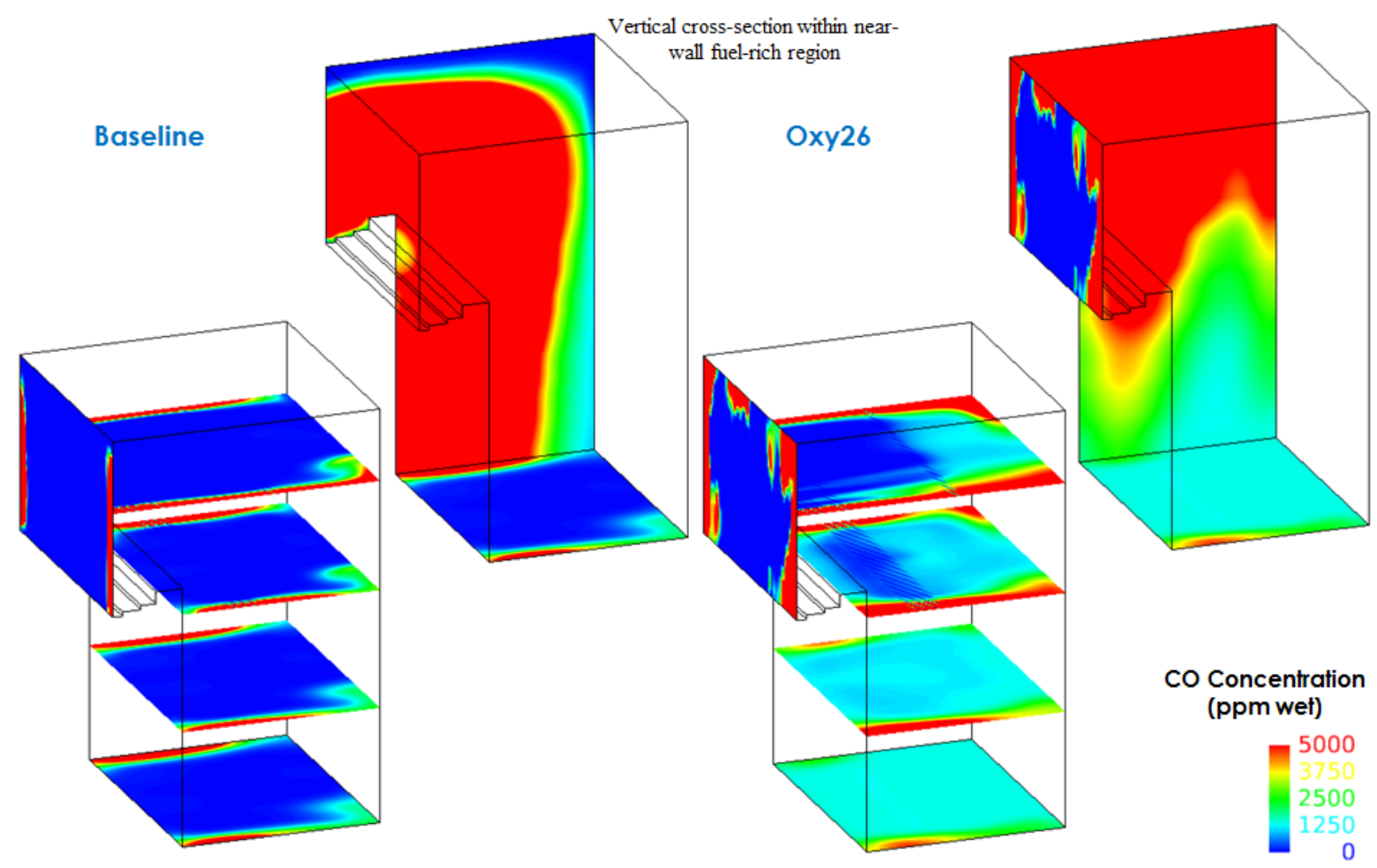

Figure 4.13-58: Model predicted CO concentration profiles in the backpass.

The model predicted wall temperature in the backpass is shown in Figure 4.13-59. The outer walls at the backpass entrance are the hottest. The reheater surfaces are warmer than the primary superheater and the economizer as per steam side data. Figure 4.13-60 shows the model predicted heat flux to the surfaces. The maximum heat flux to the convective surfaces is highest along the leading edge of the surface as expected (highest gas temperature). The oxy-fired case shows slightly decreased heat transfer as discussed above. Figure 4.13-61 shows particle deposition of the surfaces of the backpass. The highest deposition rates occur on the vertical reheater tubes as they are the first to interact with the flue gas steam in the backpass. The oxy-fired case shows approximately $23 \%$ less deposition than the air-fired case. 


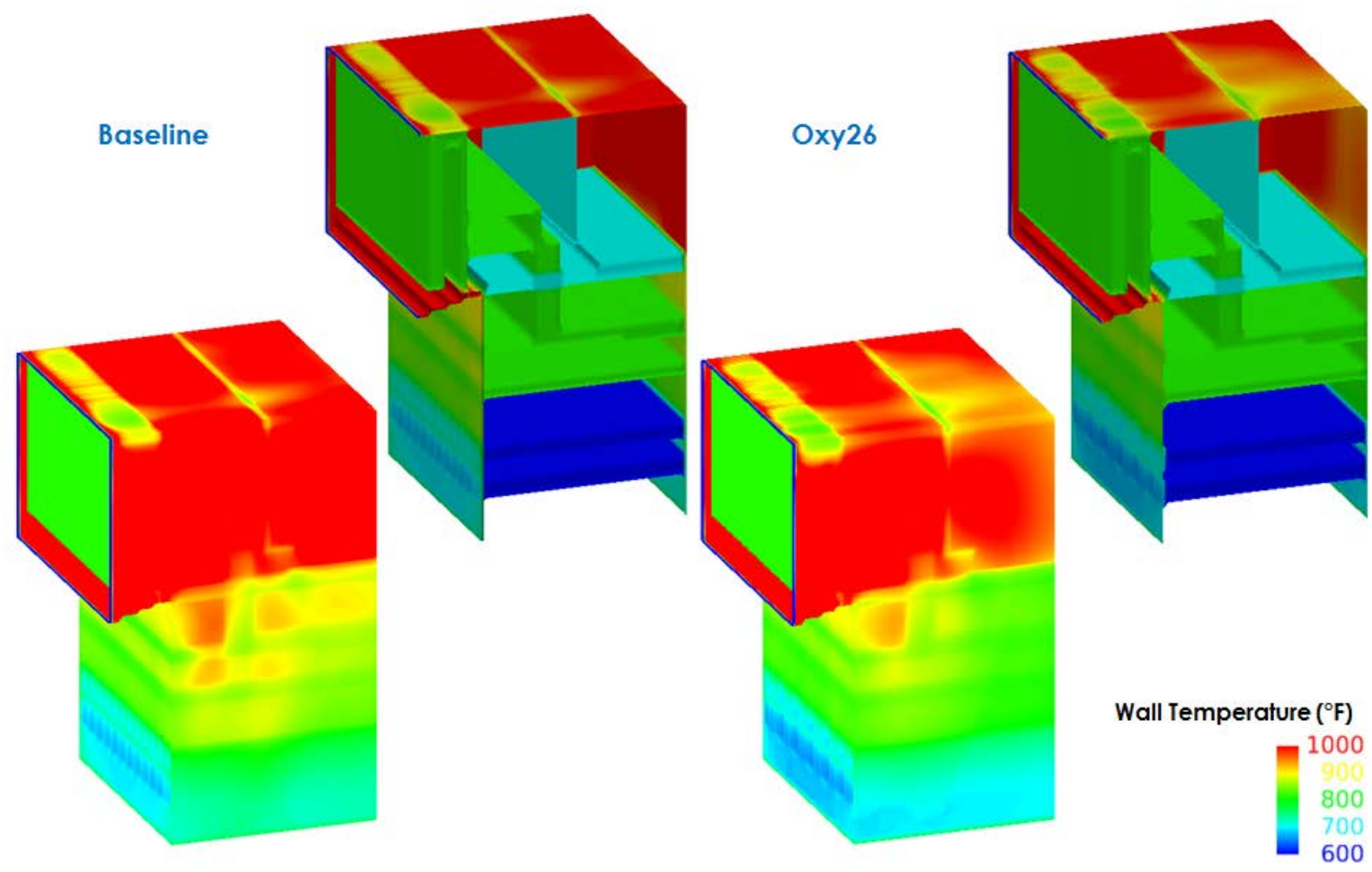

Figure 4.13-59: Model predicted wall temperature in the backpass.
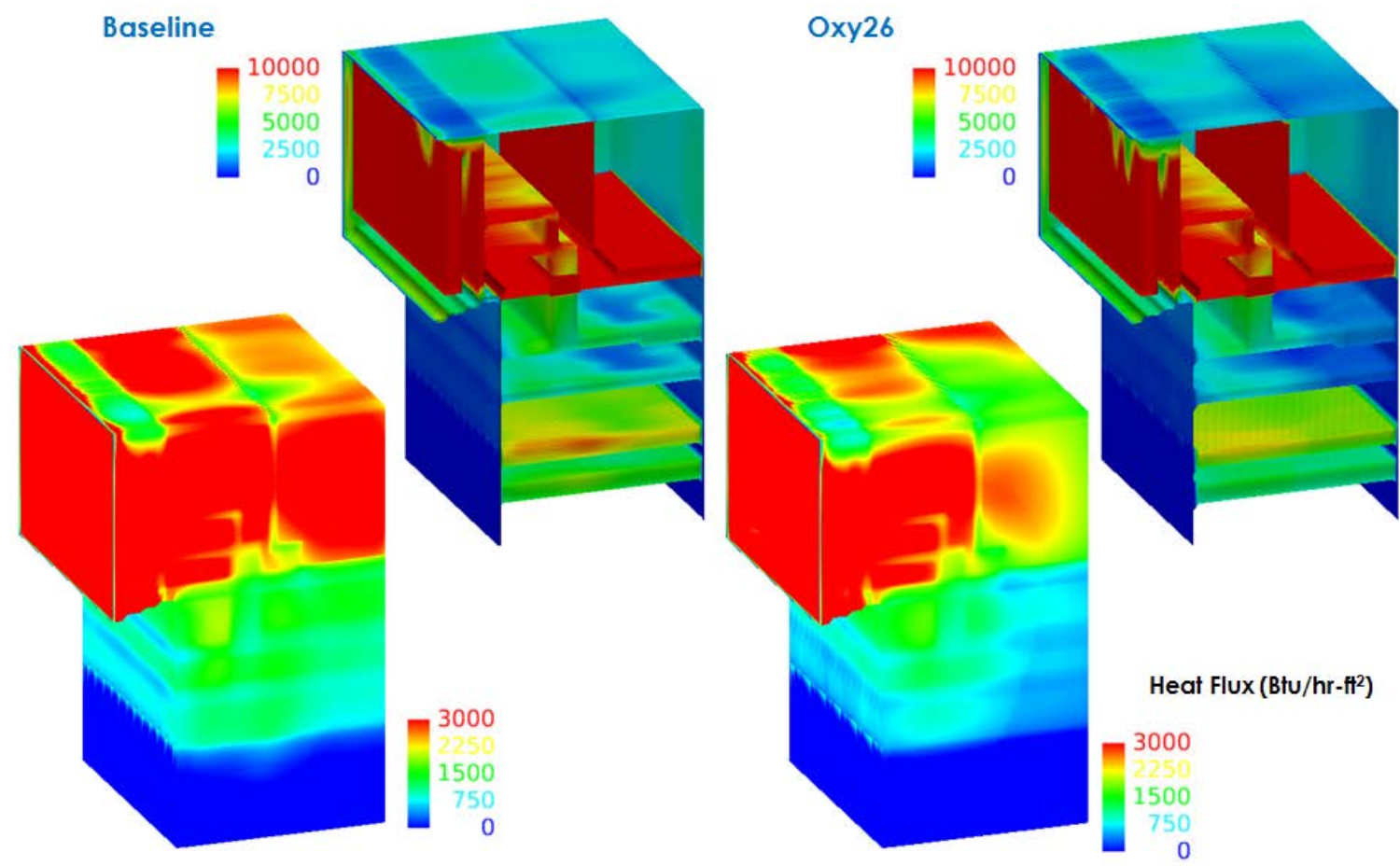

Figure 4.13-60: Model predicted net heat flux in the backpass. 

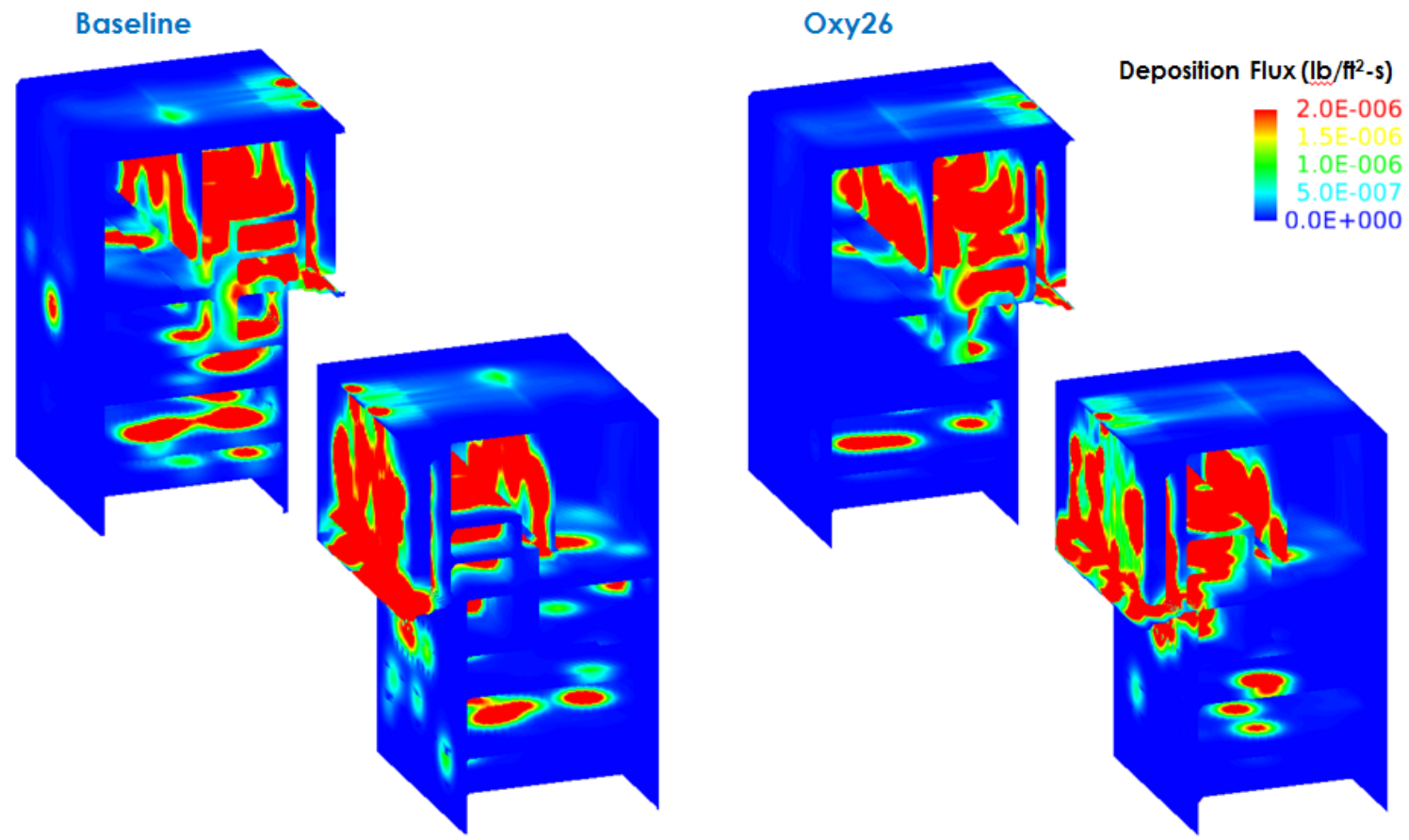

Figure 4.13-61: Model predicted wall deposition flux in the backpass.

Figure 4.13-62, Figure 4.13-63, and Figure 4.13-64 show model predicted corrosion potential for the surfaces in the backpass. The highest corrosion potential occurs on the reheater section. Corrosion potential is higher along the right and left walls of the backpass. The oxy-fired case shows increased total and peak corrosion potential for all convective surfaces.

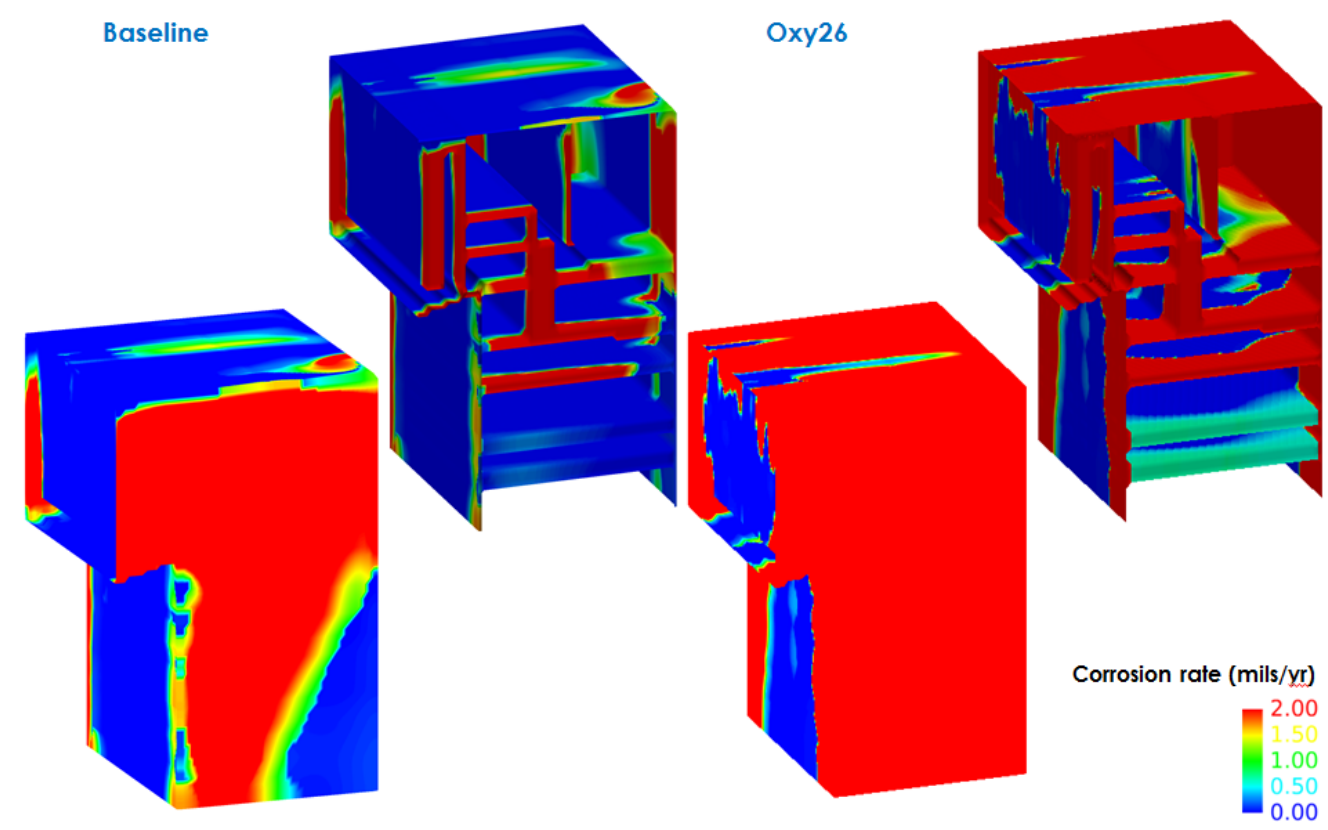

Figure 4.13-62: Model predicted wall corrosion rate in the backpass. 


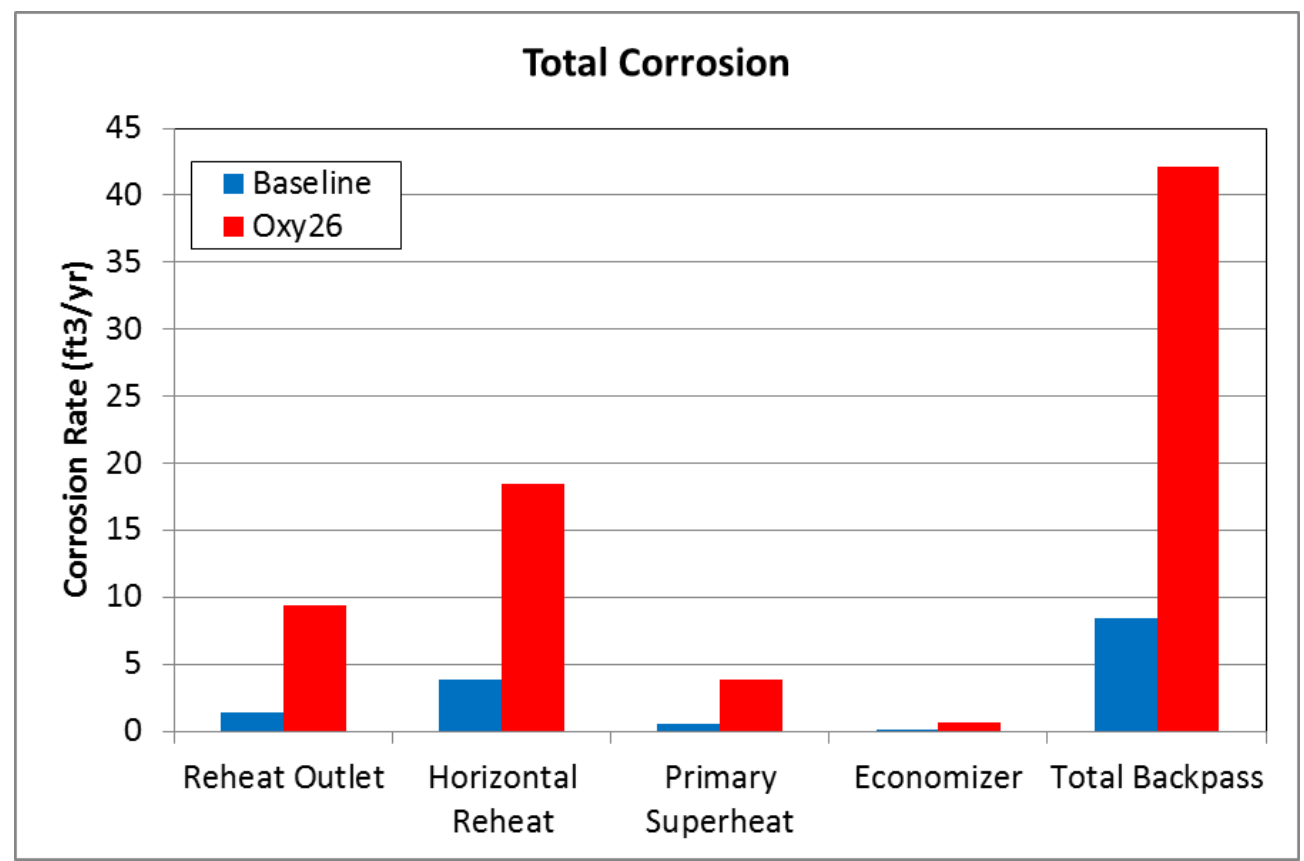

Figure 4.13-63: Model predicted total corrosion rate by furnace section in the backpass (given as total material loss).

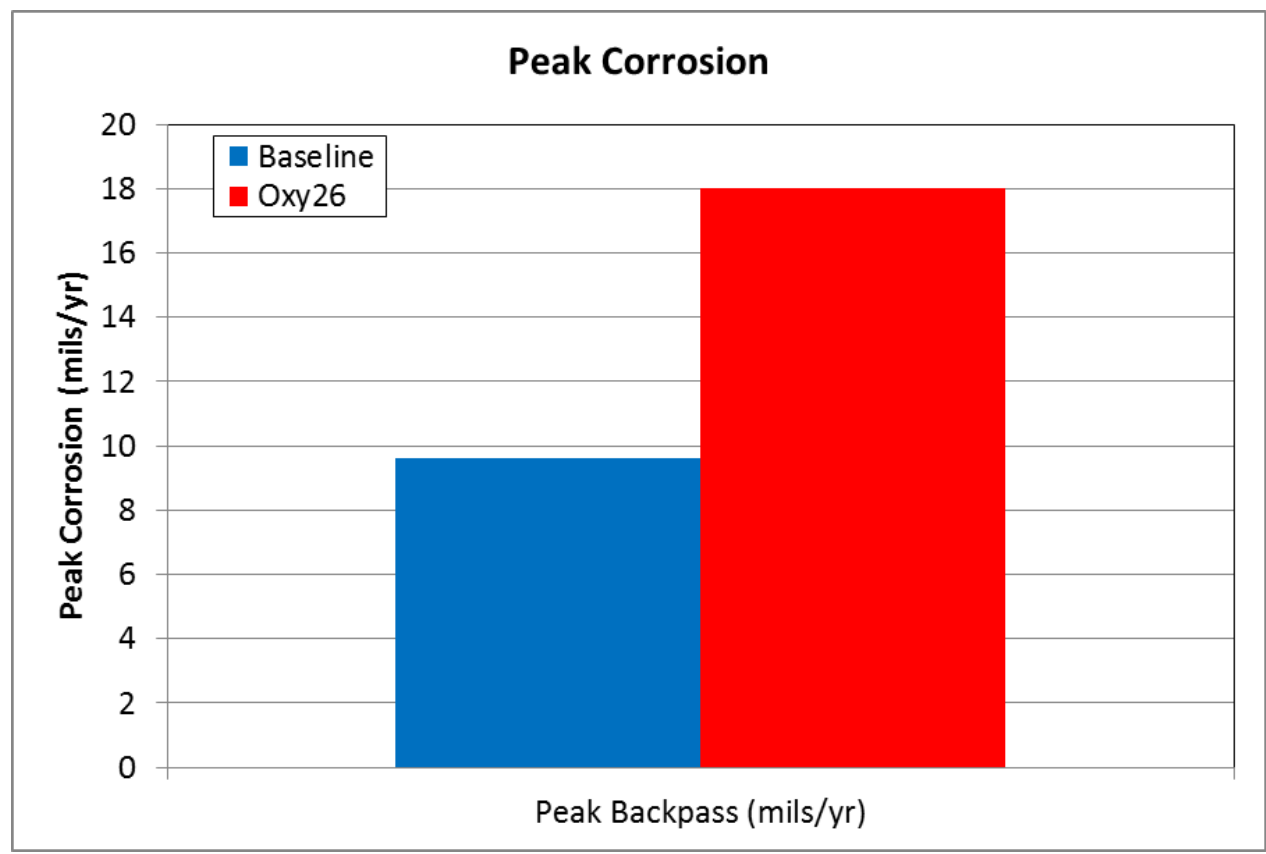

Figure 4.13-64: Model predicted peak corrosion rate by furnace section in the backpass.

\subsubsection{Overall Comparison of Air- and Oxy-fired Results}

In comparing overall heat transfer for Hunter Unit 3, a 26\% $\mathrm{O}_{2}$ mixture of oxygen and flue gas recycle was able to match the air-fired case heat transfer fairly well as shown in Figure 4.13-65. This is consistent with earlier process modeling that suggested $25 \% \mathrm{O}_{2}$ in the total $\mathrm{O}_{2} /$ FGR mixture would best 
match air-fired heat transfer (Figure 4.13-66). Further adjustments could be made to the heat transfer profile during operation by slightly adjusting the FGR recycle rate. Unburned carbon was lower in the oxy-fired case (2.1\% versus $3.6 \%$ in the air-fired case). CO concentration was higher throughout the furnace for the oxy-fired case as shown in Figure 4.13-67. Total corrosion potential was also higher for all surfaces in the oxy-fired case (Figure 4.13-68). However, peak corrosion was lower for the waterwalls in the oxy-fired case and higher for the other surfaces (Figure 4.13-69). These modeling results suggest that other than the high corrosion rates, there are not any significant differences in an oxy-fired system compared to air-firing. The high corrosion rates can be mitigated by treating the higher $\mathrm{SO}_{2} \mathrm{FGR}$ stream before it re-enters the boiler.

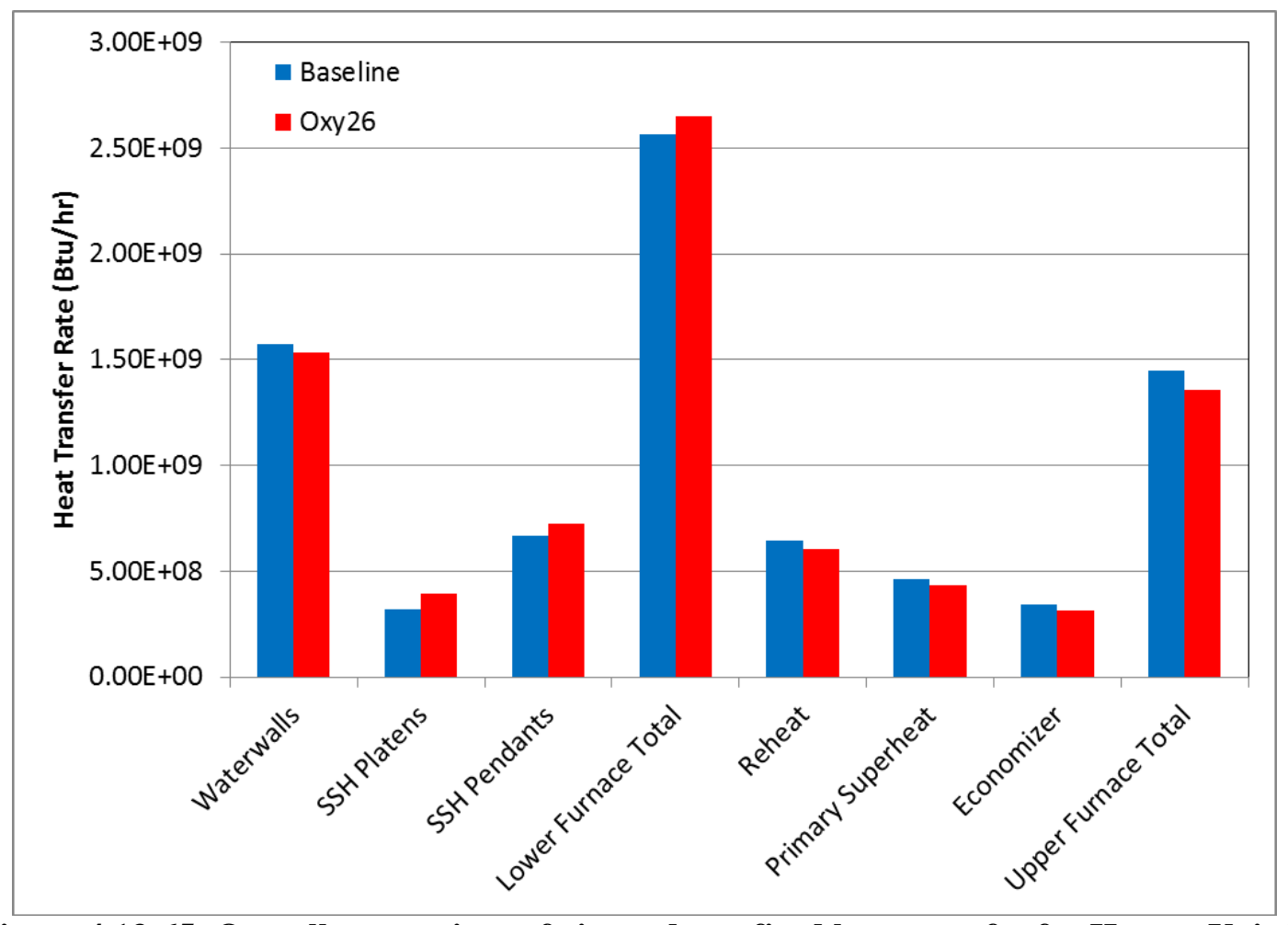

Figure 4.13-65: Overall comparison of air- and oxy-fired heat transfer for Hunter Unit 3. 


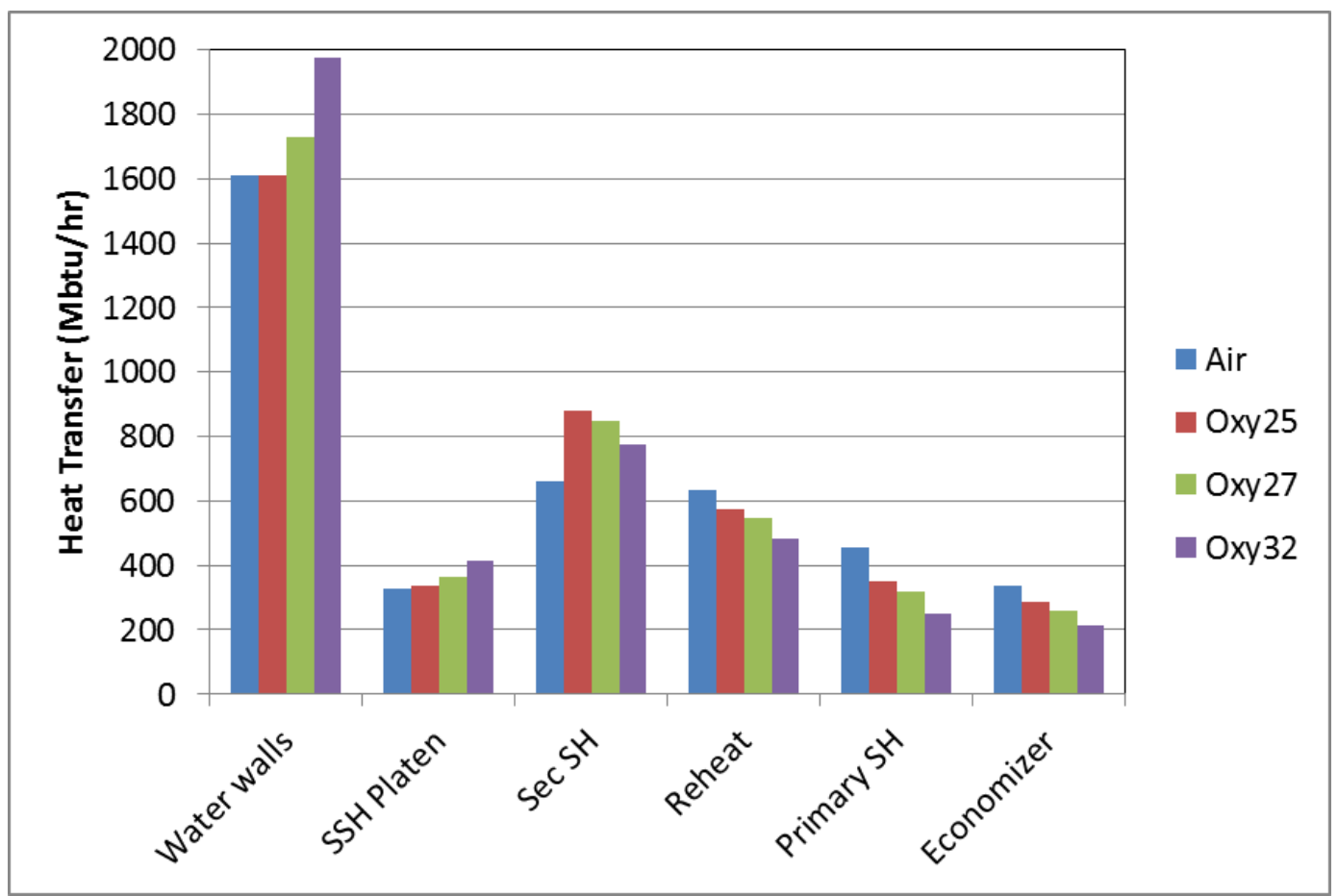

Figure 4.13-66: Process modeling results of oxy-firing heat transfer matching.

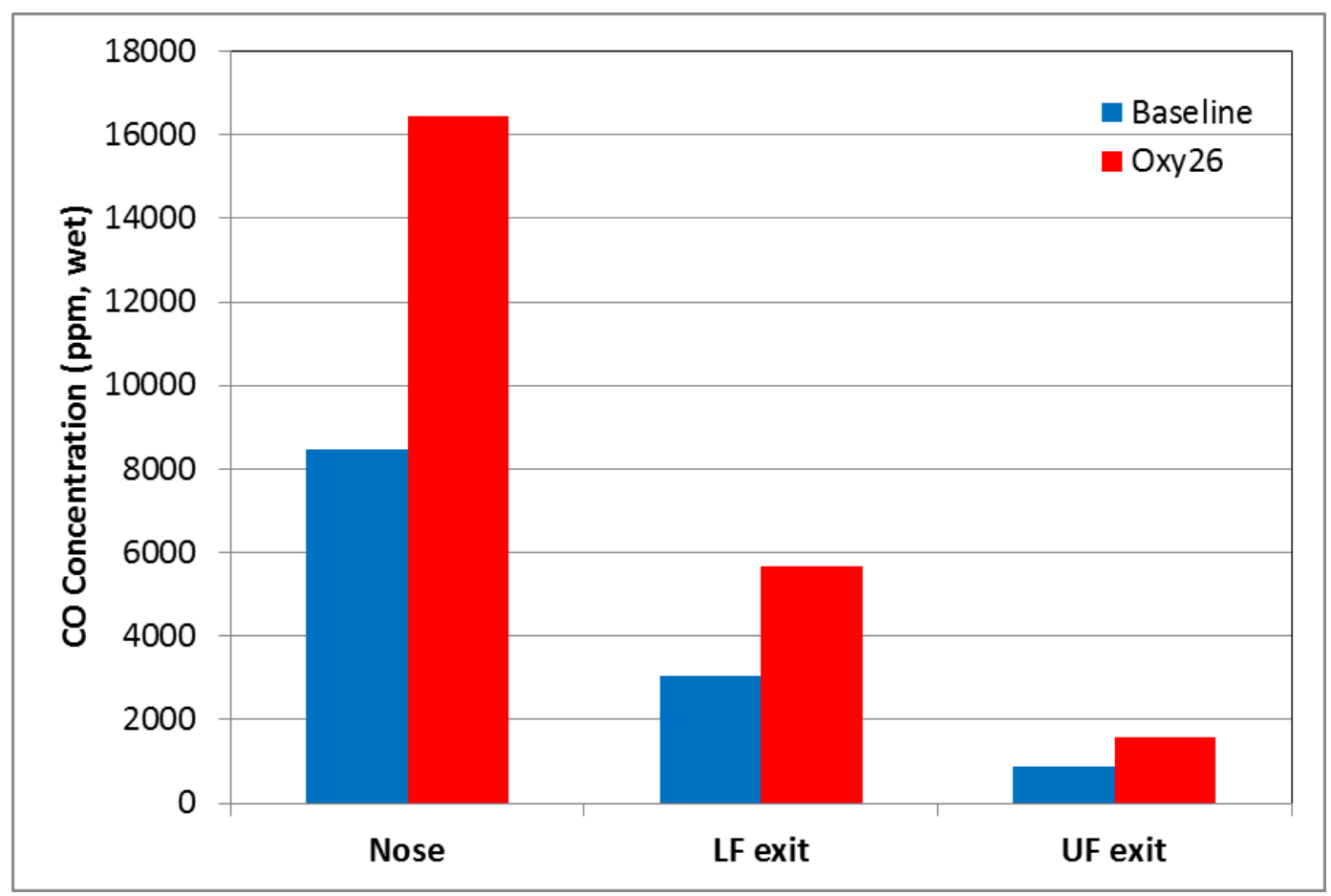

Figure 4.13-67: Comparison of model predicted air- and oxy-fired CO concentration throughout Hunter Unit 3. 


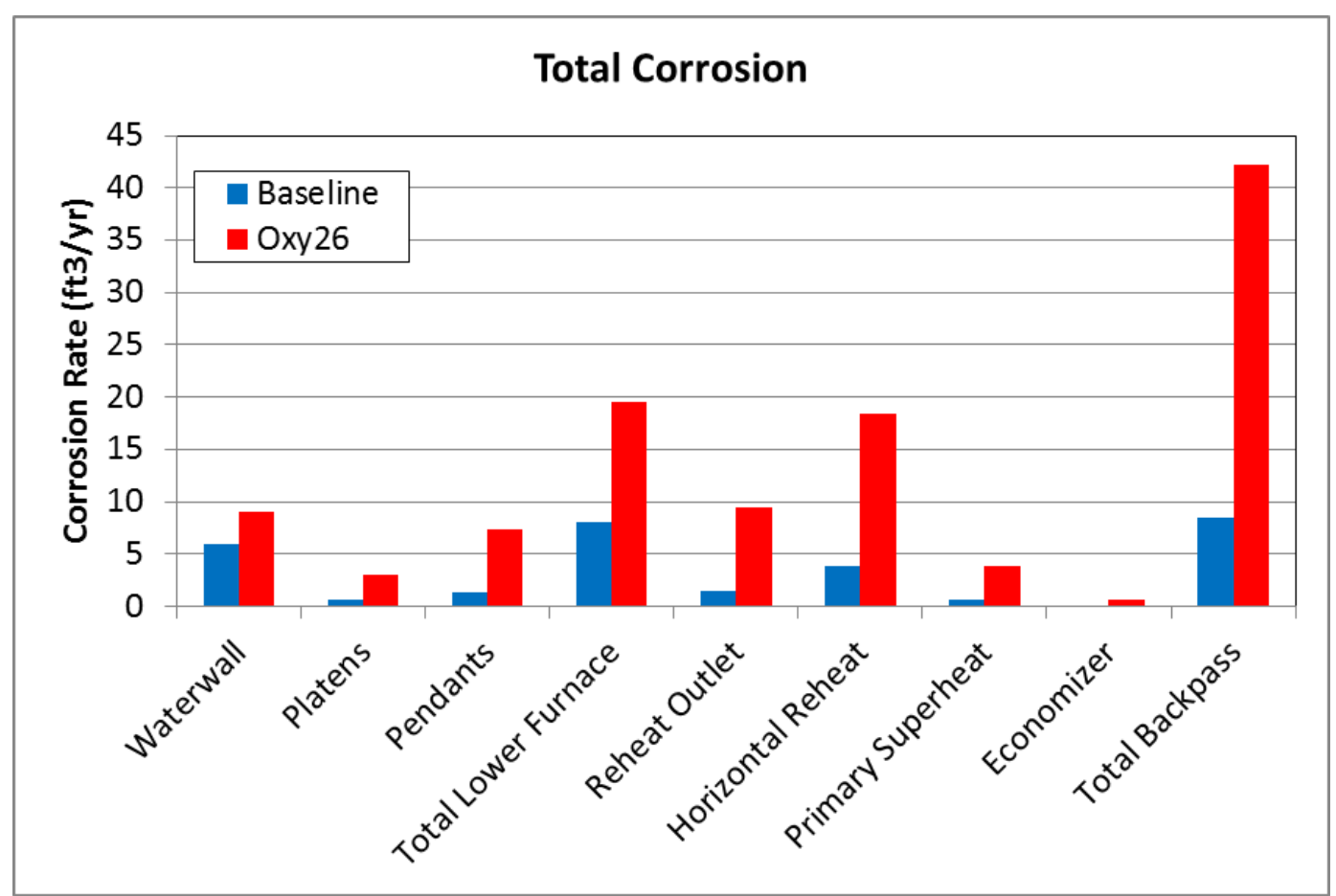

Figure 4.13-68: Comparison of model predicted air- and oxy-fired total corrosion potential throughout Hunter Unit 3 (given as total material loss).

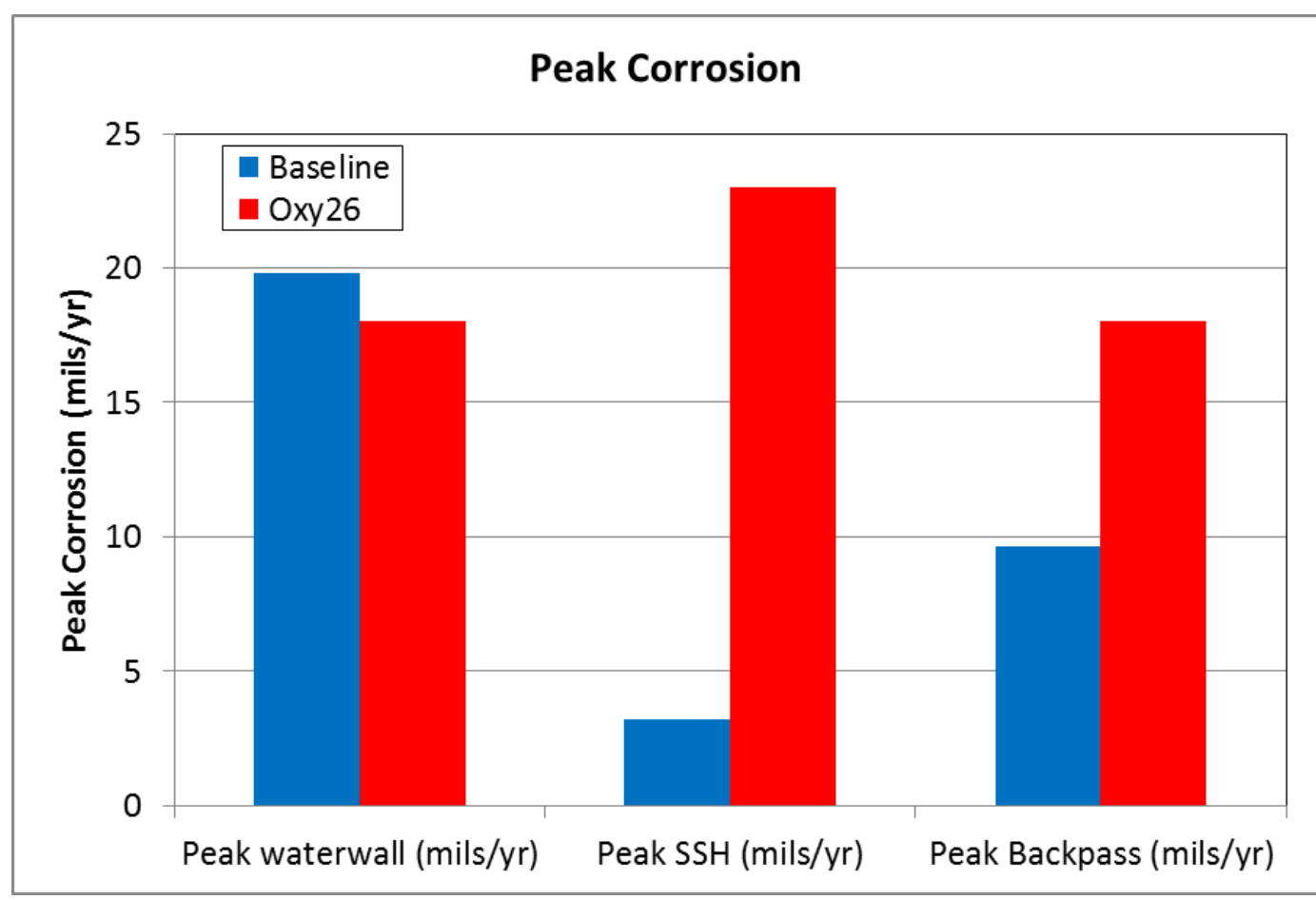

Figure 4.13-69: Comparison of model predicted air- and oxy-fired peak corrosion throughout Hunter Unit 3. 


\subsubsection{Hunter 3 Modeling Conclusions}

REI's Glacier combustion simulation (CFD) tool was used to simulate air- and oxy-firing in Hunter Unit 3. Modeling included improved char oxidation, soot, slagging and corrosion models. Those results showed:

- The original char oxidation model predicted high unburned carbon in ash (UBC) and increased UBC from air- to oxy-combustion firing. The new, enhanced char oxidation sub-model predicted reasonable UBC concentrations (3.8\% for air-firing compared with the 2 to 3\% UBC observed at the Hunter plant) and decreased UBC for oxy-combustion firing. This decrease in UBC level from air- to oxy-firing was consistent with test results from the L1500 pilot-scale tests.

- The addition of the refined soot sub-model increased CO throughout the furnace, particularly in the hopper. Exit CO concentration was $\sim 0.1 \%$ higher. The unburned carbon content of the fly ash also slightly increased $(\sim 0.3 \%)$ with the addition of the soot sub-model. Gas temperature profiles appeared fairly similar with and without the soot sub-model, with gas exit temperatures within a few degrees. Similarly, wall temperatures and heat fluxes were very similar with and without the refined soot model. Note these results were only for the Utah Skyline bituminous coal currently fired at the plant.

- The addition of the slagging model caused several shifts in modeling results:

0 Increased exit gas temperature for the air-fired case and decreased exit gas temperature for the oxy-fired case.

o Decreased UBC for both air- and oxy-fired cases.

o Increased particle deposition for both air- and oxy-fired cases.

o Decreased overall heat transfer for both air- and oxy-fired cases.

o Helped the air-fired and oxy-fired overall lower furnace heat transfer agree better.

o Slightly increased total waterwall corrosion and decreased total superheater corrosion for both air- and oxy-fired cases.

Once the enhanced sub-models were evaluated, modeling was conducted to evaluate the impact of firing Utah low-sulfur bituminous and Illinois high-sulfur coals. In comparing corrosion potential between the Utah and Illinois coals:

- The same trend of increased total corrosion rate under oxy-firing was observed for both coals.

- Consistent with pilot-scale data:

o Peak waterwall corrosion decreased under oxy-fired conditions for the Skyline coal,

o Peak SSH corrosion increased under oxy-fired conditions for both coals,

o Peak SSH corrosion under oxy-firing conditions with the Illinois coal was extremely high.

This modeling investigation suggests flue gas treatment prior to recycle will be necessary for high sulfur coals. Simulating sulfur removal (FGR conditions approximate to what might exit a wet FGD) showed mitigation of the effects of a high sulfur coal.

In comparing overall heat transfer for Hunter Unit 3, a 26\% $\mathrm{O}_{2}$ mixture of oxygen and flue gas recycle was able to match the air-fired case heat transfer fairly well. This is consistent with SGE process modeling that suggested $25 \% \mathrm{O}_{2}$ in the total $\mathrm{O}_{2}$ /FGR mixture would best match air-fired heat transfer. For the $26 \% \mathrm{O}_{2}$ condition, unburned carbon was lower in the oxy-fired case (2.1\% versus 3.6\% in the airfired case). Total corrosion potential was also higher for all surfaces in the oxy-fired case. However, peak corrosion was lower for the waterwalls in the oxy-fired case and higher for the other surfaces. These 
modeling results suggest that selection of flue gas composition with a 26\% $\mathrm{O}_{2}$ mixture of $\mathrm{O}_{2}$ and flue gas recycle can reasonably match heat transfer in an existing coal boiler and that there are not any catastrophic differences in an oxy-fired system compared to air-firing.

\subsubsection{DTE River Rouge 3 Overview}

The superheat boiler of DTE Energy's River Rouge Unit 3 is being used as an additional assessment study for oxy-combustion retrofit investigations. River Rouge Unit 3 Superheat is a front wall fired unit with 12 Foster Wheeler Intervane low-NOx burners and 4 coke oven gas burners. The geometry of this unit is shown in Figure 4.13-70. Both waterwall and radiant superheat tubes are included in the lower furnace. The air-fired coal burner geometry included in the model is shown in Figure 4.13-71 and the COG burner geometry is shown in Figure 4.13-72. The burner layout and air-fired swirl pattern is shown in Figure 4.13-73. For the oxy-fired cases, a different coal burner designed by Siemens was implemented. The burner layout was maintained, but the swirl pattern was changed to a checkerboard pattern starting with the unique burner in the top row from air-fired case. Deposit blockages on the COG burners were included in the air-fired case, but removed in the oxy-fired cases.

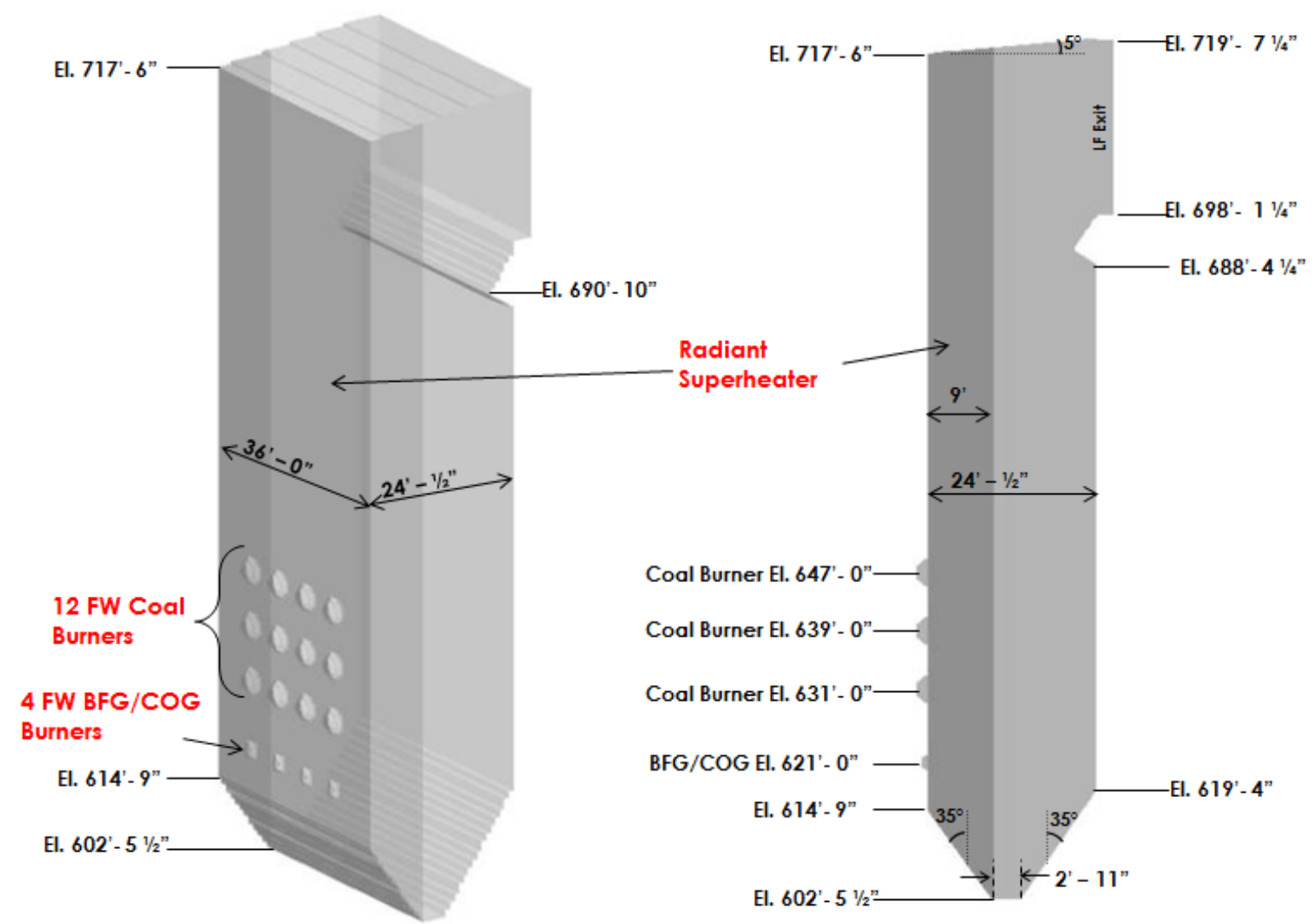

Figure 4.13-70: Model Geometry of River Rouge Unit 3. 


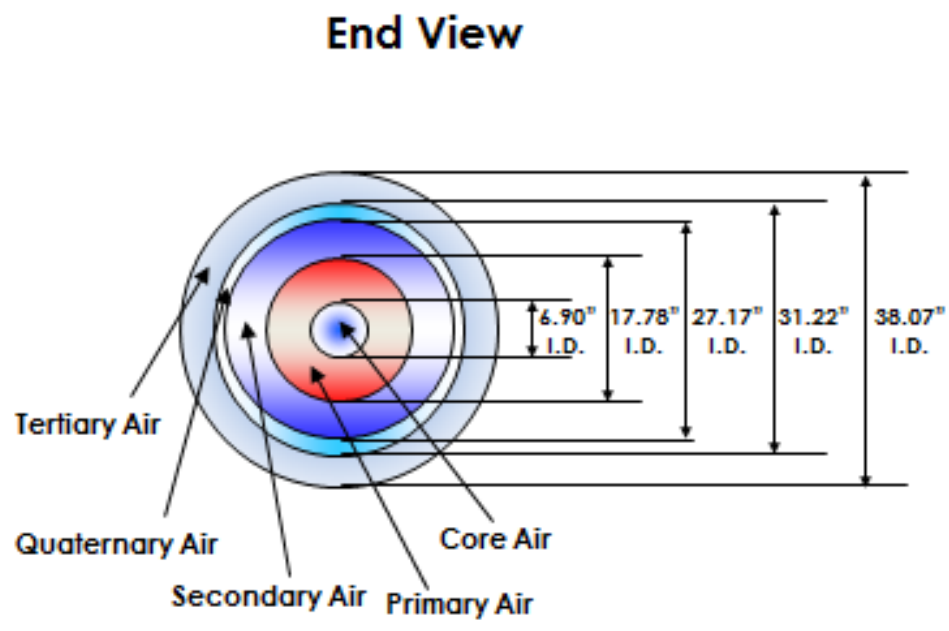

Side View

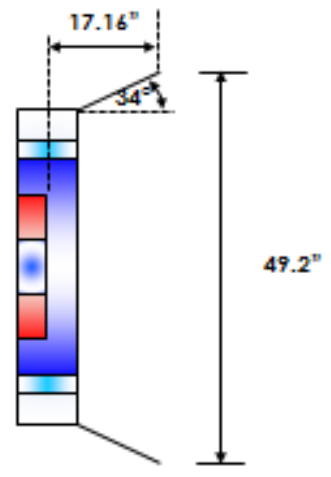

Figure 4.13-71: Air-fired coal burner geometry included in the model.

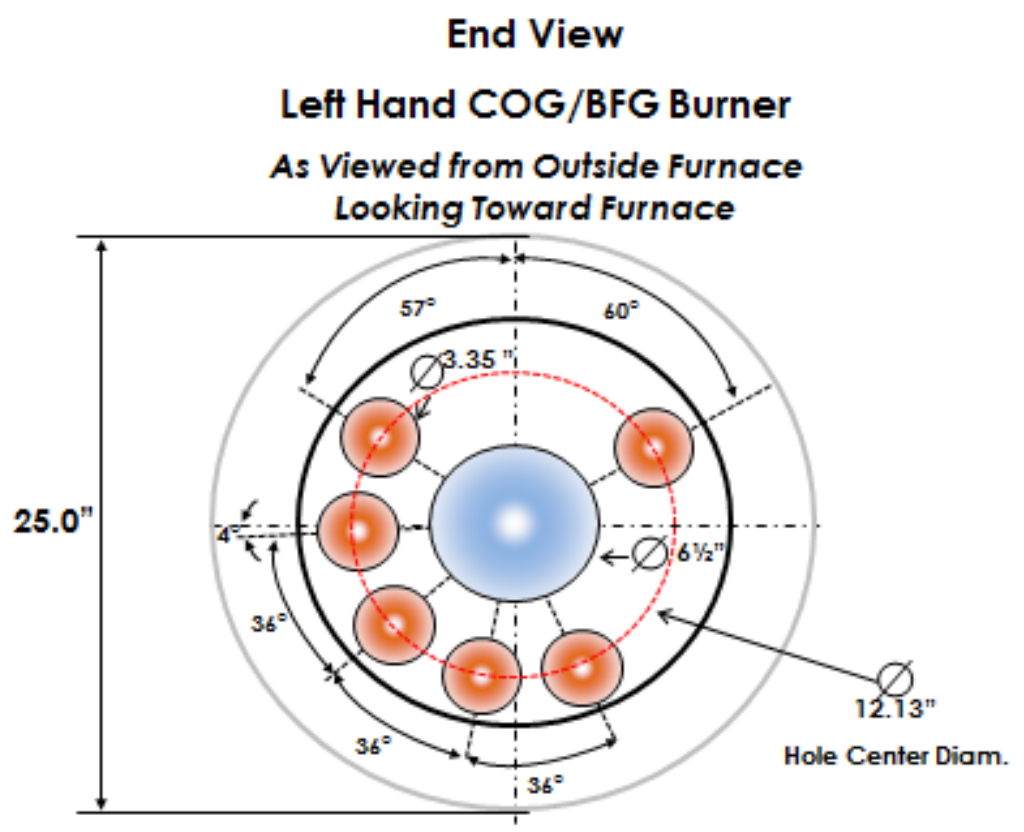

Figure 4.13-72: COG burner geometry included in the model. 


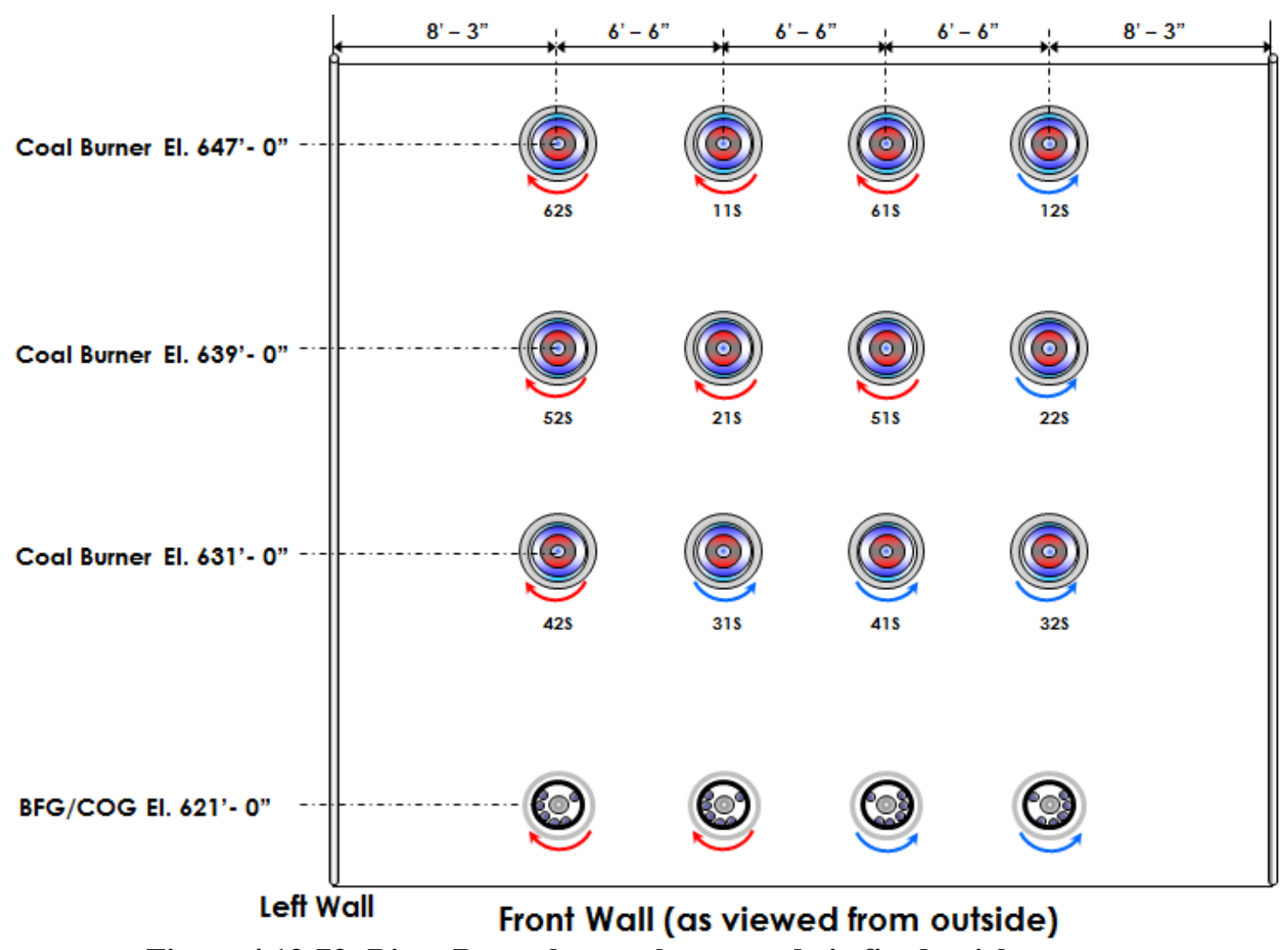

Figure 4.13-73: River Rouge burner layout and air-fired swirl pattern.

\subsubsection{River Rouge 3 Process Modeling}

A process model of DTE's River Rouge Unit 3 Superheat was developed and used to evaluate the impact of recycle rate on heat transfer in both the radiant and convective sections of the furnace. This model was created using REI's SteamGen Expert (SGE). The SGE model has the capability to represent furnace combustion and steam-side coupling. SGE is a steady-state flow sheet type application used to simulate steam generating systems firing fossil fuels. It is based on a heat and mass balance approach with extensive steam properties, coal properties, gas properties and heat transfer correlations to represent different processes relevant in the combustion and steam-side process. Various modules are available to represent the air streams, air heaters, fuel streams, steam flows, feedwater heaters, coal pulverizers, boilers, flue gas-steam heat exchangers (e.g., primary and secondary superheat, reheat, economizer), steam drum, and attemperators. The SGE model includes a module for the lower furnace which can be configured to represent the actual geometry of the unit where radiation calculations are performed using the emissive properties of mixtures of gases and a predefined heat release profile from the fuel.

The SGE model for River Rouge included: coal mills, a lower furnace model which resolved four rows of burners on the front wall (one row of COG burners and three rows of coal burners), convective superheat, economizer, attemperation, air leakage, and flue gas recycle. The model configuration is detailed in Figure 4.13-74. Once the process model was configured, the inlet conditions were adjusted to represent an operating data set provided by DTE, which included both fire and steam-side data. The conditions of the heat transfer surfaces (fouling, resistance) were then adjusted until the heat duty of each surface matched the duty provided in the data set. In this state the SGE model represented the baseline air conditions. 


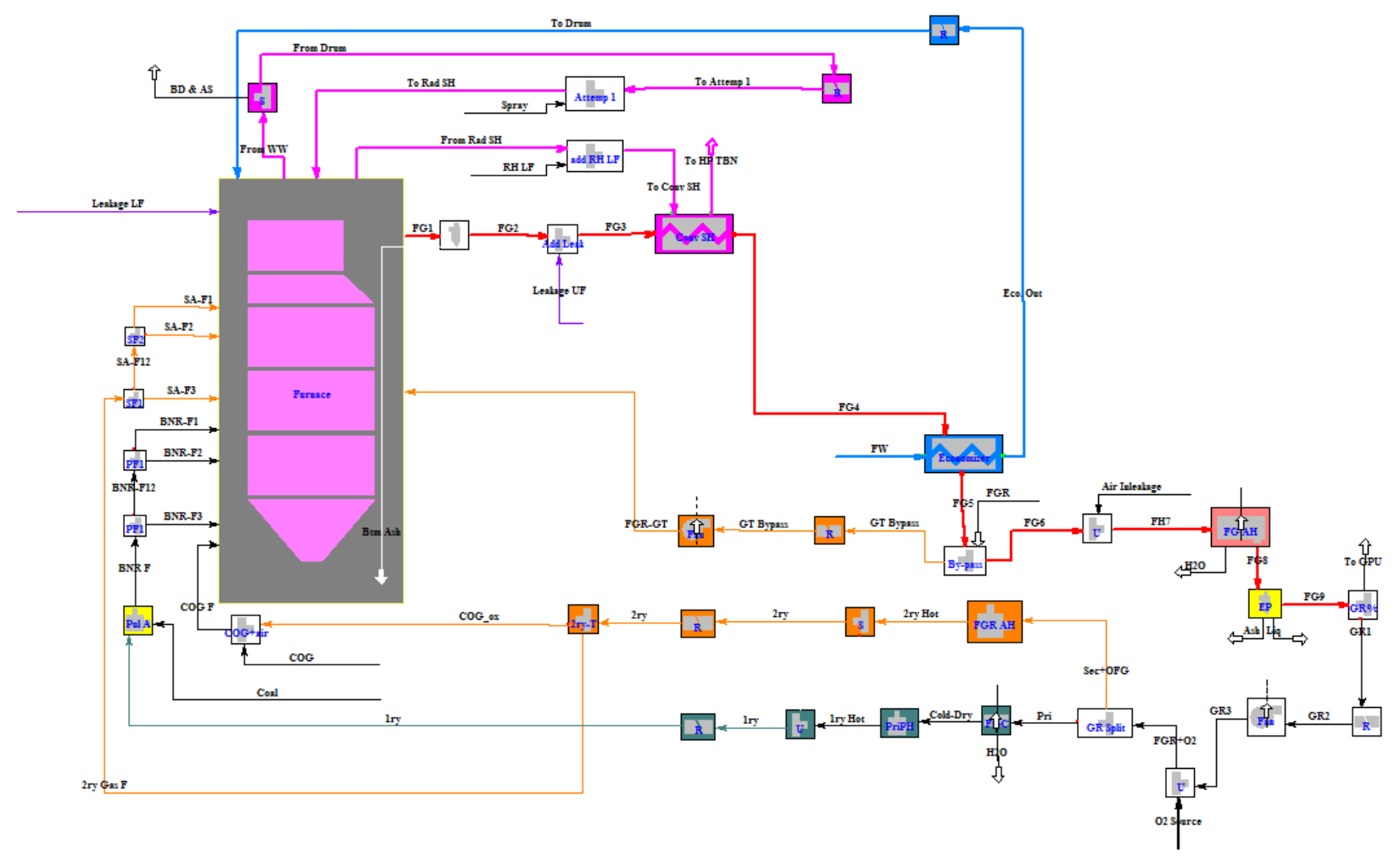

Figure 4.13-74: Process model for oxy-fired River Rouge Unit 3.

Further process modeling was performed where the inlet conditions were changed to remove air as the oxidant and oxygen was used instead. Various simulations were performed where the amount of flue gas recycled back to the furnace was adjusted. As the flue gas recycle is adjusted, the mass flow of oxygen is only slightly adjusted to maintain $3.0 \% \mathrm{O}_{2}$ (dry) at the boiler exit. However the oxygen concentration in the overall mixture of $\mathrm{O}_{2}$ and FGR (pseudo air) changes greatly. The concentrations selected for this investigation included $21,22,23,25,26$, and $27 \% \mathrm{O}_{2}$ (wet). To achieve greater $\mathrm{O}_{2}$ concentrations in the mixture of $\mathrm{O}_{2}$ and FGR, the FGR rate must be decreased. As the $\mathrm{O}_{2}$ concentration is increased the adiabatic flame temperature is also expected to increase, because there is less dilution gas to heat up. As the flame temperature increases, the radiant heat transfer is also expected to increase. However, as the $\mathrm{O}_{2}$ concentration increases, the total volume of gas decreases, reducing velocities and expected heat transfer in the convective heat transfer surfaces. Therefore the heat transfer must be balanced between the radiant and convective heat transfer sections by adjusting the FGR. The range of recycle ratios used here was expected to span the range that would produce a balanced heat transfer.

The overall heat transfer and the heat transfer by heat exchange section are presented in Figure 4.13-75. This figure indicates that both the convective and radiant heat transfer are expected to match with the airfired case when the oxygen concentration is $23 \%$ (wet) in the overall mixture of $\mathrm{O}_{2}$ and FGR. The trends in predicted heat transfer for the convective and radiant sections behave as expected. This is different than the mixture required for Hunter Unit 3, suggesting firing design for oxy-conditions must be unit specific. 


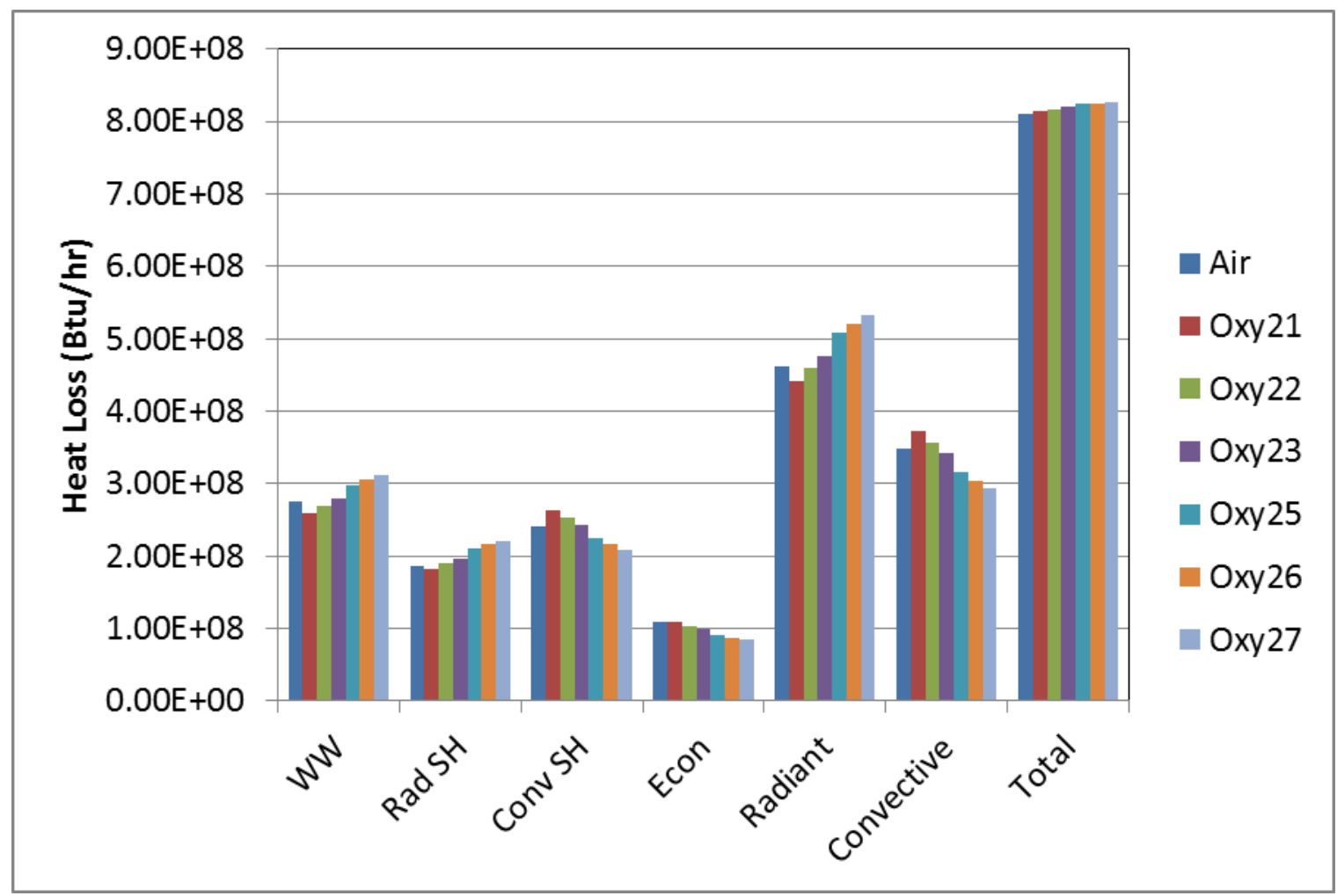

Figure 4.13-75: Process modeling heat transfer results for River Rouge.

Following the process modeling, rough CFD models of the radiant furnace were run which suggested that $24 \% \mathrm{O}_{2}$ would match the heat transfer better than $23 \% \mathrm{O}_{2}$ (a 1\% increase in the $\mathrm{O}_{2}$ concentrations was also necessary for Hunter Unit 3). It was decided that all further modeling of oxy combustion conditions would be performed at $24 \% \mathrm{O}_{2}$ (wet) in the $\mathrm{O}_{2}$ / FGR mixture.

\subsubsection{River Rouge 3 CFD Modeling}

\subsubsection{CFD Case Descriptions}

Three cases have been run for River Rouge Unit 3 Superheat using REI's standard CFD code with enhanced radiation, char oxidation, and soot sub-models. A summary of these cases is shown in Table 4.13-15. These three cases were designed to provide information sufficient to evaluate:

1. The behavior of oxy-coal combustion in a full-scale utility boiler compared with the existing airfired behavior including

a. Heat transfer profiles,

b. Deposition profiles and rate in the radiant furnace,

c. Combustion Efficiency (CO and UBC),

2. The impact of flue gas recycle moisture concentration.

Operating conditions for these cases are described in Table 4.13-16. Coal and COG fuel properties used in this modeling study are shown in Table 4.13-17. 
Table 4.13-15: Summary of River Rouge Modeling Cases.

\begin{tabular}{|l|l|l|}
\hline Case & Oxidant & FGR treatment \\
\hline Baseline & Air & NA \\
\hline Oxy24 & $\begin{array}{l}24 \% \mathrm{O}_{2} \text { in total } \\
\text { FGR/O }\end{array}$ & Primary FGR $/ \mathrm{O}_{2}$ dried to $4^{\circ} \mathrm{C}$ dew point \\
\hline Oxy24-low $\mathrm{H}_{2} \mathrm{O}$ & $\begin{array}{l}24 \% \mathrm{O}_{2} \text { in total } \\
\text { FGR/O }\end{array}$ & $\begin{array}{l}\text { Primary } \mathrm{FGR} / \mathrm{O}_{2} \text { dried to } 4^{\circ} \mathrm{C} \text { dew point, remaining flue } \\
\text { gas recycle dried to } 135^{\circ} \mathrm{F} \text { dew point }\end{array}$ \\
\hline
\end{tabular}

Table 4.13-16: Operating Conditions for River Rouge Cases.

\begin{tabular}{|c|c|c|c|}
\hline & Baseline & Oxy24 & \begin{tabular}{|l|} 
Oxy24 \\
lowH2O
\end{tabular} \\
\hline \multicolumn{4}{|l|}{ Overall Operating Conditions - SH Furnace } \\
\hline Total Furnace Firing Rate (MBtu/hr) & 940 & 940 & 940 \\
\hline Total Coal Flow Rate (klb/hr) & 97.1 & 97.1 & 97.1 \\
\hline Coal Firing Rate (MBtu/hr) & 857 & 857 & 857 \\
\hline Total COG Flow Rate (klb/hr) & 4.6 & 4.6 & 4.6 \\
\hline COG Firing Rate (MBtu/hr) & 83 & 83 & 83 \\
\hline Total Air (including leakage) or $\mathrm{O}_{2} /$ FGR Flow Rate (klb/hr) & $924^{+}$ & 758 & 805 \\
\hline Theoretical Excess $\mathrm{O}_{2}(\%$, wet $)$ & $4.7 \% *$ & $2.2 \%=$ & $2.5 \%=$ \\
\hline Coal Burner SR & 1.26 & $1.1^{-}$ & $1.1^{-}$ \\
\hline COG Burner SR & 1.76 & $1.1^{-}$ & $1.1^{-}$ \\
\hline Total Leakage Air (klb/hr) & 26.7 & 26.7 & 26.7 \\
\hline Fraction of Total $\mathrm{O}_{2}$ as leakage & $3.2 \%$ & $3.5 \%$ & $3.5 \%$ \\
\hline Fraction of Total Air leakage to Lower Furnace & $65.75 \%$ & $65.75 \%$ & $65.75 \%$ \\
\hline Total Coal Burner Air or $\mathrm{O}_{2} /$ FGR Flow Rate (klb/hr) & 802 & 666 & 704 \\
\hline Fraction of Total Air or $\mathrm{O}_{2} /$ FGR to Coal Burners & $86.9 \%$ & $87.9 \%$ & $87.4 \%$ \\
\hline Primary Air or $\mathrm{O}_{2} /$ FGR Flow Rate $(\mathrm{klb} / \mathrm{hr})$ & 170 & 174 & 174 \\
\hline Primary Gas to Fuel Ratio & 1.75 & 1.75 & 1.75 \\
\hline Primary Gas Temperature $\left({ }^{\circ} \mathrm{F}\right)$ & 122 & 122 & 122 \\
\hline Coal Burner Secondary Air or $\mathrm{O}_{2} / \mathrm{FGR}$ Flow Rate (klb/hr) & 632 & 492 & 530 \\
\hline Secondary Gas Temperature $\left({ }^{\circ} \mathrm{F}\right)$ & 572 & 572 & 572 \\
\hline Total COG Burner Air or $\mathrm{O}_{2} /$ FGR Flow Rate (klb/hr) & 94.6 & 92.0 & 102 \\
\hline COG Gas Temperature $\left({ }^{\circ} \mathrm{F}\right)$ & 572 & 572 & 572 \\
\hline Fraction of Total Air or $\mathrm{O}_{2} / \mathrm{FGR}$ to COG Burners & $10.2 \%$ & $12.1 \%$ & $12.7 \%$ \\
\hline
\end{tabular}

\section{Air Case}

* Based on Measured $\mathrm{O}_{2}$ Directly Upstream of East (SH) Air Heater

+ Total air required for $4.72 \% \mathrm{O}_{2}$, wet basis in the flue gas exiting the convective section

1) Coal burner primary air to fuel ratio from December, 1999 process data

2) Equal total air velocities assumed through coal burner SA, QA, and TA registers (based on windbox to furnace $\mathrm{dP}$ )

Oxy24 Cases

$=3.0 \%$ dry ex $\mathrm{O}_{2}$

- Equal excess $\mathrm{O}_{2}$ for COG and coal burners

1) $24 \% \mathrm{O}_{2}$ in overall $\mathrm{O}_{2} /$ FGR mixture

2) $21 \% \mathrm{O}_{2}$ in primary $\mathrm{O}_{2} /$ FGR mixture

3) $40 \% \mathrm{O}_{2}$ in inner secondary $\mathrm{O}_{2} /$ FGR mixture

3) Primary $\mathrm{O}_{2} /$ FGR mixture dried to $4^{\circ} \mathrm{C}$ dewpoint

4) For low moisture case, FGR dried to $135^{\circ} \mathrm{F}$ dewpoint 
Table 4.13-17: Fuel properties for River Rouge Unit 3.

\begin{tabular}{|c|c|}
\hline \multirow{2}{*}{\multicolumn{2}{|c|}{$\begin{array}{l}\text { Coal Analysis } \\
\text { Ultimate Analysis } \\
\text { (As Received) }\end{array}$}} \\
\hline & \\
\hline $\mathrm{C}(\mathrm{wt}, \%)$ & 50.95 \\
\hline $\mathrm{H}(\mathrm{wt}, \%)$ & 3.51 \\
\hline $\mathrm{O}(\mathrm{wt}, \%)$ & 13.39 \\
\hline $\mathrm{N}(\mathrm{wt}, \%)$ & 0.68 \\
\hline S (wt, \%) & 0.25 \\
\hline Ash (wt, \%) & 4.90 \\
\hline Moisture (wt, \%) & 26.45 \\
\hline HHV (Btu/lb) & 8,818 \\
\hline Proximate Analysis & \\
\hline Moisture (wt, \%) & 26.45 \\
\hline Ash (wt, \%) & 4.90 \\
\hline Volatile Matter (wt, \%) & 32.36 \\
\hline Fixed Carbon (wt, \%) & 36.30 \\
\hline
\end{tabular}

\begin{tabular}{|l|c|c|}
\hline \multicolumn{3}{|l|}{ Modeled Coal Size Bins } \\
\hline Size & $\begin{array}{l}\text { Mass } \\
\text { Fraction }\end{array}$ & $\begin{array}{l}\text { Avg Diameter } \\
(\boldsymbol{\mu m})\end{array}$ \\
\hline 1 & 0.025 & 6.5 \\
\hline 2 & 0.050 & 14.5 \\
\hline 3 & 0.075 & 21.4 \\
\hline 4 & 0.100 & 29.6 \\
\hline 5 & 0.150 & 41.0 \\
\hline 6 & 0.200 & 60.1 \\
\hline 7 & 0.150 & 89.7 \\
\hline 8 & 0.100 & 125.9 \\
\hline 9 & 0.075 & 172.9 \\
\hline 10 & 0.050 & 249.3 \\
\hline 11 & 0.025 & 408.4 \\
\hline
\end{tabular}

\begin{tabular}{|l|c|}
\hline \multicolumn{2}{|l|}{ COG Composition } \\
\hline & vol \% \\
\hline $\mathrm{C}_{2} \mathrm{H}_{6}$ & 0.54 \\
\hline $\mathrm{C}_{2} \mathrm{H}_{4}$ & 2.03 \\
\hline $\mathrm{H}_{2}$ & 59.69 \\
\hline $\mathrm{H}_{2} \mathrm{~S}$ & 0.27 \\
\hline $\mathrm{CH}_{4}$ & 22.68 \\
\hline $\mathrm{N}_{2}$ & 7.34 \\
\hline $\mathrm{O}_{2}$ & 0.60 \\
\hline $\mathrm{CO}_{2}$ & 1.56 \\
\hline $\mathrm{CO}$ & 5.15 \\
\hline $\mathrm{C}_{3} \mathrm{H}_{8}$ & 0.16 \\
\hline & \\
\hline HHV (Btu/lb) & $\mathbf{1 8 , 2 7 0}$ \\
\hline
\end{tabular}

In Table 4.13-16 there are some operating conditions which may appear to result in an apples and oranges comparison between air and oxy-fired conditions. Specifically two of these values are the theoretical excess $\mathrm{O}_{2}$ (3.0\% dry oxy and 5.4\% dry air) and coal/COG SR (1.1/1.1 oxy and 1.26/1.76 air). The airfired conditions were assigned using plant data, which reflects the way that the boiler is currently being operated. The oxy-fired conditions were assigned to best reflect the way that a boiler would most likely be operated for oxy-fired conditions. The excess $\mathrm{O}_{2}$ would be minimized as much as possible to reduce the cost of air separation. The stoichiometric ratios of the coal and air burners were matched to distribute oxygen more uniformly.

The heat balance data provided by DTE for the air-fired baseline are shown in Table 4.13-18. The heat transfer in the air-fired baseline model was matched to this data. Boundary conditions were then fixed for the oxy-fired cases. 
Table 4.13-18: Baseline air-fired heat transfer data provided by DTE.

\begin{tabular}{|c|c|}
\hline \multicolumn{2}{|c|}{ Baseline - SH Furnace } \\
\hline \multicolumn{2}{|c|}{ Waterwall } \\
\hline Steam Temperature In $\left({ }^{\circ} \mathrm{F}\right)$ & Steam Temperature Out $\left({ }^{\circ} \mathrm{F}\right)$ \\
\hline 593 & 665 \\
\hline Pressure In (psia) & Pressure Out (psia) \\
\hline 2450 & 2450 \\
\hline Steam Mass Flow (klb/hr) & Total Heat Gained By Steam (MBtu/hr) \\
\hline 558 & 276 \\
\hline \multicolumn{2}{|c|}{ Radiant SH } \\
\hline Steam Temperature In $\left({ }^{\circ} \mathrm{F}\right)$ & Steam Temperature Out $\left({ }^{\circ} \mathrm{F}\right)$ \\
\hline 665 & 751 \\
\hline Pressure In (psia) & Pressure Out (psia) \\
\hline 2450 & 2418 \\
\hline Steam Mass Flow (klb/hr) & Total Heat Gained By Steam (MBtu/hr)* \\
\hline 740 & 186 \\
\hline \multicolumn{2}{|c|}{ Convective SH } \\
\hline Steam Temperature In $\left({ }^{\circ} \mathrm{F}\right)$ & Steam Temperature Out $\left({ }^{\circ} \mathrm{F}\right)$ \\
\hline 758 & 958 \\
\hline Pressure In (psia) & Pressure Out (psia) \\
\hline 2418 & 2304 \\
\hline Steam Mass Flow (klb/hr) & Total Heat Gained By Steam (MBtu/hr) \\
\hline 1,404 & 240 \\
\hline \multicolumn{2}{|c|}{ Economizer } \\
\hline Steam Temperature In $\left({ }^{\circ} \mathrm{F}\right)$ & Steam Temperature Out $\left({ }^{\circ} \mathrm{F}\right)$ \\
\hline 428 & 593 \\
\hline Pressure In (psia) & Pressure Out (psia) \\
\hline 2577 & 2450 \\
\hline Steam Mass Flow (klb/hr) & Total Heat Gained By Steam (MBtu/hr) \\
\hline 558 & 108 \\
\hline Total Heat Duty (MBtu/hr) & 810 \\
\hline
\end{tabular}

*Includes heat required to vaporize attemperation spray

\subsubsection{CFD Modeling Results - Radiant Furnace}

The overall model results for River Rouge are shown in Table 4.13-19. Flue gas conditions are given at the horizontal nose and the vertical model exit. The oxy-fired cases show increased CO concentrations, lower exit temperature, and lower $\mathrm{O}_{2}$ concentrations (however, the oxy-fired case was run with $3.0 \%$ dry excess $\mathrm{O}_{2}$ and the air-fired case had 5.4\% dry excess $\mathrm{O}_{2}$ ). However, this is consistent with observations from the pilot-scale testing when comparing both air and oxy-combustion at $3.0 \% \mathrm{O}_{2}$. The oxy-fired cases show higher unburned carbon in fly ash, which is not consistent with the Hunter Unit 3 CFD modeling or pilot-scale testing. This is most likely due to the significantly lower $\mathrm{O}_{2}$ concentrations. 
Table 4.13-19: Overall CFD Model Results for River Rouge Air- and Oxy-Fired Cases.

\begin{tabular}{|l|c|c|c|}
\hline & Baseline & Oxy24 & $\begin{array}{c}\text { Oxy24 } \\
\text { lowH }\end{array}$ \\
\hline Horizontal Nose Plane & & & \\
\hline Temperature ( $\left.{ }^{\mathbf{0}} \mathbf{F}\right)$ & 1982 & 1972 & 1990 \\
\hline CO Concentration, wet (ppm) & 826 & 5174 & 5049 \\
\hline $\mathbf{O}_{\mathbf{2}}$ Concentration, wet (\%) & $4.9 \%$ & $2.4 \%$ & $2.4 \%$ \\
\hline & & & \\
\hline Vertical Exit Plane & & & \\
\hline Temperature ('F) & 1850 & 1825 & 1816 \\
\hline CO Concentration, wet (ppm) & 138 & 2274 & 2255 \\
\hline $\mathbf{O}_{\mathbf{2}}$ Concentration, wet (\%) & $4.7 \%$ & $2.1 \%$ & $2.2 \%$ \\
\hline Unburned Carbon in Fly Ash & $3.9 \%$ & $7.6 \%$ & $5.3 \%$ \\
\hline Particle Burnout & $99.7 \%$ & $99.4 \%$ & $99.5 \%$ \\
\hline
\end{tabular}

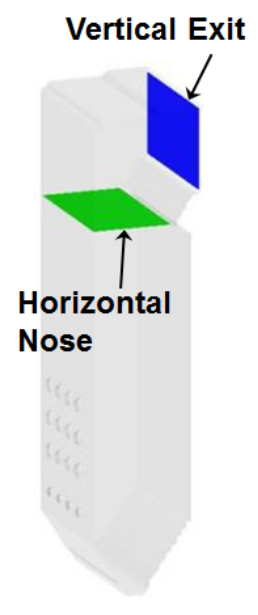

Gas temperature profiles are shown in Figure 4.13-76. A plot of average gas temperature with elevation is shown in Figure 4.13-77. Dips in temperature are seen near the burner elevations as cooler fuel and oxidant are introduced. The temperature profiles are fairly similar for all three cases.

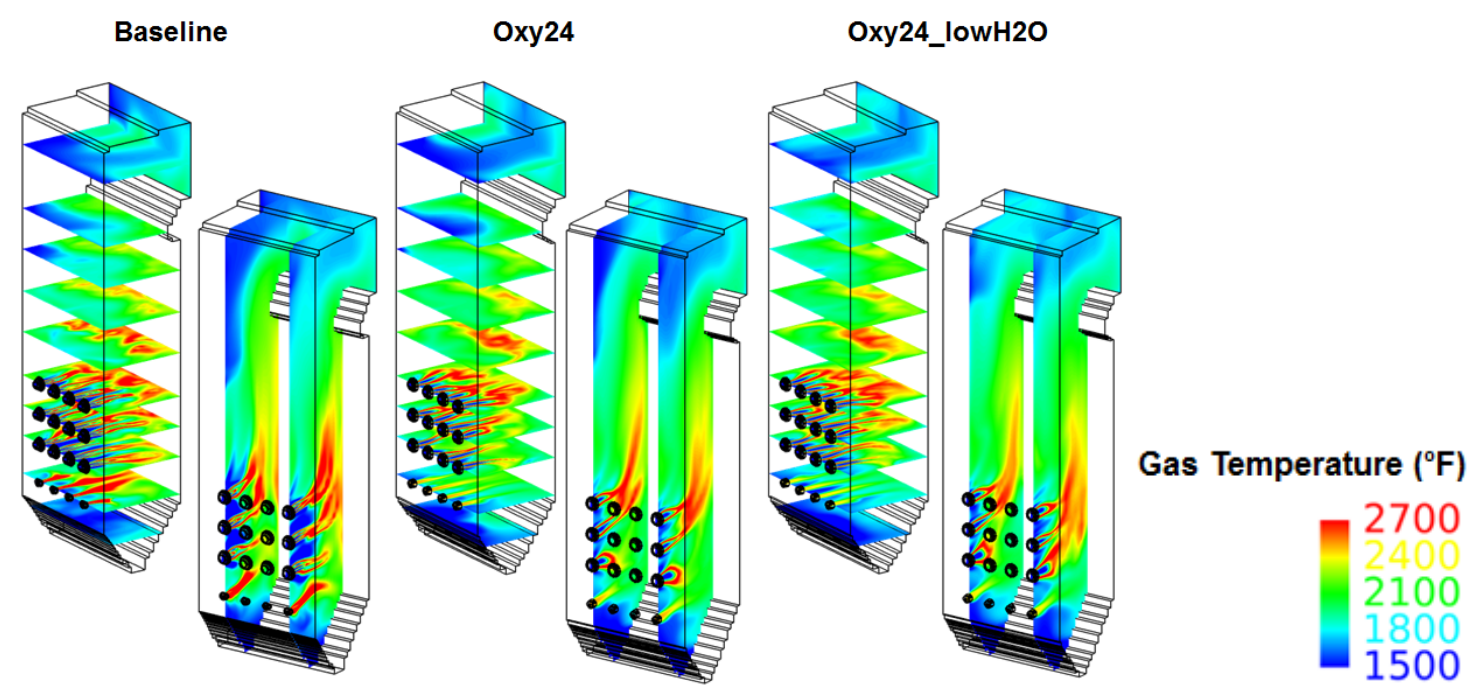

Figure 4.13-76: River Rouge model predicted gas temperature profiles. 


\section{Gas Temperature vs. Elevation}

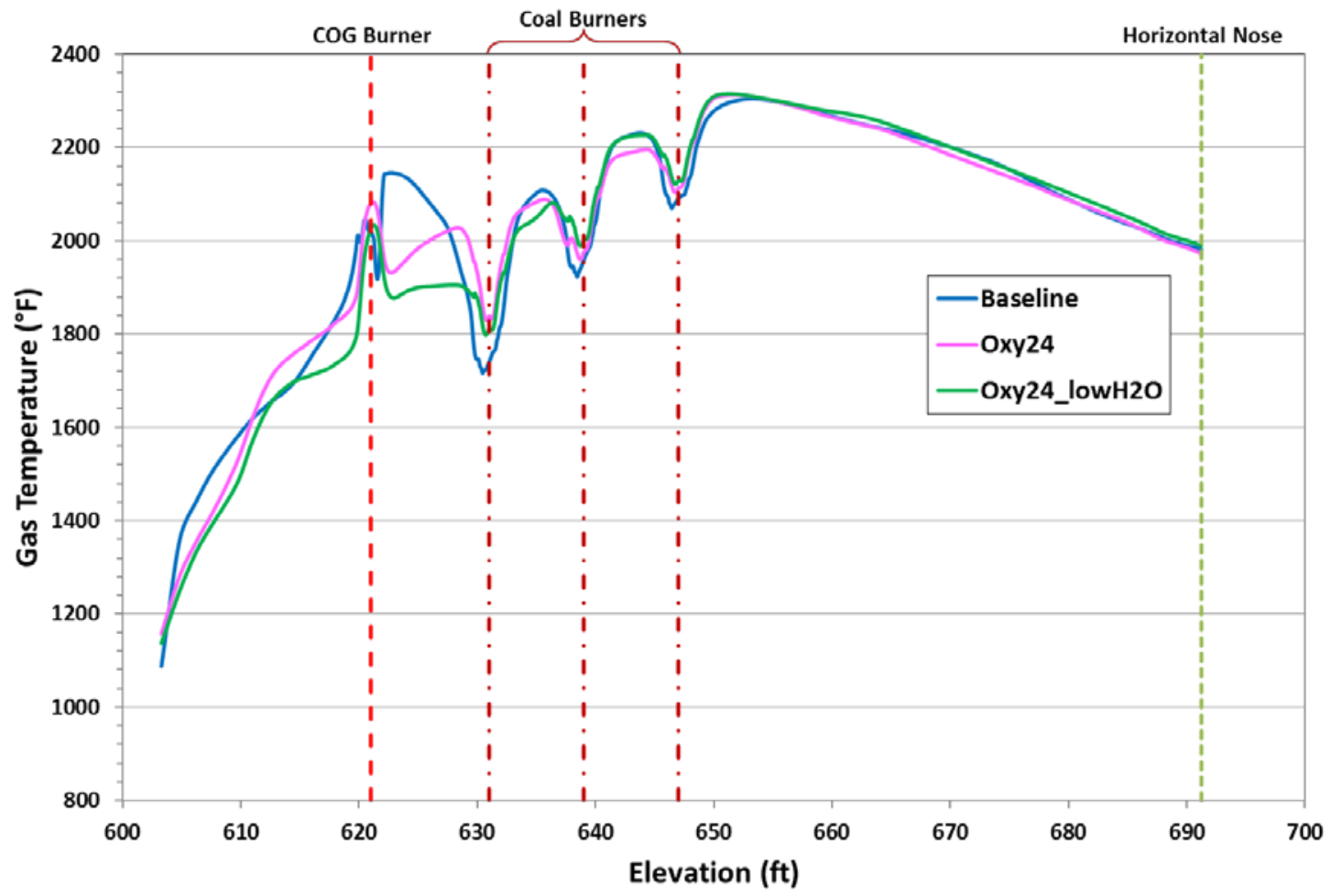

Figure 4.13-77: River Rouge model predicted gas temperature with elevation.

Predicted CO concentration profiles are shown in Figure 4.13-78 and Figure 4.13-79. Peaks in CO concentration are seen at each burner elevation where fuel-rich (CO generating conditions) are present. The oxy-fired cases show higher CO mass flow throughout the furnace. Regions of higher CO persist above the nose for the oxy-fired cases, which results in higher $\mathrm{CO}$ concentrations at the model exit for these cases. Drying the flue gas recycle resulted in higher CO peaks for the first two coal burner elevations, but CO is slightly lower at the nose.

Baseline

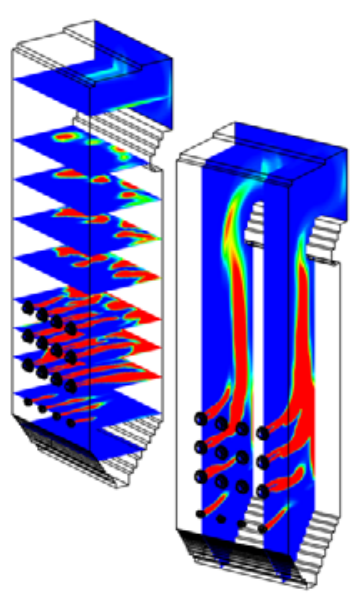

Oxy24

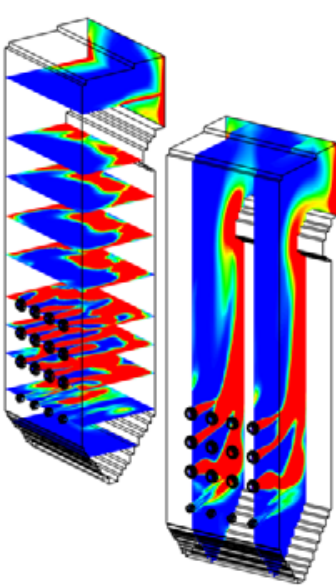

Oxy24_lowH2O

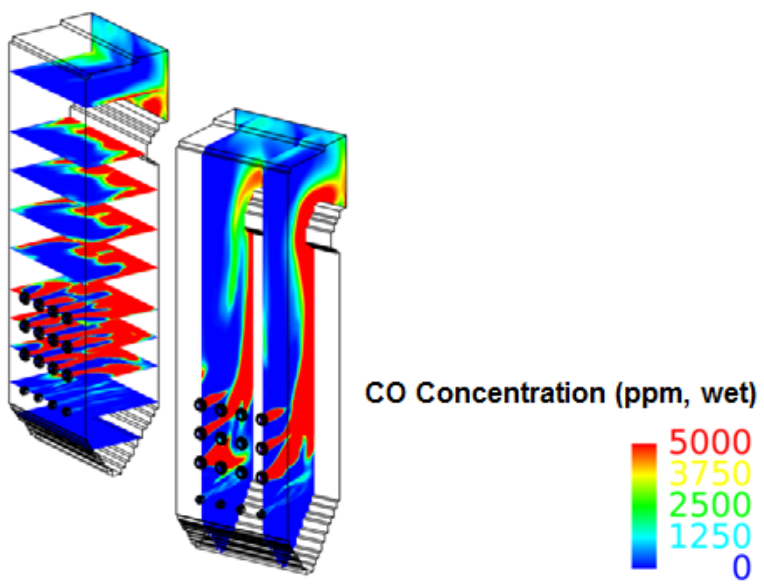

Figure 4.13-78: River Rouge model predicted CO concentration profiles. 


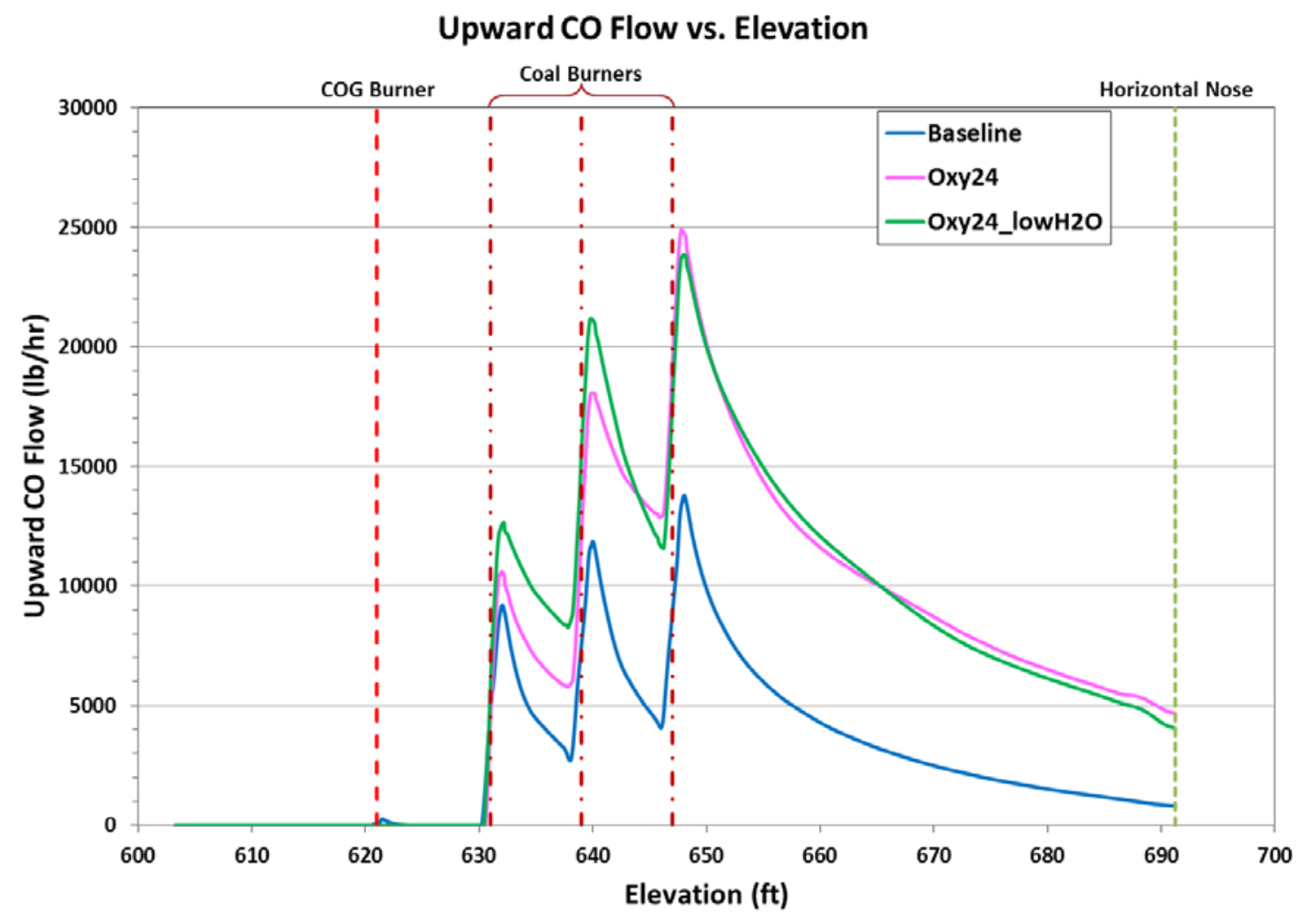

Figure 4.13-79: River Rouge model predicted CO flow with elevation.

Predicted $\mathrm{O}_{2}$ concentration profiles are shown in Figure 4.13-80 and Figure 4.13-81. Overall, the oxyfired cases were run with a lower stoichiometric ratio (3.0\% dry excess $\mathrm{O}_{2}$ versus $5.4 \%$ dry excess $\mathrm{O}_{2}$ in the air-fired case). Drying the flue gas resulted in higher $\mathrm{O}_{2}$ concentrations below the middle row of coal burners, but the two oxy-fired cases have very similar $\mathrm{O}_{2}$ profiles above this location. 


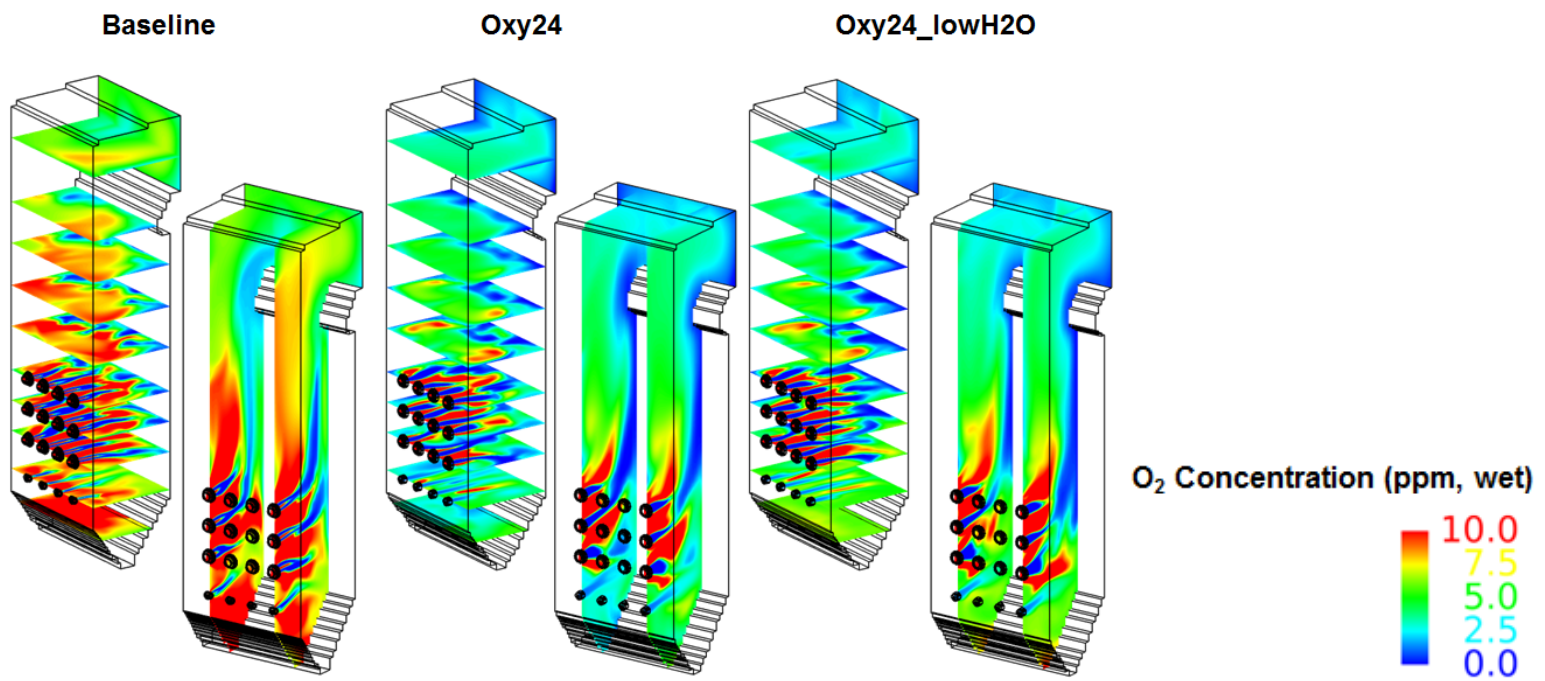

Figure 4.13-80: River Rouge model predicted $\mathrm{O}_{2}$ concentration profiles.

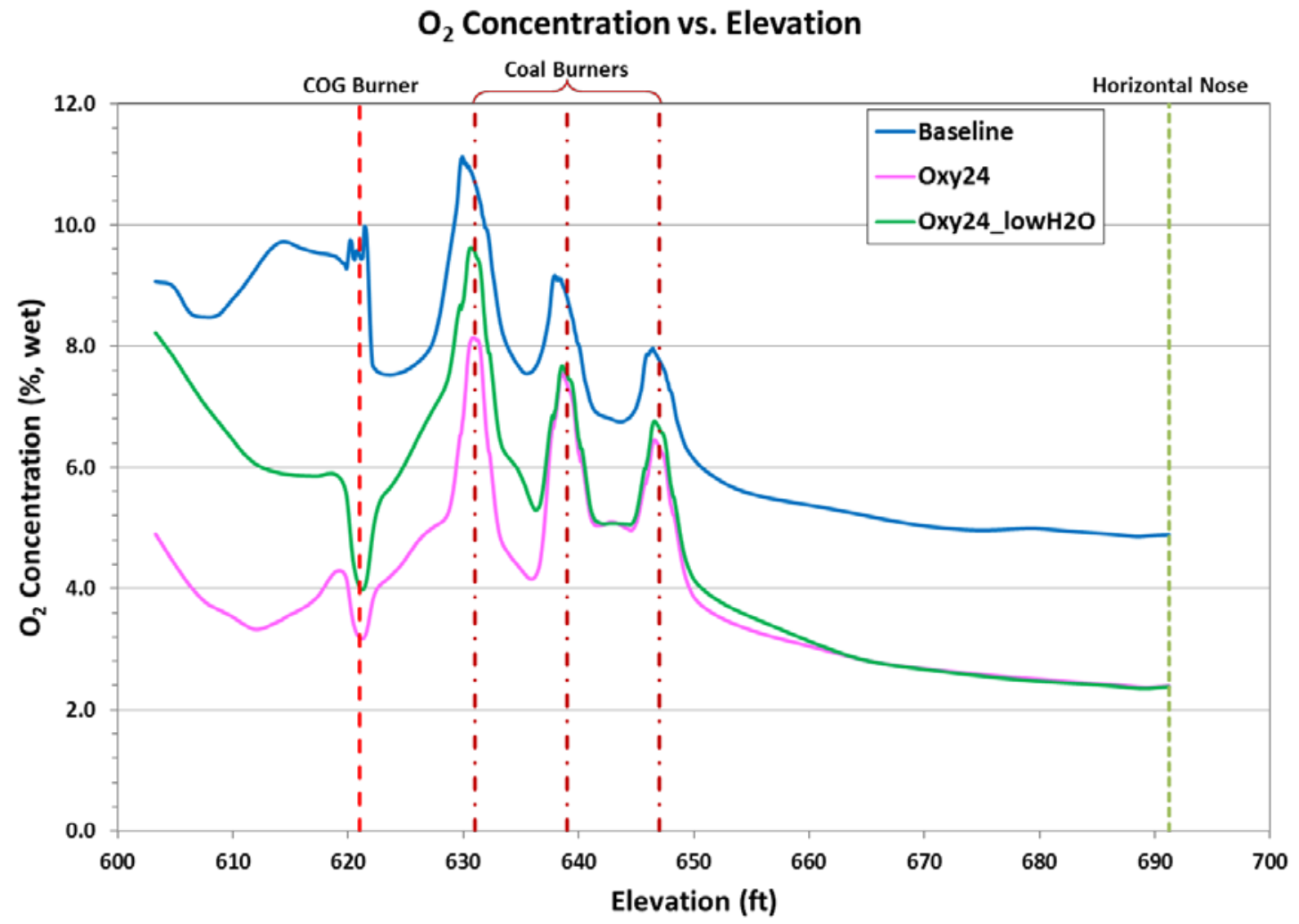

Figure 4.13-81: River Rouge model predicted $\mathrm{O}_{2}$ concentration with elevation. 
Figure 4.13-82 shows model predicted total velocity profiles. The oxy-fired cases have considerably lower velocities throughout the furnace as a result of lower gas flow. The highest velocities occur near the burners and along the rear wall for both air- and oxy-fired conditions.

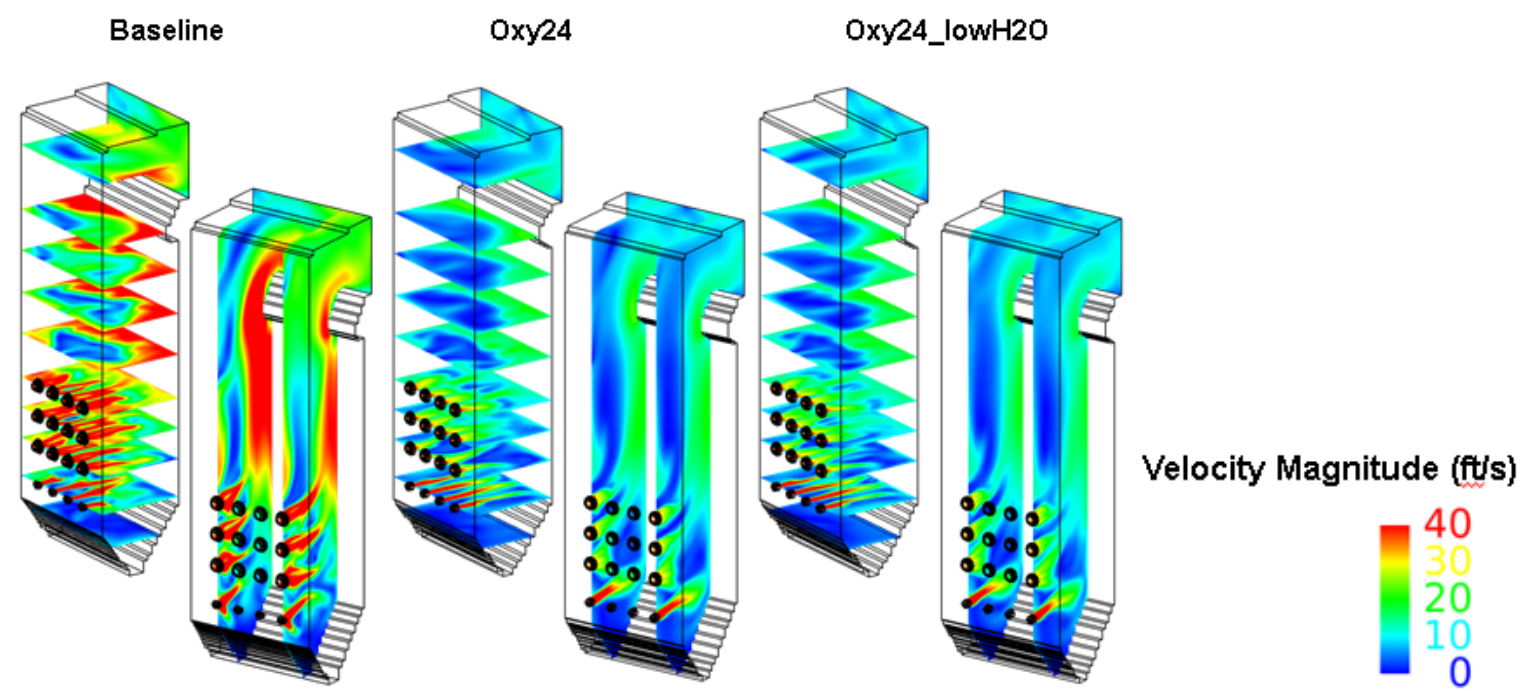

Figure 4.13-82: River Rouge model predicted velocity profiles.

Figure 4.13-83 shows particle burnout profiles. At the model exit, the oxy-fired cases show lower burnout compared to the air-fired case, which results in higher unburned carbon in the fly ash. The lowest levels of burnout at the exit occur along the left and right walls.

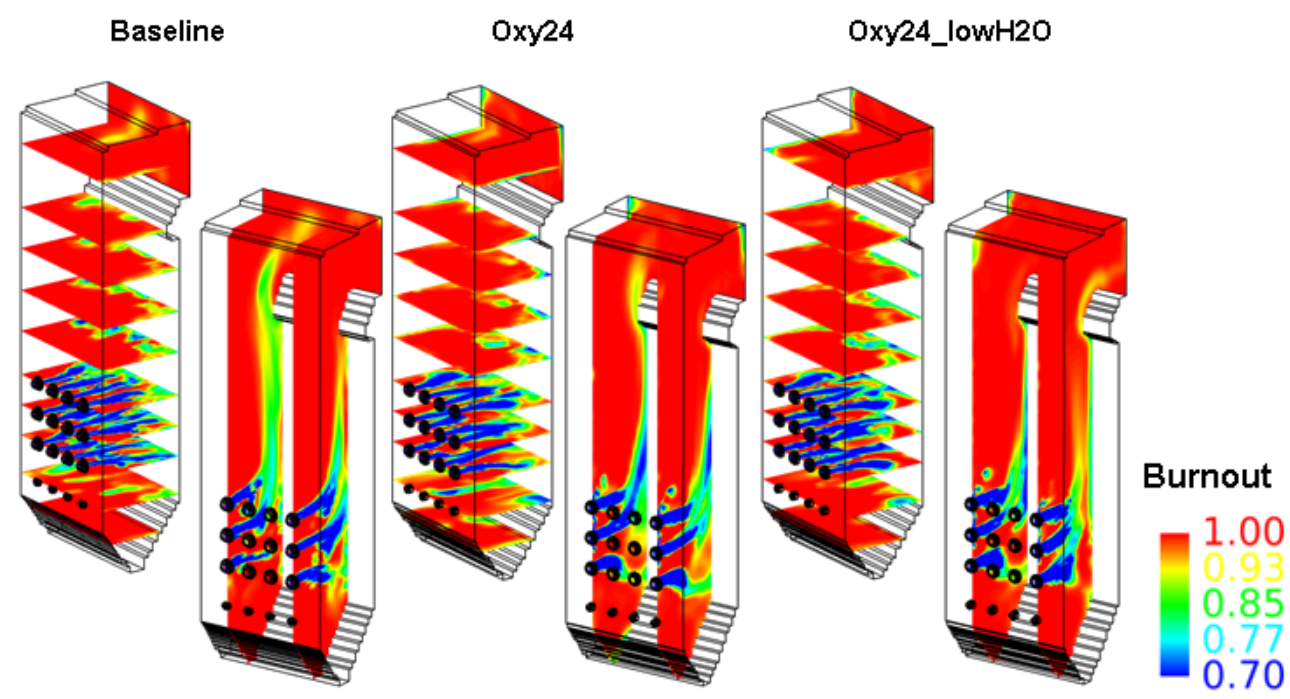

Figure 4.13-83: River Rouge model predicted particle burnout profiles.

Figure 4.13-84 shows wall deposition profiles. In the air-fired case, $2.9 \%$ of the coal mineral matter deposits on the wall. This increased to $4.0 \%$ for the oxy-fired case. Deposition decreased to $2.8 \%$ with flue gas recycle drying. The highest deposition rates occur in the hopper, on the nose, and on the rear wall. 


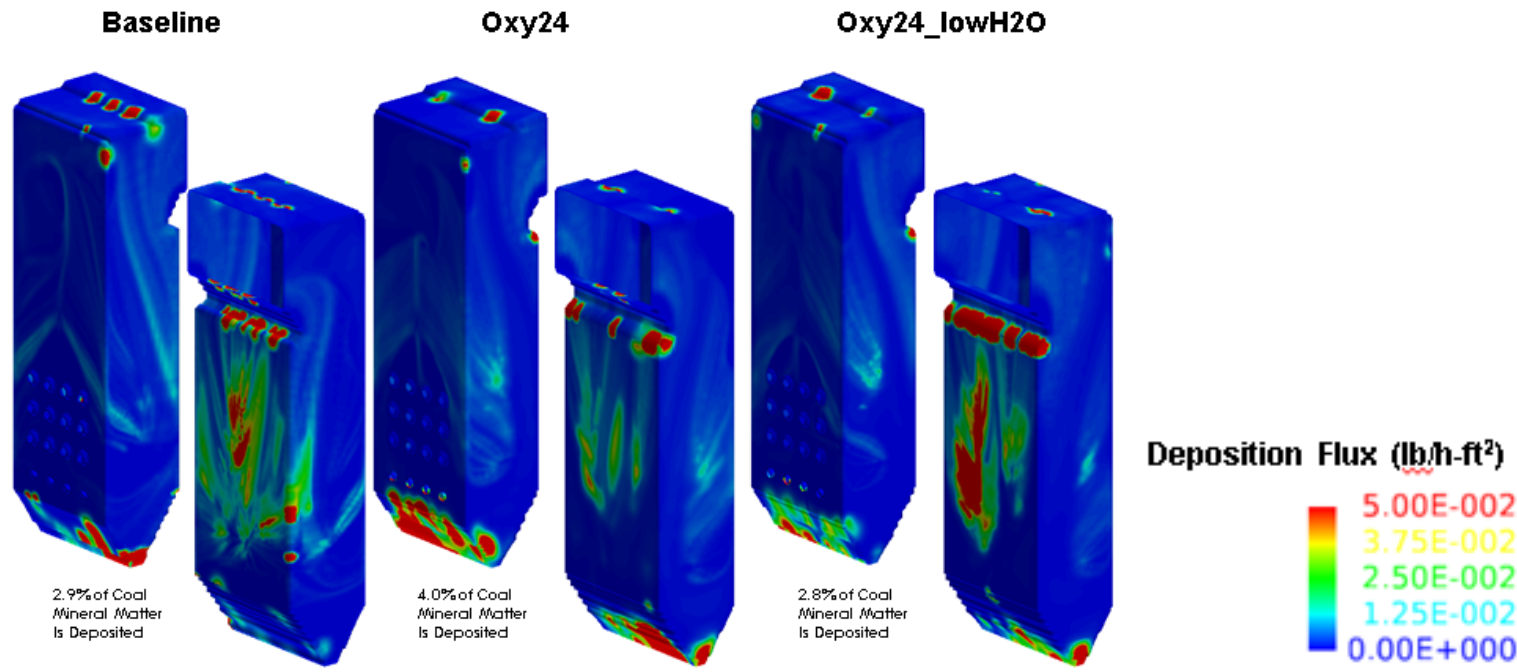

Figure 4.13-84: River Rouge model predicted particle deposition profiles.

Net heat flux profiles are shown in Figure 4.13-85. Table 4.13-20 shows net heat flux by zone and Figure 4.13-86 shows net heat flux by surface. The net heat transfer for the air-fired case was tuned to steam side data. The oxy-fired case showed the same total lower furnace heat transfer, but waterwall heat transfer was 5.6\% lower and radiative superheat heat transfer was 7.3\% higher. Heat flux moved to higher elevations in the furnace (less heat transfer in Zones 1\&2 and more in Zones $3 \& 4$ compared to the air-fired case), which is consistent with slower burnout and higher unburned carbon. Drying the flue gas before recycle did not have a significant impact on the net heat flux.
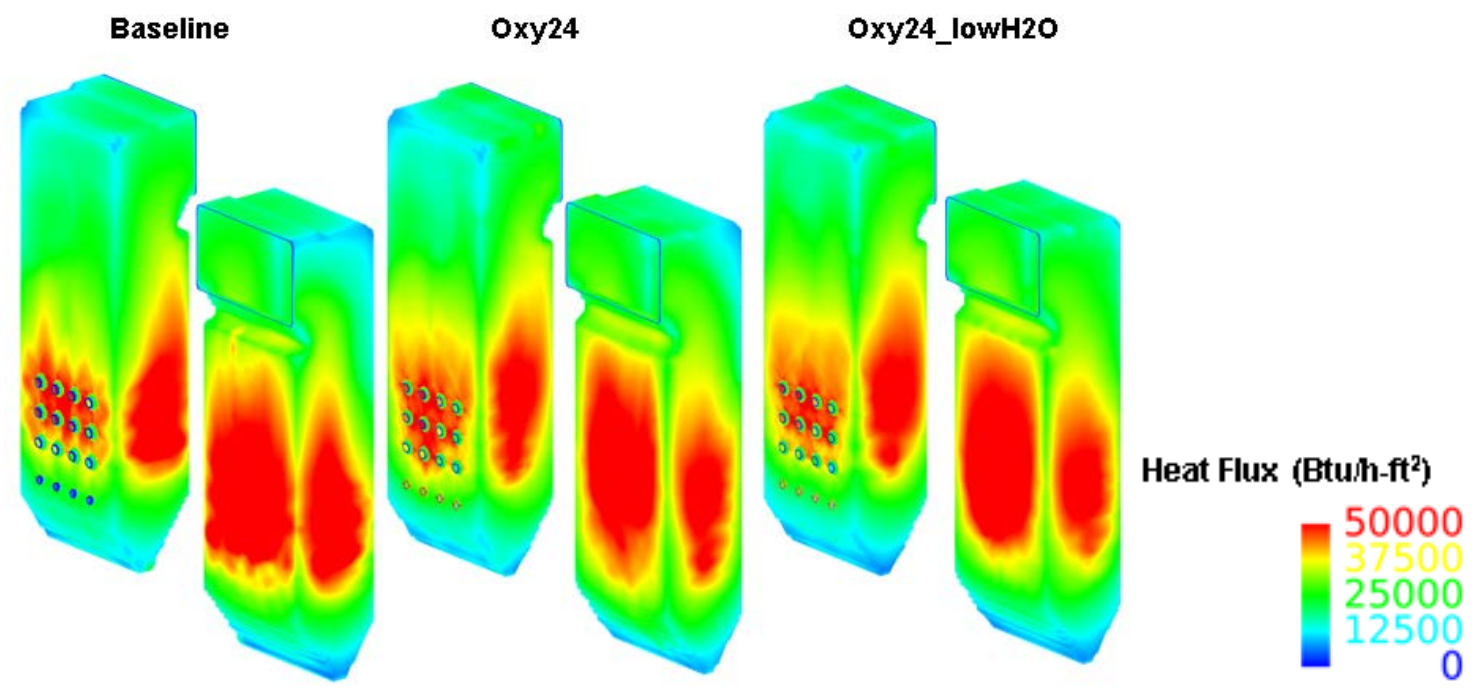

Figure 4.13-85: River Rouge model predicted net heat flux. 
Table 4.13-20: River Rouge model predicted net heat flux by zone.

\begin{tabular}{|c|c|c|c|c|c|c|}
\hline & \multicolumn{2}{|c|}{ Baseline } & \multicolumn{2}{c|}{ Oxy24 } & \multicolumn{2}{c|}{ Oxy24_lowH2O } \\
\hline Zone & $\begin{array}{c}\text { Heat Transfer } \\
\text { Rate (MBtu/hr) }\end{array}$ & $\begin{array}{c}\text { \% of } \\
\text { Total }\end{array}$ & $\begin{array}{c}\text { Heat Transfer } \\
\text { Rate (MBtu/hr) }\end{array}$ & $\begin{array}{c}\text { \% of } \\
\text { Total }\end{array}$ & $\begin{array}{c}\text { Heat Transfer } \\
\text { Rate (MBtu/hr) }\end{array}$ & $\begin{array}{c}\text { \% of } \\
\text { Total }\end{array}$ \\
\hline $\mathbf{1}$ & 42 & $9.1 \%$ & 39 & $8.6 \%$ & 35 & $7.5 \%$ \\
\hline $\mathbf{2}$ & 154 & $33.6 \%$ & 144 & $31.5 \%$ & 141 & $30.4 \%$ \\
\hline $\mathbf{3}$ & 189 & $41.2 \%$ & 197 & $43.0 \%$ & 204 & $44.0 \%$ \\
\hline $\mathbf{4}$ & 74 & $16.1 \%$ & 78 & $16.9 \%$ & 83 & $18.0 \%$ \\
\hline Total & 459 & & 459 & & 462 & \\
\hline
\end{tabular}
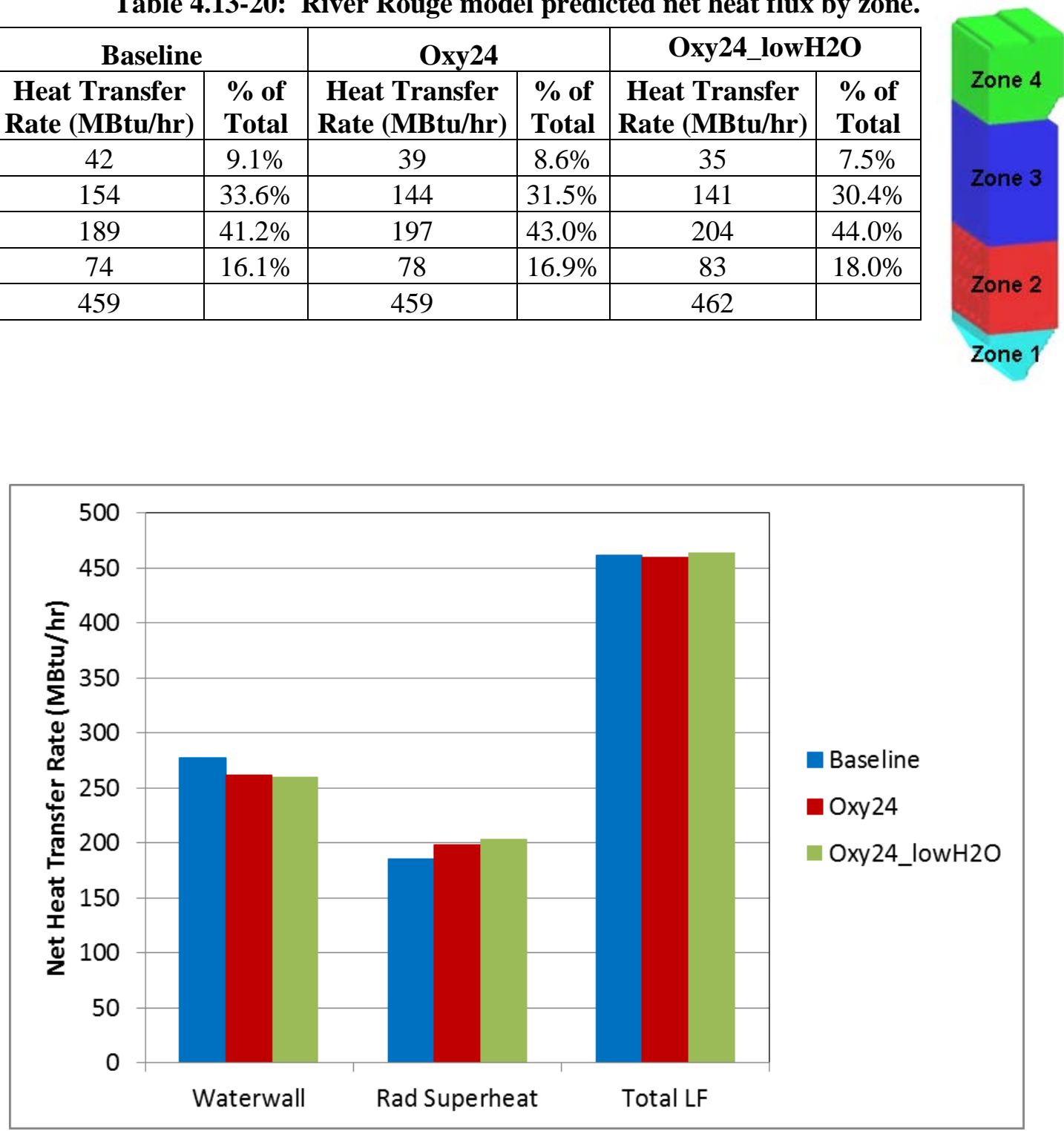

Figure 4.13-86: River Rouge model predicted net heat flux by surface.

Overall, several differences were seen between the air- and oxy-fired cases. CO concentration increased during oxy-firing, which is consistent with pilot-scale tests. $\mathrm{O}_{2}$ is consumed more slowly during oxyfiring suggesting slower burnout. Unburned carbon content of the fly ash was higher for oxy-firing. The FGR rate assumed in this modeling (24\% in the total $\mathrm{O}_{2} /$ FGR mixture) produced results which match the air-fired heat transfer well. This is consistent with previous process modeling. The previous process modeling also suggests that the heat transfer can also be fine-tuned by small adjustments to the recycle ratio. The heat transfer profile in the furnace shifted to higher elevations for oxy-firing, consist with delayed $\mathrm{O}_{2}$ consumption and current understanding of ignition and char oxidation. 


\subsubsection{CFD Modeling Results - Backpass}

The results from the lower furnace air and oxy cases were used as inputs to a backpass CFD model. A diagram of the modeled backpass geometry is shown in Figure 4.13-87. Two separate heat transfer surfaces were modeled as shown in Figure 4.13-88: convective superheat and economizer. The approach for modeling the backpass involved mapping results from the lower furnace exit plane into the upper furnace model inlet (as shown in Figure 4.13-89) and matching the heat absorption to each section of the convective pass for the air case using existing steam-side data (Table 4.13-21) by adjusting the wall boundary conditions. The convective pass model of the oxy combustion case used the same boundary conditions as the air case and was purely predictive. A non-equilibrium $\mathrm{CO}$ oxidation model was used to predict $\mathrm{CO}$ and $\mathrm{O}_{2}$ concentrations through the convective pass.
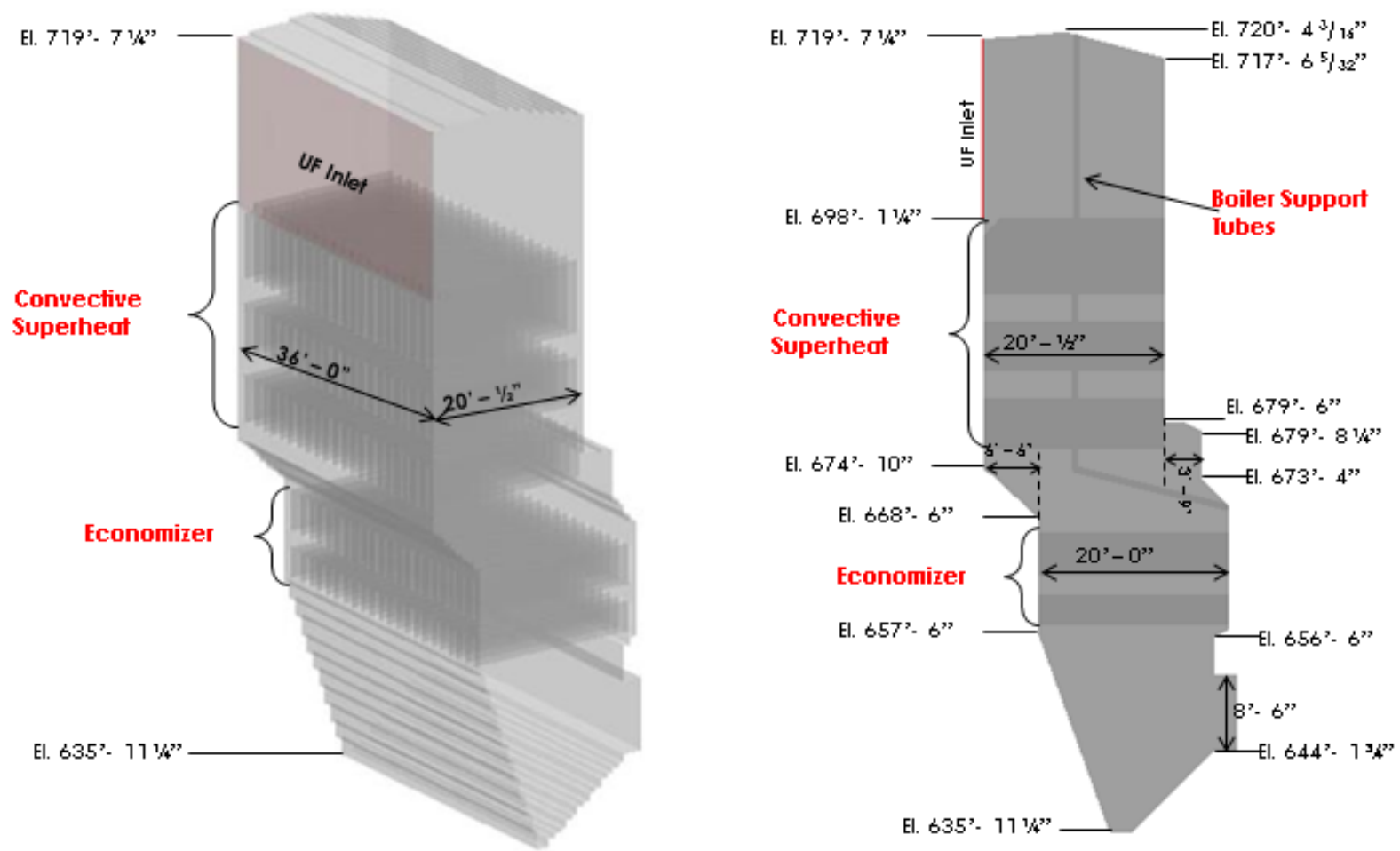

Figure 4.13-87: River Rouge Unit 3 modeled backpass geometry. 


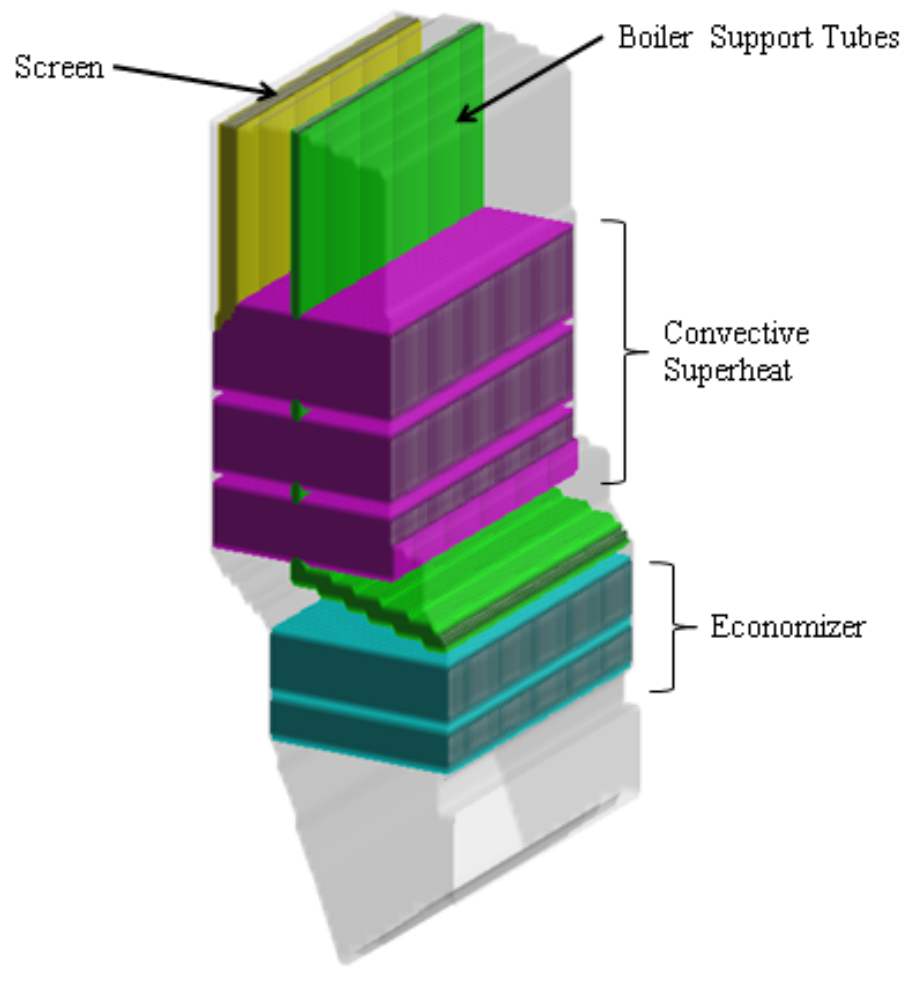

Figure 4.13-88: Convective sections in River Rouge model.

Lower Furnace Model
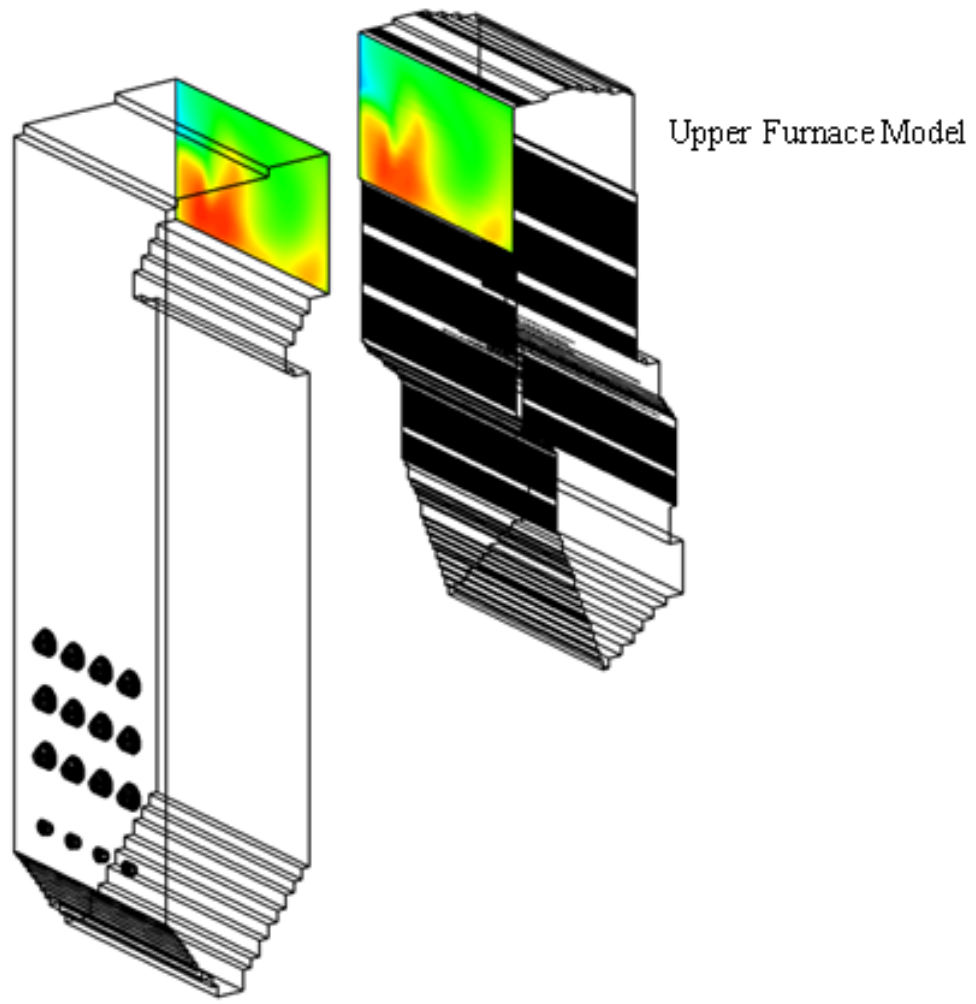

Figure 4.13-89: Mapping of River Rouge lower furnace exit plane to inlet of backpass model. 
Table 4.13-21: Steam Side Data Used to Match Predicted Heat Transfer in the River Rouge Air Backpass Model.

\begin{tabular}{|c|c|}
\hline \multicolumn{2}{|c|}{ Baseline - SH Furnace } \\
\hline \multicolumn{2}{|c|}{ Waterwall } \\
\hline Steam Temperature In $\left({ }^{\circ} \mathrm{F}\right)$ & Steam Temperature Out $\left({ }^{\circ} \mathrm{F}\right)$ \\
\hline 593 & 665 \\
\hline Pressure In (psia) & Pressure Out (psia) \\
\hline 2450 & 2450 \\
\hline Steam Mass Flow (klb/hr) & Total Heat Gained By Steam (MBtu/hr) \\
\hline 558 & 276 \\
\hline \multicolumn{2}{|c|}{ Radiant SH } \\
\hline Steam Temperature In $\left({ }^{\circ} \mathrm{F}\right)$ & Steam Temperature Out $\left({ }^{\circ} \mathrm{F}\right)$ \\
\hline 665 & 751 \\
\hline Pressure In (psia) & Pressure Out (psia) \\
\hline 2450 & 2418 \\
\hline Steam Mass Flow (klb/hr) & Total Heat Gained By Steam (MBtu/hr)* \\
\hline 740 & 186 \\
\hline \multicolumn{2}{|c|}{ Convective SH } \\
\hline Steam Temperature In $\left({ }^{\circ} \mathrm{F}\right)$ & Steam Temperature Out $\left({ }^{\circ} \mathrm{F}\right)$ \\
\hline 758 & 958 \\
\hline Pressure In (psia) & Pressure Out (psia) \\
\hline 2418 & 2304 \\
\hline Steam Mass Flow (klb/hr) & Total Heat Gained By Steam (MBtu/hr) \\
\hline 1,404 & 240 \\
\hline \multicolumn{2}{|c|}{ Economizer } \\
\hline Steam Temperature In $\left({ }^{\circ} \mathrm{F}\right)$ & Steam Temperature Out $\left({ }^{\circ} \mathrm{F}\right)$ \\
\hline 428 & 593 \\
\hline Pressure In (psia) & Pressure Out (psia) \\
\hline 2577 & 2450 \\
\hline Steam Mass Flow (klb/hr) & Total Heat Gained By Steam (MBtu/hr) \\
\hline 558 & 108 \\
\hline Total Heat Duty (MBtu/hr) & 810 \\
\hline
\end{tabular}

*Includes heat required to vaporize attemperation spray

The backpass model was run for the air- and oxy-fired cases (without flue gas recycle drying). The overall backpass model results are shown in Table 4.13-22. Air-fired convective surface heat transfer was matched to steam side data. Switching to oxy-firing with an FGR recycle rate producing $24 \% \mathrm{O}_{2}$ (wet) in the $\mathrm{O}_{2} /$ FGR mixture reduced convective pass heat transfer by $14.5 \%$ as seen in Figure $4.13-90$. From the process model results the heat transfer is expected to increase with increased FGR and the overall heat transfer is expected to be fine-tuned by slightly adjusting the FGR rate. 
Table 4.13-22: Overall CFD Model Results for River Rouge Backpass Cases.

\begin{tabular}{|l|c|c|}
\hline & Baseline & Oxy24 \\
\hline Model Inlet & & 1825 \\
\hline Temperature ( $\left.{ }^{\circ} \mathrm{F}\right)$ & 1850 & 2274 \\
\hline CO Concentration (ppm, wet) & 138 & $2.1 \%$ \\
\hline $\mathrm{O}_{2}$ Concentration (\%, wet) & $4.7 \%$ & \\
\hline Model Outlet & & 795 \\
\hline Temperature ( $\left.{ }^{\circ} \mathrm{F}\right)$ & 685 & 76 \\
\hline CO Concentration (ppm, wet) & 37 & 3.1 \\
\hline $\mathrm{O}_{2}$ Concentration (\%, wet) & 4.8 & \\
\hline Convective Surfaces $^{\circ}$ & & $1.99 \mathrm{E}+08$ \\
\hline Convective Superheat (Btu/hr) & $2.40 \mathrm{E}+08$ & $9.87 \mathrm{E}+07$ \\
\hline Economizer (Btu/hr) & $1.08 \mathrm{E}+08$ & \\
\hline
\end{tabular}

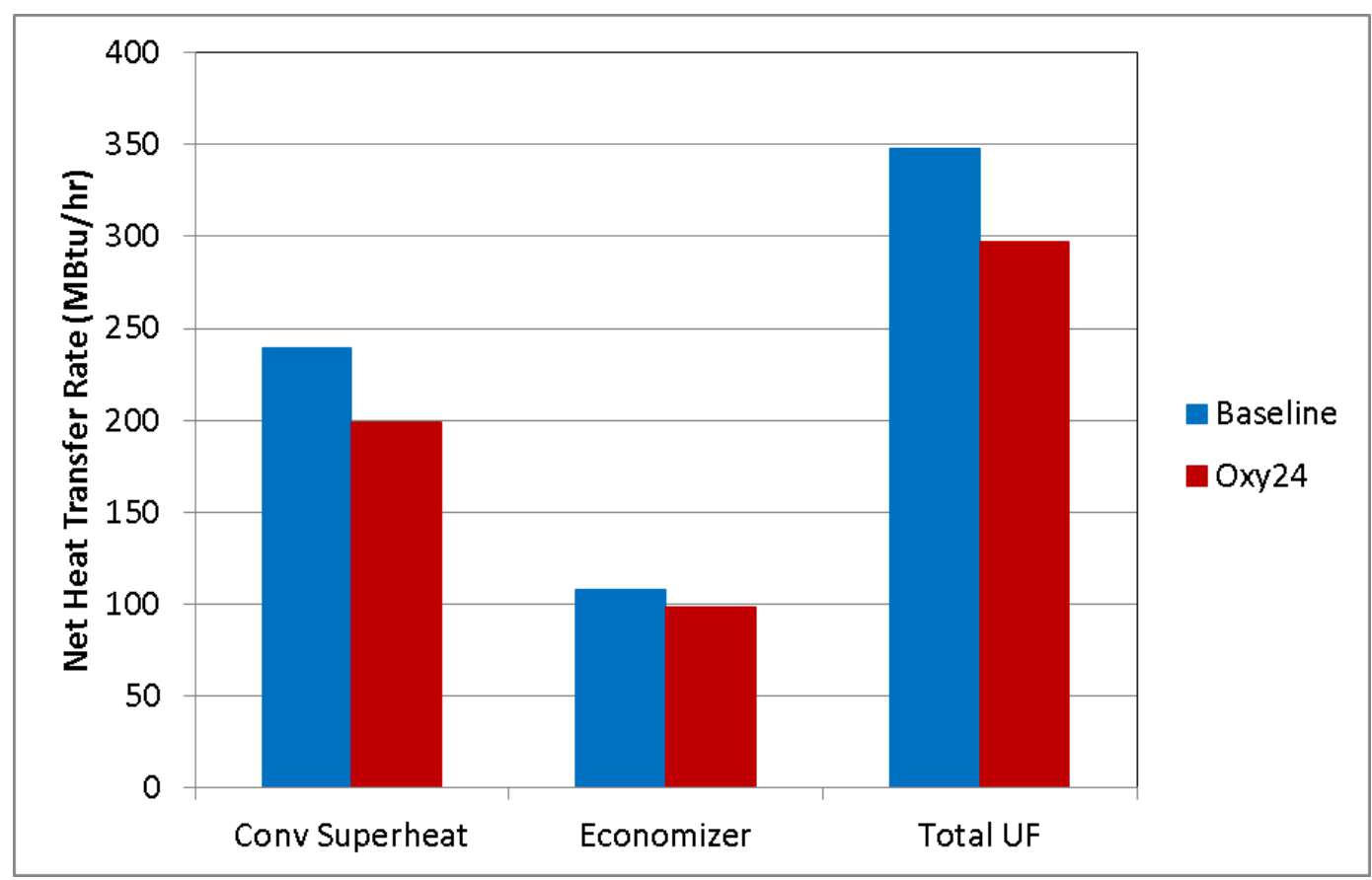

Figure 4.13-90: River Rouge backpass heat transfer for air- and oxy-fired cases. 
To aid in visualization, the convective surfaces will not be shown in the plots of model predictions. The locations of the visualization planes in reference to the convective surfaces are shown in Figure 4.13-91.

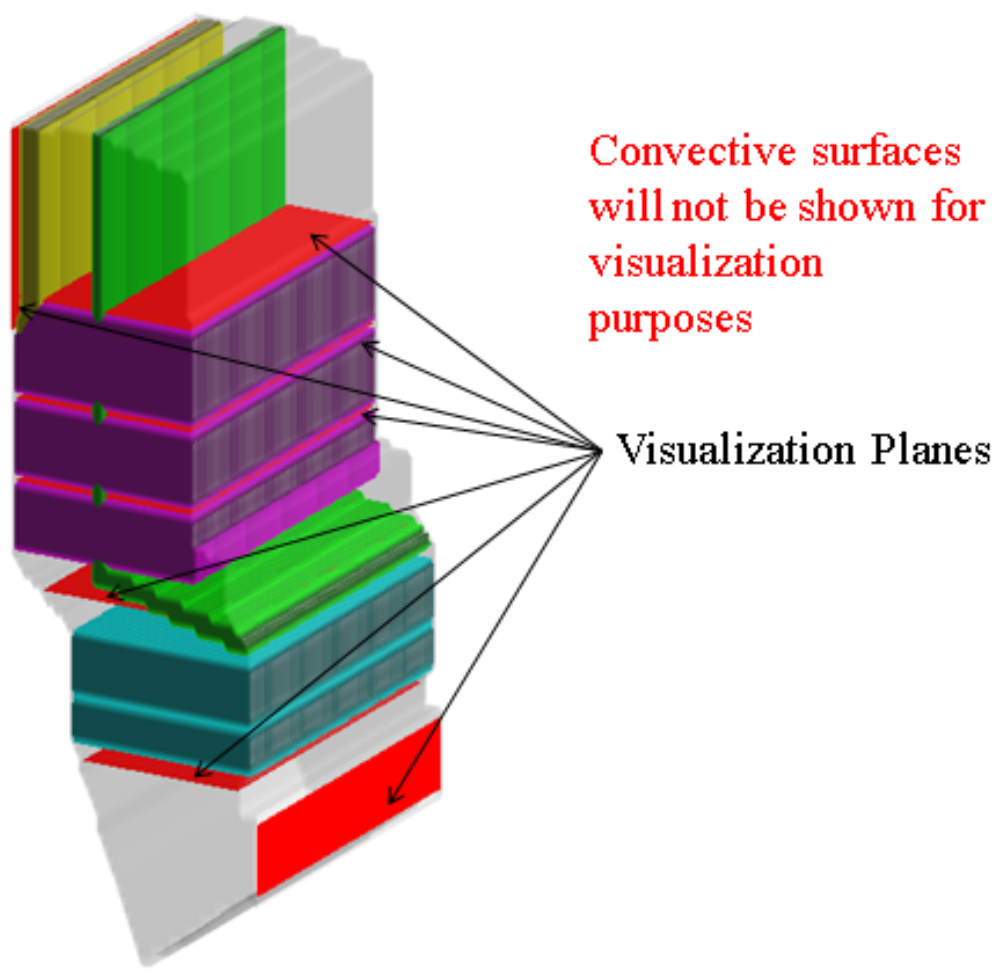

Figure 4.13-91: Location of visualization places for model prediction plots in reference to convective sections.

Plots of gas temperature, $\mathrm{O}_{2}$, and $\mathrm{CO}$ in the backpass are shown in Figure 4.13-92, Figure 4.13-93, and Figure 4.13-94 respectively. Gas temperature decreases quickly. The backpass inlet temperature is slightly lower for the oxy-fired case, but the exit temperature is lower compared to the air-fired case. The $\mathrm{O}_{2}$ plots show higher concentrations along the centerline of the gas flow for both cases. The overall $\mathrm{O}_{2}$ concentration doesn't change much in the air-fired case (4.7\% wet at model inlet and $4.8 \%$ wet at outlet), while the change in the oxy-fired case is larger (2.1\% wet at model inlet and 3.1\% wet at outlet). The $\mathrm{O}_{2}$ concentration increases through the backpass due to air leakage. There are regions of high $\mathrm{CO}$ at the inlet for both cases, though the oxy-fired backpass inlet CO concentration is about 16 times greater than the air-fired case. There are regions of high CO along the right and left walls in the oxy-fired case that persist to the model outlet. 

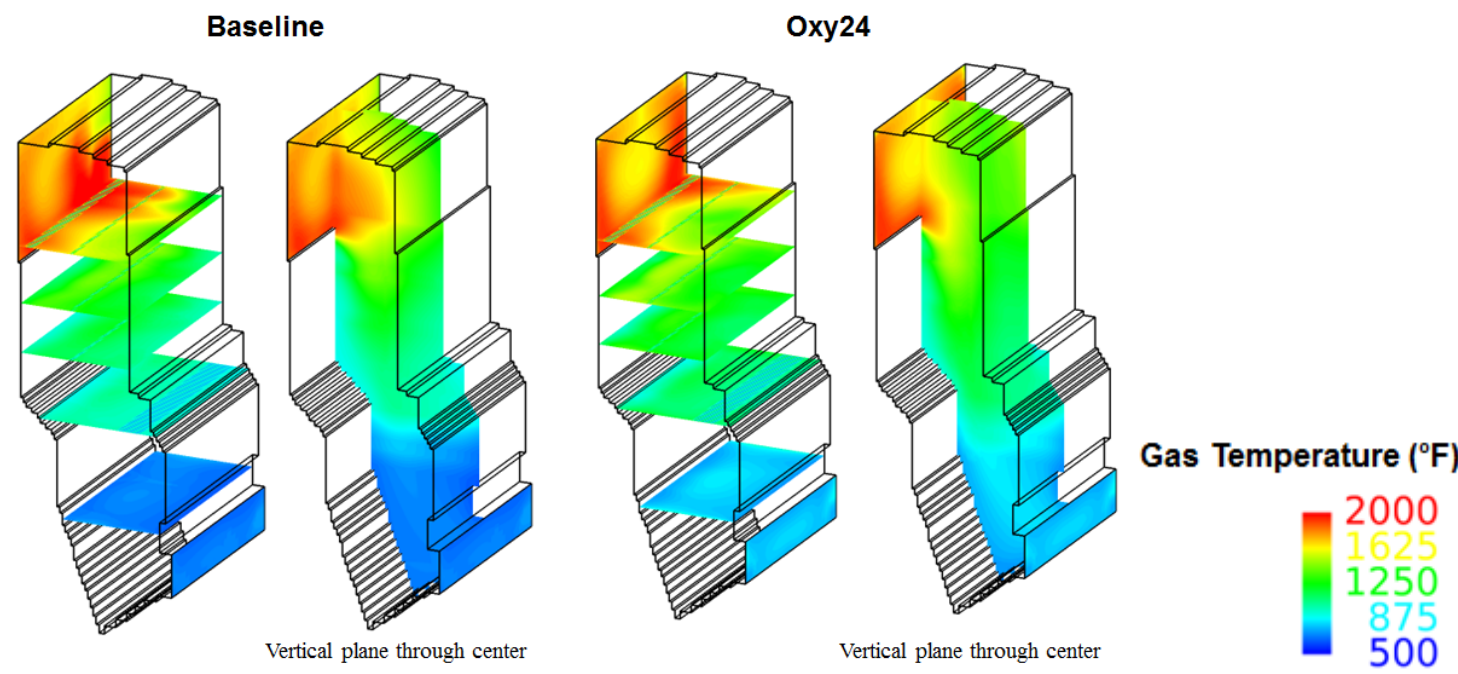

Figure 4.13-92: River Rouge model predicted gas temperature profiles in the backpass.
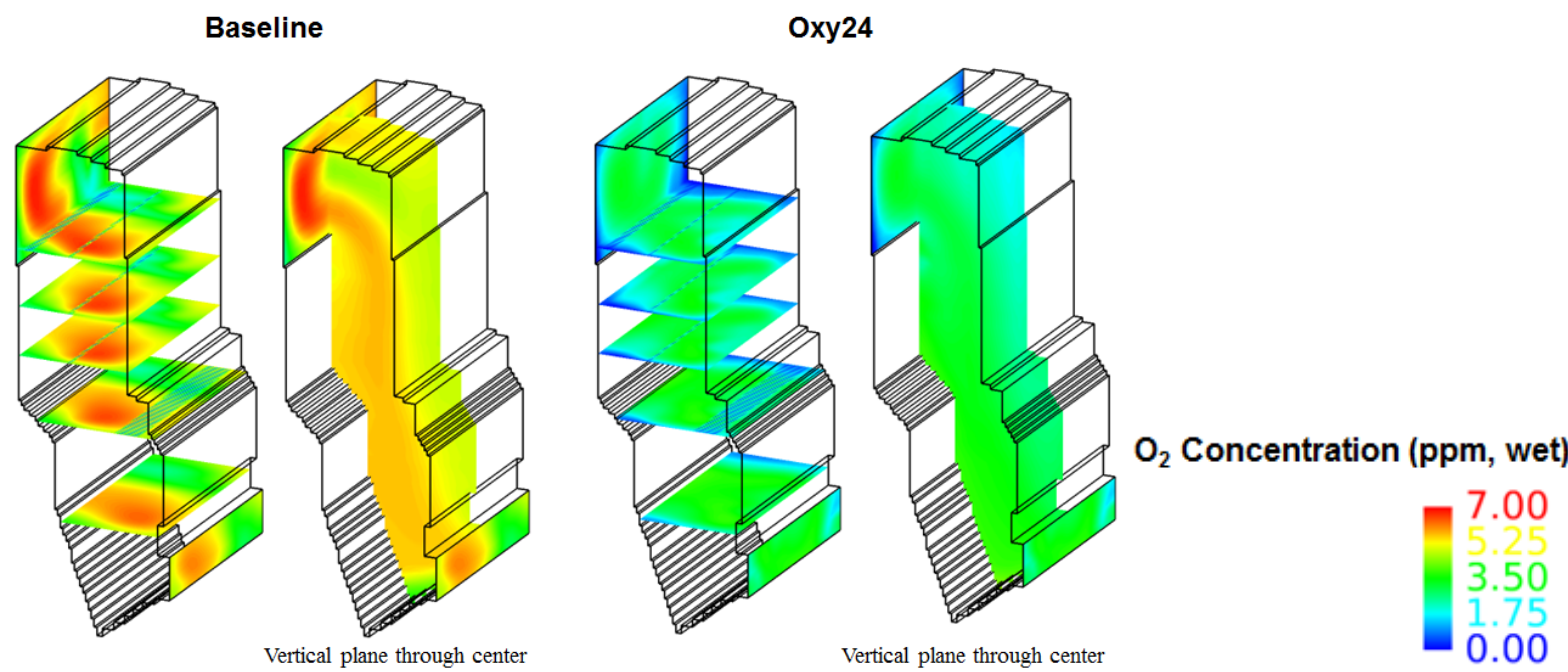

Figure 4.13-93: River Rouge model predicted $O_{2}$ concentration profiles in the backpass. 

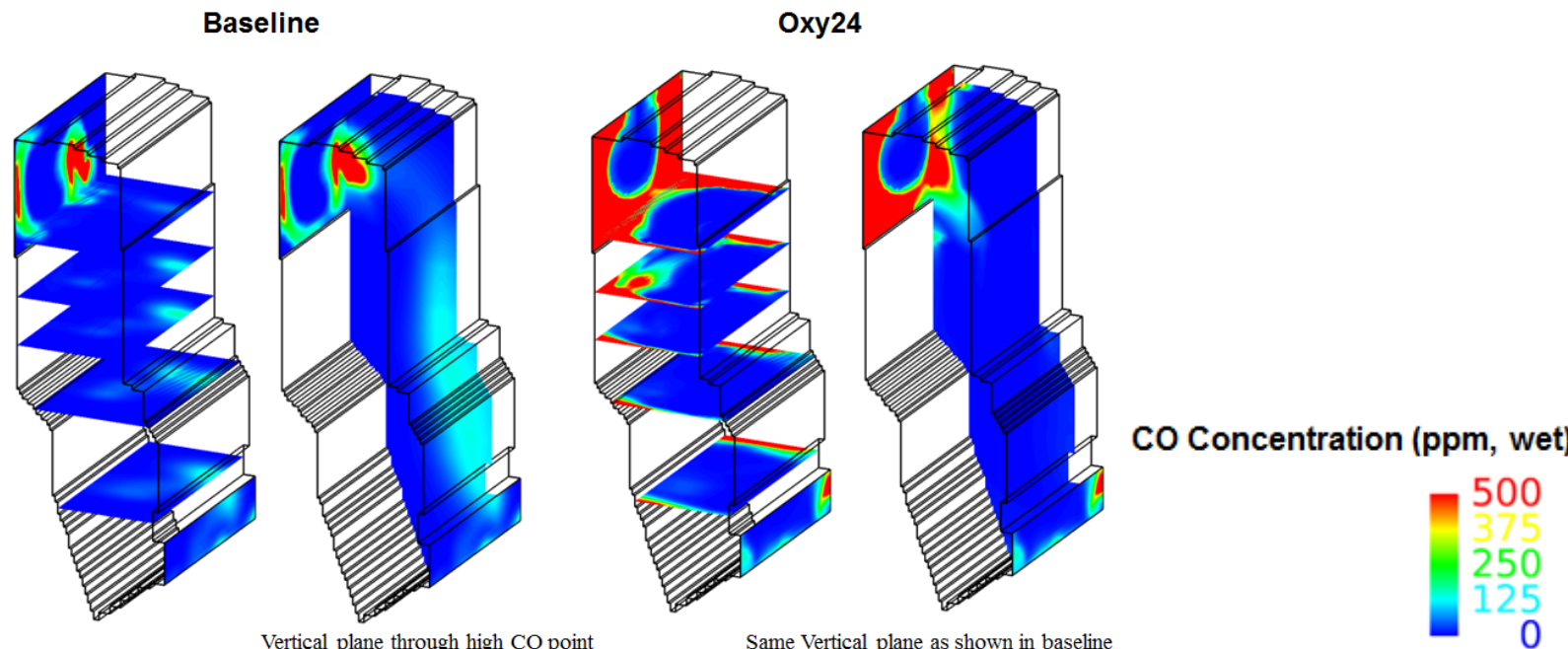

Figure 4.13-94: River Rouge model predicted CO concentration profiles in the backpass.

Figure 4.13-95 shows the model predicted heat flux to the wall surfaces and Figure 4.13-96 shows heat flux to the convective pass tube surfaces. The maximum heat flux to the convective surfaces is highest along the leading edge of the surface as expected (highest gas temperature). The oxy-fired case shows decreased heat transfer as discussed above. The convective superheater showed $17 \%$ lower heat transfer and the economizer was $9 \%$ low.
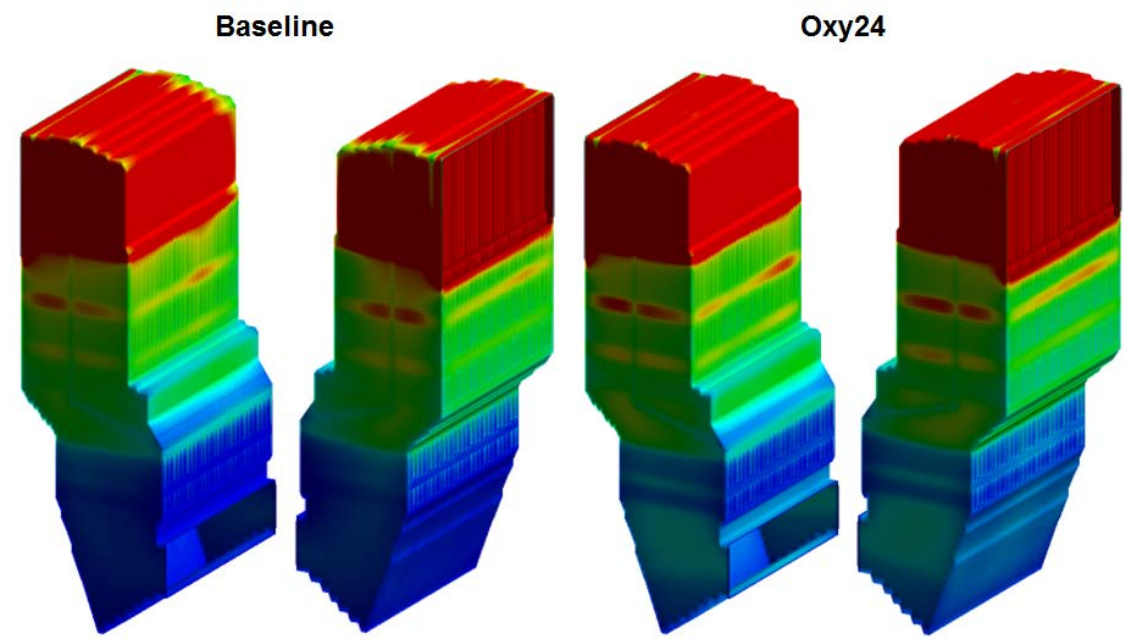

Heat Flux (Btu/h-ft²)

Figure 4.13-95: Model predicted net heat flux for walls in the backpass. 

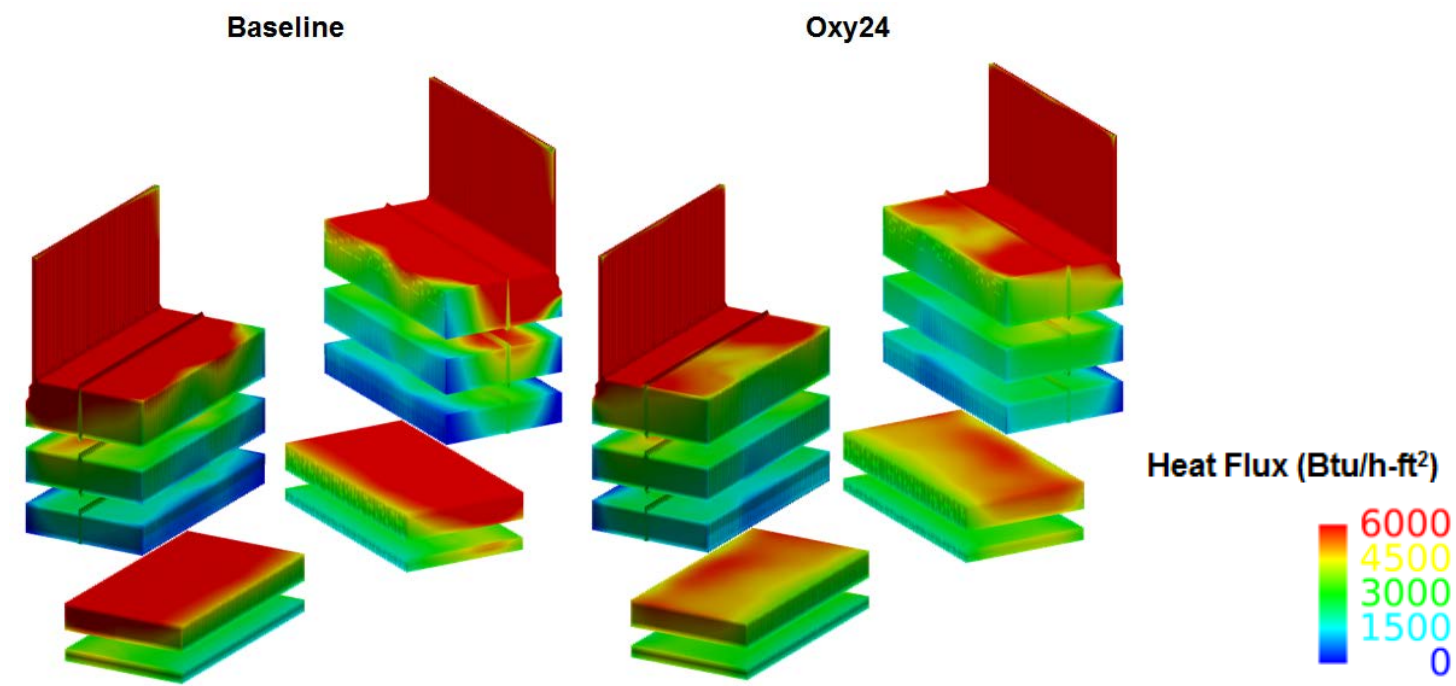

Figure 4.13-96: Model predicted net heat flux for convective surfaces in the backpass.

\subsubsection{Overall Comparison of Air- and Oxy-fired Results}

In comparing overall heat transfer for River Rouge Unit 3, a 24\% $\mathrm{O}_{2}$ mixture of oxygen and flue gas recycle was able to match the air-fired case heat transfer fairly well as shown in Figure 4.13-97. This is consistent with earlier process modeling that suggested $23 \% \mathrm{O}_{2}$ in the total $\mathrm{O}_{2}$ /FGR mixture would best match air-fired heat transfer (Figure 4.13-98). Further adjustments could be made to the heat transfer profile during operation by slightly adjusting the FGR recycle rate. Unburned carbon was higher in the oxy-fired case ( $7.6 \%$ versus $3.9 \%$ in the air-fired case). CO concentration was higher throughout the furnace for the oxy-fired case as shown in Figure 4.13-99. These modeling results suggest that there are not any catastrophic differences in an oxy-fired system compared to air-firing. 


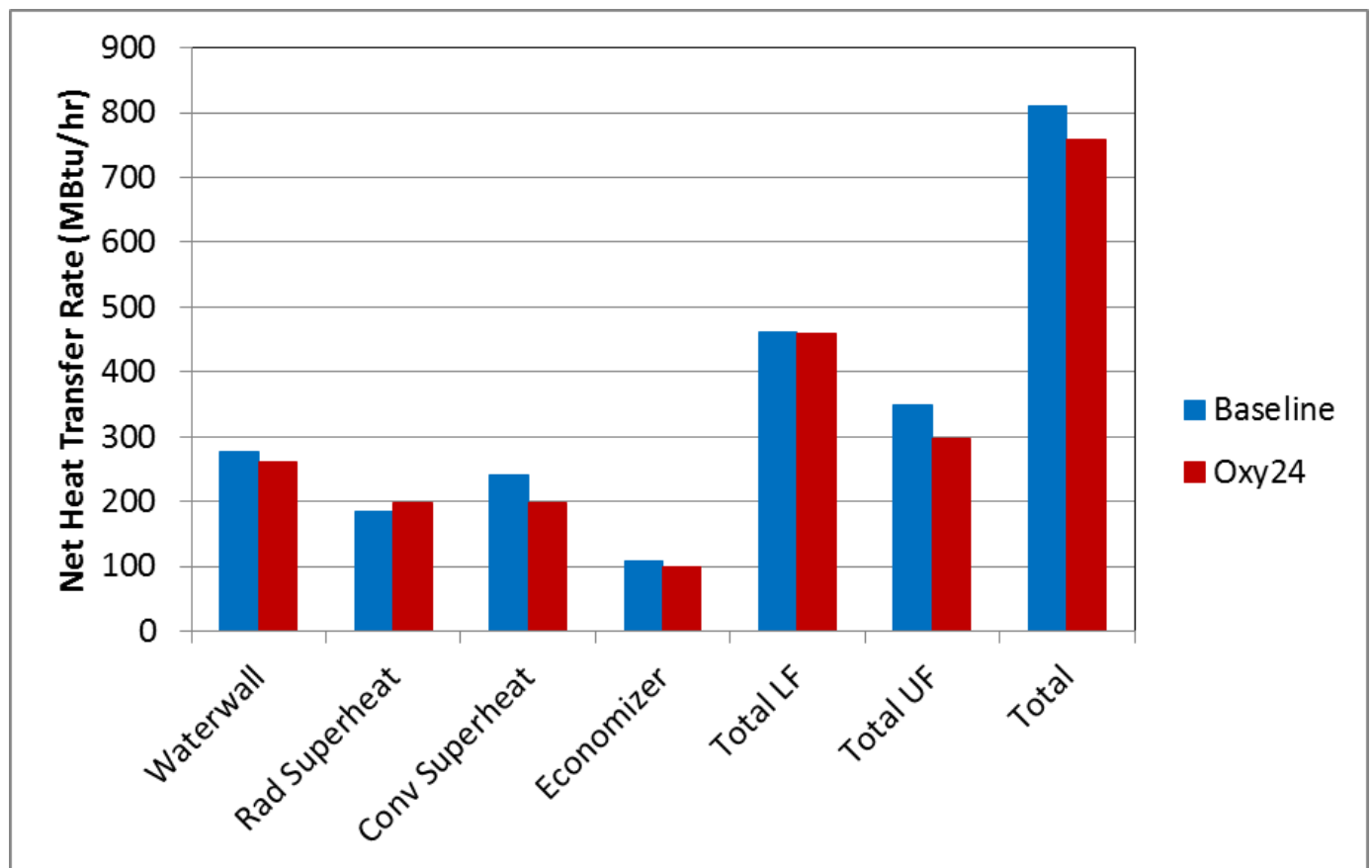

Figure 4.13-97: Overall comparison of air- and oxy-fired heat transfer for River Rouge Unit 3.

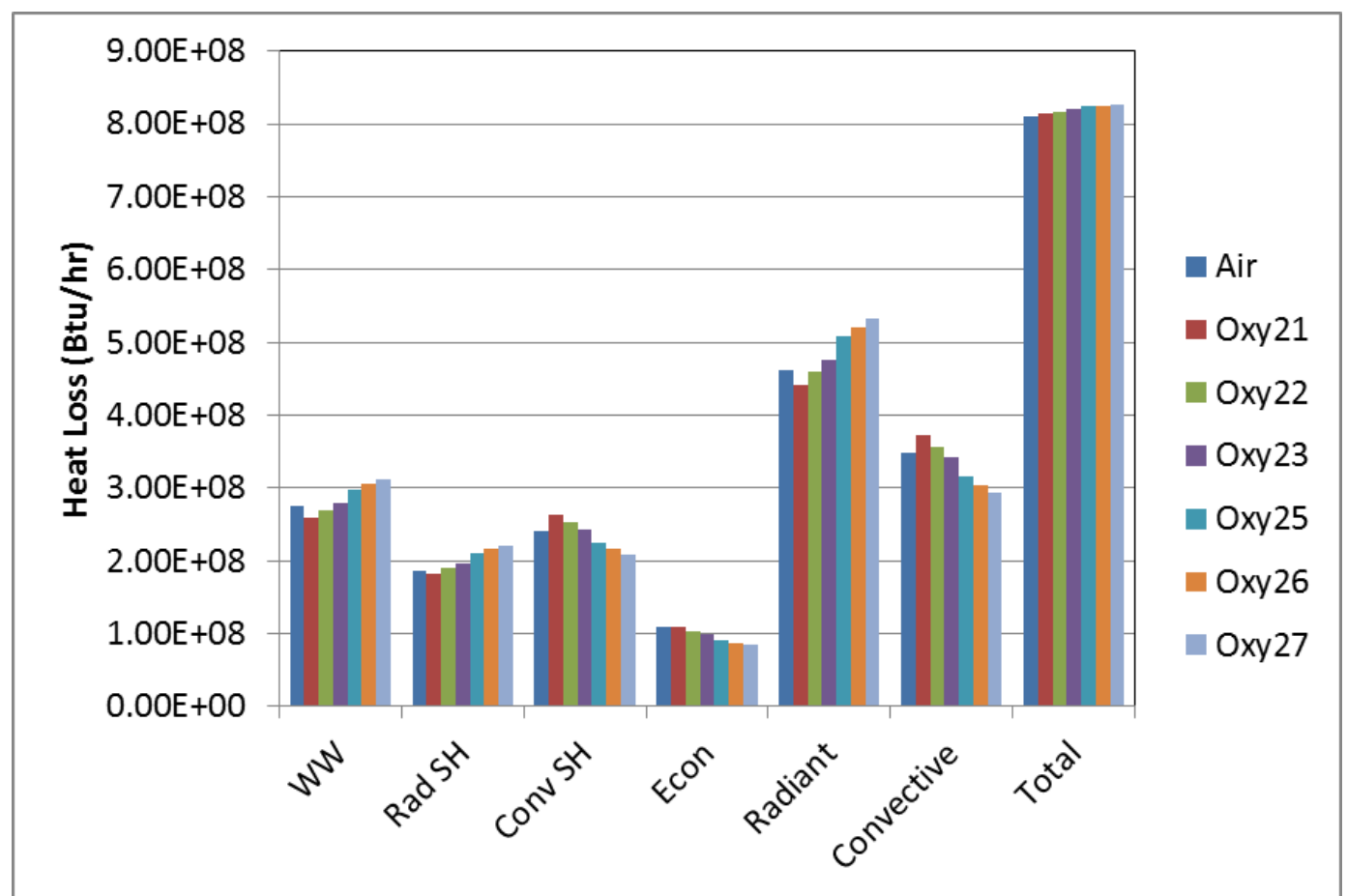

Figure 4.13-98: Process modeling results of oxy-firing heat transfer matching for River Rouge. 


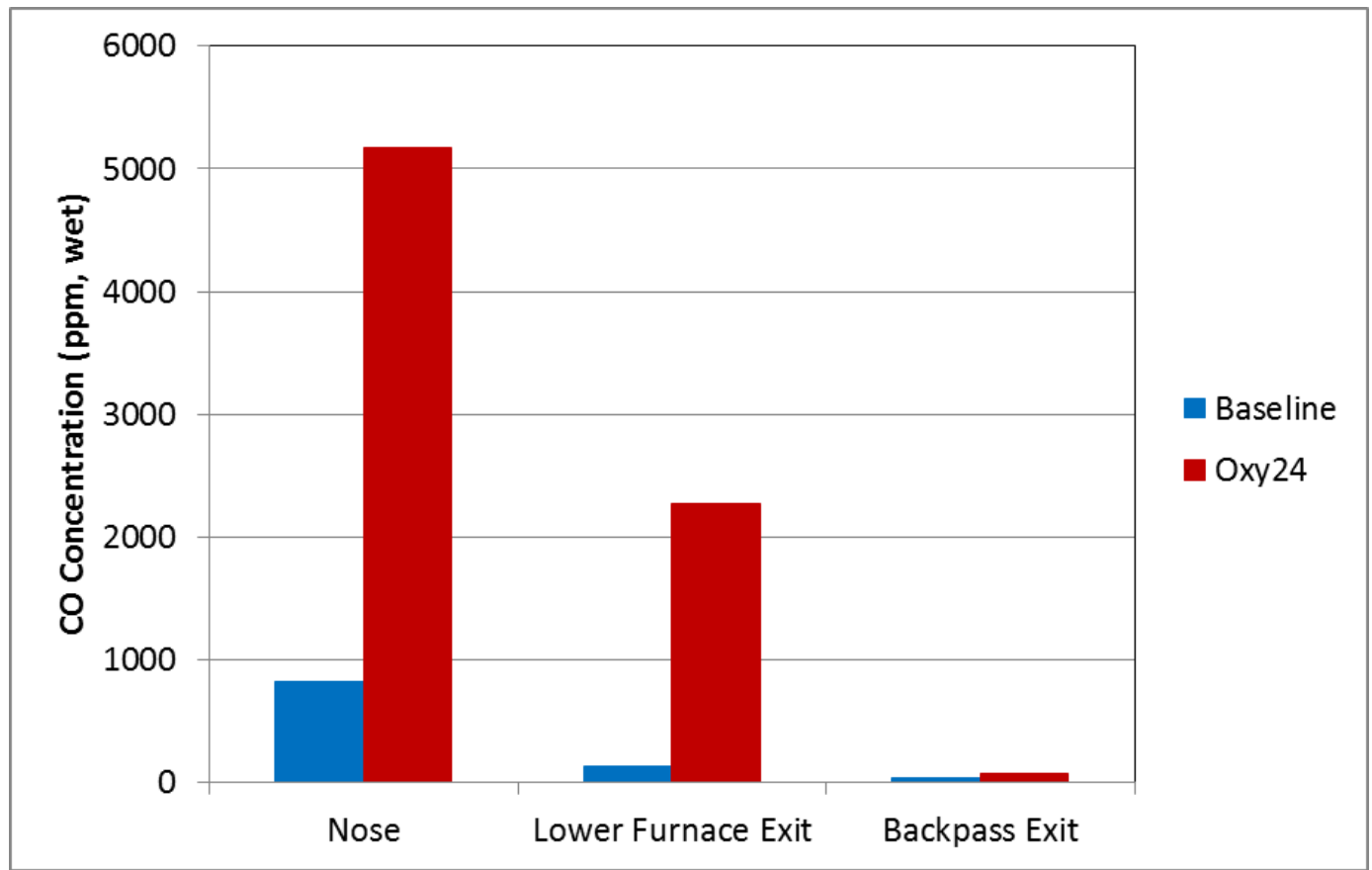

Figure 4.13-99: Comparison of model predicted air- and oxy-fired CO concentration throughout River Rouge.

\subsubsection{River Rouge 3 Modeling Conclusions}

An oxy-combustion retrofit assessment of DTE's River Rouge Unit 3 was conducted. The assessment included a firing system (burner) design and CFD simulations of air- and oxy-fired configurations.

The approach used by Siemens to identify the firing system design for River Rouge 3 was previously outlined. Once the appropriate thermodynamic and aerodynamic principles associated with burner performance were investigated, Siemens was able to design a burner for oxy-combustion retrofit of a coal-fired boiler without any major difficulty. In particular, Siemens was able to identify the following pertinent information required for an oxy-fired retrofit:

- It is critical to know the right $\mathrm{O}_{2}$ concentration in the furnace before starting the design process. This is a parameter that burner designers never had to consider before with air-fired systems and requires some boiler thermal modeling.

- It is not appropriate to match oxy-fired gas velocities with air-fired velocities. It is a better to use lower velocities for oxy-firing than air-fired velocities, particularly in the carrier stream, by a percentage that produces equal momentums between the two conditions. Siemens used 13\%, and that value proved to be successful.

- Removing moisture in the recycle stream is necessary for high moisture coals such as the fuel used at River Rouge 3, especially in the carrier gas stream. Failure to do so abates coal devolatilization and leads to condensation in the coal pipes.

- There are many oxygen enrichment schemes that have not been considered in this program that could potentially be very useful.

- Oxygen enrichment of the carrier stream poses many safety concerns. 
- When allocating oxygen and FGR to the combustion system compartments, it is advantageous to keep track of total oxygen and total FGR separately.

- Compared with an air-fired design, an oxy-fired burner will need to be adjusted primarily to account for the $\mathrm{O}_{2} \%$ in the furnace, the $\mathrm{O}_{2} \%$ in each compartment, and for the appropriate scaling factors to support combustion.

- A plant that is retrofitted for oxy-combustion can operate at full load for both the air-fired and oxy-fired condition by adjusting mill configurations accordingly (if needed).

REI's Glacier CFD combustion simulation tool was used to simulate air- and oxy-firing in the River Rouge Unit 3 Superheat boiler. Modeling included improved char oxidation, radiation, and soot, submodels. Those results showed:

- Higher CO concentrations were observed for oxy-fired conditions compared to air-firing. Gas temperature profiles were comparable. $\mathrm{O}_{2}$ concentrations were lower for oxy-firing, but the model was run with lower overall excess oxygen.

- Slower burnout during oxy-firing and lower oxygen concentrations resulted in higher unburned carbon in fly ash.

- Slightly lower heat transfer to the waterwalls and slightly higher heat transfer to the radiative superheat were predicted with oxy-firing. The overall lower furnace heat transfer was very similar for air- and oxy-firing.

- Drying the flue gas recycle stream for the oxy-fired case showed:

o Decreased exit gas temperature

o Decreased CO concentrations

o Decreased UBC

o Decreased particle deposition

o Similar heat transfer

Results from the lower furnace air- and oxy-fired cases were mapped into a model of the backpass. Compared to the air-fired backpass, the oxy-fired backpass showed:

- Higher exit temperature

- Higher CO concentrations

- Lower $\mathrm{O}_{2}$ concentrations (however the oxy-fired case was run with lower excess oxygen)

- Lower heat transfer to the convective superheat and economizer.

In comparing overall heat transfer for River Rouge Unit 3, a 24\% $\mathrm{O}_{2}$ mixture of oxygen and flue gas recycle was able to match the air-fired case heat transfer fairly well. This is consistent with SGE process modeling that suggested $23 \% \mathrm{O}_{2}$ in the total $\mathrm{O}_{2} /$ FGR mixture would best match air-fired heat transfer. For the $24 \% \mathrm{O}_{2}$ condition, unburned carbon was higher in the oxy-fired case (7.6\% versus $3.9 \%$ in the airfired case). These modeling results suggest that selection of flue gas composition with a $23-25 \% \mathrm{O}_{2}$ mixture of $\mathrm{O}_{2}$ and flue gas recycle can reasonably match heat transfer in an existing coal boiler (depending on the unit) and that there are not any insurmountable differences in combustion performance or operational impacts when converting from an air-fired system to oxy-firing. 


\subsubsection{Mercury Modeling of Full-scale Retrofits}

REI's MerSim ${ }^{\mathrm{TM}}$ mercury simulation tool calculates mercury concentration, speciation and emissions in boilers, from coal pile to stack. It includes homogeneous and heterogeneous oxidation kinetics, adsorption on fly ash, oxidation across selective catalytic reduction (SCR) units, and removal and re-emission across wet FGD scrubbers. This model can be used by utilities, given inputs that are generally available to them. After a preliminary investigation, several modifications were made to MerSim in order to better handle recycled species and predict mercury behavior. This updated version of MerSim was then used to predict mercury behavior for two full-scale oxy-combustion retrofits: Hunter Power Plant Unit 3 and River Rouge Power Plant Unit 3. These two units were the focus of the detailed retrofit study in this program. Either air- or oxy-fired conditions were used in baseline, KNX (a commercial calcium bromide-based mercury control additive, and activated carbon injection (ACI) scenarios.

\subsubsection{Preliminary Investigation}

In order to investigate mercury behavior during oxy-firing, MerSim was modified to accept a user-defined oxidant stream, which could be modified to include compositions other than air. Once this capability was added, the software was given to the University of Utah who ran a preliminary parametric study to gauge MerSim's response to varied oxidant conditions. A total of 27 cases (Table 4.13-23) were developed to look at impacts of oxidant composition, recycle location during oxy-firing, fuel type, air pollution control devices (APCD), and control technologies utilized. For KNX addition, 3 gal/hr was used and for powdered activated carbon, $2 \mathrm{lb} / \mathrm{MMacf}$ DarcoHG was injected. Diagrams for the networks used are shown in Figure 4.13-100. Fuel properties and oxidant compositions are given in Table 4.13-24 and Table 4.13-25, respectively. For simplicity, no mercury was included in the flue gas recycle during oxyfiring. MerSim does not include any feedback loops for recycle (oxidant stream must be input manually), so any mercury present in the recycle stream would have to be determined iteratively. Therefore, all mercury concentrations reported are under-estimations. Calculated mercury removal figures are expected to be very similar with or without mercury in the recycle stream. 
Table 4.13-23: MerSim cases for preliminary oxy-firing investigation.

\begin{tabular}{|c|c|c|c|c|c|}
\hline Case & Coal Type & $\begin{array}{c}\text { Oxidant } \mathrm{O}_{2} \\
\text { Content }\end{array}$ & APCD Setup & $\begin{array}{c}\text { Control } \\
\text { Technology }\end{array}$ & $\begin{array}{c}\text { FGR } \\
\text { Location }\end{array}$ \\
\hline 1 & 1-Bit (low $\mathrm{S}$, low $\mathrm{Cl}$ ) & Air (20\%) & B-SCR-APH-ESP-FGD & None & No Recycle \\
\hline 2 & 1-Bit (low $\mathrm{S}$, low $\mathrm{Cl}$ ) & $27 \%$ & B-SCR-APH-ESP-FGD & None & After FGD \\
\hline 3 & 1-Bit (low S, low Cl) & $32 \%$ & B-SCR-APH-ESP-FGD & None & After FGD \\
\hline 4 & 1-Bit (low S, low Cl) & $50 \%$ & B-SCR-APH-ESP-FGD & None & After FGD \\
\hline 5 & 2-Bit (low S, high Cl) & Air (20\%) & B-SCR-APH-ESP-FGD & None & No Recycle \\
\hline 6 & 2-Bit (low S, high Cl) & $27 \%$ & B-SCR-APH-ESP-FGD & None & After FGD \\
\hline 7 & 3-Bit (high S, low Cl) & Air (20\%) & B-SCR-APH-ESP-FGD & None & No Recycle \\
\hline 8 & 3-Bit (high S, low Cl) & $27 \%$ & B-SCR-APH-ESP-FGD & None & After FGD \\
\hline 9 & 4-Bit (high S, high Cl) & Air (20\%) & B-SCR-APH-ESP-FGD & None & No Recycle \\
\hline 10 & 4-Bit (high S, high Cl) & $27 \%$ & B-SCR-APH-ESP-FGD & None & After FGD \\
\hline 11 & $5-\mathrm{PRB}$ & Air (20\%) & B-SCR-APH-ESP-FGD & None & No Recycle \\
\hline 12 & 5-PRB & $27 \%$ & B-SCR-APH-ESP-FGD & None & After FGD \\
\hline 13 & 1-Bit (low S, low Cl) & Air (20\%) & B-APH-ESP & None & No Recycle \\
\hline 14 & 1-Bit (low S, low Cl) & $27 \%$ & B-APH-ESP & None & After ESP \\
\hline 15 & 1-Bit (low S, low Cl) & Air (20\%) & B-APH-FF & None & No Recycle \\
\hline 16 & 1-Bit (low S, low Cl) & $27 \%$ & B-APH-FF & None & After FF \\
\hline 17 & 1-Bit (low $\mathrm{S}$, low $\mathrm{Cl}$ ) & Air (20\%) & B-APH-ESP & KNX & No Recycle \\
\hline 18 & 1-Bit (low $\mathrm{S}$, low $\mathrm{Cl}$ ) & $27 \%$ & B-APH-ESP & KNX & After ESP \\
\hline 19 & 1-Bit (low S, low Cl) & Air (20\%) & B-APH-ESP & Darco Hg & No Recycle \\
\hline 20 & 1-Bit (low $\mathrm{S}$, low $\mathrm{Cl}$ ) & $27 \%$ & B-APH-ESP & Darco Hg & After ESP \\
\hline 21 & 1-Bit (low $\mathrm{S}$, low $\mathrm{Cl}$ ) & Air (20\%) & B-APH-ESP & Darco Hg-LH & No Recycle \\
\hline 22 & 1-Bit (low $\mathrm{S}$, low $\mathrm{Cl}$ ) & $27 \%$ & B-APH-ESP & Darco Hg-LH & After ESP \\
\hline 23 & 1-Bit (low S, low Cl) & $27 \%$ & B-SCR-APH-ESP-FGD & None & Before FGD \\
\hline 24 & 2-Bit (low S, high Cl) & $27 \%$ & B-SCR-APH-ESP-FGD & None & Before FGD \\
\hline 25 & 3-Bit (high S, low Cl) & $27 \%$ & B-SCR-APH-ESP-FGD & None & Before FGD \\
\hline 26 & 4-Bit (high S, high Cl) & $27 \%$ & B-SCR-APH-ESP-FGD & None & Before FGD \\
\hline 27 & 5-PRB & $27 \%$ & B-SCR-APH-ESP-FGD & None & Before FGD \\
\hline
\end{tabular}




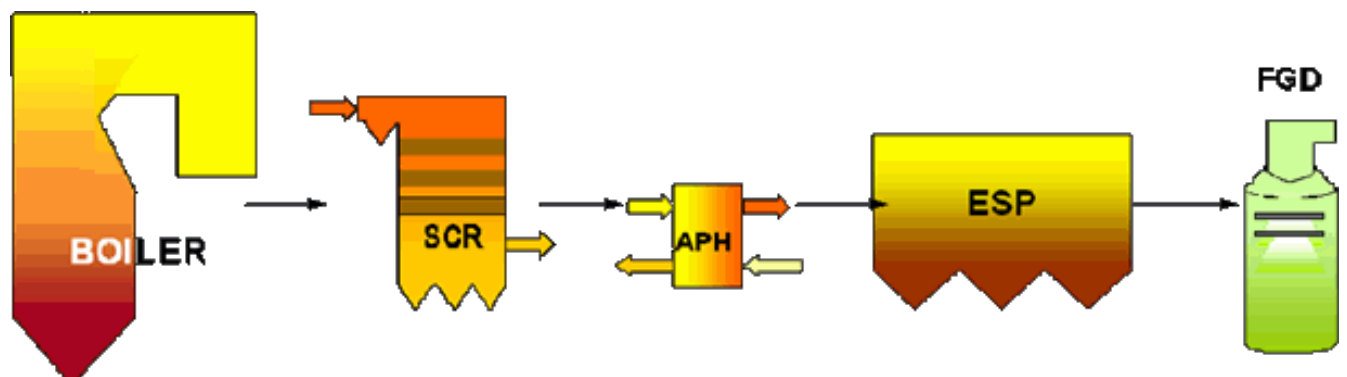

(a)
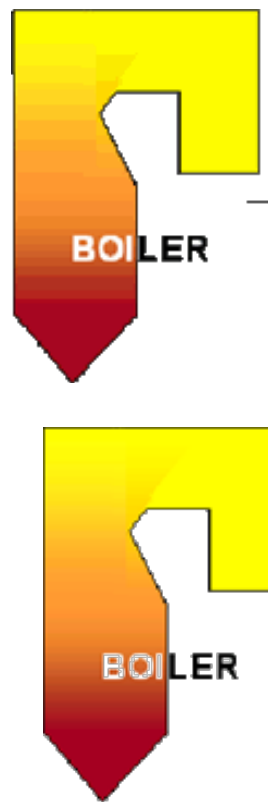

(b)

Figure 4.13-100: Diagram of MerSim networks (a) B-ACR-APH-ESP-FGD, (b) B-APH-ESP, (c) B-APH-FF.

Table 4.13-24: Coal properties for preliminary MerSim cases.

\begin{tabular}{|l|c|c|c|c|c|}
\hline Name & 1-Bit & 2-Bit & 3-Bit & 4-Bit & 5-PRB \\
\hline Rank & EBIT & EBIT & EBIT & EBIT & SUBB \\
\hline C (wt\% AR) & 70.09 & 70.09 & 68.67 & 68.67 & 54.04 \\
\hline H (wt\% AR) & 4.88 & 4.88 & 4.78 & 4.78 & 3.74 \\
\hline N (wt\% AR) & 1.71 & 1.71 & 1.68 & 1.68 & 0.82 \\
\hline O (wt\% AR) & 6.62 & 6.62 & 6.49 & 6.49 & 13.69 \\
\hline Sulfur (wt\% AR) & 1.00 & 1.00 & 3.00 & 3.00 & 0.38 \\
\hline Cl (ug/g, dry) & 500 & 3000 & 500 & 3000 & 100 \\
\hline Ash (wt\% AR) & 13.3 & 13.3 & 13.03 & 13.03 & 5.66 \\
\hline Moisture (wt\%) & 2.4 & 2.4 & 2.35 & 2.35 & 21.67 \\
\hline HHV (Btu/lb, AR) & 12659 & 12659 & 12659 & 12659 & 9320 \\
\hline Hg (ug/g, dry) & 0.218 & 0.218 & 0.22 & 0.218 & 0.065 \\
\hline Br (ug/g, dry) & 11.15 & 66.9 & 11.15 & 66.9 & 1.52 \\
\hline
\end{tabular}


Table 4.13-25: Oxidant compositions (mole fractions) for preliminary MerSim cases.

\begin{tabular}{|c|c|c|c|c|c|c|c|c|c|}
\hline $\begin{array}{c}\mathrm{O}_{2} \\
\text { Content } \\
\end{array}$ & $\begin{array}{l}\text { Coal } \\
\text { Type }\end{array}$ & $\begin{array}{c}\text { FGR } \\
\text { Location }\end{array}$ & $\mathbf{N}_{2}$ & $\mathbf{O}_{2}$ & $\mathrm{CO}_{2}$ & $\mathrm{H}_{2} \mathrm{O}$ & $\mathrm{SO}_{2}$ & $\mathrm{HCl}$ & HBr \\
\hline Air (20\%) & All & None & 0.766 & 0.203 & 0 & 0.031 & 0 & 0 & 0 \\
\hline $27 \%$ & 1-Bit & After FGD & 0.02 & 0.27 & 0.6349 & 0.075 & 0.00009 & 2.30E-06 & 2.94E-07 \\
\hline $32 \%$ & 1-Bit & After FGD & 0.0187 & 0.32 & 0.5916 & 0.0696 & 0.0001 & 2.63E-06 & $3.23 \mathrm{E}-07$ \\
\hline $50 \%$ & 1-Bit & After FGD & 0.0137 & 0.50 & 0.4347 & 0.515 & 0.0001 & $3.00 \mathrm{E}-06$ & $3.26 \mathrm{E}-07$ \\
\hline $27 \%$ & 1-Bit & Before FGD & 0.0157 & 0.27 & 0.4984 & 0.2133 & 0.0026 & 1.13E-04 & $1.13 \mathrm{E}-06$ \\
\hline $27 \%$ & $\begin{array}{l}\text { 1-Bit w/ } \\
\text { KNX }\end{array}$ & After ESP & 0.0157 & 0.27 & 0.4984 & 0.2133 & 0.0026 & 1.13E-04 & 5.66E-06 \\
\hline $27 \%$ & 2-Bit & After FGD & 0.02 & 0.27 & 0.6349 & 0.075 & 0.00009 & 1.38E-05 & $1.76 \mathrm{E}-06$ \\
\hline $27 \%$ & 2-Bit & Before FGD & 0.0157 & 0.27 & 0.4984 & 0.2133 & 0.0026 & 6.79E-04 & 6.79E-06 \\
\hline $27 \%$ & 3-Bit & After FGD & 0.0203 & 0.27 & 0.6344 & 0.075 & 0.0003 & 2.30E-06 & 2.94E-07 \\
\hline $27 \%$ & 3-Bit & Before FGD & 0.0157 & 0.27 & 0.4914 & 0.215 & 0.0079 & 1.13E-04 & $1.13 \mathrm{E}-06$ \\
\hline $27 \%$ & 4-Bit & After FGD & 0.0203 & 0.27 & 0.6344 & 0.075 & 0.0003 & 1.38E-05 & $1.76 \mathrm{E}-06$ \\
\hline $27 \%$ & 4-Bit & Before FGD & 0.0157 & 0.27 & 0.4914 & 0.215 & 0.0079 & 6.79E-04 & 6.79E-06 \\
\hline $27 \%$ & 5-PRB & After FGD & 0.017 & 0.27 & 0.638 & 0.075 & 0.000005 & $2.45 \mathrm{E}-07$ & $2.14 \mathrm{E}-08$ \\
\hline $27 \%$ & 5-PRB & Before FGD & 0.0115 & 0.27 & 0.43 & 0.2873 & 0.0011 & $1.01 \mathrm{E}-05$ & $6.94 \mathrm{E}-08$ \\
\hline
\end{tabular}

Cases 1, 2, 3, and 4 are compared in Table 4.13-26 to see the impact of oxygen content of the oxidant stream. These cases all used a boiler-SCR-APH-ESP-FGD network and fire 1-Bit coal (low S, low Cl). Case 1 was air-fired while Cases 2, 3, and 4 were oxy-fired with increasing oxygen content in the $\mathrm{O}_{2} / \mathrm{FGR}$ mixture, with a recycle placed after the FGD. Mercury removal increased $0.5 \%$ when going from airfiring to oxy-firing with $27 \% \mathrm{O}_{2}$ in the $\mathrm{O}_{2} /$ FGR mixture. Mercury removal then decreased as $\mathrm{O}_{2}$ concentration was increased. This behavior can be explained by halogen and sulfur content in the gases. As $\mathrm{O}_{2}$ levels in the $\mathrm{O}_{2} /$ FGR gas mixture rise, less FGR results in lower flue gas volumes which causes higher halogen and sulfur concentrations. For example, in each case, $\mathrm{HCl}$ levels rise consecutively from 1.99 to 3.03 to 3.65 ppmv, with Case 4 having $\mathrm{HCl}$ levels of $5.82 \mathrm{ppmv}$. $\mathrm{HBr}$ levels rise similarly from 0.16 to 0.28 to $0.45 \mathrm{ppmv}$, ending at $0.625 \mathrm{ppmv}$. However, $\mathrm{SO}_{2}$ levels in the stack gas also rise, from 71.9 ppmv to 113.2 ppmv in Cases 1 and 2, respectively. When $\mathrm{SO}_{2}$ levels rise even higher in Cases 3 and 4, at successively 136.5ppmv and $216.3 \mathrm{ppmv}$, it is possible that the $\mathrm{SO}_{2}$ levels become high enough to negate the benefit of the rising halogen concentrations, interfering with $\mathrm{Hg}$ removal. This could explain the drop in removal in Cases 3 and 4; with such a high $\mathrm{Hg}$ removal like 98\% in Case 2, it is likely that helpful halogen levels have plateaued and now an increase in $\mathrm{SO}_{2}$ will inhibit the helpfulness of further halogen increases. Mercury concentrations at the stack also increased as oxygen concentration in oxyfiring increased. This is due to the compounding effects of lower flue gas dilution and decreased mercury removal.

Table 4.13-26: Impact of oxidant $\mathrm{O}_{2}$ content on mercury.

\begin{tabular}{|c|c|c|c|c|}
\hline Case & $\begin{array}{c}\text { Oxidant } \mathrm{O}_{2} \text { Content } \\
(\%)\end{array}$ & $\begin{array}{c}\text { \% Hg } \\
\text { Removal }\end{array}$ & $\begin{array}{c}\text { Hg Concentration } \\
(\mu g / \text { dscm @3\% O2) }\end{array}$ & $\begin{array}{c}\text { Hg Emissions } \\
(\mathrm{lb} / \mathrm{TBtu})\end{array}$ \\
\hline 1 & Air (20\%) & 97.6 & 0.62 & 0.41 \\
\hline 2 & 27 & 98.1 & 0.72 & 0.32 \\
\hline 3 & 32 & 97.3 & 1.22 & 0.45 \\
\hline 4 & 50 & 94.0 & 4.44 & 1.00 \\
\hline
\end{tabular}


Cases 1, 2 and 5-12 are compared in Figure 4.13-101 and Figure 4.13-102. These cases all used a boilerSCR-APH-ESP-FGD setup with various coal types, and either air or $27 \% \mathrm{O}_{2}$ in $\mathrm{O}_{2} /$ FGR mixture (recycle after FGD) as the oxidant. Because high halogen concentrations facilitate mercury removal while high sulfur impedes removal, coal with high $\mathrm{Cl}$ and low $\mathrm{S}$ concentrations, such as 2-Bit coal, is expected to have the highest \% $\mathrm{Hg}$ removal. In this case however, 4-Bit coal performs similarly to 2-Bit coal. This can be explained by kinetics; when a high enough halogen concentration is introduced, the effect of $\mathrm{SO}_{2}$ can be weakened, resulting in nearly unaffected mercury removal levels. Other coals with lower $\mathrm{Cl}$ concentrations, such as 1-Bit and 3-Bit, followed the expected trend, having diminished mercury removal when S content was high. The poorest performing coal for mercury removal with this system was 5-PRB, which had both a low sulfur and halogen content, but also a different rank than all other coals in the simulation.

Negligible changes in Hg removal occurred with oxy-firing in all cases except for the PRB case, where oxy-firing resulted in an $11 \%$ increase in removal. All other changes were within $0.5 \%$ when comparing air to oxy-firing. These negligible changes in $\mathrm{Hg}$ removal can be attributed to reasons mentioned previously; their high levels of Hg removal (96-99\%) suggest that the bituminous coals had sufficient concentrations of halogens to promote $\mathrm{Hg}$ oxidation, and thus a high amount of $\mathrm{Hg}$ is removed in the FGD (which removes gas phase, oxidized Hg). PRB coal has significantly lower halogen content than these coals, and thus lower oxidation, so oxy-firing has a much more noticeable effect on its $\mathrm{Hg}$ removal. The flue gas recycle increases gas-phase concentrations of $\mathrm{HCl}$ and $\mathrm{HBr}$, which were calculated to increase with recycle in PRB coal from 7 to $10 \mathrm{ppmv}$ and 0.05 to $0.08 \mathrm{ppmv}$, respectively. While halogens in the FGR also increased in the bituminous coal cases, again, their high levels of removal suggest their halogen levels were already sufficient for high mercury removal, so adding a recycle had much less of an effect than with PRB.

Since 5-PRB had the lowest mercury removal, it also had the highest Hg concentrations of the cases. All cases had increased $\mathrm{Hg}$ concentrations with oxy-firing, except PRB coal, whose final Hg concentration fell. The increase in Hg concentration during oxy-firing for bituminous coals, where negligible changes in mercury removal were found, can be explained by lower flue gas dilution when recycle was employed for oxy-combustion. Mercury concentration increased most drastically in 3-Bit coal, as expected, because it had a decrease in $\mathrm{Hg}$ removal of $0.5 \%$. For the PRB coal, the increase in concentration caused by lower flue gas volume when oxy-firing was offset by the increase in mercury removal, resulting in a lower stack concentration. 


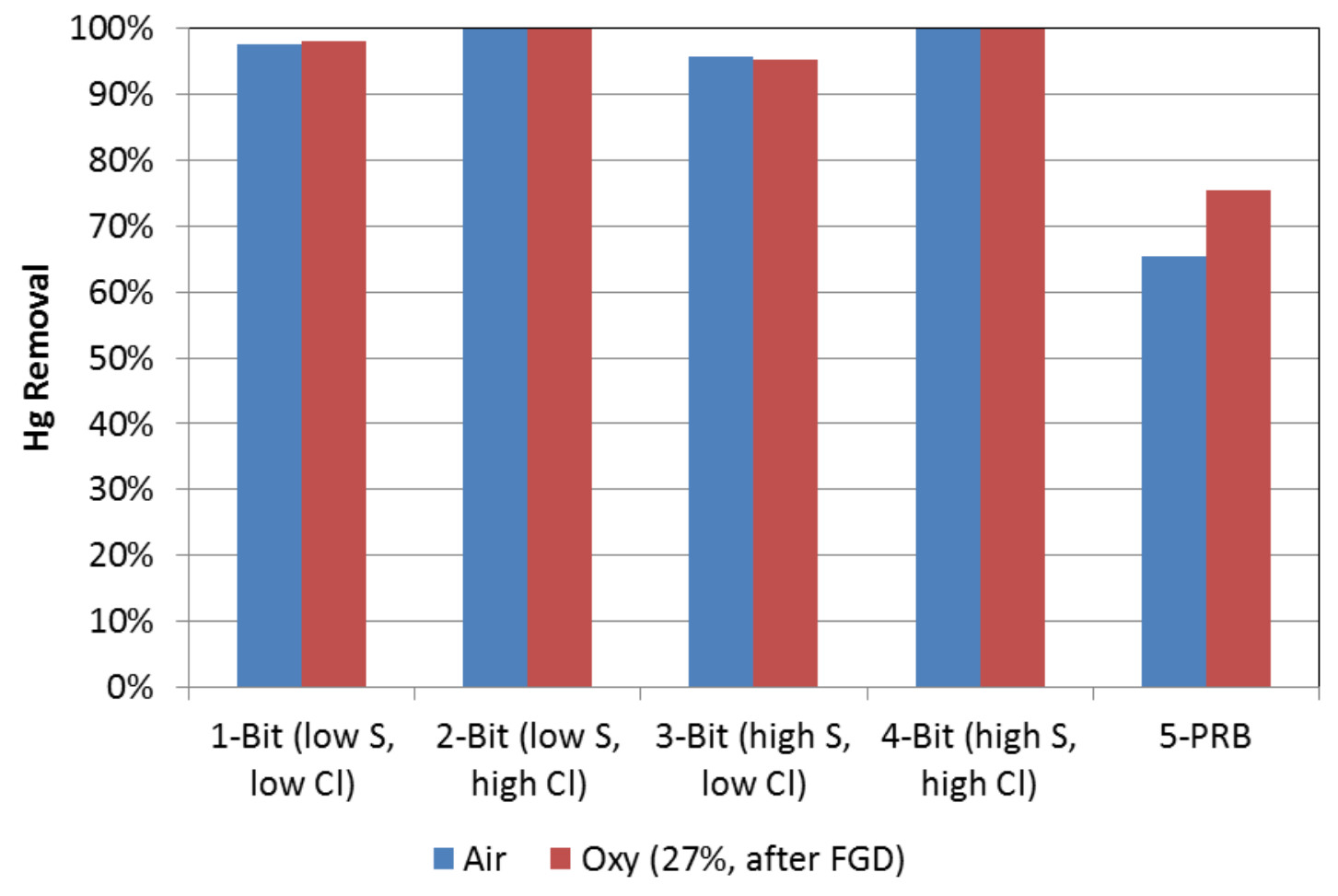

Figure 4.13-101: Impact of coal type on mercury removal.

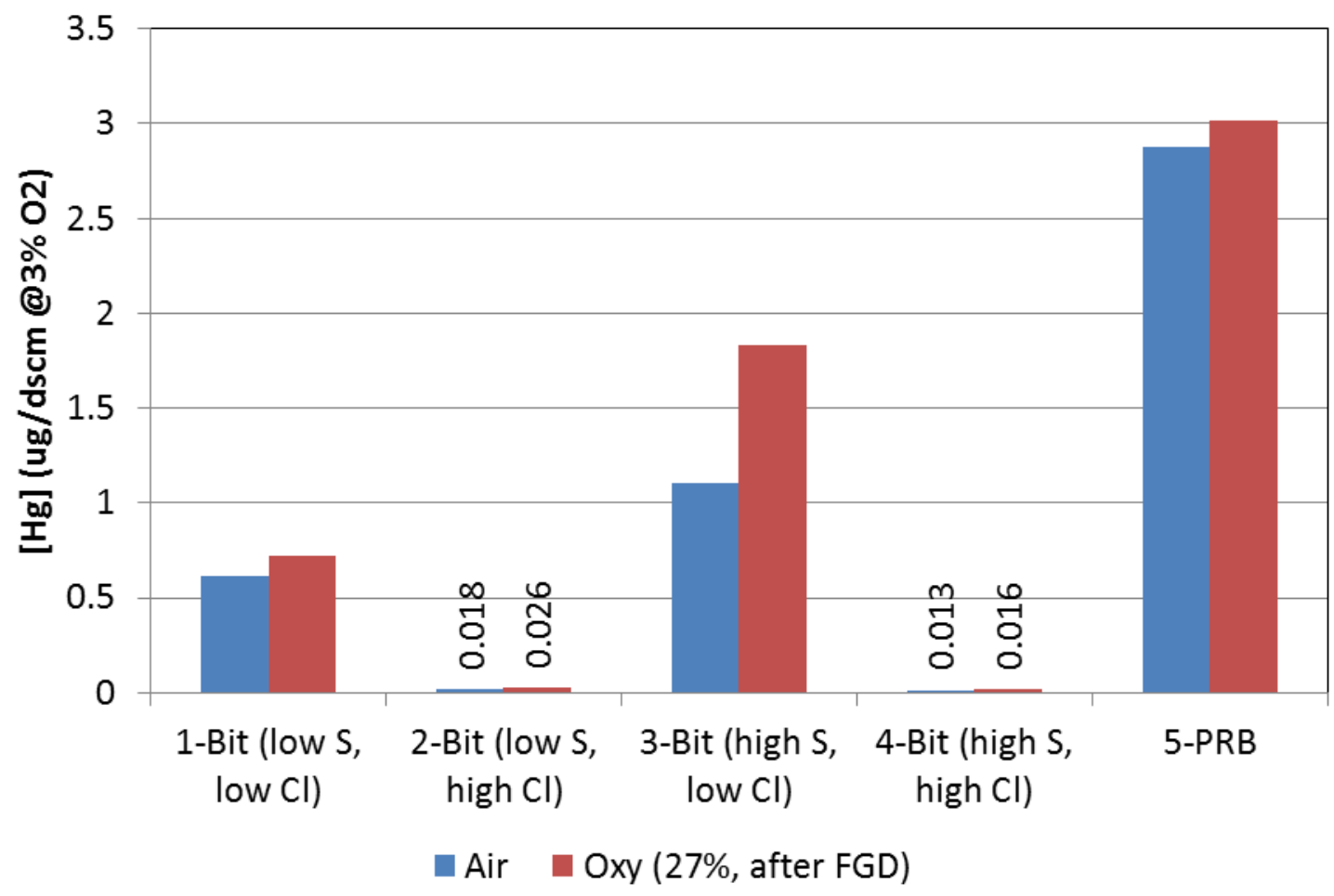

Figure 4.13-102: Impact of coal type on stack mercury concentration. 
To determine the impact on mercury removal of various APCDs with oxy-combustion, Cases 1 , 23, and 13-16 were examined. These cases were modeled using 1-Bit coal, comparing air-firing with $27 \% \mathrm{O}_{2}$ oxy-firing (recycle after FGD unit). Figure 4.13-103 shows that oxy-firing resulted in slightly increased Hg removal for the B-SCR-APH-ESP-FGD setup and decreased removal for the B-APH-FF and B-APHESP systems. Almost complete removal occurred in a full APCD setup. This setup should have the highest removal because two significant $\mathrm{Hg}$ capture mechanisms are occurring: significant gas-phase oxidation of mercury in the SCR followed by high oxidized mercury capture in the FGD and removal of particulate-bound $\mathrm{Hg}$ in the PM control device (ESP). Removal decreased for setups without an SCR or FGD because the oxidation and capture mechanisms were reduced. A possible explanation for the reduced mercury removal in the ESP and FF only cases when oxy-firing is $\mathrm{SO}_{2}$ concentration. The particulate $\mathrm{Hg}$ removal mechanism is highly sensitive to $\mathrm{SO}_{2} / \mathrm{SO}_{3}$ concentrations. Without $\mathrm{SO}_{2}$ removal (no FGD or recycle before the FGD), FGR increases the gas-phase $\mathrm{SO}_{2}$ concentration at the ESP from 726 ppmv (air-fired) to 3417 ppmv (oxy-fired). This increase in $\mathrm{SO}_{2}$ will negatively impact the particulate Hg capture for all three scenarios, but the full APCD network still has the oxidation/FGD capture mechanism to compensate.

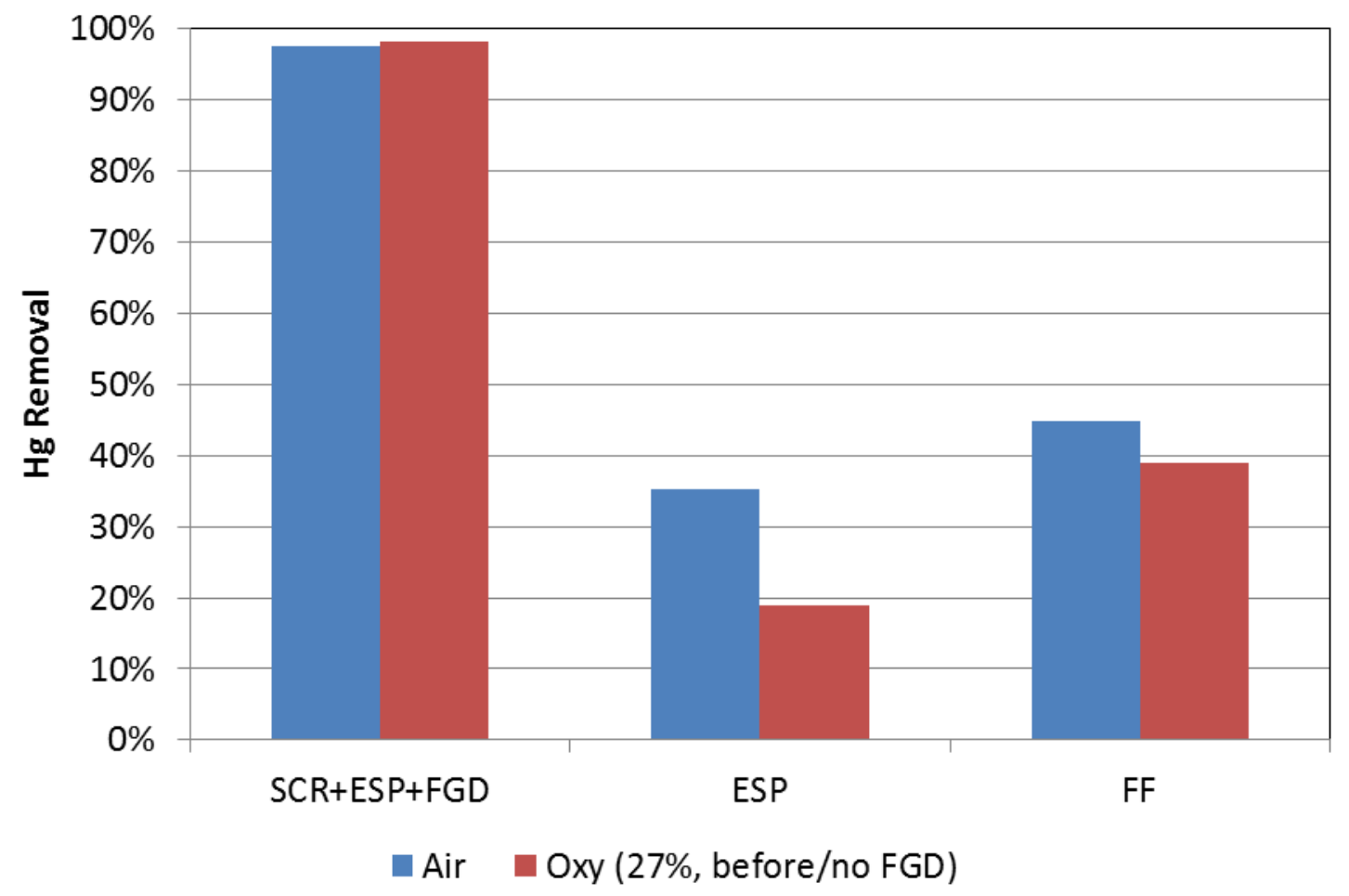

Figure 4.13-103: Impact of APCD on mercury removal. 
Results from Cases 1, 2, 5-12 and 23-27, all of which implemented the B-SCR-APH-ESP-FGD setup, were compared to determine the effect of recycle location on efficiency of mercury removal. Mercury removal for the various coal types is compared in Figure 4.13-104. For all coal types except for 3-Bit (high $\mathrm{S}$, low $\mathrm{Cl}$ ), oxy-firing caused $\mathrm{Hg}$ removal to increase, whether the recycle was placed before or after the FGD unit. The most drastic illustration of this occurs with 5-PRB coal, whose removal increases as much as $20.8 \%$ when oxy-firing with FGR before the FGD. With 1-Bit, 2-Bit, and 4-Bit coal, all removal increases are under $0.64 \%$. The 3-Bit coal $\mathrm{Hg}$ removal decreases from air-fired to oxy-fired before recycle by only $1.1 \%$. For the bituminous coals, sufficient halogens are present to produce high levels of mercury removal, only slightly impacted by flue gas recycle when oxy-firing. For pre-FGD recycle, halogen and sulfur concentrations are significantly higher compared to post-FGD recycle (where halogen and sulfur species are partially removed in the FGD). The higher halogen concentrations will tend to increase mercury removal while higher sulfur concentrations will decrease mercury removal. The competing mechanisms only slightly impact mercury removal with the bituminous coals, most likely because the halogen and sulfur levels are already in the range where effects have plateaued. The PRB coal in contrast has very low $\mathrm{Cl}$ and $\mathrm{S}$ compositions, and exhibits the most drastic increase in removal when switching from air- to oxy-firing (recycle either before or after the FGD). Because the full APCD setup involves the oxidation/FGD removal mechanism (highly dependent on halogen concentration), the increase in halogen concentrations with oxy-firing overcomes the negative impacts of increased $\mathrm{SO}_{2}$ concentrations. The halogen concentrations are highest with FGR before the FGD ( $\mathrm{HCl}=18 \mathrm{ppmv}$, $\mathrm{HBr}=0.12 \mathrm{ppmv}$ at ESP versus $\mathrm{HCl}=9.7 \mathrm{ppmv}, \mathrm{HBr}=0.08 \mathrm{ppmv}$ with after FGD recycle), hence this case has the highest removal levels.

Figure 4.13-105 shows the stack mercury concentrations for this comparison. While removal levels were fairly constant with the bituminous coals, stack mercury concentrations showed more deviation. Mercury concentrations tend to increase when oxy-firing due to lower flue gas volume (enhanced $\mathrm{O}_{2}$ concentration in the oxidant stream compared to air-firing). When the FGR stream is taken before the FGD, moisture concentrations are higher, also resulting in higher mercury concentrations when corrected to dry conditions. For the PRB coal, all three factors influence mercury concentrations: higher mercury removal (decrease [Hg]), lower flue gas volume (increase [Hg]), and increased moisture (increase [Hg]). 


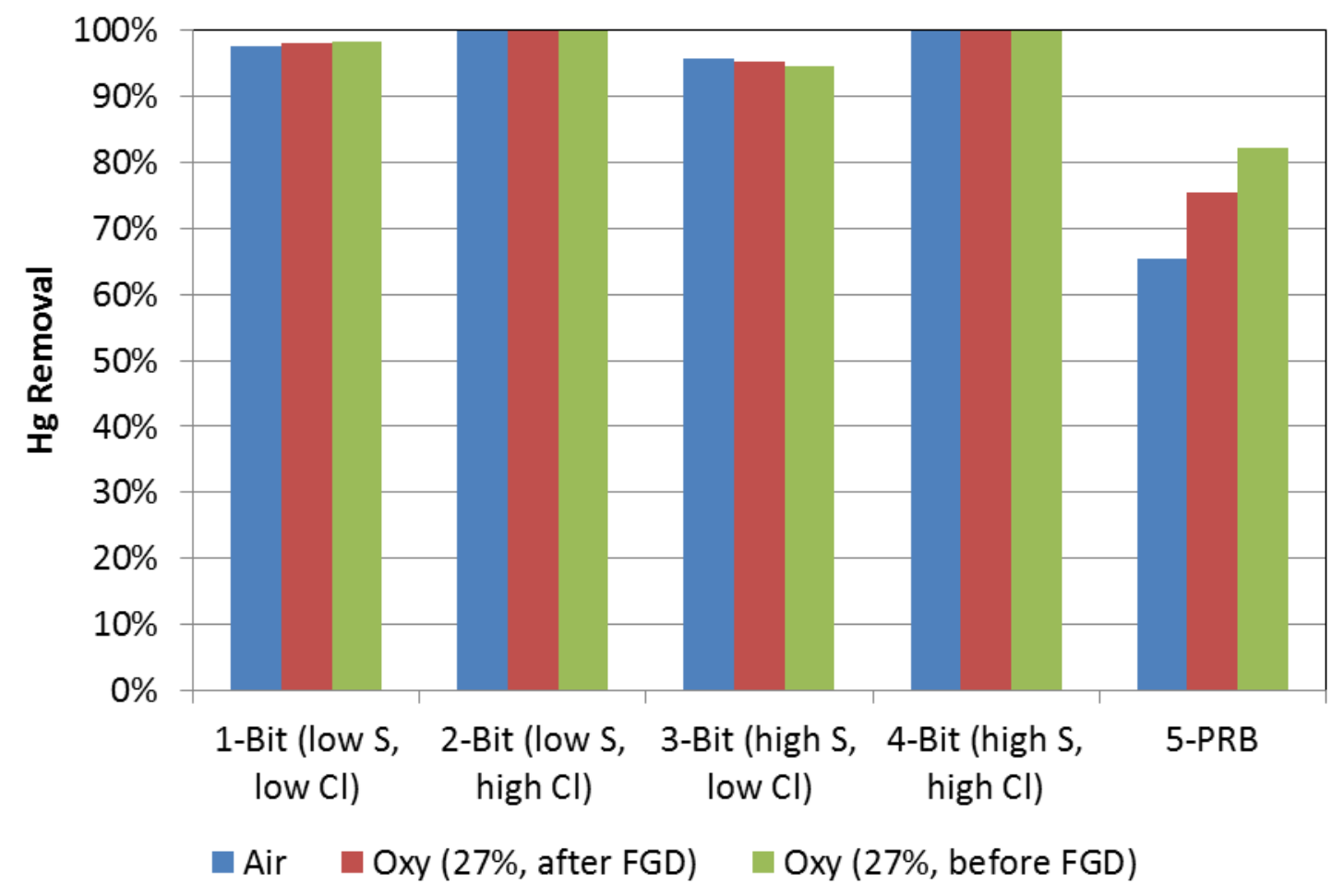

Figure 4.13-104: Impact of FGR location on mercury removal.

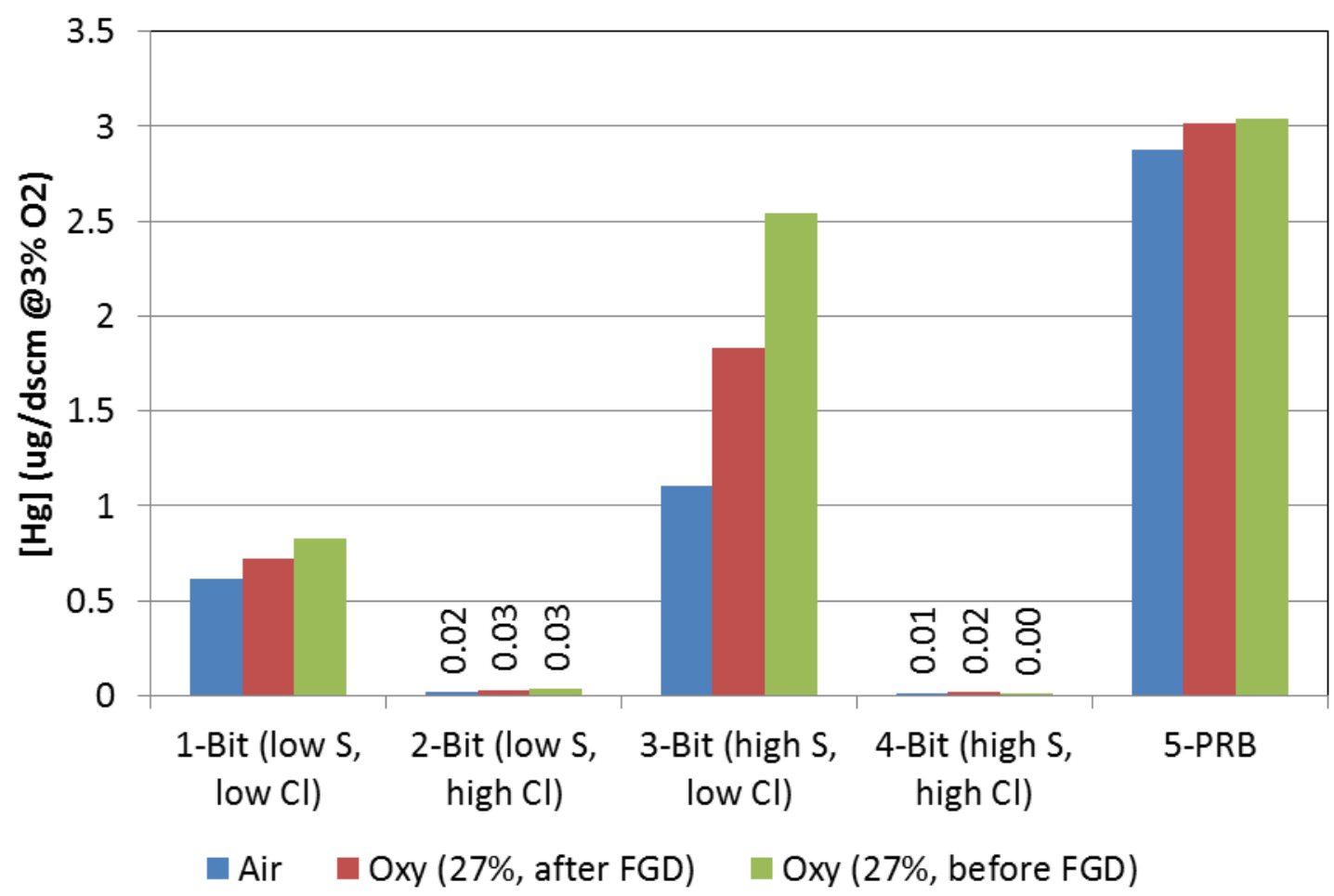

Figure 4.13-105: Impact of FGR location on stack mercury concentration. 
Mercury control technology impacts on mercury removal are shown in Figure 4.13-106. These cases all used 1-Bit coal with a boiler-APH-ESP network. Oxy-firing appears to make these control technologies less effective, compared to air-firing, although using control technologies was still more effective than using none at all. Mercury capture in this network setup (ESP only) is accomplished by capturing particulate-containing $\mathrm{Hg}$ (either fly ash or sorbent). The addition of KNX or activated carbon increases the chances of mercury capture on particles through either enhanced oxidation when using KNX (oxidized mercury is more easily captured on particulate), or an increase in available particle sites when injecting activated carbon. This particulate-centered removal mechanism is highly influenced by sulfur species, which use up available sites on the particles where mercury would be captured. Because increased recycle results in higher sulfur concentrations (no FGD), Hg removal is hindered due to oxyfiring in this system.

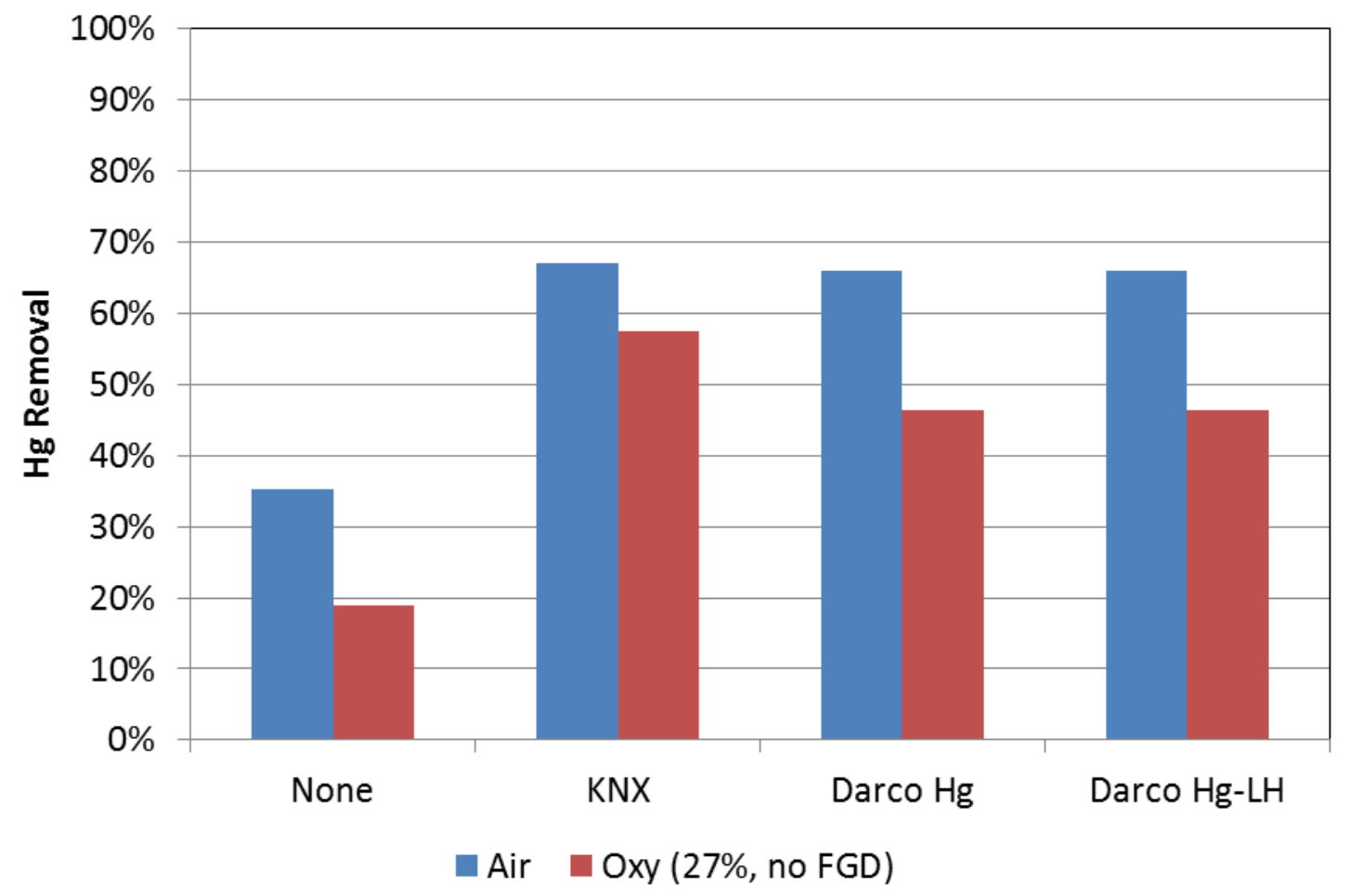

Figure 4.13-106: Impact of mercury control technologies on mercury removal.

\subsubsection{Summary of Preliminary Investigation}

Oxygen Enrichment

Mercury removal increased slightly when switching from air-fired to oxy-fired with $27 \% \mathrm{O}_{2}$ in the $\mathrm{O}_{2} /$ FGR mixture (recycle after FGD). As $\mathrm{O}_{2}$ concentration in the oxidant stream was increased during oxy-firing, mercury removal tended to decrease. As $\mathrm{O}_{2}$ in the $\mathrm{O}_{2}$ /FGR mixture increases during oxyfiring, $\mathrm{Hg}$ emissions may increase. Stack Hg concentration was shown to increase, due to decreased flue gas volume in oxy-combustion.

\section{Coal Composition}

With oxy-firing (27\% $\mathrm{O}_{2}$ in the $\mathrm{O}_{2} / \mathrm{FGR}$, recycle after the FGD), the amount of $\mathrm{Hg}$ removal increased slightly for all bituminous coals except for 3-Bit coal (high $\mathrm{S}$, low $\mathrm{Cl}$ ). Oxy-firing caused the greatest increase in $\mathrm{Hg}$ removal for PRB. In these cases, final Hg concentration increased in all coals except PRB. 
This is likely due to decreased gas dilution when oxy-firing (which causes a higher Hg density in the final gas composition).

$A P C D$

Oxy-firing caused a slight decrease in emissions in the B-SCR-APH-ESP-FGD setup, but increased emissions in both the B-APH-ESP and B-APH-FF setups. These two setups also saw Hg concentration increases of over $50 \%$. This is likely due to the fact that increased $\mathrm{SO}_{2}$ concentrations in the $\mathrm{FF}$ and ESP systems from the FGR inhibited Hg removal.

\section{Recycle Location}

All coal types except for 3-Bit coal showed an increase in $\mathrm{Hg}$ removal when utilizing oxy-firing, especially when the recycle point was placed before the FGD. The most drastic representation of this phenomenon occurred with PRB coal, which benefited from high halogen concentrations with recycle before the FGD. With the 3-Bit coal, Hg removal decreased from air-fired to oxy-fired with recycle before FGD by about $1 \%$.

\section{Control Technologies}

It was previously shown that oxy-firing hinders mercury removal in a B-APH-ESP system. This type of system was simulated implementing control technologies that, although improving efficiency, still resulted in a lower Hg removal with oxy-firing. Increased sulfur concentrations from the FGR negatively impact the mercury capture mechanism in these systems (mercury removal through capture on particulate).

\subsubsection{Mercury Oxy-fired Retrofit Study: Hunter 3}

Hunter Power Plant Unit 3 was modeled with MerSim under air- or oxy-fired conditions for baseline, KNX, and ACI scenarios. A diagram of the MerSim network is shown in Figure 4.13-107 and inputs are shown in Figure 4.13-108. The same coal used in the CFD studies was used (Utah Skyline bituminous) and is described in Table 4.13-27. For mercury control technology studies, either $3 \mathrm{gal} / \mathrm{hr} \mathrm{KNX}$ (boiler addition) or $2 \mathrm{lb} / \mathrm{MMacf}$ DarcoHG (FF addition) were included. For oxy-fired cases, $26 \% \mathrm{O}_{2}$ in the $\mathrm{O}_{2} /$ FGR stream was used (same as CFD investigation, determined to best match air-fired heat transfer through process modeling).

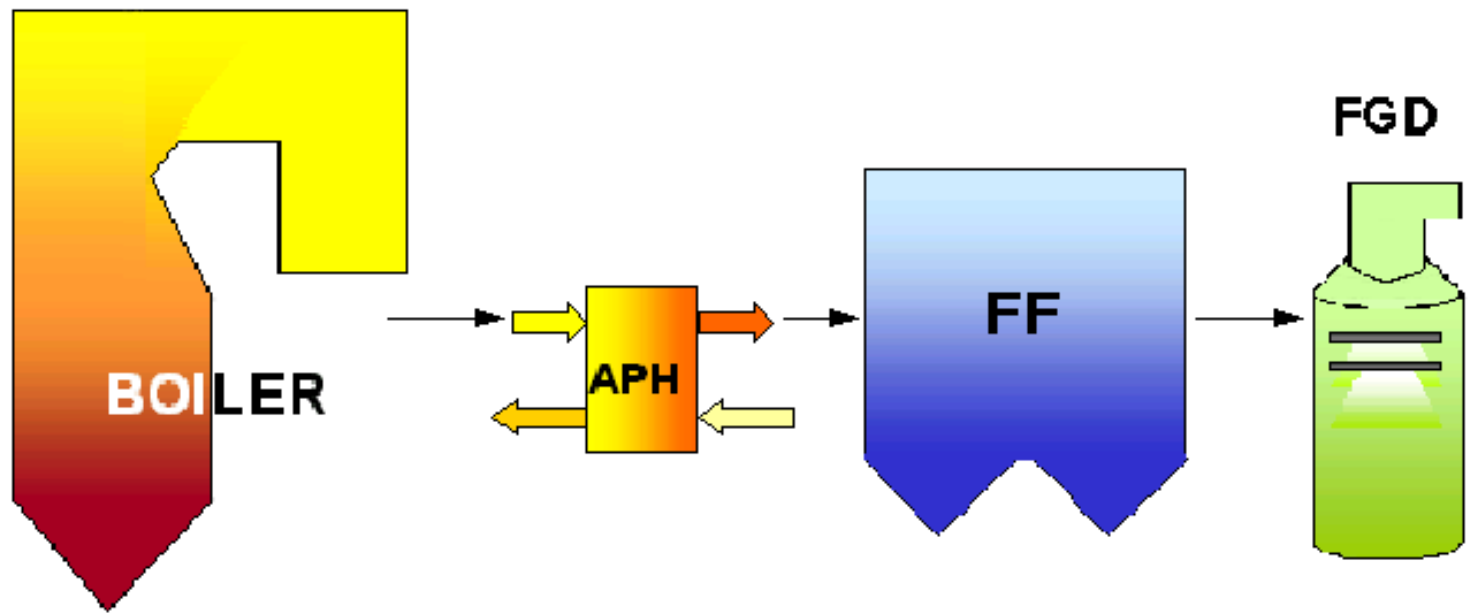

Figure 4.13-107: Hunter3 MerSim network. 


\begin{tabular}{|c|c|c|c|c|c|}
\hline \multicolumn{5}{|l|}{ Boiler } & $\mathbb{3}$ \\
\hline \multicolumn{3}{|c|}{ Boiler name } & \multicolumn{3}{|c|}{ Hunter3 } \\
\hline \multicolumn{3}{|c|}{ Combustion system } & \multicolumn{2}{|c|}{ Wall } & 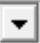 \\
\hline \multicolumn{3}{|c|}{ Gross MW } & \multicolumn{3}{|c|}{495} \\
\hline \multicolumn{3}{|c|}{ (- Boiler heat rate [Btu/kWh] } & \multicolumn{3}{|c|}{0} \\
\hline \multicolumn{3}{|c|}{$C$ Coal flow rate $[\mathrm{b} / \mathrm{hr}]$} & \multicolumn{3}{|c|}{399150} \\
\hline \multicolumn{3}{|c|}{ Infumace NOx control } & \multicolumn{2}{|c|}{ LNB } & $\boldsymbol{\nabla}$ \\
\hline \multicolumn{3}{|c|}{ NOx Rate [b/MBtu] } & \multicolumn{3}{|c|}{0.5} \\
\hline \multicolumn{3}{|c|}{ Excess 02 [vol\%, dy] (econ. exit) } & \multicolumn{3}{|c|}{3} \\
\hline \multicolumn{3}{|c|}{ UBC in fly ash $[\%]$} & \multicolumn{3}{|c|}{3} \\
\hline \multicolumn{3}{|c|}{ Econ. exit temp. [F] } & \multicolumn{3}{|c|}{700} \\
\hline \multicolumn{3}{|c|}{ Boiler additive (for $\mathrm{Hg}$ control) } & \multicolumn{2}{|c|}{ None } & $\nabla$ \\
\hline \multicolumn{3}{|c|}{ Boiler additive rate [gal/hr] } & \multicolumn{3}{|c|}{0} \\
\hline \multicolumn{6}{|l|}{$\ulcorner$ Coal } \\
\hline Coal1 & Skyline & \multicolumn{4}{|c|}{ Mass fraction 1} \\
\hline Coal2 & PRB & $\nabla$ Mass & \multicolumn{3}{|c|}{0} \\
\hline \multicolumn{6}{|c|}{ Coal Editor } \\
\hline & OK & Cancel & \multicolumn{3}{|c|}{ Help } \\
\hline
\end{tabular}

\begin{tabular}{|c|c|c|c|}
\hline \multicolumn{3}{|l|}{ Fabric Filter } & $x$ \\
\hline \multicolumn{4}{|l|}{$-\mathrm{FF}$ Inputs - } \\
\hline \multicolumn{2}{|c|}{ Flue gas inlet temp. [F] } & 300 & \\
\hline \multicolumn{2}{|c|}{ Flue gas exit temp. [F] } & 300 & \\
\hline \multicolumn{2}{|c|}{ - Flue gas exit $\mathrm{O} 2[\mathrm{vol} \%$, dry] } & 3 & \\
\hline \multicolumn{2}{|c|}{$C$ Air inleakage $[\%]$} & 0 & \\
\hline \multicolumn{4}{|c|}{ FF Design Information - } \\
\hline \multicolumn{2}{|c|}{ Air to cloth ratio } & 10 & \\
\hline \multicolumn{2}{|c|}{ Collection efficiency $[\%]$} & 99 & \\
\hline \multicolumn{4}{|c|}{ Activated Carbon Injection - } \\
\hline \multirow{2}{*}{\multicolumn{2}{|c|}{$\begin{array}{l}\text { Carbon name } \\
\text { Injection rate [b/MMacf] }\end{array}$}} & None & $\nabla$ \\
\hline & & 0 & \\
\hline OK & Cancel & Help & \\
\hline
\end{tabular}
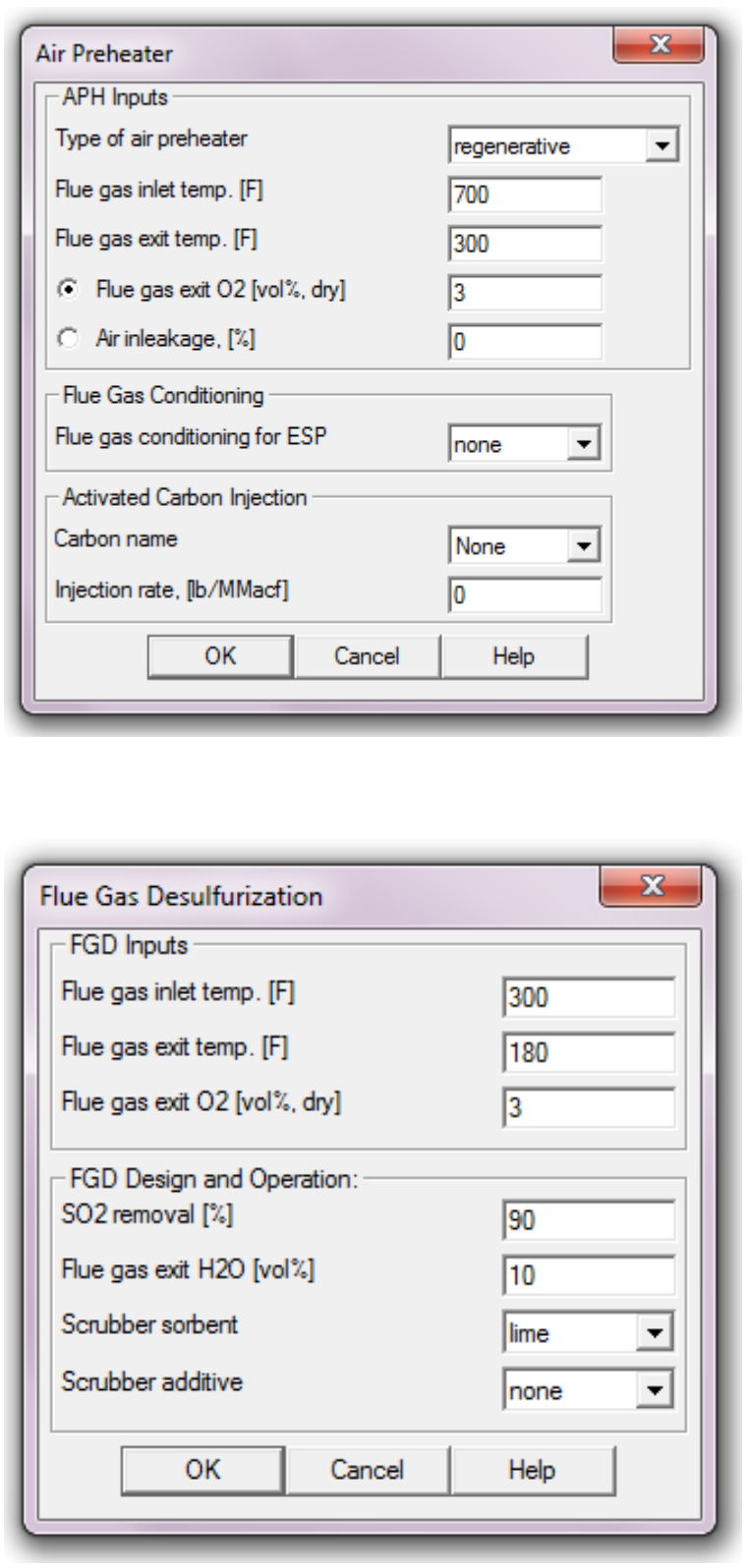

Figure 4.13-108: Hunter3 MerSim inputs. 
Table 4.13-27: Coal properties for Hunter3 MerSim cases.

\begin{tabular}{|l|c|}
\hline Name & Skyline \\
\hline Rank & EBIT \\
\hline C (wt\% AR) & 64.49 \\
\hline H (wt\% AR) & 4.44 \\
\hline N (wt\% AR) & 1.18 \\
\hline O (wt\% AR) & 9.25 \\
\hline Sulfur (wt\% AR) & 0.64 \\
\hline Cl (ug/g, dry) & 290 \\
\hline Ash (wt\% AR) & 11.14 \\
\hline Moisture (wt\%) & 8.86 \\
\hline HHV (Btu/lb, AR) & 11344 \\
\hline Hg (ug/g, dry) & 0.01 \\
\hline Br (ug/g, dry) & 6.5 \\
\hline
\end{tabular}

In MerSim, the oxidant stream must be entered manually. There is no feedback for flue gas recycle. Offline combustion calculations were performed to determine the composition of the oxidant stream. Two locations for flue gas recycle were investigated: flue gas taken either before or after the FGD. The oxidant compositions are shown in Table 4.13-28. The mercury concentration in the oxidant stream for oxy-fired conditions was determined by running iterative calculations with MerSim.

Table 4.13-28: Oxidant composition for Hunter3 MerSim cases.

\begin{tabular}{|c|c|c|c|c|c|c|c|}
\hline & Air & Oxy26 & Oxy26 & Oxy26 & Oxy26 & Oxy26 & Oxy26 \\
\hline $\begin{array}{l}\text { Recycle } \\
\text { location }\end{array}$ & before & after & before & after & before & after \\
\hline $\begin{array}{l}\text { Hg Control } \\
\text { KNX, } \\
\text { Compositiont } \\
\text { (mol frac) }\end{array}$ & & none & none & KNX & KNX & ACI & ACI \\
\hline $\mathrm{N}_{2}$ & 0.766 & 0.0039 & 0.0052 & 0.0039 & 0.0052 & 0.0039 & 0.0052 \\
\hline $\mathrm{O}_{2}$ & 0.203 & 0.2600 & 0.2600 & 0.2600 & 0.2600 & 0.2600 & 0.2600 \\
\hline $\mathrm{CO}_{2}$ & 0.0 & 0.4933 & 0.6587 & 0.4933 & 0.6587 & 0.4933 & 0.6587 \\
\hline $\mathrm{H}_{2} \mathrm{O}$ & 0.031 & 0.2411 & 0.0761 & 0.2411 & 0.0761 & 0.2411 & 0.0761 \\
\hline $\mathrm{SO}_{2}$ & 0.0 & 0.0018 & 0.0001 & 0.0018 & 0.0001 & 0.0018 & 0.0001 \\
\hline $\mathrm{HCl}^{\mathrm{HBr}}$ & 0.0 & $6.61 \mathrm{E}-5$ & $1.35 \mathrm{E}-6$ & $6.61 \mathrm{E}-5$ & $1.35 \mathrm{E}-6$ & $6.61 \mathrm{E}-5$ & $1.35 \mathrm{E}-6$ \\
\hline $\mathrm{HB}$ & 0.0 & $1.44 \mathrm{E}-6$ & $1.73 \mathrm{E}-7$ & $5.14 \mathrm{E}-6$ & $1.35 \mathrm{E}-6$ & $1.44 \mathrm{E}-6$ & $1.73 \mathrm{E}-7$ \\
\hline $\mathrm{Hg}$ & 0.0 & $3.62 \mathrm{E}-11$ & $4.02 \mathrm{E}-12$ & $2.87 \mathrm{E}-11$ & $2.52 \mathrm{E}-12$ & $1.61 \mathrm{E}-12$ & $2.62 \mathrm{E}-13$ \\
\hline
\end{tabular}


Results for the MerSim modeling of Hunter Unit 3 are shown in Figure 4.13-109. Mercury removal was generally very high for all Hunter3 cases (>90\%). This is likely due to the high halogen content (promotes gas phase oxidation of mercury and improves particulate capture of mercury) and low sulfur concentration (inhibits mercury capture on particulate) of the coal in combination with high LOI (mercury capture on particulate) and an FGD (gas phase oxidized mercury capture). The addition of KNX or ACI improved mercury removal. Oxy-firing also slightly increased mercury removal, with FGR before the FGD giving slightly improved performance compared to after FGD recycle.

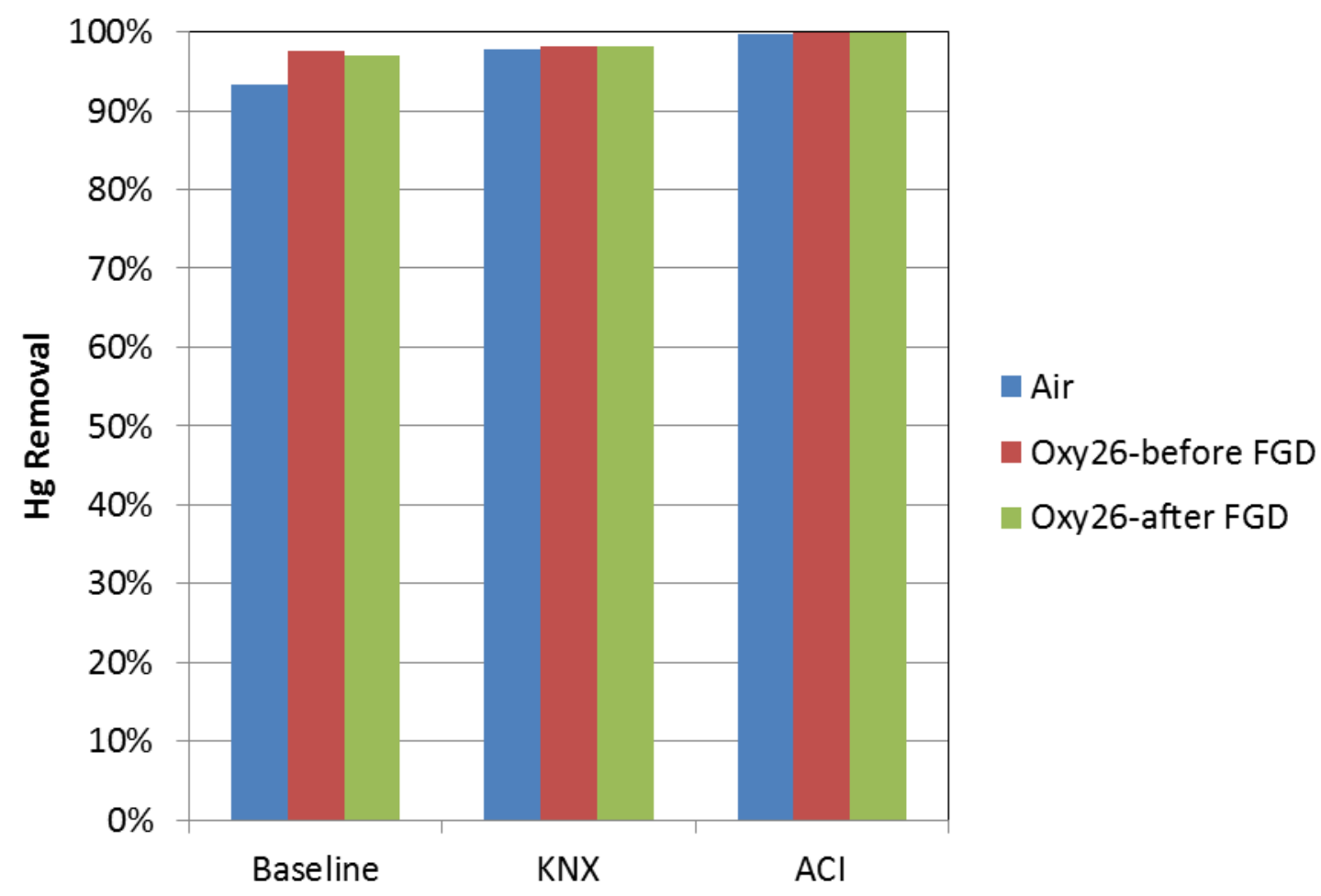

Figure 4.13-109: Hunter 3 MerSim model results for mercury removal. 
Stack mercury concentrations are shown in Figure 4.13-110. Mercury concentration is affected by removal, the amount of flue gas present, and the flue gas moisture content (when correcting to dry conditions). For oxy-firing, the oxidant stream is enriched in oxygen ( $26 \% \mathrm{O}_{2}$ vs $20 \%$ when air-firing). This results in less dilution gas and less flue gas overall, tending to increase mercury concentrations. Any mercury present in the recycle stream will also tend to increase mercury concentration. When recycle is taken before the FGD, moisture content is higher and mercury concentrations will be higher when corrected to dry conditions. In contrast, increased mercury removal (as seen with oxy-firing) decreases mercury concentrations. For baseline and ACI conditions, oxy-firing caused a decrease in stack mercury concentration, suggesting the increased mercury removal dominated. For KNX addition, oxy-firing caused an increase in stack mercury concentration, indicating the slight increase in mercury removal was not enough to overcome the effects of flue gas recycle.

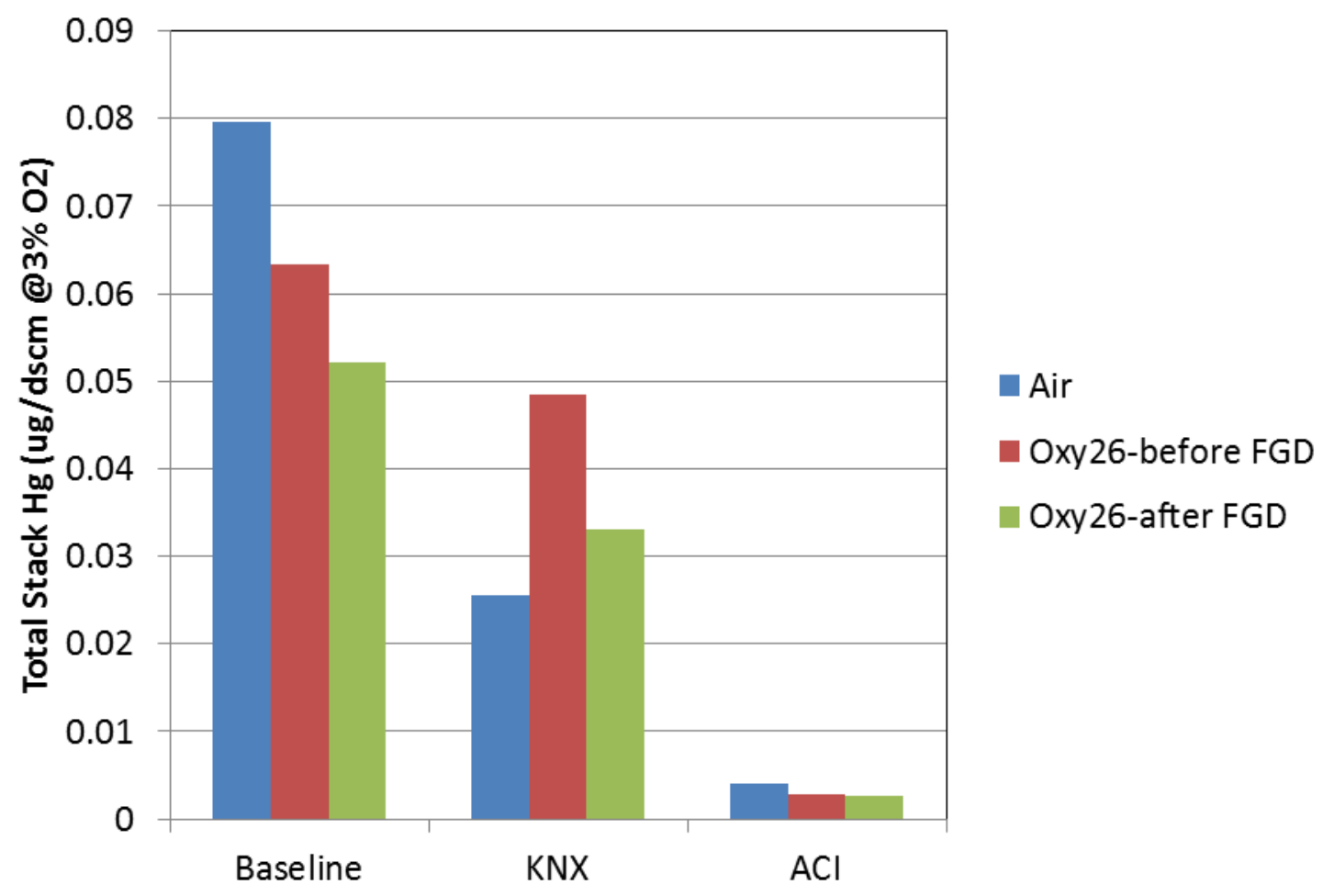

Figure 4.13-110: Hunter 3 MerSim model results for stack mercury concentration. 
Figure 4.13-111 shows stack mercury emissions for Hunter3. Emissions are affected by mercury removal and the amount of mercury recycled. Baseline and ACI conditions show a decrease in mercury emissions when oxy-firing, attributable to increased removal. With KNX addition, mercury removal was negligibly increased so the effect of mercury in the recycle stream is more apparent. It should be noted that these emission levels fall well under the MATS limit of $1.2 \mathrm{lb} / \mathrm{TBtu}$ (existing coal-fired electric generating unit firing fuel with $>8300 \mathrm{Btu} / \mathrm{lb}$ ).

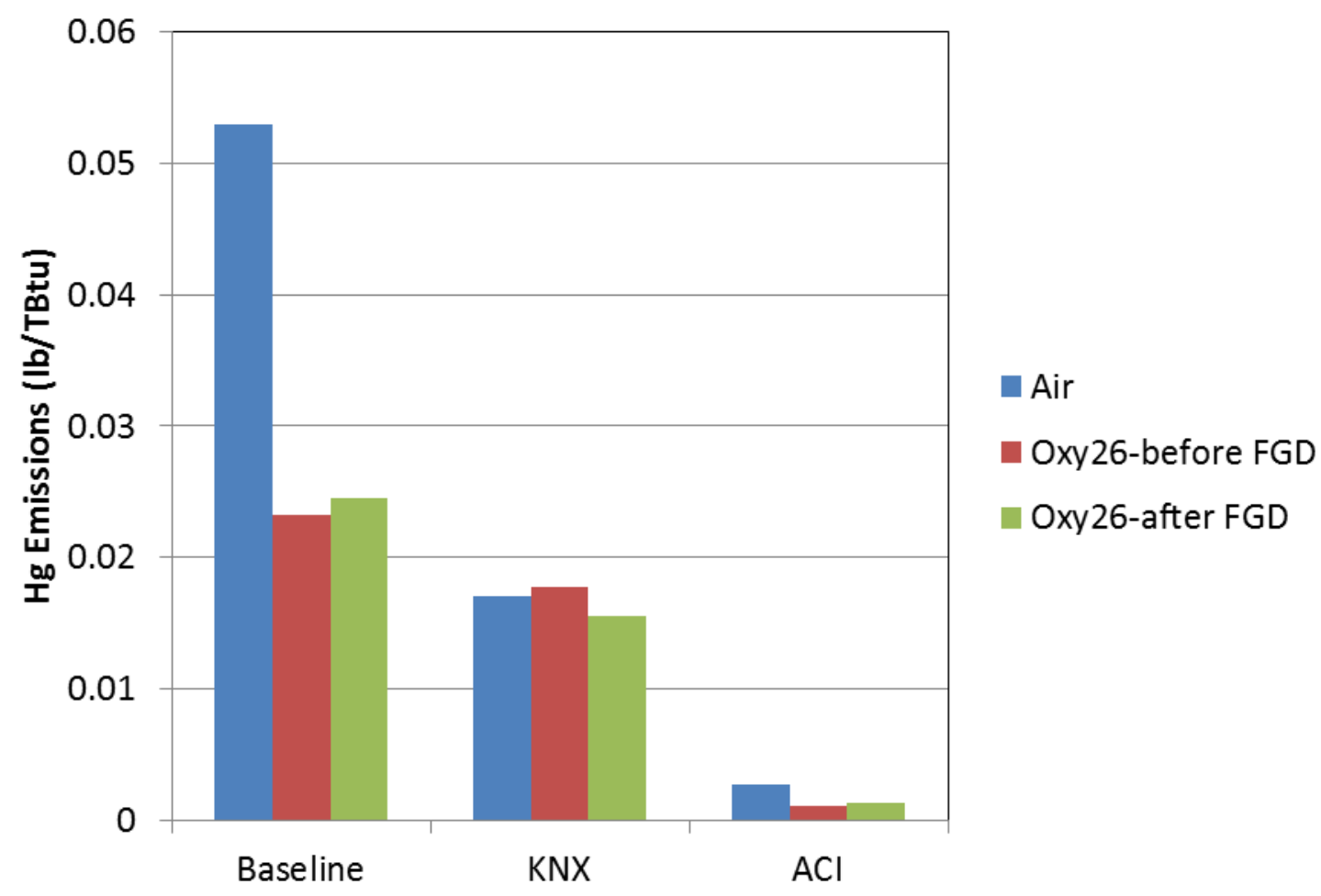

Figure 4.13-111: Hunter 3 MerSim model results for stack mercury emissions.

\subsubsection{Mercury Oxy-fired Retrofit Study: River Rouge 3}

River Rouge Power Plant Unit 3 was modeled with MerSim under air- or oxy-fired conditions for baseline, KNX, and ACI scenarios. River Rouge3 does not currently have a FGD, so cases without or with the addition of an FGD were modeled. Diagrams of the two MerSim networks are shown in Figure 4.13-112 and inputs are shown in Figure 4.13-113. The same coal used in the CFD studies was used (subbituminous) and is described in Table 4.13-29. For mercury control technology studies, either 1 gal/hr KNX (boiler addition) or $2 \mathrm{lb} / \mathrm{MMacf}$ DarcoHG (ESP addition) were included. For oxy-fired cases, 24\% $\mathrm{O}_{2}$ in the $\mathrm{O}_{2} /$ FGR stream was used (same as CFD investigation, determined to best match airfired heat transfer through process modeling). 


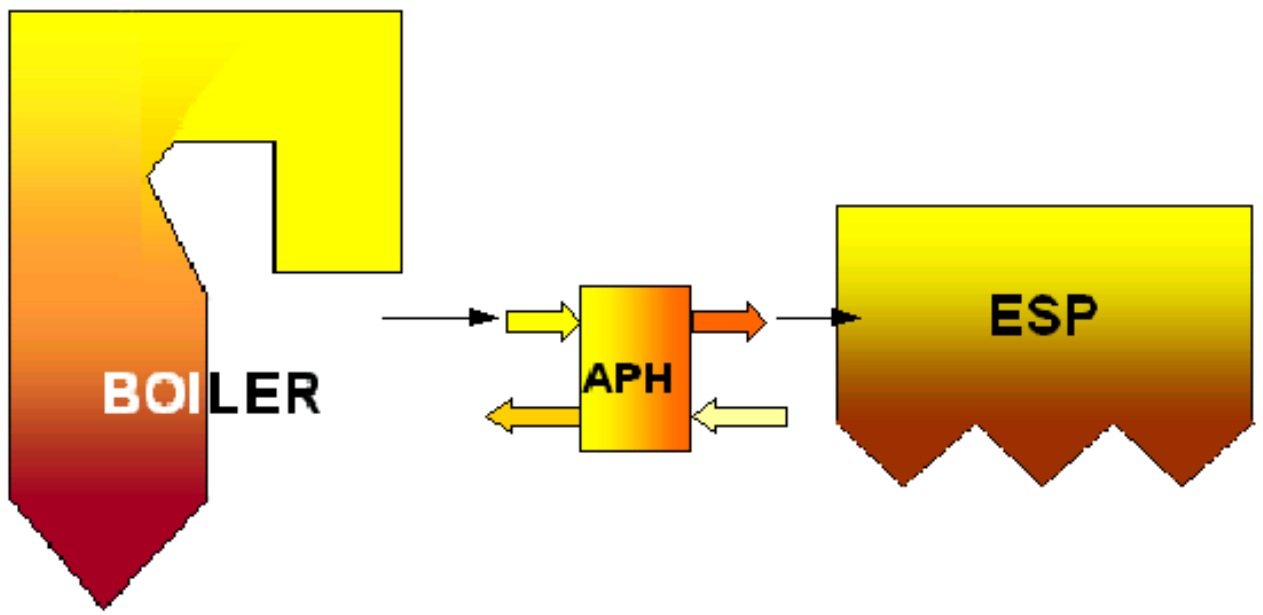

(a)

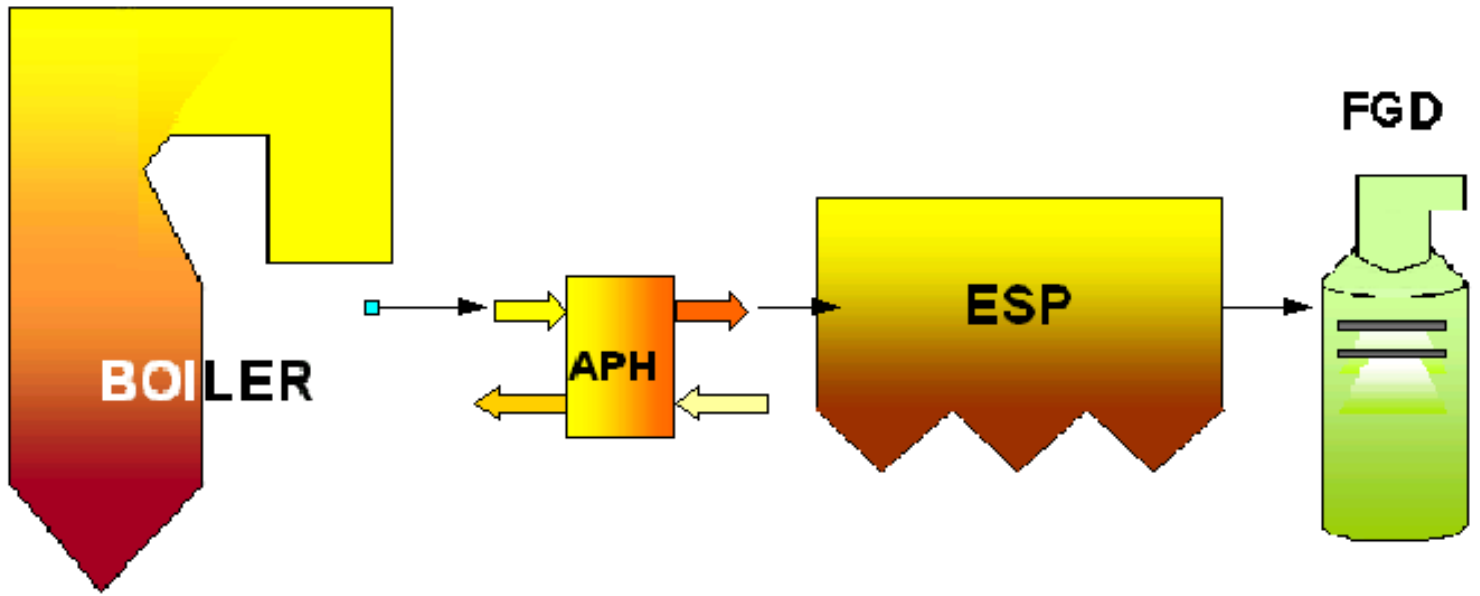

(b)

Figure 4.13-112: River Rouge 3 MerSim networks (a) as-is without FGD and (b) with the addition of an FGD. 


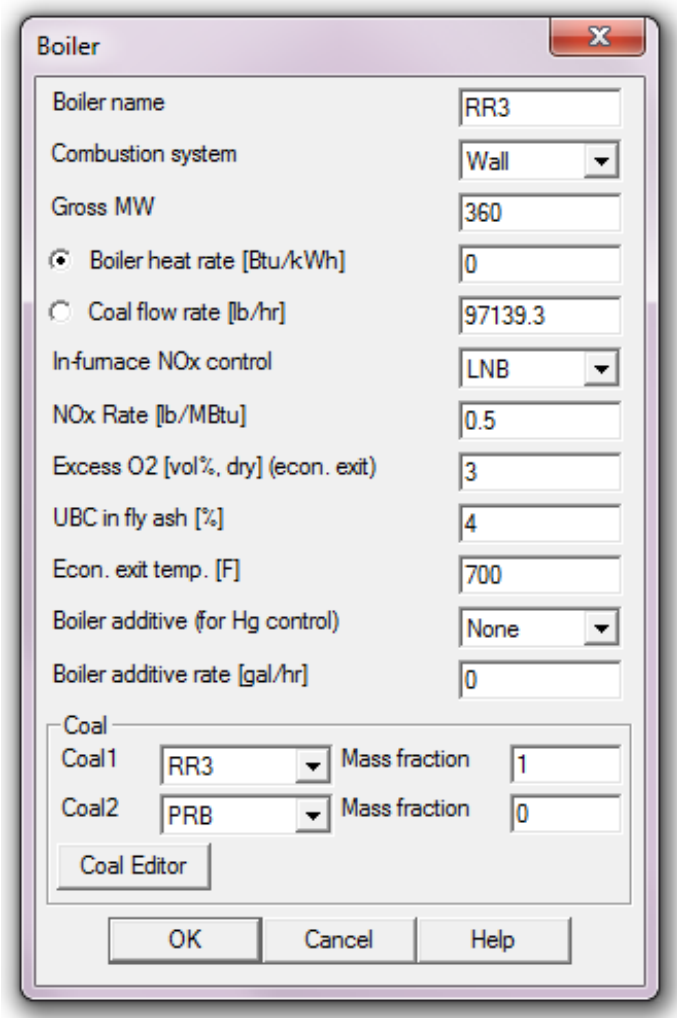

\begin{tabular}{|l|}
\hline \begin{tabular}{|ll|}
\hline Electrostatic Precipitator & \\
Flue gas inlet temp. [F] & \\
Flue gas exit temp. [F] & 300 \\
C Flue gas exit 02 [vol\%, dry] & 300 \\
$\subset$ Air inleakage [\%] & 3 \\
\hline $\begin{array}{l}\text { ESP Design Information } \\
\text { SCA ft 2/kacfm] }\end{array}$ \\
No. fields & 0 \\
\hline
\end{tabular}
\end{tabular}

-Flue Gas Conditioning

Flue gas conditioning agent (FGC)

FGC reagent conc. [ppmv, dry @3\%02]

SO3 sorbent name

SO3 sorbent injection rate [b/MMACF]

- Activated Carbon Injection

Carbon name

Injection rate, [b/MMacf]

Residence time of AC. [s]

\begin{tabular}{|c|c|}
\hline None & 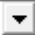 \\
\hline 0 & \\
\hline None & 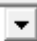 \\
\hline
\end{tabular}

OK

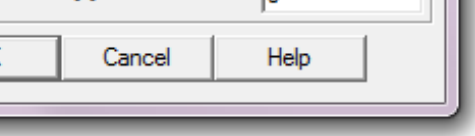

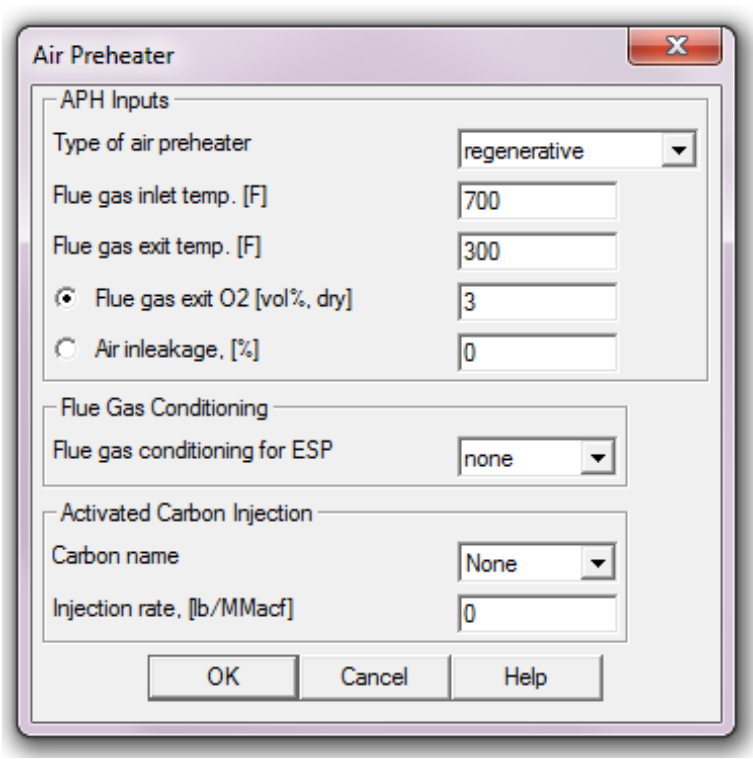

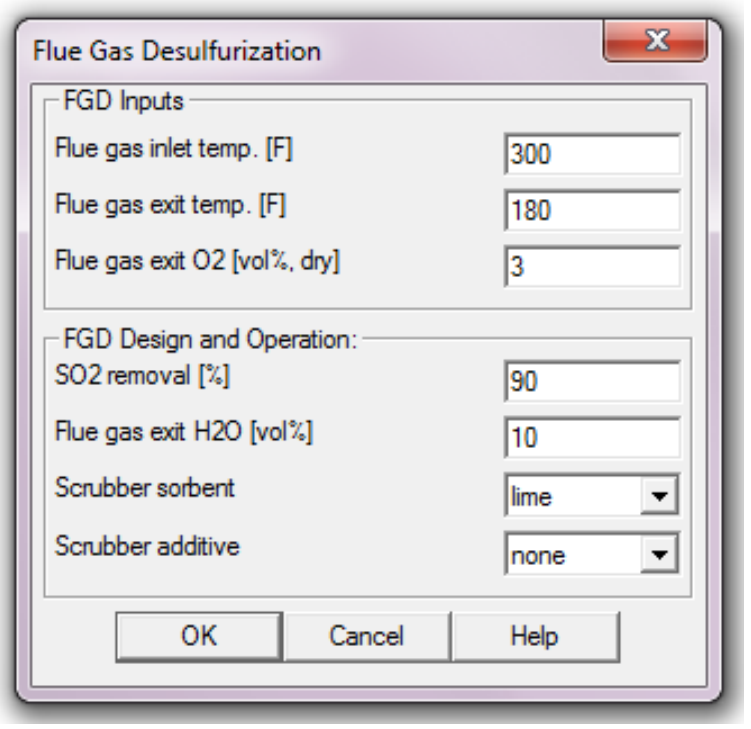

Figure 4.13-113: River Rouge 3 MerSim inputs. 
Table 4.13-29: Coal properties for River Rouge 3 MerSim cases.

\begin{tabular}{|l|c|}
\hline Name & RR3 \\
\hline Rank & SUBB \\
\hline C (wt\% AR) & 50.95 \\
\hline H (wt\% AR) & 3.51 \\
\hline N (wt\% AR) & 0.68 \\
\hline O (wt\% AR) & 13.39 \\
\hline Sulfur (wt\% AR) & 0.25 \\
\hline Cl (ug/g, dry) & 20 \\
\hline Ash (wt\% AR) & 4.9 \\
\hline Moisture (wt\%) & 26.45 \\
\hline HHV (Btu/lb, AR) & 8818 \\
\hline Hg (ug/g, dry) & 0.065 \\
\hline Br (ug/g, dry) & 0.304 \\
\hline
\end{tabular}

In MerSim, the oxidant stream must be entered manually. There is no feedback for flue gas recycle. Offline combustion calculations were performed to determine the composition of the oxidant stream. Two locations for flue gas recycle were investigated: flue gas taken either before or after the FGD (when present). The oxidant compositions are shown in Table 4.13-30. The mercury concentration in the oxidant stream for oxy-fired conditions was determined by running iterative calculations with MerSim.

Table 4.13-30: Oxidant composition for River Rouge 3 MerSim cases.

\begin{tabular}{|c|c|c|c|c|c|c|c|}
\hline & Air & Oxy24 & Oxy24 & Oxy24 & Oxy24 & Oxy24 & Oxy24 \\
\hline $\begin{array}{l}\text { Recycle } \\
\text { location }\end{array}$ & before & after & before & after & before & after \\
\hline $\begin{array}{l}\text { Oxg Control } \\
\text { Composition } \\
\text { (mol frac) }\end{array}$ & $\begin{array}{c}\text { KNX, } \\
\text { ACI }\end{array}$ & none & none & KNX & KNX & ACI & ACI \\
\hline $\mathrm{N}_{2}$ & 0.766 & 0.0025 & 0.0039 & 0.0025 & 0.0039 & 0.0025 & 0.0039 \\
\hline $\mathrm{O}_{2}$ & 0.203 & 0.2400 & 0.2400 & 0.2400 & 0.2400 & 0.2400 & 0.2400 \\
\hline $\mathrm{CO}_{2}$ & 0.0 & 0.4308 & 0.6776 & 0.4308 & 0.6776 & 0.4308 & 0.6776 \\
\hline $\mathrm{H}_{2} \mathrm{O}$ & 0.031 & 0.3259 & 0.0785 & 0.3259 & 0.0785 & 0.3259 & 0.0785 \\
\hline $\mathrm{SO}_{2}$ & 0.0 & 0.0008 & 0.00003 & 0.0008 & 0.00003 & 0.0008 & 0.00003 \\
\hline $\mathrm{HCl}_{\mathrm{HBr}}$ & 0.0 & $4.13 \mathrm{E}-6$ & $9.23 \mathrm{E}-8$ & $4.13 \mathrm{E}-6$ & $9.23 \mathrm{E}-8$ & $4.13 \mathrm{E}-6$ & $9.23 \mathrm{E}-8$ \\
\hline $\mathrm{Hg}$ & 0.0 & $2.94 \mathrm{E}-8$ & $8.10 \mathrm{E}-9$ & $5.63 \mathrm{E}-6$ & $1.63 \mathrm{E}-6$ & $2.94 \mathrm{E}-8$ & $8.10 \mathrm{E}-9$ \\
\hline & 0.0 & $1.22 \mathrm{E}-9$ & $5.09 \mathrm{E}-10$ & $5.39 \mathrm{E}-12$ & $8.43 \mathrm{E}-13$ & $5.39 \mathrm{E}-12$ & $1.02 \mathrm{E}-10$ \\
\hline
\end{tabular}


Results for the MerSim modeling of River Rouge 3 are shown in Figure 4.13-114. Baseline mercury removal was much lower for River Rouge3 compared to Hunter3. This is due to the low halogen content of the coal. The addition of the FGD improved mercury removal somewhat, but low halogen concentrations were still limiting. The addition of KNX or ACI improved mercury removal. Oxy-firing also increased mercury removal, with FGR before the FGD giving slightly improved performance compared to after FGD recycle (when an FGD was added). This is because when the recycle stream was taken before the FGD, halogen concentrations increased more drastically then when taken after the FGD. Cases with the largest increase in gas phase halogen concentration (KNX, ACI with FGR before the FGD) showed the best mercury removal.

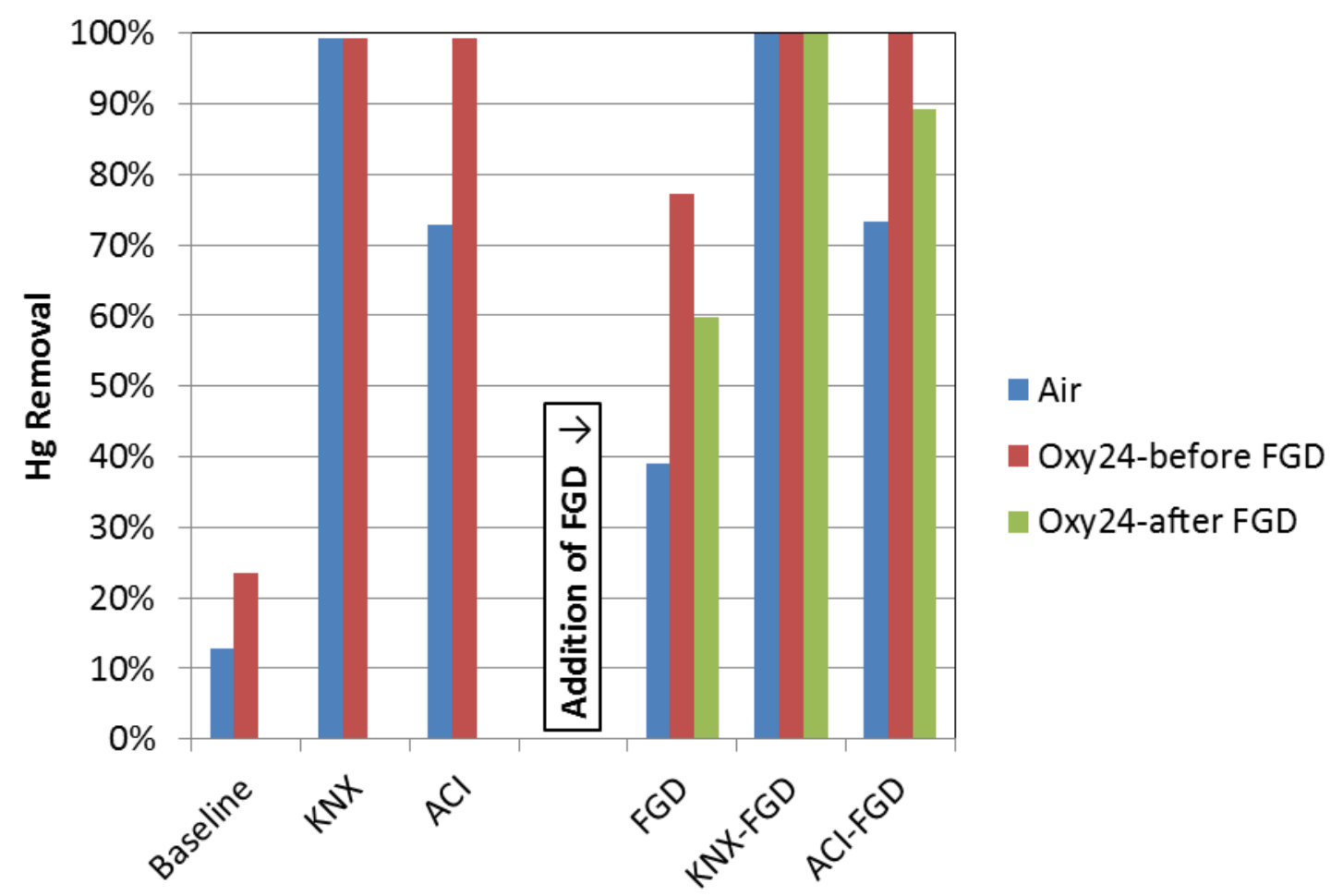

Figure 4.13-114: River Rouge 3 MerSim model results for mercury removal. 
Stack mercury concentrations are shown in Figure 4.13-115. Mercury concentration is affected by removal, the amount of flue gas present, and the flue gas moisture content (when correcting to dry conditions). For oxy-firing, the oxidant stream is enriched in oxygen ( $24 \% \mathrm{O}_{2}$ vs $20 \%$ when air-firing). This results in less dilution gas and less flue gas overall, tending to increase mercury concentrations. Any mercury present in the recycle stream will also tend to increase mercury concentration. When recycle is taken before the FGD, moisture content is higher and mercury concentrations will be higher when corrected to dry conditions. In contrast, increased mercury removal decreases mercury concentrations. For cases without any mercury specific controls, oxy-firing caused an increase in stack mercury concentration, suggesting conditions of the recycle stream were significant. For KNX addition, oxy-firing caused a slight increase in stack concentration, but these levels were extremely low $(<0.12$ ug/dscm @3\% $\mathrm{O}_{2}$.) For ACI cases, oxy-firing caused a decrease in stack concentration, indicating increased removal was the key factor.

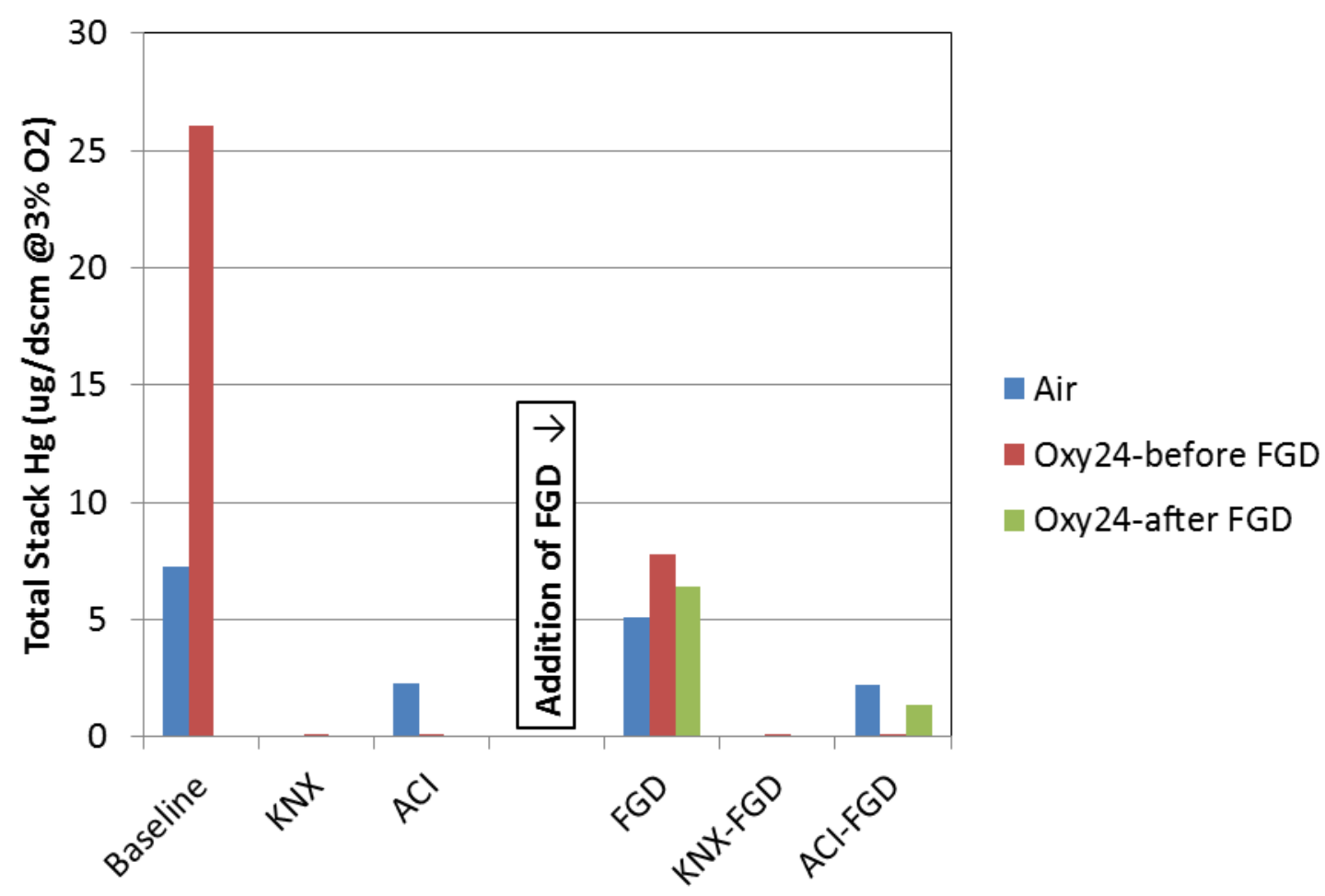

Figure 4.13-115: River Rouge 3 MerSim model results for stack mercury concentration. 
Figure 4.13-116 shows stack mercury emissions for River Rouge3. Emissions are affected by mercury removal and the amount of mercury recycled. The baseline case (without FGD) showed an increase in mercury emissions when oxy-firing (even though mercury removal increased), attributable to mercury in the recycle stream. With an FGD and no mercury specific control technology, oxy-firing caused a decrease in stack emissions (larger decrease with recycle before the FGD) indicating the large increase in mercury removal was able to dominate mercury in the recycle stream. KNX addition also showed stack emission levels remained constant or increased slightly, but these levels were extremely low $(<0.05$ lb/TBtu). All ACI cases showed a decrease in emissions when oxy-firing (due to high mercury removal).

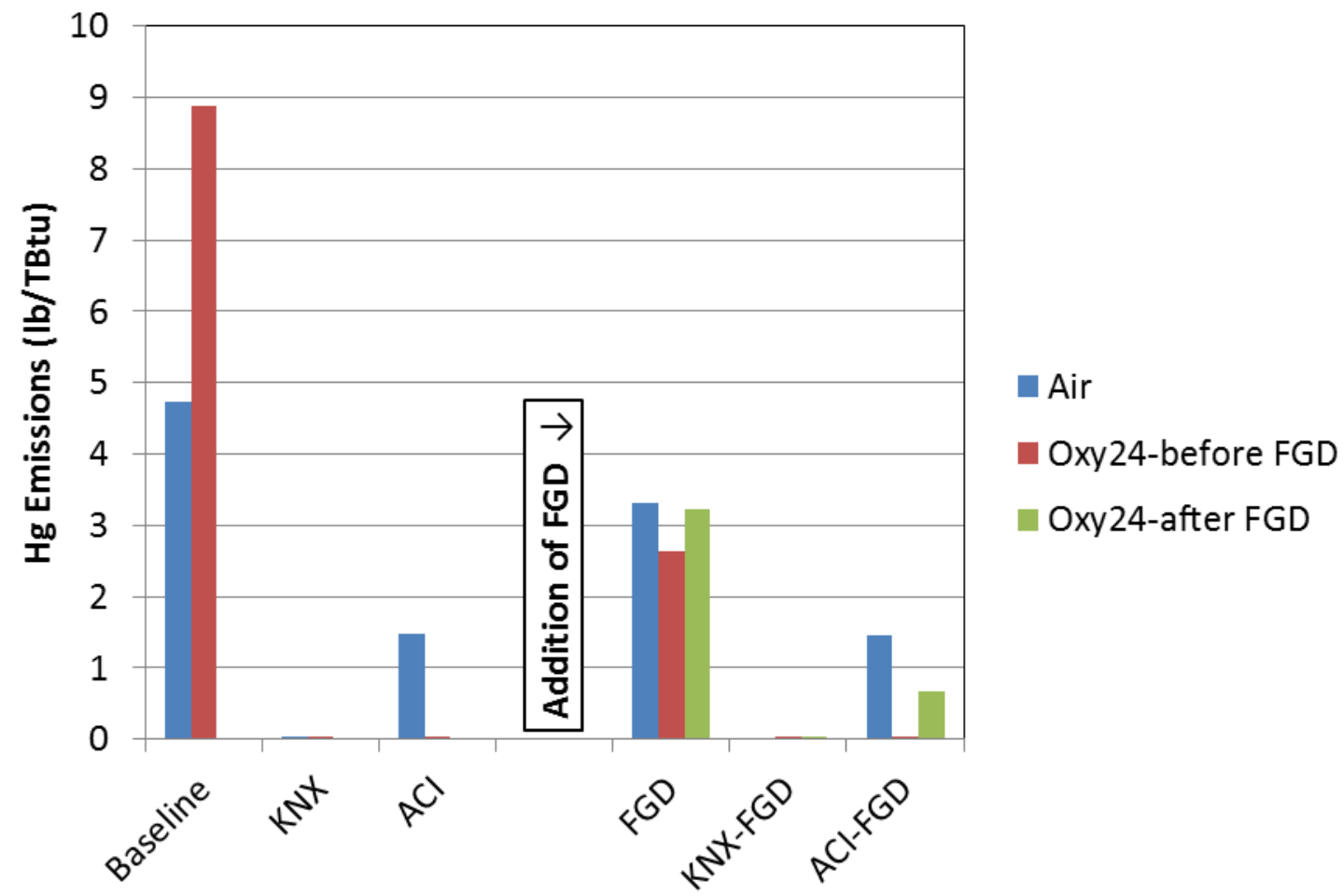

Figure 4.13-116: River Rouge 3 MerSim model results for stack mercury emissions.

\subsubsection{Full-scale Retrofit Mercury Summary}

Mercury modeling of full-scale oxy-retrofit for Hunter Unit 3 and River Rouge Unit 3 showed increased mercury removal when oxy-firing (with or without mercury control technologies). Removal levels tended to be higher with FGR before the FGD compared to after, likely due to increased halogen content of the recycle stream before the FGD. Stack mercury concentrations and emissions decreased for some oxyfired cases and increased for others. Mercury concentrations are dependent not only on mercury removal, but amount of flue gas (lower flue gas volume when oxy-firing due to oxygen enrichment of the oxidant stream), moisture content of the recycle stream (when correcting concentrations to dry conditions), and mercury content of the recycle stream. Mercury emission levels are affected by mercury removal and mercury content of the recycle stream. All Hunter 3 cases showed high mercury removal ( $>90 \%)$, due to high halogen and low sulfur content of the coal in combination with high LOI and an FGD. For River Rouge 3, cases with the largest increase in gas phase halogen concentration (KNX, ACI with FGR before the FGD) showed the best mercury removal. 


\section{SUMMARY AND CONCLUSIONS}

A five-year research and development program was conducted to acquire data and develop tools to characterize and predict impacts of $\mathrm{CO}_{2}$ flue gas recycle and burner feed design on flame characteristics (coal burnout, $\mathrm{NO}_{\mathrm{x}}, \mathrm{SO}_{\mathrm{x}}$, mercury and fine particle emissions, heat transfer), fouling, slagging and corrosion, inherent in the retrofit of existing coal-fired boilers for oxy-coal combustion. Research included testing, mechanism development, process modeling and CFD modeling. Multiple test campaigns were conducted on pilot-scale furnaces, including $100 \mathrm{~kW}$ and $1 \mathrm{MW}$ coal furnaces that were retrofitted for oxy-combustion flue gas recycle. This data was used to update mechanisms and guide oxy-coal firing system design. Finally, CFD modeling was used to assess oxy-combustion retrofit designs for two fullscale utility boilers.

The following sub-sections summarize the key results from each of the research areas described in this report. Other than the early burner tests, all testing was conducted on three coals - a western low-sulfur bituminous (Utah Skyline) coal, Power River Basin sub-bituminous (North Antelope) coal, and eastern high sulfur bituminous (Illinois \#6 Shay) coal. Mercury tests also included a high mercury, medium sulfur southeastern (Alabama Pratt) coal.

\section{Burner Tests}

A dual stage oxy-research burner developed by Siemens Energy and REI for this program was retrofitted to the University of Utah's 1 MW L1500 furnace to evaluate flame behavior under air and oxy-fired conditions. Conclusions drawn from air-fired and oxy-fired experiments with a Utah Skyline western bituminous coal were:

- Matching oxy-fired burner primary gas/fuel ratio or momentum with air-fired values resulted in a stable flame and is likely an acceptable retrofit strategy. Matching oxy-fired burner primary velocity with air-fired values resulted in a detached flame and is likely not a good retrofit strategy. The extent of the flame detachment will depend on the particular burner design and operating flexibility.

- There is a fundamental difference in particle devolatilization and ignition between air- and oxyfired operation.

- A stable flame can be achieved with no oxygen enrichment in the burner primary stream (i.e., $3 \%$ $\mathrm{O}_{2}$ in the FGR stream). However, oxygen injection can be used to intensify flames when introduced within the primary. This has the effect of increasing the adiabatic flame temperature in the fuel-laden region of the flame.

- Oxygen injection can be used to enhance ignition when introduced in the boundary layer between the burner primary and secondary streams. Velocity difference at boundary causes enhanced mixing of $\mathrm{O}_{2}$ with fuel where there are also hot gases.

- At burner stoichiometric ratios below one, furnace $\mathrm{NO}_{\mathrm{x}}$ concentrations are similar for air and oxy-fired conditions due to in-flame reburning of recycled $\mathrm{NO}_{\mathrm{x}}$ under substoichiometric conditions. At BSRs greater than one, $\mathrm{NO}_{\mathrm{x}}$ concentrations are much higher for oxy-fired conditions. $\mathrm{NO}_{\mathrm{x}}$ emissions are much lower for oxy-combustion because of the low volume of emitted flue gas.

- Flue gas recycle can produce much higher flue gas $\mathrm{SO}_{2}$ concentrations ( $\sim 5 x$ over air-firing) with untreated FGR. This resulted in gas phase $\mathrm{SO}_{2}$ concentrations near 1,800 dry ppm for the Utah coal and near 18,000 dry ppm for the Illinois coal. The sulfur mass balance for the test furnace was within $10 \%$ when including gas phase, particle and condensate sulfur. 
- Radiation measurements when firing Utah Skyline coal indicate that radiation intensity is lower for the oxy-fired condition by 25\%, 10\% and 18\%, respectively, for test furnace sections 1 through 3. Under air-fired conditions, staging the flame shifts radiation intensity from section one to section three, while under oxy-fired conditions, staging the flame generally reduces the flame intensity.

Char Oxidation

Optical measurements on individual particles burning in controlled lab-scale experiments were conducted at the Sandia Entrained Flow Reactor (EFR). Measured particle size-temperature data served as a basis for model comparison and estimation of fitting parameters for an extended single film model that could be incorporated into CFD codes. Rate parameters were fit to match observed temperatures of $100 \mu \mathrm{m}$ particles burning in $\mathrm{N}_{2}$ (with $12 \%$ and $\left.36 \% \mathrm{O}_{2}\right)$ and $\mathrm{CO}_{2}\left(36 \% \mathrm{O}_{2}\right)$. Char combustion characteristics for both environments at different $\mathrm{O}_{2}$ concentrations and particle sizes between 10 and $200 \mu \mathrm{m}$ were predicted and compared with measurements.

Measurements and particle surface kinetic modeling showed that reliable CFD predictions were feasible for both conventional and oxy-combustion environments only if heterogeneous steam and $\mathrm{CO}_{2}$ gasification reactions were included in the traditional oxidation-only single-film model. In EFR study, the new char oxidation model resulted in good agreement with the measured char consumption rates. Fullscale CFD simulation results using the extended single-film model were consistent with the trends observed in pilot-scale testing and improved predictions of LOI in full-scale boilers.

$\underline{\text { Soot }}$

Soot testing was conducted on three test furnaces and a soot model was developed based on a tar production mechanism. Results of the soot testing showed:

- Soot concentration was found to correlate with secondary flow in three reactors with three different burners.

- Coal soot is controlled primarily by the local SR where the soot is formed, so burner design/flame impacts formation.

- Soot concentrations were lower with oxy-firing than air-firing, however, when scaled to equal secondary flow rates, there was less difference in soot between air and oxy-fired flames.

- Oxy-coal burners may produce lower secondary flow rates and therefore more soot if not designed carefully.

Ash Aerosols

A series of tests at the $100 \mathrm{~kW}$ Oxy-Fuel Combustion (OFC) at the University of Utah was conducted to determine the impact of oxy-firing on black carbon (soot) emission, ultra-fine and fine particle formation, and size segregated ash aerosol composition. Tests included all three subject coals. The objective was to determine if oxy-firing conditions would significantly change ash properties such that the potential for fouling or slagging increased. Test results showed:

- Coal composition is the dominant factor in both particle size distributions and particle chemistry.

- Soot is greater under air-firing than under oxy-firing, and is also reburned in the furnace during flue gas recycle. Therefore ultrafine particles are diminished even under dirty (untreated) flue gas recycle.

- Differences between air and oxy-fired partitioning of elements in the ash are subtle and do not indicate the need for fundamental changes in ash aerosol handling or potential ash aerosol toxicity. 
- No significant changes occurred for larger super micron ash particle chemistry when changing from air to oxy-fired conditions.

- No aerosol data was discovered across a wide range of coal compositions and oxy-fired combustion conditions that would indicate a significant problem or hurdle for retrofitting an existing boiler with oxy-fired technology.

Slagging and Fouling

Three coal samples (Utah bituminous, PRB, and Illinois bituminous) and nine ash samples (each coal fired under air-fired and two oxy-fired conditions) were analyzed by CCSEM to assess changes to ash composition. The coal mineral composition measured by CCSEM agreed well with the measured ASTM mineral analysis (the PRB CCSEM was modified to include organically bound minerals). Analysis of the ash CCSEM results suggested that oxy-combustion produces slightly finer ash for the Utah bituminous coal and has little effect on the size of the PRB or Illinois bituminous coal. A mineral matter transformation (MMT) model, used to predict the properties of deposited ash, was run on each coal using standard coalescence options, no coalescence, and full coalescence. The MMT model was shown to hold a material balance throughout the calculations. The measured ash size distributions for the three firing conditions fell between the full and no coalescence options of the MMT model. This showed the MMT model can be tuned to predict the measured size distributions using coalescence options. Ash compositions predicted by the MMT model (using standard coalescence options) showed some agreement with the measured CCSEM ash composition.

A pseudo-transient slagging modeling approach was identified. The approach utilizes both a comprehensive CFD combustion code and a slagging sub-model based on MMT model results to predict the deposit build up and properties in the furnace. The approach is compatible with CFD codes and was used to predict surface deposit thermal resistance in calculations of furnace surface heat transfer.

A low temperature $\mathrm{Na}_{2} \mathrm{SO}_{4}$-based fouling model was developed to identify potential fouling in the boiler backpass and the rate at which this fouling build-up will cause a problem for the boiler operation. Key elements of the model are: 1) Vaporization of sodium during the combustion process, 2) Deposition of sodium sulfate on fly ash particles and tube surfaces due to condensation, and 3) Deposit growth rate on convective pass tubes as a function of local deposition and erosion rates.

\section{High Temperature Corrosion}

Pilot-scale corrosion experiments were performed in the University of Utah's L1500 1 MW pilot-scale furnace, using electrochemical noise (ECN) sensing technology. One waterwall probe employed SA210 low-carbon steel and three superheater probes were fabricated that employed T22, P91 and 347H materials, respectively. Baseline conditions were used to determine the difference in corrosion rate between air and oxy-fired conditions while firing the three test coals. The baseline operating conditions included a firing rate of $3.5 \mathrm{MBtu} / \mathrm{hr}$, a burner stoichiometric ratio of 0.9 and $3.0 \%$ excess $\mathrm{O}_{2}$ (dry) with the over-fire air/FGR introduced in section 6 of the furnace. The sensor elements of the waterwall were maintained at $720^{\circ} \mathrm{F}$ and the probe was installed at a gas temperature of about $2300^{\circ} \mathrm{F}$. The sensor elements on the superheater probes were controlled at $910^{\circ} \mathrm{F}$ and the sensors were installed in a region of the furnace where the gas temperature was approximately $1800^{\circ} \mathrm{F}$.

The three coals produced flue gas $\mathrm{SO}_{2}$ concentrations in the range of 128 to 3,219 ppmv (dry) for air-fired conditions and 289 to 17,624 ppmv (dry) for oxy-fired conditions. Removal of gas-phase sulfur dioxide occurred and is likely due to capture on coal mineral matter. The capture rate was shown to have linear dependence on the calcium concentration in the ash.

A summary of the key measurement results showed: 
- Waterwall (SA210) corrosion rates decreased when converting from air to oxy-firing for all coals.

- Superheater (T22, P91 and 347H) corrosion rates generally increased when converting from airto oxy-firing.

- Corrosion rates for the lower alloyed materials (SA210 and T22) were shown to increase drastically during transients between reducing and oxidizing conditions. This has relevance to inplant corrosion rates in the near-burner and near-OFA port regions. Tracking of these transient effects were unique to the ECN corrosion technique used and cannot be resolved using coupon tests.

- The presence of trisulfates strongly increases the corrosion rate of the $347 \mathrm{H}$ material under high $\mathrm{SO}_{2}(>3,000 \mathrm{ppm})$ and low temperature $\left(<1150^{\circ} \mathrm{F}\right)$ conditions.

- The dependence of corrosion rate on material temperatures was demonstrated along with the repeatable nature of the results.

- Metallographic analysis of corrosion probes showed no evidence of carburization for the conditions and coals tested.

Low Temperature Corrosion with Mercury Control Additives

Corrosion measurements were also made in the furnace ductwork just preceding the baghouse during mercury testing with a bromine $\left(\mathrm{CaBr}_{2}\right)$ additive and activated carbon injection (ACI). Corrosion probe temperatures for these tests were controlled to represent air heater basket temperatures. Results showed:

- Injection of $\mathrm{CaBr}_{2}$ resulted in a 1.5-3 fold increase in dew point corrosion rates when metal temperatures dropped below the $\mathrm{HBr}$ dew point temperature. This result was repeated for both a medium sulfur bituminous coal (Pratt) and a low sulfur sub-bituminous coal (PRB) under both oxy- and air-firing conditions.

- Oxy-coal combustion has the potential to significantly increase air heater corrosion rates.

- Corrosion appears to be caused by dew point mechanisms which appear to involve sulfuric acid, $\mathrm{HBr}, \mathrm{HCl}$ and water. Corrosion rates were dependent on flue gas concentrations and moisture level (both higher with oxy-combustion).

- While corrosion rates were lower when burning PRB coal, bromine has a much larger effect for this coal than the bituminous coal (increasing baseline acid corrosion by 3 orders of magnitude).

- ACI appears to have a more complex impact on corrosion rates; requires more data and review to understand these impacts.

Radiation Properties

A series of calculations were performed to compare gas and particle radiative property calculation methods and the impact of these differences on heat transfer predictions. The basis for the comparison was calculations from REI's in-house CFD code Glacier and Vattenfall's version of the commercial CFD code Fluent. The results of this comparison were as follows:

- Fluent exponential wide band model (EWBM) predicted gas emissivities lower than the Glacier RADCAL narrow band model (NBM); the greatest differences of $\sim 10 \%$ were for longer path length (20 m) and higher $\mathrm{H}_{2} \mathrm{O}$ concentrations. This was consistent with some earlier work done by REI comparing NBM and REI EWBM. The existing weighted sum of gray gases model (WSGGM) in Fluent predicted consistently lower gas emissivities for oxy-combustion conditions.

- Wet FGR gas had $~ 10-20 \%$ higher emissivity than air-based flue gas across the range of temperatures and path lengths studied.. The differences in gas emissivities for flue gases from air- 
fired and oxy-fired conditions was due primarily to the moisture content of the gases; $\mathrm{CO}_{2}$ concentration had a secondary effect. Dry FGR flue gas had gas emissivity similar to air. This suggests that drying the recycle gas produced during oxy-combustion could produce gas emissivities similar to air emissivities.

- Heat absorption for gas-phase heat transfer was much more dependent on gas temperature than moisture content (gas emissivity).

- In the lower furnace, particle radiation dominated gas radiation due to hot particles and higher mass density (e.g., particle loading). In the upper furnace, the lower particle temperature and lower mass density (e.g., particle loading) allowed gas radiation to play a more significant role.

- Overall, the radiative properties calculated by Fluent and Glacier were quite similar. This suggests that any differences observed between Fluent and Glacier heat transfer predictions for a full CFD case are likely to be attributable to combustion effects (particle dispersion, mixing, reaction rates, etc.) rather than to radiation calculations.

Mercury and Control Additives

Experiments were performed in University of Utah's $1500 \mathrm{~kW}$ pulverized coal furnace to investigate differences in mercury control technologies under air- and oxy-fired conditions. Experiments were performed with both a PRB and bituminous coal using either air or $\mathrm{O}_{2} / \mathrm{FGR}$ as the oxidant. Mercury measurements were performed on the flue gas using Method 30B (modified to distinguish between gasphase and particle-bound mercury), a CEM with a wet chemical conditioning system (Tekran CEM system), and a CEM with a thermal conditioning system (OL CEM system). Gas phase mercury was measured both before and after the baghouse. Two mercury control technologies were tested, including injection of solid $\mathrm{CaBr}_{2}$ into the flame and injection of Norit Darco HG activated carbon into the lowtemperature flue-gas. Coal, baghouse ash, and in-flight ash samples were collected to investigate mercury mass balance and gas-solids partitioning. Key results of the testing showed:

- No clear mercury measurement bias was noted for high $\mathrm{CO}_{2}$ environments.

- During PRB coal testing, the three mercury measurement techniques agreed well with the exception of the OL CEM measurements before the baghouse. It is suspected that during additive injection, particles on the filter of the dilution probe head contributed to biased mercury measurements. More frequent blowback of the probe and washing of the heated filter removed this bias for the bituminous testing. However, during bituminous testing none of the three measurement techniques agreed well. It is likely that ash buildup and clogging of the QSIS probe caused 30B carbon trap and Tekran CEM measurements to be biased low, suggesting the OL CEM provided more reliable results.

- Mercury mass balance was poor for many conditions, most likely due to lack of Hg measurement in ash particles that dropped out in the horizontal furnace.

- Oxidation data showed significant scatter, however data showed that $\mathrm{CaBr}_{2}$ addition increased oxidation and that oxidation was higher for oxy-firing.

- Post-bag house emissions were lower for nearly all conditions $(90 \%+$ removal). This was likely due to the filter cake build-up on the fabric filter, which captured mercury independent of the upstream condition.

- For pre-bag house measurements, PRB coal showed low removal beyond native levels, with some moderate improvement with $\mathrm{CaBr}_{2}$. For bituminous coal, the addition of $\mathrm{CaBr}_{2}$ or ACI increased removal for air-firing, but had minimal impact for oxy-firing. 
- Results suggest that untreated FGR with oxy-firing biased the expected Hg capture behavior from the additives. FGR with oxy-bituminous coal increases halogens (providing more native capture), but also increases $\mathrm{SO}_{3}$ (limiting capture). Thus capture is constrained to similar levels with and without additives under oxy-fired conditions. This highlights the need to mitigate high $\mathrm{SO}_{2}$ levels in recycled flue gases.

\section{L1500 Predictions and Data Comparison}

REI's Glacier CFD code was used to model the L1500 furnace under air and oxy-fired conditions. Comparisons of predicted gas temperatures, $\mathrm{CO}, \mathrm{CO}_{2}, \mathrm{H}_{2} \mathrm{O}, \mathrm{SO}_{2}$ and $\mathrm{O}_{2}$ concentrations, gas emissivity, and wall heat flux were made. In addition, advanced sub-models for calculating char oxidation and gas emissivity were evaluated to determine impacts on predicted results. Key conclusions from the comparisons showed:

- Predicted gas temperature trends were correct, including temperature cross-over. Oxy-fired predictions were higher than measured data in staged zone, partly due to prescribed vs actual wall temperature boundary conditions.

- The experimentally observed temperature cross-over at the OFA ports was likely due to enhanced CO oxidation near OFA ports. CO concentrations were higher in the oxy-fired case, which could account for a greater temperature increase during oxidation. Predicted results showed the same cross-over behavior and helped explain why this occurred.

- Predictions using the enhanced char oxidation model showed increased CO production in staged zone and better agreement with air data.

- Using an enhanced gas emissivity sub-model based on narrow band calculations had negligible impact on predicted gas emissivity, temperature or wall flux results. This may in part be due to the small path length of the pilot-scale furnace.

- Wall temperatures based on measured data were prescribed as boundary conditions for the air and oxy-fired cases. These prescribed profiles significantly impacted predicted incident heat flux profiles. Gas centerline temperatures and emissivities had a second-order impact on incident flux profiles.

\section{Full-Scale Oxy-Retrofit Firing System Design}

Two full-scale utility boilers, PacifiCorp's Hunter 3 and DTE's River Rouge 3, were selected for oxyretrofit assessment. The oxy-retrofit firing system design included two main tasks. First, Siemens Energy developed a conceptual oxy-burner design that could be retrofitted into the existing boiler wall cut-outs. A summary of those design guidelines include:

- It is critical to know the right $\mathrm{O}_{2}$ concentration in the furnace before starting the oxy-retrofit burner design process. This is a parameter that burner designers never had to consider before with air-fired systems and requires some boiler thermal modeling. Velocities for oxy-firing should be lower than air-fired velocities, particularly in the carrier stream, by a percentage that produces equal momentums between the two conditions. Siemens used $13 \%$, and that value proved to be successful.

- Removing moisture in the recycle stream is necessary for high moisture coals such as the fuel used at River Rouge 3, especially in the carrier gas stream. Failure to do so abates coal devolatilization and leads to condensation in the coal pipes.

- Compared with an air-fired design, an oxy-fired burner will need to be adjusted primarily to account for the $\mathrm{O}_{2} \%$ in the furnace, the $\mathrm{O}_{2} \%$ in each compartment, and for the appropriate scaling factors to support combustion. 
- A plant that is retrofitted for oxy-combustion can operate at full load for both the air-fired and oxy-fired condition by adjusting mill configurations accordingly (if needed).

The second task involved using REI's SteamGen Expert (SGE) process model to determine appropriate firing conditions and FGR properties to best match radiant furnace and backpass heat transfer for the oxyfiring design. Results showed:

- Radiant furnace heat transfer increases with increasing $\mathrm{O}_{2}$ concentration due to hotter flame temperatures and less flue gas. Convective pass heat transfer decreases with increasing $\mathrm{O}_{2}$ concentration due to reduced flue gas flow rates and potentially lower furnace exit gas temperatures. FGR properties impact flame properties and overall heat transfer.

- A flue gas recycle ratio which will produce an oxygen concentration of $25-26 \%$ in the $\mathrm{O}_{2} / \mathrm{FGR}$ mixture is expected to provide a similar heat transfer profile to air-fired conditions in Hunter 3. Alternately, a recycle ratio which will produce an oxygen concentration of $22-23 \%$ in the $\mathrm{O}_{2} / \mathrm{FGR}$ mixture is expected to provide a similar heat transfer profile to air-fired conditions in River Rouge 3 (superheat boiler). The lower oxygen concentration for the River Rouge 3 is likely due to the large surface area of radiant superheat surface.

- There is not one oxygen concentration that matches air-fired heat transfer in all boilers. Oxy-coal retrofit strategies must be tailored to specific boiler configurations.

Full-Scale Oxy-Retrofit - Hunter 3

REI's Glacier combustion simulation (CFD) tool was used to simulate air- and oxy-firing in PacifiCorp's 460 MW Hunter Unit 3. Modeling was conducted using the Utah Skyline coal fired at Hunter 3 and included improved char oxidation, soot, slagging and corrosion models. Modeling results showed:

- For oxy-firing, the $26 \% \mathrm{O}_{2} /$ FGR mixture matched air-fired heat transfer in the radiant furnace; LOI was lower (2.1\% versus 3.6\% in the air-fired case); total corrosion potential was higher for all surfaces, however, peak corrosion was lower for the waterwalls and higher for the other surfaces.

- The original char oxidation model predicted high unburned carbon in ash (UBC) and increased UBC from air- to oxy-combustion firing. The new, enhanced char oxidation sub-model predicted reasonable UBC concentrations (3.8\% for air-firing compared with the $~ 3 \%$ UBC observed at the Hunter plant) and decreased UBC for oxy-combustion firing. This decrease in UBC level from air to oxy-firing was consistent with the trend in test results from the L1500 pilot-scale tests.

- The addition of the refined soot sub-model increased CO throughout the furnace, particularly in the hopper, however exit CO concentration was $\sim 0.1 \%$ higher. The unburned carbon content of the fly ash also slightly increased $(\sim 0.3 \%)$ with the addition of the soot sub-model. Gas temperature profiles, wall temperatures and heat fluxes were very similar with and without the refined soot model.

- Use of the slagging model caused several shifts in modeling results, namely:

o Increased particle deposition and decreased UBC for both air- and oxy-fired cases.

o Decreased overall heat transfer for both air- and oxy-fired cases.

o Slightly increased total waterwall corrosion and decreased total superheater corrosion for both air- and oxy-fired cases.

Once the enhanced sub-models were evaluated, modeling was conducted to evaluate the impact of firing Utah low-sulfur bituminous and Illinois high-sulfur coals. In comparing corrosion potential between the Utah and Illinois coals, the same trend of increased total corrosion rate under oxy-firing was observed for both coals. Consistent with pilot-scale data: 
- Peak waterwall corrosion decreased under oxy-fired conditions for the Skyline coal,

- Peak SSH corrosion increased under oxy-fired conditions for both coals,

- Peak SSH corrosion under oxy-firing conditions with the Illinois coal was extremely high.

This modeling investigation suggests flue gas treatment prior to recycle will be necessary for high sulfur coals. Simulating sulfur removal (FGR conditions approximate to what might exit a wet FGD) showed mitigation of the effects of a high sulfur coal.

\section{Full-Scale Oxy-Retrofit - River Rouge 3}

REI's Glacier combustion simulation (CFD) tool was used to simulate air- and oxy-firing in the River Rouge Unit 3 Superheat boiler. Modeling included improved char oxidation, soot and corrosion submodels. Those results showed:

- For oxy-firing, a $24 \% \mathrm{O}_{2}$ mixture of oxygen and flue gas recycle was able to match the air-fired case heat transfer fairly well. Gas temperature profiles were comparable. Higher CO concentrations were observed for oxy-fired conditions compared to air-firing, primarily due to lower $\mathrm{O}_{2}$ concentrations for oxy-firing resulting from the lower overall excess oxygen (2.4\% vs $4.9 \%$ in the air-fired case). Slower burnout during oxy-firing and lower oxygen concentrations resulted in higher unburned carbon in fly ash (7.6\% versus $3.9 \%$ in the air-fired case).

- Slightly lower heat transfer to the waterwalls and slightly higher heat transfer to the radiative superheat were predicted with oxy-firing. The overall lower furnace heat transfer was very similar for air- and oxy-firing.

- Drying the flue gas recycle stream for the oxy-fired case caused:

o Decreased exit gas temperature

o Decreased CO concentrations

o Decreased UBC

o Decreased particle deposition

o Similar heat transfer

Results from the lower furnace air- and oxy-fired cases were mapped into a model of the backpass. Compared to the air-fired backpass, the oxy-fired backpass showed:

- Higher exit temperature,

- Higher CO concentrations,

- Lower $\mathrm{O}_{2}$ concentrations (the oxy-fired case was run with lower excess oxygen),

- Lower heat transfer to the convective superheat and economizer.

These full-scale modeling results suggest that appropriate selection of flue gas mixture of $\mathrm{O}_{2}$ and flue gas recycle can reasonably match heat transfer in an existing coal boiler $\left(\mathrm{O}_{2}\right.$ concentration is unit dependent) and that there are not any insurmountable differences in combustion performance or operational impacts when converting from an air-fired system to oxy-firing. Predicted results (along with test results) suggest that high sulfur flue gas recycle streams should be treated to reduce sulfur.

\section{Full-Scale Retrofit Mercury Modeling}

REI's MerSim process simulation tool was used to conduct mercury modeling of full-scale oxy-retrofit designs for Hunter Unit 3 and River Rouge Unit 3. Results showed increased mercury removal when oxyfiring (with or without mercury control technologies). Removal levels tended to be higher with FGR before the FGD compared to after, likely due to increased halogen content of the recycle stream before 
the FGD. Stack mercury concentrations and emissions decreased for some oxy-fired cases and increased for others. Mercury concentrations are dependent not only on mercury removal, but amount of flue gas (lower flue gas volume when oxy-firing due to oxygen enrichment of the oxidant stream), moisture content of the recycle stream (when correcting concentrations to dry conditions), and mercury content of the recycle stream. Mercury emission levels are affected by mercury removal and mercury content of the recycle stream. All Hunter 3 cases showed high mercury removal (>90\%), due to high halogen and low sulfur content of the coal in combination with high LOI and an FGD. For River Rouge 3, cases with the largest increase in gas phase halogen concentration (KNX, ACI with FGR before the FGD) showed the best mercury removal. Overall, Hunter 3 mercury emissions were approximately one-hundred times lower than River Rouge 3 emissions.

Overall, test results and full-scale oxy-retrofit model results did not identify any combustion-related behavior that would prevent successful retrofit of oxy-combustion systems to existing coal-fired plants. However, it is recommended that the flue gas recycle stream be treated for medium and high-sulfur coals to avoid potential operational problems.

\section{Testing Lessons Learned}

During the course of the program, researchers had several experiences that should be shared to help future researchers avoid test problems encountered during this work. The lessons learned from these experiences may be summarized as follows:

- It was helpful to visit other oxy-combustion test furnaces in the early stages of this program before starting testing. This helped identify challenges that could be accounted for in test plans.

- There is potential for significant air in-leakage in the test furnace and recycle loop. For the L1500 furnace, the expected $\mathrm{CO}_{2}$ with no in-leakage or $\mathrm{CO}_{2}$ purge was expected to be $95.6 \%$. Initial $\mathrm{CO}_{2}$ results were $80-85 \%$ until in-leakage across the fan and blower was minimized (by additional piping that balanced the pressure). With these modifications, the highest achieved dry $\mathrm{CO}_{2}$ purity was $95 \%$.

- Furnace wall temperatures significantly impact radiation intensity and heat flux measurements.

- Mercury mass balance is difficult due to ash drop-out. To improve the mercury balance, particle samples from furnace floor (or near floor) should be included in the Hg analysis. Mercury mass balance is more difficult for oxy-combustion due to FGR and particulate control device behavior.

- It is challenging to keep mercury sampling probe filters from clogging in high-particle environments (e.g., before baghouse). This plugging can lead to inconsistent results. Simultaneously running multiple Hg sampling methods can minimize this inconsistency. 


\section{REFERENCES}

Albina, D. O., K. Millrath, and N. J. Themelis. "Effects of Feed Composition on Boiler Corrosion in Waste-to-Energy Plants." Presented at 12th North American Waste to Energy Conference. 2004.

Alexander, P. A. In The mechanism of corrosion by fuel impurities, edited by R. Johnson and D. J. Littler, 571. London: Butterworths, 1963.

Anderson, C. H., and C. W. Goddard. J Inst Fuel 41, 357, 1968.

Anderson, D. W., R. Viskanta, and F. P. Incropera. "Effective Thermal Conductivity of Coal Ash Deposits at Moderate to High Temperatures." Journal of Engineering for Gas Turbine and Power, 1987: 215-221.

Anderson, J. E. Fuel Jet Burner and Combustion Method. U.S. Patent 4,878,829. November 7, 1989.

Arnott, W. Patrick, Hans Moosmuller, C. Fred Rogers, Tianfeng Jin, and Reinhard Bruch. "Photoacoustic spectrometer for measuring light absorption by aerosol: instrument description." Atmospheric Environment 33 (1999): 2845-2582.

Arnott, W.P., et al. "Evaluation of 1047-nm Photoacoustic Instruments and Photoelectric Aerosol Sensors in Source-Sampling of Black Carbon Aerosol and Particle Bound PAHs from Gasoline and Diesel Powered Vehicles." Environmental Science and Technology 39, no. 14 (2005): 5398-5406.

Ashman, P. J., and B. S. Haynes. Improved techniques for the prediction of NOx formation from char nitrogen. CSIRO Energy Technology, Project No. C4065, Australian Coal Association, 1999.

Bakker, W. T. "The effect of deposits on waterfall corrosion in fossil fuel boilers." Materials at High Temperatures, 2003: 161-168.

Bakker, W. T. Wastage in Low NOx Boilers, Root Causes and Remedies. EPRI Report TR111155, 1998.

Bakker, W. T., S. C. Kung, M. P. Heap, and J. R. Valentine. "Waterwall Corrosion in Low NOx Boilers Root Causes and Remedies." Proceedings of the EPRI-DOE-EPA Combined Utility Air Pollution Control Symposium: The MEGA Symposium, Volume 2: NOx and Multi-Pollutant Controls. Atlanta, 1999. 13-17.

Bakker, W. T., W. Y. Mok, and W. M. Cox. High-Temperature Fireside Corrosion Monitoring in the Superheater Section of a Pulverised-Coal-Fired Boiler. Palo Alto, CA: EPRI, 1992.

Baxter, L. L., et al. "Mechanistic Investigation of Chlorine-based, High-temperature Boiler Corrosion." UEF Conference: Power Production in the 21st Century: Impacts of Fuel Quality and Operations. Snowbird, UT, 2001. 
Bejarano, P.A., and Y.A. Levendis. "Single Coal Particle Combustion in O2/N2 and O2/CO2 Environments." Combustion and Flame 153, no. 1-2 (2008): 270-287.

Benson, S. A., and P. L. Holm. "Comparison of Inorganic Constituents in Three Low-Rank Coals." Ind. Eng. Chem. Prod. Res. Dev., 1985: 145-149.

Bohren, C. F. "Multiple Scattering of Light and Some of its Observable Consequences." American Journal of Physics, 1987: 524-532.

Bohren, C. F., and D. R. Huffman. Absorption and Scattering of Light by Small Particles. John Wiley \& Sons, 1983.

Boni, A.A. et al. Transformations of Inorganic Coal Constituents in Combustion Systems. Phase I Final Report, DOE Contract DE-AC22-86PC90751, Andover, MA: Physical Sciences, Inc., 1990.

Bool, L.E. et al. Fundamental Study of Ash Formation and Deposition: Effect of Reducing Stoichiometry. Final Report, DOE Contract DE-AC22-93PC92190, Andover, MA: Physical Sciences, Inc., 1995.

Borio, R. W., and R. P. Hensel. Trans ASME Ser A J Eng. Pwr. 94, 142, 1972.

Borrego, A.G., and D. Alvarez. "Comparison of Chars Obtained Under Oxy-Fuel and Conventional Pulverized Coal Combustion Atmospheres." Energy and Fuels 21 (2007): 3171-3179.

Brewster, M.Q. Thermal Radiation Transfer and Properties. John Wiley, 1992.

Brown, A. L., and T. H. Fletcher. Energy \& Fuels, 1998: 745-757.

Buhre, B., J. Hinkley, R. Gupta, P. Nelson, and T. Wall. "Factors Affecting the Vaporization of Silica During Coal Combustion." Fuel Processing Technology 88, no. 2 (2007): 157-164.

Buhre, B.J.P., Hinkley, J.T., Gupta, R.P., Wall, T.F., and P.F. Nelson. "Submicron Ash Formation From Coal Combustion." Fuel 84 (2005): 1206-1214.

C.R., Shaddix, E.S. Hecht, M. Geier, A. Molina, and B.S. Haynes. "Effect of gasification reactions on oxy-fuel combustion of pulverized coal char." Proceedings of the 35th International Technical Conference on Clean Coal \& Fuel Systems. Clearwater, FL, June 6-10, 2010.

Chang, Y. N., and F. I. Wei. Journal Mat. Sci. 26, 1991: 3693.

Chappell, J. S., and T. A. Ring. "Particle Size Distribution Effects on Sintering Rates." Journal of Applied Physics, 1986: 383-391.

Coade, R., and D. Coldham. "The Interaction of Mercury and Aluminum in Heat Exchangers in Natural Gas Plants." International Journal of Pressure Vessels and Piping 83 (2006): 336-342.

Coats, A. W., D. J. A. Dear, and D. Penfold. J Inst Fuel, 1968. 
Coble, R. L. "Effects of Particle-Size Distribution in Initial-Stage Sintering." Journal of the American Ceramic Society, 1973: 385-390.

Corey, R. C., B. J. Cross, and W. T. Reid. Trans ASME 67, 289, 1945.

Croiset, E., and K.V. Thambimuthu. "NOx and SO2 Emissions From O2/CO2 Reycle Coal Combustion." Fuel 80, no. 14 (2001): 2117-21.

Cutler, A. J. B., and E. Raask. Cor. Sci. 21, 789, 1981.

Cutler, A. J. B., C. J. Grant, J. W. Laxton, D. D. Price, and C. G. Stevens. In Corrosion resistant materials for coal conversion systems, edited by D. E. Meadowcroft and M. I. Manning, 159. Barking: Applied Science Publishers, 1983.

Damstedt, B., et al. "Biomass Cofiring Impacts on Flame Structure and Emissions." Proceedings of the Combustion Institute, Thirty-First International Symposium on Combustion. 2007. 2813-2820.

Davis, C. J., P. J. James, L. W. Pinder, and A. K. Mehta. "Effects of Fuel Composition and Combustion Parameters on Furnace Wall Fireside Corrosion in Pulverised Coal-Fired Boilers." Materials Science Forums, 2001: 857-864.

de Nevers, Noel. Air Pollution Control Engineering 2nd Edition. 2000.

Dec, J. E. A Conceptual Model of DI Diesel Combustion Based on Laser-Sheet Imaging. SAE Paper 970873, 1997.

Fairweather, M, W. P. Jones, and R. P. Lindstedt. Combustion and Flame, 1992: 45-63.

Ferguson, C. R., D. R. Tree, D. P. DeWitt, and S. A. H. Wahiduzzaman. "Design, Calibration and Error Analysis of Instruments for Heat Transfer Measurements in Internal Combustion Engines." ASME Reprint from Developments in Experimental Techniques in Heat Transfer and Combustion. HDT-Vol. 71, 1987.

Fernandez, A., J.O.L. Wendt, and M.L. Witten. "Health Effects Engineering of Coal and Biomass Combustion Particulates: Influence of Zinc, Sulfur, and Process Changes on Potential Lung Injury From Inhaled Ash." Fuel 84, no. 10 (2005): 1320-1327.

Fernandez, Art, Sheldon B. Davis, Jost O.L. Wendt, Roberta Cenni, R. Scott Young, and Mark L. Witten. "Public health: Particulate emission from biomass combustion." Nature 409 (2001): 998-998.

Fjujikawa, H., and N. Maruyama. Mat. Sci. Eng. A. 120, 1987: 399.

Fletcher, T. H., A. R. Kerstein, R. J. Pugmire, M. S. Solum, and D. M. Grant. Energy and Fuels, 1992: 414-431.

Fletcher, T.H., J. Ma, J.R. Rigby, A.L. Brown, and B.W. Webb. "Soot in Coal Combustion Systems." Progress in Energy and Combustion Science 23, no. 3 (1997): 283-301. 
French, D. N. "Creep and Creep Failures." Bulletin of the National Board of Boiler and Pressure Vessel Inspectors, July 1991.

Frenkel, J. "Viscous Flow of Crystalline Bodies Under the Action of Surface Tension." Journal of Physics, 1945: 385-390.

Gallagher, Neal B., Lawrence E. Bool, Jost O.L. Wendt, and Thomas Peterson. "Alkali metal partitioning in ash from pulverized coal combustion." Combustion Science and Technology 74 (1990): 211-221.

Gallagher, Neal B., Thomas W. Peterson, and Jost O.L. Wendt. "Sodium partitioning in a pulverized coal combustion environment." International Symposium on Combustion 26, no. 2 (1996): 3197-3204.

Geier, M., C. R. Shaddix, and B. S. Haynes. 27th Annual International Pittsburgh Coal Conference. Istanbul, Turkey, 2010.

Geier, M., C.R. Shaddix, K. Davis, and H. Shim. "On the use of single-film models to describe the oxy-fuel combustion of pulverized coal char." Proceedings of the 36th International Technical Conference on Coal Utilization and Fuel Systems. Clearwater, FL, June 5-9, 2011.

Geier, M., E. S. Hecht, and C. R. Shaddix. 26th Annual International Pittsburgh Coal Conference. Pittsburgh, PA, 2009.

Genetti, D. B., and T. H. Fletcher. ACS Division of Fuel Chemistry, 1997: 194-198.

German, R. M. Sintering Theory and Practice. New York: Wiley, 1996.

Goh, B., and E. On. UK's Pilot Scale Oxyfuel Combustion Experiences; Development, Testing and Modeling. 2008. http://www.co2captureandstorage.info/networks/Oxyfuel3rd2.htm (accessed 2010).

Goodwin, D. G. "Infrared Optical Constants of Coal Slags." Ph.D. Thesis. Stanford University, 1986.

Grabke, H. J. In Incinerating municipal and industrial waste, edited by R. W. Bryers, 161. New York: Hemisphere, 1989.

Grabke, H. J., E. Reese, and M. Spiegel. "The Effects of Chlorides, Hydrogen Chloride, and Sulfur Dioxide in the Oxidation of Steels below Deposits." Corr. Sci, 1995: 1023-1043.

Gupta, R. P., T. F. Wall, and L. Baxter. "The Thermal Conductivity of Ash Deposits: Particulate and Slag Structures." Impact of Mineral Impurities in Solid Fuel Combusion. An Engineering Foundation Conference. Kona, Hawaii, 1997.

Haanappel, V. A. C., N. W. J. Haanappel, T. Fransen, H. D. van Corbach, and P. J. Gellings. Corrosion 48, 1992: 812.

Hancock, P. Mat. Sci. Tech. 3, 536, 1987. 
Harb, J. N., and E. E. Smith. "Fireside Corrosion in Coal-Fired Boilers." Prog. Energy. Combust. Sci., 1990: 169-1990.

Harb, J. N., P. N. Slater, and G. H. Richards. "A Mathematical Model for the Build-Up of Furnace Wall Deposits." In The Impact of Ash Deposition on Coal Fired Plants, by Solihull, edited by J. Williamson and F. Wigley, 637-644. Taylor \& Francis Press, 1993.

Haynes, B. S. "Soot and Hydrocarbons in Combustion." In Fossil Fuel Combustion, edited by W. Bartok and A. F. Sarofim, 261-326. New York: Wiley \& Sons, 1991.

Haynes, B.S. Chemical Kinetic Computations of Vaporization of Mineral Constituents During Coal Combustion, A report on SKIPPY. University of Sydney, August 1999.

Hecht, E. S., C. R. Shaddix, A. Molina, and B. S. Haynes. "Effect of CO2 gasification reaction on oxy-combustion of pulverized coal char." Proceedings of the Combustion Institute, Vol 33, 2011: 1699-1706.

Hedley, A. B. J Inst Fuel 40, 142, 1967.

Hendry, A., and D. J. Lees. Cor. Sci. 20, 383, 1980.

Hill, S. C., and L. D. Smoot. Energy and Fuels, 1993: 874-883.

Hinds, William. Aerosol Technology. John Wiley and Sons Inc., 1999.

Hiramatsu, N., Y. Uematsu, T. Tanaka, and M. Kinugasa. Mat. Sci. Eng. A. 120, 1989: 319.

Ho, K., and E. P. Doane. "Current Evidence Concerning Coal Chlorine Content and Fireside Corrosion in Coal-Fired PC and Fluidized-Bed Boilers." The Proceedings of the 26th International Technical Conference on Coal Utilization \& Fuel Systems. Clearwater, FL, 2001.

Hottel, H., and F. Broughton. "Determination of True Temperature and Total Radiation from Luminous Gas Flames." Industrial and Engineering Chemistry, 1932: 166-175.

Hotttel, H.C., and A.F Sarofim. Radiative Heat Transfer. New York: McGraw Hill Book Company, 1967.

Hower, James C., Thomas L. Robl, and Gerald A. Thomas. "Changes in the quality of coal combustion by-products produced by Kentucky power plants, 1978 to 1997: consequences of Clean Air Act directives." Fuel 78 (1999): 701-712.

Huang, L.Y., J.S. Norman, M. Pourkashanian, and A. Williams. "Prediction of Ash Deposition on Superheater Tubes From Pulverized Coal Combustion." Fuel 75 (1996): 271-279.

Huenert, D., and A. Kranzmann. "Influence of Pressure and Chromium Content on Corrosion Reactions at $600^{\circ} \mathrm{C}$ in a CO2-H2O Atmosphere." NACE 2008, Paper No. 08447. 2008.

Huijbregts, W. M. M., J. B. Janssen, and O. C. J. Rens. "Corrosion in Low NOx Firing Conditions." Power Gen 98 Conference. Milan, 1998. 
Huijbregts, W. M., and R. Leferink. "Latest advances in the understanding of acid dewpoint corrosion: Corrosion and stress cracking in combustion gas condensates." Anti-Corrosion Methods and Materials, 2004: 1-26.

Hupa, M., P. Backman, R. Backman, and H. Tran. In Incinerating municipal and industrial waste, edited by R. W. Bryers, 161. New York: Hemisphere, 1989.

Ihara, Y., H. Ohgame, K. Sakiyama, and K. Hashimoto. Corr. Sci. 21, 1981: 805.

Israel, R., and D. E. Rosner. "Use of a Generalized Stokes Number to Determine the Aerodynamic Capture Efficiency of Non-Stokesian Particles from a Compressible Gas Flow." Aerosol Science Technology, 1983: 45-51.

James, P. J., and L. W. Pinder. "The Impact of Coal Chlorine on the Fireside Corrosion Behavior of Boiler Tubing: A UK Perspective." NACE 1997, Paper No. 133. 1997.

James, P. L., and L. W. Pinder. "Effect of coal chlorine on the fireside corrosion of boiler furnace wall and superheater/reheater tubing." Mat. High Temp., 1997: 187-196.

Jia, Yunlu. Particulate Formation From Pulverized Coal Under Oxy-Fuel Combustion Conditions. M.S. Thesis, Salt Lake City: University of Utah, 2011.

John, R. C., W. T. Thompson, and I. Karakaya. "Predicting Corrosion Mechanisms and Rates for Alloys in High Temperature, Complex Gases." NACE Corrosion 90 Conference, Paper 279. Las Vegas, NV, 1990.

Kennedy, I. M., W. Kollmann, and J. Y. Chen. Combustion and Flame, 1990: 73-85.

Kennedy, Ian M. "The Health Effects of Combustion Generated Aerosols." Proceedings of the Combustion Institute 32, no. 2 (2007): 2757-2770.

Kerker, M. The Scattering of Light. New York: Academic Press, 1969.

Kiang, Y. H. "Predicting dew points of acid gasses." Chemical Engineering, 1981.

Kingery, W. D., H. K. Bowen, and D. R. Uhlmann. Introduction to Ceramics, 2nd Ed. New York: John Wiley \& Sons, 1976.

Kofstad, P. High temperature corrosion. New York: Elsevier Applied Science, 1988.

Krause, H. H., A. Levy, and W. T. Reid. Trans ASME Ser A J Eng. Pwr. 91, 216, 1969.

Kung, S. C. Corrosion Studies for Low NOx Burner Technology. EPRI Report TR-108750, 1997.

Kung, S. C. "Prediction of Corrosion Rate for Alloys Exposed to Reducing/Sulfidizing Combustion Gases." Material Performance, 1997: 36-40.

Kung, S. C., and W. T. Bakker. "Effect of Sulfur and Chlorine on Furnace Wall Corrosion." NACE Corrosion/98 Conference, NACE. Houston, 1998.

Levy, A., and E. L. Merryman. Trans ASME Ser A J Eng. Pwr. 87, 374, 1965. 
Linak, W.P., et al. "Ultrafine Ash Aerosols From Coal Combustion: Characterization and Health Effects." Proceedings of the Combustion Institute 31, no. 2 (2007): 1929-1937.

Linak, William P., et al. "On trimodal particle size distributions in fly ash from pulverized-coal combustion." Proceedings of the Combustion Institute 29, no. 1 (2002): 441-447.

Lucas, D. H. J. Inst. Fuel 36, 206, 1963.

Ma, J., T. H. Fletcher, and B. W. Webb. Twenty-Sixth Symposium (International) on Combustion. Pittsburgh, PA: The Combustion Institute, 1996. 3161-3167.

Ma, J., T.H. Fletcher, and B.W. Webb. "Conversion of Coal Tar to Soot During Coal Pyrolysis in a Post-Flame Environment." Proceedings of the Combustion Institute 26, no. 2 (1996): 3161-3167.

Mackenzie, J. K., and R. Shuttleworth. "Phenomenological Theory of Sintering." Proc. Phys. Soc. London, 1949: 833-852.

Mayer, P., and A. V. Manolescu. "Influence of Hydrogen Chloride on Corrosion of Boiler Steels in Synthetic Flue Gas." Paper 80, Corrosion/NACE 1979. 1979.

Mayoral, M. C., M. T. Izquierdo, J. M. Adres, and B. Rubio. "Mechanism of interation of pyrite with hematite as simulation of slagging and fireside tube wastage in coal combustion." Thermochimica Acta, 2002: 103-111.

McKee, D. W., D. A. Shores, and K. L. Luthra. J. Electrochem. Soc. 125, 411, 1978.

McNallan, M. Modern Power 54, 95, 1998.

McNallan, M. Modern Power 54, 1994.

Meadowcroft, D. B., and W. M. Cox. "Dewpoint Corrosion: Mechanisms and Solutions." In Dewpoint Corrosion, by D. R. Holmes, Chapter 2. Ellis Horwood, 1985.

Miler, P. D., H. H. Krause, J. Zupan, and W. Boyd. Corrosion-NACE 1972. 1972.

Mills, K. C. "Estimation of Physicochemical Properties of Coal Slags and Ashes." In Mineral Matter and Ash in Coal, edited by K. S. Vorres, 195-214. Washington, D.C.: American Chemical Society, 1986.

Mobin, M., and A. U. Malik. J. Alloys Compounds, 1992.

Molina, A., and C. R. Shaddix. Proceedings of the Combustion Institute, 2007: 1905-1912.

Molina, A., et al. Combustion Science and Technology, 2002: 43-71.

Montgomery, M., A. Hjomhede, and A. Gerhardt. "Short-term Corrosion Testing in a burner rig with oxyfuel and conventional firing." EUROCORR 2009, Paper 7979. 2009. 
Montgomery, M., O. H. Larsen, and O. Biede. "Corrosion and Materials Performance in Boimass-Fired and Coal-Fired Power Plants." Paper 03356, Presented at Corrosion/2003. San Diego, California, 2003.

Morris, William. A Comparative Examination of Aerosols of Pulverized Coal Combustion in Air and in Oxygen with Carbon Dioxide Combustion Environments. M.S. Thesis, Salt Lake City: University of Utah, 2009.

Mulcahy, M.F.R., and I.W. Smith. Rev. Pure. Appl. Chem. Vol 19, 1969: 81-108.

Murphy, J. J., and C. R. Shaddix. Combustion and Flame, 2006: 710-729.

Murphy, J.J., and C.R. Shaddix. "Combustion Kinetics of Coal Chars in Oxygen-Enriched Environments." Combustion and Flame 144, no. 4 (2006): 710-729.

Nava, J. C., A. L. Plumley, and R. Knodler. "Wastage Control in Low Emission Boiler Systems." Third International Conference on Boiler Tube Failures in Fossil Plants. Nashville, TN, 1997.

Nava-Paz, J. C., A. L. Plumley, O. K. Chow, and W. Chen. "Waterwall corrosion mechanisms in coal combustion environments." Materials at High Temperatures, 2002: 127-137.

Nielsen, H. P., F. J. Frandsen, K. Dam-Johansen, and L. L. Baxter. "The Implications of Chlorine-associated Corrosion on the Operation of Biomass-fired Boilers." Prog. Energy. Combust. Sci., 2000: 283-298.

Patrick, M. A. "Experimental Investigation of Mixing and Flow in a Round Turbulent Jet Injected Perpendicularly into a Main Stream." J Inst Fuel, 1967: 425-431.

Pavlish, J. "Understanding the Fate of Hg during Oxyfuel Combustion." Proceedings of the IEAGHG Workshop Addressing SO2/SO3/Hg/Corrosion Issues in Oxyfuel Combustion Boiler and LFue Gas Processing Units. London, 2011.

Perkins, R. A., D. L. March, P. R. Clark, and W. T. Bakker. Corrosion in Syngas Coolers of Entrained Slagging Gasifiers. EPRI Report GS-6971, RP 2048-1, 1990.

Piron Abellan, J., T. Olszewski, H. J. Penkalla, G. H. Meier, and L. Singheiser. "Scale formation mechanisms of maternsitic steels in high $\mathrm{CO} 2 / \mathrm{H} 2 \mathrm{O}$ containing gases simulating oxyfuel environments." Mat High Temp, 2009: 63-72.

Quann, R. J. Ph.D. Thesis. MIT, 1992.

Quann, R.J., and A.F. Sarofim. "Vaporization of Refractory Oxides During Pulverized Coal Combustion." Proceedings of the Combustion Institute 19, no. 1 (1982): 1429-1440.

R.H., Hurt, and J.M. Calo. Combust. Flame Vol 125, 2001: 1138-1149.

R.H., Hurt, and M. Lunden J.K. Sun. Combust. Flame Vol. 113, 1998: 181-197.

Raask, E. Mineral Impurities in Coal Combustion. Washington, D.C.: Hemisphere Publishing Company, 1985. 
Rantham, R.K., L.K. Elliot, T.F. Wall, Y. Liu, and B. Moghtaderi. "Differences in Reactivity of Pulverized Coal in Air (O2/N2) and Oxy-Fuel (O2/CO2) Conditions." Fuel Processing Technology 90, no. 6 (2009): 797-802.

Rapp, R. A. Corrosion 42, 568, 1986.

Reaction Engineering International. Characterization of Oxy-combustion Impacts in Existing Coal-fired Boilers. Quarterly Progress Report, DE-NT0005288, 2009.

Reaction Engineering International. Development of Advanced Fireside Waterwall Corrosion Model for Pulverized Coal Fired Facilities. Final Report, KEPCO Research Institute, 2007.

Rehn, I. M. Fireside corrosion of superheater alloys for advanced-cycle steam plants. EPRI Rep CS-5195, 1987.

Reid, W. T. External Corrosion and Deposits. New York: Elsevier, 1971.

Richards, G. H., P. N. Slater, and J. N. Harb. "Simulation of Ash Deposit Growth in a Pulverized Coal-Fired Pilot Scale Reactor." Energy \& Fuels, 1993: 774-781.

Sander, B., et al. "Emissions, Corrosion and Alkali Chemistry in Straw-fired Combined Heat and Power Plants." Presented at 1st World Conference on Boimass for Energy and Industry. Sevilla, 2000.

Sarofim, A. F., and H. C. Hottel. In Heat Transfer, 199-217. Washington, D.C.: Hemisphere Publishing, 1978.

Sarofim, A.F., J.B. Howard, and A.S. Padia. "The physical transformation of the mineral matter in pulverized coal under simulated combustion conditions." Combustion Science and Technology 16, no. 3-6 (1977): 187-204.

Scherer, G. W. "Sintering of Low-Density Glasses: 1, Theory." Journal of the American Ceramic Society, 1997: 236-239.

Seames, W.S. The Partitioning of Trace Elements During Pulverized Coal Combustion. Doctoral Dissertation, University of Arizona, 2001.

Seames, Wayne S. "An Initial Study of the Fine Fragmentation Fly Ash Particle Mode Generated During Pulverized Coal Combustion." Fuel Processing Technology 81, no. 2 (2003): 109-125.

Senior, C, K Baldrey, W Morris, and S Sjostrom. "Multimedia Impacts of Halogen Injection for Mercury Control in Coal-Fired Boilers." Proceedings of the Electric Utility Environmental Conference (EUEC). Phoenix, AZ, 2012.

Senior, C. L. et al. Toxic Substances from Coal Cumbustion - A Comprehensive Assessment. Final Report, DOE Contract DE-AC22-95PC95101, Andover, MA: Physical Sciences, Inc., 2001. 
Senior, C. L., and S. Srinivasachar. "Viscosity of Ash Particles in Combustion Systems for Prediction of Particle Sticking." Energy \& Fuels, 1995: 277-283.

Senior, C.L., and R.C. Flagan. "Ash Vaporization and Condensation During Combustion of a Suspended Coal Particle." Aerosol Science and Technology 1 (1982): 371-383.

Shaddix, C. R. "Correcting thermocouple measurements for radiation loss: A critical review." 33rd National Heat Transfer Conference. Albuquerque, NM, USA, 1999. 1150.

Shaddix, C. R., and A. Molina. Proceedings of the Combustion Institute, 2009: 1905-1912.

-. "Effect of $\mathrm{O} 2$ and High CO2 Concentrations on PC Char Burning Rates during Oxy-Fuel Combustion." Proceedings of the 34th International Technical Conference on Coal Utilization and Fuel Systems. Clearwater, FL, 2008.

Shaddix, C. R., and A. Molina. "Particle Imaging of Ignition and Devolatilization of Pulverized Coal During Oxy-Fuel Combustion." Proceedings of the Combustion Institute 32, no. 2 (2009): 2091-2098.

Shaddix, C. R., E. S. Hecht, S. Jimenez, and S. M. Lee. "Evaluation of rank effects and gas temperature on coal char burning rates during oxy-fuel combustion." The 34th International Technical Conference on Coal Utilization \& Fuel Systems. Clearwater, FL, 2009.

Shah, Minish. "Purification of Oxy-Combustion Flue gas for SOx/NOx Removal and High CO2 Recovery." Oxyfuel Combustion Conference 2. Yeppoon: IEA Greenhouse Gas R\&D Programme, 2011.

Shaw, D. W., X. Zhu, M. K. Misra, and R. H. Essenhigh. Twenty-Third Symposium (International) on Combustion. Pittsburgh, PA: The Combustion Institute, 1990. 11551162.

Sheng, C., Y. Li, X. Liu, H. Yao, and M. Xu. "Ash Particle Formation During O2/CO2 Combustion of Pulverized Coals." Fuel Processing Technology 88, no. 11-12 (2007).

Sheng, Changdong, Yuhong Lu, Xiangpeng Gao, and Hong Yao. "Fine Ash Formation during Pulverized Coal Combustion - A Comparison of O2/CO2 Combustion versus Air Combustion." Energy and Fuels 21, no. 2 (2007): 435-440.

Shim, H., A. Sarofim, K. Davis, and M. Bockelie. "Modeling the Impacts of Soot From LowNOx Combustion Systems." The 28th International Technical Conference on Coal Utilization \& Fuel Systems. Clearwater, FL, 2003.

Shirley, H. T. Iron Steel Inst 182, 144, 1956.

Smart, J. P., and D. J. Morgan. The Comparison Between Constant Velocity and Constant Residence Time Scaling of the Aerodynamically Air Staged Burner. Livomo, Italy: International Flame Research Foundation, 1992. 
Smart, J. P., W. L. van de Kamp, and M. E. Morgan. The Effect of Scale on the Performance of the Aerodynamically Air Staged Burner. Livomo, Italy: International Flame Research Foundation, 1989.

Smith, G. P., et al. GRI-MECH 3.0. n.d. http://www.me.berkely.edu/gri_mech (accessed December 2001).

Spiegel, M., A. Zahs, and H. J. Grabke. "Fundamental aspects of chlorine induced corrosion in power plants." Proceedings of the 3rd International Workshop on Environmental Degradation in Advanced Energy Systems. Wobum, UK, 2002. 153-159.

Srinivasan, N., and K. Dombroski. "Evaluation of Balance of Plant Effects of Bromine-Based Mercury Controls." Air Quality. Washington, D.C., 2013.

Stanger, R., and T. Wall. "Sulphur Impacts During Pulverized Coal Combustion in Oxy-Fuel Technology for Carbon Capture and Storage." Progress in Energy and Combustion Science, 2010.

Stanmore, B.R., Brilhac J. F., and Gilot, P. "The oxidation of soot: a review of experiments, mechanisms and models." Carbon 39, no. 15 (2001): 2247-2268.

Syrett, B. C., and J. A. Gorman. "Cost of Corrosion in the Electric Power Industry - An Update." Materials Performance 42, no. 2 (2003): 32-38.

Thiele, E.W. Ind. Eng. Chem. Vol 31, 1939: 916-920.

Toftegaard, M. B., J. Brix, P. A. Jensen, P. Glarborg, and A. D. Jensen. "Oxy-fuel combustion of solid fuels." Prog Energy Combust Sci, 2010: 581-625.

Tognotti, L., J.P. Longwell, and A.F. Sarofim. Proceedings of the Combustion Institute, Vol 23, 1990: 1207-1213.

Trainer, Jean Pierre. "Impurities Management in an Oxy-Combustion Power Plant." Oxyfuel Combustion Conference 2. Yeppoon: IEA Greenhouse Gas R\&D Programme, 2011.

Tree, D. R., and J. A. Peart. "Two Color Transmittance Measurements in a Pulverized Coal Reactor." Proceedings of the Combustion Institute, Twenty-Eighth Symposium (International) on Combustion. 2000.

Tree, D. R., and K. I. Svensson. "Soot Processes in Compression Ignition Engines." Progress in Energy and Combustion Science Technology, 2007: 272-309.

Tree, D. R., C. Stimpson, and A. Fry. "Line of Sight Soot Measurements in Pulverized Coal Oxy Flame." The 35th International Technical Conference on Coal Utilization \& Fuel Systems. Clearwater, FL, 2010.

Tree, Dale, R, Curtis K Stimpson, Andrew Fry, William J. Morris, and Jost O. L. Wendt. "Line of Sight Soot Measurements In Staged and Unstaged Air and Oxy-Coal Flames." AIChE Annual Meeting. Minneapolis: AIChE, 2011. 
Turns, S.R. An Introduction to Combustion: Concepts and Applications. New York: McGrawHill, 1996.

Ulrich, G. D. Combust. Sci. Technol., 1971: 47-57.

Uusitalo, M. A., P. M. J. Vuoristo, and T. A. Mantyla. "High temperature corrosion of coatings and boiler steels in reducing chlorine-containing atmosphere." Surface and Coatings Technology, 161, 2002: 275-285.

Valentine, J. R., K. A. Davis, B. R. Adams, M. P. Heap, and W. Bakker. "Modeling Potential Waterwall Wastage Based on Pyritic Deposition and Wall Conditions." United Engineering Foundation Conference: Effects of Coal Quality on Power Plant Management: Ash Problems, Management and Solutions. Park City, UT, 2000.

van der Lans, R. P., P. Glarborg, and K. Dam-Johansen. "Influence of Process Parameters on Nitrogen Oxide Formation in Pulverized Coal Burners." Progress in Energy and Combustion Science, 1997: 349-377.

Viswanathan, R., and W. T. Bakker. "Materials for Boilers in Ultra Supercritical Power Plants." Proceedings of the International Joint Power Generation Conference. Miami Beach, FL, 2000.

Wall, T. F., A. Lowe, L. J. Wibberley, and I. M. Stewart. "Mineral Matter in Coal and the Thermal Performance of Large Boilers." Prog. Energy Combust. Sci., 1979: 1-29.

Wall, T. F., S. P. Bhattacharya, D. K. Zhang, R. P. Gupta, and X. He. "The Properties and Thermal Effects of Ash Deposits in Coal-Fired Furnaces." Prog. Energy Combust. Sci., 1993: 487-505.

Wall, T., et al. "An Overview on Oxyfuel Coal Combustion--State of the Art Research and Technology Development." Chemical Engineering Research and Design 87, no. 8 (2009).

Wall, Terry F. "Combustion processes for carbon capture." Proceedings of the Combustion Institute 32, no. 1 (2007): 31-47.

Walsh, P. M., A. F. Sarofim, and J. M. Beer. "Fouling of Convection Heat Exchangers by Lignitic Coal Ash." Energy \& Fuels, 1992: 709-715.

Walsh, P. M., A. N. Sayre, D. O. Loehden, L. S. Monroe, J. M. Beer, and A. F. Sarofim. "Deposition of Bituminous Coal Ash on an Isolated Heat Exchanger Tube: Effects of Coal Properties on Deposit Growth." Prog. Energy Combust. Sci., 1990: 327-346.

Wang, H. "Modeling of Ash Formation and Deposition in PC Fired Utility Boilers." Ph.D. Dissertation. Brigham Young University, 1998.

Wang, H., and J. N. Harb. "Modeling of Ash Deposition in Large Scale Combustion Facilities Burning Pulverized Coal." Progress in Energy and Combustion Science, 1997: 267-282. 
Wang, H., and J.N. Harb. "Modeling of Ash Deposition in Large Scale Combustion Facilities Burning Pulverized Coal." Progress in Energy and Combustion Science 23 (1997): 267282.

Wang, H., J. West, and J. N. Harb. "Microanalytical Characterization of Slagging Deposits in a Pilot-Scale Combustor." Energy \& Fuels, 1999: 570-578.

Yamada, T. "Pilot Scale Experiments Giving Direct Comparison Between Air and Oxy Firing of Coals and Implication for Large Scale Plan Design." 2nd Workshop of the IEA International Oxy-combustion Research Network. Windsor, USA, 2007.

Yu, Dunxi, William J. Morris, Raphael Erickson, Jost O.L. Wendt, and Andrew Fry. "Ash and deposit formation from oxy-coal combustion in a $100 \mathrm{~kW}$ test furnace." International Journal of Greenhouse Gas Control 5 (2011): S159-S167.

Zanganeh, K. E., and A. Shafeen. "A novel process integration, optimization and design approach for large-scale implementation of oxy-fired coal power plants with CO2 capture." Int J Greenhouse Gas Control, 2007: 47-54.

Zhang, Jingwei. Oxy-coal combustion: stability of coaxial pulverized coal flames in O2/CO2 environments. Ph.D. Dissertation, Salt Lake City: University of Utah, 2010.

Zheng, L., and E. Furimsky. "Assessment of Coal Combustion in O2/CO2 by Equilibrium Calculations." Fuel Processing Technology 81, no. 1 (2003): 23-34.

Zhuang, Y., J. H. Pavlish, N. B. Lentz, and L. L. Hamre. "Mercury measurement and control in a CO2-enriched flue gas." International Journal of Greenhouse Gas Control 5S (2011): S136-S142. 
Reaction Engineering International - Characterizing Oxy-combustion Impacts for Coal-fired Boilers

\section{ACKNOWLEDGMENTS}

DOE Program Managers Timothy Fout and Andrew Jones.

Intelligent Light for use of the Fieldview software for CFD graphics.

The technical staff at the University of Utah Industrial Combustion and Gasification Facility for help with L1500 and OFC testing. 
Reaction Engineering International - Characterizing Oxy-combustion Impacts for Coal-fired Boilers

\section{APPENDICES}




\section{A AEROSOL EXPERIMENTAL DATA}

\section{A.1 Sample Calculations}

Sample calculations have been provided for taking the necessary raw data, which shall be included in the CD supplement in Appendix B and creating the data points used for comparison.

\section{A.1.1 LOI}

The LOI calculations were very basic for the average ignition loss: sum of the mass of the dried samples - sum of the mass of the heated samples

sum of the mass of the heated samples

$$
\text { = Average ignition loss. }
$$

The standard deviation was calculated by taking the standard deviation of each individual sample result in Excel using the stdev(...) command.

\section{A.1.2 Black Carbon PA Calculations}

The calculations for average black carbon were made by simply averaging the data points recorded by the PA for black carbon concentration in $\mu \mathrm{g} / \mathrm{m}^{3}$. Data points that followed a sudden spike or drop in the readings were discarded as these were considered to be sampling artifacts from the critical orifice occasionally being plugged. The standard deviation was calculated by taking the standard deviation of the remaining data points in Excel using the stdev(...) command.

Raw data have been provided in the CD supplement. More information concerning the PA and data analysis can also be found in previous work (Morris 2009).

\section{A.1.3 SMPS and APS Calculations}

The SMPS and APS data were recorded and then analyzed and averaged using TSI's proprietary data merge software which provided results in a tab delimited text format. More information can be found in the help section of the software. Up to 10 scans were recorded for each condition and then averaged to produce one scan. These data files had a very large number of data points to produce a curve over such a wide range of particle diameters. As a result, tabulation of these data was impractical for print format so files have been included in the supplement, but the software, as property of the University of Utah, has not.

\section{A.1.4 BLPI Calculations}

There were far more calculations for the BLPI than other data since the calculations were not automated by the instrument. For particle size distributions, a series of samples were collected for a given condition. The mass was recorded for each plate on the impactor. The flow through the impactor was found to be $24.1 \mathrm{lpm}$. The dilution was set by the mass flow controller and recorded.

In order to transfer this information to volumetric concentration a simple calculation was performed:

$$
\begin{gathered}
\frac{(\text { mass of plate } N)}{(24.1 \text { lpm }- \text { dilution flow rate }) \times\left(\frac{1 \text { cubic meter }}{1000 \text { lpm }}\right)} \times \text { sampling time }(\mathrm{min}) \\
=\text { mass concentration of plate } N
\end{gathered}
$$


This created the concentration of a particular diameter range. In order to covert this to the differential mass plot ( $\mathrm{dM} / \mathrm{d} \log \mathrm{Dp})$ in the units of $\mu \mathrm{g} / \mathrm{m}^{3}$ another calculation was performed:

$$
\frac{\text { mass concentration of plate } N}{\log (\text { Dcut Plate } N)-\log (\text { Dcut Plate } N+1)}=d M / d \log D p
$$

This allowed for plotting the log plots for the particle size distributions of each condition collected with the BLPI.

Another step was necessary to convert this into the concentration of a particular element:

$$
\begin{gathered}
\frac{\text { mass concentration of plate } N \times\left(\frac{\text { MW Oxide }}{\text { MW Element }} x \text { concentration of element on plate } N\right)}{\log (\text { Dcut PlateN })-\log (\text { Dcut Plate } N+1)} \\
=d \text { Melemental oxide } / \text { dlogD } p
\end{gathered}
$$

However, this calculation produced the y ordinate that recorded the value on a flue gas volume basis. Since the flue gas volume differed for each case, it was decided to compare the concentration data on the basis of $\mu \mathrm{g}$ of oxide per gram of coal burned. In order to do this, a factor of cubic meter per gram of coal burned had to be calculated. Lb mols of flue gas per hour were calculated in the everyday worksheets provided in the supplement. The amount of flue gas created per hour and the amount of coal burned per hour were known and calculated in these worksheets, and these data were used to come up with a conversion factor:

$$
\frac{\frac{l b \text { mols of flue } \times 10.78\left(\frac{\text { cubic foot } x \text { psi }}{\text { Rankine } x \text { lb mol }}\right)}{(14.7 p s i)} \times\left(. \frac{3048 m}{f t}\right)^{3}}{\text { mass of coal fed in grams }}=\text { conv. factor }
$$

Then it was simply a matter of multiplying $\mathrm{dM} / \mathrm{dlogDp}$ in $\mathrm{ug} / \mathrm{m}^{3}$ by the conversion factor to get $\mathrm{dM} / \mathrm{dlogDp}$ in ug/g coal.

\section{A.2 Tables for LOI, PA, and BLPI}

Data have been tabulated for the LOI, PA and BLPI figures in the text and presented here to allow for quick reference between data point values. Reading exact data off of log scale plots is very difficult and can lead to significant errors when estimating the differences present. As a result, the tabulated data are presented here.

Tables have not been recorded for SMPS curves. Considering their large number of data points, it was not possible to tabulate results on a single page, so these data are recorded in the supplement in electronic format along with BLPI, ICP-MS, and EDS raw data. 
Table A-1: Data for Utah LOI in Figure 4.7-6 and Figure 4.7-7.

\begin{tabular}{|r|r|r|r|r|r|r|}
\hline & Air AVG & StdDev & OXY27 & StdDev & OXY32 & StdDev \\
\hline $0 \%$ & 18.9102 & 1.13253 & 30.3329 & 1.35869 & 5.19134 & 1.03013 \\
\hline $1 \%$ & 8.2661 & 1.58346 & 6.49002 & 2.27033 & 5.19439 & 1.36029 \\
\hline $2 \%$ & 5.8329 & 2.02084 & 6.00315 & 1.55274 & 2.40168 & 0.74862 \\
\hline $3 \%$ & 4.15667 & 2.34789 & 5.17905 & 1.9776 & 5.70244 & 2.42908 \\
\hline
\end{tabular}

Table A-2: Data for PRB LOI in Figure 4.7-8.

\begin{tabular}{|r|r|r|r|r|r|r|}
\hline & Air AVG & StdDev & OXY27 & StdDev & OXY32 & StdDev \\
\hline $0 \%$ & 6.37606 & 1.36408 & 4.30672 & 1.63857 & 4.60455 & 0.9047 \\
\hline $1 \%$ & 4.50704 & 0.43062 & 3.05725 & 1.05306 & 3.92715 & 1.47771 \\
\hline $2 \%$ & 4.34549 & 2.88798 & 2.78828 & 1.17166 & 3.3046 & 0.85924 \\
\hline $3 \%$ & 5.47645 & 1.58182 & 4.62687 & 0.92747 & 4.42375 & 1.53021 \\
\hline
\end{tabular}

Table A-3: Data for Illinois LOI in Figure 4.7-9.

\begin{tabular}{|r|r|r|r|r|r|r|}
\hline & Air AVG & StdDev & OXY27 & StdDev & OXY32 & StdDev \\
\hline $0 \%$ & 14.3709 & 2.02098 & 5.13611 & 0.55318 & 19.4521 & 3.95714 \\
\hline $1 \%$ & 6.96798 & 0.40751 & 3.82387 & 0.75344 & 4.09511 & 0.93721 \\
\hline $2 \%$ & 6.3571 & 1.31499 & 3.88889 & 0.47995 & 4.02057 & 0.91207 \\
\hline $3 \%$ & 5.21801 & 1.02027 & 3.87213 & 0.49369 & 4.12634 & 0.73513 \\
\hline
\end{tabular}

Table A-4: Utah black carbon emissions data for Figure 4.7-10.

\begin{tabular}{|r|r|r|r|r|r|r|}
\hline & Air & StdDev & OXY27 & StdDev & OXY32 & StdDev \\
\hline $0 \%$ & 206336 & 55911.9 & 30188.5 & 15102.2 & 31536 & 20470.4 \\
\hline $1 \%$ & 22702.5 & 12982.8 & 15528.1 & 7879.75 & 17018.9 & 11098.2 \\
\hline $2 \%$ & 7167.65 & 3671.69 & 6225.96 & 3158.25 & 7279.71 & 3611.06 \\
\hline $3 \%$ & 3981.26 & 1198.17 & 2986.23 & 975.34 & 8124.3 & 4613.15 \\
\hline
\end{tabular}

Table A-5: Utah black carbon emission data for Figure 4.7-11.

\begin{tabular}{|r|r|r|r|r|r|r|r|}
\hline & \multicolumn{1}{|l|}{ Air } & StdDev & OXY27 & StdDev & OXY32 & StdDev & \\
\hline $0 \%$ & 2381.38 & 645.296 & 261.024 & 130.581 & 227.507 & $147.678 \mu \mathrm{gg}$ coal \\
\hline $1 \%$ & 262.017 & 149.838 & 134.263 & 68.1321 & 122.778 & $80.0648 \mu \mathrm{gg} / \mathrm{g}$ coal \\
\hline $\mathbf{2 \%}$ & 82.724 & 42.3761 & 53.8326 & 27.3077 & 52.5174 & $26.051 \mu \mathrm{\mu g} / \mathrm{g}$ coal \\
\hline $3 \%$ & 45.9489 & 13.8284 & 25.8204 & 8.43326 & 58.6105 & $33.2803 \mu \mathrm{gg} / \mathrm{g}$ coal \\
\hline
\end{tabular}

Table A-6: Utah black carbon emissions data for Figure 4.7-12, Figure 4.7-18, Figure 4.7-19, and Figure 4.7-20.

\begin{tabular}{|r|l|r|r|r|r|r|r|}
\hline \multicolumn{1}{|l|l}{ SR } & Air & StdDev & OXY27 & StdDev & FGR & \multicolumn{1}{l|}{ StdDev } & \\
\hline 0.90 & 32054.92 & 7328.42 & 6942.26 & 3063.54 & 16629.68 & $8582.44 \mu \mathrm{g} / \mathrm{m}^{3}$ \\
\hline 1.00 & 11275.66 & 3134.43 & 1905.74 & 1113.69 & 425.79 & $347.22 \mu \mathrm{g} / \mathrm{m}^{3}$ \\
\hline $1.17 / 1.1$ & 2331.81 & 896.82 & 370.20 & 108.38 & 137.40 & $52.97 \mu \mathrm{g} / \mathrm{m}^{3}$ \\
\hline
\end{tabular}


Table A-7: PRB black carbon emissions data for Figure 4.7-13.

\begin{tabular}{|r|l|l|l|l|l|l|l|}
\hline & Air & StdDev & OXY27 & StdDev & OXY32 & StdDev & \\
\hline 0 & 55845.5 & 13411.9 & 23257.6 & 11591.8 & 43856.5 & $12976.3 \mathrm{mg} / \mathrm{m}^{3}$ \\
\hline 1 & 6917.82 & 3040.07 & 10681.4 & 6316.05 & 23235.1 & $11736.7 \mathrm{mg} / \mathrm{m}^{3}$ \\
\hline 2 & 3289.89 & 2470.64 & 2981.29 & 1976.36 & 15922.4 & $8903.88 \mathrm{mg} / \mathrm{m}^{3}$ \\
\hline 3 & 2010.63 & 1120.44 & 2137.18 & 1517.3 & 13861.6 & 7661.19 & $\mathrm{mg} / \mathrm{m}^{3}$ \\
\hline
\end{tabular}

Table A-8: PRB black carbon emissions data for Figure 4.7-14, Figure 4.7-18, Figure 4.7-19, and Figure 4.7-20.

\begin{tabular}{|r|l|r|r|r|r|r|r|}
\hline SR & Air & StdDev & OXY27 & StdDev & FGR & \multicolumn{1}{l|}{ StdDev } \\
\hline 0.90 & 6319.66 & 944.37 & 465.28 & 163.43 & 1750.03 & $492.45 \mu g / \mathrm{m}^{3}$ \\
\hline 1.00 & 2702.13 & 427.58 & 175.59 & 40.68 & 202.12 & $111.94 \mu \mathrm{g} / \mathrm{m}^{3}$ \\
\hline $1.17 / 1.12$ & 1096.48 & 183.83 & 171.43 & 53.51 & 154.92 & $93.18 \mu \mathrm{g} / \mathrm{m}^{3}$ \\
\hline
\end{tabular}

Table A-9: Illinois black carbon emissions data for Figure 4.7-15.

\begin{tabular}{|r|l|r|r|r|r|l|l|}
\hline & Air & StdDev & OXY27 & StdDev & FGR & StdDev & \\
\hline 0 & 15168.5 & 10588.8 & 4366.42 & 1387.14 & 3588.19 & 1371.17 & $\mathrm{mg} / \mathrm{m}^{3}$ \\
\hline 1 & 2622.68 & 1050.75 & 1484.41 & 793.143 & 2004.55 & 982.728 & $\mathrm{mg} / \mathrm{m}^{3}$ \\
\hline 2 & 2072.52 & 1149.53 & 1009.94 & 481.47 & 882.397 & $654.458 \mathrm{mg} / \mathrm{m}^{3}$ \\
\hline 3 & 575.039 & 522.893 & 836.896 & 436.852 & 652.043 & 485.825 & $\mathrm{mg} / \mathrm{m}^{3}$ \\
\hline
\end{tabular}

Table A-10: Illinois black carbon emissions data for Figure 4.7-16.

\begin{tabular}{|r|r|r|r|r|r|r|r|}
\hline & Air & StdDev & OXY27 & StdDev & OXY32 & StdDev & \\
\hline $0 \%$ & 137.64 & 96.0833 & 29.779 & 9.46034 & 20.6143 & $7.87744 \mu \mathrm{\mu g} / \mathrm{g}$ coal \\
\hline $1 \%$ & 23.7984 & 9.53454 & 10.1237 & 5.40925 & 11.5162 & 5.64581 & $\mu \mathrm{g} / \mathrm{g}$ coal \\
\hline $2 \%$ & 18.8062 & 10.4309 & 6.88781 & 3.28363 & 5.0694 & $3.75989 \mu \mathrm{\mu g} / \mathrm{g} \mathrm{coal}$ \\
\hline $3 \%$ & 5.21794 & 4.74476 & 5.70765 & 2.97934 & 3.74601 & $2.79109 \mu \mathrm{\mu g} / \mathrm{g} \mathrm{coal}$ \\
\hline
\end{tabular}

Table A-11: Illinois black carbon emissions data for Figure 4.7-17, Figure 4.7-18, and Figure 4.7-19.

\begin{tabular}{|r|r|r|r|r|l|}
\hline SR & Air & StdDev & OXY27 & \multicolumn{1}{l|}{ StdDev } & \\
\hline 0.90 & 31936.56 & 4383.48 & 13855.40 & 2459.21 & $\mu \mathrm{g} / \mathrm{m}^{3}$ \\
\hline 1.00 & 8699.44 & 2152.93 & 793.35 & 212.46 & $\mu \mathrm{g} / \mathrm{m}^{3}$ \\
\hline $1.17 / 1.12$ & 2466.51 & 1424.06 & 478.35 & 145.91 & $\mu \mathrm{g} / \mathrm{m}^{3}$ \\
\hline
\end{tabular}


Table A-12: Utah BLPI PSD data for Figure 4.7-21, Figure 4.7-42, Figure 4.7-43, and Figure 4.7-44.

\begin{tabular}{|c|c|c|c|c|c|c|c|}
\hline & Air & & OXY27 & & OXY32 & & \\
\hline $\mathrm{Dp}(\mu \mathrm{m})$ & dm/dlogdp & std dev & dm/dlogdp & stdev & dm/dlogdp & stdev & \\
\hline 0.0324 & 16257.11 & 9312.431 & 8128.556 & 3519.768 & 18289.25 & 6096.417 & $\mu \mathrm{g} / \mathrm{m}^{3}$ \\
\hline 0.0636 & 18241.62 & 12638.16 & 14593.29 & 6319.082 & 58373.18 & 12638.16 & $\mu g / m^{3}$ \\
\hline 0.0926 & 6902.691 & 0 & 25309.87 & 10544.03 & 18407.17 & 7970.541 & $\mu \mathrm{g} / \mathrm{m}^{3}$ \\
\hline 0.168 & 11813.38 & 10230.69 & 11813.38 & 5906.69 & 21657.86 & 9022.619 & $\mu \mathrm{g} / \mathrm{m}^{3}$ \\
\hline 0.337 & 35585.49 & 17792.74 & 50412.77 & 13589.43 & 47447.32 & 27178.86 & $\mu \mathrm{g} / \mathrm{m}^{3}$ \\
\hline 0.535 & 45830.02 & 3968.996 & 59579.02 & 39090.08 & 48121.52 & 18188.22 & $\mu \mathrm{g} / \mathrm{m}^{3}$ \\
\hline 0.973 & 289369.7 & 153120.1 & 244356.7 & 190323.6 & 565878.6 & 347957.5 & $\mu \mathrm{g} / \mathrm{m}^{3}$ \\
\hline 1.98 & 744909.2 & 160684 & 1021590 & 225239.4 & 510794.9 & 170265 & $\mu \mathrm{g} / \mathrm{m}^{3}$ \\
\hline 3.77 & 680242.4 & 123680.4 & 1319258 & 786557.4 & 714598 & 289567.6 & $\mu \mathrm{g} / \mathrm{m}^{3}$ \\
\hline 7.33 & 1439531 & 459114.9 & 2921047 & 883791 & 2039335 & 1092369 & $\mu g / m^{3}$ \\
\hline & \multicolumn{2}{|c|}{ FGR Clean } & FGR Dirty & & & & \\
\hline & \multicolumn{2}{|c|}{ dm/dlogdp std dev } & \multicolumn{2}{|c|}{ dm/dlogdp std dev } & & & \\
\hline 0.0324 & 18289.25 & 6096.417 & 25063.05 & 7136.637 & $\mu g / m^{3}$ & & \\
\hline 0.0636 & 32834.91 & 10944.97 & 64453.71 & 9181.413 & $\mu g / m^{3}$ & & \\
\hline 0.0926 & 34513.45 & 24888 & 41416.14 & 13805.38 & $\mu g / m^{3}$ & & \\
\hline 0.168 & 17063.77 & 9093.945 & 30846.05 & 7957.202 & $\mu \mathrm{g} / \mathrm{m}^{3}$ & & \\
\hline 0.337 & 19769.72 & 3424.215 & 65240.06 & 37038.55 & $\mu \mathrm{g} / \mathrm{m}^{3}$ & & \\
\hline 0.535 & 18332.01 & 3968.996 & 100826 & 17300.45 & $\mu g / m^{3}$ & & \\
\hline 0.973 & 67519.61 & 16706.77 & 186482.7 & 91167.2 & $\mu \mathrm{g} / \mathrm{m}^{3}$ & & \\
\hline 1.98 & 138340.3 & 48765.75 & 148981.8 & 56309.84 & $\mu g / m^{3}$ & & \\
\hline 3.77 & 144293.8 & 47231.24 & 178649.5 & 95209.24 & $\mu g / m^{3}$ & & \\
\hline 7.33 & 80973.59 & 26991.2 & 185939.4 & 81140.03 & $\mu \mathrm{g} / \mathrm{m}^{3}$ & & \\
\hline
\end{tabular}

Table A-13: Utah SMPS concentration data for Figure 4.7-27.

\begin{tabular}{|r|r|r|r|r|}
\hline \multicolumn{1}{|l|l}{ SR } & \multicolumn{1}{l|}{ Air } & OXY27 & FGR & \\
\hline 0.90 & 16336.00 & 2828.77 & 16629.68 & $\mu \mathrm{g} / \mathrm{m}^{3}$ \\
\hline 1.00 & 2616.79 & 282.28 & 425.79 & $\mu \mathrm{g} / \mathrm{m}^{3}$ \\
\hline $1.17 / 1.1$ & 608.82 & 198.79 & 137.40 & $\mu \mathrm{g} / \mathrm{m}^{3}$ \\
\hline
\end{tabular}


Table A-14: PRB BLPI PSDs for Figure 4.7-28, Figure 4.7-42, Figure 4.7-43, and Figure 4.7-44.

\begin{tabular}{|c|c|c|c|c|c|c|c|}
\hline & Air & & OXY27 & & OXY32 & & \\
\hline $\mathrm{Dp} \mu \mathrm{m}$ & dm/dlogdp & stdev & $\mathrm{dm} / \mathrm{dlogdp}$ & stdev & \multicolumn{2}{|c|}{ dm/dlogdp stdev } & \\
\hline 0.0324 & 325142.23 & 140791 & 232772.3 & 0 & 913530.3 & 452080 & $\mu \mathrm{g} / \mathrm{m}^{3}$ \\
\hline 0.0636 & 1021530.6 & 505527 & 696498.1 & 241274 & 1171480 & 405813 & $\mu \mathrm{g} / \mathrm{m}^{3}$ \\
\hline 0.0926 & 552215.25 & 276108 & 263557.3 & 0 & 1034348 & 255935 & $\mu \mathrm{g} / \mathrm{m}^{3}$ \\
\hline 0.168 & 472535.23 & 0 & 526232.4 & 344500 & 758657.5 & 379329 & $\mu \mathrm{g} / \mathrm{m}^{3}$ \\
\hline 0.337 & 1067564.6 & 355855 & 1019039 & 0 & 2094864 & 872716 & $\mu \mathrm{g} / \mathrm{m}^{3}$ \\
\hline 0.535 & 1741540.6 & 572417 & 1049924 & 524962 & 2060248 & 254890 & $\mu \mathrm{g} / \mathrm{m}^{3}$ \\
\hline 0.973 & 1543305.3 & 353616 & 1399497 & 637895 & 2477784 & 1072912 & $\mu \mathrm{g} / \mathrm{m}^{3}$ \\
\hline 1.98 & 1787782 & 920849 & 2519147 & 1126011 & 2050209 & 1230125 & $\mu \mathrm{g} / \mathrm{m}^{3}$ \\
\hline 3.77 & 742082.58 & 247361 & 2675995 & 1658433 & 926657.7 & 229288 & $\mu \mathrm{g} / \mathrm{m}^{3}$ \\
\hline \multirow[t]{3}{*}{7.33} & 647788.74 & 374001 & 4740636 & 4122292 & 1848938 & 800614 & $\mu \mathrm{g} / \mathrm{m}^{3}$ \\
\hline & FGR Clean & & FGR Dirty & & & & \\
\hline & dm/dlogdp & stdev & $\mathrm{dm} / \mathrm{dlogdp}$ & stdev & & & \\
\hline 0.0324 & 789904.36 & 181112 & 743045.6 & 151618 & $\mu g / m^{3}$ & & \\
\hline 0.0636 & 2079115.2 & 699423 & 1694539 & 437132 & $\mu g / m^{3}$ & & \\
\hline 0.0926 & 1030801.8 & 490501 & 1500726 & 768742 & $\mu g / m^{3}$ & & \\
\hline 0.168 & 908008.87 & 297216 & 1225812 & 382771 & $\mu g / m^{3}$ & & \\
\hline 0.337 & 1807184.6 & 368755 & 2110010 & 751164 & $\mu g / m^{3}$ & & \\
\hline 0.535 & 1003946.9 & 626887 & 2015442 & 860228 & $\mu g / m^{3}$ & & \\
\hline 0.973 & 1823823.7 & 393638 & 1639535 & 363225 & $\mu g / m^{3}$ & & \\
\hline 1.98 & 2138327.5 & 803201 & 1219898 & 569051 & $\mu \mathrm{g} / \mathrm{m}^{3}$ & & \\
\hline 3.77 & 3788986.4 & 970134 & 1262995 & 673165 & $\mu g / m^{3}$ & & \\
\hline 7.33 & 4137380.1 & 999831 & 1920503 & 973497 & $\mu g / m^{3}$ & & \\
\hline
\end{tabular}

Table A-15: PRB SMPS ultrafine concentration data for Figure 4.7-34.

\begin{tabular}{|r|r|r|}
\hline SR & Air & OXY27 \\
\hline 0.90 & 1724.36 & $575.36 \mu \mathrm{g} / \mathrm{m}^{3}$ \\
\hline 1.00 & 975.62 & $308.10 \mu \mathrm{g} / \mathrm{m}^{3}$ \\
\hline $1.17 / 1.12$ & 440.16 & $206.60 \mu \mathrm{g} / \mathrm{m}^{3}$ \\
\hline
\end{tabular}


Table A-16: Illinois BLPI PSDs for Figure 4.7-35, Figure 4.7-42, Figure 4.7-43, and Figure 4.7-44.

\begin{tabular}{|c|c|c|c|c|c|c|c|}
\hline & Air & & OXY27 & & OXY32 & & \\
\hline $\mathrm{Dp} \mu \mathrm{m}$ & $\mathrm{dm} / \mathrm{dlogdp}$ & stdev & dm/dlogdp & stdev & dm/dlogdp & stdev & \\
\hline 0.0324 & 151733 & 24833.15 & 113799.8 & 16257.11 & 151733 & 0 & $\mu \mathrm{g} / \mathrm{m}^{3}$ \\
\hline 0.0636 & 544816.3 & 67403.54 & 651833.8 & 60756.73 & 590217.7 & 167969.7 & $\mu \mathrm{g} / \mathrm{m}^{3}$ \\
\hline 0.0926 & 294514.8 & 97401.61 & 484722.3 & 69688.44 & 357917.3 & 231625.3 & $\mu \mathrm{g} / \mathrm{m}^{3}$ \\
\hline 0.168 & 73505.48 & 50632.94 & 173262.9 & 27281.83 & 98007.31 & 59071.76 & $\mu \mathrm{g} / \mathrm{m}^{3}$ \\
\hline 0.337 & 47447.32 & 0 & 63263.09 & 36238.49 & 73806.94 & 31959.34 & $\mu \mathrm{g} / \mathrm{m}^{3}$ \\
\hline 0.535 & 85549.36 & 46134.54 & 97770.7 & 28002.6 & 64162.02 & 37043.96 & $\mu \mathrm{g} / \mathrm{m}^{3}$ \\
\hline 0.973 & 763078.7 & 471721.4 & 548730.8 & 157162.5 & 480139.4 & 103953.2 & $\mu \mathrm{g} / \mathrm{m}^{3}$ \\
\hline 1.98 & 851324.8 & 283774.9 & 643223.1 & 131070 & 993212.2 & 397284.9 & $\mu \mathrm{g} / \mathrm{m}^{3}$ \\
\hline 3.77 & 540529.3 & 280737.2 & 366460.5 & 63472.83 & 961958.9 & 509020.8 & $\mu \mathrm{g} / \mathrm{m}^{3}$ \\
\hline 7.33 & 2719113 & 616992.4 & 2463197 & 1883857 & 2799087 & 2255307 & $\mu \mathrm{g} / \mathrm{m}^{3}$ \\
\hline & FGR Clean & & FGR Dirty & & & & \\
\hline & $\mathrm{dm} / \mathrm{dlogdp}$ & stdev & dm/dlogdp & stdev & & & \\
\hline 0.0324 & 61497.86 & 29681.63 & 68969.56 & 29864.7 & $\mu g / m^{3}$ & & \\
\hline 0.0636 & 144458.9 & 56176.58 & 134140.4 & 35744.3 & $\mu g / m^{3}$ & & \\
\hline 0.0926 & 96312.29 & 28043.09 & 117136.6 & 33814.41 & $\mu g / m^{3}$ & & \\
\hline 0.168 & 41764.48 & 11694.05 & 105803.3 & 67515.65 & $\mu g / m^{3}$ & & \\
\hline 0.337 & 100645.8 & 65371.38 & 184517.3 & 63321.61 & $\mu g / m^{3}$ & & \\
\hline 0.535 & 103048.1 & 15914.81 & 136101.3 & 19443.04 & $\mu g / m^{3}$ & & \\
\hline 0.973 & 460133.6 & 270633.6 & 438127.2 & 216312.7 & $\mu g / m^{3}$ & & \\
\hline 1.98 & 540748.9 & 338167.9 & 496606.1 & 293964 & $\mu g / m^{3}$ & & \\
\hline 3.77 & 448914.2 & 169673.6 & 679784.3 & 357524.5 & $\mu \mathrm{g} / \mathrm{m}^{3}$ & & \\
\hline 7.33 & 643790 & 533297.7 & 1080448 & 134705.6 & $\mu \mathrm{g} / \mathrm{m}^{3}$ & & \\
\hline
\end{tabular}

Table A-17: Illinois total SMPS concentration data for Figure 4.7-41.

\begin{tabular}{|r|l|l|l|}
\hline SR & Air & OXY27 & \\
\hline 0.90 & 40386.22 & 17597.24 & $\mu \mathrm{g} / \mathrm{m}^{3}$ \\
\hline 1.00 & 6836.92 & 1621.59 & $\mu \mathrm{g} / \mathrm{m}^{3}$ \\
\hline $1.17 / 1.12$ & 1701.67 & 1945.91 & $\mu \mathrm{g} / \mathrm{m}^{3}$ \\
\hline
\end{tabular}


Table A-18: Sodium data for the Utah coal in Figure 4.7-51, Figure 4.7-83, and Figure 4.7-84.

\begin{tabular}{|c|c|c|c|c|c|c|}
\hline Dp $(\mu \mathrm{m})$ & Air & OXY27 & OXY32 & FGR Clean & FGR Dirty & \\
\hline 0.0324 & ND & 1.99484 & 0.701 & 0.261677 & ND & $\mu \mathrm{g} / \mathrm{g}$ coal \\
\hline 0.0636 & 27.01064 & 0.62684 & 0.63332 & 0.341735 & ND & $\mu \mathrm{g} / \mathrm{g}$ coal \\
\hline 0.0926 & 2.650192 & 1.06158 & 0.86172 & 0.29186 & ND & $\mu \mathrm{g} / \mathrm{g}$ coal \\
\hline 0.168 & 3.776167 & 2.73363 & 1.74157 & 0.352075 & ND & $\mu \mathrm{g} / \mathrm{g} \mathrm{coal}$ \\
\hline 0.337 & ND & 10.8073 & 5.34658 & 0.820948 & ND & $\mu \mathrm{g} / \mathrm{g} \mathrm{coal}$ \\
\hline 0.535 & 5.15506 & 3.00263 & 2.05326 & 1.521458 & 24.33832 & $\mu \mathrm{g} / \mathrm{g} \mathrm{coal}$ \\
\hline 0.973 & 233.6845 & 76.3914 & 43.3332 & 3.978872 & ND & $\mu \mathrm{g} / \mathrm{g} \mathrm{coal}$ \\
\hline 0.973 & 263.1418 & 147.364 & 279.888 & 23.09696 & 61.12427 & $\mu \mathrm{g} / \mathrm{g} \mathrm{coal}$ \\
\hline 1.98 & 221.823 & 532.978 & 218.041 & 44.71118 & 49.30206 & $\mu \mathrm{g} / \mathrm{g} \mathrm{coal}$ \\
\hline 3.77 & 289.9544 & 654.666 & 259.001 & 33.98388 & 81.06461 & $\mu \mathrm{g} / \mathrm{g} \mathrm{coal}$ \\
\hline 7.33 & 666.5641 & 1166.94 & 585.84 & 18.87815 & 37.37984 & $\mu \mathrm{g} / \mathrm{g}$ coal \\
\hline
\end{tabular}

Table A-19: Magnesium data for the Utah coal in Figure 4.7-52.

\begin{tabular}{|c|c|c|c|c|c|c|}
\hline Dp $(\mu \mathrm{m})$ & Air & OXY27 & OXY32 & FGR Clean & FGR Dirty & \\
\hline 0.0324 & ND & 0.13801 & ND & 0.016886 & ND & $\mu g / g$ coal \\
\hline 0.0636 & ND & 0.25425 & ND & 0.159242 & ND & $\mu g / g$ coal \\
\hline 0.0926 & ND & 0.44623 & 0.104693 & 0.100371 & ND & $\mu g / g$ coal \\
\hline 0.168 & 0.628708 & 0.57302 & 0.280634 & 0.087245 & ND & $\mu g / g$ coal \\
\hline 0.337 & ND & 3.22605 & 1.038163 & 0.199837 & 0.222122 & $\mu g / g$ coal \\
\hline 0.535 & 1.55191 & 0.64253 & 0.804222 & 0.40533 & 4.912763 & $\mu g / g$ coal \\
\hline 0.973 & 61.83796 & 28.449 & 10.93256 & 0.859685 & ND & $\mu g / g$ coal \\
\hline 0.973 & 60.31503 & 37.3859 & 80.09617 & 11.02241 & 19.92941 & $\mu g / g$ coal \\
\hline 1.98 & 53.49927 & 129.673 & 60.13899 & 14.3561 & 14.73995 & $\mu g / g$ coal \\
\hline 3.77 & 79.20111 & 187.067 & 86.96938 & 13.11099 & 36.78482 & $\mu g / g$ coal \\
\hline 7.33 & 233.9342 & 394.4 & 201.9987 & 7.283195 & 16.41169 & $\mu g / g$ coal \\
\hline
\end{tabular}

Table A-20: Aluminum data for the Utah coal in Figure 4.7-53.

\begin{tabular}{|c|c|c|c|c|c|c|}
\hline Dp $(\mu \mathrm{m})$ & Air & OXY27 & OXY32 & FGR Clean & FGR Dirty & \\
\hline 0.0324 & ND & 2.50352 & ND & 0.667589 & 1.284056 & $\mu \mathrm{g} / \mathrm{g}$ coal \\
\hline 0.0636 & ND & ND & ND & ND & 2.682063 & $\mu \mathrm{g} / \mathrm{g}$ coal \\
\hline 0.0926 & 0.648423 & 3.13889 & 2.676037 & 1.898406 & 3.56855 & $\mu \mathrm{g} / \mathrm{g}$ coal \\
\hline 0.168 & 5.261218 & 9.22899 & 7.934947 & 2.585622 & 2.427874 & $\mu \mathrm{g} / \mathrm{g}$ coal \\
\hline 0.337 & 19.74718 & 41.939 & 26.25165 & 5.406072 & 35.42673 & $\mu \mathrm{g} / \mathrm{g}$ coal \\
\hline 0.535 & 22.74336 & 13.0282 & 8.228712 & 10.26147 & 261.3366 & $\mu \mathrm{g} / \mathrm{g}$ coal \\
\hline 0.973 & 827.8385 & 267.661 & 101.5312 & 13.16806 & 167.8933 & $\mu \mathrm{g} / \mathrm{g}$ coal \\
\hline 0.973 & 1407.164 & 666.141 & 1190.053 & 110.0738 & 310.9433 & $\mu \mathrm{g} / \mathrm{g}$ coal \\
\hline 1.98 & 1219.43 & 2759.55 & 1012.155 & 173.6857 & 241.1056 & $\mu \mathrm{g} / \mathrm{g}$ coal \\
\hline 3.77 & 1669.839 & 3542.48 & 1354.134 & 178.172 & 280.1214 & $\mu \mathrm{g} / \mathrm{g}$ coal \\
\hline 7.33 & 4184.124 & 7155.54 & 3605.081 & 98.97512 & 232.7451 & $\mu \mathrm{g} / \mathrm{g}$ coal \\
\hline
\end{tabular}


Table A-21: Silicon data for the Utah coal in Figure 4.7-54, Figure 4.7-85, and Figure 4.7-86.

\begin{tabular}{|c|c|c|c|c|c|c|}
\hline Dp $(\mu \mathrm{m})$ & Air & OXY27 & OXY32 & FGR Clean & FGR Dirty \\
\hline 0.0324 & ND & 87.40639 & ND & 3.564211 & ND & $\mu \mathrm{g} / \mathrm{g}$ coal \\
\hline 0.0636 & ND & ND & ND & 3.376333 & ND & $\mu \mathrm{g} / \mathrm{g} \mathrm{coal}$ \\
\hline 0.0926 & 16.22693 & 64.6227 & 49.80418 & 3.579596 & ND & $\mu \mathrm{g} / \mathrm{g} \mathrm{coal}$ \\
\hline 0.168 & 27.70426 & 64.73939 & 51.11126 & 3.587378 & ND & $\mu \mathrm{g} / \mathrm{g} \mathrm{coal}$ \\
\hline 0.337 & ND & 320.8107 & 136.5051 & 5.367063 & ND & $\mu \mathrm{g} / \mathrm{g} \mathrm{coal}$ \\
\hline 0.535 & ND & 73.16162 & 94.68153 & 8.137303 & 76.20017 & $\mu \mathrm{g} / \mathrm{g} \mathrm{coal}$ \\
\hline 0.973 & 493.208 & 3890.889 & 1465.148 & 32.98455 & 7.019423 & $\mu \mathrm{g} / \mathrm{g} \mathrm{coal}$ \\
\hline 0.973 & 1878.93 & 908.0702 & 1629.194 & 154.0215 & 432.1675 & $\mu \mathrm{g} / \mathrm{g}$ coal \\
\hline 1.98 & 1934.374 & 4663.608 & 1686.361 & 268.7584 & 396.2129 & $\mu \mathrm{g} / \mathrm{g}$ coal \\
\hline 3.77 & 3072.656 & 6756.074 & 2538.557 & 367.4512 & 483.2707 & $\mu \mathrm{g} / \mathrm{g}$ coal \\
\hline 7.33 & 9252.698 & 15484.99 & 7927.97 & 204.1203 & 478.6532 & $\mu \mathrm{g} / \mathrm{g}$ coal \\
\hline
\end{tabular}

Table A-22: Phosphorus data for the Utah coal in Figure 4.7-55.

\begin{tabular}{|c|c|c|c|c|c|c|}
\hline Dp $(\mu \mathrm{m})$ & Air & OXY27 & OXY32 & FGR Clean & FGR Dirty & \\
\hline 0.0324 & ND & 0.498173 & ND & 0.163404 & 0.192316 & $\mu \mathrm{g} / \mathrm{g}$ coal \\
\hline 0.0636 & ND & 0.34051 & ND & 0.425562 & 0.471064 & $\mu \mathrm{g} / \mathrm{g}$ coal \\
\hline 0.0926 & 0.300866 & 0.446864 & 0.302095 & 0.311286 & 0.621705 & $\mu \mathrm{g} / \mathrm{g}$ coal \\
\hline 0.168 & 0.477032 & 0.719411 & 0.643714 & 0.264454 & 0.269403 & $\mu \mathrm{g} / \mathrm{g}$ coal \\
\hline 0.337 & 1.290399 & 5.829329 & 2.052943 & 0.627656 & 2.706514 & $\mu \mathrm{g} / \mathrm{g}$ coal \\
\hline 0.535 & ND & 1.008344 & 0.684184 & 1.311631 & 17.85813 & $\mu \mathrm{g} / \mathrm{g}$ coal \\
\hline 0.973 & 55.46921 & 17.4364 & 8.171229 & 0.850994 & 9.253563 & $\mu \mathrm{g} / \mathrm{g}$ coal \\
\hline 0.973 & 67.09463 & 34.8505 & 83.40289 & 15.89899 & 23.73715 & $\mu \mathrm{g} / \mathrm{g}$ coal \\
\hline 1.98 & 54.25091 & 131.6852 & 52.47422 & 35.25304 & 17.74935 & $\mu \mathrm{g} / \mathrm{g}$ coal \\
\hline 3.77 & 74.70469 & 175.4174 & 82.89672 & 12.57117 & 33.64407 & $\mu \mathrm{g} / \mathrm{g}$ coal \\
\hline 7.33 & 298.3053 & 403.4032 & 240.2504 & 6.983325 & 14.79443 & $\mu \mathrm{g} / \mathrm{g}$ coal \\
\hline
\end{tabular}

Table A-23: Potassium data for the Utah coal in Figure 4.7-56.

\begin{tabular}{|c|c|c|c|c|c|c|}
\hline Dp $(\mu \mathrm{m})$ & Air & OXY27 & OXY32 & FGR Clean & FGR Dirty \\
\hline 0.0324 & ND & 0.673099 & ND & ND & 0.124491 & $\mu \mathrm{g} / \mathrm{g}$ coal \\
\hline 0.0636 & ND & ND & ND & ND & 0.346894 & $\mu \mathrm{g} / \mathrm{g}$ coal \\
\hline 0.0926 & ND & ND & ND & ND & 0.388127 & $\mu \mathrm{g} / \mathrm{g} \mathrm{coal}$ \\
\hline 0.168 & 1.32569 & 4.096359 & 0.533795 & ND & 0.100346 & $\mu \mathrm{g} / \mathrm{g}$ coal \\
\hline 0.337 & ND & 1.472433 & 0.989338 & ND & 0.659464 & $\mu \mathrm{g} / \mathrm{g}$ coal \\
\hline 0.535 & ND & ND & ND & 0.170675 & 5.040214 & $\mu \mathrm{g} / \mathrm{g} \mathrm{coal}$ \\
\hline 0.973 & 32.21646 & 17.58422 & ND & 0.763868 & 5.649693 & $\mu \mathrm{g} / \mathrm{g} \mathrm{coal}$ \\
\hline 0.973 & 47.55069 & 19.28231 & 36.21065 & 3.51548 & 6.368503 & $\mu \mathrm{g} / \mathrm{g}$ coal \\
\hline 1.98 & 45.40805 & 90.84166 & 32.24364 & 10.24119 & 7.87666 & $\mu \mathrm{g} / \mathrm{g}$ coal \\
\hline 3.77 & 65.5834 & 117.7125 & 42.06699 & 8.645236 & 16.36996 & $\mu \mathrm{g} / \mathrm{g}$ coal \\
\hline 7.33 & 168.5163 & 285.7803 & 135.7937 & 4.802456 & 11.78492 & $\mu \mathrm{g} / \mathrm{g}$ coal \\
\hline
\end{tabular}


Table A-24: Calcium data for the Utah coal in Figure 4.7-57, Figure 4.7-87, and Figure 4.7-88.

\begin{tabular}{|c|c|c|c|c|c|c|}
\hline Dp $(\mu \mathrm{m})$ & Air & OXY27 & OXY32 & FGR Clean & FGR Dirty & \\
\hline 0.0324 & ND & 1.589856 & 1.710141 & ND & ND & $\mu$ g/g coal \\
\hline 0.0636 & ND & 0.11751 & 0.812095 & 0.39118 & ND & $\mu \mathrm{g} / \mathrm{g} \mathrm{coal}$ \\
\hline 0.0926 & ND & 1.438158 & 1.542477 & 0.347243 & ND & $\mu \mathrm{g} / \mathrm{g} \mathrm{coal}$ \\
\hline 0.168 & 4.986243 & 3.625272 & 2.620712 & 0.236066 & ND & $\mu \mathrm{g} / \mathrm{g} \mathrm{coal}$ \\
\hline 0.337 & 6.122422 & 10.56411 & 6.710665 & 0.538162 & 3.144532 & $\mu \mathrm{g} / \mathrm{g} \mathrm{coal}$ \\
\hline 0.535 & 10.10942 & 2.326315 & 2.10743 & 1.483213 & 29.95221 & $\mu \mathrm{g} / \mathrm{g} \mathrm{coal}$ \\
\hline 0.973 & 382.5501 & 140.1365 & 73.19222 & ND & 31.96872 & $\mu \mathrm{g} / \mathrm{g} \mathrm{coal}$ \\
\hline 0.973 & 392.749 & 155.2816 & 272.3351 & 35.53892 & 103.7888 & $\mu \mathrm{g} / \mathrm{g} \mathrm{coal}$ \\
\hline 1.98 & 406.5944 & 773.2104 & 247.3363 & 68.14155 & 76.80127 & $\mu \mathrm{g} / \mathrm{g} \mathrm{coal}$ \\
\hline 3.77 & 553.1231 & 931.8116 & 327.2049 & 83.75328 & 70.50028 & $\mu \mathrm{g} / \mathrm{g} \mathrm{coal}$ \\
\hline 7.33 & 1047.383 & 1637.718 & 782.6898 & 46.52521 & 122.4197 & $\mu \mathrm{g} / \mathrm{g} \mathrm{coal}$ \\
\hline
\end{tabular}

Table A-25: Titanium data for the Utah coal in Figure 4.7-58.

\begin{tabular}{|c|c|c|c|c|c|c|}
\hline Dp $(\mu \mathrm{m})$ & Air & OXY27 & OXY32 & FGR Clean & FGR Dirty & \\
\hline 0.0324 & ND & ND & ND & ND & 0.077262 & $\mu g / g$ coal \\
\hline 0.0636 & ND & 0.351558 & ND & ND & 0.200268 & $\mu g / g$ coal \\
\hline 0.0926 & 0.278878 & ND & ND & 0.06939 & 0.267838 & $\mu g / g$ coal \\
\hline 0.168 & 0.62623 & 0.228345 & 0.158261 & ND & 0.145566 & $\mu g / g$ coal \\
\hline 0.337 & 2.585575 & 2.192819 & 0.78023 & 0.096388 & 1.71867 & $\mu g / g$ coal \\
\hline 0.535 & ND & 0.388824 & 0.450794 & 0.305311 & 11.08069 & $\mu g / g$ coal \\
\hline 0.973 & 65.66519 & 21.71646 & 6.462439 & ND & 12.6192 & $\mu g / g$ coal \\
\hline 0.973 & 107.1176 & 45.30343 & 89.4448 & 10.24583 & 23.95982 & $\mu g / g$ coal \\
\hline 1.98 & 92.93839 & 187.8199 & 67.47211 & 42.42341 & 20.80482 & $\mu g / g$ coal \\
\hline 3.77 & 120.825 & 230.5485 & 88.72217 & 19.4252 & 41.94802 & $\mu g / g$ coal \\
\hline 7.33 & 331.4503 & 490.8218 & 233.3357 & 10.79076 & 40.96594 & $\mu g / g$ coal \\
\hline
\end{tabular}

Table A-26: Iron data for the Utah coal in Figure 4.7-59, Figure 4.7-89, and Figure 4.7-90.

\begin{tabular}{|c|c|c|c|c|c|c|}
\hline Dp $(\mu \mathrm{m})$ & Air & OXY27 & OXY32 & FGR Clean & FGR Dirty & \\
\hline 0.0324 & ND & 1.953832 & 0.642781 & 0.108337 & 0.368506 & $\mu \mathrm{g} / \mathrm{g}$ coal \\
\hline 0.0636 & 7.390049 & 2.211962 & 1.293834 & 0.368684 & 2.085372 & $\mu \mathrm{g} / \mathrm{g}$ coal \\
\hline 0.0926 & 4.511751 & 2.653614 & 1.537627 & 0.441137 & 4.354161 & $\mu \mathrm{g} / \mathrm{g}$ coal \\
\hline 0.168 & 4.298376 & 4.082328 & 2.801716 & 0.430193 & 1.610516 & $\mu \mathrm{g} / \mathrm{g}$ coal \\
\hline 0.337 & 8.104899 & 17.36188 & 10.1457 & 0.973225 & 15.13444 & $\mu \mathrm{g} / \mathrm{g}$ coal \\
\hline 0.535 & 9.456762 & 4.694497 & 2.511241 & 1.950197 & 105.2311 & $\mu \mathrm{g} / \mathrm{g}$ coal \\
\hline 0.973 & 285.1464 & 119.3411 & 51.3844 & 3.485363 & 56.2149 & $\mu \mathrm{g} / \mathrm{g}$ coal \\
\hline 0.973 & 420.2882 & 186.6403 & 358.065 & 46.77843 & 106.0823 & $\mu \mathrm{g} / \mathrm{g}$ coal \\
\hline 1.98 & 356.1459 & 676.9364 & 254.0062 & 91.0806 & 73.20841 & $\mu \mathrm{g} / \mathrm{g}$ coal \\
\hline 3.77 & 430.6279 & 787.9558 & 306.1714 & 75.43521 & 96.62559 & $\mu \mathrm{g} / \mathrm{g}$ coal \\
\hline 7.33 & 959.8104 & 1590.379 & 707.2161 & 41.90449 & 146.1723 & $\mu \mathrm{g} / \mathrm{g}$ coal \\
\hline
\end{tabular}


Table A-27: Arsenic data for the Utah coal in Figure 4.7-60, Figure 4.7-91, and Figure 4.7-92.

\begin{tabular}{|c|c|c|c|c|c|c|}
\hline Dp $(\mu \mathrm{m})$ & Air & OXY27 & OXY32 & FGR Clean & FGR Dirty & \\
\hline 0.0324 & 0.015818 & 0.001485 & ND & 0.00304 & 0.004439 & $\mu \mathrm{g} / \mathrm{g}$ coal \\
\hline 0.0636 & ND & 0.000807 & ND & ND & 0.003253 & $\mu \mathrm{g} / \mathrm{g}$ coal \\
\hline 0.0926 & ND & ND & ND & 0.002391 & 0.003117 & $\mu \mathrm{g} / \mathrm{g}$ coal \\
\hline 0.168 & ND & 0.001575 & ND & 0.001472 & 0.000756 & $\mu \mathrm{g} / \mathrm{g}$ coal \\
\hline 0.337 & ND & 0.008629 & ND & 0.004048 & 0.007197 & $\mu \mathrm{g} / \mathrm{g}$ coal \\
\hline 0.535 & ND & 0.355091 & 0.002832 & 0.002212 & 0.027152 & $\mu \mathrm{g} / \mathrm{g}$ coal \\
\hline 0.973 & ND & 6.731038 & 0.023497 & 0.025543 & 0.041232 & $\mu \mathrm{g} / \mathrm{g}$ coal \\
\hline 1.98 & 0.991581 & & & 0.028726 & 0.033281 & $\mu \mathrm{g} / \mathrm{g}$ coal \\
\hline 3.77 & 0.861248 & & & 0.119805 & 0.089277 & $\mu \mathrm{g} / \mathrm{g}$ coal \\
\hline 7.33 & $\mathrm{ND}$ & & & 0.068018 & 0.068362 & $\mu \mathrm{g} / \mathrm{g}$ coal \\
\hline
\end{tabular}




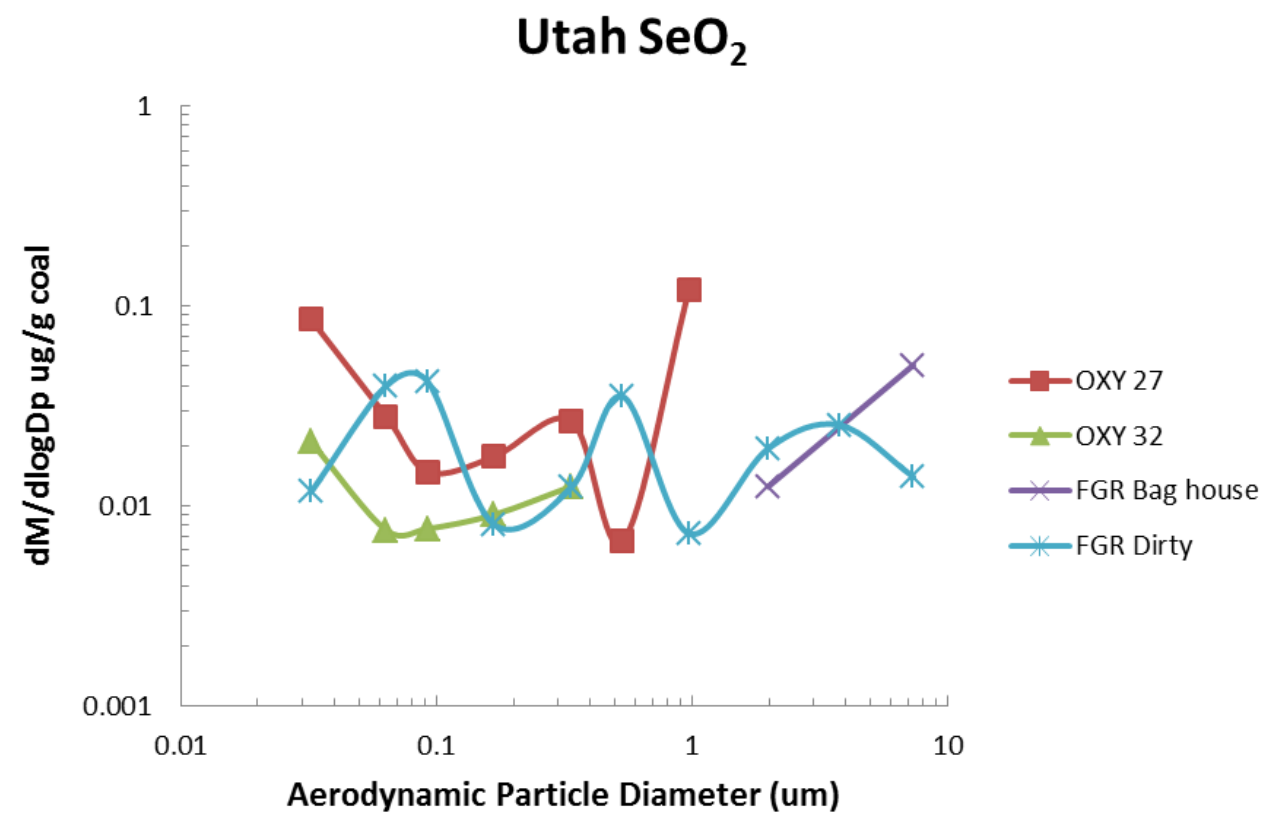

Figure 4.7-61: Selenium oxide aerosol comparison of Utah coal fired experiments.

Table A-28: Selenium data for the Utah coal in Figure 4.7-61.

\begin{tabular}{|c|c|c|c|c|c|c|}
\hline $\mathrm{Dp}(\mu \mathrm{m})$ & Air & OXY27 & OXY32 & FGR Clean & FGR Dirty & \\
\hline 0.0324 & & 0.085431 & 0.020865 & ND & 0.011805 & $\mu \mathrm{g} / \mathrm{g}$ coal \\
\hline 0.0636 & & 0.028068 & 0.007577 & ND & 0.039773 & $\mu \mathrm{g} / \mathrm{g}$ coal \\
\hline 0.0926 & & 0.014818 & 0.007711 & ND & 0.041694 & $\mu \mathrm{g} / \mathrm{g}$ coal \\
\hline 0.168 & & 0.017654 & 0.00905 & ND & 0.008078 & $\mu \mathrm{g} / \mathrm{g}$ coal \\
\hline 0.337 & & 0.026662 & 0.012551 & ND & 0.01238 & $\mu \mathrm{g} / \mathrm{g}$ coal \\
\hline 0.535 & & 0.006663 & ND & ND & 0.035312 & $\mu \mathrm{g} / \mathrm{g}$ coal \\
\hline 0.973 & & 0.120876 & ND & ND & 0.007285 & $\mu \mathrm{g} / \mathrm{g}$ coal \\
\hline 1.98 & & & & 0.012498 & 0.019357 & $\mu \mathrm{g} / \mathrm{g}$ coal \\
\hline 3.77 & & & & ND & 0.025419 & $\mu \mathrm{g} / \mathrm{g}$ coal \\
\hline 7.33 & & & & 0.05067 & 0.014003 & $\mu \mathrm{g} / \mathrm{g}$ coal \\
\hline
\end{tabular}


Table A-29: Sodium data for the PRB coal in Figure 4.7-62, Figure 4.7-83, and Figure 4.7-84.

\begin{tabular}{|c|c|c|c|c|c|c|}
\hline Dp $(\mu \mathrm{m})$ & Air & OXY27 & OXY32 & FGR Clean & FGR Dirty & \\
\hline 0.0324 & 72.71891 & 29.02623 & 148.2194 & ND & ND & $\mu g / g$ coal \\
\hline 0.0636 & 43.39863 & 40.53609 & 58.68411 & ND & ND & $\mu g / g$ coal \\
\hline 0.0926 & ND & 9.30764 & 19.87798 & ND & ND & $\mu g / g$ coal \\
\hline 0.168 & ND & 8.500409 & 11.06921 & ND & ND & $\mu g / g$ coal \\
\hline 0.337 & ND & 54.57607 & 65.02714 & 8.652709 & ND & $\mu g / g$ coal \\
\hline 0.535 & 101.3898 & 158.9765 & 177.7445 & 35.2373 & 250.7877 & $\mu g / g$ coal \\
\hline 0.973 & 296.4922 & 261.3592 & 215.3935 & 90.92341 & 1187.711 & $\mu g / g$ coal \\
\hline 0.973 & 424.995 & 333.2895 & 524.7739 & 297.603 & 211.2581 & $\mu g / g$ coal \\
\hline 1.98 & 542.0987 & 799.4411 & 463.2819 & 357.384 & 184.8015 & $\mu g / g$ coal \\
\hline 3.77 & 234.9457 & 1149.324 & 193.9219 & 660.2925 & 204.4858 & $\mu g / g$ coal \\
\hline 7.33 & 261.956 & 1574.518 & 348.4496 & 1300.181 & 258.7735 & $\mu g / g$ coal \\
\hline
\end{tabular}

Table A-30: Magnesium data for the PRB coal in Figure 4.7-63.

\begin{tabular}{|c|c|c|c|c|c|c|}
\hline MgO & & & & & \\
\hline Dp $(\mu \mathrm{m})$ & Air & OXY27 & OXY32 & FGR Clean & FGR Dirty & \\
\hline 0.0324 & 43.51824 & 5.493043 & 119.5279 & 170.6682 & ND & $\mu g / g$ coal \\
\hline 0.0636 & 26.26817 & 8.230004 & 59.54662 & ND & ND & $\mu g / g$ coal \\
\hline 0.0926 & ND & 6.159459 & 57.59882 & 58.54837 & ND & $\mu g / g$ coal \\
\hline 0.168 & 11.28692 & 8.299496 & 17.19285 & 14.6675 & 18.65402 & $\mu g / g$ coal \\
\hline 0.337 & 49.67155 & 65.35115 & 85.27838 & 39.11215 & 65.38678 & $\mu g / g$ coal \\
\hline 0.535 & 190.6986 & 162.8914 & 240.6199 & 57.94839 & 313.7708 & $\mu g / g$ coal \\
\hline 0.973 & 473.1291 & 266.8601 & 492.7109 & 106.6248 & 480.1751 & $\mu g / g$ coal \\
\hline 0.973 & 725.0823 & 466.5426 & 717.8511 & 511.4671 & 390.47 & $\mu g / g$ coal \\
\hline 1.98 & 814.5771 & 932.211 & 611.337 & 562.2309 & 283.2238 & $\mu g / g$ coal \\
\hline 3.77 & 350.6409 & 1177.302 & 272.1696 & 1013.237 & 335.6961 & $\mu g / g$ coal \\
\hline 7.33 & 285.5113 & 2123.76 & 515.4347 & 1165.724 & 395.9083 & $\mu g / g$ coal \\
\hline
\end{tabular}

Table A-31: Aluminum data for the PRB coal in Figure 4.7-64.

\begin{tabular}{|c|c|c|c|c|c|c|}
\hline Dp $(\mu \mathrm{m})$ & Air & OXY27 & OXY32 & FGR Clean & FGR Dirty & \\
\hline 0.0324 & 19.97907 & 2.062644 & 82.4543 & 710.3313 & ND & $\mu$ g/g coal \\
\hline 0.0636 & ND & 45.8964 & 108.6828 & 76.9029 & ND & $\mu$ g/g coal \\
\hline 0.0926 & ND & 59.20455 & 46.72226 & 77.55104 & ND & $\mu g / g$ coal \\
\hline 0.168 & 18.30792 & ND & 44.4682 & 92.64051 & 43.63193 & $\mu g / g$ coal \\
\hline 0.337 & 118.5932 & 178.8774 & 285.4422 & 317.2925 & 275.2887 & $\mu g / g$ coal \\
\hline 0.535 & 423.1412 & 184.4808 & 706.3573 & 184.318 & 1799.678 & $\mu g / g$ coal \\
\hline 0.973 & 1222.663 & 1056.294 & 673.1165 & 724.655 & 2962.611 & $\mu g / g$ coal \\
\hline 0.973 & 2473.689 & 1651.476 & 2473.698 & 1588.258 & 1154.768 & $\mu g / g$ coal \\
\hline 1.98 & 2919.378 & 3112.12 & 2089.938 & 1778.135 & 909.8876 & $\mu g / g$ coal \\
\hline 3.77 & 1182.843 & 2956.619 & 886.4688 & 3086.354 & 975.4136 & $\mu g / g$ coal \\
\hline 7.33 & 1106.505 & 5705.589 & 1591.839 & 3093.151 & 1249.608 & $\mu g / g$ coal \\
\hline
\end{tabular}


Table A-32: Silicon data for the PRB coal in Figure 4.7-65, Figure 4.7-85, and Figure 4.7-86.

\begin{tabular}{|c|c|c|c|c|c|c|}
\hline Dp $(\mu \mathrm{m})$ & Air & OXY27 & OXY32 & FGR Clean & FGR Dirty & \\
\hline 0.0324 & ND & 134.3068 & 3495.992 & 501.2739 & ND & $\mu g / g$ coal \\
\hline 0.0636 & ND & 1122.838 & 2475.454 & 143.8357 & ND & $\mu g / g$ coal \\
\hline 0.0926 & ND & 925.4238 & 1166.143 & 137.3996 & ND & $\mu g / g$ coal \\
\hline 0.168 & ND & ND & ND & 95.43074 & 55.0101 & $\mu g / g$ coal \\
\hline 0.337 & ND & ND & ND & 168.0188 & 143.6872 & $\mu g / g$ coal \\
\hline 0.535 & ND & 2168.994 & 3154.607 & 136.3028 & 604.925 & $\mu g / g$ coal \\
\hline 0.973 & ND & 2850.393 & 8166.116 & 528.5759 & 1254.18 & $\mu g / g$ coal \\
\hline 0.973 & 2687.112 & 1720.611 & 2736.792 & 1784.575 & 1278.964 & $\mu g / g$ coal \\
\hline 1.98 & 3461.476 & 3471.911 & 2510.695 & 2434.204 & 1109.12 & $\mu g / g$ coal \\
\hline 3.77 & 1547.496 & 2550.446 & 1273.034 & 4702.452 & 1338.543 & $\mu g / g$ coal \\
\hline 7.33 & 966.1222 & 4656.037 & 2911.144 & 4778.425 & 1748.418 & $\mu g / g$ coal \\
\hline
\end{tabular}

Table A-33: Phosphorus data for the PRB coal in Figure 4.7-66.

\begin{tabular}{|c|c|c|c|c|c|c|}
\hline Dp $(\mu \mathrm{m})$ & Air & OXY27 & OXY32 & FGR Clean & FGR Dirty & \\
\hline 0.0324 & 4.885368 & 5.062019 & 34.99573 & 34.96731 & ND & $\mu \mathrm{g} / \mathrm{g}$ coal \\
\hline 0.0636 & ND & 8.649567 & 23.97422 & 3.788585 & ND & $\mu \mathrm{g} / \mathrm{g}$ coal \\
\hline 0.0926 & ND & 9.541678 & 11.3122 & 17.08126 & ND & $\mu \mathrm{g} / \mathrm{g}$ coal \\
\hline 0.168 & 6.254433 & 6.736467 & 13.88311 & 14.80796 & 17.41081 & $\mu \mathrm{g} / \mathrm{g}$ coal \\
\hline 0.337 & 14.53286 & 29.60603 & 58.15228 & 32.66188 & 45.86902 & $\mu \mathrm{g} / \mathrm{g}$ coal \\
\hline 0.535 & 40.95932 & 68.11592 & 98.65613 & 51.03587 & 148.018 & $\mu \mathrm{g} / \mathrm{g}$ coal \\
\hline 0.973 & 82.89265 & 74.659 & 124.5065 & 67.65897 & 184.0191 & $\mu \mathrm{g} / \mathrm{g}$ coal \\
\hline 0.973 & 105.6833 & 75.09205 & 99.72118 & 148.8883 & 117.0447 & $\mu \mathrm{g} / \mathrm{g}$ coal \\
\hline 1.98 & 115.3984 & 161.6942 & 82.61048 & 146.1481 & 64.05758 & $\mu \mathrm{g} / \mathrm{g}$ coal \\
\hline 3.77 & 65.29291 & 394.1825 & 44.92077 & 298.9938 & 83.83377 & $\mu \mathrm{g} / \mathrm{g}$ coal \\
\hline 7.33 & 147.087 & 328.4829 & 106.0234 & 327.656 & 119.8157 & $\mu \mathrm{g} / \mathrm{g}$ coal \\
\hline
\end{tabular}

Table A-34: Potassium data for the PRB coal in Figure 4.7-67.

\begin{tabular}{|c|c|c|c|c|c|c|}
\hline Dp $(\mu \mathrm{m})$ & Air & OXY27 & OXY32 & FGR Clean & FGR Dirty & \\
\hline 0.0324 & ND & ND & ND & ND & 8.662363 & $\mu$ /g coal \\
\hline 0.0636 & ND & 2.095225 & ND & ND & ND & $\mu$ /g coal \\
\hline 0.0926 & ND & 2.011896 & 4.724055 & ND & ND & $\mu g / g$ coal \\
\hline 0.168 & ND & 6.183467 & 8.032066 & ND & ND & $\mu$ /g coal \\
\hline 0.337 & ND & 14.34271 & 20.9676 & ND & ND & $\mu$ /g coal \\
\hline 0.535 & ND & 25.52237 & 33.32638 & 38.57962 & ND & $\mu$ /g coal \\
\hline 0.973 & ND & 29.19885 & 53.52554 & 67.59329 & 12.83092 & $\mu$ /g coal \\
\hline 0.973 & 88.51493 & 57.22045 & 95.5956 & 66.01817 & 55.56529 & $\mu$ g g coal \\
\hline 1.98 & 112.3021 & 100.6003 & 73.05224 & 72.47508 & 31.04249 & $\mu g / g$ coal \\
\hline 3.77 & 48.85466 & 473.8683 & 37.25029 & 131.9193 & 42.41321 & $\mu g / g$ coal \\
\hline 7.33 & 130.8297 & 537.1037 & 177.5401 & 325.6979 & 68.36482 & $\mu g / g$ coal \\
\hline
\end{tabular}


Table A-35: Calcium data for the PRB coal in Figure 4.7-68, Figure 4.7-87, and Figure 4.7-88.

\begin{tabular}{|c|c|c|c|c|c|c|}
\hline Dp $(\mu \mathrm{m})$ & Air & OXY27 & OXY32 & FGR Clean & FGR Dirty & \\
\hline 0.0324 & 323.5802 & 30.2302 & 212.3013 & ND & ND & $\mu g / g$ coal \\
\hline 0.0636 & 239.1712 & 16.31561 & 82.83415 & ND & ND & $\mu g / g$ coal \\
\hline 0.0926 & \#VALUE! & 54.10099 & 59.50466 & 18.2477 & ND & $\mu g / g$ coal \\
\hline 0.168 & \#VALUE! & 49.94659 & 66.52705 & 28.57742 & ND & $\mu g / g$ coal \\
\hline 0.337 & 137.0471 & 177.9096 & 318.0815 & 130.1122 & 59.28854 & $\mu g / g$ coal \\
\hline 0.535 & 878.165 & 494.4207 & 656.4961 & 321.0197 & 536.1784 & $\mu g / g$ coal \\
\hline 0.973 & 2307.374 & 694.1901 & 1199.108 & 582.8638 & 907.2422 & $\mu g / g$ coal \\
\hline 0.973 & 3155.902 & 2224.778 & 3207.227 & 2519.462 & 2035.01 & $\mu g / g$ coal \\
\hline 1.98 & 3455.284 & 3536.109 & 2525.618 & 2859.471 & 1561.884 & $\mu g / g$ coal \\
\hline 3.77 & 1316.859 & 2605.152 & 1092.425 & 4616.826 & 1440.605 & $\mu g / g$ coal \\
\hline 7.33 & 709.1502 & 5538.692 & 1550.499 & 4407.691 & 2341.318 & $\mu g / g$ coal \\
\hline
\end{tabular}

Table A-36: Titanium data for the PRB coal in Figure 4.7-69.

\begin{tabular}{|c|c|c|c|c|c|c|}
\hline Dp $(\mu \mathrm{m})$ & Air & OXY27 & OXY32 & FGR Clean & FGR Dirty \\
\hline 0.0324 & 1.588549 & 0.864196 & 4.35597 & 11.00615 & ND & $\mu \mathrm{g} / \mathrm{g}$ coal \\
\hline 0.0636 & 0.781479 & 4.083059 & 4.745696 & 2.75948 & $\mathrm{ND}$ & $\mu \mathrm{g} / \mathrm{g}$ coal \\
\hline 0.0926 & ND & 3.412561 & 3.421188 & 3.06585 & $\mathrm{ND}$ & $\mu \mathrm{g} / \mathrm{g}$ coal \\
\hline 0.168 & 1.126331 & 1.24736 & 3.52269 & 3.382129 & $\mathrm{ND}$ & $\mu \mathrm{g} / \mathrm{g}$ coal \\
\hline 0.337 & 8.015418 & 10.13477 & 16.29627 & 10.3061 & $\mathrm{ND}$ & $\mu \mathrm{g} / \mathrm{g}$ coal \\
\hline 0.535 & 43.81276 & 28.09817 & 36.74969 & 20.53036 & 64.88576 & $\mu \mathrm{g} / \mathrm{g}$ coal \\
\hline 0.973 & 103.2609 & 38.79498 & 62.62351 & 35.36683 & 111.0677 & $\mu \mathrm{g} / \mathrm{g}$ coal \\
\hline 0.973 & 248.2736 & 175.7373 & 268.1628 & 218.9023 & 185.1259 & $\mu \mathrm{g} / \mathrm{g}$ coal \\
\hline 1.98 & 268.5485 & 304.9051 & 214.085 & 223.4149 & 133.8253 & $\mu \mathrm{g} / \mathrm{g}$ coal \\
\hline 3.77 & 121.8857 & 902.5231 & 100.2892 & 371.7408 & 152.6876 & $\mu \mathrm{g} / \mathrm{g}$ coal \\
\hline 7.33 & 261.3627 & 939.1729 & 331.1286 & 1283.211 & 212.9944 & $\mu \mathrm{g} / \mathrm{g}$ coal \\
\hline
\end{tabular}

Table A-37: Iron data for the PRB coal in Figure 4.7-70, Figure 4.7-89, and Figure 4.7-90.

\begin{tabular}{|c|c|c|c|c|c|c|}
\hline Dp $(\mu \mathrm{m})$ & Air & OXY27 & OXY32 & FGR Clean & FGR Dirty & \\
\hline 0.0324 & 27.39861 & 16.9337 & 45.92398 & 59.82077 & 69.27159 & $\mu \mathrm{g} / \mathrm{g}$ coal \\
\hline 0.0636 & 22.64742 & 8.908017 & 23.66387 & ND & ND & $\mu \mathrm{g} / \mathrm{g}$ coal \\
\hline 0.0926 & ND & 17.44226 & 15.68806 & 25.72438 & ND & $\mu \mathrm{g} / \mathrm{g}$ coal \\
\hline 0.168 & ND & 11.44387 & 26.14985 & 18.11478 & 20.49678 & $\mu \mathrm{g} / \mathrm{g}$ coal \\
\hline 0.337 & 61.65416 & 82.39064 & 131.7191 & 74.50009 & 67.92268 & $\mu \mathrm{g} / \mathrm{g}$ coal \\
\hline 0.535 & 222.9969 & 204.4075 & 324.5091 & 156.2222 & 280.3515 & $\mu \mathrm{g} / \mathrm{g}$ coal \\
\hline 0.973 & 547.4798 & 320.7161 & 528.6994 & 192.8232 & 45.49749 & $\mu \mathrm{g} / \mathrm{g}$ coal \\
\hline 0.973 & 912.9066 & 608.8883 & 892.8936 & 724.9837 & 589.3497 & $\mu \mathrm{g} / \mathrm{g}$ coal \\
\hline 1.98 & 982.8516 & 988.3666 & 696.0933 & 775.663 & 437.8133 & $\mu \mathrm{g} / \mathrm{g}$ coal \\
\hline 3.77 & 387.5747 & 1953.427 & 311.095 & 1341.469 & 390.1113 & $\mu \mathrm{g} / \mathrm{g}$ coal \\
\hline 7.33 & 546.2806 & 3123.622 & 994.942 & 1961.367 & 650.7318 & $\mu \mathrm{g} / \mathrm{g}$ coal \\
\hline
\end{tabular}


Table A-38: Arsenic data for the PRB coal in Figure 4.7-71, Figure 4.7-91, and Figure 4.7-92.

\begin{tabular}{|c|c|c|c|c|c|c|}
\hline Dp $(\mu \mathrm{m})$ & Air & OXY27 & OXY32 & FGR Clean & FGR Dirty & \\
\hline 0.0324 & 0.102448 & 0.068137 & 0.28379 & 2.70455 & ND & $\mu \mathrm{g} / \mathrm{g}$ coal \\
\hline 0.0636 & ND & 0.138911 & 0.131392 & 0.250925 & ND & $\mu \mathrm{g} / \mathrm{g}$ coal \\
\hline 0.0926 & ND & 0.072298 & 0.040975 & 6.246198 & ND & $\mu \mathrm{g} / \mathrm{g}$ coal \\
\hline 0.168 & ND & ND & 0.096735 & 0.174505 & ND & $\mu \mathrm{g} / \mathrm{g}$ coal \\
\hline 0.337 & ND & 0.2036 & 0.188119 & 5.920649 & ND & $\mu \mathrm{g} / \mathrm{g}$ coal \\
\hline 0.535 & ND & 0.327718 & 0.81618 & 0.358866 & 0.142412 & $\mu \mathrm{g} / \mathrm{g}$ coal \\
\hline 0.973 & ND & 0.353273 & 0.515822 & 0.469947 & 0.375879 & $\mu \mathrm{g} / \mathrm{g}$ coal \\
\hline 1.98 & ND & & & 0.673724 & 0.5004 & $\mu \mathrm{g} / \mathrm{g}$ coal \\
\hline 3.77 & 41.94223 & & & 0.795193 & ND & $\mu \mathrm{g} / \mathrm{g}$ coal \\
\hline 7.33 & ND & & & 2.754618 & ND & $\mu g / g$ coal \\
\hline
\end{tabular}

Table A-39: Sodium data for the PRB coal in Figure 4.7-72, Figure 4.7-83, and Figure 4.7-84.

\begin{tabular}{|c|c|c|c|c|c|c|}
\hline Dp $(\mu \mathrm{m})$ & Air & OXY27 & OXY32 & FGR Clean & FGR Dirty & \\
\hline 0.0324 & ND & 2.222938 & 2.236895 & 2.837023 & ND & $\mu \mathrm{g} / \mathrm{g}$ coal \\
\hline 0.0636 & ND & 5.492129 & 8.278631 & 2.457755 & ND & $\mu \mathrm{g} / \mathrm{g}$ coal \\
\hline 0.0926 & ND & 4.213776 & 1.39363 & 1.157641 & ND & $\mu \mathrm{g} / \mathrm{g}$ coal \\
\hline 0.168 & 10.64692 & 2.59976 & 1.287649 & 1.209867 & ND & $\mu \mathrm{g} / \mathrm{g}$ coal \\
\hline 0.337 & ND & 2.65126 & 2.182547 & 1.454871 & ND & $\mu \mathrm{g} / \mathrm{g} \mathrm{coal}$ \\
\hline 0.535 & 17.47267 & 17.68127 & 11.19477 & 5.696358 & 2.271207 & $\mu \mathrm{g} / \mathrm{g} \mathrm{coal}$ \\
\hline 0.973 & 148.8601 & 82.52787 & 36.67716 & 7.439668 & $\mathrm{ND}$ & $\mu \mathrm{g} / \mathrm{g} \mathrm{coal}$ \\
\hline 0.973 & 229.402 & 119.4559 & 92.79328 & 88.76599 & 70.05838 & $\mu \mathrm{g} / \mathrm{g}$ coal \\
\hline 1.98 & 255.7826 & 140.2019 & 207.1295 & 108.9271 & 94.26083 & $\mu \mathrm{g} / \mathrm{g}$ coal \\
\hline 3.77 & 186.9255 & 162.3524 & 120.2934 & 127.2125 & 81.83816 & $\mu \mathrm{g} / \mathrm{g}$ coal \\
\hline 7.33 & 1611.145 & 887.3255 & 477.6019 & 99.11446 & 128.5907 & $\mu \mathrm{g} / \mathrm{g}$ coal \\
\hline
\end{tabular}

Table A-40: Magnesium data for the Illinois coal in Figure 4.7-73.

\begin{tabular}{|c|c|c|c|c|c|c|}
\hline Dp $(\mu \mathrm{m})$ & Air & OXY27 & OXY32 & FGR Clean & FGR Dirty & \\
\hline 0.0324 & ND & 3.004823 & 0.448287 & ND & 0.509094 & $\mu \mathrm{g} / \mathrm{g}$ coal \\
\hline 0.0636 & ND & 3.420473 & 1.428228 & 0.111879 & 0.467586 & $\mu \mathrm{g} / \mathrm{g}$ coal \\
\hline 0.0926 & ND & 3.212248 & ND & 0.131225 & 0.393536 & $\mu \mathrm{g} / \mathrm{g}$ coal \\
\hline 0.168 & 1.485739 & 1.919548 & 0.357518 & 0.417975 & 0.289946 & $\mu \mathrm{g} / \mathrm{g}$ coal \\
\hline 0.337 & 3.54647 & 1.436331 & 1.042385 & 0.819024 & 1.750598 & $\mu \mathrm{g} / \mathrm{g}$ coal \\
\hline 0.535 & 8.696778 & 5.264172 & 4.695721 & 1.953657 & 2.656975 & $\mu \mathrm{g} / \mathrm{g}$ coal \\
\hline 0.973 & 64.51502 & 37.01348 & 24.85419 & 2.471519 & 2.612673 & $\mu \mathrm{g} / \mathrm{g}$ coal \\
\hline 0.973 & 101.3997 & 53.21627 & 47.27934 & 55.00291 & 39.20268 & $\mu \mathrm{g} / \mathrm{g}$ coal \\
\hline 1.98 & 116.1608 & 62.02925 & 89.69904 & 55.65043 & 62.80606 & $\mu \mathrm{g} / \mathrm{g}$ coal \\
\hline 3.77 & 72.16981 & 96.47171 & 95.97678 & 97.14839 & 45.31725 & $\mu \mathrm{g} / \mathrm{g}$ coal \\
\hline 7.33 & 698.9832 & 421.656 & 355.7089 & 67.82108 & 71.2061 & $\mu \mathrm{g} / \mathrm{g}$ coal \\
\hline
\end{tabular}


Table A-41: Aluminum data for the Illinois coal in Figure 4.7-74.

\begin{tabular}{|c|c|c|c|c|c|c|}
\hline Dp $(\mu \mathrm{m})$ & Air & OXY27 & OXY32 & FGR Clean & FGR Dirty \\
\hline 0.0324 & ND & ND & ND & 2.707679 & ND & $\mu \mathrm{g} / \mathrm{g}$ coal \\
\hline 0.0636 & ND & ND & ND & 1.338693 & ND & $\mu \mathrm{g} / \mathrm{g} \mathrm{coal}$ \\
\hline 0.0926 & ND & ND & ND & 2.58598 & ND & $\mu \mathrm{g} / \mathrm{g} \mathrm{coal}$ \\
\hline 0.168 & 1.701937 & 1.491034 & ND & 4.71258 & 0.313443 & $\mu \mathrm{g} / \mathrm{g} \mathrm{coal}$ \\
\hline 0.337 & 21.61996 & 15.18654 & 5.023321 & 12.50105 & 12.44762 & $\mu \mathrm{g} / \mathrm{g} \mathrm{coal}$ \\
\hline 0.535 & 98.41858 & 118.5653 & 42.05875 & 41.06448 & 33.28898 & $\mu \mathrm{g} / \mathrm{g} \mathrm{coal}$ \\
\hline 0.973 & 916.7792 & 401.3756 & 218.7167 & 34.92099 & 8.482167 & $\mu \mathrm{g} / \mathrm{g}$ coal \\
\hline 0.973 & 2037.061 & 1061.257 & 779.8056 & 681.9368 & 535.473 & $\mu \mathrm{g} / \mathrm{g}$ coal \\
\hline 1.98 & 2390.308 & 1210.667 & 1472.959 & 781.6775 & 535.8175 & $\mu \mathrm{g} / \mathrm{g}$ coal \\
\hline 3.77 & 1465.349 & 559.5359 & 1234.619 & 584.0694 & 755.9323 & $\mu \mathrm{g} / \mathrm{g}$ coal \\
\hline 7.33 & 5688.47 & 3724.348 & 2940.227 & 997.1668 & 1187.781 & $\mu \mathrm{g} / \mathrm{g}$ coal \\
\hline
\end{tabular}

Table A-42: Silicon data for the Illinois coal in Figure 4.7-75, Figure 4.7-85, and Figure 4.7-86.

\begin{tabular}{|c|c|c|c|c|c|c|}
\hline Dp $(\mu \mathrm{m})$ & Air & OXY27 & OXY32 & FGR Clean & FGR Dirty & \\
\hline 0.0324 & ND & 108.9387 & ND & 9.201301 & ND & $\mu g / g$ coal \\
\hline 0.0636 & ND & 144.6575 & 83.42549 & 5.826667 & ND & $\mu g / g$ coal \\
\hline 0.0926 & ND & 90.663 & ND & 5.089641 & ND & $\mu g / g$ coal \\
\hline 0.168 & 102.97 & 69.36874 & ND & 4.975188 & ND & $\mu g / g$ coal \\
\hline 0.337 & ND & 75.66791 & 58.34147 & 12.08706 & 4.272293 & $\mu g / g$ coal \\
\hline 0.535 & ND & 838.0324 & 461.8397 & 32.92156 & 30.82489 & $\mu g / g$ coal \\
\hline 0.973 & 421.0899 & 4110.008 & 3160.222 & 64.53584 & ND & $\mu g / g$ coal \\
\hline 0.973 & 3444.25 & 1811.449 & 1296.237 & 1253.371 & 1010.172 & $\mu g / g$ coal \\
\hline 1.98 & 4409.531 & 2269.814 & 2788.43 & 1557.75 & 1007.329 & $\mu g / g$ coal \\
\hline 3.77 & 2910.441 & 1043.344 & 3023.913 & 1321.937 & 1802.696 & $\mu g / g$ coal \\
\hline 7.33 & 12444.22 & 7189.319 & 6926.353 & 2268.77 & 2832.541 & $\mu g / g$ coal \\
\hline
\end{tabular}

Table A-43: Phosphorus data for the Illinois coal in Figure 4.7-76.

\begin{tabular}{|c|c|c|c|c|c|c|}
\hline Dp $(\mu \mathrm{m})$ & Air & OXY27 & OXY32 & FGR Clean & FGR Dirty \\
\hline 0.0324 & ND & ND & 0.208102 & 0.64806 & ND & $\mu g / g$ coal \\
\hline 0.0636 & ND & ND & ND & 0.867198 & ND & $\mu g / g$ coal \\
\hline 0.0926 & ND & ND & ND & 0.377101 & ND & $\mu g / g$ coal \\
\hline 0.168 & 0.27901 & ND & 0.12288 & 0.511437 & ND & $\mu g / g$ coal \\
\hline 0.337 & \#VALUE! & 0.42264 & 0.586218 & 1.36225 & 0.440539 & $\mu g / g$ coal \\
\hline 0.535 & 0.948542 & 1.762397 & 1.774711 & 3.173588 & 2.495885 & $\mu g / g$ coal \\
\hline 0.973 & 7.923093 & 2.42888 & 2.676014 & 1.895693 & ND & $\mu g / g$ coal \\
\hline 0.973 & 16.22396 & 8.532566 & 11.75087 & 28.24623 & 33.38793 & $\mu g / g$ coal \\
\hline 1.98 & 10.72913 & 12.7217 & 91.86733 & 38.04538 & 102.0211 & $\mu g / g$ coal \\
\hline 3.77 & 53.04387 & 42.68748 & 68.89696 & 53.58489 & 4.69752 & $\mu g / g$ coal \\
\hline 7.33 & 663.2213 & 241.5703 & 296.2097 & 14.57731 & 7.38112 & $\mu g / g$ coal \\
\hline
\end{tabular}


Table A-44: Potassium results for the Illinois coal for Figure 4.7-77.

\begin{tabular}{|c|c|c|c|c|c|c|}
\hline Dp $(\mu \mathrm{m})$ & Air & OXY27 & OXY32 & FGR Clean & FGR Dirty & \\
\hline 0.0324 & ND & ND & 2.279355 & 2.569562 & ND & $\mu$ g/g coal \\
\hline 0.0636 & ND & 4.221661 & 8.291173 & 2.528305 & ND & $\mu g / g$ coal \\
\hline 0.0926 & ND & 3.591858 & ND & 0.813375 & ND & $\mu g / g$ coal \\
\hline 0.168 & 4.125009 & 1.073925 & ND & 0.924133 & ND & $\mu g / g$ coal \\
\hline 0.337 & ND & 2.548357 & 2.122594 & 1.258292 & ND & $\mu g / g$ coal \\
\hline 0.535 & 19.48773 & 12.92941 & 11.5058 & 4.068091 & ND & $\mu g / g$ coal \\
\hline 0.973 & 173.8328 & 66.29477 & 42.13806 & 6.634965 & ND & $\mu g / g$ coal \\
\hline 0.973 & 275.2108 & 141.461 & 92.84845 & 71.66378 & 67.90129 & $\mu g / g$ coal \\
\hline 1.98 & 297.4116 & 145.4661 & 185.5606 & 97.58606 & 96.53716 & $\mu g / g$ coal \\
\hline 3.77 & 160.5449 & 72.62871 & 216.2701 & 83.82586 & 120.2934 & $\mu g / g$ coal \\
\hline 7.33 & 499.2737 & 434.4233 & 316.4716 & 158.0428 & 189.0146 & $\mu g / g$ coal \\
\hline
\end{tabular}

Table A-45: Calcium data for the Illinois coal in Figure 4.7-78, Figure 4.7-87, and Figure 4.7-88.

\begin{tabular}{|c|c|c|c|c|c|c|}
\hline $\mathrm{Dp}(\mu \mathrm{m})$ & Air & OXY27 & OXY32 & FGR Clean & FGR Dirty & \\
\hline 0.0324 & 21.75671 & 1.644796 & 0.881928 & 1.001704 & ND & $\mu \mathrm{g} / \mathrm{g}$ coal \\
\hline 0.06 & ND & 269 & .490609 & 755 & & $\mu \mathrm{g} / \mathrm{g}$ coal \\
\hline 0.0926 & ND & 2.04 & & & & coal \\
\hline 0.1 & & 2.766 & & & & \\
\hline & & 3.04 & & & & \\
\hline 0.535 & 1.54519 & 8.410 & 6.185916 & 913 & 1.857695 & coal \\
\hline 0.973 & 5.5232 & 60.9 & 71.4 & 258 & & $\mu g / \xi$ \\
\hline 0.973 & 9.0393 & 90.4 & 71.99479 & & 152.2152 & coal \\
\hline 1.9 & & 80. & & & & \\
\hline 3.77 & 112.4111 & & 74.60767 & & & $\mu \mathrm{g} / \mathrm{g}$ coal \\
\hline 7.33 & 587.5175 & 344.3804 & 501.08 & 164.3465 & 259.497 & $\mu \mathrm{g} / \mathrm{g}$ coal \\
\hline
\end{tabular}

Table A-46: Titanium data for the Illinois coal in Figure 4.7-79.

\begin{tabular}{|c|c|c|c|c|c|c|}
\hline Dp $(\mu \mathrm{m})$ & Air & OXY27 & OXY32 & FGR Clean & FGR Dirty & \\
\hline 0.0324 & ND & ND & ND & 0.189783 & ND & $\mu g / g$ coal \\
\hline 0.0636 & ND & ND & 2.607477 & 0.217472 & 0.026403 & $\mu g / g$ coal \\
\hline 0.0926 & ND & ND & ND & 0.156191 & ND & $\mu$ g/g coal \\
\hline 0.168 & 0.356948 & 0.326715 & ND & 0.186644 & ND & $\mu g / g$ coal \\
\hline 0.337 & 2.771464 & 0.673891 & 0.344329 & 0.49073 & 0.44921 & $\mu g / g$ coal \\
\hline 0.535 & 8.506989 & 3.598622 & 2.750402 & 1.505593 & 1.20363 & $\mu g / g$ coal \\
\hline 0.973 & 64.32769 & 21.04859 & 13.05193 & 3.375726 & ND & $\mu$ g/g coal \\
\hline 0.973 & 131.2232 & 67.51206 & 51.08596 & 53.6237 & 46.42423 & $\mu g / g$ coal \\
\hline 1.98 & 133.1843 & 64.57359 & 113.5503 & 69.16742 & 141.0808 & $\mu g / g$ coal \\
\hline 3.77 & 104.6745 & 67.28027 & 155.8471 & 148.5522 & 94.96359 & $\mu g / g$ coal \\
\hline 7.33 & 695.7322 & 652.8109 & 483.0694 & 111.1027 & 149.2144 & $\mu g / g$ coal \\
\hline
\end{tabular}


Table A-47: Iron data for the Illinois coal in Figure 4.7-80, Figure 4.7-89, and Figure 4.7-90.

\begin{tabular}{|c|c|c|c|c|c|c|}
\hline Dp $(\mu \mathrm{m})$ & Air & OXY27 & OXY32 & FGR Clean & FGR Dirty \\
\hline 0.0324 & 18.18037 & ND & ND & ND & 0.064884 & $\mu \mathrm{g} / \mathrm{g}$ coal \\
\hline 0.0636 & ND & ND & ND & 0.781385 & 0.222381 & $\mu \mathrm{g} / \mathrm{g}$ coal \\
\hline 0.0926 & ND & ND & ND & 0.845512 & 0.29528 & $\mu \mathrm{g} / \mathrm{g}$ coal \\
\hline 0.168 & 4.205359 & 0.941286 & 0.718111 & 2.276606 & 1.460847 & $\mu \mathrm{g} / \mathrm{g}$ coal \\
\hline 0.337 & 8.56889 & 4.821892 & 4.092574 & 4.902963 & 6.556739 & $\mu \mathrm{g} / \mathrm{g} \mathrm{coal}$ \\
\hline 0.535 & 37.56996 & 32.21912 & 24.49337 & 14.81455 & 15.44202 & $\mu \mathrm{g} / \mathrm{g}$ coal \\
\hline 0.973 & 353.4447 & 96.86376 & 70.85043 & 20.34895 & 4.125967 & $\mu \mathrm{g} / \mathrm{g}$ coal \\
\hline 0.973 & 652.2984 & 344.1468 & 265.5808 & 287.5378 & 274.0436 & $\mu \mathrm{g} / \mathrm{g}$ coal \\
\hline 1.98 & 712.9867 & 347.0831 & 531.8034 & 349.1998 & 232.0824 & $\mu \mathrm{g} / \mathrm{g}$ coal \\
\hline 3.77 & 439.1429 & 308.6095 & 469.9362 & 291.1504 & 476.9825 & $\mu \mathrm{g} / \mathrm{g}$ coal \\
\hline 7.33 & 4240.344 & 2542.703 & 1754.423 & 463.9975 & 749.4732 & $\mu \mathrm{g} / \mathrm{g}$ coal \\
\hline
\end{tabular}

Table A-48: Arsenic data for the Illinois coal in Figure 4.7-81, Figure 4.7-91, and Figure 4.7-92.

\begin{tabular}{|c|c|c|c|c|c|c|}
\hline Dp $(\mu \mathrm{m})$ & Air & OXY27 & OXY32 & FGR Clean & FGR Dirty \\
\hline 0.0324 & ND & 0.051682 & 0.085794 & 0.113936 & 0.010106 & $\mu \mathrm{g} / \mathrm{g}$ coal \\
\hline 0.0636 & 1.140369 & 0.336169 & 0.264306 & 0.092096 & 0.028715 & $\mu \mathrm{g} / \mathrm{g}$ coal \\
\hline 0.0926 & 0.229627 & 0.217562 & 0.039232 & 0.031147 & 0.018142 & $\mu \mathrm{g} / \mathrm{g}$ coal \\
\hline 0.168 & 0.085002 & 0.065052 & 0.015023 & 0.021671 & 0.013427 & $\mu \mathrm{g} / \mathrm{g}$ coal \\
\hline 0.337 & 0.021081 & 0.07748 & 0.017103 & $\mathrm{ND}$ & 0.008842 & $\mu \mathrm{g} / \mathrm{g}$ coal \\
\hline 0.535 & 0.148168 & 0.073565 & 0.05553 & 0.055965 & 0.014534 & $\mu \mathrm{g} / \mathrm{g}$ coal \\
\hline 0.973 & 0.799059 & 0.17263 & 0.109812 & $\mathrm{ND}$ & 0.004003 & $\mu \mathrm{g} / \mathrm{g}$ coal \\
\hline 1.98 & 0.449263 & & & $\mathrm{ND}$ & 0.072904 & $\mu \mathrm{g} / \mathrm{g}$ coal \\
\hline 3.77 & 0.210234 & & & $\mathrm{ND}$ & 0.090405 & $\mu \mathrm{g} / \mathrm{g}$ coal \\
\hline 7.33 & $\mathrm{ND}$ & & & $\mathrm{ND}$ & 0.090473 & $\mu \mathrm{g} / \mathrm{g}$ coal \\
\hline
\end{tabular}

Table A-49: Selenium data for the Illinois coal in Figure 4.7-82.

\begin{tabular}{|c|c|c|c|c|c|c|}
\hline $\mathrm{Dp}(\mu \mathrm{m})$ & Air & OXY27 & OXY32 & FGR Clean & FGR Dirty & \\
\hline 0.0324 & & 0.11541 & 0.170442 & 0.116246 & ND & $\mu \mathrm{g} / \mathrm{g}$ coal \\
\hline 0.0636 & & 0.329536 & 0.407054 & 0.123604 & 0.032065 & $\mu \mathrm{g} / \mathrm{g}$ coal \\
\hline 0.0926 & & 0.190864 & 0.103056 & 0.032198 & 0.022462 & $\mu \mathrm{g} / \mathrm{g}$ coal \\
\hline 0.168 & & 0.081944 & 0.033195 & 0.031364 & 0.01169 & $\mu \mathrm{g} / \mathrm{g}$ coal \\
\hline 0.337 & & 0.019369 & 0.007883 & 0.003747 & ND & $\mu \mathrm{g} / \mathrm{g}$ coal \\
\hline 0.535 & & ND & 0.01593 & 0.005573 & ND & $\mu \mathrm{g} / \mathrm{g}$ coal \\
\hline 0.973 & & ND & ND & ND & ND & $\mu \mathrm{g} / \mathrm{g}$ coal \\
\hline 1.98 & & & & ND & ND & $\mu \mathrm{g} / \mathrm{g}$ coal \\
\hline 3.77 & & & & ND & ND & $\mu \mathrm{g} / \mathrm{g}$ coal \\
\hline 7.33 & & & & ND & ND & $\mu \mathrm{g} / \mathrm{g}$ coal \\
\hline
\end{tabular}


Table A-50: Thermodynamic simulation inputs for the Utah coal.

\begin{tabular}{|c|c|c|c|c|c|}
\hline Utah & & MW & g mols & & \\
\hline LOD & 3.18 & 18 & & & \\
\hline Ash & 8.83 & & & & \\
\hline $\mathrm{C}$ & 70.6 & 12 & 5.88333 & Sr 1.17 & \\
\hline $\mathrm{H}$ & 5.41 & 1 & 5.41 & 7.98293 & $\mathrm{O} 2$ \\
\hline $\mathrm{N}$ & 1.42 & 14 & 0.10143 & 38.1959 & $\mathrm{~N} 2$ \\
\hline$S$ & 0.53 & 32 & 0.01656 & & \\
\hline $\mathrm{O}$ & 13.21 & 16 & 0.82563 & Sr 1 Air & \\
\hline & 103.18 & & & 6.82302 & $\mathrm{O} 2$ \\
\hline Ash & & & & 32.646 & $\mathrm{~N} 2$ \\
\hline $\mathrm{Al} 2 \mathrm{O} 3$ & 14.52 & 102 & 0.01257 & & \\
\hline $\mathrm{CaO}$ & 6.11 & 56 & 0.00963 & Sr 0.5 Air & \\
\hline $\mathrm{Fe} 2 \mathrm{O} 3$ & 5.09 & 160 & 0.00281 & 3.41151 & $\mathrm{O} 2$ \\
\hline MgO & 1.39 & 40.3 & 0.00305 & 16.323 & N2 \\
\hline $\mathrm{MnO}$ & 0.02 & 71 & 2.5E-05 & & \\
\hline P2O5 & 0.59 & 142 & 0.00037 & & \\
\hline K2O & 0.57 & 94 & 0.00054 & & \\
\hline SiO2 & 60.89 & 60 & 0.08961 & & \\
\hline $\mathrm{Na} 2 \mathrm{O}$ & 1.41 & 62 & 0.00201 & & \\
\hline SO3 & 2.33 & 80 & 0.00257 & & \\
\hline TiO2 & 0.88 & 80 & 0.00097 & & \\
\hline
\end{tabular}


Table A-51: Thermodynamic simulation inputs for Utah coal for oxy-firing with flue gas recycle.

\begin{tabular}{|c|c|c|c|c|c|}
\hline Utah & & MW & g mols & g mols & \\
\hline LOD & 3.18 & 18 & & & \\
\hline Ash & 8.83 & & & & \\
\hline $\mathrm{C}$ & 70.6 & 12 & 5.88333 & Sr 1.1 & \\
\hline $\mathrm{H}$ & 5.41 & 1 & 5.41 & 7.50532 & $\mathrm{O} 2$ \\
\hline $\mathrm{N}$ & 1.42 & 14 & 0.10143 & & \\
\hline$S$ & 0.53 & 32 & 0.01656 & & \\
\hline \multirow[t]{2}{*}{$\mathrm{O}$} & 13.21 & 16 & 0.82563 & Sr 1 & \\
\hline & 103.18 & & & 6.82302 & $\mathrm{O} 2$ \\
\hline \multicolumn{6}{|l|}{ Ash } \\
\hline $\mathrm{Al} 2 \mathrm{O} 3$ & 14.52 & 102 & 0.01257 & & \\
\hline $\mathrm{CaO}$ & 6.11 & 56 & 0.00963 & Sr 0.5 & \\
\hline Fe2O3 & 5.09 & 160 & 0.00281 & 3.41151 & $\mathrm{O} 2$ \\
\hline MgO & 1.39 & 40.3 & 0.00305 & & \\
\hline $\mathrm{MnO}$ & 0.02 & 71 & 2.5E-05 & & \\
\hline P2O5 & 0.59 & 142 & 0.00037 & & \\
\hline K2O & 0.57 & 94 & 0.00054 & & \\
\hline SiO2 & 60.89 & 60 & 0.08961 & & \\
\hline $\mathrm{Na} 2 \mathrm{O}$ & 1.41 & 62 & 0.00201 & & \\
\hline SO3 & 2.33 & 80 & 0.00257 & & \\
\hline $\mathrm{TiO} 2$ & 0.88 & 80 & 0.00097 & & \\
\hline & & & & & \\
\hline
\end{tabular}


Table A-52: Thermodynamic simulation inputs for the PRB coal for air-fired conditions.

\begin{tabular}{|c|c|c|c|c|c|}
\hline PRB & & MW & g mols & & \\
\hline LOD & 23.69 & 18 & & & \\
\hline Ash & 4.94 & & & & \\
\hline $\mathrm{C}$ & 53.72 & 12 & 4.47667 & Sr 1.17 & \\
\hline $\mathrm{H}$ & 6.22 & 1 & 6.22 & 5.8099 & $\mathrm{O} 2$ \\
\hline $\mathrm{N}$ & 0.78 & 14 & 0.05571 & 27.7986 & $\mathrm{~N} 2$ \\
\hline S & 0.23 & 32 & 0.00719 & & \\
\hline $\mathrm{O}$ & 34.11 & 16 & 2.13188 & Sr 1 Air & \\
\hline & 123.69 & & & 4.96573 & $\mathrm{O} 2$ \\
\hline Ash & & & & 23.7595 & $\mathrm{~N} 2$ \\
\hline $\mathrm{Al} 2 \mathrm{O} 3$ & 14.78 & 102 & 0.00716 & & \\
\hline $\mathrm{CaO}$ & 22.19 & 56 & 0.01957 & Sr 0.5 Air & \\
\hline Fe2O3 & 5.2 & 160 & 0.00161 & 2.48286 & $\mathrm{O} 2$ \\
\hline MgO & 5.17 & 40.3 & 0.00634 & 11.8797 & N2 \\
\hline $\mathrm{MnO}$ & 0.01 & 71 & 7E-06 & & \\
\hline P2O5 & 1.07 & 142 & 0.00037 & & \\
\hline $\mathrm{K} 2 \mathrm{O}$ & 0.35 & 94 & 0.00018 & & \\
\hline $\mathrm{SiO} 2$ & 30.46 & 60 & 0.02508 & & \\
\hline $\mathrm{Na} 2 \mathrm{O}$ & 1.94 & 62 & 0.00155 & & \\
\hline SO3 & 8.83 & 80 & 0.00545 & & \\
\hline $\mathrm{TiO} 2$ & 1.3 & 80 & 0.0008 & & \\
\hline
\end{tabular}


Table A-53: PRB thermodynamic simulation inputs for the oxy-fired FGR conditions.

\begin{tabular}{|c|c|c|c|c|c|}
\hline PRB & & MW & g mols & g mols & \\
\hline LOD & 23.69 & 18 & & & \\
\hline Ash & 4.94 & & & & \\
\hline $\mathrm{C}$ & 53.72 & 12 & 4.47667 & Sr 1.1 & \\
\hline $\mathrm{H}$ & 6.22 & 1 & 6.22 & 5.4623 & $\mathrm{O} 2$ \\
\hline $\mathrm{N}$ & 0.78 & 14 & 0.05571 & & \\
\hline S & 0.23 & 32 & 0.00719 & & \\
\hline \multirow[t]{2}{*}{$\mathrm{O}$} & 34.11 & 16 & 2.13188 & Sr 1 & \\
\hline & 123.69 & & & 4.96573 & $\mathrm{O} 2$ \\
\hline \multicolumn{6}{|l|}{ Ash } \\
\hline $\mathrm{Al} 2 \mathrm{O} 3$ & 14.78 & 102 & 0.00716 & & \\
\hline $\mathrm{CaO}$ & 22.19 & 56 & 0.01957 & Sr 0.5 & \\
\hline Fe2O3 & 5.2 & 160 & 0.00161 & 2.48286 & $\mathrm{O} 2$ \\
\hline MgO & 5.17 & 40.3 & 0.00634 & & \\
\hline $\mathrm{MnO}$ & 0.01 & 71 & 7E-06 & & \\
\hline P2O5 & 1.07 & 142 & 0.00037 & & \\
\hline K2O & 0.35 & 94 & 0.00018 & & \\
\hline $\mathrm{SiO} 2$ & 30.46 & 60 & 0.02508 & & \\
\hline $\mathrm{Na} 2 \mathrm{O}$ & 1.94 & 62 & 0.00155 & & \\
\hline SO3 & 8.83 & 80 & 0.00545 & & \\
\hline $\mathrm{TiO} 2$ & 1.3 & 80 & 0.0008 & & \\
\hline
\end{tabular}


Table A-54: Thermodynamic simulation inputs for the Illinois coal under air-fired conditions.

\begin{tabular}{|c|c|c|c|c|c|}
\hline Illinois & & MW & g mols & & \\
\hline LOD & 9.65 & 18 & & & \\
\hline Ash & 7.99 & & & & \\
\hline $\mathrm{C}$ & 64.67 & 12 & 5.38917 & Sr 1.17 & \\
\hline $\mathrm{H}$ & 5.59 & 1 & 5.59 & 7.33163 & $\mathrm{O} 2$ \\
\hline $\mathrm{N}$ & 1.12 & 14 & 0.08 & 35.0796 & N2 \\
\hline S & 3.98 & 32 & 0.12438 & & \\
\hline $\mathrm{O}$ & 16.65 & 16 & 1.04063 & Sr 1 Air & \\
\hline & 109.65 & & & 6.26635 & $\mathrm{O} 2$ \\
\hline Ash & & & & 29.9826 & N2 \\
\hline $\mathrm{Al} 2 \mathrm{O} 3$ & 17.66 & 102 & 0.01383 & & \\
\hline $\mathrm{CaO}$ & 1.87 & 56 & 0.00267 & Sr 0.5 Air & \\
\hline Fe2O3 & 14.57 & 160 & 0.00728 & 3.13318 & $\mathrm{O} 2$ \\
\hline MgO & 0.98 & 40.3 & 0.00194 & 14.9913 & N2 \\
\hline $\mathrm{MnO}$ & 0.02 & 71 & 2.3E-05 & & \\
\hline P2O5 & 0.11 & 142 & 6.2E-05 & & \\
\hline K2O & 2.26 & 94 & 0.00192 & & \\
\hline $\mathrm{SiO} 2$ & 49.28 & 60 & 0.06562 & & \\
\hline $\mathrm{Na} 2 \mathrm{O}$ & 1.51 & 62 & 0.00195 & & \\
\hline SO3 & 2.22 & 80 & 0.00222 & & \\
\hline TiO2 & 0.85 & 80 & 0.00085 & & \\
\hline
\end{tabular}


Table A-55: Thermodynamic simulation inputs for the Illinois coal under oxy-fired conditions with flue gas recycle.

\begin{tabular}{|c|c|c|c|c|c|}
\hline Illinois & & MW & g mols & g mols & \\
\hline LOD & 9.65 & 18 & & & \\
\hline Ash & 7.99 & & & & \\
\hline $\mathrm{C}$ & 64.67 & 12 & 5.38917 & Sr 1.1 & \\
\hline $\mathrm{H}$ & 5.59 & 1 & 5.59 & 6.89299 & $\mathrm{O} 2$ \\
\hline $\mathrm{N}$ & 1.12 & 14 & 0.08 & & \\
\hline$S$ & 3.98 & 32 & 0.12438 & & \\
\hline \multirow[t]{2}{*}{$\mathrm{O}$} & 16.65 & 16 & 1.04063 & Sr 1 & \\
\hline & 109.65 & & & 6.26635 & $\mathrm{O} 2$ \\
\hline \multicolumn{6}{|l|}{ Ash } \\
\hline $\mathrm{Al} 2 \mathrm{O} 3$ & 17.66 & 102 & 0.01383 & & \\
\hline $\mathrm{CaO}$ & 1.87 & 56 & 0.00267 & Sr 0.5 & \\
\hline Fe2O3 & 14.57 & 160 & 0.00728 & 3.13318 & $\mathrm{O} 2$ \\
\hline MgO & 0.98 & 40.3 & 0.00194 & & \\
\hline $\mathrm{MnO}$ & 0.02 & 71 & 2.3E-05 & & \\
\hline P2O5 & 0.11 & 142 & $6.2 \mathrm{E}-05$ & & \\
\hline K2O & 2.26 & 94 & 0.00192 & & \\
\hline $\mathrm{SiO} 2$ & 49.28 & 60 & 0.06562 & & \\
\hline $\mathrm{Na} 2 \mathrm{O}$ & 1.51 & 62 & 0.00195 & & \\
\hline SO3 & 2.22 & 80 & 0.00222 & & \\
\hline $\mathrm{TiO} 2$ & 0.85 & 80 & 0.00085 & & \\
\hline
\end{tabular}

Supplementary Material, which Includes Raw Data and Calculation Spreadsheets, are available from the Professor Jost Wendt at the University of Utah (jost.wendt@utah.edu)

An additional CD supplement with raw data files for the TSI SMPS and APS instruments is also available from Professor Wendt at the University of Utah. 